Matthias Schmidt

\title{
Verfassungsaufsicht in der Europäischen Union
}

Eine akteurszentrierte Analyse der Rechtsstaatlichkeitskrise der Europäischen Union 
Beiträge zum

ausländischen öffentlichen Recht und Völkerrecht

Herausgegeben von

der Max-Planck-Gesellschaft

zur Förderung der Wissenschaften e.V.,

vertreten durch Prof. Dr. Armin von Bogdandy

und Prof. Dr. Anne Peters

Band 308 
Matthias Schmidt

\section{Verfassungsaufsicht in der Europäischen Union}

Eine akteurszentrierte Analyse der

Rechtsstaatlichkeitskrise der Europäischen Union 
Die Open-Access-Veröffentlichung der elektronischen Ausgabe dieses Werkes wurde ermöglicht mit Unterstützung durch die Max-Planck-Gesellschaft.

Die Deutsche Nationalbibliothek verzeichnet diese Publikation in der Deutschen Nationalbibliografie; detaillierte bibliografische Daten sind im Internet über http://dnb.d-nb.de abrufbar.

Zugl.: Frankfurt am Main, Univ., Diss., 2020

1. Auflage 2021

(c) Der Autor

Publiziert von

Nomos Verlagsgesellschaft $\mathrm{mbH} \& \mathrm{Co}$. KG

Waldseestraße 3-5 | 76530 Baden-Baden

www.nomos.de

Gesamtherstellung:

Nomos Verlagsgesellschaft mbH \& Co. KG

Waldseestraße 3-5 | 76530 Baden-Baden

ISBN (Print): 978-3-8487-8186-7

ISBN (ePDF): 978-3-7489-2595-8

DOI: https://doi.org/10.5771/9783748925958

\section{D30}

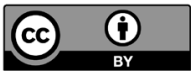

Dieses Werk ist lizensiert unter einer Creative Commons Namensnennung 4.0 International Lizenz. 


\section{Vorwort}

Die vorliegende Arbeit ist im Dezember 2020 vom Fachbereich Rechtswissenschaft der Johann Wolfgang Goethe-Universität Frankfurt a. M. als Dissertation angenommen worden. Die verwendete Literatur ist auf dem Stand vom Mai 2020, Rechtsprechung und Rechtspraxis konnten vereinzelt noch bis Anfang 2021 berücksichtigt werden.

Entstanden ist die Arbeit während meiner Zeit als wissenschaftlicher Mitarbeiter am Max-Planck-Institut für ausländisches öffentliches Recht und Völkerrecht in Heidelberg in der Zeit von Oktober 2013 bis April 2020. In diese Zeit fällt mein Aufenthalt an der ENA in Straßburg und Paris von September 2018 bis Ende 2019, wobei die dortige Praxisausbildung für diese Arbeit ebenso Verwendung fand.

Dass diese Dissertation angesichts eines sich stetig wandelnden und komplexer werdenden Themas erfolgreich abgeschlossen werden konnte, habe ich der Unterstützung und dem Zuspruch einer Reihe von Personen zu verdanken.

Meinem Doktorvater, Prof. Dr. Armin von Bogdandy, gebührt größter Dank für die konstante Förderung meiner Vorhaben und für fortlaufende gemeinsame Überlegungen zum Thema der europäischen Rechtsstaatlichkeit, überdies zu einem frühen Zeitpunkt, als die Entwicklung der Rechtsstaatlichkeitskrise noch nicht absehbar war.

Ihm und Herrn Prof. Dr. Stefan Kadelbach habe ich für die sehr rasche Begutachtung der Arbeit zu danken, die den eigenen Blick nochmals schärfte.

Den Direktoren des Instituts, Herrn Prof. Dr. Armin von Bogdandy und Frau Prof. Dr. Dr. h.c. Anne Peters, danke ich für die Aufnahme meiner Dissertation in die Schriftenreihe des Instituts.

Das Heidelberger Max-Planck-Institut und insbesondere seine Bibliothek, die mit großartigem Service Quellen verfügbar machte, schuf die Grundlage für viel Nachdenken.

Die Arbeit hat darüber hinaus davon profitiert, dass viele weitere Gesprächspartner zu entscheidenden Momenten Denkanstöße lieferten.

Das gilt zunächst für alle Mitstreiter in der Dienstagsrunde, namentlich Carlino Antpöhler, Franz Ebert, Prof. Dr. Anuscheh Farahat, Prof. Dr. Matthias Goldmann, Dr. Simon Hentrei, Dr. Michael Ioannidis, Dr. Christoph Krenn, Dr. Mariela Morales Antoniazzi, Prof. Dr. Davide Paris, Prof. 
Dr. Sabrina Ragone, Dr. Giacomo Rugge, Frauke Sauerwein, Dr. Mateja Steinbrück Platise, Dr. Ximena Soley, Leonie Vierck, Dr. Nele Yang und Catharina Ziebritzki. Besonders danken möchte ich dabei Prof. Dr. Iris Canor für ihre Anregungen zum Vertragsverletzungsverfahren und zur primärrechtlichen Systematik.

Aus dem „Team Peters“ bin ich Dr. Carolyn Moser und Prof. Dr. Paulina Starski für unsere Gespräche dankbar.

Unter den Kollegen und Freunden am Institut nimmt Prof. Russell Miller eine herausragende Rolle ein. Sein stets frischer Blick stärkte fachlich und menschlich.

An Heidelberger Freunden außerhalb des Instituts möchte ich namentlich Lukas Franke und Tim Knoche danken.

Schließlich darf hier nicht unerwähnt bleiben, dass die Arbeit zentrale Bereicherung außerhalb Heidelbergs erfahren hat, zum einen 2016-2019 durch die Förderung im Rahmen des Exzellenzclusters Normative Orders in Frankfurt a. M., zum anderen durch das vielseitige Doktorandenprogramm der École de Droit der Sciences Po, Paris, in dem ich 2015 als Gastdoktorand mitarbeiten durfte.

Essentiell für ein besseres Verständnis der Entwicklungen in Osteuropa war die Kooperation des Instituts mit der Warschauer juristischen Fakultät, vor allem die Zusammenarbeit mit Prof. Dr. Maciej Taborowski und Prof. Dr. Piotr Bogdanowicz.

Herrn em. Prof. Dr. Dres. h.c. Jochen Frowein habe ich dabei nicht nur dafür zu danken, die Mitausrichtung einer Konferenz in Warschau kurzfristig übernommen zu haben, sondern auch für die Zeit, die er sich für meine juristischen Fragen und solche zur deutsch-polnischen Zusammenarbeit nahm.

Neben ihnen allen aber hätte die Dissertation in der hier vorliegenden Form nicht geschrieben werden können, wenn ich nicht auf Zeit in der Europäischen Kommission im Referat C.1 der Generaldirektion Justiz und Verbraucher Kolleginnen und Kollegen über die Schulter hätte schauen dürfen, die dort für die Rechtsstaatlichkeit in der Europäischen Union kämpfen. Ich will sie nicht ungefragt sämtlich hier nennen, bin aber zuversichtlich, dass sie bei der Durchsicht der Arbeit sehen, wo ihre Geduld mit mir zu Ergebnissen geführt hat.

Mein tiefer Dank gilt Dr. Emmanuel Crabit, der sich in seinem übervollen Terminplan Zeit für augenöffnende Gespräche insbesondere zur aktuellen Rechtsprechung nahm und mich an Überlegungen und ihren Hintergründen teilhaben ließ, Niovi Ringou, die mir die aktive Mitarbeit 
im Referat ermöglichte, und schließlich ganz besonders Nicolaas Bel für unsere Arbeitsrunden in Brüssel und in Maastricht.

Abschließend möchte ich meiner Familie danken, die mich immer vorbehaltlos unterstützt hat und der diese Arbeit gewidmet ist.

Darmstadt, im Mai 2021

Matthias Schmidt 


\section{Inhaltsverzeichnis}

$\begin{array}{ll}\text { Abbildungsverzeichnis } & 17\end{array}$

A. Einleitung 19

I. Forschungsanlass und Erkenntnisinteresse 19

II. Gang und normative Ausrichtung der Arbeit 27

B. Rechtsstaatlichkeitskrise und systemisches Defizit 33

I. Keine leichtfertige Verwendung des Begriffs der „Krise“ 33

II. Rechtsstaatlichkeitskrise 34

1. Benennung der Krise 34

2. Europäische Krise oder Krise der Union? 36

3. Rechtsstaatlichkeitskrise oder Krise der europäischen
Demokratie?

4. Zur Existenz und Reichweite der Rechtsstaatlichkeitskrise empirischer Befund

III. Die Rechtsstaatlichkeitskrise im Spiegel verschiedener

Deutungsversuche

1. Backsliding, Creative Compliance, Backlash, Executive Aggrandizement

2. Rechtsstaatlichkeitskrise als sekundärer, systemisches

Defizit als primärer Rechtsbegriff zur dogmatischen Verklammerung der Krise

IV. Der Begriff des systemischen Defizits an Rechtsstaatlichkeit

1. Keine Hilfestellung durch die politikwissenschaftliche Defektforschung

2. Entwicklung des Begriffs in der Rechtspraxis 57

a. Mutmaßliche Ursprünge 57

b. Drei Beiträge aus der Literatur zum Piloturteilsverfahren des EGMR

c. Rechtsprechung des EuGH zum Attribut des „systemischen“" 
d. Die Figur der Verletzung „generellen und fortdauernden Charakters" und Überlegungen zur weiteren Begriffsstrukturierung

3. Verständniswandel in der Rechtswissenschaft

4. Vorsatz, Spillover und intersystemisches Konfliktpotential als zentrale Merkmale

5. Die Rechtsstaatlichkeit - Operationalisierung statt Definition

a. Allgemeine Rechtsgrundsätze

b. Funktionsbestimmung der Rahmenbedingungen für die Rechtsanwaltschaft in Mitgliedstaaten

c. Einwirkung auf die Mitgliedstaaten über staatsorganisationsrechtliche Strukturmerkmale

d. Rückgriff auf Art. 19 Abs. 1 EUV i. V. m. Art. 47 der Grundrechtecharta

aa. Entwicklung bis zum Urteil in der Rs. Associação Sindical dos Juízes Portugueses

bb. Die Entwicklung der Operationalisierung des Rechtsstaatsprinzips durch Art. 19 Abs. 1 EUV und Art. 47 GRCh infolge der Rechtsprechung zu Polen

(1) Gegenwärtiger Stand der Rechtsprechung

(2) Die Rechtssache LM (Mängel des Justizsystems)

(3) Die beiden „Aspekte“ des Prinzips der richterlichen Unabhängigkeit

C. Die Rechtsstaatlichkeitskrise in mitgliedstaatlichen Fällen

I. Aufsichtsmaßnahmen und Aufbaumaßnahmen

II. Topische Argumentationsweise zur Sichtung und Klärung des Materials

III. Polen

1. Drei Thesen

2. Die exkludierende Demokratie als normatives Fundament der Entwicklungen

3. Die Vereinnahmung des polnischen Verfassungsgerichts

4. Die Neutralisierung des Obersten Gerichtshofs und der ordentlichen Gerichtsbarkeit

b. Landesjustizrat 
c. Entlassung, Berufung und Disziplinierung der Gerichtsbarkeit

d. „Maulkorbgesetz“ gegen die Gerichtsbarkeit

5. Zwischenergebnis zu Polen

IV. Ungarn 146

1. Übersicht 146

2. Die illiberale Demokratie als normatives Fundament der Entwicklungen

3. Ungarische Grundgesetzänderung von 2012 und Richterpensionierungsfrage

4. Nationaler Richterrat gegen Nationales Justizamt 163

5. Einzelfallgesetze 164

a. Lex CEU und der Topos der Gewaltenkollusion 166

b. Lex NGO 170

6. Eingriffe in die Marktwirtschaft und die Eigentumsordnung 171

a. Beobachtungen in der Literatur 171

b. Urteile des EGMR und des EuGH 172

c. Bewertung 178

7. Verwundbare Gruppen 179

8. Uniformitätsentscheidungen und die zurückgenommene Verwaltungsgerichtsreform von $2019 \quad 184$

9. Zwischenergebnis zu Ungarn 188

V. Wechselnde Befunde und Anlass zur Sorge - die Lage in Bulgarien und Rumänien im Spiegel der Rechtspraxis

1. „Ultimus inter pares"?

2. Der „Kooperations- und Verifikationsmechanismus“ (CVM) und die divergierende Entwicklung in beiden Mitgliedstaaten

3. Topoi der Entwicklung in Bulgarien und Rumänien 200

4. Zwischenergebnis zu Bulgarien und Rumänien 204

5. Folgefragen 206

a. Relativierung empirischer Indikatoren? 207

b. Abgrenzung zur Lage in Malta 212

VI. Zum Umgang mit Beobachtungen zu Krisen in weiteren Mitgliedstaaten

1. Keine Trivialisierung des Vorwurfs, keine Ubiquität der Rechtsstaatlichkeitskrise

2. Spanien und die katalanische Frage 
3. Die Kontroverse um die Besetzung des Verfassungsgerichts in der Slowakei

4. Slowenien

VII. Zusammenfassende Bemerkungen zu den dargestellten Topoi

D. Verfassungsaufsicht in der Europäischen Union

I. Begriff und Intention

1. Aufsicht im Unionsrecht und Unionsaufsicht

a. Funktionen des Aufsichtsbegriffs für den Staat, Nutzung des föderalen Aufsichtsbegriffs im Unionsrecht

b. Der Bundesaufsichtsbegriff in der europarechtlichen Literatur

c. Zwischenergebnis und Rückführung dieser Literatur auf den deutschen Begriff der Bundesaufsicht

2. Bundesaufsicht und Verfassungsaufsicht in der deutschen Rechtswissenschaft

a. Argumente gegen die Nutzung des

Verfassungsaufsichtsbegriffs: alternative Begriffe und Begriffshistorie

aa. (Allgemeine) Unionsaufsicht

bb. Rechtsstaatlichkeitsaufsicht

cc. Historischer Kontext des Verfassungsaufsichtsbegriffs bei Johannes Heckel

b. Argumente für die Nutzung des

Verfassungsaufsichtsbegriffs

aa. Beendigung der Debatte um den Unionsnotstand

bb. Legitimierung durch rechtswissenschaftliche Arbeiten und durch die Rechtspraxis

II. Überlegungen zur praktischen Anwendung des

Verfassungsaufsichtsbegriffs im Unionsrecht

E. Das Rechtsregime der Verfassungsaufsicht der Europäischen Union

I. Überblick 
II. Die Akteure der Verfassungsaufsicht

1. Die Europäische Kommission in Relation zu anderen Organen der Union

a. Mandat aus Art. 17 EUV, Rolle der Kommission im Verfahren nach Art. 7 EUV

293

b. Verhältnis von Kommission und Rat

c. Schwache Rolle des Europäischen Parlaments trotz Aufsichtsbeteiligung

2. Reaktionen weiterer Unionsorgane

3. Rolle und Beteiligung der Europäischen Grundrechteagentur

4. Die Rolle der Venedig-Kommission und ihre Zusammenarbeit mit der Europäischen Kommission

5. Zwischenergebnis

III. Präzisierung der Akteursperspektive: Ein Blick auf die Europäische Kommission

1. Auswirkungen des Chef de File-Grundsatzes

a. Kollegium und Kabinette

b. Rechtsanwendung, Rechtsschöpfung, Rechtsberatung und Kabinettsergänzung

c. Personalstärke und Methodik

d. Einheitlichkeit der Sorgfalt, unabhängig vom intendierten Zweck

2. „Mikro-Makro"-Grundsatz

3. „Au fur et à mesure“-Grundsatz bzw. Grundsatz des strukturiert-flexiblen Dialogs

IV. Entwicklung der einzelnen Maßnahmen der Verfassungsaufsicht und der EU-Rahmen

1. Die Ursprünge des polyprozeduralen Verfassungsaufsichtsregimes im Unionsrecht

a. Konsensbildung in der Literatur "post Haider“

b. Die Kommissionsmitteilung von 2003 zu Art. 7 EUV

2. Stockholmer Programm

3. Entwicklung vom Brief der vier Außenminister über die Konferenz Assises de la Justice bis zur Vorstellung des EURahmens 
V. Partielle Verfassungsaufsichtsinstrumente im Unionsrecht

1. Zur Unterscheidung partieller und vollständiger Aufsichtsmechanismen im Unionsrecht, insbesondere mit Blick auf den EU-Rahmen

2. Der EU-Rahmen zur Stärkung des Rechtsstaatsprinzips

a. Formenwahl und Bezeichnung als „Rahmen“, Begriff der „Stärkung“ der Rechtsstaatlichkeit

b. Überblick über das Verfahren 373

c. Allgemeine Rezeption in der Literatur 376

d. Die Kompetenzfrage 377

e. Regelfallverbindlichkeit des EU-Rahmens 385

f. Der EU-Rahmen als Beispiel des Typus der „primärrechtsergänzenden" Mitteilung

g. Die Sachstandsanalyse: zugleich eine allgemeine Darstellung der Informationsgewinnung und -verarbeitung der Kommission in der Rechtsstaatlichkeitskrise

aa. Grundsätze und Problemfelder der Informationsbeschaffung und -verwertung

bb. Allgemeine Quellen

cc. Durchgestochene und platzierte Quellen $\quad 400$

dd. Die Beschwerde 405

ee. Die dienstinterne Privilegierung von Informationen 409

h. Die Stellungnahme zur Rechtsstaatlichkeit 411

aa. Aufbau der Stellungnahme gegenüber Polen 412

bb. Argumentationsweise der Kommission und fünf

Charakteristika der Stellungnahme

i. Die Empfehlung zur Rechtsstaatlichkeit 418

aa. Aufbau der Empfehlung und wesentlicher Inhalt im Fall Polen

bb. Frist beim Übergang zum Verfahren nach Art. 7 Abs. 1 EUV

j. Materieller Tatbestand der „systemischen Gefährdung der Rechtsstaatlichkeit"

a. Grundlagen 430

aa. Begriff des Barometers 430

bb. Genese, Telos und Leitbegriffe des Justizbarometers $\quad 432$

cc. Diagrammtypen und Quellen 434

b. Interpretationen in der Literatur $\quad 444$ 
c. Eigener Vorschlag zur Handhabung und Interpretation des Justizbarometers im Rahmen der Rechtsstaatlichkeitskrise

d. Aufsichtsqualität der Maßnahmen

e. Effektivität und Stichhaltigkeit der rechtsstaatsspezifischen Rügen im Rahmen des Justizbarometers - auch zum Problem des sog. relativierenden Rechtsvergleichs

VI. Verfassungsaufsichtsverfahren mit Berichtigungsphase

1. Das Europäische Semester

a. Genese, Rechtsgrundlage und Rechtsverbindlichkeit 468

b. Einordnung in der Literatur

c. Telos und Ablauf, hier mit besonderer Berücksichtigung als Verfassungsaufsichtsinstrument der Kommission

bb. Singuläre Bedeutung des Länderberichts und sein

Erarbeitungsprozess

d. Der weitere Verlauf des Europäischen Semesters bis zur Veröffentlichung der länderspezifischen Empfehlungen (CSR)

e. Effektivität des Europäischen Semesters als Verfassungsaufsichtsinstrument

2. Das Verfahren nach Art. 7 EUV

a. Stand des Verfahrens gegenüber Polen

aa. Begründeter Vorschlag und Kreis der Antragssteller in der Rechtspraxis

(1) Entwicklung seit Dezember 2017

(2) Wesentliche Merkmale und Argumentationsstil des begründeten Vorschlags

(3) Operationalisierung der Rechtsstaatlichkeit über die Funktionsfähigkeit der Justiz

bb. Gleichlauf der Ausführungen der Europäischen

Kommission mit denjenigen des Europäischen

Gerichtshofs in späterer Rechtsprechung

cc. Ausgestaltung der Handhabung des Verfahrens im Rat

b. Stand des Verfahrens gegenüber Ungarn 
bb. Unterschiede und Gemeinsamkeiten des begründeten Vorschlags gegenüber Ungarn im Vergleich zum Verfahren gegenüber Polen

3. Das Vertragsverletzungsverfahren

a. Die Kontroverse um die Nutzung des Verfahrens in der Rechtsstaatlichkeitskrise

aa. Streitstand

bb. Der Vorschlag Kim Lane Scheppeles zu „systemic infringement actions" und die Diskussion in der Literatur

(1) Prozessualer Zuschnitt

(2) Maßstab

cc. Wesentliche Argumente für die Fortführung von Scheppeles Ansatz

(1) Kongruenz mit der rechtspolitischen Ausrichtung des Verfahrens durch die Kommission

(2) Parallelität mit dem Verfahren nach Art. 7 EUV

(3) Möglichkeit des prozessualen Zuschnitts

(4) Materiell-rechtlicher Maßstab

b. Durchbruch der Akzeptanz des Verfahrens infolge der Rechtssache „Unabhängigkeit des polnischen Obersten Gerichtshofs"

aa. Ausführungen von Generalanwalt Evgeni Tanchev

bb. Klageerledigung, einstweilige Anordnungen und Beschleunigung des Verfahrens

c. Entwicklungsperspektiven des Vertragsverletzungsverfahrens: Verfahren nach Art. 259 AEUV und die Streithilfe im Rahmen des Art. 258 AEUV

F. Entwicklungsperspektiven der Verfassungsaufsicht

I. Aufsicht über die Wertetreue europäischer Parteien

II. Die „Dialoge“ im Rat - Rechtsstaatlichkeitsdialog und „Periodic Peer Review“

III. Die Vorschläge der Kommission - neue Rechtsstaatsinitiative und Konditionalisierung des ESI-Fonds-Rechts

IV. Schlussbemerkungen und Abriss in Thesen 


\section{Abbildungsverzeichnis}

Zehn, überwiegend farbige Schaubilder aus verschiedenen Ausgaben des Justizbarometers der Europäischen Kommission:

Abbildung 1: Schaubild 5 - Für den Abschluss von Zivil-, Handels-, Verwaltungs- und sonstigen Rechtssachen erforderliche Zeit

Abbildung 2: Schaubild 30 - Kriterien zur Festlegung der finanziellen Ressourcen für das Justizwesen

Abbildung 3: Schaubild 52 - Behörde, die über Disziplinarmaßnahmen für Richter entscheidet

Abbildung 4: Schaubild 54 - Ernennung von den Räten für das Justizwesen angehörenden Richtern: Rolle der Justiz

Abbildung 5: Schaubild 42 - Festgelegte Standards zu Aspekten des Justizsystems

Abbildung 6: Schaubild 30 - Kriterien zur Festlegung der finanziellen Ressourcen für das Justizwesen

Abbildung 7: Schaubild 52 - Entlassung von Richtern an Gerichten erster und zweiter Instanz

Abbildung 8: Schaubild 56 - Ernennung von Richtern: vorschlagende und ernennende Behörden

Abbildung 9: Schaubild 52 - Behörde, die über Disziplinarmaßnahmen für Richter entscheidet

Abbildung 10: Schaubild 53 - Mit förmlichen

Disziplinarmaßnahmen gegen Richter beauftragte Ermittler 


\section{A. Einleitung}

\section{Forschungsanlass und Erkenntnisinteresse}

Die vorliegende Arbeit ist ein Vorschlag zur Interpretation des Umgangs der Organe der Europäischen Union mit der sog. „Rechtsstaatlichkeitskrise" der Europäischen Union. Der Begriff der Rechtsstaatlichkeitskrise bezeichnet auf den ersten Blick eine sehr vielschichtige Verfassungskrise der Union bedingt durch die Probleme der Nichteinhaltung des Rechtsstaatsprinzips in bestimmten Mitgliedstaaten der EU. Der Versuch der Politisierung der Justiz in Polen, aber auch die Umgehung der Gewaltenteilung durch sog. versteckte Einzelfallgesetze in Ungarn sind bekannte Beispiele. Die Rechtsstaatlichkeitskrise ist entwicklungsoffen, ihr Anfang schwer zu bestimmen, und sie dauerte bei Abschluss dieser Arbeit mit ungewissem Ausgang fort. Als die Arbeit Ende 2013 begonnen wurde, war die Materie eine Frage für Spezialisten, zwischenzeitlich zählt sie zu den prominentesten Bereichen des Unionsrechts.

Die zeitliche Unbestimmtheit der Rechtsstaatlichkeitskrise, ihre Vielzahl an Ausprägungen und die hierzu bereits erschienenen Arbeiten erfordern zunächst eine Abgrenzung. Drei Dinge will ich nicht leisten. Zunächst trete ich nicht an, eine vertiefte landeskundliche Studie über die Entwicklung in Mitgliedstaaten vorzulegen. Hierzu sind Kenner der dortigen Vorgänge bereits intensiv tätig gewesen, ${ }^{1}$ und auf ihren Arbeiten muss aufgebaut

$1 \mathrm{Zu}$ Polen: Klaus Bachmann, Der Bruch: Ursachen und Konsequenzen des Umsturzes der Verfassungsordnung Polens 2015-2016, Peter Lang, Frankfurt a.M., 2016; Wojciech Sadurski, Poland's Constitutional Breakdown, Oxford University Press, Oxford, 2019; Brian Porter-Szücs, Faith and Fatherland: Catholicism, Modernity, and Poland, Oxford University Press, Oxford, 2011, insb. ab S. 392 für die gesellschaftspolitischen Hintergründe; zu Ungarn: eine hervorragende Studie mit großer landeskundlicher Tiefe bietet Paul Lendvai, Orbán: Europe's New Strongman, Oxford, Oxford University Press, 2017; Kim Lane Scheppele, „Understanding Hungary's Constitutional Revolution“, in: Armin von Bogdandy \& Pál Sonnevend (Hrsg.): Constitutional Crisis in the European Constitutional Area, C.H. Beck/ Hart/Nomos, München/Oxford/Baden-Baden, 2015, S. 111-124; Gábor Halmai: "The Rise and Fall of Constitutionalism in Hungary“, in: Paul Blokker (Hrsg.), Constitutional Acceleration within the European Union and Beyond, Routledge, London/New York, 2018, S. 217-233; János Kornai, „Hungary’s U-Turn: Retreating from Democracy“, in: Journal of Democracy 26 (2015), S. 34-48; höchst kritisch 


\section{A. Einleitung}

werden. Zum zweiten soll nicht allein die Entwicklung der Rechtsstaatlichkeitskrise als zeitgenössische Frage im Vordergrund stehen. Auch dazu ist von kundiger Seite geschrieben worden. ${ }^{2}$ Naturgemäß ergeben sich zu diesen Arbeiten Schnittmengen. Drittens schreibe ich nicht in der Absicht, zu klären, wie sich die Rechtsstaatlichkeitskrise auf das rechtswissenschaftliche Verständnis der Werte der Union auswirkt, wie sie vorrangig in Art. 2 EUV niedergelegt sind, dabei ganz besonders betreffend die Rechtsstaatlichkeit. Diese Frage war und ist in der Literatur von besonderem Interesse. Mein Heidelberger Kollege Dimitri Spieker, ${ }^{3}$ aber auch andere Verfasser, wie Werner Schroeder, ${ }^{4}$ und nicht zuletzt Mitglieder des Europäischen Gerichtshofs selbst, wie Thomas von Danwitz, ${ }^{5}$ und der Präsident des Europäischen Gerichtshofs, Koen Lenaerts, ${ }^{6}$ forschen hierzu.

Diese Arbeit setzt einen anderen Schwerpunkt und widmet sich vorrangig den Reaktionen der Europäischen Union auf die Rechtsstaatlichkeitskrise und dabei insbesondere der Arbeit eines Organs, nämlich der Europäischen Kommission. Ich versuche prioritär, die von ihr in der Krise genutzten, fortentwickelten und vorgeschlagenen Instrumentarien $\mathrm{zu}$ sichten, ihren Zweck zu interpretieren und in einen logischen Zusammenhang zu stellen. Dabei hat die Europäische Kommission selten alleine

und teils polemisch, Bálint Magyar, Post-Communist Mafia State: The Case of Hungary, Central European University Press, Budapest 2016, insb. S. 69 ff., vergleichend s. die Beiträge in: Armin von Bogdandy \& Pál Sonnevend (Hrsg.), Constitutional Crisis in the European Constitutional Area, C.H. Beck/Hart/Nomos, München/Oxford/Baden-Baden, 2015.

2 Aus der Literatur vorrangig Christoph Möllers \& Linda Schneider, Demokratiesicherung in der Europäischen Union: Studie zu einem Dilemma, Mohr Siebeck, Tübingen, 2018; Vassilios Skouris, Demokratie und Rechtsstaat: Europäische Union in der Krise, C.H. Beck, München, 2018; jüngst auch Kim Lane Scheppele \& R. Daniel Kelemen, „Defending Democracy in EU Member States: Beyond Article 7 TEU“, in: Francesca Bignami (Hrsg.), EU Law in Populist Times: Crises and Prospects, Cambridge University Press, Cambridge, 2020, S. 413-456.

3 S. insb. Luke Dimitrios Spieker, „Breathing Life into the Union's Common Values: On the Judicial Application of Article 2 TEU in the EU Value Crisis“, in: German Law Journal 20 (2019), S. 1182-1213, S. $1199 \mathrm{ff}$.

4 Werner Schroeder, "The European Union and the Rule of Law - State of Affairs and Ways of Strengthening“, in: ders. (Hrsg.), Strengthening the Rule of Law in Europe: From a Common Concept to Mechanisms of Implementation, Oxford University Press, Oxford, 2016, S. 3-34.

5 Thomas von Danwitz, „The Rule of Law in the Recent Jurisprudence of the ECJ“, in: Fordham International Law Journal 37 (2014), S. 1311-1348.

6 Koen Lenaerts, „Die Werte der Europäischen Union in der Rechtsprechung des Gerichtshofs der Europäischen Union: eine Annäherung“, in: Europäische Grundrechtezeitschrift (2017), S. 639-642. 
gehandelt. Gerichtliche Verfahren haben naturgemäß bedingt, dass der Europäische Gerichtshof in besonderem Maße und entscheidend Verfahren geprägt hat. Auch hat, um ein weiteres Beispiel zu nennen, die Venedig-Kommission des Europarates an vielen Stellen die Rechtslage in Mitgliedstaaten der Union entscheidend und häufig erstmals eingehend untersucht. Sie hat z.B. zu Polen bis jetzt sechs Gutachten erstellt, davon eines als besonders „dringend“ bezeichnetes. ${ }^{7} \mathrm{Zu}$ Ungarn sind die Gutachten noch weitaus zahlreicher. Auf diesen Gutachten hat die Europäische Kommission häufig eng aufgebaut. Dennoch bleibt die Europäische Kommission in der Krise derjenige Akteur, der viele Maßnahmen entscheidend geprägt hat, dies durch den Entschluss zur Einleitung eines Verfahrens selbst dann, wenn später der Gerichtshof zur Letztentscheidung berufen war.

Die Europäische Kommission ist dabei nicht nur zur Einhegung, sondern zur Lösung der Krise angetreten. Bedient hat sie sich dabei einer Vielzahl an Verfahren anstelle eines einzigen. Die Rechtswissenschaft muss daher bei Interesse an der Arbeit der Kommission auch diese Summe an Verfahren in den Blick nehmen. Das ist ein wesentlicher Unterschied zu einer früheren Krise, die im Zusammenhang mit der jetzigen häufig genannt wird, der sog. Haider-Krise oder Causa Austria des Jahres 2000 in Bezug auf Österreich. Die damalige Krise ist vorrangig mit Blick auf die Nutzung und Entwicklung des Verfahrens nach Art. 7 EUV, also „monoprozedural“, untersucht worden. ${ }^{8}$ Eine derartige, auf ein einzelnes

7 Venedig-Kommission, 1. CDL-AD(2016)001, Opinion 833/2015, Opinion on amendments to the Act of 25 June 2015 on the Constitutional Tribunal of Poland vom 11.03.2016; CDL-AD(2016)012, Opinion 839/2016, Poland - Opinion on the Act of 15 January 2016 amending the Police Act and certain other Acts vom 13.06.2016; 3. CDL-AD(2016)026, Opinion 860/2016, Poland - Opinion on the Act on the Constitutional Tribunal vom 14.10.2016; 4. CDL-AD(2017)028, Opinion 892/2017, Poland - Opinion on the Act on the Public Prosecutor's office vom 11.12.2017; 5. CDL-AD(2017)031, Opinion No. 904/2017, Poland - Opinion on the Draft Act amending the Act on the National Council of the Judiciary; on the Draft Act amending the Act on the Supreme Court, proposed by the President of Poland, and on the Act on the Organisation of Ordinary Courts vom 11.12.2017; 6. CDL-PI(2020)002, Opinion No. 977/2019, Poland - Urgent Joint Opinion on the amendments to the Law on organisation on the Common Courts, the Law on the Supreme Court and other Laws vom 16.01.2020.

8 Frank Schorkopf, Homogenität in der Europäischen Union - Ausgestaltung und Gewährleistung durch Art. 6 Abs. 1 und Art. 7 EUV, Duncker \& Humblot, Berlin, 2000; Ulrike Kassner, Die Unionsaufsicht: Ausmaß und Bedeutung des Überwachungsmechanismus nach Artikel 7 des Vertrags über die Europäische Union, Peter Lang, Frankfurt a. M. u. a., 2003; Thomas Pforr, 


\section{A. Einleitung}

Verfahren beschränkte Darstellung, wie sie gerade in der deutschen Europarechtswissenschaft seit der Dissertation Christian Tomuschats ${ }^{9}$ in einer großen Tradition steht, greift angesichts der Dynamik der derzeitigen Krise allerdings zu kurz. Dabei bin ich keinesfalls der erste, der das erkannt hat. ${ }^{10}$

Es geht mir hier vielmehr um die verstärkte Verzahnung der Maßnahmen der Union. Die Forschung weiß um die Entwicklung der Rechtsstaatlichkeitskrise in den verschiedenen Mitgliedstaaten und beschäftigt sich mit den Auswirkungen der Krise gerade auf das Rechtsstaatsprinzip im Unionsrecht. Bekannt ist auch die Mehrzahl der Verfahren, welche die Union nutzt. Es fehlt aber noch ein überzeugendes Gesamtverständnis der prozeduralen Reaktionen der Union in der Rechtsstaatlichkeitskrise. Dem dient diese Arbeit.

Die Leitthese lautet, dass die Europarechtswissenschaft zwar sehr wohl Rechtsbegriffe entwickelt hat, die die besondere Natur der Rechtsstaatlichkeitskrise selbst erfassen - der überzeugendste ist derjenige des sog. systemischen Defizits an Rechtsstaatlichkeit -, dass sie aber bislang die Funktionsweise des „polyprozeduralen“ Instrumentariums in Reaktion auf diese Defizite zu wenig als kohärente Antwort seitens insbesondere der Kommission in den Blick nimmt. Diese Wahrnehmungslücke möchte ich schließen. Dazu schlage ich vor, dieses Rechtsregime mit dem Begriff der Verfassungsaufsicht im Recht der Europäischen Union zu erfassen. Den

Die allgemeine Unionsaufsicht, Peter Lang, Frankfurt a.M. u. a., 2004; André Hau, Sanktionen und Vorfeldmaßnahmen zur Absicherung der europäischen Grundwerte: Rechtsfragen zu Art. 7 EU, Nomos, Baden-Baden, 2002; Katharina Serini, Sanktionen der Europäischen Union bei Verstoß eines Mitgliedstaats gegen das Demokratie- oder Rechtsstaatsprinzip, Duncker \& Humblot, Berlin, 2009; Katrin Träbert, Sanktionen der Europäischen Union gegen ihre Mitgliedstaaten: Die Sanktionsverfahren nach Art. 228 Abs. 2 EGV und Art. 7 EUV, Peter Lang, Frankfurt a. M., 2010.

9 Christian Tomuschat, Die gerichtliche Vorabentscheidung nach den Verträgen über die Europäischen Gemeinschaften, Carl Heymanns, Köln, 1964.

10 Von „Instrumenten des europäischen Rechts der Verfassungskrise“ sprechen bereits Armin von Bogdandy \& Michael Ioannidis, „Das systemische Defizit: Merkmale, Instrumente und Probleme am Beispiel der Rechtsstaatlichkeit und des neuen Rechtsstaatlichkeitsaufsichtsverfahrens", in: Zeitschrift für ausländisches öffentliches Recht und Völkerrecht 74 (2014), S. 283-328, S. 312 ff.; weiter ausführlich Christophe Hillion, "Overseeing the Rule of Law in the EU: Legal Mandate and Means“, in: Carlos Closa \& Dimitry Kochenov (Hrsg.): Reinforcing Rule of Law Oversight in the European Union, Cambridge University Press, Cambridge, 2016, S. 59-81. 
Begriff des Rechtsregimes verstehe ich anders als z.B. Jürgen Bast,${ }^{11}$ bei dem er ein Element zur Identifizierung einer unionalen Handlungsform ist. Ich bediene mich vielmehr des Verständnisses des Regimes im Sinne der Regimetheorie der Internationalen Beziehungen und insbesondere Beate Kohler-Kochs und verstehe unter ihm eine autonom entwickelte, reaktive, effektive und dauerhafte Regelung eines bestimmten - hier rechtlichen - Problemfeldes. ${ }^{12}$ Der Begriff der Verfassungsaufsicht, in der Krise teils bereits verwendet, aber nicht erklärt, ${ }^{13}$ kann in der deutschen Rechtswissenschaft auf eine lange, aber nicht unproblematische, ${ }^{14}$ Tradition zurückblicken. Zweck der Verfassungsaufsicht ist der Schutz des Verfassungskerns.

Die Verfassungsaufsicht ist Aufsicht im föderalen Gefüge der Union durch ein Unionsorgan gegenüber einem Mitgliedstaat. Sie umfasst diejenigen Maßnahmen im Unionsrecht, die bezogen auf diesen Verfassungskern mindestens die Feststellung, häufig aber auch die Berichtigung einer Handlung ermöglichen, die diesen Verfassungskern gefährdet. Dabei bedingt die Natur der gegenwärtigen Krise, dass dabei vorrangig das Rechtsstaatsprinzip in den Blick gerät. Jedenfalls kein Verfassungsaufsichtsinstrument ist, ungeachtet der überragenden Bedeutung für die Entwicklung des Unionsrechts auch in der Krise, das Vorabvorlageverfahren. Ihm fehlt gegenüber dem Mitgliedstaat die unmittelbare Gestaltung der Rüge durch ein Unionsorgan, auch die letztendliche Regelungsfunktion ist ihm genommen, sie liegt bei den mitgliedstaatlichen Gerichten. Um es mit Mattias Wendel zu sagen: „Das Vorabentscheidungsverfahren ist nicht Teil eines hierarchisch gegliederten Instanzenzuges, sondern folgt der Idee einer

11 Jürgen Bast, Grundbegriffe der Handlungsformen der EU: entwickelt am Beschluss als praxisgenerierter Handlungsform des Unions- und Gemeinschaftsrechts, Springer, Heidelberg 2006, S. 21.

12 Beate Kohler-Koch, „Zur Empirie und Theorie internationaler Regime“, in: dies. (Hrsg.), Regime in den internationalen Beziehungen, Nomos, Baden-Baden, 1989, S. 17-85, S. 18.

13 Vgl. Thomas Giegerich, „Verfassungshomogenität, Verfassungsautonomie und Verfassungsaufsicht in der EU: Zum „neuen Rechtsstaatsmechanismus“ der Europäischen Kommission“, in: Christian Calliess (Hrsg.), Herausforderungen an Staat und Verfassung: Völkerrecht - Europarecht - Menschenrechte: Liber Amicorum für Torsten Stein zum 70. Geburtstag, Nomos, Baden-Baden, 2015, S. 499-542, insb. S. 520, 528, 542.

14 Entwicklung bei Johannes Heckel, „Das Urteil des Staatsgerichtshofs vom 25.10.1932 in dem Verfassungsstreit Reich-Preußen“, in: Archiv des öffentlichen Rechts 62, N.F. 23 (1933), S. 183-246; Rezeption für das deutsche Recht z.B. bei Jochen Frowein, Die selbständige Bundesaufsicht nach dem Grundgesetz, Röhrscheid, Bonn, 1961, S. 33 ff., 40 ff. 


\section{A. Einleitung}

funktionellen Aufgabenverteilung der Gerichte, in deren Rahmen die Zuständigkeit für die Auslegung von Unionsrecht dem EuGH zugewiesen ist. Dies gilt auch im Verhältnis zu nationalen Verfassungsgerichten. "15 Der Gerichtshof hat es jüngst, in teleologischer Abgrenzung zum Vertragsverletzungsverfahren, ähnlich gesehen. ${ }^{16}$ Was hingegen im Einzelnen dem Verfassungsaufsichtsinstrumentarium zuzurechnen ist, ist im Verlauf der Arbeit auszuführen.

Das Instrumentarium der Verfassungsaufsicht darzustellen, ist der Forschungsgegenstand dieser Arbeit. Der Rechtsbegriff der Aufsicht, dessen spezielle Ausprägung die Verfassungsaufsicht darstellt, umfasst Maßnahmen, die anhand eines „Ist-Soll-Vergleichs“, ${ }^{17}$ hier in der Relation UnionMitgliedstaaten, in der Formulierung von Meike Eekhoff drei Funktionen aufweisen: Beobachtungs-, Überprüfungs- und Berichtigungsfunktion. ${ }^{18}$ Legt man dieses Schema zugrunde, sind in der derzeit in Entstehung befindlichen Verfassungsaufsicht vollständige Aufsichtsmaßnahmen, also solche, die alle drei Stadien in sich vereinen, von partiellen, also solchen, denen die Berichtigungsfunktion fehlt, zu unterscheiden. Teils werden letztere Verfahren dann mit anderen ergänzt, teils ist der berichtigende Durchgriff der Union aber auch bewusst ausgeklammert. Derart partielle Verfahren können auch mit dem Begriff des Monitoring bezeichnet werden. ${ }^{19}$

15 Mattias Wendel, „Kompetenzrechtliche Grenzgänge: Karlsruhes Ultra-vires-Vor-

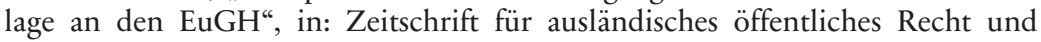
Völkerrecht 74 (2014), S. 615-670, 617-618.

16 EuGH, Verb. Rs. C-558/18 und C-563/18, Miasto Łowicz ./. Skarb Państwa Wojewoda Łódzki, und Prokurator Generalny ./. VX u.a., Urteil (GK) vom 26.03.2020, ECLI:EU:C:2020:234, Rn. 47-49.

17 Meike Eekhoff, Die Verbundaufsicht: Gemeinschaftsrechtliche Aufsichtsverfahren und -mechanismen außerhalb des Vertragsverletzungsverfahrens, Mohr Siebeck, Tübingen, 2006, S. 5.

18 Meike Eekhoff, Die Verbundaufsicht, S. 5-7.

19 Er findet sich regelmäßig in der Praxis für derartige Verfahren, vgl. etwa in der engl. Fassung des EU-Justizbarometers, Europäische Kommission, Communication from the Commission to the European Parliament, the Council, the European Central Bank, the European Economic and Social Committee and the Committee of the Regions, EU Justice Scoreboard 2019, COM(2019) 198/2, S. 1 der engl. Broschürenfassung; zum Begriffszuschnitt ähnlich, Armin von Bogdandy, „Principles and Challenges of a European Doctrine of Systemic Deficiencies“, MPIL Research Paper Series, No. 2019-14, Heidelberg 2019, S. 15; weiter Carlos Closa, „Reinforcing EU Monitoring of the Rule of Law: Normative Arguments, Institutional Proposals and the Procedural Limitations“, in: Carlos Closa \& Dimitry Kochenov (Hrsg.): Reinforcing Rule of Law Oversight in the European Union, 2016, S. 15-35. 
In ihrem Verlauf, ihrer Rechtsgrundlage, den genutzten Handlungsformen, beteiligten Akteuren und vor allem ihren Rechtswirkungen, einschließlich der Frage der Rechtsverbindlichkeit, sind diese Verfahren höchst unterschiedlich. Es sind solche Maßnahmen zu unterscheiden, die in den Verträgen bereits speziell für den Werteschutz angelegt waren (Art. 7 EUV), von solchen, die mit Blick auf die Krise unmittelbar und speziell für ihre Lösung geschaffen wurden (insbesondere der sog. EU-Rahmen zur Stärkung des Rechtsstaatsprinzips), von schließlich solchen, die im Verlauf der Krise zu einem Verfassungsaufsichtsinstrumentarium umfunktioniert (neu ausgerichtet) wurden. Für das Vertragsverletzungsverfahren nach Art. 258 AEUV lässt sich das auf spektakuläre Weise beobachten, es gibt aber auch Verfahren, wie das EU-Justizbarometer, in welchem dieser Prozess auf sehr viel subtilere Weise abgelaufen ist. Teleologisch ergeben die Verfahren gleichwohl ein einheitliches Rechtsregime.

In der derzeitigen Krise steht, als Teil des unionalen Verfassungskerns, weil durch die kritisierten Maßnahmen besonders berührt, die Rechtsstaatlichkeit im Fokus. Damit ist aber nicht gemeint, dass die unionale Verfassungsaufsicht sich ausschließlich dem Rechtsstaatsprinzip zuwenden muss. Es ist nicht ausgeschlossen, dass in ihrer späteren Entwicklung weitere Prinzipien, die Art. 2 EUV aufzählt, entsprechend angegangen werden. Der Gerichtshof hat hierfür durch sein Plenum bereits vorgesorgt. In der Wightman-Entscheidung des Gerichtshofs, in der es eigentlich um Rechtsfragen betreffend den Brexit ging, hat der Gerichtshof nämlich jüngst den „demokratischen Prozess [...] im Einklang mit seinen [scil.: des Mitgliedstaats] verfassungsrechtlichen Vorschriften " ${ }^{\text {"20 }}$ zum Schutzgut erklärt. Damit ein solcher Prozess nach mitgliedstaatlichen Vorschriften abgehalten werden kann, muss er zunächst erst einmal das Prädikat „demokratisch“ erhalten, und das könnte zukünftig durch den EuGH anlassbezogen untersucht werden.

Die Entwicklung des Zuschnitts der Verfassungsaufsicht wird also durch die Entwicklung der Krise angeleitet, deren näheres Verständnis die Arbeit daher, obwohl bereits die Verfassungsaufsicht selbst viel Material bietet, nicht ausklammern kann. Zwei Punkte sind hierbei wichtig, die das Erkenntnisinteresse weiter prägen und der Analyse des Verfassungsaufsichtsinstrumentariums vorangestellt werden müssen.

Zunächst rückt die Erörterung des Rechtsstaatsprinzips als (derzeitiges) primäres Schutzgut wieder in den Blick. Ich setze an die Stelle ausführli-

20 EuGH, Rs. C-621/18, Andy Wightman u.a. ./. Secretary of State for Exiting the European Union, Urteil (Plenum) vom 10.12.2018, ECLI:EU:C:2018:999, Rn. 66. 


\section{A. Einleitung}

cher Ergründungen eine durch die Notwendigkeit effektiver Reduktion des Materials angeleitete Darstellung der Operationalisierung dieses Prinzips in der Rechtspraxis und knüpfe dafür an die zusammen mit Piotr Bogdanowicz gemachten früheren Überlegungen an. ${ }^{21}$ Dank dieser Entwicklungen in der Praxis sind die vermeintlichen rechtstheoretischen Untiefen des Rechtsbegriffs der Rechtsstaatlichkeit, die Philipp Kunig zur Verzweiflung getrieben haben ${ }^{22}$ oder Erik Wennerström rechtspolitische Wünsche anmelden ließen, ${ }^{23}$ überzeugend aufgehellt worden.

Zum zweiten muss die Rechtswissenschaft der enormen Heterogenität der Rechtsstaatlichkeitskrise Herr werden. Das gelingt am besten durch eine topische Sichtung ihrer Entwicklung und der Identifizierung verschiedener Typen des sie erfassenden systemischen Defizits an Rechtsstaatlichkeit, die umfassend auf vorangegangene Arbeiten in der Politik- und Rechtswissenschaft aufbaut.

Die beiden wesentlichen Typen dieses Defizits sind einerseits das Phänomen des sog. schwachen Mitglieds (weak member) und andererseits der Typus der sog. vorsätzlichen Unterwanderungen des Rechtsstaatsprinzips. Der erste meint eine tragische, aber nicht gewollte Verwaltungsunfähigkeit defizitärer Mitgliedstaaten. Er stand während der Frühphase der Krise im

21 Vgl. Matthias Schmidt \& Piotr Bogdanowicz, „The Infringement Procedure in the Rule of Law Crisis: How to make effective use of Article 258 TFEU“, in: Common Market Law Review 55 (2018), S. 1061-1100, insb. S. 1088 ff. Ähnlich gelagert in der Methode Luke Dimitrios Spieker, „Breathing Life into the Union's Common Values“, insb. S. $1201 \mathrm{ff}$.

22 Philipp Kunig, Das Rechtsstaatsprinzip: Überlegungen zu seiner Bedeutung für das Verfassungsrecht der Bundesrepublik Deutschland, Mohr Siebeck, Tübingen, 1986, insb. ab S. 481 unter dem Titel „Rechtsstaatlichkeit als Kategorie juristischer und politischer Diskussion: Eine Schlußbemerkung“, S. 481-488, s. insb. S. 488: „Die im Grundgesetz niedergelegte Ordnung ist und bleibt konsensfähig durch die Freilegung von Rechtsstaatlichkeit im Verzicht auf ein Rechtsstaatsprinzip, dessen gegenwärtige Omnipräszenz und Allgewalt die integrierende Kraft dieser Ordnung bedrohen kann." Ähnlich verhalten Katharina Sobota, Das Prinzip Rechtsstaat, Verfassungs- und Verwaltungsrechtliche Aspekte, Mohr Siebeck, Tübingen, 1997, S. 253, im Anschluss an ihre „Elementereihung“ zum Rechtsstaatsprinzip, wonach damit der Begriff zwar „Elastizität, aber keine Kontur“ gewonnen habe. Sobota zählt, ebda. S. 254-257, nicht weniger als 142 Subprinzipien („Elemente“) zum Rechtsstaatsprinzip, ähnlich wie Kunig ebda., S. 258.

23 Erik O. Wennerström, The Rule of Law and the European Union, Iustus Förlag, Uppsala, 2007, S. 292 ff. zu divergierenden Rechtsstaatskonzepten im Unionsrecht, weiter insb. S. 307. 
Fokus. ${ }^{24}$ Michael Ioannidis hat dieses Konzept später fortentwickelt. ${ }^{25}$ Piotr Bogdanowicz und ich hatten diesem Typus die Beobachtung des zweiten grundsätzlich dichotom entgegengesetzt und angemerkt, dass sich in der derzeitigen Entwicklung zusätzlich im Hinblick auf derart vorsätzliche Unterwanderungen heterogene oder polythematische von homogenen oder monothematischen Mitgliedstaaten trennen lassen. Das bedeutet, dass z.B. in Polen die Änderungen vorrangig auf die Justiz, in Ungarn aber auf eine Vielzahl an Schutzgütern und Einrichtungen abzielen. ${ }^{26}$ Dieser Typus allein ist in der vorliegenden Arbeit von Interesse, denn nur gegenüber ihm gelangt derzeit das Rechtsregime der Verfassungsaufsicht zur Anwendung.

\section{Gang und normative Ausrichtung der Arbeit}

Die Arbeit gliedert sich in fünf Hauptteile. In einem ersten Teil (B.) erläutere ich den Begriff der Rechtsstaatlichkeitskrise und des systemischen Defizits sowie ihrer Beziehung zueinander. Abzugrenzen ist letzterer insbesondere von konkurrierenden Vorschlägen in der Literatur. Haupterkenntnisinteresse dieses Teils ist die Fortentwicklung des Begriffs des systemischen Defizits im Verlauf der Krise sowie die verschiedenen Stränge an Vorschlägen, auf welche dabei zurückgegriffen werden kann.

Der zweite Teil (C.) hat die topische Beschreibung der Rechtsstaatlichkeitskrise zum Gegenstand. Diese orientiert sich gleichermaßen am Erkenntnisinteresse des Wissenschaftlers wie des Praktikers. Es gilt zu klären, warum insbesondere Polen und Ungarn im Verlauf der Krise so interessiert haben, warum andere Mitgliedstaaten weniger von Interesse waren und welche von ihnen sogar fälschlicherweise in den Fokus gerückt sind.

Nachdem damit notwendige Verständnisvoraussetzungen geschaffen sind, nimmt der dritte Teil (D.) den für diese Arbeit ganz wesentlichen

24 Armin von Bogdandy \& Michael Ioannidis, „Das systemische Defizit“, S. 283-328, insb. S. 286, auch $306 \mathrm{ff}$.

25 Michael Ioannidis, „Weak Members and the Enforcement of EU Law“, in: András Jakab \& Dimitry Kochenov (Hrsg.), The Enforcement of EU Law and Values: Ensuring Member States' Compliance, Oxford University Press, Oxford, 2017, S. 476-492, insb. S. 481; zu „Schwächen“ jüngst nochmals auch Armin Bogdandy, „Principles and Challenges of a European Doctrine of Systemic Deficiencies", S. 10 und f.

26 S. näher unsere Überlegungen bei Matthias Schmidt \& Piotr Bogdanowicz, „The Infringement Procedure in the Rule of Law Crisis”, S. $1086 \mathrm{ff}$. 


\section{A. Einleitung}

Begriff der Verfassungsaufsicht in den Blick und stellt die Argumente für seine Verwendung vor.

Vor einem kurzen Blick auf Entwicklungsperspektiven im letzten Teil (F.) stellt der vierte Teil (E.) das Rechtsregime der Verfassungsaufsicht vor, strukturiert in hier sog. partielle Verfahren, die keine Berichtigungsphase kennen, und solche, die diese mit umfassen.

In diese Darstellung fließen eigene Erfahrungswerte aus teilnehmender Beobachtung ${ }^{27}$ ein, die auf der zweifachen Abordnung zum Referat Justizpolitik und Rechtsstaatlichkeit (Referat C.1) der Generaldirektion Justiz und Verbraucher der Europäischen Kommission zum einen im Frühjahr 2017 sowie im Herbst und Winter 2018-2019 beruhen.

Diese teilnehmende Beobachtung hat zunächst die Vermutung bestätigt, die durch eine Rede der früheren Justizkommissarin Viviane Reding 2013 erstmals öffentlich wurde, ${ }^{28}$ dass es, trotz erheblicher Bedeutung anderer Dienststellen, wie insbesondere des Juristischen Dienstes, die Generaldirektion Justiz und Verbraucher (GD JUST) war, die dieses Verfassungsaufsichtsregime entwickelt hat. Es liegt dort in den Händen einer Gruppe von Referenten und ihrer Vorgesetzten, die neben juristischer Expertise und Praxiserfahrung eine enorme Bandbreite europäischer akademischer Ausbildung und Werdegänge in sich vereint.

27 Zur teilnehmenden Beobachtung etwa Richard F. Fenno, Jr., „Observation, Context, and Sequence in the Study of Politics“, in: American Political Science Review 80 (1986), S. 3-15; Überblick zur Methodik und Vorarbeiten bei Helmar Schöne, „Die teilnehmende Beobachtung als Datenerhebungsmethode in der Politikwissenschaft: methodologische Reflexion und Werkstattbericht", in: Historical Social Research 30 (2005), S. 168-199. Mehrfach haben europarechtliche Dissertationen am Heidelberger Max-Planck-Institut für ausländisches öffentliches Recht und Völkerrecht auf derartigen Praxiserfahrungen aufgebaut, s. nur, Florian von Alemann, Die Handlungsform der interinstitutionellen Vereinbarung: Eine Untersuchung des Interorganverhältnisses der europäischen Verfassung, Springer, Heidelberg 2006; ebenso, Johanna Elisabeth Dickschen, Empfehlungen und Leitlinien als Handlungsform der Europäischen Finanzaufsichtsbehörden: eine dogmatische Vermessung, Springer, Heidelberg/Berlin, 2017.

28 Viviane Reding, Vice-President of the European Commission, EU Justice Commissioner, „The EU and the Rule of Law - What next?", Rede vor dem Centre for European Policy Studies, Brüssel, vom 04.09.2013, SPEECH/13/677, S. 9. Die Rolle einzelner Dienststellen der Kommission ist sicherlich kein dominierender Interessenschwerpunkt im Unionsrecht. S. aber z.B. zur Rolle des Juristischen Dienstes in den Anfangsjahren der Union Juli Bailleux, „The role of the legal service of the European executives in the invention of EC Law and the birth of the Common Market Law Review“, in: Common Market Law Review 50 (2013), S. 359-367. 
Die Konzentration von Expertise und Maßnahmengestaltung, die die Arbeit der GD JUST dabei für die Betreuung der Rechtsstaatlichkeitskrise entfaltet, ist nicht nur aus Governancegesichtspunkten oder rechtssoziologisch interessant. Sie ist wesentliches Indiz für die Annahme eines kohärenten Rechtsregimes, und sie hat des Weiteren die Annahme gestärkt, dass die Kommission im Rahmen der Krise als zentraler Akteur zu gelten hat.

Keinesfalls wird hier angetreten, investigativ vermeintliche Interna offenzulegen, noch sich die Behauptung anzumaßen, dass Vorgänge und Abläufe abschließend bekannt seien. Im Rahmen der mir eingeräumten Einblicke und nicht zuletzt der Rechtsprechung des Gerichtshofs ${ }^{29}$ lautet das Vorhaben vielmehr, Organisationsstrukturen und Arbeitsgrundsätze in der Europäischen Kommission herauszuarbeiten, von denen ich meine, dass sie der Rechtswissenschaft bislang weniger konkret vor Augen standen und welche die Praktiker vor Ort als das Vorhaben ansehen sollen, die Strukturen und Herausforderungen der Arbeit der Kommission aufzuzeigen und auch zu würdigen. Die hier geschilderten Organisationsstrukturen sind, sofern nicht bereits in Redings Rede offensichtlich, frei zugänglich, ${ }^{30}$ es gilt aber, sie besonders nachzuzeichnen. Rückschlüsse in der Sache beruhen ganz überwiegend auf öffentlich zugänglichem Material. Folgerungen, die sich auf eigene Anschauung stützen, werden als solche hervorgehoben. Weiter nennt die Arbeit keine Namen, merkt aber an, dass einige Beamte entschieden haben, in der Krise akademisch-publizistisch tätig zu sein ${ }^{31}$ und persönliche Meinungen zu einzelnen Verfahren darzulegen.

$29 \mathrm{Zu}$ den Grenzen späterer Berichterstattung über die Arbeit der Europäischen Kommission aufgrund eigener Erfahrungswerte s. EuGH, Rs. C-274/99 P, Bernard Connolly ./. Kommission, Urteil vom 06.03.2001, ECLI:EU:C:2001:127. Das Urteil betraf freilich einen Beamten der Kommission und die streitgegenständliche Schrift verfolgte eine dieser Arbeit konträr entgegengesetzte Intention.

30 Verfügbar unter: https://op.europa.eu/en/web/who-is-who.

31 S. grundlegend insb. Emmanuel Crabit \& Nicolaas Bel, „The EU Rule of Law Framework“, in: Werner Schroeder (Hrsg.), Strengthening the Rule of Law in Europe: From a Common Concept to Mechanisms of Implementation, Hart, Oxford/Portland, 2016, S. 197-206; Emmanuel Crabit \& Anna Perego, „L'État de droit: une politique de l'Union européenne“, in: Revue du Droit de l'Union européenne 20 (2019), S. 7-14; s. weiter Frank Hoffmeister, „Enforcing the EU Charter of Fundamental Rights in Member States: How Far are Rome, Budapest and Bucharest from Brussels?" in: Armin von Bogdandy \& Pál Sonnevend (Hrsg.), Constitutional Crisis in the European Constitutional Area, 2015, S. 195-233; Bernd Martenczuk, „Art. 7 EUV und der Rechtsstaatsrahmen als Instrumente der 


\section{A. Einleitung}

Aus meinem Einblick in das Innenleben der Europäischen Kommission im Rahmen der Krise folgt allerdings auch ein normativer Standpunkt. Ich meine, dass die herrschende Meinung häufig dem Reflex erliegt, vorschnell über die Kommission zu urteilen. Das verleiht denjenigen Auftrieb, die dies wohlüberlegt tun. Die ungarische Regierung hat etwa sogar gemeint, einen am Europäischen Semester beteiligten ungarischstämmigen Kommissionsbeamten einzeln herausgreifen und öffentlich und persönlich angreifen zu müssen. ${ }^{32}$ Das ist ein einmaliger Vorgang.

Auch in der Wissenschaft war die Rezeption der Arbeit der Kommission häufig reserviert ${ }^{33}$ und verstärkt von Misstrauen geprägt. Laurent Pech und Sébastien Platon bescheinigen der Kommission exemplarisch „Prokrastination" 34 und sehen im Übrigen in den Handlungen der Kommission vorrangig Fehlschläge. ${ }^{35}$ Gleichzeitig gehören beide Autoren aber zu denjenigen, die vermehrt an das Generalsekretariat von Kommission und Rat mit Auskunftsanfragen zu einer großen Bandbreite an internen Dokumenten herantreten. ${ }^{36}$ Obwohl diese Anfragen durchaus von Interesse für die Wissenschaft sein können, bedürfen sie der genaueren Abwägung und häufig auch der Zurückhaltung, da sie das Vertrauen zwischen Wissenschaft und Praxis, ${ }^{37}$ dessen es in der Rechtsstaatlichkeitskrise zur gemeinsamen Analyse und Lösung insbesondere zwingend bedarf, nicht vertiefen. Es ist insbesondere nicht ersichtlich, inwieweit Schriftsätze laufender Verfahren, deren Veröffentlichung verlangt wird, ${ }^{38}$ einen unmittelbaren Beitrag zur

Wahrung der Grundwerte der Union“, in: Stefan Kadelbach (Hrsg.), Verfassungskrisen in der Europäischen Union, Nomos, Baden-Baden, 2018, S. 41-59.

32 S. die Pressemitteilung "EU's country report is a political and campaign report" vom 08.03.2018, abrufbar unter: https://www.kormany.hu/en/government-spokes person/news/eu-s-country-report-is-a-political-and-campaign-report.

33 Jüngst exemplarisch Petra Bárd, „The von der Leyen Commission and the Future of the Rule of Law“, Verfassungsblog vom 11.11.2019, o.S.

34 Laurent Pech, Laurent \& Sébastien Platon, „Menace systémique envers l'Etat de droit en Pologne : entre action et procrastination“, Question d'Europe/Fondation Robert Schuman Policy Papers, Fondation Robert Schuman, 2017, insb. S. 4 und 9.

35 Laurent Pech, Laurent \& Anna Wójcik, „A Bad Workman always Blames his Tools': an Interview with Laurent Pech“, Verfassungsblog vom 28.05.2018, o.S.

36 Die Anfragen sind einsehbar unter: https://www.asktheeu.org.

37 Diese Maxime folgt, dort für die Politikwissenschaft entwickelt, den Forderungen von Wilhelm Hennis, „Aufgaben einer modernen Regierungslehre“, in: Politische Vierteljahresschrift 6 (1965), S. 422-441, insb. S. $427 \mathrm{ff}$.

38 Laurent Pech, , „Lex CEU: On the Commission's Refusal to Disclose its Letter of Formal Notice in the Name of Mutual Trust“, Verfassungsblog vom 07.07.2017, o.S. 
Beurteilung liefern, wenn das letzte Wort des Gerichtshofs noch aussteht. In der gegenwärtigen Krise erhalten derartige Vorstöße vielmehr häufig Applaus von der falschen Seite.

Die Herausarbeitung der Funktions-, Nutzungs- und Entwicklungsgrundsät$z e$ des Verfassungsaufsichtsinstrumentariums innerhalb der Kommission soll, neben einer Analyse des späteren Materials selbst, daher einen Gegenpol zu diesen Vorgehensweisen und Auffassungen sein. Ich bin der festen Überzeugung, dass dadurch ein akkurateres Bild vom Hauptakteur der europäischen Rechtsstaatlichkeitskrise gezeichnet wird. Auch normativ ist dies geboten. Die Kommission leistet keinesfalls stets fehlerfreie Arbeit, sie hat nicht alle Entwicklungen vorausgesehen, nicht - gerade als eine streng an die Verträge und das Legalitätsprinzip gebundene Institution - stets rechtspolitisch alle Folgen korrekt abgeschätzt. Das liegt aber in der Natur allen Krisenmanagements und rechtfertigt die stete Kritik an ihr weder im Umfang noch in der Sache. Wie das Europäische Parlament als eine gewählte Legislative aller Unionsbürger wahrgenommen wird, so sollte es der Öffentlichkeit in den Mitgliedstaaten gelingen, die Europäische Kommission nicht als graue Technokratie, sondern als eine gemeinsame, föderale Exekutive und Gubernative für alle Unionsbürger und in Kooperation, nicht Konfrontation, mit den Mitgliedstaaten zu sehen. Ungezählte Beschwerden ${ }^{39}$ gerade aus Osteuropa im Verlauf der Krise, die in den Tiefen der Kommissionsdienststellen bearbeitet werden, zeugen davon, dass sie es für viele Bürger bereits ist.

Armin von Bogdandys Feststellung eines "constitutional moment" der Union in der Krise ${ }^{40}$ muss man daher die Beobachtung eines „,anthropological moment“41 ihres wohl wirkmächtigsten Organs zur Seite stellen. Die Kommission ist in der Krise nicht nur für viele Betroffene unvermutet

39 Die Bedeutung derselben hat die Kommission nur selten deutlich gemacht, s. aber Europäische Kommission, Mitteilung der Kommission an den Rat und an das Europäische Parlament zu Artikel 7 des Vertrags über die Europäische Union. Wahrung und Förderung der Grundwerte der Europäischen Union, $\operatorname{KOM}(2003)$ 606 endgültig vom 15.10.2003, S. 4.

40 Armin von Bogdandy, „Principles and Challenges of a European Doctrine of Systemic Deficiencies“, S.3, unter Berufung auf den zuvor durch Bruce Ackerman geprägten Begriff. Vgl. auch zuvor Armin von Bogdandy, Piotr Bogdanowicz, Iris Canor, Maciej Taborowski \& Matthias Schmidt, „Guest Editorial: A potential constitutional moment for the European rule of law - The importance of red lines“, in: Common Market Law Review 55 (2018), S. 983-996, insb. S. 984-985.

41 Sehr illustrativ in dieser Hinsicht Marc Abélès, Irène Bellier, \& Maryon McDonald: „Approche anthropologique de la Commission européenne“, Studie des Centre National de la Recherche Scientifique, Paris und der University of West 


\section{A. Einleitung}

nahbar geworden, sie hat sich auch, angesichts der Beschränkungen ihrer Möglichkeiten aus den Verträgen und der Politisierung der Vorgänge, erstaunlich verwundbar, diskursiv und nachdenklich gezeigt. „Prokrastiniert" aber haben ihre Verantwortlichen wahrlich nicht.

Gleichzeitig könnten die hier getroffenen Feststellungen auch als Aufforderung an die Kommission dienen, Absichten und Überlegungen gerade der Fachöffentlichkeit noch besser als bisher darzulegen. Die Kommission hat dies für den Bürger vereinzelt, insbesondere im Hinblick auf die Lage in Ungarn, bereits getan, ${ }^{42}$ und sie hat im April 2019 eine bis dato einmalige „stakeholder consultation“, die für alle Beteiligten offenstand, abgehalten. Die Vorbereitung sog. „Rechtsstaatlichkeitsberichte“ im Frühjahr 2020 setzt diese Linie fort. ${ }^{43}$ Weder sie, noch die der Rechtsstaatlichkeit wohlwollend zugewandten und sie im Rat unterstützenden Mitgliedstaaten können aber in einer derart politisierten, gleichzeitig indes höchst technischen und kleingliedrigen Krise darauf warten, dass erst ein Kabarettist des öffentlichen Fernsehens sich der Thematik annimmt (so geschehen in den Niederlanden durch Arjen Lubach), ${ }^{44}$ bis die Öffentlichkeit einen besseren und vor allem prägnanten Zugang zum Material hat. Die deutsche Bundesregierung hat im September 2019 mit ihrer Kampagne „Wir sind Rechtsstaat“ einen Weg aufgezeigt, der dabei gegangen werden könnte, ${ }^{45}$ aber ausgebaut werden muss. Denn letztendlich wird sich die Rechtsstaatlichkeitskrise auch in der öffentlichen Meinung entscheiden.

London im Auftrag der Europäischen Kommission, 1993, abrufbar unter: https:// halshs.archives-ouvertes.fr/halshs-00374346.

42 Vgl. die Veröffentlichung „Facts Matter: European Commission responds to Hungarian government campaign" ohne Datum oder Az., abrufbar unter: https:// ec.europa.eu/commission/sites/beta-political/files/facts_matter_hungarian_govern ment_campaign_en.pdf.

43 S. hierzu https://ec.europa.eu/info/policies/justice-and-fundamental-rights/uphold ing-rule-law/rule-law/rule-law-report_en.

44 Vgl. die Sendung "Judith Sargentini en Hongarije“ vom 14.10.2018, des Kabarettisten Arjen Lubach im Rahmen seines Programms „Zondag met Lubach“ des öffentlich-rechtlichen niederländischen Senders VPRO; zur Rezeption im Ausland De Telegraaf, Zondag met Lubach-filmpje hit in Hongarije vom 21.10.2018.

45 Bundesministerium der Justiz und für Verbraucherschutz, „Informationskampagne „Wir sind Rechtsstaat“ startet bundesweit“, Pressemitteilung vom 20.09.2019, abrufbar unter: https://www.bmjv.de/SharedDocs/Pressemitteilungen/DE/20 19/092019_WirSindRechtsstaat.html. Auf die Bedeutung der Einbeziehung der Öffentlichkeit habe ich bereits hingewiesen in „Le manquement perpétué en droit de l'Union européenne“, unveröff. Abschlussarbeit der École nationale d'administration, Straßburg vom 20.11.2019, S. 18. 


\section{B. Rechtsstaatlichkeitskrise und systemisches Defizit}

Der Begriff der Rechtsstaatlichkeitskrise bezeichnet bei erster Annäherung hochpolitische Abweichungen vom europäischen Konsens der Einhaltung des Rechtsstaatsprinzips in bestimmten Mitgliedstaaten. Zeitlich zusammen fällt er ungefähr mit der Juncker-Kommission, nimmt aber seinen Anfang teils bereits davor und dauert weiter fort. Das allein rechtfertigt und konturiert den Begriff aber nicht.

\section{Keine leichtfertige Verwendung des Begriffs der „Krise“}

Der Begriff der Krise, der im Griechischen zunächst „Wendepunkt“ bedeutet, ${ }^{46}$ hat in der Literatur zu wichtigen Entwicklungsschritten der früheren Gemeinschaften zur heutigen Union regelmäßig Verwendung gefunden. Gerade das mahnt aber, ihn mit Bedacht zu nutzen und nicht zu entwerten. Werner Weidenfeld äußerte, der Krisenbegriff sei ob seiner Präsenz für die Union diskursprägend geworden. ${ }^{47}$ Jonathan White hat Jean Monnet mit den Worten zitiert, dass „Europa durch Krisen gebaut und die Summe ihrer Lösungen" sei..$^{48}$ In den 1970er Jahren haben sodann Gerda Zellentin und Dirk Läufer sich daran versucht, Gesamtdarstellungen europäischer Krisen vorzulegen. ${ }^{49}$ Selbstredend ist auch das Scheitern des Verfassungsvertrags Mitte der nuller Jahre als „europäische Verfassungskrise“ bezeich-

46 Vgl. Duden, Eintrag „Krise“.

47 Werner Weidenfeld, „Die Berichte der Europäischen Gemeinschaft zur Reform des Gemeinschaftssystems seit 1972“, in: Hans Hermann Hartwich (Hrsg.), Gesellschaftliche Probleme als Anstoß und Folge von Politik: Wissenschaftlicher Kongreß der DVPW: 4.-7. Oktober 1982 in der Freien Universităt Berlin: Tagungsbericht, Springer Fachmedien, Wiesbaden, 1982, S. 296-302, S. 296.

48 Jonathan White, Politics of last resort: governing by emergency in the European Union, Oxford University Press, Oxford, 2020, S. 3, er zitiert nach Jean Monnet, Memoirs, Collins, London, 1978, S. 417, hier meine Übersetzung.

49 Dirk Läufer, Krisen in den europäischen und atlantischen Organisationen, Duncker \& Humblot, Berlin, 1974, s. insb. S. 20 ff.; Gerda Zellentin, „Krisen der europäischen Integration. Ursachen und Wirkungen“, in: Integration: Vierteljahreshefte zur Europaforschung 2 (1970), S. 20-37, s. dort insb. S. 20, Definition und Übersicht S. 22 ff. 
net worden. ${ }^{50}$ Selbst die - für die vorliegende Arbeit besonders vorrangige - Überlegung, gerade im Rahmen einer Krise Einblick in die praktische und interne Arbeit der Europäischen Kommission zu suchen, kann auf einen Präzedenzfall verweisen. Fritz Hellwig, später deutsches Mitglied der Hohen Behörde der EGKS, hat in den 1960er Jahren einen ebensolchen Kurzbeitrag vorgelegt. ${ }^{51}$

\section{Rechtsstaatlichkeitskrise}

Die vorab zitierten Arbeiten zeigen, dass bei der Verwendung des Begriffs der europäischen Krise Vorsicht geboten ist. Doch ist das Konzept einer europäischen Rechtsstaatlichkeitskrise nicht diffus und bleibt keinesfalls bloßes Füllwort. Es ist im gegenwärtigen Diskurs von Praxis und Wissenschaft $^{52}$ fest verankert.

\section{Benennung der Krise}

Die Europäische Kommission selbst hat den Begriff „Rechtsstaatlichkeitskrise“ 2013 durch die damalige Justizkommissarin Viviane Reding eingeführt. Reding gelangte zu dem Schluss:

„[S]ince 2009, we also have been confronted on several occasions with a true ,rule of law' crisis." 53

50 Hermann-Josef Blanke, „Erweiterung ohne Vertiefung? Zur „Verfassungskrise” der Europäischen Union“, in: Europarecht 41 (2005), S. 787-801.

51 Fritz Hellwig, „Die supranationalen Vollmachten der Hohen Behörde, dargestellt an ihrer Willensbildung in Krisensituationen“, in: Gerda Zellentin (Hrsg.), Formen der Willensbildung in den Europäischen Organisationen, Athenäum, Frankfurt a.M./Bonn, 1965, S. 31-48. Hellwig war von 1967-1970 Mitglied der Hohen Behörde.

52 In der Rechtswissenschaft exemplarisch Dimitry Kochenov, „Europe's Crisis of Values“, in: Revista catalana del dregt public (2014), S. 106-118; András Jakab \& Dimitry Kochenov, „Introductory Remarks“, in: András Jakab \& Dimitry Kochenov (Hrsg.), The Enforcement of EU Law and Values: Ensuring Member States' Compliance, Oxford, Oxford University Press 2017, S. 1-5.

53 Viviane Reding, „The EU and the Rule of Law - What next?“, S. 6. 
Der Kontext der Entwicklung ist klar erkennbar:

„In parallel to the economic and financial crisis, we also have been confronted on several occasions with a true "rule of law" crisis. They included notably the Roma crisis in France in summer 2010; the Hungarian crisis that started at the end of 2011; and the Romanian rule of law crisis in the summer of 2012."

Reding erlaubt hier zwei getrennte Folgerungen. Zunächst, dass sich die europäische Rechtsstaatlichkeitskrise ihrerseits in einen größeren Krisenkontext einbettet, in dem vor allem auch die europäische Wirtschafts- und Währungskrise Bedeutung erlangt. Jean-Claude Juncker, ${ }^{55}$ Kommissionspräsident von 2014-2019, aber auch die Rechtswissenschaft ${ }^{56}$ haben hierfür den Begriff der „Polykrise“ geprägt. Stefan Kadelbach hat diese unter dem Begriff der Verfassungskrise erfasst und von dort auf die Rechtsstaatlichkeitsfrage übergeleitet. ${ }^{57} \mathrm{Am}$ weitesten holt also aus, wer die Rechtsstaatlichkeitskrise als Teilkrise der unionalen Polykrise begreift, die zu großen Umbrüchen im Unionsrecht und ihren Kompetenzen geführt hat. ${ }^{58} \mathrm{Da}$ bei kann man es nicht belassen, die Rechtsstaatlichkeitskrise ist dafür zu komplex und dauert in unverminderter Brisanz fort. Zum anderen folgt

54 Viviane Reding, „The EU and the Rule of Law - What next?", S. 2.

55 14. Norbert Schmelzer Lesung - Vortrag von EU-Kommissionspräsident JeanClaude Juncker, „Die Europäische Union - eine Quelle der Stabilität in Krisenzeiten“, SPEECH/16/583, S. 1.

56 Ausführlich Christian Calliess: „Bausteine einer erneuerten Europäischen Union: Auf der Suche nach dem europäischen Weg: Überlegungen im Lichte des Weißbuchs der Europäischen Kommission zur Zukunft Europas“, in: Neue Zeitschrift für Verwaltungsrecht 37 (2018), S. 1-9. Unberücksichtigt bleibt mit diesem Begriff die erst ganz zum Ende der Abfassung des Manuskripts weltweit wirkende sog. "Coronavirus-Krise“, die in ihrer Wirkung weit über die Union und ihr Recht hinausreicht. Ähnlich wie hier zur Begriffsgenese auch Theodore Konstadinides, The Rule of Law in the European Union: The Internal Dimension, Hart, Oxford, 2017, S. $141 \mathrm{ff}$. Er bringt, S. 142, unter Verweis auf Reding, die Rolle der Kommission auf den Nenner nicht mehr nur einer Hüterin der Verträge sondern einer „Hüterin der Rechtsstaatlichkeit“ in der Union im Rahmen dieser Krise.

57 Stefan Kadelbach, „Verfassungskrisen“, in: ders. (Hrsg.), Verfassungskrisen in der Europäischen Union, Nomos, Baden-Baden, 2018, S. 9-22.

$58 \mathrm{Zu}$ den wirtschaftsrechtlichen und -politischen Auswirkungen Michael Ioannidis, „Europe's New Transformations: How the EU Economic Constitution changed during the Eurozone Crisis“, in: Common Market Law Review 53 (2016), S. 1237-1282, s. auch Stefan Kadelbach, „Krise, Umbruch und neue Ordnung“, in: ders./Klaus Günther (Hrsg.), Europa: Krise, Umbruch und neue Ordnung, Nomos, Baden-Baden, 2014, S. 9-16. 
hieraus, dass dann andere Bestandteile der sog. „Polykrise“ nicht Teil des Zuschnitts dieser Arbeit sind.

Im April 2019 hat die Kommission den Begriff der Rechtsstaatlichkeitskrise in einer Mitteilung erneut aufgegriffen und dabei weitere Maßnahmen gegenüber einer „Krise des Rechtsstaats in einem Mitgliedstaat“ angekündigt. ${ }^{59} \mathrm{Im}$ Unterschied zur früheren Einlassung Redings hat sie dabei allerdings keine Mitgliedstaaten unmittelbar genannt. Der Begriff selbst ist für die Kommission augenscheinlich nicht dazu geeignet, die beobachteten Vorgänge analytisch zu begleiten. Vielmehr schreibt sie:

„Ein besseres Verständnis der Entwicklungen in den einzelnen Mitgliedstaaten würde es ermöglichen, diese Unterstützung gezielter einzusetzen und etwaige Risiken für die Rechtsstaatlichkeit frühzeitig zu erkennen."

Damit wird deutlich, dass der Begriff der Rechtsstaatlichkeitskrise nicht den Anspruch einer tieferen Deutung der durch sie bezeichneten Sachverhalte bezweckt. Er ist also insbesondere nicht dogmatisch verdichtet. Daran ändert sich auch nichts, wenn man mit Theodor Konstadinides aus Redings Überlegungen den Definitionsvorschlag ableitet, wonach eine derartige Krise jedenfalls vorliege bei

"any deficiencies in the independence, efficiency or quality of the justice system in another Member State. ${ }^{" 60}$

\section{Europäische Krise oder Krise der Union?}

Aus Redings Rede von 2013 resultiert, dass die Rechtsstaatlichkeitskrise jedenfalls nicht nur einen einzelnen Mitgliedstaat betrifft, dass sie aber auf mitgliedstaatlichen Vorgängen beruht. Sie ist also keine Krise der Ebene der Unionsorgane, dies unterscheidet das hier untersuchte Problem von Fragen wie solchen nach der Verwirklichung des Demokratieprinzips auf unionaler Ebene. Das heißt aber nicht zwangsläufig, dass in der Krise

59 Europäische Kommission, Mitteilung der Kommission an das Europäische Parlament, den Europäischen Rat und den Rat, Die weitere Stärkung der Rechtsstaatlichkeit in der Union: Aktuelle Lage und mögliche nächste Schritte, $\operatorname{COM}(2019)$ 163 final vom 03.04.2019, insb. S. 14, prägnanter ("rule of law crisis") in der englischen Fassung, die in der Praxis das Original darstellt, S. 12.

60 Theodore Konstadinides, The Rule of Law in the European Union, S. 142. 
ausschließlich Unionsrecht zum Tragen kommt und ausschließlich Organe und Stellen der Union ihr begegnet sind.

Zunächst ist die Rechtsstaatlichkeitskrise aus vielen nationalen Verfassungskrisen ${ }^{61}$ zusammengesetzt. Das bedeutet, dass sie alle auch aus rein nationaler Sicht bereits Bücher füllen (könnten). Zum zweiten bedingt der Begriff der Rechtsstaatlichkeit selbst eine besondere Offenheit für nationales Recht. Als in Art. 2 S. 1 EUV genannter Wert der Union, der dort nicht definiert wird, muss für seine Ergründung auf nationales Recht rekurriert werden. Das war in der Literatur vielfach abstrakt Gegenstand der Debatte. Für von Bogdandy z.B. ist es nicht ausreichend, die Prinzipien der Union gänzlich ohne Rückgriff auf nationales Recht zu denken, noch, sie schlicht als „Substrat" der kumulierten Verfassungstraditionen der Mitgliedstaaten zu sehen. Es bedürfe vielmehr einer „Herauslösung“ der Wert-„Gehalte“ und ihrer "Fortschreibung" im Unionsrecht. ${ }^{62}$ Ähnlich hat es Christian Calliess gesehen. Die Werte hätten zwar einen definitiven Ursprung in den Rechtstraditionen der Mitgliedstaaten, bedürften aber einer „Hochzonung", die sich zum einen konkret der mitgliedstaatlichen Nutzung vergewissert, ihren „selbständigen Gehalt" aber herausarbeitet. ${ }^{63}$

Das heißt aber nicht, dass die Rechtsstaatlichkeitskrise eindeutig wird, wenn man sie als Summe nationaler Vorgänge begreift. Sie ist untrennbar mit Handlungen der Unionsorgane und auch des Europarates verbunden, wie schon die rege Aktivität der Venedig-Kommission zeigt. Darüber fragt sich, ob sie dann überhaupt als Krise der Union oder nicht vager als „europäische" Krise gefasst werden muss. Christoph Möllers und Linda Schneider sind, neben der Betonung der Bedeutung des Europarates, sogar noch einen Schritt weitergegangen und haben gefolgert, seine Beteiligung sei

61 Zum Begriff der Verfassungskrise für das nationale Verfassungsrecht Sanford Levinson \& Jack M. Balkin, „Constitutional Crises“, in: University of Pennsylvania Law Review 157 (2009), S. 707-753, dort insb. S. 738 ff. zum offenen politischen Machtkampf als hier einschlägigem Subtyp.

62 Armin von Bogdandy, „Grundprinzipien“, in: Armin von Bogdandy \& Jürgen Bast (Hrsg.), Europäisches Verfassungsrecht, Springer, Heidelberg, 2009, S. 13-71, S. 31.

63 Christian Calliess, Art. 2 EUV, in: Christian Calliess \& Matthias Ruffert (Hrsg.): EUV/AEUV: Das Verfassungsrecht der Europäischen Union mit Europäischer Grundrechtecharta, 5. Aufl. C.H. Beck, München, 2016 Rn. 12-15. Für eine Berücksichtigung sowohl mitgliedstaatlicher Rechtstraditionen, die dort indes nicht vertieft werden, wie auch der Rechtsprechung des EuGH auch Ulrike Kassner, Die Unionsaufsicht, S. 85 ff. 


\section{B. Rechtsstaatlichkeitskrise und systemisches Defizit}

möglicher Ausdruck einer unionalen Kapazitätsschwäche. ${ }^{64}$ Die Krise hat aber allein auf Unionsebene zu einer solchen Verdichtung an Instrumentarien und Handlungen geführt, wie sie hier abgehandelt werden, und dies, obwohl der Europarat in seinen Versuchen nicht müde geworden ist, mit der Union in Mahnung und Gutachten gleichzuziehen. Das ficht entscheidend dafür, die Krise vorrangig als Krise der Union zu verstehen.

\section{Rechtsstaatlichkeitskrise oder Krise der europäischen Demokratie?}

Auch die Überlegung, dass die in dieser Studie beobachtete Krise der Union sich vorrangig auf das Rechtsstaatsprinzip bezieht, ist in der Literatur nicht unbestrittener Konsens.

Vassilios Skouris hat die derzeitige Rechtsstaatlichkeitskrise in den Mitgliedstaaten nicht ohne die Diskussion eines Demokratiedefizits auf unionaler Ebene abgehandelt. ${ }^{65}$ Möllers und Schneider ${ }^{66}$ meinen, die Vorgänge in den Mitgliedstaaten seien nicht vor dem Hintergrund der Rechtsstaatlichkeit, sondern des in Art. 2 S. 1 EUV ebenso genannten Demokratieprinzips zu erfassen. Entscheidend ist für sie die Überlegung, zukünftige Mehrheiten, die aus demokratischen Wahlen hervorgehen, zu schützen, also Versuche zu unterbinden, ihre Wahl oder Gestaltungsfreiheit nicht zuzulassen. ${ }^{67}$ Drei Argumente legen sie hierfür zunächst vor: Erstens, dass sie in Fragen des Rechtsstaatsschutzes ein anderes, nämlich vorrangig den hier sog. Fall der staatlichen Schwäche in Mitgliedstaaten angesprochen sehen, zweitens, dass sich für sie die Frage der Rechtsstaatseinhaltung nicht von derjenigen des Demokratieprinzips trennen lässt, und drittens, dass die Ausblendung der Einhaltung des Demokratieprinzips dieses in das freie Ermessen der Mitgliedstaaten stellen würde. ${ }^{68}$ Vorgänge wie in Ungarn und Polen sind für die Autoren daher eine Frage der Einhaltung des Demokratieprinzips, bezogen auf einen „demokratiespezifischen

64 Christoph Möllers \& Linda Schneider, Demokratiesicherung in der Europäischen Union, insb. S. 91.

65 Vassilios Skouris, Demokratie und Rechtsstaat: Europäische Union in der Krise, S. $55 \mathrm{ff}$.

66 Christoph Möllers \& Linda Schneider, Demokratiesicherung in der Europäischen Union, S. 124.

67 Christoph Möllers \& Linda Schneider, Demokratiesicherung in der Europäischen Union, S. 124.

68 Christoph Möllers \& Linda Schneider, Demokratiesicherung in der Europäischen Union, S. 130. 
Kernbestand der EU-Verfassungsrechtsordnung“, den Schutz potentieller, künftiger Mehrheiten. Reduziert auf die Überlegung dieses Begriffskerns ${ }^{69}$ grenzen sie sich ausdrücklich von Vorschlägen bezogen auf das Rechtsstaatsprinzip ab. Die Durchführung von Wahlen, die Medienverfassung und schließlich sogar die richterliche Unabhängigkeit erscheinen hier als Voraussetzung des Demokratieprinzips und gehen in diesem auf. ${ }^{70}$

Für Möllers' und Schneiders These fechten mindestens zwei Überlegungen. Zum einen können sich beide Verfasser auf die etablierte Tradition in der Europarechtswissenschaft berufen, Fragen im Umfeld des Art. 2 EUV unter Rückgriff auf das Demokratieprinzip abzuhandeln. Als Jochen Frowein Anfang der 1980er frühe Überlegungen zum verstärkten Schutz von „Verfassungsprinzipien“ auf Ebenen der Union anstellte, tat er dies, unter dem Eindruck der autokratischen Entwicklungen in Griechenland, ausdrücklich mit Blick auf das Demokratieprinzip und äußerte sich explizit auch zur Bedeutung der Sicherung von Wahlen. ${ }^{71}$ Auch in der sog. Haider-Krise in Österreich haben Verfasser vorrangig das Demokratieprinzip in den Blick genommen. Für Frank Schorkopf ist das von Karl Loewenstein übernommene Konzept der „streitbaren Demokratie“ dasjenige, das Logik in die Handlungen der „XIV“ Mitgliedstaaten gegenüber Österreich im Jahr 2000 bringt. $^{72}$ Überdies sei es darum gegangen, den zukünftigen Mitgliedstaaten Osteuropas „die unbedingte Geltung der demokratischen und rechtsstaatlichen Grundsätze in der Union vor Augen zu führen. "“73

69 Ich halte die Aussagen beider Verfasser, insb. auf S. 130-132 betreffend die Idee eines „Kernbestands“ für äußerst überzeugend, verschiebe weitere Ausführungen dazu aber auf die Beobachtungen zum Begriff der Verfassungsaufsicht.

70 Christoph Möllers \& Linda Schneider, Demokratiesicherung in der Europäischen Union, S. 130-135.

71 Jochen Abr. Frowein, „Die rechtliche Bedeutung des Verfassungsprinzips der parlamentarischen Demokratie für den europäischen Integrationsprozeß", in: Europarecht 18 (1983), S. 301-317, S.302, u. insb. 312. Die Frage des Grundrechtsschutzes, S. 306 f., ist für Frowein zwar ebenso ein bedeutendes Thema, er diskutiert ihn mit Blick auf die Mitgliedstaaten der Union aber vorrangig im Hinblick auf ihre Verpflichtungen aus der EMRK.

72 Frank Schorkopf, Die Maßnahmen der XIV EU-Mitgliedstaaten gegen Österreich: Möglichkeiten und Grenzen einer „streitbaren Demokratie“ auf europäischer Ebene, Springer, Heidelberg 2002, S. 124 und ff. Ausführlich zum Prinzip der streitbaren Demokratie für die Union auch Martin Klamt, Die Europäische Union als streitbare Demokratie: rechtsvergleichende und europarechtliche Dimensionen einer Idee, Utz, München, 2012.

73 Frank Schorkopf, Die Maßnahmen der XIV EU-Mitgliedstaaten gegen Österreich, S. 120. 


\section{B. Rechtsstaatlichkeitskrise und systemisches Defizit}

Neben der Literatur ficht für Möllers und Schneider sicherlich noch beachtlicher, dass auch das Plenum des EuGH sich in jüngster Rechtsprechung eine Hintertür offengelassen hat, um bei Entwicklungen in Mitgliedstaaten, in denen etwa die Einhaltung von Grundsätzen für demokratische Wahlen gefährdet sind, einen Zugriff auf eine Überprüfung anhand des Unionsrechts zu haben. Die sog. Wightman-Entscheidung ${ }^{74}$ hatte ich bereits angesprochen.

Gleichwohl schließe ich mich hier den Beobachtungen von Skouris einerseits und Möllers und Schneider insbesondere nicht an. Entscheidend hierfür ist eine auf die Organpraxis und dabei auf die Positionierung der Europäischen Kommission insbesondere gerichtete Sichtweise, die die Krise in der Praxis ganz besonders prägt. Kommission, aber auch Gerichtshof, trennen die hier untersuchten Maßnahmen von sonstigen Fragen des inneren Aufbaus der Union und fokussieren auf das Rechtsstaatsprinzip. Die Kommission hat seit 2014 drei programmatische Mitteilungen im Umfeld der Krise erlassen, die Grundlage für den sog. EU-Rahmen von $2014^{75}$ sowie zwei weitere Mitteilungen von 2019. ${ }^{76}$ In allen drei Mitteilungen steht das Rechtsstaatsprinzip, nicht dasjenige der Demokratie, als Analyseraster im Vordergrund.

Zum zweiten tritt hier eine das Konzept der streitbaren Demokratie keinesfalls negierende, aber in der Schutzrichtung gegenläufige Sichtweise hinzu, die ich Möllers und Schneider als Einwand entgegenhalte: Nur wenn die Funktionsfähigkeit der dritten Gewalt, der Justiz, gesichert ist, ist der Schutz demokratischer Prozesse, etwa die bei Möllers und Schneider interessierende Wahlrechtssicherung, erst möglich. ${ }^{77}$ Die Kommission folgert daher zurecht:

74 EuGH, Rs. C-621/18, Andy Wightman u.a. ./. Secretary of State for Exiting the European Union, Urteil (Plenum) vom 10.12.2018, ECLI:EU:C:2018:999, insb. Rn. 66.

75 Europäische Kommission, Mitteilung der Kommission an das Europäische Parlament und den Rat, Ein neuer EU-Rahmen zur Stärkung des Rechtsstaatsprinzips vom 11.03.2014, COM(2014) 158 final, S. 4 und Anhang I: Das Rechtsstaatsprinzip als tragendes Prinzip der Union, vgl. auch unter E.V.2. dieser Arbeit.

76 Europäische Kommission, Mitteilung der Kommission an das Europäische Parlament, den Europäischen Rat und den Rat, Die weitere Stärkung der Rechtsstaatlichkeit in der Union: Aktuelle Lage und mögliche nächste Schritte, $\operatorname{COM(2019)}$ 163 final vom 03.04.2019.

77 Vgl. Europäische Kommission, Mitteilung der Kommission an das Europäische Parlament und den Rat, Ein neuer EU-Rahmen zur Stärkung des Rechtsstaatsprinzips vom 11.03.2014, $\mathrm{COM}(2014) 158$ final, S. 5. 
„Das Rechtsstaatsprinzip ist in der EU von besonderer Bedeutung. Die Wahrung der Rechtsstaatlichkeit ist nicht nur Voraussetzung für den Schutz sämtlicher in Artikel 2 EUV aufgelisteter Grundwerte, sie ist auch eine Voraussetzung für die Wahrnehmung aller Rechte und Pflichten, die sich aus den Verträgen und dem Völkerrecht ergeben. Die EU kann nur dann als „Raum der Freiheit, der Sicherheit und des Rechts ohne Binnengrenzen" wirken, wenn alle EU-Bürger und nationalen Behörden Vertrauen in die Rechtsordnung der anderen Mitgliedstaaten haben." ${ }^{\circ 8}$

Darüber ist es konsequent, dass die Kommission mit auf die Rechtsstaatlichkeit bezogenen analytischen Figuren operiert, darunter der „systemischen Gefährdung an Rechtsstaatlichkeit“ im EU-Rahmen ${ }^{79}$ und dem Vorschlag „genereller Mängel in Bezug auf das Rechtsstaatsprinzip“ in einem Verordnungsvorschlag, ${ }^{80}$ der seinen Ursprung ungefähr ein Jahr zuvor in einer Mitteilung zur Budgetgestaltung nach dem Brexit findet. ${ }^{81}$ Bereits in ihrem EU-Rahmen von 2014 hat die Kommission daher, auf die VenedigKommission bauend, festgehalten, dass das Rechtsstaatsprinzip ein „fundamental and common European standard to guide and constrain the exercise of democratic powers"82 ist. Fünf Jahre später haben Emmanuel Crabit und Anna Perego in impliziter Anlehnung an Hannah Arendts „Recht, Rechte zu haben“ diese Überlegung auf die höchst treffende Formel ge-

78 Europäische Kommission, Mitteilung der Kommission an das Europäische Parlament und den Rat, Ein neuer EU-Rahmen zur Stärkung des Rechtsstaatsprinzips vom 11.03.2014, COM(2014) 158 final, S. 5.

79 Europäische Kommission, Mitteilung der Kommission an das Europäische Parlament und den Rat, Ein neuer EU-Rahmen zur Stärkung des Rechtsstaatsprinzips vom 11.03.2014, COM(2014) 158 final, etwa S. 7.

80 Europäische Kommission, Vorschlag für eine Verordnung des Europäischen Parlaments und des Rates über den Schutz des Haushalts der Union im Falle von generellen Mängeln in Bezug auf das Rechtsstaatsprinzip in den Mitgliedstaaten vom 02.05.2018, $\operatorname{COM(2018)~} 324$ final, 2018/0136 (COD).

81 Europäische Kommission, Mitteilung der Kommission an das Europäische Parlament, den Europäischen Rat und den Rat, Ein neuer, moderner mehrjähriger Finanzrahmen für eine Europäische Union, die ihre Prioritäten nach 2020 effizient erfüllt: Beitrag der Europäischen Kommission zur informellen Tagung der Staatsund Regierungschefs am 23. Februar 2018, COM(2018) 98 final vom 14.02.2018, S. 20.

82 Europäische Kommission, Mitteilung der Kommission an das Europäische Parlament und den Rat, Ein neuer EU-Rahmen zur Stärkung des Rechtsstaatsprinzips, 11.03.2014, $\operatorname{COM(2014)~} 158$ final, Anhang I: Das Rechtsstaatsprinzip als tragendes Prinzip der Union S. 3, engl. Zitat auch in der dt. Fassung. 
bracht, wonach das Rechtsstaatsprinzip die "Garantie der Garantien“ ist. ${ }^{83}$ Dieser Ausspruch betont die herausgehobene Rolle der Rechtsstaatlichkeit gerade in der Praxis, auch für die anderen Werte der Union.

Schließlich zeigt die faktische Entwicklung der Rechtsstaatlichkeitskrise und ihre rechtliche Beurteilung durch den Europäischen Gerichtshof, dass eben jene Priorisierung der Furcht vor der Ausschaltung der Justiz, die in der Folge erst mögliche Eingriffe auch in demokratierelevante Prozesse wie Wahlen erlaubt, völlig gerechtfertigt war. Für Polen hat z. B. vor der Großen Kammer des Gerichtshofs wiederholt die Frage der Lage der polnischen Justiz interessiert, wobei das Problembewusstsein des Gerichtshofs auf den gerichtlichen Schutz und die volle Anwendung des Unionsrechts als Konkretisierung der Rechtsstaatlichkeit im Vordergrund stand. ${ }^{84}$ Für Ungarn hat insbesondere Kim Lane Scheppele analysiert, ${ }^{85}$ was passieren kann, wenn in einem Mitgliedstaat die Justiz nicht mehr funktionsfähig ist, nämlich dass erst dann und dafür umso drängender Wahlrechtsänderungen interessieren müssen. Nicht zuletzt die OSZE hat Ungarn im Anschluss an dortige Interferenzen gerade mit der Verfassungsgerichtsbarkeit einer Beobachtermission im Hinblick auf die Parlamentswahlen unterzogen. ${ }^{86}$

Es würde diese aus der Rechtspraxis stammenden und hier darzustellenden Entwicklungen bewusst ignorieren, wenn man nicht weiterhin vorrangig auf die Rechtsstaatlichkeit schaute. Es bleibt dabei die Option des Gerichtshofs erhalten, sich bei weiterer Schwerpunktverlagerung verstärkt der Einhaltung des Demokratieprinzips zuzuwenden.

83 Emmanuel Crabit \& Anna Perego, „L'État de droit: une politique de l'Union européenne“, S. 7.

84 Vgl. nur EuGH, Rs. C-619/18 R, Kommission ... Polen, „Unabhängigkeit des Obersten Gerichts [scil.: Gerichtshofs]“, Urteil (GK) vom 24.06.2019, ECLI:EU:C:2019:531, Rn. 47; Rs. C-192/18, Kommission ./. Polen, „Unabhängigkeit der ordentlichen Gerichte“, Urteil (GK) vom 05.11.2019, ECLI:EU:C:2019:924, Rn. 98.

85 Exemplarisch Kim Lane Scheppele, „Constitutional Coups in EU Law“, in: Maurice Adams, Anne Meuwese, Anne \& Ernst Hirsch Ballin, Constitutionalism and the Rule of Law, Cambridge University Press, Cambridge, 2017, S. 446-478.

86 OSZE/ODIHR, „Hungary: Parliamentary Elections: 8 April 2018: ODIHR Limited Election Observation Mission: Final Report”, ohne Az., Warschau, 27.10.2018. Hierzu später nochmals unter C. IV. 9. 
4. Zur Existenz und Reichweite der Rechtsstaatlichkeitskrise empirischer Befund

Die Verwendung des Begriffs der Rechtsstaatlichkeitskrise stellt die Forschung sodann vor das erhebliche Problem, dass die Wissenschaft über die Frage der Reichweite, d.h. des Kreises der betroffenen Mitgliedstaaten, höchst zerstritten ist und dass die Kommission die nach ihrer Auffassung betroffenen Mitgliedstaaten nicht benennt. Auch begründet die Kommission nicht, warum bestimmte Mitgliedstaaten von einer Krise rechtsstaatlicher Standards besonders betroffen sind.

Vielfach ist daher gefragt worden, ob man überhaupt zur Feststellung einer solchen Krise gelangen kann oder ob dies nicht einseitig ist und osteuropäische Mitgliedstaaten diskriminiert. ${ }^{87}$ Ich möchte diese Diskussion in dieser Arbeit nicht nochmals aufgreifen, sondern sie mit einem Argument von Bogdandys abkürzen: die Beobachtung einer Rechtsstaatlichkeitskrise ist in Praxis und Wissenschaft derart substantiiert worden, dass nicht ein vermeintliches Herbeireden, sondern erst das Schweigen über sie die Union wirklich in eine Identitätskrise stürzt. ${ }^{88}$

Allerdings ist Kritikern zuzugestehen, dass sich der empirische Befund bei genauerem Hinsehen, abhängig vom gewählten Kriterium, durchaus erschüttern lässt. Der Befund der Rechtsstaatlichkeitskrise ist also das Er-

87 Sehr kritisch Martin Mendelski, „Das europäische Evaluierungsdefizit der Rechtsstaatlichkeit“, in: Leviathan 44 (2016), S. 366-398, S. 375 ff., der sogar von „pathologischen Effekten“ spricht; Udo Di Fabio, „Bewahrung und Veränderung demokratischer und rechtsstaatlicher Verfassungsstruktur in den internationalen Gemeinschaften“, in: Archiv des öffentlichen Rechts 141 (2018), S. 106-116, S. 111. Reaktionen von Mitgliedstaaten, denen dieses Argument zugrunde liegt, z.B. bei Kanzlei des polnischen Premierministers, White Paper on the Reform of the Polish Judiciary vom 07.03.2018, Rn. 176 ff.; Ausführungen der ungarischen Delegation bei der OSZE, „Right to Reply Delegation of Hungary, Working Session 4. Rule of Law I. HDIM, 12. September 2018. Warsaw", abrufbar unter: https://www.osce.org/odihr/397487?download=true. Zur Sorge aber auch in der Kommission, vgl. Věra Jourová, „Speech of Commissioner Jourová at the Prague European Summit: Future of Europe: A Union closer to the citizens" vom 19.06.2018, abrufbar unter: https://ec.europa.eu/commission/commissioners/20 14-2019/jourova/announcements/speech-commissioner-jourova-prague-europea n-summit-future-europe-union-closer-citizens_en. Aus der Presse facettenreich, Charlemagne, „A Carolingian folly“, The Economist vom 10.01.2019; weiter Frédéric Says, „Les pays de l'Est, boucs émissaires des discours politiques?" , Folge der Reihe „Le billet politique“, Radio France Culture vom 24.09.2019.

88 Armin von Bogdandy, „Principles and Challenges of a European Doctrine of Systemic Deficiencies“, S. 8. 
gebnis einer wertenden Gesamtschau und niemals schnell festzumachen. Es drängt sich zwar auf, dass aus den gegen Polen ${ }^{89}$ und Ungarn ${ }^{90}$ laufenden Verfahren nach Art. 7 EUV geschlussfolgert werden muss, dass beide Mitgliedstaaten im Zuge der europäischen Rechtsstaatlichkeitskrise zu nennen sind. Auch hat die Kommission zu Ungarn dem Rat ein Dokument unter dem Titel „values-related infringement actions“ vorgelegt, das nachweist, wie weit die „wertebezogenen“ Bedenken der Kommission hier gehen. ${ }^{91}$

Bei anderen Instrumenten fällt das aber deutlich schwerer. Petra Bárd und Anna Śledzińska-Simon etwa haben den Arbeitsbericht 2018 der Europäischen Kommission ausgewertet und gelangen zu dem Schluss, dass von 48 neuen Vertragsverletzungsverfahren nur zwei mit der „Rechtsstaatlichkeit" in Verbindung zu bringen seien. ${ }^{92}$ Auch der Befund z.B. im Europäischen Semester, einem später in dieser Arbeit genau zu würdigenden Instrument, ist nicht immer eindeutig. Zwar hat die Kommission 2017 in Bezug auf die Lage in Polen unmittelbar auf einen schweren Missstand im Land hingewiesen. ${ }^{93}$ Aber in den vorangegangenen Jahren tat dies die Kommission gegenüber einer großen Zahl an Mitgliedstaaten.

89 Europäische Kommission, Begründeter Vorschlag nach Artikel 7 Absatz 1 des Vertrags über die Europäische Union zur Rechtsstaatlichkeit in Polen für einen Beschluss des Rates zur Feststellung der eindeutigen Gefahr einer schwerwiegenden Verletzung der Rechtsstaatlichkeit durch die Republik Polen, COM(2017) 835 final, 2017/0360 (NLE) vom 20.12.2017.

90 Europäisches Parlament, P8_TA(2018)0340, Die Lage in Ungarn: Entschließung des Europäischen Parlaments vom 12. September 2018 zu einem Vorschlag, mit dem der Rat aufgefordert wird, im Einklang mit Artikel 7 Absatz 1 des Vertrags über die Europäische Union festzustellen, dass die eindeutige Gefahr einer schwerwiegenden Verletzung der Werte, auf die sich die Union gründet, durch Ungarn besteht (2017/2131(INL)), (2019/C 433/10), ABl. (EU) C 433/66 vom 23.12.2019.

91 Europäische Kommission, Non-paper, „The situation in Hungary: Information on values-related infringement proceedings“, ohne eigenes Az, Anhang zu: Rat der Europäischen Union, Interinstitutional File: 2018/0902(COD), Values of the Union - Hungary - Article 7 (1) vom 8. November 2018, 14022/18.

92 Petra Bárd \& Anna Śledzińska-Simon, „Rule of law infringement procedures: A proposal to extend the EU's rule of law toolbox", CEPS Papers in Liberty and Security, 2019-09 vom Mai 2019, S. 12.

93 Empfehlung des Rates vom 11. Juli 2017 zum nationalen Reformprogramm Polens 2017 mit einer Stellungnahme des Rates zum Stabilitätsprogramm Polens, 2017/C 261/20, ABl. (EU) C 261/88 vom 09.08.2017, Erwägungsgrund 14. 
So hat die Kommission 2012 für Bulgarien, ${ }^{94}$ Lettland, ${ }^{95}$ Italien, ${ }^{96}$ Polen ${ }^{97}$ und die Slowakei ${ }^{98}$ eine überlange Verfahrensdauer vor nationalen Gerichten gerügt. 2013 hat sie gegenüber Ungarn festgehalten: „Die Entwicklungen in Ungarn in den Jahren 2012 und 2013 haben die Sorgen hinsichtlich der Unabhängigkeit der Justiz verstärkt." 99 Die Kritik wird 2016 in Gestalt der Sorge vor Korruption und eines „instabilen Regelungsumfeldes“ und vor "Rechtsunsicherheit“ wiederholt. ${ }^{100} 2015$ ist die wiederholte Ermahnung an Bulgarien hervorzuheben, ${ }^{101}$ dass dort die Notwendigkeit für ein „unabhängiges, qualitativ hochwertiges und effizientes“ Justizsystem dringend ist. Ähnlich ist die Formulierung für Rumänien. ${ }^{102}$ Hinsichtlich

94 Empfehlung des Rates vom 10. Juli 2012 zum nationalen Reformprogramm Bulgariens 2012 mit einer Stellungnahme des Rates zum Konvergenzprogramm Bulgariens für die Jahre 2012 bis 2015, 2012/C/219/03, ABl. (EU) vom 24.07.12, C 219/9, Empfehlung 5.

95 Empfehlung des Rates vom 10. Juli 2012 zum nationalen Reformprogramm Lettlands 2012 mit einer Stellungnahme des Rates zum Konvergenzprogramm Lettlands für die Jahre 2012 bis 2015, 2012/C 219/15, ABl. (EU) vom 24.07.12, C 219/50, Erwägungsgrund 18.

96 Empfehlung des Rates vom 10. Juli 2012 zum nationalen Reformprogramm Italiens 2012 mit einer Stellungnahme des Rates zum Stabilitätsprogramm Italiens für die Jahre 2012 bis 2015, 2012/C 219/14, ABl. (EU) vom 24.07.12, C 219/46, Erwägungsgrund 18, Empfehlung 6.

97 Empfehlung des Rates vom 10. Juli 2012 zum nationalen Reformprogramm Polens 2012 mit einer Stellungnahme des Rates zum Konvergenzprogramm Polens für 2012 bis 2015, 2012/C 219/19, ABl. (EU) C 219/65 vom 24.07.2012, Erwägungsgrund 17.

98 Empfehlung des Rates vom 10. Juli 2012 zum nationalen Reformprogramm der Slowakei 2012 mit einer Stellungnahme des Rates zum Stabilitätsprogramm der Slowakei für die Jahre 2012 bis 2015, 2012/C 219/22, ABl. (EU) C 219/74 vom 24.07.2012, Erwägungsgrund 16, Empfehlung 7.

99 Empfehlung des Rates vom 9. Juli 2013 zum nationalen Reformprogramm Ungarns 2013 mit einer Stellungnahme des Rates zum Konvergenzprogramm Ungarns für die Jahre 2012 bis 2016, 2013/C 217/10, ABl. C 217/39 (EU) vom 30.07.13, Erwägungsgrund 15 und Empfehlung 5.

100 Empfehlung des Rates vom 12. Juli 2016 zum nationalen Reformprogramm Ungarns 2016 mit einer Stellungnahme des Rates zum Stabilitätsprogramm Ungarns, 2016/C 299/12, ABl. C 299/49 (EU) vom 18.08.16, Erwägungsgrund 9.

101 Empfehlung des Rates vom 14. Juli 2015 zum nationalen Reformprogramm Bulgariens 2015 mit einer Stellungnahme des Rates zum Konvergenzprogramm Bulgariens 2015, 2015/C 272/08, ABl. (EU) C 272/28 vom 18.08.15, Erwägungsgrund 15.

102 Empfehlung des Rates vom 14. Juli 2015 zum nationalen Reformprogramm Rumäniens 2015 mit einer Stellungnahme des Rates zum Stabilitätsprogramm 
Malta ${ }^{103}$ deuten Rat und Kommission 2014 an, die Geduld zu verlieren. Für Zypern wird 2016 von „ernsten Herausforderungen“ gesprochen. ${ }^{104}$ Es wäre unzutreffend, alle diese Mitgliedstaaten als Instanzen der Rechtsstaatlichkeitskrise der Union zu sehen. Aus den genannten Quellen geht für den Leser aber hervor, dass es augenscheinlich eine bestimmte Gruppe an Mitgliedstaaten gibt, die zusammengenommen die empirische Basis für den Befund der europäischen Rechtsstaatlichkeitskrise bilden. Es lässt sich festhalten, dass einige Mitgliedstaaten immer (Ungarn, Polen), einige manchmal (z.B. Malta, die Slowakei und Zypern) und andere (Schweden, Dänemark und Deutschland etwa) nie in diesem Zusammenhang genannt werden. Das ist für eine rechtswissenschaftliche Analyse ein wesentlicher, aber auch ein sehr unbefriedigender Befund. Die später erfolgende topische Sichtweise der Entwicklung in den Mitgliedstaaten ${ }^{105}$ vermag meines Erachtens, daraus entstehende Zweifel über den Zuschnitt der Krise aus der Welt zu schaffen.

\section{Die Rechtsstaatlichkeitskrise im Spiegel verschiedener Deutungsversuche}

Da die Europäische Kommission den Begriff der Rechtsstaatlichkeitskrise zwar konturiert, aber nicht präzise gefasst hat, ist es Aufgabe der Wissenschaft, diese Lücke zu füllen und Abgrenzungen aufzuzeigen. Dazu bedarf es eines leistungsfähigen Begriffs. Rechts- und Politikwissenschaft haben dazu eine Reihe von Vorschlägen gemacht und darüber eine Begriffskonkurrenz entfacht, die aufgelöst werden muss.

Rumäniens 2015, 2015/C 272/01, ABl. (EU) C 272/1 vom 18.08.15, Erwägungsgrund 18.

103 Empfehlung des Rates vom 8. Juli 2014 zum nationalen Reformprogramm Maltas 2014 mit einer Stellungnahme des Rates zum Konvergenzprogramm Maltas 2014, 2014/C 247/16, ABl. (EU) C 247/83 vom 29.07.2014, Erwägungsgrund 17.

104 Empfehlung des Rates vom 11. Juli 2017 zum nationalen Reformprogramm Zyperns 2017 mit einer Stellungnahme des Rates zum Stabilitätsprogramm Zyperns 2017, 2017/C 261/12, ABl. (EU) vom 09.08.17, C 261/53, Erwägungsgrund 11.

105 S. dazu unter C. II. und ff. 
1. Backsliding, Creative Compliance, Backlash, Executive Aggrandizement

Reges Interesse hat in der Krise der Begriff des democratic backsliding erfahren. ${ }^{106}$ An ihn implizit anknüpfend haben Pech und Scheppele den Begriff des „rule of law backsliding“ bzw. auch „constitutional capture“ geprägt und definiert als

„the process through which elected public authorities deliberately implement governmental blueprints which aim to systematically weaken, annihilate or capture internal checks on power with the view of dismantling the liberal democratic state and entrenching the long-term rule of the dominant party" ${ }^{107}$

Der Begriff des rule of law backsliding hat auch in der rechtswissenschaftlichen Literatur Zustimmung erhalten. ${ }^{108}$ Voll zuzustimmen ist den Beobachtungen beider Verfasser, wonach den gewählten Volksvertretern Vorsatz („,deliberately implement“) zuzuschreiben ist. Allerdings bestehen zwei Nachteile. Zum einen geht es den Autoren vorrangig um den Prozess, nicht die Auswirkungen der Umbrüche. Und zum zweiten legen sie nicht offen, dass es den Urhebern der infrage stehenden Vorgänge häufig nicht allein um die Aushöhlung des bestehenden Wertgefüges, sondern darüber hinaus um das Durchsetzen konkreter, alternativer Wertvorstellungen geht. Gerade das war aber in Polen und Ungarn häufig entscheidend.

Aus dem gleichen Grund, da nicht auf die Gesamtheit der Entwicklung bezogen, ist Agnes Batorys ansonsten auf sehr zustimmungswürdigen

106 Agnes Batory, „Defying the Commission: Creative Compliance and Respect for the Rule of Law in the EU“, in: Public Administration 94 (2016), S. 685-699, S. 686; Ulrich Sedelmeier, „Political safeguards against democratic backsliding in the EU: the limits of material sanctions and the scope of social pressure", in: Journal of European Public Policy 24 (2016), S. 337-351, insb. S. 337-338; JanWerner Müller, „Defending Democracy within the EU“, in: Journal of Democracy 24 (2013), S. 138-149, S. 148, S. 142, zudem als "authoritarian backsliding"; Nancy Bermeo, "On Democratic Backsliding“, in: Journal of Democracy 27 (2016), S. 5-19; Philip Levitz \& Grigore Pop-Eleches, „Why No Backsliding? The European Union's Impact on Democracy and Governance Before and After Accession“, in: Comparative Political Studies 43 (2009), S. 457-485.

107 Laurent Pech \& Kim Lane Scheppele, „Illiberalism Within: Rule of Law Backsliding in the EU“, in: Cambridge Yearbook of European Legal Studies (2017), S. 1-45, S. 30, bei Fn. 100.

108 Luke Dimitrios Spieker, „Breathing Life into the Union's Common Values“, S. 1182. 
Beobachtungen fußender Begriff der „creative compliance“, also des ausweichenden Verhaltens einzelner Mitgliedstaaten in Bezug auf ihre Rechtspflichten, nicht aufzugreifen. ${ }^{109} \mathrm{Er}$ scheint lose an den Begriff der „compliance crisis" bei Michael Zürn anzuknüpfen. ${ }^{110}$ Allerdings erfasst Batorys Überlegung nur einen Teil der hier interessierenden Probleme, nämlich die Frage, wie bestimmte Mitgliedstaaten ausweichend reagiert haben, wenn sie einmal im Fokus der Kommission stehen und ihnen konkrete Vorschläge gemacht oder Verpflichtungen auferlegt werden.

Keine Priorität kann schließlich der Begriff des backlash beanspruchen, der der völkerrechtlichen Literatur entstammt. Er beschreibt einen schweren, lange anhaltenden Konflikt zwischen dem höchsten Gericht einer regionalen Völkerrechtsorganisation und einem ihrer Mitgliedstaaten betreffend die Befolgung seiner Rechtsprechung. ${ }^{111}$ Die Sichtung der Spezifika der Rechtsstaatlichkeitskrise zeigt, dass sie unionsspezifisch ist, ${ }^{112}$ insbesondere etwa, weil die Defizite in mitgliedstaatlichen Justizsystemen, wie sie derzeit zu beobachten sind, gerade vor dem Hintergrund des gegenseitigen Vertrauens in der Union besondere Brisanz entfalten. Für Ximena Soley und Silvia Steininger ist der backlash zudem die kontextgebundene, eskalierte Kritik an der gesamten Institutionenstruktur der Organisation und insbesondere an ihrem Gerichtshof. ${ }^{113}$ In diese Richtung deutet die Rechtsstaatlichkeitskrise der Union indes bislang nicht.

In der Unionsspezifik der unionalen Rechtsstaatlichkeitskrise, die auch an anderer Stelle die Rezeption unionsexterner Beobachtungen und Kon-

109 Agnes Batory, „Defying the Commission“, S. 685-699, insb. S. 689.

110 Michael Zürn, „Introduction: Law and compliance at different levels“, in: Michael Zürn \& Christian Joerges (Hrsg.), Law and Governance in Postnational Europe: Compliance beyond the Nation-State, Cambridge University Press, Cambridge 2005, S. 1-39, S. 9. Demnach ist eine derartige Krise: "a significant difference between the prescriptions and proscriptions of a norm and no change in the behavior of its addressees although the practice has been detected, alleged and/or outlawed by a decision of an authorized dispute settlement body or court."

111 Nico Krisch, „The Backlash against International Courts“, Verfassungsblog vom 16.12.2014; Ximena Soley \& Silvia Steininger, „Parting ways or lashing back? Withdrawals, backlash and the Inter-American Court of Human Rights“, in: International Journal of Law in Context 14 (2018), S. 237-257.

112 S. bereits Armin von Bogdandy \& Michael Ioannidis, „Das systemische Defizit“, S. 300 ff., insb. S. 302, zur Frage der Verwendbarkeit internationaler Indizes.

113 Ximena Soley \& Silvia Steininger, „Parting ways or lashing back?“, S. 240 und zuvor insb. S. 238: „We define backlash as a process of systematic and consistent criticism of the institutional set-up of an IC as well as severe instances of non-compliance." 
zepte verhindert, folge ich daher Armin von Bogdandy und Michael Ioannidis ${ }^{114}$ in ihrem Vorschlag, als dogmatisches Begriffsfundament der derzeitigen Rechtsstaatlichkeitskrise an den Begriff des „systemischen Defizits an Rechtsstaatlichkeit“ anzuknüpfen. Dafür spricht insbesondere die Kongruenz mit der Praxis.

2. Rechtsstaatlichkeitskrise als sekundärer, systemisches Defizit als primärer Rechtsbegriff zur dogmatischen Verklammerung der Krise

Bevor man zum Begriff des systemischen Defizits gelangt, ist die Frage zu klären, wie sich der Begriff der Rechtsstaatlichkeitskrise, der ja unstreitig in der Praxis Verwendung findet, zu diesem Begriff verhält. Auch im Hinblick auf den oben beobachteten, empirisch zunächst unbefriedigenden Befund bei der Durchsicht von Primärmaterial schlage ich vor, dass die Rechtsstaatlichkeitskrise das Material zunächst als fuzzy set von mitgliedstaatlichen Vorgängen mit Rechtsstaatsbezug erfasst, der konkrete Handlungserfordernisse auslösen kann, aber nicht muss. Die Rechtsstaatlichkeitskrise ist also kein vollausgeprägter Rechtsbegriff. Sie ist ein Hilfsbegriff, der dem Forscher wie dem Praktiker die Bezeichnung von etwas Evidentem ermöglicht, ohne aber bereits präzise zu definieren und konkrete Schlussfolgerungen zu ermöglichen. Das erklärt auch, warum die definitorische Untermauerung dieser Krise in der Forschung bislang von so regem Interesse war.

Die Rechtsstaatlichkeitskrise bedarf daher eines weiteren Rechtsbegriffs, der ihre erste Einordnung aufgreift und präzise zuschneidet. Das ist meines Erachtens der durch von Bogdandy und Ioannidis erarbeitete Begriff des systemischen Defizits an Rechtsstaatlichkeit. Ich schlage dazu vor, zum besseren Verständnis der Interaktion von Rechtsstaatlichkeitskrise und systemischen Defizit eine Beobachtung der Methodenlehre von Karl Larenz heranzuziehen.

Larenz unterschied im Hinblick auf die Analysedichte und Aussagefinalität zwei Typen an Rechtsbegriffen in der Rechtswissenschaft. Der erste Typus, den er als sekundären Rechtsbegriff bezeichnet, meint die „aus Allgemeinvorstellungen gewonnenen Begriffe[...], die sich auf „natürliche“ Gegenstände oder Vorgänge beziehen“. Hingegen bezeichnet der primäre Rechtsbegriff, den Larenz auch in den Schriften von Josef Esser und Karl Engisch beobachtet, „die Vorgänge oder Verhältnisse von spezifisch recht-

114 Armin von Bogdandy \& Michael Ioannidis, „Das systemische Defizit“, S. $304 \mathrm{ff}$. 
licher Bedeutung". ${ }^{115}$ Beide Begriffe beruhen zunächst auf allgemeinen Vorstellungen, der primäre Rechtsbegriff indes ist im Unterschied zum sekundären Rechtsbegriff die juristisch präzisere - oder überhaupt erst präzise - Fassung des sich darstellenden Problems. ${ }^{116}$ Der Zweck war für Larenz eindeutig:

„[... - der Kreis der zweifelhaft bleibenden Objekte wird also zwar eingeengt, eine ganz scharfe Grenze kann indessen nicht gezogen werden -, und spätere Korrekturen, eine Änderung oder Verfeinerung der Auslegung, sind sozusagen vorbehalten $[\ldots]$..“117

Man kann also sagen, dass der Begriff der Rechtsstaatlichkeitskrise ein sekundärer, aus der Allgemeinvorstellung gewonnener Rechtsbegriff ist, auf welchem das systemische Defizit als weitaus präziserer, primärer Rechtsbegriff aufbaut. ${ }^{118}$ In Kombination könnte man auch von einem „Zweistufigen“ Rechtsbegriff sprechen, mit dem man sich also schrittweise sehr komplexen rechtlichen Vorgängen annähern kann. Die Rechtsstaatlichkeitskrise dient angesichts der derzeitigen Diskussion in der EU über die Rechtsstaatlichkeit in Mitgliedstaaten dem groben Zuschnitt eines Gesamtsachverhalts. Auf dieser Analysestufe wären etwa Fälle wie die Verfassungskrise um die Besetzung des Verfassungsgerichts in der Slowakei, insbesondere in den Jahren 2017-2018, ${ }^{119}$ aber auch die katalanische Frage in Spanien, zu der in der Literatur eine Nichtachtung der Werte des Art. 2

115 Karl Larenz, Methodenlehre der Rechtswissenschaft, 2. Aufl., Springer, Heidelberg, 1969, S. 217, mwN insb. bei Fn. 3. Das Konzept scheint leider in späteren Auflagen wieder aufgegeben worden zu sein.

116 Vgl. Karl Larenz, Methodenlehre der Rechtswissenschaft, S. 217.

117 Karl Larenz, Methodenlehre der Rechtswissenschaft, S. 217.

118 Diese Überlegung erfährt zwischenzeitlich weitere Stütze. Eine Abschichtung innerhalb des Begriffs des systemischen Defizits (Ausdruck vs. Begriff) schlägt jüngst auch Armin von Bogdandy vor, s. „Tyrannei der Werte? Herausforderungen und Grundlagen einer europäischen Dogmatik systemischer Defizite“, in: Zeitschrift für ausländisches öffentliches Recht und Völkerrecht 79 (2019), S. 503-551, S. $516 \mathrm{ff}$.

119 Hierzu Tomáš Lalík, „Constitutional Court Crisis in Slovakia: Still Far Away from Resolution“, in: I.CONnect-Blog vom 05.08.2016, o.S.; Michal Ovádek, Slovakia Tackles Its Constitutional Skeleton in the Closet, in: I.CONnect-Blog vom 05.08.2016, o.S. 
EUV diskutiert, ${ }^{120}$ in der politischen Praxis sogar bejaht worden ist, ${ }^{121}$ Teil der Diskussion; keineswegs wäre damit aber bejaht, dass es sich bei ihnen um Fälle unionsrechtlicher Relevanz, gar um Anwendungsbeispiele für das Verfahren des Art. 7 EUV handelt. Die präzise Prüfung anhand des Begriffs des systemischen Defizits widerlegt später die Vermutung, dass sie aus der hier gewählten Perspektive interessant sind und legt die Untersuchung auf konkrete und andere Anwendungsbeispiele fest.

\section{Der Begriff des systemischen Defizits an Rechtsstaatlichkeit}

Der Begriff des systemischen Defizits ist infolge der soeben gemachten Ausführungen derjenige, der in der Rechtsstaatlichkeitskrise der Gesamtheit der empirisch beobachten Vorgänge dogmatischen Grund verschafft. Urheber des Begriffs ist zunächst die Rechtspraxis, prominent insbesondere der Europäische Gerichtshof für Menschenrechte, sodann, ausgehend von der Rechtssache M.S.S. und der diese rezipierenden Rechtsprechung des EuGH in der Rechtssache N.S., ${ }^{122}$ nachfolgend die Europäische Kommission. Handhabbar gemacht für das Europarecht haben den Begriff indes vorrangig von Bogdandy und Ioannidis in der Rechtswissenschaft. ${ }^{123}$ Beide Verfasser vertreten dabei im Wesentlichen zwei Thesen: zum einen, dass der Begriff des systemischen Defizits anlassbezogen auf die Rechtsstaatlichkeitskrise großes Erklärungspotential bietet und zum zweiten, dass der Be-

120 Diskussion (ablehnend) bei Miguel Beltrán de Felipe, Myths and Realities of Secessionisms: A Constitutional Approach to the Catalonian Crisis, Palgrave Macmillan/Springer Nature Switzerland, Cham, 2019, S. 95 und ff.; verfassungsrechtliche Aufarbeitung bei Sabrina Ragone, „Das Unabhängigkeitsreferendum in Katalonien - Wie ist der Stand aus vergleichender und kontextualer Perspektive?“, in: Die öffentliche Verwaltung 71 (2018), S. 341-350.

121 Vgl. Aufruf von Barbara Spinelli, Open Letter to Commission President Juncker and European Council President Tusk cc. First Vice-President Frans Timmermans: Upholding the Rule of Law in the European Union vom 31.10.2017.

122 EuGH, Verb. Rs. C-411/10 und C-493/10, N.S. ./. Secretary of State for the Home Department und M.E. u.a./Refugee Applications Commissioner u.a., Urteil (GK) vom 21.12.2011, Slg. 2011 I-13991, ECLI:EU:C:2011:865; EGMR, M.S.S. ... Belgien und Griechenland, Beschwerdenr.: 306096/09, Urteil (GK) vom 21. Januar 2011.

123 Armin von Bogdandy \& Michael Ioannidis, „Das systemische Defizit“", S. 304 ff.; Michael Ioannidis, „Weak Members and the Enforcement of EU Law“, S. 484-485; Armin von Bogdandy, „Tyrannei der Werte?”, S. 516 ff. 
griff nicht „herbeigeredet“ wurde, dass er vielmehr in der Praxis vielfache Anleihen fand.

Ich möchte letztere These hier noch stärker betonen, darüber aber auf Folgeprobleme hinweisen. Wenn man sich dem Begriff des systemischen Defizits widmet, sind durchaus viele Entwicklungsstränge feststellbar. Man muss sich aber gewahr sein, dass trotz aller Nutzung, die das Attribut „systemisch“ und das Substantiv „Defizit“ erfahren haben, diese Nutzung vorrangig kontextabhängig und disziplinspezifisch ist. Sie bestärken zwar den Eindruck, dass Wissenschaft und Praxis seit langem über das Problem systemischer Rechtsverletzungen nachdenken. Aber das hier interessierende Verständnis bleibt unionsspezifisch und auf die Rechtsstaatlichkeitskrise bezogen. Die unter vergleichbaren Begriffen erfolgende Diskussion seitens der Rechtsprechung von EuGH und EGMR und der Politikwissenschaft verfolgt häufig andere Zwecke. Das will ich kurz darlegen und auch zeigen, welche Probleme sich selbst bei Betrachtung der Judikatur des EuGH ergeben.

1. Keine Hilfestellung durch die politikwissenschaftliche Defektforschung

Eine Möglichkeit der begrifflichen Absicherung ist, in der Politikwissenschaft als rechtswissenschaftliche Nachbardisziplin, Hilfestellung für das Verständnis des Begriffs des systemischen Defizits zu suchen. ${ }^{124}$

Tatsächlich geht die Politikwissenschaft der Frage sog. defekter politischer Systeme im Bereich der sog. Transformationsforschung nach, einem Forschungsgebiet, das sowohl Anleihen im politikwissenschaftlichen Teilbereich der Vergleichenden Regierungslehre als auch der Internationalen Beziehungen macht. ${ }^{125}$ Die Transformationsforschung beschäftigt sich mit dem Systemwechsel, ${ }^{126}$ d.h. den Gründen und dem Ablauf des politischen, rechtlichen, gesellschaftlichen und ökonomischen Wandels von Staaten, insbesondere solchen, die grundlegend ihre Staatsform ändern. Dabei steht

124 In diesem Sinne auch Armin von Bogdandy, „Principles and Challenges of a European Doctrine of Systemic Deficiencies", S. 3, m.w.N.

125 Zur ganzen Breite dieses Forschungsfeldes Raj Kollmorgen, Wolfgang Merkel \& Hans-Jürgen Wagener Transformation und Transformationsforschung: Zur Einführung, in: dies. (Hrsg.), Handbuch Transformationsforschung, Springer VS, Wiesbaden, 2015, S. 11-27.

126 Übersicht, auch zum urspr. Forschungsprogramm, bei Klaus von Beyme \& Dieter Nohlen, „Systemwechsel“, in: Dieter Nohlen (Hrsg.), Wörterbuch Staat und Politik, Pieper, München, 3. Aufl. 1995, S. 765-776. 
der Wandel hin zum Rechtsstaat oder der Demokratie, gerade des ehemaligen Ostblocks, im Vordergrund. ${ }^{127}$ Wie Klaus von Beyme festhielt, war der Grund für das rege Interesse der Politikwissenschaft an den auch rechtlichen Änderungsprozessen dort nicht allein dieser Wandel selbst, sondern vor allem das Versagen der Disziplin, die Änderungen vorherzusehen. ${ }^{128}$

Obwohl, etwa in der Studie von Beymes, auch deskriptive Modelle der Transformationsforschung beobachtet worden sind, ${ }^{129}$ ist das Grundverständnis der Transformationsforschung normativ: es besteht ein zu begrüßender Wandlungsprozess von Nichtdemokratien bzw. Unrechtsstaaten hin zu einem Verfassungsmodell westlichen Vorbilds. Diesen Prozess gilt es zu analysieren und zu begleiten. Die Transformationsforschung nimmt dabei Anleihen an zuvor bestehender Forschung zu Lateinamerika, wird aber von dieser unterschieden. ${ }^{130}$

Daneben gibt es in der Politikwissenschaft seit langem Arbeiten, die sich der Qualität von Demokratieverwirklichung anhand sog. Defekte in Staaten widmen. Seymor Martin Lipsets Aufsatz „Some Social Requisites of Democracy“ ist ein früher Klassiker. ${ }^{131}$ Eigentlicher Fokus seiner Studie ist der Stabilitätsgrad eines politischen Systems aufgrund der Faktoren Effektivität und Legitimität. ${ }^{132}$ Lipset entwickelt aber nicht nur Aussagen hierzu, sondern auch, aufgrund statistisch messbarer Unterschiede, ${ }^{133} \mathrm{Ka}-$ tegorisierungen zum Gütestatus des von ihm beobachteten politischen Systems. Er schlägt vor, anhand des gewählten Fallsets Staaten genau vier

127 Wolfgang Merkel, Systemtransformation: Eine Einführung in die Theorie und Empirie der Transformationsforschung, Leske + Budrich, 1999, S. 15.

128 Klaus von Beyme: Transition to Democracy in Eastern Europe, Macmillan, Basingstoke und London, 1996, S. 6 ff. Von Beyme meint sogar, die Umbrüche von 1989 seien aus diesem Grund ein „black Friday“ für die Sozialwissenschaften gewesen.

129 Klaus von Beyme: Transition to Democracy in Eastern Europe, S. 25 und ff., dort im Hinblick auch auf die Modelle von Lipset.

130 Wolfgang Merkel, Systemwechsel: Theorien, Ansätze und Konzeptionen, Leske + Budrich, Opladen, 1996, S. 12.

131 Seymor Martin Lipset, „Some Social Requisits of Democracy: Economic Development and Political Legitimacy“, in: American Political Science Review 53 (1959), S. 69-105.

$132 \mathrm{Zu}$ diesem Aspekt insbesondere Gert Pickel \& Susanne Pickel, Politische Kultur- und Demokratieforschung, VS Verlag für Sozialwissenschaften, Wiesbaden, 2006, S. 88-89. S. bei Seymor Martin Lipset, „Some Social Requisits of Democracy“, S. 86. Die dortige Vielschichtigkeit des Effektivitätsbegriffs zeigt dabei durchaus Parallelen zu demjenigen des Justizbarometers, hierzu ausf. unter E.V.3.

133 Seymor Martin Lipset, „Some Social Requisits of Democracy“, S. 76 ff. 
Aggregatzuständen der Verfassung zuzuordnen: „Stabilen Demokratien“, „instabilen Demokratien und Diktaturen“ bzw. in umgekehrter Nennung „Demokratien und instabile Diktaturen“ und schließlich „stabilen Diktaturen“. ${ }^{134}$ In Kongruenz mit den beiden mittleren Kategorien hat die spätere Forschung von sog. „diminished subtypes“135 gesprochen.

Rezeptionsprobleme dieser Ansätze in der Rechtswissenschaft ergeben sich aufgrund der besonders markanten methodischen Eigenheiten dieses politikwissenschaftlichen Forschungsfelds. Die Transformations- und die Defektforschung haben sich nämlich bis dato nicht dazu durchringen können, ihren Blick auf spezifische Eigenheiten eines bestimmten Ausschnitts verfasster Staaten - insbesondere also der EU - zu fokussieren und zu fragen, ob Veränderungen durch konkrete Anlässe verbessert und verschlechtert werden - sieht man einmal vom Zusammenbruch des Ostblocks ab. Damit ist dieser Forschungsansatz für die Zwecke der vorliegenden Arbeit grundsätzlich nur eingeschränkt verwendbar, die auf die Union und einen ganz konkreten Anlass zugeschnitten ist.

Überdies, was die Rezeption weiter verkompliziert, hat die Politikwissenschaft enorme Ressourcen auf die Validierung ihrer Methodik und Modelle verwandt, die Anschlussfähigkeit zu anderen Disziplinen aber weitgehend hintangestellt. Die Politikwissenschaft war vielmehr bemüht, große Fallzahlen global angelegter Studien zu handhaben und sich häufig ganz der Frage empirisch-quantitativer Erhebungen zu widmen. Das zeigt sich bereits in dem ebenfalls diesem Forschungskorpus zuzurechnenden Hauptwerk Robert Dahls, der „Polyarchie“. ${ }^{136}$ Unter dem Begriff der Polyarchie, welchen Dahl an die Stelle des Demokratiebegriffs setzt, erarbeitet Dahl nicht nur beschreibende Merkmale eines solchen Gemeinwesens,

134 Seymor Martin Lipset, „Some Social Requisits of Democracy“, insb. S. 74.

135 Hierzu s. Hans-Joachim Lauth \& Jenniver Sehring, „Putting Deficient Rechtsstaat on the Research Agenda: Reflections on Diminished Subtypes“, in: Comparative Sociology 8 (2009), S. 165-201; Jørgen Møller, Svend-Erik Skaaning, "Sub-components of the Rule of Law: Reassessing the Relevance of Diminished Subtypes“, in: Comparative Sociology 12 (2013), S. 391-421, S. 393 ff. zur Genese verschiedener Modelle.

136 Robert Alan Dahl, Polyarchy: Participation and Opposition, Yale University Press, New Haven u.a., 1971; Besprechung bei Arno Waschkuhn, „Robert A. Dahl, Polyarchy: Participation and Opposition, New Haven 1971“, in: Steffen Kailitz (Hrsg.), Schlüsselwerke der Politikwissenschaft, VS Verlag für Sozialwissenschaften, Wiesbaden, 2007, S. 86-88; Des Weiteren auch bei Gert Pickel \& Susanne Pickel, Politische Kultur- und Demokratieforschung, S. 162 ff., mit Auswertung auch weiterführender Studien zum Polyarchiemodell und Dahls Nachfolgern. 
sondern unternimmt insbesondere eine Zuordnung einer großen Anzahl von Staaten zum Polyarchiemodell. Die Zuordnung aller Staaten erfolgt indes anhand weniger Operationalisierungsmerkmale zu klaren Typen, die miteinander im offenen Wettstreit stehen. Sein im Annex veröffentlichtes Fall-Set ${ }^{137}$ misst Staaten allein in Bezug auf die Verwirklichung des aktiven und passiven Wahlrechts.

Über die Jahre sind die entwickelten Modelle zur Messung der Demokratiegüte in Staaten trotz oder gerade wegen anfänglicher Reduktionsversuche immer komplexer geworden und die Politikwissenschaft hat erbittert über die Validität ihrer Messvorschläge, empirisch-analytisch ermittelten Ergebnisse und vor allem Konzepte gestritten. Besonders einprägsam und hart ist der Streit über die Validität des „Demokratie-Barometers“ ausgefallen. 138

Dabei hat die Politikwissenschaft, gerade mit dem Begriff der „Defekten Demokratie“, ${ }^{139}$ dem Vanhanen-Index ${ }^{140}$ oder dem „Index defekter Demokratien"141 sehr vielversprechende Ansätze entwickelt. Auch der Begriff der „illiberalen Demokratie“ findet seine Ursprünge in der Transformationsforschung. ${ }^{142}$ Später sind diese Überlegungen sogar auf die Rechtsstaat-

137 Robert Alan Dahl, Polyarchy: Participation and Opposition, S. 231 und ff.

138 Marc Bühlmann, Wolfgang Merkel, Lisa Müller, Heiko Giebler \& Bernhard Weßels, „Demokratiebarometer: ein neues Instrument zur Messung von Demokratiequalität“, in: Zeitschrift für Vergleichende Politikwissenschaft 6 (2012), S. 115-159; Sebastian Jäckle, Uwe Wagschal \& Rafael Bauschke, „Das Demokratiebarometer: „basically theory driven“?“, in: Zeitschrift für Vergleichende Politikwissenschaft 6 (2012), S. 99-125; Wolfgang Merkel, Dag Tanneberg \& Marc Bühlmann, „„Den Daumen senken“: Hochmut und Kritik“, in: Zeitschrift für Vergleichende Politikwissenschaft 7 (2013), S. 75-84; Sebastian Jäckle, Uwe Wagschal \& Rafael Bauschke, „Allein die Masse macht's nicht - Antwort auf die Replik von Merkel et al. zu unserer Kritik am Demokratiebarometer", in: Zeitschrift für Vergleichende Politikwissenschaft 7 (2013), S. 143-153.

139 Wolfgang Merkel, Hans-Jürgen Puhle, Aurel Croissant, Claudia Eicher \& Peter Thiery, Defekte Demokratie, Band 1: Theorie, Springer Fachmedien, Wiesbaden, 2003, Einleitung, S. 13 ff.

140 Tatu Vanhanen, „A New Dataset for Measuring Democracy, 1810-1998“, in: Journal of Peace Research 37 (2000), S. 252-265.

141 Peter Thiery \& Aurel Croissant, „Defekte Demokratie: Konzept, Operationalisierung und Messung“, in: Hans-Joachim Lauth, Gert Pickel \& Christian Welzel (Hrsg.), Demokratiemessung: Konzepte und Befunde im internationalen Vergleich, Springer Fachmedien, Wiesbaden, 2000, S. 89-111, zur dortigen Definition der defekten Demokratie s. S. 95, zum Index S. 98 ff. Grundlegend zudem etwa Kenneth A. Bollen, „Issues in the Comparative Measurement of Political Democracy“, in: American Sociological Review 45 (1980), S. 370-390.

142 Dazu unten im Abschnitt C.IV. zu Ungarn. 
lichkeit übertragen worden, wobei hier insbesondere die Arbeiten der dänischen Politologen Svend-Erik Skaaning und Jørgen Møller zu nennen sind. ${ }^{143}$ Aber gerade letztere Arbeiten haben es bislang nicht vermocht, die Übertragbarkeit der dort gemachten Ausführungen spezifisch für die Europäische Union und überdies für jüngere Krisen zu testen, da eine Kontextualisierung fehlt. Dies gilt insbesondere deshalb, weil unionale Rechtspraxis und Rechtsprechung kaum Berücksichtigung finden, auch wenn teils in der Politikwissenschaft sehr interessante Operationalisierungsvorschläge gemacht werden. ${ }^{144}$ Denkbar, aber ausstehend, wäre hier, dass die Politikwissenschaft ihre Indizes und qualitativen Überlegungen auf den europäischen Rechtsraum fokussiert und vermehrt den Rückschritt anstatt des Fortschrittes mittels Defektkonzepten erfasst. Dass dies bislang zu fehlen scheint, ist umso betrüblicher, bedenkt man, dass Politikwissenschaftler wie Jan-Werner Müller oder Scheppele an anderer Stelle die ersten waren, die auf die Rechtsstaatlichkeitskrise in der Union hingewiesen haben.

Der bleibende disziplinäre Graben zwischen Rechts- und Politikwissenschaft erschwert eine echte ,interdisziplinäre“ Arbeit an dieser Stelle ganz erheblich. Eine Rezeption politikwissenschaftlicher globaler Defektmodelle für die unionale Rechtsstaatlichkeitskrise wäre aufgrund deren derzeitigen Zuschnitts wohl nicht einmal in der Typologie Sanne Taekemas und Bart van Klinks „heuristisch" 145 oder „auxiliar“. ${ }^{146}$ Das muss nicht so bleiben, wenn die Politikwissenschaft erkennt, dass ihre Modelle lokal

143 Jørgen Møller, \& Svend-Erik Skaaning, „On the limited interchangeability of rule of law measures“, in: European Political Science Review 3 (2011), S. 371-394, insb. S.388f. zur mangelnden Kongruenz von Indizes, Jørgen Møller, \& Svend-Erik Skaaning, „Sub-components of the Rule of Law: Reassessing the Relevance of Diminished Subtypes“, insb. S. 393 f.; Jørgen Møller \& Svend-Erik Skaaning, The Rule of Law: Definitions, Measures, Patterns and Causes, Palgrave Macmillan, Basingstoke, 2014, S. 41 ff., nochmals zu Indizes. S. aber auch Hans-Joachim Lauth \& Jenniver Sehring, „Putting Deficient Rechtsstaat on the Research Agenda“, S. 179 f. zu möglichen Manifestationen defizitärer Rechtsstaaten in politischen Systemen.

144 S. insb. Svend-Erik Skaaning, „Measuring the Rule of Law“, in: Political Research Quarterly 63 (2010), S. 449-460, S. $451 \mathrm{ff}$.

145 Sanne Taekema \& Bart van Klink, „On the Border. Limits and Possibilities of Interdisciplinary Research“, in: Bart van Klink \& Sanne Taekema (Hrsg.), Law and Method: Interdisciplinary Research into Law, Mohr Siebeck, Tübingen, 2011, S. 7-32, S. 10-11: „In such research the legal discipline provides the problem definition, but the researcher looks for useful material or ideas in another discipline.".

146 Sanne Taekema \& Bart van Klink, „On the Border. Limits and Possibilities of Interdisciplinary Research", S. 11: "In this type of research, material derived 
begrenzte und rechtssystemspezifische Fragen aufwerfen, und wenn der interne Streit um die Methodik ihrer Modelle nicht mehr derart raumgreifend ist. Hier indes ist daraus zu folgern, dass die Rechtswissenschaft aus dieser Forschung bislang nur schwer unmittelbar nutzbare Ergebnisse gewinnt. Es ist damit zur Entwicklung des Begriffs des systemischen Defizits in der Rechtspraxis zurückzukehren, welche nicht minder heterogen verlaufen ist.

\section{Entwicklung des Begriffs in der Rechtspraxis}

\section{a. Mutmaßliche Ursprünge}

Die mutmaßlichen Ursprünge des Begriffs des systemischen Defizits liegen für die Europarechtswissenschaft in der qualifizierten Befolgungswidersetzung sowie der Minderleistung unterer Gerichte gegenüber bzw. in Beziehung zu einem höheren Gericht. Dieses Problem hat sowohl den EuGH als auch den EGMR beschäftigt.

Bereits in den 1970er Jahren schlugen Josse Mertens de Wilmars, Richter am Gerichtshof, und sein référendaire Ivan Verougstraete, später Präsident des belgischen Kassationshofs, die Figur der „systemischen“ Verletzung zur Beantwortung der - jüngst wieder sehr aktuellen ${ }^{147}$ - Frage vor, wann der Gerichtshof sich einer gerichtlichen Vertragsverletzung durch ein mitgliedstaatliches Gericht zuwenden könne. ${ }^{148}$ Auch auf Seiten des EGMR ist die Beobachtung systemischer oder struktureller Probleme weiter zurückzuverfolgen, als nur bis zur Entscheidung M.S.S. Bereits in der Entscheidung Martins Moreira ${ }^{149}$ in den 1980er Jahren hatte der Gerichtshof die Beobachtung gemacht, der massive Entscheidungsstau bei portugiesi-

from the other discipline serves as a necessary contribution to the legal arguments".

147 EuGH, Rs. C-416/17, Kommission ./. Frankreich (Vertragsverletzung wegen nicht erfolgter Vorabvorlage), Urteil vom 04.10.2018, ECLI:EU:C:2018:811, s. insb. 111-114, vgl. auch die Schlussanträge des Generalanwalts Melchior Wathelet vom 25.07.2018, ECLI:EU:C:2018:626, Rn. 86 ff., vorgehend Rs. C-310/09, Ministre du Budget, des Comptes publics et de la Fonction publique ./. Accor SA, Urteil vom 15. September 2011, ECLI:EU:C:2011:581.

148 Josse Mertens de Wilmars, Josse \& Ivan M. Verougstraete, „Proceedings against Member States for Failure to Fulfil Their Obligations“, in: Common Market Law Review 7 (1970), S. 385-406, S. 390.

149 EGMR, Martins Moreira ./. Portugal, Beschwerdenr.: 11371/85, Urteil vom 07.10.1988, Rn. 53 und ff. Zur Bedeutung dieses Urteils speziell für die Entwick- 
schen Gerichten sei ein „structural problem“. Der EGMR hat diese Überlegung aber meiner Kenntnis nach nicht auf dieser Entscheidung aufbauend fortentwickelt.

\section{b. Drei Beiträge aus der Literatur zum Piloturteilsverfahren des EGMR}

Hiervon soweit ersichtlich völlig separat hat sich der EGMR dann der Frage großer anhängiger Fallzablen („heavy caseload“) und seiner eigenen dadurch drohenden Funktionsuntüchtigkeit angenommen und dabei erneut auf den Begriff des „structural“ oder „systemic problem“ zurückgegriffen. ${ }^{150}$ Die Lösung des EGMR hierfür war das Piloturteilsverfahren. ${ }^{151}$ Geht man ins Detail, so sieht man, wie unterschiedlich allein für die Judikatur des EGMR die Erklärungsansätze sind.

Die schlichteste Umschreibung der Funktion des „systemischen Problems" in der Rechtsprechung des EGMR stammt zunächst von seinem ehemaligen Präsidenten Luzius Wildhaber.

„The feature common to these cases is the attempt to address a problem affecting large numbers of persons through a judgment in an individual case, whether this is expressly acknowledged or not." 152

Entscheidend ist also, wie der Gerichtshof im Fall Broniowski bereits ausführt, ${ }^{153}$ ergebnisorientiert die hohe Fallzahl der Betroffenen im Mitglied-

lung des Vertragsverletzungsverfahrens, Matthias Schmidt, Le manquement perpétué en droit de l'Union européenne, S. 22.

150 Vgl. dazu insb. auch Armin von Bogdandy, „Principles and Challenges of a European Doctrine of Systemic Deficiencies“, S. 10-11.

151 Grundlegend Markus Fyrnys, „Expanding Competences by Judicial Lawmaking: The Pilot Judgment Procedure of the European Court of Human Rights“, in: German Law Journal 12 (2011), S. 1231-1260.

152 Luzius Wildhaber, „Pilot Judgments in Cases of Structural or Systemic Problems on the National Level“, in: Wolfrum/Deutsch (Hrsg.), The European Court of Human Rights Overwhelmed by Applications: Problems and Possible Solutions: International Workshop Heidelberg, December 17 - 18, 2007, Springer, Heidelberg, 2009, S. 69-75, S. 75.

153 EGMR, Broniowski ./. Polen, Beschwerdenr.: 31443/96, Urteil (GK) vom 22.06.2004, Reports of Judgments and Decisions EGMR 2004- V, 1 Rn. $189 \mathrm{ff}$, 193 insb.; wenig später ähnlich EGMR, Öcalan ./. Türkei, Beschwerdenr.: 46221/99, Urteil (GK) vom 12.05.2005, ECHR 2005-IV, Rn. 210; Verweis auch im Urteil M.S.S. ./. Belgien und Griechenland, Urteil (GK) vom 21. Januar 2011, Beschwerdenr. 306096/09, Rn. 400. 
staat zu verwalten. Das Telos des Verfahrens zeichnet Wildhaber exakt nach:

„The Court stressed that the measures to be taken must be such as to remedy the systemic defect underlying the Court's finding of a violation so as not to overburden the Convention system with large numbers of applications."154

Ganz anders sieht es Dominik Haider. Er hält die hohe Fallzahl für einen möglichen, aber keinen ausreichenden Hinweis auf das Vorliegen eines systemischen Problems. ${ }^{155}$ Ein systemisches Problem könne nämlich auch bestehen, wenn der Konventionsstaat auf fortgesetzte Art und Weise die sich aus einem früheren Urteil bereits ergebenden Verpflichtungen nicht umsetze. Alternativ, und gleichrangig, könne der Gerichtshof auf ein „regulatory shortcoming“ oder eine Verwaltungspraxis („administrative conduct $^{\text {") }}$ eingehen. ${ }^{156}$ Charakteristisch für ein systemisches Problem i.S.d. Piloturteilsverfahrens sei also „the failure of Contracting States to fully implement the Convention." 157 Wolle der Gerichtshof gerade die Rechtsverletzung des Beschwerdeführers betonen, spreche er zudem präziser von einer systemischen Verletzung („violation“ anstatt „problem“). ${ }^{158}$

Wiederum unterschiedlich argumentiert Jessica Baumann ${ }^{159}$ unter Rückgriff auf einen Beitrag Pierre-Henri Imberts, ${ }^{160}$ des ehemaligen Generaldirek-

154 Luzius Wildhaber, „Pilot Judgments in Cases of Structural or Systemic Problems on the National Level“, S. 71.

155 Dominik Haider, The Pilot-Judgment Procedure of the European Court of Human Rights, Brill u. Martinus Nijhoff, Leiden \& Boston 2013, S. 53: „appear to point to deficiencies“; s. insb. die Ausführungen auf S. 54 und ff.

156 Dominik Haider, The Pilot-Judgment Procedure of the European Court of Human Rights, S. 37, unter Verweis u.a. auf EGMR, Burdov ./. Russland (Nr. 2), Beschwerdenr.: 33509/04, Urteil vom 15.01.2009, Rn. 131.

157 Dominik Haider, The Pilot-Judgment Procedure of the European Court of Human Rights, S. 53-54, unter Verweis auf u.a. EGMR, Hutten-Czapska ./. Polen, Beschwerdenr.: 35014/97, Urteil (GK) vom 19.06.2006; Hirst (Nr. 2) ./. Vereinigtes Königreich, Beschwerdenr.: 74025/01, Urteil (GK) vom 06.10.2005; Rumpf ./. Deutschland, Beschwerdenr. 46344/06, Urteil vom 02.09.2010, Rn. 70.

158 Dominik Haider, The Pilot-Judgment Procedure of the European Court of Human Rights, S. 68.

159 Jessica Baumann, „Das Piloturteilsverfahren als Reaktion auf massenhafte Parallelverfahren: eine Bestandsaufnahme der Rechtswirkungen der Urteile des Europäischen Gerichtshofs für Menschenrechte“, Duncker \& Humblot, Berlin, 2016, S. $109 \mathrm{ff}$.

160 Pierre-Henri Imbert, „Follow-up to the Committee of Ministers' Recommendations on the implementation of the Convention at the domestic level and 


\section{B. Rechtsstaatlichkeitskrise und systemisches Defizit}

tors für Menschenrechte beim Europarat. Imbert unterscheidet zunächst die Begriffe des - für ihn gleichbedeutenden - „systemischen“ bzw. „strukturellen“ Problems („systemic“ or „structural“ problem) sowie des „spezifischen Problems“ („specific problem“). Beide könnten Gegenstand eines Piloturteilsverfahrens sein. ${ }^{161}$ Das spezifische Problem zeichne sich dadurch aus, dass es aus einer einzelnen Teilsachmaterie des staatlichen Rechts, ggf. sogar aus einer einzelnen Norm, oder einem in seinen Grundstrukturen stets gleichen Sachverhalt besteht. Archetypus dieses Falls ist für Imbert das Broniowski-Urteil, in welchem sich alle Betroffenen substantiell sehr stark ähneln. Für Imbert liegt hier kein systemisches Problem vor, und zwar auch ungeachtet der hohen Anzahl der Betroffenen. ${ }^{162}$ Imbert sieht in diesem so umrissenen spezifischen Problem vielmehr den Ausdruck eines Masseverfahrens, die Betroffenen stellten eine „Klasse“ an Betroffenen dar - womit mutmaßlich auf die US-amerikanische class action Bezug genommen wird.

Ein „echtes“ „systemisches“ oder „strukturelles“ Problem ist für Imbert hingegen im Umkehrschluss bedingt durch

„an endemic or really structural and widespread problem or dysfunctioning in the national legal order (such as non-execution of domestic courts' judgments, general slowness in the administration of justice, unacceptable prison conditions in a country, etc. ) “. ${ }^{163}$

Es ergibt sich damit eine große Nähe zur Beobachtung Haiders: nicht die Funktionsfähigkeit des Gerichtshofs vor dem Hintergrund der subjektiv

the Declaration on ,Ensuring the effectiveness of the implementation of the European Convention on Human Rights at national and European levels"“, in: Directorate General of Human Rights of the Council of Europe (Hrsg.): Reform of the European Human Rights System: Proceedings of the high-level seminar, Oslo, 18 October 2004, Straßburg, 2004, S. 33-43.

161 Pierre-Henri Imbert, „Follow-up to the Committee of Ministers' Recommendations on the implementation of the Convention at the domestic level and the Declaration on ,Ensuring the effectiveness of the implementation of the European Convention on Human Rights at national and European levels“", S. 39.

162 Pierre-Henri Imbert, „Follow-up to the Committee of Ministers' Recommendations on the implementation of the Convention at the domestic level and the Declaration on ,Ensuring the effectiveness of the implementation of the European Convention on Human Rights at national and European levels“", S. 39.

163 Pierre-Henri Imbert, „Follow-up to the Committee of Ministers' Recommendations on the implementation of the Convention at the domestic level and the Declaration on ,Ensuring the effectiveness of the implementation of the European Convention on Human Rights at national and European levels“", S. 39. 
Betroffenen, sondern die objektiv-rechtliche Rechtstreue im Konventionssystem ist entscheidend. Baumann greift Imberts Ausführungen auf und entwickelt sie fort. Für sie ist nicht nur zwischen einerseits speziellen und andererseits strukturellen bzw. systemischen Problemen zu unterscheiden. Sie sieht vielmehr den Begriff des strukturellen Problems als Oberbegriff, dem sich die Spezialität bzw. der systemische Charakter als Unterkategorien unterordnen. Die Gleichsetzung des „strukturellen“ mit dem Begriff des „systemischen“, wie bei Imbert, gibt sie auf. ${ }^{164}$ Sie schlägt die Begriffspaare des „strukturell-systemischen“ Problems einerseits und des „strukturell-spezifischen Problems" andererseits vor. ${ }^{165}$ Ausschlaggebend ist, ob, angelehnt an das Plaumann-Urteil des EuGH, „eine identifizierbare Personengruppe" vorliege, die von dem strukturellen Problem betroffen sei.

c. Rechtsprechung des EuGH zum Attribut des „systemischen“

Für das Unionsrecht ist aus den obigen Darstellungen mitzunehmen, dass sich substantielle Teile, wie Imberts und Haiders Überlegungen der objektiv feststellbaren Dysfunktion in einem Mitgliedstaat zwar auch hier in der Diskussion wiederfinden, es aber unzutreffend wäre, etwa eine Übertragbarkeit der feingliedrigen Begriffsunterscheidungen, wie Baumann sie vornimmt, auf das Unionsrecht zu befürworten und darüber von einer grundsätzlich gemeinsamen Begriffsgenese in Unionsrecht und Recht des Europarats zu sprechen. Für letzteres stand und steht die Wahrung der Funktionsfähigkeit des EGMR ungeachtet der einzelnen Interpretationsvorschläge ganz im Vordergrund. Dem EGMR geht es immer zumindest auch um die Handhabung großer Fallzahlen oder vergleichbarer Fallkonstellationen. ${ }^{166}$

Der EuGH hingegen ist implizit regelmäßig zur ursprünglichen Beobachtung Mertens de Wilmars' und Verougstraetes zurückgekehrt. Ihm ging es um besonders hervorgehobene Rechtsverletzungen, insbesondere

164 Jessica Baumann, „Das Piloturteilsverfahren als Reaktion auf massenhafte Parallelverfahren“, S. 110.

165 Jessica Baumann, „Das Piloturteilsverfahren als Reaktion auf massenhafte Parallelverfahren“, S. $109 \mathrm{ff} ., 111$ insb.

166 S. dazu nochmals die Beiträge bei Rüdiger Wolfrum \& Ulrike Deutsch (Hrsg.): The European Court of Human Rights Overwhelmed by Applications: Problems and Possible Solutions: International Workshop Heidelberg, December 17 - 18, 2007, Springer, Heidelberg 2009; weiter Dominik Haider, The Pilot-Judgment Procedure of the European Court of Human Rights, S. $35 \mathrm{ff}$. 
im Mitgliedstaat selbst, wobei die Frage der quantitativen Befassung des Gerichtshofs nicht relevant war. Die Frage der Rückwirkung auf das Unionsgerichtssystem durch die Lage in den Mitgliedstaaten wiederum beginnt sich in jüngster Zeit, und dabei im Hinblick auf qualitative Vorgänge und die Funktionsfähigkeit des Vorabvorlagemechanismus, erst zu entwickeln. ${ }^{167}$

Damit korreliert, dass die Entwicklung des Konzepts systemischer Rechtsverletzungen im Unionsrecht weitaus heterogener und viel weniger linear verlaufen ist als im Konventionsrecht. Das zeigt sich bereits bei der Begrifflichkeit als solcher. Kommission und Gerichtshof ringen noch mit präzisen Ausgestaltungen, leiten sie häufig nur fragmentarisch her und definieren sie nicht durchgängig.

Die Europäische Kommission hat 2014 in ihrem EU-Rahmen den Begriff der „systemischen Gefährdung der Rechtsstaatlichkeit“ ${ }^{168}$ eingeführt. Auch ist dieser Begriff dort, allerdings allein für den speziellen Mechanismus, definiert worden. In ihrem Verordnungsvorschlag über den Schutz des EU-Haushalts spricht sie hingegen von generellen Mängeln in Bezug auf das Rechtsstaatsprinzip ${ }^{169}$ und definiert diesen Begriff wiederum speziell im Kontext dieses Vorschlags. Offensichtlich wollte man ursprünglich im Referentenentwurf ebenso von „systemischen“ Mängeln sprechen, dies ging indes in der inter-service consultation verloren. Der Nachweis hierfür findet sich in der deutschen Fassung der Vorschlagsbegründung des Verordnungsentwurfs. Hier allein - und wohl versehentlich bei der Übersetzung aus der englischen Fassung vergessen - ist noch ein Hinweis auf den „systemischen Mangel[...] in Bezug auf das Rechtsstaatsprinzip“170 enthalten. Warum entschieden wurde, begrifflich zwischen „systemisch“

167 Vgl. dazu EuGH, Rs.C-619/18 R, Kommission ./. Polen, „Unabhängigkeit des polnischen Obersten Gerichtshofs“, Urteil (GK) vom 24.06.2019, ECLI:EU:C:2019:531, Rn. 45, dort heißt es, das Vorabentscheidungsverfahren sei „Schlüsselelement“ des Unionsgerichtssystems.

168 Europäische Kommission, Mitteilung der Kommission an das Europäische Parlament und den Rat, Ein neuer EU-Rahmen zur Stärkung des Rechtsstaatsprinzips, 11.03.2014, COM(2014) 158 final, etwa S. 5, 7 und passim.

169 Europäische Kommission, Vorschlag für eine Verordnung des Europäischen Parlaments und des Rates über den Schutz des Haushalts der Union im Falle von generellen Mängeln in Bezug auf das Rechtsstaatsprinzip in den Mitgliedstaaten vom 02.05.2018, $\mathrm{COM}(2018) 324$ final.

170 Europäische Kommission, Vorschlag für eine Verordnung des Europäischen Parlaments und des Rates über den Schutz des Haushalts der Union im Falle von generellen Mängeln in Bezug auf das Rechtsstaatsprinzip in den Mitgliedstaaten, COM(2018) 324 final vom 2.5.2018, S. 3 (Begründung). 
und „generell“ zu trennen, hat die Kommission nicht offengelegt. Es bietet sich zwar an, in beiden Begriffen funktional gleiche Phänomene angesprochen zu sehen, präzise Unterscheidungen müssen aber noch geklärt werden.

Auch in der Judikatur des Gerichtshofs deuten sich Ansätze weiterer begrifflicher Ausgestaltung an. So heißt es in der sog. LM-Entscheidung des Gerichtshofs, die die Unabhängigkeit polnischer Justizbehörden zum Gegenstand hat, entscheidend sei „das Vorhandensein systemischer oder zumindest allgemeiner Mängel“ („l'existence de défaillances systémiques ou, du moins, généralisées“/"systemic deficiencies, or, at all events, generalised deficiencies“). ${ }^{171}$ Dass der Gerichtshof mit der Unterscheidung „oder zumindest“ die Existenz von systemischen Defiziten in qualitativer Abgrenzung als „Mehr“ zum Minus, verstanden wissen wollte, erscheint plausibel, ist aber nicht eindeutig.

Widmet man sich der Rechtsprechung noch vertiefter, zeigt sich, dass der EuGH die Figur des „systemischen“ in großer Bandbreite genutzt hat, weit über die Asylrechtsprechung hinausgehend, die hierfür an den Anfang gesetzt wurde. ${ }^{172} \mathrm{Im}$ Zusammenhang mit der sog. Finanz- und Währungskrise der Union ab 2008 ist zunächst die Diskussion um die "Systemrelevanz" und die "Systemkrise“ hervorzuheben. ${ }^{173}$ Eine zweite Gruppe von Fällen umfasst Entscheidungen zu Fragen systemimmanenter Diskriminierungen bestimmter Personengruppen, wie in der Rechtssache Kenny. ${ }^{174}$ In der Rechtssache Petru ${ }^{175}$, die die Frage der Erstattung von Kosten einer Herzoperation in Deutschland durch eine rumänische Krankenversicherung betraf, wenn diese in Rumänien aufgrund möglicher

171 EuGH, Rs. C-216/18 PPU, LM (Mängel des Justizsystems), Urteil (GK) vom 25.07.2018, ECLI:EU:C:2018:586, Rn. 60.

172 Dazu aber Armin von Bogdandy \& Michael Ioannidis, „Das systemische Defizit", S. 319 ff. m.w.N.

173 EuG, Rs. T-457/09, Westfälisch-Lippischer Sparkassen- und Giroverband ./. Kommission, Urteil vom 17.07.2014, ECLI:EU:T:2014:683, Rn. 180-182 und ff; EuG, Rs. T-319/11, ABN Amro Group NV ./. Kommission, Urteil vom 8. April 2014, ECLI:EU:T:2014:186, Rn. 205; EuGH, Urteil vom 22. Januar 2014, Rs. C-270/12, Großbritannien .. Parlament und Rat, „ESMA“, ECLI:EU:C:2014:18, Rn. 109.

174 EuGH, Rs. C-427/11, Margaret Kenny u.a. ./. Minister for Justice, Equality and Law Reform u.a., Schlussanträge des Generalanwalts Pedro Cruz-Villalón vom 29. November 2012, ECLI:EU:C:2012:762, Rn. 54.

175 EuGH, Rs. C-268/13, Eleana Petru ./. Casa Județeană de Asigurări de Sănătate Sibiu u.a., Schlussanträge des Generalanwalts Pedro Cruz-Villalón vom 19.06.2014, ECLI:EU:C:2014:2023, Rn. 28. 
Mängel im Gesundheitssystem nicht ohne erhöhte Risiken für den Patienten durchgeführt werden kann, prüfte Generalanwalt Pedro Cruz-Villalón, wann solche Mängel vorliegen könnten: „Konkreter gesprochen tritt das wirkliche Problem in Erscheinung, wenn der Mangel [...] über eine punktuelle, lokal begrenzte und letztlich zufällige Situation hinausgeht und Ausprägung einer Situation strukturellen, allgemeinen und andauernden Mangels ist, also letztlich als „systemischer" Mangel bezeichnet werden kann." "176

Mit der Rechtssache $R a d u^{177}$ fand das Konzept des systemischen Mangels erstmals Anwendung auf einen Sachverhalt betreffend europäische Haftbefehle. ${ }^{178}$ Generalanwältin Eleanor Sharpston hatte zu klären, ob ein nationales Gericht die Übergabe einer Person ablehnen durfte, wenn darüber die Verletzung von Grundrechten aus der GRCh und der EMRK im Raum standen. ${ }^{179}$ Die Generalanwältin hielt fest, eine Übergabe einer natürlichen Person sei unzulässig, wenn „,begründete Tatsachen für die Annahme‘ bzw. ,ernsthafte und durch Tatsachen bestätigte Gründe für die Annahme“ vorliegen, dass ein ,reales Risiko' bzw. die ,tatsächliche Gefahr besteht, dass die genannte Bestimmung in dem Staat, an den der Betreffende ansonsten zu überstellen wäre, verletzt wird." ${ }^{180}$ In Aranyosi und Căldăraru griff Generalanwalt Yves Bot explizit diese Argumentationstechnik auf und sprach in seinen Schlussanträgen zur Entscheidung von einer „Sachverhaltsanalogie“. Er berief sich dabei auf „mehrere Mitgliedstaaten“,

176 EuGH, Rs. C-268/13, Eleana Petru ./. Casa Județeană de Asigurări de Sănătate Sibiu u.a., Schlussanträge des Generalanwalts Pedro Cruz-Villalón vom 19.06.2014, ECLI:EU:C:2014:2023, Rn. 28.

177 EuGH, Rs. C-396/11, Ministerul Public - Parchetul de pe lângă Curtea de Apel Constanța .. Ciprian Vasile Radu, Urteil (GK) vom 29.01.2013, ECLI:EU:C:2013:39.

178 EuGH, Rs. C-396/11, Ministerul Public - Parchetul de pe lângă Curtea de Apel Constanța ./. Ciprian Vasile Radu, Schlussanträge der Generalanwältin Eleanor Sharpston vom 18.10.2012, ECLI:EU:C:2012:648.

179 Vgl. zur so von der Generalanwältin rezipierten Vorlagefrage EuGH, C-396/11, Ministerul Public - Parchetul de pe lângă Curtea de Apel Constanţa ./. Ciprian Vasile Radu, Schlussanträge der Generalanwältin Eleanor Sharpston vom 18.10.2012, Rn. 63, weiter insb. Rn. 76 zur Nutzung des Begriffes des systemischen Mangels. Der Sachverhalt, nicht aber die Rechtsfrage, ist vergleichbar mit BVerfGE 140, 317, Europäischer Haftbefehl II.

180 EuGH, C-396/11, Ministerul Public - Parchetul de pe lângă Curtea de Apel Constanța ./. Ciprian Vasile Radu, Schlussanträge der Generalanwältin Eleanor Sharpston vom 18.10.2012, ECLI:EU:C:2012:648, Rn.77. Für die Würdigung der N.S.-Entscheidung vgl. zuvor Rn. 76 der Schlussanträge. 
die diese Überlegung teilten. ${ }^{181}$ Das wiederum entwickelte der Gerichtshof zum sog. Aranyosi-Test fort, der schließlich in der Rechtsstaatlichkeitskrise der Union überragende Bedeutung entfalten sollte, weil sich die Frage der Transplantation seiner Logik auf andere Sachverhalte stellte. Der Test lief darauf hinaus, dass die vollstreckende Behörde neben allgemeinen Feststellungen betreffend einen derartigen systemischen Mangel im ersuchenden Mitgliedstaat stets die Auswirkung im konkreten Fall zu berücksichtigen hatte. ${ }^{182}$ Der Gerichtshof hat diese Logik im LM-Urteil für die Frage, wie eine vollstreckende Justizbehörde systemische Mängel im Justizsystem eines anderen Mitgliedstaats zu beurteilen habe, übernommen. ${ }^{183}$

Der Begriff des systemischen Defizits gewinnt aber trotz dieser regen Nutzung in der Unionsrechtsprechung nur begrenzt an Kontur, weil der Gerichtshof lediglich aufzeigt, wie die mitgliedstaatliche Justizbehörde mit dem Begriff umzugehen hat, ohne ihn selbst zu definieren. Damit bleibt die konkrete Handhabbarmachung immer noch ungelöst.

d. Die Figur der Verletzung "generellen und fortdauernden Charakters“ und Überlegungen zur weiteren Begriffsstrukturierung

Vor dem Hintergrund dieser unterschiedlichen Entwicklungsstränge zum Begriff des „systemischen“ Problems in Mitgliedstaaten schlage ich vor, dass man zum besseren Problemverständnis zunächst von einer zu engen Auslegung des Begriffs abrücken muss.

Der Begriff des systemischen Defizits an Rechtsstaatlichkeit ist in seinem Kern ein solcher zur Beschreibung einer besonders qualifizierten Rechtsuntreue eines Mitgliedstaats im Hinblick auf das Unionsrecht.

Der Gerichtshof kennt seit längerem eine Figur, die präzise derartige Konstellationen erfasst, nämlich die der Vertragsverletzung ,generellen als auch fortdauernden Charakters" (manquement à "caractère tout à la fois

181 EuGH, Verb. Rs. C-404/15 und C-659/15 PPU, Pál Aranyosi und Robert Căldăraru, Schlussanträge des Generalanwalts Yves Bot vom 3. März 2016, ECLI:EU:C:2016:140, Rn.39; Urteil (GK) vom 5. April 2016, ECLI:EU:C:2016:198. Dort zum Begriff des „systemischen Mangels“, insb. Rn. 89, 93 und 104 des Urteils.

182 EuGH, Verb. Rs. Rs. C-404/15 und C-659/15 PPU, Pál Aranyosi und Robert Căldăraru, Urteil (GK) vom 5. April 2016, ECLI:EU:C:2016:198, insb. Rn. 92-94, weiter 95 ff.

183 EuGH, Rs. C-216/18 PPU, LM (Mängel des Justizsystems), Urteil (GK) vom 25.07.2018, ECLI:EU:C:2018:586, Rn. 68. 
général et persistant“ bzw. "general and persistent“ infringement, ${ }^{184}$ daher auch GAP-Verletzung oder GAP infringement). Sie findet ihren Ursprung in der Rechtssache Irish Waste und dort insbesondere in den Schlussanträgen des Generalanwalts Ad Geelhoed. ${ }^{185}$

Darin hielt Generalanwalt Geelhoed insbesondere fest, dass das Unionsrecht, qualitativ von anderen Vertragsverletzungen unterschieden, eine „allgemeine und strukturelle Zuwiderhandlung“ kenne, die sich durch drei „Dimensionen“, nämlich „Skalendimension“, „Zeitdimension“ und „Schweredimension“, auszeichne. ${ }^{186}$

Durch diese drei „Dimensionen“ betreffend die Fallzahl (Skalendimension), ${ }^{187}$ die Dauer der Rechtsverletzung (Zeitdimension) ${ }^{188}$ und vor allem die Schwere, die Geelhoed als „den Grad, um den die wirkliche Situation in dem Mitgliedstaat von dem Ergebnis abweicht, das mit Hilfe der Gemeinschaftspflicht erreicht werden soll“, umschreibt, ${ }^{189}$ soll es dem Gerichtshof möglich gemacht werden, besonders komplexe und hervorgehobene Vertragsverletzungen zu unterscheiden. Vor dem Hintergrund der prozeduralen Besonderheiten des Vertragsverletzungsverfahrens sind sie weder vorzeitig von einer Erledigung betroffen, noch ist nachträglich

184 EuGH, Rs. C-494/01, Kommission ./. Irland, „Irish Waste“, Urteil vom 26.04.2005, Slg. 2005 I-3382, ECLI:EU:C:2005:250, Rn. 127. In Teilen variiert die Formulierung geringfügig vgl. etwa zuvor Rn.37, „generell und fortdauernd", "généralité et la constance“/ general and consistent". In den Schlussanträgen des Generalanwalts Geelhoed vom 23.9.2004, Slg. 2005, I-3338, ECLI:EU:C:2004:546, bei Rn. 113 ist auch von einem „allgemeinen und strukturellen Verstoß“/,manquement généralisé et structurel“/,general and structural infringement" die Rede.

185 EuGH, Rs.C-494/01, Kommission ./. Irland, „Irish Waste“, Slg. 2005 I-3382, ECLI:EU:C:2005:250; Schlussanträge des Generalanwalts L. A. Geelhoed vom 23.9.2004, Slg. 2005, I-3338, ECLI:EU:C:2004:546. S. später auch EuGH, Rs. C-248/05, Kommission ./. Irland, Urteil vom 25.10.2007, Slg. 2007, I-9265, ECLI:EU:C:2007:629, Rn. 64 und ff.

186 EuGH, Rs. C-494/01, Kommission ./. Irland, „Irish Waste“, Schlussanträge des Generalanwalts L. A. Geelhoed vom 23.9.2004, Slg. 2005, I-3338, ECLI:EU:C:2004:546, Rn. $44 \mathrm{ff}$.

187 EuGH, Rs. C-494/01, Kommission ... Irland, „Irish Waste“, Schlussanträge des Generalanwalts L. A. Geelhoed vom 23.9.2004, Slg. 2005, I-3338, ECLI:EU:C:2004:546, Rn. 44.

188 EuGH, Rs. C-494/01, Kommission ... Irland, „Irish Waste“, Schlussanträge des Generalanwalts L. A. Geelhoed vom 23.9.2004, Slg. 2005, I-3338, ECLI:EU:C:2004:546, Rn. 45.

189 EuGH, Rs. C-494/01, Kommission ./. Irland, „Irish Waste“, Schlussanträge des Generalanwalts L. A. Geelhoed vom 23.9.2004, Slg. 2005, I-3338, ECLI:EU:C:2004:546, Rn. 46. 
die „Präzisierung“ des Klagegegenstands verhindert, wenn der Streitgegenstand selbst dabei identisch bleibt.

Die allgemeine und strukturelle Verletzung „kann kurz gesagt stets dann angenommen werden, wenn der Rechtsbehelf für diesen Sachverhalt nicht nur im Ergreifen von Maßnahmen besteht, um eine Reihe von Einzelfällen zu lösen, die nicht mit der betreffenden Gemeinschaftspflicht im Einklang stehen, sondern wenn die Pflichtverletzung nur durch eine Umstellung der allgemeinen Politik und Verwaltungspraxis des Mitgliedstaats bezüglich des Gegenstandes behoben werden kann, für den die betreffende Gemeinschaftsmaßnahme Geltung beansprucht. “190

Der Gerichtshof hat sich dem vollumfänglich angeschlossen. ${ }^{191}$

Die Figur der allgemeinen und strukturellen Vertragsverletzung - und damit die Überlegung der dort geschaffenen „Dimensionen“ der Berücksichtigung ihrer Relevanz - ist zunächst in der Literatur, insbesondere bei Pål Wennerås, der auch die spätere erneute Rezeption in der Rechtsprechung nachgezeichnet hat, eingehend besprochen worden ${ }^{192}$ und war dann Anlass für mehrere Anläufe in der Literatur, darunter insbesondere von Scheppele, das Vertragsverletzungsverfahren auf den Schutz von Unionswerten auszurichten. ${ }^{193}$

Auch hat die Europäische Kommission bereits 2002 Überlegungen zu „systembedingten Verstößen“ im Rahmen des Vertragsverletzungsverfahrens vorgelegt, die eine gewisse Kongruenz zu diesen Überlegungen des Generalanwalts Geelhoed zeigen. Sie sprach von der

„Verletzung der Grundsätze des Vorrangs und der einheitlichen Anwendung des Gemeinschaftsrechts (es handelt sich um systembedingte

190 EuGH, Rs. C-494/01, Kommission ... Irland, „Irish Waste“, Schlussanträge des Generalanwalts L. A. Geelhoed vom 23.9.2004, Slg. 2005, I-3338, ECLI:EU:C:2004:546, Rn. 43-48, Zitat Rn. 48.

191 S. etwa insb. EuGH, Rs. C-494/01, Kommission ./. Irland, „Irish Waste“, Urteil vom 26.04.2005, Slg. 2005 I-3382, ECLI:EU:C:2005:250, Rn. 37-38.

192 Pål Wennerås, „A new dawn for Commission Enforcement under Articles 226 and 228 EC: General and Persistent (Gap) Infringements, Lump Sums and Penalty Payments“, in: Common Market Law Review 43 (2006), S. 31-62, insb. ab S. 36.

193 Kim Lane Scheppele, „Enforcing the Basic Principles of EU Law through Systemic Infringement Actions“, in: Carlos Closa \& Dimitry Kochenov (Hrsg.), Reinforcing Rule of Law Oversight in the European Union, Cambridge University Press, Cambridge, 2016, S. 105-132, S. 112-113, implizit bezogen auf die „Skalendimension“ des Gerichtshofs, auf sie aufbauend und in der Absicht weiterzugehen, s. Matthias Schmidt \& Piotr Bogdanowicz, „The Infringement Procedure in the Rule of Law Crisis", S. $1076 \mathrm{ff}$. 
Verstöße, die z. B. bewirken, dass das Verfahren der Vorlage an den Gerichtshof zur Vorabentscheidung nicht reibungslos funktioniert, dass der innerstaatliche Richter daran gehindert ist, dem Gemeinschaftsrecht Vorrang einzuräumen, oder dass auf innerstaatlicher Ebene wirksame Beschwerdewege fehlen [...]). “194

Schließlich hat sich auch Generalanwalt Miguel Poiares Maduro später in der Rs. Centro Europa einer sehr ähnlichen Figur bedient. ${ }^{195}$ Ich schlage daher vor, die seinerzeit im Rahmen der sog. Irish-Waste-Rechtsprechung ${ }^{196}$ gemachten Ausführungen Geelhoeds zum Ausgangspunkt der Beantwortung der Frage zu machen, worum es geht, wenn das Unionsrecht von systemischen Defiziten spricht: um qualifizierte Rechtsuntreue eines Mitgliedstaats, die anhand bestimmter „Dimensionen“, nämlich Fallzahl, Dauer und Schwere, zu messen ist.

Die Rechtswissenschaft hat, bauend auf der Entwicklung in der Praxis, verschiedene Typen des systemischen Defizits einschließlich Kriterien der Erhebungsrelevanz entwickelt, auf die nun einzugehen ist.

194 Europäische Kommission, Mitteilung der Kommission zur besseren Kontrol-

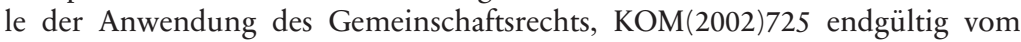
11.12.2002, S. 12; Hinweis bereits bei Damian Chalmers, Gareth Davies und Giorgio Monti, European Union Law, Cambridge University Press, Cambridge, 2010, S. 320-324; nachfolgend Matthias Schmidt \& Piotr Bogdanowicz, „The Infringement Procedure in the Rule of Law Crisis“, 1068.

195 EuGH, Rs. C-380/05, Centro Europa 7 Srl v Ministero delle Comunicazioni u.a., Schlussanträge des Generalanwalts M. Poaires Maduro, Rn. 14 ff., insb. Rn. 21 und 22 („schwerwiegender und andauernder Verstoß“ in einem Mitgliedstaat) vom 12.09.2007, dt. Fassung nicht in der amtl. Slg., franz. Ausg. 2007, S. I-352, ECLI:EU:C:2007:505, Hinweis bei Dimitry Kochenov, Laurent Pech \& Sébastien Platon, „Ni panacée, ni gadget: le ,nouveau cadre de l'Union européenne pour renforcer l'État de droit““, in: Revue Trimestrielle de Droit Européen (2014), S. 689-714, S. 700, bei Fn. 58, vgl. auch nochmals unter D.I.2.b.bb.

196 Zur weiteren Entwicklung dieser Rspr. s. bei Pål Wennerås, „A new dawn for Commission Enforcement under Articles 226 and 228 EC“, S. 48 ff., weiter Luca Prete \& Ben Smulders, „The Coming of Age of Infringement Procedures“, in: Common Market Law Review 47 (2010), S. 9-61, S. $24 \mathrm{ff}$, unter Verweis auf EuGH, Rs. C-189/07, Kommission ./. Spanien, Urteil vom 22.12.2008, Slg. 2008 I-195, ECLI:EU:C:2008:760 (Begr. nicht in dt. Spr.), Rs. C-150/07, Kommission ./. Portugal, Urteil vom 22.01.2009, Slg. 2009 I-7, ECLI:EU:C:2009:28 (Begr. nicht in dt. Spr.), die dort bemängelten Vorgänge waren allgemeine Verwaltungspraktiken bzw. verspätete Zahlungen. 


\section{Verständniswandel in der Rechtswissenschaft}

Zu Anfang der Rechtsstaatlichkeitskrise war der Begriff des systemischen Defizits ausschließlich auf mitgliedstaatliche Schwäche bezogen und sollte dort weit verbreitete Kapazitätsmängel und Umsetzungsschwierigkeiten des Rechts durch staatliche Stellen in einer recht kleinen Gruppe von Mitgliedstaaten erfassen, dies in Abgrenzung zu lediglich isolierten Vorgängen, die in jeder Rechtsordnung, auch als Krise, auftauchen können, von Verwaltung und Justiz aber nicht nur gemeistert werden, sondern sogar der Fortentwicklung der Rechtsordnung dienen. ${ }^{197}$ Für sie war die große Fallzahl und die weite Verbreitung prägend. So formulierten von Bogdandy und Ioannidis: „Dieser Beitrag richtet sein Augenmerk auf eine weitere Dimension: institutionelle Schwächen statt autoritärer Versuchungen. Es geht um den Willen und die Fähigkeit einiger Mitgliedstaaten, das Recht durchzusetzen." 198 Dabei stand die Bestimmung der Begriffsbestandteile des „Defizits“ und des „systemischen“ im Vordergrund, das Schutzgut bzw. der Bezugspunkt desselben, nämlich der Begriff des Rechtsstaats, interessierte weniger. ${ }^{199}$ Wenn auch die Verfasser Italien, Bulgarien und Rumänien einer Prüfung unterzogen, so war es doch ganz zuvörderst Griechenland, auf den der Begriff gemünzt war, ${ }^{200}$ und damit stand er noch ganz unter dem Eindruck des dortigen Zusammenbruchs der Wirtschaft nach 2008, die mit einem offensichtlichen Versagen vieler staatlicher Stellen korrelierte.

Entschieden wurde weiter, für den Begriff des systemischen Defizits keine präzise Definition anzubieten. ${ }^{201}$ Verwiesen wurde vielmehr auf eine Spannungslage, die sich daraus ergab, dass zum einen sowohl in der Rechtsprechung von EGMR und EuGH zunehmend Begriffe wie der „systemische Mangel“, ganz im Hinblick auf die zuvor identifizierten staatlichen Schwächen, Verwendung fanden, zum anderen der Begriff zahlreiche Anleihen in der allgemeinen Völkerrechtslehre (Begriff des failed oder weak state) wie auch bei entsprechenden Indikatoren machen konnte, drittens

197 Armin von Bogdandy \& Michael Ioannidis, „Das systemische Defizit“, S. 299.

198 Armin von Bogdandy \& Michael Ioannidis, „Das systemische Defizit“, S. 286.

199 Armin von Bogdandy \& Michael Ioannidis, „Das systemische Defizit“, S. 297 ff. Beide Verfasser gingen von einem vorrangig prozeduralen Rechtsstaatsverständnis aus, vgl. S. 288.

200 Vgl. dazu Armin von Bogdandy \& Michael Ioannidis, „Das systemische Defizit", S. $306 \mathrm{ff}$.

201 Armin von Bogdandy \& Michael Ioannidis, „Das systemische Defizit“, S. 296, 298. 
aber eben der Besonderheit Rechnung zu tragen war, dass der Begriff ein solcher des Unionsrechts sein sollte, auf den völkerrechtliche Begriffe schon deswegen nicht passten, weil selbst ein schwacher Mitgliedstaat mit versagenden Staaten i.S.d. Völkerrechts nicht zu vergleichen war. ${ }^{202}$ Von Bogdandy und Ioannidis lösten diese Spannungslage durch Abstellen auf ein in der subjektiven Einschätzung der Betrachter liegendes Kriterium, das Vertrauen in die Einhaltung des Rechts. Demnach war in einem Mitgliedstaat der Europäischen Union die Schwelle von einer schweren Verwaltungskrise zu einem systemischen Defizit überschritten, „wenn eine signifikante Anzahl sozialer Akteure in wichtigen Feldern aufhört, auf öffentliche Einrichtungen zur Bestätigung ihres normativen Erwartens zu setzen". 203

Ioannidis hat diese Überlegungen spezifisch unter dem Eindruck der Lage in Griechenland später unter Einführung des Begriffs des „schwachen Mitglieds“ („weak member“) als Subtyp des systemischen Defizits weiter ausdifferenziert. ${ }^{204}$ Ein solches schwaches Mitglied, statt Mitgliedstaat ${ }^{205}$ zeichnet sich für Ioannidis dadurch aus, dass „due to widespread corruption, lack of resources, or bad organization, it fails to give real effect to its law, thereby falling short of the Rule of Law requirement set out in Article 2 TFEU“. ${ }^{206}$ Für Ioannidis war insbesondere Griechenland in diesem Zusammenhang diskussionswürdig. ${ }^{207}$

Dass damit aber der Begriff des systemischen Defizits nicht abschließend auf staatliche Schwäche festgelegt war, sondern vielmehr ein Subtyp geschaffen wurde, zeigt insbesondere eine 2019 durch von Bogdandy vorgelegte Fortentwicklung des Begriffs vor dem Hintergrund insbesondere der Lage in Polen. Ein systemisches Defizit bezeichnet dabei zunächst eine signifikante Verschlechterung der internen Rechtslage eines Mitgliedstaates. ${ }^{208}$ Eine systemische Komponente erhält diese Entwicklung, wenn die sich daraus ergebende Lage zwischen den Mitgliedstaaten („intersystemisch“ statt „intrasystemisch“) besonders problematisch und eine Eskalati-

202 Vgl. Armin von Bogdandy \& Michael Ioannidis, „Das systemische Defizit“, S. $297 \mathrm{ff}$.

203 Armin von Bogdandy \& Michael Ioannidis, „Das systemische Defizit“, S. 300.

204 Michael Ioannidis, „Weak Members and the Enforcement of EU Law“, insb. S. 477-479 zur spezifischen Typik dieses Falles.

205 Michael Ioannidis, „Weak Members and the Enforcement of EU Law“, S. 481.

206 Michael Ioannidis, „Weak Members and the Enforcement of EU Law“, S. 485.

207 Michael Ioannidis, „Weak Members and the Enforcement of EU Law“, S. $485 \mathrm{ff}$.

208 Armin von Bogdandy, „Principles and Challenges of a European Doctrine of Systemic Deficiencies“, S. 11. 
on wahrscheinlich ist, da damit die Funktionsweise des gesamten Verbundes der Union gefährdet sei und der Grundsatz des gegenseitigen Vertrauens gefährdet werde. ${ }^{209}$ Eine systemische, im Unterschied zur einzelnen qualifizierten Rechtsverletzung bestehe gerade

„particularly when phenomena of illegality in one legal order impair the functioning of another system. Systems are often considered systemically deficient when they do not provide their services to other related systems." 210

Das gelte insbesondere, wenn die Justiz eines Mitgliedstaats die Regierung nicht mehr effektiv kontrollieren könne. ${ }^{211}$ Das systemische Defizit wird damit im Wesentlichen von einem Begriff, der sich zuvor vorrangig auf staatliche Schwächen erstreckt hatte, zu einem solchen, der auf die Rechtsstaatlichkeit bezogene Missstände von besonderer Tragweite erfasst.

4. Vorsatz, Spillover und intersystemisches Konfliktpotential als zentrale Merkmale

Ich stimme insbesondere den 2019 durch von Bogdandy gemachten Beobachtungen weitgehend zu und möchte ihnen hier einige eigene Bemerkungen zur Seite stellen. ${ }^{212}$ Im Rahmen der Entwicklung der Rechtsstaatlichkeitskrise sind die 2014 ursprünglich in Mitgliedstaaten beobachteten Schwächen zunehmend in den Hintergrund getreten. Was nun interessiert, ist der mitgliedstaatliche Vorsatz, die vorsätzliche Unterwanderung des Rechtsstaatsprinzips. Sie findet, auch wenn ich den Begriff zuvor abgelehnt habe, erhebliche Rückversicherung in der Definition von Pech und Scheppele zum Begriff des „democratic backsliding“. ${ }^{213}$ Im Grundsatz kann sich diese Beobachtung an Merkmalen der allgemeinen Strafrechtslehre orientieren und liegt folglich vor, wenn der Erfolg bewusst und gewollt herbeigeführt oder zumindest in Kauf genommen wurde. Auch die Europäische

209 Armin von Bogdandy, „Principles and Challenges of a European Doctrine of Systemic Deficiencies“, S. 12.

210 Armin von Bogdandy, „Principles and Challenges of a European Doctrine of Systemic Deficiencies“, S. 16.

211 Armin von Bogdandy, „Principles and Challenges of a European Doctrine of Systemic Deficiencies“, S. 16-17.

212 Vgl. auch bereits Matthias Schmidt \& Piotr Bogdanowicz, „The Infringement Procedure in the Rule of Law Crisis", S. 1083-184.

213 S. supra B.III.1. 
Kommission weiß zwischenzeitlich um die Bedeutung eines solchen Vorsatzes. Sie schreibt:

„Generell lässt sich feststellen, dass Korruption und Amtsmissbrauch auf hoher Ebene häufig im Zusammenhang mit Situationen vorkommen, in denen politische Kräfte den Rechtsstaat auszuhebeln trachten, und Versuche, den Pluralismus zu beschränken und wichtige Kontrollinstanzen wie die Zivilgesellschaft und unabhängige Medien zu schwächen, Warnzeichen für eine Gefährdung der Rechtsstaatlichkeit darstellen". 214

Die Zurechnung eines solchen Vorsatzes zum Mitgliedstaat ist hier nicht derartig zu verdichten wie etwa im Strafrecht. Eindeutig ist sie, wenn auf Gesetzesvorhaben und Handlungen der Regierung abgestellt wird, dann gilt der kollektive Wille des Staatsorgans pars pro toto als derjenige des Mitgliedstaats. ${ }^{215}$ Bei Fragen etwa der Korruption, die von Einzelpersonen als Amtsträger herrührt, muss man sich auf die Beobachtung Dritter verlassen, dass diese so weit verbreitet ist, dass sie die Gesamtheit einer staatlichen Einrichtung, wie etwa des Parlaments, der Staatsanwaltschaft usw. in Mitleidenschaft zieht.

$\mathrm{Zu}$ messen ist die Qualität dieses Vorsatzes anhand der „Dimensionen“, die aus der Rechtsprechung des Gerichtshofs in seinem Irish Waste-Urteil folgen.

$\mathrm{Zu}$ bejahen ist die systemische Relevanz eines solchen Vorsatzes nach meinem Dafürhalten zum einen aufgrund des bei von Bogdandy beobachteten „intersystemischen Konfliktpotentials“, zusätzlich aber auch wenn die Defekte einen sog. Spillover-Effekt im Rechtsverkehr zwischen den Mitgliedstaaten verursachen, der dadurch gekennzeichnet ist, dass ein hoheitlich handelnder Akteur im europäischen Rechtsraum, insbesondere also die Mitgliedstaaten selbst oder ein Unionsorgan, sich gezwungen sieht,

214 Europäische Kommission, Mitteilung der Kommission an das Europäische Parlament, den Europäischen Rat, den Rat, den Europäischen Wirtschafts- und Sozialausschuss und den Ausschuss der Regionen: Die Stärkung der Rechtsstaatlichkeit in der Union: Ein Konzept für das weitere Vorgehen, $\operatorname{COM}(2019) 343$ final vom 17.07.2019, S. 2.

215 Dies entspricht der Beurteilung des EuGH, wonach bei Vertragsverletzungen die Handlungen eines Staatsorgans für die Verletzung ausreichen, ohne dass sich ein anderes Organ durch Verweis auf sie exkulpieren kann, s. etwa bei Ulrich Karpenstein, Art. 258 AEUV, in: Eberhard Grabitz, Meinhard Hilf \& Martin Nettesheim (Begr./Hrsg.), Das Recht der Europäischen Union, C.H. Beck, München, 68. EL Oktober 2019, Rn. 62. 
eine eigentlich dem vom Defizit betroffenen Mitgliedstaat obliegende Rechtspflicht mittels Selbsteintritt, d.h. Pflichteneintritt, zu übernehmen.

Auch die Überlegung einer Selbsteintrittspflicht, die ein zuvor den Mitgliedstaaten, den Unionsorganen, ganz besonders der Kommission infolge ihres Mandats aus Art. 17 Abs. 1 EUV, und Einrichtungen des Europarates zustehendes Ermessen auf Null zu einer Pflicht reduziert, entstammt der Rechtsprechung des Gerichtshofs. Es handelt sich um eine zentrale Figur, mit der Generalanwältin Verica Trstenjak in ihren Schlussanträgen zur Rechtssache N.S. begründet hat, warum angesichts systemischer Mängel in den Asylsystemen bestimmter Mitgliedstaaten, die darüber ihren Verpflichtungen aus dem Dublin-System nicht nachgekommen sind, andere Mitgliedstaaten in ihre Pflichten eintreten. ${ }^{216}$

Die Bedeutung des Selbsteintritts zeigt sich im Rahmen der Rechtsstaatlichkeitskrise insbesondere in allen Fällen, in denen mitgliedstaatliche Justizbehörden mit Übergabegesuchen konfrontiert sind, wie im Fall LM. ${ }^{217}$ Unter „normalen“ 218 Umständen wären weder Europäischer Gerichtshof noch Europäische Kommission, noch aber die vollstreckende Justizbehörde in einem anderen Mitgliedstaat dazu veranlasst gewesen, durch Nutzung von Konstrukten wie Art. 19 Abs. 1 i.V.m. Art. 47 der Charta derart umfassend, wie sie dies später getan haben, beaufsichtigend in die Justizpolitik eines Mitgliedstaats einzugreifen bzw. Vorbehalte anzumelden. Sie taten dies, weil aus ihrer Einschätzung ein systemisches Versagen von Gesetzgebern und Gerichten bei der Einhaltung des Rechtsstaatsprinzips im Raum stand. Unter „normalen“ Umständen hätte ebenso keinerlei Anlass bestanden, Motive, dienstliche Motive und Verfahrensabläufe der ausländischen Kollegen zu hinterfragen. Die Antwort des seinerzeit vorlegenden irischen Gerichts ${ }^{219}$ und zwischenzeitlich auch deutscher Gerichte ist aber ein klares Beispiel dafür, dass diese normale Lage nicht mehr gilt. Man

216 EuGH, Verb. Rs C-411 \& 493/10, N.S., Schlussanträge der Generalanwältin Verica Trstenjak in den ECLI:EU:C:2011:610, Rn.3. Im Original eigentlich "Selbsteintrittpflicht“ (sic). In der französischen Fassung lautet die Formulierung „obligation d'évocation”. Die englische Fassung spricht von „duty to assume responsibility“.

217 EuGH, Rs. C-216/18 PPU, LM (Mängel des Justizsystems), Urteil (GK) vom 25.07.2018, ECLI:EU:C:2018:586, s. etwa Rn. $14 \mathrm{ff}$.

218 Zum Normalzustand im Unterschied zu systemischen Defiziten etwa bei Armin von Bogdandy, „Principles and Challenges of a European Doctrine of Systemic Deficiencies“, S. 15.

219 Vgl. High Court of Ireland, Minister for Justice and Equality v. Celmer, Record No. 2013 EXT 295 u.a., Vorabvorlagebeschluss vom 12.03.2018. 
fühlt sich vielmehr umfassend verpflichtet, anstatt der in Mitleidenschaft gezogenen ausländischen Behörden selbst zu prüfen, ${ }^{220}$ eben: selbst in die Pflichten der früheren Kollegen auf Augenhöhe einzutreten.

Auch das intersystemische Konfliktpotential, das von Bogdandy als weiteres Kriterium zur Ermittlung systemischer Defizite herausgearbeitet hat, bestätigt sich umfassend an vielen Schlüsselstellen der Rechtsstaatlichkeitskrise. Es zeigt sich z.B. in der Debatte um den Verbleib der Central European University in Budapest, ${ }^{221}$ der zu höchst energischer Kritik des ungarischen Vorgehens im Europäischen Parlament in Gegenwart des ungarischen Premierministers Viktor Orbán geführt hat. ${ }^{222}$ Noch markanter, wenn auch weniger sichtbar, ist der Konflikt zwischen ganzen Blöcken an Mitgliedstaaten, die aufgrund der Krise inzwischen aufeinandertreffen. Im Rahmen der Verhandlungen zur Einführung einer besonderen Konditionalität zum Schutz des EU-Haushalts bei „generellen Mängeln“ im Hinblick auf das Rechtsstaatsprinzip hat sich eine feste Gruppe von jedenfalls 9 Mitgliedstaaten, darunter Deutschland und Frankreich, etabliert, die den Vorschlag offen unterstützen, während andere zögern oder vehement dagegen sind. Die Delegationen Frankreichs und Deutschlands einerseits und Ungarns andererseits lieferten sich im Juni 2019 einen Schlagabtausch durch Einreichen gegenläufiger „Working Papers“. ${ }^{223}$ Im Hinblick auf die Position zu Art. 7 EUV sind die Positionen Deutschlands und Frankreichs gegenüber Polen und Ungarn im Rat inzwischen so eng, dass sich die deutschen und französischen Delegationen gegenseitig Redezeit überlassen und der

220 Eindrucksvoll Oberlandesgericht Karlsruhe, Beschluss vom 17.02.2020, Az. Ausl 301 AR 156/19.

221 S. dazu Venedig-Kommission, Opinion 891/2017, CDL-AD(2017)022-e, Hungary, Opinion on Article XXV of 4 April 2017 on the Amendment of Act CCIV of 2011 on National Tertiary Education vom 09.10.2017.

222 Vgl. Venedig-Kommission, Opinion 889/2017, CDL-AD(2017)015-e, Hungary, Opinion on the Draft Law on the Transparency of Organisations receiving support from abroad vom 20.10.2017.

223 Nachweise der verschiedenen Vorschläge im Übersichtsdokument des Rates der Europäischen Union, List of working papers (WK) distributed to the ad hoc Working Party on MFF in the first semester of 2019, 10848/19 vom 01.07.2019. Der Vorschlag zur Schaffung der Konditionalität hat derzeit bereits die Unterstützung Belgiens, Deutschlands, Dänemarks, Frankreichs, Luxemburgs, der Niederlande, von Portugal, Schweden und Finnland, dazu insb. der erste Eintrag der Liste auf S. 3 , ebda. 
Bericht hierüber dann z.B. vermerkt, Frankreich habe „also on behalf of Germany“ eine Stellungnahme abgegeben. ${ }^{224}$

So konturiert wird der Begriff des systemischen Defizits handhabbar. Mir geht es nachfolgend also allein um den Typus vorsätzlicher Unterwanderungen, der sich in einem Selbsteintritt eines anderen Akteurs oder in einem besonderen intersystemischen Konfliktpotential im Unionsrecht niederschlägt.

\section{Die Rechtsstaatlichkeit - Operationalisierung statt Definition}

Noch nicht erörtert worden ist bei der Klärung des systemischen Defizits dessen Bezugspunkt, die Rechtsstaatlichkeit selbst. Es ist weder möglich noch zielführend, für diesen Begriff eine erschöpfende Sichtung zu liefern, die Gegenstand einer eigenständigen Monographie sein müsste. ${ }^{225}$ Art. 2 S. 1 EUV, der das Rechtsstaatsprinzip bzw. den Wert der Rechtsstaatlichkeit $^{226}$ iterativ für das Unionsrecht nennt, liefert gerade keine Definition.

224 Rat der Europäischen Union, „Values of the Union - Hungary - Article 7 (1) TEU Reasoned Proposal - Report on the hearing held by the Council on 16 September 2019“, 12345/19 vom 19.09.2019, Limité, verfügbar unter: https://w ww.asktheeu.org/de/request/7287/response/23784/attach/6/st12345.en19.pdf ?cookie_passthrough=1, S. 7. Zu beiden Punkten auch Matthias Schmidt, „Le manquement perpétué en droit de l'Union européenne“, S. 87.

225 S. insb. Maria Luisa Fernandez Esteban, The Rule of Law in the European Constitution, Kluwer, Den Haag u.a., 1999; Erik O. Wennerström, The Rule of Law and the European Union; Laurent Pech, „The Rule of Law as a Constitutional Principle of the European Union“, Jean Monnet Working Paper 04/09, NYU School of Law, New York, 2009. Für das deutsche Recht Philipp Kunig, Das Rechtsstaatsprinzip, 1986; Katharina Sobota, Das Prinzip Rechtsstaat: Verfassungs- und Verwaltungsrechtliche Aspekte, Mohr Siebeck, Tübingen, 1997; Rechtsvergleichend zudem Luc Heuschling, État de droit, Rechtsstaat, rule of law, Dalloz, Paris, 2002.

226 Zur Bedeutung des Begriffs des Prinzips im Unionsrecht, inklusive der Rechtsstaatlichkeit, bereits Armin von Bogdandy, "Grundprinzipien“, insb. S. 62 und f.; beispielhaft kritisch im Hinblick auf die Änderung des Vertragswortlautes durch den Vertrag von Lissabon, der nunmehr in Art. 2 EUV von „Werten“ statt "Prinzipien“ spricht, Werner Schroeder, "The European Union and the Rule of Law - State of Affairs and Ways of Strengthening“, S. 12-14, auch mit Auswertung der Judikatur. Ich schlage vor, den begrifflichen Unterschied hier zu vernachlässigen und die Begriffe funktional gleichzusetzen, auch wenn das dogmatisch nicht befriedigt. Dafür ficht nicht zuletzt, dass die Europäische Kommission, auch unter dem Vertrag von Lissabon, ihren EU-Rahmen im Deutschen auf die Stärkung nicht allein der Rechtsstaatlichkeit, sondern des 
Er erlaubt auch keine Rückschlüsse auf eine besondere Vorrangstellung im Unionsrecht.

Traditionell haben Rechtswissenschaftler, die sich Norm und Prinzip gewidmet haben, daher auf verschiedene analytische Ansätze zur Entwicklung einer jeweils autonomen Arbeitsgrundlage zurückgegriffen. Schorkopf etwa hat zwei Methoden, die Möglichkeit induktiver bzw. deduktiver positiver Annäherung oder umgekehrt die der Subtraktion, d.h. der Bildung eines kleinsten gemeinsamen Nenners, unterschieden, ${ }^{227}$ die auch bei Katharina Serini angeklungen ist. 228 Thomas Pforr ${ }^{229}$ und Ulrike Kassner ${ }^{230}$ haben die Möglichkeit der positiven Begriffsergründung ${ }^{231}$ gewählt.

Auch die Europäische Kommission (wenn auch sichtlich vorsichtig), vor allem aber das Europäische Parlament, sind diesen Überlegungen jüngst mit dem Vorschlag einer Legaldefinition der Rechtsstaatlichkeit - der überhaupt ersten eines Unionswerts im positiven Recht - erheblich entgegengekommen, und zwar im bereits genannten Verordnungsentwurf über den Schutz des Unionshaushalts bei generellen Mängeln. Dort, in Art. 2 Abs. 1 lit. a, heißt es, wobei die kursiven Passagen die Änderungswünsche des Parlaments markieren, das Rechtsstaatsprinzip fuße auf:

„Artikel 2 EUV und in den Kriterien für die Mitgliedschaft in der Union gemäß Artikel 49 EUV verankerten Werte, auf die sich die Union gründet; es umfasst die Grundsätze der Rechtmäßigkeit, die gleichbedeutend ist mit einem transparenten, rechenschaftspflichtigen, demokratischen und pluralistischen Gesetzgebungsprozess, der Rechtssicherheit, des Verbots der willkürlichen Ausübung von Hoheitsgewalt, des $\mathrm{Zu}$ gangs zur Justiz und des wirksamen Rechtsschutzes einschließlich des Schutzes der Grundrechte, wie sie in der Charta der Grundrechte der

Rechtsstaatsprinzips bezogen hat. Thomas Würtenberger \& Jan W. Tkaczyński, „Nowe ramy Unii Europejskiej na rzecz umocnienia praworządności (analiza krytyczna)“, in: Pańtswo i Prawo 71 (2017), S. 16-29, S. 16, haben gemeint, es bestünde in der deutschen Rechtssprache ein rechtserheblicher Unterschied zwischen den Begriffen Rechtsstaatsprinzip und Rechtsstaatlichkeit. Dafür habe ich keine weiteren Belege gefunden.

227 Frank Schorkopf, Homogenität in der Europäischen Union, S. 79 ff.

228 Katharina Serini, Sanktionen der Europäischen Union bei Verstoß eines Mitgliedstaats gegen das Demokratie- oder Rechtsstaatsprinzip, S. $41 \mathrm{ff}$.

229 Thomas Pforr, Die allgemeine Unionsaufsicht, S. $91 \mathrm{ff}$.

230 Ulrike Kassner, Die Unionsaufsicht, S. 104 ff.

231 Übersicht über konkrete Definitionsvorschläge für das deutsche Recht bei Katharina Sobota, Das Prinzip Rechtsstaat, S. 21-24, unter Verweis insb. auf Klaus Stern. 
Europäischen Union und in internationalen Menschenrechtsübereinkommen niedergelegt sind, vor unabhängigen und unparteiischen Gerichten, der Gewaltenteilung, der Nichtdiskriminierung und der Gleichheit vor dem Gesetz“.232

Das Parlament hat dieser Positivbestimmung, die über einen Erwägungsgrund mit Vollzitat umfassender Rechtsprechung abgesichert wird, ${ }^{233} \mathrm{zu}-$ dem über die, von der Kommission wohlweislich vermiedene, Legaldefinition des generellen Mangels eine weitere Negativbestimmung zur Seite gestellt. ${ }^{234}$

232 Europäisches Parlament, P8_TA-PROV(2019)0349, Schutz des Haushalts der Union im Falle von generellen Mängeln in Bezug auf das Rechtsstaatsprinzip in den Mitgliedstaaten, „Legislative Entschließung des Europäischen Parlaments vom 4. April $2019 \mathrm{zu}$ dem Vorschlag für eine Verordnung des Europäischen Parlaments und des Rates über den Schutz des Haushalts der Union im Falle von generellen Mängeln in Bezug auf das Rechtsstaatsprinzip in den Mitgliedstaaten (COM(2018)0324 - C8-0178/2018 - 2018/0136(COD))“, o. S., Abänderung 29.

233 Europäisches Parlament, P8_TA-PROV(2019)0349, Schutz des Haushalts der Union im Falle von generellen Mängeln in Bezug auf das Rechtsstaatsprinzip in den Mitgliedstaaten, „Legislative Entschließung des Europäischen Parlaments vom 4. April 2019 zu dem Vorschlag für eine Verordnung des Europäischen Parlaments und des Rates über den Schutz des Haushalts der Union im Falle von generellen Mängeln in Bezug auf das Rechtsstaatsprinzip in den Mitgliedstaaten (COM(2018)0324 - C8-0178/2018 - 2018/0136(COD))“, o. S., Erwägungsgrund 2 = Abänderung 4.

234 Der Vollständigkeit halber ist sie hier abzudrucken, Europäisches Parlament, P8_TA-PROV(2019)0349, Schutz des Haushalts der Union im Falle von generellen Mängeln in Bezug auf das Rechtsstaatsprinzip in den Mitgliedstaaten, „Legislative Entschließung des Europäischen Parlaments vom 4. April 2019 zu dem Vorschlag für eine Verordnung des Europäischen Parlaments und des Rates über den Schutz des Haushalts der Union im Falle von generellen Mängeln in Bezug auf das Rechtsstaatsprinzip in den Mitgliedstaaten (COM(2018)0324 C8-0178/2018 - 2018/0136(COD)) “, Art. 2a, Generelle Mängel, o. S.:

„Als generelle Mängel in Bezug auf das Rechtsstaatsprinzip werden - sofern sie die Grundsätze der wirtschaftlichen Haushaltsführung oder den Schutz der finanziellen Interessen der Union beeinträchtigen oder zu beeinträchtigen drohen - insbesondere angesehen:

a) die Gefährdung der Unabhängigkeit der Gerichte, darunter die Auferlegung von Beschränkungen in Bezug auf die Fähigkeit, justizielle Aufgaben autonom wahrzunehmen, durch Eingriffe von außen in die garantierte Unabhängigkeit, durch die Erzwingung von Urteilen auf Anweisung von außen, durch die willkürliche Änderung der Vorschriften über die Ernennung oder Amtsdauer der Mitarbeiter des Justizwesens, durch deren Beeinflussung in einer Form, die 
Trotz der Raumfülle dieser Definition bringt jegliche inhaltliche Bestimmung des Gesetzgebers erhebliche Probleme mit sich. Abschließende Festlegungen lassen sich nicht vornehmen, ohne dass es zu Friktionen kommt oder schlicht Punkte übersehen werden. Auch der Verweis auf die Rechtsprechung durch den Gerichtshof bleibt in jedem Gesetzestext statisch und kann wesentliche Entwicklungen, die das Rechtsstaatsprinzip etwa in jüngerer Zeit durchlaufen hat, nicht wiedergeben. Große Überschneidungen des Rechtsstaatsbegriffs mit der Problematik des „essentially contested concept" sind vor diesem Hintergrund unbestreitbar. ${ }^{235}$

Ich schließe mich daher denjenigen Juristen an, ${ }^{236}$ die für das Europarecht den Versuch einer abschließenden oder gar positivrechtlichen Defi-

deren Unparteilichkeit beeinträchtigt, oder durch Maßnahmen, die die Unabhängigkeit der Anwaltschaft beeinträchtigen;

b) das Versäumnis, willkürliche oder rechtswidrige Entscheidungen von Behörden einschließlich Strafverfolgungsbehörden zu verhüten, zu korrigieren und zu ahnden, die ihre ordnungsgemäße Arbeit beeinträchtigende Zurückhaltung finanzieller und personeller Ressourcen oder das Versäumnis sicherzustellen, dass Interessenkonflikte ausgeschlossen sind;

c) die Einschränkung der Zugänglichkeit und Wirksamkeit des Rechtswegs, unter anderem mittels restriktiver Verfahrensvorschriften, der Nichtumsetzung von Gerichtsentscheidungen oder der Einschränkung einer wirksamen Untersuchung, Verfolgung oder Ahndung von Rechtsverstößen;

d) die Gefährdung der Verwaltungskapazität eines Mitgliedstaats im Hinblick darauf, die mit der Mitgliedschaft in der Union einhergehenden Verpflichtungen zu erfüllen, einschließlich der Fähigkeit, die zum gemeinsamen Besitzstand gehörenden Regeln, Normen und politischen Vorgaben wirksam umzusetzen;

e) Maßnahmen, die den Schutz der vertraulichen Kommunikation zwischen Rechtsanwalt und Mandant beeinträchtigen."

235 Begriff bei Walter Bryce Gallie, „Essentially Contested Concepts“, in: Proceedings of the Aristotelian Society 56 (1956), S. 167-198; speziell zum Rechtsstaatsprinzip in diesem Zusammenhang Armin von Bogdandy, Gubernative Rechtsetzung: eine Neubestimmung der Rechtsetzung und des Regierungssystems unter dem Grundgesetz in der Perspektive gemeineuropäischer Dogmatik, Mohr Siebeck, Tübingen, 2000, S. 29 ff., 34 insb.

236 Bereits Armin von Bogdandy, Piotr Bogdanowicz, Iris Canor, Maciej Taborowski \& Matthias Schmidt, „Guest Editorial: A potential constitutional moment for the European rule of law - The importance of red lines“, S. 985, weiterführend insb. auch Luke Dimitrios Spieker, „From Moral Values to Legal Obligations: On how to activate the Union's common values in the EU rule of law crisis", MPIL Research Paper Series, No. 2018-24, Heidelberg, 2018, S. 9. In der Intention gleich verstehe ich ebenso Vassilios Skouris, „Die Rechtsstaatlichkeit in der Europäischen Union“, in: Armin Hatje (Hrsg.), Verfassungszustand und Verfassungsentwicklung der Europäischen Union, Europarecht Beiheft 2 (2015), S. 8-19, S. 11. 
nition komplexer Rechtsbegriffe, insbesondere aber der Grundprinzipien der Europäischen Union, wie der Rechtsstaatlichkeit, abgelehnt haben, sondern vielmehr vorschlagen, sich der Methode der Operationalisierung zu bedienen, die in der Rechtsprechung des EuGH zu erkennen ist. ${ }^{237}$ Diese ist an die Methodik der reinen Sozialwissenschaften angelehnt, die mit der Operationalisierung traditionell die Beherrschbarmachung komplexer Konzepte durch Unterteilung in weniger komplexe, dem Begriff immanente, funktional eigenständige und daher besser erfassbare Bestandteile bezeichnen. ${ }^{238}$ Im Unterschied zur bereits genannten politikwissenschaftlichen Defektforschung, die diese Methode kennt, gründet die Operationalisierung hier aber in Entwicklungen der Rechtspraxis. In der dortigen Operationalisierung geht zudem die gerade in der Politikwissenschaft als selbstständiger methodischer Schritt gedachte und vorgelagerte Konzeptualisierung auf. Gerichtshof und Kommission scheinen einer solchen Operationalisierung zunehmend zuzuneigen. Dabei bin ich selektiv; die Frage der Entwicklung des Rechtsstaatsprinzips in ihren Außenbeziehungen aufgrund von Art. 49 EUV bleibt außen vor. 239

Drei wesentliche Entwicklungsstränge der Operationalisierung der Rechtsstaatlichkeit haben Bogdanowicz und ich bereits an früherer Stelle

237 Matthias Schmidt \& Piotr Bogdanowicz, „The Infringement Procedure in the Rule of Law Crisis“, S. $1086 \mathrm{ff}$., $1090 \mathrm{ff}$. insb., s. auch Luke Dimitrios Spieker, „Breathing Life into the Union's Common Values“, S. $1201 \mathrm{ff}$.

238 Vgl. dazu etwa spezifisch für das Demokratieprinzip aus sozialwissenschaftlicher Sicht, Hans-Joachim Lauth, Gert Pickel \& Christian Welzel, „Grundfragen, Probleme und Perspektiven der Demokratiemessung“, in: dies. (Hrsg.), Demokratiemessung: Konzepte und Befunde im internationalen Vergleich, VS Verlag für Sozialwissenschaften, Wiesbaden, 2000, S. 7-26; Peter Thiery \& Aurel Croissant, „Defekte Demokratie: Konzept, Operationalisierung und Messung“, S. 89 und ff.; zur Einführung weiter exemplarisch Ulrich von Alemann \& Wolfgang Tönnesmann: „Grundriß: Methoden in der Politikwissenschaft“, in: Ulrich von Alemann (Hrsg.), Politikwissenschaftliche Methoden: Grundriß für Studium und Forschung, VS Verlag für Sozialwissenschaften, Wiesbaden 1995, S. 17-140, S. 45.

239 Zur Relevanz des Rechtsstaatsprinzips im Umgang mit Drittstaaten aber etwa Erik O. Wennerström, The Rule of Law and the European Union, S. $224 \mathrm{ff}$;; weiter Dimitry Kochenov, EU Enlargement and the Failure of Conditionality: Pre-accession Conditionality in the Fields of Democracy and the Rule of Law, Wolters Kluwer, Alphen aan den Rijn, 2008, S. 85 ff., der (vgl. S. 87 insb.), nicht ohne Kritik, von einer „Verbindung von Demokratie und Rechtsstaatlichkeit“ durch die Europäische Kommission im Rahmen des Erweiterungsprozesses und mangelnder Kohärenz der Konzepte ausgeht. 
beobachtet. ${ }^{240}$ Ich greife sie hier nochmals für den deutschsprachigen Leser auf und ergänze sie, wo geboten.

\section{a. Allgemeine Rechtsgrundsätze}

Der erste Entwicklungsstrang ist nicht nur nach unserer, sondern nach weit verbreiteter Auffassung, die Rechtsprechung des Europäischen Gerichtshofs zu allgemeinen Rechtsgrundsätzen. ${ }^{241}$

Hiermit ist zunächst dem Umstand Rechnung getragen, dass die Werte der Union, wie sie Art. 2 S. 1 EUV nennt, abweichend vom Grundsatz des EuGH zur Auslegung von Begriffen des Unionsrechts nicht ohne Rückgriff auf mitgliedstaatliches Recht auszulegen sind. ${ }^{242}$ Der Gerichtshof hat sich mitgliedstaatlicher Rechtsauffassungen für die Ergründung der Unionswerte regelmäßig, wenn auch vielleicht nicht immer durchweg explizit, vergewissert. So lag der Entscheidung Algera betreffend den Vertrauensschutz und Amtshaftung der Gemeinschaft eine Rechtsvergleichung hinsichtlich der Lage in den Mitgliedstaaten zugrunde. ${ }^{243}$ Von Danwitz sieht in dieser und anderen Entscheidungen, unter Berufung auf Pierre Pescatore, lediglich „die Spitze eines Eisbergs“, mit dem der Gerichtshof sicherstellen

240 Matthias Schmidt \& Piotr Bogdanowicz, „The Infringement Procedure in the Rule of Law Crisis“, S. $1088 \mathrm{ff}$.

241 Dazu vgl. exemplarisch Christian Calliess, Art. 2 EUV, in: Christian Calliess \& Matthias Ruffert (Hrsg.): EUV/AEUV: Das Verfassungsrecht der Europäischen Union mit Europäischer Grundrechtecharta, 5. Aufl. C.H. Beck, München, 2016, Rn. 26; zur Funktion allgemeiner Rechtsgrundsätze Jürgen Schwarze, „Zwischen Tradition und Zukunft: Die Rolle allgemeiner Rechtsgrundsätze im Recht der Europäischen Union“, in: ders. (Hrsg.), Europarecht: Strukturen, Dimensionen und Wandlungen des Rechts der Europäischen Union: Ausgewählte Beiträge, Nomos, Baden-Baden, 2012, S. 114-127; zur konkreten Beobachtung auch zuvor Matthias Schmidt \& Piotr Bogdanowicz, „The Infringement Procedure in the Rule of Law Crisis“, S. $1090 \mathrm{ff}$. Für das deutsche Recht, in größter Ausführlichkeit, vgl. den Vorschlag einer „Elementereihung“ bei Katharina Sobota, Das Prinzip Rechtsstaat, S. 24 ff., 253 ff., s. bereits unter A. der hiesigen Arbeit aber ihre eigene Skepsis dazu.

242 Thomas Pforr, Die allgemeine Unionsaufsicht, S. 32, ähnlich Ulrike Kassner, Die Unionsaufsicht, S. 33.

243 EuGH, Rs. Verb. Rs. 7/56 und 3-7/57, Dineke Algera u.a. .. Gemeinsame Versammlung der EGKS, Urteil vom 12. Juli 1957, Slg. 1957, 91, ECLI:EU:C:1957:7, vgl. insb. S. 118 der dt. Fassung; zur Relevanz des Urteils und des dortigen Rechtsvergleichs Thomas von Danwitz, „The Rule of Law in the Recent Jurisprudence of the ECJ“, S. 1315. 
wolle, vergleichend die Traditionen der Mitgliedstaaten in seiner Rechtsprechung aufnehmen zu können. ${ }^{244}$ Damit ist denjenigen Kritikern entgegengetreten, die den Unionsorganen, insbesondere der Kommission, eine Interpretation des Rechtsstaatsprinzips losgelöst von mitgliedstaatlichen Traditionen vorgeworfen haben. ${ }^{245}$

Darüber hinaus betreibt die Rechtsprechung, ausgehend vom vielbeschworenen Grundsatz der Rechtsgemeinschaft im Les Verts-Urteil, 246 eine unionsrechtsautonome Handhabbarmachung des Rechtsstaatsprinzips. Sie erfolgt durch Konkretisierung unter Zerlegung in weitere Subprinzipien und der Benennung der konkreten Wirkung dieser Rechtsprinzipien für das Unionsrecht und in sowie gegenüber den Mitgliedstaaten. Auch die weitere Literatur hat sich dieser Methode bedient. ${ }^{247}$

Das bedeutendste Dokument der jüngeren Rechtspraxis, in dem eine derartige Operationalisierung durch Erarbeitung von Subprinzipien der Rechtsstaatlichkeit in der Rechtsprechung erarbeitet worden ist, ist der Anhang I zum 2014 durch die Kommission vorgestellten EU-Rahmen. ${ }^{248}$

244 Thomas von Danwitz, „The Rule of Law in the Recent Jurisprudence of the ECJ“, S. 1317, mit umf. w. N.

245 S. insb., auch sehr kritisch zum EU-Rahmen als solchem, Thomas Würtenberger \& Jan W. Tkaczyński, „Nowe ramy Unii Europejskiej na rzecz umocnienia praworządności (analiza krytyczna)", S. 22 und f.

246 Ausgehend vom Les-Verts-Urteil und dann einzelne Grundsätze konturierend etwa Erik O. Wennerström, The Rule of Law and the European Union, S. $117 \mathrm{ff}$.

247 S. nämlich bei Thomas Pforr, Die allgemeine Unionsaufsicht, S. 93-94, mit umfassender Auswertung einschlägiger Rechtsprechung, der zu diesen Grundsätzen zählt: „die Gewährung von Grundrechten, de[n] Grundsatz des Vertrauensschutzes, das Rückwirkungsverbot, de[n] Bestimmtheitsgrundsatz, das Verhältnismäßigkeitsprinzip, de[n] Grundsatz der Gesetzmäßigkeit der Verwaltung, de[n] Schutz wohlerworbener Rechte, das Gebot der Rechtssicherheit, de[n] Grundsatz ,ne bis in idem', de[n] Grundsatz der Gleichbehandlung und das Gebot effektiven Rechtsschutzes“. Umfassende Auswertung der Rspr. auch bei Cordula Stumpf, Art. 6 EUV, in: Jürgen Schwarze (Hrsg.), EU-Kommentar, Nomos, Baden-Baden, 2. Aufl. 2009, Rn.3-11, 28-31; weiter in diesem Sinne auch Werner Schroeder, „The European Union and the Rule of Law - State of Affairs and Ways of Strengthening“, S. 9 ff. Ähnlich bei Jörg Polakiewicz \& Jenny Sandvig, "The Council of Europe and the Rule of Law“, in: Werner Schroeder (Hrsg.), Strengthening the Rule of Law in Europe: From a Common Concept to Mechanisms of Implementation, Hart, Oxford, 2016, S. 115-133, S. $117 \mathrm{ff}$.

248 Vgl. Europäische Kommission, Mitteilung der Kommission an das Europäische Parlament und den Rat, Ein neuer EU-Rahmen zur Stärkung des Rechtsstaatsprinzips, 11.03.2014, $\operatorname{COM(2014)~} 158$ final, Anhang I: Das Rechtsstaatsprinzip als tragendes Prinzip der Union. 
In ihm sichert die Kommission die bestehende Rechtsprechung und konturiert das Rechtsstaatsprinzip für die Union durch Benennung und Erläuterung von sechs allgemeinen Rechtsgrundsätzen: Rechtmäßigkeitsprinzip, ${ }^{249}$ Rechtssicherheit, ${ }^{250}$ Willkürverbot, ${ }^{251}$ unabhängige und wirksame gerichtliche Kontrolle, ${ }^{252}$ Anspruch auf einen fairen Prozess bei Beachtung der Gewaltenteilung ${ }^{253}$ und Gleichheit vor dem Gesetz. ${ }^{254}$ Der Ausspruch der „Rechtsgemeinschaft“, nunmehr „Rechtsunion“, den der Gerichtshof erstmals im Les Verts Urteil ${ }^{255}$ genutzt hat, tritt ergänzend hinzu.

Das Gericht (erster Instanz) hat es, beginnend mit seinem Klyuyev-Urteil, mehrfach unternommen, eine ähnliche und nicht abschließende Liste an allgemeinen Rechtsgrundsätzen mit dem Rechtsstaatsprinzip zu verknüpfen. ${ }^{256}$ Der EuGH hat es aber bislang vermieden, die dortige Formel wörtlich aufzugreifen.

249 EuGH, Rs. C-496/99 P, Kommission ./. CAS Succhi di Frutta SpA, Urteil vom 29.04.2004, Slg. 2004, I-3801, ECLI:EU:C:2004:236, Rn. 63.

250 EuGH, Verb. Rs. 212 bis 217/80, Amministrazione delle finanze dello Stato ./. Salumi, Urteil vom 12.11.1981, Slg. 1981, 2735, ECLI:EU:C:1981:270, Rn. 10.

251 EuGH, Verb. Rs. 46/87 und 227/88, Hoechst AG ./. Kommission, Urteil vom 21.09.1989, Slg. 1989, 2859, ECLI:EU:C:1989:337, Rn. 19.

252 EuGH, Rs. C-583/11 P; Inuit Tapiriit Kanatami u. a. ./. Parlament und Rat, Urteil (GK) vom 03.10.2013, ECLI:EU:C:2013:625, nur in der elektr. Slg., Rn. 91; Rs. C-550/09, E und F, Urteil vom 29.06.2010, Slg. 2010, I-6213, ECLI:EU:C:2010:382, Rn.44; Rs. C-50/00 P, Unión de Pequeños Agricultores, Urteil vom 25.07.2002, Slg. 2002, I-6719, ECLI:EU:C:2002:462, Rn. 38 und 39.

253 EuGH, Verb. Rs. C-174/98 P und C-189/98 P, Niederlande und van der Wal ./. Kommission, Urteil vom 11.01.2000, Slg. 2000, I-1, ECLI:EU:C:2000:1, Rn. 17.

254 EuGH, Rs. C-550/07 P, Akzo Nobel Chemicals und Akcros Chemicals ./. Kommission, Urteil vom 14.09.2010, Slg. 2010, I-8301, ECLI:EU:C:2010:512, Rn. 54.

255 EuGH, Rs. 294/83, Parti écologiste „Les Verts“./. Europäisches Parlament, Urteil vom 23.04.1986, Slg. 1986, 1357, ECLI:EU:C:1986:166, Rn. 23.

256 EuG, Rs. T-340/14, Andriy Klyuyev ./. Rat, Urteil vom 15.09.2016, ECLI:EU:T:2016:496, Rn. 88:

„In der Rechtsprechung des Gerichtshofs und des Europäischen Gerichtshofs für Menschenrechte sowie den Arbeiten der Europäischen Kommission für Demokratie durch Recht, einer Einrichtung des Europarats, findet sich eine nicht erschöpfende Aufzählung der Grundsätze und Normen, die die Rechtsstaatlichkeit ausmachen. Dazu gehören die Grundsätze der Rechtmäßigkeit, der Rechtssicherheit und des Verbots der Willkür der Exekutive; unabhängige und unparteiische Gerichte, eine wirksame gerichtliche Kontrolle einschließlich der Wahrung der Grundrechte sowie die Gleichheit vor dem Gesetz (vgl. dazu die Liste der Kriterien der Rechtsstaatlichkeit, die die Europäische Kommission für Demokratie durch Recht in ihrer 106. Vollsitzung am 11./12. März 2016 in Venedig verabschiedet hat). Ferner wird in bestimmten Rechtsakten im Zusammenhang mit dem auswärtigen Handeln der Union u. a. die Bekämpfung der 
Während der EuGH dieser Liste in Zukunft weitere Subprinzipien hinzufügen dürfte, ist auch denkbar, dass neben unionseigener Judikatur Quellen des regionalen Völkerrechts mehr an Einfluss gewinnen, was angesichts der Eigenständigkeit, die der EuGH dem Unionsrecht als supranationaler Rechtsordnung in ständiger Rechtsprechung zuerkennt, beachtlich ist. Der Gewinn an Einfluss lässt sich nicht nur beobachten, sondern auch mit der traditionell guten Kooperationsbeziehung erklären, die insbesondere die Europäische Kommission und die Venedig-Kommission des Europarates pflegen. Sie färbt auf den Europäischen Gerichtshof zwischenzeitlich ab. In seiner Entscheidung vom November 2019 zur Beurteilung der Rechtmäßigkeit der Disziplinarkammer am polnischen Obersten Gerichtshof griff der EuGH u.a. bei der Auswertung der Vorlagefrage den Hinweis auf ein Gutachten der Venedig-Kommission auf,257 kurz zuvor war der Gerichtshof in gleicher Weise bereits auf die Berücksichtigung von Gutachten der Venedig-Kommission zu Ungarn durch ein dort ansässiges, vorlegendes Gericht, eingegangen. ${ }^{258}$ Die Venedig-Kommission wiederum hat eine sog. "rule of law"-Checkliste vorgelegt, die deduktiv Entscheidungsträgern als Entscheidungsgrundlage dienen soll und die jedenfalls das Gericht (erster Instanz) bereits herangezogen hat. ${ }^{259}$

b. Funktionsbestimmung der Rahmenbedingungen für die Rechtsanwaltschaft in Mitgliedstaaten

In einer in Entwicklung befindlichen Rechtsprechungslinie widmet sich der EuGH seit kurzem verstärkt der Rechtsanwaltschaft in Mitgliedstaaten und darüber ihrer Bedeutung für das Rechtsstaatsprinzip. Die Judikatur hierzu hatte zuvor häufig die Frage zum Gegenstand, inwiefern Juristen,

Korruption als ein der Rechtsstaatlichkeit innewohnender Grundsatz genannt $[\ldots]^{\text {“. }}$

Weiter Urt. vom gleichen Tag in der Rs. T-346/14, Viktor Fedorovych Yanukovych ./. Rat, ECLI:EU:T:2016:497, Rn.98; Zuletzt EuG, Rs. T-290/17 Edward Stavytskyi ./. Rat, Urteil vom 30.01.2019, ECLI:EU:T:2019:37, Rn. 68.

257 EuGH, Verb. Rs. C-585/18 u.a. , A.K. ./. Krajowa Rada Sądownictwa, u.a., Urteil (GK) vom 19.11.2019, ECLI:EU:C:2019:982, Rn. 41.

258 EuGH, Rs. C-118/17, Zsuzsanna Dunai ./. ERSTE Bank Hungary Zrt., Urteil vom 14.03.2019, ECLI:EU:C:2019:207, Rn. 27.

259 Venedig-Kommission, CDL-AD(2016)007, Study No. 711 / 2013, Rule of Law Checklist vom 18.03.2016, und vgl. nochmals EuG, Rs. T-340/14, Andriy Klyuyev ./. Rat, Urteil v. 15.09.2016, ECLI:EU:T:2016:496, Rn. 88. 
die in einem Mitgliedstaat juristische Hochschulabschlüsse bzw. die Befähigung zum Richteramt oder Zulassung als Rechtsanwalt erworben haben, in einem anderen Mitgliedstaat als solche tätig sein können. ${ }^{260}$ Nun fragt der EuGH auch nach den Rahmenbedingungen der Anwälte in den Mitgliedstaaten im Allgemeinen. In der derzeitigen Krise akut geworden ist dies noch nicht, hier aber zu erwähnen.

In der ersten einschlägigen Rechtssache Graham Wilson, auch durch die Kommission aufgegriffen, ${ }^{261}$ nutzte der Gerichtshof eine Streitigkeit betreffend die Zulassung eines britischen Juristen als Anwalt in Luxemburg und den sich daraus ergebenden Rechtsstreit mit der Rechtsanwaltskammer zu Äußerungen über die Richterschaft, indem er festhielt: „Der Begriff der Unabhängigkeit, die dem Auftrag des Richters innewohnt, bedeutet vor allem, dass die betreffende Stelle gegenüber der Stelle, die die mit einem Rechtsbehelf angefochtene Entscheidung erlassen hat, die Eigenschaft eines Dritten hat. “262 Während Kommissionspraxis und Literatur bislang auf die erste Hälfte dieser Feststellung (also die richterliche Unabhängigkeit) fokussiert haben, gebieten nun sowohl die Schlussanträge von Michal Bobek ${ }^{263}$ in der Rs. Uniwersytet Wroctawski als auch das spätere Urteil der Großen Kammer, den zweiten Halbsatz der Wilson-Formel in den Blick zu nehmen. In dieser Entscheidung, in der der polnische Kontext keinen Bezug zu den hier sonst interessierenden Fragen aufweist, machte der Gerichtshof grundlegende Ausführungen zum „Erfordernis der Unabhängigkeit des Anwalts“. ${ }^{264}$ Es muss sich noch zeigen, ob hieraus ein weiterer rechtspolitischer Impetus folgt.

260 Grundlegend EuGH, Rs. C-340/89, Irène Vlassopoulou ./. Ministerium für Justiz, Bundes- und Europaangelegenheiten Baden-Württemberg, Urteil vom 07.05.1989, Slg. 1991 I-2379, ECLI:EU:C:1991:193.

261 Europäische Kommission, Mitteilung der Kommission an das Europäische Parlament, den Europäischen Rat und den Rat, Die weitere Stärkung der Rechtsstaatlichkeit in der Union: Aktuelle Lage und mögliche nächste Schritte, $\operatorname{COM}(2019) 163$ final vom 03.04.2019, S. 4 bei Fn. 19.

262 EuGH, Rs. C-506/04, Graham J. Wilson ./. Ordre des avocats du barreau de Luxembourg, Urteil (GK) vom 19.09.2006, ECLI:EU:C:2006:587, Rn. 49.

263 EuGH, Verb. Rs. C-515/17 P und C-561/17 P, Uniwersytet Wrocławski ./. Exekutivagentur für die Forschung (REA), u.a., Schlussanträge des Generalanwalts Michal Bobek vom 24.09.2019, ECLI:EU:C:2019:774, Rn. 79 ff.

264 EuGH, Verb. Rs. C-515/17 P und C-561/17 P, Uniwersytet Wrocławski .. Exekutivagentur für die Forschung (REA), u.a., Urteil (GK) vom 04.02.2020, ECLI:EU:C:2020:73, insb. Rn. 63. 
c. Einwirkung auf die Mitgliedstaaten über staatsorganisationsrechtliche Strukturmerkmale

Ein weiterer Entwicklungsstrang, den Bogdanowicz und ich betreffend die Operationalisierung der Rechtsstaatlichkeit zuvor identifiziert hatten, ist eine Rechtsprechungslinie des EuGH, durch die das Rechtsstaatsprinzip als eigenständige staatsorganisationsrechtliche Anforderung strukturierend seitens der Union auf Mitgliedstaaten einwirkt.

Es findet seine Grundlage im Prinzip der Gewaltenteilung, indes nicht hinsichtlich derjenigen auf Unionsebene, ${ }^{265}$ sondern mit Blick auf die Mitgliedstaaten, und hier in der Doppelentscheidung Kovalkovas ${ }^{266}$ und Polto$r a k,{ }^{267}$ die wiederum in wesentlichen Punkten auf das Urteil in der Rechtssache $D E B$ zurückgehen. ${ }^{268}$ Der Präsident des Gerichtshofs, Lenaerts, griff, mutmaßlich in Bestätigung ihrer Bedeutung, die Urteile in einer Rede vor der polnischen Anwaltschaft mit Blick auf die Rechtsstaatlichkeitskrise in Polen auf. ${ }^{269}$

Wie später in den Rechtssachen Aranyosi und LM, hatte der EuGH über die Frage der Vollstreckung mitgliedstaatlicher Europäischer Haftbefehle zu befinden, konkret, ob diese nicht nur durch ein Gericht, wie der Rahmenbeschluss über den Haftbefehl erwarten ließ, sondern auch durch die Justizverwaltung oder die Polizei ausgestellt werden konnten. In der Rechtssache Kovalkovas betraf dies einen vom litauischen Justizministerium ausgestellten Haftbefehl, ${ }^{270}$ in der Rechtssache Poltorak einen durch eine Polizeibehörde (schwedisches Reichspolizeiamt) ausgestellten Haftbefehl. ${ }^{271}$ Das Bezirksgericht Amsterdam hatte Zweifel hinsichtlich der Vereinbarkeit dieses Vorgehens mit dem Wortlaut "Justizbehörde“

265 Dazu übersichtlich Erik O. Wennerström, The Rule of Law and the European Union, S. 123-124 und die dort zit. Lit.

266 EuGH, Rs. C-477/16 PPU, Ruslanas Kovalkovas, Urteil vom 10.11.16, ECLI:EU:C:2016:861, Rn. 14, bezogen auf das litauische Justizministerium.

267 Nahezu wortgleich, dort bezogen auf eine Polizeibehörde (schwedisches Reichspolizeiamt), EuGH, Rs. C-452/16 PPU, Krzystof Marek Poltorak, Urteil vom 10.11.16, ECLI:EU:C:2016:858, Rn. 35.

268 EuGH, Rs. C-279/09, DEB Deutsche Energiehandels- und Beratungsgesellschaft $\mathrm{mbH}$./. Deutschland, Urteil vom 22.10.2010, Slg. 2010, I-13849, Rn. 58.

269 Koen Lenaerts, „On Judicial Independence and the Quest for National, Supranational and Transnational Justice: Speech at the National Congress of the Polish Bar, Katowice“, Redemanuskript vom 20.05.2017, S. 3, einzige Fn., Manuskript beim Verfasser archiviert.

270 Vgl. EuGH, Rs. C-477/16 PPU, Kovalkovas, Rn. 10.

271 Vgl. EuGH, Rs. C-452/16 PPU, Poltorak, Rn. 2. 
in Art. 6 des Rahmenbeschlusses über den Europäischen Haftbefehl. Der EuGH hielt hierzu fest:

„Erstens erfasst der Begriff „Justiz“ in seiner gewöhnlichen Bedeutung nicht die Ministerien der Mitgliedstaaten. Er bezieht sich nämlich auf die Judikative, [... die], nach dem für einen Rechtsstaat kennzeichnenden Grundsatz der Gewaltenteilung von der Exekutive zu trennen ist. Daher werden unter den Justizbehörden herkömmlich die an der Rechtspflege mitwirkenden Behörden verstanden, im Unterschied insbesondere zu Ministerien oder anderen Regierungsstellen, die zur Exekutive gehören“. ${ }^{272}$

In dieser Feststellung, welcher eine Passage aus dem zuvor ergangenen Urteil $D E B$ aufgreift, ${ }^{273}$ ist nicht nur, wie die Europäische Kommission hervorhebt, ${ }^{274}$ der Gewaltenteilungsgrundsatz als allgemeiner Rechtsgrundsatz hervorzuheben, sondern insbesondere, dass der EuGH Bezug auf den Rechtsstaat nimmt und dabei das Rechtsstaatsprinzip mit weiteren Aussagen über seine Funktion verknüpft, und zweitens, dass er dies gerade in Bezug auf die innere Beschaffenheit der Mitgliedstaaten tut.

Der EuGH hat diese Feststellung später in der Rs. Rosneft ${ }^{275}$ flankiert, in welcher er sowohl die Grundprinzipienfunktion der Rechtsstaatlichkeit und die Bedeutung von Art. 2 EUV hervorhob als auch festhielt, dass bestimmte Rechtsgrundsätze - im konkreten Fall der des effektiven Rechtsschutzes - nicht nur konkreten Normen des Unionsrechts, sondern auch dem „Wesen eines Rechtsstaats inhärent“ sein können. In gleicher Formulierung, in Bezug auf das „Rechtsstaatsprinzip“ und Art. 2 EUV, auf welchen die Union baue, hat der EuGH die „wirksame Anwendung des

272 Vgl. EuGH, Rs. C-477/16 PPU, Kovalkovas, Rn. 36; EuGH, Rs. C-477 PPU, Poltorak, Rn. 35, dort lautet der Wortlaut, anstelle der Bezugnahme auf Ministerien oder andere Regierungsstellen, ,insbesondere zu Verwaltungs- oder Polizeibehörden"; meine Hervorhebung.

273 Vgl. nochmals, EuGH, Rs. C-279/09, DEB Deutsche Energiehandels- und Beratungsgesellschaft $\mathrm{mbH}$./. Deutschland, Urteil vom 22.12.2010, Slg. 2010, I-13880, ECLI:EU:C:2010:811, Rn. 58.

274 Vgl. Europäische Kommission, Mitteilung der Kommission an das Europäische Parlament und den Rat, Ein neuer EU-Rahmen zur Stärkung des Rechtsstaatsprinzips vom 11.03.2014, $\operatorname{COM}(2014) 158$ final, Anhang I, S. 2, bei Fn. 8.

275 EuGH, Rs. C-72/15, The Queen, auf Antrag der PJSC Rosneft Oil Company, vormals Rosneft Oil Company OJSC ./. Her Majesty's Treasury u.a., Urteil (GK) vom 28.03.2017, ECLI:EU:C:2017:236, Rn. 72 und 73. 
Unionsrechts“, bezogen ausdrücklich auf die Mitgliedstaaten der Union, als der Rechtsstaatlichkeit inhärent befunden. ${ }^{276}$

Noch ungeklärt im Hinblick auf die zukünftige ganze Tragweite der Entscheidungen in Kovalkovas und Poltorak und der späteren Entscheidung in Aranyosi ist ein justizpolitischer „Fallout" dieser Rechtsprechungslinie in anderen Mitgliedstaaten, nachdem sie jedenfalls schon Auswirkungen gegenüber Ersuchen von Drittstaaten hat. ${ }^{277}$ Spätestens 2019 hat sich nämlich auch im Hinblick auf die Bundesrepublik gezeigt, dass der EuGH die Überprüfung von Strukturmerkmalen nationaler Justizbehörden auch dort fortsetzt, wo auf den ersten Blick kein Anlass zur Sorge bestehen sollte. Erneut konfrontierten niederländische Gerichte den Gerichtshof mit der Frage, in welchem Umfang die nationalen, diesmal deutschen Staatsanwaltschaften bei der Ausstellung eines Europäischen Haftbefehls „unmittelbar oder mittelbar Anordnungen oder Einzelweisungen seitens der Exekutive, etwa eines Justizministers" unterworfen sein dürften. In der Entscheidung $O G$ und PI erklärte der Gerichtshof eine Vorschrift des GVG, die im Wesentlichen seit Ende des 19. Jahrhunderts unverändert als vorkonstitutionelles Recht besteht ${ }^{278}$ und wonach die Justizminister des Bundes und der Länder zumindest dem Grunde nach weisungsbefugt über die Staatsanwaltschaften sind, für mit dem Unionsrecht bei der Bearbeitung europäischer Haftbefehle unvereinbar. ${ }^{279}$ Die Bundesregierung sah sich daraufhin zu Änderungen im Verfahrensablauf veranlasst. ${ }^{280}$ Auch in Bezug auf Frankreich hat der Gerichtshof jüngst in der Rs. $J R$ die Frage der

276 EuGH, Rs. C-441/17 R, Kommission ./. Polen, „Puszcza Białowieska“, Beschluss (GK) vom 20.11.2017, ECLI:EU:C:2017:877, Rn. 102.

277 S. dazu (Auslieferungsersuchen seitens der Russischen Föderation), EuGH, Rs. C-182/15, Aleksei Petruhhin, Urteil (GK) vom 06.09.2016, ECLI:EU:C:2016:630, insb. Rn. 58.

278 Zur Normgenese der $\mathbb{S} 146 \mathrm{ff}$. GVG, der Entwicklung der Weisungsgebundenheit der deutschen Staatsanwaltschaft und den diversen Reformdebatten übersichtlich bei Wolfgang Wohlers, Vorbemerkungen zu den $\$ \mathbb{S} 141 \mathrm{ff}$. GVG, in: Jürgen Wolter (Hrsg.), Systematischer Kommentar zur Strafprozessordnung, Band IX, Carl Heymanns, Köln, 5. Aufl. 2016, Rn. 53 ff.

279 EuGH, Verb. Rs. C-508/18 u. C-82/19 PPU, OG und PI (Staatsanwaltschaft Lübeck und Zwickau), Urteil (GK) vom 27.05.2019, ECLI:EU:C:2019:456. Vorgehendes Zitat aus dem zweiten Leitsatz des Tenors.

280 Vgl. Rat der Europäischen Union, Judgments of the CJEU of 27 May 2019 in joined cases C-508/18 and C- 82/19 PPU and in case C-509/18 - public prosecutors offices acting as judicial authorities - Exchange of views on the follow-up = Paper by the Presidency, 9974/19 vom 12.06.2019, insb. S. 5 2. Abs. (Erklärung Deutschlands). 
Weisungsunterworfenheit der dortigen Strafverfolgungsbehörden kritisch untersucht. ${ }^{281}$

Die in der Trias DEB, Kovalkovas und Poltorak aufgestellten und später in Rosneft gestützten Ausführungen ziehen daher eine staatsorganisationsrechtliche Grenze in die Freiheit der Mitgliedstaaten ein, was den inneren Aufbau bestimmter Stellen und Organe und ihr Zusammenwirken angeht. Gewissermaßen sind die Urteile damit als Gegenstück von Rechtsprechung wie im Urteil Omega zu sehen, ${ }^{282}$ in welchem der EuGH den Mitgliedstaaten Spielraum bei der Ausgestaltung der Handhabung etwa der Grundrechtseinschränkung gewährt. Hier schränkt er, organisationsrechtlich anstatt im Hinblick auf die Grundrechtsausgestaltung, derartige Freiheit zugunsten größerer Kohärenz ihrer Justizsysteme ein.

$\mathrm{Zu}$ betonen ist, ${ }^{283}$ dass keiner der o.g. Fälle, insbesondere also nicht die Entscheidungen Kovalkovas und Poltorak, noch die jüngsten Entscheidungen des Gerichtshofs zur Unabhängigkeit der Justizbehörden in Deutschland $(O G)$ oder Frankreich $(J R)$, auf der Annahme seitens des Gerichtshofs beruhen, dass im dortigen Fall ein systemisches Defizit an Rechtsstaatlichkeit anzutreffen gewesen wäre. Das mindert aber nicht die Relevanz der Entscheidungen für die hiesigen Zwecke. Der Figur der strukturellen Vorgabe des Gerichtshofs an Mitgliedstaaten kommt vielmehr ein Reservepotential zu, das sich bei eskalierender Verschlechterung an anderer Stelle durchaus zusätzlich aktivieren lässt, ähnlich wie der Gerichtshof es in der Wightman-Entscheidung auch für das Demokratieprinzip angelegt hat.

d. Rückgriff auf Art. 19 Abs. 1 EUV i. V. m. Art. 47 der Grundrechtecharta

Der vierte Entwicklungsstrang ist schließlich derjenige der Operationalisierung des Rechtsstaatsprinzips über substitutsweise genutzte (im Engli-

281 EuGH, Verb. Rs. C-566/19 PPU und C-626/19 PPU, JR und YC (Parquet général du Grand-Duché de Luxembourg und Openbaar Ministerie (Staatsanwaltschaften Lyon und Tours)), Urteil vom 12.12.2019, ECLI:EU:C:2019:1077.

282 EuGH, Rs. C-36/02, Omega Spielhallen- und Automatenaufstellungs GmbH ./. Oberbürgermeisterin der Bundesstadt Bonn, Urteil vom 14.10.04, Slg. 2004, I-9641, ECLI:EU:C:2004:614, Rn. 34 und 37 ff. Zur Bedeutung der Omega-Entscheidung etwa Koen Lenaerts, „Kooperation und Spannung im Verhältnis von EuGH und nationalen Verfassungsgerichten“, in: Europarecht 50 (2015), S. 3-27, S. 20-21.

283 S. dazu auch nochmals Matthias Schmidt \& Piotr Bogdanowicz, „The Infringement Procedure in the Rule of Law Crisis“, insb. S. 1092. 
schen als "proxy“ bezeichnete) ${ }^{284}$ andere Rechtsgarantien und vor allem Normen, die in sich funktionell eigenständige Teile des Rechtsstaatsprinzips aufnehmen und dadurch konkret handhabbar machen. Er ist eine Variante der Erarbeitung mitgliedstaatlicher Strukturmerkmale. Diese Operationalisierung hat in der jüngeren Rechtsprechung in Bezug auf die Unabhängigkeit der Justiz in den Mitgliedstaaten eine überragende Bedeutung entfaltet, weil sie insbesondere gegenüber Polen genutzt worden ist. Von zentraler Bedeutung ist dabei zunächst Art. 19 Abs. 1 (präziser: UAbs. 2) EUV, welcher in einer Norm, die ansonsten die Funktion des Gerichtshofs regelt, lautet: „Die Mitgliedstaaten schaffen die erforderlichen Rechtsbehelfe, damit ein wirksamer Rechtsschutz in den vom Unionsrecht erfassten Bereichen gewährleistet ist." Mit ihm verknüpft wird Art. 47 GRCh, das Recht auf einen wirksamen Rechtsbehelf.

Die Diskussion dieser Entwicklung war und ist eng mit der Frage der Nutzung des Vertragsverletzungsverfahrens verwoben. Ich trenne letzteres hier ab und diskutiere zunächst allein den Prüfungsmaßstab, bevor ich im Verlauf der Arbeit die Funktion der Vertragsverletzungsklage bespreche.

aa. Entwicklung bis zum Urteil in der Rs. Associação Sindical dos Juízes Portugueses

Der verstärkte Fokus des Gerichtshofs auf diese beiden Normen und damit den Grundsatz der richterlichen Unabhängigkeit korreliert mit der Entscheidung der Kommission im Spätsommer 2017, sie gegenüber Polen in Stellung zu bringen. Die so angestoßene weitere Beschäftigung mit dem Rechtsstaatsprinzip ist folglich aus der Rechtsstaatlichkeitskrise der Union entstanden.

In der Pressemitteilung zur sog. dritten Empfehlung zur Rechtsstaatlichkeit, einem Teilabschnitt des gegen Polen bemühten EU-Rahmenverfahrens, findet sich meiner Kenntnis nach erstmals der Hinweis darauf, die Kommission werde gegen Polen ein Vertragsverletzungsverfahren in Bezug auf die dortigen Umbrüche im Justizsystem einleiten, und zwar basierend auf Art. 19 Abs. 1 EUV i.V.m. Art. 47 der Grundrechtecharta. ${ }^{285}$

284 Matthias Schmidt \& Piotr Bogdanowicz, „The Infringement Procedure in the Rule of Law Crisis“, S. $1092 \mathrm{ff}$.

285 Europäische Kommission, European Commission acts to preserve the rule of law in Poland/The European Commission acts today to protect the rule of law in Poland. Pressemitteilung vom 26.07.2017, IP/17/2161. 
Art. 19 Abs. 1 UAbs. 2 EUV ist eine relativ junge Vorschrift. Sie fand in die Verträge erst mit dem Vertrag von Lissabon Eingang und gilt in der Literatur als Reaktion der Vertraggeber auf die starke Bedeutung des mitgliedstaatlichen Rechtsschutzsystems, die der EuGH diesem namentlich in der Rechtssache Unión de Pequeños Agricultores hatte zukommen lassen. ${ }^{286}$

Als die Kommission im Juli 2017 ihre Klage gegen Polen per Mahnschreiben vorbereitete, schien aber eine nachrangige Rolle für Art. 19 Abs. 1 UAbs. 2 EUV wahrscheinlich. Dies ergab sich aus einer Parallelentscheidung zum späteren Grundsatzurteil Associação Sindical dos Juizes Portugueses (auch: ASJP), die dort im Urteil fehlt, in den Schlussanträgen indes durch Generalanwalt Henrik Saugmansgaard Øe genau berücksichtigt wurde: der Rechtssache Berlioz und wiederum insbesondere den dort durch Generalanwalt Melchior Wathelet gemachten Ausführungen. In Berli$o z$, entschieden nur zwei Tage vor Ergehen der Schlussanträge in ASJP, war der EuGH gehalten, sich speziell zu Art. 47 der Charta, dem Recht auf einen wirksamen Rechtsbehelf und ein unparteiisches Gericht, zu äußern. Generalanwalt Wathelet hielt fest, Art. 47 der Charta könne „nicht unabhängig von Art. 19 Abs. 1 UAbs. 2 EUV“ betrachtet werden. ${ }^{287}$ Dem schloss sich der Gerichtshof zunächst mit der Formulierung an, das Recht nach Art. 47 GRCh entspreche der Pflicht der Mitgliedstaaten nach Art. 19 Abs. 1 UAbs. 2 AEUV. ${ }^{288}$ Damit erschien Art. 19 Abs. 1 UAbs. 2 EUV als dem Chartagrundrecht nachgeordneter Auslegungsannex, bestenfalls aber als Regelungsbekräftigung, und als eine Norm, die diesem Recht zusätzlichen Ausdruck verlieh, indes keine größere eigenständige Bedeutung entfalten dürfte. Insbesondere stand damit jeglicher eigenständigen Nutzung von Art. 19 Abs. 1 UAbs. 2 EUV der Wortlaut und Telos des Art. 51 der Charta entgegen, der den Anwendungsbereich der Charta „ausschließlich“ auf die „Durchführung des Unionsrechts“ festlegt.

Saugmansgaard Øe war mit dieser Entwicklung sichtlich unzufrieden und setzte sich darüber ausführlich mit der Auffassung seines Kollegen

286 Bernhard W. Wegener, Art. 19 EUV, in: Christian Calliess \& Matthias Ruffert, EUV/AEUV, 5. Aufl., C.H. Beck, München, 2016, Rn. 43 ff.; EuGH, Rs. C-55/00 P, Unión de Pequeños Agricultores ./. Rat, Slg. 2002, I - 6719, Urteil, ECLI:EU:C:2002:462, insb. Rn. 41.

287 EuGH, Rs. C-682/15, Berlioz Investment Fund SA ./. Directeur de l'administration des Contributions directes, Schlussanträge des Generalanwalts Melchior Wathelet vom 10.01.2017, ECLI:EU:C:2017:2, Rn. 38.

288 EuGH, Rs. C-682/15, Berlioz Investment Fund SA ./. Directeur de l'administration des Contributions directes, Urteil (GK) vom 16.05.2017, ECLI:EU:C:2017:373, Rn. 44. 
Wathelet auseinander. Er hielt fest, dass, „[a]uch wenn nicht ausgeschlossen werden kann, dass gewisse Erwägungen zu Art. 47 der Charta nützliche Erkenntnisse für die Auslegung von Art. 19 EUV, und umgekehrt, bringen können[,]“ es sich um „Bestimmungen [handele], die der Gerichtshof - meiner Ansicht nach getrennt - auszulegen haben wird, falls er sich für zuständig ansieht, um in beiderlei Hinsicht zu entscheiden." 289

Der EuGH vollzog daraufhin eine Kehrtwende in seinem Urteil in der Rs. ASJP. ${ }^{290}$ Dieses hatte eigentlich Fragen der Gehaltszumessung für portugiesische Richter zum Gegenstand, indes nutzte der Gerichtshof das Urteil über weite Strecken derart deutlich gemünzt auf die Krise in Polen, dass das selbst der Tagespresse auffiel. Die „Süddeutsche Zeitung" schrieb sarkastisch von „Grüßen nach Warschau“"291 der Economist titelte vom „Aufbrüllen Luxemburgs“. ${ }^{292}$

Es komme, so der EuGH zunächst, für das Verständnis von Art. 19 Abs. 1 UAbs. 2 EUV nicht darauf an, ob eine Durchführung von Unionsrecht vorliege, wie Art. 51 der Charta bestimme. ${ }^{293}$

Damit war der Weg frei für eine autonome Auslegung der Norm und des durch sie aufgestellten Gebots an die Mitgliedstaaten. Hier nun sorgte der EuGH in der ersten zentralen Festlegung des Urteils für eine handfeste Überraschung. Wäre es ihm auch möglich gewesen festzustellen, und dies angesichts des Berlioz-Urteils sogar wahrscheinlicher gewesen, dass die Auslegung sich an Art. 47 der Charta zu orientieren hatte, schlug der EuGH nun hier die Brücke zu Art. 2 EUV und hielt fest:

„Art. 19 EUV, mit dem der Wert der in Art. 2 EUV proklamierten Rechtsstaatlichkeit konkretisiert wird, überträgt die Aufgabe, in der Rechtsordnung der Union die gerichtliche Kontrolle zu gewährleisten, nicht nur dem Gerichtshof, sondern auch den nationalen Gerichten“ [...]

289 EuGH, Rs. C-64/16, ASJP, Schlussanträge des Generalanwalts Henrik Saugmansgaard Øe vom 18.05.2017, Rn. 56, vorgehendes Zitat ebd., Fn. 54.

290 EuGH, Rs. C-64/16, Associação Sindical dos Juízes Portugueses ./. Tribunal de Contas, nachfolgend: ASJP, Urteil (GK) vom 27.02.18, ECLI:EU:C:2018:117.

291 Wolfgag Janisch, „Grüße nach Warschau: Der Europäische Gerichtshof definiert in einem portugiesischen Fall richterliche Unabhängigkeit - Adressat ist aber Polen“, Süddeutsche Zeitung vom 14.03.2018.

292 „Hear Luxembourg roar: The EU's top judges take on Poland: The European Court of ]ustice may be itching for a scrap with over-mighty politicians“, The Economist vom 26.04.2018.

293 EuGH, Rs. C-64/16, ASJP, Urteil (GK) vom 27.02.18, ECLI:EU:C:2018:117, Rn. 29. 
„Der Grundsatz des wirksamen gerichtlichen Schutzes der Rechte aus dem Unionsrecht, von dem in Art. 19 Abs. 1 Unterabs. 2 EUV die Rede ist, ist nämlich ein allgemeiner Grundsatz des Unionsrechts, der sich aus den gemeinsamen Verfassungsüberlieferungen der Mitgliedstaaten ergibt; er ist in den Art. 6 und 13 der [EMRK] und nun auch in Art. 47 der Charta verankert". [...]

"Schon das Vorhandensein einer wirksamen, zur Gewährleistung der Einhaltung des Unionsrechts dienenden gerichtlichen Kontrolle ist dem Wesen eines Rechtsstaats inhärent [.]“294

Diese Ausführung hatte der EuGH bereits im Urteil Schrems ${ }^{295}$ und kurz danach in vergleichbarer Weise in der Rechtssache Rosneft ${ }^{296}$ gemacht, dort aber zunächst allein auf Art. 47 Abs. 1 der Charta bezogen. Im Urteil El Hassani hatte der Gerichtshof überdies festgehalten, dass Art. 47 der Charta „den Grundsatz des wirksamen gerichtlichen Rechtsschutzes bekräftigt“. ${ }^{297}$

Weiter hieß es nun in ASJP:

„Deshalb hat jeder Mitgliedstaat dafür zu sorgen, dass Einrichtungen, die als Gerichte im Sinne des Unionsrechts Bestandteil seines Rechtsbehelfssystems sind, in den vom Unionsrecht erfassten Bereichen einen wirksamen gerichtlichen Rechtsschutz gewähren. “298

Insbesondere auch um die Funktion des Vorabvorlageverfahrens nach Art. 267 AEUV zu wahren, ${ }^{299}$ entwirft der EuGH schließlich an einer für

294 EuGH, Rs. C-64/16, ASJP, Urteil (GK) vom 27.02.18, ECLI:EU:C:2018:117, Rn, 32, 35, 36. Meine Hervorhebungen.

295 EuGH, Rs. C-362/14, Maximilian Schrems ./. Data Protection Commissioner, Urteil (GK) vom 06.10.15, ECLI:EU:C:2015:650, Rn.95. Der Gerichtshof verweist dort auch noch auf andere, frühere Entscheidungen, meiner Kenntnis nach ist dieses Urteil indes das erste, in dem sich die Formulierung von dem Rechtsstaat inhärenten Prinzipien findet.

296 EuGH, Rs. C-72/15, The Queen, auf Antrag der PJSC Rosneft Oil Company, vormals Rosneft Oil Company OJSC ./. Her Majesty's Treasury u.a., Urteil (GK) vom 28.03.2017, ECLI:EU:C:2017:236, Rn. 72 u. 73.

297 EuGH, Rs. C-403/16, Soufiane El Hassani ./. Minister Spraw Zagranicznych, Urteil vom 13.12.2017, ECLI:EU:C:2017:960, Rn. 38.

298 EuGH, Rs. C-64/16, ASJP, Urteil (GK) vom 27.02.18, ECLI:EU:C:2018:117, Rn, 37.

299 EuGH, Rs. C-64/16, ASJP, Urteil (GK) vom 27.02.18, ECLI:EU:C:2018:117, Rn. 43. 
das Urteil zentralen Stelle einen vierstufigen ${ }^{300}$ Test, der wie ein maßgeschneidertes Prüfprogramm für Krisen wie derjenigen in Polen erscheint:

„Der Begriff der Unabhängigkeit setzt u. a. voraus, dass

[1] die betreffende Einrichtung ihre richterlichen Funktionen in völliger Autonomie ausübt,

[2] ohne mit irgendeiner Stelle hierarchisch verbunden oder ihr untergeordnet zu sein und

[3] ohne von irgendeiner Stelle Anordnungen oder Anweisungen zu erhalten, und dass sie auf diese Weise

[4] vor Interventionen oder Druck von außen geschützt ist, die die Unabhängigkeit des Urteils ihrer Mitglieder gefährden und deren Entscheidungen beeinflussen könnten“..301

bb. Die Entwicklung der Operationalisierung des Rechtsstaatsprinzips durch Art. 19 Abs. 1 EUV und Art. 47 GRCh infolge der Rechtsprechung zu Polen

\section{(1) Gegenwärtiger Stand der Rechtsprechung}

Seit dem Urteil der Großen Kammer in der Rs. ASJP hat der Gerichtshof Ende 2019 in den beiden erneut zu Polen ${ }^{302}$ entschiedenen Vertragsverletzungsverfahren ${ }^{303}$ betreffend die Unabhängigkeit des polnischen Obersten Gerichtshofs und die polnische ordentliche Gerichtsbarkeit weiter ausgebaut. Der Europäische Gerichtshof hat dabei sukzessive die gesamte Bandbreite der Umbrüche in Polen zu entscheiden (gehabt), über Änderungen betreffend das Verfassungsgericht, die Richterpensionierung am polnischen Obersten Gerichtshof, die Besetzung des Landesjustizrates, die

300 Vgl. auch die Analyse bei Matthias Schmidt \& Piotr Bogdanowicz, „The Infringement Procedure in the Rule of Law Crisis“, S. 1097-1098.

301 EuGH, Rs. C-64/16, ASJP, Urteil (GK) vom 27.02.18, ECLI:EU:C:2018:117, Rn. 44. Meine Aufteilung.

$302 \mathrm{Zu}$ den Topoi der Krise in Polen vgl. ausf. infra unter C. III.

$303 \mathrm{Zu}$ diesen Verfahren s. nun auch Matthias Schmidt \& Piotr Bogdanowicz, „Ascertaining the ,Guarantee of Guarantees': Recent Developments Regarding the Infringement Procedure in the EU's Rule of Law Crisis“, in: Armin von Bogdandy, Piotr Bogdanowicz, Iris Canor, Christoph Grabenwarter, Maciej Taborowski, Matthias Schmidt (Hrsg.): Defending Checks and Balances in EU Member States: Taking Stock of Europe's Actions, Springer, Heidelberg, 2021, S. 207-236. 
neu geschaffene Disziplinarkammer und Kammer für außerordentliche Rechtsbehelfe am Obersten Gerichtshof bis hin zur konkreten Umsetzung dieser Gesetzesänderungen.

Für Polen insbesondere hat der Europäische Gerichtshof insgesamt, Stand Frühjahr 2020, zwei Vertragsverletzungsverfahren betreffend die „Unabhängigkeit des Obersten Gerichtshofs“ sowie eines zur „Unabhängigkeit der ordentlichen Gerichte" (eigentlich aber betreffend eine Pensionsaltersdifferenzierung nach Geschlecht auch am Obersten Gerichtshof) entschieden. ${ }^{304}$ Ein weiteres Verfahren zur Rolle der Disziplinarkammer am polnischen $\mathrm{OGH}$ ist anhängig. ${ }^{305}$ Die Europäische Kommission hat also zum Gesamtkomplex der polnischen Krise vier Verfahren angestrengt, ein in der Geschichte der Union wohl einmaliger Vorgang. Nicht minder beeindruckend ist die Anzahl der Vorabvorlagen, inklusive mehrerer oberster polnischer Gerichte. Neben der Rechtssache LM hat der Gerichtshof mehrere Vorlagen betreffend die Richterpensionierung am polnischen Obersten Gerichtshof zu einem gemeinsamen Verfahren verbunden. ${ }^{306}$ Mindestens acht weitere Verfahren, von denen aber sieben zur Entscheidung zu verbinden sein dürften, sind anhängig. ${ }^{307}$

Nicht immer hat der Europäische Gerichtshof dabei aber jede Gelegenheit, die sich ihm bot, auch für opportun gehalten, die Frage der Wahrung der Rechtsstaatlichkeit in der Europäischen Union zu erörtern. In mindestens einem Verfahren $(D S ́)$ hat der Gerichtshof auf Erledigung erkannt, obwohl der polnische Oberste Gerichtshof eine Entscheidung in der Sa-

304 EuGH, Rs. C-619/18 R, Kommission ./. Polen, „Unabhängigkeit des polnischen Obersten Gerichtshofs“, Urteil (GK) vom 24.06.2019, ECLI:EU:C:2019:531; Rs. C-192/18, Kommission ./. Polen, „Unabhängigkeit der polnischen Gerichtsbarkeit“, Urteil (GK) vom 05.11.2019, ECLI:EU:C:2019:924.

305 Nämlich: Rs.791/19, Europäische Kommission/Republik Polen betreffend die sog. Disziplinarkammer, Klage vom 25.10.19, ABl.(EU) C 413/36 vom 09.12.2019, s. zwischenzeitlich Beschluss (GK) vom 08.04.2020, ECLI:EU:C:2020:277. Ob und wie Polen insbesondere den Maßnahmen im vorläufigen Rechtsschutz nachkommt, war bei Abschluss des Manuskripts offen.

306 EuGH, Rs. C-216/18 PPU, LM (Mängel des Justizsystems), Urteil (GK) vom 25.07.2018, ECLI:EU:C:2018:586; EuGH, Verb. Rs. C-585/18 u.a., A.K. ./. Krajowa Rada Sądownictwa, CP, DO ./. Sąd Najwyższy, Urteil (GK) vom 19.11.2019, ECLI:EU:C:2019:982.

307 EuGH, Rs. C-824/18, Vorabentscheidungsersuchen des Naczelny Sąd Administracyjny [Obersten Verwaltungsgerichts] (Polen), eingereicht am 28. Dezember 2018 - A.B., C.D., E.F., G.H., I.J./Krajowa Rada Sądownictwa, ABl. (EU) C 164/5 vom 13.05.2019; Rs. C-748/19 bis C-754/19, alle vorgelegt vom Bezirksgericht Warschau (Sąd Okręgowy w Warszawie) am 15.10.2019, ABl. (EU) C 54/17 und ff. vom 17.02.2020. 
che angeregt hatte. ${ }^{308} \mathrm{Im}$ Vorabentscheidungsersuchen Miasto Eowicz wies der Europäische Gerichtshof überdies zwei Vorlagen polnischer Instanzgerichte, die einen Eingriff in die Entscheidungsfindung der vorlegenden Richter aufgrund eines Disziplinarverfahrens im Kontext der neuen Disziplinarkammer am polnischen OGH gegen diese befürchteten, als unzulässig mangels Bezug zur Anwendung des Unionsrechts im konkreten Fall zurück und sah hierin einen ausdrücklichen Unterschied zur Rs. ASJP. ${ }^{309}$

Besondere Bedeutung hat bei der Entwicklung der Rechtsprechung der ernannte Generalanwalt und ehemalige Präsident des bulgarischen Verfassungsgerichts sowie Vizepräsident der Venedig-Kommission Evgeni Tanchev erlangt, der sich durchgehend ${ }^{310}$ mit der Lage in Polen zu beschäftigen hatte. Tanchevs Hintergrund hier zu nennen ist rechtssoziologisch durchaus interessant, weil in seiner Rolle die Bemühung des Europäischen Gerichtshofs durchschimmert, ${ }^{311}$ ein Mitglied mit besonderer rechtsvergleichender Erfahrung an rechtsstaatsbezogene Fälle zu setzen, der darüber aber aus Osteuropa und einem neuen Mitgliedstaat stammt, welcher zudem selbst unter kritischer Beobachtung steht.

(2) Die Rechtssache LM (Mängel des Justizsystems)

Die Rechtsprechung zur Operationalisierung der Rechtsstaatlichkeit nach $A S J P$ ist in der Rechtssache Celmer (später, infolge neuer Anonymisierung seitens des Gerichtshofs: $L M$, mit dem amtlichen Zusatz „Mängel des Justizsystems“) fortgesetzt worden. ${ }^{312}$ Die vorliegende Arbeit hat bereits

308 EuGH, Rs. C-522/18, DŚ ./. Zakład Ubezpieczeń Społecznych Oddział w Jaśle, Beschluss vom 29.01.2020, „Vorlage zur Vorabentscheidung - Erledigung“, ECLI:EU:C:2020:42, s. insb. Rn. $21 \mathrm{ff}$.

309 EuGH, Verb. Rs. C-558/18 und C-563/18, Miasto Łowicz ./. Skarb Państwa Wojewoda Łódzki, und Prokurator Generalny ./. VX u.a., Urteil (GK) vom 26.03.2020, ECLI:EU:C:2020:234, insb. Rn. 49. Zu wichtigen teleologischen Unterscheidungen betreffend das Vorabvorlageverfahren und das Vertragsverletzungsverfahren, dort Rn. 47.

310 Schlussanträge zu den Rs.C-216/18 PPU; C-619/18 R; C-192/18; Verb. Rs. C-585/18, C-624/18 und C-625/18; C-558/18.

311 Nach Art. 16 Abs. 1 der VerfOEuGH entscheidet der Erste Generalanwalt (derzeit: Maciej Szpunar) über die Benennung des Generalanwalts.

312 EuGH, Rs. C-216/18 PPU, LM (Mängel des Justizsystems), Urteil (GK) vom 25.07.2018, ECLI:EU:C:2018:586, Anmerkung insb. bei Armin von Bogdandy, Piotr Bogdanowicz, Iris Canor, Matthias Schmidt \& Maciej Taborowski: „Drawing Red Lines and Giving (Some) Bite - the CJEU's Deficiencies Judgment on 
angesprochen, dass diese Rechtssache grundlegend für die Frage der Beurteilung systemischer Defizite durch Feststellung eines „Spillover“ in Bezug auf die Rechtsordnung anderer Mitgliedstaaten ist. Der Entscheidung LM lag eine Vorabvorlage des irischen High Court zugrunde. ${ }^{313}$ Der High Court hatte über die Beschwerde des Celmer zu entscheiden, der durch die polnischen Strafverfolgungsbehörden wegen des Verdachts eines Verstoßes gegen Betäubungsmittelgesetze der Anklage zugeführt werden sollte, weswegen gegen ihn ein in Irland zu vollstreckender europäischer Haftbefehl vorlag. Celmer rügte aufgrund der in Polen bestehenden Lage eine „echte Gefahr" einer willkürlichen Behandlung aufgrund „weitreichender und unkontrollierter" Befugnisse der polnischen Justiz und dadurch letztendlich eine Verletzung seines Grundrechts auf ein faires Verfahren nach Art. 6 EMRK bei Stattgabe des Übergabegesuchs, eine Einschätzung, der das vorlegende Gericht folgte. ${ }^{314}$ Der High Court ging nicht nur von einer Vermutung potentieller Missstände in Polen aus, sondern bejahte „die systemische Verletzung der Rechtsstaatlichkeit [, die] ihrem Wesen nach eine $[\mathrm{m}]$ grundlegenden Mangel des Justizsystems [scil.: entspricht]." 315 Das vorlegende Gericht sah sich aber an der Entscheidung gehindert, weil der Europäische Gerichtshof für Fälle systemischer Mängel in Mitgliedstaaten in seiner Aranyosi-Entscheidung einen zweistufigen Test zugrunde gelegt habe, aufgrund dessen das mit der Übergabeentscheidung beauftragte Gericht nicht nur abstrakt, sondern im konkreten Fall die Auswirkung eines solchen Mangels zu bejahen habe. Der High Court wollte wissen, ob dies auch bei Mängeln im Justizsystem wie in Polen gelte. ${ }^{316}$

the European Rule of Law“, Verfassungsblog vom 03.08.2018, abrufbar unter: https://verfassungsblog.de/drawing-red-lines-and-giving-some-bite-the-cjeus-def iciencies-judgment-on-the-european-rule-of-law/, sowie die im Verfassungsblog in der Rubrik „The CJEU's deficiencies judgment“, weiter etwa Mattias Wendel, „Rechtsstaatlichkeitsaufsicht und gegenseitiges Vertrauen - Anmerkung zum Urteil des EuGH v. 25.7.2018, Rs. C-216/18 PPU (Minister for Justice and Equality gegen LM)“, in: Europarecht 54 (2019), S. 111-131.

313 High Court of Ireland, Minister for Justice and Equality v. Celmer, Record No. 2013 EXT 295 u.a., Vorabvor-lagebeschluss vom 12.03.2018.

314 EuGH, Rs. C-216/18 PPU, LM (Mängel des Justizsystems), Urteil (GK) vom 25.07.2018, ECLI:EU:C:2018:586, Rn. 22.

315 EuGH, Rs. C-216/18 PPU, LM (Mängel des Justizsystems), Urteil (GK) vom 25.07.2018, ECLI:EU:C:2018:586, Rn. 24.

316 EuGH, Rs. C-216/18 PPU, LM (Mängel des Justizsystems), Urteil (GK) vom 25.07.2018, ECLI:EU:C:2018:586, Rn. 24. 
Die Vorabvorlage entfaltete, etwa wegen persönlicher Angriffe auf die vorlegende irische Richterin, auch in der Presse ein beachtliches Interesse. ${ }^{317}$

Aus dem Urteil folgen mindestens vier für die weitere Entwicklung des Unionsrechts substantielle Feststellungen. Eine fünfte, nämlich die vielbesprochene Frage der Auswirkung auf den Grundsatz des gegenseitigen Vertrauens im Unionsrecht, lasse ich hier unter Verweis auf weitere Arbeiten außen vor. ${ }^{318}$

Der EuGH, der sich die Bejahung des systemischen Mangels im polnischen Justizsystem durch den High Court nicht zu eigen machte, ${ }^{319}$ klärt die Frage, unter welchen Umständen ein derartiger systemischer Mangel für die „vollstreckende Justizbehörde“ Relevanz erlangt:

„[1] wenn sie über Anhaltspunkte - wie diejenigen in einem begründeten Vorschlag der Kommission nach Art. 7 Abs. 1 EUV - dafür verfügt, dass wegen systemischer oder allgemeiner Mängel in Bezug auf die Unabhängigkeit der Justiz des Ausstellungsmitgliedstaats eine echte Gefahr der Verletzung des in Art. 47 Abs. 2 der Charta verbürgten Grundrechts auf ein faires Verfahren besteht,

[2] [muss sie] konkret und genau prüfen [...], ob es in Anbetracht der persönlichen Situation dieser Person sowie der Art der strafverfolgungsbegründenden Straftat und des Sachverhalts, auf denen der Europäische Haftbefehl beruht, und unter Berücksichtigung der Informationen, die der Ausstellungsmitgliedstaat gemäß Art. 15 Abs. 2 des genannten Rahmenbeschlusses mitgeteilt hat, ernsthafte und durch Tatsachen bestätigte Gründe für die Annahme gibt, dass die besagte

317 Exemplarisch Mary Carolan, „Extradition ordered of Polish man in controversial landmark case", The Irish Times vom 12.11.2019; Ralf Sotschek, "High Court sagt Nie”, Die Tageszeitung, vom 15.03.2018.

318 S. dazu insb. Koen Lenaerts, „La Vie après l'avis: Exploring the Principle of Mutual (yet not blind) Trust", in: Common Market Law Review 54 (2017), S. 804-850, etwa S. 806, 808 ff.; speziell zum Begriff des gegenseitigen Vertrauens im Kontext des Urteils Mattias Wendel, „Rechtsstaatlichkeitsaufsicht und gegenseitiges Vertrauen“, S. 113 ff., 116 ff.; Armin von Bogdandy u.a., „Drawing Red Lines and Giving (Some) Bite - the CJEU's Deficiencies Judgment on the European Rule of Law“, o.S.

319 EuGH, Rs. C-216/18 PPU, LM (Mängel des Justizsystems), Urteil (GK) vom 25.07.2018, ECLI:EU:C:2018:586, Rn. 34. 
Person im Fall ihrer Übergabe an den Ausstellungsmitgliedstaat einer solchen Gefahr ausgesetzt sein wird.“320

Damit hat der Europäische Gerichtshof den in der Entscheidung Aranyosi und Căldăraru aufgestellten zweistufigen Test für die Berücksichtigung systemischer Mängel allein bei konkreter Auswirkung im Einzelfall übernommen und hier auf die Funktionsfähigkeit des Justizsystems übertragen. ${ }^{321}$ Das hieß im konkreten Fall, dass später die Überstellung von $L M$ trotz der beobachteten Mängel vollzogen wurde, da sich im konkreten Fall keine Auswirkung ergab. 322

Zum zweiten folgt aus dem Urteil eine Anleitung zur Berücksichtigung des Verfahrens nach Artikel 7 EUV. Der Europäische Gerichtshof bindet sich an dieses Verfahren nicht, spricht ihm aber gegenüber den mitgliedstaatlichen Gerichten bei der Beurteilung der Lage besondere Beachtlichkeit zu, über die diese sich (allein/jedoch) in „außergewöhnlichen Umständen“ bzw. „Ausnahmefällen“ hinwegsetzen könnten, also dann einen systemischen Mangel gleichwobl bejahen dürfen. ${ }^{323}$

Drittens deutet der Europäische Gerichtshof eine mögliche weitere Binnensystematik bei der Unterscheidung verschiedener Typen mit der Formulierung „systemisch oder zumindest allgemeiner Mangel“324 an, auf die bereits hingewiesen wurde. Was genau mit dieser Unterscheidung, die sich nur an dieser Stelle, dafür konsistent aber auch in anderen Sprachfassungen („défaillances systémiques $o u, d u$ moins, généralisées“/systemic deficiencies, or, at all events, generalised deficiencies“, meine Hervorhebungen) findet, gemeint sein könnte, ist durch den Gerichtshof noch zu klären.

Viertens, und das interessiert an dieser Stelle besonders, macht der EuGH umfassende Ausführungen zur Frage der richterlichen Unabhängigkeit

Der Gedankengang hierzu ist, wie im ASJP-Urteil, mehrstufig. Nach einem Einstieg über den seit dem Les Verts-Urteil vertrauten Ausspruch der

320 EuGH, Rs. C-216/18 PPU, LM (Mängel des Justizsystems), Urteil (GK) vom 25.07.2018, ECLI:EU:C:2018:586, Rn. 74.

321 EuGH, Verb. Rs. C-404/15 u. C-659/15 PPU, Pál Aranyosi und Robert Căldăraru, Urteil (GK) vom 05.04.2016, ECLI:EU:C:2016:198, Rn. 89 f., dazu Mattias Wendel, „Rechtsstaatlichkeitsaufsicht und gegenseitiges Vertrauen“, S. 118.

322 Vgl. letztinstanzlich Irischer Supreme Court, Minister for Justice and Equality ./. Artur Celmer, Urteil vom 12.11.2019, ECLI:S:AP:IE:2018:00018, Rn. 87.

323 EuGH, Rs. C-216/18 PPU, LM (Mängel des Justizsystems), Urteil (GK) vom 25.07.2018, ECLI:EU:C:2018:586, Rn. 36-37.

324 EuGH, Rs. C-216/18 PPU, LM (Mängel des Justizsystems), Urteil (GK) vom 25.07.2018, ECLI:EU:C:2018:586, Rn. 60. Dazu bereits zuvor unter IV. 2.c. 
„Rechtsunion“ (Rechtsgemeinschaft) folgen zwei Festlegungen zur objektiven Funktion der mitgliedstaatlichen Justiz für die Europäische Union, die teleologisch auf die Wahrung der Funktionsfähigkeit des Unionsrechts infolge ihrer Bedeutung für das Vorabvorlageverfahren zulaufen.

„Die Union ist nämlich eine Rechtsunion, in der den Einzelnen das Recht zusteht, die Rechtmäßigkeit nationaler Entscheidungen oder jeder anderen nationalen Handlung, mit der eine Handlung der Union auf sie angewandt wird, gerichtlich anzufechten [...]

Gemäß Art. 19 EUV, mit dem der in Art. 2 EUV proklamierte Wert der Rechtsstaatlichkeit konkretisiert wird, ist es Sache der nationalen Gerichte und des Gerichtshofs, die volle Anwendung des Unionsrechts in allen Mitgliedstaaten und den Schutz der Rechte, die den Einzelnen aus diesem Recht erwachsen, zu gewährleisten [...]

Schon das Vorhandensein einer wirksamen gerichtlichen Kontrolle, die der Gewährleistung der Einhaltung des Unionsrechts dient, ist einem Rechtsstaat inhärent [...]

Deshalb hat jeder Mitgliedstaat dafür zu sorgen, dass Einrichtungen, die als „Gerichte“ im Sinne des Unionsrechts Bestandteil seines Rechtsbehelfssystems sind, in den vom Unionsrecht erfassten Bereichen einen wirksamen gerichtlichen Rechtsschutz gewähren [...]

Zur Gewährleistung dieses Schutzes ist aber die Wahrung der Unabhängigkeit dieser Einrichtungen von grundlegender Bedeutung, wie Art. 47 Abs. 2 der Charta bestätigt, wonach zu den Anforderungen im Zusammenhang mit dem Grundrecht auf einen wirksamen Rechtsbehelf der Zugang zu einem „unabhängigen“ Gericht gehört [...]

Die Unabhängigkeit der nationalen Gerichte ist insbesondere für das reibungslose Funktionieren des Systems der justiziellen Zusammenarbeit, das durch den in Art. 267 AEUV vorgesehenen Mechanismus des Vorabentscheidungsersuchens verkörpert wird, von grundlegender Bedeutung, da nach der ständigen Rechtsprechung des Gerichtshofs dieser Mechanismus nur von einer mit der Anwendung des Unionsrechts betrauten Einrichtung, die u. a. dieses Kriterium der Unabhängigkeit erfüllt, in Gang gesetzt werden kann [...]“.325

Wie sich zeigt, entwickelt der Europäische Gerichtshof hier eine rein objektiv-rechtliche Normenkette: Art. 19 Abs. 1 EUV dient der Konkretisierung des Wertes, also: der Operationalisierung der Rechtsstaatlichkeit

325 EuGH, Rs. C-216/18 PPU, LM (Mängel des Justizsystems), Urteil (GK) vom 25.07.2018, ECLI:EU:C:2018:586, Rn. 49-54. 
nach Art. 2 EUV durch Erläuterung der Unabhängigkeit der Justiz als Funktionsmerkmal des mitgliedstaatlichen Staatsaufbaus. Art. 47 Abs. 2 der Charta konkretisiert weiter: die Norm hat eine fast dienende Funktion („bestätigt“), auf die Eigenschaft als subjektives Recht kommt es nicht an. Insbesondere findet sich weder in den Schlussanträgen noch im Urteil ein Verweis auf Art. 51 GRCh.

Die objektive Funktion des Art. 47 GRCh ging Generalanwalt Tanchev, wie in späteren Entscheidungen deutlich wird, offensichtlich zu weit, seine Auffassung divergiert damit deutlich vom Verständnis Wathelets und selbst dem von Saugmansgaard Øe. ${ }^{326}$

Im Verfahren Kommission ./. Polen (Unabhängigkeit des polnischen Obersten Gerichtshofs) hatte Tanchev zunächst im Fall betreffend den polnischen Obersten Gerichtshof das Konzept einer gemeinsamen Lesart der Normen Art. 19 Abs. 1 EUV und Art. 47 der Charta abgelehnt ${ }^{327}$ und dies gerade auch auf das vorangegangene Urteil in der Rs. ASJP gestützt. ${ }^{328}$ Jede andere Lesart der Verträge laufe den Grenzen des Art. 51 der Charta zuwider, wonach ein Rückgriff auf die Charta selbst eben nur bei der Durchführung des Unionsrechts gegeben sei, worum es gerade in den Fällen in Polen nicht gehe, denn hier stehe nationale Justizpolitik allein im Raum.

Der EuGH hat in seinem späteren Urteil in der gleichen Rechtssache offensichtlich versucht, zwischen den verschiedenen Rechtsauffassungen seiner Generalanwälte zu vermitteln. Er greift den Klageantrag der Kommission, die beantragt hatte, „aus Art. 19 Abs. 1 Unterabs. 2 EUV in Verbindung mit Art. 47 der Charta“ 329 zu erkennen, nicht auf. Er formuliert stattdessen: „In der mündlichen Verhandlung hat die Kommission klargestellt, dass sie mit ihrer Klage im Wesentlichen die Feststellung beantragt,

326 Zur Relation beider Normen gerade vor dem Hintergrund der Erwägungen in der Rs. C-619/18 des Europäischen Gerichtshofs jüngst auch Laura Hering, „Das Vertragsverletzungsverfahren als Instrument zum Schutz der Unionswerte - Zugleich Bemerkungen zu EuGH, Urt. v. 24.6.2019, C-619/18, Kommission/Polen“, in: Die öffentliche Verwaltung 73 (2020), S. 293-302, S. 297 f.

327 EuGH, Rs. C-619/18 R, Kommission ./. Polen, „Unabhängigkeit des polnischen Obersten Gerichtshofs“, Schlussanträge des Generalanwalts Evgeni Tanchev vom 11.04.2019, ECLI:EU:C:2019:325, Rn. $52 \mathrm{ff}$.

328 EuGH, Rs. C-619/18 R, Kommission ./. Polen, „Unabhängigkeit des polnischen Obersten Gerichtshofs", Schlussanträge des Generalanwalts Evgeni Tanchev vom 11.04.2019, ECLI:EU:C:2019:325, insb. Rn. 55 und 58.

$329 \mathrm{EuGH}$, Rs. C-619/18 R, Kommission ./. Polen, „Unabhängigkeit des polnischen Obersten Gerichtshofs“, Urteil (GK) vom 24.06.2019, ECLI:EU:C:2019:531, Rn. 1. 
dass ein Verstoß gegen Art. 19 Abs. 1 Unterabs. 2 EUV, ausgelegt im Licht von Art. 47 der Charta, vorliegt." 330

Hieran anknüpfend wiederholt der Europäische Gerichtshof seine auf das Urteil ASJP aufbauende Formel:

„In diesem Kontext überträgt Art. 19 EUV, mit dem der in Art. 2 EUV proklamierte Wert der Rechtsstaatlichkeit konkretisiert wird, den nationalen Gerichten und dem Gerichtshof die Aufgabe, die volle Anwendung des Unionsrechts in allen Mitgliedstaaten und den gerichtlichen Schutz, die den Einzelnen aus diesem Recht erwachsen, zu gewährleisten." 331

In seiner Entscheidung zum Jahresende 2019 betreffend die Unabhängigkeit der polnischen ordentlichen Gerichtsbarkeit, welcher auch aufgrund der im Raum stehenden Frage der Geschlechtergleichbehandlung andere Normen zum Gegenstand hatte, hat der Gerichtshof diese Ausführungen nochmals im Wesentlichen bestätigt, ${ }^{332}$ nachdem Tanchev wegen der bereits genannten Überlegungen erneut Bedenken angemeldet hatte, ${ }^{333} \mathrm{da}$ er zwar eine „verfassungsrechtliche Verbindung zwischen beiden Normen sah, ${ }^{334}$ aufgrund der Anwendungsbereichsbeschränkung der Charta aber eine Überschneidung des Anwendungsbereichs beider Normen zu vermeiden sei.

„Ich bin daher der Ansicht, dass zumindest in dem Fall, dass ein Mitgliedstaat nicht im Sinne von Art. 51 Abs. 1 der Charta das Unionsrecht durchführt, Vorsicht walten sollte bei einer unmittelbaren Heranziehung von Art. 47 der Charta zur Erläuterung des Schutzes, den Art. 2 EUV in Bezug auf die Rechtsstaatlichkeit vorsieht, und der

330 EuGH, Rs. C-619/18 R, Kommission ./. Polen, „Unabhängigkeit des polnischen Obersten Gerichtshofs“, Urteil (GK) vom 24.06.2019, ECLI:EU:C:2019:531, Rn. 32.

331 EuGH, Rs. C-619/18 R, Kommission ./. Polen, „Unabhängigkeit des polnischen Obersten Gerichtshofs“, Urteil (GK) vom 24.06.2019, ECLI:EU:C:2019:531, Rn. 47.

332 EuGH, Rs. C-192/18, Kommission ./. Polen, „Unabhängigkeit der ordentlichen Gerichtsbarkeit“, Urteil (GK) vom 05.11.2019, ECLI:EU:C:2019:924, Rn. 98 und ff.

333 EuGH, Rs. C-192/18, Kommission ./. Polen, „Unabhängigkeit der ordentlichen Gerichtsbarkeit", Schlussanträge des Generalanwalts Evgeni Tanchev vom 20.06.2019, ECLI:EU:C:2019:529, Rn. $67 \mathrm{ff}$.

334 EuGH, Rs. C-192/18, Kommission ./. Polen, „Unabhängigkeit der ordentlichen Gerichtsbarkeit“, Schlussanträge des Generalanwalts Evgeni Tanchev vom 20.06.2019, ECLI:EU:C:2019:529, Rn. 97. 
Unabsetzbarkeit von Richtern und des Rechts auf ein unabhängiges und unparteiisches Gericht, die eng mit Art. 19 Abs. 1 Unterabs. 2 EUV verbunden sind, und dies unbeschadet der Überschneidung zwischen diesen beiden Bestimmungen, zu der es aufgrund gemeinsamer Quellen unvermeidlich kommt." 335

Es wird abzuwarten bleiben, wie sich diese Rechtsprechungslinie im Verlauf der Krise weiterentwickelt. Die Europäische Kommission jedenfalls hat in der jüngsten Vertragsverletzungsklage betreffend die Disziplinarkammer am polnischen Obersten Gerichtshof Art. 47 GRCh nicht mehr in ihren Antrag aufgenommen. ${ }^{336}$

(3) Die beiden „Aspekte“ des Prinzips der richterlichen Unabhängigkeit

Ungeachtet der bereits sehr beachtlichen Konkretisierung des Prinzips der richterlichen Unabhängigkeit - und dadurch des Rechtsstaatsprinzips ist der EuGH sichtlich bemüht, durch weitere zusätzliche Ausführungen jedem Instanzrichter in unterschiedlichen Mitgliedstaaten ein zwar flexibles, aber durchaus schablonenhaftes Prüfungsschema anzubieten, das die Handhabung (nur) von Art. 19 Abs. 1 EUV so weit wie möglich erleichtert und vereinheitlicht, und ihn dadurch gewissermaßen ,an die Hand nimmt“. Es ist anzumerken, dass sich die Venedig-Kommission der gleichen Handhabbarmachung das Prinzips der richterlichen Unabhängigkeit bedient hat. ${ }^{337}$

Beispielhaft hierfür ist das Urteil zur Unabhängigkeit des polnischen Obersten Gerichtshofs, in dem eine zunächst in zwei Schritten eingeführte Prüfung zugrunde gelegt wird, an die sich nachfolgend zwei Annex-Beobachtungen anschließen.

335 EuGH, Rs. C-192/18, Kommission ./. Polen, „Unabhängigkeit der ordentlichen Gerichtsbarkeit", Schlussanträge des Generalanwalts Evgeni Tanchev vom 20.06.2019, ECLI:EU:C:2019:529, Rn. 99.

336 EuGH, Klage, eingereicht am 25. Oktober 2019 - Europäische Kommission/Republik Polen, Rs. C-791/19, ABl. (EU) C 413/36 vom 09.12.2019, anhängig. Für die Berücksichtigung von Art. 47 GRCh im vorläufigen Rechtsschutz desselben Verfahrens s. aber Beschluss (GK) vom 08.04.2020, ECLI:EU:C:2020:277, Rn. 33-35.

337 Vgl. Venedig-Kommission, CDL-AD(2012)001, Opinion 663/2012, Opinion on Act CLXII of 2011 on the Legal Status and Remuneration of Judges and Act CLXI of 2011 on the Organisation and Administration of Courts of Hungary vom 19.03.2012, Rn. $69 \mathrm{ff}$. 
Der Europäische Gerichtshof stellt dort klar, ${ }^{338}$ dass die richterliche Unabhängigkeit aus zwei Kriterienkatalogen bestehe, einem „das Außenverhältnis betreffenden Aspekt", das im Wesentlichen die bereits in Prüfpunkte unterteilten Ausführungen des ASJP-Urteils in sich aufnimmt und aus einem zweiten, „das Innenverhältnis betreffenden Aspekt“. Der Gerichtshof bringt dies auf folgende Formel:

„Das Erfordernis der richterlichen Unabhängigkeit, deren Wahrung die Mitgliedstaaten nach Art. 19 Abs. 1 Unterabs. 2 EUV, [...] in Bezug auf die nationalen Gerichte sicherstellen müssen, die [...] über Fragen zu entscheiden haben, die mit der Auslegung und der Anwendung des Unionsrechts verknüpft sind, umfasst zwei Aspekte.

Der erste, das Außenverhältnis betreffende Aspekt erfordert, dass die betreffende Einrichtung ihre Funktionen in völliger Autonomie ausübt, ohne mit irgendeiner Stelle hierarchisch verbunden oder ihr untergeordnet zu sein und ohne von irgendeiner Stelle Anordnungen oder Anweisungen zu erhalten, so dass sie auf diese Weise vor Interventionen oder Druck von außen geschützt ist, die die Unabhängigkeit des Urteils ihrer Mitglieder gefährden und deren Entscheidungen beeinflussen könnten [...].

Der zweite, das Innenverhältnis betreffende Aspekt steht mit dem Begriff der Unparteilichkeit in Zusammenhang und bezieht sich darauf, dass den Parteien des Rechtsstreits und ihren jeweiligen Interessen am Streitgegenstand mit dem gleichen Abstand begegnet wird. Dieser Aspekt verlangt, dass Sachlichkeit obwaltet und neben der strikten Anwendung der Rechtsnormen keinerlei Interesse am Ausgang des Rechtsstreits besteht [...]“.339

Maßstab für die Beurteilung der Verwirklichung beider Kriterienkataloge ist in einem dritten Schritt, angelehnt an das Urteil Wilson ${ }^{340}$ des Gerichtshofs, der objektive Empfängerhorizont der am Rechtsstreit Beteiligten in teilweiser Wiederholung der soeben gemachten Ausführungen. Es muss „bei den Rechtsunterworfenen jede[r] berechtigte Zweifel an der Unemp-

338 EuGH, Rs. C-619/18, Kommission ./. Polen, „Unabhängigkeit des Obersten Gerichts", Urteil (GK) vom 24.06.2019, Rn. 72-77.

339 EuGH, Rs. C-619/18, Kommission ./. Polen, „Unabhängigkeit des Obersten Gerichts“, Urteil (GK) vom 24.06.2019, Rn. 71-73, zit. Rspr. hier entfallen.

340 EuGH, Rs. C-506/04, Graham J. Wilson ./. Ordre des avocats du barreau de Luxembourg, Urteil (GK) vom 19.09.2006, ECLI:EU:C:2006:587, insb. Rn. 53, s. auch die dort zit. Rspr. 


\section{B. Rechtsstaatlichkeitskrise und systemisches Defizit}

fänglichkeit dieser Einrichtung für äußere Faktoren und an ihrer Neutralität in Bezug auf die widerstreitenden Interessen aus[ge $]$ räum[t $t]^{“ 341}$ sein.

In einem weiteren Schritt behält sich der Gerichtshof vor, zusätzliche Kriterien aus der Gesamtheit der richterlichen Unabhängigkeit fallspezifisch abzuleiten, darunter den „Grundsatz der Unabsetzbarkeit“ ${ }^{342}$ Es folgt die konkrete Subsumtion. ${ }^{343}$

Die so ausgestaltete „Zwei-Aspekte-Formel“ der richterlichen Unabhängigkeit mitgliedstaatlicher Gerichte als Konkretisierung schlägt sich zunehmend in der Judikatur nieder. Zuletzt war sie Grundlage umfassender Erwägungen von Generalanwältin Juliane Kokott im noch anhängigen Verfahren UX betreffend die Funktion der italienischen „Friedensrichter“. ${ }^{344}$

\section{Zwischenergebnis}

In diesem Abschnitt bin ich summarisch auf den bisherigen Wissensstand und einige Vorschläge betreffend die Konzepte Rechtsstaatlichkeitskrise und systemisches Defizit an Rechtsstaatlichkeit eingegangen. Die Arbeit hat deutlich gemacht, dass beide Begriffe im Sinne eines "zweistufigen“ Rechtsbegriffs voneinander abgrenzt werden, wonach die Rechtsstaatlichkeitskrise als loses Konzept, das systemische Defizit hingegen als eine die Krise untermauernde dogmatische Grundlage zu verstehen ist, welche die Erfassung der verschiedenen Vorgänge in den Mitgliedstaaten erlaubt.

Ich habe, unter Verweis auf Vorarbeiten, deutlich gemacht, dass ich systemische Defizite an Rechtsstaatlichkeit auffasse als auf das Rechtsstaatsprinzip bezogene Vorgänge in Mitgliedstaaten von besonderer Schwere, Fallzahl oder Dauer, die dadurch einen intersystemischen Konflikt und einen sog. Spillover-Effekt im Rechtsverkehr zwischen den Mitgliedstaaten erzeugen, der einen hoheitlich handelnden Akteur im europäischen Rechtsraum, insbesondere also die Mitgliedstaaten selbst oder ein Unions-

341 EuGH, Rs. C-619/18, Kommission ./. Polen, „Unabhängigkeit des Obersten Gerichts", Urteil (GK) vom 24.06.2019, Rn. 74, unter Verweis auf das zuvor zitierte Urteil in der Rs. Wilson.

342 EuGH, Rs. C-619/18, Kommission ./. Polen, „Unabhängigkeit des Obersten Gerichts“, Urteil (GK) vom 24.06.2019, Rn.76.

343 EuGH, Rs. C-619/18, Kommission ./. Polen, „Unabhängigkeit des Obersten Gerichts", Urteil (GK) vom 24.06.2019, Rn. 77 und ff.

344 EuGH, Rs. C-658/18, UX ./. Governo della Repubblica italiana, Schlussanträge der Generalanwältin Juliane Kokott vom 23.01.2020, ECLI:EU:C:2020:33, Rn. $38 \mathrm{ff}$. 
organ dazu zwingt, eine eigentlich dem anderen Mitgliedstaat übertragene Pflicht mittels „Selbsteintritt“ zu übernehmen. Von alleinigem Interesse sind dabei hier Vorgänge, die auf die vorsätzliche Unterwanderung des Rechtsstaatsprinzips in Mitgliedstaaten abzielt.

In einem weiteren Abschnitt hat die Arbeit dann im Überblick dargelegt, wie Überlegungen zum Defekt von Demokratie und Rechtsstaatlichkeit als Gegenstand der Politikwissenschaft die Debatte anreichern, hier aber nicht entscheidend zur Lösung beitragen.

Sodann wurde in der Arbeit umfassend auf die Handhabung des Rechtsstaatsprinzips eingegangen, desjenigen Unionswertes, der in der gegenwärtigen Krise zentrale rechtliche Grundlage und Maßstab für alle Erwägungen ist. Es wurde dargelegt, wie insbesondere der Gerichtshof diesen Wert im Wege hier sog. Operationalisierung handhabbar macht.

In einem nächsten Abschnitt ist nun auf die Beispiele in Mitgliedstaaten einzugehen, die dieses Konzept in der Praxis illustriert, vor Herausforderungen gestellt und vor allem wesentliche Entwicklungen angeregt haben. 


\section{Die Rechtsstaatlichkeitskrise in mitgliedstaatlichen Fällen}

\section{Aufsichtsmaßnahmen und Aufbaumaßnahmen}

Der nachfolgende Abschnitt dieser Arbeit dient dazu, die Entwicklungen der Rechtsstaatlichkeitskrise in den Mitgliedstaaten darzustellen. Die europäische Rechtsstaatlichkeitskrise ist von immenser Komplexität, die sich nur mittels drastischer Reduzierung des berücksichtigten Materials und mittels vereinfachender Strukturierung der Entwicklungen in den Griff bekommen lässt, und zwar selbst dann, wenn man den zuvor erarbeiteten Begriff des systemischen Defizits zugrunde legt. Die Rechtsstaatlichkeitskrise ist häufig ein fuzzy set an Entwicklungen.

Trotz der Komplexität der Krise ist es möglich, eine gute Übersicht zu behalten, wenn man sich ihren Aufbau als drei konzentrische „Problem-

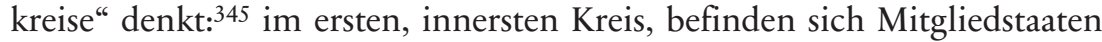
der Union, die von „echten“ systemischen Defiziten des Subtyps der vorsätzlichen Unterwanderung der Rechtsstaatlichkeit durch staatliche Stellen betroffen sind. Das sind, nach nahezu einhelliger Auffassung, Ungarn und Polen. Sie sind Archetypen dieses Subtyps und als solche sind sie Gegenstand einer Vielzahl der hier interessierenden Verfassungsaufsichtsverfahren gewesen, darunter zahlreicher Vertragsverletzungsverfahren, von zwei Verfahren nach Art. 7 EUV und zahlloser Reaktionen in Parlament, Rat und Kommission. Sie sind daher hier auch zuerst zu behandeln. Es wird sich zeigen, dass auch Rumänien diesem Problemkreis zugeordnet werden kann.

In einem zweiten Kreis sind Mitgliedstaaten, darunter etwa Griechenland, aber auch Bulgarien und Italien, anzusiedeln, die nach vielfacher Literaturauffassung vorrangig durch staatliche Schwäche Defizite aufweisen.

In einem dritten Kreis befinden sich scheinbare Beispiele eines Defizits, also Mitgliedstaaten, für die fälschlich ein Defizit angenommen worden ist oder wird. Zu nennen sind neben Spanien auch die Slowakei oder Slowenien, darüber auch Frankreich, welches durch die damalige Justizkommis-

345 Dass derartige, zumal graphische, Figuren gut geeignet sind, komplexe Rechtsfragen im Umfeld des Art. 2 EUV zu lösen, zeigen bereits Frank Schorkopf, Homogenität in der Europäischen Union, S. 43; ähnlich Luke Dimitrios Spieker, „Breathing Life into the Union's Common Values“, S. 1206, 1211. 
sarin Reding mit der Krise in Verbindung gebracht wurde. Die Gründe für die Vermutungen, die durch Praxis und Rechtswissenschaft erhoben worden sind, sind sehr unterschiedlich und können von anfänglichen konzeptuellen Unschärfen bis hin zu politischen Agenden der Verwender reichen.

Nur diejenigen Entwicklungen, die ich hier als vorsätzliche Unterwanderungsvorgänge des Rechtsstaatsprinzips durch Mitgliedstaaten bezeichne, interessieren im Rahmen dieser Arbeit. Das hängt mit dem zu untersuchenden Rechtsregime zusammen, das als Aufsicht zu begreifen ist. Derartige Aufsichtsmaßnahmen der Union sind zum einen grds. kurzfristig und zum anderen darauf ausgerichtet, auf der obersten politischen Ebene und häufig zumindest am Anfang gegen den Willen der nationalen Regierungen zu bestehen.

Gegenüber Mitgliedstaaten, die nicht derartigen Vorsatz, sondern systemische Schwächen aufweisen, kommt ein Rechtsregime einer ganz anderen Logik zur Anwendung. Ioannidis hat sie, wie bereits erwähnt, herausgearbeitet und dabei insbesondere ihren Charakter im Rahmen der makroökonomischen Aufsicht betont. ${ }^{346}$ Einprägsamstes Instrumentarium und Akteur gegenüber derartigen Mitgliedstaaten ist der Structural Reform Support Service (SRSS), der im Wesentlichen der Nachfolger der in der Finanzkrise geschaffenen Task Force for Greece (TFGR) ${ }^{347}$ ist, welche durch ihn ersetzt wird und deren Wirksamkeit der SRSS begutachtete. ${ }^{348}$ Seit Januar 2020 firmiert der SRSS als „Unterstützungsdienst für Strukturreform (DG REFORM)“.349

Der SRSS, nunmehr DG REFORM, hat zur Aufgabe, das sog. SRSP (Structural Reform Support Programme) umzusetzen. Das SRSP wiederum ist ein weitgefächertes und mit finanzieller Unterstützung verknüpftes Hilfsprogramm, bei dem die Europäische Kommission koordinierend

346 Bereits Michael Ioannidis, „EU Financial Assistance Conditionality after ,Two Pack““, in: Zeitschrift für ausländisches öffentliches Recht und Völkerrecht 74 (2014), S. 61-104, $69 \mathrm{ff}$.

347 Ausführlich zu ihrer Tätigkeit Sebastian Weinzierl, „Die EU Task-Force für Griechenland: Internationale Beratung am Beispiel der griechischen Steuerverwaltung“, in: Ulf-Dieter Klemm \& Wolfgang Schultheiß (Hrsg.), Die Krise in Griechenland: Ursprünge, Verlauf, Folgen, Campus , Frankfurt/New York, 2015, S. 448-459.

348 Vgl. die „Evaluation Roadmap““ des SRSS, Ares(2017)5585177 vom 15.11.2017. Ausweislich des Dokuments soll die Evaluierung zum 4. Quartal 2018 abgeschlossen sein.

349 https://ec.europa.eu/info/departments/structural-reform-support_en. 


\section{Die Rechtsstaatlichkeitskrise in mitgliedstaatlichen Fällen}

Experten in die Verwaltung des um Unterstützung nachsuchenden Mitgliedstaats entsendet; die entsandten Experten wiederum können, neben unionalen Stellen, aus nationalen Verwaltungen oder auch internationalen Organisationen kommen. ${ }^{350}$ Es kann grundsätzlich alle seit langem defizitären Bereiche staatlicher Verwaltung, wie ineffiziente Strukturen oder mangelndes Wissen, betreffen. Seine Grundlage ist eine Verordnung aus dem Jahr 2017, ${ }^{351}$ sie ist allerdings bereits 2015 durch die Kommission in den Rechtsetzungsprozess eingebracht worden, sodass 2015 häufig als Entstehungsjahr des SRSS genannt wird. ${ }^{352}$ Die SRSP-Verordnung stützt sich auf Art. 9 und 11 AEUV sowie Art. 120 und 121 AEUV. Erstere sind zwei sog. "Querschnittsklauseln“, d.h. zwei zielvorgebende, zugleich alles Handeln der Union leitende Vorschriften. Letztere sind Vorgaben betreffend die grundlegende Ausgestaltung der Wirtschaftspolitik der Union.

Interessanterweise schafft die SRSP-Verordnung selbst explizit keinen ausführenden Dienst für das Programm. Man wird in seiner Einrichtung eine aus der Formulierung des SRSP zwangsläufig folgende Annexkompetenz der Kommission sehen müssen. ${ }^{353}$ Über die Bündelung von Expertise innerhalb der Kommission kann der Kommissionspräsident bzw. die Kommissionspräsidentin gem. Art. 17 Abs. 6 lit. b) EUV i. V. m. Art. 248 AEUV grundsätzlich frei entscheiden. Die Einrichtung von Dienststellen erfolgt dabei durch Mehrheitsbeschluss im Kollegium. ${ }^{354}$ Bis zu seiner Aufwertung $2020 \mathrm{zu}$ einer eigenen Generaldirektion war der SRSS indes kein sog. „gleichgestellter Dienst“ i.S.v. Art. 21 UAbs. 2 der Geschäftsordnung

350 Vgl. unter https://ec.europa.eu/info/departments/structural-reform-support_en\#r esponsibilities.

351 Verordnung (EU) 2017/825 des Europäischen Parlaments und des Rates vom 17. Mai 2017 über die Auflegung des Programms zur Unterstützung von Strukturreformen für den Zeitraum 2017-2020 und zur Änderung der Verordnungen (EU) Nr. 1303/2013 und (EU) Nr. 1305/2013, ABl. (EU) L 129/1 vom 19.5.2017.

352 Vgl. Vorschlag der Europäischen Kommission für eine Verordnung des Europäischen Parlaments und des Rates über ein Programm zur Unterstützung von Strukturreformen für den Zeitraum 2017-2020 und zur Änderung der Verordnungen (EU) Nr. 1303/2013 und (EU) Nr. 1305/2013, COM(2015) 701 final vom 26.11.2015. Zum entsprechenden Entstehungsdatum „Juli 2015“ etwa https://ec.europa.eu/info/sites/info/files/srss-information-brochure_en.pdf.

353 In diesem Sinne verstehe ich die Pressemitteilung der Kommission, „Griechenlandkrise: Unterzeichnung des dreijährigen ESM-Stabilitätshilfeprogramms für Griechenland" vom 20.08.2015, abgedr. in EuZW 2015, 652, a.E.

354 Vgl. Bernd Martenczuk, Art. 17 EUV, in: in: Eberhard Grabitz, Meinhard Hilf \& Martin Nettesheim (Begr./Hrsg.), Das Recht der Europäischen Union, C.H. Beck, München, 68. EL Dezember 2019, Rn. 95. 
der Kommission, sondern organisationsrechtlich dem Generalsekretariat unterstellt. $^{355}$

Insgesamt führt das SRSP nicht vorrangig zum Aufsichtsdurchgriff seitens der Union gegenüber den Mitgliedstaaten, sondern dient dem Kapazitätsaufbau. Es entsendet insbesondere Beamte anderer Mitgliedstaaten, die gemeinsam mit nationalen Kollegen mit der Durchführung mitgliedstaatsinterner Hoheitsbefugnisse beauftragt werden. ${ }^{356}$ Die Tätigkeit des SRSS und die Existenz des SRSP ist folglich, ungeachtet seiner Qualität auch eines Aufsichtsmechanismus, vorrangig ein Sonderfall des post-akzessorischen (nach dem Beitritt erfolgenden) state-building innerhalb der Union, die die Union vor langwierige Herausforderungen stellen wird. Eindrückliche Schilderungen aus der Praxis stützen diese Beobachtung. So hat Sebastian Weinzierl (noch zur TFGR) festgehalten, die seitens der Union geleistete Unterstützung müsse „[s]trukturelle[n] Verwaltungsdefizite[n] als dauerndes Hindernis“ begegnen. ${ }^{357}$ Sein Ausblick auf die Entwicklung, speziell zu Griechenland, stimmt nachdenklich, selbst wenn dort nur bzw. gerade auf die Finanzverwaltung Bezug genommen wird.

„Allen Beteiligten muss klar sein, dass noch ein sehr weiter, schwieriger Weg vor Griechenlands [...V]erwaltung liegt, die entwicklungsbedingt in den letzten drei Jahrzehnten weit hinter den Standard zurückgefallen ist, den die Bevölkerung Griechenlands, aber auch die Partner Griechenlands erwarten und auch einfordern dürfen".358

Für die vorliegende Arbeit lautet die Konsequenz aus diesen Schilderungen, sich der Parallelen systemischer Schwächen zu den hier interessierenden, vorsätzlichen, Entwicklungen bewusst zu sein, sie aber aufgrund

355 Vgl. Europäische Kommission, Annual Activities Report 2016: Annexes: Structural Reform Support Service - SRSS, Ares(2017)1709495 - 30/03/2017, S. 2 und 29.

356 Ein Programm des SRSS in Griechenland beinhaltete etwa die „Optimierung der Mittelverwendung“ und die „Identifizierung von Fällen der Steuervermeidung“. Das impliziert ein über das bloße Consulting hinausgehendes, mit der aktiven Berichtigung mitgliedstaatlicher Maßnahmen beauftragtes Vorgehen der entsandten Experten einschließlich umfassender Einsicht und Bearbeitung von Akten, vgl. Europäische Kommission, „Modernising tax audits in Greece for the national Revenue Authority“, ohne Az. oder Datum, abrufbar über: https://ec.europa.eu/info/examples-reform-support_en\#governance-and-public-a dministration.

357 Sebastian Weinzierl, „Die EU Task-Force für Griechenland“, S. 451.

358 Sebastian Weinzierl, „Die EU Task-Force für Griechenland“, S. 458. 
ihrer eigenständigen Entwicklung aus der weiteren Betrachtung auszuklammern.

\section{Topische Argumentationsweise zur Sichtung und Klärung des Materials}

Selbst bei Eingrenzung der Sichtung der Rechtsstaatlichkeitskrise durch die Fokussierung auf vorsätzliche Vorgänge bleibt die Materialfülle enorm. Legte man an die Aufarbeitung der polnischen Krise denselben akribischen Maßstab wie die Praxis, so zeigt sich, dass sowohl die facettenreiche akademische Aufarbeitung ${ }^{359}$ als auch das Primärquellenmaterial in einem Maße umfangreich geworden sind, dass es den Forscher wie den Praktiker nicht nur ob seiner Technizität und Kleingliedrigkeit ermüdet, sondern geradezu erschlägt. Das ist ein wesentlicher Unterschied insbesondere zur Krise in Österreich im Jahr 2000, bei der die Darstellung, trotz zahlreicher Entwicklungsstufen, auf einen übersichtlichen und abgeschlossenen Zeitraum und Quellenkorpus gestützt werden konnte.

Exemplarisch zeigt sich das für Polen. Seit Ende 2015 befindet sich Polen in einer durch die amtierende Regierung und ihre Mehrheit im polnischen Parlament, dem Sejm, hervorgerufenen, schweren Staats- oder Verfassungskrise. ${ }^{360}$ Die Vorgänge in Polen können im Sinne Sanford Levinsons und Jack Balkins als „a turning point in the health and history of a constitutional order" 361 bezeichnet werden. Zwischen dem Ursprung

359 Vgl. nochmals, Wojciech Sadurski, Poland's Constitutional Breakdown; Klaus Bachmann, Der Bruch; weiter, zu einzelnen Aspekten exemplarisch Agnieszka Kublik, „Auf Linie gebracht: Polens öffentlich-rechtlicher Rundfunk unter PiSKuratel“, in: Osteuropa 66 (2016), S. 153-159; Kai-Olaf Lang, „Zwischen Rückbesinnung und Erneuerung: Polens PiS und Ungarns Fidesz im Vergleich“, in: Osteuropa 66 (2016), S. 61-78; Kamil Marcinkiewicz, „Der politische Rechtsruck in Polen: Analyse von Ursachen und außenpolitischen Konsequenzen“, in: Zeitschrift für Außen- und Sicherheitspolitik 9 (2016), S. 463-476; Michael Minkenberg, The Radical Right in Eastern Europe: Democracy under Siege?, Palgrave Macmillan, New York, 2017; zu den gesellschaftspolitischen Hintergründen und Geschichte gerade im Hinblick auf die Frage der Religion Brian Porter-Szücs, Faith and Fatherland, für die hiesigen Zwecke insb. ab S. 392.

360 Der Begriff der Staatskrise hat in deutschen Medien einhellig Verwendung gefunden vgl. etwa Florian Hassel, „Schwere Staatskrise in Polen“, Süddeutsche Zeitung vom 09.03.2016; zum Begriff der Verfassungskrise in den englischsprachigen Presse s. Christan Davies, „Poland's supreme court constitutional crisis approaches a standoff", The Guardian vom 2. Juli 2018.

361 Sanford Levinson \& Jack M. Balkin, „Constitutional Crises“, S. 714. 
der polnischen Staats- und Verfassungskrise Ende 2015 und dem Ende des Untersuchungszeitraums Anfang 2020, währenddessen sie lange Teil der europäischen Rechtsstaatlichkeitskrise geworden war, sind nicht nur seitens der Europäischen Kommission zunächst die bei der Durchführung des EU-Rahmens ergangene Stellungnahme zur Rechtsstaatlichkeit, sodann vier Empfehlungen ${ }^{362}$ zur Rechtsstaatlichkeit und der begründete Vorschlag nach Art. 7 EUV $^{363}$ zu erwähnen.

Seitens des Europäischen Parlaments, dabei nur mit Blick auf die Plenarsitzungen, sind zehn allgemeine Aussprachen, auch zur Rechtsstaatlich-

362 1. Europäische Kommission, Empfehlung der Kommission vom 27.07.2016 zur Rechtsstaatlichkeit in Polen, C(2016) 5703 final, (EU) 2016/1374, ABl. (EU) L 217/53 vom 12.08.2016; 2. Europäische Kommission, Empfehlung der Kommission vom 21.12.2016 zur Rechtsstaatlichkeit in Polen in Ergänzung zur Empfehlung (EU) 2016/1374, C(2016) 8950 final, (EU) 2017/146, ABl. (EU) L 22/65 vom 27.01.2017; 3. Europäische Kommission, Empfehlung (EU) 2017/1520 der Kommission vom 26. Juli 2017 zur Rechtsstaatlichkeit in Polen in Ergänzung der Empfehlungen (EU) 2016/1374 und (EU) 2017/146, C(2017) 5320 final, ABl. (EU) L 228/19 vom 02.09.2017; 4. Europäische Kommission, Empfehlung (EU) 2018/103 der Kommission vom 20. Dezember 2017 zur Rechtsstaatlichkeit in Polen in Ergänzung der Empfehlungen (EU) 2016/1374, (EU) 2017/146 und (EU) 2017/1520, ABl. (EU) L 17/50 vom 23.01.2018.

363 Europäische Kommission, Begründeter Vorschlag nach Artikel 7 Absatz 1 des Vertrags über die Europäische Union zur Rechtsstaatlichkeit in Polen für einen Beschluss des Rates zur Feststellung der eindeutigen Gefahr einer schwerwiegenden Verletzung der Rechtsstaatlichkeit durch die Republik Polen, $\operatorname{COM}(2017) 835$ final, 2017/0360 (NLE) vom 20.12.2017. 
keit, ${ }^{364}$ eine Aussprache betreffend die Lage der Union, ${ }^{365}$ eine Erklärung des Präsidenten, ${ }^{366}$ eine Entschließung zur Lage der Rechtsstaatlichkeit, ${ }^{367}$ eine Entschließung zum eingeleiteten Verfahren nach Art. 7 EUV, ${ }^{368}$ zwei

364 Europäisches Parlament, 1. Plenardebatte vom Mittwoch, 13. April 2016 zur Lage in Polen, mit anschließender Entschließung des Europäischen Parlaments vom 13. April 2016 zur Lage in Polen (2015/3031(RSP)); 2. Plenardebatte mit anschließender Entschließung, Aktuelle Entwicklungen in Polen und ihre Auswirkungen auf die in der Charta der Grundrechte der Europäischen Union verankerten Grundrechte (Aussprache) zu den Erklärungen des Rates und der Kommission zum Thema „Aktuelle Entwicklungen in Polen und ihre Auswirkungen auf die in der Charta der Grundrechte der Europäischen Union verankerten Grundrechte" (2016/2774(RSP)); 3. Vom gleichen Tag, Plenardebatte Aussprache über die Erklärung des Präsidenten der Kommission zur Lage der Union (2016/2734(RSP)); 4. Plenardebatte vom 14. Dezember 2016, Lage der Rechtsstaatlichkeit und der Demokratie in Polen (Aussprache), in Anwesenheit des EVP der Kommission Timmermans 2016/3030(RSP); 5. Plenardebatte vom 19. Januar 2016, in Anwesenheit des Ratspräsidenten und EVP Timmermans (2015/2989(RSP); 6. Plenardebatte vom 15. November 2017, Die Lage der Rechtstaatlichkeit und der Demokratie in Polen (B8-0594/2017, B8-0595/2017), in Anwesenheit des EVP Timmermans (2017/2931(RSP)); 7. Plenardebatte vom 13. Juni 2018, Unabhängigkeit der Justiz in Polen (Aussprache) (2018/2761(RSP); . Plenardebatte vom 25. März 2019, Lage in Bezug auf die Rechtsstaatlichkeit und die Bekämpfung der Korruption in der EU, insbesondere in Malta und der Slowakei (O-000015/2019 - B8-0017/2019) (2018/2965(RSP); 9. Plenardebatte vom 15. Januar 2020, Laufende Anhörungen nach Artikel 7 Absatz 1 EUV - Polen (Aussprache) 2019/2986(RSP)); 10. Plenardebatte vom 11. Februar 2020, Die anhaltende Bedrohung der Rechtsstaatlichkeit in Polen (Aussprache), in Anwesenheit der Kommissarin Jourová (2020/2561(RSP)).

365 Plenardebatte vom 13. September 2017, Lage der Union (Aussprache) zur vorangegangenen Erklärung des Kommissionspräsidenten Juncker, (2017/2709(RSP)), zur Lage der Union, wenn auch dort nur kursorisch.

366 Vgl. dazu Europäisches Parlament, Pressemitteilung vom 19.01.2016, Poland: MEPs debate rule of law issues with Prime Minister Szydło zur vorg. Aussprache vom gleichen Tag, abrufbar unter: https:/www.europarl.europa.eu/news/en/ press-room/20160114IPR09899/poland-meps-debate-rule-of-law-issues-with-p rime-minister-szydlo; s. dort den Link zur Videoaufzeichnung mit der entspr. Erklärung.

367 Europäisches Parlament, P8_TA-PROV(2017)0442, Die Lage der Rechtstaatlichkeit und der Demokratie in Polen: Entschließung des Europäischen Parlaments vom 15. November 2017 zur Lage der Rechtsstaatlichkeit und der Demokratie in Polen (2017/2931(RSP)).

368 Europäisches Parlament, P8_TA-PROV(2018)0055, Beschluss der Kommission, im Hinblick auf die Lage in Polen das Verfahren gemäß Artikel 7 Absatz 1 EUV einzuleiten, Entschließung des Europäischen Parlaments vom 1. März 2018 zu 
Aussprachen über den sog. DRF-Pakt, ${ }^{369}$ der Polen erwähnt, zwei Aussprachen über Änderungen der Strukturfonds, ${ }^{370}$ eine Aussprache zur Lage der Grundrechte ${ }^{371}$ sowie eine Aussprache in Anwesenheit des polnischen Ministerpräsidenten ${ }^{372} \mathrm{zu}$ nennen.

Im Rat hat es 2018 drei Anhörungen (im Juli, September und Dezember) gegeben ${ }^{373}$ und danach 2019, nach längerer Pause, ${ }^{374}$ gegen Jahresen-

dem Beschluss der Kommission, im Hinblick auf die Lage in Polen das Verfahren gemäß, Artikel 7 Absatz 1 EUV einzuleiten (2018/2541(RSP)).

369 Europäisches Parlament, 1. Plenardebatte vom 25. Oktober 2016, EU-Mechanismus für Demokratie, Rechtsstaatlichkeit und Grundrechte (Aussprache) (2015/2254(INL)) (A8-0283/2016), in Anwesenheit des Ersten Vizepräsidenten der Kommission, Timmermans; 2. Plenardebatte vom 17. April 2018, Ein Instrument für europäische Werte zur Unterstützung zivilgesellschaftlicher Organisationen, die die Demokratie, Rechtsstaatlichkeit und Grundwerte in der Europäischen Union fördern (Aussprache), in Anwesenheit der Justizkommissarin Jourová (2018/2619(RSP)).

370 Europäisches Parlament, 1. Plenardebatte vom 13. März 2018, Der nächste MFR: Vorbereitung des Standpunkts des Parlaments zum MFR nach 2020 Reform des Eigenmittelsystems der Europäischen Union (Aussprache), debattierte Berichte als (2017/2052(INI)) (A8-0048/2018) und (2017/2053(INI)) (A8 -0041/2018), s. dort insb. die Äußerungen des Kommissars Oettinger, 2. Plenardebatte vom 13. November 2018, Zwischenbericht über den Mehrjährigen Finanzrahmen 2021-2027: Standpunkt des Parlaments im Hinblick auf eine Einigung (Aussprache), in Anwesenheit von Kommissar Oettinger.

371 Europäisches Parlament, Plenardebatte vom 16. Januar 2019, Lage der Grundrechte in der Europäischen Union 2017 (Aussprache) (2018/2103(INI)) (A80466/2018), in Anwesenheit der Justizkommissarin Jourová.

372 Europäisches Parlament, Plenardebatte vom 4. Juli 2018, Aussprache mit dem polnischen Ministerpräsidenten Mateusz Morawiecki über die Zukunft Europas (Aussprache), (2018/2729(RSP)) Aussprachen vergleichbaren Formats wurden mit diversen Regierungschefs, darunter am 13.11.2018 auch mit der deutschen Kanzlerin geführt, in dieser war die Rechtsstaatlichkeit indes besonderes Thema (ohne eig. Nr., erste Nr. dieser Aussprache (A8-0358/2018) (2018/0166R(APP)), Punkt 8 der Tagesordnung).

373 Rat der Europäischen Union, 1. Rule of Law in Poland / Article 7(1) TEU Reasoned Proposal - Report of the hearing held by the Council on 26 June 2018, 12970/18 vom 08.08.2018; 2. Rule of Law in Poland / Article 7(1) TEU Reasoned Proposal - Report of the hearing held by the Council on 18 September 2018, 12970/18 vom 5. November 2018; 3. Rule of Law in Poland / Article 7(1) TEU Reasoned Proposal - Report on the hearing held by the Council on 11 December 2018, 15469/18 vom 20. Dezember 2018.

374 Zu den Gründen Laurent Pech \& Patryk Wachowiec, „1460 Days Later: Rule of Law in Poland R.I.P. (Part I)“, Verfassungsblog vom 13.01.2020. Beide Verfasser führen dies erstens auf bewusste Verschleppung durch die selbst von Rechtsstaatsskandalen betroffene rumänische Ratspräsidentschaft, und hiernach 


\section{Die Rechtsstaatlichkeitskrise in mitgliedstaatlichen Fällen}

de zwei weitere Aussprachen zu Art. 7 EUV gegeben, zuletzt im Dezember 2019. Zusätzlich hat die Kommission mehrfach einen Zwischenstand ihrer Beobachtungen im Rat eingereicht. ${ }^{375}$ Die Form der Anhörung leitet der Rat aus dem Wortlaut des Art. 7 Abs. 1 EUV ab. ${ }^{376}$ Die Anhörungen sind dabei sowohl im Rat für Allgemeine Angelegenheiten („General Affairs Council“, GAC) als auch im Rat für Justiz und Inneres („Justice et Affaires intérieures“, JAI) erfolgt.

Vor dem Gerichtshof der Europäischen Union sind zwei Vertragsverletzungsverfahren entschieden worden, ${ }^{377}$ ein weiteres ist anhängig. ${ }^{378}$ 18 Vorabvorlageersuchen, ${ }^{379}$ u.a. von polnischen Instanzgerichten ${ }^{380}$ und dem Obersten Gerichtshof, ${ }^{381}$ stützen die Kommission dabei zusätzlich in ihren Bemühungen. ${ }^{382}$ Zum Abschluss des Manuskripts entwickelte sich die Lage weiter schnell fort. ${ }^{383}$

Die Venedig-Kommission des Europarates hat sechs Gutachten erlassen, davon zuletzt eines als „dringendes Gutachten“ gemeinsam mit der GD

auf den Beschluss der finnischen Ratspräsidentschaft zurück, nicht im Umfeld der polnischen Parlamentswahlen vom Oktober 2019 auf diese Einfluss nehmen zu wollen.

375 Vgl. Rat der Europäischen Union (GAC), Draft Minutes vom 10.12.2019, 14943/1/19 vom 14.01.2020. Ein Bericht über diese letzte Aussprache ist noch nicht verfügbar. Einen Überblick über die weiteren Aussprachen im Jahresverlauf verschafft nochmals Laurent Pech \& Patryk Wachowiec, „1460 Days Later“.

376 Vgl. Rat der Europäischen Union, Rule of Law in Poland / Article 7(1) TEU Reasoned Proposal - Hearing of Poland on 26 June 2018, 10354/18 vom 21. Juni 2018, Rn. 6.

377 Vgl. EuGH, Rs. C-619/18 R, Kommission ./. Polen, „Unabhängigkeit des Obersten Gerichts“, Urteil (GK) vom 24.06.2019, ECLI:EU:C:2019:531; Rs. C-192/18, Kommission ./. Polen, „Unabhängigkeit der ordentlichen Gerichtsbarkeit“, Urteil (GK) vom 05.11.2019, ECLI:EU:C:2019:924.

378 EuGH, Rs. C-791/19, Kommission ./. Polen, anhängig.

379 Statistik ebenso nach Laurent Pech \& Patryk Wachowiec, „1460 Days Later“.

380 EuGH, Verb. Rs. C-558/18 und C-563/18, Miasto Łowicz ./. Skarb Państwa Wojewoda Łódzki, und Prokurator Generalny ./. VX u.a., Urteil (GK) vom 26.03.2020, ECLI:EU:C:2020:234.

381 EuGH, Rs. C-824/18, A.B. u.a. ./. Krajowa Rada Sądownictwa, anhängig.

382 Zur Übersicht s. auch Luke Dimitrios Spieker, „Breathing Life into the Union's Common Values“, S. 1186.

383 Zum zukünftig wohl nächsten großen Vertragsverletzungsverfahren, das in seinem frühesten Stadium steht, s. noch Europäische Kommission, „Rechtsstaatlichkeit - Europäische Kommission leitet Vertragsverletzungsverfahren zum Schutz der Unabhängigkeit polnischer Richter ein“, Pressemitteilung vom 29.04.2020, IP/20/772. 
Menschenrechte und Rechtsstaatlichkeit des Europarates. ${ }^{384}$ Das „Büro für demokratische Institutionen und Menschenrechte“ (BDIMR(ODIHR) der OSZE hat in schneller Folge vier Gutachten zu Polen erlassen. ${ }^{385}$

Seitens der Vereinten Nationen haben sich sowohl der UN-Sondergesandte für die Unabhängigkeit von Richtern und Anwälten, ${ }^{386}$ Diego García-Sayán, wie auch in einem Brief der damalige UN-Hochkommissar für Menschenrechte der Vereinten Nationen, ${ }^{387}$ Zeid bin Ra'ad Zeid al-Hussein, geäußert. Mehrere negative Berichte des US Departement of

384 Venedig-Kommission, 1. CDL-AD(2016)001, Opinion no. 833/2015, Opinion on amendments to the Act of 25 June 2015 on the Constitutional Tribunal of Poland vom 11.03.2016; 2. CDL-AD(2016)012, Opinion no. 839/2016, Poland - Opinion on the Act of 15 January 2016 amending the Police Act and certain other Acts vom 13.06.2016; 3. CDL-AD(2016)026, Opinion 860/2012, Poland - Opinion on the Act on the Constitutional Tribunal vom 14.10.2016; 4 . CDL-AD(2017)028, Opinion 892/2017, Poland - Opinion on the Act on the Public Prosecutor's office vom 11.12.2017; 5. CDL-AD(2017)031, Opinion no. 904/2017, Poland - Opinion on the Draft Act amending the Act on the National Council of the Judiciary; on the Draft Act amending the Act on the Supreme Court, proposed by the President of Poland, and on the Act on the Organisation of Ordinary Courts vom 11.12.2017; 6. CDL-PI(2020)002, Opinion no. $977 / 2019$, Poland- Urgent Joint Opinion on the amendments to the Law on organisation on the Common Courts, the Law on the Supreme Court and other Laws vom 16.01.2020.

385 ODIHR der OSCE, 1. Final Opinion on Draft Amendments to the Act on the National Council of the Judiciary and certain other acts of Poland OpinionNr.: JUD-POL/305/2017-Final [AlC/YM] vom 05.05.2017; 2. Opinion On The Draft Act Of Poland On The National Freedom Institute - Centre For The Development Of Civil Society, Opinion-Nr.: NGO-POL/303/2017 [AlC] vom 22.08.2017; 3. Opinion on certain provisions of the Draft Act on the Supreme Court of Poland, Opinion-Nr.: JUD-POL/313/2017 [AlC] vom 30.08.2017; 4 . Opinion on the Draft Act on the Supreme Court of Poland, Opinion-Nr.: JUD-POL/315/2017 [AlC] vom 13.11.2017.

386 Preliminary observations on the official visit to Poland (23-27 October 2017) United Nations Special Rappor-teur on the independence of judges and lawyers Mr. Diego García-Sayán, Warsaw, 27 October 2017, abrufbar unter: http://ww w.ohchr.org/EN/NewsEvents/Pages/DisplayNews.aspx?NewsID=22313\&LangID=E.

387 Brief von Zeid bin Ra'ad Zeid al-Hussein an den polnischen Außenminister Witold Waszczykowski vom 23.10.2017, ohne Az., s. nachfolgend auch Press briefing on Poland, Spokesperson for the UN High Commissioner for Human Rights: Rupert Colville, Subject: Poland vom 20.12.2019, abrufbar unter: https:/ /www.ohchr.org/EN/NewsEvents/Pages/DisplayNews.aspx?NewsID=25447\&La ngID=E. 


\section{Die Rechtsstaatlichkeitskrise in mitgliedstaatlichen Fällen}

State, ${ }^{388}$ eine Aussprache des UN-Menschenrechtsrates ${ }^{389}$ zahllose Gutachten von Nichtregierungsorganisationen und polnischen Richtervereinigungen $^{390}$ und ungezählte Beschwerden von Bürgern und Amtsträgern bei der Europäischen Kommission kommen hinzu.

Diese Materialfülle macht zum einen offensichtlich, dass in Polen ein schwerer Missstand zu beobachten ist, zum anderen ruft sie nach einer effektiven Sichtung. Die Methode, die dies schließlich der Rechtswissenschaft ermöglicht, kann dabei nicht allein und vorrangig auf die Entwicklung einer Systematik dieser Entwicklung abstellen. Die dogmatische Erfassung des Materials bedarf vielmehr einer Erfassung vorrangig mittels der Methode der Topik.

Die Topik ist namentlich durch Theodor Viehweg als eigene juristische Methodik erarbeitet und vertreten worden. ${ }^{391}$ Topik bezeichnet die „am Problem orientiert[e]“ Arbeitsweise. ${ }^{392}$ Zweck der Topik ist es, „Gesichtspunkte [zu sammeln] und diese schließlich in Kataloge [zusammenzufassen], die nicht von einem Ableitungszusammenhang beherrscht werden und deshalb besonders leicht zu erweitern und zu ergänzen sind.“393 Sie hat in der deutschen Rechtswissenschaft, gerade im öffentlichen Recht, vielfach Unterstützung erfahren. ${ }^{394}$

388 United States Department of State, Poland 2016 Human Rights Report, ohne Az. oder Datum, abrufbar unter: state.gov, s. auch die nachfolgenden Berichte gleichen Titels, jüngst von 2019.

389 Die vollständige Videoaufzeichnung der Aussprache im Menschenrechtsrat ist verfügbar unter: http://webtv.un.org/search/poland-review-27th-session-of-unive rsal-periodic-review/5425972482001/?term=\&lan=english\&cat=Universal\%20Per iodic\%20Review\&sort=date\&page $=9$.

390 Vgl. insb. das Papier der polnischen Richtervereinigung Iustitia, „Response to the White Paper Compendium on the Reforms of the Polish Justice System, presented by the Government of the Republic of Poland to the European Commission" vom 16.03.2018.

391 Theodor Viehweg, Topik und Jurisprudenz: Ein Beitrag zur rechtswissenschaftlichen Grundlagenforschung, 4., durchgesehene Aufl., C.H. Beck, München, 1969 [1953], nachfolgend alle Zitate nach dieser Auflage; umfassende Rezeption bei Karl Larenz, Methodenlehre der Rechtswissenschaft, S. 150 ff., insb. S. 152; weiter Agnes Launhardt, Topik und Rhetorische Rechtstheorie: Eine Untersuchung zu Rezeption und Relevanz der Rechtstheorie Theodor Viehwegs, Peter Lang, Frankfurt a.M. u.a., 2010, S. $20 \mathrm{ff}$.

392 Theodor Viehweg, Topik und Jurisprudenz, S. 17.

393 Theodor Viehweg, Topik und Jurisprudenz, S. 36.

394 Andreas von Arnauld, „Erster Beratungsgegenstand: Öffnung der öffentlichrechtlichen Methode durch Internationalität und Interdisziplinarität: Erscheinungsformen, Chancen, Grenzen: 2. Referat“, in: Uwe Volkmann (Hrsg.), Veröffentlichungen der Vereinigung der Deutschen Staatsrechtslehrer, Bd. 74, De 
Der Topos ist also ein mit einem Rechtsbegriff verknüpftes Rechtsproblem und zugleich dessen tatsächliche Erscheinungsform in der Lebenswirklichkeit. Die sowohl assoziative wie analytische Identifizierung entspricht dem „issue-spotting “ US-amerikanischen Verständnisses. Viehweg konzipierte die Topik als Dichotom zum systematischen Arbeiten und erklärte beide für unvereinbar. ${ }^{395}$ Das dies indes nicht durchzuhalten ist, zeigt schon die bei ihm selbst anzutreffende Aussage der Zusammenfassung von Topoi in „Katalogen“, welches eine Typisierung und folglich bis zu einem gewissen Grad auch eine Systematisierung darstellt. Das topische Arbeiten kann es also ermöglichen, Topoi zu Typen zusammenzufassen und damit zu systematisieren und anhand der identifizierten Topoi auch Rechtsbegriffe zu erarbeiten, ohne die mit letzterer verbundene dogmatische Arbeit aufzugeben. Die Systematisierung folgt allerdings der topischen Erfassung nach.

Im vorliegenden Fall dient die Topik weniger der Lösung als vielmehr der Erfassung und Reduktion der sich darbietenden Sachverhalte, also der Rechtfertigung der Sachverhaltsverschlankung und der bis zu einem gewissen Grade axiomatischen Auswahl der in der Rechtsstaatlichkeitskrise erfolgten Entwicklungen. Die Topik kann auch erklären, warum in Kombination und allgemeiner Wahrnehmung, d.h. also in wertender Gesamtschau, verschiedene Vorgänge in einem Mitgliedstaat gerade dort als besonderes Problem gelten müssen, obwohl isoliert betrachtet das gleiche Problem in einem anderen Mitgliedstaat ebenso besteht. So gilt z.B. die Korruption für Rumänien und Bulgarien, aber auch für Ungarn, als besonders prägend. Daten, wie sie für ein Eurobarometer erhoben wurden, zeigen indes, dass in anderen Mitgliedstaaten, wie Griechenland, Zypern oder sogar Spanien die Werte weit höher liegen. ${ }^{396}$ Es ist dann das Zusammen-

Gruyter, Berlin, 2015, S.39-87, S. 61 ff, mit umfassenden w. N.; ebenso das Koreferat von Peter Schneider \& Horst Ehmke, „Erster Beratungsgegenstand: Prinzipien der Verfassungsinterpretation“, in (ohne Red./Hrsg.): Prinzipien der Verfassungsinterpretation: Gefährdungshaftung im öffentlichen Recht, Veröffentlichungen der Vereinigung der Deutschen Staatsrechtslehrer, Bd. 20, De Gruyter, Berlin, 1963, S. 1-134, insb. S. 37 ff. (Schneider) und 53 ff. (Ehmke); weitere Nachweise auch bei Wolfgang Kahl, „Dogmatik im EU-Recht“, in: Archiv des öffentlichen Rechts 144 (2019), S. 159-201, S. 199-200, derselbe zeigt sich indes kritisch, dazu sogl. unten. Armin von Bogdandy \& Michael Ioannidis, „Das systemische Defizit“, S. 298, sprechen ebenso von „Topoi“, die es zu identifizieren gelte.

395 Theodor Viehweg, Topik und Jurisprudenz, S. 34.

396 Vgl. Eurostat, Special Eurobarometer 470, October 2017, Corruption, S. 18, Tabelle zu „QB 5 How widespread do you think the problem of corruption is 


\section{Die Rechtsstaatlichkeitskrise in mitgliedstaatlichen Fällen}

wirken mit anderen Topoi, das rechtfertigt, warum die Auswahl sich in der Rechtspraxis und der Rechtsprechung auf bestimmte Mitgliedstaaten konzentriert und z.B. dann Ungarn, Bulgarien oder Rumänien in den Fokus rücken. Dies verlangt aber auch, sich der gemachten Beobachtungen regelmäßig zu vergewissern und sie zu hinterfragen.

Der hier gewählte Ansatz wendet sich nicht gegen eine spätere systematisierende, dogmatische Aufarbeitung der Rechtsstaatlichkeitskrise, ${ }^{397}$ hält aber eine Vorsortierung des Materials, entsprechend des zuvor aufgestellten Theorems vom „zweistufigen“ Rechtsbegriff, bestehend aus Vorsortierung durch den Begriff der Rechtsstaatlichkeitskrise und späterer präziser Aufarbeitung anhand des Begriffs des systemischen Defizits, für unerlässlich.

\section{Polen}

\section{Drei Thesen}

Der topischen Sichtung der Lage in Polen stelle ich anfangs drei Thesen voran.

Die erste These lautet, dass die Staatskrise in Polen als Katalysator für die Entwicklung der Rechtsstaatlichkeitskrise, damit auch für den Begriff des systemischen Defizits und schließlich für die Entwicklung des europäischen Verfassungsaufsichtsregimes fungiert hat. Darin liegt eine gewisse Tragik. Ein Katalysator ist in der Chemie bekanntlich ein Stoff, der eine Reaktion erst ermöglicht, ohne durch diese aber selbst beeinflusst zu werden. Nach derzeitigem Stand der Lage ist diese Beobachtung deswegen gerechtfertigt, weil Polen, trotz aller genutzten Mechanismen, in seiner Entwicklung ungehindert fortschreitet. Das teilt Polen zwar mit Ungarn, in Polen ist die Entwicklung aber besonders prägnant. Egal ob Art. 7 EUV oder multiple Vertragsverletzungsverfahren oder gesellschaftlicher Druck,

in (OUR COUNTRY)?”. Demnach halten in den Mitgliedstaaten Griechenland (96), Spanien (94), Portugal (92) und Zypern (94) jeweils weit über $90 \%$ der Befragten Korruption für ein zentrales Problem, gegenüber Rumänien mit „nur“ 80 und Ungarn mit $86 \%$.

397 Ich sehe daher nicht, wie Kahl dies zu befürchten scheint, in der Befürwortung der Topik eine Aufgabe dogmatischer Arbeit, näher Wolfgang Kahl, „Dogmatik im EU-Recht“, S. 199-200. Auch die bei Karl Larenz, Methodenlehre der Rechtswissenschaft, S. 153, befürchtete Beliebigkeit des Begriffs steht hier nicht im Raum. Die Topoi der Rechtsstaatlichkeitskrise lassen sich klar benennen. 
die Regierung treibt die Reformen deutlich sichtbar und ungeachtet politischer Opposition voran. Das bedeutet nicht, dass die konkreten Defizite in Polen nicht lösbar wären, es bedeutet indes, dass sie bislang nicht gelöst worden sind.

Die katalysatorische Funktion der Vorgänge in Polen rechtfertigt, die Sachstandsdarstellung hier mit Polen und nicht mit Ungarn zu beginnen, obwohl es insbesondere die Lage in Ungarn war, die die Kommission 2014 zur Schaffung des EU-Rahmens bewog. ${ }^{398}$

Außerdem ist es Teil der katalysatorischen Funktion der Krise in Polen, dass gerade anhand dieser Krise und keiner anderen, die Kommission die Entwicklung ihrer Instrumente vorangebracht hat. Das gilt in überragendem Maße für die hier sog. Operationalisierung des Rechtsstaatsbegriffs, gerade über Art. 19 Abs. 1 EUV i.V.m. Art. 47 der Grundrechtecharta.

Auch wenn die Kommission an zahlreichen Stellen gegen andere Mitgliedstaaten, denen der Vorwurf der Missachtung des Rechtsstaatsprinzips gemacht wird, insbesondere gegen Ungarn, Vertragsverletzungsverfahren eingeleitet hat, so hat sie dies doch nicht unter der Prämisse getan, wie im Falle Polens, sich spezifischen Fragen der Rechtsstaatlichkeit zu widmen.

Die zweite These lautet, dass ungeachtet der Technizität der Entwicklung in Polen das zugrundeliegende verfassungsrechtliche Problem von verblüffender Simplizität ist. Die Staatskrise in Polen ist zunächst Beispiel des spezifischen Subtyps vorsätzlich betriebener Unterwanderungen des Rechtsstaatsprinzips als Ausprägung des systemischen Defizits. Darüber hinaus bestand in Polen lange Zeit eine weitgehend monothematische Entwicklung. Monothematisch bedeutet, dass sich ohne Weiteres dem Beobachter ein „Leitmotiv“ der Krise aufdrängt, nämlich der Umgang der polnischen Stellen mit der eigenen Justiz. Diese Beobachtung behält Gültigkeit selbst bei Würdigung jüngster Entwicklungen.

In Ungarn, dem am häufigsten parallel zu Polen genannten Beispiel, ist die Unterwanderung hingegen zwar ebenso vorsätzlich, aber polythematisch, betrifft also diverse Bereiche des öffentlichen Lebens, wie die Medien- und Forschungsfreiheit, den Stand der Zivilgesellschaft und nur zwar gleichrangig, aber als eines unter vielen Themen auch die Justiz. Auf diesen zentralen Unterschied bei der Bewertung der Entwicklung habe ich mit Bogdanowicz bereits an anderer Stelle hingewiesen und dabei zwischen einer homogenen thematischen Ausprägung der für die Rechtsstaatlichkeit

398 Hierzu mehr infra unter E. IV. 2., betreffend die Genese des EU-Rahmens. 
in Polen und einer heterogenen Themenvielzahl der gleichen Problematik in Ungarn getrennt. ${ }^{399}$

Die Klarheit der Krise in Polen hat Forschung und Praxis Gewissheit über den funktionalen Kern der Rechtsstaatlichkeitskrise gegeben.

Ich gebe dabei zu, dass die These von der dichotomen Unterscheidbarkeit Polens von Ungarn anhand der adressierten Topoi in der Rechtsstaatlichkeitskrise hier eine bewusste Verschlankung der Problematik darstellt. Es ist durchaus möglich, thematisch anders gelagerte, aber seinerzeit ebenso interessierende Fragen, wie insbesondere die Rolle der Medien ${ }^{400}$ oder spätere Fragen, etwa zur Rolle der Frau, ${ }^{401}$ hervorzuheben. In Wojciech Sadurskis Studie zur polnischen Lage etwa ist diesen Vorgängen auch im Rahmen einer Monographie umfassend nachgegangen worden. ${ }^{402}$ Sadurski zitiert auch den polnischen Bürgerbeauftragen Adam Bodnar mit den Worten, es werde in Polen zunehmend schwierig, politische Rechte auszuüben, was zeigt, dass auch staatliche Einrichtungen sich dieser Entwicklung gewahr werden. ${ }^{403}$ Ich bleibe trotzdem bei meiner These, wonach in Polen die vorsätzliche Unterwanderung und politische Vereinnahmung der Justiz prägendes Leitmotiv ist und stütze mich dazu auf den Korpus der unionalen Reaktionen, insbesondere also von Europäischer Kommission und Europäischem Gerichtshof, in denen diese Vorgänge allein im Vordergrund standen.

Die dritte These lautet, dass der Einstieg über die Lage in Polen die Rechtsstaatlichkeitskrise greifbar macht. Dabei kommt eine in vier Schritten ablaufende, bewusste Ausschaltung der polnischen Justiz durch die kollusiv zusammenwirkende polnische Regierung und das polnische Parlament zum Vorschein. Nach einer politischen Unterwerfung des Verfassungsgerichtshofs ist gegen den Obersten Gerichtshof, sodann gegen die ordentliche Gerichtsbarkeit vorgegangen worden. Thematisch eigenstän-

399 Matthias Schmidt \& Piotr Bogdanowicz, „The Infringement Procedure in the Rule of Law Crisis“, S. 1086.

400 Vg. bereits Agnieszka Kublik, „Auf Linie gebracht“ und Venedig-Kommission, CDL-AD(2016)012, Opinion no. 839/2016, Poland - Opinion on the Act of 15 January 2016 amending the Police Act and certain other Acts vom 13.06.2016.

401 Vgl. Europäisches Parlament, Plenardebatte vom 05.10.2016, Frauenrechte in Polen (Aussprache), 2016/2918(RSP), weiter die Presseerklärung des UN-Hochkommissar für Menschenrechte, „Poland: UN experts say Government must not roll back women's rights", vom 13.12.2018.

402 Wojciech Sadurski, Poland's Constitutional Breakdown, s. Kapitel 6, ab S. $150 \mathrm{ff}$.

403 Wojciech Sadurski, Poland's Constitutional Breakdown, S. 150. 
dig ist dabei auch gegen andere Justizorgane, so den Landesjustizrat und die Landesrichterschule vorgegangen worden, obwohl die Grundlage hierzu dieselben Gesetzesänderungen sind. Der letzte, vierte und noch andauernde Schritt ist die Ende 2019 im Fluss befindliche zusätzliche Disziplinierung von Richtern über weitere Gesetze. Hiermit ist die Darstellung dann zu beschließen.

Diese vier Entwicklungsschritte sind nachfolgend herauszuarbeiten, ihnen voranzustellen ist aber das normative Fundament der polnischen Regierung, das die Entwicklung angestoßen hat.

2. Die exkludierende Demokratie als normatives Fundament der Entwicklungen

Der profunde Konflikt zwischen Polen und der Europäischen Union wirft unweigerlich die Frage nach ihrem Warum auf. Es muss ein politisches Ziel geben, dass die polnische Regierung mit den beanstandeten Maßnahmen verfolgt. Sonst ließe sich allenfalls ein temporärer, nicht aber ein derart langanhaltender Konflikt wie der jetzige, erklären.

Die Erfassung der politischen Intentionen der Partei PiS und der von ihren Parlamentsmehrheiten seit 2015 gestützten Regierungen fällt aber deutlich schwerer als insbesondere im späteren Vergleichsfall Ungarn. Nachfolgend sollen daher, sich stützend auf Kenner der Materie auch aus innerstaatlicher Sicht, einige Grundsätze herausgearbeitet werden. Dies ist schon deswegen notwendig, da damit deutlich wird, dass das aus den unbestreitbar erheblichen Wahlerfolgen folgende Mandat der derzeitigen polnischen Regierung kein allseitig legitimierendes und relativierendes Argument sein kann. Dies gilt auch, wenn man ausdrücklich anzuerkennen hat, dass es sich um Maßnahmen gewählter Vertreter handelt, die sich auf ebendieses Mandat berufen und berufen können. ${ }^{404}$ Es geht nicht darum, dieses Mandat in Abrede zu stellen, noch, da die nachfolgenden Ausführungen notwendiger Weise nicht erschöpfend sind, pauschale Urteile zu fällen, sondern die von überaus zahlreichen, kundigen Beobachtern dargelegte Sorge nicht zuletzt um Polen selbst und seine Rolle in der Union herauszuarbeiten. ${ }^{405}$

$404 \mathrm{Zu}$ dieser Problematik insbesondere Armin von Bogdandy, „Tyrannei der Werte?", S. 511.

405 Ich war Teil einer multinationalen, dabei auch polnisch-deutschen, Autorengruppe, die diese Sorge bereits in der Vergangenheit zum Ausdruck gebracht 


\section{Die Rechtsstaatlichkeitskrise in mitgliedstaatlichen Fällen}

$\mathrm{Zu}$ beginnen ist die Darstellung, wie später diejenige für Ungarn, mit Einzelpersonen, die die Entwicklung angestoßen haben. Mit Jarostaw Kaczyński kennt die polnische Politik einen als gewieften Taktiker geltenden Übervater, der zudem von 2006-2007 polnischer Ministerpräsident war. ${ }^{406}$ In der derzeitigen Lage tritt Kaczyński vermeintlich aus der zweiten Reihe hervor. Damit einher geht ein teils rascher Wechsel der polnischen Kabinette und Ministerpräsidenten. War letzteres während weiter Teile der Entwicklungen Beata Szydto, so trat sie 2017 überraschend zurück und machte Platz für den derzeitigen, als eloquenter geltenden und polyglotten Mateusz Morawiecki. ${ }^{407}$ Der polnische Präsident Andrzej Duda wiederum gilt trotz zwischenzeitlicher Emanzipationsversuche von Kaczyński ${ }^{408}$ diesem insbesondere bei der Ausfertigung von Gesetzen als so hörig, dass hierüber in Polen Flüsterwitze im Umlauf sind. ${ }^{409}$ Kaczyński selbst hat mit seiner parlamentarischen Allmacht ungeachtet der ihm formell nicht zustehenden Ämter gelegentlich kokettiert. Während einer wichtigen Abstimmung Ende 2017 zur polnischen Justiz etwa setzte er sich im Sejm demonstrativ in die vordere Reihe seiner Fraktion und las ein Kinderbuch, einen „Katzenatlas“, den er später „für einen guten Zweck“ versteigern ließ. 410

Zweitens ist es, angesichts dieser Inversionslage der politischen Machtverhältnisse, in der der „einfache Abgeordnete“ Kaczyński die Fäden in der Hand hält, umso schwieriger, die Gründe des Vorgehens der PiS zu ermitteln, und dies insbesondere, weil im Unterschied zu Ungarn kein

hat, Armin von Bogdandy, Piotr Bogdanowicz, Iris Canor, Maciej Taborowski \& Matthias Schmidt, „Guest Editorial: A potential constitutional moment for the European rule of law - The importance of red lines“, S. 994-995.

406 Ein sehr gelungenes Personenporträt, das dieses Bild zeichnet, stammt von Konrad Schuller, „Ein versehrtes Leben“, Frankfurter Allgemeine Sonntagszeitung vom 26.11.2017.

407 Eine gute Analyse findet sich bei Anna Grzymala-Busse, „Poland's right-wing government has a new prime minister. Here are the 5 things you need to know“, Washington Post vom 12.12.2017.

408 Dazu Konrad Schuller, „Der Lehrling fordert den Meister heraus“, Frankfurter Allgemeine Zeitung vom 08.09.2017.

409 So berichtet von einem polnischen Kollegen. Demnach schickt Kaczyński zum Dank für Dudas treue Dienste und in dem Glauben, dieser habe Freude daran, dem Staatspräsidenten zum Geburtstag ein Kaninchen. Zu seiner größten Überraschung erhält Kaczyński es postwendend am nächsten Tag, auf dem Rücken sorgsam unterschrieben, zurück.

410 Hierzu Rzeczpospolita vom 24.11.2017, „AP: Kaczyński w parlamencie czyta książkę o kotach“ sowie vom 25.11.2017, „Jarosław Kaczyński przekazał Atlas kotów na aukcję charytatywną." 
Schlüsseldokument vorliegt, mit dem die Partei ein entsprechendes Programm vorgelegt hätte.

Bisherige Analysen von Parteiprogrammen und Reden ${ }^{411}$ belegen jedenfalls einen strengen Wertkonservativismus mit strikter Ablehnung des Sozialismus. Treibend als politisches Motiv für die Ausübung der politischen Richtlinienkompetenz ist das Verständnis der polnischen Nation und des polnischen Volkes als ethnisch und religiös homogen, welches es zu behaupten und zu wahren gilt. Kaczyński zeigt sich hinsichtlich des Wunsches nach der zukünftigen Orientierung Polens sehr stark wertegeleitet, bringt den Wertebegriff aber nicht mit dem Pluralismus in Bezug. Als Grundlage für die Etablierung dieses Wertekanons gilt die Lehre der katholischen Kirche, indes in enger Auslegung. ${ }^{412}$ Kaczyński sieht die Umformung des Staates, explizit auch der Justiz, als Durchsetzung einer nach innen radikal-egalitären, nach außen aber exkludierenden, dem „einfachen Bürger“ zugewandten und seine echte soziale Teilhabe verwirklichende Demokratie. ${ }^{413}$ Damit einher geht eine nur eingeschränkt der Marktwirtschaft zugewandte Wirtschaftspolitik. Wie für die Fidesz in Ungarn gilt für die PiS „das Leitbild einer produktions- und mittelstandsbasierten Gemeinwohlökonomie mit großen, öffentlich kontrollierten Unternehmen in strategischen Sektoren und dem Ziel einer spürbaren Verringerung der Abhängigkeit von ausländischen Investoren." gelten dabei makroökonomisch unterschiedliche Ausgangslagen, wobei Polen ein starkes Wirtschaftswachstum zu verzeichnen hat und infolge des Balcerowicz-Plans mit dem Złoty über eine stabile Hartwährung verfügt, während Ungarn ungeachtet wirtschaftlicher Verbesserungen mit Währungsproblemen, insbesondere hoher Volatilität und erhöhter Inflati-

411 S. die Aufarbeitung des Dokumentenkonvoluts mit Parteiprogramm und Reden unter dem Titel "PiS in their own words", durch Brian Porter-Szücs, abrufbar unter: http://porterszucs.pl/2016/02/05/pis-in-their-own-words/. Für die Auseinandersetzung des Einflusses und vor allem der historischen Ursprünge dieser Denkweise auf die polnische Gesellschaft in ganzer Breite, s. Brian Porter-Szücs, Faith and Fatherland.

412 Jarosław Kaczyński, Auszug aus einer Rede vom 14. Februar 2005, vor der Stefan-Batory-Stiftung in Warschau, aus der vorbenannten Quellensammlung. Brian Porter-Szücs, Faith and Fatherland, S. 232 ff., identifiziert die hinter dieser Auffassung hervortretende Anschauung des Katholizismus als besonders persistente, in anderen Ländern überholte Form der „ecclesia militans“.

413 Jarosław Kaczyński, Rede vor dem Sejm vom 14.03.2016, aus der Sammlung in Fn. 409.

414 Kai-Olaf Lang, „Zwischen Rückbesinnung und Erneuerung: Polens PiS und Ungarns Fidesz im Vergleich“, S. 66. 
on, zu kämpfen hat. ${ }^{415}$ Diese Leitlinien der PiS-Politik werden unter dem selbstpropagierten Schlüsselbegriff des „Wandels zum Guten (dobra zmiana) " zusammengefasst. ${ }^{416}$ Während der Legislaturperiode von 2005-2007, in welcher die PiS in einer Koalition regierte und vorgezogene Neuwahlen stattfanden, wurde im Parteiprogramm zusätzlich angestrebt, die derzeitige Verfassungsordnung durch eine „Vierte Republik“ abzulösen. ${ }^{417}$

Es mangelt in der Wissenschaft, wie für Ungarn, nicht an Vorschlägen zur begrifflichen Verortung des durch die PiS begründeten Politikstils. Möllers und Schneider sprechen im Hinblick auf die verfassungspolitische Lage in Polen von einer Auslegung auf eine „sozial konservative Politik der inneren und äußeren Souveränität [...] sowie auf die Kontrolle der Medien und der Justiz." 418 Paulina Starkki und, ihr folgend, Andreas Kulick tauften den Zustand in Polen „Demokratura“.419 Klaus Bachmann nahm Bezug auf einen „zentralistischen Autarkismus“, der den reinen Populismus abgelöst habe. ${ }^{420}$ Wojciech Sadurski sprach von einem "anti-constitutional populist backsliding" und sieht eine erwiesene ideelle Nähe zwischen Kaczyński und Viktor Orbán in Ungarn. ${ }^{421}$ Ich schlage vor, basierend auf

415 Vgl. Joanna Fomina \& Jacek Kucharczyk: „Populism and Protest in Poland“, in: Journal of Democracy 27 (2016), S. 58-68, S. 59. Die Inflationsrate Ungarns betrug 2019 3,34\%, die in Polen 2,31\%, in der Eurozone 1,2\%, Zahlen nach: https://de.statista.com/statistik/daten/studie/227302/umfrage/inflationsrate-in-po len/ sowie https:/de.statista.com/statistik/daten/studie/272220/umfrage/inflation srate-in-ungarn/ und https://de.statista.com/statistik/studie/id/25001/dokument/i nflation-in-eu-und-euro-zone-statista-dossier/.

416 Katarina Bader \& Tomasz Zapart: „Polarisiert, politisiert, vielfältig: Polens Medien 27 Jahre nach dem Systemwechsel“, in: Osteuropa 66 (2016), S. 131-148, S. 131.

417 Łukas Scheffs, „Recht und Gerechtigkeit‘ (PiS) als Protestpartei? Eine kurze politologische Reflexion“, in: Dieter Bingen, Maria Jarosz, Oliver Loew (Hrsg.), Legitimation und Protest: Gesellschaftliche Unruhe in Polen, Ostdeutschland und anderen Transformationsländern nach 1989, Harrassarowitz, Wiesbaden, 2012, S. 70-84, S. 76 insb., s. auch bereits zuvor S. 75 bei Fn. 19 und 20.

418 Christoph Möllers \& Linda Schneider, Demokratiesicherung in der Europäischen Union, S. 69.

419 Paulina Starski „The Power of the Rule of Law: The Polish Constitutional Tribunal's Forceful Reaction“, Verfassungsblog, vom 17.03.2016, o.S., abrufbar unter https://verfassungsblog.de/the-power-of-the-rule-of-law-the-polish-consti tutional-tribunals-forceful-reaction/; Andreas Kulick, „Rechtsstaatlichkeitskrise und gegenseitiges Vertrauen im institutionellen Gefüge der EU“, in: Juristenzeitung 75 (2020), S. 223-231, S. 224.

420 Klaus Bachmann, Der Bruch, S. 135 ff., zur Machtfülle der PiS in diesem Modell S. 326 und $f$.

421 Wojciech Sadurski, Poland's Constitutional Breakdown, S. 1, 3 ff. 
den zuvor von Brian Porter-Szücs übersetzten Textpassagen, ${ }^{422}$ dem hieraus erkenntlichen eigenen Demokratieverständnis der PiS und zur Verknüpfung ihrer politischen Philosophie mit dem Begriff der illiberalen Demokratie Orbáns, ${ }^{423}$ den Begriff der exkludierenden Demokratie zu verwenden. Es handelt sich, wie schon beim Begriff der illiberalen Demokratie, um einen Defekt der Demokratie, der sich dabei am PiS-Parteiprogramm orientiert. Dieses bekennt sich vehement zur Demokratie. ${ }^{424}$ Aber es ist eben eine Demokratie, die nur nach innen, dem polnischen Volk und Staat gegenüber, umfassend inklusiv ist, während alle sonstigen, sowohl von außen als auch von innen als „fremd“ Empfundenen, den Staat nicht betreten, noch in den Genuss seiner Inklusionsleistung gelangen und vor allem nicht seine Entwicklung beeinflussen können sollen. ${ }^{425}$

\section{Die Vereinnahmung des polnischen Verfassungsgerichts}

Die PiS hat das polnische Verfassungsgericht als Garant der heutigen polnischen Verfassung offensichtlich als Hindernis bei der Durchsetzung ihrer politischen Absichten erkannt, denn jegliche Gesetzesänderung hätte vor einem unabhängigen Gericht per abstrakter Normenkontrolle und ggf. Verfassungsbeschwerde kontrolliert werden können. ${ }^{426}$ Entsprechend eingelassen hat sich die PiS dazu selbstredend nie. Gleichwohl müssen die Schwere der Auswirkungen für die polnische Verfassung und das pol-

422 Vgl. Brian Porter-Szűcs, Aufarbeitung von Parteiprogramm und Reden in englischer Sprache unter dem Titel „PiS in their own words“, abrufbar unter: http:// porterszucs.pl/2016/02/05/pis-in-their-own-words/. Zum ähnlich gestalteten Begriff der „exklusiven Demokratie“, der allerdings auf den Ausschluss bestimmter Gruppen im Staatsinneren abzielt, s. Wolfgang Merkel, Hans-Jürgen Puhle, Aurel Croissant, Claudia Eicher \& Peter Thiery, Defekte Demokratie, S. $239 \mathrm{ff}$.

423 Dazu unter IV.2.

424 Parteiprogramm der PiS, 14. Programmpunkt („Democracy Overcomes the Dilemma of Security vs. Liberty“), aus der vorbenannten Sammlung.

425 Wie vor, Parteiprogramm der PiS, insb. 14. Programmpunkt („The Polish State as a Primary Value“), 18. Programmpunkt („Europe Strengthened by Diversity“) und 20. Programmpunkt („It is Worthwhile to Hold our Values“).

426 Zur Rechtslage vor 2015 gibt Auskunft Piotr Tuleja, „\$103 Der polnische Verfassungsgerichtshof", in: Armin von Bogdandy, Christoph Grabenwarter \& Peter M. Huber (Hrsg.), Ius Publicum Europaeum Band VI: Verfassungsgerichtsbarkeit in Europa, C. F. Müller, Heidelberg, 2015, S. 471-518, insb. Rn. 32 ff., $50 \mathrm{ff}$. 


\section{Die Rechtsstaatlichkeitskrise in mitgliedstaatlichen Fällen}

nische Rechtssystem und die dahinter zu Tage tretenden Absichten als erwiesen gelten.

Die Verfassungskrise Polens beginnt ${ }^{427}$ mit einer verfassungsrechtlichen Verfehlung derjenigen Kräfte, denen mutmaßlich eine Gefährdung der Rechtsstaatlichkeit in Polen fern lag, der Bürgerlichen Plattform (PO), gleichzeitig auch politischer Hauptwidersacher der PiS. Angesichts ihrer Wahlniederlage bei den Parlamentswahlen zur achten Legislaturperiode („VIII. Kadenz“) des polnischen Sejm der 3. Republik vom 25. Oktober 2015 benannte die scheidende Regierung der PO kurz vor Ablauf der Legislaturperiode als eine der letzten Amtshandlungen fünf Richter zum polnischen Verfassungsgericht. Davon betrafen drei Ernennungen Nachfolger auf scheidende Richter, deren Amtszeit noch vor Ende der Legislaturperiode zum 12. November endete. Die Nachfolger nahmen ihre Tätigkeit also vor Ablauf der siebten Legislaturperiode auf. Zwei der Richterbesetzungen indes betrafen die Nachfolge auf Stellen, deren Amtszeit erst nach dem Beginn der neuen Legislaturperiode begann. Offensichtlicher Zweck der Ernennungen war das Sichern der politischen Gesinnung der neu ernannten Richter im Sinne der proeuropäisch-liberalen Ausrichtung der PO. Die derart vorgreifende Ernennung wurde durch eine im Juni 2015 erlassene Änderung im Verfassungsgerichtsgesetz möglich.

Gegen die Entscheidung der PO regte sich unmittelbar Protest im Sejm, auch von Unterstützern der Partei selbst. ${ }^{428}$ Mit einem Urteil vom 03.12.2015 hob das Verfassungsgericht die neue Ernennung teilweise auf. Es unterschied zwischen den drei Richtern, die ihr Amt noch vor Ablauf der Legislaturperiode angetreten hatten und denjenigen, die erst nach Beginn der neuen Legislaturperiode ihr Amt antreten durften. Allein erstere, so befand das Gericht, seien verfassungsgemäß ernannt, für die beiden anderen hingegen stand es dem neuen, PiS-dominierten, Sejm zu, Richter

427 Zur präzisen Aufarbeitung der einzelnen Schritte seitens Regierung und Parlament betreffend das Verfassungsgericht vgl. Piotr Tuleja, „The Polish Constitutional Tribunal“, in: Armin von Bogdandy, Peter M. Huber \& Christoph Grabenwarter (Hrsg.), The Max Planck Handbooks of Public Law in Europe: Volume III: Constitutional Adjudication: Institutions, Oxford University Press, Oxford, 2020, S. 619-672, S. 658 ff, der dabei auch von einer „Verfassungskrise“ spricht.

428 Vgl. das Gutachten der Venedig-Kommission, CDL-AD(2016)001, Opinion no. 833/2015, Opinion on amendments to the Act of 25 June 2015 on the Constitutional Tribunal of Poland vom 11.03.2016, Rn. 15 und 17. 
zu ernennen. ${ }^{429}$ Hierbei hätte es die PiS belassen können, allein sie tat dies nicht.

Am 25.11.2015 hob der neue Sejm nämlich nicht nur die Ernennung der zwei rechtswidrig ernannten, sondern aller ernannten Richter auf. Er setzte an die Stelle der fünf des Amtes enthobenen Richter am 02.12.2015 fünf eigene Kandidaten. Diese neuernannten Richter, von welchen Präsident Duda frühmorgens am 03.12.2015 um 01:30 Uhr, und damit wenige Stunden vor dem späteren Urteil des Verfassungsgerichts, den Amtseid abnahm, ${ }^{430}$ werden inzwischen gemeinhin als die "Dezemberrichter" bezeichnet, die anderen, also noch von der PO ernannten, als die „Oktoberrichter".

Überdies verabschiedete der Sejm am 22.12.2015 ein weiteres Gesetz zur Änderung des Verfassungsgerichtsgesetzes, ${ }^{431}$ das diverse Verfahrenseinzelheiten änderte. ${ }^{432}$ Die Änderungen zielen unverkennbar darauf, die Arbeit des Gerichts, insbesondere seine Beschlussfassung und die zeitnahe Entscheidung in Eilsachen empfindlich zu beeinträchtigen. Das polnische Verfassungsgericht reagierte am 09.12.15 und 09.03.16 auf diese Konfrontation in zwei Grundsatzurteilen und hob die Änderungen im Wesentlichen auf. 433

Die polnische Regierung setzte ihre Konfrontation fort, indem der Premierminister eines der beiden Urteile vom März, zum ersten Mal in der Geschichte der Republik Polen, nicht im polnischen Amtsblatt veröffentlichte. ${ }^{434}$ Nach polnischem Recht ist dies erforderlich, damit der Tenor in Rechtskraft erwächst. Die Regierung berief sich hierzu u.a. auf den Umstand, dass nach der von ihr als rechtmäßig erachteten Neubesetzung

429 PolnVerfG, Urteil vom 09.12.2015, Az. K 34/15, vgl. Piotr Tuleja, „The Polish Constitutional Tribunal“, S. 660-661.

430 S. Venedig-Kommission, CDL-AD(2016)001, Opinion no. 833/2015, Opinion on amendments to the Act of 25 June 2015 on the Constitutional Tribunal of Poland vom 11.03.2016, Rn. 25, weiter Piotr Tuleja, „The Polish Constitutional Tribunal“, S. 660 und ff.

431 Gesetz vom 22. Dezember 2015 zur Änderung des Gesetzes vom 25. Juni 2015 über den Verfassungsgerichtshof, Poln. GBl. (Dz. Ustaw) vom 28.12.2015, Nr. 2217.

432 Ausführlich zu den Details Venedig-Kommission, CDL-AD(2016)001, Opinion no. 833/2015, Opinion on amendments to the Act of 25 June 2015 on the Constitutional Tribunal of Poland vom 11.03.2016, S. 9-16, Rn. 49-66.

433 PolnVerfG, Urteil vom 09.12.2015, Az. K 35/15, Poln. GBl. (Dz. Ustaw) vom 18.12.2015, Nr. 2147, Urteil vom 09.03.2016, Az. K 47/15; weiter Piotr Tuleja, „The Polish Constitutional Tribunal“, S. 662-663.

434 Piotr Tuleja, „The Polish Constitutional Tribunal“, S. 663. 


\section{Die Rechtsstaatlichkeitskrise in mitgliedstaatlichen Fällen}

des Gerichts und der neuen, gerade überprüften Rechtslage, 15 Richter im Plenum hätten entscheiden müssen, das Gericht selbst, welches 3 Richter als verfassungswidrig ernannt ansah, aber mit 12 Richtern entschied. ${ }^{435}$ Einzelne PiS-Politiker verstiegen sich in der Folge zu der Aussage, beim sog. Märzurteil handele es sich um die private Meinungsäußerung eines „Kaffeekränzchens“. 436

Nach regem Schriftwechsel zwischen der Europäischen Kommission, dort dem damaligen Ersten Vizepräsident Frans Timmermans und Polen, ${ }^{437}$ teils auch unter Beteiligung anderer Mitgliedstaaten, leitete die Kommission dann am 13.01.2016 ein Verfahren nach dem 2014 geschaffenen EURahmen ein, als sie per „Fact Sheet“ bekanntgab, das Kommissionskollegium habe eine „Orientierungsaussprache des Kollegiums über die jüngsten Entwicklungen in Polen und den Rahmen zur Stärkung des Rechtsstaatsprinzips“438 abgehalten, womit die erste Phase des Verfahrens eingeleitet war.

Die polnische Regierung und der sie stützende Sejm ließen sich von den Einwänden der Kommission weder beeindrucken noch umstimmen. Auch eine Intervention des französischen Präsidenten Emmanuel Macron

435 Im Einzelnen vgl. Piotr Tuleja, „The Polish Constitutional Tribunal“, S. 663-664.

436 Vgl. Gabrielle Lesser, „Verfassungsrichter werden erpresst“, Die Tageszeitung vom 28.10.2016.

437 Brief von Frans Timmermans vom 23. Dezember 2015 an Witold Waszczykowski, Minister für Auswärtige Angelegenheiten der Republik Polen und Zbigniew Ziobro, Justizminister der Republik Polen, Ares(2015) 6664696; Presseerklärung des polnischen Außenministeriums vom 24.12.2015, "Today, the Ministry of Foreign Affairs has replied to a letter by Vice-President of the European Commission Frans Timmermans.”; Brief von Frans Timmermans vom 30. Dezember 2015 an Witold Waszczykowski, Minister für Auswärtige Angelegenheiten der Republik Polen und Zbigniew Ziobro, Justizminister der Republik Polen, bekanntgemacht ohne Az.; Brief von Unterstaatssekretär Alexander Stẹpkowski vom 07.01.2016 an Frans Timmermans, ohne Az.; Brief von Zbigniew Ziobro an Frans Timmermans vom 11.01.2016, BM-I-0830-2/16; Der Brief wurde einen Tag später von Ziobro selbst auf Twitter veröffentlicht; Replik hierzu von Frans Timmermans vom 13.01.2016, BM-I-0830-2/16, Brief von Guido Westerwelle, Frans Timmermans, Villy Søvndal und Erkki Tuomioja vom 06.03.2013 an Kommissionspräsident José Manuel Barroso, ohne Az.

438 Europäische Kommission, „Orientierungsaussprache des Kollegiums über die jüngsten Entwicklungen in Polen und den Rahmen zur Stärkung des Rechtsstaatsprinzips: Fragen und Antworten“, MEMO/16/62, Factsheet vom 13.01.2016. S. weiter auch nochmals ausführlich infra, E. V. 2. 
bei der polnischen Regierung blieb ohne Erfolg. ${ }^{439}$ Polen ließ durch seinen Europaminister Konrad Szymański mitteilen, man akzeptiere kein „Diktat der Interpretation" der Unionswerte von außerhalb. 440

Am 22.07.2016 verabschiedete der Sejm ein drittes Änderungsgesetz zum Verfassungsgerichtsgesetz. ${ }^{441}$ Die Kommission rügte diesbezüglich insbesondere die kurze Legisvakanz von 14 Tagen und seine Auswirkung auf offene Entscheidungen. ${ }^{442} \mathrm{Zu}$ diesem dritten Änderungsgesetz ergingen im August und November zwei weitere Urteile des polnischen Verfassungsgerichts. Die polnische Regierung setzte sich über die Rechtsauffassung des Gerichts erneut hinweg. Präsident Duda berief am 19.12.2016 die vom 8. Sejm rechtmäßig gewählte Richterin Julia Przytębska zur kommissarischen Gerichtspräsidentin. Obwohl als Richterin rechtmäßig im Amt, gilt im Schrifttum als gesichert, ${ }^{443}$ dass ihre Ernennung auch zur kommissarischen Präsidentin des Verfassungsgerichts gegen die Verfassung verstieß. Przyłębska berief unmittelbar die im Dezember 2015 rechtswidrig ernannten drei Richter zum Dienst - zuvor hatten sie ihr Amt nicht ausgeübt - und ließ sich am 20.12.2016 kurzfristig in einer fehlerhaft besetzten Plenarentscheidung zur ordentlichen Gerichtspräsidentin wählen bzw. durch das Plenum im Amt bestätigen. Ebenso rechtswidrig ins Amt des Vizepräsidenten berufen wurde Mariusz Muszyński. ${ }^{444} \mathrm{Er}$ ist heute Vizepräsident des Verfassungsgerichts und zwischenzeitlich auch Ersatzmitglied der

439 Dietmar Nickel, „Integrationspolitische Herausforderungen an den Europäischen Rechtsstaat: „Zur Zukunft der europäischen Rechts- und Wertegemeinschaft"“, in: Europarecht 52 (2017), S. 663-680, S. 671.

440 Dietmar Nickel, „Integrationspolitische Herausforderungen an den Europäischen Rechtsstaat: „Zur Zukunft der europäischen Rechts- und Wertegemeinschaft“", S. 671.

441 Verfügbar seitens der Venedig-Kommission, CDL-REF(2016)052-e, Opinion No. 860 / 2016, Poland - The Constitutional Tribunal Act of 22 July 2016, published in the Journal of Laws of the Republic of Poland [Dz. Ustaw] on 1 August 2016, item 1157.

442 Europäische Kommission, Europäische Kommission, Empfehlung der Kommission vom 27.07.2016 zur Rechtsstaatlichkeit in Polen, C(2016) 5703 final, (EU) 2016/1374, ABl. (EU) L 217/53 vom 12.08.2016 (erste Empfehlung zur Rechtsstaatlichkeit), Rn. 58-64.

443 S. u.a. Wojciech Sadurski, Poland's Constitutional Breakdown, S. 221; ausführlich zur nationalen Rechtslage Tomasz Tadeusz Koncewicz, „Of institutions, democracy, constitutional self-defence and the rule of law: The judgments of the Polish Constitutional Tribunal in Cases K 34/15, K 35/15 and beyond", in: Common Market Law Review 53 (2016), S. 1753-1792, insb. S. 1766-1767.

444 Wojciech Sadurski, Poland's Constitutional Breakdown, S. 82, spricht von einem „improperly elected ,quasi-judge ${ }^{\text {““. }}$ 


\section{Die Rechtsstaatlichkeitskrise in mitgliedstaatlichen Fällen}

Venedig-Kommission auf Vorschlag der polnischen Regierung. Muszyński zögerte nicht, seine rechtspolitischen Ansichten deutlich herauszustellen. In einem Gastbeitrag für die führende polnische Tageszeitung Rzeczpospolita deutete er an, dass sich das polnische Verfassungsgericht zukünftig Urteilen des EuGH widersetzen könnte; der Beitrag fand über Polen hinaus Beachtung. 445

Damit war der Umbau der polnischen Verfassungsgerichtsbarkeit abgeschlossen. Es war nun überwiegend mit regierungstreuen Richtern besetzt und verfahrensrechtlich seiner Kontrollfunktion weitestgehend beraubt. Für die PiS war der Weg für weitere Änderungen frei.

4. Die Neutralisierung des Obersten Gerichtshofs und der ordentlichen Gerichtsbarkeit

a. Derzeitige Rechtslage

Den Änderungen des Rechtsrahmens und der Zusammensetzung des polnischen Verfassungsgerichts folgten 2016 und 2017 seitens des Sejm vier Gesetze nach, die nun auf die ordentliche Gerichtsbarkeit und auf den dieser als Letztinstanz vorstehenden Obersten Gerichtshof abzielten. Die Änderungen begannen mit einem Gesetz über die Staatsanwaltschaft, das bereits Ende 2016 erlassen, 2017 aber mehrfach abgeändert wurde, ${ }^{446}$ und das Amt des Generalstaatsanwalts mit dem Amt des Justizministers verschmolz. 447

445 „Polski Trybunał w unijnej rzeczywistości - Mariusz Muszyński o mocy wyroków TSUE w Polsce“, Rzeczpospolita vom 22.03.2018; vgl. auch Armin von Bogdandy, Piotr Bogdanowicz, Iris Canor, Maciej Taborowski \& Matthias Schmidt, „Guest Editorial: A potential constitutional moment for the European rule of law - The importance of red lines“, S. 989.

446 Verfügbar auf Englisch seitens der Venedig-Kommission, CDL-REF(2017)048e, Opinion No. 892/2017, Poland - Act on Public Prosecutor's OfficeCDL(2017)037-e vom 29.09.2017.

447 Analyse bei Venedig-Kommission, CDL-AD(2017)028, Opinion 892/2017, Poland - Opinion on the Act on the Public Prosecutor's Office, as amended, vom 11.12.2017, Rn. 20, vorgehende "Draft Opinion" als CDL(2017)037 vom 24.11.2017; weiter CDL-AD(2017)031, Opinion no. 904/2017, Poland - Opinion on the Draft Act amending the Act on the National Council of the Judiciary; on the Draft Act amending the Act on the Supreme Court, proposed by the President of Poland, and on the Act on the Organisation of Ordinary Courts vom 11.12.2017, Rn. 14-15. 
Dem folgten im Jahresverlauf 2017 drei weitere Gesetze nach. Zunächst zu nennen ${ }^{448}$ ist ein Änderungsgesetz zum „Gesetz über die ordentlichen Gerichte“ (Gerichtsverfassungsgesetz). ${ }^{449}$ Hierauf ergingen seitens des Staatspräsidenten Duda Vorschläge zu Änderungen des Gesetzes über den Obersten Gerichtshof, ${ }^{450}$ nachdem Duda vorherige Änderungen per Veto blockiert hatte, worauf das Gesetz dann zum 15.12.2017 verabschiedet wurde. ${ }^{451}$ Weiter erging schließlich ein ebenso zunächst per Veto blockiertes Gesetz über den Landesjustizrat. ${ }^{452}$

Zum Gesetz über den Landesjustizrat und den Obersten Gerichtshof reichte die polnische Regierung „Memoranden“ ein, ${ }^{453}$ die Venedig-Kommission verband die drei im Jahresverlauf 2017 ergangenen Gesetze über die Ordentliche Gerichtsbarkeit, den Obersten Gerichtshof und den Landesjustizrat in einem gemeinsamen Gutachten, ${ }^{454}$ und seitens der Europä-

448 Hier in der Reihenfolge des Eingangs zur Prüfung bei der Venedig-Kommission. Zur gesamten Liste vgl. https://www.venice.coe.int/webforms/documents/?c ountry=23\&year=all.

449 Verfügbar auf Englisch seitens der Venedig-Kommission, CDL-REF(2017)046-e, Opinion no. 904/2017, Poland - Act on the Organisation of the Ordinary Courts vom 20.12.2017.

450 Übersetzung durch die Venedig-Kommission, CDL-REF(2017)052-e, Opinion no. 904/2017, Poland - Presidential Draft Act on amending the Act on the Supreme Court vom 20.12.2017.

451 Vgl. Europäische Kommission, Begründeter Vorschlag nach Artikel 7 Absatz 1 des Vertrags über die Europäische Union zur Rechtsstaatlichkeit in Polen für einen Beschluss des Rates zur Feststellung der eindeutigen Gefahr einer schwerwiegenden Verletzung der Rechtsstaatlichkeit durch die Republik Polen, $\operatorname{COM}(2017) 835$ final, 2017/0360 (NLE), vom 20.12.2017, Rn. 5, lit. (a) und (d). Zum ursprünglichen Veto s. Michał Broniatowski, „Polish President Andrzej Duda to veto controversial court laws", Politico vom 24.07.2017.

452 Übersetzung durch die Venedig-Kommission, CDL-REF(2017)053-e, Opinion no. 904/2017, Poland - Presidential Draft Act on amending the Act on the National Council of the Judiciary, veröffentlicht am 20.12.2017.

453 Venedig-Kommission, CDL-REF(2017)052add, Opinion no. 904/2017, Explanatory Memorandum to the Presidential Draft Act Amending the Act on the National Council of the Judiciary vom 23.11.2017 sowie CDL-REF(2017)052add, Opinion no. 904/2017, Explanatory Memorandum to the Presidential Draft Act Amending the Act on the Supreme Court, vom 23.11.2017. Die Venedig-Kommission merkt an, die englische Übersetzung sei von den polnischen Stellen kontrolliert worden.

454 Venedig-Kommission, CDL-AD(2017)031, Opinion no. 904/2017, Poland Opinion on the Draft Act amending the Act on the National Council of the Judiciary; on the Draft Act amending the Act on the Supreme Court, proposed by the President of Poland, and on the Act on the Organisation of Ordinary Courts vom 11.12.2017. 


\section{Die Rechtsstaatlichkeitskrise in mitgliedstaatlichen Fällen}

ischen Kommission fanden sie umfassend teils schon in der sog. dritten Empfehlung zur Rechtsstaatlichkeit der Kommission vom Juli 2017 und schließlich im begründeten Vorschlag zu Art. 7 EUV Berücksichtigung. ${ }^{455}$

Nachdem die Europäische Kommission noch im September 2017 im Rat für Allgemeine Angelegenheiten einen letzten Versuch unternommen hatte, die Vorgänge, inklusive derer betreffend das polnische Verfassungsgericht, ad hoc beizulegen, ${ }^{456}$ sah sie schließlich keinen anderen Ausweg als die Nutzung des Verfahrens nach Art. 7 EUV. Parallel zum Verfahren nach Art. 7 EUV hat der Europäische Gerichtshof in weiten Teilen zu den Vorgängen Stellung bezogen, bzw. es sind damit bei ihm in Zusammenhang mit diesen Umbrüchen stehende Fragen weiter anhängig.

Der polnische Sejm hat die Gesetze infolge dieser Rechtsprechung am 20. Dezember 2019 erneut abgeändert, sodass diese Fassung, die in der Praxis weiterer Prüfung bedürfen wird, der derzeit und für diese Arbeit der letzte Stand ist. ${ }^{457}$

Die Europäische Kommission hat sich, ungeachtet ihrer Darstellung unter dem Titel „Gefährdung der Unabhängigkeit der ordentlichen Gerichtsbarkeit", in ihrer Analyse im Rahmen des begründeten Vorschlags nach Art. 7 Abs. 1 EUV im Jahr 2017 dafür entschieden, die Vorgänge chro-

455 Europäische Kommission, Empfehlung (EU) 2017/1520 der Kommission vom 26. Juli 2017 zur Rechtsstaatlichkeit in Polen in Ergänzung der Empfehlungen (EU) 2016/1374 und (EU) 2017/146, C(2017) 5320 final, ABl. (EU) L 228/19 vom 02.09.2017, Rn. 12 ff.; Europäische Kommission, Begründeter Vorschlag nach Artikel 7 Absatz 1 des Vertrags über die Europäische Union zur Rechtsstaatlichkeit in Polen für einen Beschluss des Rates zur Feststellung der eindeutigen Gefahr einer schwerwiegenden Verletzung der Rechtsstaatlichkeit durch die Republik Polen, COM(2017) 835 final, 2017/0360 (NLE), vom 20.12.2017, Rn. 114 ff. insb.

456 Vgl. Dietmar Nickel, „Integrationspolitische Herausforderungen an den Europäischen Rechtsstaat: „Zur Zukunft der europäischen Rechts- und Wertegemeinschaft“"“, S. 674.

457 Vgl. Venedig-Kommission, 1. CDL-REF(2020)005, Opinion no. 977/2017, Poland - Supreme Court Act of 8 December 2017 with Amendments of 20 December 2019 vom 14.01.2020; 2. CDL-REF(2020)004, Poland - Act on Law Common Courts Organisation [gemeint ist das zuvor als "Act on the Organisation of Ordinary Courts" bezeichnete und unter der Nr. CDL-REF(2017)046-e bereits in vorheriger Fassung übersetzte Gesetz] of 27 July 2001 with Amendments of 20 December 2019 vom 14.01.2020; 3. CDL-REF(2020)003, Opinion no. 977/2020, Poland - Act on the National Council of the Judiciary of 12 May 2011 with Amendments of 20 December 2019 vom 14.01.2020; vgl. vorgehend die Übersetzung der früheren Entwurfsfassung unter der Nr. CDLREF(2017)052add .Es ist nicht auszuschließen, dass diese später weiter aktualisiert oder ersetzt werden. 
nologisch und getrennt nach den Regelungsmaterien der verschiedenen Gesetze aufzuschlüsseln. ${ }^{458}$ Dem stelle ich hier zugunsten einer besseren Übersichtlichkeit - während die Kommission die Vollständigkeit in den Blick nehmen musste - eine Einteilung in Problemkomplexe gegenüber, die jeweils gleichgelagerte Regelungsmaterien in den verschiedenen Gesetzen übergreifend behandelt.

\section{b. Landesjustizrat}

Den Änderungen am Landesjustizrat ${ }^{459}$ (Krajowa Rada Sądownictwa, KRS) ist voranzustellen, dass Polen, ähnlich anderen osteuropäischen Ländern, aber auch z.B. mit Parallelen zu den Niederlanden oder Frankreich, mit dem Justizrat und der Richterschule zwei Staatsorgane kennt, die in Mitteleuropa unbekannt sind, Entsprechung aber in einigen romanischen Ländern finden. Der Justizrat mit Sitz in Warschau ist als Verfassungsorgan zentral für die Ernennung und Auswahl von Richtern zuständig, die

458 Vgl. Europäische Kommission, Begründeter Vorschlag nach Artikel 7 Absatz 1 des Vertrags über die Europäische Union zur Rechtsstaatlichkeit in Polen für einen Beschluss des Rates zur Feststellung der eindeutigen Gefahr einer schwerwiegenden Verletzung der Rechtsstaatlichkeit durch die Republik Polen, $\operatorname{COM}(2017) 835$ final, 2017/0360 (NLE), vom 20.12.2017, Rn. 114 ff., geteilt nach „Gesetz über das Oberste Gericht“, Rn. 115-136 (mit teils thematischer Abschichtung), „Gesetz über den Landesrat für Gerichtswesen [scil.: Landesrichterrat]“, Rn. 137-145, nach „Gesetz über die ordentlichen Gerichte“, Rn. 146-163 (mit teils thematischer Abschichtung), und „weitere Rechtsvorschriften“, Rn. 164-170.

459 Die Bezeichnung folgt hier der in den Dokumenten des Gerichtshofs überwiegenden Übersetzung. Alternativ findet sich im Deutschen auch die Übersetzung als „Landesrichterrat", vgl. EuGH, Verb. Rs. C-585/18 u.a., A.K. ./. Krajowa Rada Sądownictwa, CP, DO ./. Sąd Najwyższy, Schlussanträge des Generalanwalts Evgeni Tanchev vom 27.10.2019, Rn. 32. Im Französischen lautet die Übersetzung, soweit ersichtlich, einheitlich „Conseil/conseil national de la magistrature“, im Englischen ist die Bezeichnung „National Council of the Judicary (statt vieler vgl. Rs. C-192/18, etwa Rn. 41 und 43 d. Urt.), abweichend auch „National Council for the Judiciary“ (Klage zur Rs. C-791/19, ABl. (EU) C 413/36 vom 09.12.2019) anzutreffen, was als „Nationaler Justizrat“ zu übersetzen wäre. Sofern sich letztere Bezeichnung im Text findet, ist das hier genannte Organ gemeint. 


\section{Die Rechtsstaatlichkeitskrise in mitgliedstaatlichen Fällen}

zuvor die sog. Nationale Richterschule (ähnlich dem in Frankreich anzutreffenden Modell) durchlaufen haben. ${ }^{460}$

Die neue Rechtslage ändert insbesondere die Zusammensetzung des Justizrates und baut die Möglichkeit von Regierung und Parlament aus, durch Bestellung seiner Mitglieder mittelbar auf die Auswahl späterer Richter Einfluss zu nehmen.

Sowohl die Venedig-Kommission ${ }^{461}$ als auch später, zu Teilfragen, der $\mathrm{EuGH}^{462}$ haben zu den Änderungen Stellung bezogen. Die Venedig-Kommission bemängelte in ihrem Gutachten insbesondere, dass die rechtlichen Änderungen die bislang durch die polnische Justiz autonom bestellten Mitglieder einem Vorschlag durch die Öffentlichkeit oder Parlamentarier und Wahl durch den Sejm selbst unterwarfen, womit eine vollständige Politisierung und Einflussnahme durch die Regierung auf die Zusammenstellung des Landesjustizrates möglich wurde. Dieser Vorgang wurde noch verstärkt durch eine Verkürzung von Mandatszeiten und „Zusammenlegung" von Mandaten, womit Regierung und Sejm unmittelbar die Ernennung aller 15 zuvor durch die Gerichtsbarkeit ernannten Mitglieder des Rates zugefallen wäre. ${ }^{463}$ Die Kommission merkte hierzu vor dem Europäischen Gerichtshof an, die Änderungen führten dazu, „dass ihre Unabhängigkeit angezweifelt werden könne“. ${ }^{464}$

460 Darstellung der Diskussion um die Vorzüge und Nachteile von Justizräten mit rechtsvergleichenden Überlegungen bei Mareike Jeschke, „Justizielle Autonomie in Europa“, in: Peter-Alexis Albrecht (Hrsg.), Autonomie für eine Dritte Gewalt in Europa: Transferaufgabe für aufgeklärte Gesellschaften der Vernunft, Berliner Wissenschaftsverlag, Berlin, 2016, S. 495-818, S. 515 ff.; s. aber auch die übrigen Beiträge in diesem Band zur gesamten Breite der Diskussion.

461 Venedig-Kommission, CDL-AD(2017)031, Opinion no. 904/2017, Poland Opinion on the Draft Act amending the Act on the National Council of the Judiciary; on the Draft Act amending the Act on the Supreme Court, proposed by the President of Poland, and on the Act on the Organisation of Ordinary Courts vom 11.12.2017, Rn. 15 ff. EuGH, Rs. Verb. Rs. C-585/18, C-624/18 und C-625/18, A. K. ./. Krajowa Rada Sądownictwa u.a., Urteil (GK) vom 19.11.2018, ECLI:EU:C:2019:982, insb. Rn. $73 \mathrm{ff}$.

462 S. insb. EuGH, EuGH, Rs. C-619/18 R, Kommission ./. Polen, „Unabhängigkeit des Obersten Gerichts“, Urteil (GK) vom 24.06.2019, ECLI:EU:C:2019:531.

463 Venedig-Kommission, CDL-AD(2017)031, Poland, Opinion no. 904/2017, Opinion on the Draft Act amending the Act on the National Council of the Judiciary; on the Draft Act amending the Act on the Supreme Court, proposed by the President of Poland, and on the Act on the Organisation of Ordinary Courts, vom 11.12.2017, Rn. 19-31.

464 EuGH, Rs. C-619/18 R, Kommission ./. Polen, „Unabhängigkeit des Obersten Gerichts“, Urteil (GK) vom 24.06.2019, ECLI:EU:C:2019:531, Rn. 100. 


\section{c. Entlassung, Berufung und Disziplinierung der Gerichtsbarkeit}

Im Hinblick auf den Obersten Gerichtshof und die ordentlichen Gerichte bietet es sich an, nach den Problemkomplexen Entlassung bereits ernannter, Berufung neuer und Disziplinierung verbleibender Richter zu unterscheiden, und zwar übergreifend für die verschiedenen Gerichte, obwohl Rechtsgrundlage und Regelungen zwischen Oberstem Gerichtshof und der ordentlichen Gerichtsbarkeit variieren.

$\mathrm{Zu}$ beginnen ist mit der Frage der Entlassung, die stark an ein Gesetzesvorhaben Ungarns erinnert, welches ebenso Gegenstand einer Entscheidung des EuGH wurde. 465

Für den polnischen Obersten Gerichtshof wurde das Pensionierungsalter für Richter durch ein Gesetz mit dessen Inkrafttreten zum 3. April 2018 generell von 70 auf 65 Jahre herabgesetzt. ${ }^{466}$ Für die ordentliche Gerichtsbarkeit war die Herabsetzung ebenso auf 65 Jahre vorgesehen, das dortige vorherige Pensionsalter betrug im Grundsatz 67 Jahre, bei Verlängerung auf Antrag maximal 70 Jahre. ${ }^{467}$ Nachträglich wurde mit Wirkung zum 1. Oktober 2017, erneut geändert mit Wirkung zum 23. Mai 2018,468 eine Unterscheidung von Männern und Frauen eingeführt, wobei für Frauen das Pensionsalter nun schon 60 Jahre betrug. ${ }^{469}$ Diese Änderungen galt auch für die Staatsanwaltschaft. ${ }^{470}$ Die sich daraus ergebenden Auswirkungen auf die Ruhegehälter der Betroffenen, insbesondere aufgrund der Berücksichtigung der jeweils letzten aktiven Gehälter für deren Berech-

465 EuGH, Rs. C-286/12, Kommission ./. Ungarn, „Ungarische Richterpensionierung“, Urteil vom 06.11.2012, ECLI:EU:C:2012:687, dazu Näheres im nachfolgenden Abschnitt zu Ungarn.

466 EuGH, Rs. C-619/18 R, Kommission ./. Polen, „Unabhängigkeit des Obersten Gerichts“, Urteil (GK) vom 24.06.2019, ECLI:EU:C:2019:531, Rn. 10-11.

467 Vgl. EuGH, Rs. C-192/18, Kommission ./. Polen, „Unabhängigkeit der ordentlichen Gerichtsbarkeit“. Urteil (GK) vom 05.11.2019, ECLI:EU:C:2019:924, Rn. 15-17.

$468 \mathrm{Zu}$ den daraus sich ergebenden Fragen EuGH, Rs. C-619/18 R, Kommission ./. Polen, „Unabhängigkeit des Obersten Gerichts“, Urteil (GK) vom 24.06.2019, ECLI:EU:C:2019:531, Rn. 41 ff. Der Gerichtshof hat es abgelehnt, deswegen auf eine Erledigung zu erkennen.

469 EuGH, Rs. C-192/18, Kommission ./. Polen, „Unabhängigkeit der ordentlichen Gerichtsbarkeit“. Urteil (GK) vom 05.11.2019, ECLI:EU:C:2019:924, Rn. 15-18.

470 EuGH, Rs. C-192/18, Kommission ./. Polen, „Unabhängigkeit der ordentlichen Gerichtsbarkeit“. Urteil (GK) vom 05.11.2019, ECLI:EU:C:2019:924, Rn. 25. 


\section{Die Rechtsstaatlichkeitskrise in mitgliedstaatlichen Fällen}

nung, waren ebenso Gegenstand des streitigen Verfahrens, wurden vom Gerichtshof auch beanstandet, ${ }^{471}$ sollen hier aber zurückstehen.

Für beide Gerichte wurde durch die Änderungsgesetze die Möglichkeit für die Exekutive geschaffen, die Mandate der durch die Pensionierung betroffenen Richter zu verlängern. Für den Obersten Gerichtshof fällt dieses Recht dem Staatspräsidenten, für die ordentlichen Gerichte dem Justizminister zu. ${ }^{472}$ Die Verfahren zur Mandatsverlängerung über die Pensionsgrenze hinaus stehen weitestgehend im freien Ermessen von Präsident bzw. Minister und sehen keinen Rechtsschutz vor. ${ }^{473}$ Für den Obersten Gerichtshof insbesondere hatten die Betroffenen nach dem o.g. Gesetz vom 3. April 2018 für einen maximal 3 Jahre dauernden Zeitraum, der einmal verlängert werden konnte, den Staatspräsidenten um dessen Zustimmung zu bitten. ${ }^{474}$ Die Betroffenenzahlen variierten dabei. Hatte der Oberste Gerichtshof selbst die Anzahl auf 31 (37\%) der insgesamt 83 Richter beziffert und die Europäische Kommission diese Zahl zunächst übernommen, ${ }^{475}$ spricht sie in späteren Erklärungen von immerhin noch 27 Richtern. ${ }^{476}$ Betroffen durch die Pensionierung am Obersten Gerichtshof war insbesondere auch dessen Erste Präsidentin (Gerichtspräsidentin),

471 S. dazu EuGH, Rs. C-192/18, Kommission ./. Polen, „Unabhängigkeit der ordentlichen Gerichtsbarkeit“. Urteil (GK) vom 05.11.2019, ECLI:EU:C:2019:924, Rn. 58 ff. 78; Im Verfahren betreffend den obersten Gerichtshof waren Pensionsfragen nur sekundär von Interesse, vgl. EuGH, Rs. C-619/18 R, Kommission .. Polen, „Unabhängigkeit des Obersten Gerichts“, Urteil (GK) vom 24.06.2019, ECLI:EU:C:2019:531, Rn. 106.

472 Europäische Kommission, Begründeter Vorschlag nach Artikel 7 Absatz 1 des Vertrags über die Europäische Union zur Rechtsstaatlichkeit in Polen für einen Beschluss des Rates zur Feststellung der eindeutigen Gefahr einer schwerwiegenden Verletzung der Rechtsstaatlichkeit durch die Republik Polen, $\operatorname{COM}(2017) 835$ final, 2017/0360 (NLE) vom 20.12.2017, Rn. 124, 147.

473 Europäische Kommission, European Commission statement on the judgment of the European Court of Justice on Poland's Supreme Court law, vom 24.06.2019, STATEMENT/19/3376, S. 1.

474 Europäische Kommission, European Commission statement on the judgment of the European Court of Justice on Poland's Supreme Court law, vom 24.06.2019, STATEMENT/19/3376, S. 1.

475 Europäische Kommission, Begründeter Vorschlag nach Artikel 7 Absatz 1 des Vertrags über die Europäische Union zur Rechtsstaatlichkeit in Polen für einen Beschluss des Rates zur Feststellung der eindeutigen Gefahr einer schwerwiegenden Verletzung der Rechtsstaatlichkeit durch die Republik Polen, $\operatorname{COM}(2017) 835$ final, 2017/0360 (NLE) vom 20.12.2017, Rn. 116.

476 Europäische Kommission, European Commission statement on the judgment of the European Court of Justice on Poland's Supreme Court law, vom 24.06.2019, STATEMENT/19/3376, S. 1. 
Matgorzata Gersdorf, der sie sich, bis zu ihrem ordentlichen Ausscheiden aus dem Amt Ende April 2020, erfolgreich widersetzte. ${ }^{477}$ Für die ordentlichen Gerichte sind genaue Zahlen nicht bekannt, sie müssen aber naturgemäß weitaus höher liegen.

Die Europäische Kommission schreibt daher in Bezug auf den Obersten Gerichtshof, die betroffenen Richter seien „ganz dem Gutdünken des Präsidenten der Republik ausgeliefert. “478 Die Möglichkeit der nach freiem Ermessen erfolgenden Aufhebung der zuvor gesetzlich verordneten Pensionierung soll offensichtlich dazu dienen, politisch genehme Richter im Amt zu belassen oder den Anreiz zu schaffen, sich durch Ausdruck entsprechender Gesinnung den entscheidenden Stellen anzudienen. In der Praxis lag die Erfolgsquote der Anträge bei lediglich ca. $53 \%{ }^{479}$

Sowohl am Obersten Gerichtshof als auch an den ordentlichen Gerichten wird zudem für den Justizminister die Möglichkeit geschaffen, die Gerichtspräsidenten gesondert abzuberufen, nämlich im Falle eines „ernsthaften oder anhaltenden Versagens [des Gerichtspräsidenten] bei der Ausführung seiner Amtspflichten“, im Falle „anderer Gründe, [die] das Verbleiben im Amt mit der ordentlichen Ausführung richterlicher Tätigkeit unvereinbar machen" sowie bei „außerordentlich ineffizienter" Amtsausführung. Die Venedig-Kommission befand diese Vorgaben für „recht vage“ und ohne Ermessenseingrenzung gegenüber dem Minister. ${ }^{480}$

477 Vgl. den unverändert aufrechterhaltenen biographischen Eintrag auf der Webseite des polnischen Obersten Gerichtshofs, abrufbar unter: http://www.sn.pl/os adzienajwyzszym/SitePages/Organizacja.aspx?ListName=Org_PPSN\&ItemSID= 1-f3401771-a994-4154-aacb-2602671d3fb5.

478 Europäische Kommission, Begründeter Vorschlag nach Artikel 7 Absatz 1 des Vertrags über die Europäische Union zur Rechtsstaatlichkeit in Polen für einen Beschluss des Rates zur Feststellung der eindeutigen Gefahr einer schwerwiegenden Verletzung der Rechtsstaatlichkeit durch die Republik Polen, $\operatorname{COM}(2017) 835$ final, 2017/0360 (NLE) vom 20.12.2017, Rn. 124, in der englischen Fassung heißt es noch treffender ",at the mercy' of the decision of the President $[\ldots]^{\text {“. }}$.

479 Nach Małgorzata Szuleka, „New retirement rules for Polish judges contravene EU law - according to Advocate General“ vom 20.06.2019, abrufbar unter https://ruleoflaw.pl/new-retirement-rules-for-polish-judges-contravene-eu-la w-according-to-advocate-general/. Demnach gingen bis Juni 2019130 Anträge beim Justizminister ein, von denen 69 bewilligt, 61 abgelehnt wurden.

480 Venedig-Kommission, Opinion No. 904/2017, Poland - Opinion on the Draft Act amending the Act on the National Council of the Judiciary; on the Draft Act amending the Act on the Supreme Court, proposed by the President of Poland, and on the Act on the Organisation of Ordinary Courts vom 11.12.2017, Rn. 105. Meine Übersetzung nach der dortigen englischen 


\section{Die Rechtsstaatlichkeitskrise in mitgliedstaatlichen Fällen}

Ebenso rügte die Venedig-Kommission die potentiellen Auswirkungen im Gerichtsalltag, etwa im Rahmen des Deputatzuschnitts für Richter. ${ }^{481}$ Für die ordentliche Gerichtsbarkeit wurde von den Entlassungen in dramatischem Ausmaß Gebrauch gemacht. Zwischen August 2017 und Februar 2018 allein wurden 140 Präsidenten und Vizepräsidenten diverser Instanzgerichte nach Gutdünken der vollziehenden Gewalt abberufen. ${ }^{482}$

Die Gesetzesvorhaben machten aber bei der Entlassung von Richtern nicht halt, sondern betrafen auch die Ernennung neuer Richter. Der polnische Präsident ging im Oktober 2018 dazu über, ungeachtet der laufenden Verfahren vor dem Europäischen Gerichtshof und betreffend Art. 7 EUV auf die 27 vakanten Stellen am polnischen Obersten Gerichtshof Nachfolger zu berufen. ${ }^{483}$ Durch zusätzliche Ausschreibungen im März 2018 war die Gesamtzahl der offenen Stellen im Sommer 2018 auf insgesamt 44 gestiegen, dies schloss auch völlig neu geschaffene Stellen ein. ${ }^{484}$

Aufgrund der Entschlossenheit der Europäischen Kommission, diese Vorgänge vor dem Gerichtshof für rechtswidrig befunden zu sehen, ruderte der Sejm mit einem Gesetz, das zum 1. Januar 2019 in Kraft trat, durch Aussetzung der Pensionierungsmaßnahmen zurück und trug anschließend vor dem Gerichtshof vor, der Streitgegenstand habe sich erledigt. Kommission und Gerichtshof schlossen sich dem nicht an und befanden, die wirkliche Vereinbarkeit der Maßnahmen bedürfe gleichwohl der Klärung. ${ }^{485}$

Übersetzung aus dem Original. Wohl mit Rücksicht auf Entlassungsgründe in anderen Rechtsordnungen beließ es die Venedig-Kommission bei dem abgemilderten Befund „recht vage“, dazu weiter, auch rechtsvergleichend, Rn. $100 \mathrm{ff}$.

481 Venedig-Kommission, Opinion No. 904/2017, Poland - Opinion on the Draft Act amending the Act on the National Council of the Judiciary; on the Draft Act amending the Act on the Supreme Court, proposed by the President of Poland, and on the Act on the Organisation of Ordinary Courts vom 11.12.2017, Rn. 71-72.

$482 \mathrm{Zu}$ den Zahlen Małgorzata Szuleka, „New retirement rules for Polish judges contravene EU law - according to Advocate General“" vom 20.06.2019, abrufbar unter https://ruleoflaw.pl/new-retirement-rules-for-polish-judges-contravene-eu-1 aw-according-to-advocate-general/.

483 Vgl. etwa BBC, "Poland defies EU over Supreme Court judge appointments" vom 10.10.2018, abrufbar unter: https:/www.bbc.com/news/world-europe-4581 6561.

484 EuGH, Rs. C-619/18 R, „Unabhängigkeit des Obersten Gerichts“, Beschluss der Vizepräsidentin des Gerichtshofs vom 19. Oktober 2019, ECLI:EU:C:2018:852, Rn. 18 und ff, in franz. Spr.

485 EuGH, Rs. C-619/18 R, Kommission ./. Polen, „Unabhängigkeit des Obersten Gerichts“, Urteil (GK) vom 24.06.2019, ECLI:EU:C:2019:531, Rn. 27-31. 
Schließlich schuf die Gesetzesnovelle über das Oberste Gericht jenseits der Frage der Richterpensionierung und -neuernennung auch weitere Probleme. Die Kommission bemängelte insbesondere umfassende Disziplinarmöglichkeiten gegen Richter, bei denen ggf. auch rechtswidrig erlangte Beweismittel verwendet werden konnten und bei denen die Verjährung zum Nachteil der Richter „für die Dauer des Disziplinarverfahrens ausgesetzt“ war, „sodass ein Richter zeitlich unbegrenzt Gegenstand eines Verfahrens sein" konnte. ${ }^{486} \mathrm{Im}$ Jahresverlauf 2019 wurde diese Gesetzgebung nochmals drastisch verschärft. Nach neuer Rechtslage dürfen Richter die Ernennung anderer Richter und deren Rechtsprechung nicht mehr kritisieren und sich nicht politisch betätigen. Bei Zuwiderhandlung können sie mit Bußgeldern belegt oder sogar entlassen werden. ${ }^{487}$ Darauf wird im folgenden Abschnitt nochmals eingegangen.

Darüber hinaus schuf das Gesetz zwei neue Kammern am polnischen Obersten Gerichtshof, die darüber hinaus mit neuen Richtern besetzt wurden. Bei beiden Kammern sollen ad hoc durch den Senat ernannte ehrenamtliche Richter mitwirken. ${ }^{488}$ Einer ersten Kammer wurden Kompetenzen über „außerordentliche Rechtsbehelfe“ zugewiesen. ${ }^{489}$ Hieraus erwuchs die Kompetenz, mittels neuen „außerordentlichen Rechtsbehelfs“ nach Zustimmung des Justizministers und Generalstaatsanwalts, binnen 20 Jahren beliebige, rechtskräftige Urteile aller Instanzen der ordentlichen Gerichtsbarkeit und mit Einschränkungen des Obersten Gerichtshofs

486 S. Europäische Kommission, Begründeter Vorschlag nach Artikel 7 Absatz 1 des Vertrags über die Europäische Union zur Rechtsstaatlichkeit in Polen für einen Beschluss des Rates zur Feststellung der eindeutigen Gefahr einer schwerwiegenden Verletzung der Rechtsstaatlichkeit durch die Republik Polen, $\operatorname{COM}(2017) 835$ final, 2017/0360 (NLE) vom 20.12.2017, Rn. 134-135, Zitat Rn. 134.

487 New York Times, „In Poland, Controversial Legislation Restricting Judiciary Is Signed Into Law“, vom 04.02.2020.

488 Europäische Kommission, Begründeter Vorschlag nach Artikel 7 Absatz 1 des Vertrags über die Europäische Union zur Rechtsstaatlichkeit in Polen für einen Beschluss des Rates zur Feststellung der eindeutigen Gefahr einer schwerwiegenden Verletzung der Rechtsstaatlichkeit durch die Republik Polen, $\operatorname{COM}(2017) 835$ final, 2017/0360 (NLE) vom 20.12.2017, Rn. 136.

489 Europäische Kommission, Begründeter Vorschlag nach Artikel 7 Absatz 1 des Vertrags über die Europäische Union zur Rechtsstaatlichkeit in Polen für einen Beschluss des Rates zur Feststellung der eindeutigen Gefahr einer schwerwiegenden Verletzung der Rechtsstaatlichkeit durch die Republik Polen, $\operatorname{COM}(2017) 835$ final, 2017/0360 (NLE) vom 20.12.2017, Rn. 135-136. 


\section{Die Rechtsstaatlichkeitskrise in mitgliedstaatlichen Fällen}

selbst einer Wiederaufnahme zu unterwerfen. ${ }^{490}$ Damit ist „jede Rechtssache, die in den vergangenen 20 Jahren in dem Land entschieden wurde, aus praktisch jedem Grund wieder aufzunehmen, "womit die Endgültigkeit von Urteilen nicht mehr gewährleistet ist. ${ }^{491}$ Der Kammer fällt auch, wie bereits geschildert, die Befugnis der Entscheidung über Wahlprüfungsbeschwerden zu. Außerdem standen nun allein dieser Kammer besondere Befugnisse, insbesondere im Hinblick der Überprüfung von Wahlen zum Sejm, zu. Einer weiteren, noch umstritteneren, Kammer, der sog. „Disziplinarkammer“, wurden die übrigen Richter des Obersten Gerichtshofs zwecks Disziplinarmaßnahmen unterworfen. ${ }^{492}$ Die Kammer wurde Anfang 2020 gegen einen Richter am Obersten Gerichtshof tätig, enthob ihn seiner Tätigkeiten und sprach ihm $40 \%$ seiner Dienstbezüge ab. ${ }^{493}$

Europäische Kommission und Europäischer Gerichtshof sind mit diversen Schritten gegen diese Entwicklungen vorgegangen. Alle Vorgänge sind im Grunde bereits umfassend im begründeten Vorschlag zur Einleitung des Verfahrens nach Art. 7 EUV berücksichtigt worden. ${ }^{494}$ Die polnische Regierung wiederum sieht die Änderungsbestrebungen von ihrem demokratischen Mandat gedeckt und hat sie vielfach verteidigt, in beachtlicher Form, da ad hoc, insbesondere in einem sog. "Weißbuch“ (White Paper)

$490 \mathrm{Zu}$ diesem Punkt insb. etwa Christian Davies, „Polish MPs pass judicial bills amid accusations of threat to democracy“, The Gurdian vom 08.12.2017.

491 Vgl. Europäische Kommission, Begründeter Vorschlag nach Artikel 7 Absatz 1 des Vertrags über die Europäische Union zur Rechtsstaatlichkeit in Polen für einen Beschluss des Rates zur Feststellung der eindeutigen Gefahr einer schwerwiegenden Verletzung der Rechtsstaatlichkeit durch die Republik Polen, $\operatorname{COM}(2017) 835$ final, 2017/0360 (NLE), vom 20.12.2017, Rn. 128-131.

492 Europäische Kommission, Begründeter Vorschlag nach Artikel 7 Absatz 1 des Vertrags über die Europäische Union zur Rechtsstaatlichkeit in Polen für einen Beschluss des Rates zur Feststellung der eindeutigen Gefahr einer schwerwiegenden Verletzung der Rechtsstaatlichkeit durch die Republik Polen, $\operatorname{COM}(2017) 835$ final, 2017/0360 (NLE) vom 20.12.2017, Rn. 135-136.

493 New York Times, „In Poland, Controversial Legislation Restricting Judiciary Is Signed Into Law“, vom 04.02.2020, im Hinblick auf den Richter Pawel Juszczyszyn, weiter auch Gerhard Gnauck, „Nach Kritik wird suspendiert“, Frankfurter Allgemeine Zeitung vom 07.01.2020.

494 Europäische Kommission, Begründeter Vorschlag nach Artikel 7 Absatz 1 des Vertrags über die Europäische Union zur Rechtsstaatlichkeit in Polen für einen Beschluss des Rates zur Feststellung der eindeutigen Gefahr einer schwerwiegenden Verletzung der Rechtsstaatlichkeit durch die Republik Polen, $\operatorname{COM}(2017) 835$ final, 2017/0360 (NLE) vom 20.12.2017, Rn.91-170, Gesamtschau der Lage ab Rn. 171. 
zur polnischen Justiz vom März 2018, das unmittelbar an die Europäische Kommission übersandt wurde. ${ }^{495}$

Die Venedig-Kommission, die Anfang 2020 in einer Stellungnahme die Reformen nochmals Revue passieren ließ, zeigte sich in höchstem Maße besorgt, nicht nur über die Auswirkungen der Gesetze auf die Unabhängigkeit der Justiz im Allgemeinen, sondern auch darüber, dass angesichts der zunehmend gegenläufigen Ansichten bei fortlaufenden Ernennungen von Richtern zwei Richterschaften entstehen könnten, von denen jede der anderen ihre Legitimität absprach:

„In sum, the Polish legal order faces a schism between the old judicial institutions and judges, on one side, and, on the other, those bodies and judges who were created/appointed on the basis of the new rules introduced by the legislative amendments of 2017. There is a risk of legal chaos with the decisions of some courts not recognised as valid by other courts." 496

\section{d. „Maulkorbgesetz“ gegen die Gerichtsbarkeit}

Als letzter und thematisch vierter, immer noch andauernder Vorgang, ist schließlich die zusätzliche Disziplinierung der Richter im Anschluss bzw. in unmittelbarer Parallele zu den Ende 2019 ergangenen Vertragsverletzungsurteilen im Hinblick auf den polnischen Obersten Gerichtshof und die ordentliche Gerichtsbarkeit zu nennen. Die entsprechenden Gesetzesänderungen sind am 20.12.2019 vom Sejm zunächst angenommen, ${ }^{497}$ im Senat dann verworfen und schließlich doch unter schärfster Kritik der

495 Kanzlei des polnischen Premierministers, White Paper on the Reform of the Polish Judiciary vom 07.03.2018.

496 Venedig-Kommission, CDL-PI(2020)002, Opinion No. 977/2019, Joint Urgent Opinion of the Venice Commission and the Directorate General of Human Rights and Rule of Law (DGI) of the Council of Europe on Amendments to the Law on the Common Courts, the Law on the Supreme Court, and some other laws vom 16.01.2020, Rn. 17.

497 Venedig-Kommission, CDL-PI(2020)002, Opinion No. 977/2019, Joint Urgent Opinion of the Venice Commission and the Directorate General of Human Rights and Rule of Law (DGI) of the Council of Europe on Amendments to the Law on the Common Courts, the Law on the Supreme Court, and some other laws vom 16.01.2020, Einleitung, S. 1. 


\section{Die Rechtsstaatlichkeitskrise in mitgliedstaatlichen Fällen}

Opposition in Kraft getreten. ${ }^{498}$ Sie war zu Jahresanfang 2020 Gegenstand einer „urgent opinion“ der Venedig-Kommission, erstellt zusammen mit der Generaldirektion für Menschenrechte des Europarates. ${ }^{499}$ Die PiS-Regierung verteidigte die Reform als aufgrund von Korporatismus, Korruption, Ineffizienz und verbleibenden kommunistischen Tendenzen in der polnischen Gerichtsbarkeit als notwendig ${ }^{500}$ und griff damit Motive zur Verteidigung auf, die sie bereits 2018 mit dem o.g. sog. „Weißbuch“ an die Kommission vorgetragen hatte. ${ }^{501}$

Mit der landläufig als sog. „Maulkorbgesetz“ bezeichneten Gesetzesänderung ist es Richtern künftig unter Androhung einer Disziplinarstrafe verboten, „die Ernennung von Richtern“ oder die „Gültigkeit [scil.: Integrität] eines Verfassungsorgans“ infrage zu stellen. Außerdem ist den Richtern „öffentliche Tätigkeit, die mit dem Grundsatz der richterlichen Unabhängigkeit und Unparteilichkeit unvereinbar sind" sowie die richterliche Aussprache zu „politischen Angelegenheiten“ untersagt. ${ }^{502}$ Auch die Mitgliedschaft in Vereinigungen, d.h. insbesondere im polnischen Richterbund u.ä., muss angezeigt werden. ${ }^{503}$ Verstöße werden nicht von der neuen Disziplinarkammer am Obersten Gerichtshof, sondern - etwas überra-

498 Vgl. Florian Kellermann, „Justizreform in Polen Parlament verabschiedet sogenanntes Maulkorbgesetz", Deutschlandfunk vom 24.01.2020.

499 Venedig-Kommission, CDL-PI(2020)002, Opinion No. 977/2019, Joint Urgent Opinion of the Venice Commission and the Directorate General of Human Rights and Rule of Law (DGI) of the Council of Europe on Amendments to the Law on the Common Courts, the Law on the Supreme Court, and some other laws vom 16.01.2020.

500 Vgl. zur Darstellung der Motivlage Venedig-Kommission, CDL-PI(2020)002, Opinion No. 977/2019, Joint Urgent Opinion of the Venice Commission and the Directorate General of Human Rights and Rule of Law (DGI) of the Council of Europe on Amendments to the Law on the Common Courts, the Law on the Supreme Court, and some other laws vom 16.01.2020, Rn. 12.

501 Kanzlei des polnischen Premierministers, White Paper on the Reform of the Polish Judiciary vom 07.03.2018, vgl. dort Rn. 1 ff. zu den angeführten Mängeln im polnischen Justizsystem.

502 Venedig-Kommission, CDL-PI(2020)002, Opinion No. 977/2019, Joint Urgent Opinion of the Venice Commission and the Directorate General of Human Rights and Rule of Law (DGI) of the Council of Europe on Amendments to the Law on the Common Courts, the Law on the Supreme Court, and some other laws vom 16.01.2020, Rn. 24.

503 Venedig-Kommission, CDL-PI(2020)002, Opinion No. 977/2019, Joint Urgent Opinion of the Venice Commission and the Directorate General of Human Rights and Rule of Law (DGI) of the Council of Europe on Amendments to the Law on the Common Courts, the Law on the Supreme Court, and some other laws vom 16.01.2020, Rn. 29. 
schend - von der Kammer für außerordentliche Rechtsbehelfe verfolgt. ${ }^{504}$ Auch wurde nochmals die Gesetzesgrundlage zur Wahl des Präsidenten des Obersten Gerichtshof geändert. Die Venedig-Kommission bemängelte, dass der Gerichtspräsident, statt wie vor 2017 unter zwei, nun von einer Liste aus fünf Kandidaten zu wählen war, was das Risiko mangelnder Unterstützung seitens der Richterschaft drastisch erhöhte, da der Staatspräsident, der die Wahl zu treffen hatte, an den Vorschlag nicht gebunden war. Zudem wurde die Möglichkeit geschaffen, einen Kandidaten ad interim rein exekutiv durch den Staatspräsidenten zu ernennen. ${ }^{505}$ Dabei sind, in absteigender Reihenfolge, diejenigen Kandidaten mit den meisten Stimmen auf die Liste zu setzen. Bei der Auswahl aus dieser Liste ist der Staatspräsident indes frei. Galt dies zuvor, bei zwei Kandidaten, als Ausdruck politischer Machtbalance zwischen Gericht und Gubernative, so fürchtete die Venedig-Kommission, dass bei fünf Kandidaten, von denen z.B. der letzte nur eine kleine Minderheit des Kollegiums hinter sich versammelte, der Staatspräsident aus politischen Gründen auch diesen Kandidaten ernennen und damit die Abstimmung der Kollegiumsmehrheit beim Gericht unterlaufen könnte. ${ }^{506}$

Die Venedig-Kommission stellte, beachtlich für eine Einrichtung des Europarats, eine klare Unvereinbarkeit und direkten Konflikt mit Grundentscheidungen des Unionsrechts fest. Sie seien von Einwänden, wie sie etwa das deutsche Bundesverfassungsgericht mit seiner „Verfassungsidentitätslehre" geltend gemacht habe, deutlich zu unterscheiden. ${ }^{507}$

504 Venedig-Kommission, CDL-PI(2020)002, Opinion No. 977/2019, Joint Urgent Opinion of the Venice Commission and the Directorate General of Human Rights and Rule of Law (DGI) of the Council of Europe on Amendments to the Law on the Common Courts, the Law on the Supreme Court, and some other laws vom 16.01.2020, Rn. 35.

505 Venedig-Kommission, CDL-PI(2020)002, Opinion No. 977/2019, Joint Urgent Opinion of the Venice Commission and the Directorate General of Human Rights and Rule of Law (DGI) of the Council of Europe on Amendments to the Law on the Common Courts, the Law on the Supreme Court, and some other laws vom 16.01.2020, Rn. 54.

506 Venedig-Kommission, CDL-PI(2020)002, Opinion No. 977/2019, Joint Urgent Opinion of the Venice Commission and the Directorate General of Human Rights and Rule of Law (DGI) of the Council of Europe on Amendments to the Law on the Common Courts, the Law on the Supreme Court, and some other laws vom 16.01.2020, Rn. 52-54.

507 Venedig-Kommission, CDL-PI(2020)002, Opinion No. 977/2019, Joint Urgent Opinion of the Venice Commission and the Directorate General of Human Rights and Rule of Law (DGI) of the Council of Europe on Amendments to the 


\section{Zwischenergebnis zu Polen}

Die Auswirkungen der Umbrüche in Polen sind von höchster Dramatik. Die Bedenken über sie spiegeln sich auch in der Öffentlichkeit wider, wobei hier zunächst auf die zahlreichen Demonstrationen, die seit 2015 in Polen stattgefunden haben, zu verweisen ist. Auch in Statistiken zur Wahrnehmung der Justiz schlagen sie sich nieder. Das Land ist im Hinblick auf die öffentliche Wahrnehmung der Unabhängigkeit der Justiz zwischen 2017 und 2019 um über 10 Prozentpunkte abgestürzt, ${ }^{508}$ auch wenn es nicht das Schlusslicht in Europa bildet. Hierin verdeutlicht sich einmal mehr die später noch zu diskutierende Diskrepanz zwischen der Qualität der Justiz im Allgemeinen und politischen Attacken auf die Rechtsstaatlichkeit im Besonderen. Auch andere Indizes, wie der sog. „Ease of Doing Business"-Index, zeigen dramatische Verschlechterungen. Zwischen 2017 und 2020 ist ein Absturz um 16 Plätze zu verzeichnen. ${ }^{509}$

Derart statistische Verschiebungen stehen indes hinter der materiellrechtlichen Tragweite, wie sie oben dargestellt wurde, weit zurück.

In der Natur der Vorgänge sind die Umbrüche in Polen, gerade im direkten Kontrast zum folgenden Beispiel Ungarn trotz ihrer frappierenden Wirkung linear, direkt und erstaunlich offen abgelaufen. Zwar hat es Momente innerhalb der Entwicklung gegeben, in denen die PiS taktisch subtiler verfahren ist, wie z.B. die geschilderte Ernennung neuer Verfassungsrichter zur Nachtzeit. Es ist ebenso nicht unerheblich, dass 2015 und 2019 Gesetze im Wesentlichen zum Jahresende und damit in die sowohl für die betroffenen Akteure hektischen wie auch in der Öffentlichkeit wenig mit Aufmerksamkeit bedachten Weihnachtsfeiertage, die im katholischen Polen beachtliche Bedeutung haben, gefallen sind. Aber im Übrigen hat die Regierung der PiS und vor allem ihre parlamentarische

Law on the Common Courts, the Law on the Supreme Court, and some other laws vom 16.01.2020, Rn. 38 .

508 Europäische Kommission, Mitteilung der Kommission an das Europäische Parlament, den Rat, die Europäische Zentralbank, den Europäischen Wirtschaftsund Sozialausschuss und den Ausschuss der Regionen, EU-Justizbarometer 2019, $\operatorname{COM(2019)~} 198$ final vom 26.04.2019, S. 55 Schaubild 47, „Wahrnehmung der Unabhängigkeit von Gerichten und Richtern durch die breite Öffentlichkeit”. Am schlechtesten wird, auch in den folgenden Schaubildern, konsistent Kroatien bewertet.

509 Vgl. die auf den Daten der Weltbank beruhende Gegenüberstellung nach Jahren: https://de.wikipedia.org/wiki/Ease_of_Doing_Business_Index. 2017 befand sich Polen auf Platz 24 aller indizierten Staaten, 2020 auf Platz 40. 
Mehrheit Stück für Stück und ohne dass dies für Beobachter schwer erkennbar gewesen wäre, ihre Pläne umgesetzt.

Am besten fasst die Brisanz der Entwicklung meines Erachtens daher der damalige Erste Vizepräsident der Kommission, Timmermans, 2017 in einer Rede vor dem Europäischen Parlament zusammen. Er war zugleich entsetzt über die Auswirkungen in Polen, wie auch über die standhafte Weigerung der polnischen Stellen, einen Schritt auf die Kommission zuzugehen, und hielt fest:

„you know the old joke about the 'ghost rider' [driving the wrong way on the motorway]. Somebody is sitting in his car listening to the radio, and on the radio the announcer says 'Be careful, on the A2 there is a ghost rider driving the other way' and the person sitting in the car says: 'One? I see hundreds!' This is how I would react [...]. It is not the European Commission only. It is not the European Parliament only. It is organisations of European judges, it is the Venice Commission, it is the United Nations. Are all these people wrong?" 510

Sadurski schließlich sah in den Vorgängen in Polen die Versinnbildlichung einer

„taxonomy of three main strategies - as described by Levitsky and Ziblatt in their recent book under the ominous title How Democracies Die - that elected authoritarians use in order to consolidate their power: capturing the referees, sidelining the key players, and rewriting the rules ,to tilt the playing field against opponents'. PiS attempted, with varying success, all three of these strategies."

Schließen möchte ich indes nochmals mit dem jüngsten Gutachten der Venedig-Kommission. Diese gelangt darin zu dem Schluss, die durch den Sejm erlassenen Änderungen gingen soweit, vorangegangene EuGH-Urteile quasi zu annullieren und sich in offene Abweichung („open defiance“) zu diesem und zum Unionsrecht insgesamt zu setzen. ${ }^{512}$ Die polnische

510 Europäisches Parlament, Replik von Frans Timmermans in der Aussprache vom 15.11.2017, „Die Lage der Rechtstaatlichkeit und der Demokratie in Polen (Aussprache)“, CRE 15/11/2017 - 7.

511 Wojciech Sadurski, Poland's Constitutional Breakdown, S. 261.

512 Venedig-Kommission, CDL-PI(2020)002, Opinion No. 977/2019, Joint Urgent Opinion of the Venice Commission and the Directorate General of Human Rights and Rule of Law (DGI) of the Council of Europe on Amendments to the Law on the Common Courts, the Law on the Supreme Court, and some other laws vom 16.01.2020, Rn. 38 . 


\section{Die Rechtsstaatlichkeitskrise in mitgliedstaatlichen Fällen}

Regierung hatte in einem Memorandum zu den Änderungen u.a. geltend gemacht, sie folgten der auch in Deutschland bekannten Verfassungsidentitätslehre. Dies sah die Venedig-Kommission völlig anders. Die Regelungen seien geeignet, jeglichen Dialog zwischen nationalen Gerichten und EuGH zu unterbinden und ermöglichten, im nationalen Streitfall, ein späteres Urteil des polnischen Verfassungsgerichts, das sich offen gegen den Vorrang des Unionsrechts stelle.

Das ist die wohl dramatischste Feststellung, die ein begutachtendes Gremium zur Frage einer verfassungsrechtlichen Rechtsverletzung durch einen Mitgliedstaat festzustellen in der Lage ist. Sie stellt einen bis dato in dieser Deutlichkeit in der gesamten Geschichte der Europäischen Union unerreichten Höhepunkt eines Konfliktes zwischen einem Mitgliedstaat und der supranationalen Rechtsordnung dar, der dieser Mitgliedstaat aus freien Stücken beigetreten ist.

\section{Ungarn}

\section{1. Übersicht}

Die rechtsstaatsbezogene Entwicklung in Ungarn steht an Schwere den Entwicklungen in Polen nicht nach.

Fungiert Polen, wie ich in meiner Einleitung zu den dortigen Entwicklungen festhielt, als „Katalysator“ der Krise, so ist in Ungarn die gesamte gesellschaftliche Tragweite der gegenwärtigen Rechtsstaatlichkeitskrise aufgezeigt.

Gegenüber Polen ergeben sich dabei im Charakter der Krise in Ungarn deutliche Unterschiede. Die Krise in Polen ist, trotz Tangierung etwa auch der staatlichen Medien, im Wesentlichen monothematisch, sie betrifft die Justiz. Die Vorgänge in Ungarn sind polythematisch, d.h.im Hinblick auf Dauer, Art des Vorgangs, betroffene Rechtsgüter und -subjekte deutlich heterogener als in Polen. Die Darstellung z.B. bei Möllers und Schneider zeigt, dass die in Ungarn seitens der Regierung von Viktor Orbán und seiner Partei Fidesz seit 2010 unternommenen Änderungen vorrangig auf diverse Verwirklichungsfelder der Zivilgesellschaft abzielen, darunter die Medien- oder die Forschungsfreiheit. ${ }^{513}$ Ihre Verknüpfung erfahren sie indes durch einen stets gleich gelagerten Vorsatz der staatlichen Handelnden

513 Christoph Möllers \& Linda Schneider, Demokratiesicherung in der Europäischen Union, S. 53 ff; weiter auch Paul Lendvai, Orbán, S. 101 ff. 
und eine klar herauszuarbeitende Finalität der Maßnahmen, sodass man zugespitzt auch von einer „Tatmehrheit“ sprechen könnte.

Ein weiteres verklammerndes Motiv für die Vorgänge in Ungarn ist, dass nach politischer Vereinnahmung der Justiz (also den Vorgängen in Polen nicht unähnlich), durch schnelle, erratische und unübersichtliche, die Schwächen des Gesetzgebungsprozesses ausnutzende Änderungen materiell-rechtliche Fakten geschaffen wurden. Man kann von einer Pervertierung und Unterwanderung des Gesetzgebungsprozesses sprechen. Wie in Polen genießt die Regierung in Ungarn breite demokratische Legitimierung, auch wenn dort Änderungen des Wahlrechts ihre Mehrheiten ungewöhnlich deutlich machen. Das vermag aber diese Änderungen nicht pauschal zu legitimieren.

Aufgrund der Überlegung, dass die Vorgänge in Ungarn rechtsetzende Strukturen ausnutzen, materiell-rechtlich Gesetze diskriminierend zugeschnitten sind und der Rechtsschutz gegen sie unzureichend ist, bleibt die Figur des systemischen Defizits an Rechtsstaatlichkeit die treffendste. A fortiori ist dem hinzuzufügen, dass die bis dato jüngste Entwicklung, die seitens der Venedig-Kommission begutachtet worden ist, eine geplante, aber zurückgenommene Einführung einer neuen Verwaltungsgerichtsbarkeit in Ungarn betraf, womit, wie in Polen, Umbrüche im nationalen Justizsystem zur Debatte standen.

Bevor ich mit der Darstellung beginne, ist zunächst, wie in Bezug auf Polen, die Quellenlage darzustellen.

Dabei besteht eine merkliche Diskrepanz in der Haltung der Unionsorgane gegenüber Ungarn im Vergleich zu Polen. Insbesondere hat sich die Europäische Kommission der Idee eines systemischen Defizits an Rechtsstaatlichkeit auch in Ungarn, im Unterschied zu Polen, lange verweigert.

Die damalige EU-Justizkommissarin Věra Jourová teilte 2015 mit, dass die Qualifizierung der Lage in Ungarn als systemisches Problem daran scheitere, dass sie zum einen mit verschiedenen Vertragsverletzungsverfahren angegangen würde und die ungarische Justiz zum anderen sich der Beanstandungen vorrangig annehmen müsse..$^{514}$

Frans Timmermans, der sich seinerzeit als Erster Vizepräsident der Kommission im Rahmen seines Rechtsstaatlichkeitsportfolios ebenso zur Lage in Ungarn äußerte, wiederholte noch kurz vor einer Plenardebatte im April 2017 unter Anwesenheit Viktor Orbáns, er sehe im Land „keine sys-

514 Věra Jourová, Hungary: no systemic threat to democracy, says Commission, but concerns remain, Presseerklärung des Europäischen Parlaments vom 02.12.2015, Nr. 20151201IPR05554. 


\section{Die Rechtsstaatlichkeitskrise in mitgliedstaatlichen Fällen}

temische Bedrohung der Rechtsstaatlichkeit“" ${ }^{515}$ Ausschlaggebend hierfür sei nicht, dass es in Ungarn nicht ausreichend Fälle gäbe, die ein „allgemeines Muster" (general pattern) ergäben, sondern vielmehr, dass dieses im politischen Dialog mit den ungarischen Behörden und Verantwortlichen angegangen werden könne.

Die Europäische Kommission hat gegen Ungarn weder den EU-Rahmen von 2014 noch das Verfahren nach Art. 7 EUV eingeleitet oder öffentlich erwogen. Als entscheidender Faktor hierfür ist vorgebracht worden, dass die Fidesz, wie der damalige Kommissionspräsident Juncker, auf europäischer Ebene der Europäischen Volkspartei (EVP) angehört und innerhalb des Europäischen Parlaments auch der entsprechenden Fraktion. Die PiS wiederum gehört den Europäischen Konservativen und Reformern (ECR) an. ${ }^{516} \mathrm{Ob}$ die Parteigruppen- und Fraktionsidentität von Fidesz und Kommissionspräsidentschaft kausal für die relative Milde der Juncker-Kommission gegenüber Ungarn gewesen ist, lässt sich nicht nachweisen, eine Korrelation ist indes unbestreitbar. ${ }^{517}$

Ein Ausschluss der Fidesz seitens der EVP ist, trotz Suspendierung der Mitgliedschaft, nicht erfolgt, ${ }^{518}$ Gerüchte um einen möglichen freiwilligen Austritt und Zusammenschluss mit der PiS hielten zum Abschluss des Manuskripts an..$^{519}$

Mit der politischen Milde gegenüber Ungarn kontrastiert indes die Entschlossenheit der Europäischen Kommission, vorrangig gerichtlich gegen die Vorgänge in Ungarn vorzugehen. Die Rolle des Beaufsichtigenden seitens der Union ist vor diesem Hintergrund prominent auch durch das Europäische Parlament wahrgenommen worden, jedenfalls was die beiden Phasen der Beobachtung und Überprüfung angeht, ${ }^{520}$ und dies obwohl die Ausgangslage der Handlungen als Organ eine gänzlich andere ist.

515 Europäische Kommission, Read-out of the weekly meeting of the Juncker [Commission] by Frans Timmermans, First Vice-President of the EC, EbS-Reference I-136589, vom 12.04.2017, abrufbar unter: https://ec.europa.eu/avservices/v ideo/player.cfm?sitelang=en\&ref=I136589.

516 Überzeugend Charlemagne, „How Hungary's leader, Viktor Orban, gets away with it“, The Economist, vom 02.04.2020.

517 Eine Kausalität sehen hingegen Christoph Möllers \& Linda Schneider, Demokratiesicherung in der Europäischen Union, S. 63.

518 S. dazu Maïa de La Baume, „Fidesz MEPs remain in the EPP group, for now“, Politico, vom 26.03.2019.

519 Alexandra Brzozowski, „Fidesz-PiS talks point towards potential exit from EPP”, EurActiv vom 08.01.2020.

520 Diese Beobachtung teilen auch Christoph Möllers \& Linda Schneider, Demokratiesicherung in der Europäischen Union, S. 63. 
Das Parlament soll als pluralistisches Meinungsforum nicht nur keine geschlossene Linie verfolgen, sondern im Gegenteil eine solche ja gerade nicht entwickeln. Vielmehr soll sich dort die gesamte Bandbreite politischer Ansichten zur Rechtsstaatlichkeitskrise widerspiegeln. Das muss zu sehr unterschiedlichen Standpunkten und Wünschen nach Handlungen führen.

Ein plastisches Beispiel dafür ist der aus der Mitte der ECR-Fraktion eingebrachte Gegenentwurf zu den Entschließungen betreffend die Einleitung des Verfahrens nach Art. 7 EUV vom November 2017 bezüglich Polen, ${ }^{521}$ in dem u.a. bestritten wird, dass die Kommission gem. Art. 7 Abs. 1 EUV eine eigenständige Funktion ausüben könne ${ }^{522}$ oder dass es in ihrem Ermessen stehe, einen begründeten Vorschlag vorzulegen. Dort heißt es auch:

„in der Erwägung, dass Polen sein Eintreten für das Rechtsstaatsprinzip nie infrage gestellt hat; in der Erwägung, dass sich die Regierung bei der Durchführung der im Wahlkampf angekündigten Reformen nach ebendiesem Prinzip richtet“".523

Ungeachtet derartiger Besonderheiten und Heterogenität im Falle Polens hat die Parlamentsmehrheit gegen Ungarn regelmäßig deutliche Worte gefunden und dies obwohl die Fidesz dort der EVP-Fraktion angehört.

Ungarn war Gegenstand mehrerer Berichte des Plenums. Besonders hervorzuheben sind die nach ihren jeweiligen Berichterstattern hier die sog. Schöpflin-Stellungnahme, ${ }^{524}$ der sog. Tavares-Bericht, ${ }^{525}$ der sog. in 't-Veld-

521 Europäisches Parlament, Entschließungsantrag eingereicht im Anschluss an Erklärungen des Europäischen Rates [sic, Übersetzungsfehler, scil.: des Rates] und der Kommission gemäß Artikel 123 Absatz 2 der Geschäftsordnung zur Lage der Rechtsstaatlichkeit und der Demokratie in Polen (2017/2931(RSP)) [...] im Namen der ECR-Fraktion, B8-0594/2017 vom 06.11.2017.

522 Erwägungsgrund $\mathrm{C}$ des vorgenannten Entschließungsantrags.

523 Erwägungsgrund D des vorgenannten Entschließungsantrags.

524 Stellungnahme des Ausschusses für konstitutionelle Fragen für den Ausschuss für bürgerliche Freiheiten, Justiz und Inneres zur Einrichtung eines EU-Mechanismus für Demokratie, Rechtsstaatlichkeit und Grundrechte (2015/2254(INL)), Verfasser der Stellungnahme: György Schöpflin vom 16.06.2016, nachfolgend auch: Schöpflin-Stellungnahme.

525 Europäisches Parlament, Bericht über die Lage der Grundrechte: Standards und Praktiken in Ungarn (gemäß der Entschließung des Europäischen Parlaments vom 16. Februar 2012), (2012/2130(INI)), Ausschuss für bürgerliche Freiheiten, Justiz und Inneres, Berichterstatter: Rui Tavares vom 24.06.2013, A7-0229/2013, nachfolgend auch: Tavares-Bericht. 


\section{Die Rechtsstaatlichkeitskrise in mitgliedstaatlichen Fällen}

Bericht, ${ }^{526}$ mit dem das Parlament zugleich einen neuen Mechanismus im Unionsrecht vorgeschlagen hat, der sog. DRF-Pakt, und schließlich der sog. Sargentini-Bericht, ${ }^{527}$ der der Einleitung eines Verfahrens nach Art. 7 Abs. 1 EUV am 12.09.2018 durch das Europäische Parlament ${ }^{528}$ vorausging.

Der Tavares-Bericht vom Juni 2013 verdient dabei besondere Beachtung, denn er bezieht erstmals ausdrücklich Stellung zur Lage in Ungarn, nachdem das Europäische Parlament zuvor in mehreren Entschließungen Besorgnis über die Rechtsumbrüche in Ungarn seit 2010 geäußert hatte. ${ }^{529}$ Der Großteil des Berichts ist indes eine minutiöse, dadurch aber auch ermüdende Aufstellung derjenigen Daten, die das Parlament zu seiner Besorgnis hinsichtlich der Lage in Ungarn erwogen haben. Die Akribie der Analytik ist für die Sachverhaltsaufarbeitung durch diesen, wie auch für spätere Berichte, prägend. Diese Akribie schlägt sich etwa darin nieder, dass der Berichterstatter zu verschiedensten Gesetzesvorhaben in Ungarn

526 Bericht mit Empfehlungen an die Kommission zur Einrichtung eines EU-Mechanismus für Demokratie, Rechtsstaatlichkeit und die Grundrechte (2015/2254(INL)) Ausschuss für bürgerliche Freiheiten, Justiz und Inneres, Berichterstatterin: Sophia in 't Veld, A8-0283/2016 vom 10.10.2016: nachfolgend auch: in 't Veld-Bericht.

527 Europäisches Parlament, Ausschuss für bürgerliche Freiheiten, Justiz und Inneres, Entwurf eines Berichts über einen Vorschlag, mit dem der Rat aufgefordert wird, im Einklang mit Artikel 7 Absatz 1 des Vertrags über die Europäische Union festzustellen, dass die eindeutige Gefahr einer schwerwiegenden Verletzung der Grundwerte der Europäischen Union durch Ungarn besteht (2017/2131(INL)), A8-0250/2018, Berichterstatterin: Judith Sargentini, nachfolgend auch: Sargentini-Bericht.

528 Europäisches Parlament, P8_TA(2018)0340 Die Lage in Ungarn, Entschließung des Europäischen Parlaments vom 12. September 2018 zu einem Vorschlag, mit dem der Rat aufgefordert wird, im Einklang mit Artikel 7 Absatz 1 des Vertrags über die Europäische Union festzustellen, dass die eindeutige Gefahr einer schwerwiegenden Verletzung der Werte, auf die sich die Union gründet, durch Ungarn besteht (2017/2131(INL)), (2019/C 433/10), ABl. (EU) C 433/66 vom 23.12.2019.

529 Vorgehend: 1.: Europäisches Parlament, P7_TA(2012)0053 Politische Entwicklungen in Ungarn in letzter Zeit: Entschließ $u$ ung des Europäischen Parlaments vom 16. Februar $2012 \mathrm{zu}$ den aktuellen politischen Entwicklungen in Ungarn (2012/2511(RSP)), 2.: Europäisches Parlament, P7_TA(2011)0094 Mediengesetz in Ungarn: Entschließung des Europäischen Parlaments vom 10. März 2011 zum Mediengesetz in Ungarn; 3.: P7_TA(2012)0053 Politische Entwicklungen in Ungarn in letzter Zeit: Entschließ $u n g$ des Europäischen Parlaments vom 16. Februar $2012 \mathrm{zu}$ den aktuellen politischen Entwicklungen in Ungarn $(2012 / 2511(\mathrm{RSP}))$. 
Stellung nimmt, einschließlich der Verabschiedung des neuen Grundgesetzes, deren Verfahrensgang kleinschrittig nachgezeichnet wird. ${ }^{530}$ Der Berichterstatter macht insbesondere folgende Feststellung:

„die Tragweite der umfassenden und systematischen verfassungsrechtlichen und institutionellen Reformen, die die neue ungarische Regierung und das neue Parlament Ungarns innerhalb einer außerordentlich kurzen Zeitspanne durchgeführt haben, [ist] beispiellos. “531

Im Verlauf der Entwicklung ist Ungarn im Europäischen Parlament mindestens fünfmal auch Gegenstand allgemeiner Aussprachen im Plenum gewesen, erstmals 2012,532 hiernach 2013,533 zweifach im Jahr $2015^{534}$ und dann im April 2017 im Rahmen einer Plenardebatte unter Anwesenheit von Premier Orbán, welcher eine Entschließung vom Mai 2017 nachfolgte. ${ }^{535}$ Nach Einleitung des Verfahrens nach Art. 7 EUV im September 2018

530 Europäisches Parlament, Bericht über die Lage der Grundrechte: Standards und Praktiken in Ungarn (gemäß der Entschließung des Europäischen Parlaments vom 16. Februar 2012), (2012/2130(INI)), Ausschuss für bürgerliche Freiheiten, Justiz und Inneres, vom 24.06.2013, A7-0229/2013, Berichterstatter: Rui Tavares, Rn. AB ff., II 1 und ff. zum neuen Grundgesetz insbesondere.

531 Europäisches Parlament, Bericht über die Lage der Grundrechte: Standards und Praktiken in Ungarn (gemäß der Entschließung des Europäischen Parlaments vom 16. Februar 2012), (2012/2130(INI)), Ausschuss für bürgerliche Freiheiten, Justiz und Inneres, vom 24.06.2013, A7-0229/2013, Berichterstatter: Rui Tavares, Erwägungsgrund Y.

532 Europäisches Parlament, P7_TA(2012)0053, Politische Entwicklungen in Ungarn in letzter Zeit, Entschließung des Europäischen Parlaments vom 16. Februar $2012 \mathrm{zu}$ den aktuellen politischen Entwicklungen in Ungarn (2012/2511(RSP)).

533 Europäisches Parlament, P7_TA(2013)0315, Lage der Grundrechte: Standards und Praktiken in Europa, Entschließung des Europäischen Parlaments vom 3. Juli 2013 zu der Lage der Grundrechte: Standards und Praktiken in Ungarn (gemäß der Entschließung des Europäischen Parlaments vom 16. Februar 2012), (2012/2130 (INI)), ABl. (EU) C 75/52 vom 25.06.2019.

534 Europäisches Parlament, P8_TA(2015)0227, Lage in Ungarn: Entschließung des Europäischen Parlaments vom 10. Juni 2015 zur Lage in Ungarn (2015/2700(RSP)), (2016/C 407/06), ABl.(EU) C 407/46 vom 04.11.2016; P8_TA(2015)0461, Lage in Ungarn: Folgemaßnahmen zur Entschließung des Europäischen Parlaments vom 10. Juni 2015, Entschließung des Europäischen Parlaments vom 16. Dezember 2015 zur Lage in Ungarn (2015/2935(RSP)), (2017/C 399/13), ABl. (EU) C 399/127 vom 24.11.2017.

535 Europäisches Parlament, P8_TA(2017)0216, Lage in Ungarn: Entschließung des Europäischen Parlaments vom 17. Mai 2017 zur Lage in Ungarn (2017/2656(RSP)), (2018/C 307/09), ABl. (EU) C 307/75 vom 30.08.2018; zuvor 


\section{Die Rechtsstaatlichkeitskrise in mitgliedstaatlichen Fällen}

sind regelmäßige Aussprachen mit Entschließungen und entsprechenden Anträgen zum Verfahren hinzugetreten. Der bis dato letzte EntschlieBungsantrag, in welchem das Parlament auch eine Verschleppung des Verfahrens im Rat beklagt, stammt vom Januar 2020.536

Auf Seiten des Europarates ist insbesondere der beachtliche Korpus an Gutachten der Venedig-Kommission zu nennen.

War Ungarn bis zum Antritt der Regierung Orbán Gegenstand nur eines einzigen Gutachtens, sind seit 2011 bis dato nach meiner Zählung insgesamt siebzehn Stellungnahmen zur Lage in Ungarn ergangen, davon mehrere gemeinsam mit dem ODIHR, eine gemeinsam mit dem Rat für Demokratische Wahlen ${ }^{537}$ und eine als „follow-up“ zu einer bereits ergangenen Stellungnahme. ${ }^{538}$ Teils sind diese am selben Tag ergangen,

Plenardebatte vom 26.04.2017, Protokoll abrufbar unter: https://www.europarl. europa.eu/doceo/document/CRE-8-2017-04-26_EN.pdf.

536 Europäisches Parlament, Entschließungsantrag eingereicht im Anschluss an Erklärungen des Rates und der Kommission gemäß Artikel 132 Absatz 2 der Geschäftsordnung zu den laufenden Anhörungen gemäß Artikel 7 Absatz 1 EUV zu Polen und Ungarn, (2020/2513(RSP)), nachfolgend Entschließung des Europäischen Parlaments vom 16. Januar 2020 zu den laufenden Anhörungen gemäß Artikel 7 Absatz 1 EUV zu Polen und Ungarn.

537 Der Rat für Demokratische Wahlen ist eine gesonderte Einrichtung des Europarates, die die Stellungnahmen der Venedig-Kommission sichtet, bevor sie der Plenarsitzung der Parlamentarischen Versammlung vorgelegt werden, vgl. näher unter: https://www.venice.coe.int/WebForms/pages/?p=01_Elections_and Referendums\&lang=DE.

538 Die Venedig-Kommission stellt diese Liste unter: http://www.venice.coe.int/web forms/documents/?country=17\&year=all bereit. Im Einzelnen:

1. CDL-AD(2011)001-e, Opinion no. 614/2011, Opinion on three legal questions arising in the process of drafting the New Constitution of Hungary vom 28.03.2011; 2. CDL-AD(2011)016, Opinion no. 621/2011, Opinion on the new Constitution of Hungary vom 20.06.2011; 3. CDL-AD(2012)001, Opinion 663/2012, Opinion on Act CLXII of 2011 on the Legal Status and Remuneration of Judges and Act CLXI of 2011 on the Organisation and Administration of Courts of Hungary vom 19.03.2012; 4. CDL-AD(2012)004, Opinion 664/2012, Opinion on Act CCVI of 2011 on the right to freedom of conscience and religion and the legal status of churches, denominations and religious communities of Hungary vom 19.03.2012; $\underline{5}$. CDL-AD(2012)008, Opinion no. 668/12, Opinion on Act CLXIII of 2011 on the Prosecution Service and Act CLXIV of 2011 on the Status of the Prosecutor General, Prosecutors and other Prosecution Employees and the Prosecution Career of Hungary vom 19.06.2012; $\underline{6}$. CDL-AD(2012)009, Opinion no. 665/2012, Opinion on Act CLI of 2011 on the Constitutional Court of Hungary vom 19.06.2012; 7. CDL-AD(2012)011, Opinion no. 671/2012, Opinion on the Act on the Rights of Nationalities of Hungary vom 19.06.2012; . CDL-AD(2012)012, CDL-AD(2012)012, Joint 
insgesamt begleiten sie den gesamten Änderungsprozess seit Schaffung des ungarischen Grundgesetzes. Das erste Gutachten, das während des Ausarbeitungsprozesses des Grundgesetzes erging, lässt sich in der Retrospektive auch so verstehen, dass man seitens der ungarischen Regierung ausloten wollte, wie weit man hierbei gehen konnte.

Ebenso hat sich die Parlamentarische Versammlung des Europaparlaments (PACE) geäußert. ${ }^{539}$

Auch auf größerer internationaler Bühne war Ungarn Thema, darunter bereits 2013 das damalige neue ungarische Grundgesetz. ${ }^{540} 2018$ zeigten

Opinion [by the Council for Democractic Elections and the Venice Commission] on the Act on the Elections of Members of Parliament of Hungary vom 18.06.2012; 9. CDL-AD(2012)020, Opinion no. 683/2012, Opinion on the Cardinal Acts on the Judiciary that were amended following the adoption of Opinion CDL-AD(2012)001 on Hungary vom 15.10.2012; 10. CDL-AD(2012)023, Opinion 672/2012, Opinion on Act CXII of 2011 on informational Self-determination and Freedom of Information of Hungary vom 18.10.2012; 11. CDL$\mathrm{AD}(2013) 012$, Opinion 720/2013, Opinion on the Fourth Amendment to the Fundamental Law of Hungary vom 17.06.2013; 12. CDL-AD(2015)015, Opinion no. 798/2015, Opinion on Media Legislation (ACT CLXXXV on Media Services and on the Mass Media, Act CIV on the Freedom of the Press, and the Legislation on Taxation of Advertisement Revenues of Mass Media) of Hungary vom 22.06.2015; 13. CDL-AD(2017)015, Opinion 889/2017, Hungary - Opinion on the Draft Law on the Transparency of Organisations receiving support from abroad vom 20.06.2017; 14. CDL-AD(2017)022, Opinion 891/2017, Hungary Opinion on Article XXV of 4 April 2017 on the Amendment of Act CCIV of 2011 on National Tertiary Education vom 09.10.2017; 15. CDL-AD(2018)013, Venice Commission Opinion No. 919/2018, OSCE/ODIHR Opinion No. Opinion-Nr. NGO- HUN/326/2018, Joint Opinion on the Provisions of the so-called "Stop Soros" draft Legislative Package which directly affect NGOs (in particular Draft Article 353A of the Criminal Code on Facilitating Illegal Migration) vom 25.06.2018; 16. CDL-AD(2018)035, Venice Commission Opinion No. 941/2018, OSCE/ODIHR Opinion No. NGO- HUN/336/2018, Joint Opinion on Section 253 on the special immigration tax of Act XLI of 20 July 2018 amending certain tax laws and other related laws and on the immigration tax vom 17.12.2018; 17. CDL-AD(2019)004, Opinion no. 843/2018, Hungary - Opinion on the law on administrative courts and the law on the entry into force of the law on administrative courts and certain transitional rules vom 19.03.2019.

539 Vgl. etwa Parlamentarische Versammlung des Europarats, Resolution 2162 (2017): Alarming developments in Hungary: draft NGO law restricting civil society and possible closure of the European Central University vom 27.04.2017. Die Entschließung ist einen Tag nach der Aussprache des Europäischen Parlaments in der gleichen Sache ergangen.

540 United Nations, Office of the UN High Commissioner for Human Rights, "UN human rights office voices concern over changes to Hungarian constitution, Pressemitteilung vom 15.03.2013. 


\section{Die Rechtsstaatlichkeitskrise in mitgliedstaatlichen Fällen}

sich die Vereinten Nationen wiederholt unzufrieden mit der Behandlung von Flüchtlingen. Der damalige Hochkommissar für Menschenrechte, Zeid Ra'ad Al Hussein, nannte die ungarische Politik „offen fremdenfeindlich“ und „eine Schande“. ${ }^{541}$ Infolge der Auseinandersetzung um die Central European University äußerte sich auch die US-Regierung „enttäuscht“ über den Verlauf. 542

\section{Die illiberale Demokratie als normatives Fundament der} Entwicklungen

Wie schon für Polen, so ist auch für Ungarn zunächst der Frage nachzugehen, woher der politische Wille rührt, in derart offenem und anhaltenden politischen Konflikt mit der EU zu treten.

Für die Erfassung der Entwicklung Ungarns werden seitens der Rechtsund Politikwissenschaft verschiedene Deutungen angeboten. Von der USamerikanischen Politologin Scheppele, mit der Ungarn ihre wohl prominenteste ausländische Fürsprecherin im englischsprachigen Raum hat, stammen mindestens zwei Einordnungen. Zum einen beschrieb sie Vorgänge betreffend das ungarische Verfassungsgericht als sog. „constitutional coup" ${ }^{543}$ der sich durch Attacken gegen das Verfassungsgericht auszeichne, und setzte die Entwicklung zugleich unverhohlen in Verbindung zur Weimarer Republik. Zum anderen bezeichnete sie die Entwicklung als „Verfassungsrevolution“, da sie das gesamte Rechtssystem umfassend umwälze. ${ }^{544}$ Mark Tushnet wiederum setzte Ungarn als Fall sog. „autoritären

541 Eine Zusammenstellung verschiedener Positionen unterschiedlicher UN-Organe, darunter zur genannten Feststellung findet sich seitens des Pressedienstes der UN als „Hungary's laws on helping vulnerable foreigners are ,blatantly xenophobic': UN rights chief" vom 21.06.2018, unter https://news.un.org/e $\mathrm{n} /$ story/2018/06/1012722 und „Hungarian government, fuels discrimination against migrants', say UN human rights experts“ vom 11.08.2018, abrufbar unter: https://news.un.org/en/story/2018/09/1018962.

542 U.S. Department of State, Hungary: Central European University (CEU), Press Statement (Heather Nauert) vom 03.12.2018, oder Az., abrufbar unter: https://w ww.state.gov/hungary-central-european-university-ceu/.

543 Kim Lane Scheppele, „Constitutional Coups and Judicial Review: How Transnational Institutions Can Strengthen Peak Courts at Times of Crisis (With Special Reference to Hungary)", in: Transnational Law \& Contemporary Problems 23 (2014), S. 51-118, S. 52, 60 ff.

544 Kim Lane Scheppele, „Understanding Hungary's Constitutional Revolution“, insb. S. 113. 
Konstitutionalismus“ in Relation zur Lage in Singapur, ${ }^{545}$ Gábor Halmai spricht von einem „Hybridsystem“.546 Paul Lendvai hat betont, es sei der westlichen Presse völlig entgangen, dass in keinem anderen demokratischen Staat eine derart kleine bestens mit einander bekannte Gruppe um eine einzelne Person eine derartige Machtfülle besitze und dass darüber eindeutig eine Autokratie entstanden sei.547 Die in der Wortwahl wohl drastischste Darstellung stammt von Bálint Magyar, der zahlreiche Umbrüche in der Gubernative und in der Zivilgesellschaft Ungarns nachzeichnet und diese als Verkörperung eines „Mafiastaates“ fasst, als von ihm beschriebenen Unterfall des autokratischen Staates, für welchen Ungarn archetypisch identifiziert wird. ${ }^{548}$

Ich bleibe hier bei der Vermutung, dass die Lage in Ungarn eine echte Staats- oder Verfassungskrise darstellt und dass der Nachweis anzutreten ist, dass sie so sehr die Gesamtheit des ungarischen Rechtssystems in Mitleidenschaft zieht, dass darüber auch von einem Fall der unionalen Rechtsstaatlichkeitskrise, und zwar ihrer vorsätzlichen Ausprägung, zu sprechen ist.

Dieser Vorsatz, d.h. die Ausgestaltung der gubernativen Richtlinienkompetenz Viktor Orbáns, wird dabei durch einen konkreten politischen Leitbegriff bestimmt, den es als teleologischen Fluchtpunkt seines Handelns voranzustellen gilt. Er ist aus Sicht der Fidesz durchaus als Staatsgrundprinzip für Ungarn zu werten. Dies ist der Begriff des illiberalen Staats bzw. der illiberalen Demokratie, der daher hier vor allen anderen Vorschlägen Vorzug erhalten muss.

Der Begriff der „illiberale Demokratie“ findet seine Ursprünge bereits in der Transformationsforschung der Politikwissenschaft ${ }^{549}$ und dort unmittelbar im Anschluss an den Zusammenbruch des früheren Ostblocks, zum anderen auch in der Forschung zu Wirtschaftssystemen Asiens. ${ }^{550}$ Er ist

545 Mark Tushnet, „Authoritarian Constitutionalism“, in: Cornell Law Review 100 (2015), S. 391-461, S. 433.

546 Gábor Halmai: „The Rise and Fall of Constitutionalism in Hungary“, S. 225 f.

547 Paul Lendvai, Orbán, S. 10 ff., unter Berufung auf den Juristen Tamás Sárközy.

548 Bálint Magyar, Post-Communist Mafia State: The Case of Hungary; weiter sehr deutlich in der Kritik auch Paul Lendvai, Orbán, S. 177 ff.

549 Fareed Zakaria, „The Rise of Illiberal Democracy“, in: Foreign Affairs 76 (1997), S. 22-43; für eine Analyse vorrangig nichteuropäischer Entwicklungen s. etwa Li-Ann Thio, „Constitutionalism in Illiberal Polities“, in: Michel Rosenfeld \& András Sajó (Hrsg.), The Oxford Handbook of Comparative Constitutional Law, Oxford University Press, Oxford, 2012, S. 133-152.

550 Daniel A. Bell, Daniel A. \& Kanishka Jayasuriya, „Understanding Illiberal Democracy: A Framework” in: Daniel A. Bell, David Brown, Kanishka Jaya- 


\section{Die Rechtsstaatlichkeitskrise in mitgliedstaatlichen Fällen}

dort stets durch den Beobachter, nicht den Handelnden, verwendet und regelmäßig pejorativ verstanden worden.

Als prägende Merkmale der illiberalen Demokratie hat die Politikwissenschaft herausgearbeitet, dass erstens Grundrechte und bürgerliche Freiheiten mangelhaft durchgesetzt würden, zweitens die rechtsstaatliche Funktionsweise der Justiz eingeschränkt sei und drittens der betroffene Staat ein "systematisches“ Korruptionsproblem habe. ${ }^{551}$ Bezeichnend ist hier auch die Verknüpfung des Demokratiebegriffs unmittelbar mit dem Rechtsstaatsprinzip.

Im Falle Ungarns hingegen wird der Begriff durch die Regierung Viktor Orbáns selbst verwendet und soll dabei positiv besetzt werden, hat also folglich eine gänzlich eigene Prägung erfahren. Zentrales Dokument bei dieser Begriffsummünzung durch Orbán ist eine Rede vor der ungarischen Minderheit der Szekler im rumänischen Bad Tuschnad. ${ }^{552}$ Orbán hielt in dieser insbesondere fest:

„Wir sind auf der Suche nach einer Organisationsform des Gemeinwesens, die fähig ist, uns in diesem großen globalen Wettrennen [scil.: mit nichteuropäischen Staaten] wettbewerbsfähig zu machen (und wir tun unser Bestes, um Wege zu finden, von westlichen Dogmen getrennte Wege zu gehen, uns von ihnen unabhängig zu machen). [...] Um dies 2010 und insbesondere heutzutage zu erreichen, mussten wir mutig einen Ausspruch finden, der, [...] in der liberalen Weltordnung als Sakrileg galt. Wir mussten festhalten, dass eine Demokratie nicht notwendigerweise liberal ist. Nur weil etwas nicht liberal ist, kann es immer noch eine Demokratie sein.“ $[\ldots]$.

„Der neue Staat, den wir bauen, ist ein illiberaler Staat, ein nicht-liberaler Staat. Er verneint die grundlegenden Werte des Liberalismus nicht, wie etwa die Freiheit usw. Aber diese Ideologie stellt kein

suriya, \& David Martin (Hrsg.): Towards Illiberal Democracy in Pacific Asia, St. Martin's Press/Palgrave Macmillan, Houndmills/Basingstoke/London, 1995, S. 1-16, insb. S. 15-16 mit Blick auf das beobachtete kulturelle Verständnis der staatlichen Ordnungsmacht einer ,asiatischen Demokratie“.

551 Wolfgang Merkel, Hans-Jürgen Puhle, Aurel Croissant, Claudia Eicher \& Peter Thiery, Defekte Demokratie, S. 262-263.

552 Englische Übersetzung durch Csába Toth für die Zeitung Budapest Beacon, „Full text of Viktor Orbán's speech at Băile Tuşnad (Tusnádfürdő) of 26 July 2014“, o.S., verfügbar unter: https://budapestbeacon.com/full-text-of-viktor-orba ns-speech-at-baile-tusnad-tusnadfurdo-of-26-july-2014/. Eigene Übertragung des Zitats ins Deutsche auf Grundlage der englischen Übersetzung. Zitat beginnend im siebten Absatz (Anreden nicht mitgezählt) a.E., fortgeführt im elften Absatz. 
zentrales Element der Staatsorganisation dar, vielmehr setzt er [scil.: der Staat] an ihre Stelle einen spezifischen, nationalen, eigenständigen Ansatz".

Aus dieser Rede sind wesentliche Elemente der illiberalen Demokratie ungarischer Prägung unmittelbar abzuleiten. Insbesondere steht diese also einem pluralistischen Staatsverständnis ablehnend gegenüber, betont die Eigenständigkeit des Staates und der Nation und bezweckt eine ganzheitliche Umformung des Rechts- und Wirtschaftssystems.

Dem steht das durch das Unionsrecht vorgegebene Rechts- und Wirtschaftssystem offensichtlich in weiten Teilen konträr entgegen. Der Konflikt wird dabei aber durch Orbán und die Fidesz nicht direkt gesucht, sondern es wird sachbereichsspezifisch versucht, dieses Wunschbild des eigenen Gesellschaftsmodells umzusetzen.

Zum zweiten hat die ungarische Regierung wiederholt außerhalb der Gesetzgebung durch politische Kampagnen Feindbilder aufgebaut, die im Zusammenhang mit dieser so bezeichneten Illiberalität stehen. Ein derartiger Feind im klassisch Schmittschen Sinne ${ }^{553}$ ist aus der Sicht Orbáns und der Fidesz unverkennbar der ungarischstämmige jüdische Milliardär George (Györgi) Soros, der sein Vermögen vorrangig mit Börsenwetten erworben hat und dessen „Open Society Foundation“ u.a. die Central European University trägt, deren Schließung die ungarische Regierung im Frühjahr 2017 per Gesetz bezweckte. Gegen ihn ist die ungarische Regierung vorrangig mit Realakten bzw. sui-generis Rechtsakten vorgegangen. So lancierte die Fidesz eine, zwischenzeitlich ausgesetzte, Plakatkampagne ${ }^{554}$ gegen Soros, bei der landesweit großflächige Plakatflächen im öffentlichen Raum genutzt wurden. Zweitens führte die ungarische Regierung mehrfach unverbindliche "nationale Konsultationen“ durch, darunter im Frühjahr 2017 eine „Stoppt Brüssel!“-Kampagne, die die Europäische Kommission in einer bis dato ungekannten Reaktion zu einer Richtigstellung veranlasste, ${ }^{555}$ da sie sich gleich Soros durch die Aktion direkt angegriffen sah. Im Herbst 2017 erfolgte eine weitere Kampagne

553 Zur Prägewirkung Carl Schmitts auf das Denken Orbáns vgl. ausf. auch Paul Lendvai, Orbán, S. 179, m.w.N.

554 „Ungarn: Orbán stoppt Anti-Soros-Kampagne“, Die Zeit vom 28.02.2017.

555 Europäische Kommission, „Facts Matter: European Commission responds to Hungarian National Consultation“, vom 27.04.2017, ohne Az., abrufbar unter: https://ec.europa.eu/commission/publications/stop-brussels-european-commissi on-responds-hungarian-national-consultation_en. 
der ungarischen Regierung, gerichtet gegen den in Ungarn auch sog. „Soros-Plan“.

Drittens verläuft eine der Hauptkonfliktlinien zwischen Ungarn und auch anderen Staaten, darunter Polen einerseits und der Europäischen Kommission sowie dem Europäischen Parlament andererseits entlang unterschiedlicher Auffassungen über den richtigen Umgang mit Migration und Flüchtlingen. Ungarn zählt dabei zu einer Gruppe von Mitgliedstaaten, die etwa zu sog. „Umverteilungskontingenten“ von Flüchtlingen den offenen Konflikt vor dem EuGH gesucht hat. ${ }^{556}$ Dieser Streit wird in der institutionellen Praxis regelmäßig mit den hier interessierenden Punkten vermischt. Aufgrund ihrer faktischen und rechtlichen Komplexität kann auf diese gesonderte Krise hier aber nicht eingegangen werden, sie stellt vielmehr einen eigenen Diskussionspunkt innerhalb der europäischen Polykrise dar und ist anderen Bearbeitern zur Analyse zu überlassen.

3. Ungarische Grundgesetzänderung von 2012 und Richterpensionierungsfrage

Ausgangspunkt der untersuchungserheblichen Entwicklung in Ungarn ist die Außerkraftsetzung der alten ungarischen Verfassung, welche nach einer Totalrevision aus dem Jahr 1989 die kommunistische Verfassung aus dem Jahr 1949 fortgeführt hatte. Ausarbeitung und Ratifikation des sie ersetzenden neuen ungarischen Grundgesetzes erfolgten 2011 parlamentarisch ohne Annahme durch ein Referendum. Das Grundgesetz trat zum Jahreswechsel 2012 in Kraft. Die Grundgesetznovelle und weitere Änderungen führten neben zahlreicher internationaler Kritik, etwa der Vereinten Nationen, ${ }^{557}$ zu einer beachtlichen Reihe an Gutachten der Venedig-Kommission.

Das neue ungarische Grundgesetz wurde für den ausländischen Betrachter, etwa bei András Jakab und Pál Sonnevend, zeitnah kritisch kommen-

556 EuGH, Verb. Rs. C-643/15 und C-647/15, Urteil (GK) vom 06.09.2017, Slowakische Republik und Ungarn gegen Rat („Umverteilungskontingente“), ECLI:EU:C:2017:631.

557 Vereinte Nationen, Office of the UN High Commissioner for Human Rights, „UN human rights office voices concern over changes to Hungarian constitution“, Pressemitteilung vom 15.03.2013. 
tiert, ${ }^{558}$ und ich sehe hier von der Ausarbeitung von Einzelheiten ab. Beide Verfasser hielten zum einen fest, dass das Grundgesetz grundsätzlich wesentliche Grundrechtsgarantien und Staatsgrundprinzipien nicht veränderte, ${ }^{559}$ in Einzelfragen aber höchst problematisch sei. Neben der in der Wortwahl irritierenden Präambel - dem „nationalen Bekenntnis“560 - betraf dies vorrangig die Zuständigkeit des ungarischen Verfassungsgerichts. ${ }^{561}$ Erschwerend, so die ungarischen Beobachter, kommt hinzu, dass das neue Grundgesetz eine ganze Reihe von verfassungsrechtlichen Sachverhalten im Grundgesetz nur in Grundzügen regelt, die Ausarbeitung aber sog. „Kardinalgesetzen“ überlässt. Es handelt sich um eine in Deutschland unbekannte Form des Gesetzes, die aber auch in anderen europäischen Staaten (etwa in Frankreich mit der „loi organique“ (Organgesetz)) im Grundsatz eine Entsprechung findet. Die Erlassmodalitäten der Kardinalgesetze in Ungarn führen aber potentiell zu einer Perpetuierung der Entscheidung über die Legislaturperiode ohne Möglichkeit der Revidierung hinaus, sind nämlich nur mit einer Zweidrittelmehrheit im Parlament zu erlassen oder abzuändern. ${ }^{562}$ Gleiches gilt für die Frage des Haushaltsgesetzes. Für dieses ist die Zustimmung eines gesondert besetzten Kontrollgremiums erforderlich, dessen Amtszeit über die Legislaturperiode hinausgeht. ${ }^{563}$ Das Phänomen langer Amtszeiten setzt sich auch bei der Ernennung anderer hochrangiger Beamter fort, wie insbesondere dem Vorsitzenden des nationalen Rechnungsamtes oder des Generalstaatsanwalts. Dazu äußerte die Wissenschaft die Sorge, dass dies dazu diene,

558 András Jakab \& Pál Sonnevend, „Kontinuität mit Mängeln: Das neue ungarische Grundgesetz", in: Zeitschrift für ausländisches öffentliches Recht und Völkerrecht 72 (2012), S. 79-102.

559 András Jakab \& Pál Sonnevend, „Kontinuität mit Mängeln“, S. 86, 88, 93.

560 Ausführlich Pál Sonnevend, András Jakab \& Lóránt Csink, „The Constitution as an Instrument of Everyday Party Politics: The Basic Law of Hungary“, in: Armin von Bogdandy \& Pál Sonnevend (Hrsg.): Constitutional Crisis in the European Constitutional Area, Hart, Oxford, 2015, S. 33-109, S. 72-74. Die Autoren dort übersetzen das ungarische Original als „Nationales Glaubensbekenntnis“, die von der ungarischen Regierung bereitgestellte deutsche Übersetzung spricht von „Bekenntnis“.

561 András Jakab \& Pál Sonnevend, „Kontinuität mit Mängeln“, S. 97 ff.

562 Aus diesem Grund kritisch die Analyse der Venedig-Kommission, CDL$\mathrm{AD}(2013) 012$, Opinion 720/2013, Opinion on the Fourth Amendment to the Fundamental Law of Hungary vom 17.06.2013, Rn. $129 \mathrm{ff}$.

563 Vgl. András Jakab \& Pál Sonnevend, „Kontinuität mit Mängeln“, S. 95 ff. 


\section{Die Rechtsstaatlichkeitskrise in mitgliedstaatlichen Fällen}

die politische Macht der Fidesz-Partei über die Legislaturperiode hinaus sicherzustellen. ${ }^{564}$

Das ungarische Verfassungsgericht leistete bezüglich dieser Novellen, die später durch weitere wie die Aufhebung von Präzedenzurteilen und Änderungen im Verfassungsprozessrecht begleitet wurden, erheblichen Widerstand, welchem die Regierung mit insgesamt fünf Verfassungsänderungen zeitnah zur Verabschiedung der Verfassung selbst begegnete. Die Venedig-Kommission des Europarates begleitete diese Kritik von Beginn an, zunächst mit zwei Gutachten. ${ }^{565}$ Ihre Einwände, namentlich hinsichtlich der Verfassung als Ganzes, waren dabei noch vergleichsweise mild und hoben vor allem die Frage der Kardinalgesetze und die neue Stellung des Verfassungsgerichts hervor. ${ }^{566}$

Insbesondere die vierte Verfassungsänderung vom 11.03.2013, welche die frühere Rechtsprechung des ungarischen Verfassungsgerichts für nichtig erklärte, rief nicht nur in Ungarn sondern auch durch den Europarat scharfe Kritik hervor, nachdem das Verfassungsgericht den Inhalt der Verfassungsänderung und seine eigene Entmachtung letztendlich aus formellen Gründen akzeptierte und gewissermaßen vor den Änderungen „kapitulierte“. Die Venedig-Kommission hob in einem Resümee ihrer früheren Gutachten insbesondere hervor, es sei durch die häufigen Änderungen „a serious and worrisome undermining of the role of the Constitutional Court as the protector of the Constitution" festzustellen. ${ }^{567}$ Auch an weiterer Stelle war die Kritik schneidend: „During the visit in Budapest and in the documentation provided, the Hungarian Government referred to parliamentary sovereignty as if it were the ultimate instance of legitimacy and no further checks applied. [...]A constitution's permanence may not be based solely on arithmetical considerations stemming from the relationship between the numerical strength of the ruling and opposition parties

564 Miklós Bánkuti, Gábor Halmai \& Kim Lane Scheppele, „Disabling the Constitution“, in: Journal of Democracy 23 (2012), S. 138-146, S. $144 \mathrm{ff}$. unter dem Stichwort des "Entrenching Fidesz".

565 Venedig-Kommission, CDL-AD(2011)016, Opinion no. 621/2011, Opinion on the new Constitution of Hungary vom 20.06.2011.

566 Venedig-Kommission, CDL-AD(2011)016, Opinion no. 621/2011, Opinion on the new Constitution of Hungary vom 20.06.2011, Rn. $141 \mathrm{ff} .145,146,148$.

567 Venedig-Kommission, CDL-AD(2013)012, Opinion 720/2013, Opinion on the Fourth Amendment to the Fundamental Law of Hungary vom 17.06.2013, Rn. 87. 


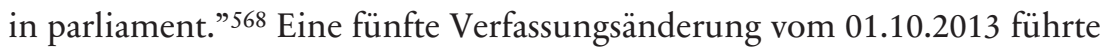
nur zu wenigen Abschwächungen kritischer Passagen. ${ }^{569}$

Die erheblichen Umbrüche, die durch das ungarische Grundgesetz angestoßen wurden, trafen zusätzlich die ungarische Justiz schwer und brachten weite Teile der Richterschaft unter die Kontrolle der Fidesz in Regierung und Parlament.

Besondere Beachtung erfuhren dabei zwei Vertragsverletzungsverfahren vor dem EuGH. Mark Dawson und Elise Muir beobachteten treffend, die darin aufgeworfene Frage der Wahrung der Grundrechte einzelner Betroffener müsse in Wahrheit als Anlass zur Analyse grundlegender verfassungsrechtlicher Probleme in Ungarn verstanden werden. ${ }^{570}$

Das erste, wohl bekanntere, Verfahren betraf die allgemeine Absenkung des Pensionsalters der ungarischen Richterschaft. Sie führte zu einem Austausch von ca. 10\% der gesamten ungarischen Gerichtsbarkeit und um 20\% aller Richter am Obersten Gerichtshof, der zwischenzeitlich in „Kúria“ umbenannt worden war. ${ }^{571}$ Die Kommission beantragte angesichts der Dringlichkeit des Verfahrens seine Beschleunigung. ${ }^{572}$ Im Parallelverfahren betreffend den Datenschutzbeauftragten unterblieb dies, mit beachtlichen Unterschieden. Das dortige Urteil erging erst gute zwei Jahre später. ${ }^{573}$ Ungeachtet der Verfahrensbeschleunigung hier wählte die Kommission einen engen Verfahrenszuschnitt. Daraufhin erkannte der EuGH zwar auf eine Unionsrechtsverletzung seitens Ungarns, stellte aber auf pekuniäre Fragen der verfrühten Pensionierung und die Gleichbehandlung mit jüngeren Vergleichspersonen statt auf die richterliche Unabhängigkeit $a b,{ }^{574}$ womit für Ungarn die Möglichkeit einer Abfindungsregelung statt

568 Venedig-Kommission, CDL-AD(2013)012, Opinion 720/2013, Opinion on the Fourth Amendment to the Fundamental Law of Hungary vom 17.06.2013, Rn. 137.

569 Pál Sonnevend, András Jakab \& Lóránt Csink, „The Constitution as an Instrument of Everyday Party Politics", S. 63.

570 Mark Dawson \& Elise Muir, „Hungary and the Indirect Protection of EU Fundamental Rights and the Rule of Law", in: German Law Journal 14 (2013), S. 1959-1979., S. 1961 ff., 1973 insb.

571 Kim Lane Scheppele, „Constitutional Coups in EU Law“, S.454, in einem vorherigen Beitrag, Kim Lane Scheppele, „Constitutional Coups and Judicial Review“, S. 75, ist sogar von $25 \%$ die Rede.

572 EuGH, Rs. C-286/12, Kommission ./. Ungarn, „Ungarische Richterpensionierung“, Urteil vom 06.11.2012, ECLI:EU:C:2012:687, Rn. 18-21.

573 S. dazu ausführlicher im Abschnitt E.VIII.2. zum Vertragsverletzungsverfahren.

574 EuGH, Rs. C-286/12, Kommission ./. Ungarn, „Ungarische Richterpensionierung“, Urteil vom 06.11.2012, ECLI:EU:C:2012:687, etwa Rn. 61 ff. 


\section{Die Rechtsstaatlichkeitskrise in mitgliedstaatlichen Fällen}

einer Wiedereinsetzung in allen Fällen bestand. Es gilt als wahrscheinlich, dass trotz des Urteils ein Großteil der betroffenen Richter statt einer Rückkehr ins Amt eine finanzielle Abfindung akzeptierte. ${ }^{575}$ Die Frage der richterlichen Unabhängigkeit wurde nicht diskutiert, noch der Begriff erwähnt. Damit verfehlte das Verfahren seinen in der Retrospektive eigentlichen Zweck und galt, indes wohlgemerkt im Hinblick auf den Verfahrenszuschnitt durch die Kommission, nicht etwa im Hinblick auf das Urteil des EuGH, in der Literatur weitestgehend als Fehlschlag. ${ }^{576}$ Dort war man sich der Schwere der gerügten Änderungen überaus bewusst. In für einen amtierenden Richter recht einmaliger Deutlichkeit kommentierte Thomas von Danwitz die Rechtssache mit der Aussage, das Verfahren „spread the flavor of a court-packing plan“. .577 Ebenso legte von Danwitz offen, dass sich der Europäische Gerichtshof bewusst auf technische Feststellungen beschränkt, dies aber in der Absicht getan habe, Ungarn eine Revidierung seiner Vertragsverletzungen zu ermöglichen. ${ }^{578}$

Gleichsam eingehend beurteilt wurde ein parallel angestrengtes Vertragsverletzungsverfahren der Kommission betreffend den ungarischen Datenschutzbeauftragten, in welchem die Kommission ebenfalls gerügt hatte, dass die dortigen Gesetzesänderungen in die ordentliche Funktionsweise des Beauftragten eingreife und dessen Unabhängigkeit verletze. ${ }^{579}$ Der ungarische Gesetzgeber hatte die Amtszeit des Datenschutzbeauftragten herabgesetzt und diesen infolge der Änderung ausgetauscht, und der EuGH gab der Kommission wiederum Recht. Das Gebot der Unabhängigkeit des

$575 \mathrm{Zu}$ dieser Frage und den teils widersprüchlichen Angaben vgl. Kim Lane Scheppele, „Constitutional Coups in EU Law“, S. 459, bei Fn. 43.

576 Urteilsanmerkung bei Uladzislau Belavusau, „On age discrimination and beating dead dogs: Commission v. Hungary Case C-286/12, Commission v. Hungary, Judgment of the Court of Justice (First Chamber) of 6 November 2012, nyr.“, in: Common Market Law Review 50 (2013), S. 1145-1160, insb. S. 1149 ff., weitere Einordnung, mit zusätzlichen Nennungen bei Luca Prete, Infringement Proceedings in EU Law, Kluwer, Alphen aan den Rijn, 2017, S. 144 ff., S. 184.

577 Thomas von Danwitz, "The Rule of Law in the Recent Jurisprudence of the ECJ“, S. 1343, m.w.N.

578 Thomas von Danwitz, "The Rule of Law in the Recent Jurisprudence of the ECJ“, S. 1344. Den pragmatischen Ansatz, auf Seiten der Kommission, sehen ebenso bestätigt Mark Dawson \& Elise Muir, „Hungary and the Indirect Protection of EU Fundamental Rights and the Rule of Law“, S. 1973.

579 EuGH, Rs. C-288/12, Kommission ./. Ungarn, „Ungarischer Datenschutzbeauftragter“, Urteil vom 08.04.2014, ECLI:EU:C:2014:237. Zum Umstand der Beschleunigung dieses Verfahrens und den praktischen Unterschieden Kim Lane Scheppele, „Enforcing the Basic Principles of EU Law through Systemic Infringement Actions“, S. 109-110. 
Datenschutzbeauftragten leitete er aus der Vorgabe aus Art. 16 Abs. 2 S. 2 EUV an die Mitgliedstaaten, unabhängige Datenschutzbehörden zu schaffen sowie aus Art. 8 Abs. 3 GRCh, der diese Vorgabe wiederholte, her. ${ }^{580}$ $\mathrm{Zu}$ einer Revidierung der Lage führte dies nicht, der des Amtes Enthobene wurde lediglich entschädigt. ${ }^{581}$ Mitzunehmen aus dieser Entscheidung ist der seitens des EuGH genutzte Prüfungsmaßstab, eine Kombination einer primärrechtlichen Strukturvorgabe betreffend nationale Behörden aus dem EUV in Verbindung mit einem Chartagrundrecht. Er ähnelt der späteren Überprüfung der Unabhängigkeit mitgliedstaatlicher Gerichte aus Art. 19 Abs. 1 EUV i.V.m. Art. 47 der Charta. Ob der Fall des ungarischen Datenschutzbeauftragten für diesen Prüfungsmaßstab Pate stand, lässt sich indes nicht definitiv beantworten.

Separat hiervon Bedeutung erlangt hat schließlich ein Rechtsstreit vor dem EGMR. András Baka, entlassener Präsident des ungarischen Obersten Gerichtshofs und zuvor langjähriger Richter am EGMR, strengte vor ebendiesem erfolgreich eine Individualbeschwerde in Bezug auf seine Entlassung an. 582

\section{Nationaler Richterrat gegen Nationales Justizamt}

In engem Zusammenhang mit dem Austausch von Teilen der Richterschaft und dem großen Druck auf das Verfassungsgericht einerseits und die Gerichtsbarkeit ${ }^{583}$ andererseits stehen organisatorische Änderungen in der Justizverwaltung, die denjenigen in Polen ähneln. So wurde der alte, dem in Osteuropa gängigen Modell dieses Verfassungsorgans folgende

580 Vgl. die Urteilsanmerkung wie zuvor bei Thomas von Danwitz, „The Rule of Law in the Recent Jurisprudence of the ECJ“, S. 1345.

581 Vgl. den entsprechenden Bericht von Károly Lencsés, „Bocsánatkérés és 69 millió - erről szólt a megállapodás” [„Eine Entschuldigung und 69 Millionen darum ging es in der Vereinbarung“] des Onlineportals „NOL“ vom 09.07.2014, abrufbar unter http://nol.hu/belfold/bocsanatkeres-es-69-millio-errol-szolt-a-me gallapodas-1473191. Demnach betrug die Entschädigungssumme 69 Millionen Forint (ca. 199.000 Euro).

582 EGMR, Baka ./. Ungarn, Beschwerdenr.: 20261/12, Urteil (GK) vom 23.06.2016, Dazu nochmals sogleich unten betreffend die Frage sog. getarnter Einzelfallgesetze.

583 Von „ordentlicher“ Gerichtsbarkeit ist hier insoweit nicht zu sprechen, als das derzeitige ungarische Rechtssystem eine strikte Trennung in Zweige der Gerichtsbarkeit nicht kennt. 


\section{Die Rechtsstaatlichkeitskrise in mitgliedstaatlichen Fällen}

Nationale Justizrat (OIT) abgeschafft. ${ }^{584}$ An seine Stelle trat der weitgehend auf beratende Funktionen beschränkte Nationale Richterrat (OBT) sowie schließlich das Nationale Justizamt bzw. Gerichtsverwaltungsamt $(\mathrm{OBH})$. Diese Zweiteilung führte zu einem offenen Machtkampf beider formell nur unzulänglich voneinander abzugrenzenden Behörden. ${ }^{585}$ Auch wenn das Nationale Justizamt dem Richterrat förmlich zuarbeitet und dieser eine Aufsichtsfunktion ausüben soll, ist es doch allein das Amt selbst, das von Regierung und Parlament bevorzugt wird, Macht ausübt und überdies finanziell ausreichend ausgestattet ist. Hinzu tritt, dass das Amt die Fallverteilung zwischen Gerichten beeinflussen kann. ${ }^{586}$ Die Präsidentin des Amtes, vom Parlament direkt gewählt, war bis Ende 2019 die Juristin und frühere Richterin Tünde Handó, zugleich die Ehefrau des Vizepräsidenten der Fidesz. Zum Jahresende 2019 ernannte das ungarische Parlament sie zur Richterin des Verfassungsgerichts, ${ }^{587}$ der zuvor wenig bekannte Instanzrichter György Senyei hat ihre Nachfolge angetreten.

Während der Amtszeit Handós kam es zu regelmäßigen Machtkämpfen beider Behörden, sodass der Justizrat seine ursprüngliche Funktion als Selbstvertretungsorgan der ungarischen Gerichtsbarkeit kaum noch effektiv ausüben konnte. Es kam überdies zu offenen Angriffen seitens Handós auf den Richterrat, dessen Mitglieder von ihr als „Vaterlandsverräter“ bezeichnet wurden. ${ }^{588}$

\section{Einzelfallgesetze}

Eine Besonderheit der Entwicklung in Ungarn sind Umbrüche im öffentlichen Leben und der Zivilgesellschaft durch sog. getarnte Einzelfallgeset-

584 Über den Vorgang und die notwendige präzise Unterscheidung der Behördenbezeichnungen sowie der jeweiligen Akronyme informiert das U.S. Department of State, Country Reports on Human Rights Practices for 2011: Hungary, verfügbar unter: http://www.state.gov/j/drl/rls/hrrpt/humanrightsreport/index.htm? dlid $=186359$, S. 8 und 11.

585 Vgl., wenig übersichtlich, unter https://birosag.hu/en/national-office-judiciary.

586 Pál Sonnevend, András Jakab \& Lóránt Csink, „The Constitution as an Instrument of Everyday Party Politics“, S. 63.

587 Marton Dunai, „Hungary shakes up top jobs in justice, highlighting government's struggle for influence", Reuters vom 29.10.2019, abrufbar unter: https:// www.reuters.com/article/us-hungary-orban-justice/hungary-shakes-up-top-jobs-i n-justice-highlighting-governments-struggle-for-influence-idUSKBN1X824E.

588 Vgl. Dániel G. Szabó, „A Hungarian Judge Seeks Protection from the CJEU Part I", Verfassungsblog vom 28.07.2019. 
$z e, 589$ die hier vorrangig im Hinblick auf ihre Identifizierbarkeit als solche, statt ihre Vereinbarkeit mit einer bestimmten Rechtsordnung (etwa ungarischem Recht) darzustellen sind. Als Analysemaßstab kann zum einen herangezogen werden, dass der Gerichtshof sich dem Topos bislang vereinzelt zugewandt hat. ${ }^{590}$ Zum anderen können zur Maßstabspräzisierung Anleihen beim Bundesverfassungsgericht gemacht werden, welches vor dem Hintergrund des ausdrücklichen Verbots von Einzelfallgesetzen nach Art. 19 Abs. 1 GG unter dem Grundgesetz zu entscheiden hatte und die Figur des „getarnten Einzelfallgesetzes“ in seiner Entscheidung „PlatowAmnestie" wie folgt fasst:

„Von einem solchen kann [...] gesprochen werden, wenn der Gesetzgeber ausschließlich einen bestimmten Einzelfall oder eine bestimmte Gruppe von Einzelfällen regeln will und zur Verdeckung dieser Absicht generell formulierte Tatbestandsmerkmale dergestalt in einer Norm zusammenfaßt, daß diese nur auf jene konkreten Sachverhalte Anwendung finden kann, die dem Gesetzgeber vorschwebten und auf die die Norm zugeschnitten ist. " ${ }^{\text {"591 }}$

Regelmäßig haben Gesetze, auf welche diese Definition passt, seit 2017 Ungarn in das Licht der breiten europäischen Öffentlichkeit gerückt. Der Topos ist in der Literatur auch mittels verwandter Begriffe bereits diskutiert worden. Magyar spricht von „custom tailored legislation“ und notiert:

„Equality before the law has been replaced by inequality after the law. Travel back in time has become possible with retroactive laws, and legislation tailored to individuals, groups, political friends and foes is carried on with the precision of a surgeon using laser technology based on the case-by-case authorizations given by the head of the political family: offering reward or punishment, privilege or discrimination. This is the era of occasional arbitrary laws (commonly named "lex ..."), when the legal environment is adjusted to the continuously

589 Vgl. hierzu bereits kursorisch die Analyse bei Matthias Schmidt \& Piotr Bogdanowicz, „The Infringement Procedure in the Rule of Law Crisis“, S. 1087.

590 S. näher, wenn auch noch fragmentarisch, EuGH, Rs. C-85/12, Schlussanträge des Generalanwalts Pedro Cruz-Villalón Société Landsbanki Islands HF ./. Kepler Capital Markets SA, Frédéric Giraux, vom 30.05.2013, ECLI:EU:C:2013:352, Rn. 60 ; Rs. C-46/93, Schlussanträge des Generalanwalts Giuseppe Tesauro, Brasserie du pêcheur ./. Bundesrepublik Deutschland und The Queen ./. Secretary of State for Transport, ex parte Factortame and Others, ECLI:EU:C:1995:407, Rn. 36 bei Fn. 41.

591 BVerfGE 10, 234 (244) - Platow-Amnestie. 
changing whims of the political family, with mass ad hoc procedures that shame legislative principles. They form incidental exceptions rather than general rules." 592

Der Befund derartiger Gesetze findet in der Rechtspraxis weitere Bekräftigung. Nachdem die Venedig-Kommission in ihrem Gutachten aus dem Jahr 2012 betreffend den rechtlichen Status und die Vergütung von Richtern sowie die Gerichtsverfassung und -verwaltung hinsichtlich der Änderungen, die insbesondere den Präsidenten des Obersten Gerichtshofs, Ba$\mathrm{ka}$, betrafen, ${ }^{593}$ festgehalten hatte: „[a]lthough the Law was formulated in a general way, its effect was directed against a specific person",, 594 ergänzten die Richter Pinto de Alberquerque und Dedov in ihrer Concurring Opinion zum Urteil Baka ./. Ungarn unter dem Titel der "ad hominem"Gesetzgebung:

„To phrase this differently, this was legislation conceived to achieve a specific result that was detrimental to a concrete individual (ad hominem, konkret-individuelles Maßnahmegesetz), which was secured by a constitutional straitjacket in order to avoid any possibility of judicial review." 595

Neben diesem Beispiel lassen sich meines Erachtens auch die folgenden Fälle mit dieser Figur erfassen.

a. Lex CEU und der Topos der Gewaltenkollusion

Mutmaßlich prominentestes Beispiel eines "getarnten Einzelfallgesetzes“ ist eine Änderung des ungarischen Hochschulgesetzes vom Frühjahr 2017, welches nach vielfach vertretener Auffassung ${ }^{596}$ allein auf die in Budapest ansässige Central European University abzielte, eine sowohl mit ungarischer

592 Bálint Magyar, Post-Communist Mafia State: The Case of Hungary, S. 117.

593 S. bereits supra unter C. IV. 3.

594 Venedig-Kommission, CDL-AD(2012)001, Opinion 663/2012, Opinion on Act CLXII of 2011 on the Legal Status and Remuneration of Judges and Act CLXI of 2011 on the Organisation and Administration of Courts of Hungary vom 19.03.2012, Rn. 59.

595 EGMR, Baka ./. Ungarn, Beschwerdenr.: 20261/12, Urteil (GK) vom 23.06.2016, Joint Concurring Opinion Of Judges Pinto De Albuquerque and Dedov, dort Rn. $14 \mathrm{f}$.

596 Sogleich im Einzelnen unten. 
als auch mit amerikanischer Akkreditierung operierende private Hochschule.

Das sie betreffende Änderungsgesetz zum ungarischen Hochschulgesetz wurde in einem beschleunigten Verfahren angenommen. ${ }^{597}$ Die Öffentlichkeit erlangte davon Kenntnis im Verlauf des 28. März 2017, einem Dienstag. Die Annahme des Gesetzes ${ }^{598}$ erfolgte am 4. April, nur eine Woche später. Abzüglich des Wochenendes blieben gerade 5 Werktage zur Erörterung des Vorhabens. Zwischen Verabschiedung des Gesetzes und Ausfertigung durch den Staatspräsidenten János Áder, der das Gesetz ohne Weiteres am 10. April ausfertigte, verblieb eine knappe weitere Woche.

Angesichts der großen Geschwindigkeit des Gesetzgebungsprozesses, den Möllers und Schneider neben dem Fall der „Lex CEU“, 599 bereits für die Verfassungsnovelle 2012 beobachtet haben, ${ }^{600}$ ist hier der zusätzliche Topos der Gewaltenkollusion einzuführen, der diese Gesetzgebungspraxis der „Blitzgesetze“ prägt. Ich bezeichne mit Gewaltenkollusion den Zustand eine Interaktion von Parlament und Regierung in einem Mitgliedstaat der Union, in der nicht nur eine bloße Gewaltenverschränkung im Sinne vertrauensvollen Zusammenarbeitens zu beobachten ist, sondern Parlament und Regierung bedingungslos der durch die Mehrheitspartei vorgegebenen Linie folgen, ohne dass hieran aber verfahrensrechtlich etwas auszusetzen oder förmlich die Gewaltentrennung aufgegeben wäre. Der Begriff der Gewaltenkollusion kann als Gegenstück zum Gewaltenmonismus ${ }^{601}$ verstanden werden, bei welchem eine Gewalt eine Gewaltenausübung umfassend von ihrem Vorbehalt abhängig macht. Bei der Gewaltenkollusion hinge-

597 Venedig-Kommission, CDL-AD(2017)022, Opinion 891/2017, Hungary - Opinion on Article XXV of 4 April 2017 on the Amendment of Act CCIV of 2011 on National Tertiary Education vom 09.10.2017, Rn $52 \mathrm{ff}$.

598 Eine Zeitleiste stellt die CEU selbst unter https://www.ceu.edu/istandwithceu/ti meline-events bereit.

599 Christoph Möllers \& Linda Schneider, Demokratiesicherung in der Europäischen Union, S. 60-61.

600 Christoph Möllers \& Linda Schneider, Demokratiesicherung in der Europäischen Union, S. 55.

$601 \mathrm{Zu}$ ihm vgl. - für die deutsche Rechtssprache - BVerfGE 68, 1 (87) [1984] - „Atomwaffenstationierung“, dort als hypothetische Negativfolie ebenso pejorativ besetzt. Der Begriff des Gewaltenmonismus dieser Prägung, also als $\mathrm{Zu}$ stand in einem Staat, der förmlich die Gewaltenteilung weiter kennt, ist sehr sorgfältig von seiner Verwendung in sozialistischen Staaten zu trennen, zur Verwendung in diesen, also als Gegensatz zur Gewaltentrennung, vgl. Manfred G. Schmidt, Sozialpolitik der DDR, VS Verlag für Sozialwissenschaften, Wiesbaden, 2013, S. 10, Fn. 4. Der Begriff der Gewaltenkollusion wiederum scheint mir bislang nicht besetzt, kann hier also entsprechend frei geprägt werden. 


\section{Die Rechtsstaatlichkeitskrise in mitgliedstaatlichen Fällen}

gen wird letzterer vollständig zugunsten gubernativen Ermessens aufgegeben. ${ }^{602}$ Damit ist dem parlamentarischen Prozess seine Deliberierungs-, Informations- und ggf. auch Berücksichtigungsfunktion genommen. In einer solchen Lage tritt dem Beobachter die Legislative und die Gubernative einschließlich des Staatschefs, ${ }^{603}$ der das Gesetz ausfertigt, als quasi einheitlicher Akteur gegenüber, von dem eine Berücksichtigung von Oppositionsinteressen nicht zu erwarten ist.

Durch die „Lex CEU“ wurde der CEU ein Verbleib in Ungarn in bestehender Form unmöglich gemacht. Das Gesetz zielte dabei auf den Umstand ab, dass die CEU de facto ausschließlich als eine Hochschule operierte, deren besonderer Reiz für die Studenten der wahlweise Erwerb im jeweiligen Land voll akkreditierter ungarischer oder aber US-amerikanischer Abschlüsse war, dass sie dafür aber de jure aus zwei juristischen Personen bestehen musste, jeweils einer amerikanischen und einer ungarischen Hochschule, die (selbstredend) beide den gleichen Hochschulnamen nutzten. Das Gesetz schuf strikte Vorgaben, die aus dem Kontext genommen unverdächtig waren, wie solche zum Schutz des Hochschulnamens vor Verwechslung oder die tatsächliche Ausrichtung von Hochschulangeboten im Heimatland. Im Hinblick auf die US-amerikanische Hochschulhälfte in Budapest sah sich die CEU, trotz des lebhaften Protestes ihres Rektors Michael Ignatieff, ${ }^{604}$ eines früheren kanadischen Politikers, im Dezember 2018 mit Wirkung zum Herbst 2019 gezwungen, nur die in Ungarn akkreditierten Kurse in Budapest zu belassen und die gerade für Ausländer attraktiven US-amerikanischen und englischsprachigen Programme nach Wien auszulagern. ${ }^{605}$

Der Entscheidung der Universität waren im Frühjahr 2017 vielfache Versuche vorausgegangen, den Verbleib der CEU, die 1991 auch mit der

602 Den Eindruck dieser Lage in Ungarn teilt z.B. János Kornai, „Hungary’s UTurn“, S. 35, der auch festhält, das ungarische Parlament sei eine „Gesetzesfabrik" geworden.

603 Dass diese Situation landläufig auch in Polen beobachtet wurde, verdeutlicht die dortige Auseinandersetzung mit der Beziehung Kaczyński-Duda.

604 Die CEU bietet auf ihrer Homepage eine ausführliche Dokumentation des Vorgangs, einschließlich einer Zeitleiste, vgl. unter: https://www.ceu.edu/istand withceu/timeline-events.

605 Shaun Walker, „Classes move to Vienna as Hungary makes rare decision to oust university“, The Guardian vom 16.11.2019. 
Intention gegründet worden war, US-amerikanische Hochschulstandards in Osteuropa Fuß fassen zu lassen, ${ }^{606}$ in Budapest zu retten.

Die Europäische Kommission zeigte sich überzeugt, dass das Hochschulgesetz ganz auf die CEU zugeschnitten war. ${ }^{607}$ Die Venedig-Kommission erstattete ein Gutachten und bescheinigte der CEU eine europaweit einzigartige Konstellation. ${ }^{608}$ Seitens der Universität und in der ungarischen Zivilgesellschaft wurde massiv protestiert. ${ }^{609}$ Einen Tag nach einer Aussprache im Europäischen Parlament am 26.04.2017, an der Ungarns Ministerpräsident Orbán sowie der Erste Vizepräsident der Kommission, Frans Timmermans, teilnahmen, leitete die Europäische Kommission ein Vertragsverletzungsverfahren gegen Ungarn ein. ${ }^{610}$ Orbán wurde aus der Mitte des Parlaments scharf angegriffen, auch der Vorsitzende der EVPFraktion, welcher die Fidesz angehört, äußerte deutliche Kritik. ${ }^{611}$ Die CEU wiederum schloss im September 2017 ein Abkommen mit einem US-amerikanischen College, um physisch in den USA Kurse anbieten zu können, wie seitens der ungarischen neuen Gesetzgebung verlangt, und nachdem seitens des US-Bundesstaates New York mehrfach darauf hingewiesen worden war, dass in den USA die Entscheidung hierüber nicht auf Bundesebene liege. Die ungarischen Behörden reakkreditierten im Februar 2018 schließlich allein die ungarische juristische Person der CEU, deren Verbleib in Budapest, allein mit den ungarischen Angeboten, damit ermöglicht wurde, während für die US-akkreditierten Kurse die Abwanderung unvermeidlich wurde. ${ }^{612}$

606 Vgl. hierzu die Selbstdarstellung der Universität unter https://www.ceu.edu/abo ut/history.

607 Vgl. die Remarks of First Vice-President Frans Timmermans after the College discussion on legal issues relating to Hungary vom 12.04.2017, SPEECH/17/966.

608 Venedig-Kommission CDL-AD(2017)022, Opinion 891/2017, Hungary - Opinion on Article XXV of 4 April 2017 on the Amendment of Act CCIV of 2011 on National Tertiary Education vom 09.10.2017, Rn. 16, $24 \mathrm{ff}$.

609 Eine Übersicht über verschiedene Reaktionen findet sich im vorg. Gutachten der Venedig-Kommission, Rn. 13.

610 Vgl. die Ankündigung der Europäischen Kommission, „Hungary: Commission takes legal action on Higher Education Law and sets record straight on ,Stop Brussels" consultation ["updated 26/04/17 at 15:25]" vom 26.04.2017, verfügbar unter: http://europa.eu/rapid/press-release_MEX-17-1116_en.htm.

611 Eine Zusammenfassung der Aussprache findet sich als „MEPs discuss situation in Hungary with Prime Minister Orbán“ vom 26.04.2017 unter: http://www.eur oparl.europa.eu/news/en/press-room/20170424IPR72035/meps-discuss-situation -in-hungary-with-prime-minister-orban.

612 Vgl. zu den vorgenannten Daten nochmals https://www.ceu.edu/istandwithceu/ timeline-events. 


\section{Die Rechtsstaatlichkeitskrise in mitgliedstaatlichen Fällen}

Der Europäische Gerichtshof hat über die Klage der Kommission, mit der insbesondere eine Verletzung des GATT, der Dienstleistungsrichtlinie für den Binnenmarkt, der Arbeitnehmer- und Kapitalfreizügigkeit sowie der Chartagrundrechte der Forschungsfreiheit (Art. 13 GRCh), der Freiheit zur Einrichtung einer Lehranstalt (Art. 14 Abs. 3 GRCh) und der unternehmerischen Freiheit (Art. 16 GRCh) gerügt wird, ${ }^{613}$ bislang nicht entschieden.

\section{b. Lex NGO}

Ähnlich gestrickt wie die „Lex CEU“ ist die sog. „Lex NGO“.614 Das Gesetz vom Juli 2017 zwingt alle Nichtregierungsorganisationen in Ungarn, die mehr als umgerechnet ca. 23.500 Euro an Zuwendungen aus dem Ausland erhalten, sich in ein Register der „ausländisch unterstützten Organisationen" einzutragen, das öffentlich eingesehen werden kann, und diese Eintragung durch einen deutlichen Hinweis auf ihrer Webseite öffentlich zu machen. ${ }^{615}$ Die ungarische Regierung begründet ihr Vorgehen mit der Furcht vor der ausländischen Finanzierung terroristischer Vereinigungen. Die rechtswissenschaftliche Literatur bemängelt aber, dass durch das Gesetz wiederum einzelne Akteure besonders betroffen sind, darunter das sog. ungarische Helsinki-Komitee, ${ }^{616}$ das zur Gruppe der gleichnamigen Komitees zählt, die sich im Anschluss an die KSZE-Schlussakte von Helsinki in zahlreichen osteuropäischen Ländern gegründet hatten und dort rechtliche Expertise und Aufarbeitung bei zivilgesellschaftlich relevanten Themen liefern sollten. Das ungarische Helsinki-Komitee hatte sich zuvor mit Gutachten zu Vorgängen im Land einen Namen gemacht.

613 EuGH, Rs. C-66/18, Kommission ./. Ungarn, Klage anhängig, ABl.(EU) C 211/17, vom 18.06.2018 weiter auch die Schlussanträge der Generalanwälting Juliane Kokott vom 05.03.2020, ECLI:EU:C:2020:172.

614 Vom ungarischen Helsinki-Kommittee übersetzt vorgelegt als "Act LXXVI of 2017 on the Transparency of Organisations Receiving Foreign Funds" vom 13.06.2017. abrufbar unter: https://www.helsinki.hu/wp-content/uploads/LexN GO-adopted-text-unofficial-ENG-14June2017.pdf.

615 Eine genaue Aufarbeitung findet sich bei Petra Bárd, „The Hungarian ,Lex NGO' before the CJEU: Calling an Abuse of State Power by its Name“, Verfassungsblog vom 27.01.2020, o.S.

616 Petra Bárd, „The Hungarian ,Lex NGO` before the CJEU:Calling an Abuse of State Power by its Name“. 
Das Gesetz wurde in Ungarn lebhaft diskutiert und führte u.a. zu einem Protestbrief von 31 Nichtregierungsorganisationen an die OSZE, der insbesondere den durch das Gesetz geschaffene "chilling effect" beklagte. ${ }^{617}$ Auch die Europäische Agentur für Grundrechte FRA äußerte sich besorgt und berichtete von vereinzelten Übergriffen auf Angehörige von NGOs. ${ }^{618}$

Wiederum reichte die Kommission beim Europäischen Gerichtshof eine Vertragsverletzungsklage ein und rügte eine Verletzung der Kapitalverkehrsfreiheit nach Art. 63 AEUV sowie eine Verletzung der Grundrechte der Artikel 7, 8 und 12 der Grundrechtecharta (Achtung des Privatlebens, Recht auf Datenschutz und Vereinigungsfreiheit). Sie trug insbesondere vor, das Gesetz verfehle seinen Zweck. Ungarn habe in keiner Weise dargelegt, dass und warum die benannten Organisationen die öffentliche Sicherheit gefährdeten. ${ }^{619}$ Generalanwalt Manuel Campos Sánchez-Bordona schlug vor, der Klage umfassend stattzugeben. ${ }^{620}$ Ein Urteil steht aus.

\section{Eingriffe in die Marktwirtschaft und die Eigentumsordnung}

a. Beobachtungen in der Literatur

Weiter eng verwandt mit dem o.g. Topos der Einzelfallgesetze, indes zu verklammern unter eine selbstständige Beobachtung, ist der wiederholte Eingriff der ungarischen Regierung in marktwirtschaftliche Abläufe im Land. Herausgearbeitet hat diese Beobachtung beispielhaft der Ökonom János Kornai ${ }^{621}$ Kornai beobachtet infolge der Politikgestaltung durch die Fidesz und die Regierung Orbán „frequent legal, economic, and ideological attack $[s]$ " auf das Privateigentum. ${ }^{622}$ Kornai wiederholt den Vorwurf

617 OSCE, "Independent Civil Society under Attack in Hungary: Statement by Hungarian NGOs”, Dokumentennr.: HDIM.NGO/0052/17/EN vom 22.09.2017.

618 Europäische Agentur für Grundrechte, „FRA expresses concern over threats to civil society and freedom of education in the EU“, Pressemitteilung vom 10.04.2017.

619 EuGH, Rs. C-78/18, Kommission ./. Europäische Kommission (Transparenz von Vereinigungen), Schlussanträge des Generalanwalts Manuel Campos SánchezBordona vom 14.01.2020, ECLI:EU:C:2020:1, Rn. 53.

620 EuGH, Rs. C-78/18, Kommission ./. Europäische Kommission (Transparenz von Vereinigungen), Schlussanträge, Rn. 117.

621 János Kornai, „Hungary’s U-Turn“; summarisch hierauf Bezug nehmend ebenso bereits Matthias Schmidt \& Piotr Bogdanowicz, „The Infringement Procedure in the Rule of Law Crisis“, S. 1087.

622 János Kornai, „Hungary’s U-Turn“, S. 36. 
schneller Gesetzgebung ohne ausreichende Konsultierung zivilgesellschaftlicher Akteure. ${ }^{623} \mathrm{Er}$ identifiziert in der makroökonomischen Politik der Fidesz den Typus eines „overreaching state“, 624 der damit weit über ordoliberale Grundprinzipien bzw. solche der sozialen Marktwirtschaft betreffend die Wirtschaftslenkung hinausgeht, sondern insbesondere auf die Schaffung und Begünstigung sog. „,Fideszközeli cég,' meaning ,a near-toFidesz company “" abziele. ${ }^{625}$ Beispielhaft für Handlungen zugunsten derartiger parteinaher Unternehmen seien widersprüchliche Steuersysteme, ${ }^{626}$ die Ausgrenzung von Geringverdienern, gerade in staatsnahen Unternehmen $^{627}$ und strenge Hierarchien innerhalb der Unternehmen, ${ }^{628}$ welche auf eine Kontrolle von Parteifunktionären hinausliefen.

"This is not a case of ,state capture" carried out by oligarchs in order to establish regulations and pass measures in their own interest. Rather, it is the state that is in command. Orbán and his inner circle decide who should become or remain an oligarch, and how far that oligarch's sphere of authority should extend." 629

\section{b. Urteile des EGMR und des EuGH}

Eine Auswertung verschiedener Urteile des EGMR und des EuGH vermag diese Beobachtung zu stützen.

Zunächst zu nennen ist hierbei das Urteil des EGMR in der Sache Vékony... Ungarn. ${ }^{630}$

Die Individualbeschwerde betraf ein ungarisches Gesetz zur Errichtung eines Verkaufsmonopols für Tabakprodukte, das so ausgestaltet war, dass es einem neu gegründeten Staatsunternehmen die Verantwortung für die

623 János Kornai, „Hungary’s U-Turn“, S. 37.

624 János Kornai, „Hungary's U-Turn“, S. 36 ff.

625 János Kornai, „Hungary's U-Turn“, S. 38 und ff.

626 János Kornai, „Hungary’s U-Turn“, S. 38.

627 János Kornai, „Hungary’s U-Turn“, S. 39.

628 János Kornai, „Hungary’s U-Turn“, S. 37.

629 János Kornai, „Hungary’s U-Turn“, S. 37.

630 EGMR, Vékony ./. Ungarn, Beschwerdenr.: 65681/13, Urteil vom 13.01.2015; Einordnung bei Jörg Gundel, „Der Schutz der unternehmerischen Freiheit durch die EU-Grundrechtecharta", in: Zeitschrift für das gesamte Handels- und Wirtschaftsrecht 180 (2016), S. 323-357, 327. 
Ausgabe staatlicher Verkaufslizenzen übertrug. ${ }^{631}$ Die drastische Reduzierung der Lizenzen führten zur erzwungenen Geschäftsaufgabe vorrangig kleiner Einzelhändler, darunter befand sich der Beschwerdeführer. Vergeben wurden die neuen Lizenzen in einem öffentlichen Bieterverfahren. Wie im Falle der Lex CEU handelt es sich um einen prima facie legitimen Regelungszweck - hier die Reduzierung einer gesundheitsschädlichen Aktivität in der Bevölkerung, dort die Integrität des Hochschulsystems -, wobei andere europäische Staaten ebenso Monopoleinrichtungen, etwa für den Alkoholverkauf oder das Glücksspiel, kennen. Ähnlich sah es auch das ungarische Verfassungsgericht, das Verfassungsbeschwerden mit der Begründung verwarf, den Beschwerdeführern sei die Möglichkeit der Beantragung von Lizenzen nicht generell verwehrt und aus der vorherigen Rechtslage und faktischen wirtschaftlichen Situation ergäben sich keine vom Eigentumsgrundrecht geschützten legitimen Erwartungen. ${ }^{632}$

Der EGMR befand, die Ausgestaltung des Gesetzes und seine Handhabung im konkreten Fall seien aus mehreren Gründen unverhältnismäßig. ${ }^{633}$ Hierzu zählte der Straßburger Gerichtshof die sehr kurze Zeit zwischen Vorschlag und Erlass des Gesetzes - wie sie aus anderen Beispielen, etwa der Lex CEU, bereits bekannt ist - und das Fehlen „elementarer Transparenz" sowie jeglichen Rechtsschutzes im Bieterverfahren. ${ }^{634}$ Aufgrund dieser deutlichen Mängel könne auch ein prima facie legitimer Zweck, nämlich der Schutz der öffentlichen Gesundheit und die damit einhergehende weite Einschätzungsprärogative des Gesetzgebers, das Gesetz nicht als verhältnismäßig erscheinen lassen. ${ }^{635}$ Der Gerichtshof notierte eine an „Willkür grenzende“ Ausgestaltung und eine Abwesenheit einer ernsthaften Abhilfemöglichkeit für die Betroffenen, ${ }^{636}$ da es ungeachtet des Bestandes des jeweiligen Unternehmens diesen jeweils nur wenige Monate zur Antragsstellung und Erlangung der neuen Lizenz gegeben habe und eine Entschädigung nicht vorgesehen gewesen sei. 637

631 EGMR, Vékony ./. Ungarn, Rn. 8, zu den weiteren Punkten der Lizenzvergabe vgl. Rn. 6-13.

632 EGMR Vékony ./. Ungarn, Rn. 16.

633 EGMR, Vékony ./. Ungarn, Rn. 32 ff.

634 EGMR, Vékony ./. Ungarn, Rn. 34, 36.

635 EGMR, Vékony ./. Ungarn, Rn. 35.

636 EGMR, Vékony ./. Ungarn, Rn.34, 36. Der EGMR spricht von „verging on arbitrariness", im Ergebnis scheint dies dem Verstoß gegen das Willkürgebot weitestgehend gleichgesetzt.

637 EGMR, Vékony ./. Ungarn, Rn. 35. 


\section{Die Rechtsstaatlichkeitskrise in mitgliedstaatlichen Fällen}

Zwei weitere Entscheidungen des EuGH werfen sodann ein Schlaglicht auf wirtschaftspolitisch ähnlich gelagerte Vorgänge. Es ist allerdings hervorzuheben, dass der Gerichtshof dabei zu den Rügen der Kläger der Ausgangsverfahren in der Sache nicht Stellung nahm, sondern die finale Beurteilung den mitgliedstaatlichen Gerichten überließ.

Zunächst zu nennen ist die Entscheidung des EuGH in der Rechtssache Berlington, eine Vorabvorlage eines ungarischen Gerichts. ${ }^{638}$ Hier rügten die Klägerinnen des Ausgangsverfahrens, Handelsgesellschaften im Glücksspielgewerbe, dass Änderungen im Steuerrecht eine Glücksspielsteuer auf bestimmte Automaten änderten, die der ungarische Gesetzgeber ad-hoc um ein Vielfaches steigerte. ${ }^{639}$ Sie trugen insbesondere vor, die Regelungen führten, ungeachtet ihrer einheitlichen Anwendbarkeit gegenüber allen Marktteilnehmern, zu einer „De-Facto-Exklusivität“ für bestimmte Markteilnehmer, nämlich Spielkasinos im Unterschied zu Spielhallen. ${ }^{640}$ Die vorher bestehenden Lizenzen erloschen automatisch. Der EuGH verwies diese Frage, die der indirekten Einrichtung eines Monopols in einem Marktbereich gleichkommt (während im EGMR-Fall Vékony eine unmittelbare Monopol-Schaffung zu beobachten war) allerdings zur Beurteilung an das nationale Gericht zurück. Gleich verfuhr der EuGH mit der Frage der Rechtssicherheit und des Vertrauensschutzes, die er allerdings im Rahmen seiner sich an die Grundfreiheitsprüfung anschließenden Grundrechtsprüfung nach der Charta thematisierte. ${ }^{641} \mathrm{Er}$ traf dabei die Feststellung, dass im Spannungsfeld des legitimen Interesses der Mitgliedstaaten hinsichtlich der geordneten Lenkung des Glücksspiels und den wirtschaftlichen Interessen der Betreiber, die im Rahmen der Verhältnismäßigkeitsprüfung hinsichtlich einer möglichen Verletzung der Dienstleistungsfreiheit, Art. 56 AEUV, beachtlich waren, ${ }^{642}$ die Ziele der Bekämpfung von Kriminalität und Betrug wirklich, kohärent und systematisch verfolgt sein müssten. ${ }^{643}$

Ein weiterer Fall gleicher Prägung ist die EuGH-Entscheidung in SZÉPKarte und Erzsebet-Gutscheine, diesmal in Form einer Vertragsverletzungs-

638 EuGH, Rs. C-98/14, Berlington Hungary Tanácsadó és Szolgáltató kft u.a. ./. Magyar Állam [Ungarischer Staat], Urteil (GK) vom 11.06.2015, ECLI:EU:C:2015:386.

639 EuGH, Rs. C-98/14, Berlington, Rn. 2, 13 ff., 18.

640 EuGH, Rs. C-98/14, Berlington, Rn. 39-40.

641 EuGH, Rs. C-98/14, Berlington, Rn. 79-80.

642 EuGH, Rs. C-98/14, Berlington, Rn. 62 ff, $69 \mathrm{ff}$.

643 EuGH, Rs. C-98/14, Berlington, Rn. 92. 
klage der Kommission. ${ }^{644}$ Die Entscheidung betraf die gesetzliche Einführung einer Rabatt-Freizeitkarte (sog. SZÉP-Karte) und eines Couponrabattsystems, der sog. Erzsebet-Gutscheine. Beide Systeme konnten zum Erhalt von verschiedenen Dienstleistungen, wie bei der Freizeitgestaltung (SZÉPKarte) und warmen Mahlzeiten (Erzsebet-Gutscheine) verwendet werden. Sie wurden an Arbeitnehmer ausgegeben, von den Arbeitgebern mit Geldbeträgen „aufgeladen“, welche diese wiederum steuerlich geltend machen können. Die Kommission rügte eine Vertragsverletzung durch die Ausgestaltung des Programms, die darauf hinauslaufe, dass nur Unternehmen bestimmter Beschaffenheit, Größe und Marktetablierung das Programm als Dienstleister anbieten konnten, was aufgrund der Beschaffenheit des Marktes in Ungarn darauf hinausliefe, allein drei ungarische Banken in den Genuss dieser Tätigkeitsmöglichkeit zu bringen. ${ }^{645}$ Diese komme einer Monopolschaffung gleich. ${ }^{646}$

Der EuGH prüfte insbesondere die Frage der Monopolschaffung ausführlich, bejahte sie und befand die gesetzliche Regelung u.a. aus diesem Grund für mit Art. 49 und 56 AEUV unvereinbar. ${ }^{647}$ Allerdings äußerte er sich nicht zu einer weiteren Einordnung in die wirtschaftliche Entwicklung Ungarns. Diese bleibt folglich dem wissenschaftlichen Betrachter überlassen, der, wie hier, Parallelen zu Fällen betreffend Ungarn aufzeigen kann.

Erst in späteren Urteilen ist der EuGH schließlich auch in der Sache kritisch geworden, als er sich mit grundlegenden Änderungen in der ungarischen Eigentums- und Wirtschaftsordnung zu beschäftigen hatte. Prominent geworden ist das in zwei Fällen, in denen sich der Gerichtshof mit der Behandlung von Nießbrauchsrechten an Grundstücken durch den ungarischen Gesetzgeber zu beschäftigen hatte.

In der Rechtssache SEGRO und Horváth klagten ein Unternehmen und eine natürliche Person hinsichtlich der Behandlung von Nießbrauchsrechten an landwirtschaftlichen Grundstücken, die die ungarischen Behörden in einem Fall vorab, im anderen Fall nach dem Beitritt Ungarns zur Union gelöscht hatten. Ausgangspunkt hierfür ist zunächst die Besonderheit im postsozialistischen ungarischen Immobiliarsachenrecht, wonach Ausländer kein Grundeigentum, wohl aber ein Nießbrauchsrecht erwerben

644 EuGH, Rs. C-179/14, Kommission ./. Ungarn, s. insb. zur Rechtslage Rn.1, $10 \mathrm{ff} ., 21 \mathrm{ff}$.

645 EuGH, Rs. C-179/14, Kommission ./. Ungarn, Rn. 72-76.

646 EuGH, Rs. C-179/14, Kommission ./. Ungarn, Rn. 1.

647 EuGH, Rs. C-179/14, Kommission ./. Ungarn, Rn. 172, 2. Leitsatz des Tenors. 


\section{Die Rechtsstaatlichkeitskrise in mitgliedstaatlichen Fällen}

konnten. Dies führte im Verlauf der 2000er Jahre zu einer sehr großen Zahl derartiger dinglicher Belastungen an Grundstücken. 2013 änderte der ungarische Gesetzgeber überraschend nachträglich die Rechtslage am entsprechenden Gesetz, die das Nießbrauchsrecht nur „nahen Angehörigen“ zugestand, zu welchen die Kläger nicht zählten, im Übrigen bestellte Rechte aber für nichtig erklärten. ${ }^{648}$ Die Eigentümer der Klägerin zu 1 waren in Deutschland wohnende Staatsangehörige anderer Mitgliedstaaten, der Kläger zu 2 war Österreicher. ${ }^{649}$

Im ausländischen Journalismus fanden die Änderungen einige Beachtung, u.a. machte der Deutschlandfunk geltend, die Änderungen beträfen eine Vielzahl an Investoren und bis zu $20 \%$ der agrarisch genutzten Fläche Ungarns. Zudem begünstigten sie vor allem Großbauern, die Parteifreunde Viktor Orbáns seien. 650

Der EuGH hielt zunächst fest, dass Art. 345 AEUV zwar die Neutralität des Unionsrechts gegenüber nationalen Eigentumsordnungen vorsehe, dies aber nicht dazu führen könne, dass nationale Regelungen gegen die Grundfreiheiten des Unionsrechts verstießen. ${ }^{651}$ Im vorliegenden Fall sah der EuGH in der Regelung eine mittelbare Diskriminierung von Angehörigen anderer Mitgliedstaaten, ${ }^{652}$ die nur durch ein allgemeines Interesse zu rechtfertigen sei. ${ }^{653}$ Dies liege aber nicht vor, denn die bloße Bestimmung, dass nur nahe Angehörige Nießbrauchsrechte erwerben dürften, führe gerade nicht dazu, einer möglichen Bodenspekulation vorzubeugen. ${ }^{654}$ Auch das Ziel der Bekämpfung von Landflucht lasse sich allein durch das Abstellen auf Verwandtenverhältnisse nicht garantieren. ${ }^{655}$ Auch zwei weitere Gegenargumente der ungarischen Regierung verwarf der Gerichtshof. So könne keine Rede davon sein, mit der Regelung den Zufluss von Devisen nach Ungarn kontrollieren zu wollen, wenn gleichzeitig gut 95.000 Ungarn von der Regelung betroffen $\operatorname{seien}^{656}$ und zum

648 EuGH, Verb. Rs. C-52/16 und C-113/16, „SEGRO“ Kft. ./. Vas Megyei Kormányhivatal Sárvári Járási Földhivatala und Günther Horváth ./. Vas Megyei Kormányhivatal, Urteil (GK) vom 06.03.2018, ECLI:EU:C:2018:157, zur nationalen Rechtslage insb. Rn. 5 ff.

649 EuGH, Verb. Rs. C-52/16 und C-113/16, SEGRO und Horváth, Rn. 15 und 30.

650 Jan-Uwe Stahr, „Ungarnland in Bauernhand? Viktor Orbáns agrarischer Neustart", Deutschlandfunk vom 30.10.2013.

651 EuGH, Verb. Rs. C-52/16 und C-113/16, SEGRO und Horváth, Rn. 51.

652 EuGH, Verb. Rs. C-52/16 und C-113/16, SEGRO und Horváth, Rn. 76.

$653 \mathrm{EuGH}$, Verb. Rs. C-52/16 und C-113/16, SEGRO und Horváth, Rn. $81 \mathrm{ff}$.

654 EuGH, Verb. Rs. C-52/16 und C-113/16, SEGRO und Horváth, Rn. 87.

655 EuGH, Verb. Rs. C-52/16 und C-113/16, SEGRO und Horváth, Rn. 89.

656 EuGH, Verb. Rs. C-52/16 und C-113/16, SEGRO und Horváth, Rn. 104. 
anderen diene die Regelung auch nicht der Vermeidung eines bewussten Unterlaufens ungarischen Rechts, wenn vorher geklärt worden sei, dass mit der Regel eben kein legitimer Zweck verfolgt werde. ${ }^{657}$ Art. 63 AEUV stehe daher den Gesetzesänderungen entgegen.

In einem weitgehend identisch gelagerten Fall hat die Kommission wenig später Vertragsverletzungsklage erhoben. ${ }^{658}$ Die Kommission rügte ebenso eine Unvereinbarkeit derselben gesetzlichen ungarischen Vorschriften mit der Niederlassungs- und Dienstleistungsfreiheit (Art. 49 und 63 AEUV) sowie der Eigentumsgarantie der Grundrechtecharta aus ihrem Art. 17.659 Der Gerichtshof wiederholte unter Verweis auf das Urteil in SEGRO den Eingriff in Art. 63 AEUV aufgrund des Entzuges „ex lege“ der Nießbrauchsrechte. ${ }^{660}$

Sehr interessant ist sodann die Argumentation hinsichtlich des von der Kommission geltend gemachten Eingriffs in Art. 17 der Grundrechtecharta. Der Gerichtshof befand den Anwendungsbereich der Charta i.S.d. Art. 51 derselben schon deswegen für eröffnet, weil sich Ungarn auf einen Ausnahmetatbestand des Unionsrechts berufen habe. ${ }^{661}$ In der Sache ähnelt die - bejahte - Verletzung von Art. 17 der Charta durch Entziehung von Eigentumsrechten derjenigen in SEGRO. Weder sei der Entzug der Nießbrauchsrechte zur Kontrolle des Devisenzuflusses erforderlich gewesen, noch habe Ungarn nachgewiesen, dass eine Umgehung nationaler Eigentumsrechte im Raum gestanden habe. ${ }^{662} \mathrm{Im}$ Ergebnis gelangt der EuGH zum harten Befund einer Entziehung von Eigentumspositionen unter Verstoß gegen Art. 17 Abs. 1 der Charta. 663

657 EuGH, Verb. Rs. C-52/16 und C-113/16, SEGRO und Horváth, Rn. 118 ff., 119-122 insb.

658 EuGH, Rs. C-235/17, Kommission ./. Ungarn (Nießbrauchsrechte an landwirtschaftlichen Flächen), Urteil (GK) vom 21.05.2019, ECLI:EU:C:2019:432.

659 EuGH, Rs. C-235/17, Kommission ./. Ungarn (Nießbrauchsrechte an landwirtschaftlichen Flächen), Rn. 1.

660 EuGH, Rs. C-235/17, Kommission ./. Ungarn (Nießbrauchsrechte an landwirtschaftlichen Flächen), Rn. 58.

661 EuGH, Rs. C-235/17, Kommission ./. Ungarn (Nießbrauchsrechte an landwirtschaftlichen Flächen), Rn. 65.

662 EuGH, Rs. C-235/17, Kommission ./. Ungarn (Nießbrauchsrechte an landwirtschaftlichen Flächen), Rn. 75-77.

663 EuGH, Rs. C-235/17, Kommission ./. Ungarn (Nießbrauchsrechte an landwirtschaftlichen Flächen), Rn. 86. 


\section{Die Rechtsstaatlichkeitskrise in mitgliedstaatlichen Fällen}

\section{c. Bewertung}

In keinem der vorbenannten Urteile des EGMR und des EuGH haben die Parteien unmittelbar die Rechtsstaatlichkeit als solche, mit ihr i.S. ihrer Operationalisierung ${ }^{664}$ verknüpfte Prinzipien oder eine systematische Unterwanderung der Unionsrechtsordnung geltend gemacht. ${ }^{665}$ Die „systematische Löschung“" von Nießbrauchsrechten, die der EuGH beobachtet, ${ }^{666}$ bezieht sich vorrangig auf die einheitliche Anwendung der Gesetzesänderung selbst. Die Kommission hat eine Verletzung von Grundprinzipien der Union in keinem der Fälle geltend gemacht, sie hat ihre Klage im letztgenannten Fall auf Grundfreiheiten und das Chartagrundrecht der Eigentumsgarantie gestützt.

Insofern ist die Feststellung, dass die benannten Urteile das Argument einer willkürlichen und weitverbreiteten Unterwanderung rechtsstaatlicher Prinzipien zum Gegenstand haben, eine Rekonstruktion der Wissenschaft, die über den Wortlaut der Urteile hinausgeht und deswegen angreifbar ist. Die systemische Komponente ergibt sich nach meiner Überzeugung aber gleichwohl aufgrund der Konstanz der sowohl vom EGMR als auch vom EuGH beobachteten realen Auswirkungen der untersuchten Gesetzesvorhaben. Stets wurde seitens des Gesetzgebers schnell und stark diskriminierend mit Blick auf bestimmte Personengruppen und dazu plötzlich eine gesetzliche Regelung grundlegend geändert. Die Motivbündel des Gesetzgebers zur Rechtfertigung der Vorhaben haben EGMR und EuGH stets vollständig verworfen oder aber den nationalen Gesetzen genaue Leitlinien bei der eigenen Würdigung vorgegeben, die auf starke Zweifel schließen lassen. Durch Beobachter ist regelmäßig der Verdacht angeführt worden, dass durch den Entzug der Rechtspositionen andere Teilnehmer am Wirtschaftsleben seitens des Gesetzgebers begünstigt werden sollten. Besonders nützlich ist hier eine Feststellung Scheppeles, die später bei der Sichtung des Vertragsverletzungsverfahrens als Verfassungsaufsichtsmechanismus nochmals anklingen muss. Scheppeles Überlegungen zu diesem Verfahren beruhen im Kern auf der Vorstellung einer Zusammenfassung (Bündelung) verschiedener Vertragsverletzungen.

664 S. dazu oben unter B. II. und IV.

665 Der EuGH hat die Überlegung eines systematischen Vorgehens nur insoweit zum Gegenstand seiner Überlegung gemacht, dass umgekehrt Maßnahmen des Mitgliedstaats nur dann zu rechtfertigen sind, wenn sie systematisch und kohärent dem angestrebten Anliegen des Gesetzgebers gerecht werden, vgl. etwa Verb. Rs. C-52/16 und C-113/16, SEGRO und Horváth, Rn. 78.

666 Verb. Rs. C-52/16 und C-113/16, SEGRO und Horváth, Rn. 104. 
Wenn sie auch in ihrem Vorschlag hierüber hinausgeht und insbesondere die Subsumierung unter einen grundlegenden Maßstab des Unionsrechts, wie den Wertekatalog des Art. 2 EUV fordert ${ }^{667}$ so beruht ihr Gedanke doch auf der Feststellung, dass es der Europäischen Kommission gelingen müsse, zunächst in parallelen und augenscheinlich nicht miteinander in Verbindung stehenden Vertragsverletzungen tiefer gelagerte, vorsätzliche Motivbündel seitens der mitgliedstaatlichen Verantwortlichen zu erkennen. ${ }^{668}$ Es gilt, die vorgenannte Rechtsprechung und die Beobachtungen in Presse und Wissenschaft in eine Gesamtschau paralleler, durch Regierung und Gesetzgeber in Ungarn angestoßene Vorgänge zu fassen, hinter denen trotz der Unterschiede im Einzelfall ein vorsätzlicher, in Etappen erfolgender Eingriff in alle Teilbereiche der Gesellschaft, an dieser Stelle in das Wirtschaftsleben und die Eigentumsordnung, zutage tritt.

\section{Verwundbare Gruppen}

Sicherlich teils auch einem der vorab genannten Topoi zuzuordnen, meines Erachtens aber vorrangig einen weiteren Punkt betreffend, sind sodann ungarische Gesetze, die auf die besondere Exponiertheit der betroffenen Gruppe innerhalb der ungarischen Gesellschaft abzielen. Der treffende Rechtsbegriff zu ihrer Charakterisierung ist derjenige der verwundbaren Gruppe (vulnerable group). 669

Der deutschen Rechtssprache und Rechtsdogmatik, die sich hier als Vergleichsobjekt anbietet, scheint ein solcher Begriff aus eigenem Antrieb bislang weitgehend fremd, auch wenn das Bundesverfassungsgericht in jüngerer Rechtsprechung auf die besondere Schutzbedürftigkeit von „Angehörige[n] strukturell diskriminierungsgefährdeter Gruppen vor Benachteiligung" eingegangen ist. ${ }^{670}$ Bislang standen, z.B. im Rahmen von Art. 5 GG, entweder die jeweiligen Einzelpersonen im Verbund oder die juristische Person, die der Verwirklichung dienen, im Vordergrund, wobei dann

667 Kim Lane Scheppele, „Enforcing the Basic Principles of EU Law through Systemic Infringement Actions“, S. 114.

668 Vgl. Kim Lane Scheppele, „Enforcing the Basic Principles of EU Law through Systemic Infringement Actions", S. 112.

669 Nochmals hierzu kursorisch bereits die Ausführungen bei Matthias Schmidt \& Piotr Bogdanowicz, „The Infringement Procedure in the Rule of Law Crisis“, S. 1087.

670 BVerfGE 147, 1 = NJW 2017, 3643 = 1 BvR 2019/16 - Geschlechtliche Identität, Rn. 59 der Urteilsbegründung. 


\section{Die Rechtsstaatlichkeitskrise in mitgliedstaatlichen Fällen}

auf den Schutz derselben oder der einzelnen in ihr verbundenen Individuen abgestellt wurde. ${ }^{671} \mathrm{Im}$ Unionsrecht ist der Begriff der verwundbaren Gruppe zwar bekannt, aber hier für die Analyse noch nicht ausreichend. Er weist nämlich nach bisherigem Verständnis vorrangig auf eine Gruppe natürlicher Personen hin, die aufgrund eines höchstpersönlichen Merkmals von der Masse der anderen Menschen abgehoben ist. So jedenfalls ist der Begriff etwa vom Rat für Allgemeine Angelegenheiten oder den Wissenschaftlichen Dienst des Europäischen Parlaments in Bezug auf diverse Minderheiten verwendet worden, ${ }^{672}$ ebenso wie durch den Europäischen Gerichtshof. ${ }^{673}$ Auch die Unionsrechtswissenschaft, die für „besonders schutzbedürftige Personengruppen" Kategorisierungen entwickelt hat, ${ }^{674}$ verharrt auf dieser Ebene der Betrachtung. Ähnlich wird der Begriff in der Rechtsprechung des EGMR verwendet. 675

Ich übernehme deswegen hier das Begriffsverständnis des interamerikanischen Rechts, um den Begriff der verwundbaren Gruppe auch im Unionsrecht für die Rechtsstaatlichkeitskrise nutzbar zu machen. Die dortige

671 Vgl. etwa Christoph Grabenwarter, in Theodor Maunz \& Günter Dürig (Begr./ Hrsg.), Grundgesetz-Kommentar, Art. 5 Abs. 1 und 2, Rn. 38 ff., insb. Rn. 40, 88. EL, August 2019.

672 Schlussfolgerungen des Rates für Allgemeine Angelegenheiten vom 16.12.2014, zitiert in: Wissenschaftlicher Dienst des Europäischen Parlaments, An EU mechanism on democracy, the rule of law and fundamental rights: Annex II Assessing the need and possibilities for the establishment of an EU Scoreboard on democracy, the rule of law and fundamental rights, PE 579.328 - April 2016, S. 34 (für LGBTQ-Personen); eigenes Verständnis des wissenschaftlichen Dienstes des Parlaments auf S. 98 ("insular or vulnerable minorities").

673 EuGH, Rs. C-103/16, Jessica Porras Guisado ./. Bankia SA u.a., Schlussanträge der Generalanwältin Eleanor Sharpston vom 14.09.2017, ECLI:EU:C:2017:691, Rn. 38 (schwangere Frauen).

674 Ausführlich zu Kindern, älteren Menschen und Menschen mit Behinderungen als „besonders schutzbedürftige Personengruppen“ nach der GRCh Dieter Kugelmann, „Gleichheitsrechte und Gleichheitsgrundsätze“, in: Detlef Merten \& Hans-Jürgen Papier (Hrsg.), Handbuch der Grundrechte, Bd. VI/1: Europäische Grundrechte I, Springer, Heidelberg, 2010, S. 979-1029. Rn. 72-80.

675 EGMR, M.S.S. ./. Belgien und Griechenland, Beschwerdenr.: 306096/09, Urteil (GK) vom 21. Januar 2011, Sondervotum des Richters Sajó, S. 100 ff., S. 101-102 (ohne Rn.) der engl. Fassung, mit umf. w. N. d. Rspr. Rezeption dieses Begriffsverständnisses die deutsche Rechtsprechung etwa durch das OVG Magdeburg, Beschluss vom 31.08.2016 - Aktenzeichen 3 L 94/16 = BeckRS 2016, 53928 (Flüchtlinge als „besonders schutzbedürftigen Personengruppe“). Das BVerwG hat den Begriff hingegen bislang wohl nicht selbst übernommen, sondern ihn lediglich als solchen des EGMR angeführt, s. BVerwG, Urt. v. 31.10.2013, Az. 10 C 15.12, ECLI:DE:BVerwG:2013:310113U10C15.12.0. Rn. 24. 
Rechtslehre, die insbesondere Ximena Soley prägnant dargestellt hat, ${ }^{676}$ unterscheidet zunächst sog. inhärente Vorbedingungen (inherent conditions), d. h. höchstpersönliche und dauerhafte Merkmale, die sich auf den körperlichen Entwicklungszustand oder das Verstandesvermögen auswirken. Eine zweite Kategorie sind verwundbare Gruppen aufgrund sog. struktureller Merkmale, d.h. dauerhafter oder temporärer körperlicher oder auf die eigene Identität bezogener Merkmale, die die Person einer bestimmten Gruppe zuweisbar machen. Schließlich aber besteht in der interamerikanischen Rechtslehre eine dritte Gruppe von Personen, nämlich solche, die deswegen besonders verwundbar sind, weil sie „situationsspezifischen Risiken ausgesetzt sind“. Es ist diese Gruppe, die an dieser Stelle ganz besonders interessiert.

„Situational risk refers to the special interaction between a person and state authorities. State power is exercised over a person with a special intensity or a person is placed at the mercy of public officials. This is the vulnerability experienced by people who are incarcerated or those committed to psychiatric facilities. Situational risk can also cover other categories of persons, human rights defenders, and journalists in certain political and security contexts." ${ }^{677}$

In Anlehnung an diese Gruppe kann im Deutschen und für das Unionsrecht von im Verfassungsleben exponierten Gruppen ${ }^{678}$ bzw. auch Personen in besonders grundrechtsintensiven Tätigkeitsbereichen gesprochen werden. Legt man über die Entwicklung in Ungarn diese letzte Kategorie der im Verfassungsleben exponierten und dadurch verwundbaren Personen, wird die benachteiligende Entwicklung dieser Gruppen als einem kohärenten Mus-

676 Ximena Soley, „The Transformative Dimension of Inter-American Jurisprudence“, in: Armin von Bogdandy, Eduardo Ferrer Mac-Gregor, Mariela Morales Antoniazzi, Flávia Piovesan (Hrsg.), Transformative Constitutionalism in Latin America, Oxford University Press, Oxford, 2017, S. 337-355, S. 345 unter Bezugnahme auf Romina I. Sijniensky, „From the Non-Discrimination Clause to the Concept of Vulnerability in International Human Rights Law: Advancing on the Need for Special Protection of Certain Groups and Individuals“, in: Yves Haeck, Briane McGonigle Ley, Clara Burbano Herrera, Diana Contreras Garduno (Hrsg.), The Realisation of Human Rights: When Theory Meets Practice: Studies in Honour of Leo Zwaack, Intersentia, Cambridge, 2014, S. 259-272.

677 Ximena Soley, „The Transformative Dimension of Inter-American Jurisprudence", S. 345.

678 Dieser Begriff ist nicht zu verwechseln mit der „politisch exponierten Person“ (PEP), einem Begriff des Wirtschaftsstrafrechts. 


\section{Die Rechtsstaatlichkeitskrise in mitgliedstaatlichen Fällen}

ter folgend sichtbar. Mehrere Gesetzesänderungen in Ungarn sind dann entsprechend einzuordnen.

Eine konsistente Verklammerung dieser Vorgänge ergibt sich insbesondere aus dem Gutachten der Venedig-Kommission zum 4. Verfassungsänderungsgesetz und darüber zu mehreren Gesetzesnovellen bereits im Jahr 2013. Die dort zusammen überprüften Gesetze betrafen die Anerkennung religiöser Gemeinschaften als öffentlich-rechtlich privilegierte Körperschaft („,inkorporierte Kirche“), ${ }^{679}$ die Parteienwerbung, ${ }^{680}$ die finanzielle Unabhängigkeit von Hochschuleinrichtungen, ${ }^{681}$ die Gewährung verbesserter Rückzahlungskonditionen für Studienkredite an Personen, die nach ihrem Studium in Ungarn bleiben und nicht von ihrer unionsrechtlichen Freizügigkeit Gebrauch machen ${ }^{682}$ und ein gesetzliches Nächtigungsverbot für Obdachlose. ${ }^{63}$ Die Regelungsmaterie dieser Gesetze ist überaus heterogen. Es gilt daher für die Beobachtung der einheitlichen Motivlage, neben der gemeinsamen Diskussion durch die Venedig-Kommission, für die Bündelung dieser unterschiedlichen Gesetze das zuvor zu den Urteilen betreffend den Eingriff des ungarischen Gesetzgebers in marktwirtschaftliche Abläufe Gesagte. Es ist Aufgabe der Rechtswissenschaft, aufbauend auf das vermutete Telos der Maßnahmen und eine topische Verklammerung eine einheitliche Struktur herauszuarbeiten, ohne dass der Wortlaut der Gesetze selbst, noch häufig die unmittelbare rechtliche Würdigung durch die Gerichte, hierbei Unterstützung bieten, auch wenn die Gesetze, wie im Fall der Novelle zum Kirchengesetz, Gegenstand eines EGMR-Urteils

679 Venedig-Kommission, CDL-AD(2013)012, Opinion 720/2013, Opinion on the Fourth Amendment to the Fundamental Law of Hungary vom 17.06.2013, Rn. 30 ff. Der Begriff der „inkorporierten Kirche“ findet sich dort nicht, sondern entstammt der sogleich unten zitierten Rspr. des EGMR.

680 Venedig-Kommission, CDL-AD(2013)012, Opinion 720/2013, Opinion on the Fourth Amendment to the Fundamental Law of Hungary vom 17.06.2013, Rn. $37 \mathrm{ff}$.

681 Venedig-Kommission, CDL-AD(2013)012, Opinion 720/2013, Opinion on the Fourth Amendment to the Fundamental Law of Hungary vom 17.06.2013, Rn. $54 \mathrm{ff}$.

682 Venedig-Kommission, CDL-AD(2013)012, Opinion 720/2013, Opinion on the Fourth Amendment to the Fundamental Law of Hungary vom 17.06.2013, Rn. 58 und ff.

683 Venedig-Kommission, CDL-AD(2013)012, Opinion 720/2013, Opinion on the Fourth Amendment to the Fundamental Law of Hungary vom 17.06.2013, Rn. 62 und ff. 
waren, ${ }^{684}$ wobei im Gerichtshof der Fall keinesfalls einheitlich beurteilt wurde. ${ }^{685}$

Abgesehen von Obdachlosen sind alle benannten Gruppen (Kirchen, Parteien, Hochschulen und deren Studenten) vorrangig zwar nicht Personen, die notwendigerweise als „schwach“ einzustufen wären. Regelmäßig sind sie sogar in der Lage, wie etwa NGOs, sehr öffentlichkeitswirksam auf sich aufmerksam zu machen. Ihre Verwundbarkeit resultiert vielmehr aus ihrem besonderen Daseinszweck (Kirche, Partei, Hochschule), der für ihre Angehörigen regelmäßig auf eine ganz bestimmte Zielerreichung ausgelegt ist, in der sie durch staatliche Eingriffe besonders schnell gestört werden können. Oder aber, es steht der Zweck ihrer Tätigkeit im konkreten Fall im Vordergrund, etwa bei Studenten, durch welchen der Erfolg spezifisch an die Ausübung eines bestimmten Rechts, sei es Grundrecht oder Grundfreiheit, geknüpft ist. Auch Begleitumstände, wie besondere Subordinationsverhältnisse, wiederum bei Studenten oder auch bei Kirchen oder Hochschulen gegenüber den Zuwendungsgebern oder durch besondere Unberechenbarkeit und zeitliche Relevanz von Vorhaben, wie bei Parteien, setzen diese Gruppen aufgrund des Angewiesenseins auf besondere situative Vorteile in ein Abhängigkeitsverhältnis zum Staat. Dies hat sich in den bereits geschilderten Fällen gerade der Lex CEU wiederholt. Ziel des Gesetzes war es schließlich, diejenige zentrale Verwundbarkeit auszumachen, die die Universität letztlich zwang, mit einem Großteil ihres akademischen Angebots Ungarn zu verlassen.

Es steht zu beobachten, dass die ungarische Gesetzgebung, welche im Fokus von Union und Europarat steht, darauf abzielt, diese Situationsvorteile abzuschaffen und damit indirekt den Daseinszweck bzw. die Zweckerreichung der Gruppe oder der ihr angehörenden Personen zu vereiteln. So bescheinigt die Venedig-Kommission den von der ungarischen Regierung und dem Parlament verantworteten Gesetzesnovellen, durch über-

684 EGMR, Magyar Keresztény Mennonita Egyház [Ungarische Christlich-Mennonitische Kirche] u.a. ./. Ungarn, Beschwerdenr. 70945/11 u.a., Urteil vom 08.04.2014, zum Urteil auch Katalin Kelemen, „The New Hungarian Constitution: Legal Critiques from Europe“, in: Review of Central and East European Law 42 (2017), S. 1-49, S. 4.

685 EGMR, Magyar Keresztény Mennonita Egyház u.a. ./. Ungarn, Abweichende Meinung des Richters Spáno, unterstützt vom Richter Raimondi, Rn. 12 und 13, der den Änderungen im Wesentlichen einen zuwendungsrechtlichen Charakter zuschrieb und daher bereits die Eröffnung des Schutzbereichs von Art. 9 und 11 der EMRK ablehnte. 


\section{Die Rechtsstaatlichkeitskrise in mitgliedstaatlichen Fällen}

schießende Regelungen oder unbestimmte Tatbestände ${ }^{686}$ die Novellen nicht hinreichend gegen eine Nutzung zu sichern, die diese Gruppen in ihrer Existenz oder Rechtsverwirklichung beeinträchtigen könnte. Sie spricht ebenso von einer ,instrumentellen Verwendung der Verfassung“ ${ }^{687}$

\section{Uniformitätsentscheidungen und die zurückgenommene Verwaltungsgerichtsreform von 2019}

Zwei jüngere Topoi hinsichtlich Ungarn, mit denen die Darstellung der dortigen Krise zu beschließen ist, betreffen Änderungen im Justizsystem, die bislang zum einen den Gerichtshof nur marginal beschäftigt haben, zum anderen zwar prominent diskutiert wurden, durch die ungarische Seite aber nicht weiterverfolgt wurden.

Ihre Verbindung ergibt sich wiederum dadurch, dass die Venedig-Kommission den ersten Topos, die sog. Uniformitätsentscheidung (abgeleitet aus der im Englischen regelmäßig anzutreffenden ,uniformity decision“) ${ }^{688}$ zum wiederholten Male im Rahmen des zweiten Topos der im Jahr 2018 zunächst angekündigten, 2019 dann zurückgenommenen Verwaltungsgerichtsreform diskutiert hat. 689

Die erste Problematik, die sog. Uniformitätsentscheidung, ist eine besondere, in Ungarn seit langem etablierte und bis ins 19. Jahrhundert zurückreichende Ausprägung des stare-decisis-Prinzips. ${ }^{690}$ Das Rechtsinstitut

686 S. etwa Venedig-Kommission, CDL-AD(2013)012, Opinion 720/2013, Opinion on the Fourth Amendment to the Fundamental Law of Hungary vom 17.06.2013, Rn. 36, 141 insb.

687 Venedig-Kommission, CDL-AD(2013)012, Opinion 720/2013, Opinion on the Fourth Amendment to the Fundamental Law of Hungary vom 17.06.2013, Rn. 135 und ff.

$688 \mathrm{Vgl}$. dazu die entsprechende Informationsseite des ungarischen Obersten Gerichtshofs (Kúria), https://kuria-birosag.hu/en/uniformity-decisions.

689 Amtliche Übersetzung des Gesetzesvorhabens in englischer Sprache verfügbar gemacht durch die Venedig-Kommission als CDL-REF(2019)003, Opinion no. 943/2018, Hungary - Act on Administrative Courts and Act on the entry into force of the Act on Administrative Courts and certain transitional rules vom 29.01.2019.

$690 \mathrm{Zu}$ den historischen Wurzeln Venedig-Kommission, CDL-AD(2019)004, Opinion no. 843/2018, Hungary - Opinion on the law on administrative courts and the law on the entry into force of the law on administrative courts and certain transitional rules vom 19.03.2019, Rn. 103, 104 bei Fn. 42, weiter Venedig-Kommission, CDL-AD(2019)004, Opinion no. 843/2018, Hungary - Opinion on the law on administrative courts and the law on the entry into force of the 
der Uniformitätsentscheidung hat zur Folge, dass der ungarische Gerichtshof (Kúria) in bestimmten Fällen Grundsatzurteile trifft, deren Tenor für die nachrangigen Gerichte umfassende Bindungswirkung entfaltet. ${ }^{61}$ Die Venedig-Kommission sah hierin einen möglichen Eingriff in den Grundsatz der internen Unabhängigkeit der Richterschaft, d.h. die Unabhängigkeit von Entscheidungen anderer Instanzen. ${ }^{692}$ Denn die neu gefasste Uniformitätsentscheidung verpflichtet Gerichtspräsidenten nachrangiger Instanzgerichte, konstant die Rechtsprechung des eigenen Gerichts auf tatsächlich oder auch nur „theoretische“ Vereinbarkeit mit der Rechtsprechung der Kúria durchzugehen, womit sie zu „Überwachern“ der entsprechenden Rechtsprechung ihrer Gerichte würden. Zusätzlich stellte die VenedigKommission fest, dass die Abweichung von dieser Rechtsprechung in die Evaluierung von Richtern einfloss. ${ }^{693}$ Wenn auch damit eine Einrichtung des Europarates große Zweifel am Institut der Uniformitätsentscheidung hat, steht eine Beurteilung durch die Union weitestgehend aus. Bis heute hat der Europäische Gerichtshof meiner Kenntnis nach nicht zu der Konformität dieser Verfahrensbesonderheit des ungarischen Rechts Stellung bezogen.

Das gilt nicht für eine - gewaltenüberschreitende - Variante dieser Uniformitätsentscheidung im ungarischen Asylrecht. Hier hatte der ungarische Gesetzgeber 2015 den Gerichten die Möglichkeit genommen, Asylbescheide der zuständigen Behörden aufzuheben und abzuändern. Er beließ ihnen nur die reine Kassationsmöglichkeit mit Rückverweisung, womit die materielle Entscheidung bei den Asylbehörden verbleib, und berief sich dabei auf eine vermeintliche Prozessoptimierung. Nachdem bereits

law on administrative courts and certain transitional rules vom 19.03.2019, Rn. 102-105.

691 Hierzu, sowohl für die Wirkung in der ordentlichen Gerichtsbarkeit wie auch für die nicht in Kraft getretene Möglichkeit in Bezug auf die Verwaltungsgerichte, Venedig Kommission, CDL-AD(2019)004, Opinion no. 843/2018, Hungary - Opinion on the law on administrative courts and the law on the entry into force of the law on administrative courts and certain transitional rules vom 19.03.2019, Rn. 102.

692 Venedig-Kommission, CDL-AD(2012)001, Opinion 663/2012, Opinion on Act CLXII of 2011 on the Legal Status and Remuneration of Judges and Act CLXI of 2011 on the Organisation and Administration of Courts of Hungary vom 19.03.2012, Rn. 69.

693 Venedig-Kommission, CDL-AD(2012)001, Opinion 663/2012, Opinion on Act CLXII of 2011 on the Legal Status and Remuneration of Judges and Act CLXI of 2011 on the Organisation and Administration of Courts of Hungary vom 19.03.2012, Rn. 71-72. 


\section{Die Rechtsstaatlichkeitskrise in mitgliedstaatlichen Fällen}

Generalanwalt Bobek große Zweifel an dieser Regelung angemeldet hatte, erklärte der Gerichtshof sie mit Sekundärrecht und Art. 47 der Grundrechtecharta unvereinbar, da es den Gerichten gleichwohl möglich sein müsse, in der Sache nochmals eine objektive neue Prüfung vorzunehmen. ${ }^{694} \mathrm{Die}$ Kritik des Gerichtshofs am ungarischen Gesetzgeber war scharf und hielt im Wesentlichen fest, der Gesetzgeber habe stellenweise die Bedeutung des Unionsrechts vollkommen verkannt:

„Nationale Rechtsvorschriften, die zu einer solchen Situation führen, enthalten der Person, die internationalen Schutz beantragt, jedoch de facto den wirksamen Rechtsbehelf im Sinne von Art. 46 Abs. 3 der Richtlinie 2013/32 vor und verkennen den Wesensgehalt des in Art. 47 der Charta verankerten Rechts auf einen wirksamen Rechtsbehelf, da das nach einer den Anforderungen des Art. 46 Abs. 3 der Richtlinie 2013/32 entsprechenden Prüfung ergangene Urteil des Gerichts, mit dem dieses entschieden hat, dass diese Person die in der Richtlinie 2011/95 vorgesehenen Voraussetzungen für die Zuerkennung der Flüchtlingseigenschaft oder des Status eines subsidiär Schutzberechtigten erfüllt, ins Leere läuft, wenn das Gericht über keinerlei Mittel verfügt, um seinem Urteil Geltung zu verschaffen.“695

In der Debatte um die Verwaltungsgerichtsreform von 2018/2019 in Ungarn hat sich die Frage einer Uniformitätsentscheidung erneut Bahn gebrochen, wenn auch, wie 2012 im Rahmen der Änderungen in der ordentlichen Gerichtsbarkeit, wiederum als eine unter mehreren Fragen.

Ungarn zählt zu denjenigen europäischen Staaten, die in jüngerer Zeit traditionell keine separate Verwaltungsgerichtsbarkeit kennen. Stattdessen wird diese Gerichtsbarkeit von besonderen Kammern innerhalb der ordentlichen Gerichtsbarkeit ausgeübt, das System funktioniert im Allgemeinen gut. ${ }^{696}$ Mit dem Gesetzentwurf vom Juni 2018 fügte der ungarische Gesetzgeber zunächst im ungarischen Grundgesetz eine entsprechende

694 Vgl. EuGH, Rs. C-556/17, Alekszij Torubarov ./. Bevándorlási és Menekültügyi Hivatal, Schlussanträge des Generalanwalts Michal Bobek, vom 30.04.2019, ECLI:EU:C:2019:339, dort insb. Rn. 1-6, 72, 80-85; Urteil (GK) vom 29.07.2019, ECLI:EU:C:2019:626, Rn. $66 \mathrm{ff}$. und Tenor.

695 EuGH, Rs. C-556/17, Alekszij Torubarov ./. Bevándorlási és Menekültügyi Hivatal, Urteil (GK) vom 29.07.2019, ECLI:EU:C:2019:626, Rn. 72.

696 Vgl. dazu Venedig-Kommission, CDL-AD(2019)004, Opinion no. 843/2018, Hungary - Opinion on the law on administrative courts and the law on the entry into force of the law on administrative courts and certain transitional rules vom 19.03.2019, Rn. 8 und ff. 
Rechtsgrundlage für die Schaffung einer Verwaltungsgerichtsbarkeit ein und schuf im Dezember 2018 zwei Ausführungsgesetze, inklusive einer neuen VwGO, die als Rechtsgrundlage für die neue Verwaltungsgerichtsbarkeit hätten dienen sollen. ${ }^{697}$ Vorgesehen war dazu ein eigener Verwaltungsgerichtshof (im Englischen abgekürzt als SAC) und ein eigener Nationaler Verwaltungsrichterrat (im Englischen abgekürzt als NAJC). ${ }^{698}$

Dabei gab der ungarische Gesetzgeber als Rechtfertigung an, an die ungarische Rechtstradition von vor 1949 anknüpfen zu wollen und die Justizreform an bestehende Regelungen in Bayern und Österreich anzulehnen. ${ }^{699}$ Tatsächlich hat Österreich 2012 eine novellierte Verwaltungsgerichtsbarkeit eingeführt, die insbesondere das stark fragmentierte System der zuvor bestehenden sog. Verwaltungssenate und entsprechend zuständiger Ämter abgelöst hat. ${ }^{700}$

Die Venedig-Kommission, die zum wiederholten Male um Begutachtung gebeten wurde, bewegte sich, schon aufgrund der sehr verschiedenen Verwaltungsgerichtstraditionen im europäischen Rechtsraum, auf glattem Parkett und ging ausdrücklich auf Möglichkeiten der Verzahnung und Interaktion etwa der Verwaltungsgerichtsbarkeit mit der Verwaltung selbst, darunter in Deutschland und Frankreich, ein. ${ }^{701}$

Gleichwohl war es ihr möglich, eindeutige Kritik an dem Vorhaben zu äußern, darunter die exzessiven Befugnisse des Nationalen Verwaltungsgerichtsrates und des Justizministers, die beide zu einer großen Politisierung der Gerichtsbarkeit geführt hätten. Insbesondere gerügt wurde aber die

697 Venedig-Kommission, CDL-AD(2019)004, Opinion no. 843/2018, Hungary Opinion on the law on administrative courts and the law on the entry into force of the law on administrative courts and certain transitional rules vom 19.03.2019, Rn. 7 und ff.

698 Venedig-Kommission, CDL-AD(2019)004, Opinion no. 843/2018, Hungary Opinion on the law on administrative courts and the law on the entry into force of the law on administrative courts and certain transitional rules vom 19.03.2019, Rn. 7.

699 Venedig-Kommission, CDL-AD(2019)004, Opinion no. 843/2018, Hungary Opinion on the law on administrative courts and the law on the entry into force of the law on administrative courts and certain transitional rules vom 19.03.2019, Rn. 25 ff.

700 Dazu konzise die Regierungsvorlage zur Verwaltungsgerichtsbarkeits-Novelle 2012, 1618 der Beilagen XXIV. GP - Regierungsvorlage - Vorblatt und Erläuterungen, S. 3-5.

701 Venedig-Kommission, CDL-AD(2019)004, Opinion no. 843/2018, Hungary Opinion on the law on administrative courts and the law on the entry into force of the law on administrative courts and certain transitional rules vom 19.03.2019, Rn. 34 . 


\section{Die Rechtsstaatlichkeitskrise in mitgliedstaatlichen Fällen}

Ernennung von Verwaltungsrichtern, die aufgrund eines „Punktesystems“ erfolgt wäre, das nachweislich Kandidaten aus der Verwaltungspraxis und damit potentiell Parteikader bevorzugt hätte. ${ }^{702}$

Im Juli 2019 gab Ungarn überraschend bekannt, die Reform nicht weiterverfolgen zu wollen. ${ }^{703}$ Damit erledigt sich eine eingehendere Analyse, die ansonsten an dieser Stelle hätte erfolgen müssen. Auch die sehr schwierige Frage einer Vergleichbarkeit mit dem Recht anderer Mitgliedstaaten hätte dann im Raum gestanden.

\section{Zwischenergebnis zu Ungarn}

Die vorangegangenen Ausführungen zu Ungarn haben gezeigt, wie heterogen die Vorhaben sind, die die Rechtswissenschaft und die interessierte Öffentlichkeit als Beispiele für die krisenhaften Umbrüche in Ungarn seit 2010 ausmacht. Im Unterschied zu den Vorgängen in Polen ist die thematische Verzahnung mit den Ausführungen gerade des Europäischen Gerichtshofs zur Rechtsstaatlichkeit, wie ich sie in Teil B. dieser Arbeit dargestellt habe, nicht immer evident, denn sie betreffen gerade nicht ausschließlich die Gerichtsbarkeit in Ungarn. Die Umbrüche in Ungarn, die seitens der Europäischen Kommission, des Europäischen Gerichtshofs und im Straßburger System seitens des EGMR und der Venedig-Kommission seit 2010 kritisiert und begutachtet worden sind, sind so vielschichtig wie eine moderne Gesellschaft eben ist, sie erfassen einen Gutteil des gesellschaftlichen öffentlichen Lebens, von Hochschulen über Nichtregierungsorganisationen, Grundlagen der Wirtschaftsordnung und die Eigentumsgarantie, die Grundlagen von Religionsgemeinschaften bis zur Frage der Rechte von Obdachlosen.

Haben daher Möllers und Schneider nicht doch recht, wenn sie meinen, es sei das Demokratieprinzip und nicht dasjenige der Rechtsstaatlichkeit, das den materiellen Kern der Krise am besten treffe? Gerade in Ungarn hat es auch ein Beispiel gegeben, das ich noch aufgespart habe, da es diesen Eindruck ganz besonders stützt, und zwar die Änderung des unga-

702 Venedig-Kommission, CDL-AD(2019)004, Opinion no. 843/2018, Hungary Opinion on the law on administrative courts and the law on the entry into force of the law on administrative courts and certain transitional rules vom 19.03.2019, Rn. $49 \mathrm{ff}$.

703 Vgl. Krisztina Than \& Larry King Reuters, „Hungary abandons plan for administrative courts, justice minister says“, Reuters vom 23.07.2019. 
rischen Wahlrechts von 2014, welches insbesondere durch Scheppele in der New York Times ausführlich besprochen und kritisiert wurde 704 und für die Parlamentswahlen 2018 eine OSZE-Beobachtermission ${ }^{705}$ zur Folge hatte. Scheppele identifizierte dort als Hauptschwächen der Wahlrechtsänderung die sehr hohen Margen, mit denen Wahlkreise vom Durchschnitt der erfassten Wähler abweichen könnten, was zusätzlich nicht im Landesdurchschnitt, wie von der Venedig-Kommission gefordert, sondern pro Wahlkreis gemessen werde. Weiter hob sie den einheitlichen Zuschnitt aller Wahlkreise im Land nach dem Willen der Fidesz hervor, die Abschaffung eines zweiten Wahldurchgangs zugunsten eines einzigen, bei dem die relative Mehrheit im Wahlkreis für ein Direktmandat ausreicht, die hohen Hürden für kleine Parteien im Hinblick auf die Berücksichtigung von Zweitstimmen sowie schließlich Ausgleichsmandate, die der stärksten Partei (Fidesz) dafür zugestanden werden, in Wahlkreisen mehr als die für die relative Mehrheit notwendigen Stimmen erreicht zu haben. Separat hiervon hielt sie fest, das Wahlgesetz habe 2014 53\% der abgegebenen Zweitstimmen in eine Zweidrittelmehrheit für die Fidesz umgewandelt. ${ }^{706}$

In ihrem Bericht zur Wahl von 2018 sieht die OSZE zwar Grundrechte und -freiheiten der Wähler gewahrt, allerdings die gesamte Wahl von sehr einschüchternder Rhetorik seitens der Presse und Regierungsmehrheit geprägt:

„the parliamentary elections were characterized by a pervasive overlap between state and ruling party resources, undermining contestants' ability to compete on an equal basis. Voters had a wide range of political options but intimidating and xenophobic rhetoric, media bias and opaque campaign financing constricted the space for genuine political debate, hindering voters' ability to make a fully-informed choice. The

704 Kim Lane Scheppele, „An Election in Question“, Parts 1-5, Fünfteilige Serie für die New York Times, veröffentlicht am 28.02.2014 als Teil der Opinion Pages und Gastbeitrag zur Kolumne von Paul Krugman, „The Conscience of a Liberal“, abrufbar unter: https://krugman.blogs.nytimes.com/2014/02/28/hunga ry-an-election-in-question-part-1/.

705 Die gesamte Dokumentation der Mission ist verfügbar unter: https:/www.osce. org/odihr/elections/hungary/373603.

706 Kim Lane Scheppele, „Constitutional Coups and Judicial Review“, S. 61; weiter Kim Lane Scheppele, „Constitutional Coups in EU Law“, S. 457-458. 
technical administration of the elections was professional and transparent" '“707

Auch das im Frühjahr 2020 im Zuge der sog. „Corona-Krise“ verabschiedete Notstandsgesetz, das für diese Arbeit nicht mehr eingehend berücksichtigt werden konnte, ist in ersten Reaktionen durch die Europäische Kommission oder die OSZE vorrangig aus der Warte der Gefährdung der Demokratie kritisiert worden. ${ }^{708}$

Gleichwohl bleibe ich an dieser Stelle bei meiner anfänglichen Beobachtung, dass es gerade die Frage der Beeinträchtigung der Rechtsstaatlichkeit ist, die es erlaubt, die Vorgänge in Ungarn als Gesamtentwicklung zu betrachten. ${ }^{709}$ Ich stelle dabei also nicht vorrangig auf die Auswirkungen der jeweiligen Gesetze in der ungarischen Gesellschaftswirklichkeit ab, sondern vorrangig auf gemeinsame Merkmale ihres Zuschnitts und $\mathrm{Zu}-$ standekommens. Ich habe dargelegt, dass sehr häufig der Gesetzgebungsprozess ad-hoc, im Sinne einer Gewaltenkollusion, schnell und unvorhersehbar abläuft. Ich habe gezeigt, wie häufig Gesetze sog. versteckte Einzelfallgesetze sind, dass sie verwundbare Gruppen im Gesellschaftsleben isolieren, dass sie Rechtspositionen willkürlich und ohne Entschädigung entziehen. Dies läuft, greift man die 2014 seitens der Kommission in ihrem EU-Rahmen vorgelegten Katalog der mit dem Rechtsstaatsprinzip assoziierten Prinzipien in der Judikatur des EuGH auf, insbesondere der Rechtssicherheit, dem Willkürverbot und der Gleichheit vor dem Gesetz zuwider. ${ }^{710}$ Umbrüche im ungarischen Justizsystem, darunter diejenigen

707 OSZE/ODIHR, „Hungary: Parliamentary Elections: 8 April 2018: ODIHR Limited Election Observation Mission: Final Report”, ohne Az., Warschau, 27.10.2018, Executive Summary, S. 1.

708 OSZE, „Newly declared states of emergency must include a time limit and parliamentary oversight, OSCE human rights head says", Presseerklärung vom 30.03.2020, abrufbar unter: https://www.osce.org/odihr/449311, Statement by President von der Leyen on emergency measures in Member States, vom 31.03.2020, STATEMENT/20/567.

709 Wie hier auch z.B. Gábor Attila Tóth, „Illiberal Rule of Law? Changing Features of Hungarian Constitutionalism“, in: Maurice Adams, Anne Meuwese and Ernst Hirsch Ballin (eds), Constitutionalism and the Rule of Law: Bridging Idealism and Realism (Cambridge University Press 2017), S. 386-415, insb. S. 389 f., der allerdings einen Schwerpunkt auf die rechtstheoretischen Wurzeln des Rechtsstaatsbegriffs legt.

710 Vgl. dazu nochmals Europäische Kommission, Mitteilung der Kommission an das Europäische Parlament und den Rat, Ein neuer EU-Rahmen zur Stärkung des Rechtsstaatsprinzips vom 11.03.2014, $\operatorname{COM(2014)~} 158$ final, Anhang I: Das Rechtsstaatsprinzip als tragendes Prinzip der Union. 
im Verfassungsprozessrecht und der ordentlichen Gerichtsbarkeit weisen starke Parallelen zu Polen auf und rücken zu Polen gemachte Feststellungen zur Bedeutung der richterlichen Unabhängigkeit, auch seitens des Gerichtshofs, in den Vordergrund, obwohl sie für Ungarn bislang nicht durch den EuGH entschieden worden sind. Darauf, dass sich dies ggf. ändern könnte, deuten einzelne Vorabvorlagen, etwa in der Rechtssache IS hin, die zum Zeitpunkt der Beendigung der Arbeit noch nicht entschieden war. ${ }^{711}$

Ein intersystemischer Konflikt, wie von Bogdandy formuliert, ein Spillover-Effekt oder auch die besondere Schwere, Dauer und Fallzahl, wie sie Generalanwalt Geelhoed seiner Figur der "general and persistent infringement" im Unionsrecht zugeschrieben hat, sind folglich eindeutig erwiesen. Ungarn zählt damit, neben Polen, zu denjenigen Fällen, in denen sich durch Regierung und Parlament vorsätzlich herbeigeführte systemische Defizite in besonders klarer Form verwirklicht haben. Kurz vor Manuskriptschluss dieser Arbeit kündigte Kommissionspräsidentin von der Leyen in einem Brief an Parlamentspräsident Sassoli an:

„I can assure you that the Commission is closely monitoring the emergency measures taken by Member States, including Hungary. This monitoring concerns the consistency with the essential values of our Union set out in Article 2 TEU, as well as with EU law in general and with the Charter of Fundamental Rights in particular." 712

Inwiefern sich hieraus weitere Maßnahmen gegenüber Ungarn, nun gerade explizit unter Bezugnahme auf alle Werte der Union in Art. 2 EUV, ableiten lassen, müssen zukünftige Arbeiten zeigen.

711 EuGH, Rs. C-564/19, IS, anhängig, die Zusammenfassung der Vorlage des Pesti Központi Kerületi Bíróság (Zentrales Stadtbezirksgericht Pest, Ungarn) vom 11.07.2019 durch die Kanzlei des Gerichtshofs ist einsehbar unter: http://curi a.europa.eu/juris/showPdf.jsf?text=\%2522judicial\%2Bindependence $\% 2522$ $\% 2$ Bhungary $\&$ docid $=220134 \&$ pageIndex $=0 \&$ doclang $=$ DE $\&$ mode $=$ req $\&$ dir $=$ \&occ=first\&part=1\&cid=7611835, lässt darauf schließen, dass das vorlegende Gericht insbesondere eine Beurteilung des Nationalen Justizrates durch den EuGH wünscht. Eine Veröffentlichung der Vorabvorlagefragen im Amtsblatt ist bislang nicht erfolgt.

712 Ursula von der Leyen, Letter to David Maria Sassolli, President of the European Parliament, vom 07.04.2020, Ares (2020) 1925071, publik gemacht in Bulletin Quotidien Europe 12468 - 17/4/2020, Eintrag „Viktor Orbán's full powers in European Parliament's crosshairs“, o.S. 
V. Wechselnde Befunde und Anlass zur Sorge - die Lage in Bulgarien und Rumänien im Spiegel der Rechtspraxis

1. „Ultimus inter pares"?

$\mathrm{Zu}$ den bereits 2014 durch von Bogdandy und Ioannidis als Beispiele für systemische Defizite identifizierten Mitgliedstaaten ${ }^{713}$ zählen auch die Mitgliedstaaten Bulgarien und Rumänien, die sich bislang in vielfacher Hinsicht von anderen Mitgliedstaaten unterscheiden. Augenscheinlich wird dies durch Umstände wie den bislang nicht erfolgten Beitritt in den Schengenraum oder das weit unter dem EU-Durchschnitt liegende Einkommen der Arbeitnehmer. ${ }^{714}$ Auch im Hinblick auf die Beobachtungen der Union zur dortigen Einhaltung rechtsstaatlicher Grundsätze und guter Verwaltung ergeben sich bedeutende Unterschiede zu anderen Mitgliedstaaten. Fehlt es auch bislang in Literatur und Praxis, wie dies im Hinblick auf Polen und Ungarn herauszuarbeiten war, an Vermutungen über politische Programme, die in beiden Mitgliedstaaten verwirklicht würden, so zeigt sich doch das Misstrauen der Union und der anderen Mitgliedstaaten gerade gegenüber Bulgarien und Rumänien in dem Umstand, dass seit ihrem Beitritt 2007 ununterbrochen ein sui-generis-Verfahren des Unionsrechts zur Anwendung gelangt ist, der sog. Kooperations- und Verifikationsmechanismus (Cooperation and Verification Mechanism, CVM). ${ }^{715}$ Obwohl die Mechanismen, die die Union im Rahmen der Rechtsstaatlichkeitskrise genutzt hat, erst im nachfolgenden Teil der Arbeit behandelt werden, ist hier die Sichtung des CVM vorzuziehen, weil sich der Befund, dass dort Probleme mit der Rechtsstaatlichkeit bestehen, seit dem Beitritt beider Staaten unmittelbar auf die Nutzung des Verfahrens stützt, während für

713 Armin von Bogdandy \& Michael Ioannidis, Das systemische Defizit, S. $304 \mathrm{ff}$.

714 Hierüber informiert Eurostat, „Löhne und Arbeitskosten“, abrufbar unter: https://ec.europa.eu/eurostat/statistics-explained/index.php?title=Wages_an d_labour_costs/de\#Bruttol.C3.B6hne.2F-verdienste.

715 Vgl. jeweils Europäische Kommission, Entscheidung vom 13. Dezember 2006 zur Einrichtung eines Verfahrens für die Zusammenarbeit und die Überprüfung der Fortschritte Bulgariens bei der Erfüllung bestimmter Vorgaben in den Bereichen Justizreform und Bekämpfung der Korruption und des organisierten Verbrechens, ABl. (EU) L 354/58 vom 14.12.2006, und andererseits die Entscheidung der Kommission vom 13. Dezember 2006 zur Einrichtung eines Verfahrens für die Zusammenarbeit und die Überprüfung der Fortschritte Rumäniens bei der Erfüllung bestimmter Vorgaben in den Bereichen Justizreform und Korruptionsbekämpfung, ABl. (EU) L 354/56 vom 14.12.2006. 
Polen und Ungarn etwa die Beobachtung derartiger Schwierigkeiten der Nutzung der Verfahren vorausging.

2. Der „Kooperations- und Verifikationsmechanismus“ (CVM) und die divergierende Entwicklung in beiden Mitgliedstaaten

Der CVM findet seine Rechtsgrundlage sowohl im verbindlichen Sekundär- als auch im Primärrecht, zunächst in Art.36-42 der Beitrittsakte Bulgariens und Rumäniens zur Union, eine Rechtsgrundlage, die Primärrechtsrang hat. Gem. Art. 2 Abs. 2 S. 2 des - mit der Beitrittsakte ${ }^{716}$ nicht $\mathrm{zu}$ verwechselnden - Beitrittsvertrags ${ }^{717}$ ist die Akte Bestandteil des Beitrittsvertrags, gleichzeitig aber selbst in Form eines gesonderten Vertrages ausgestaltet. Die Akte stellt gem. Art. 2 Abs. 2 S. 1 1. HS des Beitrittsvertrages "Aufnahmebedingungen“ an die adressierten Mitgliedstaaten. Gem. Art. 37 und 38 der Akte kann die Union „Maßnahmen“ gegenüber beiden Mitgliedstaaten ergreifen, damit potentiell auch direkte Sanktionen, die in der Akte nur durch Grundsätze, namentlich den Verhältnismäßigkeitsgrundsatz, eingegrenzt sind. Der CVM ist die Umsetzung dieser Ermächtigung und findet seit Beitritt Bulgariens und Rumäniens zur Europäischen Union 2007 Anwendung. Die Europäische Kommission stützt ihn ${ }^{718}$ gegenüber Bulgarien und Rumänien insbesondere auf Art. 37 und 38 der Beitrittsakte. Um den CVM auszugestalten, ist getrennt gegenüber Bulgarien und Rumänien jeweils eine Entscheidung ergangen (nach heutiger Rechtslage des Vertrages von Lissabon: Beschluss), deren Anhänge einzelne Vorgaben (engl.: Benchmarks) schaffen, welche beide Länder erfül-

716 Akte über die Bedingungen des Beitritts der Republik Bulgarien und Rumäniens und die Anpassungen der Verträge, auf denen die Europäische Union beruht, ABl. (EU) L 157/203 vom 21.06.2005.

717 Vertrag [...] über den Beitritt der Republik Bulgarien und Rumäniens zur Europäischen Union, ABl. (EU) L 157/11 vom 21.06.2005.

718 Vgl. jeweils Europäische Kommission, Entscheidung vom 13. Dezember 2006 zur Einrichtung eines Verfahrens für die Zusammenarbeit und die Überprüfung der Fortschritte Bulgariens bei der Erfüllung bestimmter Vorgaben in den Bereichen Justizreform und Bekämpfung der Korruption und des organisierten Verbrechens, ABl. (EU) L 354/58 vom 14.12.2006, Erwägungsgrund 5, und andererseits die Entscheidung der Kommission vom 13. Dezember 2006 zur Einrichtung eines Verfahrens für die Zusammenarbeit und die Überprüfung der Fortschritte Rumäniens bei der Erfüllung bestimmter Vorgaben in den Bereichen Justizreform und Korruptionsbekämpfung, ABl. (EU) L 354/56 vom 14.12.2006, Erwägungsgrund 5. 
len müssen - die Entscheidungen formulieren ausdrücklich „to be addressed/doit atteindre“, im Deutschen heißt es hingegen lediglich „Vorgaben an “ ${ }^{719}$ Hierzu überprüft die Kommission regelmäßig die Fortschritte in beiden Mitgliedstaaten und erstattet dazu in zwei Berichtsreihen Bericht, den sog. „Fortschrittsberichten“ und den „technischen Berichten“. Auch sind in der Vergangenheit, wenn auch bis dato lediglich einmalig, finanzielle Sanktionen an mangelnde Fortschritte in Form der Aussetzungen von Förderungen ausgesprochen worden, die insgesamt $€ 820$ Millionen betrugen..$^{720}$

Der CVM erfüllt daher alle in der Literatur identifizierten drei Stadien von Aufsichtsmaßnahmen, d.h. eine Beobachtungs-, Überprüfungs- und Berichtigungsfunktion. Durch ihn wird die Entwicklung in Bulgarien und Rumänien einschließlich ihrer Fortschritte und Rückschläge in besonderem Maße sichtbar.

Aber er lässt aufgrund des Zuschnitts seiner „Benchmarks“ - und obwohl diese die Lage der Justiz in den Blick nehmen und spezifische Probleme wie die organisierte Kriminalität ansprechen - keinen unmittelbaren Rückschluss auf die hier besonders interessierende Frage systemischer Defizite zu. Denn die unter dem CVM ergangenen Fortschritts- und technischen Berichte operieren nicht mit einer dem EU-Rahmen oder Art. 7 EUV vergleichbaren Terminologie. Die Europäische Kommission hat 2019 gegenüber Rumänien den CVM sogar ausdrücklich durch Androhung zusätzlicher Schritte nach dem EU-Rahmen von diesem und damit von der Beobachtung systemischer Gefährdungen aus Sicht der Praxis abgegrenzt. ${ }^{721}$

719 Vgl. jeweils Europäische Kommission, Entscheidung vom 13. Dezember 2006 zur Einrichtung eines Verfahrens für die Zusammenarbeit und die Überprüfung der Fortschritte Bulgariens bei der Erfüllung bestimmter Vorgaben in den Bereichen Justizreform und Bekämpfung der Korruption und des organisierten Verbrechens, ABl. (EU) L 354/58 vom 14.12.2006, und andererseits die Entscheidung der Kommission vom 13. Dezember 2006 zur Einrichtung eines Verfahrens für die Zusammenarbeit und die Überprüfung der Fortschritte Rumäniens bei der Erfüllung bestimmter Vorgaben in den Bereichen Justizreform und Korruptionsbekämpfung, ABl. (EU) L 354/56 vom 14.12.2006; jeweils auch insbesondere die Anhänge. $\mathrm{Zu}$ den Entscheidungen und ihren Benchmarks auch insb. Armin von Bogdandy \& Michael Ioannidis, „Das systemische Defizit“, S. 314.

720 Armin von Bogdandy \& Michael Ioannidis, „Das systemische Defizit“, S. 315.

721 Europäische Kommission, Bericht der Kommission an das Europäsiche Parlament und den Rat über Rumäniens Fortschritte im Rahmen des Kooperations- 
Das erfordert von der Rechtswissenschaft folglich nicht nur die selbsttätige, aus dem Material schöpfende, rekonstruktive Beantwortung der Frage, ob in Rumänien und Bulgarien gleichwohl systemische Defizite im Sinne der obigen Kriterien festzustellen sind, sondern darüber später hinaus auch, warum der CVM gleichwohl Teil der hier vermuteten Verfassungsaufsicht der Union sein kann, die sich der Behebung derartiger Defizite widmet.

Keine größere Unterstützung leistet dabei bislang die Judikatur des Gerichtshofs. Vor diesem sind nunmehr, insbesondere betreffend die Frage der Disziplinierung rumänischer Richter und gegenläufiger Entscheidungen politisierter Spruchkörper, Verfahren anhängig, in denen das vorlegende Gericht einen Verstoß gegen Art. 19 Abs. 1 EUV i.V.m. Art. 47 EUV vermutet. ${ }^{722}$

Diese Lücken in der unionalen Praxis lassen sich nur teilweise durch die Gutachten auffangen, die vonseiten des Europarates ergangen sind. Hinzuweisen ist darauf, dass die Venedig-Kommission wiederum, sowohl gegenüber Rumänien als auch gegenüber Bulgarien, eine rege Tätigkeit entfaltet hat. Sie hat zu Rumänien seit 2006, und damit kurz vor Beitritt zur Union, sieben ${ }^{723}$ und zu Bulgarien seit 2008 bis dato sogar 17 Gutach-

und Kontrollverfahrens, $\operatorname{COM}(2019) 499$ final vom 22.10.2019, S. 2, s. insb. dort auch Fn. 10.

722 Vgl. EuGH, Rs. C-547/19, CY und Asociația „Forumul Judecătorilor din România“, Vorabvorlagebeschluss der Înalta Curte de Casaţie şi Justiţie (Oberster Kassationsgerichtshof) vom 15.07.2019, bislang nicht im ABl. veröffentlicht, Arbeitsdokument der Kanzlei des Gerichtshofs einsehbar über, http://curia.eu ropa.eu/juris/showPdf.jsf?text=judiciary \&docid $=219979 \&$ pageIndex $=0 \&$ do clang=DE\&mode=req\&dir=\&occ=first \&part=1\&cid=7557380. Die Vorabvorlage betrifft im Wesentlichen die Frage der Beziehung von Verfassungsgericht und Oberstem Richterrat bei Disziplinarmaßnahmen gegen eine Richterin am Obersten Kassationsgerichtshof.

723 Venedig-Kommission, 1. CDL-AD(2006)006, Opinion no. 370/2006, Opinion on the Two Draft Laws amending Law No. 47/1992 on the organisation and functioning of the Constitutional Court of Romania vom 20.03.2006; 2. CDL$\mathrm{AD}(2012) 026$, Opinion no. 685/2012, Opinion on the compatibility with Constitutional principles and the Rule of Law of actions taken by the Government and the Parliament of Romania in respect of other State institutions and on the Government emergency ordinance on amendment to the Law $\mathrm{N}^{\circ} 47 / 1992$ regarding the organisation and functioning of the Constitutional Court and on the Government emergency ordinance on amending and completing the Law $\mathrm{N}^{\circ} 3 / 2000$ regarding the organisation of a referendum of Romania vom 17.12.2012; 3. CDL-AD(2014)010, Opinion no. 731/2013, Opinion on the Draft Law on the Review of the Constitution of Romania vom 24.03.2014; 4. CDL$\operatorname{AD}(2018) 004$, Romania - Joint Opinion on Draft Law No. 140/2017 on amend- 
ten erlassen, ${ }^{724}$ die regelmäßig auf Änderungen im Justizsystem abgestellt haben.

ing Governmental Ordinance No. 26/2000 on Associations and Foundations; 5. CDL-AD(2018)017 (vorgehend in vorläufiger Fassung als CDL-PI(2018)007), Opinion No. 924/2018 Romania - Opinion on draft amendments to Law No. 303/2004 on the Statute of Judges and Prosecutors, Law No. 304/2004 on Judicial Organisation, and Law No. 317/2004 on the Superior Council for Magistracy vom 20.10.2018; 6. CDL-AD(2018)021, Opinion No. 930/2018, Romania - Opinion on draft amendments to the Criminal Code and the Criminal Procedure Code vom 20.10.2018; 7. CDL-AD(2019)014, Opinion No. 950/29018, Romania - Opinion on Emergency Ordinances GEO No. 7 and GEO No. 12 amending the Laws of Justice.

724 Aufgrund der zeitlichen Verzögerung sind nachfolgend zwei Interim-Gutachten gesondert gezählt, Venedig-Kommission, 1. CDL-AD(2008)009, Opinion no. 444/2007, Opinion on the Constitution of Bulgaria vom 31.03.2008; 2. CDL-AD(2008)034, Opinion no. 505/2008; Opinion on the Draft Amendments to the Law on Political Parties of Bulgaria vom 15.12.2008; 3. CDL$\operatorname{AD}(2009) 011$, Opinion no. 515/2009, Opinion on the Draft Law amending and supplementing the Law on Judicial Power of Bulgaria vom 16.03.2009; 4. CDL-AD(2009)018, Opinion No. 501/2008, Opinion on the concept paper for a new Law on Statutory Instruments of Bulgaria vom 18.03.2009; $\underline{5}$. CDL$\mathrm{AD}(2009) 035$, Opinion no. 532/2009; Opinion on the Draft Law on Meetings, Rallies and Manifestations of Bulgaria vom 23.06.2009; 6. CDL-AD(2009)053, Opinion no. 536/2009, Opinion on the draft law on normative acts of Bulgaria vom 11.12.2009; 7. CDL-AD(2010)010, Opinion No. 563/2009, Interim Opinion on the Draft Act on Forfeiture in favour of the State of Illegally acquired Assets of Bulgaria vom 16.03.2010; 8. CDL-AD(2010)019, Opinion No. 563/2009, Second Interim Opinion on the Draft Act on Forfeiture in favour of the State of Criminal Assets of Bulgaria vom 10.06.2010; 9. CDL$\operatorname{AD}(2010) 030$, Opinion No. 563/2009, Final opinion on the third revised draft act on forfeiture in favour of the state of assets acquired through illegal activity of Bulgaria vom 18.10.2010; 10. CDL-AD(2010)041, Opinion no. 591/2010, Opinion on the Draft Law amending the Law on Judicial Power and the Draft Law amending the Criminal Procedure Code of Bulgaria vom 20.12.2010; 11 . CDL-AD(2011)013, Opinion no. 607/2011, Joint opinion on the election code of Bulgaria of the Venice Commission and the OSCE/ODIHR vom 21.06.2011; 12. CDL-AD(2011)023, Opinion no. 563/2009, Opinion on the sixth revised draft act on forfeiture of assets acquired through criminal activity or administrative violations of Bulgaria vom 20.06.2009; zum gleichen Gesetz nochmals 13. CDL-AD(2014)001, Joint Opinion on the draft Election Code of Bulgaria adopted by the Council for Democratic Elections and the Venice Commission vom 24.03.2014; 14. CDL-AD(2015)022, Opinion No. 816/2009, Opinion on the draft Act to amend and supplement the Constitution (in the field of the Judiciary) of the Republic of Bulgaria vom 23.10.2015; nochmals zum gleichen Gesetz 15. CDL-AD(2017)016, Opinion no. 867/2016/ODIHR Opinion-Nr.: ELE-BGR/307/2017, Joint Opinion of the Council for Democratic Elections 
Hinzu treten, insbesondere im Falle Rumäniens die GRECO (Group of States against Corruption) hinzu, eine im Rahmen des Europarates gegründete Organisationseinheit, die auch anderen Staaten (Mitglied sind etwa ebenso die USA) offen steht und die im Bereich der Korruptionsbekämpfung Mitgliedstaaten begutachtet, dies indes vorrangig anhand standardisierter und regelmäßig ausgerichteter Evaluierungen aller Mitglieder vornimmt. ${ }^{725}$ Im Falle Rumäniens ist die GRECO bezeichnenderweise dazu übergangen, außer der Reihe im Juli 2019 einen sog. „Interim Compliance Report“" zu veröffentlichen, der sich wiederholt sehr besorgt über die Lage zeigt, ${ }^{726}$ nachdem nur einen Monat zuvor ein weiterer Bericht ergangen war. ${ }^{727}$ Jörg Polakiewicz hat dankenswerterweise zu beiden Gutachtenkonvoluten für die Wissenschaft eine summarische Auswertung vorgelegt und im Wesentlichen vier Themen herausgearbeitet, zu denen Verbesserungen angemahnt wurden: eine bessere, d.h. insbesondere rechtssichere und transparentere, dadurch inklusivere Gesetzgebung, eine Stärkung individueller Freiheiten und Spielräume für Richter einschließlich der Möglichkeit ihrer Äußerung zu rechtspolitischen Fragen, eine Rücknahme politischer Einmischung seitens insbesondere der Regierung in rechtsprechende Tätigkeit, insbesondere etwa durch „Notverordnungen“, und schließlich eine aktive und effektive Bekämpfung der Korruption in allen Bereichen. ${ }^{728}$

Damit ergibt sich ein gemischtes Bild, das sowohl auf staatliche Schwächen, etwa im Rahmen der Gesetzgebung, als auch potentiell im hier verstandenen Sinne auf vorsätzliche Vorgänge hindeutet. Jedenfalls dann ist von vorsätzlichem Vorgehen seitens staatlicher Stellen zu sprechen,

and of the Venice Commission on Amendments to the Electoral Code vom 19.06.2017; 16. CDL-AD(2017)018, Opinion no. 855/2016, Bulgaria - Opinion on the Judicial System Act vom 09.10.2017; 17. CDL-AD(2019)031, Opinion no. $968 / 2019$, Bulgaria - Opinion on draft amendments to the Criminal Procedure Code and the Judicial System Act, concerning criminal investigations against top magistrates vom 09.12.2019.

725 Vgl. zur Rolle der GRECO https:/www.coe.int/en/web/greco/about-greco/what -is-greco, zu den Evaluierungen insbesondere https://www.coe.int/en/web/greco /evaluations\#\{"22359946":[0]\}. Die gegenwärtig durchlaufende Evaluierungsrunde ist die fünfte.

726 GRECO, GrecoRC4(2019)1, „Fourth Evaluation Round: Corruption prevention in respect of members of parliament, judges and prosecutors" vom 09.07.2019, vgl. dort insb. Rn. 8, 12 und 13.

727 GRECO, Greco-AdHocRep(2019)1, Follow-up Report to the Ad hoc Report on Romania (Rule 34) vom 21.06.2019.

728 Jörg Polakiewicz, „Addressing systemic Rule of Law Deficiencies“, in NYU Global and Comparative Law Colloquium, Europarat, Straßburg, 2019, S. 6-7 insb. 


\section{Die Rechtsstaatlichkeitskrise in mitgliedstaatlichen Fällen}

wenn Korruptionsermittlungen durch die Justiz vereitelt oder verschleppt werden. Hierfür finden sich sowohl seitens der Europäischen Kommission wie auch der Venedig-Kommission Nachweise.

Allerdings ist bei Rückgriff auf diese Gutachten aus der Praxis die Frage des systemischen Charakters der Zustände in Bulgarien und Rumänien immer noch unbeantwortet.

Hinzu kommt zunehmend die Frage, ob es überhaupt noch statthaft ist, beide Mitgliedstaaten gemeinsam zu nennen. Hierfür focht zunächst, dass Rumänien und Bulgarien nicht nur 2007 gemeinsam der Union beigetreten sind, sondern auch gemeinsam und ausschließlich dem CVM unterworfen wurden. Für das erst 2013 beigetretene Kroatien hingegen ist an diese Entscheidung nicht angeknüpft worden. Der zu ihm vorgelegte sog. „Überwachungsbericht“, dessen Grundlage sich in Art. 36 der Beitrittsakte Kroatiens zur EU findet, ${ }^{729}$ ist lediglich einmalig erfolgt. ${ }^{730}$ Seine Einführung mutatis mutandis gegenüber Kroatien wurde aufgrund des ihm bescheinigten Fortschritts verworfen. ${ }^{731}$

Bei genauerem Hinsehen divergieren die Befunde zwischen Bulgarien und Rumänien gerade in der Rechtspraxis zunehmend.

Davon zeugt zunächst der Fortschrittsbericht vom November 2018 und nochmals ein Jahr später vom Oktober 2019 gegenüber Rumänien und die dort zum Ausdruck gebrachte Sorge der Kommission, wonach dort die rechtspolitische Entwicklung alle erzielten Fortschritte, insbesondere im Bereich der Justizpolitik, infrage stelle. Bei im Jahresverlauf erfolgten Reformen gerade in der Justizpolitik seien nicht nur keine Fortschritte,

729 Zu diesem Verfahren Adam Łazowski, „European Union do not Worry, Croatia is Behind you: A Commentary on the Seventh Accession Treaty,", in: Croatian Yearbook of European Law and Policy 8 (2012), S. 1-39, S.34; Vgl. weiter Art. 36 der Akte über die Bedingungen des Beitritts der Republik Kroatien und die Anpassungen des Vertrags über die Europäische Union, des Vertrags über die Arbeitsweise der Europäischen Union und des Vertrags zur Gründung der Europäischen Atomgemeinschaft, ABl. (EU) v. 24.04.2012 L 112/21; zu den Auswirkungen dieser Norm, EuGH, Rs. C-240/16 P, Vendran Vidmar u.a. ./. Kommission, Beschluss vom 01.02.2017, ECLI:EU:C:2017:89, Rn $20 \mathrm{ff.}$

730 Vgl. Art. 36 Abs. 1 Sätze 3 und 4 der genannten Akte: „Im Herbst 2011 legt die Kommission dem Rat und dem Europäischen Parlament ein Sachstandsbericht vor. Im Herbst 2012 legt die Kommission dem Rat und dem Europäischen Parlament einen umfassenden Überwachungsbericht vor."

731 Vgl. den Bericht des EU Scrutiny Committee des britischen Unterhauses, 16. EU enlargement: Bulgaria and Romania: lessons learned, Sitzung vom 13. April 2016, Punkt 16.2, abrufbar unter: https://publications.parliament.uk/pa/cm2015 16/cmselect/cmeuleg/342-xxvii/34218.htm. 
sondern sogar ein Rückschritt gegenüber bereits Erreichtem festzustellen, sodass der CVM gegenüber Rumänien definitiv nicht beendet werden könne und zusätzliche Empfehlungen notwendig seien. ${ }^{732}$

Zum zweiten ist, überraschend für viele Beobachter, die Kommission gegenüber Bulgarien im November 2019 zu der Auffassung gelangt, den CVM mit Jahresablauf beenden zu wollen. An seine Stelle soll auf Initiative der bulgarischen Regierung nun ein sog. „Rat für Nachbegleitung“ („post-monitoring council“/“conseil de suivi“) treten. „Den Vorsitz würden die stellvertretende Ministerpräsidentin mit Zuständigkeit für die Justizreform und der Vertreter des Obersten Justizrats gemeinsam führen“. ${ }^{733}$ Damit wäre der CVM in der Rechtsstaatlichkeitskrise nicht nur ein Sonderfall aufgrund seines spezifischen Zuschnitts allein auf bestimmte Mitgliedstaaten, sondern auch der erste, der nicht nur eingeleitet, sondern beendet worden ist.

Die Kommission bemühte sich um Abfederung der Ankündigung zu Bulgarien durch Betonung „der Entwicklung einer breiteren Infrastruktur für Rechtsstaatlichkeit auf EU-Ebene und auf nationaler Ebene. Hier geht die Entwicklung in eine Richtung, die Möglichkeiten für neue Instrumente eröffnet, die der Konsolidierung der Rechtsstaatlichkeit neuen Schwung geben können - auch hinsichtlich Fragen, die unter das CVM fallen. " 734

Die Reaktion in der Literatur auf diese Ankündigung schwankte gleichwohl zwischen Sarkasmus und Galgenhumor. Radosveta Vassileva titelte "So Why Don't We Just Call the Whole Rule of Law Thing Off, Then?"“735

Ich bleibe hier, nicht ungeachtet sondern gerade aufgrund der divergierenden Lage zwischen beiden Mitgliedstaaten, bei einer gemeinsamen Betrachtung, um die Unterschiede besser herausarbeiten zu können und

732 Europäische Kommission, Bericht der Kommission an das Europäische Parlament und den Rat über Rumäniens Fortschritte im Rahmen des Kooperations- und Kontrollverfahrens, SWD(2018) 551 final, $\operatorname{COM(2018)~} 851$ final vom 13.11.2018, dort insb. S. 1, Einleitung a.E., weiter S. 3 ff.; Bericht der Kommission an das Europäische Parlament und den Rat über Rumäniens Fortschritte im Rahmen des Kooperations- und Kontrollverfahrens, SWD(2019) 393 final, $\operatorname{COM}(2019) 499$ final, exemplarisch dort S. 2.

733 Europäische Kommission, Bericht der Kommission an das Europäische Parlament und den Rat über Bulgariens Fortschritte im Rahmen des Kooperationsund Kontrollverfahrens, $\operatorname{COM}(2019) 498$ final vom 22.10.2019, S. 4.

734 Europäische Kommission, Bericht der Kommission an das Europäische Parlament und den Rat über Bulgariens Fortschritte im Rahmen des Kooperationsund Kontrollverfahrens, $\operatorname{COM}(2019) 498$ final vom 22.10.2019, S. 3.

735 Radosveta Vassileva, „So Why Don't We Just Call the Whole Rule of Law Thing Off, Then?““, Verfassungsblog vom 24.10.2019. 
um konzise die Frage zu beantworten, ob anhand der zuvor identifizierten Merkmale von einem systemischen Defizit an Rechtsstaatlichkeit ausgegangen werden kann oder nicht.

\section{Topoi der Entwicklung in Bulgarien und Rumänien}

Der divergierenden Entwicklung in beiden Staaten im Vergleich haben sich kundig Aneta Spendzharova und Milada Vachudova gewidmet. Sie identifizieren zwei größere Problemkomplexe.

Einerseits sei, und dabei für Bulgarien und Rumänien einheitlich, eine Gruppe makroökonomischer und allgemeiner gesellschaftlicher Probleme zu beobachten, geprägt durch ineffektive, d.h. häufig wechselnde und stark parteipolitisch polarisierte Regierungen. Hinzu komme mangelnde gesetzgeberischer Qualität. Weiter hinzu träten größere transformatorische Umbrüche infolge der Wandlungen in den jeweils postsozialistischen Volkswirtschaften Bulgariens und Rumäniens. ${ }^{736}$ Namentlich letztere haben hier außen vor zu bleiben, das gilt auch, obwohl unter Hinblick einer durch Operationalisierung seitens der Praxis geprägten Rechtsstaatlichkeit relevant, für Fragen mangelnder staatlicher Kapazitäten, die hier die Gesetzgebung betreffen. Damit deckt sich die Analyse immerhin mit der bereits genannten von Polakiewicz. ${ }^{737}$

Davon trennen beide Verfasserinnen spezifischere Fragen, wobei sie sich, wie Polakiewicz, sowohl auf Gutachten von Einrichtungen des Europarates, des CVM der Europäischen Kommission und auch der Weltbank stützen. Aufbauend auf letztere bestätigen sie die in beiden Staaten, wie aber auch im nachfolgend der Union beigetretenen Kroatien, erheblich gegenüber den übrigen EU-Mitgliedstaaten verschärfte Korruption, die ungefähr 10 Prozentpunkte für Kroatien und 20 Prozentpunkte für Bulgarien und Rumänien schlechter ausfällt als nur für die übrigen ostmitteleuropäischen Mitgliedstaaten. ${ }^{738}$ Ähnlich drastische, um ca. 20-25 Prozentpunkte

736 Aneta B. Spendzharova \& Milada Anna Vachudova, „Catching Up? Consolidating Liberal Democracy in Bulgaria and Romania after EU Accession", in: West European Politics 35 (2012), S. 39-58, insb. S. 41, 43, 45 ff.

737 S. Jörg Polakiewicz, „Addressing systemic Rule of Law Deficiencies“.

738 Aneta B. Spendzharova \& Milada Anna Vachudova, „Catching Up? Consolidating Liberal Democracy in Bulgaria and Romania after EU Accession“, S. 45. 
schlechtere Werte, ermitteln sie für den „rule of law"-Indikator der Weltbank. ${ }^{739}$

Qualitativ sehen beide Verfasserinnen indes klare Unterschiede zwischen beiden Staaten, die sich nun, wie oben geschildert, in der Rechtspraxis wiederfinden. Für beide Staaten sei es wichtig, zunächst im Hinblick auf tatsächliche wie rechtliche Fortschritte zwischen den Motivlagen der politischen Akteure zu unterscheiden. ${ }^{740}$

Bulgarien habe bei Beitritt zur Union höchst drastischen Problemen, wie den unionsweit höchsten Korruptionswerten, und dramatischem Klientelismus und Missbrauch von Einrichtungen sowie Verbänden zur persönlichen Bereicherung, entgegenzutreten gehabt, ${ }^{741}$ wobei erhebliche Fortschritte allerdings deswegen erzielt worden seien, weil infolge von Abgrenzungsbemühungen der politischen Partei GERB in Abgrenzung zu ihrem Widersacher BSP ernsthafte Reformbemühungen unternommen worden seien, über die jedoch weiterer Kapazitätenaufbau in der Justiz insbesondere unerlässlich sei. ${ }^{72}$ Eine besondere Rolle spielte dabei auch ein Amtsenthebungsverfahren gegen drei als korrupt angesehene Richter. Michael Hein hat in einer Länderstudie für Bulgarien diese Beobachtungen bestätigt. Insgesamt sei Bulgarien ein schrittweiser auch durch zahlreiche Rückschläge geprägter Transformationsprozess zu bescheinigen, der zahlreiche Problemfelder kennt, darunter die Kapazitäten in der Justiz und die Qualität der Gesetzgebung. Eine insgesamt positive Entwicklung sei aber unverkennbar. ${ }^{743}$

Für Rumänien hingegen fällt die Einordnung in der Wissenschaft gänzlich anders aus. Spendzharova und Vachudova stellen keinerlei Fortschritt fest. Vielmehr hätten sich dort die größeren Parteien geradezu verbündet, um Fortschritte, die unterschiedslos ihre Funktionäre betroffen hätten,

739 Aneta B. Spendzharova \& Milada Anna Vachudova, „Catching Up? Consolidating Liberal Democracy in Bulgaria and Romania after EU Accession“, S. 44.

740 Aneta B. Spendzharova \& Milada Anna Vachudova, „Catching Up? Consolidating Liberal Democracy in Bulgaria and Romania after EU Accession“, insb. S. 47.

741 Aneta B. Spendzharova \& Milada Anna Vachudova, „Catching Up? Consolidating Liberal Democracy in Bulgaria and Romania after EU Accession“, S. 48-49.

742 Aneta B. Spendzharova \& Milada Anna Vachudova, „Catching Up? Consolidating Liberal Democracy in Bulgaria and Romania after EU Accession“, S. 48-51.

743 Michael Hein, „Bulgaria“, in: Anna Fruhstorfer \& Michael Hein (Hrsg.), Constitutional Politics in Central and Eastern Europe: From Post-Socialist Transitions to the Reform of Political Systems, Springer Fachmedien, Wiesbaden, 2016, S. $145-171$, insb. S. $162 \mathrm{ff} ., 165 \mathrm{ff}$. 


\section{Die Rechtsstaatlichkeitskrise in mitgliedstaatlichen Fällen}

zu verhindern. ${ }^{74}$ Auch die Einrichtung einer neuen Nationalen Integritätsagentur (ANI) und der Nationalen Antikorruptionsagentur (DNA) konnte dies nicht ändern. Die Rechtsgrundlage der ANI wurde vom Verfassungsgericht 2010 für verfassungswidrig erklärt, wobei die Autorinnen vermuten, dass sieben der neun Richter des Gerichts selbst Gegenstand von Ermittlungen waren. Auch sei zu beobachten gewesen, dass die Gerichtsbarkeit ganz überwiegend selbst als korrupt erschienen sei, so seien Verfahren verschleppt oder eingestellt worden, und wenn es zu Verurteilungen gekommen sei, seien allenfalls Mindeststrafen verhängt worden. ${ }^{745}$ Damit ergibt sich an dieser Stelle, betreffend Rumänien, ein zentraler Unterschied zu Ungarn und ganz besonders zu Polen. Sind dort die Gerichte Schutzgut unionaler Bemühungen, so gelten sie in Rumänien selbst zumindest partiell als Teil des Problems.

Diese Beobachtung wird - bezeichnenderweise - auch von der Europäischen Kommission geteilt. Zum einen sei die Effektivität der Justiz ein bleibendes und drängendes Problem, ${ }^{746}$ zum anderen seien aber auch die Vorgänge bei der Ernennung von Richtern und die Integrität der Justiz besorgniserregend, bis hin zu Fragen der politisch motivierten Ermittlung gegen Richter durch eine „besondere Abteilung zur Untersuchung von durch Richter und Staatsanwälte begangene Straftaten" und andererseits etwa durch Fragen einer möglichen Kooperation der Justiz mit den rumänischen Geheimdiensten. ${ }^{747}$

Hinzugetreten ist seit 2013 ein massiver Widerstand gegen die Leiterin der DNA, Laura Codruța Kövesi, die trotz Widerstands des Staatspräsidenten Klaus Johannis schließlich den Posten räumen musste, dafür aber auf Betreiben anderer Mitgliedstaaten und gegen den Willen der rumänischen Regierung zur neuen Leiterin der europäischen Staatsanwaltschaft

744 Aneta B. Spendzharova \& Milada Anna Vachudova, „Catching Up? Consolidating Liberal Democracy in Bulgaria and Romania after EU Accession", insb. S. 52 .

745 Aneta B. Spendzharova \& Milada Anna Vachudova, „Catching Up? Consolidating Liberal Democracy in Bulgaria and Romania after EU Accession“, S. 51-55.

746 Europäische Kommission, Bericht der Kommission an das Europäische Parlament und den Rat über Bulgariens Fortschritte im Rahmen des Kooperations- und Kontrollverfahrens, SWD(2019) 392 final, $\operatorname{COM(2019)~} 498$ final vom 22.10.2019, S. 4.

747 Europäische Kommission, Bericht der Kommission an das Europäische Parlament und den Rat über Bulgariens Fortschritte im Rahmen des Kooperationsund Kontrollverfahrens, COM(2019) 498 final vom 22.10.2019, S. 4-5. 
bestimmt wurde. ${ }^{748}$ Zentrale Figuren, die dabei gegen Kövesi opponierten, waren zum einen der rumänische Justizminister Tudorel Toader und insbesondere der damalige Parlamentspräsident Liviu Dragnea, der schließlich selbst zu einer Gefängnisstrafe verurteilt wurde. ${ }^{749}$ Hinzu trat, diesmal ähnlich gelagert wie in Polen, eine Justizreform im Jahr 2017, mit der, wie dort, am Obersten Gerichtshof eine neue „Disziplinarkammer“ geschaffen wurde, die bedeutende Zweifel daran weckte, ob sie nicht vielmehr dazu gedacht war, Richter, die sich der Korruption im Allgemeinen und unter Kollegen im Besonderen entgegenstellten, zu sanktionieren. ${ }^{750}$

Auch an anderer Stelle in der Literatur ist die Kritik an der Entwicklung in Rumänien geteilt worden. Martin Mendelski, der sich im Übrigen häufig sehr kritisch zur Beaufsichtigung in Rumänien geäußert hat, fokussiert ebenso auf die Lage der Justiz und differenziert dabei zwischen einem Kapazitätenausbau der Justiz, welcher im Allgemeinen gelungen sei, und der Unparteilichkeit, an der es infolge beträchtlicher Politisierung der Justiz nach wie vor mangele. ${ }^{751}$

Sergiu Gherghina und Michael Hein schließen sich an und halten im Wesentlichen fest, bisherige Forschungsansätze wären aufgrund der persistenten Interessen nationaler Akteure und häufiger stark politisierter Konflikte zwischen hochrangigen Staatseliten und Politikern nur eingeschränkt in der Lage, die Entwicklung nachzuzeichnen. ${ }^{752}$

Die Europäische Kommission brachte schließlich im Mai 2019 in bis dato schärfster Form ihre besondere Sorge über die Lage in Rumänien zum Ausdruck. In einem Brief an die Staats- und Regierungschefs der Union drohte der damaligen Erste Vizepräsident der Kommission Timmermans damit, die Kommission werde „unverzüglich“ den EU-Rahmen

748 Michael Stabenow, „Verständigung auf Kövesi“, Frankfurter Allgemeine Zeitung vom 26.09.2019.

749 Vgl. zu diesen Vorgängen Michael Martens, „Aufräumarbeiten im rumänischen Staat“, Frankfurter Allgemeine Zeitung vom 31.05.2019 und „Nicht korrupt genug"vom 23.04.2019.

750 S. dazu etwa Der Standard, „Rumänisches Parlament verabschiedete umstrittene Justizreform"vom 21.12.2017.

751 Martin Mendelski, „Rule of Law Reforms in the Shadow of Clientelism: The Limits of the EU's Transformative Power in Romania“, in: Polish Sociological Review 174 (2011), S. 235-253, insb. S. 238 ff.

752 Sergiu Gherghina \& Michael Hein, „Romania“, in: Anna Fruhstorfer \& Michael Hein (Hrsg.), Constitutional Politics in Central and Eastern Europe: From PostSocialist Transition to the Reform of Political Systems, Springer VS, Wiesbaden, 2016, S. 173-198, S. 187 ff., insb. S. $191 \mathrm{ff}$. 
von 2014 gegen Rumänien zum Einsatz bringen, sollte sich die Lage weiter verschlechtern. ${ }^{753}$

\section{Zwischenergebnis zu Bulgarien und Rumänien}

Nach Sichtung dieser Beobachtungen fragt sich, ob die Lage in Bulgarien oder Rumänien die hier identifizierten Merkmale eines systemischen Defizits an Rechtsstaatlichkeit erfüllt.

Für Bulgarien lässt sich dies unter Abwägung zwischen dem dortigen Fortschritt und den beobachteten Kapazitätsschwächen in Justiz und Verwaltung vorrangig für den bei von Bogdandy und Ioannidis identifizierten Topos der staatlichen Schwäche bestätigen, was aber auch zur Folge hat, dass Bulgarien aus der Betrachtung in dieser Arbeit ausscheidet. Es erledigt sich damit auch eine eingehende Untersuchung der Frage, ob die Europäische Kommission im Hinblick auf ihre Entscheidung, den CVM betreffend Bulgarien zu beenden, richtig gehandelt hat. Es ist hier allein festzuhalten, dass dieser Schritt getroffen wurde und dass diejenigen, die sich staatlichen Schwächen in der Union widmen, dies gesondert analysieren könnten.

Was Rumänien angeht, so steht die Entscheidungsfindung vor einer echten Herausforderung.

Pech u.a. ${ }^{754}$ sehen in den Vorgängen in Rumänien jedenfalls eine „systematische Unterwanderung“ des Kampfes gegen die Korruption. Sie fordern daher sogar, ein Vertragsverletzungsverfahren besonderer Art nach Art. 325 AEUV gegen Rumänien einzuleiten. Bogdan Iancu gelangt in seiner Analyse des rumänischen Rechtssystems zu einem ähnlichen Ergebnis, er stört sich insbesondere an den mangelnden Kompetenzabgrenzungen innerhalb der Justiz und ihrer starken Politisierung und hält fest:

„Gaps in the constitutional structure, such as the vague and overlapping attributions which characterise the separation of powers framework, as well as the systemic malfunctions ensuing from a lack of

753 Florian Eder, „Brussels to Bucharest: We're running out of patience”, Politico vom 13.05.2019. Der Wortlaut des Briefs ist nicht publik geworden.

754 Laurent Pech, Vlad Perju \& Sébastien Platon, How to Address Rule of Law Backsliding in Romania, Verfassungsblog vom 29.05.2019. 
proper foundations, allow the justices a considerable amount of discretion." ${ }^{755}$

Angesichts dieser Stimmen ist zumindest eine intrasystemische Eskalation der allgemeinen justiziellen und gubernativen Missstände in Rumänien klar ausgemacht. Meines Erachtens erlangt sie darüber auch eine intersystemische Dimension bzw. einen Spillover-Effekt auf andere Mitgliedstaaten und die gesamte unionale Rechtsordnung. Das wird in dramatischer Weise deutlich beispielsweise am mangelnden Fortschritt der Ermittlungen im Rat gegenüber Polen und Ungarn nach Art. 7 EUV während der rumänischen Ratspräsidentschaft. ${ }^{756}$ Es erscheint als erwiesen, dass unter der rumänischen Ratspräsidentschaft die im Rat anhängigen Verfahren bewusst verschleppt wurden, und auch die im Europäischen Parlament seitens der rumänischen Ratspräsidentschaft gemachten Aussagen sind nicht überzeugend. Exemplarisch kann auf die Rede der rumänischen Ministerpräsidentin Viorica Dăncilă vor dem Europäischen Parlament verwiesen werden. Dort - und nur in dieser Passage - heißt es zum Stichwort der Rechtsstaatlichkeit:

„We will continue to act, in a pragmatic manner, to promote the Principles of the Sibiu Declaration, and we remain deeply committed to observing the democratic values and the rule of law. It is important, however, that there are no differences between the Member States, divisions that can create different standards for European citizens. " 757

Während die Betonung der unterschiedslosen Behandlung von Mitgliedstaaten, die angesprochen wird, Primärrechtsrang hat, Art. 4 Abs. 2 EUV, kann sie hier auch so verstanden werden, dass die gegen bestimmte Mitgliedstaaten laufende Maßnahmen, darunter der CVM gegen Rumänien und Bulgarien, aber eben auch etwa die Maßnahmen gegen Polen und Ungarn, als Ungleichbehandlung einzustellen sind. Auch der Zusatz der „pragmatischen Weise“ der Behandlung lässt sich als Drohung lesen, die Verfahren zurückzunehmen und gleichzeitig als Ankündigung, dies selbst

755 Bogdan Iancu, „Separation of Powers and the Rule of Law in Romania: The Crisis in Concepts and Contexts", in: Armin von Bogdandy, \& Pál Sonnevend(Hrsg.), Constitutional Crisis in the European Constitutional Area, C.H. Beck/Hart/Nomos, München/Oxford/Baden-Baden, 2015, S. 153-169, S. 162.

756 Vgl. den Beitrag von Laurent Pech \& Patryk Wachowiec, „1460 Days Later“.

757 „Prime Minister Viorica Dăncilă's address at the plenary session of the European Parliament" vom 18.07.2019, o.S., abrufbar unter: https://www.romania2019.eu /2019/07/18/prime-minister-viorica-dancilas-address-at-the-plenary-session-of-the -european-parliament/. 


\section{Die Rechtsstaatlichkeitskrise in mitgliedstaatlichen Fällen}

tun zu wollen. Auch der erstaunliche Umstand, dass durch die rumänische Regierung versucht wurde, die Benennung der Leiterin der neuen EUStaatsanwaltschaft zu verhindern, wobei zumindest substantiell gemutmaßt werden kann, dass dies mit Blick auf zu befürchtende Ermittlungen gegen sie geschieht, ist Teil des belastenden Materials.

Diese Entwicklungen, gerade die Verschleppung der Aufarbeitung rechtsstaatsspezifischer Vorgänge in anderen Mitgliedstaaten im Rat, die wiederholte, systematische Einmischung in die Aufarbeitung nationaler Korruptionsskandale und der Versuch, eine schlagkräftige unionale Institution in diesem Bereich zu verhindern, sind aus meiner Sicht hinreichend dafür, im Falle Rumäniens das intersystemische Konfliktpotential der dortigen Entwicklungen und damit ein systemisches Defizit an Rechtsstaatlichkeit jedenfalls auch vorsätzlichen Typus im Sinne dieser Arbeit zu bejahen. Dies gilt ungeachtet des Umstands, dass die Union bislang mit ihren Reaktionen gegenüber Rumänien relativ zurückhaltend war.

\section{Folgefragen}

Allerdings wird der soeben gemachte Befund eines systemischen Defizits für Rumänien überraschenderweise von anderer Seite geschwächt, nämlich im Hinblick auf die empirische Belastbarkeit des vorherigen Befundes der Korruption. Verfügbare Datensätze belegen zwar, dass Rumänien ein ernsthaftes Problem hat, aber es ist nicht das Schlusslicht der Union. Aus Daten, die für ein Sondereurobarometer 2017 erhoben wurden, folgt z.B., dass in Rumänien zwar 80\% aller Befragten die Lage für schwerwiegend einstufen, doch andere Mitgliedstaaten erzielen weit höhere Werte. ${ }^{758}$ Auch andere Daten stellen Rumänien kein Zeugnis als Klassenschlechtester aus. Nach einer Kostenaufstellung der Korruption in den EU-Mitgliedstaaten durch die Partei Grüne-EFA erzielt die Korruption in Rumänien

758 Vgl. Eurostat, Special Eurobarometer 470, October 2017, Corruption, S. 18, Tabelle zu "QB 5 How widespread do you think the problem of corruption is in (OUR COUNTRY)?”. Demnach halten in den Mitgliedstaaten Griechenland (96), Spanien (94), Portugal (92) und Zypern (94) jeweils weit über 90\% der Befragten Korruption für ein zentrales Problem, gegenüber Rumänien mit „nur“ 80 und Ungarn mit 86\%. 
mit $15 \%$ des BIP zwar einen absoluten Spitzenwert, stellt man aber auf die Auswirkungen pro Kopf ab, so ist Italien Spitzenreiter. ${ }^{759}$

Warum also gilt es, gerade für Rumänien den Befund der Korruption derart hervorzuheben? Für Griechenland lässt sich für die Nichterwähnung der immerhin 96\% der Bevölkerung, die Korruption als Problem sehen, hier anführen, dass das Fallbeispiel aufgrund mangelnden Zuschnitts der Betrachtung hier aus der Studie herausfällt. Aber wäre es darüber angebracht gewesen, Portugal mit immerhin 92\% der Bevölkerung mit vergleichbaren Werten zu erwähnen?

Die Antwort hierauf muss, wie schon zuvor angedeutet, wieder das Argument der Gesamtschau sein. Es ist das Zusammenspiel verschiedener Topoi in Rumänien, welches gerade dort das Korruptionsproblem besonders drängend erscheinen lässt. Die geschilderten empirischen Befunde hinsichtlich anderer Mitgliedstaaten können allerdings nicht einfach ignoriert werden. Dies führt zu zwei Fragen, die auch an anderer Stelle hätten Erwähnung finden können, gerade hier aber gesondert erwähnt werden sollen, weil sie besondere Relevanz entwickeln. Erstens nämlich ist auf die Frage der Belastbarkeit empirischer Indikatoren in der gegenwärtigen Krise einzugehen und zweitens die Frage der darüber zu erfolgenden Abgrenzung von Staaten, die nicht nur durch derartige Daten, sondern auch durch qualitative Einordnungen in der Praxis kritisiert worden sind, zu erörtern.

\section{a. Relativierung empirischer Indikatoren?}

Seit Beginn der Sorge um eine krisenhafte Verschlechterung der Rechtsstaatlichkeit in der Europäischen Union operieren Wissenschaft und Praxis, und dabei sowohl Union als auch Europarat, mit Indikatoren, um diese Verschlechterung zum Ausdruck zu bringen und Mitgliedstaaten voneinander auch qualitativ unterscheiden zu können. In der zuvor diskutierten Defekt- und Transformationsforschung der Politikwissenschaft bilden diese, und ihre Validität, häufig den Schwerpunkt der Operationalisierung. Ich habe dort dargelegt, warum die dortigen Studien (noch) nicht für die Rechtswissenschaft Verwendung finden können.

759 Vgl. Greens-EFA, „The Costs Of Corruption Across The EU”, abrufbar unter: https:/www.greens-efa.eu/files/assets/docs/the_costs_of_corruption_across_the_ eu.pdf, S. 4. 


\section{Die Rechtsstaatlichkeitskrise in mitgliedstaatlichen Fällen}

Aber auch in der Rechtswissenschaft sind Indikatoren hier sehr relevant. Bei von Bogdandy und Ioannidis standen Indikatoren u.a. der Weltbank mit im Zentrum ihrer Beobachtung staatlicher Schwäche in bestimmten Mitgliedstaaten. ${ }^{760}$ Die Venedig-Kommission hat 2016 ihre „rule of law checklist" vorgelegt, ${ }^{761}$ und Jörg Polakiewicz sowie Jenny Sandvig riefen kurz zuvor dazu auf, derartiges Material bei der Entwicklung weiterer Indikatoren aktiv zu nutzen. ${ }^{762}$ Und seit 2013 erarbeitet die Europäische Kommission mit dem sog. Justizbarometer eigene empirische Grundlagen, die die Effektivität der Justiz in Mitgliedstaaten, verstanden als zusammengesetzter Indikator der drei Themenfelder Effizienz, Qualität und Unabhängigkeit, ${ }^{763}$ misst.

Es hat bei der topischen Darstellung der Rechtsstaatlichkeitskrise zu interessieren, dass Indikatoren einerseits und qualitative Einschätzungen andererseits teils stark divergieren und dass hieraus zum einen rechtswissenschaftliche Irritation und zum anderen harte politische Verhandlungsmasse erwachsen. Das zeigt sich nicht nur für Rumänien, sondern besonders prägnant auch für Polen und Ungarn. Besonders deutlich tritt diese Problematik zutage, wenn man sich nochmals einige Schaubilder des o.g. Justizbarometers der Kommission vor Augen führt.

Was exemplarisch die Effizienz gemessen an der notwendigen Zeit für die Bearbeitung neu eingehender Akten bei Gericht angeht, sind Polen und Ungarn top performer, nur übertroffen u.a. von Dänemark und liegen vor den Niederlanden und weit vor Frankreich. ${ }^{764}$ Auch im Hinblick auf die anderen Themenfelder des Justizbarometers wird dieser überraschende Eindruck zunächst nicht widerlegt. Denn noch nicht einmal für den Indikator der „wahrgenommenen Unabhängigkeit“, eine Frage, die schließlich

760 Armin von Bogdandy \& Michael Ioannidis, „Das systemische Defizit“, S. 300 und ff.

761 Venedig-Kommission, CDL-AD(2016)007, Study No. 711 / 2013, Rule of Law Checklist vom 18.03.2016, s. auch zuvor unter IV.1.

762 Jörg Polakiewicz \& Jenny Sandvig, „Council of Europe and the Rule of Law“, in: Journal of Civil \& Legal Sciences, (4) 2015, o. S., S. 6.

763 Europäische Kommission, Mitteilung der Kommission an das Europäische Parlament, den Rat, die Europäische Zentralbank, den Europäischen Wirtschaftsund Sozialausschuss und den Ausschuss der Regionen, EU-Justizbarometer 2019, COM(2019) 198 final vom 26.04.2019, Vorwort (nur in der englischen Fassung), vgl. dazu auch unter E.V.3.

764 Europäische Kommission, Mitteilung der Kommission an das Europäische Parlament, den Rat, die Europäische Zentralbank, den Europäischen Wirtschaftsund Sozialausschuss und den Ausschuss der Regionen, EU-Justizbarometer 2019, $\operatorname{COM(2019)~} 198$ final vom 26.04.2019, Schaubild 5, S. 16. 
im Zentrum der zuvor beschriebenen Analyse steht, sind Polen und Ungarn Schlusslicht. Dies sind vielmehr die Slowakei und Kroatien. ${ }^{765}$ Teils hat dies in der Rechtswissenschaft zu überwältigend positiven Analysen der Lage in Polen geführt. ${ }^{766}$ In der Praxis wiederum hat die polnische Regierung versucht, aus dem Justizbarometer Argumente für ihre eigene Position abzuleiten und die Interpretation der Daten beliebig in alle Richtungen vorzunehmen. Dies gilt insbesondere für ihr sog. White Paper. An einer Stelle dieses Dokuments etwa weist sie zum einen auf die ihrer Auffassung nach relativ hohe Effizienz der polnischen Justiz hin, nur um dann einen Anstieg der Fallbearbeitungszeit festzustellen, was die Handlungen seitens der Regierung rechtfertige. ${ }^{767}$ Auch die ungarische Regierung hat den Umstand genutzt, dass verschiedene Indikatoren des Justizbarometers dem Land gute Noten ausstellen. Sie hielt fest, dass einzelne Indikatoren dem Land eine unterdurchschnittliche Lage bescheinigten, die Situation aber keineswegs als sehr schlecht eingeordnet werden könne und kritisierte hierzu eine Falschberichterstattung auch in der Presse. ${ }^{768}$ Scheppele sprach im Hinblick auf Ungarn schließlich von einem „Schuss in den Ofen“, den sich die Kommission im Hinblick auf das gute Abschneiden Ungarns im Justizbarometer geleistet habe. ${ }^{769}$ Zwischen der rumänischen Regierung und der Weltbank schließlich diente das Justizbarometer (in der Ausgabe von 2016) ebenso als positive Verhandlungsmasse, die Bank bescheinigte Rumänien die „höchste Erledigungsrate“ von anhängigen Verfahren in der gesamten EU. ${ }^{770}$

765 Dazu Europäische Kommission, Mitteilung der Kommission an das Europäische Parlament, den Rat, die Europäische Zentralbank, den Europäischen Wirtschafts- und Sozialausschuss und den Ausschuss der Regionen, EU-Justizbarometer 2019, COM(2019) 198 final vom 26.04.2019, Schaubild 47, S. 55.

766 Vgl. Nina Poltorak, „Enlargement and administrative law: The Polish Experience", in: Carol Harlow, Päivi Leino \& Giacinto della Cananea (Hrsg.), Research Handbook on EU Administrative Law Edward Elgar, Cheltenham/Northampton, MA, 2017, S. 521-544, insb S. 524-525.

767 Vgl. Kanzlei des polnischen Premierministers, White Paper on the Reform of the Polish Judiciary vom 07.03.2018, Rn. $9 \mathrm{ff}$.

768 Pressemitteilung der ungarischen Regierung vom 29.04.2019, „Minister of State Zoltán Kovács criticised European Commission's justice scoreboard of last week", abrufbar unter: https://www.kormany.hu/en/government-spokespers on/news/minister-of-state-zoltan-kovacs-criticised-european-commission-s-justice -scoreboard-of-last-week.

769 Kim Lane Scheppele, „Constitutional Coups in EU Law“, S. 461, „backfire“.

770 Weltbank (International Bank for Reconstruction and Development), Project Appraisal Document on a Proposed Loan [...] to Romania for a Justice Services Improvement Project, vom 09.01.2017, Report No: PAD2059, abrufbar unter 


\section{Die Rechtsstaatlichkeitskrise in mitgliedstaatlichen Fällen}

Vor dem Hintergrund dieses Befundes ist als zentrales Unterscheidungskriterium zunächst festzuhalten, dass die vielfach in unterschiedlichen Indikatoren und empirischen Datensätzen gemessene Funktionsweise eines Justizsystems nicht notwendigerweise auf systemische Defizite an Rechtsstaatlichkeit hindeuten muss.

In sozialwissenschaftlicher Terminologie gefasst ist also ein Defekt bei ersterer keine notwendige Bedingung für letztere, noch besteht augenscheinlich eine zwingende Korrelation zwischen beiden. Letztere ist stabil, wenn, wie seinerzeit bei von Bogdandy und Ioannidis beschrieben, gerade der Subtyp der staatlichen Schwäche im Fokus steht. Das Justizbarometer weist z.B. recht konsistent etwa Italien bei der Fallerledigungszahl einen der letzten Plätze zu. ${ }^{771} \mathrm{Ob}$ die dort noch schlechter beurteilten Mitgliedstaaten auch interessieren müssten, bleibt hier außen vor, denn für diese Arbeit interessiert eben allein die vorsätzliche Unterwanderung der Rechtsstaatlichkeit, und diese drückt sich nicht notwendigerweise in der Effizienz der Justiz aus. Auch ein stark politisiertes und defizitäres, auf Anweisung innerhalb der Justizhierarchie oder sogar von außen wartendes Justizsystem kann Fälle schnell erledigen, umso mehr, wenn dadurch der Deliberationsprozess abgekürzt wird.

Deswegen ist zu betonen, dass viele Indikatoren entweder ausschließlich derartige Effizienzgesichtspunkte berücksichtigen, womit sie für die hier interessierende Problematik zu punktuell bleiben oder dies eben nur Teil der Untersuchung ist, wie insbesondere im Justizbarometer der Europäischen Kommission. Denn die dortige Effizienz ist neben der Unabhängigkeit und der Qualität der Justiz nur einer von drei empirisch untersuchten Teilbereichen hinsichtlich der Frage nach einem insgesamt effektiven Justizsystem in einem Mitgliedstaat. Ausdrücklich und in anderen Sprachfassungen unerreicht griffig heißt es in der englischen Fassung: „Independence, quality and efficiency are essential parameters of an effective justice system, whatever the model of the national justice system or the legal

http://documents.worldbank.org/curated/en/275511486133734057/text/Romani a-PAD-v2-01102017.txt, S. 9, s. unter Punkt B.5.

771 Dazu Europäische Kommission, Mitteilung der Kommission an das Europäische Parlament, den Rat, die Europäische Zentralbank, den Europäischen Wirtschafts- und Sozialausschuss und den Ausschuss der Regionen, EU-Justizbarometer 2019, $\operatorname{COM(2019)~} 198$ final vom 26.04.2019, S. 16, Schaubild 5: „Für den Abschluss von Zivil-, Handels-, Verwaltungs- und sonstigen Rechtssachen erforderliche Zeit“. Verfügbar sind Zahlen für 2010 sowie 2015-2017. 
tradition in which it is anchored." 772 Die Effektivität ist also der Oberbegriff, und es zeigt sich insbesondere im zur Effizienz separat untersuchten Bereich der Unabhängigkeit, namentlich der strukturellen Unabhängigkeit, dass Indikatoren sehr wohl krasse Abweichungen einzelner Mitgliedstaaten von der unionalen Norm aufweisen. ${ }^{773}$ Hierauf und auf die dabei verwandten Methoden wird später bei der Darstellung des Justizbarometers als Aufsichtsmechanismus nochmals einzugehen sein.

Zum zweiten hat, was jedenfalls ihren Zuständigkeitsbereich angeht, die Europäische Kommission selbst das Problem der potentiellen Diskrepanz bei der qualitativen Beurteilung der Unterwanderung der Rechtsstaatlichkeit einerseits und eines Gutteils ihrer auf justizielle Effizienz abstellenden Indikatoren andererseits erkannt und deswegen 2018 erstmals eine Kontextualisierung spezifisch zur Abgrenzung der Funktionsweise des Justizbarometers von weiteren Maßnahmen zum Schutz der Rechtsstaatlichkeit vorgenommen, die 2019 fortgesetzt worden ist. ${ }^{774}$ Diese Kontextualisierung und Einbettung des Justizbarometers seitens der Kommission ist nicht nur eine höchst wertvolle Stärkung der in dieser Arbeit vorgeschlagenen Beobachtung eines unionalen Verfassungsaufsichtsregimes, da sie, wie hier, von einem kohärent ineinandergreifenden Rechtsregime ausgeht.

772 Europäische Kommission, Mitteilung der Kommission an das Europäische Parlament, den Rat, die Europäische Zentralbank, den Europäischen Wirtschaftsund Sozialausschuss und den Ausschuss der Regionen, EU-Justizbarometer 2019, $\operatorname{COM(2019)~} 198$ final vom 26.04.2019, Einleitung, S. 2 der engl. Broschürenfassung. In der dt. Fassung (dort. S. 4) heißt es etwas verschachtelt: „Unabhängig vom Modell des nationalen Justizsystems oder der Rechtstradition, in der dieses System verankert ist, gehören Unabhängigkeit, Qualität und Effizienz zu den wesentlichen Parametern einer leistungsfähigen Justiz.“

773 Europäische Kommission, Mitteilung der Kommission an das Europäische Parlament, den Rat, die Europäische Zentralbank, den Europäischen Wirtschaftsund Sozialausschuss und den Ausschuss der Regionen, EU-Justizbarometer 2019, $\operatorname{COM(2019)~} 198$ final vom 26.04.2019, EU-Justizbarometer 2019, vgl. ab S. 55 und ab S. 58 insb. Im Justizbarometer finden sich auch Indikatoren, wie auf S. 48 ff. diejenigen zur „strukturellen Unabhängigkeit“, die die Rechtsstaatlichkeitskrise klar hervortreten lassen.

774 Vgl. dazu Europäische Kommission, Mitteilung der Kommission an das Europäische Parlament, den Rat, die Europäische Zentralbank, den Europäischen Wirtschafts- und Sozialausschuss und den Ausschuss der Regionen, EU-Justizbarometer 2018, $\operatorname{COM}(2018) 364$ final, vom 28.05.2018, erschienen in zwei Teilen, Part 1/2, S. 5 ff.; sodann Europäische Kommission, Mitteilung der Kommission an das Europäische Parlament, den Rat, die Europäische Zentralbank, den Europäischen Wirtschafts- und Sozialausschuss und den Ausschuss der Regionen, EU-Justizbarometer 2019, $\operatorname{COM(2019)~} 198$ final vom 26.04.2019, S. 9 ff. 


\section{Die Rechtsstaatlichkeitskrise in mitgliedstaatlichen Fällen}

Auch wird dadurch ein hinreichender Beweis dafür geliefert, dass die scheinbare Widerlegung krisenhafter Zustände, gerade im Hinblick auf Polen, Ungarn oder Rumänien, im Kontext der vorsätzlichen Unterwanderung der Rechtsstaatlichkeit zu sehen ist und folglich durch vermeintlich gegenläufige Indikatoren nicht widerlegt wird.

\section{b. Abgrenzung zur Lage in Malta}

Die soeben zur Abgrenzung und Einschätzung der Lage für notwendig erachtete Kontextualisierung der Entwicklung in bestimmten Mitgliedstaaten führt nun aber dazu, dass jedenfalls ein weiterer Mitgliedstaat, der bislang nicht berücksichtigt worden ist, mutmaßlich in den Fokus der Arbeit rückt. Er hebt sich zwar durch die vorgenannten Indikatoren nicht von den übrigen Mitgliedstaaten markant $a b$, indes besteht im Kontext der Krise durchaus Material, das ihn in die Nähe krisenbetroffener Mitgliedstaaten rückt. Dieses Beispiel ist Malta.

Malta ist, wieder mit Blick z.B. auf das EU-Justizbarometer, vielfach unauffällig. Es hat z.B. im Allgemeinen den niedrigstes Pro-Kopf-Eingang von Fällen in der Gerichtsbarkeit in der gesamten EU. ${ }^{775}$ Im Hinblick auf die allgemeine Wahrnehmung der richterlichen Unabhängigkeit befindet sich Malta im Mittelfeld, und die Europäische Kommission ordnet das Land im Hinblick auf die Disziplinierung von Richtern, um weitere Beispiele zu geben, der größeren Gruppe von Mitgliedstaaten zu, die hierzu über einen Justizrat verfügen. ${ }^{776}$ Vor 2014 war das Land weiter für die Venedig-Kommission nicht von Interesse. ${ }^{777}$

775 Europäische Kommission, Mitteilung der Kommission an das Europäische Parlament, den Rat, die Europäische Zentralbank, den Europäischen Wirtschaftsund Sozialausschuss und den Ausschuss der Regionen, EU-Justizbarometer 2019, $\operatorname{COM(2019)~} 198$ final vom 26.04.2019, S. 14-15, Schaubild 2 und 4, „Zahl der neuen Zivil-, Handels-, Verwaltungs- und sonstigen Rechtssachen“ und „Zahl der neuen Verwaltungssachen“. Für die nur streitigen Rechtssachen (Schaubild 3) liegt Malta im Mittelfeld.

776 Europäische Kommission, Mitteilung der Kommission an das Europäische Parlament, den Rat, die Europäische Zentralbank, den Europäischen Wirtschaftsund Sozialausschuss und den Ausschuss der Regionen, EU-Justizbarometer 2019, $\operatorname{COM}(2019) 198$ final vom 26.04.2019, S. 55 und 62, Schaubilder 47 und 52.

777 Seitdem sind drei Gutachten ergangen, vgl. 1. Venedig-Kommission, CDL-AD(2014)035, Opinion No. 780/2014, ODIHR Opinion-Nr.: POLITMLT/262/2014, Joint Opinion on the Draft Act to regulate the formation, the 
Seitdem aber hat sich das allgemeine Bild in schneller Folge gewandelt und bleibt dabei erstaunlich unübersichtlich.

Das bedeutendste Argument für die Annahme, in Malta bestehe ebenso ein systemisches Defizit an Rechtsstaatlichkeit, liefert das Europäische Parlament. Es nahm 2017 eine „Resolution zur Rechtsstaatlichkeit in Malta“ an, ${ }^{778}$ noch dazu am selben Tag wie diejenige zu Polen. Malta zählt damit zu einer Gruppe von bislang drei Mitgliedstaaten (der dritte ist Rumänien), ${ }^{779} \mathrm{zu}$ welchen das Parlament eine derart bedeutende Entschließung angenommen hat.

Gleichwohl zeigt die Durchsicht dieser Entschließung und insbesondere auch diejenige eines 2018 ergangenen Gutachtens der Venedig-Kommission bislang kein Bild einer verfestigten, systemisch relevanten Rechtsstaatlichkeitskrise in Malta. Es ergibt sich vielmehr der Eindruck einer durchaus in bestimmten Bereichen des öffentlichen Lebens defizitären Verwaltung und Regierung, inklusive bestimmter schwerwiegender Dysfunktionen an zentraler Stelle, denen allerdings durch gezielte Gegenreaktionen in diesen Bereichen begegnet werden kann. Darüber stellen sie weder einen genuin intrasystemischen noch aber intersystemischen Konflikt dar. Auch bestehen keine weiteren Spillover-Effekte besonderer Fallzahl, Schwere oder Dauer, wie sie für den Begriff des systemischen Defizits zuvor als erforderlich angesehen worden ist.

Diese Einschätzung findet Material zunächst bei der Durchsicht der Entschließung des Europäischen Parlaments.

Auslöser für den politischen Mehrheitskonsens im Europäischen Parlament, eine Mahnung an Malta in Form der Entschließung und spezifisch

inner structures, functioning and financing of political parties and their participation in elections of Malta vom 14.10.2014; 2. CDL-AD(2018)014, Opinion No. 920/2018, Malta - Opinion on the draft act amending the Constitution, on the draft act on the human rights and equality commission, and on the draft act on equality vom 23.06.2018; 3. CDL-AD(2018)028, Opinion no. 940/2018, Malta - Opinion on Constitutional arrangements and separation of powers and the independence of the judiciary and law enforcement vom 17.12.2018.

778 P8_TA(2017)0438, Rechtsstaatlichkeit in Malta, Entschließung des Europäischen Parlaments vom 15. November 2017 zur Rechtsstaatlichkeit in Malta (2017/2935(RSP)); Kursorische Würdigung in der Literatur etwa bei Gabriel N. Toggenburg, „Menschenrechtspolitik“, in: Werner Weidenfeld \& Wolfgang Wessels (Hrsg.), Jahrbuch der Europäischen Integration 2018, Nomos, BadenBaden, 2018, S. 229-234, S. 233-234.

779 Europäisches Parlament, P8_TA(2018)0446, Rechtsstaatlichkeit in Rumänien, Entschließung des Europäischen Parlaments vom 13. November 2018 zur Rechtsstaatlichkeit in Rumänien (2018/2844(RSP)). 


\section{Die Rechtsstaatlichkeitskrise in mitgliedstaatlichen Fällen}

zur Rechtsstaatlichkeit auf den Weg zu bringen, ist ausweislich der Erwägungsgründe ein konkreter Einzelfall betreffend eine einzelne natürliche Person: die Ermordung der investigativ zu Fragen der Korruption arbeitenden Journalistin Daphne Caruana Galizia 2017 durch eine Autobombe. ${ }^{780}$

Das Parlament identifiziert in der weiteren Folge 9 Vorgänge, die in Malta rechtlich bedenklich sind:

- die Beschaffenheit der Medienlandschaft ${ }^{781}$

- die Beziehung politischer Amtsträger zu den Medien ${ }^{782}$

- den Umgang mit Geldwäsche durch bestimmte Banken und die Bankenaufsicht ${ }^{783}$

- die mutmaßliche Anfälligkeit von Amtsträgern für Korruption und Geldwäsche und Reaktionen hierauf ${ }^{784}$ sowie sektorale Anfälligkeit bestimmter Wirtschaftsbereiche für Geldwäsche ${ }^{785}$

- den Umgang mit und Schutz von Hinweisgebern („whistleblowers“), die durch eigene Kenntnis Missstände wie Korruption von Amtsträgern aufdecken $^{786}$

- die Auswahl und Ernennung maltesischer Richter und Polizeibeam$\operatorname{ter}^{787}$

780 Europäisches Parlament, P8_TA(2017)0438 Rechtsstaatlichkeit in Malta, Entschließung des Europäischen Parlaments vom 15. November 2017 zur Rechtsstaatlichkeit in Malta (2017/2935(RSP)) (2018/C 356/04), ABl. (EU) C 356/29 vom 04.10.2018, Entschließung des Europäischen Parlaments vom 15. November 2017 zur Rechtsstaatlichkeit in Malta (2017/2935(RSP)), Erwägungsgründe E, J, K, M, 1-4. Das Parlament fordert im Hinblick auf den Mord an Daphne Caruana Galizia daher, Erwägungsgrund 4, von der Konferenz der Präsidenten, dem Gremium des EP-Präsidiums und der Fraktionsvorsitzenden, einen nach ihr benannten Preis für Journalisten auszuloben.

781 Entschließung des Europäischen Parlaments vom 15. November 2017 zur Rechtsstaatlichkeit in Malta (2017/2935(RSP)), Erwägungsgründe G, L, 5.

782 Entschließung des Europäischen Parlaments vom 15. November 2017 zur Rechtsstaatlichkeit in Malta (2017/2935(RSP)), Erwägungsgründe G, H, I, J, K, L, P.

783 Entschließung des Europäischen Parlaments vom 15. November 2017 zur Rechtsstaatlichkeit in Malta (2017/2935(RSP)), Erwägungsgründe L, T und V.

784 Entschließung des Europäischen Parlaments vom 15. November 2017 zur Rechtsstaatlichkeit in Malta (2017/2935(RSP)), Erwägungsgründe S, U, Z.

785 Entschließung des Europäischen Parlaments vom 15. November 2017 zur Rechtsstaatlichkeit in Malta (2017/2935(RSP)), Erwägungsgrund AA.

786 Entschließung des Europäischen Parlaments vom 15. November 2017 zur Rechtsstaatlichkeit in Malta (2017/2935(RSP)), Erwägungsgrund M und N.

787 Entschließung des Europäischen Parlaments vom 15. November 2017 zur Rechtsstaatlichkeit in Malta (2017/2935(RSP)), Erwägungsgrund O. 
- die Fähigkeit und den Strafverfolgungswillen dieser Stellen einschließlich der Weigerung Maltas, der europäischen Staatsanwaltschaft beizutreten, insbesondere beim Umgang mit Geldwäsche, Korruption und dem Umgang mit verfügbarem Material wie etwa den sog. „Panama Papers“, im Internet durchgestochenen Nachweisen über Offshore-Konten und Geldwäsche ${ }^{788}$

- den „Verkauf“ der maltesischen Staatsbürgerschaft ohne Auflagen oder Veröffentlichung der Identität der Eingebürgerten. ${ }^{789}$

Das Parlament verknüpft diese Vorgänge miteinander, weil sie Reaktionen auf die journalistische Tätigkeit der ermordeten Journalistin waren oder durch sie selbst aufgedeckt wurden. Teils, wie im Fall der sog. „Panama-Papers" bzw. der Thematik des Verkaufs der Staatsbürgerschaft, dient der Fall der Ermordung Galizias zum Anlass, weitere Missstände aus Sicht des Parlaments zu benennen.

Es bietet sich an, die vom Europäischen Parlament identifizierten Topoi zusammen zu betrachten. Dann ist Malta allenfalls Exemplar eines Mitgliedstaats, in welchem für den Betrachter in hohem Maße eine verstärkte Unsicherheit über die wirkliche Intention und Rechtstreue von Entscheidungsträgern und Interessengruppen besteht, die vorrangig von strafrechtlicher Relevanz in diesem Mitgliedstaat selbst sein könnten bzw. ein solcher Mitgliedstaat, in welchem sektorale Fehlleistungen in der Leistungsverwaltung, insbesondere der öffentlichen Daseinsvorsorge, bestehen. Es fehlt aber der Nachweis einer unmittelbaren Auswirkung auf die Rechtsstaatlichkeit insbesondere dergestalt, dass die maltesische Aufarbeitung nicht willens oder nicht in der Lage wäre, sich der Problematik anzunehmen. Die vom Parlament gerügten Fehlentwicklungen betreffen sowohl die Ausermittlung der Fälle als auch die konsequente Strafverfolgung bei unsicherer Beweislage. Der Umgang mit derartigem „bösen Anschein“ ist für die rechtliche Ahndung aus strafrechtlicher Sicht, insbesondere bei Straftaten im Amt, ein schwieriges Problem für viele Rechtsordnungen. ${ }^{790}$ Es handelt sich aber um ein Problem von vorrangigem Interesse allein für mitgliedstaatliche Stellen, d.h. die maltesische Justiz und Verwaltung.

788 Entschließung des Europäischen Parlaments vom 15. November 2017 zur Rechtsstaatlichkeit in Malta (2017/2935(RSP)), Erwägungsgrund Q.

789 Entschließung des Europäischen Parlaments vom 15. November 2017 zur Rechtsstaatlichkeit in Malta (2017/2935(RSP)), Erwägungsgrund, W, X, Y, Z.

790 Exemplarisch für das deutsche Strafrecht zum „bösen Anschein der Käuflichkeit" als dogmatischem Novum bei $\$ 331$ StGB grundlegend BGH, Urteil vom 2. 2. 2005 - 5 StR 168/04 = NStZ 2005, 334. 


\section{Die Rechtsstaatlichkeitskrise in mitgliedstaatlichen Fällen}

Der damit geschilderte Typus staatlicher Fehlleistungen wird entweder dann zu einem Beispielsfall der Rechtsstaatlichkeitskrise, wenn die Unsicherheit des Betrachters in den Befund konkret nachweisbaren Vorsatzes von Entscheidungsträgern der Gubernative oder anderer oberster Staatsorgane oder Behörden umschlägt und diese nicht nur im Einzelfall strafrechtlich erheblich sind, sondern erhebliche Auswirkungen auf den $\mathrm{Zu}-$ stand des mitgliedstaatlichen Rechtssystems insgesamt haben. Oder aber eine Bezugnahme auf das Rechtsstaatsprinzip scheint gerechtfertigt, wenn die Missstände nicht durch Verwaltungs- oder Gerichtsverfahren des Mitgliedstaates selbst zu einem befriedigenden Abschluss gebracht werden können, d.h. die maltesischen Verfassungsorgane, die Verwaltung oder Justiz überfordert wären und damit ein Fall mitgliedstaatlicher Schwäche vorläge. Nach derzeitigem Entwicklungsstand, so wie das Parlament ihn schildert, ist das aber in Malta nicht der Fall.

Die ergänzende Begutachtung seitens der Venedig-Kommission ein Jahr später ${ }^{791}$ stützt dieses Bild. Das Gutachten bescheinigt Malta in zahlreichen Punkten deutliche Schwächen in Verwaltung und Staatsaufbau, wobei vorrangig das politische System Großbritanniens, aus dem Malta viele Merkmale abgeleitet hat, als Vergleich dient. So bemängelt die VenedigKommission u.a., dass im maltesischen Strafverfolgungssystem in vielen Fällen eine parallele Zuständigkeit der Polizei und der Staatsanwaltschaft bzw. vorrangige Zuständigkeit der Polizei besteht, ${ }^{792}$ dass aufgrund der traditionell nicht als Diät sondern als Teilgehalt ausgestalteten Zahlungen an Parlamentarier und ihrer weiteren Berufstätigkeit Interessenkonflikte bestehen können, ${ }^{793}$ dass eine Stärkung des Präsidenten und des Ombudsmanns im Hinblick auf die Befugnisse des Ministerpräsidenten erforderlich sei, da die Kabinettsregierung britischen Stils einer „Premierministerregierung" gewichen sei, in welcher dieser zu viel Einfluss habe, ${ }^{794}$ und

791 Venedig-Kommission, CDL-AD(2018)028, Opinion no. 940/2018, Malta - Opinion on Constitutional arrangements and separation of powers and the independence of the judiciary and law enforcement vom 17.12.2018.

792 Venedig-Kommission, CDL-AD(2018)028, Opinion no. 940/2018, Malta - Opinion on Constitutional arrangements and separation of powers and the independence of the judiciary and law enforcement vom 17.12.2018, Rn. $54 \mathrm{ff}$.

793 Venedig-Kommission, CDL-AD(2018)028, Opinion no. 940/2018, Malta - Opinion on Constitutional arrangements and separation of powers and the independence of the judiciary and law enforcement vom 17.12.2018, Rn. 21.

794 Venedig-Kommission, CDL-AD(2018)028, Opinion no. 940/2018, Malta - Opinion on Constitutional arrangements and separation of powers and the independence of the judiciary and law enforcement vom 17.12.2018, Rn. $111 \mathrm{ff}$., sehr beachtlich dort die Fn. 78 . 
dass bestimmte Ernennungen von Beamten nicht mehr in seinem Ermessen stehen dürfe. ${ }^{795}$ Diese Beobachtungen lassen durchaus auf einen direkten Handlungsbedarf schließen. Aber die Venedig-Kommission zeigt regelmäßig auch, dass diese Diskrepanzen seit langem bestehen, dass sie aus häufig kurzsichtiger legislativer Neuordnung der maltesischen Rechtslage nach der Unabhängigkeit von Großbritannien bei mangelnder späterer Reform herrühren und durchaus weiter von der britischen Rechtstradition geprägt seien. ${ }^{796}$ Sie weist keine Fälle nach, in denen aufgrund der bestehenden Rechtslage Missstände sich auch akut und systemisch realisiert haben. Am deutlichsten wird das ausgerechnet mit Blick auf die Frage der Richterernennung. Hier ist die Kritik der Venedig-Kommission sehr deutlich: Die zu große Beteiligung der Legislative sei nicht vereinbar mit europäischen Standards. Aber im Unterschied zu Polen stellt die Venedig-Kommission keine akute Realisierung von Einflussnahmen fest: „The Venice Commission wishes to clarify that it has no principled objections against the current members of the JAC. Ensuring a more balanced composition could also be achieved by adding judicial nominees to the JAC." $" 797$

Der zentrale Unterschied, gerade zu Polen und Ungarn, scheint mir daher im Hinblick auf diese Beobachtungen das zwar latente Konflikt- und Eskalationspotential dieser Schwächen in Malta zu sein, ohne dass sich dieses Potential bislang aber konkretisiert oder auf das gesamte System ausgewirkt hat. Sofern schwere Straftaten im Raum stehen, ist vorrangig zunächst abzuwarten, ob und wie sich die mitgliedstaatlichen Strafverfolgungsbehörden der Fälle annehmen, bevor unmittelbar eine systemische Qualität der Taten bejaht wird. Es gilt insbesondere zu vermeiden, aufgrund der bloßen Prominenz dieser Fälle allein bereits auf eine Systemrelevanz zu schließen. So sind weder die Kommission noch im Übrigen

795 Venedig-Kommission, CDL-AD(2018)028, Opinion no. 940/2018, Malta - Opinion on Constitutional arrangements and separation of powers and the independence of the judiciary and law enforcement vom 17.12.2018, Rn. 115 ff. für sog. "Permanent Secretaries".

796 Venedig-Kommission, CDL-AD(2018)028, Opinion no. 940/2018, Malta - Opinion on Constitutional arrangements and separation of powers and the independence of the judiciary and law enforcement vom 17.12.2018, Rn. $54 \mathrm{ff}$. etwa im Hinblick auch auf die in Großbritannien traditionell starken Polizeirechte, Rn. 58 im Hinblick auf die prominente Rolle des Generalstaatsanwalts, Rn. 143 im Hinblick auf Reformen in der Gerichtsbarkeit.

797 CDL-AD(2018)028, Opinion no. 940/2018, Malta - Opinion on Constitutional arrangements and separation of powers and the independence of the judiciary and law enforcement vom 17.12.2018, Rn. 42, zuvor ab Rn. 30. 


\section{Die Rechtsstaatlichkeitskrise in mitgliedstaatlichen Fällen}

der EuGH bei ihrer Würdigung systemischer Probleme in Mitgliedstaaten verfahren, stets wurden die konkreten Einzelfälle des Falls kontextualisiert. Eine solche „Hochzonung“ ist, z.B. im Fall der ermordeten Daphne Caruana Galizia, bislang nicht geboten.

Hier nicht berücksichtigt wird schließlich die gerade seitens des Europäischen Parlaments erwähnte Problematik des „Verkaufs“ von Pässen an Drittstaatsangehörige in Malta; gemeint ist damit die Verleihung der Staatsbürgerschaft oder dauerhafter Aufenthaltsgenehmigungen gegen die Leistung von Geldzahlungen in diversen Formen, z.B. durch Zuwendungen an den Staatshaushalt oder den Erwerb von Immobilien. Dieser Vorgang, und überhaupt die Berücksichtigung der persönlichen Finanzlage bei der Einbürgerung, ist in der Literatur auch als ius pecuniae bezeichnet worden, ${ }^{798}$ führt aber letztendlich zu gänzlich anderen Fragen als den hier im Vordergrund stehenden, nämlich insbesondere zur Frage der autonomen Ausgestaltung der nationalen Staatsbürgerschaft angesichts der mit ihr korrespondierenden Vorteile und Verpflichtungen aufgrund der damit einhergehenden Unionsbürgerschaft und der materiell-rechtlichen Zulässigkeit des Pass- und Visa-,_Verkaufs“ im Hinblick auf sie. ${ }^{799}$

798 Joachim Stern, „Ius Pecuniae - Staatsbürgerschaft zwischen ausreichendem Lebensunterhalt, Mindestsicherung und Menschenwürde“, in: Julia Dahlvik, Heinz Fassmann \& Wiebke Sievers (Hrsg.), Migration und Integration - wissenschaftliche Perspektiven aus Österreich. Jahrbuch 1/2011, Vienna University Press, Wien, 2011, S. 55-74, dort aber nicht zum hier bezeichneten Problem sondern den allgemeinen Anforderungen an Vermögensverhältnisse vor der Einbürgerung in Österreich; weiter, speziell zum hier bezeichneten Problem Jelena Dzankic, „The Pros And Cons Of Ius Pecuniae: Investor Citizenship In Comparative Perspective“, in: EUI Working Papers RSCAS 2012/14, European University Institute, Florenz, 2012.

799 Zum Überblick Claus Hecking, „Pässe für Millionen“, Die Zeit vom 13.05.2015; Sergio Carrera Núñez, „How much does EU citizenship cost? The Maltese citizenship-for-sale affair: A breakthrough for sincere cooperation in citizenship of the union?“, in: Sergio Carrera Núñez \& Gerard-René de Groot (Hrsg.), European Citizenship at the Crossroads: The Role of the European Union on Loss and Acquisition of Nationality, Oisterwijk, WLP, 2014, S. 293-326. Konziser Überblick über den Streitstand zur Vereinbarkeit dieser Fragen mit dem Unionsrecht bei Christoph Schönberger, Art. 20 EUV, in: Eberhard Grabitz, Meinhard Hilf \& Martin Nettesheim (Begr./Hrsg.), Das Recht der Europäischen Union, C.H. Beck, München, 68. EL Dezember 2019, Rn. 46-47. Eine konträr entgegengesetzte, sehr bedenkliche und jedenfalls aktuell nicht vorzugswürdige Ansicht vertritt Dimitry Kochenov, „Case C-135/08, Janko Rottmann v. Freistaat Bayern, Judgment of the Court (Grand Chamber) of 2 March 2010", in: Common Market Law Review 47 (2010), S. 1831-1846, insb. S. 1838-1839, wo- 
Nach alledem erscheint es mir gerechtfertigt, im Hinblick auf die zum Abschluss des Manuskripts verfügbaren Informationen, Malta nicht in den Kreis derjenigen Mitgliedstaaten aufzunehmen, denen vonseiten der Praxis und der Rechtswissenschaft der Vorwurf eines systemischen Defizits an Rechtsstaatlichkeit zu machen ist. Damit sollen die seitens des Europäischen Parlaments erhobenen Vorwürfe nicht relativiert werden, aber zu dem hier interessierenden Problem passen sie nicht.

\section{Zum Umgang mit Beobachtungen zu Krisen in weiteren Mitgliedstaaten}

1. Keine Trivialisierung des Vorwurfs, keine Ubiquität der Rechtsstaatlichkeitskrise

Als letztem Abschnitt dieses Teils ist zu einer Gruppe von Mitgliedstaaten Stellung zu nehmen, für welche unterschiedliche Stimmen in der Literatur, aber auch in der europäischen Politik, also z.B. durch Abgeordnete des Europäischen Parlaments oder nationaler Politiker im Wesentlichen der Vorwurf erhoben worden ist, auch dort liege ein systemisches Defizit an Rechtsstaatlichkeit vor, ohne dass nach vernünftiger Würdigung ein solches bestätigt werden kann. Eine Unterscheidung zwischen staatlicher Schwäche und Vorsatz ist dabei dort nicht gemacht worden, aber im Wesentlichen lauten die Vorwürfe auf eben jene vorsätzliche Unterwanderung durch staatliche Stellen.

Diese Fälle hier darzustellen ist keine rein akademische Übung. Zum einen entwickeln derartige Vorwürfe in der Praxis eine beträchtliche Irritation. Sie verlangen, was speziell die Tätigkeit von Unionsorganen betrifft, seitens der zuständigen Dienststellen der Europäischen Kommission zumindest eine Prüfung auf Schlüssigkeit der Vorwürfe. Umgekehrt wäre es der Kommission potentiell zum Vorwurf zu machen, wenn sie im Rahmen ihres Aufsichtsmandats nach Art. 17 Abs. 1 EUV einen relevanten Vorgang übersähe. Dabei tritt teils die aufwendige Sichtung von Material allenfalls marginal im Ausland gesprochener Sprachen erschwerend hinzu. Doch auch für die Rechtswissenschaft steht viel auf dem Spiel. Der öffentlich erhobene Vorwurf, ein Mitgliedstaat der Europäischen Union hintergehe auf systemische Weise ein Grundprinzip der Verträge, ist höchst schwerwiegend und darf niemals leichtfertig erhoben werden, sondern

nach das Unionsrecht de facto das nationale Staatsbürgerschaftsrecht überlagert habe. 


\section{Die Rechtsstaatlichkeitskrise in mitgliedstaatlichen Fällen}

muss stets auf einer belastbaren empirischen Grundlage aufbauen. Dies zu vernachlässigen, droht nicht nur einer Ubiquität der Rechtsstaatlichkeitskrise in der Union das Wort zu reden, sondern auch, denjenigen Munition zu liefern, die die gegen sie zurecht erhobenen Vorwürfe mit einem „tu quoque“- Argument zu erwidern versuchen.

Es gilt daher, exemplarisch einige Überlegungen zu entwickeln, wie mit derartigen Fällen umzugehen ist. Vorsicht ist ebenso geboten, wie die Notwendigkeit, sich nicht in Details zu verlieren, sondern präzise und bündig zu einem Ergebnis zu gelangen. Nicht jeder Vorgang in den nachfolgend genannten Mitgliedstaaten, der in den vergangenen Jahren durch die europäische und internationale Presse gegangen ist, muss dabei Berücksichtigung finden. Aus diesem Grund etwa nehme ich nicht Stellung zur Kontroverse in der Slowakei um die Ermordung des Journalisten Ján Kuciak, in deren Folge dort eine schwere politische Krise mit direktem Einfluss auf die Regierungsbildung zu beobachten war, womit gewisse Parallelen zum zuvor im Hinblick auf Malta erörterten Fall der dort ermordeten Journalistin Daphne Caruana Galizia bestehen. Es fehlt diesem Vorfall, ungeachtet der Tragik, bislang insbesondere an hinreichender Schwere und schlicht an auf das slowakische Rechtssystem bezogenen Konfliktwirkung, um hierzu von einer Instanz eines systemischen Versagens der slowakischen Stellen auszugehen.

Im Folgenden soll ein Überblick über weitere Vorgänge gegeben werden, die in Praxis und Wissenschaft Interesse erregt haben oder die dort aus eigenem Anlass genauer verfolgt worden sind. Dazu zählen Vorgänge in Spanien und ein anderer als der zuvor benannte in der Slowakei insbesondere. Aus der Literatur tritt das Beispiel Slowenien hinzu.

2. Spanien und die katalanische Frage

Der mutmaßlich prominenteste Fall, für den im Rahmen der Rechtsstaatlichkeitskrise eine Äquivalenz der dortigen Vorgänge zu jenen gerade in Polen und Ungarn behauptet wurde, ist Spanien. Die dortige katalanische Frage, d.h. die Frage einer möglichen Unabhängigkeit oder jedenfalls größeren Autonomie der autonomen Gemeinschaft Kataloniens, ist inzwischen wiederholt auch für den ausländischen juristischen Leser aufbereitet worden. ${ }^{800}$

800 Sabrina Ragone, „Das Unabhängigkeitsreferendum in Katalonien“; Carmen Gonzalez, „The Catalan National Identity and Catalonia's Bid for Indepen- 
Die Debatte nahm eine hier relevante neue Wendung, als in Form eines „offenen Briefes“ die Abgeordnete des Europäischen Parlaments Barbara Spinelli (GUE-NGL/IT) in scharfem Ton die rechtliche Gleichsetzung der Entwicklung in Spanien mit derjenigen in Polen forderte. Die Verfasserin forderte die Europäische Kommission auf, den EU-Rahmen von 2014, der gegenüber Polen genutzt worden war, auch gegenüber Spanien zur Anwendung zu bringen, ${ }^{801}$ dies u.a. aufgrund einer „systematischen Verletzung“(,systematic violation“) der Rechtsstaatlichkeit in Spanien und einer „miscarriage of justice“. ${ }^{802}$ Die Verfasserin rügte die systemische Relevanz zahlreicher einzelner Sachverhalte in Spanien im Zusammenhang mit der Debatte um die Reform, darunter Verhaftungen, repressive Maßnahmen zur Unterbindung des angekündigten Referendums in Katalonien gegenüber diversen Gruppen, welche eine Einschränkung der Redefreiheit darstellten sowie die Festnahme von Amtsträgern. Insbesondere die Verhinderung des Referendums selbst wird als „systematic violation of the Rule of Law in Spain" 803 angesehen und dem spanischen Verfassungsgericht durch Urteile, die die Verhinderung anordnen, selbst Verfassungsbruch vorgeworfen..$^{804}$

Der Aufruf fand global dutzende Unterzeichner, darunter namhafte Wissenschaftler und Intellektuelle, wie Seyla Benhabib, Robert Menasse oder Philipp Pettit. Die Unterzeichner beanstandeten neben dem Verbot des Referendums selbst auch dessen robuste Durchsetzung, u.a. durch Festnahme prominenter katalanischer Politiker. Sie sehen hierin sowohl eine grundlegende Verletzung der Rechtsstaatlichkeit und gleichzeitig des Prinzips der liberalen Demokratie als auch einen Machtmissbrauch. ${ }^{805}$ Adressat des Aufrufs waren der Präsident der Europäischen Kommission, Jean-Claude Juncker, der Präsident des Europäischen Rates, Donald Tusk, und weiter der Erste Vizepräsident der Europäischen Kommission, Frans Timmermans. Die katalanische Regierung hat den dort gemachten Vorwurf später im Wesentlichen wiederholt und insbesondere vorgetragen,

dence“, in: Connecticut Journal of International Law 32 (2016), S. 115-145, insb. S. $129 \mathrm{ff}$.

801 Barbara Spinelli u.a., Open Letter to Commission President Juncker and European Council President Tusk cc. First Vice-President Frans Timmermans: Upholding The Rule Of Law In The European Union vom 03.11.17, S. 3.

802 Spinelli-Aufruf, S. 1 und 3.

803 Spinelli-Aufruf, S. 1.

804 Spinelli-Aufruf, S. 2.

805 Spinelli-Aufruf, S. 3 und 4. 


\section{Die Rechtsstaatlichkeitskrise in mitgliedstaatlichen Fällen}

die spanische Zentralregierung "missbrauche“ die Justiz zur rechtswidrigen Verhinderung der Sezession Kataloniens. ${ }^{806}$

Angesichts dieser sehr pointierten Kritik, der beachtlichen Gruppe an Unterzeichnern und im Hinblick auf die Schwere der Vorwürfe steht hier die Frage im Raum, ob in Spanien ein schwerwiegendes, womöglich sogar ein systemisches Problem bei der Einhaltung rechtsstaatlicher Prinzipien auszumachen ist, was hier nicht speziell an den Tatbestandsmerkmalen des EU-Rahmens, sondern wiederum anhand der in der Rechtswissenschaft erarbeiteten Merkmale eines systemischen Defizits an Rechtsstaatlichkeit zu klären wäre.

Die Entwicklung in Katalonien wirft drei Fragenkomplexe auf, von denen zwei von vornherein außerhalb des Zuschnitts dieser Studie liegen, da sie umfangreiche verfassungsrechtliche Arbeiten im spanischen nationalen Recht oder eine völkerrechtliche Begutachtung bedingen würden. Hierzu zählt zunächst die Frage einer de lege lata verfassungsrechtlichen Möglichkeit größerer Autonomie Kataloniens in Spanien oder der Unabhängigkeit Kataloniens von Spanien sowie, de lege ferenda, potentiell die Modifizierung der spanischen Verfassungsordnung hin zu einer z.B. genuin bundesstaatlichen Ordnung, die diese Entwicklungen begleiten kann. ${ }^{807}$ Der zweite Problemkomplex ist der einer möglichen Sezession Kataloniens von Spanien nach völkerrechtlichen Maßstäben, insbesondere ein mögliches „right to self-determination“ und einer sog. „privilegierten Sezession“ oder „remedial secession". .808

Von Interesse für diese Studie hingegen ist ein dritter Fragekomplex, ob nämlich die konkret im zeitlichen Umfeld und im sachlichen Zusammenhang mit dem katalanischen Referendum getroffenen Maßnahmen, insbesondere Urteile des spanischen Verfassungsgerichts und die Strafverfolgung des ehemaligen katalanischen Ministerpräsidenten, Carles Puigdemont, einen aus unionsrechtlicher Perspektive systemischen Verstoß gegen rechtsstaatliche Vorgaben für wahrscheinlich erscheinen lassen. Dafür ist hier vorrangig der oben entwickelte unionale Maßstab zu nutzen. Da die Aufarbeitung des Sachstands seitens Union und Europarat sehr viel

806 Generalitat de Catalunya, „Spain's Misuse of the Judiciary as Regards Catalonia", ohne Az. oder Datum.

807 Dazu etwa ausführlich Sabrina Ragone, „Das Unabhängigkeitsreferendum in Katalonien“, S. 342-348.

808 Hierzu Carmen Gonzalez, „The Catalan National Identity and Catalonia's Bid for Independence“, S. 140-141; Anne Peters, „Populist International Law? The Suspended Independence and the Normative Value of the Referendum on Catalonia“, EJIL Talk, vom 12.10.2017, o.S. 
fragmentarischer ist als namentlich im Hinblick auf Polen und Ungarn, müssen die Arbeiten von Rechtswissenschaftlern berücksichtigt werden, in denen sie für den ausländischen Leser die Lage aufbereitet haben.

Hiernach ist ein systemisches Defizit an Rechtsstaatlichkeit in Spanien $\mathrm{zu}$ verneinen. ${ }^{809}$ Es zeigt sich vielmehr, dass die beanstandeten Handlungen grundsätzlich der Durchsetzung spanischen Rechts gedient haben, wobei auf sehr robuste Vorgaben der spanischen Verfassung zurückgegriffen wurde, wie den Art. 155 der spanischen Verfassung und dass, sofern im Rahmen der hierzu getroffenen Maßnahmen eine Verletzung von Grundrechten gerügt wurde, es an den Beschwerten liegt, zunächst den Rechtsweg voll auszuschöpfen. Kritik an der inneren Beschaffenheit etwa der Justiz ist ernst zu nehmen, aber bislang nicht hinreichend substantiiert worden, um ihn mit derart schweren Defekten, wie in Polen oder Ungarn, gleichzusetzen.

Der Spinelli-Aufruf kritisierte, dass das spanische Verfassungsgericht das Abhalten des Referendums verboten habe und dadurch das Recht zur friedlichen Versammlung und die Redefreiheit verletzt habe. „Ohne in spanische Verfassungsstreitigkeiten oder spanisches [Strafrecht] eingreifen“ $\mathrm{zu}$ wollen sei es eine "rechtliche Farce“ (travesty of justice), dass das spanische Verfassungsgericht eine verfassungsrechtliche Norm durchsetze, indem es "Grundrechte verletze“ ${ }^{810}$ Ein solcher Vorwurf ließe sich nur substantiieren, wenn die Rechtsprechung des Verfassungsgerichts in eklatanter Weise allgemeine Grundsätze der Rechtsprechung verletzt hätte oder sich das Verfassungsgericht eine Rolle angemaßt oder dieser verweigert hätte. Beides scheint bei Rückgriff auf Kenner der nationalen Rechtslage ausgeschlossen. Sabrina Ragone hat im Einzelnen nachgewiesen, wie umfassend und sorgfältig das spanische Verfassungsgericht sich den zahlreichen Fragen der Materie angenommen hat und dass das entscheidende Urteil einstimmig ergangen ist. ${ }^{811}$ Die derzeitige Lage ist damit ganz vorrangig in den inneren spanischen verfassungsrechtlichen Zusammenhang

809 Vgl. in diesem Sinne Armin von Bogdandy, „Tyrannei der Werte?“, S. 511, der als Faktoren „ein klares demokratisches Mandat, ein entwickeltes Nationalbewusstsein, das Instrument des Bundeszwangs" nennt, auch bereits die Einschätzung bei Matthias Schmidt \& Piotr Bogdanowicz, „The Infringement Procedure in the Rule of Law Crisis“, S. 1083.

810 Spinelli-Aufruf, S. 2.

811 Sabrina Ragone, „Das Unabhängigkeitsreferendum in Katalonien“, insb. S. 347-348. 


\section{Die Rechtsstaatlichkeitskrise in mitgliedstaatlichen Fällen}

einer langen Unsicherheit über den Status Kataloniens einzubetten und nach seinen Maßstäben aufzulösen. ${ }^{812}$

Dass man persönlich eine Auffassung des Gerichts nicht teilt, bedeutet nicht, dass darüber rechtsstaatliche Grundsätze verletzt worden wären. Auch im Hinblick auf die Rolle, die das Verfassungsgericht in der Krise einzunehmen hatte, ergeben sich bei Rückgriff auf die Literatur keine konkreten Anhaltspunkte für derartige Zweifel. Gemäß Art. 53 Abs. 2, $159 \mathrm{ff}$. der spanischen Verfassung ist allein das Verfassungsgericht als Verfassungsorgan dazu berufen, über Grundrechtsverletzungen von Bürgern und staatsorganisationsrechtliche Streitigkeiten zu entscheiden. Das spanische Verfassungsgericht war also nicht nur das richtige Forum, es ist gemäß der Verfassung das einzige richtige Forum zur Entscheidung der Frage, ob und wie Katalonien möglicherweise Unabhängigkeit von Spanien erlangen kann.

Es bestehen auch keine substantiierten Zweifel an der Unabhängigkeit der Richter am Verfassungsgericht, dessen Autonomie bei der Schaffung seines eigenen Organisationsrechts gut untersucht ist. ${ }^{813}$ Die VenedigKommission, die sich jüngst nicht gänzlich unkritisch einer Reform der einfachrechtlichen Rechtsgrundlagen des spanischen Verfassungsgerichts angenommen hat, sah darüber keine Zweifel an der Integrität des Gerichts, vielmehr sah sie sogar seine Unabhängigkeit gestärkt. ${ }^{814}$

Auch die Frage möglicher erheblicher Polizeigewalt seitens der spanischen Polizei im Umfeld des Referendums führt, jedenfalls aus der hier interessierenden Perspektive, nicht zu einer Änderung des Befundes. Sie ist gut dokumentiert. ${ }^{815}$ Allerdings ist anzumerken, dass, wie in allen Rechtsordnungen, für die Betroffenen zunächst über die zuständigen Gerichte eine Aufarbeitung der Vorgänge anzustreben ist.

Das führt zum letzten Punkt in Bezug auf Spanien; der Frage nämlich, ob die ordentliche und unterinstanzliche Gerichtsbarkeit Gewähr für die Aufarbeitung der im Rahmen der katalonischen Unabhängigkeits-

812 Vgl. Sabrina Ragone, „Das Unabhängigkeitsreferendum in Katalonien“, S. 350.

813 Vgl. dazu Juan Luis Requejo Pagés, „\$106 Das spanische Verfassungsgericht“, in: Armin von Bogdandy, Christoph Grabenwarter \& Peter M. Huber (Hrsg.), Ius Publicum Europaeum: Band VI: Verfassungsgerichtsbarkeit in Europa, C. F. Müller, Heidelberg, 2017, S. 639-704, Rn. 33 ff.

814 Venedig-Kommission, CDL-AD(2017)003, Opinion 827/2015, Spain - Opinion on the law of 16 October 2015 amending the Organic Law No. 2/1979 on the Constitutional Court vom 13.03.2017, vgl. insb. Rn. 77.

815 Etwa The Guardian, "Violence against Catalan voters: what we know so far", vom 01.10.2017. 
bewegung entstehenden und nicht dem Verfassungsgericht zufallenden Fragen bietet. Von spanischen Rechtswissenschaftlern ist dies, auch unter Hinweis auf das schlechte Abschneiden Spaniens in der Ausgabe 2019 des EU-Justizbarometers, bestritten worden. ${ }^{816}$ Die Vorwürfe ähneln dabei überraschend denjenigen, die in Polen gegen die dortige Justiz erhoben werden. Die spanische Justiz sei stark politisiert, was sich an einzelnen Urteilen gerade des Obersten Gerichtshofs (Tribunal Supremo) zeige, nach wie vor seien Richter des Franco-Regimes im Amt und im Übrigen habe das Parlament ein zu starkes Mitbestimmungsrecht bei der Auswahl der Mitglieder des Justizrates und damit mittelbar über die Justiz.

Die Dokumentation zu diesem Punkt in der Rechtspraxis bleibt bislang dünn und meines Erachtens nicht ausreichend, um den Befund hinreichend zu untermauern. Im spanischen Parlament ist derzeit eine profunde Debatte über eine Änderung der Richterbestellung im Gange. Diese unterscheidet sich indes eindeutig von der Stoßrichtung, die mit scheinbar gleichgelagerten Debatten zuvor insbesondere in Polen angestrebt worden ist. In Spanien zielen die Bestrebungen darauf ab, die Autonomie der Richter durch Rücknahme der parlamentarischen Befugnisse im Justizrat zu stärken, ${ }^{817}$ statt zu schwächen. Das spricht entscheidend dafür, den Ausgang dieser Debatte in Spanien abzuwarten und eine intra- oder intersystemische Konfliktlage um die Beschaffenheit der Justiz in Spanien zu verneinen.

Damit aber muss der Vorwurf systemischer Defizite an Rechtsstaatlichkeit in Spanien entfallen.

3. Die Kontroverse um die Besetzung des Verfassungsgerichts in der Slowakei

Außerhalb der Grenzen der Slowakei meines Wissens nach wenig beachtet, dort aber durchaus eine genuine Verfassungskrise hervorrufend, war eine Auseinandersetzung zwischen dem slowakischen Staatspräsidenten und dem slowakischen Verfassungsgericht über die Besetzung vakanter Richterstellen. Der Fall ist in mehrfacher Hinsicht besonders, denn zum

816 Joaquín Urías, „Spain has a Problem with its Judiciary“, Verfassungsblog vom 15.01.2020.

817 Dokumentation der jüngeren Entwicklungen bei Reyes Rincón, „El Gobierno descarta dejar la elección del Poder Judicial en manos de los jueces como piden PP y Ciudadanos“, El País vom 17.02.2020. 


\section{Die Rechtsstaatlichkeitskrise in mitgliedstaatlichen Fällen}

einen ist meiner Kenntnis nach in seinem Zusammenhang nicht vorgetragen worden, es gebe systemische Probleme im Hinblick auf das Rechtsstaatsprinzip, zum anderen hat sich der Fall erledigt. Gleichwohl will ich ihn hier erörtern, denn er zeigt, wie sehr Verfassungskrisen in ihrem Verlauf vom Wohlwollen der Beteiligten abhängen können und wie relativ einfach sie sich dann lösen lassen.

In der Slowakei kam es zwischen Verfassungsgericht und amtierendem Staatspräsidenten in den Jahren 2016 bis 2017 zu einem offenen Konflikt, sodass man von einer echten Verfassungskrise sprechen kann, die nicht nur geeignet schien, die Funktionsfähigkeit des Gerichts erheblich zu beeinträchtigen, sondern großes Potential hatte, im Verhältnis zu anderen Mitgliedstaaten zu einem „Spillover“ in Bezug auf die Funktionsfähigkeit der Justiz zu führen, wenn die slowakische Justiz aus der Perspektive anderer mitgliedstaatlicher Gerichte z.B. keine Gewähr für eine verfassungsgerichtliche Sicherung mehr geboten hätte. Sie kann auch als sog. „constitutional gridlock“ bezeichnet werden, ${ }^{818}$ d.h. als Sachverhalt, in dem eine Streitschlichtung durch andere Organe, insbesondere das Verfassungsgericht, nicht möglich schien.

Außerhalb der Slowakei scheint diese Krise kaum beachtet worden zu sein, wohl einzig eine englischsprachige slowakische Tageszeitung ${ }^{819}$ und der „I.CONnect“- Blog ${ }^{820}$ berichteten für den ausländischen Leser. Die Krise endete im Dezember 2017 mit der Ernennung von drei Kandidaten durch den slowakischen Staatspräsidenten. Obwohl sie damit zu einem

$818 \mathrm{Zu}$ diesem Begriff, bezogen aber vorrangig auf das Gesetzgebungsverfahren, Michael J. Gerhardt, „Why Gridlock Matters“, in: Notre Dame Law Review 88 (2013), S. 2107-2120.

819 Insb. Slovak Spectator, „Kiska again rejects Constitutional Court candidates“, vom 07.07.2016; Slovak Spectator, „President appoints missing Constitutional Court judges“, vom 14.12.2017; Der "Slovak Spectator" ist eine von der slovakischen Zeitung SME betriebene Zeitung.

820 Simon Drugda, „Symposium on ,The Slovak Constitutional Court Appointments Case 6 -Intermezzo to the Constitutional Conflict in Slovakia: A Case Critique“,I.CONnect Blog vom 24.012018; Tomáš Lalík, „Constitutional Court Crisis in Slovakia“; Kamil Baraník, „Symposium on ,The Slovak Constitutional Court Appointments Case - Perplexities of the Appointment Process Resolved by Means of ,Fire and Fury“", I.CONnect Blog vom 26.01.2018; Tomáś Lalík, „Symposium on ,The Slovak Constitutional Court Appointments Case is the King: The Day When Effective Judicial Review Arrived“, in: I.CONnectBlog vom 27.01.2018, abrufbar unter: http://www.iconnectblog.com/2018/01/sy mposium-slovak-appointments-case-lalik/.; jeweils ohne Seiten oder Rn. 
für alle Beteiligten befriedigenden Abschluss gelangte, ist sie hier zwecks Einordnung kurz zu erörtern.

Die Slowakei verfügt, wie andere Mitgliedstaaten auch, über ein Verfassungsgericht. Die slowakische Verfassung macht über dieses in den Art. 124-140 recht ausführliche Angaben. Gem. Art. 134 Abs. 1 der Verf. besteht das Verfassungsgericht aus 13 Richtern, die für eine einzige Amtszeit von zwölf Jahren ernannt werden. Der Präsident der Republik beruft aus einer vom Nationalrat (Parlament) vorgeschlagenen Anzahl von Kandidaten neue Richter, wobei die Kandidatenliste die doppelte Anzahl der freien Stellen betragen muss, vgl. Art. 134 Abs. 2 S. 2 der Verfassung. Der in der Slowakei, wie in anderen ostmitteleuropäischen Mitgliedstaaten, bestehende Justizrat ist an der Auswahl der Kandidaten oder deren Ernennung nicht beteiligt. Die Verfassung äußert sich nicht darüber, ob dem Präsidenten bei der Ernennung der Richter ein Ermessen zukommt und, wenn ja, ob dieses ein formelles oder materielles Prüfungsrecht beinhaltet. In Bezug auf die Reichweite und Dichte dieses Prüfrechts des Staatspräsidenten, auch aus dem deutschen Verfassungsrecht als Streitstand bei der Verabschiedung von Gesetzen bekannt, kam es 2014 zu einer Krise betreffend die Besetzung vakanter Stellen.

Andrej Kiska wurde im Sommer 2014 als Kontrahent des derzeitigen Premierministers Robert Fico zum Staatspräsidenten gewählt. ${ }^{821}$ Im Juni und Juli 2014 schieden drei Verfassungsrichter aus dem Gericht aus und der zum 15. Juni 2014 scheidende Staatspräsident Ivan Gasparovic sah davon ab, die Stellen vor dem Ende seiner Amtszeit neu zu besetzen, obwohl die Venedig-Kommission, welche um ein Gutachten gebeten worden war, eine solche Besetzung für verfassungsrechtlich zulässig erachtet hatte. ${ }^{822}$ Gasparovic wollte die Ernennung dem mit neuer politischer Legitimität versehenen Amtsnachfolger überlassen.

Nach seinem Amtsantritt wählte Kiska nicht aus den vom Nationalrat vorgeschlagenen sechs Kandidaten drei Kandidaten aus, sondern lehnte, bis auf eine Kandidatin, alle Kandidaten ab.

Zur Begründung der Ablehnung der übrigen fünf Kandidaten bemängelte Kiska gegenüber dem Parlament im Wesentlichen die fachliche Qualifikation der Kandidaten und berief sich im Hinblick auf sein mate-

821 Tomáš Lalík, „Constitutional Court Crisis in Slovakia“.

822 Tomáš Lalík, „Constitutional Court Crisis in Slovakia“; Venedig-Kommission, CDL-AD(2014)015, Opinion no. 772/2014, Opinion on the procedure for appointing judges to the Constitutional Court in times of the Presidential transition in the Slovak Republic vom 13.06.2014. 


\section{Die Rechtsstaatlichkeitskrise in mitgliedstaatlichen Fällen}

rielles Prüfungsrecht der Kandidaten auf einen Präzedenzfall betreffend die Ablehnung eines Kandidaten für das Amt des Generalstaatsanwalts. ${ }^{823}$ Alle fünf abgelehnten Kandidaten strengten vor dem Verfassungsgericht Klagen gegen die Entscheidung des Präsidenten an und rügten eine Verletzung ihres verfassungsrechtlich garantierten Rechts auf Wählbarkeit zum Gericht. Mit Urteil vom 17. März $2015^{824}$ gab der dritte Senat des Verfassungsgerichts den Klagen dreier Nominierter statt. Der vierte Senat, vor dem Klagen zweier weiterer Nominierter anhängig waren, schloss dieses Verfahren, als die Kläger ihre Kandidatur zurückzogen.

Präsident Kiska ignorierte das Urteil des dritten Senats im Rahmen einer politischen Kampagne und wandte sich an das Plenum des Verfassungsgerichts, da er der Auffassung war, dass das Verfassungsgericht in seinem Urteil rechtserheblich von dem vorher mündlich verhandelten Ergebnis und dem Präzedenzfall abgewichen war. Das Plenum des Verfassungsgerichts wies diesen Vortrag mit Urteil vom 28. Oktober 2015 zurück $^{825}$ und erneuerte damit die Aufforderung, die vakanten Stellen zu besetzen. Der Präsident setzte es allerdings nicht um.

Dies führte zum Februar 2016 dazu, dass das Verfassungsgericht nur noch aus zehn statt 13 Richtern bestand. Auch ein erneuter Versuch im Februar 2016, nach den Wahlen zum Nationalrat die vakanten Stellen durch neue Kandidaten zu besetzen, scheiterte an der Weigerung Kiskas, die Kandidaten zu ernennen. ${ }^{826}$ Die Minderbesetzung des Gerichts hatte potentiell zur Folge, dass das Plenum des Gerichts nicht mehr entscheiden konnte. Auch auf die Senatsbildung ergaben sich Auswirkungen. Dies hätte unbestreitbar die Funktionsfähigkeit der slowakischen Justiz substantiell in Mitleidenschaft gezogen.

Allerdings nahm die Entwicklung schließlich einen anderen Ausgang, da sich der slowakische Präsident durchaus um Lösung bemüht zeigte und sich nach Stand der öffentlich gewordenen Meinungsäußerungen in

823 Slowakisches Verfassungsgericht, Urteil (Plenum) vom 28.10.2015, Az. ÚS 45/2015, Rn. I $10 \mathrm{ff}$. des Tatbestands, engl. Übersetzung durch die VenedigKommission zur Verfügung gestellt als Anlage CDL-REF(2017)013 zu Opinion No. 877/2017 vom 27.02.2017.

824 Tomáš Lalík, „Constitutional Court Crisis in Slovakia“; Urteil des slowakischen Verfassungsgerichts vom 17. März 2015, Az. III. ÚS 571/2014 (nur in slowakischer Sprache).

825 Verfassungsgericht der Slowakischen Republik, Urteil (Plenum) vom 28.10.2015, Az. PL: ÚS 45/2015.

826 Slovak Spectator, „Kiska again rejects Constitutional Court candidates“, vom 7. Juli 2016. 
einem echten Verfassungsorganstreit unter Wahrung der seinem Amt zustehenden Rechte wähnte. Auf Ersuchen Kiskas besuchte im Januar 2017 die Venedig-Kommission Pressburg und erstattete in der Sache ein zweites Gutachten im Anschluss an dasjenige aus dem Jahr 2014. ${ }^{827}$ Die Venedig-Kommission nahm dabei unmittelbar zur Lage in der Slowakei nicht Stellung, zeigt sich aber unter Verweis auf rechtsvergleichende Ergebnisse überzeugt, dass Kiska ein Prüfungsrecht in der Sache, d.h. nicht allein hinsichtlich der verfahrensrechtlich ordnungsgemäßen Wahl, sondern auch im Hinblick auf die fachliche Eignung der Kandidaten nicht zustünde.

Die Entwicklung endete im Dezember 2017, als Kiska nach nochmaligem Beschluss des Verfassungsgerichts drei Richter der ursprünglichen Liste am 12. Dezember ernannte und am 13. Dezember vereidigte. ${ }^{828}$ Damit ist das Gericht wieder ordnungsgemäß besetzt.

Möglicherweise hat die Venedig-Kommission mit vorsichtigen Formulierungen in ihren Gutachten entscheidend zur Lösung der Krise beigetragen. Sie sprach zunächst dem Präsidenten ein prinzipiell weites Prüfrecht $\mathrm{zu}^{829}$ stellte diesem dann aber die Kompetenz des Verfassungsgerichts gegenüber und hielt verklausuliert fest: „[I]t is the Constitutional Court which in the final run determines whether state organs have operated within the limits of the Constitution. This competence and duty of the Constitutional Court also applies to the President [...]." 830 Offenbar, um den Präsident nicht in die Enge zu treiben und ihm eine gesichtswahrende Lösung zu ermöglichen, verweigerten sich die Gutachter aber einer konkreten Entscheidung. Sie deuteten dem slowakischen Präsidenten indes die aus ihrer Perspektive richtige Richtung an: „The Venice Commission has been asked to address disputed facts and to determine subtle issues of national procedure. The Commission cannot assume the role of a supranational ,arbiter ${ }^{6}$ or of a fourth instance; it can only provide its view from

827 Venedig-Kommission, CDL-AD(2017)001, Opinion No. 877/2017, Opinion on questions relating to the appointment of Judges of the Constitutional Court vom 13.03. 2017. Auf den Seiten 5-9 findet sich eine ausführliche Zeitleiste.

828 Vgl. den Beitrag des Slovak Spectator, „President appoints missing Constitutional Court judges" vom 14.10.2017.

829 Venedig-Kommission, CDL-AD(2017)001, Opinion No. 877/2017, Opinion on questions relating to the appointment of Judges of the Constitutional Court vom 13.03. 2017, Rn. 59-62.

830 Venedig-Kommission, CDL-AD(2017)001, Opinion No. 877/2017, Opinion on questions relating to the appointment of Judges of the Constitutional Court vom 13.03. 2017, Rn. 63. 
a comparative and European perspective." 831 Staatspräsident Kiska scheint die Botschaft verstanden zu haben.

\section{Slowenien}

Bevor ich für dieses Kapitel zu Schlussbemerkungen komme, sei ein letzter Fall genannt, für den wiederum seitens der Literatur die Behauptung aufgestellt worden ist, dass die Entwicklung in diesem Mitgliedstaat Anlass sei, ihn gleich Polen und Ungarn in das Fallset der von systemischen Defiziten betroffenen Mitgliedstaaten aufzunehmen. Wie für Spanien ergibt sich, dass der Vorwurf nicht haltbar ist. Urheber dieses Vorwurfs ist indes, neben Bojan Bugarič und Alenka Kubelj, ${ }^{832}$ der slowenische Rechtswissenschaftler Matej Avbelj, 833 ein an anderer Stelle ${ }^{834}$ ausgewiesener Kenner der Materie der unionalen Rechtsstaatlichkeitskrise. Im Wesentlichen werden zwei Punkte geltend gemacht. Avbelj u.a. haben vor kurzem den Vorwurf gegenüber Slowenien erneuert, wobei sie auf sehr beachtliche Weise slowenische Verfassungsgeschichte zugänglich machen. ${ }^{835}$

831 Venedig-Kommission, CDL-AD(2017)001, Opinion No. 877/2017, Opinion on questions relating to the appointment of Judges of the Constitutional Court vom 13.03. 2017, Rn. 64.

832 Bojan Bugarič \& Alenka Kuhelj, „Slovenia in crisis: A tale of unfinished democratization in East-Central Europe“, in: Communist and Post-Communist Studies 48 (2015), S. 273-279; Bojan Bugarič, „A crisis of constitutional democracy in post-Communist Europe: ,Lands in-between' democracy and authoritarianism“, in: International Journal of Constitutional Law 13 (2015), S. 219-245, S. $221 \mathrm{f}$.

833 Matej Avbelj, „Failed Democracy: The Slovenian Patria Case - (Non)Law in Context“, SSRN-Working Paper, 2014; Matej Avbelj, „Will Slovenia join Hungary and Romania as examples of constitutional back-sliding?” Verfassungsblog vom 14.06.2014; und Matej Avbelj, „Crises and Perspectives in building a European Nation - The Case of Slovenia“, in: Peter Jambrek (Hrsg.): Nation's Transitions - Social and Legal issues of Slovenia's Transitions 1945-2015, Tiskarna Januš/Graduate School of Government and European Studies, Brdo pri Kranju and European Faculty of Law, Kraj/Nova Gorica, 2015, S. 395-410.

834 Matej Avbelj, „Pluralism and Defiance in the EU“, in: Dimitry Kochenov \& András Jakab (Hrsg.): The Enforcement of EU Law and Values: Ensuring Member States' Compliance, Oxford University Press, Oxford, 2017, S. 44-61.

835 Matej Avbelj, Jernej Letnar \& Justinek Gorazd, The Impact of European Institutions on the Rule of Law and Democracy: Slovenia and Beyond, Hart, Oxford, 2020, in Teilen scharf, vgl. etwa S.32, "systemic deficiencies in the building blocks of the country's constitutional democracy". In diesem Sinne weiter etwa S. 81, wonach die slowenischen Regierung sich nur rhetorisch zur Rechtsstaatlichkeit und Demokratie bekenne und in der Praxis hiervon weit abweiche. 
Zum einen halten die genannten Autoren fest, dass sich aus dem Übergang Sloweniens als ehemals sozialistische jugoslawische Teilrepublik hin zu einem demokratischen Rechtsstaat ergebende Probleme nicht aufgearbeitet seien bzw. ihre Aufarbeitung verschleppt werde. Oder aber, sie erkennen in Vorgängen Rückschritte des slowenischen Rechtssystems im Vergleich zu einem erreichten Standard.

Dem Land wird dabei grundsätzlich attestiert, ein „Musterschüler“836 unter den neuen Mitgliedstaaten der Union zu sein. Material von Europarat und Europäischer Kommission bestätigen dies im Wesentlichen. Die letzte - und einzige - Stellungnahme der Venedig-Kommission stammt aus dem Jahr 2000, lange vor dem Beitritt Sloweniens zur Europäischen Union $^{837}$ und betraf mit der Begutachtung der Wahlrechtsreform einen typischen Transitionsprozess einer ehemaligen Teilrepublik des früheren Jugoslawien. Im EU-Justizbarometer für das Jahr 2017 ist das Land weitgehend unauffällig. Es hat eine effiziente Gerichtsbarkeit ${ }^{838}$ und eine hohe Richterzahl. ${ }^{839}$

Im Länderbericht 2017 des Europäischen Semesters würdigt die Kommission zudem sowohl die öffentliche Verwaltung als auch das Justizsystem als in einem positiven Reformprozess begriffen, wenn auch merkliche Probleme bestehen. ${ }^{840}$ Dies betrifft nach Ansicht der Kommission vorrangig die Korruption und die hohe anhängige Fallzahl vor den Gerichten. Negativ ist auch die „wahrgenommene Unabhängigkeit“ der Richter in Slowenien, unter der von Unternehmen mitgeteilten Wahrnehmung

836 Bojan Bugarič \& Alenka Kuhelj, „Slovenia in crisis: A tale of unfinished democratization in East-Central Europe", S. 274.

837 Venedig-Kommission, CDL-INF(2000)013, Opinion on the constitutional amendments concerning legislative elections in the Republic of Slovenia vom 16.10.2000.

838 Europäische Kommission, Mitteilung der Kommission an das Europäische Parlament, den Rat, die Europäische Zentralbank, den Europäischen Wirtschaftsund Sozialausschuss und den Ausschuss der Regionen, EU-Justizbarometer 2019, $\operatorname{COM(2019)} 198$ final vom 26.04.2019, Schaubilder 5 , für alle Verfahrensarten steht Slowenien an 6. Stelle und damit unter den effizientesten Mitgliedstaaten.

839 Europäische Kommission, Mitteilung der Kommission an das Europäische Parlament, den Rat, die Europäische Zentralbank, den Europäischen Wirtschaftsund Sozialausschuss und den Ausschuss der Regionen, EU-Justizbarometer 2019, $\operatorname{COM(2019)~} 198$ final vom 26.04.2019, Schaubild 32: Slowenien liegt an 2. Stelle.

840 Europäische Kommission, Commission Staff Working Document, Country Report Slovenia 2017, SWD(2017) 89 final, vom 22.02.2017, S. 45 ff. Zum Länderbericht ausführlich unter E.VI. 


\section{Die Rechtsstaatlichkeitskrise in mitgliedstaatlichen Fällen}

rangiert Slowenien im EU-Justizbarometer an drittletzter Stelle, die allgemeine Wahrnehmung ist nur wenig besser. ${ }^{841} 2019$ ist dies wiederholt worden. ${ }^{842}$

Es folgt daraus zwar durchaus der Rückschluss, dass das slowenische Rechtssystem nicht ohne Probleme dasteht, die Aussage Avbeljs u.a., wonach internationale Beobachter durchgehend der slowenischen Regierung oder voreingenommenen inländischen NGOs auf den Leim gingen und die Vorgänge in Slowenien „similar or worse“ $\mathrm{zu}$ denen in Polen und Ungarn seien, ist dadurch noch nicht substantiiert. ${ }^{843}$ Hierauf lässt sich der Befund eines systemischen Defizits an Rechtsstaatlichkeit also noch nicht stützen.

Es bestehen aber in der Literatur noch weitere Vorwürfe. Der erste betrifft die Verurteilung Sloweniens in mehreren Piloturteilsverfahren durch den EGMR.

Avbelj benennt hierfür ${ }^{844}$ vorrangig das Urteil Lukenda ./. Slowenien. ${ }^{845}$ Der Beschwerdeführer machte eine Verletzung seiner Grundrechte aus Art. 6 Abs. 1 und 13 EMRK infolge überlangen Gerichtsverfahrens geltend. Die Entscheidung betraf die Durchsetzung von Schadensersatz- und Restitutionsansprüchen im Zuge eines Arbeitsunfalls. Der Straßburger Gerichtshof erkannte in der schleppenden gerichtlichen Durchsetzung der Ansprüche ein „systemisches Problem“ bei der zeitnahen Gewährung von Rechtsschutz, welches potentiell jede Person treffe, die im slowenischen Rechtssystem Schutz suche. Für dieses Rechtssystem wies der EGMR auch auf die hohen Fallzahlen von ca. 500 Fällen betreffend überlange Verfah-

841 Europäische Kommission, Mitteilung der Kommission an das Europäische Parlament, den Rat, die Europäische Zentralbank, den Europäischen Wirtschaftsund Sozialausschuss und den Ausschuss der Regionen, EU-Justizbarometer 2019, $\operatorname{COM}(2019) 198$ final vom 26.04.2019, S. 55 und 56, Schaubilder 47 und 49.

842 Europäische Kommission, Commission Staff Working Document, Country Report Slovenia 2019, SWD(2019) 1023 final vom 27.02.2019, S. 41.

843 Matej Avbelj, Jernej Letnar \& Justinek Gorazd, The Impact of European Institutions on the Rule of Law and Democracy, S. 85-86. Die Autoren führen zuvor selbst den Nachweis, dass der Menschenrechtsausschuss der UN ein differenzierteres Bild zeichnet.

844 Matej Avbelj, „Crises and Perspectives in building a European Nation - The Case Of Slovenia“, S. 406. Später erneuert, Matej Avbelj, Jernej Letnar, Jernej \& Justinek Gorazd, The Impact of European Institutions on the Rule of Law and Democracy, S. $100 \mathrm{ff}$.

845 EGMR, Lukenda ./. Slowenien, Beschwerdenr. 23032/02, Urteil vom 06.10.2005. 
ren hin. ${ }^{846}$ Für Avbelj ist das Urteil Anlass für eine drastische Feststellung: "This crisis is so deep that it would be more correct to speak only of the gradual emergence rather than of the existence of the rule of law in Slovenia. The country features a dysfunctional judiciary." 847

An dieser Stelle gelangt nun die Unterscheidung der Intention in der Rechtsprechung von EGMR bei der Identifizierung systemischer Probleme einerseits und die Entwicklung und Nutzung des Begriffs des systemischen Defizits für die Entwicklung in der Union andererseits zum Tragen, auf die ich eingehend ${ }^{848}$ hingewiesen hatte und die hier nochmals zu unterstreichen ist. Es ist in Erinnerung zu rufen, dass der EGMR der Rüge des überlangen Verfahrens in sehr unterschiedlichen Konstellationen stattgegeben hat. Dies macht die Feststellung, wonach jeder Fall, der mittels dieses Verfahrens einer Lösung zugeführt worden sei, einer fundamentalen Gefährdung der Rechtsstaatlichkeit entspreche, unmöglich. Verwiesen werden kann etwa auf den Fall Rumpf ./. Deutschland, für dessen Rechtssystem keinerlei Hinweise im Hinblick auf ein umfassendes Versagen unter rechtsstaatlichen Gesichtspunkten besteht. ${ }^{849} \mathrm{Im}$ Fall Greens betreffend das Vereinigte Königreich ${ }^{850}$ nutzte der EGMR das Piloturteilsverfahren und die mit ihm einhergehende Begrifflichkeit für die in Großbritannien immer noch kontrovers diskutierte Frage um das Wahlrecht von Strafgefangenen. Dies ist keine mit der Versagung effektiven Rechtsschutzes in Verbindung zu bringende Frage, sondern vielmehr ein Problem des politischen Gestaltungsspielraums eines Konventionsstaats, welches im europäischen Rechtsraum sehr unterschiedlich beurteilt wird. Das zeigt sich nicht nur anhand der sehr lebhaften Debatte, die die EGMR-Rechtsprechung in Großbritannien ausgelöst hat, sondern etwa auch am Urteil des EuGH in der Rs. Delvigne, ${ }^{851}$ in welchem der EuGH zu einem der EGMR-Rechtsprechung konträr entgegengesetzten Ergebnis gelangte. Die

846 EGMR, Lukenda ./. Slowenien, Beschwerdenr. 23032/02, Urteil vom 06.10.2005, Rn. 90-93, unter Verweis auch auf das vorgehende Urteil Bellinger ./. Slowenien vom 02.10.2001, Beschwerdenr. 42320/98.

847 Matej Avbelj, „Crises and Perspectives in building a European Nation - The Case Of Slovenia“, S. 406.

848 Vgl. unter B.IV.2.

849 EGMR, Rumpf ./. Deutschland, Beschwerdenr. 46344/06, Urteil vom 02.09.2010.

850 EGMR, Greens und M.T. ./. Vereinigtes Königreich, Beschwerdenr. 60041/08 und 60054/08, Urteil vom 23.11.2010.

851 EuGH, Rs. C-650/13, Thierry Delvigne ./. Commune de Lesparre-Médoc, Préfet de la Gironde, Urteil (GK) vom 06.10.2015, ECLI:EU:C:2015:648, , Rn. 49 und ff. 


\section{Die Rechtsstaatlichkeitskrise in mitgliedstaatlichen Fällen}

durch Avbelj getroffene Aussage, wonach Slowenien ein Mitgliedstaat sei, der umfassende Mängel in seinem Rechtssystem aufweise, muss folglich auf eine belastbarere Grundlage als allein ein Urteil des EGMR zu einem systemischen Problem speziell aufgrund der Logik und des Telos des Konventionsrechtsschutzsystems gestützt werden. Hieran aber mangelt es; es ist bislang weder durch die EU noch durch Organe des Europarates entsprechendes vorgetragen worden.

Der zweite Sachverhaltskomplex betreffend Slowenien, den Avbelj als vermeintlichen Beweis für systemische Defekte der Rechtsstaatlichkeit in Slowenien ins Feld führt, ist die sog. „Patria-Affäre“. Hierunter wird die strafrechtliche Verurteilung des früheren, und zwischenzeitlich wiedergewählten, slowenischen Ministerpräsidenten Janez Janša verstanden. ${ }^{852}$

Ihm wurde ab 2008 Bestechlichkeit zugunsten des finnischen Rüstungsunternehmens Patria vorgeworfen, in deren Folge Janša die Beschaffung eines Truppentransporters gleichen Namens dieses Unternehmens für die slowenische Armee durchgesetzt haben soll. Janša verwahrte sich gegen die Anschuldigungen, welche in der nachfolgenden Wahl zum Amtsverlust führten, und legte gegen die strafgerichtlichen Entscheidungen zwischenzeitlich außerordentliche Beschwerde beim slowenischen Verfassungsgericht ein. Dieses verwarf die Beschwerde unter Verweis auf die hohen Tatbestandsanforderungen als nicht begründet. Avbelj meint, ${ }^{853}$ der Fall und die sich hierüber entwickelnde politische Kontroverse in Slowenien deute auf ein Versagen des slowenischen Justizsystems, insbesondere auf den politisch-motivierten Versuch gleich mehrerer Gerichte Sloweniens hin, einen politischen Widersacher in seinen Rechten zu beschneiden. Es drohe ein nicht tolerierbarer Grad an Verletzung des Fairnessprinzips, das Gerichtsverfahren sei im Wesentlichen von dem Ziel geprägt gewesen, eine Wiederwahl des Angeklagten zu verhindern, woraus sich Auswirkungen auf das gesamte politische System Sloweniens ergäben. Mehrfach nutzt Avbelj für dieses daher den Begriff der "failed democracy" und in einem Fall den Begriff des „hijacked state“. ${ }^{854}$

Dem Beschwerdeführer war durch das Urteil und das Verbleiben in Haft ein persönlicher Wiederantritt bei der slowenischen Parlamentswahl

852 Ein kritisches Porträt von Janša zeichnet etwa Peter Münch, „Der Viktor Orbán der slowenischen Politik", Süddeutsche Zeitung vom 28.02.2020.

853 Matej Avbelj, „Failed Democracy: The Slovenian Patria Case - (Non)Law in Context", S. $7 \mathrm{ff}$.

854 Matej Avbelj, „Failed Democracy: The Slovenian Patria Case - (Non)Law in Context", S. 1, 3, 21. 
verwehrt. Allerdings ist dies durch den ordnungsgemäßen Gang des Verfahrens bedingt gewesen. Janša blieben ungeachtet des für ihn nachteiligen Urteils alle ihm zustehenden Rechtsmittel zur weiteren Fortsetzung des Verfahrens. Im Dezember 2014 ordnete das Verfassungsgericht die Haftentlassung Janšas an. ${ }^{855}$ Zwischenzeitlich hat Janša die Parlamentswahl erneut gewonnen.

Es zeigt sich damit im Ergebnis, dass auch Slowenien - ungeachtet der teils sehr harten Kritik einiger slowenischer Rechtswissenschaftler kein Fall der europäischen Rechtsstaatlichkeitskrise ist und anhand des dort präsentierten Materials keine substantiierten Beweise für den Vorwurf einer defizitären Nichtachtung rechtsstaatlicher Grundsätze bestehen. Ich möchte damit Avbeljs Kritik nicht pauschal relativieren, Mahnungen eines Beobachters aus dem Inneren eines nationalen Rechtssystems sind ernst zu nehmen. Weitere genannte Beispiele, wie die Nichtausführung von 14 Verfassungsgerichtsurteilen oder die Nichtöffentlichkeit bestimmter Gerichtssitzungen lassen aufhorchen. ${ }^{856}$ Es fehlt aber der Nachweis, wie genau diese sich im slowenischen Rechtssystem auswirken und insbesondere, dass sie systemischer Natur sind. Die hier angelegten Kriterien des intersystemischen Konflikts oder eines Selbsteintritts eines europäischen Akteurs haben sich nicht feststellen lassen.

\section{Zusammenfassende Bemerkungen zu den dargestellten Topoi}

Der bisherige Teil dieser Arbeit diente dazu, dem Leser einen Überblick über die sehr verschiedenen Vorgänge in zahlreichen Mitgliedstaaten zu verschaffen, für welche in der Literatur und in der Praxis die Beobachtung gemacht worden ist, es handele sich um ein Beispiel eines systemischen Defizits an Rechtsstaatlichkeit. Anhand des zuvor identifizierten Subtyps der vorsätzlichen Unterwanderung der Rechtsstaatlichkeit habe ich die Auffassung vertreten, dass in Polen und Ungarn jedenfalls dieser Typus systemischer Defizite in je eigener, gleichwohl in beiden Fällen höchst besorgniserregenden Ausprägung, vorliegt. Ich habe auch die Lage in Rumänien, ungeachtet des für diesen Mitgliedstaat in der Praxis teils divergie-

855 Leos Rousek, „Ex-Slovenian Premier Janez Jansa Leaves Prison - Constitutional Court Issued Temporary Injunction on Prison Sentence”, Wall Street Journal vom 12.12.2014.

856 Matej Avbelj, Jernej Letnar, Jernej \& Justinek Gorazd, The Impact of European Institutions on the Rule of Law and Democracy, S. 87 und S. 90. 


\section{Die Rechtsstaatlichkeitskrise in mitgliedstaatlichen Fällen}

renden Befundes, dem Fallset zugeordnet. Andere Mitgliedstaaten, denen der Vorwurf „staatlicher Schwäche“ bei der Durchsetzung rechtsstaatlicher Grundsätze zu machen ist, habe ich aus dieser Betrachtung ausgenommen.

Im Anschluss daran habe ich mich Vorgängen in verschiedenen Mitgliedstaaten gewidmet, darunter Spanien, der Slowakei und Slowenien, für welche in der Literatur und Praxis der gleiche Vorwurf lautgeworden ist bzw., so im Falle der Slowakei, die in den vergangenen Jahren eine schwere und hier insbesondere auf die Justiz bezogene Verfassungskrise durchlaufen hat, ohne dass darüber aber der Befund eines systemischen Defizits an Rechtsstaatlichkeit zu substantiieren gewesen wäre.

Letzteres insbesondere lehrt Vorsicht und Bedacht beim Umgang mit dem vorgefundenen Material. Nicht jede Verfassungskrise in einem Mitgliedstaat der EU erfüllt die in der Rechtswissenschaft herausgearbeiteten Kriterien eines systemischen Defizits, noch würde sie die Tatbestandskriterien der nachfolgend darzustellenden Mechanismen erfüllen. Der Ton und die Vehemenz, mit der dieser Befund gleichwohl in der Rechtswissenschaft teils erhoben wird, ist daher umso erstaunlicher. Selbst die Europäische Kommission ist hiervor nicht gefeit geblieben. So war es niemand anderes als die damalige Justizkommissarin Viviane Reding, die 2013 den Gründungsmitgliedstaat Frankreich aufgrund des damaligen Vorgehens unter Staatspräsident Sarkozy gegen Angehörige der Volksgruppe der Roma in eine Linie insbesondere mit Ungarn stellte. Sie hielt fest, erforderlich sei „respect of the rule of law agreed upon by all Member States, including France“ .857 Redings Kritik war dabei ausgesprochen scharf. Das gilt etwa für ihre - im Druckbild der Rede proklamatisch hervorgehobene - Feststellung, ein Vertragsverletzungsverfahren gegen Frankreich sei unvermeidlich, was auch anderen Beobachtern auffiel. ${ }^{858}$ Aus heutiger Sicht ist Redings Befund unzutreffend und allenfalls damit zu rechtfertigen, dass die Kommission, wie die Wissenschaft, erst am Anfang eines langen Lernprozesses im Hinblick auf die Krise stand, wobei hier nicht behauptet werden soll, er sei bereits abgeschlossen. Frankreich stellte jedenfalls, wie

857 Viviane Reding, Vice-President of the European Commission responsible for Justice, Fundamental Rights and Citizenship: „Statement on the latest developments on the Roma situation", Readout im Hebdomadaire der Kommission vom 14.09.2010, SPEECH/10/428, S. 3.

858 S. Robert Gould, „Roma rights and Roma expulsions in France: Official discourse and EU responses“, in: Critical Social Policy 35 (2014), S. 1-21, S. 8. 
Reding bereits in ihrer Rede selbst ansprach ${ }^{859}$ die vielfach kritisierte ${ }^{860}$ Praxis zeitnah wieder ein, und es ergaben sich niemals substantiierte Zweifel, dass insbesondere die französische Justiz unwillig oder unfähig gewesen wäre, sich der Lage anzunehmen. Insbesondere hob der französische Conseil d'État im Rahmen seiner etablierten Rechtsaktkontrolle eine sog. circulaire der französischen Regierung betreffend den Umgang mit der Minderheit auf. ${ }^{861}$ Armin von Bogdandy und Jochen von Bernstorff etwa, die sich im Hinblick auf die Lage der Roma ebenso besorgt äußerten, stellten konsequentermaßen bei ihrer Dokumentation auf die Lage in anderen Mitgliedstaaten $a b,{ }^{862}$ ohne, wie die Europäische Kommission dies getan hatte, Frankreich in den Vordergrund zu rücken.

Für beide hier geschilderten Mitgliedstaatsgruppen, solche, die „echte“ systemische Defizite an Rechtsstaatlichkeit, und gerade solchen des vorsätzlichen Typs, darstellen, wie auch bloß vermeintliche Beispiele, müssen Rechtswissenschaft und Praxis zunehmend schnell und bündig unterscheiden können, ohne den Überblick zu verlieren. Die Union hat sich damit weit von jenem Zustand entfernt, wie er noch im Rahmen der sog. Haider-Krise im Jahr 2000 bestand, als es möglich war, sich ausführlich und präzise einem einzelnen mitgliedstaatlichen Vorgang zu widmen, wie die frühen Arbeiten gerade zu Art. 7 EUV zeigen. ${ }^{863}$ Nicht nur in ihrem Zuschnitt auf betroffene Mitgliedstaaten, auch im Hinblick auf ihre Reichweite, verlangt die gegenwärtige Rechtsstaatlichkeitskrise dem Praktiker und dem Forscher eine systemische Sichtweise ab. Dem diente die hier mittels einer auf verschiedene Topoi abstellenden Darstellung anstelle einer systematischen Sichtung.

Damit aber will ich es nicht bewenden lassen. Die vorangegangenen Ausführungen bleiben vielmehr die notwendige empirische Grundlage,

859 Viviane Reding, Vice-President of the European Commission responsible for Justice, Fundamental Rights and Citizenship: „Statement on the latest developments on the Roma situation", Readout im Hebdomadaire der Kommission vom 14.09.2010, SPEECH/10/428, S. 3.

860 Dokumentation etwa durch Matthew Saltmarsh, „Sarkozy Toughens on Illegal Roma“, New York Times vom 29.07.2010.

861 Vgl. Robert Gould, „Roma rights and Roma expulsions in France“, S. 9.

862 Armin von Bogdandy \& Jochen von Bernstorff, „Die Europäische Agentur für Grundrechte in der europäischen Menschenrechtsarchitektur und ihre Fortentwicklung durch den Vertrag von Lissabon“, in: Europarecht 46 (2010), S. 141-164, S. 162, bei Fn. 100 mit umfassenden wN.

863 Vgl. nochmals Frank Schorkopf, Homogenität in der Europäischen Union; Frank Schorkopf, Die Maßnahmen der XIV EU-Mitgliedstaaten gegen Österreich. 
um sich nunmehr dem eigentlichen Forschungsanliegen dieser Arbeit zu widmen, nämlich der Frage, wie und mit welchen Mitteln die Europäische Union auf die ihre Mitgliedstaaten betreffende Krise reagiert hat.

In Teilen ist dies bereits angeklungen. Ich habe auch angesprochen, dass die Europäische Kommission - erstmals in der Geschichte der Union - gegenüber Polen das Verfahren, welches Art. 7 EUV den Unionsorganen bietet, in Form seines Absatzes 1 aufgrund einer „ernsthaften Gefährdung" des Rechtsstaatsprinzips zur Anwendung gebracht hat. Gegenüber Ungarn, so ist weiter angeklungen, hat das Europäische Parlament gleichgezogen. Der Europäische Gerichtshof hat sich in mehreren Vertragsverletzungsverfahren einzelner Fragen der Krise angenommen. Und darüber hinaus hat die Kommission eine Reihe von Instrumenten, wie das vielfach zitierte sog. EU-Justizbarometer oder das Europäische Semester dazu genutzt, auf die Krise in noch anderer Form zu reagieren. 


\section{Verfassungsaufsicht in der Europäischen Union}

\section{Begriff und Intention}

Der folgende Teil präsentiert meine Argumente für die Nutzung des Begriffs der Verfassungsaufsicht zur Verklammerung des unionalen Rechtsregimes in Reaktion auf die Rechtsstaatlichkeitskrise. Es handelt sich nicht um eine (nochmalige) rechtsdogmatische Erarbeitung des Begriffs (oder gar um eine möglichst vollständige Darstellung seiner Entwicklung), und dies, obwohl es bislang an jüngeren, umfassenden rechtsvergleichenden Studien zur Aufsicht in verschiedenen Mitgliedstaaten insbesondere zu fehlen scheint, ${ }^{864}$ sondern um eine argumentativ abgesicherte These. Ich beanspruche nicht, dass diese die einzig mögliche Deutung für das Funktionieren des Rechtsregimes ist. Verglichen mit anderen Optionen überzeugt sie aber aufgrund des Ordnungspotentials für die Wissenschaft und Praxis.

1. Aufsicht im Unionsrecht und Unionsaufsicht

a. Funktionen des Aufsichtsbegriffs für den Staat, Nutzung des föderalen Aufsichtsbegriffs im Unionsrecht

Der Begriff der Verfassungsaufsicht ist eine besondere Ausprägung des Aufsichtsbegriffs. Dieser wiederum entstammt ursprünglich dem öffentlichen Recht des Nationalstaats. Er erfasst dort zwei getrennte Funktionen, zum einen die Sicherstellung der Weisungs- und Rechtsbefolgung in einem Hierarchiegefälle, z.B. zwischen staatlichen Funktionsebenen, dem Staat und Privaten oder auch verwaltungsintern. Derjenige Staat, der diese Aufsicht zwischen staatlichen Funktionsebenen in besonders markanter

864 Einen derartigen Rechtsvergleich, zwischenzeitlich entsprechend in die Jahre gekommen, unternimmt Heinrich Triepel, Die Reichsaufsicht, Springer, Berlin, 1917, S. 71 ff.; bei Wolfgang Kahl, Die Staatsaufsicht: Entstehung, Wandel und Neubestimmung unter besonderer Berücksichtigung der Aufsicht über die Gemeinden, Mohr Siebeck, Tübingen, 2000, S. 29 f. ist er ausdrücklich unterblieben. 
Form ausgebildet hat, ist Frankreich mit seinem etablierten und aufgrund reger Reformbemühungen des Gesetzgebers teils überholten Rechtsinstitut der tutelle. ${ }^{865} \mathrm{Um}$ diese Aufsicht soll es hier nicht gehen, auch wenn sie den Europäischen Gerichtshof durchaus interessiert hat. ${ }^{866}$

Zum anderen hat der Aufsichtsbegriff, naturgemäß nur in Staaten entsprechenden Aufbaus, als rechtsdogmatisches Konzept zur Beschreibung desjenigen Rechtsinstrumentariums gedient, das in Bundesstaaten die Homogenität im Bund sichert, d.h. die Rechtsbefolgung des Bundesrechts seitens der Gliedstaaten des Bundes beobachtet, überprüft und ggf. berichtigend eingreift. Dieses Begriffsverständnis der Aufsicht ist dasjenige der Bundesaufsicht. Von großer Tradition, über die Verfassungen hinweg, ist dieser Begriff im deutschen Recht. Heinrich Triepels 1917 noch zur Verfassung von 1871 erschiene Monographie „Die Reichsaufsicht“"867 hat dabei eine solche Prägewirkung und Langlebigkeit erzielt, dass allein die Rezeption der Arbeit Triepels in späteren Schriften ein eigenständiger Forschungsgegenstand sein könnte. Wolfgang Kabl hat sie in seiner Habilitationsschrift zur Staatsaufsicht als eine „das sonstige aufsichtsrechtliche Schrifttum turmhoch überragende" Arbeit gewürdigt. ${ }^{868} \mathrm{Pforr}$ hat der Arbeit Triepels auch für das Unionsrecht unter Berücksichtigung weiterer Würdigungen einen „epochalen“ und „wirkmächtigen“ Charakter zugesprochen. ${ }^{869}$

Bevor ich zu den Pfadabhängigkeiten komme, die diese deutsche Tradition hier schafft, ist aber zu betonen, dass der Bundesaufsichtsbegriff kein rein deutscher Begriff ist. Das ist wichtig, weil man sich damit des Vor-

865 Die tutelle hat in der deutschen Literatur durchaus Beachtung gefunden, hierzu und zur französischen Begriffsgenese sehr übersichtlich bei Wolfgang Kahl, Die Staatsaufsicht, S. 58-60. Konzise, nunmehr zum Begriff der contrôle, aus der französischen Literatur Nadine Poulet-Gibot Leclerc, Droit administratif: sources, moyens, contrôles, Bréal, Rosny-sous-Bois, 2007, S. 28 ff. Vgl. zum jetzigen Stand der Verfassung insb. Art. 72 UAbs. 5 CF 1958.

866 Aus der sehr frühen Rechtsprechung vgl. EuGH, Rs.33/59, Compagnie des hauts-fourneaux de Chasse ./. Hohe Behörde, Ergänzende Schlussanträge des Generalanwalts Maurice Lagrange, Slg. 1959, S. 817-828 (821-822), ECLI:EU:C:1962:33. Das eigentliche Rechtsproblem des Falles, nämlich die Frage der Unionshaftung, bleibt hier außen vor.

867 Heinrich Triepel, Die Reichsaufsicht, frühe Rezension, die den späteren Einfluss bereits andeutet bei Leo Wittmayer, „Heinrich Triepel, Die Reichsaufsicht. Untersuchungen zum Staatsrecht des Deutschen Reiches“, in: Archiv des öffentlichen Rechts 41 (1921), S. 107-112, S. 108.

868 Wolfgang Kahl, Die Staatsaufsicht, S. 172.

869 Thomas Pforr, Die allgemeine Unionsaufsicht, S. 29, mit weiteren Quellen. 
wurfs erwehrt, der Rechtsstaatlichkeitskrise einen deutschen Verfassungsbegriff überzustülpen.

Wer den Begriff der Bundesaufsicht nutzt, meint indes damit zunächst, dass die Homogenitätssicherung nicht allein durch die Gerichte erfolgt.

Das könnte erklären, warum z.B. im U.S.-amerikanischen Verfassungsrecht, in welchem die durch den Obersten Gerichtshof (Supreme Court) ausgeübte constitutional review eine überragende und hier nicht in Ansätzen hinreichend darzustellende Bedeutung hat, ${ }^{870}$ das Konzept einer "federal supervision" spezifisch als nicht gerichtlich überformte Rechtsbeziehung zwischen Bund und Bundestaaten dort nur fragmentarisch erörtert zu sein scheint. ${ }^{871}$

In kontinentaleuropäischen Bundesverfassungen ergibt sich indes ein aus deutscher Sicht vertrauteres Bild.

In der belgischen Verfassung regelt insbesonder Art. 162 UAbs. 2 Nr. 6 die Rechtsgrundlage für die Bundesaufsicht. Sie spricht in der deutschen Fassung von Aufsicht (konkret von der Aufsichtsbehörde) im Niederländischen von der toezicht (toezichthoudende overheid), im Französischen von der tutelle (autorité de tutelle). Auch hat die belgische Rechtswissenschaft Fragen der Kompetenzverteilung zwischen Bund und föderierten Gliedern einschließlich der Bundestreue als Frage der Interverbandsrelation disku-

870 S. im Überblick exemplarisch Peter E. Quint, „\$109 Der Einfluss des Supreme Court der Vereinigten Staaten von Amerika auf die Verfassungsgerichtsbarkeit in Europa“, in: Armin von Bogdandy, Christoph Grabenwarter \& Peter M. Huber (Hrsg.), Handbuch Ius Publicum Europaeum: Band VI: Verfassungsgerichtsbarkeit in Europa: Institutionen, C. F. Müller, Heidelberg, 2017, S. 1031-1099.

871 Vgl. aber etwa als Begriff bei Westel Woodbury, „Chapter XI. Federal Supervision of State Activities; The Fourteenth Amendment", in, ders., Constitutional Law of the United States, Baker, Voorhis \& Co., New York, 1910, S. 175-193, dort aber auch auf den U.S. Supreme Court bezogen. Vorsichtig auch Heinrich Triepel, Die Reichsaufsicht, S. 79 und f. Mir ist, trotz intensiver Suche, in der jüngeren Literatur kein Werk bekannt geworden, das erkennbar ein Konzept der auch gubernativen Aufsicht für das US-Verfassungsrecht eigenständig oder gar unter Rückgriff auf europäische Begriffe erarbeitet hätte. Rechtsvergleichend ist vielmehr die Konfliktbeilegung ex ante, durch Kooperation, Schaffung neuer Institutionen bzw. „Verfahrensföderalismus“ betont worden, vgl. Dirk Hanschel, Konfliktlösung im Bundesstaat: Die Lösung föderaler Kompetenz-, Finanz- und Territorialkonflikte in Deutschland, den USA und der Schweiz, Mohr Siebeck, Tübingen, 2012, S. 329 ff. insb. 349 ff., 393 ff. 
tiert, ${ }^{872}$ wobei das belgische Recht der ex-ante-Regelung zur Vermeidung von späteren Konflikten besondere Aufmerksamkeit zuteil werden zu lassen scheint. ${ }^{873}$

In Österreich ist der Begriff nahe am deutschen Begriff diskutiert worden, ${ }^{874}$ auf welchen ich weiter unten eingehen werde.

Für die Schweiz, die zwar kein Mitgliedstaat der Union ist, deren Rechtswissenschaft ebenso eine klare Tradition des Aufsichtsbegriffs als Frage des Föderalismus kennt, ${ }^{875}$ etabliert Art. 169 der heutigen Bundesverfassung die „Oberaufsicht“ der Bundesversammlung über andere Bundesorgane, Art. 187 BV die bundesinterne Aufsicht der Exekutive über die Bundesverwaltung und Art. $186 \mathrm{BV}$ die Bundesaufsicht als ebenenübergreifende, d.h. zwischen Bund und Gliedstaaten erfolgende, Aufsicht. ${ }^{876}$

Wie scharf ggf. diese Berichtigung sein kann, ob sie etwa sogar offenen Bundesdurchgriff in Form von Zwang und Exekution ermöglicht, ist eine dogmatische und letztlich verfassungspolitische Frage des jeweiligen Bundesstaats. Die Europäische Union, nur um das vorwegzunehmen, kennt derartige Durchgriffsmaßnahmen nicht. ${ }^{877}$

Aber sie und ihr Recht kennen, vielfach erörtert, den Bundesaufsichtsbegriff. Das bedingt zunächst, davon auszugehen, dass die Union föderalen Charakter hat. Das ist hier nicht noch einmal zu belegen, dafür ist genügend Beweismaterial zusammengetragen worden. ${ }^{878}$ Ich leite hieraus

872 Exemplarisch André Alen \& Koen Muylle, Handboek van het Belgisch staatsrecht, Wolters Kluwer, Mechelen, 2011, S. 468 ff., insb. S. 469 zur « federale loyauteit ».

$873 \mathrm{Zu}$ Modellen eines « fédéralisme conflictuel » gegenüber einem « fédéralisme coopératif » und verschiedenen „accords de coopération » im belgischen Staatsrecht Christian Behrendt \& Martin Vrancken, Principes de droit constitutionnel belge, La Charte, Brüssel, 2019, S. $467 \mathrm{ff}$.

874 Vgl. etwa Peter Pernthaler \& Karl Weber, Theorie und Praxis der Bundesaufsicht in Österreich, Braumüller, Wien, 1979; ausführliche Darstellung für Österreich unter dem Stichwort der Verfassungsautonomie bei Funk, Bernd-Christian: „Die Bedeutung gliedstaatlichen Verfassungsrechts für die Gegenwart“, in: Martin Kriele (Hrsg.), Veröffentlichungen der Vereinigung der Deutschen Staatsrechtslehrer, Band 46, De Gruyter, Berlin \& New York, 1988, S. 57-91, S. $59 \mathrm{ff}$. insb.

875 Vgl. etwa Bernard Schaub, Die Aufsicht des Bundes über die Kantone, H. R. Sauerländer \& Co. Aarau, Zürich, 1957.

876 Im Einzelnen s. insb. Giovanni Biaggini, Art. 187 BV, Rn. 17, in: Bernhard Ehrenzeller u.a. (Hrsg.), St. Galler Kommentar, Dike, Zürich, 3. Aufl. 2014.

877 S. dazu auch Armin von Bogdandy, „Tyrannei der Werte?“, S. 533.

878 Armin von Bogdandy, „Die Europäische Union als supranationale Föderation“, in: Integration 22 (1999), S. 95-112; insbesondere auch Christoph Schönberger, 
$\mathrm{ab}$, dass der Bundesaufsichtsbegriff auch für das Unionsrecht Geltung beanspruchen kann. Das ist zunächst nicht sonderlich innovativ, eine lange Reihe an Publikationen und Verfassern hat es ebenso gesehen. Dafür aber ist der Beweis erstaunlich mühsam zu führen. Der Wortlaut der Verträge und des Sekundärrechts macht den Begriff der Bundesaufsicht nämlich nicht stark.

Im Primärrecht findet sich der Aufsichtsbegriff vereinzelt und nicht dogmatisch eindeutig, z.B. in Art. 43 Abs. 2 S. 2 EUV, als horizontale Aufsicht im Unionsrecht, nämlich die des Rates über den Hohen Vertreter für Außen- und Sicherheitspolitik bei der Durchführung bestimmter Missionen. Insbesondere nutzt das Primärrecht ihn für das Finanzrecht. Art. 65 Abs. 1 lit. b) AEUV etwa bekennt sich zum Recht der Mitgliedstaaten hinsichtlich der Aufsicht über die Finanzinstitute, Art. 124 AEUV wiederholt die gleiche Aufsicht in einem größeren, auch die Union umfassenden, Rahmen („aufsichtsrechtliche Gründe“); ähnlich Art. 127 Abs. 5 und 6 AEUV („Aufsicht“) für das ESZB und den Rat. Aufgrund dessen, und nicht zuletzt aufgrund der jüngeren Finanzkrise der Europäischen Union, ist der Begriff der Aufsicht (supervision, sowohl im Englischen wie auch im Französischen) gerade in diesem Bereich in der jüngeren Literatur genutzt worden. ${ }^{879}$ Das ist derart prominent erfolgt, dass darüber das hier

„Die Europäische Union als Bund: zugleich ein Beitrag zur Verabschiedung des Staatenbund-Bundesstaat-Schemas“, in: Archiv des öffentlichen Rechts 129 (2004), S. 81-120.

879 Pieter van Cleynenbreugel, „Market Supervision in the European Union: Integrated Administration in Constitutional Context", Martinus Nijhoff, Leiden, 2014, S. 9 ff. Der Begriff existiere, so dort in Fn. 1, auch im niederländischen Recht in dieser speziellen Ausprägung, ohne Verknüpfung mit einem übergeordneten Konzept der Aufsicht (supervision). Weiter Eddy Wymeersch, Eddy, Klaus J. Hopt \& Guido Ferrarini (Hrsg.), Financial Regulation and Supervision: A post-crisis analysis, Oxford University Press, Oxford, 2012; Rosa M. Lastra, „Multilevel Governance in Banking Regulation“, in: Edoardo Chiti \& Vittorio Santoro (Hrsg.), The Palgrave Handbook of European Banking Union Law, Palgrave Macmillan/Springer Nature, Cham, 2019, S.3-17. Aus der deutschen Literatur insb. Alexander Thiele, Finanzaufsicht: Der Staat und die Finanzmärkte, Mohr Siebeck, Tübingen, 2014, S. $201 \mathrm{ff}$., $257 \mathrm{ff}$, dort vorrangig für den deutschen staatlichen Rahmen; Ann-Katrin Kaufhold, „Systemaufsicht: Der Europäische Ausschuss für Systemrisiken im Finanzsystem als Ausprägung einer neuen Aufsichtsform“, in: Die Verwaltung 46 (2013), S. 21-57, S. 23 (Aufsicht als Unterbegriff der Kontrolle), S. 38 für das Zusammenspiel ökonomischer Makro- und Mikroaufsicht. Auch ihre spätere Habilitationsschrift, Systemaufsicht: Anforderungen an die Ausgestaltung einer Aufsicht zur Abwehr systemischer Risiken entwickelt am Beispiel der Finanzaufsicht, Mohr Siebeck, Tübingen, 
anvisierte Verständnis der Aufsicht weitgehend entfällt. Avbelj hat sogar in einem Aufsatz ein vollständig eigenständiges System dieser Finanzaufsicht im Unionsrecht vorgelegt. ${ }^{880}$

Im Sekundärrecht wiederum ist der Begriff ähnlich fragmentarisch und heterogen verwendet worden, das hat z.B. Generalanwalt Jean Mischo einiges Kopfzerbrechen bereitet. ${ }^{881}$ Diese Ausführungen sind hier mit Hinblick auf den Schwerpunkt der Arbeit nicht weiter zu verfolgen, sie mahnen indes, bei der dogmatischen Verdichtung im Unionsrecht Vorsicht walten zu lassen.

Mangels Stütze im Wortlaut hat es sich eingebürgert, für die Erarbeitung der Aufsicht in der Europäischen Union auf das Mittel der teleologischen Verknüpfung einer Norm als Zugehörigkeit bzw. Ausdruck des dahinterliegenden Konzepts zurückzugreifen.

Grundlegend etabliert hat dieses Verfahren bereits eine Festlegung des Gerichtshofs im Urteil Van Gend en Loos. Dort heißt es nämlich, in Bezug auf das Vertragsverletzungsverfahren des EGV in der ursprünglichen Fassung:

„Die Wachsamkeit der an der Wahrung ihrer Rechte interessierten Einzelnen stellt eine wirksame Kontrolle dar, welche die durch die Kommission und die Mitgliedstaaten gemäß den Artikeln 169 und 170 ausgeübte Kontrolle ergänzt." ${ }^{882}$

Die deutsche Sprachfassung geht hier vom Begriff der „Kontrolle“ aus, der dem französischen Original folgt. ${ }^{883}$

2014, S. 23 ff. und S. 124 ff., sieht den Ursprung im wirtschaftswissenschaftlich begründeten Begriff des „Systemrisikos“.

880 Matej Avbelj; „Constitutional and Administrative Pluralism in the EU System of Banking Supervision“: in Matthias Goldmann \& Silvia Steininger (Hrsg.): Democracy and Financial Order: Legal Perspectives, Springer, Heidelberg, 2018, S. 77-94.

881 EuGH, Rs. C-237/99, Kommission ./. Frankreich, Schlussanträge des Generalanwalts Jean Mischo vom 19. Oktober 2000, Slg. 2000 I-941, ECLI:EU:C:2000:577, Rn. $31 \mathrm{ff}$, hier für einen Sekundärrechtsakt.

882 EuGH, Rs. 26/63, N.V. Algemene Transport- en Expeditie Onderneming Van Gend \& Loos ./. Niederländische Finanzverwaltung, Urteil v. 5. Februar 1963, Slg. 1962, S. 7, ECLI:EU:C:1963:1, S. 26, meine Hervorhebungen.

883 Ebenso nicht sonderlich prägnant: “[...] la vigilance des particuliers intéressés à la sauvegarde de leurs droits entraîne un contrôle efficace qui s'ajoute à celui que les articles 169 et 170 confient à la diligence de la Commission et des États membres »., Quelle wie vor, S. 25 der französischen Slg., meine Hervorhebungen. 
Sehr viel griffiger hingegen ist die englische Fassung, die wiederum den Begriff der supervision nutzt:

„The vigilance of individuals concerned to protect their rights amounts to an effective supervision in addition to the supervision entrusted by Articles 169 and 170 to the diligence of the Commission and of the Member States. " 884

Paul Craig und Gráinne de Búrca sehen die Van Gend-Entscheidung deswegen, ungeachtet der sonstigen Bedeutung des Urteils, auch als Grundsatzurteil ebenso auf dem Feld des „public enforcement“ an. ${ }^{885}$

\section{b. Der Bundesaufsichtsbegriff in der europarechtlichen Literatur}

Keineswegs immer unter Rückgriff auf diese Festlegung des Gerichtshofs, dafür umso eigenständiger, hat eine beachtliche Reihe an Verfassern den Bundesaufsichtsbegriff im Unionsrecht beschrieben und konzeptualisiert, wobei das Vertragsverletzungsverfahren früh ganz vorrangig berücksichtigt worden ist und sich deswegen als das klassische Aufsichtsinstrument im Unionsrecht herauskristallisiert hat.

Das war z.B. in der Arbeit von Dieter Bandell ${ }^{886}$ der Fall, der die Übertragung des deutschen staatsrechtlichen Aufsichtsbegriffs auf das Unionsrecht für unproblematisch hält. Die auch in völkerrechtlichen Organisationen bekannte Aufsicht sei hingegen, im Unterschied zur Aufsicht in Staaten und der Union, als „internationale Kontrolle“ zu bezeichnen. ${ }^{887}$

Manfred Zuleeg hat die Bedeutung des Vertragsverletzungsverfahrens unter Nutzung des Aufsichtsbegriffs für ähnlich grundlegend erachtet und sich dabei für ein überraschend weites Verständnis des Verfahrens ausgesprochen:

„Die Rechtsgrundlagen bilden die Art. 88 EGKSV, 169 EWGV und 141 EAGV, die man kurz als "Aufsichtsnormen“ bezeichnen

884 Quelle wie vor, S. 13 der englischen Slg, meine Hervorhebungen.

885 Paul Craig \& Gráinne de Búrca, EU Law: Text, Cases and Materials, 6. Aufl., Oxford University Press, Oxford, 2015, S. 436.

886 Dieter Bandell, Die Aufsicht der Europäischen Gemeinschaften über die Mitgliedstaaten, verglichen mit der Bundesaufsicht und unter Berücksichtigung der internationalen Kontrolle, Walter Kleikamp, Köln, 1965, S. 3.

887 S. Dieter Bandell, Die Aufsicht der Europäischen Gemeinschaften über die Mitgliedstaaten, S. 6 ff. mit umfangreichem Verweis auf entsprechende Vorarbeiten. 
kann. Gegenstand der Gemeinschaftsaufsicht kann danach die gesamte staatliche Tätigkeit der Mitgliedstaaten sein, soweit sie irgendwie das Gemeinschaftsrecht berührt. “888

Auch Hans Peter Ipsen sieht die Frage quasi identisch, mit ähnelnden Ausführungen. ${ }^{889}$

Gleichwohl stehen, für den Umfang der Sichtung des Unionsrechts anhand des Aufsichtsbegriffs, diese Arbeiten erst am Anfang. Denn im Wesentlichen handelt es sich bei ihnen um eine besondere Würdigung des Vertragsverletzungsverfahrens.

In die Tradition einer breiten, das gesamte Gemeinschaftsrecht sichtenden Arbeit, stellen sich mit Huиb Audretsch und Alberto J. Gil Ibañez zwei englischsprachige Dissertationen, die beide mit dem Begriff der „supervision" operieren. ${ }^{890}$ Sie leiten den Begriff autonom, d.h. ohne Rückgriff auf nationale Vorbilder, wie etwa den ihnen augenscheinlich unbekannten Diskurs in Deutschland, aber insbesondere auch ohne eigene dogmatische Vertiefung etablieren, was Kommentatoren teils auch etwas irritiert hat. ${ }^{891}$ Bei Audretsch insbesondere ist der Begriff der „community supervision“ eine unionseigene Ausprägung einer völkerrechtlichen Figur, der „international supervision“. „It is a species of the genus of international supervi-

888 Vgl. Manfred Zuleeg, „Die Kompetenzen der Europäischen Gemeinschaften gegenüber den Mitgliedstaaten“, in: Jahrbuch des öffentlichen Rechts der Gegenwart N.F. 20 (1971), S. 1-64, S. 52.

889 Hans Peter Ipsen, Europäisches Gemeinschaftsrecht, Mohr, Tübingen, 1972, S. 220 ff., 222 insb. und nachfolgend Hans Peter Ipsen: „Über Verfassungs-Homogenität in der Europäischen Gemeinschaft“, in: Hartmut Maurer (Hrsg.), Das akzeptierte Grundgesetz: Festschrift für Günter Dürig zum 70. Geburtstag, C.H. Beck, München, 1990, S. 159-182, S. 180. Ebenso Dieter Bandell, Die Aufsicht der Europäischen Gemeinschaften über die Mitgliedstaaten, S. 2 und ff.

890 Huub A. H. Audretsch, Supervision in European Community Law: Observance by the Member States of their Treaty Obligations: A Treatise on International and Supra-national Supervision, North Holland, Amsterdam, New York, Oxford, 1978, später vorgelegt 1986 in erw. Aufl; Alberto J. Gil Ibáñez, „The Administrative Supervision and Enforcement of EC Law: Powers, Procedures and Limits“, Hart, Oxford \& Portland, 1999; Später, allerdings speziell zur Marktaufsicht, Pieter van Cleynenbreugel, Market Supervision in the European Union, insb. S. 9 ff. und S. 10 bei Fn. 3 zu den begrifflichen Wurzeln.

891 Vgl. Blaise G.A. Pasztory, „Audretsch, Supervision in European Community Law: Observance by the Member States of Their Treaty Obligations (2d Rev. Ed.)“, in: Fordham International Law Journal 11 (1987), S. 453-460, insb. S. 453, 454 . 
sion“ ${ }^{892}$ Er leistet aber selbst keinerlei weitere Begriffsgenese. ${ }^{893}$ Dies gilt, obwohl Audretsch, indes ohne Quellenangabe, auf die noch zu erörternde Arbeit Heinrich Triepels und dessen zweistufiges Aufsichtsmodell, bestehend aus „Beobachtungs“- und „Berichtigungsfunktion“ ${ }^{894}$ eingeht. ${ }^{895}$ Stine Andersen hat sich später in ihrer Abhandlung zum „enforcement“ im Unionsrecht durchweg auf beide Arbeiten gestützt, ohne dabei allerdings den Aufsichtsbegriff aufzuarbeiten, und ein Verweis auf fremdsprachige Literatur findet sich ebenso nicht. ${ }^{896} \mathrm{Im}$ Rahmen jüngerer Literatur ist dabei auch der Begriff der „(rule of law) oversight“" 897 hinzugetreten. Auch in der französischsprachigen Literatur ist der Aufsichtsbegriff für das Unionsrecht, wenn auch nur sehr vereinzelt, eigenständig verwendet worden, etwa bei Louis Cartou. ${ }^{898}$

In keiner dieser Arbeiten ist der Begriff, anders als bei den vorangegangenen und ihnen nachfolgenden deutschen Arbeiten, mit der Idee des Föderalismus verbunden worden. Indes ist das gesichtete Material und die Absicht, mit Ausnahme des an den Begriff der tutelle angelehnten Entwurfs Cartous, funktional weitgehend identisch mit eben jenem Begriff.

892 Huub Audretsch, Supervision in European Community Law, S. 2. Peter Wollenschläger, Die Gemeinschaftsaufsicht über die Rechtsprechung der Mitgliedstaaten, Duncker \& Humblot, Berlin 2006. S. 41 ff., hat sich der Frage der Bedeutung der völkerrechtlichen Aufsicht für das Unionsrecht zwar ebenso gewidmet, für ihn bleibt dies aber neben der nationalen Aufsicht eine von mehreren zu berücksichtigenden Quellen.

893 Wollte man weiter suchen, wäre etwa zu nennen: Ernest Alfred Landy, The effectiveness of international supervision: 30 years of I.L.O. experience, Stevens \& Sons, London, 1966; weiter Ernest Alfred Landy, „Implementation Procedures of the International Labor Organization“, in: Santa Clara Law Review 20 (1980), S. 633-663, S. 635 ff., 647 f., 661 zur Vergleichbarkeit mit anderen IOs und zur Verfahrensvielfalt im ILO-System.

894 Heinrich Triepel, Die Reichsaufsicht, S. 120.

895 Huub Audretsch, Supervision in European Community Law, S. 4.

896 Stine Andersen: The Enforcement of EU Law: The Role of the European Commission, Oxford University Press, Oxford, 2012, insb. S. 36 ff.

897 Vgl. Joseph H. H. Weiler, Carlos Closa \& Dimitry Kochenov, „Reinforcing Rule of Law Oversight in the European Union“, RSCAS 2014/25, EUI Working Papers, San Domenico di Fiesole, 2014; Christophe Hillion, „Overseeing the Rule of Law in the EU: Legal Mandate and Means“, weiter Mark Dawson, The Governance of EU Fundamental Rights, Cambridge University Press, Cambridge, 2017, S. 144.

898 Louis Cartou, Europäische Organisationen, Eurobuch-Verlag Lutzeyer, Freudenstadt, 1967, S. 185. Hinweis bei Manfred Zuleeg, „Die Kompetenzen der Europäischen Gemeinschaften gegenüber den Mitgliedstaaten“, S. 53, Fn. 346, 348. 
Jüngere deutsche Arbeiten haben sich der föderalen Logik dann wieder umfassend verschrieben. Eekhoffs Arbeit zur „Verbundaufsicht“ untersucht gerade Aufsichtsverfahren jenseits des Vertragsverletzungsverfahrens und macht zusätzlich höchst nützliche Beobachtungen für den Aufsichtsbegriff, die ich hier übernehme.

Nachdem Eekhoff festgehalten hat, dass es dort keine allgemeingültige Definition des Aufsichtsbegriffs für das Gemeinschaftsrecht gibt, ${ }^{899}$ gelangt sie zu der Feststellung, die Aufsicht sei eine durch die Gemeinschaft ausgeübte Tätigkeit, die einen Ist-Soll-Vergleich vornehme und prozesshaften Charakter habe. ${ }^{900}$ Die Aufsicht sichert die Befolgung des Rechts, schöpft aber selbst keines. Dazu orientiert sie sich an einem konkreten Maßstab, der, jedenfalls für das damalige Gemeinschaftsrecht, weitgehend mit dem Begriff der Kontrolle identisch sei. ${ }^{901}$ Zentral ist für sie, wie zuvor im Übrigen schon für Kahl, ${ }^{902}$ der, im Unterschied zu Triepel, ${ }^{903}$ dreistufige Aufbau der Aufsicht, bestehend aus Beobachtung, Überprüfung und Berichtigung als Stadien ihres Ablaufs. ${ }^{904}$ Auch Alexander Thiele ist so verfahren. ${ }^{905}$ Ich übernehme diese Überlegung, gehe dabei aber davon aus, dass die hier interessierenden Mechanismen im Grundsatz das Durchlaufen aller drei Stufen ermöglichen und dass es eine Abweichung von Grundmodell darstellt, wenn dies nicht der Fall ist.

c. Zwischenergebnis und Rückführung dieser Literatur auf den deutschen Begriff der Bundesaufsicht

Resümierend zeigt sich zunächst, dass der Begriff der Aufsicht für das Unionsrecht durchaus bekannt und in vielen Kontexten Anwendung gefunden hat, darunter unstreitig in der Hierarchiebeziehung Union-Mitgliedstaaten und für das Vertragsverletzungsverfahren. Das ficht sehr für seine

899 Meike Eekhoff, Die Verbundaufsicht, S. 5.

900 Meike Eekhoff, Die Verbundaufsicht, S. 5-6.

901 Meike Eekhoff, Die Verbundaufsicht, S. 7.

902 Wolfgang Kahl, Die Staatsaufsicht, S. 565-568. Kahl betont überdies, zu Recht, S. 565, das Prozesshafte der Aufsicht.

903 Bei Triepel entfällt die Überprüfungsphase, dazu auch Alexander Thiele, Finanzaufsicht, S.13; wie bei Triepel auch Jochen Frowein, Die selbständige Bundesaufsicht nach dem Grundgesetz, S. 17-18, weiter bei Thomas Pforr, Die allgemeine Unionsaufsicht, S. $31 \mathrm{ff}$.

904 Meike Eekhoff, Die Verbundaufsicht, S. 112 und ff.

905 Sehr eingängig Alexander Thiele, Finanzaufsicht, S. 12-18. 
Nutzbarkeit, im Übrigen ebenso die Beobachtung, dass der Begriff auf zahlreiche, unterschiedlich gelagerte, Mechanismen anwendbar ist.

Nicht deutschsprachige Arbeiten greifen für den Aufsichtsbegriff aber häufig auf keine weitere dogmatische Grundlage zurück, noch scheinen diese aus dem nationalen Rahmen überhaupt bekannt. Es ist bei deutschsprachigen unionsrechtlichen Arbeiten, wie der von Eekhoff, die das Vertragsverletzungsverfahren ausklammert, ${ }^{906}$ wie auch bei anderen Arbeiten, die sich wie bei Emanuel Ionescu ihm spezifisch widmen, ${ }^{907}$ eine Konstante, dass all diese Arbeiten den zugrunde gelegten Rechtsbegriff auf die bereits genannte Arbeit Triepels zurückführen. Das gilt schließlich auch für zwei Arbeiten, die den Begriff der Aufsicht speziell für das Verfahren des Art. 7 EUV genutzt haben, die Arbeiten von Pforr zur „Allgemeinen Unionsaufsicht“ und diejenige Kassners zur „Unionsaufsicht“.

Für Pforr dient die „Grundstruktur“ der bei Triepel herausgearbeiteten Aufsicht für die Ableitung der Funktionsgrundsätze dieses Verfahrens, dazu wird auch ausdrücklich geprüft, inwieweit ein Begriff des nationalen Rechts auf das Unionsrecht übertragbar sei. ${ }^{908}$ Kassner ist fast identisch vorgegangen. ${ }^{909}$

Dabei gilt die Übernahme des aus dem deutschen Staatsrecht stammenden Aufsichtsbegriffs seit langem als unproblematisch. Insbesondere Pforr meint, für die Übertragung ${ }^{910}$ des Aufsichtsbegriffs vom Bundesstaats- auf

906 Zum Zuschnitt auf andere Verfahren dort vgl. insb. Meike Eekhoff, Die Verbundaufsicht, S. 6, S. 170, S. 235.

907 Emanuel C. Ionescu, Innerstaatliche Wirkungen des Vertragsverletzungsverfahrens: Die Aufsichtsklage im föderalen Gefüge der Europäischen Union, Mohr Siebeck, Tübingen, 2016, S. 61-62, weitere Nachweise zur Nutzung des Unionsaufsichtsbegriffs dort insb. bei Fn.215. Bei Ionescu dient Triepels Reichsaufsichtsbegriff als Grundlage für die Identifizierung eines „föderalen Hierarchieprinzips" im Unionsrecht, der „Unionsaufsicht“, dessen „Kernbestandteil“ für die „föderale Streitschlichtung zwischen [...] Union und [...] Mitgliedstaaten" das Vertragsverletzungsverfahren sei. In diesem Sinne zum Vertragsverletzungsverfahren auch Wolfgang Kahl, Die Staatsaufsicht, S. 399. S. auch die zuvor zitierten Arbeiten, insbesondere Manfred Zuleeg, „Die Kompetenzen der Europäischen Gemeinschaften gegenüber den Mitgliedstaaten“, in: Jahrbuch des öffentlichen Rechts der Gegenwart N.F. 20 (1971), S. 1-64., S. 52-53.

908 Thomas Pforr, Die allgemeine Unionsaufsicht, S. $29 \mathrm{ff}$.

909 Ulrike Kassner, Die Unionsaufsicht, S. 32 ff.

910 Zur ganzen Komplexität dieses Vorgangs vergleiche den Streit zwischen Watson und Legrand: Pierre Legrand, „The Impossibility of Legal Transplants“, in: Maastricht Journal of European and Comparative Law 4 (1997), S. 111-124; Alan Watson, „Legal Transplants and European Private Law”, in: Ius Commune Lectures on European Private Law, 2, Maastricht, 2000, o.S. 
das Unionsbundesrecht sei ausreichend, dass die Grundstrukturen, trotz einiger Unterschiede der mit ihm assoziierten Verfahren, vergleichbar seien. ${ }^{911}$ Auch Ipsen stützt diese Überlegung auf den EWG-Vertrag. Ipsen hält zwar den Wortlaut der Verträge für nicht aussagekräftig genug, um bereits deswegen von einem Rechtsbegriff der Aufsicht im dortigen Gemeinschaftsrecht auszugehen, sieht aber seine Übertragung insbesondere aufgrund der Existenz des Vertragsverletzungsverfahrens für geboten an und folgert:

„Das überlieferte deutsche Institut der Reichs- und Bundesaufsicht liefert Anschauungsmaterial für den Charakter der Aufsichtsgewalt, Gegenstand und Maßstab der Beaufsichtigung, ihren sachlichen Bereich, ihre Maßstäbe und Mittel, ihre Organe, Ausübung, Sanktionierung und Kontrolle. Von diesen Elementen, die sich aus dem staatlichen Charakter des Bundes und seiner Strukturierung ergeben, stehen für eine Aufsicht innerhalb der Gemeinschaft nur solche in Frage, die der Rechtsgestalt der EG und der Stellung der Staaten in ihr adäquat sind. "912

Dass die Begriffsübernahme dabei letztlich auch bedeutet, auf eine Monographie zurückzugreifen, die 1917 zur Verfassung des damaligen Kaiserreichs erschienen ist, ist gute 100 Jahre später nicht nur Zeugnis eines tragfähigen Begriffs, sondern auch von Kritik nicht frei. Kahl insbesondere hat, nicht zuletzt in der Absicht, den Aufsichtsbegriff auf ein „zeitgemäßeres Fundament zu stellen“, ${ }^{913}$ befunden, dass die „ganz außergewöhnliche Dominanz eines Buches aus der Zeit des Kaiserreichs" vorrangig "Ausdruck der Rückwärtsgewandtheit" sei. .14

Die vorliegende Arbeit kommt aber aus drei Gründen ebenso an Triepels Bundes- bzw. Reichsaufsichtsbegriff nicht vorbei und das, obwohl ich hier in Anlehnung an Eekhoff bereits einer Modifizierung seiner Überlegungen folge. Erstens, aus bloßer Pfadabhängigkeit in der Rechts-

911 Ausführlich Thomas Pforr, Die allgemeine Unionsaufsicht, S. $28 \mathrm{ff}$.

912 Hans Peter Ipsen, „Über Verfassungs-Homogenität in der Europäischen Gemeinschaft“, in: Maurer (Hrsg.), Das akzeptierte Grundgesetz: Festschrift für Günter Dürig zum 70. Geburtstag, C.H. Beck, München, 1990, S. 159-182, S. 180.

913 S. später auch die Ausführungen bei Wolfgang Kahl, Die Staatsaufsicht, S. 15, m. W. N.

914 Umfassende weitere Literatur zu Triepel ebendort, Wolfgang Kahl, Die Staatsaufsicht, S. 3 und 4 bei Fn. 20 und 21-23. 
wissenschaft, was nicht unbedingt disqualifiziert, ${ }^{915}$ zweitens, weil Triepel eine bestechend überzeugende Typik verschiedener Bundesaufsichtsformen vorgelegt hat und drittens, weil der Begriff der Verfassungsaufsicht, auf den es mir ankommt, sich aus der Triepelschen Logik entwickelt hat, was seine Adaption zwingend erfordert.

Nachfolgend geht es mir nicht darum, Triepels Arbeit zu exzerpieren. Es müssen aber drei weitere Punkte ausgeführt werden. Erstens, welche Typik er entwickelt hat, zweitens, warum der in der Vergangenheit gerade bei Pforr und Kassner entwickelte Begriff der (Allgemeinen) Unionsaufsicht nicht mehr ausreicht, und drittens, was dann unter dem Begriff der Verfassungsaufsicht zu verstehen ist, welche Wurzeln er hat, welche Gefahren er mit sich bringt, vor allem aber, welche entscheidenden explikatorischen Vorzüge er genießt.

2. Bundesaufsicht und Verfassungsaufsicht in der deutschen Rechtswissenschaft

Triepels 1917 erschienene Arbeit zur Reichsaufsicht ist sowohl eine Studie zur damaligen Verfassung als auch das Vorhaben, das Verständnis des Begriffs grundlegend zu klären. Ausgangspunkt hierfür ist die, unter Ausarbeitung der für spätere Studien prägenden „Beobachtungs“- und einer „Berichtigungsfunktion“ der Aufsicht, ${ }^{916}$ eine Definition der Staatsaufsicht. Er fasst sie als

„die Gesamtheit staatlicher Handlungen, die zum Zwecke haben, das Verhalten der dem Staate Unterstellten in Übereinstimmung mit einem feststehenden Richtmaß zu setzen oder zu erhalten. “917

Es ist ersichtlich, dass hier alle dem Staat Unterstellten gemeint sind. Diese Definition ist später, namentlich bei Kahl, modifiziert worden. ${ }^{918}$

915 Zur Funktion ebendieser vgl. insb. Jakob Hohnerlein, „Rechtliche Pfadabhängigkeiten als Legitimations- und Verfassungsproblem“"in: Eva Ellen Wagner, u.a. (Hrsg.), Pfadabhängigkeit hoheitlicher Ordnungsmodelle: 56. Assistententagung Öffentliches Recht, Nomos/Helbing-Lichtenhahn, Baden-Baden/Basel, 2016, S. 133-154.

916 Heinrich Triepel, Die Reichsaufsicht, S. 120.

917 Heinrich Triepel, Die Reichsaufsicht, S. 121.

918 Wolfgang Kahl, Die Staatsaufsicht, S. 528: „Staatsaufsicht ist die im Rahmen eines Rechtsverhältnisses erfolgende, als gestuftes Verfahren $\mathrm{zu}$ begreifende Verwaltungstätigkeit von Staatsbehörden, die darauf abzielt, im öffentlichen 
Die Staatsaufsicht unterliegt bei Triepel zunächst einigen, für weitere Aufsichtsformen gültigen, Funktionsgrundsätzen. Dazu zählt, dass die gesetzgebende Gewalt keine solche Aufsicht ausüben kann, ${ }^{919}$ sondern sie zu gleichen Teilen Rechtsprechung und vollziehender Gewalt zukommt, und dass die Aufsichtsermächtigung nicht identisch mit einer allgemeinen Weisungsbefugnis ist. ${ }^{920}$ Ersteres wird für die Union später zu hinterfragen sein. In dieser Form ist die Aufsicht aber immer noch nicht föderal, sondern eigentlich deckungsgleich insbesondere mit der französischen tutelle, die Triepel gekannt haben muss, ${ }^{921}$ also zentralstaatlich gedacht.

Um den Begriff einzugrenzen, trennt Triepel andere staatsinterne Aufsichtsformen ab. ${ }^{922}$ Auch andere Aufsichtsformen, ${ }^{923}$ wie die Aufsicht des Staates über Private, insbesondere im Wirtschaftsleben, die staatliche Aufsicht über Gemeinden, die Rechts- und Fachaufsicht als Doppelinstitut innerhalb einer behördenübergreifenden Verwaltungshierarchie, die behördeninterne Dienstaufsicht oder auch insbesondere die Aufsicht zwischen Staatsorganen, vorrangig die Frage einer Kontrollbefugnis des Parlaments gegenüber der Exekutive stehen nicht im Fokus seiner Untersuchung. Was bleibt, ist also allein die Aufsicht innerhalb einer Hierarchie staatlicher Stellen, die mit der Ausübung öffentlicher Gewalt beauftragt sind. Das ist für weitere Überlegungen mitzunehmen.

In einem zweiten Schritt trennt Triepel von der Staatsaufsicht die sog. Reichsaufsicht ab. Die Staatsaufsicht, und damit die zu ihr erarbeitete o.g. berühmte Definition Triepels, ist also nicht identisch mit der bei Triepel den Titel vorgebenden Reichsaufsicht. ${ }^{924}$ Bei Triepel besteht zunächst eine

Interesse die Funktionsfähigkeit grundsätzlich koordinierter verselbständigter Verwaltungseinheiten durch Schutz, Förderung und Vermittlung zu sichern sowie das Verhalten der verselbständigten Verwaltungseinheiten in kooperativpartnerschaftlichem Geist zu beobachten, auf seine Vereinbarkeit mit einem vorgegebenen Richtmaß hin zu überprüfen und erforderlichenfalls zu berichtigen."

919 Dabei wird die Kontrollbefugnis des Parlaments nicht negiert, aber unter dem Begriff der „Verfassungskontrolle“ ausgegliedert, Triepel, Die Reichsaufsicht, S. 148.

920 Heinrich Triepel, Die Reichsaufsicht, S. 127 ff., 140.

921 Ausdrücklich ist für Triepel die Aufsicht im „Einheitsstaat“ der Ausgangspunkt seiner Beobachtungen, s. Heinrich Triepel, Die Reichsaufsicht, S. 145.

922 Heinrich Triepel, Die Reichsaufsicht, S. 147.

923 S. bereits bei Jochen Frowein, Die selbständige Bundesaufsicht nach dem Grundgesetz, S. 17, Heinrich Triepel, Die Reichsaufsicht, S. $160 \mathrm{ff}$.

924 Das verdient der Betonung, denn es bleibt häufig unklar. Richtig differenziert, aber die Unterschiede nicht wiederholend, etwa bei Thomas Pforr, Die allgemeine Unionsaufsicht, S. 31, Wolfgang Kahl, Die Staatsaufsicht, S. 174-176. 
Linie vom dort vorrangig rechtshistorisch interessierenden und häufig amorphen Konzept der „Oberaufsicht" des Alten Reichs zur „staatlichen Beaufsichtigung" (Staatsaufsicht). ${ }^{925}$ Allein für diese hatte Triepel die o.g. Definition erarbeitet. ${ }^{926}$ Das ist nicht immer erkannt worden, Ernst Forsthoff etwa hat beide Begriffe verwechselt. ${ }^{927}$ Die Reichsaufsicht ist funktional äquivalent ${ }^{928}$ zur heutigen Bundesaufsicht, ich verwende letzteren Begriff daher vorrangig, da er nicht auf die damalige und überholte Staatsform bezogen ist.

Die Bundesaufsicht ist diejenige Staatsaufsicht, die den Aufsichtsbegriff auf eine föderale Verfassung, zunächst also auf einen Bundesstaat, überträgt. Sie ist bei Triepel verbandsübergreifend, d.h. durch den Staat (Bundesstaat) gegenüber „dem ganzen“ nachrangigen „Verband“ (Gliedstaat) auszuüben. Diese Aufsicht ${ }^{929}$ bezeichnet Triepel ebenso als „Oberaufsicht“ (und fasst den Begriff folglich neu), im Unterschied zur „unmittelbaren Staatsaufsicht" innerhalb des Verbands (einen Begriff der mittelbaren Staatsaufsicht gibt es bei ihm nicht). ${ }^{930}$ Über die Idee der verbandsübergreifenden Aufsicht (Oberaufsicht) gelangt Triepel dann zum auf die föderale Verfassung zugeschnittenen Modell: die Aufsicht des damaligen Reichs (Bundesebene) über die Bundesstaaten. ${ }^{931}$ Sie ist bei Triepel die Reichsaufsicht (Bundesaufsicht) im eigentlichen Sinne.

In einem letzten Schritt differenziert Triepel drei Typen der so als Verbandsaufsicht gefassten Bundesaufsicht, von denen einer hier besondere Relevanz entfaltet, was schließlich erklären wird, warum die Sichtung seines Werkes geboten war.

Der bei Triepel letzte, ${ }^{932}$ heute aber durchaus sehr bedeutende Bundesaufsichtstypus ist die sog. „unparteiische Aufsicht“. Regelmäßig ist Trie-

925 S. bereits zuvor Heinrich Triepel, Die Reichsaufsicht, S. 121 und ff.

926 S. rekapitulierend Heinrich Triepel, Die Reichsaufsicht, S. 124-126, Triepel wiederholt seine Definition entsprechend auf S. 126.

927 Ernst Forsthoff, „Die unmittelbare Reichsaufsicht“, in: Archiv des öffentlichen Rechts 58 (N.F. 19) (1930), S. 61-82, S. 67.

928 S. insb. Jochen Frowein, Die selbständige Bundesaufsicht nach dem Grundgesetz , S. 17; Konzise und m.w.N. auch Eckart Klein, Art. 37 GG, in: Theodor Maunz \& Günter Dürig (Begr./Hrsg.), Grundgesetz-Kommentar, Loseblatt, C.H. Beck, München, 88. EL, Rn. 38 ff. Aus unionsrechtlicher Perspektive auch noch Manfred Zuleeg, „Die Kompetenzen der Europäischen Gemeinschaften gegenüber den Mitgliedstaaten“, S. 52.

929 Übersicht auch bei Wolfgang Kahl, Die Staatsaufsicht, S. 181.

930 Heinrich Triepel, Die Reichsaufsicht, S. 149-151.

931 Später ausdrücklich Heinrich Triepel, Die Reichsaufsicht, S. 163.

932 Heinrich Triepel, Die Reichsaufsicht, S. 453 ff. 
pels System der Bundesaufsicht unter Auslassung dieses Typus ausschließlich auf die beiden verbleibenden Unterscheidungen zurückgefahren worden, ${ }^{933}$ teils und gerade bei Arbeiten zu Art. 7 EUV, ist er schlicht übersehen worden. ${ }^{934} \mathrm{Im}$ Wesentlichen entspricht die unparteiische Aufsicht dem heutigen Bund-Länder-Streit vor dem Bundesverfassungsgericht, mit der Besonderheit, dass Triepel sie ohne das damals der Verfassung unbekannte Verfassungsgericht diskutiert, sondern sie beim Bundesrat (in der Form der Verfassung von 1871) verortet.

Die beiden anderen funktional unterscheidbaren, und wie festgehalten, sehr viel „prominenteren“ Typen der Triepelschen Typik sind die der „abbängigen“ und der „selbstständigen“ Reichsaufsicht (Bundesaufsicht). Auf sie kommt Triepel wegen der Ausgestaltung des damaligen Art. 4 RV $1871 \mathrm{zu}$ sprechen. Die Norm unterwarf „der Beaufsichtigung [...] und der Gesetzgebung $[\ldots]$ die nachstehenden Angelegenheiten“.

Aus dieser Formulierung leitet Triepel zunächst ab, dass der Bund jedenfalls dann föderale Verbandsaufsicht in denjenigen Bereichen über die föderierten Glieder (die Länder) ausübt, wenn er Gesetze erlassen hat und diese durch die Länder bereits ausgeführt werden. Art. 84 Abs. 3 und 85 Abs. 3 und 4 des Grundgesetzes haben diese Aufsichtsform übernommen. ${ }^{935}$ Dies ist die sog. abhängige Aufsicht. Bei bundeseigener Ausführung stellt sich die vertikal-föderale Aufsichtsfrage nicht.

Ihr stellt Triepel, wiederum fußend auf der vorgenannten Norm, die sog. selbstständige Aufsicht gegenüber. Hierunter fasst er, dass eine vollumfängliche Verbandskompetenz zur Aufsicht bereits durch die bloße Möglichkeit, d.h. die abstrakte Kompetenz der Bundesebene zur Gesetzgebung ausgelöst wird, ohne dass diese konkret ausgeübt worden sein muss. ${ }^{936}$

Diese Aufsichtsform hat in der deutschen Staatsrechtswissenschaft eine bedeutende Dynamik entwickelt, sowohl für die Weimarer Reichsverfas-

933 Eckart Klein, Art. 37 GG, in: Theodor Maunz \& Günter Dürig (Begr./Hrsg.), Grundgesetz-Kommentar, Loseblatt, C.H. Beck, München, 88. EL, Rn. 38 ff., ähnlich wohl bei Hans Lühmann, „Von der Staatsaufsicht zur Unionsaufsicht?“, in: Deutsches Verwaltungsblatt 114 (1999), S. 752-764, bei Fn. 73.

934 Ulrike Kassner, Die Unionsaufsicht, S. 33, schreibt etwa lediglich: „Nach Triepels Verständnis ist die Aufsicht in zwei verschiedene Formen zu unterteilen: die selbständige und die unselbständige Aufsicht“.

935 Eckart Klein, Art. 37 GG, in: Theodor Maunz \& Günter Dürig (Begr./Hrsg.), Grundgesetz-Kommentar, Loseblatt, C.H. Beck, München, 88. EL, Rn. 38 ff.

936 Heinrich Triepel, Die Reichsaufsicht, S. 355 ff. 
sung allgemein ${ }^{937}$ als auch unter dem Grundgesetz, insbesondere in der Dissertation Jochen Froweins, der darin die Auffassung vertreten hat, u.a. unter Rückgriff auf den soeben bereits genannten Art. 37 GG bestehe sie dort weiter. 938

Für das Unionsrecht ist nie abschließend beantwortet worden, ob es die selbstständige Aufsicht auch dort gibt. Pforr hat das verneint und meint, es „besteht kein unmittelbarer Zusammenhang zwischen der Rechtssetzungsbefugnis der Organe der Union und dem Umfang der Beaufsichtigung nach Art. 7 EU. [....] Der Aufsichtsgegenstand ist zwar in beiden Aufsichtsvarianten (mit-)gliedstaatliches Handeln. Jedoch erfaßt die Aufsicht nach Art. 7 EU dieses komplett.” „Eine weitergehende Differenzierung beispielsweise zwischen selbständiger und unselbständiger Aufsicht nach Art. 7 EU erübrigt sich daher." 939

Ich weiche von letzterer Aussage insoweit ab, als dass die selbstständige Aufsicht doch noch ein weit über die Rechtsetzungsbefugnis der Union, die hier außen vor bleibt, hinausgehendes Nachspiel hat.

Das hängt mit einer Aussage zusammen, die Triepel im Hinblick auf ihren Maßstab und Telos trifft. Er beschränkt den Anwendungsbereich der selbstständigen Aufsicht nämlich nicht auf die bloße Wahrung von Gesetzgebungskompetenzen des Bundes gegenüber den Gliedstaaten im Allgemeinen, sondern überlegt, ob aus entsprechenden allgemeinen Ausführungen nicht eine unter die selbstständige Aufsicht subsumierbare und besonders bedeutende Tätigkeit des Bundes folgt, und zwar der Schutz der Verfassung selbst. Er schreibt dazu an zentraler Stelle:

„[Die selbständige Aufsicht] ist [...] gerichtet auf die Erfüllung der [... Bundes]verfassung selbst, genauer: auf die Erfüllung der verfassungsmäßigen Bundespflicht, die Interessen des [Bundes] oder andere von der [Bundes] verfassung anerkannte Gemeininteressen."940

937 Ernst Forsthoff, „Die unmittelbare Reichsaufsicht“, S. 68, die erste Lesart andeutend.

938 Jochen Frowein, Die selbständige Bundesaufsicht nach dem Grundgesetz, S. $44 \mathrm{f}$., $65 \mathrm{ff}$. Weiterer Streitstand bei Martin Bullinger, „Der Anwendungsbereich der Bundesaufsicht", in: Archiv des öffentlichen Rechts N.F. 44 (1958), S. 279-308, insb. S. 297; Klaus Vogel, „Selbständige Bundesaufsicht“ nach dem Grundgesetz, besonders bei der Anwendung europäischen Rechts“, in: Joachim Burmeister (Hrsg.), Verfassungsstaatlichkeit: Festschrift für Klaus Stern zum 65. Geburtstag, C.H. Beck, München, 1997, S. 819-829, S. 824.

939 Thomas Pforr, Die allgemeine Unionsaufsicht, S. 34.

940 Heinrich Triepel, Die Reichsaufsicht, S. 451, Würdigung bei Jochen Frowein, Die selbständige Bundesaufsicht nach dem Grundgesetz, S. 26. 
Damit lässt sich die selbständige Bundesaufsicht auf die Aussage zuspitzen, dass es bei dieser föderalen Verbandsaufsicht um nichts weniger geht als den Schutz der Bundesverfassung für alle föderalen Verfassungen.

Verschiedentlich haben spätere Verfasser das Potential und das Gewicht dieser Aussage aufbereitet. Zu unterscheiden sind zwei Lesarten.

Die erste Lesart ist diejenige Froweins. Frowein hat dieses Triepelsche Telos als Gegenstück zur „Grundpflicht“ aller Gliedstaaten verstanden, zum „Schutz der Verfassung des Bundes“ selbst beizutragen. ${ }^{941}$ Damit ist die so gesehene selbständige Aufsicht, sowohl was den Gegenstand, den Maßstab, die Verfahren, die Beaufsichtigten und die Mittel angeht, allgemein und weit. Frowein fasst darunter mehrere getrennte Verfahren, auch und nicht unwidersprochen ${ }^{942}$ - die Bundesexekution gem. Art. 37 GG als „schärfste Form“ dieser Aufsicht ${ }^{943}$ sowie weiter Art. 91 GG. ${ }^{944}$

Froweins Lesart der selbständigen Bundesaufsicht steht aber eine weitere zur Seite, die Maßstab und Telos derselben sehr viel enger fasst. Dies ist nun die sog. Verfassungsaufsicht, die Johannes Heckel 1933 in einer Urteilsanmerkung zum berüchtigten letzten Urteil des Staatsgerichtshofs der Weimarer Republik in dem Rechtsstreit „Preußen contra Reich“ vorgelegt hat. ${ }^{945}$ Heckel nutzte diese Urteilsanmerkung nicht nur zu einer profunden Kritik am Ausgang des Verfahrens, sondern vor allem zur Entwicklung des Verfassungsaufsichtsbegriffs als Rechtsbegriff zur Lösung besonders schwerer Verfassungskrisen. Frowein hat im Grundsatz Heckels Vorschlag bereits selbst anerkannt, wenn er auch der Unterscheidung später keine Bedeutung beigemessen hat und die Untersuchung von Heckels Vorschlag recht schnell beendet. ${ }^{946}$ Bei Kahl ist die eingehende Diskussion des Umstands, dass Triepel eine derartige Verfassungsschutzfunktion in

941 Jochen Frowein, Die selbständige Bundesaufsicht nach dem Grundgesetz, S. 40-41, auch zum Zitat.

942 S. sehr eingängig Eckart Klein, Art. 37 GG, in: Theodor Maunz \& Günter Dürig (Begr./Hrsg.), Grundgesetz-Kommentar, Loseblatt, C.H. Beck, München, 88. EL, Rn. 34 ff., 38 ff. insbesondere.

943 Jochen Frowein, Die selbständige Bundesaufsicht nach dem Grundgesetz, S. 44.

944 Jochen Frowein, Die selbständige Bundesaufsicht nach dem Grundgesetz, S. 47.

945 Johannes Heckel, „Das Urteil des Staatsgerichtshofs vom 25.10.1932 in dem Verfassungsstreit Reich-Preußen“.

946 Jochen Frowein, Die selbständige Bundesaufsicht nach dem Grundgesetz, S. 50-51. 
seinem selbstständigen Aufsichtsbegriff angelegt hatte und die spätere Diskussion hierzu, insbesondere bei Heckel, entfallen. ${ }^{947}$

Der Wille, sich überhaupt hier mit dem Begriff der Verfassungsaufsicht zu beschäftigen, bedingt die Annahme, dass die Union eine Verfassung hat, ähnlich wie zuvor die Bejahung ihres föderalen Charakters. Wie dort möchte ich diese Debatte nicht vertiefen, sondern für weiteres insbesondere auf Zuleeg verweisen, der für die Existenz einer Verfassung im Unionsrecht sogar von einem „Faktum“ gesprochen hat; von Bogdandy und Bast sind zum gleichen Ergebnis gelangt. ${ }^{948}$ Für den Fall, dass man dies als Nachweis nicht ausreichen lässt, kann nochmals insbesondere auf das Les Verts-Urteil des Europäischen Gerichtshofs verwiesen werden, ${ }^{949}$ in welchem der EuGH nicht den Begriff der „Rechtsgemeinschaft" geprägt hat, sondern den EWG-Vertrag auch als „Verfassungsurkunde“ bezeichnete, eine Festlegung, die seitdem in ständiger Rechtsprechung für die Verträge wiederholt worden ist. 950

Die damit grundsätzlich für die Union denkbare Verfassungsaufsicht dieses speziellen Zuschnitts zielt, insbesondere was den Maßstab der Aufsicht angeht, im Gegensatz zu Triepels ursprünglicher selbstständiger Aufsicht als allen Bundesinteressen zugewandter Aufsicht auf einen ganz besonders herausgehobenen, besonders geschützten Verfassungskern. Diese Unterscheidung sieht in der frühen bundesrepublikanischen Aufsichtsliteratur insbesondere Günter Dux. Er schreibt:

947 Wolfgang Kahl, Die Staatsaufsicht, S. 175. Dort heißt es lediglich: „Sie [die selbständige Aufsicht] ist gerichtet auf die Erfüllung der Reichsverfassung“. S. aber sehr wohl S. 244, Fn. 166, dazu auch nochmals im nachfolgenden Abschnitt cc.

948 Manfred Zuleeg, „Die Vorzüge der Europäischen Verfassung“, in: Armin von Bogdandy \& Jürgen Bast (Hrsg.), Europäisches Verfassungsrecht, Springer, Heidelberg/Berlin, 2009, S. 1045-1076, S. 1045 und f.; ebenso Armin von Bogdandy, Jürgen Bast: „Der verfassungsrechtliche Ansatz und das Unionsrecht: Von einem Konstitutionalismus der Verrechtlichung zwischenstaatlicher Beziehungen zu einer liberaldemokratischen Politisierung der EU“, in: Armin von Bogdandy, \& Jürgen Bast (Hrsg.), Europäisches Verfassungsrecht: Theoretische und dogmatische Grundzüge, Springer, Heidelberg, 2. Aufl., 2009, S. 1-9.

949 EuGH, EuGH, Rs. 294/83, Parti écologiste „Les Verts“./. Europäisches Parlament, Urteil vom 23.04.1986, Slg. 1986, 1339, ECLI:EU:C:1986:166, Rn. 23.

950 EuGH, Verb. Rs. C-402/05 P und C-415/05 P, Yassin Abdullah Kadi und Al Barakaat International Foundation ./. Rat, Urteil (GK) vom 03.09.2008, ECLI:EU:C:2008:461, Rn. 281; ausdrücklich für alle "Gründungsverträge" s. Rs. C-621/18, Andy Wightman u.a. ./. Secretary of State for Exiting the European Union, Urteil (Plenum) vom 10.12.2018, ECLI:EU:C:2018:999, Rn. 44. 
„Heckel versteht unter der Verfassungsaufsicht nur die Aufsicht, die eingreift, wenn Fortbestand oder Untergang der bundesstaatlichen Ordnung insgesamt oder doch in ihren derzeitigen wesentlichen Grundzügen infolge der Pflichtverletzung durch ein Land infrage steht. “951

Die Verfassungsaufsicht ist für Heckel in seinen eigenen Worten, wiederum teleologisch, wie folgt definiert:

„Das Ziel der Verfassungsaufsicht ist die Abwehr eines spezifisch [...]verfassungsfeindlichen Verhaltens oder einer ebensolchen Lage, also von Gefahren, die das Mark des Verfassungslebens treffen, die den Kern seiner Ordnung ändern oder zerstören. [...] Der Verfassungsaufsieht geht es [...] um die „objektive Geltung der Verfassung“ des [Bundes] in der Verfassungswirklichkeit, um die Rechtsbeständigkeit der Verfassung im ganzen wie ihrer einzelnen Institute und Institutionen, zu denen [...] auch die Länderautonomie gehört. Ob die Verfassungsfeindlichkeit aus der gefährlichen Intention des Pflichtsubjekts der Verfassungsaufsicht oder nur aus der objektiven Gefährlichkeit eines Verhaltens zu entnehmen ist, ist unerheblich. ${ }^{\text {“952 }}$

Heckel stützt diese Aussage auf Ausführungen von Albert Hänel, der den Begriff selbst aber nicht kennt. ${ }^{953}$

Dabei ist Heckels Aufsatz, neben den bereits zitierten Arbeiten etwa von Frowein und Dux, auch unter dem Grundgesetz der Bundesrepublik von Beachtung gewesen, häufig allerdings erstaunlich kryptisch. Klaus Vogel schreibt, Peter Lerche zitierend: „der von J. Heckel mit spezifischer Farbe

951 Günter Dux, Bundesrat und Bundesaufsicht, Duncker \& Humblot, Berlin 1963, S. 17. Dux unterscheidet dieses Verständnis dort auch ausdrücklich von der Interpretation Froweins.

952 Johannes Heckel, „Das Urteil des Staatsgerichtshofs vom 25.10.1932 in dem Verfassungsstreit Reich-Preußen“, S. 217-218.

953 Nämlich auf Albert Hänel, Deutsches Staatsrecht, Duncker \& Humblot, Leipzig, 1892, S. 567 ff. Hänel spricht aber, abweichend von Heckels Formulierung, S. 568 von der „Anerkennung der Geltung einer Verfassung oder Verfassungsbestimmung“, die zugleich in jedem Verfassungsstreit neben dem konkreten Streitgegenstand zutage trete. Interessant, dort S. 573, wiederum die Idee einer ungeschriebenen Verfassungsgarantie gerade auch in den Einzelstaaten nach damaligem Recht. 
erfüllte Begriff der ,Verfassungsaufsicht"“ habe für das Grundgesetz seinen „Erkenntniswert nicht eingebüßt ““. 954 Was damit gemeint ist, bleibt offen.

Nachfolgend gilt es nun zu klären, welcher Erkenntniswert der von Heckel auf „das Mark der Verfassung“ eines föderalen Gemeinwesens gemünzte Verfassungsaufsichtsbegriff in der unionalen Rechtsstaatlichkeitskrise entfalten kann. Dazu muss zunächst beantwortet werden, ob es Hinweise für die Verwendung im Unionsrecht gibt, sodann, ob die Verwendung des Begriffs zulässig, geboten und möglich ist. Dies soll erfolgen, ohne bereits im Einzelnen auf die angesprochenen Maßnahmen einzugehen.

a. Argumente gegen die Nutzung des Verfassungsaufsichtsbegriffs: alternative Begriffe und Begriffshistorie

Drei Argumente fechten gegen die Nutzung des Verfassungsaufsichtsbegriffs, nämlich (mindestens) zwei alternative Begriffe und schließlich die Begriffsgenese des Verfassungsaufsichtsbegriffs.

aa. (Allgemeine) Unionsaufsicht

Wiederholt hat die Europarechtswissenschaft eigene Ausprägungen des Aufsichtsbegriffs vorgelegt. Besondere Beachtung zu finden hat hier zunächst derjenige der Unionsaufsicht bzw. der Allgemeinen Unionsaufsicht. Er ist von Kassner bzw. Pforr für das Verfahren des Art. 7 EUV vorgelegt worden. Er ist damit, konträr zum Titel, weit spezifischer als der zuvor bereits

954 Klaus Vogel, „Selbständige Bundesaufsicht“ nach dem Grundgesetz“, S. 823 unter Berufung auf Peter Lerche in: Theodor Maunz \& Günter Dürig (Begr./ Hrsg.), Grundgesetz-Kommentar, Art. 84 GG, Rn. 124 ff (zit. ohne Aufl.), noch gleich aber 53. EL 2009, ab Rn. 127. Hinzuzufügen ist, dass Vogel unter Berufung auf Lerche indes sogleich im Anschluss meint, der Begriff sei „nur noch teilweise Schlüssel für das Verständnis der heutigen Verfassungslage“, was die Sache nicht weiter erhellt. Für Lerche fällt, ebda, 53. EL, Rn. 135, der Bundeszwang auch unter den Verfassungsaufsichtsbegriff, dieser könne „aber nicht als eigenständiger grundgesetzlicher Begriff beurteilt werden“. Warum dem so ist, wird nicht deutlich. 
genutzte Begriff der allgemein verstandenen, die Gesamtheit aller Aufsichtsmaßnahmen umfassenden, „Gemeinschafts- bzw. Unionsaufsicht“.955

Pforr trifft, im Hinblick auf dieses Verfahren, zunächst die Feststellung, Art. 7 EUV ermögliche eine Beaufsichtigung der Mitgliedstaaten unabhängig von einer etwaigen Gesetzgebungskompetenz der Union, überhaupt losgelöst von ihren Kompetenzen, sei folglich enorm breit, bis in den ausschließlichen Kompetenzbereich der Mitgliedstaaten erstreckt, allerdings, im Unterschied zu staatlichen Aufsichtsmodellen, in seiner Korrekturphase weit weniger intensiv. ${ }^{956}$ Der Unionsaufsichtsbegriff erstrecke sich im Unterschied zur staatlichen Bundesaufsicht nicht „mit ihrem umfassenden Aufsichtsmaßstab auf einen beschränkten Bereich des gliedstaatlichen Handelns“, sondern „mit ihrem beschränkten Aufsichtsmaßstab auf einen umfassenden Bereich des gliedstaatlichen Handelns“.957 Als „allgemeine“ Unionsaufsicht sei sie darüber zu bezeichnen, weil sie im „allgemeinen Teil" des Unionsrechts verankert sei. ${ }^{958}$ Die Unionsaufsicht sei, da bestehend aus Beobachtungs- und Korrekturfunktion, jedenfalls „echte Aufsicht im Sinne des staatsrechtlichen Aufsichtsbegriffs“. .959

Für Kassner ist die Unionsaufsicht von der aus dem deutschen Recht bekannten Aufsicht in einem föderalen Staatssystem zwar inspiriert, aber eindeutig unterschieden. Sie sei nicht schlicht die Aufsicht, die im EUV angelegt sei, sondern eine spezielle, ausschließlich auf die „Grundsätze“ der Union, d.h. den in Art. 2 EUV genannten Prinzipien, bezogene Aufsicht, die dabei allerdings nicht an die Kompetenzen der Union geknüpft sei. ${ }^{960}$

Der Bezug auf die Grundsätze der Union bringt den Unionsaufsichtsbegriff den Überlegungen, die hinter der Verfassungsaufsicht stehen, schon bedeutend näher. Trotzdem gilt es, den Unionsaufsichtsbegriff aufzugeben und ihn durch denjenigen der Verfassungsaufsicht zu ersetzen.

Die Veranlassung hierzu folgt zunächst aus einer Änderung des Lissabonner Vertrages. Mit ihm wurde nicht nur die Existenz der früheren Gemeinschaften zugunsten einer einheitlichen Union, die ihr Rechtsnachfolger ist, aufgehoben, Art. 1 UAbs. 3 S. 2 EUV, sondern auch der den EGV ablösende AEUV mit dem EUV, dem früheren „Unionsrecht“ für

955 So, gleichsetzend bereits für den Vertrag von Amsterdam, Wolfgang Kahl, Die Staatsaufsicht, S. $399 \mathrm{f}$.

956 Thomas Pforr, Die allgemeine Unionsaufsicht, S. 34-35.

957 Thomas Pforr, Die allgemeine Unionsaufsicht, S. 36.

958 Thomas Pforr, Die allgemeine Unionsaufsicht, S. 37, 229.

959 Thomas Pforr, Die allgemeine Unionsaufsicht, S. 33.

960 Ulrike Kassner, Die Unionsaufsicht, S. 33-34. 
gleichrangig befunden, Art. 1 Abs. 2 S. 2 AEUV und Art. 1 UAbs. 3 S. 2 EUV. Damit ist insbesondere Pforrs Überlegung einer „allgemeinen“ Unionsaufsicht im Unterschied zu einem besonderen Unionsrecht widerlegt. Alles Recht der Union ist einheitlich Unionsrecht.

Es besteht seit 2009 also nur (noch) ein lediglich in den einzelnen Regelungsinhalten, in keinem Fall aber qualitativ oder grundsätzlich funktional getrennter Korpus des Unionsrechts. ${ }^{961}$

Der EUV „überwölbt“ nicht mehr, wie Pforr nach alter Rechtslage dies sieht, den AEUV. ${ }^{962}$ Und auch die bei ihm vorgetragene Idee, spezieller, nämlich nur für Art. 7 EUV, von einer „allgemeinen“ Unionsaufsicht zu sprechen, da sie im vorderen Teil des EUV als dessen „allgemeinen“ Teil geregelt sei, ${ }^{963}$ ist nicht mehr zutreffend. Folglich ist es auch nicht möglich, die im Zuge der Rechtsstaatlichkeitskrise entstandenen oder kontextspezifisch angewandten Mechanismen mit diesem Begriff zu bezeichnen.

Insbesondere die Sonderstellung des Art. 7 EUV zum Schutz desselben ist zugunsten einer Verfahrensvielfalt entfallen. Der EuGH hat diese Überlegung im Verfahren zur Unabhängigkeit des polnischen Obersten Gerichtshofs ausdrücklich anerkannt, als er eine Klage nach Art. 258 AEUV parallel zum anhängigen Verfahren nach Art. 7 EUV für zulässig erachtete. 964

Damit entfällt auch eine früher vermutete zwingende Vorrangstellung bestimmter Verfahren für in ihrer normativen Wirkung besonders bedeutende Vorschriften, wie die Relation Art. 7 EUV und Art. 2 EUV, die bei Kassner für den Begriff so bedeutend war.

Folglich muss jede Aufsicht, die das Unionsrecht regelt und die durch unionale Organe oder nachrangige Einrichtungen durchgeführt oder verantwortet wird, als „Unionsaufsicht“ bezeichnet werden. Der Begriff verliert damit bereits in dieser Kurzform seine Unterscheidungskraft, zwar nicht nach außen etwa zur Staatsaufsicht, aber, und dies ist hier von beson-

961 Zu Zweifeln an einer qualitativen Trennung bereits vor dem Vertrag von Lissabon schon Armin von Bogdandy \& Martin Nettesheim, „Die Verschmelzung der Europäischen Gemeinschaften in der Europäischen Union“, in: Neue Juristische Wochenschrift (1995), S. 2324-2328, insb. S. 2326.

962 Zu beiden Punkten Thomas Pforr, Die allgemeine Unionsaufsicht, S. 37 und 38.

963 Thomas Pforr, Die allgemeine Unionsaufsicht, S. 37.

964 EuGH, Rs. C-619/18 R, Europäische Kommission ./. Polen, „Unabhängigkeit des Obersten Gerichts“, Schlussanträge des Generalanwalts Evgeni Tanchev vom 11.04.2019, insb. bei Fn. 28; s. weiter Urteil (GK) in ders. Rs. vom 24. Juni 2019, in welchem der Gerichtshof diese Ausführungen implizit durch Annahme zur Entscheidung übernommen hat. Hierzu nochmals ausführlich im Teil E. 
derem Interesse, was seine Formen innerhalb des Unionsrechts angeht. Der Begriff der Unionsaufsicht fällt, ganz wie bei Kahl zuvor angelegt, auf die recht konturlose Beschreibung aller Aufsichtsmaßnahmen seitens der Europäischen Union gegenüber den Mitgliedstaaten zurück.

bb. Rechtsstaatlichkeitsaufsicht

Der zweite Aufsichtsbegriff, der in Konkurrenz zum Begriff der Verfassungsaufsicht tritt, ist derjenige der Rechtsstaatlichkeitsaufsicht bzw. des Rechtsstaatlichkeitsaufsichtsverfahrens, der durch von Bogdandy und Ioannidis für den 2014 geschaffenen EU-Rahmen der Kommission vorgeschlagen wurde ${ }^{965}$ und den z.B. Wendel später aufgegriffen hat. ${ }^{966}$ Neben dem Umstand, dass ein Sammelband sich des Begriffs im Titel bedient hat, ${ }^{967}$ hat auch Mark Dawson von einer „EU Rule of Law Oversight“ gesprochen.968 Für ihn ficht, dass er das Schutzgut gerade des EU-Rahmens, wie auch die Operationalisierungsbemühungen seitens der Kommission, die immer vorrangig auf die Rechtsstaatlichkeit und eben im Unterschied zum Parlament nicht auf alle Werte des Katalogs des Art. 2 EUV abgestellt hat, griffig einfängt. Der Begriff bleibt damit grundsätzlich vollumfänglich in der Krise gültig.

Allerdings hat der Verfassungsaufsichtsbegriff gegenüber diesem Begriff den Vorteil, dass er das Telos der Maßnahmen, den Schutz des Verfassungskerns, klar benennt und entwicklungsoffen ist, nämlich zukünftigen Entwicklungen der Krise, in der möglicherweise andere Werte verstärkt in den Vordergrund rücken, flexibel Rechnung tragen kann. Ich ziehe ihn aus beiden Gründen vor.

965 Armin von Bogdandy \& Michael Ioannidis, „Das systemische Defizit“, S. 322.

966 Mattias Wendel, „Rechtsstaatlichkeitsaufsicht und gegenseitiges Vertrauen“, etwa S. 112, 119, indes ohne Erörterung.

967 Carlos Closa \& Dimitry Kochenov (Hrsg.), Reinforcing Rule of Law Oversight in the European Union, Cambridge University Press, Cambridge, 2016. Keines der dort abgedruckten Beispiele hat sich aber soweit ersichtlich mit dem Begriff auseinandergesetzt.

968 Mark Dawson, The Governance of EU Fundamental Rights, S. $144 \mathrm{ff}$. 
cc. Historischer Kontext des Verfassungsaufsichtsbegriffs bei Johannes Heckel

Damit allein ist es aber noch nicht getan, es ist nun auf das schwerwiegendste Argument gegen die Berücksichtigung des Verfassungsaufsichtsbegriffs einzugehen, seine Begriffsgenese. Der Verfassungsaufsichtsbegriff entstammt, wie bereits erwähnt, einem Beitrag des deutschen Staats- und Kirchenrechtlers Johannes Heckel. Er diente Heckel zur Kritik an der Unterwanderung der Weimarer Verfassung. Der Begriff muss folglich hier aus diesem historischen Zusammenhang gelöst werden. Darüber hinaus darf seine Nutzung den weiteren Werdegang seines Urhebers nicht ausblenden.

Wenn Heckel sich auch in der Spätphase der Weimarer Republik mittels dieses Beitrags für ihre Verfassung eingesetzt hat, so ist er aufgrund seiner wissenschaftlichen Tätigkeit zwischen 1933-1945, ungeachtet späterer Rehabilitation (die Carl Schmitt insbesondere nicht gewährt wurde), substantiell vorbelastet, ein Umstand, dessen Einzelheiten insbesondere in der Biographie von Gisela Emling eingehend berücksichtigt worden sind. ${ }^{969}$ Die Urteilsanmerkung, der der Begriff der Verfassungsaufsicht entstammt, ist davon nicht unbeeinträchtigt. Sie enthält problematische Formulierungen, die Emlings These des sich ankündigenden rechtswissenschaftlichen Opportunisten untermauern. ${ }^{970}$

Aus dem Beitrag geht aber nicht eindeutig hervor, ob diese Andeutungen, die nicht ausgeführt werden, ebenso wie die teils sehr bildhafte und vieldeutige Sprache Heckels, bereits Ausdruck echter Überzeugung waren oder nicht der Absicht dienten, einen im Übrigen ausgesprochen kritischen Beitrag noch 1933 in den Druck bringen zu können.

Heckels Beiträge aus der Spätzeit der Weimarer Republik scheinen in der Literatur im Übrigen nur recht wenig berücksichtigt worden zu sein.

969 Gisela Emling, Johannes Heckel: Leben und Wirken (1889 - 1963), Peter Lang, Frankfurt a.M. u.a., 2011.

970 Johannes Heckel, „Das Urteil des Staatsgerichtshofs vom 25.10.1932 in dem Verfassungsstreit Reich-Preußen“, exemplarisch S. 205, problematisch auch S. 212 die Ausführungen zum Begriff der Diktatur; weiter insb. Gisela Emling, Johannes Heckel, S. 199. Zu den gleichwohl beachtlichen Unterscheidungen des Diktaturbegriffs i.R.d. Art. 48 WRV bei Heckel zu denjenigen Carl Schmitts näher Dieter Grimm, „Verfassungserfüllung - Verfassungsbewahrung - Verfassungsauflösung: Positionen der Staatsrechtslehre in der Staatskrise der Weimarer Republik“, in: Heinrich August Winkler (Hrsg.), Die deutsche Staatskrise 1930-1933: Handlungsspielräume und Alternativen, Oldenbourg, München, 1992, S. 183-199, dort insb. S. 193. 
Bei Emling selbst stellten sie keinen Schwerpunkt der Auswertung dar. Michael Stolleis spricht Heckel partiell frei, bleibt aber unschlüssig. Er meint zum einen, speziell zur Urteilsanmerkung, dem der Begriff der Verfassungsaufsicht entstammt, mit dem Aufsatz habe Heckel zu den, wenn auch wohl wenig ruhmreichen, Rechtswissenschaftlern gezählt, die die Weimarer Verfassung ,in modifizierter Form “ hätten bewahren wollen. ${ }^{971}$ Allgemein aber ist Stolleis kritisch, was Emling für zu prononciert hält. ${ }^{972}$ Stolleis hält fest, Heckel habe Carl Schmitt und Carl Bilfinger politisch nahegestanden und deren Linie in der Rechtfertigung der Urteilsfindung im Verfahren Preußen contra Reich gestützt. ${ }^{973}$

Zwei Fragen sind daher aufgeworfen: erstens, ob die späteren biographischen Entwicklungen Heckels den Rekurs auf sein Konzept der Verfassungsaufsicht, zumal für das Recht der Europäischen Union, sperren, und zum zweiten, wie der Begriff aufgrund der damaligen Intentionen des Verfassers heute zu nutzen ist. Die Entscheidungen hierüber darf nicht leichtfertig erfolgen, will der hier gemachte Vorschlag, gerade auBerhalb des deutschen Sprachraums, anschlussfähig bleiben. Hiervon bin ich gleichwohl, auch angesichts der Nutzung des Aufsichtsbegriffs in anderen europäischen Rechtsordnungen, überzeugt. Das Schicksal einer wechselhaften Geschichte teilt er mit vielen großen Rechtsbegriffen. Der Verfassungsaufsichtsbegriff lässt sich von seinem Entstehungskontext lösen. Dann steht er dichotom insbesondere zu Schmitts Absichten, dann ist er normativ eindeutig positioniert, rechtswissenschaftlich abgesichert, praktisch sofort nutzbar und darüber hinaus eine ideale Ausprägung des Aufsichtsbegriffs für die unionale Rechtsstaatlichkeitskrise. Hierfür fechten mehrere Überlegungen.

Eine Antwort auf die Frage der Rezeption von Rechtsbegriffen kontextuell problematischer Verfasser der deutschen Rechtswissenschaft und ihrer Rechtsbegriffe, gerade für das Unionsrecht, haben Armin von Bogdandy und Stephan Hinghofer-Szalkay geliefert, als sie sich mit der Frage der Nutzbarkeit des Begriffs des „Ius (Jus) Publicum Europaeum“ befasst haben, der in der Literatur des 20. Jahrhunderts vorrangig durch Carl Schmitt geprägt worden ist, und dem sie deswegen auch das Prädikat „etwas unheim-

971 Michael Stolleis, Geschichte des öffentlichen Rechts in Deutschland, Dritter Band: 1914-1945, C.H. Beck, München 1999, S. 123, bei Fn. 286.

972 Gisela Emling, Johannes Heckel, S. 69. Heckel habe keinesfalls zu den stärksten Kritikern des Urteils gezählt.

973 Dazu Michael Stolleis, Geschichte des öffentlichen Rechts in Deutschland, Dritter Band, S. 121-122, kritisch auch S. 121 insb., weiter S. 302, weiter auch Gisela Emling, Johannes Heckel, S. 69. 
lich" verleihen. ${ }^{974}$ Sie bescheinigen der Nutzung dort eine tendenziöse Umprägung des Begriffs durch Schmitt. ${ }^{975}$ Dessen ungeachtet zeigen beide Verfasser vor dem Hintergrund der Wirkmächtigkeit des Begriffs, dass ein der Schmittschen Logik diametral entgegengesetztes Verständnis des Begriffs des Ius Publicum Europaeum und darauf aufbauend des europäischen Rechtsraums möglich ist. ${ }^{976}$ Ich möchte hieran anknüpfen, was den Begriff der Verfassungsaufsicht angeht. Insbesondere die Wirkung und die Prägnanz des Begriffes scheinen mir dabei größte Vorzüge zu haben.

Dabei ist zunächst festzuhalten, dass die bei von Bogdandy und Hinghofer-Szalkay mit großem Aufwand betriebene Inbezugsetzung des Schmittschen Begriffs mit seinem weiteren Werk nach den für Heckel zur Verfügung stehenden Quellen für den Begriff der Verfassungsaufsicht entfällt. Insbesondere haben weder seine Biographin, ${ }^{977}$ die das Gesamtwerk, noch Stolleis, der Teile der Veröffentlichungen Heckels berücksichtigt hat, ${ }^{978}$ für spätere Publikationen eine erneute Verwendung des Begriffs nachgewiesen, obwohl Heckel nach seiner Rehabilitierung auch in der Bundesrepublik tätig gewesen ist. ${ }^{979}$ Der Begriff ist nur einmal verwendet worden, er steht vom späteren Werk getrennt und wird von ihm nicht in Mitleidenschaft gezogen. Damit ist er zunächst allein aus der zitierten Urteilsanmerkung schöpfend zu bewerten.

974 Armin von Bogdandy \& Stephan Hinghofer-Szalkay, „Das etwas unheimliche Ius Publicum Europaeum: Begriffsgeschichtliche Analysen im Spannungsfeld von europäischem Rechtsraum, droit public de l'Europe und Carl Schmitt“, in: Zeitschrift für ausländisches öffentliches Recht und Völkerrecht 73 (2013), S. 209-248.

975 Armin von Bogdandy \& Stephan Hinghofer-Szalkay, „Das etwas unheimliche Ius Publicum Europaeum“, S. 237-238 insb.

976 Armin von Bogdandy \& Stephan Hinghofer-Szalkay, „Das etwas unheimliche Ius Publicum Europaeum“, S. 245-246. Dessen ungeachtet sehr kritisch die Würdigung des Begriffs bei Wolfgang Kahl, „Dogmatik im EU-Recht“, S. 171, Fn. 66.

977 Gisela Emling, Johannes Heckel, dort nämlich allein bei S. 67-69 für den hier betrachteten Beitrag.

978 Michael Stolleis, Geschichte des öffentlichen Rechts in Deutschland, Dritter Band, insb. bei S. 302, 317, später Michael Stolleis, Geschichte des öffentlichen Rechts in Deutschland: Vierter Band: Staats- und Verwaltungsrechtswissenschaft in West und Ost (C.H. Beck 2012), S. 64, 346.

979 Dazu Gisela Emling, Johannes Heckel, S. 201, weiter auch Michael Stolleis, „Geschichte des öffentlichen Rechts in Deutschland: Vierter Band: Staats- und Verwaltungsrechtswissenschaft in West und Ost“, C.H. Beck, München, 2012, S. 64. In dieser Rehabilitierung liegt nicht zuletzt ein zentraler Unterschied zu Schmitt. 
Aus dieser folgt, was die hier entscheidenden Teile angeht, ein, wenn auch verklausuliertes und nicht ungetrübtes Bekenntnis ${ }^{980}$ zur Weimarer Verfassung, aus dem die Überlegung entnommen werden kann, dass, wer den Begriff der Verfassungsaufsicht nutzt, sich für den Bestand des Verfassungskerns einer föderalen, demokratischen und rechtsstaatlichen Verfassung einsetzt. Bedeutende Unterstützung erfährt diese These der Verteidigung einer derartigen Ordnung durch den Verfassungsaufsichtsbegriff bereits bei Heckel auch durch Kahl. Er setzt sich zwar mit dem Begriff selbst nicht auseinander, weist aber, in Widerspruch zu Stolleis, nach, wie scharf Schmitt den Begriff angriff. ${ }^{981}$ Das spricht sehr dafür, dass Heckel mit dem Verfassungsaufsichtsbegriff einen höchst wirksamen Vorschlag gegen autoritäre Bestrebungen in föderalen Verfassungen vorgelegt hat, dessen Brisanz deren „Kronjuristen“ so offenkundig war, dass er mit aller Kraft versuchte, den Begriff der Verfassungsaufsicht zu diskreditieren.

Zum zweiten bindet die Übernahme eines Begriffs den Rezipienten nicht an alle Erwägungen seines Urhebers. Es geht mir allein darum, die funktionalen Vorzüge des Verfassungsaufsichtsbegriffs stark zu machen und aus seinem historischen Kontext herauszulösen. Es muss betont werden, dass seine primäre Quelle, der vorgenannte Aufsatz Heckels, rechtspolitisch problematische Passagen enthält, die als querstehend zur hier herausgearbeiteten Begriffsintention gerade des Schutzes einer freiheitlichdemokratischen Grundordnung verstanden werden können und die ich mir ausdrücklich nicht zu eigen mache.

Drittens aber ist gerade dieser Vorgang der Begriffsrezeption für jüngere Verfassungen bereits an anderer Stelle erfolgt. Das halte ich für ganz entscheidend. Der Begriff der Verfassungsaufsicht ist in der Nachkriegs-

980 Problematisch zwar etwa Johannes Heckel, „Das Urteil des Staatsgerichtshofs vom 25.10.1932 in dem Verfassungsstreit Reich-Preußen“, S. 200, Punkt 7 zur möglichen Rechtfertigung des Urteils; sehr kritisch zum Urteil im Übrigen aber ebda., S. 201; der Weimarer Staatsgerichtshof, so Heckel, habe sein Urteil auf „eine zu schmale staatsrechtliche Basis gestellt“; s. weiter S. 189-190, auch S. 185, wonach der Staatsgerichtshof erheblich über die Grenzen des Vertretbaren hinausgehe und damit das Urteil für unvertretbar gefunden wird, sodann S. 190 das Zitat, wonach „[d]er Atomzertrümmerung der deutschen Reichsverfassung mit Hilfe der Diktatur [...] damit ein weiterer Erfolg gelungen“ sei, weiter S. 186 für die offene Sorge um den Fortbestand des deutschen Föderalismus.

981 Wolfgang Kahl, Die Staatsaufsicht, S. 244, Fn. 166, wonach Schmitt im Verfassungsaufsichtsbegriff den „äußerste[n] Grad der Zerstörung politischen Führertums“ gesehen habe. Dieter Grimm, „Verfassungserfüllung - Verfassungsbewahrung - Verfassungsauflösung“, S. 193, trennt Heckels Absichten, wenn auch nach einigem Zögern, ebenso von denjenigen Schmitts. 
zeit durch zahlreiche Verfasser, die sich in ihrem Wirken eindeutig für die Verfassungsordnung des Grundgesetzes und die europäische Einigung verwandt haben, genutzt und dadurch nicht nur rehabilitiert, sondern im Unionsrecht erst wirklich etabliert worden. Auf die legitimierende Natur dieser Beiträge, die den Begriff teils ausdrücklich, teils jedenfalls mutmaßlich in Kenntnis des Heckelschen Ursprungs genutzt haben, stütze ich mich daher hier ganz vorrangig. Frowein macht für das Unionsrecht wohl den Anfang. ${ }^{982}$ Schorkopf hat den Aufsichtsbegriff ohne weiteren Zusatz speziell für die Rechtsstaatlichkeitskrise aufgegriffen und vor dem Hintergrund der im Rahmen der Krise durch die Kommission geschaffenen Mechanismen den Begriff einer „Kommissionsaufsicht“ in die Debatte eingebracht. ${ }^{983}$ Der Begriff der Verfassungsaufsicht, speziell für die hier untersuchten Instrumente, findet sich schließlich insbesondere bei Thomas Giegerich, aber auch bei Zuleeg, der davon spricht, dass Art. 7 EUV „eine Art Verfassungsaufsicht“ einführe. ${ }^{984}$ Giegerich spricht davon, ${ }^{985}$ die Verfassungsaufsicht sei eine Verstärkung der Aufsicht seitens der Kommission über die Mitgliedstaaten, sie sei politisiert, an Effektivitätsgesichtspunkten zu messen und scheint sie mit dem Begriff Rechtsstaatlichkeitsaufsicht zumindest in der aktuellen Situation gleichzusetzen. Weder Zuleeg noch Giegerich erläutern aber den Begriff. Das ist kein Nachteil, bietet es doch hier die Gelegenheit einer Ergänzung.

982 Jochen Abr. Frowein, „Die rechtliche Bedeutung des Verfassungsprinzips der parlamentarischen Demokratie für den europäischen Integrationsprozeß“, S. 314: Art. 224 und 225 EWGV (die Vorläufer der heutigen Art. 347 und 348 AEUV) seien „selbständige[...] Aufsicht im Sinne der Verfassungsaufsicht“.

983 Frank Schorkopf, „Wertesicherung in der Europäischen Union. Prävention, Quarantäne und Aufsicht als Bausteine eines Rechts der Verfassungskrise?", in: Europarecht (2016), S.147-164, S.160, durchaus kritisch konnotiert, die Kommission greife einzelne Mitgliedstaaten deutlich sichtbar heraus. S. weiter auch bei Jörg Luther, „Die Verfassung in Zeiten des ,Übergangs': Italienische Betrachtungen“, in: Jahrbuch des öffentlichen Rechts der Gegenwart N.F. 1950 (2002), S. 331-360, S. 331.

984 Manfred Zuleeg, „Die föderativen Grundsätze der Europäischen Union“, in: Neue Juristische Wochenschrift (2000), S. 2846-2851, S. 2850.

985 Thomas Giegerich, „Verfassungshomogenität, Verfassungsautonomie und Verfassungsaufsicht in der EU“, S. 499-542, insb. S. 523, 528, 542, Giegerich führt den Begriff aber nicht aus. 
b. Argumente für die Nutzung des Verfassungsaufsichtsbegriffs

Zwei Argumente sprechen schließlich, nun da Einwände ausgeräumt sind, entscheidend für die Nutzung des Verfassungsaufsichtsbegriffs zur Verklammerung der hier untersuchten Mechanismen.

aa. Beendigung der Debatte um den Unionsnotstand

Das erste Argument ist, dass sich darüber eine Diskussion des Notstandsbegriffs erledigt. Damit soll hier nicht Stellung bezogen werden zum Vorwurf von Stolleis, dass Heckels Beitrag eigentlich eine Verteidigung des „extrakonstitutionellen Notstands“ unter den konkreten Umständen der Weimarer Verfassung sei. ${ }^{986}$ In der Tat hat der Verfassungsaufsichtsbegriff in der Literatur eine Verknüpfung mit demjenigen des Notstands erfahren. Heckel meint: „Die Verfassungsaufsicht ist hiernach keine Einrichtung des normalen Verfassungslebens, sondern ein außerordentlicher Behelf für den bundesstaatlichen casus extremus." ${ }^{\circ 87}$ Auch Frowein hat die Verfassungsaufsicht als selbstständige Aufsicht, welche er für das Grundgesetz ausmacht, mit Notstandsdurchgriffskompetenzen des Bundes gegenüber den Ländern explizit gleichgesetzt. ${ }^{988}$ Das überzeugt allerdings nicht. Der Begriff der Verfassungsaufsicht bietet vielmehr die Möglichkeit, gerade für das Unionsrecht echtes aliud zum trügerischen Notstandsbegriff zu sein. ${ }^{989}$

Während eine Vermischung der Rechtsbegriffe Aufsicht und Notstand bereits für das Grundgesetz dessen Systematik über Bord werfen muss, ${ }^{990}$ wäre sie für das Unionsrecht unvertretbar.

986 Michael Stolleis, Geschichte des öffentlichen Rechts in Deutschland, Dritter Band, S. 123.

987 Johannes Heckel, „Das Urteil des Staatsgerichtshofs vom 25.10.1932 in dem Verfassungsstreit Reich-Preußen“, S. 218.

988 Jochen Frowein, Die selbständige Bundesaufsicht nach dem Grundgesetz, S. 47.

989 Bei Jochen Abr. Frowein, „Die rechtliche Bedeutung des Verfassungsprinzips der parlamentarischen Demokratie für den europäischen Integrationsprozeß“, S. 314, ist diese Gleichsetzung für das damalige Gemeinschaftsrecht auch nicht übernommen.

990 Für diese und die Abgrenzung beider Institute Eckart Klein, Art. 37 GG, in Theodor Maunz \& Günter Dürig (Begr./Hrsg.), Grundgesetz-Kommentar, 89. EL Oktober 2019, C.H. Beck, München; vgl. insb Rn.39, wonach die h.M. zuvor eine Bemühung des Bundesverfassungsgerichts für zwingend erforderlich hält. 
Der Notstandsbegriff, zumal der Typus des Staatsnotstandes, also gerichtet auf die Durchsetzung der Verfassung bei inneren Umsturzbestrebungen, hat für alle Verfassungen eine enorme Sprengwirkung. Er zwingt nicht nur eine rechtstheoretisch sehr komplexe Diskussion auf, ${ }^{991} \mathrm{er}$ führt auch zu diversen Randfragen des Verfassungslebens bereits auf staatlicher Ebene, wie den immer wieder diskutierten Fragen, ob Notstandsmaßnahmen einer konstitutionellen Grundlage überhaupt bedürfen und inwieweit ein schlichter Durchgriff staatlicher Stellen zum Schutz der Verfassung geboten und gestattet ist.

Derartige Überlegungen geraten auf unionaler Ebene schnell in einen offenen Konflikt mit hergebrachten Grundsätzen des Unionsprimärrechts, da das Denken vom Notstand her regelmäßig auf eine Veränderung oder sogar Aussetzung der durch die Verfassung etablierten Kompetenzregelungen hinausläuft. Wenn auch Art. 7 Abs. 1 EUV gerade eine Ausnahme vom Prinzip der begrenzten Einzelermächtigung, Art. 5 Abs. 1 S. 1 EUV, ist, so hieße das Verfechten eines Notstands im Unionsrecht, ihn weit über diese Ausnahme hinweg auszuhebeln. Das hieße nicht zuletzt, die Absichten dieser Arbeit ad absurdum zu führen.

Auch im Hinblick auf die Finalität der Union ist der Notstandsbegriff unvertretbar. Seine Abwesenheit ist entscheidendes Kriterium für ihre Abgrenzung vom Staat. Damit sind insbesondere Überlegungen unvereinbar, die der Union gegenüber den Mitgliedstaaten Durchgriffsbefugnisse zugestehen würden, wie sie folgen müssten, um eine Gleichstellung zu Notstandsbefugnissen bzw. zu einer „Unionsexekution“ zu erreichen. Das Unionsrecht kennt keine Normen, die z.B. Form und Inhalt des Art. 37 GG oder des Art. 155 der spanischen Verfassung auch nur im Ansatz vergleichbar wären - selbst wenn man von weitreichenden Vollstreckungsmaßnahmen ausginge, die die Union z.B. im Anschluss an ein Urteil nach Art. 260 Abs. 2 AEUV treffen kann. ${ }^{992}$ Die Union verfügt schlicht nicht

991 Die Literatur ist uferlos. Grundlegend bleibt trotz aller Kritik Carl Schmitt, Politische Theorie - Vier Kapitel zur Lehre von der Souveränität, 2. Aufl. Duncker \& Humblot, München und Leipzig, 1934; Eine sehr gelungene Synopse der bundesdeutschen Debatte bietet András Jakab, „Das Grunddilemma und die Natur des Staatsnotstandes - Eine deutsche Problematik mit ausländischen Augen“, in: Kritische Justiz 38 (2005), S. 323-336.

992 Zu dieser Problematik Marcus Klamert, „Die Durchsetzung finanzieller Sanktionen gegenüber den Mitgliedstaaten“, in: Europarecht (2018), S. 159-174; Tobias Hofmann, „How long to compliance? Escalating infringement proceedings and the diminishing power of special interests", in: Journal of European Integration 40 (2018), S. 785-801; ebenso Pål Wennerås, „Making Effective Use of 
über entsprechende Verfahren, Stellen und Kräfte, noch kann sie sich solche zu eigen machen.

Dass die Abgrenzung der Verfassungsaufsicht, wie sie hier vertreten wird, zum Notstand darüber überhaupt näher auszuführen ist, ist einer teilweise irritierenden Nennung des Notstandsbegriffs im Kontext unionaler Aufsichtsmaßnahmen und Reaktionen zu verdanken, die über die Diskussion der heutigen Art. 347 und 348 AEUV hinausgeht, wie sie noch bei Klaus Wirbel Gegenstand waren. Seine Dissertation ist die mutmaßlich einzige Monographie zu diesem Thema anhand der damaligen Art. 224 und 225 EGV (Maastricht). Er spricht zwar, sich auf weitere Verfasser wie Thomas Oppermann und Frowein stützend, ${ }^{993}$ explizit von einer „Notstandsregelung“ der damaligen Verträge, ${ }^{994}$ meint aber damit, wie seine Arbeit später zeigt, den ,inneren“ wie den „äußeren“ Notstand der Mitgliedstaaten und ihre Pflichten untereinander und gegenüber der Union und gerade nicht hingegen die Möglichkeit eines etwaigen Notstandsdurchgriffs seitens der Union gegenüber den Mitgliedstaaten. ${ }^{995}$

In der europäischen Finanz- und Währungskrise der 2000er und 2010er Jahre ist der Begriff des Notstands für das Unionsrecht prominenter erwähnt worden, allerdings war dort die Vieldeutigkeit ein beliebtes Mittel. Paul Kirchhof hat, was die Änderungen im Unionsrecht während der Krise, potentiell zu Lasten der Mitgliedstaaten, anging, von einer „Verfassungsnot" gesprochen. ${ }^{996} \mathrm{Ihm}$ ging es ersichtlich um die besonders dringende Frage der Rechtmäßigkeit der damaligen Maßnahmen, die er verneint,

Article 260 TFEU“, in: András Jakab \& Dimitry Kochenov (Hrsg.), The Enforcement of EU law and Values, Oxford University Press, Oxford, 2017, S. 79-98, insb. S. 83 ff., auch nochmals zu Überlegungen betreffend GAP-Verletzungen im Rahmen dieses Verfahrens.

993 Mit Verweis u.a. auf Jochen Abr. Frowein, „Die rechtliche Bedeutung des Verfassungsprinzips der parlamentarischen Demokratie für den europäischen Integrationsprozeß“, S. 312; Thomas Oppermann, Europarecht: ein Studienbuch, C.H. Beck, München, 1. Aufl. 1991, Rn. 1771.

994 Klaus Wirbel, Der Ausnahmezustand im Gemeinschaftsrecht - Zu Inhalt und Grenzen des Art. 224 EG-Vertrag, zugleich Bonn, Rheinische Friedrich-Wilhelms-Universität, Diss.; verlegt ohne Verlag (Universitätsdruck), Bonn 1994, S. 27, dort Fn. 5 m.w.N. zur Terminologie.

995 Das zeigt der weitere Gang seiner Studie, s. insb. 33 ff., 36, wonach eine „Durchbrechung der Vorschriften des Gemeinschaftsrechts“ im Raume stehe, S. $60 \mathrm{ff}$. insbesondere.

996 Paul Kirchhof, „Verfassungsnot!“, Frankfurter Allgemeine Zeitung vom 12.07.2012. 
ohne den Notstandsbegriff aufzugreifen. Auch Jonathan White, ${ }^{997}$ widmet sich unter dem Begriff der „emergency“ letztlich der Rechtmäßigkeit dieser Entwicklungen, wie etwa durch die sog. troika. ${ }^{998}$

Schorkopf fragt in Bezug auf die dann getroffenen Änderungen im Unionsrecht:

„Gibt es einen Unionsnotstand? Bereits die Frage ist heikel. Sie ist bislang nicht gestellt worden und weder nach dem Selbstverständnis der Union noch nach deren Konzeption als Rechtsgemeinschaft könnte sie eigentlich gestellt werden. "999

Auch überlegt er, ob es im Hinblick auf potentielle Kompetenzüberschreitungen einen Unionsnotstand gegenüber den Mitgliedstaaten oder nicht vielmehr einen „Gesamthandsnotstand“ der Mitgliedstaaten gegeben habe. ${ }^{1000}$ Aufgelöst hat er dies nicht. ${ }^{1001}$

Im Übrigen hat Schorkopf im Hinblick auf Art. 7 EUV zwar angemerkt, dass die dortige Formulierung „schwerwiegend“ eine Parallele zu Art. 347 AEUV und den dort angesprochenen Notstandslagen in Mitgliedstaaten

997 Jonathan White, „Politics of last resort: governing by emergency in the European Union“, zuvor Jonathan White, „Emergency Europe“, in: Political Studies 63 (2015), S. 300-318.

998 Vgl. Jonathan White, „Politics of last resort: governing by emergency in the European Union“, S. 16 ff., zuvor auch die Einleitung, S. 3 ff. Die Rechtsstaatlichkeit berücksichtigt White nur insofern, als dass er Unionsorganen selbst eine Abweichung von ihr vorwirft, s. dazu ab S. 149.

999 Frank Schorkopf, „Gestaltung mit Recht: Prägekraft und Selbststand des Rechts in einer Rechtsgemeinschaft", in: Archiv des öffentlichen Rechts 136 (2011), S. 323-344, S. 341.

1000 Frank Schorkopf, „Gestaltung mit Recht“, S. 342.

1001 S. aber Frank Schorkopf, „Finanzkrisen als Herausforderung der internationalen, europäischen und nationalen Rechtsetzung“, in: Wolfram Höfling (Red.), Grundsatzfragen der Rechtsetzung und Rechtsfindung, Veröffentlichungen der Vereinigung der deutschen Staatsrechtslehrer, Bd. 71, De Gruyter, Berlin, 2012, S. 183-225, S. 186 lediglich zum Notstandsbegriff allgemein, dann aber S. 197, Fn. 55, mit Zitat von Dimitris Triantafyllou, „Zur Verantwortung des Staates für die Geldwirtschaft. Auf dem Weg zu einer europäischen Bankenaufsicht“, in: Europarecht 45 (2010), S. 585-597, S. 594. Dort in Gänze: „So bewegen sich die jüngsten Mitteilungen zur Rettung der Banken am Rande der ständigen Praxis der Europäischen Kommission. Es handelt sich offensichtlich um ein Notstandsrecht, das die Abweichung von der normalen Praxis bis zu einem gewissen Punkt rechtfertigt." 
sei, eine abschließende Qualifizierung damit allein nicht ermöglicht werde. ${ }^{1002}$

Im Kontext der Rechtsstaatlichkeitskrise schließlich diskutieren von Bogdandy und Ioannidis den Begriff des Notstandes ausdrücklich als möglichen konzeptuellen Hintergrund für ihren Begriff der „Rechtsstaatlichkeitsaufsicht", also des 2014 durch die Kommission veröffentlichten EURahmens, und erwähnen dabei sogar die bundesdeutschen Regelungen zum Verteidigungsfall. ${ }^{1003}$ Dabei wollen sie dies allerdings vor allem als Warnung vor vorschnellen Schritten in der Praxis verstanden wissen. Es dürfe nicht sein, so die Verfasser, dass im Rahmen der Rechtsstaatlichkeitskrise Verfahren fehlten, aber ebenso wenig, dass „einem semi-hegemoniellen Exekutivföderalismus Vorschub" 1004 geleistet werde.

Sofern vereinzelt tatsächlich Anleihen beim Notstandsbegriff in Bezug auf Artikel 7 EUV gemacht worden sind, ist dies vorrangig im Hinblick auf die Frage geschehen, ob die Union ungeachtet einer fehlenden expliziten Möglichkeit hierfür die Mitgliedschaft eines Mitgliedstaates suspendieren könne, ${ }^{1005}$ die indes regelmäßig und damit implizit der Rückgriff auf ein Konzept des Unionsnotstands, zurückgewiesen worden ist. ${ }^{1006}$

Ulrich Preu $\beta$ hat die Idee eines Unionsnotstandes gegenüber den Mitgliedstaaten, unter Diskussion des Art. 7 EUV, schließlich explizit abgelehnt. ${ }^{1007}$ Zwar sei die geregelte Situation durchaus außergewöhnlich, die Annahme einer Notstandsmaßnahme scheitere aber insbesondere daran, dass durch Art. 7 EUV nicht, wie für eine solche erforderlich „zur Bewältigung außergewöhnlicher Notfälle die für den Regelbetrieb einer rechtlich verfassten Institution geltenden Kompetenzen, Befugnisse und Rechte zeitlich begrenzt verändert werden.“ Es handele sich vielmehr um „ein

1002 Frank Schorkopf, Art. 7 EUV, in: Eberhard Grabitz, Meinhard Hilf \& Martin Nettesheim (Begr./Hrsg.), Das Recht der Europäischen Union, C.H. Beck, München, 68. EL 2019, Rn. 31 und 32.

1003 Armin von Bogdandy \& Michael Ioannidis, „Das systemische Defizit“, S. 324 f., insb. S. 324 bei Fn. 186.

1004 Armin von Bogdandy \& Michael Ioannidis, „Das systemische Defizit“, S. 325.

1005 Darstellung des Diskussionsstands bei André Hau, Sanktionen und Vorfeldmaßnahmen zur Absicherung der europäischen Grundwerte, S. 32-33.

1006 So z.B. bei Jochen Abr. Frowein, „Die rechtliche Bedeutung des Verfassungsprinzips der parlamentarischen Demokratie für den europäischen Integrationsprozeß“, S.315, was André Hau, Sanktionen und Vorfeldmaßnahmen zur Absicherung der europäischen Grundwerte, S. 32-33, nicht gänzlich deutlich macht.

1007 Ulrich K. Preuß, „Die Krise der Europäischen Union als Ausnahmezustand?“, in: Kritische Justiz 50 (2017), S. 51-67. 
Mittel des Selbstschutzes der Union gegen Gefährdungen ihrer sozial-moralischen Grundlagen von Seiten eines Mitgliedstaates. Denn die Staaten haften gewissermaßen als Gründer der Union für die konstitutionelle Integrität ihrer Schöpfung und müssen daher ihrerseits die Gründungsprinzipien erfüllen." ${ }^{1008}$

Ich mache mir diese Ablehnung des Notstandsbegriffs im Unionsrecht ausdrücklich zu eigen. Wer von einer Verfassungsaufsicht im Unionsrecht spricht, behauptet also nicht einen Unionsnotstand, der zu besonderen Maßnahmen der Union gegenüber den Mitgliedstaaten ermächtigte. Vielmehr ist gemeint, dass mit bestehenden Maßnahmen eben der Schutz eines ganz besonders herausgehobenen Verfassungskerns im Unionsrecht in den Blick gerät. Es geht also nicht primär um die Intensität oder sui-generis-Natur der Maßnahmen, sondern um das, was auf dem Spiel steht, sollten diese Maßnahmen versagen, um den wirklichen Bestand des Verfassungskerns der Europäischen Union.

bb. Legitimierung durch rechtswissenschaftliche Arbeiten und durch die Rechtspraxis

Damit ist zum zweiten Argument zu kommen. Es lautet, dass es mit dem Begriff der Verfassungsaufsicht gelingt, vorangegangene Arbeiten aufzugreifen, die sich gerade dieser Idee eines Verfassungskerns im Unionsrecht gewidmet haben. Letzteres nämlich kann auf zahlreiche Vorarbeiten bauen, die zeigen, dass die These eines solchen Verfassungskerns im Unionsrecht legitim und abgesichert ist. Der Verfassungsaufsichtsbegriff macht diese Idee zum Gegenstand eines objektiv-rechtlichen Aufsichtsregimes im Unionsrecht.

Der Begriff des Verfassungskerns bzw. synonym der Verfassungsidentität findet seinen Ursprung in den mitgliedstaatlichen Verfassungen. ${ }^{1009}$

1008 Beide Zitate Ulrich K. Preuß, „Die Krise der Europäischen Union als Ausnahmezustand?", S. 53.

1009 Ablehnend für das dt. Grundgesetz zwar Monika Polzin, Verfassungsidentität: Ein normatives Konzept des Grundgesetzes?, Mohr Siebeck, Tübingen, 2018, S. 133 und ff., der Begriff sei insb. mit dem Demokratieprinzip nicht vereinbar; dort aber m. umf. N. zur Begriffsverwendung, ebenso weist sie nach, Fn. 185, dass u.a. bereits Karl-Peter Sommermann, in: Hermann von Mangoldt, Friedrich Klein \& Christian Starck (Begr./Hrsg.), Kommentar zum Grundgesetz, Bd. 2, 6. Aufl. 2010, Art. 20 Rn. 3, die Begriffe Verfassungsidentität und Verfassungskern gleichgesetzt hat. 
Er kann dort zunächst als Argument zur Abwehr von Verdichtungstendenzen des Unionsrechts verstanden werden, die nicht die Gemeinsamkeiten, sondern die Eigenständigkeit der Mitgliedstaaten betont. ${ }^{1010}$ Das Bundesverfassungsgericht etwa spricht, insbesondere im Lissabon-Urteil, vom „unantastbaren Kerngehalt der Verfassungsidentität des Grundgesetzes“, ${ }^{1011}$ verwendet aber auch korrespondierende Begriffe wie die "verfassungsrechtliche Identität als Mitgliedstaaten" 1012 oder spricht von Grundsätzen, die Art. 79 Abs. 3 GG als „Identität der Verfassung“ festschreibt. ${ }^{1013}$ Mit seinem sog. „Europäischer Haftbefehl II“-Urteil hat es Ende 2015 diese „Identitätskontrolle“ erstmals angewandt. ${ }^{1014}$ Der Begriff des Verfassungskerns oder der Verfassungsidentität ist mittlerweile ein in vielen Mitgliedstaaten der Union präsenter Rechtsbegriff. Paris hat ihn für Italien im Detail untersucht, ${ }^{1015}$ David Kosař und Ladislav Vyhnánek für Tschechien, ${ }^{1016}$ Maja Walter hat Unterschiede zwischen Deutschland und Frankreich aufgezeigt. ${ }^{1017}$ Auch im Überblick ist die Auseinandersetzung mit dieser Lehre und die Existenz im positiven Verfassungsrecht, etwa für Dänemark, Polen, Tschechien und Spanien nachgewiesen worden, wie auch für den

1010 Dazu dann in großer Ausführlichkeit Armin von Bogdandy \& Stephan Schill, „Die Achtung der nationalen Identität unter dem reformierten Unionsvertrag: Zur unionsrechtlichen Rolle nationalen Verfassungsrechts und zur Überwindung des absoluten Vorrangs“, in: Zeitschrift für ausländisches öffentliches Recht und Völkerrecht 70 (2010), S. 701-734, S. $716 \mathrm{ff}$.

1011 BVerfGE 123, 267, 4. Leitsatz des Tenors.

1012 BVerfGE 123, 267, S. 347.

1013 BVerfGE 123, 267, S. 340.

1014 Ausführlich zum Urteil Dana Burchhardt, „Die Ausübung der Identitätskontrolle durch das Bundesverfassungsgericht - Zugleich Besprechung des Beschlusses 2 BvR 2735/14 des BVerfG vom 15.12.2015 ("Solange III"/“Europäischer Haftbefehl II”)“, in: Zeitschrift für ausländisches öffentliches Recht und Völkerrecht 76 (2016), S. 527-551. Monika Polzin, Verfassungsidentität“, S. 178 ff., hält diese Rechtsprechungslinie für „unhaltbar“.

1015 Davide Paris, „Carrot and Stick: The Italian Constitutional Court's Preliminary Reference in the Case Taricco“, in: Questions of International Law Questioni di diritto internazionale 37 (2017), S. 5-20.

1016 David Kosař \& Ladislav Vyhnánek, „Constitutional Identity in the Czech Republic: A new twist on the old fashioned idea?", MUNI Law Working Paper Series No. 2017.05, Masaryk University Law Faculty, Brünn, 2017, insb. S. 8 f.

1017 Maja Walter, „Integrationsgrenze Verfassungsidentität - Konzept und Kontrolle aus europäischer, deutscher und französischer Perspektive“, in: Zeitschrift für ausländisches öffentliches Recht und Völkerrecht 72 (2012), S. 177-200, S. 183 ff., wonach der Begriff in Frankreich grds. eine dem deutschen Verständnis entgegengesetzte, das Unionsrecht im nationalen Recht zum Ausdruck bringende Funktion habe. 
EGMR und den UN-Menschenrechteausschuss auf völkerrechtlicher Ebene. ${ }^{1018}$

Unionsrechtlicher Niederschlag derartiger Überlegungen ist Art. 4 Abs. 2 EUV. Er bringt zum Ausdruck, dass die Union gegenüber ihren Mitgliedstaaten einen objektiven Gehalt der Verfassungen achtet, der der Ausgestaltung durch die nationalen Verfassungsgerichte insbesondere offensteht. ${ }^{1019}$ Allerdings ergibt sich dabei von vornherein eine Einschränkung, die das Konzept eines Verfassungskerns auf mitgliedstaatlicher Ebene aus der Warte auch des Unionsrechts betont:

„Nur die grundlegenden Verfassungsentscheidungen und Verfassungsstrukturen der Mitgliedstaaten" sind umfasst, so z.B. Armin von Bogdandy und Stephan Schill. ${ }^{1020}$ Hierin liegt, wie sie an anderer Stelle formulieren, der „Kern der Verfassung“ , ${ }^{1021}$ im Englischen ist der Begriff des „,core“ ${ }^{1022}$ genutzt worden. Ähnlich gelagert war, vor Schaffung des Art. 4 Abs. 2 EUV, die Überlegung Schorkopfs, wonach der Rechtsbegriff der Homogenität im Unionsrecht, neben der Frage der Relation zur Union selbst, auf gemeinsamen Verfassungsüberzeugungen der Mitgliedstaaten untereinander, d.h. horizontaler wie auch vertikaler Homogenität beruht, nämlich auf grundlegenden Überzeugungen ungeachtet aller verfassungsrechtlicher Unterschiede der Mitgliedstaaten, zu denen jedenfalls das Demokratieund das Rechtsstaatsprinzip zählen. ${ }^{1023}$

1018 S. bei Armin von Bogdandy, Matthias Kottmann, Carlino Antpöhler, Johanna Dickschen, Simon Hentrei \& Maja Smrkolj: „Ein Rettungsschirm für europäische Grundrechte - Grundlagen einer unionsrechtlichen Solange-Doktrin gegenüber Mitgliedstaaten“, in: Zeitschrift für ausländisches öffentliches Recht und Völkerrecht 72 (2012), S. 45-78, S. 68-69, bei Fn. 124 und ff, weiter Fn. 122 für den Nachweis der Auseinandersetzung des EGMR und den UN-Menschenrechteausschuss unter Verweis auf Jochen von Bernstorff, „Kerngehaltsschutz durch den UN-Menschenrechtsausschuss und den EGMR: Vom Wert kategorialer Argumentationsformen“, in: Der Staat 50 (2011), S. 165-190. S. $170 \mathrm{ff}$ insb.

1019 Armin von Bogdandy \& Stephan Schill, „Die Achtung der nationalen Identität unter dem reformierten Unionsvertrag“, S. $712 \mathrm{ff}$.

1020 Armin von Bogdandy \& Stephan Schill, „Die Achtung der nationalen Identität unter dem reformierten Unionsvertrag“,, S. 714.

1021 Armin von Bogdandy \& Stephan Schill, „Die Achtung der nationalen Identität unter dem reformierten Unionsvertrag", S. 721.

1022 S. Armin von Bogdandy \& Stephan Schill, „Overcoming absolute primacy: Respect for national identity under the Lisbon Treaty“, in: Common Market Law Review 48 (2011), S. 1417-1454, etwa S. 1437.

1023 Frank Schorkopf, Homogenität in der Europäischen Union, S. 35 ff. 
Die konsequente Fortschreibung dieser Überlegungen für die unionale Verfassungsaufsicht ist nun die Annahme, dass es ebenso einen Verfassungskern gibt, der aus dem Unionsrecht fließend den Mitgliedstaaten entgegengestellt wird.

Dabei ist zu beachten, dass sich ein solcher immer auch aus den Verfassungstraditionen der Mitgliedstaaten speist, insbesondere deswegen, weil einschlägige Normen wie Art. 2 EUV gänzlich unionseigene Begriffe nicht kennen. Das ist bereits bei der Frage der Operationalisierung des Rechtsstaatsprinzips angeklungen. Ganz besondere Bedeutung hat dieses Konzept durch die sog. Heidelberger Gruppe" 1024 um von Bogdandy mit ihrem „Reverse Solange“-Vorschlag ${ }^{1025}$ entwickelt. Bogdandy u.a. gehen unter Berufung insbesondere auf das Urteil Ruiz Zambrano ${ }^{1026}$ und Grzelczyk ${ }^{1027}$ des Europäischen Gerichtshofs davon aus, dass das Konzept eines „Kernbestands" der Unionsbürgerschaft folgt, das zwar nicht unmittelbar subjektive Rechte, z.B. auf Wahrung des Rechtsstaatsprinzips verleiht, aber durch jedweden Hoheitsakt, auch innerstaatlich, verletzt sein kann. ${ }^{1028}$

Dieser Kernbestand manifestiert sich für die Verfasser in Art. 2 EUV, dort allerdings nicht in der gesamten Norm, sondern lediglich in „menschenrechtlichen Essentialia“, 1029 d.h. dem „Wesensgehalt der Grundrechte“, der den Mitgliedstaaten gemeinsam ist. ${ }^{1030}$

1024 Bezeichnung bei Anna Maria Russo, „La cittadanza ,sostanziale‘ dell'UE alla luce della proposta del Gruppo di Heidelberg: Verso una "Reverse Solange"?“, in: Federalismi 12 (2014), S. 1-19.

1025 Armin von Bogdandy, Matthias Kottmann, Carlino Antpöhler, Johanna Dickschen, Simon Hentrei \& Maja Smrkolj: „Ein Rettungsschirm für europäische Grundrechte - Grundlagen einer unionsrechtlichen Solange-Doktrin gegenüber Mitgliedstaaten“, in: Zeitschrift für ausländisches öffentliches Recht und Völkerrecht 72 (2012), S. 45-78.

1026 EuGH, Rs. C-34/09, Gerardo Ruiz Zambrano ./. Office national de l'emploi (ONEm), Urteil (GK) vom 08.03.2011, Slg. 2011, I-1232, ECLI:EU:C:2011:124, dazu Armin von Bogdandy u.a., „Ein Rettungsschirm für europäische Grundrechte", S. 58, $61 \mathrm{ff}$.

1027 EuGH, Rs. C-184/99, Rudy Grzelczyk ./. Centre public d'aide sociale d'Ottignies-Louvain-la-Neuve, Urteil vom 20.09.2001, Slg. 2001, I-6229, ECLI:EU:C:2001:458, dazu Armin von Bogdandy u.a., „Ein Rettungsschirm für europäische Grundrechte“, S. 60, 61.

1028 Armin von Bogdandy u.a., „Ein Rettungsschirm für europäische Grundrechte", S. 58-59.

1029 Armin von Bogdandy u.a., „Ein Rettungsschirm für europäische Grundrechte“, S. 68.

1030 Armin von Bogdandy u.a., „Ein Rettungsschirm für europäische Grundrechte“, etwa S. 72, 74. 
Diese Feststellung ist für die Zwecke dieser Arbeit sehr bedeutend, denn sie widerlegt die vielleicht angestellte Vermutung, dass die Verfassungsaufsicht als Kern der Verfassung stets den Schutz einer Mehrzahl an Rechtsgütern oder, hier, Prinzipien, wie sie Art. 2 EUV wiedergibt, zum Gegenstand haben muss. Das Konzept findet seinen Ausdruck gerade auch dann, wenn nur der Schutz eines einzelnen, in der gegenwärtigen Lage besonders bedeutenden, Prinzips im Raum steht, wie in der derzeitigen Lage die Rechtsstaatlichkeit. Dies steht zukünftige Entwicklungen nicht entgegen. Gewissermaßen besteht dann also ein „Kern eines Kerns“.

Gleiches zeigt sich auch beim „Reverse Solange“-Konzept: innerhalb des Kernbestands der Unionsbürgerschaft, bereits Kern der gemeinsamen Verfassung der Union, wird ein weiterer Kern ausgemacht, der diese zu schützenden Grundrechte enthält. Diese Idee ist auch zuvor im Hinblick auf das Rechtsstaatsprinzip angeklungen ${ }^{1031}$ und kann für diese Arbeit die Überlegung bestärken, wonach es bei der Operationalisierung desselben Prinzipien geben muss, die in jedem Fall zu ihm zählen müssen. Berufen zum Schutz dieses Kerns, der den Unionsbürger, nicht die Union selbst in den Mittelpunkt rückt, sind bei von Bogdandy u.a. keine unionalen Stellen, sondern vorrangig die Mitgliedstaaten selbst. ${ }^{1032}$ Wird nämlich, für den Fall eines systemischen Defizits, ${ }^{1033}$ die Vermutung widerlegt, dass der Mitgliedstaat seine Bürger schützt, können dessen Gerichte sich, auch „in rein innerstaatlichen Sachverhalten“, auf die Unionsgrundrechte berufen, ${ }^{1034}$ folglich also ohne Rücksicht auf Art. 51 der Grundrechtecharta, und ggf. den EuGH per Vorabvorlageverfahren anrufen. ${ }^{1035}$

Der Vorschlag der Heidelberger Gruppe, und damit auch der hier interessierende Rechtsbegriff des Kerngehalts eines bestimmten Teils der Unionsverfassung als dessen besonders bedeutender materieller Bereich, hat zwischenzeitlich die ausdrückliche Unterstützung durch Mitglieder des Europäischen Gerichtshofs und damit die vielleicht größtmögliche

1031 Armin von Bogdandy \& Stephan Schill, „Die Achtung der nationalen Identität unter dem reformierten Unionsvertrag“, S. 720 zur Beobachtung eines „Kerngehalts des Rechtsstaatsprinzips".

1032 Armin von Bogdandy u.a., „Ein Rettungsschirm für europäische Grundrechte", S. $48,60$.

1033 Armin von Bogdandy u.a., „Ein Rettungsschirm für europäische Grundrechte", S. 72.

1034 Armin von Bogdandy u.a., „Ein Rettungsschirm für europäische Grundrechte", S. 48.

1035 Armin von Bogdandy u.a., „Ein Rettungsschirm für europäische Grundrechte“, S. 73, 74. 
Legitimierung erhalten. Dimitry Kochenov u.a. haben aufgezeigt, dass Generalanwalt Miguel Poaires Maduro in der Rs. Centro Europa, unter Nutzung des Begriffs des „systemischen“, eine Prüfung in diesem Sinne seitens des Gerichtshofs selbst in Betracht zog. ${ }^{1036}$ Und Generalanwalt Tanchev sprach, unmittelbar unter Nennung des Beitrags, von einem „innovativen Vorschlag“. ${ }^{1037}$

Hier ist aus dem „Reverse-Solange“-Vorschlag die Nutzbarkeit des Begriffs des Verfassungskerns als auch aus dem Unionsrecht fließend und gegenüber den Mitgliedstaaten wirkend zu entnehmen. Darauf gilt es für den Begriff der unionalen Verfassungsaufsicht Bezug zu nehmen. Der verfahrensrechtliche Vorstoß der damaligen Verfasser, also die Nutzung des Vorabvorlageverfahrens, ist, trotz seiner unbestrittenen Bedeutung gerade im Rahmen der gegenwärtigen Krise, indes keine Verfassungsaufsicht. ${ }^{1038}$ Der Vorschlag dort ist eine subjektiv-rechtliche Erweiterung des Grundrechtsschutzes für den Einzelnen und hängt zentral an der unerschütterten Funktionstüchtigkeit der mitgliedstaatlichen Gerichte. In der Rechtsstaatlichkeitskrise zeigt sich, wie anfällig die Gerichte sein können.

Das Instrumentarium der Verfassungsaufsicht ergänzt diese Überlegung daher durch ein objektiv-rechtliches Rechtsregime, in welchem unionale Stellen, insbesondere Kommission und Gerichtshof, gegenüber den Mitgliedstaaten tätig werden.

Armin von Bogdandy u.a. lassen die Möglichkeit einer ebensolchen Ergänzung ihres Vorschlags zu, wenn sie z.B. schreiben:

„Die Union schützt ihre Bürger gegen diejenigen Statusverletzungen ihres Heimatstaates, welche die Unionsbürgerschaft ihrer praktischen Wirksamkeit berauben."1039

1036 Dimitry Kochenov, Laurent Pech \& Sébastien Platon, „Ni panacée, ni gadget : le ,nouveau cadre de l'Union européenne pour renforcer l'État de droit'“, S. 700, bei Fn. 58 unter Verweis auch auf die engl. Fassung des Beitrags der Heidelberger Gruppe und insb. auf EuGH, Rs. C-380/05, Centro Europa $7 \mathrm{Srl}$ v Ministero delle Comunicazioni u.a., Schlussanträge des Generalanwalts M. Poaires Maduro vom 12.09.2007, Rn. 14 ff., vgl. insb. Rn. 20 und 21 („schwerwiegender und andauernder Verstoß" in einem Mitgliedstaat), dt. Fassung nicht in der amtl. Slg., franz. Ausg. 2007, S. I-352, ECLI:EU:C:2007:505.

1037 EuGH, Schlussanträge des Generalanwalts Evgeni Tanchev in der Rs. C-192/18, Kommission ./. Polen, „Unabhängigkeit der ordentlichen Gerichtsbarkeit“, ECLI:EU:C:2019:529, Rn. 72, Fn. 36.

1038 Vgl. hierzu bereits in der Einleitung.

1039 Armin von Bogdandy u.a., „Ein Rettungsschirm für europäische Grundrechte", S. 62-63. 
Dabei findet das Konzept des Verfassungskerns als objektiv-rechtliches Abwehrargument der Union zum Selbstschutz prominente Unterstützer. Generalanwältin Kokott und ihr Référendaire Christoph Sobotta haben z.B. vom Schutz von "constitutional core values“ im Hinblick auf das Urteil Kadi gesprochen und dabei angemerkt, vorherrschend sei sein Verständnis als "underscoring and defending the autonomy of EU law".1040 Auch das Bundesverfassungsgericht hat diese Lesart akzeptiert. ${ }^{1041}$ In die Literatur ist die Figur des Verfassungskerns ebenfalls als objektiv-rechtliche Schutzüberlegung eingegangen. Halmai spricht, in Bezug auf die Vorgänge in Ungarn, von „Kernwerten“ (core values), die es zu schützen gelte. ${ }^{1042}$

Ein aus objektiv-rechtlicher Schutzrichtung verstandener Verfassungskern der Europäischen Union, der sich auf die Werte des Art. 2 EUV stützt, kann in der Praxis unterschiedliche Ausgestaltungen erfahren.

Christophe Hillion zeigt auf, dass die Europäische Kommission von einem „core meaning of the rule of law" spricht, ${ }^{1043}$ den es zu schützen gelte. Er greift damit die bei von Bogdandy und Schill genutzte Figur der Bestimmung des Verfassungskerns durch Herausarbeitung eines reduzierten Kerns eines einzelnen, ihm zuzuschreibenden Prinzips, auf.

Der Europäische Gerichtshof ist selbst bereits seit längerem dabei, die Figur des Verfassungskerns unionsautonom zu entwickeln und zu nutzen. ${ }^{1044}$

1040 Juliane Kokott \& Christoph Sobotta, „The Kadi Case - Constitutional Core Values and International Law - Finding the Balance?“, in: European Journal of International Law 23 (2012), S. 1015-1024, S. 1017.

1041 BVerfGE 123, 267, S. 401, Nachweise und Aufarbeitung bei Nele Yang, Die Leitentscheidung: Zur Grundlegung eines Begriffs und seiner Erforschung im Unionsrecht anhand des EuGH-Urteils Kadi, Springer, Heidelberg, 2017, S. 216.

1042 Gábor Halmai, „The Application of European Constitutional Values in EU Member States“, in: European Journal of Law Reform 20 (2018), S. 10-34, S. 12, S. 33, dabei durchaus kritisch.

1043 Christophe Hillion, „Overseeing the Rule of Law in the EU: Legal Mandate and Means“, S. 69, unter Verweis auf Europäische Kommission, Mitteilung der Kommission an das Europäische Parlament und den Rat, Ein neuer EU-Rahmen zur Stärkung des Rechtsstaatsprinzips vom 11.03.2014, COM(2014) 158 final, S. 4.

1044 Matthias Schmidt \& Piotr Bogdanowicz, „The Infringement Procedure in the Rule of Law Crisis“, S. 1088, unter Hinweis auf die Schlussanträge des Generalanwalts Yves Bot in der Rs. C-643 \& 647/15, Slowakische Republik u.a. Kommission, ECLI:EU:C:2017:618, Rn 19: « [...] un ensemble de valeurs et de principes qui constitue 'le socle de la construction européenne"; zur Frage der Grundrechtsbedeutung weiter die Schlussanträge der Generalanwäl- 
Nach alledem meine ich: das Konzept, dass es im Unionsrecht einen aus ihm selbst gegenüber den Mitgliedstaaten wirkenden Verfassungskern gibt, ist hinreichend in Literatur und Rechtsprechung gesichert. Aufgrund des derzeitigen Zuschnitts der Rechtsstaatlichkeitskrise manifestiert sich die Diskussion um den unionalen Verfassungskern gerade im Rechtsstaatsprinzip, ist aber nicht zwingend auf diesen festgelegt. Aus der dieser Diskussion vorausgehenden Literatur zum Aufsichtsbegriff folgt, dass der zunächst durch Heckel konzipierte, später aber durch mehrere namhafte Verfasser aufgegriffene und im Unionsrecht fest etablierte Begriff der Verfassungsaufsicht es am besten vermag, dasjenige Instrumentarium im Unionsrecht zu beschreiben, das objektiv-rechtlich auf den Schutz dieses Kerns durch Beobachtung, Überprüfung und ggf. Berichtigung mitgliedstaatlicher Maßnahmen abzielt.

\section{II. Überlegungen zur praktischen Anwendung des Verfassungsaufsichtsbegriffs im Unionsrecht}

Die Nutzung des Verfassungsaufsichtsbegriffs für die in dieser Arbeit interessierenden Mechanismen meint nicht, dass der Begriff selbst bei der Durchsicht von Primärmaterial im Rahmen der Krise unmittelbar ins Auge springt. Er ist eine Übertragung aus der Rechtswissenschaft. In der Mitteilung von 2014 über den „EU-Rahmen“ hat die Europäische Kommission keine in diese Richtung deutende Ausführung gemacht, vielmehr ist dort (bereits im Titel) eine „Stärkung“ der Rechtsstaatlichkeit angesprochen worden. ${ }^{1045}$ Auch in den beiden weiteren programmatischen Mitteilungen der Kommission von 2019 zur Rechtsstaatlichkeitskrise ${ }^{1046}$ ist der Begriff nicht genutzt worden.

tin Eleanor Sharpston in der Rs. C-34/09, Gerardo Ruiz Zambrano ./. Office national de l'emploi, ECLI:EU:C:2010:560, Rn. 154: „Die Grundrechte sind somit zu einem Kernelement der Entwicklung der Union geworden [...].

1045 Europäische Kommission, Mitteilung der Kommission an das Europäische Parlament und den Rat, Ein neuer EU-Rahmen zur Stärkung des Rechtsstaatsprinzips, 11.03.2014, COM(2014) 158 final.

1046 Europäische Kommission, Mitteilung der Kommission an das Europäische Parlament, den Europäischen Rat, den Rat, den Europäischen Wirtschafts- und Sozialausschuss und den Ausschuss der Regionen: Die Stärkung der Rechtsstaatlichkeit in der Union: Ein Konzept für das weitere Vorgehen, COM(2019) 343 final vom 17.07.2019. 
Allerdings ergeben sich aussagekräftige Indizien, die sehr dafür fechten, dass gerade die Europäische Kommission um die kumulierte Wirkung ihrer Maßnahmen weiß. Sie spricht nämlich, entwicklungsoffen und flexibel, seit 2019 von einer gemeinsamen „Toolbox“ (im Deutschen bedauerlicherweise wenig aussagekräftig als „Instrumentarium“ übersetzt), und vor allem gruppiert sie unter diesem Begriff weitestgehend diejenigen Instrumente, die auch hier in den Blick geraten. ${ }^{1047}$

Überdies ist die Aufsichtsqualität für die Rechtsstaatlichkeitskrise in Maßnahmen anderer Institutionen angedeutet worden. Im Vorschlag zum „DRF-Pakt“ des Europäischen Parlaments findet sich die Überlegung einer „Überwachung“ („monitoring compliance“/,contrôle“) der Unionswerte, die durch den Mechanismus angestrebt wird. ${ }^{1048}$

Am deutlichsten ist bislang der Juristische Dienst des Rates geworden. Er bezeichnet Artikel 7 EUV und die ihm ähnlichen Mechanismen ausdrücklich als Aufsichtsverfahren, wenn auch im Hinblick auf das Ergebnis skeptisch. Er hielt nämlich in Bezug auf den EU-Rahmen von 2014 fest:

„die Verträge [bieten] keine Rechtsgrundlage [...], aufgrund deren [sic] die Organe befugt wären, einen neuen Aufsichtsmechanismus in Bezug auf die Achtung der Rechtsstaatlichkeit durch die Mitgliedstaaten zusätzlich zu dem in Artikel 7 EUV festgelegten Vorgehen zu schaffen, weder zur Änderung noch zur Abwandlung oder Ergänzung des in diesem Artikel festgelegten Verfahrens." ${ }^{\text {1049 }}$

1047 Europäische Kommission, Mitteilung der Kommission an das Europäische Parlament, den Europäischen Rat und den Rat, Die weitere Stärkung der Rechtsstaatlichkeit in der Union: Aktuelle Lage und mögliche nächste Schritte, $\operatorname{COM}(2019) 163$ final, S. 3 und ff., s. auch insb. die engl. Originalfassung. $\mathrm{Zu}$ den Mechanismen im Einzelnen infra, E.

1048 Europäisches Parlament, P8_TA(2016)0409, EU-Mechanismus für Demokratie, Rechtsstaatlichkeit und Grundrechte, Entschließung des Europäischen Parlaments vom 25. Oktober 2016 mit Empfehlungen an die Kommission zur Einrichtung eines EU-Mechanismus für Demokratie, Rechtsstaatlichkeit und die Grundrechte, (2015/2254(INL)), Rn. 9.

1049 Rat der Europäischen Union, Gutachten des Juristischen Dienstes, Betr.: Mitteilung der Kommission "Ein neuer EU-Rahmen zur Stärkung des Rechtsstaatsprinzips": - Vereinbarkeit mit den Verträgen, 10296/14 vom 27. Mai 2014, S. 7, Rn. 24, meine Hervorhebung. Nachweis auch (ohne Kommentar) bei Matthias Niedobitek, „Right and duty to pursue the "wrongdoer" and a possible abuse of Art. 7 TEU”, in: Armin Hatje \& Tichý Luboš (Hrsg.), Liability of Member States for the Violation of Fundamental Values of the European Union, Europarecht, Beiheft 1, Nomos, Baden-Baden, 2018, S. 233-242, S. 237, Fn. 24. 
Das ist also eine ausdrückliche Anerkennung des Aufsichtskonzepts in Bezug auf die Relation Union-Mitgliedstaaten (wenn auch gerade im Rahmen seiner Zurückweisung). Interessant ist hier auch die Übersetzung des Begriffs in den anderen Arbeitssprachen. Im Englischen lautet sie in genauer Entsprechung „supervision mechanism“, im Französischen „mécanisme de contrôle“. Leonard Besselink hat gerade dieses Vorgehen kritisiert. Es handele sich um einen unzulässigen „rhetorischen Trick“, da das im EU-Rahmen angelegte „Monitoring" nicht „a hierarchical device to which Member States are subjected" sei. ${ }^{1050}$ Das kann, im Hinblick auf das Konzept des Schutzes eines unionalen Verfassungskerns, nicht überzeugen.

Gerade hier schließlich zeigen sich nochmals die durchschlagenden Vorzüge des Verfassungsaufsichtsbegriffs, wenn man sich verdeutlicht, dass neben die Überlegungen zum Schutz eines unionalen Verfassungskerns seitens Heckel eine Art Prüfungsschema tritt, das den Begriff auch im Unionsrecht unmittelbar nutzbar macht und die hierarchische Beziehung zwischen Union und Mitgliedstaaten nicht in der Schwebe lässt. Ich will weder hier, noch in Bezug auf die nachfolgend dargestellten Mechanismen, eine Subsumtion in Bezug auf diese Ausführungen vorschlagen, sondern vielmehr, dass man sich bei ihm rückversichern kann, wenn die Zuordnung eines Mechanismus zum Rechtsregime der Verfassungsaufsicht oder aber seine Vorzüge in Zweifel gezogen werden. Aus der Eingängigkeit dieser Überlegungen und den Parallelen mit der jetzigen Krise ergibt sich ein drittes Argument für die Nutzung des Verfassungsaufsichtsbegriffs im Unionsrecht.

Für Heckel ist das Schutzgut der Verfassungsaufsicht die nach innen gerichtete Verfassungsordnung im Bund als „Bundesverfassungsaufsicht“, also die aus der „bündischen Staatenordnung hervorgehenden Arten von Länderpflichten“ selbst, oder als „Länderverfassungsaufsicht" diejenige in Bezug auf die Landesverfassung. ${ }^{1051}$ Für die vorliegende Arbeit wäre es angebracht, dies grundsätzlich zu übernehmen und zwischen der Unionsverfassungsaufsicht und derjenigen ihrer Mitgliedstaaten zu trennen, indes den Schutz der Bundesverfassung selbst gesondert zu betonen.

1050 Leonard Besselink, „The Bite, the bark and the howl: Article 7 TEU and the Rule of Law Initiatives“, in: András Jakab \& Dimitry Kochenov (Hrsg.), The Enforcement of EU Law and Values: Ensuring Member States' Compliance, Oxford University Press, Oxford, 2017, S. 128-144, S. 139-140, Zitat S. 140.

1051 Johannes Heckel, „Das Urteil des Staatsgerichtshofs vom 25.10.1932 in dem Verfassungsstreit Reich-Preußen“, S. 214. 
Drei Pflichten sieht Heckel in seinen Überlegungen als verletzbar an: die Folgepflicht gegenüber dem Bund, die Friedenspflicht gegenüber den anderen Ländern und die Ordnungspflicht, was den eigenen, mit der Bundesverfassung in Einklang stehenden Aufbau und die Funktion der Länder angeht. ${ }^{1052}$

In der derzeitigen Rechtsstaatlichkeitskrise ist in der Union die zweite Pflicht, die Friedenspflicht gegenüber anderen Mitgliedstaaten, wohl nicht akut relevant geworden, sieht man von einiger aggressiver Rhetorik bestimmter Mitgliedstaaten gegenüber anderen ab. Im Raum stehen aber insbesondere und ganz prioritär die Folgepflicht der Mitgliedstaaten gegenüber der Union und die Ordnungspflicht in ihren eigenen Rechtsordnungen. Ruft man sich in Erinnerung, dass in Ungarn ad-hoc-Gesetzgebung die Vorhersehbarkeit staatlichen Handelns erschwert und in Polen die Zukunft der Gerichtsbarkeit ungewiss ist und weiter, dass der Europäische Gerichtshof wie die Kommission diese Vorgänge als unvereinbar mit rechtsstaatlichen Grundsätzen angesehen haben, ist die Folgepflicht gegenüber der Union insbesondere infrage gestellt. Dann ist es geboten, dass die betroffenen Mitgliedstaaten Rechtssicherheit in ihren eigenen Rechtsordnungen zur Erfüllung der „Ordnungspflicht“ wiederherstellen.

Zwei Arten der Pflichtverletzung sind denkbar: die schuldhafte Missachtung der Verfassung und die Verfassungsstörung. ${ }^{1053}$ Diese Beobachtung deckt sich, auch wenn Heckel den Schuldbegriff und nicht den des Vorsatzes anführt, quasi vollständig mit der in dieser Studie beobachteten Unterscheidung von staatlicher Schwäche und vorsätzlichen Vorgängen. Letztere ist also die schuldhafte Missachtung der Bundesverfassung.

Der Maßstab der Verfassungsaufsicht bestimmt sich teleologisch an der Verfassung selbst.

Für den „Aufsichtsfall“ der Verfassungsaufsicht ist es erforderlich, dass der Verstoß gegen eine dieser Pflichten „sich als Teil eines verfassungsfeindlichen Gesamtverhaltens des Landes qualifiziert". ${ }^{1054} \mathrm{Mit}$ anderen Worten: er muss systemischen Charakter haben.

Da die Verfassungsaufsicht folglich immer eine gewisse Drastik und damit auch eine politische Komponente hat, steht sie unter dem Vorbehalt

1052 Johannes Heckel, „Das Urteil des Staatsgerichtshofs vom 25.10.1932 in dem Verfassungsstreit Reich-Preußen“, S. 213.

1053 Johannes Heckel, „Das Urteil des Staatsgerichtshofs vom 25.10.1932 in dem Verfassungsstreit Reich-Preußen“, S. 217, versteht den Begriff hingegen enger und sieht in ihm das Versagen spezifisch eines obersten Staatsorgans.

1054 Johannes Heckel, „Das Urteil des Staatsgerichtshofs vom 25.10.1932 in dem Verfassungsstreit Reich-Preußen“, S. 218-219. 
der strengen Subsidiarität. Letztere hängt für Heckel an drei Abwägungsmerkmalen.

Es bedarf nach Heckel zunächst der Erforderlichkeit zur „Abwehr eines spezifisch [...]verfassungsfeindlichen Verhaltens oder einer ebensolchen Lage, also von Gefahren, die das Mark des Verfassungslebens treffen, die den Kern seiner Ordnung ändern oder zerstören". ${ }^{1055}$ Es muss sich also um eine Lage ganz besonderer verfassungspolitischer und -rechtlicher Brisanz handeln. Nochmals lässt sich hier an Überlegungen anknüpfen, die zuvor zum systemischen Defizit gemacht worden sind, wie insbesondere die Überlegung, dass eine Unterwanderung des Rechtsstaatsprinzips nicht nur Grundlagen der Verfassung des Mitgliedstaats in Mitleidenschaft zieht, sondern insbesondere auch diejenige der Union selbst.

Verfassungsaufsichtsmaßnahmen dürfen nur zum Tragen kommen, wenn die beaufsichtigten Länder nicht selbst Herr der Lage werden würden. ${ }^{1056}$ Gemeint ist also das Erfordernis des subsidiären Selbsteintritts des Bundes. Das zeigt klare Parallelen auch zum Reverse-Solange-Vorschlag, auch dieser stellt auf eine Subsidiarität der Maßnahmen ab.

Zweitens ergibt sich eine strenge Subsidiarität auch aus dem beaufsichtigten Sachverhalt und dem in ihm enthaltenen Trivialisierungsverbot der Verfassungsaufsicht. Erforderlich ist zum einen eine bedeutende Schwere der vom beanstandeten Verhalten ausgehenden Gefahr und des Weiteren aus dieser resultierend eine - bis hin zur Irreversibilität reichende - Prägewirkung der Gefabr auf das Verfassungsleben bei ungehinderter Fortwirkung. „Nur wenn der Verstoß sich als Teil eines verfassungsfeindlichen Gesamtverhaltens des Landes qualifiziert, greift die Verfassungsaufsicht durch. In leichteren Fällen dagegen sind reguläre Bundesaufsichtsmaßnahmen zu treffen. ${ }^{1057}$

Auch hinsichtlich der konkreten Durchführung der Verfassungsaufsicht stellt Heckel Überlegungen an. Sie erfolgt durch die gemäß der Verfassung selbst benannten Aufsichtsorgane, denen alle von der Verfassung vorgesehenen „Aufsichtsmaßnahmen" zur Abhilfe zur Verfügung stehen. ${ }^{1058}$ Folglich ergibt sich hier die Annahme bzw. zumindest die Möglichkeit

1055 Johannes Heckel, „Das Urteil des Staatsgerichtshofs vom 25.10.1932 in dem Verfassungsstreit Reich-Preußen“, S. 217-218.

1056 Johannes Heckel, „Das Urteil des Staatsgerichtshofs vom 25.10.1932 in dem Verfassungsstreit Reich-Preußen“, S. 217.

1057 Johannes Heckel, „Das Urteil des Staatsgerichtshofs vom 25.10.1932 in dem Verfassungsstreit Reich-Preußen“, S. 218-219.

1058 Johannes Heckel, „Das Urteil des Staatsgerichtshofs vom 25.10.1932 in dem Verfassungsstreit Reich-Preußen“, S. 221 ff., 223 ff. 
einer Verfahrensmehrzahl. Weitere Ausführungen, die Heckel naturgemäß auf den rechtlichen Rahmen der Weimarer Reichsverfassung zuschneidet, sind hier uninteressant. Heckel schreibt aber bestimmte Abläufe der „Aufsichtsaktion" vor. Sie erfordert demnach „gegenwärtige Gefahren“, wenn auch im Hinblick auf diese präventiv gehandelt werden kann und gestufte Verfahren inklusive von „Warnungen“ an das Land gerichtet werden können. ${ }^{1059}$ Auch dies zeigt sehr nützliche Parallelen zum gestuften Ablauf heutiger unionaler Maßnahmen, denkt man insbesondere an Art. 7 EUV oder das Vertragsverletzungsverfahren. Heckel betont zuletzt die Rolle der Verfassungsgerichtsbarkeit und des Rechtsschutzes der Länder gegen ergriffene Maßnahmen. ${ }^{1060}$ Das ist, bedenkt man die Rolle des EuGH bei der Aufarbeitung der gegenwärtigen Krise, wiederum unmittelbar nutzbar und auch erforderlich.

1059 Johannes Heckel, „Das Urteil des Staatsgerichtshofs vom 25.10.1932 in dem Verfassungsstreit Reich-Preußen“, S. 226 ff.

1060 Johannes Heckel, „Das Urteil des Staatsgerichtshofs vom 25.10.1932 in dem Verfassungsstreit Reich-Preußen“, S. 228 und ff. 


\section{E. Das Rechtsregime der Verfassungsaufsicht der Europäischen Union}

\section{I. Überblick}

Im vorletzten Teil dieser Arbeit möchte ich das Rechtsregime der unionalen Verfassungsaufsicht darstellen. Die Arbeit hat in den vorangegangenen Teilen dargelegt, auf welche komplexe Krise dieses Regime reagieren muss. Es ist festgehalten worden, dass es sich deshalb anbietet, von einem „zweistufigen" Rechtsbegriff auszugehen, bei welchem der Begriff der Rechtsstaatlichkeitskrise eine allgemeine Abgrenzung der diversen Sachstände in mehreren Mitgliedstaaten erlaubt und dass der Begriff des systemischen Defizits, dessen wesentliche Entwicklungsstränge dargestellt worden sind, eine präzisere Untersuchung der Vorgänge ermöglicht. Sie darzustellen und mit dem Begriff des systemischen Defizits zu verknüpfen, ist aufgrund ihrer Heterogenität im Rahmen einer topischen Sichtung erfolgt. Zur Verklammerung derjenigen Maßnahmen, die seitens der Union in Reaktion auf die Krise genutzt und entwickelt worden sind, dient der Begriff der Verfassungsaufsicht im Unionsrecht, der auf den Schutz ihres Verfassungskerns, wie er durch andere Verfasser herausgearbeitet worden ist, abstellt.

Nun soll es darum gehen, den Nachweis zu führen, dass tatsächlich ein Rechtsregime besteht, das sich der Funktionslogik des Verfassungsaufsichtsbegriffs bedient und dessen Telos ausfüllt, und wer dieses ausübt.

Dabei geht es mir nicht darum, eine weitere detaillierte, und darüber kumulierende, Darstellung der genutzten Verfahren anzubieten. Derartige rechtsdogmatische Ausführungen finden sich zu den jeweiligen Verfahren in gebührender Tiefe insbesondere bereits zu Art. 7 EUV, dem Vertragsverletzungsverfahren in dessen allgemeiner Handhabung und selbst zum sog. EU-Rahmen, auf die daher entsprechend zu verweisen ist. Ich möchte einen Mehrwert für den Stand der Debatte dadurch schaffen, dass ich ganz vorrangig die Verzahnung dieser Verfahren statt ihres isolierten Wirkens in den Blick nehme. Darüber hinaus interessieren besonders die Überlegungen bei ihrer praktischen Handhabung insbesondere seitens der Europäischen Kommission. Dabei ist ebenso zu betonen, dass viele Beobachter bereits über eine derartige Verzahnung nachgedacht haben, sowohl 
lange vor der jetzigen Krise, ${ }^{1061}$ als auch spezifisch mit Blick auf deren gegenwärtige Entwicklung. ${ }^{1062}$ Ein zusätzlicher Beitrag für die Debatte soll hier mit Blick auf drei Punkte versucht werden: zunächst durch Aktualisierung vorangegangener Arbeiten, zum zweiten durch eine noch stärkere Verzahnung der ermittelten Verfahren insbesondere unter Fokussierung auf den Beitrag der Kommission und schließlich durch nochmalige Betonung der Bedeutung des Vertragsverletzungsverfahrens in der gegenwärtigen Krise.

Die Europäische Kommission hat in ihrer Mitteilung vom Juli 2019 die Gruppierung und Erfassung verschiedener Mechanismen jüngst entscheidend erleichtert und vorgeprägt; sie hat gleichzeitig damit den Anspruch der Nutzung und Entwicklung eines kohärenten Instrumentariums erhoben, wenn sie auch dies nicht dogmatisch untermauert.

Frühere Überlegungen zu einem miteinander in Verbindung stehenden Instrumentarium aus mehreren unterschiedlichen Verfahren finden sich bereits zuvor in den Ausgaben 2018 und 2019 des Justizbarometers, ${ }^{1063}$ was die Beobachtungen hier zusätzlich absichert.

In ihrer „Toolbox“1064 der Mitteilung von Juli 2019 unterscheidet die Kommission zunächst an der Spitze des Instrumentariums und in dieser Reihenfolge das Verfahren nach Artikel 7 EUV und das von ihr geschaffene EU-Rahmenverfahren. Es folgen zwei gerichtliche Verfahren, Vertrags-

1061 Vgl. relativ früh zum Ineinandergreifen von Vertragsverletzungsverfahren und Artikel 7 EUV Katrin Träbert, Sanktionen der Europäischen Union gegen ihre Mitgliedstaaten, insb. ab S. 369.

1062 Etwa bei Michael Blauberger, „Europäischer Schutz gegen nationale Demokratiedefizite?", in: Leviathan 44 (2016), S. 280-302, S. 287 ff.; Christophe Hillion, "Overseeing the Rule of Law in the EU: Legal Mandate and Means", S. $74 \mathrm{ff}$., früh auch Armin von Bogdandy \& Michael Ioannidis, „Das systemische Defizit", S. $312 \mathrm{ff}$.

1063 Europäische Kommission, Mitteilung der Kommission an das Europäische Parlament, den Rat, die Europäische Zentralbank, den Europäischen Wirtschafts- und Sozialausschuss und den Ausschuss der Regionen, EU-Justizbarometer 2018, Part 1/2, $\operatorname{COM(2018)~} 364$ final, vom 28.05.2018, S. 5, vgl. insb. auch die engl. Ausgabe, z.B. S. 5 der Broschürenfassung; weiter: Mitteilung der Kommission an das Europäische Parlament, den Rat, die Europäische Zentralbank, den Europäischen Wirtschafts- und Sozialausschuss und den Ausschuss der Regionen, EU-Justizbarometer 2019, COM(2019) 198 final, vom 26.04.2019, S. 8 ff. Zum Justizbarometer ausführlich infra E. V. 3.

1064 Europäische Kommission, Mitteilung der Kommission an das Europäische Parlament, den Europäischen Rat und den Rat, Die weitere Stärkung der Rechtsstaatlichkeit in der Union: Aktuelle Lage und mögliche nächste Schritte, $\operatorname{COM}(2019) 163$ final, vom 03.04.2019, S. 3 und ff. 
verletzungs- und Vorabentscheidungsverfahren - wobei in verschiedenen Sprachfassungen insbesondere erste im Plural gesetzt sind und sich die Kommission nicht auf das Verfahren des Art. 258 AEUV beschränkt und schließlich unter dem Titel „Andere Mechanismen und Rahmen“ nicht weniger als acht weitere Mechanismen bzw. der Verweis auf Organisationseinheiten der Kommission, nämlich das Europäische Semester, das EU-Justizbarometer, der CVM, der SRSS, die Strukturfonds einschließlich des neu geschaffenen Fonds für "Justiz, Rechte und Werte“, der Verordnungsvorschlag betreffend die Berücksichtigung „genereller Mängel“ bei Haushaltszuwendungen, das OLAF einschließlich der zukünftigen Europäischen Staatsanwaltschaft - ersteres bislang weitestgehend in der Diskussion ${ }^{1065}$ ausgeblendet - und schließlich die Überprüfung der Werteeinhaltung in der europäischen Nachbarschafts- und Beitrittspolitik aufgeführt werden.

Ich hatte bereits dargelegt, warum meines Erachtens die Tätigkeit des SRSS als intra-unionalem state-building hier nicht weiter zu berücksichtigen ist. ${ }^{1066}$ Wie sich das OLAF wiederum in der Krise einbringen kann, scheint mir noch offen. Gleichzeitig soll sich die Darstellung hier nicht allein auf die Mechanismen unter unmittelbarer Kontrolle der Kommission beschränken, und das Vorabvorlageverfahren bleibt, weil ihm zwar ggf. eine rein judikative, aber keine in Verbindung mit der Kommission erfolgende Aufsichtsnatur zufällt, ebenso unberücksichtigt.

Lässt man diese Einschränkungen zu, so gelangen, bei Anwendung der bereits in der Einleitung gemachten Unterscheidungen, folgende Verfahren in den Blick:

I. Als hier sog. „partielle“, da nicht mit einer eigenen Berichtigungsphase versehene, Verfassungsaufsichtsverfahren:

1. der sog. „EU-Rahmen zur Stärkung des Rechtsstaatsprinzips“1067 der Europäischen Kommission

1065 Von Bogdandy, Ioannidis und Antpöhler haben aber darauf hingewiesen, dass zukünftige institutionelle Entwicklungen auf den Erfahrungen des OLAF und seine besondere Unabhängigkeit innerhalb der Kommission bauen könnten, dazu Armin von Bogdandy, Carlino Antpöhler \& Michael Ioannidis, „Protecting EU values: Reverse Solange and the Rule of Law Framework“, in: Jakab, András \& Kochenov, Dimitry (Hrsg.), The Enforcement of EU Law and Values, Oxford University Press, Oxford, 2017, S. 218-233, S. 232.

1066 S. supra unter C.I.

1067 Europäische Kommission, Mitteilung der Kommission an das Europäische Parlament und den Rat, Ein neuer EU-Rahmen zur Stärkung des Rechtsstaatsprinzips vom 11.03.2014, $\operatorname{COM(2014)~} 158$ final. 
2. das sog. "Justizbarometer der Europäischen Kommission“, das seit 2013 in jährlichen Ausgaben erscheint und bei Fertigstellung des Manuskripts in der Fassung von 2019 vorlag 1068

3. der sog. „Rechtsstaatlichkeitsdialog“ des Rates ${ }^{1069}$ mit erheblichen Einschränkungen in der tatsächlichen Durchführung

4. als dessen Nachfolger die sog. „periodic peer review“, eine deutsche und belgische Initiative. ${ }^{1070}$

Die beiden Verfahren des Justizbarometers und die Länderberichte sowie die länderspezifischen Empfehlungen des Europäischen Semesters sind auch als „neuausgerichtete“ Verfahren zu bezeichnen, denn sie sind solche, mit denen ursprünglich ein rechtsstaatsspezifisches Monitoring, noch dazu im Hinblick auf Defizite, nicht intendiert war, die die Kommission aber im Verlauf der Krise hierauf zugeschnitten hat.

II. „Vollständige“, d.h. mit eigener Berichtigungsphase versehene Aufsichtsverfahren, darunter aus dem Primärrecht:

1. das Verfahren nach Art. 7 EUV insbesondere

2. das Vertragsverletzungsverfahren, wobei vor allem dessen „ordentliche“ Fassung, also das Verfahren nach Art. 258 AEUV, bislang zur Anwendung gelangt ist, in der Literatur aber auch Varianten, wie insbesondere das Verfahren nach Art. 259 AEUV, 325 AEUV und Art. 348 AEUV, zur Anwendung vorgeschlagen worden sind

3. abhängig von ihrem konkreten Inhalt, die sog. Länderberichte bzw. länderspezifischen Empfehlungen des Europäischen Semesters, ${ }^{1071}$ die die Kommission bzw. die Kommission und der Rat jährlich an die Mitgliedstaaten richten.

1068 Europäische Kommission, Mitteilung der Kommission an das Europäische Parlament, den Rat, die Europäische Zentralbank, den Europäischen Wirtschafts- und Sozialausschuss und den Ausschuss der Regionen, EU-Justizbarometer 2019, $\operatorname{COM}(2019) 198$ final vom 26.04.2019.

1069 Vgl. insb. Rat der Europäischen Union, Schlussfolgerungen des Rates der EU und der im Rat vereinigten Mitgliedstaaten über die Gewährleistung der Achtung der Rechtsstaatlichkeit, 16134/14 vom 12.12.2014.

1070 U.a. Opening speech by Minister of State for Europe Michael Roth at the PeerReview-Workshop on Rule of Law“, of 7 November 2018, verfügbar unter: https://www.auswaertigesamt.de/en/newsroom/news/-/2158210.

1071 Vgl. Europäische Kommission Commission Staff Working Document Country Report Poland 2019 Accompanying the document Communication from the Commission to the European Parliament, the Council, the European Parliament, the Council, the European Central Bank and the Eurogroup, 2019 European Semester: Assessment of progress on structural reforms, prevention and correction of macroeconomic imbalances, and results of in-depth 
Aus dem Sekundärrecht treten hinzu:

1. der bereits in Grundzügen dargestellte und nicht nochmals vertieft aufzugreifende CVM, also das spezifisch gegenüber Rumänien und Bulgarien genutzte Verfahren

2. die Novelle der sog. Parteienverordnung, die nunmehr gegenüber europäischen politischen Parteien Sanktionen bei Unvereinbarkeit eigener Aktivitäten mit den Werten des Art. 2 EUV ermöglicht.

III. Zu diesen Verfahren im bestehenden Recht, von denen nicht alle zur Anwendung gelangt sind, treten schließlich eine Reihe von gesetzgeberischen Vorschlägen bzw. nichtlegislativen Initiativen, für welche der Ausgang ungewiss ist, deren Analyse sich hier aufgrund ihres $\mathrm{Zu}$ schnitts aber lohnt. Es handelt sich zunächst um zwei im Falle ihres Inkrafttretens rechtsverbindliche Verfahren, nämlich:

1. Den Verordnungsvorschlag der Europäischen Kommission betreffend die Schaffung einer neuen Konditionalität zum Schutz des EU-Haushalts bei sog. „generellen Mängeln“ in Bezug auf das Rechtsstaatsprinzip ${ }^{1072}$

2. Den Vorschlag des Europäischen Parlaments zur Schaffung eines organübergreifenden Verfahrens zum Schutz der „Demokratie, Rechtsstaatlichkeit und der Grundrechte", besser bekannt unter seinem Kürzel „DRF-Pakt““.1073

Hinzu tritt schließlich, in enger Parallele zur sog. „periodic peer review“ des Rates, indes bislang weit weniger konkret:

reviews under Regulation (EU) No 1176/2011, SWD(2019) 1020 final, vom 27.02.2019; Commission Staff Working Document, Country Report Hungary 2019, Accompanying the document Communication from the Commission to the European Parliament, the Council, the European Central Bank and the Eurogroup, 2019 European Semester: Assessment of progress on structural reforms, prevention and correction of macroeconomic imbalances, and results of in-depth reviews under Regulation (EU) No 1176/2011, SWD(2019) 1016 final vom 27.02.2019. Zur besseren Lesbarkeit ist nachfolgend das Vollzitat der Dokumente abgekürzt.

1072 Europäische Kommission, Vorschlag für eine Verordnung des Europäischen Parlaments und des Rates über den Schutz des Haushalts der Union im Falle von generellen Mängeln in Bezug auf das Rechtsstaatsprinzip in den Mitgliedstaaten vom 02.05.2018, $\operatorname{COM}(2018) 324$ final.

1073 Vgl. Europäisches Parlament, P8_TA(2016)0409, EU-Mechanismus für Demokratie, Rechtsstaatlichkeit und Grundrechte, Entschließung des Europäischen Parlaments vom 25. Oktober 2016 mit Empfehlungen an die Kommission zur Einrichtung eines EU-Mechanismus für Demokratie, Rechtsstaatlichkeit und die Grundrechte (2015/2254(INL)). 
3. Ein durch die Kommission bislang lose ausgearbeiteter Vorschlag, den sie „Zyklus zur Überprüfung der Rechtsstaatlichkeit“" nennt, ${ }^{1074}$ und der, soll er einsetzbar sein bzw. einen echten Beitrag zum Instrumentarium der Kommission liefern, weiter substantiiert werden muss. Es ist derzeit offen, ob er eine Alternative zum an anderer Stelle sog. „umfassenden europäischen Rechtsstaatlichkeitsmechanismus"1075 ist oder ob er vielmehr eine weitere Ausprägung dieses Verfahrens darstellt.

Schließlich sind sowohl in der Literatur als auch in der Praxis einige wenige Normen des Unionsprimärrechts regelmäßig zur weiteren Nutzung im Rahmen der Rechtsstaatlichkeitskrise vorgeschlagen worden, ohne dass darüber aber bislang konkrete Vorschläge vorliegen. Wiederholte Bedeutung hat diesbezüglich Art. 70 AEUV erlangt. ${ }^{1076}$ Auch hat es einen Vorschlag aus der Rechtswissenschaft zur Schaffung einer neuen nachrangigen Behörde oder sogar eines weiteren Organs gegeben, nämlich die zunächst bei Müller und später bei von Bogdandy u.a. nochmals aufgegriffene Idee einer sog. „Kopenhagen-Kommission“. 1077 Da für diese Arbeit vorrangig die bereits in Kraft befindliche Rechtslage interessiert, greife ich diese Vorschläge nur bei gegebenem Anlass auszugsweise auf.

1074 Europäische Kommission, Mitteilung der Kommission an das Europäische Parlament, den Europäischen Rat, den Rat, den Europäischen Wirtschafts- und Sozialausschuss und den Ausschuss der Regionen: Die Stärkung der Rechtsstaatlichkeit in der Union: Ein Konzept für das weitere Vorgehen, COM(2019) 343 final vom 17.07.2019, S. 11.

1075 Vgl. Ursula von der Leyen, Mission Letter to Dider Reynders, vom 10.09.2019, ohne Az., S. 4.

1076 So bei Christophe Hillion, „Overseeing the Rule of Law in the EU: Legal Mandate and Means“, S.77, Fn. 67; Laurent Pech \& Kim Lane Scheppele, „Illiberalism Within: Rule of Law Backsliding in the EU“, S.34. Vgl. auch Art. 10 des Entwurfs einer Entschließung des Europäischen Parlaments mit Empfehlungen an die Kommission zur Einrichtung eines EU-Mechanismus für Demokratie, Rechtsstaatlichkeit und die Grundrechte (2015/2254(INL)).

1077 Jan-Werner Müller „Protecting the Rule of Law (and Democracy!) in the EU: The Idea of a Copenhagen Commission“, in: Carlos Closa \& Dimitry Kochenov (Hrsg.), Reinforcing Rule of Law Oversight in the European Union, 2016, S. 206-224, S. 213 ff.; Armin von Bogdandy, Carlino Antpöhler \& Michael Ioannidis, „Protecting EU values: Reverse Solange and the Rule of Law Framework", in: András Jakab \& Dimitry Kochenov Hrsg., The Enforcement of EU Law and Values, Oxford University Press, Oxford, 2017, S. 218-233, S. 228 ff. mit umfassenden Ausführungen, die insbesondere auf den Funktionsstrukturen des OLAF bauen. 
Bevor ich zu Überlegungen betreffend die einzelnen Mechanismen komme, schalte ich zwei Punkte vor. Zunächst sind einige Ausführungen zu den Akteuren zu machen, die im Rahmen der Rechtsstaatlichkeitskrise in Erscheinung getreten sind. Dabei bleibt der Fokus auf die Tätigkeit der Europäischen Kommission gerichtet, und es ist, von ihr ausgehend, zur Verständigung und Kooperation mit weiteren EU-Organen, nachrangigen Agenturen, insbesondere der FRA, sodann zu Einrichtungen des Europarates Stellung zu nehmen.

Ein zweiter Punkt betrifft verfahrensübergreifende Überlegungen zu Handlungsgrundsätzen innerhalb der Kommission, die die dortige Arbeit grundlegend strukturieren. Für diese ist die Quellenlage dünn, außer der Verbürgung für Sorgfalt beim Gespräch mit beteiligten Praktikern im Wege einer teilnehmenden Beobachtung kann ich wenig anbieten. Ich meine indes, dass sie doch für die Rechtswissenschaft von Mehrwert sind. Ich habe mich dabei bewusst für eine Reduzierung der Eindrücke auf derartige Grundsätze entschieden und biete keine Feldstudie o.ä. an, die gerade in Bezug auf die Kommission auf eine recht große Tradition verweisen kann. ${ }^{1078}$ Ebenso bewusst spreche ich vorrangig von Grundsätzen, statt Prinzipien oder sogar Maximen, da mit letzteren eine gedankliche Durchdringung bei ihrer Nutzung impliziert ist, die sich mit der Pragmatik in der Praxis nicht durchweg deckt.

\section{Die Akteure der Verfassungsaufsicht}

Wie schon die Rechtsstaatlichkeitskrise in ihrem Sachstandsverlauf höchst komplex ist und wie darüber die Verfassungsaufsicht der Union aus einer

1078 Hussein Kassim, John Peterson, Michael W. Bauer, Sara Connolly, Renaud Dehousse, Liesbet Hooghe, \& Andrew Thompson, The European Commission of the Twenty-First Century, Oxford University Press, Oxford, 2013; Mark A. Pollack, The Engines of European Integration, Oxford University Press, Oxford, 2003, dort insb. Kap. 2, wonach die Kommission als Stellvertreter (agent) in einem Freiraum aus übertragenen Komptenzen und eigenem Ermessen handele; Grundlegend und sehr informativ Neill Nugent (Hrsg.), At the Heart of the Union: Studies of the European Commission, Macmillan, Houndmills, Basingstoke/London, 1997; zur Rolle einzelner Referenten und ihrer Ausbildung auch bei Didier Georgakakis \& Marine de Lassalle, „Where Have all the Lawyers Gone? Structure and Transformations of Top European Officials' Legal Training “, in: Antoine Vauchez \& Bruno de Witte (Hrsg.), Lawyering Europe: European Law as a Transnational Social Field, Hart, Oxford \& Portland, 2013, S. 137-151. 
Mehrzahl an Verfahren besteht, so ist auch im Hinblick auf die Akteure, d.h. die mit Hoheitsbefugnissen oder jedenfalls politischem Einfluss ausgestatteten, in der Krise handelnden Strukturen, ${ }^{1079}$ eine enorme Vielfalt an parallelen und gegenläufigen Initiativen auszumachen und teils ein Wettstreit um öffentliche Aufmerksamkeit, Deutungshoheit und Obsiegen eigener Regelungsvorschläge zu erkennen.

Zum Zweck der Überschaubarkeit blende ich dabei hier diejenigen Akteure aus, die nicht öffentliche Gewalt ausüben. ${ }^{1080}$ Es ist indes anzumerken, dass - die Wissenschaft nicht eingerechnet - private Akteure, darunter namentlich zahlreiche NGOs, in der Krise zum besseren Verständnis der Vorgänge vielfach beigetragen haben. ${ }^{1081}$

1. Die Europäische Kommission in Relation zu anderen Organen der Union

a. Mandat aus Art.17 EUV, Rolle der Kommission im Verfahren nach Art. 7 EUV

Der Europäischen Kommission erwächst im Rahmen der Rechtsstaatlichkeitskrise eine ganz herausgehobene Relevanz. Dies zeigt sich zunächst bei einem Blick auf die durch die Verträge zugewiesene Rolle der Kommission und daraus folgend die durch sie ergriffenen konkreten Schritte. ${ }^{1082}$ Art. 17 Abs. 1 EUV beschreibt u.a. drei Aufgaben der Kommission als „Hüterin

1079 In diesem Sinne erfreut sich der Begriff des Akteurs in der jüngeren Wissenschaft vom öffentlichen Recht allgemein, und im Europarecht im Besonderen, reger Beliebtheit, vgl. insb. Steffen Augsberg: „\$2 Akteure im Verfahren“, in: Stefan Leible \& Jörg-Philipp Terhechte (Hrsg.), Europäisches Rechtsschutzund Verfahrensrecht, Band 3 der Enzyklopädie Europarecht, Nomos, BadenBaden, 2014, S. 63-74. insb. S. 64 mit Berücksichtigung der Begriffsgenese.

1080 Rezeption des Begriffs der öffentlichen Gewalt für das Unionsrecht bei Johanna Elisabeth Dickschen, Empfehlungen und Leitlinien als Handlungsform der Europäischen Finanzaufsichtsbehörden, S. 2 und 16 ff., bauend auf Matthias Goldmann, Internationale öffentliche Gewalt: Handlungsformen internationaler Institutionen im Zeitalter der Globalisierung, Springer, Heidelberg, 2015.

1081 Vgl. etwa die zahlreichen Veröffentlichungen des sog. „Helsinki-Komitees“ in Ungarn, das u.a. Rechtsgutachten und Übersetzungen von Gesetzestexten zur Verfügung gestellt hat, verfügbar über die Webseite der NGO unter helsinki.hu.

1082 Zur alten Rechtslage nach Art. 211 EGV bereits Ulrike Kassner, Die Unionsaufsicht, S. 56 ff., m. w. N. 
der Verträge“, 1083 die im Rahmen der Krise von Bedeutung sind: zunächst, Art. 17 Abs. 1 S. 1 EUV, die Aufgabe der Förderung der Unionsinteressen und des Vorschlags von Initiativen, die regelmäßig durch Mitteilungen erfolgen und welche etwa bei der Vorlage des sog. EU-Rahmens oder der beiden programmatischen Mitteilungen zur Rechtsstaatlichkeit 2019 eine konkrete Form gefunden haben, sodann, Art. 17 Abs. 1 S. 2 EUV, die aus eigenem Antrieb vorgenommenen Maßnahmen zur Anwendung des Unionsrechts und schließlich, S. 3, die Überwachung dieser Anwendung unter der „Kontrolle“ des Gerichtshofs. Regelmäßig sind die beiden letzten Sätze des Mandats aus Art. 17 EUV auch zu einer einheitlichen Aufgabe zusammengefasst worden, ${ }^{1084}$ doch man mag hierin auch eine gestufte Aufgabe sehen, in der zunächst eigene Initiativen, wie z.B. rechtsunverbindliches Monitoring der Kommission, im Vordergrund steht (Sätze 1 und 2) und hieran umfassende Aufsichtsmaßnahmen, letztlich unter Einleitung des kontradiktorischen Vertragsverletzungsverfahrens vor dem Gerichtshof, anknüpfen.

Die Kommission hat sich auf ihre Aufgabenbenennung aus Art. 17 Abs. 1 EUV, ungeachtet der nicht zwingend damit unmittelbar einhergehenden Kompetenzen, regelmäßig berufen, um konkretes Handeln in der Krise zu legitimieren. So heißt es in der Mitteilung über den EU-Rahmen: „Der Kommission obliegen als Hüterin der Verträge die Achtung der Werte, auf die sich die EU gründet, und der Schutz der allgemeinen Interessen der Union. Sie muss daher jetzt aktiv werden." 1085 In einer Mitteilung aus dem Jahr 2017, der hier sog. „Better Results“-Mitteilung, hat die Europäische Kommission die Norm sogar ausdrücklich mit dem Rechtsstaatsprinzip verknüpft und die Stärkung desselben unter Erfüllung ihrer

1083 Art. 17 EUV beschreibt und fasst Aufgaben der Kommission zusammen, ohne ihre Tätigkeit oder ihre Kompetenzen abschließend zu umschreiben, vgl. Bernd Martenczuk, Art. 17 EUV, in: Eberhard Grabitz, Meinhard Hilf \& Martin Nettesheim (Begr./Hrsg.), Das Recht der Europäischen Union, C.H. Beck, München,, Rn. 6 ff., ebenso Florian Schmidt \& Helmut Schmitt von Sydow, Art. 17 EUV, in: Hans von der Groeben, Jürgen Schwarze \& Armin Hatje (Begr./Hrsg.), Europäisches Unionsrecht, 7. Aufl. 2015, Rn. 14 ff.

1084 Bernd Martenczuk, Art. 17 EUV, in: Eberhard Grabitz, Meinhard Hilf \& Martin Nettesheim (Begr./Hrsg.), Das Recht der Europäischen Union, C.H. Beck, München, 68. EL 2019, Rn. 15 ff.

1085 Europäische Kommission, Mitteilung der Kommission an das Europäische Parlament und den Rat, Ein neuer EU-Rahmen zur Stärkung des Rechtsstaatsprinzips vom 11.03.2014, $\operatorname{COM}(2014) 158$ final, S. 2. 
Aufgaben als politische Priorität der Juncker-Kommission beschrieben. ${ }^{1086}$ Der Gerichtshof wiederum hat, wenn auch nicht spezifisch im Hinblick auf die hiesige Situation, aus Art. 17 Abs. 1 EUV für die Kommission auch unmittelbare Pflichten abgeleitet. ${ }^{1087}$

Verschiedene Verfahren, die in der Rechtsstaatlichkeitskrise besondere Prominenz erlangt haben, spiegeln diese Aufgabenwahrnehmung durch die Kommission unmittelbar. Das gilt neben dem EU-Rahmen, für welchen die Kommission dies unmittelbar anführt, vorrangig für das Vertragsverletzungsverfahren, insbesondere dasjenige aus Art. 258 AEUV, dessen Einleitung allein der Europäischen Kommission zufällt. Auch das Verfahren nach Art. 259 AEUV, das die Klagebefugnis den Mitgliedstaaten zuweist, sieht im Grundsatz zumindest eine Konsultierung der Kommission vor. Da in der Krise, im Unterschied zum früheren Kenntnisstand in der Literatur Anfang der nuller Jahre, diese Verfahren, die der Kommission ohnehin eine entscheidende Rolle zuweisen, zur Anwendung gelangt sind, ist darüber auch ihre Bedeutung umso mehr gewachsen.

Gerade im Hinblick auf das Vertragsverletzungsverfahren bleibt es darüber bei allenfalls akzessorischen Rechten und Befugnissen anderer Organe, wie insbesondere des Parlaments, das folglich an Befugnissen gegenüber der Kommission stark zurücksteht. Luca Prete hat zwar jüngst exemplarisch in Erinnerung gerufen, dass das Parlament 1983 die sog. „Sieglerschmidt-Entschließung" betreffend größere Transparenz bei der Nutzung des Vertragsverletzungsverfahrens angenommen hatte und dass infolge dieser Entschließung die Kommission seitdem regelmäßig Bericht über

1086 Europäische Kommission, Mitteilung der Kommission, EU-Recht: Bessere Ergebnisse durch bessere Anwendung, ABl. (EU) C 18/10 vom 19.01.2017. Das Zitat lautet: „Die Europäische Union gründet auf dem Rechtsstaatsprinzip. Sie stützt sich auf Rechtsvorschriften, um sicherzustellen, dass ihre Politik und ihre Prioritäten in den Mitgliedstaaten umgesetzt werden. Die Kommission ist nach Artikel 17 Absatz 1 des Vertrags über die Europäische Union für die wirksame Anwendung, Umsetzung und Durchsetzung der Rechtsvorschriften zuständig. Dies ist eine wichtige politische Priorität der Kommission Juncker und Bestandteil der von der Kommission angestrebten besseren Rechtsetzung“. Der Kurztitel „Better-Results“-Mitteilung ist dem englischen Titel der Mitteilung entlehnt.

1087 Vgl. insb. EuGH, Verb. Rs. C-8/15 P bis C-10/15 P, Ledra Advertising Ltd u.a. ./. Kommission, Urteil (GK) vom 20.09.2016, ECLI:EU:C:2016:701, Rn. 66 und 67, Koen Lenaerts \& José A. Gutiérrez-Fons, „The European Court of Justice as the Guardian of the Rule of EU Social Law", in: Frank Vandenbroucke; Catherine Barnard \& Geert De Baere (Hrsg.), A European Social Union after the Crisis, Cambridge University Press, Cambridge, 2017, S. 433-456, S. 441. 
ihre Handhabung des Vertragsverletzungsverfahrens erstattet. ${ }^{1088}$ Doch zu einer eigenen Aufsichtskompetenz des Parlaments oder anderer Organe hat dies in diesem Verfahrensrahmen nicht geführt. Wäre die Rechtsstaatlichkeitskrise also eine solche, die allein die Nutzung des Vertragsverletzungsverfahrens zum Gegenstand gehabt hätte, hätte sich die Akteursperspektive wohl weitgehend erübrigt.

Da die Aufmerksamkeit zu Beginn in Praxis und Wissenschaft indes nicht auf dem Vertragsverletzungsverfahren, sondern auf Art. 7 EUV lag, ist die Lage sehr viel weniger eindeutig. Der Wortlaut dieser Norm, auf welche die Kommission die Schaffung des EU-Rahmens in ihrem „Vorfeld“ gestützt hat, weist die Feststellungsbefugnis über das Vorliegen der Tatbestandsvoraussetzungen des Art. 7 Abs. 1 EUV dem Rat, für Abs. 2 dem Europäischen Rat und für Abs. 3 EUV wiederum dem Rat zu. Den übrigen genannten Organen bzw. den Mitgliedstaaten bleibt in den Absätzen 1 und 2 lediglich eine Vorschlagskompetenz, wobei die Kommission immer als letzte unter mehreren Vorschlagsbefugten genannt wird. In Art.7 Abs. 1, der bislang in der Krise genutzten Verfahrensstufe heißt es: „Auf begründeten Vorschlag eines Drittels der Mitgliedstaaten, des Europäischen Parlaments oder der Europäischen Kommission kann der Rat $[\ldots]$ nach Zustimmung des Europäischen Parlaments feststellen [...].“ Schorkopf ist, gerade mit Blick auf die Zustimmungsbefugnis des Parlaments, in seiner Kommentierung zum Verfahren sogar so weit gegangen, eine eigenständige Organbeteiligung der Kommission nach Einleitung des Verfahrens, wenn dieses also vor dem Rat anhängig ist, auszusparen. ${ }^{1089}$ Auch Kassner hat die stark verminderte Bedeutung der Kommission, gerade im Unterschied zum Rat, betont. ${ }^{1090}$

\section{b. Verhältnis von Kommission und Rat}

Mit der dem Wortlaut nach sehr nachrangigen Rolle der Kommission aus Art. 7 EUV, insbesondere dem derzeit genutzten Abs. 1, kontrastiert ihre überragende Bedeutung im Zuge der Krise in der Rechtswirklichkeit

1088 Luca Prete, Infringement Proceedings in EU Law, S. $296 \mathrm{ff}$., insb. 298. Die Berichte seit 1983 sind abrufbar unter: https://ec.europa.eu/info/publications/a nnual-reports-monitoring-application-eu-law_en.

1089 Frank Schorkopf, Art. 7 EUV, in: Eberhard Grabitz, Meinhard Hilf \& Martin Nettesheim (Begr./Hrsg.), Das Recht der Europäischen Union, C.H. Beck, München, 68. EL Oktober 2019, Rn. 24.

1090 Ulrike Kassner, Die Unionsaufsicht, S. 56 ff, insb. S. 57. 
im Bereich der Entwicklung und Durchführung der Verfassungsaufsichtsinstrumente. Hierfür sind drei Gründe maßgeblich.

Zunächst ist der Umstand zu nennen, dass die Kommission in der Krise sehr früh gehandelt hat („first mover“-Vorteil). ${ }^{1091}$ Das gilt in mehrfacher Hinsicht. Sie war die erste, die im März 2014 mit dem neu vorgestellten EU-Rahmen ein spezifisch neues Verfahren in der Krise eingeführt hat, der Rat hat mit seinem „Rechtsstaatlichkeitsdialog“ im Herbst 2014 erst nachgezogen. Es war die Kommission, die als erste das Verfahren nach Art. 7 Abs. 1 EUV nutzte und darüber den bis dato in der Praxis nicht existenten „begründeten Vorschlag“ formte. Man kann hier sogar von der erstmaligen Nutzung einer insofern neuen Handlungsform im Unionsrecht sprechen. Das Parlament zog zu Ungarn erst nach. Und es war die Kommission, die das Vertragsverletzungsverfahren gegenüber den Mitgliedstaaten auch in Bezug auf den Schutz der Rechtsstaatlichkeit in Anschlag brachte. Kein Mitgliedstaat hat, obwohl nach Art. 259 AEUV dazu befugt, bis heute mit der Kommission gleichgezogen.

Der zweite Grund ist die in der Kommission konzentrierte Sachexpertise. Dieses Argument hat in Kontrast zu seiner vorherigen Kommentierung Schorkopf, dort für die Rolle der Kommission nach Art.7 EUV, entwickelt, und ich stimme ihm zu. Er meint, die dortigen Ressourcen in personeller wie sachlicher Hinsicht seien derart betont und vorteilhaft, dass man der Kommission sogar nach Einleitung des Verfahrens nach Art. 7 EUV, ${ }^{1092}$ also heute nach Ausübung ihres Vorschlagsrechts nach Art. 7 Abs. 1 EUV, ein weitgehendes Beteiligungsrecht in den Ratsverhandlungen über den Wortlaut der Norm hinaus zugestehen müsse. ${ }^{1093}$ Die Beteiligungspraxis ab 2017 zeigt, wie sehr die Kommission dort umfassend Prägewirkung entfaltet hat und den Diskurs bestimmt, auch wenn die Vorgänge nur fragmentarisch öffentlich geworden sind. So hat der Rat der Kommission, nicht etwa seinem eigenen juristischen Dienst, die Aufgabe zukommen lassen, ein Arbeitspapier betreffend „faktische Informationen zu wertebezogenen Vertragsverletzungsverfahren im Hinblick auf

1091 In einigen wesentlich späteren Beratungen zu anderen Fragen der zuständigen Dienststellen ist dies unter dem Schlagwort „il faut occuper le terrain“ auch nochmals Gegenstand der Überlegungen gewesen, wenn darin auch kein Handlungsgrundsatz zu sehen ist, wie ich sie unter E. III. darstelle.

1092 Bezugspunkt ist dort noch der heute im wesentlichen Art. 7 Abs. 2 EUV entsprechende Art. 7 Abs. 1 EUV in der Fassung von Amsterdam.

1093 Frank Schorkopf, Homogenität in der Europäischen Union, S. 154. 
Ungarn" vorzulegen, ${ }^{1094}$ das anschließend die Arbeitsgrundlage im Rat war. Die Europäische Kommission erstattet regelmäßig Bericht durch Vorlage eines „state of play“ und zwar zu beiden Verfahren, die im Rat nach Art. 7 Abs. 1 EUV anhängig sind, nämlich das durch sie selbst angestoßene und das durch das Parlament durchgeführte Verfahren.

Entscheidend ist drittens der Umstand, dass die Kommission sowohl in diesem Verfahren, als auch im Vertragsverletzungsverfahren, durch ihre Antragsbefugnis das Verfahren kanalisieren und formen kann.

Für das Parlament, in einer Frühphase aber insbesondere für die Dienststellen des Rates, bestand im Hinblick auf die Vorstöße der Kommission unter dem Eindruck des Wortlauts des Art. 7 Abs. 1 EUV nicht nur ein Kontrast, sondern auch ein Widerspruch, bis hin zum Vorwurf der unzulässigen Kompetenzanmaßung. Die Irritation der anderen EU-Organe fußte dabei sowohl auf der Ausübung des Vorschlagsrechts der Kommission wie auch auf ihrer konkreten Ausgestaltung.

In einer scharfen Reaktion im Mai 2014 wies der Juristische Dienst des Rates den Vorschlag der Kommission zurück, den von ihr vorgeschlagenen EU-Rahmen einzuführen. Die Ausführungen der Kommission, wonach der Rahmen „im Vorfeld“ des Art. 7 EUV anzusiedeln sei, ein Umstand, auf den die Arbeit noch eingeht, wurde zunächst in dem Gutachten ausführlich auf ihre Vereinbarkeit mit den Verträgen hin überprüft. ${ }^{1095}$ Konsequenterweise hat die Aufarbeitung in der Literatur ebenso vorrangig diese Kompetenzfrage aus dem Gutachten herausgearbeitet. ${ }^{1096}$ Der eigentliche Stein des Anstoßes für den Juristischen Dienst des Rates findet sich aber, etwas versteckt aufgrund des Katalogs der zuvor geltend gemachten Primärrechtsnormen, am Ende des Dokuments. Der Juristische Dienst des Rates bemängelt darin, dass die Mitgliedstaaten, nicht die Kommission, über die Beurteilung der Einhaltung des Rechtsstaatsprinzips entscheiden können müssten. Der Juristische Dienst des Rates sah aber, das ist in die

1094 Rat der Europäischen Union, Interinstitutional File: 2018/0902(COD), Values of the Union - Hungary - Article 7 (1) vom 8. November 2018, 14022/18, vom 08.11.2018. Die Originalformulierung auf dem Deckblatt lautet: „Delegations will find in the Annex a Commission non-paper providing factual information on the values-related infringement proceedings in relation to Hungary."

1095 Juristischer Dienst des Rates, „Mitteilung der Kommission „Ein neuer EURahmen zur Stärkung des Rechtsstaatsprinzips": Vereinbarkeit mit den Verträgen“, vom 27.05.2014, 10296/14, Rn. 15 ff.

1096 Peter Oliver \& Justine Stefanelli, „Strengthening the Rule of Law in the EU: The Council's Inaction“, in: Journal of Common Market Studies 54 (2016), S. 1075-1084, S. $1076 \mathrm{ff}$. 
Feststellung hineinzulesen, den Rat dabei als zentrales Forum dieser Aussprache an, womit der Kommission lediglich die „Möglichkeit zur Teilnahme bliebe“, den Mitgliedstaaten wiederum verbleibe größtmöglicher Spielraum. ${ }^{1097}$ Letzteres hat insbesondere Möllers und Schneider interessiert, es sei den Mitgliedstaaten um eine Verhinderung der Beschneidung ihres diplomatischen Spielraums gegangen. ${ }^{1098}$ Das halte ich für zutreffend, man mag aber hinzufügen, dass zumindest vermutet werden darf, dass die Rolle des Rates als Forum der Mitgliedstaaten weiteres zentrales Anliegen war.

Die Kommission entschied, das Gutachten des Juristischen Dienstes des Rates zumindest öffentlich weitgehend zu ignorieren, ${ }^{1099}$ und damit einen Konflikt zu vermeiden, am wahrscheinlichsten aufgrund des Umstandes, dass man die Lage gerade im Hinblick auf die potentiell adressierten Mitgliedstaaten nicht anheizen wollte und darum wusste, dass jegliche Entscheidung nach Art. 7 EUV zur engen Einbindung des Rates führen würde.

Der Rat selbst ließ, nur einen Monat nach dem so kritischen Gutachten seines Juristischen Dienstes, dabei durchaus versöhnlichere Töne anklingen. In seinem „Achtzehnmonatsprogramm“ vom Juni 2014, also einen Monat nach Veröffentlichung des soeben genannten Gutachtens, findet sich unter dem Titel „Rechtsstaatlichkeit“ der Passus:

„Der Rat wird die künftigen Entwicklungen eines neuen EU-Rahmens zur Stärkung der Rechtsstaatlichkeit genau verfolgen, damit zukünftige systembedingte Gefahren für die Rechtsstaatlichkeit in den Mitgliedstaaten beseitigt werden können, noch bevor die Bedingungen

1097 Juristischer Dienst des Rates, „Mitteilung der Kommission „Ein neuer EURahmen zur Stärkung des Rechtsstaatsprinzips“: Vereinbarkeit mit den Verträgen“, vom 27.05.2014, 10296/14, Rn. 25 und 26. Das Zitat lautet: „Nach Auffassung des Juristischen Dienstes des Rates gäbe es allerdings eine mit den Verträgen in Einklang stehende Lösung, die eine stärkere Überwachung der Achtung der Rechtsstaatlichkeit als solche durch die Mitgliedstaaten ermöglichen würde. Die Lösung besteht darin, dass die Mitgliedstaaten - und nicht der Rat - ein System zur Überprüfung des Funktionierens der Rechtsstaatlichkeit in den Mitgliedstaaten, das erforderlichenfalls der Kommission und anderen Organen die Möglichkeit zur Teilnahme bietet, vereinbaren und sich darüber einigen, welche Konsequenzen die Mitgliedstaaten bereit wären, aus einer solchen Überprüfung zu ziehen.“

1098 Christoph Möllers \& Linda Schneider, Demokratiesicherung in der Europäischen Union, S. $142 \mathrm{ff}$.

1099 So auch Peter Oliver \& Justine Stefanelli, „Strengthening the Rule of Law in the EU“, S. 1078, wonach Frans Timmermans hierauf bei nächster Gelegenheit in einer Rede schlicht nicht eingegangen sei. 
für die Aktivierung des in Artikel 7 EUV vorgesehenen Mechanismus eintreten." 1100

Das liest sich im Grundsatz als Unterstützung für die Kommission und auch Akzeptanz des durch sie gemachten Vorstoßes, „systembedingte Gefahren" in Mitgliedstaaten genauer zu berücksichtigen.

Fast zeitgleich mit dieser Feststellung ergriff der Rat dann unter Auslotung der Möglichkeiten zum Handeln seitens der Mitgliedstaaten selbst die Initiative und stellte sein eigenes, mit dem Verfahren der Kommission implizit konkurrierendes, Verfahren, den sog. „Rechtsstaatlichkeitsdialog“, vor, ${ }^{1101}$ womit sich aufdrängt, dass er diesen in direkter Konkurrenz zum EU-Rahmen sehen wollte und der Kommission eine autonome Ausgestaltung des Verfassungsaufsichtsinstrumentariums absprach. Dieser Rechtsstaatlichkeitsdialog, der vom Rat später einer Evaluierung unterzogen worden ist, ${ }^{1102}$ soll durch die seitens Belgien und Deutschland vorgezogene „periodic peer review“ ersetzt werden, ${ }^{1103}$ beide Verfahren sind noch darzustellen. Was das Verfahren nach Art. 7 Abs. 1 EUV, sowohl im Hinblick auf Polen als auch auf Ungarn, angeht, dürfen mögliche Bedenken des Rates als erledigt gelten - die Kommission erstattet hier regelmäßig Bericht, und der Rat fungiert folglich als zentrales Forum zur Verhandlung der Beurteilung, ganz wie durch die Norm vorgesehen. ${ }^{1104}$

1100 Rat der Europäischen Union, „Vermerk der künftigen Vorsitze (Italien, Lettland und Luxemburg), Achtzehnmonatsprogramm des Rates (1. Juli 2014 31. Dezember 2015)“, 11258/14 vom 23.06.2014, S. 22.

1101 Zum zeitlichen Zusammenhang Peter Oliver \& Justine Stefanelli, „Strengthening the Rule of Law in the EU”, S. 1078.

1102 Rat der Europäischen Union, „Rechtsstaatlichkeit - Bewertung des Mechanismus“, 13980/16, vom 09.11.2016.

1103 Vgl. dazu insb. „Discours du Ministre D. Reynders lors de la 5ème Conférence belgo-allemand [sic] (Debeko), axée cette année sur les thèmes de la digitalisation, l'énergie et le transport" vom 18. März 2019, S. 5, verfügbar unter: https:/ /diplomatie.belgium.be/sites/default/files/downloads/discours_debeko_201 90318.pdf; „Opening speech by Minister of State for Europe Michael Roth at the Peer-Review-Workshop on Rule of Law“, of 7 November 2018, verfügbar unter: https://www.auswaertigesamt.de/en/newsroom/news/-/2158210.

1104 Die Sitzungsdokumente sind nur vereinzelt öffentlich geworden, vgl. aber exemplarisch Rat der Europäischen Union, Values of the Union - Hungary - Article 7 (1) TEU Reasoned Proposal - Report on the hearing held by the Council on 16 September 2019, 12345/19 vom 19.09.2019, Limité, verfügbar unter: https://www.asktheeu.org/de/request/7287/response/23784/attach/6/st12 345.en19.pdf?cookie_passthrough=1, insb. S. 7 . 
In die Arbeit im Rat selbst ist nur vereinzelt Einblick gewährt worden, dafür sind die wenigen verfügbaren Quellen indes sehr aufschlussreich, sie weisen auf ein profundes Schisma anhand mindestens zweier großer Gruppen hin, wie ich dies bereits angesprochen hatte.

Zur ersten Aussprache des Rates für Allgemeine Angelegenheiten im Hinblick auf die Rechtsstaatlichkeit in Polen und zu Art. 7 EUV veröffentlichte das niederländische Außenministerium 2018 eine kurze Notiz, die unter dem Stichwort „Rule of Law Polen“ wie folgt festhielt:

„Alle Mitgliedstaaten, darunter die Niederlande, unterstützen die Bemühungen der Kommission und Polens. Das Kräfteverhältnis im Rat teilt sich in zwei Gruppen: Mitgliedstaaten, die in den angekündigten polnischen Gesetzesänderungen einen Weg zum Abschluss [des Verfahrens nach Art. 7 EUV] erblicken, und Mitgliedstaaten, die diesen ersten Schritt begrüßen und mehr erwarten. Die Niederlande erachtet den Respekt für die Rechtsstaatlichkeit als essentielle Voraussetzung für das gute Funktionieren der Union und gehören aus diesem Grund zur zweiten Gruppe“. 1105

In einer Antwort des niederländischen Kabinetts zur zweiten Ratssitzung vom 26.06.2018 wiederholt die niederländische Regierung die Grundzüge dieser Formulierung, betont, man habe dem polnischen Vertreter genaue Fragen gestellt, meint aber auch, die Fragen seien zufriedenstellend beantwortet worden. ${ }^{1106}$ Letzteres scheint eher eine diplomatische Formulierung zu sein, die Kritik bleibt offensichtlich bestehen.

Für Deutschland und Frankreich, auf deren Reaktionen ich hier die Sichtung exemplarisch beschränke, ${ }^{1107}$ zeigte sich in diversen Reaktionen

1105 Niederländisches Außenministerium, „Verslag Raad Algemene Zaken van 17 april 2018“, Anlage zu Schreiben BZDOC-819551856-33., abrufbar unter: https://www.rijksoverheid.nl/documenten/vergaderstukken/2018/04/23/verslag -raad-algemene-zaken-van-17-april-2018. Meine Übersetzung.

1106 Niederländisches Außenministerium, Inbreng van een besloten schrifteljik overleg Raad Algemene Zaken, Anlage zu Schreiben BZDOC-586679304-63 vom 18. Juli 2018, abrufbar unter: https:/www.rijksoverheid.nl/documenten/k amerstukken/2018/07/18/aanbiedingsbrief-bij-verslag-besloten-schriftelijk-overl eg-raad-algemene-zaken.

1107 S. aber zu divergierenden, nämlich deutlich verhalteneren Reaktionen, seitens z.B. etwa der tschechischen Regierung die Presseerklärung: „Premier Babiš spoke on the phone with the Polish Prime Minister Morawiecki“, Presseerklärung vom 20.12.2017, abrufbar unter: https://www.vlada.cz/en/media-centrum /aktualne/premier-babis-spoke-on-the-phone-with-the-polish-prime-minister-m orawiecki-162424/. 
der diplomatischen Dienste eine fragmentarische, gleichwohl konsistente Linie vorsichtiger aber eindeutiger Kritik.

Für Deutschland hielt im März 2017 der Botschafter in Warschau, Rolf Nikel, in Bezug auf populistische Strömungen fest:

„Diesen müssen wir klar entgegentreten. Populisten spielen mit der Angst der Menschen und bieten scheinbar einfache Lösungen für komplexe Probleme an. Im 20. Jahrhundert mussten wir in Europa viele, bittere Erfahrungen machen. Heute gründet unsere Zusammenarbeit auf einem festen Fundament gemeinsamer Werte. Freiheit und Menschenrechte, Rechtsstaat und Demokratie sind nicht verhandelbar und dürfen unter keinen Umständen gefährdet werden. " ${ }^{1108}$

Staatssekretär Michael Roth übernahm die Aufgabe, zur Entwicklung in Ungarn Position zu beziehen und äußerte sich dezidiert kritisch, insbesondere zur sog. „Stopp-Soros“-Kampagne. ${ }^{1109}$ In einer späteren Stellungnahme hielt er überdies fest:

„Ich rege an, künftig einen eigenen EU-Fonds für Grundwerte und Rechtsstaatlichkeit einzurichten. Mit diesem Fonds könnte die Zivilgesellschaft überall dort unterstützt werden, wo der Rechtsstaat unter Druck gerät. Denkbar wäre es, einen solchen Geldtopf im Rahmen des bestehenden Europäischen Fonds für Strategische Investitionen anzulegen." 1110

Sofern also nicht parallel oder alternativ zu Roths „Anregung“ Pläne für den späteren "Justice, Rights and Values Fund" in der Kommission separat bestanden, erscheint es aus diesem Interview, als sei der Fonds zumindest auch auf eine Anregung der deutschen Bundesregierung zurückzuführen.

Die französische Regierung wiederum hatte in Bezug auf Ungarn im Juli 2018 zunächst eine diplomatische Peinlichkeit zu verwalten. Staatspräsident Macron rief den amtierenden Botschafter mit sofortiger Wirkung ab, nachdem dieser sich ohne Rücksprache mit dem Quai d'Orsay sehr positiv zur Politik Viktor Orbáns geäußert hatte, was nicht der Linie der

1108 Rede vor Studierenden der höheren Handelsschule in Radom am 16. März 2017, abrufbar unter: https://polen.diplo.de/pl-de/rede-radom/484964.

1109 „Die EU ist eine Wertegemeinschaft“, Interview mit Michael Roth vom 27.02.2018, abrufbar unter: https://www.auswaertiges-amt.de/de/newsroom /roth-tagesspiegel/1625460, zunächst veröffentlicht im Tagesspiegel.

1110 „Die EU ist eine Wertegemeinschaft“, Interview mit Michael Roth vom 27.02.2018, abrufbar unter: https://www.auswaertiges-amt.de/de/newsroom /roth-tagesspiegel/1625460, zunächst veröffentlicht im Tagesspiegel. 
französischen Regierung entsprach und nachdem die französische Enthüllungsplattform Mediapart eine entsprechende Depesche durchgestochen hatte. ${ }^{1111}$ Die französische Regierung sprach indes von einem „turnusgemäßen Wechsel."1112

An anderer Stelle schloss Frankreich sehr deutlich die Reihen gerade mit Deutschland und den Niederlanden, und, wie die periodic-peer-review-Initiative erkennen lässt, auch etwa mit Belgien.

Die französische Regierung äußerte sich auch mehrfach kritisch zu einzelnen Vorgängen in Ungarn, namentlich zur „Lex NGO“1113 und zur „Lex CEU“. ${ }^{1114}$ Nach der Wiederwahl Orbáns im April 2018 hatte es die französische Regierung zudem, in einem für das diplomatische Protokoll sehr beachtlichen Schritt, vermieden, dem Wiedergewählten in der offiziellen Reaktion zu gratulieren. Stattdessen hieß es im Wortlaut:

„La France et la Hongrie [...] poursuivront leur dialogue politique au service du projet européen et de ses valeurs, auxquelles la France est attentive." 1115

Die französische Nationalversammlung stellte sich demonstrativ hinter die Regierung, die Kommission (Ausschuss) für Europaangelegenheiten nahm im Herbst 2018 einen voluminösen Bericht zur Rechtsstaatlichkeit an. ${ }^{1116}$

1111 Marguerite Zimmer, „ L'ambassadeur en Hongrie remplacé après la révélation d'une note pro-Orbán“, Mediapart vom 29.06.2018, weiter ebda., Corentin Léotard, "Macron ,désapprouve“ le soutien de l'ambassadeur de France en Hongrie à Viktor Orbán“vom 30.06.2018.

1112 Hongrie - Q/R - Extrait du point de presse (2 juillet 2018), abrufbar unter : https://www.diplomatie.gouv.fr/fr/dossiers-pays/hongrie/evenements/article/ho ngrie-q-r-extrait-du-point-de-presse-2-07-18.

1113 Hongrie - Q\&R - Extrait du point de presse du 15 juin 2017, https://www.diplo matie.gouv.fr/fr/dossiers-pays/hongrie/evenements/article/hongrie-q-r-extrait-d u-point-de-presse-du-15-juin-2017.

1114 Hongrie - Université d'Europe centrale - Déclaration de Harlem Désir (6 avril 2017), https:/www.diplomatie.gouv.fr/fr/dossiers-pays/hongrie/evenements/art icle/hongrie-universite-d-europe-centrale-declaration-de-harlem-desir-06-04-17.

1115 Hongrie - Q\&R - Extrait du point de presse (09.04.18), https://www.diplomatie .gouv.fr/fr/dossiers-pays/hongrie/evenements/article/hongrie-q-r-extrait-du-poi nt-de-presse-09-04-18. Die Frage des Journalisten lautete: „Bonjour, quelle est la réaction officielle de la France sur la victoire de Viktor Orban en Hongrie ?“

1116 Französische Nationalversammlung, Rapport d'information déposé par la Commission des affaires européennes sur le respect de l'État de droit au sein de l'Union européenne, $\mathrm{N}^{\circ} 1299$, vom 10.10.2018, abrufbar unter : http://www .assemblee-nationale.fr/dyn/15/rapports/due/115b1299_rapport-information. 
Staatspräsident Macron äußerte sich ebenso wiederholt. Er gab etwa mehreren osteuropäischen Zeitungen ein gemeinsames Interview. ${ }^{1117}$

Spätere Ratsdokumente bestätigen schließlich die durch die niederländische Regierung offengelegte Gruppenbildung im Rat, gerade im Umfeld der wertebezogenen Erweiterung der Rechtsregeln betreffend die ESIFonds. ${ }^{1118}$

\section{c. Schwache Rolle des Europäischen Parlaments trotz Aufsichtsbeteiligung}

Auch das Europäische Parlament hat es nicht unwidersprochen hingenommen, dass die Kommission in der Krise vorrangig früh tätig geworden ist. Wie der Rat, so hat auch das Parlament, jedenfalls die Mehrheit der Abgeordneten, eine eigenständige Rolle im Rahmen der Krise angemeldet.

Nachdem in verschiedenen Entschließungen und Berichten immer wieder betont wurde, dass sich das Parlament eine eigenständige Zuständigkeit in der Krise zusprach, darunter sowohl in der Frühphase der Krise 2013 in Bezug auf Ungarn, ${ }^{1119}$ als auch z.B. gute vier Jahre später 2017

1117 Vgl., Emmanuel Macron, „Interview de M. Emmanuel Macron, Président de la République, dans "Rzeczpospolita", "Hospodárské noviny", "SME" et "HVG" du 26 octobre 2018, sur l'Etat de droit en Pologne et en Hongrie, l'Union européenne et l'OTAN et sur la construction européenne“, abrufbar unter : https://www.vie-publique.fr/discours/207034-interview-de-m-emmanuel-macro n-president-de-la-republique-dans-rzecz.

1118 Sehr eingängig sind dabei öffentlich einsehbare Übersichtslisten, da aus ihnen entsprechende Mehrheiten ableitbar sind, vgl. Rat der Europäischen Union, List of working papers (WK) distributed to the ad hoc Working Party on MFF in the first semester of 2019, 10848/19 vom 01.07.2019.

1119 So heißt es z.B. in der Entschließung des Europäischen Parlaments, P7_TA(2013)0315, Lage der Grundrechte: Standards und Praktiken in Europa: Entschließung des Europäischen Parlaments vom 3. Juli 2013 zu der Lage der Grundrechte: Standards und Praktiken in Ungarn (gemäß der Entschließung des Europäischen Parlaments vom 16. Februar 2012) (2012/2130(INI)), 3. Erwägungsgrund (Spgstr. von oben): „unter Hinweis auf seine Entschließung vom 16. Februar 2012 zu den politischen Entwicklungen in Ungarn in letzter Zeit, in der der Ausschuss für bürgerliche Freiheiten, Justiz und Inneres angewiesen wurde, in Zusammenarbeit mit der Kommission, dem Europarat und der Venedig-Kommission die Umsetzung der Empfehlungen in dieser Entschließung zu prüfen und seine Ergebnisse in einem Bericht darzulegen“. Die Formulierung entstammt dem dort wortgleichen Entwurf des sog. Tavares-Berichts, A7-0229/2013, Bericht über die Lage der Grundrechte: Standards 
in Bezug auf die Nutzung des Art. 7 EUV-Verfahrens gegenüber Polen, ${ }^{1120}$ untermauerte das Parlament zwischenzeitlich, nämlich 2016, seinen Beteiligungsanspruch in der Rechtsstaatlichkeitskrise als gleichrangiges Aufsichtsorgan und zwar nicht nur im Hinblick auf eine Beobachtungsfunktion bezüglich der Lage in den Mitgliedstaaten, sondern strebte auch offen danach, bei der Überprüfung und Korrektur verstärkt eingebunden zu sein. Hierzu nahm es mehrheitlich den zuvor in einem Bericht der niederländischen Abgeordneten Sophia in 't Veld (ALDE (Renew)/NL) vorgelegten Vorschlag ${ }^{1121}$ betreffend die Schaffung eines neuen interinstitutionellen Mechanismus, des sog „DRF-Pakts“ an, der dem Parlament eine zentrale Rolle zugewiesen hätte. ${ }^{1122}$ Der Vorschlag ist in der Praxis nicht umgesetzt worden.

und Praktiken in Ungarn (gemäß der Entschließung des Europäischen Parlaments vom 16. Februar 2012) (2012/2130(INI)), vom 24.06.2013, dort 3. Erwägungsgrund (Spgstr. von oben).

1120 Vgl. Europäisches Parlament, P8_TA-PROV(2017)0442, Die Lage der Rechtstaatlichkeit und der Demokratie in Polen, Entschließung des Europäischen Parlaments vom 15. November 2017 zur Lage der Rechtsstaatlichkeit und der Demokratie in Polen (2017/2931(RSP)), Erwägungsgrund D: ,in der Erwägung, dass die Rechtsstaatlichkeit zu den gemeinsamen Werten gehört, auf die sich die EU stützt, und in der Erwägung, dass die Kommission zusammen mit dem Parlament und dem Rat gemäß den Verträgen dafür zuständig ist, die Wahrung des Rechtsstaatsprinzips als eines grundlegenden Werts der Union zu gewährleisten und dafür zu sorgen, dass das Recht der EU befolgt sowie ihre Werte und Grundsätze geachtet werden“.

1121 Europäisches Parlament, Bericht mit Empfehlungen an die Kommission zur Einrichtung eines EU-Mechanismus für Demokratie, Rechtsstaatlichkeit und die Grundrechte (2015/2254(INL)) Ausschuss für bürgerliche Freiheiten, Justiz und Inneres, Berichterstatterin: Sophia in 't Veld, A8-0283/2016 vom 10.10.2016. Aufbereitung insb. bei Laurent Pech \& Kim Lane Scheppele, „Illiberalism Within: Rule of Law Backsliding in the EU“, S. $33 \mathrm{ff}$.

1122 Europäisches Parlament, Bericht mit Empfehlungen an die Kommission zur Einrichtung eines EU-Mechanismus für Demokratie, Rechtsstaatlichkeit und die Grundrechte, (2015/2254(INL)) Ausschuss für bürgerliche Freiheiten, Justiz und Inneres, Berichterstatterin: Sophia in 't Veld, A8-0283/2016, vom 10.10.2016, insb. dort die Anlage zum Entschließungsantrag: Ausführliche Empfehlungen für einen Entwurf einer Interinstitutionellen Vereinbarung mit Bestimmungen zu Überwachungs- und Follow-up-Verfahren zur Lage der Demokratie, der Rechtsstaatlichkeit und der Grundrechte in den Mitgliedstaaten und den Organen der EU: Entwurf einer interinstitutionellen Vereinbarung: Pakt der Europäischen Union für Demokratie, Rechtsstaatlichkeit und die Grundrechte; angenommen durch: P8_TA(2016)0409, EU-Mechanismus für Demokratie, Rechtsstaatlichkeit und Grundrechte, Entschließung des Europäischen Parlaments vom 25. Oktober 2016 mit Empfehlungen an die Kommis- 


\section{E. Das Rechtsregime der Verfassungsaufsicht der Europäischen Union}

Das Parlament schlug insbesondere vor, unter Rückgriff auf die nach Art. 295 AEUV mögliche sog. interinstitutionelle Vereinbarung, hier zwischen Parlament, Rat und Kommission, einen jährlichen, sachlich umfassenden Aufsichtszyklus hinsichtlich der „Demokratie, Rechtsstaatlichkeit und Grundrechte“ in den Mitgliedstaaten zu schaffen. In ihm sollte insbesondere der EU-Rahmen aufgehen. Zentrales Dokument wäre ein „Europäischer Bericht über Demokratie, Rechtsstaatlichkeit und die Grundrechte" gewesen. ${ }^{1123}$ Dem Parlament wäre eine organisatorisch zentrale Rolle zugefallen. ${ }^{1124}$ Das Instrument wäre weiter sanktionsbewehrt gewesen, nach dem Willen des Parlaments hätte die Kommission insbesondere auf der Grundlage des Berichts ggf. „wegen ,systemischer Vertragsverletzungen “" ein Verfahren nach Art. 258 AEUV gegenüber einem Mitgliedstaat eröffnen sollen. ${ }^{1125}$ Eine „interinstitutionelle Arbeitsgruppe zu Folgenabschätzungen“ hätte den Organen, die wiederum Mitglieder in ein „Sachverständigengremium für Demokratie, Rechtsstaatlichkeit und die Grundrechte" mit deutlichem Überhang zugunsten des Parlaments entsandt hätten, ${ }^{1126}$ zuarbeiten sollen. ${ }^{1127}$

Die Kommission hat auf den Vorschlag, im Unterschied zur stillen Ignorierung der Vorschläge im Rat betreffend das dortige Vorgehen, mit außergewöhnlich herber Kritik am Parlament in Form eines Non-Papers reagiert. ${ }^{1128}$ Nicht auszuschließen ist, dass die Kommission damit auch auf die zuvor geäußerte Kritik des Wissenschaftlichen Dienstes des Europäischen Parlaments an ihr reagierte. ${ }^{1129}$ Die Kommission teilte mit, sie habe „ernsthafte Zweifel“" „am Bedarf und der Machbarkeit“ des Vorschlags,

sion zur Einrichtung eines EU-Mechanismus für Demokratie, Rechtsstaatlichkeit und die Grundrechte (2015/2254(INL)).

1123 Art. 7 und 10 der interinstitutionellen Vereinbarung.

1124 Vgl. insb. Art. 10 1. Spgstr. der interinstitutionellen Vereinbarung.

1125 Art. 10 4. Spgstr. der interinstitutionellen Vereinbarung.

1126 Art. 8 (8.1) der interinstitutionellen Vereinbarung.

1127 Art. 12 der interinstitutionellen Vereinbarung.

1128 Europäische Kommission, Follow up to the European Parliament resolution on with recommendations to the Commission on the establishment of an EU mechanism on democracy, the rule of law and fundamental rights, adopted by the Commission on 17 January 2017, ohne Az. inbs. S. 2, beim Verfasser archiviert.

1129 Vgl. dazu Wissenschaftlicher Dienst des Europäischen Parlaments, An EU mechanism on democracy, the rule of law and fundamental rights: Annex II Assessing the need and possibilities for the establishment of an EU Scoreboard on democracy, the rule of law and fundamental rights, PE 579.328 - April 2016, S. 30 und ff. 
überdies gelte es, eine „Verdoppelung“ von Mechanismen zu vermeiden. In der sonst zurückhaltenden Wortwahl der Kommission muss dies dahingehend verstanden sein, dass das Verfahren unnötig, schlecht durchdacht, kompetenzwidrig und nicht abgesprochen sei und zuvörderst nach der Verwirklichung eigener Vorrangstellung seitens des Parlaments strebe. Der Vorschlag musste damit als politisch aussichtslos gelten. Insofern erübrigt sich eine ausführliche rechtliche Würdigung, die allerdings die Zweifel der Kommission durchaus bestätigen müsste. So scheint es insbesondere sehr fraglich, ob die gewählte Form der interinstitutionellen Vereinbarung, die der Koordination der Organe dient, aber nicht eine Änderung und Erweiterung ihrer Befugnisse oder verbindliche Auslegung des Unionsrechts ermöglicht, ${ }^{1130}$ Grundlage für einen derart umfassenden Mechanismus hätte sein können.

Seitdem hat die Kommission den Vorschlag des Parlaments ignoriert, das Parlament wiederum hat seinen Vorschlag, zuletzt etwa im Januar 2020 in Bezug auf Ungarn, immer wieder und fast reflexhaft in die Diskussion eingebracht. ${ }^{1131}$

Dabei schwächt es das Parlament, dass es eben gerade kein nach außen einheitlich auftretender Akteur ist, sondern sich, naturgemäß, in der gesamten Bandbreite der Fraktionsmeinungen auch ausdrücklich Stimmen finden, die die nationalen Parteien, welche die Krise in ihren Heimatmitgliedstaaten verursacht haben, auf europäischer Ebene unterstützen. ${ }^{1132}$

1130 Vgl. Markus Krajewski \& Ulrich Rösslein, Art. 295 AEUV, in: Eberhard Grabitz, Meinhard Hilf \& Martin Nettesheim (Begr./Hrsg.), Das Recht der Europäischen Union, C.H. Beck, München, 68. EL Oktober 2019, Rn. 17. Insbesondere mutmaßlich ablehnend im Hinblick auf den konkreten Fall Florian von Alemann, Die Handlungsform der interinstitutionellen Vereinbarung, S. 174, S. 234, wonach unter den Verträgen mittels interinstitutioneller Vereinbarung vorrangig Selbstorganisationsrecht der Organe geschaffen werden kann. Vgl. S. 174: „Die Steuerungswirkung interinstitutioneller Vereinbarungen bleibt somit generell auf die Verfahrens- und Organisationsebene beschränkt. Sie äußert sich [...] in der Festlegung von Verfahrensabläufen, der Einrichtung von Kooperationsgremien und der Festsetzung von inhaltlichen Anforderungen an Entscheidungen."

1131 Zuletzt etwa Europäisches Parlament, P9_TA-PROV(2020)0014, Laufende Anhörungen gemäß Artikel 7 Absatz 1 EUV - Polen und Ungarn, Entschließung des Europäischen Parlaments vom 16. Januar 2020 zu den laufenden Anhörungen gemäß Artikel 7 Absatz 1 EUV zu Polen und Ungarn (2020/2513(RSP)), 9. Erwägungsgrund (Spgstr. von oben).

1132 Hierzu auch Christoph Möllers \& Linda Schneider, Demokratiesicherung in der Europäischen Union, S. 88-89. Ein gutes Beispiel der politischen Kräfte, die im Parlament wirken, zeigt sich in den Gegenentwürfen zu den Ent- 
Auf der anderen Seite droht dem Parlament die Bedeutungslosigkeit im Prozess durch Beharren auf seinen früheren und politisch zwischenzeitlich weitestgehend aussichtslosen Vorschlägen. Auf beide Aspekte hat jüngst etwa Renáta Uitz hingewiesen und, im Hinblick auf die soeben genannte Entschließung, insbesondere festgehalten: „The resolution may of course be read as a desperate attempt by the newly elected Parliament to still be included once the process reaches the Council (i.e. a thinly veiled assertion of its institutional prerogatives)."1133

Auch hinsichtlich der Verhandlungen über den Status des Art. 7 EUVVerfahrens im Hinblick auf Polen und Ungarn ist die Rolle des Parlaments, jedenfalls nach Einleitung des Verfahrens, dort verschwindend gering. Die Rolle des Parlaments hatte zuvor in der Literatur bereits etwa André Hau interessiert, der unter dem Stichwort der „Aufsichtskompetenz des Parlaments“ u.a. die Frage einer Verfahrensbeeinflussung seitens des Parlaments durch etwaige Ausübung eines Rücknahmerechts des Antrags diskutiert, dies verneint hatte und zur Feststellung gelangt war, dass, einmal eingeleitet, der Rat, nicht aber das Parlament „Herr des Sanktionsverfahrens" sei. ${ }^{1134}$ Nicht nur ist in der derzeitigen Lage betreffend Ungarn die Rücknahme des Antrags zum Verfahren nach Art. 7 Abs. 1 EUV fernliegend, auch ansonsten bestätigt sich Haus Eindruck von einer sehr schwachen Rolle des Parlaments, jedenfalls nach Einleitung des Verfahrens.

Wie in anderen Verfahren im Rat auch nimmt zwar sehr wohl die Kommission an zahlreichen Treffen mit Vertretern des Rates teil und entsendet Vertreter in die nicht öffentlichen Sitzungen, kann überdies dort auch Erklärungen zu Protokoll geben, ${ }^{1135}$ dem Parlament als Organ oder einzelnen Abgeordneten steht indes eine solche Rolle nicht zu.

schließungen des Parlaments, exemplarisch: Entschließungsantrag eingereicht im Anschluss an Erklärungen des Europäischen Rates [sic, Übersetzungsfehler, scil.: des Rates] und der Kommission gemäß Artikel 123 Absatz 2 der Geschäftsordnung zur Lage der Rechtsstaatlichkeit und der Demokratie in Polen (2017/2931(RSP)) im Namen der ECR-Fraktion, B8-0594/2017 vom 06.11.2017, s. bereits bei B. IV. 5. d. bb.

1133 Renáta Uitz: „EU Rule of Law Dialogues: Risks - in Context“, Verfassungsblog, vom 23.01.2020, o.S.

1134 André Hau, Sanktionen und Vorfeldmaßnahmen zur Absicherung der europäischen Grundwerte, S. 106-108, Zitat S. 108.

1135 Zum Ablauf von Verhandlungen im Rat zwischen Vertretern der Mitgliedstaaten und solchen der Kommission illustrativ Philipp Dann, Parlamente im Exekutivföderalismus: Eine Studie zum Verhältnis von föderaler Ordnung und 
Dabei hatten einzelne Abgeordnete durchaus versucht, an den allgemeinen Verfahrensvorgaben vorbei an Sitzungen des Rates teilzunehmen, wobei die Einleitung des Verfahrens gegen Ungarn durch das Parlament und das dadurch zu wahrende Interesse ein Argument gewesen sein dürfte. Der Rat hatte zunächst im Juli 2019 Verfahrensregeln zur Handhabung des Artikel-7-Verfahrens angenommen, die im entsprechenden Abschnitt noch darzustellen sind. ${ }^{1136}$ Eine vertiefte Rolle des Parlaments war nicht vorgesehen. Nachdem man sich auf Brüsseler Fluren zwischenzeitlich berichtete, der Rat habe insistierende Abgeordnete gerne montags morgens um Punkt 8 Uhr einbestellt, nur um sie entdecken zu lassen, dass es keinen Kaffee mehr gab und man für sie die Stühle in der letzten Reihe leider vergessen hatte, schloss die finnische Ratspräsidentschaft Ende 2019 schließlich Abgeordnete des Parlaments förmlich von allen Sitzungen betreffend Art. 7 EUV in Bezug auf Ungarn aus. ${ }^{1137}$ Kochenov, Pech und Platon, die geltend gemacht haben, sie hätten Zugriff auf entsprechende interne Dokumente, die sonst nicht veröffentlicht worden sind, haben geschildert, der Rat habe hierzu ein Gutachten seines Juristischen Dienstes eingeholt und sich zuletzt gegen die Auffassung einer Gruppe von Mitgliedstaaten, inklusive Deutschlands, entschieden, das Parlament doch noch zu beteiligen. ${ }^{1138}$ Einsehbare Dokumente zum Gang des Verfahrens gegen Polen aus dem Jahr 2018 und gegen Ungarn aus dem Jahr 2019 lassen erkennen, dass man außerhalb der Ratssitzungen sehr wohl Mitglieder des Parlaments getroffen hatte, allein aber die Kommission auch im Rat zur Sprache gekommen war und es darüber bei einer „klassischen“ Ratssitzung, geprägt v.a. durch die Aussprachen der Vertreter der Mitgliedstaaten, blieb. ${ }^{1139}$

parlamentarischer Demokratie in der Europäischen Union, Springer, Heidelberg, 2004, S. 101, 106, weiter S. 103 zur Abgabe von Protokollerklärungen.

1136 Rat der Europäischen Union, „Standard modalities for hearings referred to in Article 7(1) TEU”, 10641/2/19, vom 09.07.2019.

1137 Vlagyiszlav Makszimov, „MEPs shut out of Hungary Council hearing as rule of law situation worsens“, Euractiv vom 22.11.2019.

1138 Laurent Pech, Dimitry Kochenov and Sébastien Platon, The European Parliament Sidelined, Verfassungsblog vom 08.12.2019, unter Berufung auf "European Parliament, GRI Meeting of 26 October 2018, SI(2018) 579”. Demnach hätten Ungarn, Lettland und Großbritannien dem Juristischen Dienst des Rates zugestimmt, Deutschland, Dänemark, Belgien, Griechenland, die Niederlande und Spanien hätten die Beteiligung des Parlaments empfohlen.

1139 Rat der Europäischen Union, „Rule of Law in Poland / Article 7(1) TEU Reasoned Proposal - Report of the hearing held by the Council on 18 September 2018", 12970/18 vom 05.11.2018, ebenso id., "Values of the Union - Hungary - Article 7 (1) TEU Reasoned Proposal - Report on the hearing held by the 
Mit der stark nachrangigen Rolle des Parlaments im Hinblick auf die Überprüfungs- und Berichtigungsphase verschiedener Aufsichtsmechanismen kontrastiert wiederum, dass das Parlament, gerade in Bezug auf Ungarn, durch große Publikationsaktivität hervorgetreten ist, lange bevor es ein Verfahren nach Art. 7 Abs. 1 EUV in Gang setzte. Auf die Bedeutung etwa der sog. Schöpflin-Stellungnahme ${ }^{1140}$ oder des Tavares-Berichts ${ }^{1141}$ hatte ich bereits bei der Darstellung der Lage in Ungarn hingewiesen. Hinzu kommt, bislang noch nicht berücksichtigt, die sehr umfangreiche Tätigkeit der Parlamentsausschüsse, insbesondere diejenige des damals dem Vorsitz des Briten Claude Moraes unterstehenden Ausschusses für bürgerliche Freiheiten und Inneres (LIBE). ${ }^{1142}$ Der LIBE-Ausschuss des Parlaments war regelmäßig Adressat der „großen“ Berichte, die die Wahrnehmung der Krise dort entscheidend geprägt haben. Auch Judith Sargentini erstattete ihren Bericht zunächst gegenüber dem LIBE-Ausschuss in einer Entwurfsfassung am 11.04.2018. ${ }^{1143}$ Der LIBE-Ausschuss war auch Forum für zahlreiche Anhörungen von Experten, etwa des Präsidenten des Verbunds der europäischen Justizräte (ENCJ) Kees Sterk. ${ }^{1144}$

Council on 16 September 2019”, 12345/19, vom 19.09.2019, insb. dort S. 2 zur Einbeziehung des Europäischen Parlaments.

1140 Europäisches Parlament, Stellungnahme des Ausschusses für konstitutionelle Fragen für den Ausschuss für bürgerliche Freiheiten, Justiz und Inneres zur Einrichtung eines EU-Mechanismus für Demokratie, Rechtsstaatlichkeit und Grundrechte (2015/2254(INL)), Verfasser der Stellungnahme: György Schöpflin.

1141 Europäisches Parlament, Bericht über die Lage der Grundrechte: Standards und Praktiken in Ungarn (gemäß der Entschließung des Europäischen Parlaments vom 16. Februar 2012), (2012/2130(INI)), Ausschuss für bürgerliche Freiheiten, Justiz und Inneres, Berichterstatter: Rui Tavares vom 24.06.2013, A7-0229/2013.

1142 Ein allgemeiner Überblick über die rechtsstaatsspezifische Tätigkeit des Ausschusses ist verfügbar über: https:/www.europarl.europa.eu/committees/en/lib e-working-group-on-the-rule-of-law-in/product-details/20190103CDT02662.

1143 Europäisches Parlament, Bericht über einen Vorschlag, mit dem der Rat aufgefordert wird, im Einklang mit Artikel 7 Absatz 1 des Vertrags über die Europäische Union festzustellen, dass die eindeutige Gefahr einer schwerwiegenden Verletzung der Grundwerte der Europäischen Union durch Ungarn besteht (2017/2131(INL)), Ausschuss für bürgerliche Freiheiten, Justiz und Inneres, Berichterstatterin: Judith Sargentini; der Bericht erging ungeachtet der besonderen Kompetenz aus Art. 83 der Geschäftsordnung zunächst nur als Sonderbericht i.S.d. Art. 46 und 52 GeschO EP.

1144 ENCJ, Kees Sterk, President of the ENCJ LIBE hearing on the Rule of Law in Poland, vom 20.11.2018, ohne Az., verfügbar unter: https:/www.encj.eu/node/ 510. 
Wie sehr schließlich z.B. auch die ungarische Regierung diesen Ausschuss in der Folge im Blick hatte, zeigt der offene Schlagabtausch mit Ungarn, etwa im Zuge einer Stellungnahme des ungarischen Außenministers Péter Szijjártó vor dem Ausschuss im April 2018. Szijjártó hielt fest, die Position des LIBE-Ausschusses gegenüber Ungarn wachse in die Anmaßung aus: „to insult a member state, its democratically elected government and the clearly manifested will of the people". ${ }^{1145}$ Frans Timmermans wiederum lieferte sich im Ausschuss offene Auseinandersetzungen mit polnischen Abgeordneten. ${ }^{1146}$

Schließlich hat das Parlament versucht, sich gestaltend im Hinblick auf die Rechtsstaatlichkeitskrise durch seine zentrale Rolle in Gesetzgebungsverfahren einzubringen. Auf die umfassenden Ergänzungen zum Verordnungsvorschlag der Kommission betreffend „generelle Mängel“ an Rechtsstaatlichkeit in Mitgliedstaaten hatte ich hingewiesen. Das Parlament hat es aber verstanden, auch scheinbar sachfremde Vorschläge mit der Thematik anzureichern, um sich ins Spiel zu bringen. So finden sich im sog. four-column-document betreffend eine Überarbeitung der Verordnung zur Schaffung der ACER (Kooperationsagentur der europäischen Energieregulierungsbehörden), die im Rat sehr zeitnah zur Entschließung zu Ungarn durch das Parlament besprochen wurden, überraschend umfassende Änderungswünsche zur Schaffung rechtsstaatlicher Garantien, die auch so gelesen werden können, dass das Parlament „über die Bande“ hier den Ratsvertretern zu signalisieren wünschte, dass man Mittel und Wege finden werde, sich mit der Thematik zu beschäftigen. ${ }^{1147}$

Aufgrund der dem Parlament verbleibenden Rolle als Beobachter und Mahner in der Krise bleibt ihm in der Rechtsstaatlichkeitskrise auch die Rolle eines zumindest partiell für die Verfassungsaufsicht zuständigen Organs erhalten. Eine umfassende Aufsichtsfunktion, einschließlich einer Sanktionspraxis oder dem Zugang zu privilegierten Informationskanälen im Austausch mit den Mitgliedstaaten, wie dies für Kommission und Rat

1145 Presseerklärung der Ungarischen Regierung vom 27.04.2018, "The dispute with the EP's LIBE Committee is expected to continue in future", abrufbar unter: http://www.kormany.hu/en/ministry-of-foreign-affairs-and-trade/news/t he-dispute-with-the-ep-s-libe-committee-is-expected-to-continue-in-future.

1146 Alexandra Brzozowski, „Timmermans clashes with Polish MEPs on rule of law", Euractiv vom 05.09.2019.

1147 Rat der Europäischen Union, Proposal for a Regulation on [scil.: of] the European Parliament and of the Council, establishing a European Union Agency for the Cooperation of Energy Regulators (recast), 9754/3/18 vom 11.10.2018, Annex, vgl. dort insb. S. 76. 
der Fall ist, kommt ihm indes nicht zu, und der Prozess des „sidelining“ in vielen Bereichen ist eindeutig. Was die jedenfalls eingeschränkte Aufsichtsfunktion angeht, ist hinzuzufügen, dass sich die Berichtspraxis des Parlaments teils eng an diejenige der Kommission anlehnt und diese vorrangig der akribischen Tatbestandssicherung statt einer eigenständigen weitergehenden Rechtsanalyse dient. Das zeigt sich exemplarisch etwa anhand des vorgenannten Tavares-Berichts. Dadurch ergibt sich weiter auch eine Abgrenzung zu den deutlich analytischeren Berichten der Venedig-Kommission, und in letzter Konsequenz ergeben sich damit Anhaltspunkte für eine Rollenverteilung und -zuweisung zwischen Kommission, Parlament und Rat insbesondere. Es sind also Kommission und Rat, denen besonders die politische Entscheidungsgewalt und vorrangige Analysekompetenz zufällt, während das Parlament beobachtend und mahnend hinzutritt, insbesondere in frühen Stadien problematischer Entwicklungen.

Die in Umfang und Bedeutung folglich stark reduzierte oder, je nach Auffassung, mangelhafte Beteiligung des Europäischen Parlaments in der gegenwärtigen Rechtsstaatlichkeitskrise kann sicherlich vor dem Hintergrund des sog. „Demokratiedefizits“ der Union kritisiert werden. Es besteht aber auch eine andere Lesart, die mir vorzugswürdiger erscheint. Sie betont zunächst, dass das Parlament zum einen ungeachtet seiner Benachteiligung etwa im Rat, durch vorherige Handlungen, namentlich durch öffentlich wirksame Entschließungen, die Rolle eines beaufsichtigenden Beobachters und Mahners durchaus einnimmt und ausfüllt. Was seinen politischen Handlungswillen angeht, gereicht es dem Parlament zum Nachteil, auf den politisch aussichtslosen DRF-Pakt zu beharren, wodurch es sich selbst unnötig marginalisiert. Schließlich ist das klare Mandat gerade der Kommission aus Art. 17 Abs. 1 EUV anzuführen, welches die in Art. 7 EUV zunächst schwach ausgeprägten Kompetenzen der Kommission auffängt.

\section{Reaktionen weiterer Unionsorgane}

Neben dem "Quartett“ aus Parlament, Kommission, Rat und Gerichtshof ${ }^{1148}$ sind, ungeachtet der gerade zwischen Kommission und Rat einer-

1148 Die Rolle des Europäischen Gerichtshofs ist aufgrund seiner jüngeren Rechtsprechung in der Krise offensichtlich und an dieser Stelle nicht separat zu behandeln. Skeptisch indes Christoph Möllers \& Linda Schneider, Demokratiesicherung in der Europäischen Union, S. 89. 
seits und Kommission und Parlament andererseits öffentlich ausgetragenen Kontroversen um Kompetenzen, eigene Vorschläge und ihre Umsetzung, keine weiteren öffentlichen Reaktionen oder Vorschläge anderer Unionsorgane festzustellen gewesen, bis auf zwei Ausnahmen.

Der Europäische Rechnungshof hat im Mai 2018 zum Verordnungsvorschlag der Kommission betreffend den Schutz des Unionshaushalts bei generellen Rechtsstaatsmängeln in einem Mitgliedstaat Stellung genommen. ${ }^{1149}$

Der Europäische Ausschuss der Regionen ${ }^{1150}$ hat 2015 und 2017, obwohl er nicht Adressat der jeweiligen Mitteilungen der Kommission oder der Entschließungen des Parlaments war, eigene Dokumente zur Lage der Rechtsstaatlichkeit angenommen. Diese Dokumente stimmen den Leser unschlüssig, denn zum einen tritt in ihnen eine ernsthafte Sorge um die Verwirklichung rechtsstaatlicher Grundsätze gerade im Bereich der Lokalverwaltung hervor, zum anderen aber bleiben die Vorschläge und Beobachtungen höchst vage, und es fehlt an einer plausiblen Darlegung, warum genau der Beitrag des Ausschusses der Regionen in der Debatte erforderlich sein soll.

In einer ersten Stellungnahme aus dem Jahr 2015 nahm der Ausschuss der Regionen ausdrücklich begrüßend ${ }^{1151}$ und darüber summarisch zum

1149 Europäischer Rechnungshof, Stellungnahme Nr.1/2018 (gemäß Artikel 322 Absatz 1 Buchstabe a AEUV) zu dem Vorschlag vom 2. Mai 2018 für eine Verordnung des Europäischen Parlaments und des Rates über den Schutz des Haushalts der Union im Falle von generellen Mängeln in Bezug auf das Rechtsstaatsprinzip in den Mitgliedstaaten (2018/C 291/01), ABl. (EU) C 291/1 vom 17.8.2018, im Überblick auch in den Kurzdarstellung der Bemerkungen des EuRH zu den Legislativvorschlägen der Kommission für den nächsten mehrjährigen Finanzrahmen (MFR) Februar 2019, ohne Az.

1150 Der Ausschuss der Regionen ist durch Art. 13 Abs. 4 EUV als eines der weiteren Organe oder „Nebenorgane“ im Primärrecht geschaffen. Zum Überblick

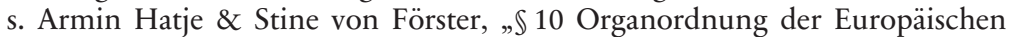
Union“, in: Peter-Christian Müller-Graff \& Armin Hatje (Hrsg.), Enzyklopädie Europarecht, Band 1: Europäisches Organisations- und Verfassungsrecht, Nomos, Baden-Baden, 2014, S. 543-621, Rn. 194.

1151 Europäischer Ausschuss der Regionen, Stellungnahme des Europäischen Ausschusses der Regionen - Die lokalen und regionalen Gebietskörperschaften und der Schutz der Rechtsstaatlichkeit und der Grundrechte auf mehreren Ebenen in der EU, ABl.(EU) C 140/32, 28.04.2015. Die Erwägungsgründe, darunter die Unterstützung für die Kommission, sind im Amtsblatt nicht abgedruckt worden, finden sich aber in der Arbeitsfassung des Ausschusses unter der Dokumentennr.: CIVEX-V-050 zur 110. Plenartagung vom 11.-13. Februar 2015 . 
EU-Rahmen der Kommission Stellung, auch wird ein eigener Gremienvorschlag durch Einberufung eines gesonderten „Dreiergespanns“ zwischen Ausschuss der Regionen, dem sog. „Kongress“ des Europarates (der mit dem Ausschuss in Grundsätzen vergleichbaren Versammlung lokaler gewählter Volksvertreter) und der Europäischen Grundrechteagentur gemacht. ${ }^{1152}$ Die besondere Rolle der lokalen Verwaltung beim Schutz der Rechtsstaatlichkeit wird ausdrücklich betont, ${ }^{1153}$ was nicht per se unplausibel ist. So erscheint es recht offensichtlich, dass gerade bei Korruptionsdelikten die nachgeordnete Territorialverwaltung der Mitgliedstaaten anfällig und gefordert sein kann. Warum aber gerade dort besondere Kompetenzen bei der Ermittlung und zur Behebung rechtsstaatlicher Defizite anzusiedeln sind und wie diese Verwaltungsebene etwa mit der Gerichtsbarkeit zusammenarbeitet, lässt die Stellungnahme offen. Auch in weiteren Punkten bleibt sie unklar, so wird ohne weiteres auf den Schutz der Grundrechte, nicht der Rechtsstaatlichkeit, eingegangen und darüber eine stärkere Rolle des Parlaments eingefordert, ohne dass dies im Einzelnen begründet wird. ${ }^{1154}$

In einem weiteren Dokument aus dem Jahr 2017, diesmal einer „Entschließung “ ${ }^{1155}$ womit möglicherweise eine Nähe auch in der Form zu Äußerungen des Parlaments gesucht werden sollte, ist der Ausschuss augenscheinlich um mehr Stringenz bemüht. An die Operationalisierung des Rechtsstaatsprinzips über weitere Prinzipien aus der Rechtsprechung von EuGH und auch EGMR wird im Wesentlichen angeknüpft. ${ }^{1156}$ Da der EU-Rahmen der Kommission ohne Ergebnis geblieben sei, sei nun das Par-

1152 Europäischer Ausschuss der Regionen, Stellungnahme des Europäischen Ausschusses der Regionen - Die lokalen und regionalen Gebietskörperschaften und der Schutz der Rechtsstaatlichkeit und der Grundrechte auf mehreren Ebenen in der EU, ABl. (EU) C 140/32, 28.04.2015, insb. Rn. 7, 20, 26, 29 letzter Spglstr.

1153 Europäischer Ausschuss der Regionen, Stellungnahme des Europäischen Ausschusses der Regionen - Die lokalen und regionalen Gebietskörperschaften und der Schutz der Rechtsstaatlichkeit und der Grundrechte auf mehreren Ebenen in der EU, Rn. 7.

1154 Europäischer Ausschuss der Regionen, Stellungnahme des Europäischen Ausschusses der Regionen - Die lokalen und regionalen Gebietskörperschaften und der Schutz der Rechtsstaatlichkeit und der Grundrechte auf mehreren Ebenen in der EU, Rn. 21.

1155 Europäischer Ausschuss der Regionen, „Entschließung: Die Rechtsstaatlichkeit in der EU aus lokaler und regionaler Perspektive“, RESOL-VI/020 zur 122. Plenartagung, 22./23. März 2017.

1156 Europäischer Ausschuss der Regionen, „Entschließung: Die Rechtsstaatlichkeit in der EU aus lokaler und regionaler Perspektive“, Rn. 4. 
lament in seinem Bestreben betreffend den DRF-Pakt zu unterstützen. ${ }^{1157}$ Dabei wendet sich der Ausschuss der Regionen aber auch ausdrücklich gegen die Einführung einer „politischen Konditionalität“ im Zuge des Umgangs mit der Rechtsstaatlichkeit. ${ }^{158}$ Was damit genau bezeichnet ist, etwa die später durch die Kommission vorgeschlagene Schaffung einer neuen Konditionalität bei der Kontrolle der EU-Haushaltsmittel, bleibt darüber offen. Auch eine Begründung der einzelnen Beobachtungen fehlt weitestgehend.

Der Mehrwert beider Dokumente in der Rechtsstaatlichkeitsdebatte ist darüber sehr begrenzt. Insgesamt drängt sich bei beiden der Eindruck auf, als sei man bemüht gewesen, sich als weiterer Akteur in der Krise ins Spiel zu bringen, ein Vorstoß, dem die anderen Organe durch schlichtes Ignorieren begegnet sind. Eine größere Resonanz auf beide Papiere hat sich nicht feststellen lassen.

\section{Rolle und Beteiligung der Europäischen Grundrechteagentur}

In der Krise seitens der Organe weitgehend ohne eigenständige Rolle und ohne Berücksichtigung geblieben ist die Europäische Agentur für Grundrechte (Fundamental Rights Agency, kurz: FRA). Das ist zunächst umso bemerkenswerter, als die Rechtsgrundlage für die Schaffung und Arbeitsweise der FRA eine Verordnung ist, ${ }^{1159}$ in der zunächst eine konkret unterstützende Rolle im Rahmen des Verfahrens nach Art. 7 EUV angedacht war. ${ }^{1160}$ Dies wird in einer Erklärung des Rates für Justiz und Inneres als weiterhin für möglich erachtet. ${ }^{1161}$ Die FRA selbst indes, so hat Andreas

1157 Europäischer Ausschuss der Regionen, „Entschließung: Die Rechtsstaatlichkeit in der EU aus lokaler und regionaler Perspektive“, Rn. 5, 10, $11 \mathrm{ff}$.

1158 Europäischer Ausschuss der Regionen, „Entschließung: Die Rechtsstaatlichkeit in der EU aus lokaler und regionaler Perspektive“, Rn. 16.

1159 Verordnung (EG) Nr. 168/2007 des Rates vom 15. Februar 2007 zur Errichtung einer Agentur der Europäischen Union für Grundrechte, ABl. (EU) L 53/1 vom 22.02.2007.

1160 Andreas Orator, „The competence entanglements of the EU Fundamental Rights Agency“, in: Otto Kammerlander (Hrsg.), Expertenforum SpringerRecht.at, Springer, Wien, 2010, S. 123-155, S. 135.

1161 Gabriel N. Toggenburg \& Jonas Grimheden, „Upholding Shared Values in the EU: What Role for the EU Agency for Fundamental Rights?", in: Journal of Common Market Studies 54 (2016), S. 1093-1104, S. 1094, mit Verweis auf eine entsprechende Erklärung des Rates: Declaration by the Council on proceedings under Article 7 of the Treaty on European Union, 6396/07 ADD 1, 
Orator aufgezeigt, hat in der Folge 2009 eine Gutachtenanfrage zu einem litauischen Gesetz, welche möglicherweise in eine Überprüfung der Konformität mit Art. 2 EUV gemündet hätte, unter Verweis auf ihr anders gelagertes Mandat abgelehnt. ${ }^{1162}$

Die FRA ist eine mit eigenständiger Rechtspersönlichkeit ausgestattete nachrangige Behörde (Agentur) der Europäischen Union und 2007 als Nachfolgerin der sog. „Europäischen Stelle zur Beobachtung von Rassismus und Fremdenfeindlichkeit" geschaffen worden. ${ }^{1163}$ Sie dient, als Exemplar des Typus der sog. europäischen Informationsagentur, ${ }^{1164}$ anderen Unionsorganen, ganz vorrangig der Kommission, und den Mitgliedstaaten als Expertisestelle bei der Beurteilung eigener Politiken in Bezug auf die Unionsgrundrechte bei der Durchführung des Unionsrechts. ${ }^{1165}$ So sieht es insbesondere Art. 2 der sie einrichtenden Verordnung vor. Neben der genuinen Politikberatung fallen ihr auch wissenschaftliche Aufarbeitung und "Grundrechtskommunikation" in ihrem Zuständigkeitsbereich zu. ${ }^{1166}$

In der rechtswissenschaftlichen Literatur ist für die FRA regelmäßig eine stärkere Einbindung in den interinstitutionellen Austauschprozess gefordert worden. Von Bogdandy hielt im Hinblick auf das eingeschränkte Mandat der Grundrechteagentur bereits früh fest, diese operiere in einem äußerst schwierigen Umfeld, könne aber eine wichtige Rolle dabei spielen,

vom 27.02.2007, Anhang zu: „2781st meeting of the Council of the European Union (Justice And Home Affairs), held in Brussels on 15 February 2007“ mit gleichem Datum/Az., S. 3.

1162 Andreas Orator, „The competence entanglements of the EU Fundamental Rights Agency“, S. 136.

1163 Zur Genese Armin von Bogdandy, „Grundrechtsschutz durch die Europäische Grundrechteagentur“, in: Detlef Merten \& Hans-Jürgen Papier (Hrsg.), Handbuch der Grundrechte in Deutschland und Europa: Band VI/: Europäische Grundrechte I, C. F. Müller, Heidelberg, 2010, S. 1241-1266, S. 1249 ff., zu Aufbau und Mandat S. $1251 \mathrm{ff}$.

1164 Armin von Bogdandy, „Grundrechtsschutz durch die Europäische Grundrechteagentur“, S. 1250-1251; Bal Sokhi-Bulley, „The Fundamental Rights Agency of the European Union: A New Panopticism“, in: Human Rights Law Review 11 (2011), S. 683-706, S. 686 hat zusätzlich darauf hingewiesen, dass Philip Alston und Joseph Weiler zentrale Anstöße zur weiteren Entwicklung der FRA lieferten, vgl. Philip Alston \& Joseph H. H. Weiler, „An ,Ever Closer Union“ in Need of a Human Rights Policy“, in: European Journal of International Law 4 (1998), S. 658-723, insb. S. 669, 677, Nr. 2.

1165 Armin von Bogdandy, „Grundrechtsschutz durch die Europäische Grundrechteagentur", S. 1255.

1166 Armin von Bogdandy, „Grundrechtsschutz durch die Europäische Grundrechteagentur", S. 1257. 
die konkrete Bedeutung der Unionsgrundrechte gegenüber den Mitgliedstaaten durch Politikberatung weiter auszubuchstabieren. ${ }^{1167}$

Gabriel Toggenburg und Jonas Grimbeden haben sich später der Rolle der FRA vor dem Hintergrund spezifisch der Rechtsstaatlichkeitskrise angenommen und eine Stärkung der Agentur gefordert. Zwar sei die Aufgabe der Beurteilung der Grundrechtskonformität nationaler Politiken nicht gleichzusetzen mit dem Prüfmaßstab der Rechtsstaatlichkeit, es bestünden aber substantielle Parallelen. ${ }^{1168}$ Auch seien nicht nur vergleichende Arbeiten, sondern auch eingehende Länderstudien, wie sie im Rahmen der Krise besonders erforderlich seien, vom Mandat der FRA umfasst. ${ }^{1169}$ Am bemerkenswertesten ist, dass beide Verfasser mehrfache Versuche der FRA nachweisen, in der Krise als eigenständiger Akteur mit Gutachtenprogrammen an die Seite insbesondere der Kommission zu treten. $\mathrm{Zu}$ diesen zählen der Vorschlag für einen „strategischen Rahmen für Grundrechte“ und die Einführung eines sog. „European Fundamental Rights Information System (EFRIS), ${ }^{1170}$ das zwischenzeitlich zwar in Vorbereitung scheint, bislang aber nicht der Öffentlichkeit vorliegt. ${ }^{1171}$

Auch die Stärkung der FRA über die Aufnahme eines Grundrechteprüfkatalogs im Europäischen Semester, den die beiden Verfasser an anderer Stelle vorgeschlagen haben und der von der FRA und der Kommission ihrer Vorstellung nach gemeinsam überprüft werden könnte, ist ein Desideratum geblieben. ${ }^{172}$

Für die Rolle der FRA ist dabei nicht hilfreich, dass auch bei sorgfältiger Sichtung des von ihr veröffentlichten Materials dieses sowohl an Übersichtlichkeit, als auch in Stringenz und Substanz, sehr deutlich hinter den Veröffentlichungen derjenigen Einrichtung zurücksteht, mit der sie

1167 Armin von Bogdandy, „Grundrechtsschutz durch die Europäische Grundrechteagentur", S. 1262-1263.

1168 Gabriel N. Toggenburg \& Jonas Grimheden, „Upholding Shared Values in the EU", S. 1095.

1169 Gabriel N. Toggenburg \& Jonas Grimheden, „Upholding Shared Values in the EU”, S. 1096.

1170 Gabriel N. Toggenburg \& Jonas Grimheden, „Upholding Shared Values in the EU”, 1098.

1171 Vgl. zum Stand des Projekts unter https://fra.europa.eu/en/project/2018/eu-fun damental-rights-information-system.

1172 Gabriel N. Toggenburg \& Jonas Grimheden, „Managing the Rule of Law in a Heterogeneous Context: A Fundamental Rights Perspective on Ways Forward“, in: Werner Schroeder (Hrsg.), Strengthening the Rule of Law in Europe: From a Common Concept to Mechanisms of Implementation, Hart, Oxford, 2016, S. 221-240, S. 230 f., 232. 
wohl am ehesten in einem Wettbewerb gesehen werden muss, nämlich mit der Venedig-Kommission. Die FRA operiert, gute 15 Jahre nach ihrer Einrichtung, ganz vorrangig über ihre Webseite, auf der sie diverse Analysereihen in unterschiedlichen Formaten bereitstellt, die sie selbst häufig als "Produkte“ bezeichnet, ${ }^{1173}$ womit unnötigerweise ein kommerzieller Charakter impliziert wird. Die wohl ressourcenintensivste Publikationsreihe ist die Falldatenbank zu Leitentscheidungen betreffend die Europäische Grundrechtecharta, in welcher die Agentur sowohl nationale als auch europäische Rechtsprechung zur Charta bereitstellt. ${ }^{1174}$ In der Rechtsstaatlichkeitskrise bleibt diese Datenbank aber sowohl für den Praktiker als auch für den Wissenschaftler sekundär. Sie ist, insbesondere im Hinblick auf die durch die Gerichte selbst bereitgestellten Datenbanken - beim EuGH tritt zusätzlich noch dessen eigenes thematisch geordnetes répertoire hinzu - zu fragmentarisch und vor allem zu unspezifisch mit Blick auf konkrete Probleme. Das zeigt sich insbesondere beim verfügbaren Material zu Art. 47 der Charta, auf den, wie im Teil B. gezeigt, die Operationalisierung der Rechtsstaatlichkeit u.a. gestützt worden ist. Die FRA scheint hierzu keine spezifische Aufarbeitung vorgelegt zu haben.

Etwas substantieller sind Teile der jährlich veröffentlichten „Fundamental Rights Reports “. ${ }^{1175}$ Seit 2016 widmet die FRA dort einen Abschnitt des Analysepunktes „Access to justice including rights of crime victims” auch der Wahrung der Rechtsstaatlichkeit in der EU, in einer Aufmachung, die in Stil, Duktus und Problemzuschnitt entsprechenden Abschnitten der Länderberichte des Europäischen Semesters ähnelt. Sprach die FRA 2016 noch von „European and international actors continue to push for stronger rule of law and justice" und benannte dabei Ungarn und Polen ausdrücklich als Problemfälle, ${ }^{1176}$ so ist, mit schrittweiser Erweiterung in den zwischenzeitlich ergangenen Berichten, 2019 von „Rule of law challenges and hurdles to justice continue to grow" die Rede, und auf Entwicklungen

1173 Europäische Grundrechteagentur, s. unter https://fra.europa.eu/en/news-and-e vents/fra-calendar-2020.

1174 Europäische Grundrechteagentur, verfügbar unter: https://fra.europa.eu/en/cas e-law-database.

1175 Verfügbar unter https://fra.europa.eu/en/publications-and-resources/publicatio ns/annual-reports. Bis 2014 firmierte die Reihe unter dem Titel „Fundamental rights: challenges and achievements in 2014“. Für 2015 scheint kein Bericht erstellt worden zu sein.

1176 Europäische Grundrechteagentur, Fundamental Rights Report 2016, S. 161-162, ohne Az., verfügbar unter: https://fra.europa.eu/sites/default/file s/fra_uploads/fra-2016-fundamental-rights-report-2016-2_en.pdf. 
in Bezug auf Polen, Ungarn und Rumänien, aber auch die Slowakei und Malta wird ausdrücklich Bezug genommen. ${ }^{1177}$ Das Problem ist dabei indes zweifach. Was die systemischen Entwicklungen in Polen und Ungarn angeht, dupliziert die FRA summarisch im Wesentlichen bekanntes Material aus Dokumenten insbesondere der Europäischen Kommission, was die anderen Mitgliedstaaten betrifft, kommt es zu einer Vermengung mit Einzelfällen, für welche ich zuvor in Teil C. darauf hingewiesen hatte, dass eben hier eine Trennung erforderlich ist. Eine weitergehende Analyse, gerade etwa der Judikatur oder der nationalen Rechtslage bietet die FRA nicht einmal im Ansatz, womit sie fundamental hinter dem Beitrag der Venedig-Kommission, teils selbst von NGOs wie der sog. Helsinki-Komitees, zurücksteht. Dabei hat die FRA durchaus weitergehende Publikationen, wie Handbücher, anzubieten, ${ }^{1178}$ aber sie scheint, trotz Zuspitzung der Krise, nicht dazu übergegangen zu sein, ihre Analyse zu präzisieren und zu aktualisieren.

Allenfalls Irritationswirkung hat schließlich die Entscheidung der Agentur, im sog. „snippet“-Format nationale Parlamentsdebatten mit Bezug auf Grundrechte und Grundprinzipien zusammenzufassen, was teilweise höchst sinnentstellend geschieht. So findet sich in der Datenbank der FRA ein Hinweis auf einen Antrag der Opposition im französischen Senat, bei welchem die Effizienz des Strafverfolgungssystems vor dem Hintergrund der sog. Gelbwestenproteste durch diese unter dem Titel „Assistons-nous au recul de l'État de droit en France?" diskutiert wurde. ${ }^{1179}$ Die FRA machte hieraus folgende zusammenfassende Feststellung: „Rule of law in France: During the debates on the vanishing of the Rule of law in France the Charter was referenced in order to recall that any limitation of freedoms should be necessary, proportionate and placed under the control of a judge." ${ }^{1180}$ Ein derartiger Fehler muss dem Bestreben der FRA,

1177 Europäische Grundrechteagentur, Fundamental Rights Report 2019, S. 203-205, ohne Az., verfügbar unter: https://fra.europa.eu/sites/default/file s/fra_uploads/fra-2019-fundamental-rights-report-2019_en.pdf.

1178 Vgl. insbesondere Europäische Grundrechteagentur, Handbook on European law relating to access to justice, erstellt gemeinsam mit dem EGMR und der CEPEJ, Ausgabe 206, ohne Nr., verfügbar unter: https://fra.europa.eu/sites/defa ult/files/fra_uploads/fra-ecthr-2016-handbook-on-access-to-justice_en.pdf.

1179 Senat der Französischen Republik, Séance du 29 octobre 2019 (compte rendu intégral des débats), JORF 2019, No. 92 S. (C.R.), 14658 vom 30.10.2019, Punkt 4 der Tagesordnung, S. 14701 ff., auch abrufbar unter: http://www.senat. fr/seances/s201910/s20191029/s20191029010.html.

1180 Abrufbar unter https://fra.europa.eu/en/content/rule-law-france und beim Verfasser archiviert, ohne Az. 
als ernsthafter Partner im interinstitutionellen Dialog wahrgenommen zu werden, nachhaltig schaden.

4. Die Rolle der Venedig-Kommission und ihre Zusammenarbeit mit der Europäischen Kommission

Bleibt die FRA, obwohl unionseigene Agentur, in der Rechtsstaatlichkeitskrise allenfalls von sekundärem Interesse für Wissenschaft und Praxis, so ist eine Einrichtung des Europarates, die Europäische Kommission für Demokratie durch Rechtsstaatlichkeit, kurz: Venedig-Kommission, weitgehend an die Stelle einer Behörde getreten, die für die Entscheidungsträger auf unionaler Organebene komplexe nationale Sachverhalte aufarbeitet, hierzu eigene Rechtsauffassungen abgibt und damit wesentlich zum besseren Verständnis der Topoi der unionalen Rechtsstaatlichkeitskrise beiträgt. Für andere Einrichtungen des Europarates, wie die GRECO oder die CEPEJ, könnten sich in Zukunft verstärkt ähnliche Fragen ergeben.

Die vorliegende Arbeit beschränkt sich hier auf die Venedig-Kommission, da die Kooperation von Europäischer Union und Europarat in der Rechtsstaatlichkeitskrise dort besonders eindringlich zutage tritt; de facto in einem Maße, dass sie vollständig die Diskussion um die Zuhilfenahme sog. „unabhängiger Persönlichkeiten“ ersetzt hat, die noch im Vertrag von Nizza prominent angelegt war. Auch die Frage der Schaffung einer sog. „Kopenhagen-Kommission“ hat sich durch die stetig wachsende Prominenz und Bedeutung der Venedig-Kommission erübrigt.

Die Venedig-Kommission ist in jüngerer Zeit vermehrt Gegenstand von Analysen gewesen, ${ }^{1181}$ und es scheint auch vorstellbar, dass spezifisch die

1181 Gianni Buquicchio \& Simona Granata-Menghini: „The Venice Commission Twenty Years on", in: Marjolein van Roosmalen, Ben Vermeulen, Fried van Hoof \& Marten Oosting (Hrsg.): Fundamental Rights and Principles: Liber Amicorum Pieter van Dijk, Intersentia, Cambridge u.a., 2013, S. 241-254, insb. S. 242 ff.; Finola Flanagan, „The Venice Commission and the Protection of Human Rights“, in: Marjolein van Roosmalen, Ben Vermeulen, Fried van Hoof, \& Marten Oosting, Fundamental Rights and Principles: Liber Amicorum Pieter van Dijk, Intersentia, Cambridge u.a., 2013, S. 255-65; Wolfgang Hoffmann-Riem, „The Venice Commission of the Council of Europe - Standards and Impact", in: European Journal of International Law 25 (2014), S. 579-597; Kaarlo Tuori, „From Copenhagen to Venice“, in: Dimitry Kochenov \& Carlos Closa (Hrsg.), Reinforcing Rule of Law Oversight in the European Union, Cambridge University Press, Cambridge, 2015, S. 225-246; Joakim Nergelius, „The Role of the Venice Commission in Maintaining the Rule of Law in Hun- 
Beziehung zur Europäischen Kommission an anderer Stelle noch einmal Gegenstand einer eigenen Untersuchung wird, auf die ich hier allein im Rahmen des Interesses an der unionalen Verfassungsaufsicht eingehe.

Die Venedig-Kommission, deren Rechtsgrundlage eine Entschließung (Resolution) des Ministerkomitees des Europarates ist, ${ }^{1182}$ dient dem Europarat seit ihrer Schaffung 1990 als Expertengremium zur Beurteilung von Verfassungsänderungen, insbesondere vor dem Hintergrund der Reformen in den Ländern des ehemaligen Warschauer Pakts. ${ }^{1183}$ Im Unterschied zu vielen anderen Einrichtungen des Europarates steht die Beteiligung in der Venedig-Kommission auch Staaten offen, die nicht Mitglied des Europarates sind, ${ }^{1184}$ weswegen Valentina Volpe die internationale Dimension der Kommission betont hat. ${ }^{1185}$ Kaarlo Tuori, heute Mitglied der Kommission, hat als Konsequenz abgeleitet, dass die Venedig-Kommission obwohl dem Europarat angeschlossen, niemals Teil seiner regulären Organisationsstruktur gewesen sei. ${ }^{1186}$

Jeder Staat, der sich an der Venedig-Kommission beteiligt, entsendet Experten in die Kommission, ${ }^{1187}$ nämlich regelmäßig ein ordentliches Mitglied und ein oder mehrere Ersatzmitglieder, die auf Antrag eines Staates, der sich an der Venedig-Kommission beteiligt bzw. auf Antrag

gary and in Romania“, in: Armin von Bogdandy \& Pál Sonnevend (Hrsg.), Constitutional Crisis in the European Constitutional Area, C.H. Beck/Hart/ Nomos, München/Oxford/Baden-Baden, 2015, S. 291-308; Valentina Volpe, „Drafting Counter-Majoritarian Democracy: The Venice Commission's Constitutional Assistance“, in: Zeitschrift für ausländisches öffentliches Recht und Völkerrecht (2016), S. 811-843, dort weitere umfassende Literaturnachweise in Fn. 1.

1182 Ministerkomitee des Europarates, Statute: Resolution(2002)3 Revised Statute of the European Commission for Democracy through Law, vom 21.02.2002.

1183 Valentina Volpe, „Drafting Counter-Majoritarian Democracy”, S. $813 \mathrm{ff}$.

1184 Rechtsgrundlage seitens des Europarates hierfür ist die Statutory Resolution No. (93) 28 on partial and enlarged agreements adopted by the Committee of Ministers on 14 May 1993 at its 92nd Session.

1185 Valentina Volpe, „Drafting Counter-Majoritarian Democracy“, S. 815 ff.; Maartje de Visser, „A Critical Assessment of the Role of the Venice Commission in Processes of Domestic Constitutional Reform", in: American Journal of Comparative Law 63 (2015), S.963-1008, S.965-966, führt die Ursprünge der Venedig-Kommission auf einen Vorstoß des damaligen italienischen Europaministers Antonio La Pergola zurück, was auch die besondere Bereitschaft Italiens erklärt, die Kommission gerade im eigenen Land, und sodann in Venedig, anzusiedeln.

1186 Kaarlo Tuori, „From Copenhagen to Venice“, S. 237.

1187 Vgl. Art. 2 Punkt 2 des Revised Statute der Venedig-Kommission. 
der in Art. 3 Punkt 3 des Revised Statute genannten Organen und Einrichtungen des Europarates, ein Gutachten zu einer bestimmten nationalen verfassungsrechtlichen Rechtsfrage erstellen. Maartje De Visser unterteilt diese Gutachten in drei Themenfelder, nämlich zunächst rein innerstaatliche Verfassungsfragen, für die die Venedig-Kommission als „constitutional helpdesk“ fungiere, sodann davon ausgehend die Klärung von Fragen, die in mehreren begutachteten Staaten wiederholt auftreten („transnational issues“) und schließlich die Erleichterung des Austausches zwischen ihren Mitgliedstaaten und insbesondere deren Verfassungsgerichten. ${ }^{1188}$

Rechtsgrundlage der Beurteilung ist dabei weder mit abschließendem Anspruch die Konvention, noch Unionsrecht, noch insbesondere nicht nationales Verfassungsrecht, die Venedig-Kommission substituiert also nicht etwa für dortige Verfassungsgerichte. Vielmehr bildet sie, in einer Art Gesamtschau, aus der Judikatur europäischer Höchstgerichte (EuGH und EGMR) und verschiedener soft law-Quellen insbesondere des Europarates, einschließlich eigener Veröffentlichungen, gemeinsame „Standards“, aufgrund derer sie im konkreten Fall eine Beurteilung durchführt. ${ }^{1189}$

Im Verlauf der Rechtsstaatlichkeitskrise ist die Venedig-Kommission in großem Umfang um Gutachten ersucht worden, sowohl vonseiten der betroffenen Mitgliedstaaten, ${ }^{1190}$ aber auch durch Organe des Europarates, wie die PACE. ${ }^{1191}$ Im Unterschied zur Tätigkeit der FRA handelt es sich

1188 Maartje de Visser, „A Critical Assessment of the Role of the Venice Commission in Processes of Domestic Constitutional Reform", S. 967-968.

1189 Vgl. dazu sogleich meine Beispiele zu Ungarn und Polen aus der Begutachtungspraxis. Ist der um Begutachtung ersuchende Staat nicht Mitglieds des Europarates oder der Union, verzichtet die Venedig-Kommission auf derartige Standardbildung aus europäischen Quellen und leitet den Prüfungsmaßstab axiomatisch, im Ergebnis aber weitgehend gleichwertig, her, s. dazu etwa CDL-AD(2009)014-e Opinion No. 504/2008, Opinion on the Law on the High Constitutional Court of the Palestinian National Authority, vom 20.03.2009.

1190 Das Gutachten der Venedig-Kommission CDL-AD(2019)004, Opinion no. $843 / 2018$, Hungary - Opinion on the law on administrative courts and the law on the entry into force of the law on administrative courts and certain transitional rules vom 19.03.2019 ist z.B. durch den ungarischen Justizminister angefragt worden, vgl. ebda., Rn. 1; weiter CDL-PI(2020)002, Opinion No. $977 / 2019$, Poland - Urgent Joint Opinion on the amendments to the Law on organisation on the Common Courts, the Law on the Supreme Court and other Laws vom 16.01.2020, Rn. 1, (Anfrage durch den polnischen Senatsmarschall).

1191 Venedig-Kommission, CDL-AD(2017)031-e, Opinion no. 904/2017, Poland Opinion on the Draft Act amending the Act on the National Council of the Judiciary; on the Draft Act amending the Act on the Supreme Court, proposed 
stets um nicht zyklische, konkrete Fallstudien, die die Venedig-Kommission in sehr übersichtlicher Weise wiederum auf einer dezidierten Webseite veröffentlicht.

In der öffentlichen Wahrnehmung scheint die Bedeutung und Aufmerksamkeit für die Venedig-Kommission ob dieser Gutachtenpraxis stetig zu wachsen ${ }^{1192}$ und ist längst in der Tagespresse angekommen. Die New York Times zitierte 2018 Sarah Cleveland als Expertin und Angehörige der Venedig-Kommission noch mit erläuterndem Zusatz. ${ }^{1193}$ Als die VenedigKommission Anfang $2020 \mathrm{zu}$ Polen Stellung bezog, fand sich ihre Position ohne Weiteres in Berichten der Deutschen Welle und der Süddeutschen Zeitung. ${ }^{1194}$

Vier Besonderheiten erklären diesen Bedeutungszuwachs.

Die erste, vielleicht entscheidendste, ist Schnelligkeit. Die Rechtsstaatlichkeitskrise ist in höchstem Maße schnelllebig, wie etwa der Topos der ad-hoc und Einzelfallgesetzgebung in Ungarn zeigt, teilweise geht es eher um Tage und Wochen, als Monate. Aber die Venedig-Kommission ist in der Rechtsstaatlichkeitskrise mutmaßlich der am schnellsten handelnde und gleichzeitig darüber als umfassend glaubwürdig ${ }^{1195}$ erachtete Akteur, sieht man also von Gutachten z.B. der sog. Helsinki-Komitees ab, die häufig die ersten „auf dem Markt“ sind, aber nicht annähernd die gleiche Reputation genießen dürften. Das liegt an der europaweit einmaligen Kombination aus schlankem Verwaltungsunterbau, höchstqualifizierten Mitgliedern und der von Verfahrensvorgaben weitestgehend befreiten

by the President of Poland, and on the Act on the Organisation of Ordinary Courts, Rn. 1.

1192 Skeptisch noch Valentina Volpe, „Drafting Counter-Majoritarian Democracy“, S. 813 , insb. Fn. 1.

1193 Mark Santora, „Polish Crisis Deepens as Judges Condemn Their Own Court“, New York Times vom 05.07.2018.

1194 Deutsche Welle, „Polens ,Maulkorbgesetz' gefährdet den Rechtsstaat“, vom 16.01.2020, Süddeutsche Zeitung, „Streit um den Rechtsstaat eskaliert“, vom gleichen Tag.

1195 Nachweise zur Reputation in der Rechtswissenschaft bei Maartje de Visser, „A Critical Assessment of the Role of the Venice Commission in Processes of Domestic Constitutional Reform“, S. 968; Paul Craig, „Transnational Constitution-Making: The Contribution of the Venice Commission on Law and Democracy“, in: UC Irvine Journal of International, Transnational, and Comparative Law 2 (2017), S. 57-86, S. 66, sieht in der Zeitfrage hingegen auch eine große Belastung. Zur "reputational authority" seitens der Mitgliedstaaten auch Valentina Volpe, „Drafting Counter-Majoritarian Democracy”, S. 819. 
Entscheidungsweise der Venedig-Kommission. Zugespitzt formuliert kombiniert die Venedig-Kommission die Schlagkraft eines "Gemeinsamen Senats" europäischer nationaler Verfassungsgerichte ${ }^{1196}$ mit der Flexibilität eines Privatgutachtens.

Im Hinblick auf das Verfahren insbesondere macht das Statut der Venedig-Kommission kaum Vorgaben, es benennt allenfalls Prinzipien, die bei der Gutachtenausfertigung anleiten. ${ }^{1197}$ Während ein Sekretariat mit Sitz in Straßburg die Mitglieder bei der alltäglichen Arbeit unterstützt, gruppieren sich die Mitglieder thematisch in Ausschüssen (sub-commissions), ${ }^{1198}$ allerdings werden konkrete Gutachtenaufträge an sog. „working groups" vergeben, die dann die späteren auch in den Gutachten ersichtlichen Berichterstatter (rapporteurs) sind. ${ }^{1199}$ Für jedes Gutachten wird seitens des Sekretariats ein zuständiges Mitglied zur Unterstützung ernannt. Das Sekretariat bereitet den Gutachtern ebenso die konkrete Anfrage auf und stellt die infrage stehende nationale Gesetzgebung (mutmaßlich damit auch übersetzt) zur Verfügung. Angeleitet werden die Gutachter durch interne „Guidelines on Working Methods“, die damit eine Verfahrensordnung im Wesentlichen ersetzt. ${ }^{1200}$

Die Schnelligkeit der Venedig-Kommission beeindruckt. Im Falle der Begutachtung des durch Ungarn nicht umgesetzten Verwaltungsgerichtssystems betrug die Zeitspanne von der Anfrage bis zum fertigen Gutachten nur gute 4 Monate, ${ }^{1201}$ im Falle des als „dringend“ angefragten Gutachtens zu jüngsten Änderungen betreffend die polnische ordentliche Gerichtsbar-

1196 Viele Mitglieder sind oder waren Angehörige nationaler Verfassungsgerichte.

1197 Maartje de Visser, „A Critical Assessment of the Role of the Venice Commission in Processes of Domestic Constitutional Reform", S. 972.

1198 Wolfgang Hoffmann-Riem, „The Venice Commission of the Council of Europe - Standards and Impact", in: European Journal of International Law 25 (2014), S. 579-597, S. 580.

1199 Zu Working Groups und Berichterstattern Maartje de Visser, „A Critical Assessment of the Role of the Venice Commission in Processes of Domestic Constitutional Reform“, S. 1004 ff., dort indes auch kritisch und mit Reformvorschlägen betreffend die Benennung der Mitglieder.

1200 Vgl. Paul Craig, „Transnational Constitution-Making”, S. 66, zu diesen Interna.

1201 Venedig-Kommission, CDL-AD(2019)004, Opinion no. 843/2018, Hungary Opinion on the law on administrative courts and the law on the entry into force of the law on administrative courts and certain transitional rules vom 19.03.2019, Rn. 1 und Titel: Das Gutachten wurde am 9. November 2018 angefragt und am 19. März 2019 veröffentlicht. 
keit sogar nur gute 14 Tage. ${ }^{1202}$ Damit kann kein Gericht, selbst in Fällen vorläufigen Rechtsschutzes mithalten, zumal die Venedig-Kommission stets unmittelbar die Problematik in der Sache begutachtet.

Der zweite Faktor für die Bedeutung der Venedig-Kommission ist die Qualität und die Struktur ibrer Gutachten. Dabei bürgt der Werdegang der Mitglieder der Kommission, auch wenn dieser durchaus variieren kann, teils bereits auf den ersten Blick für ihre juristische Expertise. Für Deutschland gehören aktuell etwa Angelika Nußberger, ehemalige Vizepräsidentin des EGMR und Monika Herrmanns, Richterin des BVerfG, der Kommission an. Frankreich, Österreich und Lettland, um bei Beispielen zu bleiben, haben jeweils ebenso Mitglieder ihrer Verfassungsgerichte ernannt, Finnland, Spanien, Schweden und die Schweiz Professoren mit einer venia für Verfassungsrecht. ${ }^{1203}$

Die Gutachten der Venedig-Kommission im Umfeld der Rechtsstaatlichkeitskrise sind, gerade im Unterschied zu Entschließungen des Europäischen Parlaments aber auch Darstellungen der Europäischen Kommission im Rahmen von Art. 7 EUV, denen vorrangig eine Tatbestandssicherungsfunktion zukommt bzw. deren Analyse weit summarischer erfolgt, genuine analytische Auseinandersetzungen mit der vorgefundenen Rechtslage.

Anhand des jüngst ergangenen Gutachtens zu Polen soll dies pars pro toto erläutert werden, auch wenn dieses unter besonderem Zeitdruck ergangen ist. Auf eine kurze Einleitung und eine Einführung in den weiteren Sachstand, wobei die Venedig-Kommission bewusst den Kontext der Entwicklung rekapituliert, ${ }^{1204}$ führt sie über eine summarische Darstellung unmittelbar zurückliegender Urteile des EuGH in die aktuelle Problemlage ein und schreckt dabei auch vor deutlichen Feststellungen bereits zu Anfang des Gutachtens nicht zurück. ${ }^{1205}$ Nach einer Würdigung des

1202 Venedig-Kommission, CDL-PI(2020)002, Opinion No. 977/2019, Poland Urgent Joint Opinion on the amendments to the Law on organisation on the Common Courts, the Law on the Supreme Court and other Laws vom 16.01.2020.

1203 Die einzelnen Mitglieder sind genannt unter https://www.venice.coe.int/WebF orms/members/default.aspx.

1204 Venedig-Kommission, CDL-PI(2020)002, Opinion No. 977/2019, Poland Urgent Joint Opinion on the amendments to the Law on organisation on the Common Courts, the Law on the Supreme Court and other Laws vom 16.01.2020, Rn. 1-5, 7-10.

1205 Venedig-Kommission, CDL-PI(2020)002, Opinion No. 977/2019, Poland Urgent Joint Opinion on the amendments to the Law on organisation on the Common Courts, the Law on the Supreme Court and other Laws vom 16.01.2020, Rn.11-17. In Rn. 17 hält die Venedig-Kommission fest: „In sum, 
formellen Verfahrensgangs, den die Venedig-Kommission nicht anhand nationalen Verfassungsrechts beurteilt, sondern den sie unter Rückgriff auf allgemeine Grundsätze beim Abfassen von Gesetzen untersucht, folgt eine schrittweise und allgemeiner Subsumtionstechnik weitgehend folgende Begutachtung einzelner Gesetzesabschnitte, wobei die Venedig-Kommission zuvor zu den Fragen der richterlichen Unabhängigkeit ergangene Urteile des EGMR und des EuGH zu einem gemeinsamen ,international legal framework" verbindet, welches den Prüfungsmaßstab bildet und wozu sie zusätzlich affirmativ auf einschlägige Normen sowohl der EMRK als auch der Grundrechtecharta der Union verweist. ${ }^{1206}$ Die Sichtung des materiellen Rechts erfolgt schließlich anhand der Unterscheidung konkreter Problempunkte im Gesetz (wiederum also einer topischen Arbeitsweise), wie etwa hinsichtlich der Frage des neuen Disziplinarregimes oder der Rückwirkung der Änderungen. In ihrer Zusammenfassung versucht die Venedig-Kommission sodann sichtlich, der polnischen Regierung vermittelnd entgegenzukommen, und schließt mit konkreten Vorschlägen zur Behebung der Krise an den polnischen Gesetzgeber durch Umsetzung früherer Empfehlungen. ${ }^{1207}$ Andere Gutachten der Venedig-Kommission, wie z.B. diejenige zum ungarischen Verwaltungsgerichtssystem, bestätigen, dass es sich hier um einen regelmäßig anzutreffenden Gutachtenaufbau handelt, insbesondere, dass die Kommission eine in Problembereiche unterteilte Analyse des vorgefundenen Gesetzesmaterials in das Zentrum ihrer Arbeit stellt ${ }^{1208}$ wie auch, dass die Kommission regelmäßig pragmati-

the Polish legal order faces a schism between the old judicial institutions and judges, on one side, and, on the other, those bodies and judges who were created/appointed on the basis of the new rules introduced by the legislative amendments of 2017. There is a risk of legal chaos with the decisions of some courts not recognised as valid by other courts.".

1206 Venedig-Kommission, CDL-PI(2020)002, Opinion No. 977/2019, Poland Urgent Joint Opinion on the amendments to the Law on organisation on the Common Courts, the Law on the Supreme Court and other Laws vom 16.01.2020, Rn. $19 \mathrm{ff}$.

1207 Venedig-Kommission, CDL-PI(2020)002, Opinion No. 977/2019, Poland Urgent Joint Opinion on the amendments to the Law on organisation on the Common Courts, the Law on the Supreme Court and other Laws vom 16.01.2020, vgl. insb. Rn. 58-62.

1208 Venedig-Kommission, CDL-AD(2019)004, Opinion no. 843/2018, Hungary Opinion on the law on administrative courts and the law on the entry into force of the law on administrative courts and certain transitional rules vom 19.03.2019, Rn. 25 ff. 
sche Verständigung mit den begutachteten Staaten anstrebt. ${ }^{1209}$ Und auch dort steht zuvor eine Ausarbeitung eines Prüfungsmaßstabs aus verschiedenen Quellen des Europarates, einschließlich von der Venedig-Kommission selbst erarbeiteter Standards, im Vordergrund. ${ }^{1210}$

Diese topische Sichtung ist für die Rezeption der Gutachten der Venedig-Kommission seitens anderer Stellen, nun eben vor allem der Europäischen Kommission und sogar durch den $\mathrm{EuGH}$, sehr gut geeignet und führt zum dritten Faktor für die Bedeutung der Venedig-Kommission, die Verwendung dieser Gutachten seitens der Unionsorgane, insbesondere der beiden vorgenannten. Die Große Kammer des Europäischen Gerichtshofs hat die Gutachten der Venedig-Kommission geadelt, nämlich zum unmittelbar zu berücksichtigenden analytischen Primärmaterial erklärt, auf welches eigene Argumentation weiter aufbauen könne. ${ }^{1211}$ Die Europäische Kommission wiederum hat sich, insbesondere in ihrem begründeten Vorschlag nach Art. 7 Abs. 1 EUV betreffend Polen, nicht nur auf Gutachten der Venedig-Kommission gestützt, sondern auch betont, sie habe Polen empfohlen, Gutachten der Venedig-Kommission zu beachten. ${ }^{1212}$

Angesichts dieser intensiven Berücksichtigung der Gutachten einer nicht-unionalen Stelle im Rahmen der unionalen Rechtsstaatlichkeitskrise ist der Versuch zu machen, die Einbindung systematisch und teleologisch zu erklären. Dabei habe ich hier nicht legitimierende Gesichtspunkte allgemeiner Art im Blick, ${ }^{1213}$ sondern es geht mir spezifisch um die Rolle der Venedig-Kommission als Akteur in der Rechtsstaatlichkeitskrise.

1209 Vgl. etwa auch Venedig-Kommission, CDL-AD(2017)022, Opinion 891/2017, Hungary - Opinion on Article XXV of 4 April 2017 on the Amendment of Act CCIV of 2011 on National Tertiary Education vom 09.10.2017, Rn. 55.

1210 Venedig-Kommission, CDL-AD(2019)004, Opinion no. 843/2018, Hungary Opinion on the law on administrative courts and the law on the entry into force of the law on administrative courts and certain transitional rules vom 19.03.2019, Rn. 16 ff., insb. 22.

1211 EuGH, Rs. C-619/18 R, Kommission ./. Polen, „Unabhängigkeit des Obersten Gerichts“, Urteil (GK) vom 24.06.2019, ECLI:EU:C:2019:531, Rn. 82. Zuvor bereits Schlussanträge des Generalanwalts Evgeni Tanchev in derselben Rs., vom 11.04.2019, ECLI:EU:C:2019:325, insb. bei Fn. 51 und 53.

1212 Europäische Kommission, Begründeter Vorschlag nach Artikel 7 Absatz 1 des Vertrags über die Europäische Union zur Rechtsstaatlichkeit in Polen für einen Beschluss des Rates zur Feststellung der eindeutigen Gefahr einer schwerwiegenden Verletzung der Rechtsstaatlichkeit durch die Republik Polen, $\operatorname{COM}(2017) 835$ final, 2017/0360 (NLE) vom 20.12.2017, Rn. 13, 18, 20, insb. 26.

1213 Dazu Valentina Volpe, „Drafting Counter-Majoritarian Democracy”, S. 841 und ff., die es als Paradoxon bezeichnet, dass die Venedig-Kommission die 


\section{E. Das Rechtsregime der Verfassungsaufsicht der Europäischen Union}

Der Venedig-Kommission selbst und ihren Mitgliedern dürfte die Beobachtung einer engen organisatorischen Einbindung in das Unionsgefüge mutmaßlich weniger recht sein. Sie betonen, wie soeben gezeigt, neben eindringlicher Kritik an Mitgliedstaaten wie Polen und Ungarn auch stets ihre Rolle als Vermittler. Die Venedig-Kommission will also bis zu einem gewissen Grad als neutral wahrgenommen werden, auch wenn sie sich nicht gescheut hat, in von der Krise betroffenen Mitgliedstaaten Mängel auch als „systematic“ zu bezeichnen und offen zu rügen. ${ }^{1214}$

Ich schlage vor, die Sichtweise und ggf. dieses Selbstverständnis der Venedig-Kommission als bloß neutralem und unparteiischen Beobachter in der Krise aufzugeben. Damit ist man beim vierten Faktor für ihren Bedeutungszuwachs.

Für diese geänderte Rolle ficht zunächst die Dringlichkeit der Krise, in welcher sich die Venedig-Kommission eindeutig auf Seiten derjenigen positioniert hat, die vor weiterer Eskalation warnen und die, schon aufgrund der in den jeweiligen Dokumenten erfolgenden Referenzen, im engen Austausch nicht nur mit der Europäischen Kommission stehen, sondern sogar für den EuGH Grundlagen der Beurteilung liefern. Die Venedig-Kommission kämpft für die Erhaltung der Rechtsstaatlichkeit in von systemischen Defiziten bedrohten Mitgliedstaaten der Europäischen Union, wie deren eigenen Organe, sie ist längst nicht mehr Zaungast noch ein neutraler Beobachter.

Dagegen könnte entscheidend sprechen, dass der Venedig-Kommission darüber ein Legitimitäts- und Reputationsverlust, gerade bei den kritisierten Mitgliedstaaten droht. Das trägt meines Erachtens nicht mehr, im Gegenteil, die Flucht nach vorn ist geboten.

Zunächst haben die avisierten Mitgliedstaaten, Polen, Ungarn und Rumänien insbesondere, sehr deutlich gemacht, dass sie die Venedig-Kommission nicht länger als vermittelnden Akteur, sondern als politischen Gegner sehen, den es auszuschalten gälte. Das heißt nicht, dass die Reputation der Venedig-Kommission gelitten hat und man sie nicht länger konsultiert, aber, dass jedes Gutachten den Filter der politischen Überlegungen in den begutachteten Ländern passieren muss. Umgesetzt worden

Demokratieförderung besonders im Blick habe, indes von außen, statt von innen, auf politische Systeme einwirke.

1214 Ein weiteres, eindrückliches Beispiel hierfür ist der Schlussteil des Gutachtens Venedig-Kommission, CDL-AD(2013)012, Opinion 720/2013, Opinion on the

Fourth Amendment to the Fundamental Law of Hungary vom 17.06.2013, Rn. $138 \mathrm{ff}$. 
sind die Gutachten bis heute weitestgehend nicht, die Anrufung der Venedig-Kommission darf daher nicht reines „Feigenblatt“ bleiben. Dabei droht indes gerade eine solche „Uminterpretation“ der Gutachten von staatlicher Seite. So vermeldete die ungarische Regierung unter Berufung auf das Gutachten der Venedig-Kommission z.B., dass das geplante ungarische Verwaltungsgerichtssystem „europäischen Normen“ entspreche, ${ }^{1215}$ wobei sich dies in dieser Deutlichkeit aus dem Gutachten schlicht nicht folgern lässt. Die polnische Regierung wiederum wählte den Weg der offenen Konfrontation. Sie sprach im Hinblick auf das Gutachten zu den Änderungen in der ordentlichen Gerichtsbarkeit von einer „Parodie“ eines Gutachtens. ${ }^{1216}$

Als zweites Mittel der Wahl seitens der im Fokus stehenden Mitgliedstaaten ist eine „Unterwanderung durch politisierende Fehlbesetzung“ nicht auszuschließen, d.h. die Berufung politisierter oder unzureichend qualifizierter Mitglieder: für Polen ist derzeitiges Mitglied Marcin Warchol, ein Unterstaatssekretär im Justizministerium, und damit unmittelbar der Kontrolle seitens der PiS-Regierung unterworfen, schließlich als Ersatzmitglied Mariusz Muszyński, verfassungswidrig ernannter Angehöriger des polnischen Verfassungsgerichts. ${ }^{1217}$ Für Rumänien gehört u.a. Tudorel Toader der Venedig-Kommission an, der zuvor als Justizminister u.a. die Berücksichtigung Laura Codruța Kövesis im Rahmen der Europäischen Staatsanwaltschaft zu verhindern suchte. ${ }^{1218}$ Hinsichtlich des ungarischen Mitglieds András Varga, ebenso Richter des ungarischen Verfassungsgerichts, ist immerhin anzumerken, dass er ein Papier unter dem Titel „Beyond the rule of law" veröffentlicht hat, das u.a. dahingehend verstanden werden kann, der Bedeutungsinhalt der Rechtsstaatlichkeit sei tautologisch und einzig legitime Kontrollkraft im Staat sei das Parlament. ${ }^{1219}$ Dass

1215 Ungarische Regierung, „The Hungarian Act on Public Administration Courts conforms to European norms", Pressemitteilung vom 19.03.2019, abrufbar unter: https:/www.kormany.hu/en/ministry-of-justice/news/the-hungarian-act -on-public-administration-courts-conforms-to-european-norms.

1216 So die Meldung des polnischen Senders TV24, „Ziobro: Venice Commission issued a parody of an opinion“, vom 16.02.2020, abrufbar unter: https://tvn24. $\mathrm{pl} /$ tvn24-news-in-english/polands-justice-minister-says-venice-commission-opin ion-is-a-parody-3092252.

1217 S. zu den Einzelheiten bereits oben unter C. III. 4.

1218 Vgl. Georgi Gotev, „Romania’s Kovesi in pole position for European Chief Prosecutor“, Euractiv vom 06.02.2019.

1219 Andras Zs. Varga, „Beyond Rule of Law“, in: Iustum Aequum Salutare IX. 2013, S. 117-127, insb. S. 124, abrufbar unter: http://ias.jak.ppke.hu/hir/ias/201 32sz/07.pdf. 
es höchst wahrscheinlich ohne Mehrwert wäre, Muszyński die Rechtslage in Ungarn, Varga diejenige in Polen begutachten zu lassen, scheint recht offensichtlich.

Der Umstand, dass die Venedig-Kommission selbst derart angegriffen wird und mutmaßlich unterwandert werden könnte, sollte dazu führen, in ihr erst recht eine weitere Aufsichtsstelle zu sehen, die für die Europäische Union besonders drängende und mit besonderer Sachexpertise ausgestattete unverbindliche Gutachtenaufträge ausführt, dafür aber auch nicht an Verfahren gebunden ist.

Es ist dabei hier nicht mein Anliegen, dazu de lege ferenda-Vorschläge zu machen, insbesondere, weil dies wiederum zur Frage der Schaffung weiterer unionaler Behörden oder Organe, wie der „Kopenhagen-Kommission", führt. ${ }^{1220}$ Ich merke allerdings an, dass es in jedem Fall geboten sein dürfte, die Einbindung der Venedig-Kommission in den Entscheidungsfindungsprozess der Union mehr zu substantiieren als dies bislang in der wohl einzigen positiv-rechtlichen Grundlage dafür erfolgt, dem sog. Memorandum of Understanding der Union und des Europarates, in welchem festgehalten wird, beide Signatare „will make full use of the Venice Commission's expertise“. ${ }^{1221}$

Die Europäische Kommission ist auf eine Stärkung ihrer Zusammenarbeit mit der Venedig-Kommission bereits eingegangen. Im Juli 2019 hielt sie fest, sie werde „die Zusammenarbeit mit dem Europarat einschließlich der Venedig-Kommission und GRECO ausbauen und prüfen, wie diese hinsichtlich der Prioritäten der EU auf dem Gebiet der Rechtsstaatlichkeit weiter unterstützt werden können“. ${ }^{1222}$

In der Zwischenzeit könnte die engere Einbindung und Formalisierung der Beziehung von Europäischer Kommission und Venedig-Kommission allerdings auch über dogmatische Figuren gelöst werden, die keiner unmittelbaren Rechtsänderung bedürfen. Eine solche Figur, die sich dabei vorrangig anbietet, ist die der Organleihe in föderalen Verfassungen. Die

1220 Zur Abgrenzung beider Kommissionen daher auch ausführlich Kaarlo Tuori, „From Copenhagen to Venice“, S. $237 \mathrm{ff}$.

1221 Memorandum of Understanding between the Council of Europe and the European Union, ohne Az., Rn. 28, abrufbar z.B. unter: https://rm.coe.int/1680 4e437b.

1222 Europäische Kommission, Mitteilung der Kommission an das Europäische Parlament, den Europäischen Rat, den Rat, den Europäischen Wirtschafts- und Sozialausschuss und den Ausschuss der Regionen: Die Stärkung der Rechtsstaatlichkeit in der Union: Ein Konzept für das weitere Vorgehen, COM(2019) 343 final vom 17.07.2019, S. 10. 
Organleihe bezeichnet im Bundesstaat das rechtsträgerübergreifende Tätigwerden eines Organs des einen Rechtsträgers für den entleihenden Rechtsträger, wobei das Organ dessen Weisungen unterworfen, dem Entleiher dafür seine Entscheidungen und Maßnahmen zugerechnet werden. ${ }^{1223}$ Diskutiert worden ist diese Figur für das Unionsrecht bislang vorrangig mit Blick auf die Übertragung mitgliedstaatlicher Zuständigkeiten auf die Union. ${ }^{1224}$ Der Übertragung dieser Figur zur Deutung der intensivierten Relation von Europäischer und Venedig-Kommission dürfte bislang noch an diversen Unterschieden scheitern. $\mathrm{Zu}$ berücksichtigen sind der Wille beider Beteiligter, die im Hintergrund schwelende offene Frage der Berücksichtigung der EMRK im Unionsrecht wie auch möglicher Einwände bei der Einbindung einer im Kern völkerrechtlichen Einrichtung in supranationalen Strukturen. Von einer künftigen Organleihe der Venedig-Kommission durch die Unionsorgane, die Europäische Kommission insbesondere, auszugehen, könnte sich aber als wünschenswerte und recht pragmatisch zu bewerkstelligende Grundlage für eine Intensivierung und Formalisierung der Beziehungen anbieten.

\section{Zwischenergebnis}

In diesem Abschnitt habe ich in Grundzügen die Beziehungen verschiedener Unionsorgane und anderer Einrichtungen, auch des Europarates, darüber ganz besonders der Venedig-Kommission, dargestellt. Damit sollte deutlich geworden sein, dass die Ausübung von Aufsichtsmaßnahmen in Bezug auf systemische Defizite auch mit Blick auf die beteiligten Akteure komplex ist, verschiedene Akteure große Bedeutung haben oder aber eine solche zumindest anmelden.

Dieses Geflecht an Beziehungen zwischen Organen und nachrangigen Einrichtungen, wobei hier zusätzliche Fragen wie die Beteiligung privater Akteure ausgeblendet wurde, bedarf der Beachtung. Die Interaktionen der verschiedenen Akteure laufen aber, berücksichtigt man insbesondere ihr Mandat aus Art. 17 Abs. 1 EUV und die dort ansässige Expertise, schließ-

1223 Für das Grundgesetz etwa Martin Ibler, Art. 87 GG, in: Theodor Maunz \& Günter Dürig (Begr./Hrsg.), Grundgesetz-Kommentar, 88. EL August 2019, C.H. Beck, München, Rn. 58 .

1224 Konzise vgl. Wissenschaftlicher Dienst des Deutschen Bundestags, „Unionsrechtliche Anforderungen an die Übertragung von Aufgaben an die Europäische Kommission durch die Mitgliedstaaten“, PE 6 - 3000 - 124/16, vom 29.08.2016, Punkt 2.2. und 2.3 insb. und die dort zit. Rspr. 
lich auf die ganz vorrangige Rolle der Europäischen Kommission als in der Krise handelnder Verfassungsaufsichtsakteur zu.

Sie soll nun bei der Darstellung einzelner Mechanismen im Vordergrund stehen.

\section{Präzisierung der Akteursperspektive: Ein Blick auf die Europäische Kommission}

Das vielleicht stärkste Argument für die Annahme, dass im Rahmen der derzeitigen Rechtsstaatlichkeitskrise von einem einheitlichen Rechtsregime der Verfassungsaufsicht gesprochen werden kann, ist der Umstand, dass alle im Rahmen der Krise in Wissenschaft und Tagespresse debattierten Verfahren innerhalb der Europäischen Kommission durch einige, bestimmte Dienststellen zentral behandelt werden, auch wenn, abhängig vom Sachverhalt, diverse andere Dienste und Akteure „input“ liefern und hierzu angefragt werden. Die unionale Verfassungsaufsicht liegt also, was die Europäische Kommission betrifft, in der Verantwortung nicht einer einzelnen Generaldirektion, sie liegt in den Händen von wenigen Spezialisten innerhalb bestimmter Generaldirektionen und dabei einer Gruppe von Verantwortlichen innerhalb der Generaldirektion Justiz und Verbraucher insbesondere.

Damit ist das Argument eines kohärenten Verfassungsaufsichtsregimes nicht nur auf dem handlungsformzentrierten Eindruck des kohärenten Ineinandergreifens verschiedener Mechanismen aufgebaut, es findet vielmehr auch eine organisatorische Stütze. Das gilt selbst für diejenigen Verfahren, die in der Kommission nicht ihren Ursprung hatten, wie den sog. DRF-Pakt, sie sind in diesen Dienststellen nämlich eingehend berücksichtigt worden.

\section{Auswirkungen des Chef de File-Grundsatzes}

Die bei der Handhabung der zuvor genannten Mechanismen handelnden Dienststellen sind für die Reaktion der Europäischen Kommission auf systemische Defizite in Mitgliedstaaten „chef de file“ oder federführender Dienst (lead service), auch wenn finale Entscheidungen das Privileg der Kabinette der zuständigen Kommissare, und dieser selbst, geblieben sind.

Der Umstand, dass eine Gubernative auch im Innenbereich einer bereits global zuständigen Abteilung einen federführenden Dienst bestimmt, ist 
dabei zunächst ein dem Grundsatz guter Verwaltung entsprechender und recht natürlicher Vorgang zur Kanalisierung des Arbeitsflusses, Schaffung klarer Zuständigkeiten und Förderung einer Sachkompetenzbildung. ${ }^{1225}$ In der Wissenschaft hat die interne Zuständigkeitsverteilung innerhalb eines Dienstes im Unterschied etwa zur Unterteilung in die Generaldirektionen in der Europäischen Kommission häufig wenig interessiert. ${ }^{1226}$ In der Rechtsstaatlichkeitskrise hingegen hat die Zuständigkeitsabgrenzung innerhalb der Kommission aufgrund des besonderen politischen Gewichts der ergriffenen Maßnahmen aber eine besondere Dynamik entwickelt.

Zunächst ist darauf hinzuweisen, dass, obwohl verschiedene Kommissionsdienststellen entscheidend zu vielen der in der Krise ergriffenen Maßnahmen beitragen, wobei dies je nach Sachthema variieren kann - zwei Dienste besonders in der Krise hervorgetreten sind. Das ist, schon kraft Gesetzes, im Übrigen aber aufgrund seiner juristischen Expertise, der Juristische Dienst der Kommission, welcher gem. Art. 21 UAbs. 2 S. 2 der Geschäftsordnung der Kommission ${ }^{1227}$ „zu allen Entwürfen von Beschlüssen und Vorschlägen von Rechtsakten sowie zu allen Vorlagen, die rechtliche Wirkungen haben können, zu hören“ ist und der gem. Art. 12 UAbs. 1 der Geschäftsordnung Vorschlägen aus der Mitte der Dienststellen zustimmen muss, damit diese Vorschläge im Kollegium im schriftlichen Verfahren beschlossen werden können. Der Juristische Dienst hat auch die Prozessvertretung der Kommission, insbesondere in einschlägigen Vertragsverletzungsverfahren vor dem Gerichtshof übernommen.

Neben den Juristischen Dienst aber treten, nach meiner Beobachtung und der mir zugestandenen Perspektive, mit ebenso prononcierter juristischer Schlagkraft und rechtspolitischem Sachverstand, bestimmte hochspezialisierte Dienststellen der Generaldirektion Justiz und Verbraucher, darunter ganz besonders diejenigen der Direktion C (Grundrechte und

1225 Die Kommission hat den Zweck der chef de file-Benennung genau umschrieben, vgl. Mitteilung an die Kommission, Synergien und Effizienzgewinne bei der Kommission - Neue Arbeitsmethoden, SEC(2016) 170 final, vom 04.04.2016, S.3, vgl. weiter auch Europäische Kommission, Document Management in the European Commission, Collected Decisions and Implementing Rules, Amt für Veröffentlichungen der Europäischen Union, Luxemburg, 2010, insb. S. $53 \mathrm{ff}$.

1226 Nur kursorisch etwa bei Deirdre Curtin, Executive Power of the European Union: Law, Practices, and the Living Constitution, Oxford University Press, Oxford, 2009, S. 221, s. im Übrigen S. $106 \mathrm{ff}$; interessante Fallstudie zu Konfliktlagen aufgrund einer Benennung bei Mihalis Kritikos, EU Policy-Making on GMOs, Palgrave Macmillan, London, 2018, S. 68.

1227 ABl. (EG) L 308/26 vom 08.12.2000; konsolidierte Fassung als (K(2000) 3614). 
Rechtsstaatlichkeit) und spezieller des Referats C.1 (Justizpolitik und Rechtsstaatlichkeit), sodass die nachfolgenden Verweise auf konkrete Dienststellen im Regelfall auf diese zu beziehen sind. Dass die GD JUST bei der Bearbeitung von Rechtsstaatlichkeitsfragen seit Beginn der Entwicklung eine besondere Rolle spielte, hatte bereits die damalige Justizkommissarin Viviane Reding 2013 deutlich gemacht, als sie deren Arbeit ausdrücklich würdigte und darüber hinaus anmerkte, möglicherweise könne man an die US-amerikanische Tradition des dort auch mit der Durchsetzung des Bundesrechts beauftragten Justizdepartments einmal anknüpfen:

„We are not yet the United States of Europe! Unlike the U.S., the Commission does not have a Department of Justice, 200 years old, with more than 116000 officials and lawyers in-house with the experience of having fought through the Civil Rights legislation. The Commission has a young and small DG Justice, just 4 years old and with barely 250 officials, most of them kept very busy with implementing the legislative agenda laid down in the Stockholm Programme. DG Justice has made enormous progress in developing its comparative expertise, for example, on sound, efficient and independent legal systems." 1228

Man kann daher davon sprechen, dass für die GD JUST aus dieser regelmäßigen chef de file-Rolle eine primus-inter-pares-Funktion folgt. Diese Funktion ist zwar auch an anderen Stellen im Kommissionsgeschehen, insbesondere etwa der sog. inter-service consultation im Gesetzgebungsverfahren, für andere Dienststellen anzutreffen, hier aber aufgrund der Bedeutung der Sachverhalte und der erforderlichen Sachkenntnis ganz besonders ausgeprägt.

\section{a. Kollegium und Kabinette}

Die GD JUST und ihre Dir. C, dort wiederum ihr Referat C.1 „Justizpolitik und Rechtsstaatlichkeit“, insbesondere hat über den Verlauf der Krise beachtliche Expertise in der Entwicklung und Nutzung der verschiedenen Verfassungsaufsichtsverfahren und vor allem auch herausragendes und in der Kommission wohl einmaliges Sachstandsverständnis für die gerade Polen und Ungarn betreffenden komplexen Sachstände entwickelt. Auf

1228 Viviane Reding, „The EU and the Rule of Law - What next?“, S. 9. 
diese Sachexpertise waren andere Dienststellen, aber auch die Kabinette verschiedener Kommissare, zwingend angewiesen.

Eine Besonderheit ist dabei, dass, nach Ausscheiden Viviane Redings aus der Kommission nach Ende der Barroso-Kommission, über den Verlauf der Entwicklungen stets zwei verschiedene Kommissare und damit auch zwei getrennte Kabinette auf Kollegiumsebene die Krise verfolgt, auf die Leistungen der Dienststellen gebaut und mit ihnen folglich eine besondere Vertrauensbeziehung gesucht haben.

Während der Juncker-Kommission 2014-2019 waren dies der Erste Vizepräsident Frans Timmermans, dem explizit das Rechtsstaatlichkeitsportfolio zufiel. Seine tschechische Kollegin Vèra Jourová betreute als Kommissarin für „Justiz, Verbraucher und Gleichstellung“ Schnittmengen der Problematik. Es bestand also eine potentiell überlappende Zuständigkeit beider Kommissare und ihrer Kabinette. Ein derart überlappender Portfoliozuschnitt von "project teams" hat in der Barroso-Kommission, gerade in Bezug auf die Bedeutung der Vizepräsidenten, besondere Bedeutung erfahren, ${ }^{1229}$ was hier als Blaupause des Zusammenwirkens beider Kommissare erscheint. Dabei ergab sich förmlich indes im speziellen Fall eine klare Abstufung. Im sog. Mission Letter Junckers an Jourová, also der Grundlage für die Aufgabenverteilung im Kollegium, wurde sie beauftragt, Timmermans bei Rechtsstaatlichkeitsfragen zu unterstützen, autonome Zuständigkeiten blieben ihr allein im Bereich Gleichstellung und Datenschutz. ${ }^{1230}$ Timmermans wiederum fiel breites Ermessen bei der Ausgestaltung zu, eine Arbeitsbeziehung zu Jourová wurde nicht festgelegt, vielmehr habe er die Rechtsstaatlichkeitspolitik zu steuern (steer) und zu koordinieren (coordinate). ${ }^{1231}$

In der von-der-Leyen-Kommission, die seit Ende 2019 im Amt ist, hat sich dieses Duopol auf Kollegiumsebene der Kommission verschärft. Timmermans, nunmehr u.a. für den sog. „Green Deal“ der Kommission zu-

1229 Robert Böttner, "Project Teams in the European Commission - A fair balance between efficiency and politics?", in: Jörn Ege, Michael W. Bauer \& Stefan Becker, The European Commission in Turbulent Times: Assessing Organizational Change and Policy Impact, Nomos, Baden-Baden, 2018, S. 113-132, S. 118 insb.

1230 Jean-Claude Juncker, Mission Letter to Věra Jourová, Commissioner for Justice, Consumers and Gender Equality, vom 01.11 2014, ohne Az, insb. S. 4.

1231 Jean-Claude Juncker, Mission Letter to Frans Timmermans, First Vice-President, in charge of Better Regulation, Interinstitutional Relations, the Rule of Law and the Charter of Fundamental Rights, vom 01.11.2014, insb. S. 2, 4 und 5 . 
ständig, wurde durch seinen belgischen Kollegen Didier Reynders ersetzt, der für das Rechtsstaatsportfolio eine eigene Expertise mitbrachte - er war als belgischer Außenminister einer der Urheber der sog. „periodic peer review“ im Rat. Von der Leyens „Mission Letter“ an Reynders war eine klare Berücksichtigung dieser Kompetenz und dabei zugleich eine Mitteilung an die impliziten Adressaten in Polen und Ungarn. Er habe die Rechtsstaatlichkeit aufrechtzuerhalten (uphold), einen „umfassenden“ (comprehensive) neuen Rechtsstaatlichkeitsmechanismus zu entwickeln, das gesamte nutzbare Instrumentarium zur Anwendung zu bringen und eine strengere Durchsetzung (tighter enforcement) anzustreben. ${ }^{1232}$ Bei Jourová, die zur Vizepräsidentin aufstieg, findet sich hingegen, im Unterschied zur klaren Rollenverteilung der Juncker-Kommission, nunmehr ebenso ein Auftrag zur „Aufrechterhaltung der Werte und Rechte“ der Union, also mutmaßlich ein Teil der zuvor Timmermans zustehenden Kompetenz, wobei sie mit Reynders „eng zusammenarbeiten soll“. ${ }^{1233}$

Jourovás Berufung und Timmermans Abberufung ist in der Literatur mit gemischten Gefühlen begleitet worden, wobei man den Kommentatoren zugestehen muss, dass dem Kollegium an einer klaren Zuständigkeitsabgrenzung gelegen sein sollte, um ihr Aufsichtsregime effektiv anzuwenden. ${ }^{1234}$ Bislang scheint sich diese noch herauszubilden.

Die Dienststellen sind vor dem Hintergrund dieses Duopols im Kollegium gehalten, bei der Zuarbeit für beide Kommissare und Kabinette Grundsätze der Verwaltungsdeontologie ${ }^{1235}$ zu wahren. Umgekehrt sollten Kabinette es vermeiden, gegenüber den zuständigen Referaten in einen offenen Wettbewerb um privilegierten Zugang zu Informationen oder Kapazitäten zu treten. Vielmehr müssen sie sich bei der Abgrenzung der Aufgaben nicht nur durch die jeweiligen Mission Letters, sondern zuletzt auch die Frage der Interessenschwerpunkte und schlicht meritokratisch

1232 Ursula von der Leyen, Mission Letter, Didier Reynders, Commissioner-designate for Justice, vom 10.09.2019, S. 4, ohne Az.

1233 Ursula von der Leyen, Mission Letter, Věra Jourová, Vice-President-designate for Values and Transparency, vom 10.09.2019, ohne Az, insb. S. 5.

1234 Vgl. Daniel Hegedüs, „Fighting Fire with Fire Věra Jourova might be the EU's next rule of law Commissioner",Verfassungsblog vom 06.09.2019.

1235 Fragen der guten Verwaltung (déontologie) sind vor allem für französische Verwaltungswissenschaftler seit langem ein Forschungsthema und folglich auch dort für die Europäische Kommission nachgezeichnet worden, vgl. etwa Sophie Perez, Rapport Union européenne, „La déontologie des fonctionnaires“, abrufbar unter: https://hal-univ-tln.archives-ouvertes.fr/hal-01526906/doc ument. 
von der Frage nach den jeweiligen Kapazitäten bei der Betreuung der in den Details sehr komplexen Dossiers leiten lassen.

\section{b. Rechtsanwendung, Rechtsschöpfung, Rechtsberatung und Kabinettsergänzung}

Aus dem chef de file-Prinzip folgen für die in der Rechtsstaatlichkeitskrise gefragten Dienststellen, der GD JUST insbesondere, vier Grundaufgaben. Sie sind in Bezug auf bestehendes Recht rechtsanwendend, bereiten also z.B. für das Kollegium oder Prozessvertreter der Kommission die Entscheidungsgrundlage und den notwendigen tatbestandlichen wie rechtlichen Hintergrund auf. Dabei können ihnen auch Aufgaben zufallen, die sonst spezialisierten Stellen zukommen, wie einer sog. „Infringement Unit ${ }^{“ 1236}$ im Rahmen des Vertragsverletzungsverfahrens. Sie sind aber ebenso rechtsschöpfend, wobei dies weiter zu verstehen ist als die Initiativkompetenz im Gesetzgebungsverfahren. Letztere spielt etwa eine Rolle für den im Mai 2018 vorgelegten Verordnungsvorschlag betreffend „generelle Mängel“. Der EU-Rahmen aber etwa ist, da in Form einer Mitteilung ergangen, außerhalb dieses Gesetzgebungsverfahrens ein rein kommissionsinternes Produkt, gebunden an die Mehrheit im Kollegium, womit das anzuwendende Verfahren sich nach dem grundsätzlich nicht kodifizierten kommissionsinternen Verwaltungsverfahren bestimmt. Auch der neue „umfassende Rechtsstaatsmechanismus" bzw. „Zyklus“ in Vorbereitung dürfte diesem Schema folgen.

Schließlich sind die auf die Rechtsstaats- und Justizpolitik der Europäischen Kommission fokussierten Referate aufgrund ihrer Expertise rechtsberatend und darüber hinaus aufgrund des Umfangs der geleisteten Betreuung sogar kabinettsergänzend tätig. Das gilt insbesondere für einen engen Austausch der Kabinettschefs mit den Dienststellen der GD JUST.

1236 Zur Tätigkeit einer solchen vor dem Hintergrund des Umweltrechts Levente Borzsák, The Impact of Environmental Concerns on the Public Enforcement Mechanism under EU Law: Environmental Protection in the 25th Hour, Kluwer, Alphen aan den Rijn, 2011, S. 126-129. 
c. Personalstärke und Methodik

Die Personalstärke, die dabei diesen Dienststellen zur Verfügung steht, ist überraschend klein, ${ }^{1237}$ Reding selbst sprach von insgesamt ca. 250 Beamten für die gesamte GD JUST, innerhalb derselben (andere Dienste hier nicht berücksichtigt) reduziert sich dies auf wenige Referate, jeweils mit wenigen dutzend Vollzeitplanstellen, hinzu kommen Zeitbedienstete. Das überträgt den beteiligten Referenten eine enorme Verantwortung, gleichzeitig fordert es von ihnen aber auch ein großes Maß an Willen und persönlichem Einsatz.

Die bei der Handhabung der verschiedenen Mechanismen angewandte Methodik und Arbeitsgestaltung ist divers. Abhängig vom konkreten Einzelfall werden Vorgänge, insbesondere diejenigen in Ungarn und Polen, von einer kleinen Gruppe (einer gelegentlich auch sog. task force) von Referenten bearbeitet, die dann fast ausschließlich für eine einzelne Problematik, etwa in Polen oder Ungarn, zuständig ist und entsprechend im Krisenmodus operiert. Weitere Deputate, etwa diejenigen Referenten, die das Justizbarometer zu verantworten haben, betreuen diese Verfahren in einem vorrangig auf die Zyklik der Verfahren ausgerichteten Arbeitsmodus, vernetzten sich aber bei Bedarf eng mit denjenigen Kollegen, die justizpolitisch besonders heikle Fälle zu betreuen haben. Für das Europäische Semester, zu welchem die für die Rechtsstaatlichkeit und Justizpolitik zuständigen Referenten zusätzlich zu den sog. „core DGs“, die das Semester insbesondere entwickeln, Input zu liefern hatten, werden die dienstübergreifende Erarbeitung von Sachständen für einen Mitgliedstaat, die durch sog. „Country Teams“ erfolgt, häufig durch informelle hier sog. „country desks" gespiegelt, die also die Entwicklung in einem spezifischen Mitgliedstaat betreuen. Dies ist eine Arbeitsteilung, die in vielen mitgliedstaatlichen Außenämtern ebenso gängig ist, hier indes einem anderen Zweck dient, nämlich der Nachverfolgung spezifischer mitgliedstaatlicher Politiken.

Die Kommission arbeitet dabei ganz überwiegend digital und über hauseigene Plattformen, erstellt und verwaltet durch die GD DIGIT. Neben den Plattformen ARES und CHAP $^{1238}$ zur Verwaltung der Interakti-

1237 Die Kommission erlaubt zwischenzeitlich eine Einsichtnahme in ihre Personalstruktur im Einzelnen über ihr amtliches Verzeichnis (früher auch bekannt als „Who is who"), abrufbar unter: https://op.europa.eu/de/web/who-is-who.

1238 Akronym für „Advanced Records System“, Akronym für „Complaints Handling/Accueil Plaignants“. 
on mit Dritten ist intern die Datenbank BASIS, ${ }^{1239}$ in der die Briefings für das Kollegium erstellt werden, zentrales Dokumentenarchiv. Hinzu treten Datenbanken, die besondere Berechtigungen erfordern, hierunter insbesondere das Zentralregister für Vertragsverletzungsverfahren, auch NIF genannt. ${ }^{1240}$ Die Kommission hat auf dieses Register jüngst im $\mathrm{Zu}-$ sammenhang mit Polen prominent hingewiesen. ${ }^{1241}$

Das angeforderte Output ist vielfältig. Es reicht vom klassischen Schriftsatz, der für die Verwendung vor dem Europäischen Gerichtshof bestimmt ist, über Rechtsgutachten zu konkreten Rechtsfragen, über den Sonderfall der Aufarbeitung und korrekten Darstellung der nationalen Rechtslage (ein in der Praxis extrem zeitaufwendiges Verfahren), bis hin zur sozialwissenschaftlich angeleiteten Auswertung statistischer Daten und der Erstellung eigener Datensätze aus Rohmaterial. Trotz letzterer ist Kern und "Goldstandard" allen Handelns der Kommission in der Krise, sowohl im internen Schriftverkehr als auch bei zur Veröffentlichung bestimmten Dokumenten aller Art, die nur zum Teil Handlungsformen darstellen, der hermeneutisch angeleitete, geschriebene Text.

\section{d. Einheitlichkeit der Sorgfalt, unabhängig vom intendierten Zweck}

Auf Schriftstücke verwendet die Kommission größte und minutiöse Sorgfalt. Wie ein Gericht sich durch seine eigenen Präzedenzfälle leiten lässt, so leitet die Kommissionsdienststellen dabei vorrangig die von den Kabinetten abgezeichnete Sprachregelung, die ligne à suivre oder line to take. Eine Abweichung von oder Novellierung einer solchen LTT, deren Inhalt sich von einer Rede bis zum Legislativtext in allen (Handlungs-)Formen widerspiegeln kann und die im Dialog mit der Öffentlichkeit in Sprechund Defensivpunkten von Briefings Eingang findet, erfordert in der Regel

1239 Akronym für „Briefings and Speeches“.

1240 Wohl abgeleitet aus „numéro d'infraction“. Eine Fassung ohne interne Datensätze steht auch der Öffentlichkeit unter https://ec.europa.eu/atwork/applying -eu-law/infringements-proceedings/infringement_decisions/?lang_code=en zur Verfügung. Die öffentliche Fassung dieser Datenbank kann daher zumindest in Teilen Antwort auf die Rüge, etwa bei Luca Prete, Infringement Proceedings in EU Law, S. 350-351 liefern, wonach mangels derartiger Datenbanken das Vertragsverletzungsverfahren im Frühstadium besonders intransparent sei.

1241 Vgl. Europäische Kommission, „Rechtsstaatlichkeit - Europäische Kommission leitet Vertragsverletzungsverfahren zum Schutz der Unabhängigkeit polnischer Richter ein“, Pressemitteilung vom 29.04.2020, IP/20/772, a.E. 
enormen Argumentationsaufwand. Wird sie für zulässig erachtet, entfaltet sie sich, vom außen vorstehenden Beobachter vielleicht unbemerkt, in scheinbar zu vernachlässigenden Schattierungen der Formulierung, selten indes in offenen Brüchen mit Vorangegangenem. Das ist gewollt. Die Rechtsstaatlichkeitskrise ist in der Praxis auch eine Schlacht in Kommata, Fußnoten und Halbsätzen.

Die Erfahrung lehrt, dass gerade die Wissenschaft gut daran tut, sich der vielleicht nicht gegenwärtigen, aber zukünftigen Potentiale derartiger Formulierungsänderungen zu vergewissern und vermehrt "graue Literatur" seitens der EU-Organe zu berücksichtigen. In einschlägigen Fällen sollte sie künftig einer Mitteilung der Kommission die gleiche Sorgfalt zuteil werden lassen wie einem Urteil des Gerichtshofs. So sei in Erinnerung gerufen, dass die Europäische Kommission die Entscheidung im Spätsommer 2017, nunmehr unter Rückgriff auf die Judikatur des Gerichtshofs, eine Operationalisierung der Rechtsstaatlichkeit über Art. 19 Abs. 1 i.V.m. Art. 47 der Grundrechtecharta anzustreben, zunächst scheinbar lapidar in einer Pressemitteilung bekannt gab. ${ }^{1242}$ Sie erscheint als Ursprung dieser Sprachregelung, die die Kommission schließlich bis vor die Große Kammer des Gerichtshofs führte.

Maßgeblich ist bei jeder Formulierung die aktuelle oder potentielle Außenwirkung, die erwünschte oder vorhersehbare Außendarstellung der Kommission und die Möglichkeit der Selbstbindung der Kommission.

Unmittelbarer Ausfluss dieser allgemeinen Sorgfalt ist einer der, meiner Anschauung nach, bedeutendsten Arbeitsgrundsätze der Europäischen Kommission in der Krise, das Prinzip der Einheitlichkeit der Sorgfalt. Aus ihm folgt, dass es in der Praxis irrelevant ist, in welcher Form eine zuvor gemachte Formulierung oder ein Ergebnis später verwendet wird, insbesondere, ob das Dokument Handlungsformenqualität aufweisen soll und welche konkrete Handlungsform am Ende steht. Ganz besonders irrelevant im Abfassungsprozess ist die für die Rechtswissenschaft so erhebliche Trennung von Rechtsverbindlichkeit und soft law. Was also Zeit, Ressourcen, Fallrechtswürdigung oder Abwägung und Genauigkeit („vetting“) bei der Formulierung angeht, verwenden die Dienststellen der Kommission grundsätzlich stets dasselbe $\mathrm{Ma}$ an Sorgfalt, gleich, ob das spätere „Zielprodukt" eine bloße Mitteilung, ein Schriftsatz oder ein Verordnungsvorschlag ist. Der Vorteil dieses Vorgehens ist, dass die gewonnenen Ergebnis-

1242 Europäische Kommission, European Commission acts to preserve the rule of law in Poland/The European Commission acts today to protect the rule of law in Poland. Pressemitteilung vom 26.07.2017, IP/17/2161, S. 2 der PDF-Fassung. 
se, bis hin zu Textstellen, jedenfalls kommissionsintern stets querverwendet werden können, denn die Zustimmung der Hierarchien kann, einmal erteilt, grundsätzlich vorausgesetzt werden. In Teilen kann dieses Prinzip bis hin zu Dokumenten niedrigster Breitenwirkung, wie Briefe oder Antworten auf Beschwerden, Verwendung finden. Auch hier etwa sind festgelegte Sprachregelungen zu verwenden.

\section{2. „Mikro-Makro“-Grundsatz}

Ein weiterer, alle Maßnahmen der Kommission im Rahmen der Krise leitender Grundsatz, ist der sog. „Mikro-Makro“-Grundsatz, eine Formulierung, die dem internen Sprachgebrauch entstammt.

Der Mikro-Makro-Grundsatz lässt sich dahingehend verstehen, dass die Kommission stets die Auswirkung einer Maßnahme nach innen, also im Rahmen unterschiedlicher Meinungen im Kollegium und der Diensthierarchie, wie auch nach außen berücksichtigt. Sie hat stets die Auswirkungen auf den konkreten Einzelfall, wie die mögliche Präzedenzwirkung für noch unbekannte zukünftige Fälle im Blick und zusätzlich sowohl im Hinblick auf kurzfristige wie auch langfristige Wirkung.

Im Hinblick auf die Außenwirkung hat die Kommission bei der Handhabung einer Verfassungsaufsichtsmaßnahme dabei nicht nur die Wirkung auf den Adressaten - insbesondere also die mitgliedstaatliche Gubernative - im Blick, sondern berücksichtigt insbesondere auch die Rezeption durch Gerichte im Europäischen Gerichtsverbund, durch andere Behörden des adressierten Mitgliedstaats, durch die Stellen anderer Mitgliedstaaten und Organe der Union und nicht zuletzt auch der Zivilgesellschaft.

3. „Au fur et à mesure“-Grundsatz bzw. Grundsatz des strukturiertflexiblen Dialogs

Die Kommission hat mehrfach bei der Ausarbeitung und Durchführung verschiedener Verfassungsaufsichtsmechanismen betont, sie wolle mit dem adressierten Mitgliedstaat in einen Dialog treten. Die Formulierung „strukturierter Dialog" ist ein Schlüsselbegriff des EU-Rahmens. ${ }^{1243}$ Er war da-

1243 Europäische Kommission, Mitteilung der Kommission an das Europäische Parlament und den Rat, Ein neuer EU-Rahmen zur Stärkung des Rechtsstaatsprinzips vom 11.03.2014, COM(2014) 158 final, S. 8. 


\section{E. Das Rechtsregime der Verfassungsaufsicht der Europäischen Union}

nach, als „konstruktiver Dialog“, stets in der Schlussformel der Stellungnahme ${ }^{1244}$ und der jeweiligen Empfehlung zur Rechtsstaatlichkeit ${ }^{1245}$ enthalten. Selbst bei Erlass des begründeten Vorschlags nach Art. 7 Abs. 1 EUV, in welchem die Kommission ihre Frustration über die Fruchtlosigkeit der vorangegangenen Maßnahmen und die signifikante Verschlechterung der Lage nicht verbarg, wollte die Kommission den Begriff des Dialogs nicht aufgeben und sprach von einer „neuen Phase des Dialogs“. 1246

Die in diesen Formulierungen zutage tretende Bereitschaft für einen Dialog ist der Kommission häufig zu ihrem Nachteil ausgelegt worden. ${ }^{1247}$ Pech und Platon schrieben etwa, es bestünde „the default tendency of the Commission to believe, despite all contrary available evidence, in the virtue of dialogue". ${ }^{1248}$

In der Betonung des Dialogs ist indes ein drittes wichtiges Funktionsprinzip der Handhabung der Verfassungsaufsicht begründet. Ich bezeich-

1244 Europäische Kommission, Commission Opinion of 1.6.2016 regarding the Rule of Law in Poland, C(2016) 3500 final, S. 18, Rn. 90.

1245 Europäische Kommission, Empfehlung der Kommission vom 27.07.2016 zur Rechtsstaatlichkeit in Polen, C(2016) 5703 final, (EU) 2016/1374, ABl. (EU) L 217/53 vom 12.08.2016 (erste Empfehlung zur Rechtsstaatlichkeit), Rn. 77; Europäische Kommission, Empfehlung der Kommission vom 21.12.2016 zur Rechtsstaatlichkeit in Polen in Ergänzung zur Empfehlung (EU) 2016/1374, C(2016) 8950 final, (EU) 2017/146, ABl. (EU) L 22/65 vom 27.01.2017, (zweite Empfehlung der Kommission zur Rechtsstaatlichkeit), Rn.70; Europäische Kommission, Empfehlung (EU) 2017/1520 der Kommission vom 26. Juli 2017 zur Rechtsstaatlichkeit in Polen in Ergänzung der Empfehlungen (EU) 2016/1374 und (EU) 2017/146, C(2017) 5320 final, ABl. (EU) L 228/19 vom 02.09.2017 (dritte Empfehlung zur Rechtsstaatlichkeit), Rn. 59; Europäische Kommission, Empfehlung (EU) 2018/103 der Kommission vom 20. Dezember 2017 zur Rechtsstaatlichkeit in Polen in Ergänzung der Empfehlungen (EU) 2016/1374, (EU) 2017/146 und (EU) 2017/1520, ABl. (EU) L 17/50 vom 23.01.2018 (vierte Empfehlung zur Rechtsstaatlichkeit), Rn. 51.

1246 Europäische Kommission, Begründeter Vorschlag nach Artikel 7 Absatz 1 des Vertrags über die Europäische Union zur Rechtsstaatlichkeit in Polen für einen Beschluss des Rates zur Feststellung der eindeutigen Gefahr einer schwerwiegenden Verletzung der Rechtsstaatlichkeit durch die Republik Polen, COM(2017) 835 final, 2017/0360 (NLE) vom 20.12.2017, Rn. 184.

1247 Vgl. Dimitry Kochenov, „The EU and the Rule of Law - Naiveté or a Grand Design?“, in: Maurice Adams, Anne Meuwese, Ernst Hirsch Ballin, Constitutionalism and the Rule of Law, 2017, S. 419-445, S. 434 und f.

1248 Laurent Pech \& Sébastien Platon, „Judicial Independence under Threat:The Court of Justice to the rescue in the ASJP case: Case C-64/16, Associação Sindical dos Juízes Portugueses, Judgment of the Court of Justice (Grand Chamber) of 27 February 2018, EU:C:2018:117“, in: Common Market Law Review 55 (2018), S. 1827-1854, S. 1850. 
ne dieses als „au fur et à mesure“-Grundsatz oder Grundsatz des strukturiert-flexiblen Dialogs.

Die französische Redewendung „au fur et à mesure“ bringt hier zum Ausdruck, dass die Kommission bei jedem Verfahrensschritt eines Verfassungsaufsichtsinstruments von dem Grundsatz ausgeht, dass der adressierte Mitgliedstaat, dem Prinzip der loyalen Zusammenarbeit und des gegenseitigen Vertrauens entsprechend, gewillt ist, mit der Kommission zusammenzuarbeiten. Die einzelnen Verfahrensstadien sind daher so bemessen, dass dem Mitgliedstaat jederzeit die Möglichkeit zum Einlenken und zur Kooperation bleibt und ihn nicht in die Enge treibt. Die Kommission will ersichtlich vermeiden, „das Kind mit dem Bade auszuschütten“. Gleichzeitig müssen die einzelnen Verfahrensstadien aber so formuliert sein, dass sie rechtlich hinreichend eindeutig und bestimmt sind, um dem Mitgliedstaat ein intendiertes Verhalten klar aufzuzeigen.

Die Kommission vollzieht dies durch die Strukturierung des Dialogs, etwa durch den Verfahrenscharakter oder der Betonung der Zyklik des jeweiligen Mechanismus, die einen Ausstieg aus dem Verfahren in jeder Stufe gestattet, und durch die Vermeidung der zu großen Schärfe der Formulierung.

Ebenso ist die Kommission ersichtlich bemüht, keine irreparablen $\mathrm{Zu}$ stände zu schaffen. Sie versucht aus diesem Grund, alle Maßnahmen im Hinblick auf die Mitgliedstaaten nicht nur zu strukturieren, sondern so flexibel wie möglich zu gestalten. Dass das nicht durchweg gelungen ist, hat die Kommission zwar teils selbst eingestanden. ${ }^{1249}$

Das heißt aber nicht, dass das Prinzip selbst darüber zurückzuweisen wäre. Schließlich ist auch zu bedenken, dass zahlreiche Figuren, wie die Operationalisierung der Rechtsstaatlichkeit und die Entwicklung des Vertragsverletzungsverfahrens, sich in der Praxis erst entwickeln mussten.

Im Übrigen hat die Kommission das Konzept eines strukturierten Dialogs trotz des Resultats des EU-Rahmens nach wie vor nicht aufgegeben. So heißt es in ihrer Mitteilung vom April 2019, in welcher die Kommission eine „toolbox“ und weitere Schritte zur Handhabung der Rechtsstaatlichkeitskrise erwägt, zur Differenzierung der Reaktionen sei eine vom Dialog mit dem Mitgliedstaat ausgehende Perspektive unerlässlich: „Der Dialog spielt dabei eine wesentliche Rolle. Wird er zusätzlich in einen

1249 Europäische Kommission, Mitteilung der Kommission an das Europäische Parlament, den Europäischen Rat und den Rat, Die weitere Stärkung der Rechtsstaatlichkeit in der Union: Aktuelle Lage und mögliche nächste Schritte, $\operatorname{COM}(2019) 163$ final, vom 03.04.2019, S. 4, Fn. 18. 
strukturierten Prozess eingebettet, erhöht sich die Chance, dass das im Dialog beschlossene Vorgehen die erforderliche Fokussierung und Orientierung besitzt." 1250

\section{Entwicklung der einzelnen Maßnahmen der Verfassungsaufsicht und der EU-Rahmen}

Im Anschluss an diese allgemeinen Überlegungen betreffend Organisationsprinzipien, die die Kommission meiner Anschauung nach bei der Entwicklung und Nutzung der unionalen Verfassungsaufsichtsmechanismen angeleitet haben, ist auf die einzelnen Verfahren einzugehen.

Dabei ist in der Literatur die Herausbildung verschiedener Überlegungen zu rechtsstaatsspezifischen Mechanismen im Anschluss an die sog. Haider-Krise bis zur Entstehung des sog. EU-Rahmens als erster Teilabschnitt der Entwicklung bereits aufgezeigt worden und hier nochmals aufzugreifen.

Ein zweiter Abschnitt der Entwicklung umfasst die Nutzung dieses Mechanismus und Überlegungen in Wissenschaft und Praxis bis zum Ende des Jahres 2017, als der EU-Rahmen gegenüber Polen durch die erstmalige Nutzung des Verfahrens nach Art. 7 EUV abgelöst wird.

Der dritte bis zum Abschluss dieser Arbeit entwicklungsoffene Abschnitt der Reaktionen der Europäischen Union auf die Rechtsstaatlichkeitskrise umfasst den Zeitraum ab erstmaliger Nutzung des Verfahrens nach Artikel 7 EUV bis ungefähr zum Ende der Juncker-Kommission gegen Ende des Jahres 2019. Er geht einher mit der Ankündigung der Europäischen Kommission, einen weiteren Mechanismus zur Stärkung des Rechtsstaatsprinzips einzuführen, dessen Ausformung und weitere Beurteilung sich erst in Grundzügen abschätzen lassen.

Obwohl chronologisch die Nutzung des Vertragsverletzungsverfahrens nicht diejenige ist, die am Ende der Krise steht, beschließe ich mit ihr die Darstellung der Mechanismen, da das Verfahren nach bisherigem Stand der Entwicklung sowohl für die rechtliche Erfassung der Krise aufgrund der Festlegungen des Europäischen Gerichtshofs als auch unter Effektivitätsgesichtspunkten überragende Bedeutung erlangt hat.

1250 Europäische Kommission, Mitteilung der Kommission an das Europäische Parlament, den Europäischen Rat und den Rat, Die weitere Stärkung der Rechtsstaatlichkeit in der Union: Aktuelle Lage und mögliche nächste Schritte, $\operatorname{COM}(2019) 163$ final, vom 03.04.2019, S. 11. 
1. Die Ursprünge des polyprozeduralen Verfassungsaufsichtsregimes im Unionsrecht

\section{a. Konsensbildung in der Literatur „post Haider“}

Als am Ende des Jahres 2000 die sog. „Causa Haider“ in Österreich infolge des durch die sog. „drei Weisen“1251 erstatteten Berichts endete, ${ }^{1252}$ beugte sich die Rechtswissenschaft über die Ergebnisse. Obwohl diese Krise gerade keinen Fall der Nutzung des Art. 7 EUV darstellte, sondern es sich um zwischenstaatliche Maßnahmen gehandelt hatte, die im Nachhinein als rechtswidrig eingestuft worden waren, ${ }^{1253}$ wurde die Aufarbeitung durch die Debatte um die Nutzung und Entwicklung von Art. 7 EUV angeleitet und hatte auf seine Entwicklung unmittelbar Einfluss. Im Zuge der Aufarbeitung der Entwicklung in Österreich erhielt die Norm mit dem Vertrag von Nizza einen neuen Absatz 1, ${ }^{1254}$ den 2009 der Lissabonner Vertrag, mit wenigen Änderungen, ${ }^{1255}$ fast unverändert übernahm. Schorkopf zeichnete den Verlauf der österreichischen Verfassungskrise im Einzelnen

1251 Das so bezeichnete Gremium umfasste die Juristen Martti Ahtisaari, Jochen Frowein und Marcelino Oreja.

1252 Abgedruckt als Anhang zu Frank Schorkopf, Die Maßnahmen der XIV EUMitgliedstaaten gegen Österreich, S. 163 ff. Auch veröffentlicht als Martti Ahtisaari, Jochen Frowein \& Marcelino Oreja, „Report on the Austrian Government's Commitment to the Common European Values, in particular concerning the Rights of Minorities, Refugees and Immigrants, and the Evolution of the Political Nature of the FPÖ (the Wise Men Report)“, in: International Legal Materials 40 (2000), S. 102-123.

1253 Vgl. etwa Frank Schorkopf, Art. 7 EUV, in: Eberhard Grabitz, Meinhard Hilf \& Martin Nettesheim (Begr./Hrsg.), Das Recht der Europäischen Union, C.H. Beck, München, Rn. 58-59, der insbesondere zum Befund einer Unverhältnismäßigkeit gelangt.

1254 Darstellung der Diskussion hierzu, insbesondere im Rat, bei Schorkopf, Die Maßnahmen der XIV EU-Mitgliedstaaten gegen Österreich, S. 99 ff.; Katharina Serini, Sanktionen der Europäischen Union bei Verstoß eines Mitgliedstaats gegen das Demokratie- oder Rechtsstaatsprinzip, S. $185 \mathrm{ff}$.

1255 Es entfiel die in Art. 7 Abs. 1 S. 2 EUV (Nizza) vorgesehene Möglichkeit der Konsultierung unabhängiger Persönlichkeiten. Serini hat aber unter Berufung auf eine Festlegung des Rates im Rahmen der Diskussion des Verfassungsentwurfs (zit. als CONV 648/03 vom 02.04.2003, S. 8) dargelegt, dass diese Möglichkeit als „Selbstverständlichkeit“ auch in der neuen Fassung enthalten sein soll, s. Katharina Serini, Sanktionen der Europäischen Union bei Verstoß eines Mitgliedstaats gegen das Demokratie- oder Rechtsstaatsprinzip, S. 284. 
nach, ${ }^{1256}$ bot eine erste Analyse des infolge der Ereignisse mit dem Vertrag von Nizza neu geschaffenen Art. 7 Abs. 1 EUV a.F. an und entwickelte das zuvor bereits in seiner Dissertation mit dem Begriff der Homogenität aufgestellte normative und teleologische Fundament der Norm unter Rückgriff auf den Begriff der streitbaren Demokratie weiter. ${ }^{1257}$

2003 und 2004 legten Kassner ${ }^{1258}$ und Pforr ${ }^{1259}$ ihre Dissertationen zu Art. 7 EUV, nunmehr in der Fassung von Nizza, vor, erarbeiteten unabhängig voneinander den Begriff der (allgemeinen) Unionsaufsicht, analysierten die Funktion und die Tatbestände der Norm nochmals im Einzelnen ${ }^{1260}$ und grenzten sie im Unionsrecht zum Vertragsverletzungsverfahren, und rechtsvergleichend, von anderen ähnlichen Verfahren ab. $\mathrm{Hau}^{1261}$ und Serini, ${ }^{1262}$ die sich auch der Frage widmete, ob nicht Vorgänge in Italien unter Ministerpräsident Silvio Berlusconi möglicherweise einen weiteren Anwendungsfall hätte darstellen können, zogen nach. Der Katalog der deutschsprachigen Monographien zur Frage des Art. 7 EUV schloss sich mit der Arbeit Katrin Träberts, die der Frage der Sanktionswirkung der nach dem Verfahren getroffenen Maßnahmen, gerade im Unterschied zu Art. 228 EGV, dem heutigen Art. 260 AEUV, nachging. ${ }^{1263}$ Für die englischsprachige Leserschaft übernahm Gráinne de Búrca die Aufarbeitung. ${ }^{1264}$

1256 Frank Schorkopf, Die Maßnahmen der XIV EU-Mitgliedstaaten gegen Österreich, vgl. insbesondere den dortigen „Sachbericht“, ab S. 15.

1257 Frank Schorkopf, Die Maßnahmen der XIV EU-Mitgliedstaaten gegen Österreich, vgl. insb. S. $99 \mathrm{ff} ., 119 \mathrm{ff}$.

1258 Ulrike Kassner, Die Unionsaufsicht.

1259 Thomas Pforr, Die allgemeine Unionsaufsicht.

1260 Bei Ulrike Kassner, Die Unionsaufsicht., S. 43 ff., 79 ff.

1261 André Hau, Sanktionen und Vorfeldmaßnahmen zur Absicherung der europäischen Grundwerte.

1262 Katharina Serini, Sanktionen der Europäischen Union bei Verstoß eines Mitgliedstaats gegen das Demokratie- oder Rechtsstaatsprinzip.

1263 Katrin Träbert, Sanktionen der Europäischen Union gegen ihre Mitgliedstaaten, S. $369 \mathrm{ff}$.

1264 Gráinne de Búrca, „Beyond the Charter: How Enlargement Has Enlarged the Human Rights Policy of the European Union", in: Fordham International Law Journal 27 (2003), S. 679-714, S. 695 ff., weiter Michael Merlingen, Cas Mudde, \& Ulrich Sedelmeier, "The Right and the Righteous? European Norms, Domestic Politics and the Sanctions Against Austria“, in: Journal of Common Market Studies 39 (2001), S. 59-77, aus dem französischen Schrifttum vgl. Olivier Beaud, „La question de l'homogénéité dans une fédération“, in: Lignes 13 (2004), S. 110-128, S. $121 \mathrm{f}$. 
Obwohl in Inhalt und Zuschnitt verschieden, lassen sich diese Arbeiten, insbesondere in der deutschen Rechtswissenschaft, im Wesentlichen in drei Festlegungen zusammenfassen.

Erstens war man sich weitgehend darüber einig, dass die Existenz des Verfahrens nach Art. 7 EUV zu einer großen Bandbreite an Grundfragen des europäischen Verfassungslebens führte und dass, da das Verfahren auf die Einhaltung der Werte des Art. 2 EUV gerichtet war, damit eine Diskussion über Zustand und Entwicklungsperspektiven der Union angesprochen war, die man aber im Rahmen klassischer juristischer Textinterpretation erschließen musste. ${ }^{1265} \mathrm{Zu}$ trennen waren dabei Fragen des im materiellen Tatbestand der Norm angelegten normativen Gehalts des Art. 2 EUV, die man allenfalls in Grundzügen erörtern konnte, ${ }^{1266}$ von Fragen nach den konkreten Gefährdungs- und Verletzungstatbeständen der Absätze 1 und 2, ${ }^{1267}$ bis hin zur Reichweite der Sanktionstatbestände des Art. 7 Abs. 3 EUV. 1268

Zum zweiten bestand überwiegender Konsens darin, dass Art. 7 EUV im Unionsrecht einmalig war. Es war ein außergewöhnliches Verfahren für außergewöhnliche Fälle, nicht gebunden an die Kompetenzvorgaben für die Union aus Art. 5 EUV, ${ }^{1269}$ aber allein in seltenen Ausnahmen zu bemü-

1265 Vgl. bei Katharina Serini, Sanktionen der Europäischen Union bei Verstoß eines Mitgliedstaats gegen das Demokratie- oder Rechtsstaatsprinzip, S. $17 \mathrm{ff}$., André Hau, Sanktionen und Vorfeldmaßnahmen zur Absicherung der europäischen Grundwerte, S. 30 ff., 103 ff.; Ulrike Kassner, Die Unionsaufsicht, S. 18 ff., kommt sogar auf Grundfragen der geschichtlichen Entwicklung der Union zu sprechen.

1266 Bei Frank Schorkopf, Homogenität in der Europäischen Union, S. 74 ff., S. 79 ff. zu Methoden der Inhaltsbestimmung, S. 84 ff. zu den einzelnen Prinzipien; bei Ulrike Kassner S. 83 ff., 93 ff.; bei Thomas Pforr, Die allgemeine Unionsaufsicht, S. 77 ff., bei André Hau, mit Einschränkungen, Sanktionen und Vorfeldmaßnahmen zur Absicherung der europäischen Grundwerte, S. $112 \mathrm{ff}$; bei Katharina Serini, Sanktionen der Europäischen Union bei Verstoß eines Mitgliedstaats gegen das Demokratie- oder Rechtsstaatsprinzip, S. 17, 40 ff., $51 \mathrm{ff}$. insb.

1267 Etwa bei Ulrike Kassner, Die Unionsaufsicht, S. 43 ff.; Thomas Pforr, Die allgemeine Unionsaufsicht S. $77 \mathrm{ff}$., $187 \mathrm{ff}$.

1268 Hierzu insbesondere Frank Schorkopf, Homogenität in der Europäischen Union, S. $161 \mathrm{ff}$.

1269 Sehr eingängig bei Thomas Pforr, Die allgemeine Unionsaufsicht, S. 34-35, der dies auf folgende Formel bringt: „[...D]ie Aufsicht nach Art. 7 EU [erfasst mitgliedstaatliches Handeln] komplett. Die Beaufsichtigung nach Art. 7 EU ist umfassend. Sie erstreckt sich nicht nur auf das Handeln der Mitgliedstaaten in Kompetenzbereichen der Union und der Gemeinschaften, sondern kontrolliert auch das mitgliedstaatliche Handeln in ausschließlichen Kompe- 
hen. Als solches war das Verfahren ohnegleichen im Unionsrecht, es bestand eine dichotome Abgrenzung zum Vertragsverletzungsverfahren, ${ }^{1270}$ und es fand ansonsten keine weitere Entsprechung. Die vermittelnde Perspektive scheint die Ausnahme gewesen zu sein. Zu ihren Vertretern zählte aber insbesondere, als früherer Angehöriger des Juristischen Dienstes der Kommission, Frank Hoffmeister, der der Auffassung war, die Verträge legten sich nicht fest und mögliche Überschneidungen beider Verfahren stünden im Ermessen des Kommissionskollegiums. ${ }^{1271}$ Sein Kollege Bernd Martenczuk hingegen widersprach. ${ }^{1272}$

Und drittens war die Untersuchung der praktischen Bedeutung des Art.7 EUV eine solche im Reagenzglas. Rechtsprechung des EuGH zur Norm selbst, und darüber unmittelbar zu Art. 2 EUV, gab es keine, ${ }^{1273}$ sie schien auch nicht realistisch. Art. 269 AEUV UAbs. 1 AEUV und dessen

tenzbereichen der Mitgliedstaaten(!).“ Kursivsetzung im Original hier entfallen. Die Kommission hat sich dieser Auffassung ausdrücklich angeschlossen, Mitteilung der Kommission an den Rat und das Europäische Parlament zu Artikel 7 des Vertrags über die Europäische Union. Wahrung und Förderung der Grundwerte der Europäischen Union, $\operatorname{KOM(2003)~} 606$ endgültig vom 15.10.2003, S. 5: „Die Anwendbarkeit von Artikel 7 ist nicht auf den Anwendungsbereich des Unionsrechts beschränkt. Das bedeutet, dass die Union nicht nur bei einer Verletzung der gemeinsamen Werte in diesem beschränkten Rahmen, sondern auch dann tätig werden kann, wenn die Verletzung i[n] einem Bereich erfolgt, der unter die Handlungsautonomie eines Mitgliedstaats fällt."

1270 Das haben vertreten: Frank Schorkopf, Homogenität in der Europäischen Union, S. 106 ff.; Mit ähnlicher Begründung Thomas Pforr, Die allgemeine Unionsaufsicht, S. 47 ff., André Hau, Sanktionen und Vorfeldmaßnahmen zur Absicherung der europäischen Grundwerte, $53 \mathrm{ff}$. Zur Unterscheidung von Art. 7 EUV und Art. 228 EGV (dem heutigen Art. 260 AEUV), nochmals Katrin Träbert, Sanktionen der Europäischen Union gegen ihre Mitgliedstaaten, S. $369 \mathrm{ff}$, für sie sind beide Maßnahmen unvereinbar.

1271 Frank Hoffmeister, „Enforcing the EU Charter of Fundamental Rights in Member States“, S. 205 ff. Für eine Zulässigkeit des Vertragsverletzungsverfahrens parallel zu Art. 7 EUV auch Ulrike Kassner, Die Unionsaufsicht, S. 196.

1272 Bernd Martenczuk, „Art. 7 EUV und der Rechtsstaatsrahmen als Instrumente der Wahrung der Grundwerte der Union“, S. 45-46, der auch ausdrücklich der Ansicht ist, Art. 7 EUV sei lex specialis zum Vertragsverletzungsverfahren.

1273 Bis in jüngere Kommentarliteratur ist zudem teils eine merkwürdige Scheu zu beobachten, sich auf die Suche nach konkreter Auseinandersetzung mit beiden Normen vor dem Gerichtshof zu begeben, als fürchtete man, hier handele es sich nicht um ernstzunehmende Fragen. Fast kurios etwa der Hinweis bei Jörg Philipp Terhechte, Art. 2 EUV, in: Matthias Pechstein/Carsten Nowak/Ulrich Häde, Frankfurter Kommentar EUV/GRC/AEUV, Mohr Siebeck, Tübingen, 2017, Rn. 11, Fn. 31, der anmerkt, es ließen sich zu Art. 2 EUV lediglich 
Vorgängernorm Art. 309 Abs. 2 EGV beschränkte die Justiziabilität der nach Art. 7 EUV durch die dort beteiligten Organe seitens des EuGH auf „lediglich im Hinblick auf die Einhaltung der in dem genannten Artikel vorgesehenen Verfahrensbestimmungen“ (Art. 269 AEUV) bzw. in seiner Vorgängernorm auf die „reinen Verfahrensbestimmungen“.1274 Von dem Konsens hierüber wich man nur vereinzelt ab. Pforr etwa identifizierte einen Widerspruch zwischen diesem Ausschluss und dem nach Art. 6 EGV (dem heutigen Art. 2 EUV) geforderten umfassenden Rechtsschutz und gelangte im Wege der Analogie doch noch zu einem materiellen Überprüfungsrecht des EuGH. ${ }^{1275}$

Da die Entwicklung in Österreich dem Verfahren ebenso nicht zur Anwendung verholfen hatte, konnte die Wissenschaft daher allenfalls den für Österreich abgeschlossenen und überschaubaren Sachstand als „Fiktion" im Licht des Art. 7 Abs. 1 EUV analysieren, wie Pforr schrieb, ${ }^{1276}$ oder aber, wie Serini, kritisch bislang weitgehend unbeachtete Vorgänge in einem anderen Mitgliedstaat in den Blick nehmen. ${ }^{1277}$ Auch bei Kassner ${ }^{1278}$ und $\mathrm{Hau}^{1279}$ blieb der Vorgang in Österreich der zentrale, aber theoretische Testfall für Art. 7 EUV. Das machte die Lage keineswegs einfacher, schuf allerdings die Möglichkeit, das begutachtete Material recht präzise abzustecken.

Auf Seiten der Rechtspraxis ebbte das Interesse nach der intensiven Arbeit gerade im Rat zur Schaffung des neuen Art. 7 Abs. 1 EUV mit dem Vertrag von Nizza ${ }^{1280}$ indes nicht ab. Die Debatte wurde nur weniger

zwei Urteile des EuGH nachweisen, diese dann aber nicht nennt, da sie „keine Kernfragen des Integrationsprozesses" beträfen.

1274 Diskussion bei André Hau, Sanktionen und Vorfeldmaßnahmen zur Absicherung der europäischen Grundwerte, S. $186 \mathrm{ff}$.

1275 Thomas Pforr, Die allgemeine Unionsaufsicht, S. 212.

1276 Thomas Pforr, Die allgemeine Unionsaufsicht, S. $201 \mathrm{ff}$.

1277 Katharina Serini, Sanktionen der Europäischen Union bei Verstoß eines Mitgliedstaats gegen das Demokratie- oder Rechtsstaatsprinzip, S. $201 \mathrm{ff}$. in beeindruckender Akribie zur Lage Italiens unter Berlusconi.

1278 Für eine Zulässigkeit des Vertragsverletzungsverfahrens parallel zu Art. 7 EUV nach alter Rechtslage aber Ulrike Kassner, Die Unionsaufsicht, S. 160 ff., insb. S. 229, allerdings eingeschränkt in ihrem Anwendungsbereich.

1279 André Hau, Sanktionen und Vorfeldmaßnahmen zur Absicherung der europäischen Grundwerte, S. $100 \mathrm{ff}$., $127 \mathrm{ff}$.

1280 Umfassende Würdigung des Primärmaterials zur Schaffung von Art. 7 Abs. 1 EUV (Nizza) und der damaligen Diskussion gerade im Rat bei Frank Schorkopf, Die Maßnahmen der XIV EU-Mitgliedstaaten gegen Österreich, S. 99 ff.; André Hau, Sanktionen und Vorfeldmaßnahmen zur Absicherung der europäischen Grundwerte, S. $168 \mathrm{ff}$. 
sichtbar. Die drei überwiegenden Feststellungen in der deutschen Rechtswissenschaft zu Art. 7 EUV wurden darüber zunehmend hinfällig.

\section{b. Die Kommissionsmitteilung von 2003 zu Art. 7 EUV}

Den Anfang mit der Aufarbeitung und Fortentwicklung des Art. 7 EUV „post Haider“ machte die Kommission, die 2003 und damit nach dessen Änderung durch den Vertrag von Nizza eine Mitteilung zur zukünftigen Handhabung des Art. 7 EUV veröffentlichte. Sie verdient aus mehreren Gründen auch heute noch besondere Beachtung. Zum einen deutete die Kommission noch - dabei indes vor dem Hintergrund des alten Vertragswortlauts - an, dass sie sich eher der damaligen Mehrheitsmeinung in der Literatur anzuschließen gedachte, wonach Art. 7 EUV vom Vertragsverletzungsverfahren, insbesondere was die Frage der Einhaltung der Charta anging, zu trennen sei, ${ }^{1281}$ eine Auffassung, die infolge der Rechtsprechung des Europäischen Gerichtshofs ab 2018 keinen Bestand mehr haben kann. Sie zeigt aber, wie sehr sich die Rechtsauffassung auch in der Praxis gewandelt hat. Die dazu geleistete Ergründung der Tatbestände des Art. 7 EUV blieb im Unterschied zur Literatur recht kursorisch, allerdings nahm die Kommission ausdrücklich Bezug auf das Konzept eines „systematischen Problems“ als Voraussetzung für beide Tatbestände des Art. 7 Abs. 1 und 2 EUV und entwickelte die Tatbestandskriterien für beide Absätze in der Folge vorrangig mit Blick auf den Schutz von Minderheitenrechten. ${ }^{1282}$

Zum zweiten betonte die Kommission die Novellierungswirkung des neuen Art. 7 Abs. 1 EUV als Vorverfahren. Während aus der Mitteilung der Kommission noch die Überzeugung spricht, dass das Verfahren „in angemessener Weise“ die Möglichkeit biete, einen Mitgliedstaat in einer frühen Phase der Zuwiderhandlung gegen die Werte des Art. 2 EUV zu

1281 Europäische Kommission, Mitteilung der Kommission an den Rat und das Europäische Parlament zu Artikel 7 des Vertrags über die Europäische Union. Wahrung und Förderung der Grundwerte der Europäischen Union, $\operatorname{KOM}(2003) 606$ endgültig vom 15.10.2003, S. 6.

1282 Europäische Kommission, Mitteilung der Kommission an den Rat und das Europäische Parlament zu Artikel 7 des Vertrags über die Europäische Union. Wahrung und Förderung der Grundwerte der Europäischen Union, $\operatorname{KOM}(2003) 606$ endgültig vom 15.10.2003, vgl. insb. S. 8-9, Punkt 1.41. zur Frage des systematischen Problems, Punkte 1.4.2. ff. zu den einzelnen Tatbestandsmerkmalen. 
warnen, ${ }^{1283}$ ist diese Position spätestens mit dem EU-Rahmen 11 Jahre später wieder aufgegeben und noch weiter in das Vorfeld des heutigen Art. 7 Abs. 2 EUV verlagert worden.

Drittens schließlich führte die Kommission in dieser Mitteilung, versteckt und wohl in der Literatur wenig berücksichtigt, ${ }^{1284}$ die Idee eines umfassenden, auf die gemeinsamen Werte der Union bezogenen „Monitoring“ „auf der Grundlage von Art.7“ EUV ein. ${ }^{1285}$ Damit stärkt die Kommission, in Vorgriff der 2014 nochmals angestoßenen Debatte, nicht nur ihre eigene Rolle, denn sie sieht sich selbst, ungeachtet etwa der Koordinierung zwischen Parlament, Mitgliedstaaten und darüber dem Rat, als zentrale Schaltstelle eines dazu geschaffenen „Netzes“ an Akteuren. Zudem kann man festhalten, dass in der Betonung dieses Netzes der Kern und Ursprung des heutigen Verfassungsaufsichtsregimes bereits enthalten ist. Das gilt sowohl für die Betonung informeller, und wenn formell dann nicht rechtsverbindlicher Verfahren, wie auch im Hinblick auf die Zusammenarbeit mit einer Vielzahl unterschiedlicher Akteure und der Diversifizierung der zur Verfügung stehenden Verfahren neben Art. 7 EUV.

Ein zentraler Unterschied zur späteren Einschätzung der Lage in den Mitgliedstaaten bestand indes 2003 auch seitens der Kommission, sie ging fest davon aus, dass kein konkreter Anlass zur Sorge bestehe. Vielmehr schrieb sie ausdrücklich:

1283 Europäische Kommission, Mitteilung der Kommission an den Rat und das Europäische Parlament zu Artikel 7 des Vertrags über die Europäische Union. Wahrung und Förderung der Grundwerte der Europäischen Union, $\operatorname{KOM}(2003) 606$ endgültig vom 15.10.2003, S. 8, Punkt 1.4.2.

1284 In der Literatur haben dafür andere Aspekte dieser Mitteilung im Vordergrund gestanden, vgl. bei Armin von Bogdandy, „Grundprinzipien“, S. 52, bei Fn. 227, der die Mitteilung als Positionierung der Kommission zur Schaffung eines Prinzips der Verfassungshomogenität sieht, dies aber selbst ablehnt; als Beitrag zur Auslegung des Art. 7 EUV vorrangig bei Laurent Pech, The Rule of Law as a Constitutional Principle of the European Union S.63, Fn. 202; bei Andreas Orator, „The competence entanglements of the EU Fundamental Rights Agency“, S. 135, Fn. 121, der auf die Rolle der FRA eingeht.

1285 Europäische Kommission, Mitteilung der Kommission an den Rat und das Europäische Parlament zu Artikel 7 des Vertrags über die Europäische Union. Wahrung und Förderung der Grundwerte der Europäischen Union, $\operatorname{KOM}(2003) 606$ endgültig vom 15.10.2003, S. 9, Punkt 2. und ff. 
„Die Kommission hält an ihrer Überzeugung fest, dass die Verhängung von Sanktionen gemäß Artikel 7 EU-Vertrag und Artikel 309 EGVertrag in dieser Union der Werte nicht notwendig sein wird."1286

Hier irrte sie.

\section{Stockholmer Programm}

Nachdem die Kommission 2003 mit der soeben erörterten Mitteilung ihre Positionierung zur weiteren Fortführung der praktischen Handhabung der Werteeinhaltung durch die Mitgliedstaaten dargelegt hatte, zog der Europäische Rat (und nicht der Ministerrat) 2009 mit seinem sog. Stockholmer Programm, ${ }^{1287}$ aufbauend auf dem Haager Programm des Rates von 2004, ${ }^{1288}$ nach. Das Stockholmer Programm ist zunächst eine rechtsunverbindliche Sammlung politischer Leitlinien der europäischen Staats- und Regierungschefs, beruhend auf der Leitlinienkompetenz des Europäischen Rates aus Art. 68 AEUV, ${ }^{1289}$ die insbesondere von anderen

1286 Europäische Kommission, Mitteilung der Kommission an den Rat und das Europäische Parlament zu Artikel 7 des Vertrags über die Europäische Union. Wahrung und Förderung der Grundwerte der Europäischen Union, $\operatorname{KOM}(2003) 606$ endgültig vom 15.10.2003, S. 14.

1287 Europäischer Rat, „Das Stockholmer Programm - Ein offenes und sicheres Europa im Dienste und zum Schutz der Bürger“, ABl. (EU) C 115/1 vom 04.05.2010. Einordnung etwa bei Emmanuel Crabit \& Nicolaas Bel, „The EU Rule of Law Framework“, S. 202; Milada Anna Vachudova, „Why Improve EU Oversight of Rule of Law?: The Two-Headed Problem of Defending Liberal Democracy and Fighting Corruption“, in: Carlos Closa, \& Dimitry Kochenov (Hrsg.), Reinforcing Rule of Law Oversight in the European Union, 2016, S. 270-289, S. 286. Weiter insbesondere bei, Ernst Hirsch Ballin: „Mutual Trust: The Virtue of Reciprocity - Strengthening the Acceptance of the Rule of Law through Peer Review“, in: Carlos Closa \& Dimitry Kochenov (Hrsg.), Reinforcing Rule of Law Oversight in the European Union, Cambridge University Press, Cambridge, 2016, S. 133-146, S. 138 ff.

1288 Rat der Europäischen Union, Haager Programm zur Stärkung von Freiheit, Sicherheit und Recht in der Europäischen Union, ABl. (EU) C 53/1 vom 3.3.2005.

1289 Zur Kompetenz und Rechtsgrundlage sowie zum Programm siehe Frank Meyer, Chapter 4: An Area of Freedom, Security and Justice, in: Martin Böse, Frank Meyer; Frank \& Anne Schneider (Hrsg.): Conflicts of Jurisdiction in Criminal Matters in the European Union, Volume II: Rights, Principles and Model Rules, Nomos, Baden-Baden, 2014, S. 169-213, S. 172 und ff. 
Organen umgesetzt werden sollen ${ }^{1290}$ und mit der die Debatte über die Entwicklung des europäischen Werteschutzes fortgeführt wurde. Hieraus ergaben sich zwei Nachwirkungen. Die erste fand ihren Niederschlag im Elan der Justizkommissarin unter Barroso, Viviane Reding, das Stockholmer Programm als breit angelegtes Legislativprogramm zu verstehen, das es umzusetzen galt. ${ }^{1291}$ Tatsächlich hatte die Kommission zur Umsetzung des Programms 2010 einen „Aktionsplan“ angenommen, in welchem sich indes eine Werteförderung explizit allein im Hinblick auf die Beziehung der Union zu Drittstaaten findet. ${ }^{1292}$ Auch das Europäische Parlament kam 2014 nochmals auf die legislative Umsetzung des Programms zu sprechen. ${ }^{1293}$

Die zweite Stoßrichtung des Stockholmer Programms, die durch Ernst Hirsch Ballin herausgearbeitet worden ist, ${ }^{1294}$ aber augenscheinlich für die Kommission zunächst sekundär blieb, war ein Versuch der Stärkung nicht mehr allgemein der Werte und nicht mehr vor allem als außenpolitisches Kriterium, sondern eine spezifische, intraunionale Stärkung der Rechtsstaatlichkeit. Ballin weist nach, dass das Programm Anregungen zur Ausarbeitung einer neuen „Unionsstrategie“ enthielt, die die Rechtsstaatlichkeit einschließen sollte und zu einer vermehrten Zusammenarbeit mit dem Europarat aufforderte. ${ }^{1295}$ Dabei wurde ein neues „peer-review“-Verfahren ${ }^{1296}$

1290 Zur Einstufung etwa Volker Röben, Art. 68 AEUV, in: Eberhard Grabitz, Meinhard Hilf \& Martin Nettesheim (Begr./Hrsg.), Das Recht der Europäischen Union, C.H. Beck, München, 68. EL 2019, Rn. 6. Zur „Leitlinienbedeutung“ der Handlungen des Europäischen Rates und seiner Programme weiter: Weiß, in Rudolf Streinz (Hrsg.), EUV/AEUV, Art. 68 AEUV, 3. Aufl. 2018, Rn. 3 ff.

1291 Vgl. Viviane Reding, „The EU and the Rule of Law - What next?", S.9. Anzumerken ist, dass in dieser Rede andererseits das Krisenbewusstsein schon präsent ist.

1292 Europäische Kommission, Mitteilung der Kommission an das Europäische Parlament, den Rat, den Europäischen Wirtschafts- und Sozialausschuss und den Ausschuss der Regionen. Ein Raum der Freiheit, der Sicherheit und des Rechts für die Bürger Europas, Aktionsplan zur Umsetzung des Stockholmer Programms, KOM(2010) 171 endgültig, vom 20.04.2017, S. 2 und 63 insb.

1293 Europäisches Parlament, P7_TA(2014)0276, Bericht über die Halbzeitbilanz des Stockholmer Programms (2013/2024(INI)) vom 04.03.2014, Rn. 2 ff. insb.

1294 Ernst Hirsch Ballin, „Mutual Trust“, S. 138-140.

1295 Eine thematische Auswertung und Einordnung findet sich etwa bei Stefania Bariatti: Cases and Materials on EU Private International Law, Hart, Oxford \& Portland, 2011, S. 20-21.

1296 Europäischer Rat, „Das Stockholmer Programm - Ein offenes und sicheres Europa im Dienste und zum Schutz der Bürger“, ABl. (EU) C 115/1, S. 115/17. 


\section{E. Das Rechtsregime der Verfassungsaufsicht der Europäischen Union}

sowie die Nutzung bis dato wenig genutzter Mechanismen, insbesondere von Art. 70 AEUV, ${ }^{1297}$ gefordert. ${ }^{1298}$

Dieser Schwenk auf die Rechtsstaatlichkeit bereits 2009 überrascht, denn er stellt eine gewisse Zäsur, wenn nicht sogar einen Bruch mit der zuvor dominierenden Annäherung an den Wertekatalog des Art. 2 EUV dar. ${ }^{1299}$ In der Kommissionsmitteilung von 2003 fand sich noch keinerlei Fokussierung auf bestimmte Werte, sieht man von der Formulierung „a Union of values and of the rule of law" in der Schlussfolgerung ab, wobei der Zusatz „rule of law“ in der deutschen Übersetzung verlorenging.

Es fragt sich, was die Praxis dazu bewogen haben kann, 2009 eine solche Änderung zu vollziehen. Dafür liefert Ballin einen höchst pragmatischen Grund. Demnach geht der Paradigmenwechsel infolge des Stockholmer Programms auf eine erstmals 2007 geäßerte und 2014 schließlich verschriftlichte Position der niederländischen Regierung zurück, ${ }^{1300}$ welche vor dem Hintergrund der gegenseitigen Anerkennung von Entscheidungen der Justizbehörden um eine Aufweichung niederländischer Standards, insbesondere in Bezug auf die Untersuchungshaft im Strafverfahren, fürchtete, eine Sorge, die Belgien, Luxemburg, Frankreich und Deutschland aufgriffen. Von diesem Anstoß aus und vor dem Hintergrund der sich verdichtenden Sorge auch um die Lage von Asylsuchenden in bestimmten Mitgliedstaaten der Union wurde der niederländische Vorstoß zunächst im Sommer 2009 in Maastricht diskutiert und fand schließlich im Verlauf des gleichen Jahres Eingang in das Stockholmer Programm. Ballin sieht weitere Entwicklungen, darunter das 2013 erstmals vorgelegte Justizbarometer und einen Brief aus dem gleichen Jahr, der aufgrund seiner Unterzeichner nachfolgend „Brief der vier Außenminister“ genannt werden soll, immer noch als Ausfluss der ursprünglich also auf die Sicherung straf- und

1297 Die Norm ermöglicht dem Rat auf Vorschlag der Kommission den Erlass von Maßnahmen zur Bewertung der Durchführung von Maßnahmen im Umfeld des Raumes der Freiheit, der Sicherheit und des Rechts.

1298 Europäischer Rat, „Das Stockholmer Programm - Ein offenes und sicheres Europa im Dienste und zum Schutz der Bürger", ABl. (EU) C 115/1, S. 115/6; Ernst Hirsch Ballin, „Mutual Trust“, S. 138 f.

1299 Dazu bereits unter B. III. 2.

1300 Mirte van den Berge \& Leonard Bas, Nederland en de onderhandelingen over het Stockholm Programma: Casestudie 3 bij IOB Evaluatie nr. 395: ,Strategie bij benadering. Nederlandse coalitievorming en de multi-bi benadering in het kader van de EU-besluitvorming (2008-2012)', Hinweis bei Ernst Hirsch Ballin, „Mutual Trust“, S. 138, Fn. 22. 
verwaltungsprozessualer Standards abzielenden Besorgnis einiger weniger Mitgliedstaaten. ${ }^{1301}$

3. Entwicklung vom Brief der vier Außenminister über die Konferenz Assises de la Justice bis zur Vorstellung des EU-Rahmens

Im Laufe des Jahres 2013 erfuhr die im Stockholmer Programm angestoßene Entwicklung eine erhebliche Steigerung ihrer Dynamik. Dafür zeichnet insbesondere verantwortlich, dass Mitglieder des Kommissionskollegiums zunehmend im Hinblick auf die Rechtsstaatlichkeit problematische Vorgänge in den Blick nahmen. Insbesondere Giegerich hat diese Entwicklung im Einzelnen dargestellt. ${ }^{1302} \mathrm{Er}$ sieht den Anstoß hin zu einem rechtsstaatsspezifischen Aufsichtsregime, nun sich lösend vom niederländischen Fokus auf die Strafjustizsysteme ab 2007, in einer in drei Mitgliedstaaten im Wesentlichen gleichzeitigen, indes nicht notwendigerweise verknüpften, Zuspitzung von Problemen: die Frage der Lage der Roma in Frankreich, die ab 2010 infolge des dortigen Wahlsiegs der Fidesz erfolgenden politischen Umbrüche in Ungarn und schließlich die Frage der rechtsstaatlichen Entwicklung in Rumänien. ${ }^{1303}$ Dabei war die Lage der Roma, wenn auch nicht in Frankreich, bereits seit längerem wiederholt Gegenstand der Frage gewesen, ob hierin eine Verwirklichung eines Tatbestands des Art. 7 EUV zutage treten könnte. ${ }^{1304}$

Giegerich folgert, dass man sich, obwohl es der Kommission durch Verhandlungsgeschick ${ }^{1305}$ gegenüber insbesondere Rumänien und Frankreich gelang, die Fragen bis auf Weiteres zu lösen, in der Praxis darüber gewahr geworden sei, dass das bisherige Instrumentarium der Verträge zur Aufsicht über die „Verfassungshomogenität“ der Union, nämlich das Vertragsverletzungsverfahren zur „Feinsteuerung“ und das „politische“ Verfahren

1301 Ernst Hirsch Ballin, „Mutual Trust“, S. 139 und ff.

1302 Thomas Giegerich, „Verfassungshomogenität, Verfassungsautonomie und Verfassungsaufsicht in der EU“, S. $519 \mathrm{ff}$.

1303 Thomas Giegerich, „Verfassungshomogenität, Verfassungsautonomie und Verfassungsaufsicht in der EU“, S. 514.

1304 Armin von Bogdandy \& Jochen von Bernstorff, „Die Europäische Agentur für Grundrechte in der europäischen Menschenrechtsarchitektur und ihre Fortentwicklung durch den Vertrag von Lissabon“, S. 162.

1305 Im Umgang mit Frankreich und Rumänien, Thomas Giegerich, „Verfassungshomogenität, Verfassungsautonomie und Verfassungsaufsicht in der EU“, S. 516 . 
des Art. 7 EUV zur „Grobsteuerung“, nicht ausreichte, um derartigen Fragen effektiv zu begegnen. ${ }^{1306}$

Daraufhin griff der damalige Kommissionspräsident Barroso in seinen beiden Reden „zur Lage der Union“ 2012 und 2013 die Frage des unionalen Werteschutzes explizit auf und spitzte sie dabei auf den Schutz gerade der Rechtsstaatlichkeit zu.

Ob dabei auf der Kabinettsebene Barrosos eine Korrelation zu den früheren Anstößen des Stockholmer Programms beabsichtigt wurde, ist heute nicht mehr definitiv zu beantworten. Ebenso nicht zu beantworten, aber mutmaßlich zu bejahen, ist, dass sich Barroso bei der Einleitung beginnender Aufarbeitung seitens der Kommission von Vorarbeiten des Europäischen Parlaments leiten ließ. ${ }^{1307}$ Den zuständigen Dienststellen der Kommission indes waren diese Dokumente im Einzelnen geläufig. ${ }^{1308}$

Das Parlament hatte u.a. im 2013 erschienen Tavares-Bericht auf die Sorge betreffend Ungarn unter dem Eindruck insbesondere der dortigen Grundgesetzänderungen hingewiesen und deswegen neue Verfahren im Unionsrecht sowie gemeinsame Anstrengungen der Mitgliedstaaten gefordert. ${ }^{1309}$ Weitere Parlamentsdokumente, wie der Bericht aus dem Jahr 2012 betreffend politische Entwicklungen in Ungarn, ${ }^{1310}$ könnten Barroso ebenfalls vorgelegen haben, womit sich hier nochmals die Rolle des Parlaments als beobachtende Stelle im Rahmen unionaler Aufsichtsmaßnahmen verdeutlicht.

1306 Thomas Giegerich, „Verfassungshomogenität, Verfassungsautonomie und Verfassungsaufsicht in der EU“, S. 510 f. zu Art. 7 EUV, 515 f. zum Vertragsverletzungsverfahren, S. 517 f. zur Gesamteinschätzung.

1307 Ähnlich zum Einfluss der Vorarbeiten des Parlaments und auch der Mitgliedstaaten auch Thomas Giegerich, „Verfassungshomogenität, Verfassungsautonomie und Verfassungsaufsicht in der EU“, S. $520 \mathrm{f}$.

1308 Nachweise bei Emmanuel Crabit \& Nicolaas Bel, „The EU Rule of Law Framework", S. 202.

1309 Europäisches Parlament, Bericht über die Lage der Grundrechte: Standards und Praktiken in Ungarn (gemäß der Entschließung des Europäischen Parlaments vom 16. Februar 2012), (2012/2130(INI)), Ausschuss für bürgerliche Freiheiten, Justiz und Inneres, Berichterstatter: Rui Tavares vom 24.06.2013, A7-0229/2013 (Tavares-Bericht), insb. Erwägungsgründe $58 \mathrm{ff}$. und 77.

1310 Europäisches Parlament, P7_TA(2012)0053, Politische Entwicklungen in Ungarn in letzter Zeit: Entschließung des Europäischen Parlaments vom 16. Februar $2012 \mathrm{zu}$ den aktuellen politischen Entwicklungen in Ungarn (2012/2511(RSP)). 
Barroso sprach in seiner Rede zur Lage der Union $2012^{1311}$ erstmals von Entwicklungen betreffend "Demokratie und Rechtsstaatlichkeit" in bestimmten Mitgliedstaaten, die ein Einschreiten der Kommission bedingten. In Gänze lautet die Passage wie folgt:

„Eine politische Union bedeutet auch, dass wir das Fundament unserer Union stärken müssen: die Achtung unserer Grundwerte, der Rechtsstaatlichkeit und der Demokratie.

In den vergangenen Monaten war das rechtliche und demokratische Gefüge einiger europäischer Staaten in Gefahr. Das Europäische Parlament und die Kommission schlugen als erste Alarm. Sie waren es, die maßgeblich dafür sorgten, dass diese beunruhigenden Entwicklungen unter Kontrolle gebracht wurden.

Gleichzeitig wurden uns aber auch die Grenzen unserer institutionellen Vereinbarungen aufgezeigt. Wir brauchen ein besseres Instrumentarium - nicht nur die Alternative zwischen der „sanften Gewalt“ politischer Überzeugungskunst und der „radikalen Option“ von Artikel 7 des Vertrags.

Wir sind dem Grundsatz der Recht $[s]$ staatlichkeit verpflichtet. Aus diesem Grund möchten wir - wie in den Verträgen vorgesehen - eine Europäische Staatsanwaltschaft schaffen. In Kürze werden wir einen Vorschlag dazu vorlegen." 1312

Aus heutiger Sicht, da sich die Union mit zwei Verfahren nach Art. 7 EUV und eskalierenden Lagen in Polen und Ungarn insbesondere konfrontiert sieht, mutet Barrosos Feststellung von einer Gefahr für das „rechtliche und demokratische Gefüge“ der Union zwar nicht anachronistisch, indes oszillierend zwischen verfrühter Dramatisierung und Hellsichtigkeit an. Als Barroso bereits von einer derartigen Gefahr sprach, waren die Entwicklungen insbesondere in Polen noch völlig unbekannt, und in Ungarn fehlte es, ungeachtet der Schwere der Umbrüche in der dortigen Verfassung, an einer derart sichtbaren Zuspitzung der Lage wie etwa im Hinblick auf die CEU.

Die damalige Alarmierung über, aus heutiger Sicht, ungleich weniger dramatische Zustände in Mitgliedstaaten ist nicht dahingehend zu verstehen, dass man seinerzeit zu sensibel auf Veränderungen reagierte, sehr

1311 Zu beiden Reden im Überblick auch Thomas Giegerich, „Verfassungshomogenität, Verfassungsautonomie und Verfassungsaufsicht in der EU“, S. 520.

1312 José Manuel Barroso, Präsident der Europäischen Kommission, Rede zur Lage der Union 2012 vom 12.09.2012, SPEECH/12/596, S. 11. 
wohl aber zeigt die damalige Bestürzung, für wie unwahrscheinlich man systemische Defizite im Unionsrecht zuvor gehalten hatte. ${ }^{1313}$ Dass Barroso gleichwohl bereits damit begann, war sicherlich in guten Teilen auch auf einen intendierten Schulterschluss zur sehr drastischen Rhetorik Viviane Redings 2010 in ihrer „Stellungnahme zur Lage der Roma“ in Frankreich zurückzuführen, in welcher Reding u.a. von einer "disgrace“ sprach. ${ }^{1314}$ Wenn Redings Kritik auch heute angesichts der schnellen Erledigung der Frage weit überzogen anmutet, ${ }^{1315}$ zumal gegenüber einem Gründungsmitgliedstaat der Union mit einer historisch unbestreitbaren Verbürgung für die Menschenrechte, konnte die Kommission aus Redings Vorpreschen zwei Vorteile ziehen: die Fokussierung und Priorisierung der Sorge um die zuvor allenfalls abstrakten Unionswerte gerade auch auf Ebene des Kollegiums und eine deutliche Ausweitung des politischen Freiraums zum Handeln, denn Reding betonte den Willen zur lückenlosen Aufsicht über alle, auch große Mitgliedstaaten, und Barroso zog nun gleich.

Des Weiteren bedeutete die konkrete Entwicklung von Verfahren für eine Gefährdungslage der Unionswerte später, dass sie im Falle Polens bereits zur Verfügung standen und genutzt werden konnten.

An anderer Stelle indes erwiesen sich Barrosos Formulierungen als kontraproduktiv. Seine Interpretation von Art. 7 EUV als „radikaler Option“ sperrte die Nutzung dieses Verfahrens bis auf Weiteres. Im Englischen lautete die Wortwahl, deutlich dramatischer, nämlich „nuclear option“, womit Barroso das Verfahren figurativ einer Atombombe gleichgesetzt hatte, was wohl nicht nur auf die Zerstörungswirkung im Hinblick auf den durch die Maßnahme betroffenen Mitgliedstaat anspielen sollte, sondern insbesondere auch eine Allegorie auf die verheerende Wirkung der Erwiderung des vom „Erstschlag“ Betroffenen zu sein schien. Erst die Nutzung 2015 gegen Polen und später die ausdrückliche Revidierung dieser Sprachregelung durch den damaligen Ersten Vizepräsidenten Timmermans, nunmehr für die Juncker-Kommission, brachen mit dieser Sprachre-

1313 Vgl. etwa zu gleichlaufenden, früh deutlichen Warnungen auch der Literatur, Jan-Werner Müller, „The Commission gets the point - but not necessarily the instruments“, Verfassungsblog vom 15.03.2014.

1314 Viviane Reding, Vice-President of the European Commission responsible for Justice, Fundamental Rights and Citizenship: "Statement on the latest developments on the Roma situation", Readout im Hebdomadaire der Kommission vom 14.09.2010, SPEECH/10/428, vgl. insb. S. 3.

1315 Vorsichtig zustimmend in Bezug auf die Deutlichkeit der Kritik Robert Gould, „Roma rights and Roma expulsions in France“, S. 8, $10 \mathrm{ff}$. 
gelung wieder. ${ }^{1316}$ Die Rechtswissenschaft hatte die Formulierung bereits vor dieser Revidierung aus Gründen der Reduzierung zur Verfügung stehender Möglichkeiten kritisiert, offenbarte indes selbst - und noch 2016 als wie unwahrscheinlich die Nutzung des Verfahrens galt. ${ }^{1317}$

2013 griff Barroso seine ein Jahr zuvor gemachten Ausführungen erneut auf. Er präzisierte dabei in mehrfacher Hinsicht: zum einen die Rolle der Kommission, die er nun als "unabhängige und neutrale Schlichterin“ bezeichnete - eine Funktion, die sich eher am gemeinschaftlich koordinierten Lösen anstatt einer hierarchischen Aufsicht orientiert - und zum zweiten, mit der Ankündigung, dass die Kommission hierzu eine „Mitteilung" vorlegen werde. Auch in materiell-tatbestandlicher Hinsicht zeigt sich nun, da Barroso ein Jahr zuvor noch vom „rechtlichen und demokratischen Gefüge" der Union gesprochen hatte, ein definitiver Fokus allein auf das Rechtsstaatsprinzip als Schutzgut. Auch die neue zu behebende Herausforderung in Bezug auf dieses Schutzgut ist nun, drittens, klar benannt, Barroso spricht von „eine[r] großen, systembedingten Gefahr für die Rechtsstaatlichkeit [...] und vorab festgelegte[n] Benchmarks“. ${ }^{1318}$

Immer noch, und gerade aus heutiger Sicht, ergibt sich indes bei der Entschlossenheit der Kommission, das bestehende Aufsichtsinstrumentarium zu erweitern, ein durch die Sachlage selbst nicht unmittelbar erklärbarer Elan. Die verfassungspolitischen Umbrüche in Ungarn etwa wurden zwar zunehmend auch von der Venedig-Kommission begleitet, ${ }^{1319}$ die Europäische Kommission indes griff die Entwicklung aber, abgesehen von ihren beiden 2012 eingeleiteten Vertragsverletzungsverfahren betreffend die Justiz und den Datenschutzbeauftragten, ${ }^{1320}$ nicht in Maßnahmen ge-

1316 Frans Timmermans, „Opening remarks of First Vice-President Frans Timmermans, Readout of the European Commission discussion on the Rule of Law in Poland”, 20.12.2017, SPEECH/17/5387, o.S.

1317 Armin von Bogdandy, Michael Ioannidis \& Carlino Antpöhler: „Enforcing EU Values - Reverse Solange and a Systemic Deficiency Committee“, MPIL Research Paper Series, No. 2016-04, Heidelberg, S. 11. Die Verfasser sprachen noch davon, die Nutzung sei politisch nicht wahrscheinlich.

1318 José Manuel Durão Barroso, Rede zur Lage der Union, vom 11.09.2013, REDE/13/684, S. 12.

1319 Bis 2013 hatte die Venedig-Kommission bereits wiederholt zu den Verfassungsänderungen in Ungarn, insbesondere der Stellung des Verfassungsgerichts, und verschiedener einzelner Gesetze Stellung genommen.

1320 EuGH, Rs. C-286/12, Kommission ./. Ungarn, „Ungarische Richterpensionierung“, Urteil vom 06.11.2012, ECLI:EU:C:2012:687; EuGH, Rs. C-288/12, Kommission ./. Ungarn, „Ungarischer Datenschutzbeauftragter“, Urteil vom 08.04.2014, ECLI:EU:C:2014:237. 
genüber dem Mitgliedstaat auf. Die spätere Dramatik in Polen war z.B. weiterhin völlig unabsehbar. Hätte sie sich nicht ergeben, hätte man der Europäischen Kommission darüber möglicherweise sogar nicht den Vorwurf der Untätigkeit, sondern des übereilten Tätigwerdens gemacht. Auch dies ist eine Überlegung, die aus heutiger Sicht dafür ficht, vorschnelle Kritik an der Kommission zu überdenken.

Den Handlungswillen der Kommission partiell aufhellen kann erst der Blick auf den Umfang der Aufforderungen zum Handeln auf mitgliedstaatlicher Ebene ${ }^{1321}$ wie auch das Ausmaß der weiteren Vorbereitungen hierzu durch Barrosos Justizkommissarin Reding, die nur teils von konkreten Anlässen ausgingen, sondern vielmehr aus Sorge um zukünftige Entwicklungen eine vorbeugende Maßnahme forderten.

Bei mindestens vier Gelegenheiten wurde der Kommission die Schaffung eines neuen Mechanismus für zukünftige Entwicklungen nahe gelegt. Zunächst legten die Außenminister der sog. „Future for Europe Group “, eines Zusammenschlusses der elf Mitgliedstaaten Österreich, Belgien, Dänemark, Frankreich, Italien, Deutschland, Luxemburg, Niederlande, Polen, Portugal und Spanien, einen Abschlussbericht ihrer Aktivitäten vor, mit welchem bislang ihre Tätigkeit auch definitiv geendet hat, in welchem sie die Kommission zur Schaffung eines „new, light mechanism“ aufforderten. Mit ihm sollte die Kommission im Falle von „concrete evidence of violations of the values of Article 2 TEU“ einen Bericht erstatten und die Sache an den Rat weiterleiten. Die Rechtsstaatlichkeit wurde dabei besonders hervorgehoben, allerdings sah der Bericht keine Notwendigkeit, die Überprüfung allein auf diesen Unionswert zu beschränken. ${ }^{1322}$

Zum Bericht der „Future for Europe“-Gruppe hinzu trat das hier, aufgrund seiner Signatare, als sog. „Brief der vier Außenminister“ bezeichnete Schreiben vom März 2013. ${ }^{1323}$

1321 Dazu umfassend auch bei Thomas Giegerich, „Verfassungshomogenität, Verfassungsautonomie und Verfassungsaufsicht in der EU“, S. 521 und f.

1322 Zitat und Hinweis bei Thomas Giegerich, „Verfassungshomogenität, Verfassungsautonomie und Verfassungsaufsicht in der EU“, S. 521; s. weiter Final Report of the Future of Europe Group of the Foreign Ministers of Austria, Belgium, Denmark, France, Italy, Germany, Luxembourg, the Netherlands, Poland, Portugal and Spain vom 17.09.2012 abrufbar unter: https:/www.cer.e $\mathrm{u} /$ sites/default/files/westerwelle_report_sept12.pdf.

1323 Brief der vier Außenminister Deutschlands (Guido Westerwelle), der Niederlande (Frans Timmermans), Dänemarks (Villy Søvndal) und Finnlands (Erkki Tuomioja) an Kommissionspräsident Barroso, ohne Az., vom 06.03.2013. Der Brief setzte den damaligen irischen Außenminister (Eamon Gilmore) in Kopie, 
Dieser Vorgang ist deswegen besonders bemerkenswert, weil der den Brief unterzeichnende niederländische Außenminister Timmermans wenig später Kommissar mit dem Portfolio der Rechtsstaatlichkeit wurde und sich zuvor jedenfalls auch mit dem Brief - den weitere umfangreiche Diskussionen im Umfeld des Rates begleitet haben müssen - als mit besonderer Sachexpertise ausgestattet empfahl. Es ist noch interessanter, dass sich dieses Schema - also die Berufung eines Außenministers eines westeuropäischen kleineren Mitgliedstaats auf den Posten des entsprechenden Kommissars - 2019 mit dem Belgier Reynders im Wesentlichen wiederholt hat. Reynders hatte zuvor durch seinen Vorstoß betreffend die sog. "periodic peer review“ erkennen lassen, dass er für die Problematik der Rechtsstaatlichkeit Expertise und Policy-Vorstellungen mitbrachte.

Im Brief der vier Außenminister wird die konkrete Ausgestaltung eines Mechanismus wieder aufgegriffen, in Bezug auf das Schutzgut desselben bleibt das Schreiben indes vage.

Der Brief macht auch nicht deutlich, warum ein solcher Mechanismus erforderlich scheint. Er nimmt zwar explizit Bezug auf die Finanzkrise der Eurozone und leitet aus ihr eine "critical stage in European history“ $a b,{ }^{1324}$ die weiteres erfordere. Eine Verknüpfung oder Überleitung etwa zur Lage in Ungarn oder Rumänien fehlt. Der Brief deutet an, dass die Unterzeichner die Stärkung der Rolle der Kommission, die sie explizit fordern, durch mögliche Schwächen im Rat sehen, sie sprechen von „limits to our institutional arrangements" und der Notwendigkeit eines Mechanismus ,independent of political expediency“. Hierauf antwortend soll ein „strukturierter Dialog“verbindliche Abmachungen zwischen Kommission und Mitgliedstaat ermöglichen und als letztem Schritt die Aussetzung von EU-Förderung aus den Fonds ermöglichen. ${ }^{1325}$

Mehrere Punkte sind aus diesem Satz abzuleiten, zum einen meines Erachtens der Ursprung für den bereits zuvor herausgearbeiteten Grundsatz des strukturiert flexiblen Dialogs, ${ }^{1326}$ den die Kommission später so prominent verwendet hat, zum zweiten, dass zwar sich die Rechtsverbindlichkeit des Mechanismus nicht ergeben hat, drittens aber, dass mit dem Brief die Idee einer Fondskonditionalität für den Fall der Nichtachtung der Werte

was andeutete, dass die Iren das Vorhaben grundsätzlich ebenfalls unterstützten.

1324 S. 2 des Briefs.

1325 Hierzu siehe auch nochmals Thomas Giegerich, „Verfassungshomogenität, Verfassungsautonomie und Verfassungsaufsicht in der EU“, S. 521.

1326 S. dazu, und zur Funktion der Line to take für die Politik- und Rechtsgestaltung durch die Kommission in der Krise, unter E. II und III. 
durch einen Mitgliedstaat im Raum stand, den die Kommission dann 2018 in einen konkreten Vorschlag goss.

Ein finnisch-irisches „Non-Paper“ zog nach, rief indes zu einer Evaluierung aller Mitgliedstaaten und im Rat auf. Auch auf mitgliedstaatlicher Ebene äußerte man sich. ${ }^{1327}$ Während sich dabei zunehmend die Idee eines niedrigschwelligen Verfahrens herausbildete, blieb die Frage nach dem Schutzgut weiter offen. ${ }^{1328}$

Auf Seiten der Kommission reagierte Viviane Reding, nachdem sie bereits 2010 zur Lage der Roma Stellung bezogen hatte, ohne indes dabei ein neues Verfahren zu fordern, 2013 mit zwei Reden, in denen sie dies nun nachholte.

In einer ersten Rede vom April 2013, also einen guten Monat nach dem sog. „Brief der vier Außenminister“, legte Reding offen, dass die Kommission angesichts der „Lücke“, die zwischen ihrer sog. „soft power“, d.h. den informellen Einflussmöglichkeiten auf Mitgliedstaaten und der dort nach wie vor „nuclear option“ genannten Möglichkeit des Art. 7 EUV an einem ganzen Instrumentarium („number of tools“) arbeitete, mit welchen diese Lücke geschlossen werden sollte. ${ }^{1329}$ Das erklärende Narrativ, das Reding hierfür entwickelte, war indes ein gänzlich anderes als noch die anlassbezogene Dramatik der Roma-Frage. Reding schlug vielmehr implizit die Brücke zum Stockholmer Programm und kam vor dem Hintergrund des sich entwickelnden EU-Justizbarometers und des CVM in Bulgarien und Rumänien auf die wirtschaftlichen Vorteile einer funktionierenden Justiz

1327 Zu beidem Thomas Giegerich, „Verfassungshomogenität, Verfassungsautonomie und Verfassungsaufsicht in der EU“, S. 521, Bezug nehmend auf „Rule of law - enhancing the respect for the rule of law in the EU"vom November 2013. Das Papier ist nicht mehr öffentlich verfügbar, aber beim Verfasser archiviert; weiter unter Verweis auf den Koalitionsvertrag der CDU, CSU und SPD, „Deutschlands Zukunft gestalten: Koalitionsvertrag zwischen CDU, CSU und SPD für die 18. Legislaturperiode“, S. 115.

1328 Der soeben genannte Koalitionsvertrag etwa nimmt auf alle Werte des Art. 2 EUV und insbesondere den Schutz „demokratischer und rechtsstaatlicher Standards" Bezug.

1329 Viviane Reding, Vice-President of the European Commission, EU Justice Commissioner: Safeguarding the rule of law and solving the "Copenhagen dilemma": Towards a new EU-mechanism, Rede vor dem Rat für Allgemeine Angelegenheiten vom 22.04.2013, SPEECH/13/348, S. 3. 
zu sprechen. ${ }^{1330}$ Die Fokussierung auf die Rechtsstaatlichkeit, ${ }^{1331}$ die Reding, wie im September des gleichen Jahres Barroso, nunmehr eindeutig macht, erscheint daher vor dem Hintergrund der heutigen Systematik der systemischen Defizite als eine vorrangig auf staatliche Schwäche gerichtete Sichtweise.

Am 4. September 2013, nur fünf Tage vor der jährlichen Rede Barrosos zur Lage der Union, erging Redings Rede zur „EU und Rechtsstaatlichkeit“, die ich bereits im Hinblick auf die Betonung der Rolle der GD JUST zitiert hatte und die derart zahlreiche programmatische Anstöße enthält, dass ich sie hier nicht im Einzelnen zusammenfassen möchte. Herausgestellt sei vielmehr, dass Reding die tatbestandlichen Ursachen für das Handeln der Kommission, und obwohl die Frage der Effektivität der mitgliedstaatlichen Justizsysteme betont wird, nun wiederum überwiegend in qualitativen Fragen sieht und dabei u.a. auch die Lage in Ungarn als explizite Herausforderung nennt. ${ }^{1332}$ Vor dem Hintergrund dieser qualitativen Entwicklungen macht sie umfassende Ausführungen zur Bedeutung des Rechtsstaatsprinzips, die nun die wirtschaftliche Komponente funktionierender Justizsysteme hinter sich ließen ${ }^{1333}$ und verknüpfte die Entwicklung in Ungarn, Rumänien und - erneut - Frankreich vor dem explizit genannten Auftrag des Stockholmer Programms ${ }^{1334}$ mit der Schlussfolgerung, dass es neuer Mechanismen seitens der Kommission bedürfe, ${ }^{1335}$ und brachte sogar eine Vertragsänderung ins Spiel. ${ }^{1336}$

Um sich weitere Denkanstöße für die Ausarbeitung der Mechanismen $\mathrm{zu}$ holen, richtete die Kommission aus eigenem Antrieb im November

1330 Viviane Reding, Vice-President of the European Commission, EU Justice Commissioner: Safeguarding the rule of law and solving the "Copenhagen dilemma": Towards a new EU-mechanism, Rede vor dem Rat für Allgemeine Angelegenheiten vom 22.04.2013, SPEECH/13/348, S. 3 und 4.

1331 Viviane Reding, Vice-President of the European Commission, EU Justice Commissioner: Safeguarding the rule of law and solving the "Copenhagen dilemma": Towards a new EU-mechanism, Rede vor dem Rat für Allgemeine Angelegenheiten vom 22.04.2013, SPEECH/13/348, S. 4.

1332 Viviane Reding, The EU and the Rule of Law - What next?, SPEECH/13/677 vom 04.09.2013, S. 2.

1333 Viviane Reding, The EU and the Rule of Law - What next?, SPEECH/13/677 vom 04.09.2013, S. 4 und 5.

1334 Viviane Reding, The EU and the Rule of Law - What next?, SPEECH/13/677 vom 04.09.2013, S. $6 \mathrm{ff}$.

1335 Viviane Reding, The EU and the Rule of Law - What next?, SPEECH/13/677 vom 04.09.2013, S. $10 \mathrm{ff}$.

1336 Viviane Reding, The EU and the Rule of Law - What next?, SPEECH/13/677 vom 04.09.2013, S. 11. 
2013 eine große Konferenz aus, die sowohl Praktiker als auch Wissenschaftler unter dem Titel „Assises de la Justice“1337 im Rahmen einer sog. „stakeholder consultation“, also Befragung von Parteien mit besonderem Wissen oder Interesse an bzw. Einfluss auf das Thema, an einen Tisch brachte. Sie ist in der weiteren Krise ohne Parallele geblieben, selbst als die Kommission im Frühjahr 2019 mit einer weiteren Mitteilung diverse Angehörige der interessierten oder beteiligten Öffentlichkeit zur Einreichung von Vorschlägen aufforderte, ${ }^{1338}$ ebenso wenig wie in den anderen im Maßstab kleineren Konferenzen zur Thematik im Winter 2013.1339 Die durch die Generaldirektion Justiz und Verbraucher (GD JUST) veranstaltete Konferenz brachte neben Rechtswissenschaftlern vorrangig Entscheider aus der Praxis ${ }^{1340}$ in mehreren Panels zusammen. Die Dokumentation der Konferenz in der Literatur, einschließlich derjenigen der Kommission selbst, ${ }^{1341}$ weist nach, dass insbesondere Effektivitätsgesichtspunkte der Justiz in den Mitgliedstaaten im Allgemeinen zur Debatte standen, wobei die

1337 Vgl. Europäische Kommission, Building Trust in Justice Systems in Europe: ,Assises de la Justice' forum to shape the future of EU Justice Policy, Pressemitteilung vom 21. November 2013, IP/13/1117. Die zur Konferenz ursprünglich zur Verfügung gestellte Website und damit auch die seinerzeit öffentlich einsehbaren Papiere der Teilnehmer sind bedauerlicherweise zwischenzeitlich nicht mehr zugänglich. Der Titel der Konferenz zeigt gewisse Parallelen zum im französischen Rechtssystem bei besonders schweren Tatvorwürfen als Strafgeschworenengericht zusammentretenden Gericht (vgl. franz.: Cour d'assises).

1338 Europäische Kommission, Mitteilung der Kommission an das Europäische Parlament, den Europäischen Rat und den Rat, Die weitere Stärkung der Rechtsstaatlichkeit in der Union: Aktuelle Lage und mögliche nächste Schritte, $\operatorname{COM}(2019) 163$ final, vom 03.04.2019, S. $12 \mathrm{ff}$.

1339 Armin von Bogdandy \& Michael Ioannidis, „Das systemische Defizit“, weisen in den Danksagungen zum Beitrag u.a. auf einen Runden Tisch in Brüssel im November 2013 hin.

1340 U.a. Viviane Reding, den damaligen EuGH-Präsidenten Vassilios Skouris, den litauischen und irischen Justizminister, den damaligen Präsidenten der Venedig-Kommission, Gianni Buquicchio, und den ehemaligen Vizepräsidenten des französischen Staatsrats, Jean-Marc Sauvé. Deutschland war durch Klaus Tolksdorf, den damaligen Präsidenten des BGH, vertreten, die Kommission durch die damalige Generaldirektorin der GD JUST, Françoise Le Bail, s. dazu die wie vor die Pressemitteilung der Kommission Pressemitteilung vom 21. November 2013, IP/13/1117, S. 6 f.

1341 Europäische Kommission, Building Trust in Justice Systems in Europe: ,Assises de la Justice' forum to shape the future of EU Justice Policy, Pressemitteilung vom 21. November 2013, IP/13/1117, S. 2. 
Kommission nochmals das Stockholm-Programm des Europäischen Rates aufgriff und das spätere Justizbarometer bereits vorbereitete. ${ }^{1342}$

Allerdings war dies nicht der einzige Zweck der Konferenz. Wie Skouris später öffentlich machte, diente das Panel zur Rechtsstaatlichkeit bereits unmittelbar zur Vorbereitung des vier Monate später veröffentlichten EURahmens. ${ }^{1343}$

Unter den akademischen Beiträgen der Konferenz ist der Rechtswissenschaft insbesondere einer in Erinnerung geblieben: Scheppeles Vorschlag zur Schaffung sog. ,systemic infringement actions“ ${ }^{\text {“ }}{ }^{1344}$

Auf die Instrumente ist nun näher einzugehen.

\section{Partielle Verfassungsaufsichtsinstrumente im Unionsrecht}

1. Zur Unterscheidung partieller und vollständiger

Aufsichtsmechanismen im Unionsrecht, insbesondere mit Blick auf den EU-Rahmen

Ich rufe in Erinnerung, dass in der Literatur drei Phasen einer föderalen, also hier durch die Union gegenüber den Mitgliedstaaten erfolgenden, Aufsicht unterschieden worden sind, nämlich die Beobachtung/Informationsbeschaffung, die Überprüfung und schließlich die Berichtigung. ${ }^{1345}$ Keines der im Rahmen der unionalen Rechtsstaatlichkeitskrise genutzten oder entwickelten Verfahren beschränkt sich auf eine dieser Phasen, sie umfassen stets zumindest die Informationsbeschaffung und die Überprüfung.

1342 S. zur späteren Würdigung etwa Adriani Dori, „The EU Justice Scoreboard - Judicial Evaluation as a New Governance Tool“, MPILux Working Paper Series, No. 2/2015, Max Planck Institute Luxembourg for International, European and Regulatory Procedural Law, S. 13; Matthias Weller, „Mutual trust: in search of the future of European Union private international law", in: Journal of Private International Law 11 (2015), S. 64-102, S. 64 ff.

1343 Vassilios Skouris, „Die Rechtsstaatlichkeit in der Europäischen Union“, in: Armin Hatje (Hrsg.), Verfassungszustand und Verfassungsentwicklung der Europäischen Union, Europarecht Beiheft 2 (2015), S. 8-19, S. 15, bei Fn. 25.

1344 Kim Lane Scheppele, „What Can the European Commission Do when Member States Violate Basic Principles of the European Union? The Case for Systemic Infringement Actions“, undatiertes Working Paper, Verfassungsblog, 2013.

1345 Nochmals dazu Meike Eekhoff, Die Verbundaufsicht, S. $112 \mathrm{ff}$. Alexander Thiele, Finanzaufsicht, S. $12 \mathrm{ff}$. 
Indes steht zu beobachten, dass einige der Verfahren, die Teil des auf die Krise reagierenden Verfassungsaufsichtsregimes sind, keine Berichtigungsphase kennen, und ich schlage vor, sie als einen von zwei großen Teilen der unionalen Verfassungsaufsicht zu verstehen, nämlich als „partielle“, d.h. als nur teilweise ausgeprägte Aufsichtsverfahren zu bezeichnen. Ihnen stehen vollständige, die Berichtigungsphase also mit umfassende, Aufsichtsverfahren gegenüber. Thiele hat bereits für das deutsche Recht nachgewiesen, dass vielfach Aufsichtsmaßnahmen auch durch Kooperation und Koordination wirken und man daher nicht zwingend allen Aufsichtsmaßnahmen eine ,imperative Maßstabsdurchsetzung“ zuschreiben muss. ${ }^{1346}$

Für partielle Aufsichtsverfahren im Unionsrecht, wie sie hier in den Blick genommen werden, ergibt sich die Berichtigungsfunktion erst aus der Verknüpfung, aus einer "Querverwertung" der Ergebnisse mit und bei anderen Verfahren, z.B. für den EU-Rahmen und das Justizbarometer aus dem Zusammenspiel mit dem Verfahren nach Art. 7 EUV oder dem Vertragsverletzungsverfahren. Für die hier interessierenden Länderberichte und länderspezifischen Empfehlungen des Europäischen Semesters ergibt sich die Möglichkeit einer Berichtigung etwa unmittelbar aufgrund des Zusammenspiels mit anderen Sekundärrechtsakten des sog. „Six Pack“1347, weswegen ich das Semester nicht zu den partiellen Verfassungsaufsichtsmechanismen zähle, mittelbar durch das sog. „Two Pack“1348 oder aber mit der Primärrechtsnorm des Art. 121 AEUV, ${ }^{1349}$ aber potentiell eben auch durch die weitere Verwendung vor dem Rat, inklusive des Art. 7 EUV-Verfahrens.

1346 Alexander Thiele, Finanzaufsicht, S. 17-24, in Abgrenzung u.a. zu Dirk Ehlers und Jan Hecker. Thiele macht sichtlich Anleihen bei Kahls kooperativem Aufsichtsmodell, das hier in Einzelheiten außen vor bleibt.

1347 Zum Sixpack etwa Carlino Antpöhler, „Emergenz der europäischen Wirtschaftsregierung - Das Six Pack als Zeichen supranationaler Leistungsfähigkeit“, in: Zeitschrift für ausländisches öffentliches Recht und Völkerrecht 72 (2012), S. 353-394.

1348 Zum damit etablierten "Budgetkontrollregime für den Euroraum“ sehr kritisch Ulrich Hufeld, „\$22 Das Recht der Europäischen Wirtschaftsunion“, in: Peter Christian Müller-Graff (Hrsg.), Enzyklopädie Europarecht, Band 4: Europäisches Wirtschaftsordnungsrecht, Nomos, Baden-Baden, 2014, S. 1299-1386, Rn. 61 („Aufstieg der Kommission zur europäischen Generalrechenkammer“).

1349 Zur Nachverfolgung des Semester mittels Art. 121 AEUV vgl. Jens Harmer, Art. 121 AEUV, Hans von der Groeben, Jürgen Schwarze \& Armin Hatje (Begr./Hrsg.), Europäisches Unionsrecht, Nomos, Baden-Baden, 7. Aufl. 2015, Rn. $52 \mathrm{ff}$. 
Die Beobachtung, dass einem Teil des unionalen Verfassungsaufsichtsregimes erst aufgrund des Zusammenspiels dieser Maßnahmen mit rechtsverbindlichen Maßnahmen an anderer Stelle eine Berichtigungsphase zuzuschreiben ist, ist aufgrund des teils divergierenden Verständnisses der Kriterien, die an dieses Verfahrensstadium im Unionsrecht anzulegen sind, nicht unbestritten und deswegen zu begründen. Es gilt also zu fragen, was überhaupt unter der Berichtigungsfunktion zu verstehen ist.

Peter Wollenschläger z.B. unterscheidet „eingreifende“ von „nicht eingreifenden " Aufsichtsinstrumenten, ${ }^{1350}$ was zunächst vermeintlich der hier vorgeschlagenen Unterscheidung entspricht. Letztere seien nicht bindend, d.h. sie begründeten „keinerlei Handlungspflichten für den Beaufsichtigten“, während eingreifende Aufsichtsinstrumente verpflichtenden Charakter hätten.

Diese Unterscheidung kann in Bezug gerade auf den EU-Rahmen so nicht unmittelbar übernommen werden. Ich hatte zuvor festgehalten, dass das Verfahren nach Bast dem Typus der sog. regelfallverbindlichen Handlungsform zugeordnet werden kann. Demzufolge wäre es unzutreffend, dem EU-Rahmen „keinerlei“ Handlungspflichten zu entnehmen, sie bestehen jedenfalls de facto.

Konträr zu Wollenschläger, aber auch meinem Vorschlag in dieser Arbeit, stehen die Ausführungen zur Berichtigungsphase von Aufsichtsverfahren bei Eekhoff. ${ }^{1351}$ Für Eekhoff besteht keine Notwendigkeit der Unterteilung von Aufsichtsverfahren in verschiedene Gruppen, und sie wäre vermutlich auch mit der hier gemachten Unterscheidung vollständiger und partieller Aufsichtsverfahren nicht einverstanden. Denn sie legt ein sehr weit gefasstes Verständnis von der Berichtigungsphase der Aufsicht als ihrer letzten Phase zugrunde. „Alle Instrumente [...], mit denen die Gemeinschaft die Mitgliedstaaten zu einem europarechtskonformen Verhalten anhält bzw. mit denen sie einen rechtmäßigen Vollzug sicherstellt“,

1350 Peter Wollenschläger, Die Gemeinschaftsaufsicht über die Rechtsprechung der Mitgliedstaaten, S. 53, m. w. N.

1351 Eekhoff problematisiert sogar, ob das Unionsrecht neben dem Vertragsverletzungsverfahren weitere Aufsichtsverfahren zulasse, vgl. Meike Eekhoff, Die Verbundaufsicht, S. 187 ff. Das EuG habe in der Rs. T-260/94, Air Inter SA ./. Kommission, Urteil vom 19.06.1997, Slg. II-1000, ECLI:EU:T:1994:265, Rn. 106, die Frage nach der grundsätzlichen Zulässigkeit derartiger Verfahren neben dem Vertragsverletzungsverfahren offen gelassen. Weiter ebda, S. 211 ff., zu Verhältnismäßigkeitsgrundsätzen für die Kodifzierung derartiger Maßnahmen. 
darunter ausdrücklich auch „formlose Aufforderungen“1352 wie Empfehlungen sind für Eekhoff unterschiedslos mit einer Berichtigungsphase versehen und folglich nach hiesiger Überlegung „vollständige“ Aufsichtsmaßnahmen.

Für Eekhoffs weites Verständnis spricht im Unionsrecht, dass dieses auf vielen Gebieten mit rechtsunverbindlichen Berichtigungsvorschlägen operiert und dass derartige Mechanismen nach Möglichkeit in die Analyse unionaler Aufsichtsmaßnahmen aufgenommen werden müssen.

Dennoch scheint es mir gerade im Hinblick auf das hier untersuchte Rechtsregime teleologisch und systematisch zwingend geboten, eine Unterscheidung im Hinblick auf die Berichtigungsphase der Aufsicht zu machen; zunächst, ganz allgemein, weil sie den Korpus der unionalen Verfassungsaufsichtsmaßnahmen strukturieren hilft, was allein aufgrund der Unterscheidung rechtsunverbindlicher und rechtsverbindlicher Maßnahmen, man denke nur an die Besonderheiten des EU-Rahmens, nicht gelingt. ${ }^{1353}$ Zum zweiten, weil zwar die Verträge im Ursprung von rechtsverbindlichen Primärrechtsaufsichtsmaßnahmen ausgegangen sind, in der späteren Rechtsstaatlichkeitskrise indes die Entwicklung neuer und darüber zunächst rechtsunverbindlicher und vor allem nicht berichtigender Maßnahmen im Vordergrund stand. Und zuletzt, weil nur die Trennung zwischen nicht berichtigenden und berichtigenden Aufsichtsmaßnahmen die Querverwertung der Ergebnisse ersterer in den anderen Verfahren vor Augen führt, die neben der Identität von Schutzgut und Telos der verschiedenen Verfahren so zentral dafür ficht, in ihnen allen ein gemeinsames Rechtsregime zu erblicken.

Nachfolgend stehen also zunächst diejenigen Verfahren im Vordergrund, denen eine eigene Berichtigungsphase fehlt. Unter Berichtigung verstehe ich, anders als bei Eekhoff, nicht bereits all diejenigen Verfahrensstufen, mit denen die Kommission, förmlich oder nicht, den Mitgliedstaaten die Änderung ihres Verhaltens empfiehlt oder sie dazu auffordert, sondern erst solche Verfahren, bei denen die Abweichung verbindlich festgehalten und unmittelbar Sanktionen angekündigt werden oder die infolge der Verfahrensnatur selbst im Raum stehen. Die „Mängelrüge“, die diesem vorangeht, ist indes noch Teil der Überprüfungsphase. In der

1352 Meike Eekhoff, Die Verbundaufsicht, S. 127-128 und f., Zitat S. 127.

1353 Dazu infra mit Blick auf die sog. Regelfallverbindlichkeit des EU-Rahmens. 
Trennung der rechtsunverbindlichen Aufforderung zur Berichtigung von der Berichtigung selbst schließe ich mich Bandell an. ${ }^{1354}$

\section{Der EU-Rahmen zur Stärkung des Rechtsstaatsprinzips}

Am 11. März 2014, ${ }^{1355}$ für die englische Fassung mit Korrigendum vom 19. März 2014, ${ }^{1356}$ setzte die Europäische Kommission ihren eigenen Reflexionsprozess, die Aufforderungen durch Mitgliedstaaten und durch das Europäische Parlament und schließlich die Anstöße aus der Wissenschaft in einer Mitteilung um, die im Unionsrecht ein neues Verfahren einführte, den EU-Rahmen zur Stärkung des Rechtsstaatsprinzips. Der Mitteilung beigefügt waren zwei Anhänge, veröffentlicht als zusammenhängendes Dokument. Der erste Anhang 1357 enthielt eine zuvor bereits angesprochene Operationalisierung des Rechtsstaatlichkeitsbegriffs seitens der Kommission durch Verweis auf die Judikatur des EuGH zu allgemeinen Rechtsgrundsätzen. Der zweite Anhang ${ }^{1358}$ enthielt eine graphische Darstellung des Verfahrens, wobei es in der Literatur nicht unüblich war, diese Graphik abzudrucken. ${ }^{1359}$ Die Kommission hat den EU-Rahmen fünf Jahre später mit zwei weiteren Mitteilungen vom April und Juli 2019 fortent-

1354 Dieter Bandell, Die Aufsicht der Europäischen Gemeinschaften über die Mitgliedstaaten, S. 55-57, dort auch zur Figur der „Mängelrüge“.

1355 Europäische Kommission, Mitteilung der Kommission an das Europäische Parlament und den Rat, Ein neuer EU-Rahmen zur Stärkung des Rechtsstaatsprinzips vom 11.03.2014, COM(2014) 158 final;

1356 Korrigendum vom 19.03.2014, veröffentlicht unter COM (2014) 158 final/2. Grund hierfür war ein einzelner Formulierungsfehler, auf S. 5 der ursprünglichen Fassung hieß es versehentlich: „This is why the EU has a strong interest in safeguarding and strengthening the rule of law threats [meine Hervorhebung] across the Union."

1357 Europäische Kommission, Mitteilung der Kommission an das Europäische Parlament und den Rat, Ein neuer EU-Rahmen zur Stärkung des Rechtsstaatsprinzips vom 11.03.2014, $\operatorname{COM(2014)~} 158$ final, Anhang I: Das Rechtsstaatsprinzip als tragendes Prinzip der Union.

1358 Europäische Kommission, Mitteilung der Kommission an das Europäische Parlament und den Rat, Ein neuer EU-Rahmen zur Stärkung des Rechtsstaatsprinzips vom 11.03.2014, $\operatorname{COM(2014)~} 158$ final, Anhang II (ohne Titel) mit graphischer Darstellung des Verfahrens.

1359 S. etwa bei Hannes Hofmeister, „Polen als erster Anwendungsfall des neuen ,EU Rahmens zur Stärkung des Rechtsstaatsprinzips““, in: Deutsches Verwaltungsblatt (2016), S. 869-875, S. 873. 


\section{E. Das Rechtsregime der Verfassungsaufsicht der Europäischen Union}

wickelt. ${ }^{1360}$ Diese Mitteilungen haben zwar vorrangig eine eigenständige Bedeutung. Sie sind Programmmitteilungen ohne einen dem EU-Rahmen vergleichbaren Verfahrenscharakter, indes sind die dort gemachten Ausführungen punktuell von großer Bedeutung für das ex post bessere Verständnis des EU-Rahmens und daher nachfolgend, wo geboten, zu berücksichtigen.

\section{a. Formenwahl und Bezeichnung als „Rahmen“, Begriff der „Stärkung“ der Rechtsstaatlichkeit}

Hinsichtlich der Beurteilung des EU-Rahmens sind zwei Handlungsformen bzw. -konvolute zu unterscheiden: der eigentliche „Rahmen“, d.h. das Zusammenwirken der drei Stadien dieses Mechanismus, in dessen Zentrum eine Stellungnahme und eine Empfehlung stehen, und eine Mitteilung als äußere Einkleidung des Verfahrens. Bei letzterer handelt es sich um eine rechtsunverbindliche, im Typenkatalog des Art. 288 AEUV nicht angesprochene Handlungsform im ausschließlichen Verantwortungsbereich der Kommission, ${ }^{1361}$ die die Kommission in der Praxis in sehr großer Zahl erlässt. Adressaten einer Mitteilung sind, jeweils ab-

1360 Europäische Kommission, Mitteilung der Kommission an das Europäische Parlament, den Europäischen Rat und den Rat, Die weitere Stärkung der Rechtsstaatlichkeit in der Union: Aktuelle Lage und mögliche nächste Schritte, $\operatorname{COM}(2019) 163$ final, vom 03.04.2019; Europäische Kommission, Mitteilung der Kommission an das Europäische Parlament, den Europäischen Rat, den Rat, den Europäischen Wirtschafts- und Sozialausschuss und den Ausschuss der Regionen: Die Stärkung der Rechtsstaatlichkeit in der Union: Ein Konzept für das weitere Vorgehen, $\operatorname{COM(2019)~} 343$ final vom 17.07.2019.

1361 S. dazu grundlegend Linda Senden, Soft Law in European Community Law, Hart, Oxford/Portland, 2004, S. 132 ff.; Armin von Bogdandy, Jürgen Bast \& Felix Arndt: „Handlungsformen im Unionsrecht: Empirische Analysen und dogmatische Strukturen in einem vermeintlichen Dschungel“, in: Zeitschrift für ausländisches öffentliches Recht und Völkerrecht 62 (2002), S.77-161, S. 118. Vgl. weiter auch zur Einführung Heike Adam, Die Mitteilungen der Kommission: Verwaltungsvorschriften des Europäischen Gemeinschaftsrechts? Eine Untersuchung zur rechtsdogmatischen Einordnung eines Instruments der Kommission zur Steuerung der Durchführung des Gemeinschaftsrechts, Nomos, Baden-Baden, 1999, S. 2-4, Markus U. Brohm, Die "Mitteilungen“ der Kommission im Europäischen Verwaltungs- und Wirtschaftsraum: Typologie, Rechtsnatur und Bindungswirkung für die Behörden der Mitgliedstaaten, Nomos, Baden-Baden 2012., S. 25 ff. Der Rat nimmt traditionell keine Mitteilungen an, vergleichbare Akte heißen dort insb. „Entschließung“, s. Armin 
hängig von der konkreten Ausgestaltung, neben solchen, die an die Mitgliedstaaten gerichtet sind, hauptsächlich die Organe der Union, wobei der Adressatenumfang variiert und z.B. die weiteren Organe, wie den Ausschuss der Regionen, aussparen kann. Im Unterschied zu mitteilungsähnlichen Dokumenten, die kommissionsintern als Verwaltungsinnenrecht an die Dienststellen ergehen und die im interinstitutionellen Umlauf grundsätzlich nur mittelbare Adressaten haben, die SEKs oder, hiervon unterschieden, sog. "SWDs (für „staff working document" = Arbeitsdokumente der Dienststellen), ${ }^{1362}$ bedürfen Mitteilungen der ausdrücklichen Zustimmung durch das Kollegium der Kommissare, müssen also mindestens mehrheitsfähig sein. ${ }^{1363}$

Mit der Wahl einer Mitteilung zur Schaffung eines neuen Verfahrens entschied sich die Kommission 2014 gegen den Versuch einer Primärrechtsänderung, wie etwa von Reding noch öffentlich überlegt, und im Übrigen, den späteren Verordnungsvorschlag ausgenommen, grundsätzlich gegen die Entwicklung der Verfassungsaufsicht durch Schaffung rechtsverbindlicher Sekundärrechtsakte. Was die Schaffung von Aufsichtsmöglichkeiten durch Rechtsetzung anging, wurde das Regime vielmehr

von Bogdandy, Jürgen Bast \& Felix Arndt: „Handlungsformen im Unionsrecht", S. $120 \mathrm{f}$.

1362 Die Kommission unterscheidet zwischenzeitlich zwischen reinem Innenrecht (Nomenklatur „SEK“) und adressatemlosen soft law (Nomenklatur „SWD“), das aber jdf. fallabhängig mittelbare Beachtung durchaus durch Dritte erfahren soll. Für ein Verfahren, das sowohl derartige „SWD“s als auch Handlungsformen des Katalogs des Art. 288 AEUV zur Anwendung bringt s. das Europäische Semester, dessen „Länderberichte“ zunächst als SWD ergehen, worauf als Empfehlung die „Länderspezifischen Empfehlungen“ (CSR), also eine Empfehlung i.S.d. Art. 288 UAbs. 4 AEUV, folgen. Selbstredend werden die Länderberichte, obwohl „SWD“, in den Mitgliedstaaten genauestens berücksichtigt. S. auch infra zum Semester. Übersicht über die Nomenklatur durch die Kommission unter https://eur-lex.europa.eu/content/help/faq/com-jo in-sec-swd-documents.html?locale=de.

1363 Exemplarisch für den Gang einer solchen Aussprache und Abstimmung, hier indes zu einer gänzlichen anderen Sache, Procès verbal de la deux mille deux cent quatre-vingt-septième réunion de la Commission, PV(2019) 2287 final, vom 03.04.2019, Punkt 7, S. 21 ff. (authentische Fassung nur in französischer Sprache). Nach einer Vorstellung durch das Mitglied der Kommission, dessen Portfolio der federführende Dienst zuzurechnen ist, erfolgt die Abstimmung. Das Sitzungsprotokoll zur Annahme des EU-Rahmen selbst ist meiner Kenntnis nach nicht öffentlich zugänglich gemacht worden. Für die Annahme des Korrigendums im gleichen Verfahren s. aber Procès verbal de la deux mille septante-huitième [sic] réunion de la Commission, vom 19.03.2014, PV(2014) 2078 final, S. 13. 
ins unionale soft law verlagert. Das heißt nicht, dass die Kommission nicht gewillt war, Primärrecht oder verbindliches Sekundärrecht zur Anwendung zu bringen, aber sie war bis auf Weiteres augenscheinlich nicht gewillt, sich auf eine Rechtsetzungsdebatte einzulassen. Darüber waren andere Methoden, nämlich insbesondere die hier sog. Neuausrichtung bestehender Verfahren, zu wählen. ${ }^{1364}$

Die Bezeichnung „EU-Rahmen“ findet sich auch in den anderen Arbeitssprachen der Union weitgehend entsprechend als "new EU framework“ bzw. „nouveau cadre de l'UE“. Die Bezeichnung „Rahmen“ ist aus dem Unionsrecht durchaus aufgrund seiner Verwendung an anderer Stelle geläufig - erinnert sei an den „Rahmenbeschluss“ oder auch die sog. „Rahmenprogramme“, insbesondere umgesetzt im Programm „Horizon 2020“ zur Forschungsförderung.

Für den EU-Rahmen zur Stärkung des Rechtsstaatsprinzips ist der Begriff des Rahmens aber nach bisheriger Entwicklung nicht mit einer tieferen Dogmatik versehen, sondern meint wörtlich den Verhandlungsrahmen, in welchem die Kommission mit dem adressierten EU-Mitgliedstaat in ihren strukturierten Dialog eintritt.

Im EU-Rahmen selbst hat der Begriff der "Stärkung“ des Rechtsstaatsprinzips noch keine eigenständige Bedeutung erlangt, während er sich prominent im Titel der Mitteilung findet. Nachdem die Kommission fünf Jahre später, im April 2019, angekündigt hatte, sie wolle ein „Konzept der Stärkung der Rechtsstaatlichkeit" vorlegen, ${ }^{1365}$ hat sie dies schließlich im Juli des gleichen Jahres als Entwicklung zusätzlicher Maßnahmen verstanden. ${ }^{1366}$ Der Stärkungsbegriff deutet also insbesondere auf die Entwicklung von Verfahren hin.

Schließlich ist, auch wenn es üblich ist, Mitteilungen im Amtsblatt zu veröffentlichen, dies für den EU-Rahmen nicht geschehen.

1364 Vgl. hierzu infra die Ausführungen zum Justizbarometer und zum Vertragsverletzungsverfahren.

1365 Europäische Kommission, Mitteilung der Kommission an das Europäische Parlament, den Europäischen Rat und den Rat, Die weitere Stärkung der Rechtsstaatlichkeit in der Union: Aktuelle Lage und mögliche nächste Schritte, $\operatorname{COM}(2019) 163$ final, vom 03.04.2019.

1366 Europäische Kommission, Mitteilung der Kommission an das Europäische Parlament, den Europäischen Rat, den Rat, den Europäischen Wirtschafts- und Sozialausschuss und den Ausschuss der Regionen: Die Stärkung der Rechtsstaatlichkeit in der Union: Ein Konzept für das weitere Vorgehen, $\operatorname{COM}(2019)$ 343 final vom 17.07.2019. 
b. Überblick über das Verfahren

Mit der Mitteilung führt die Kommission einen „grundsätzlich in drei Stufen" 1367 ablaufenden Mechanismus im Unionsrecht ein. Damit ergibt sich, unstrittig, ein Gleichlauf mit der Abstufung des Vertragsverletzungsverfahrens (bestehend aus Mahnschreiben, begründeter Stellungnahme und kontradiktorischem Verfahren vor dem Gerichtshof) sowie, nach richtiger Auffassung, mit der Struktur des Art. 7 EUV-Verfahrens.

Die Formulierung „grundsätzlich“ lässt darauf schließen, dass sich die Kommission situationsabhängig den Entfall einer Stufe, wie durch verkürzten Übergang zum Verfahren nach Art. 7 EUV, vorbehalten wollte. Ein derartiger „Entfall“ einer Verfahrensstufe ist parallel auch innerhalb des Verfahrens nach Art. 7 EUV diskutiert worden, insbesondere, wenn die Entwicklung in einem Mitgliedstaat zu der Einschätzung führt, dass nicht eine Gefahr i.S.d. Absatzes 1, sondern bereits eine Verletzung i.S.d. Absatzes 2 vorliegt. ${ }^{1368}$ Übertragen auf den Ablauf des EU-Rahmens ergäbe sich dann insbesondere die Verkürzung oder der Entfall der ersten Verfahrensstufe.

Die Kommission hat ausdrücklich betont, dass sie sich, neben einer späteren Nutzung des Art. 7 EUV-Verfahrens nach Durchlaufen des Verfahrens, auch eine Nutzung des Vertragsverletzungsverfahrens vorbehält. ${ }^{1369}$ Dieser Vorbehalt, der sich auch in anderen jüngeren rechtsunverbindli-

1367 Europäische Kommission, Mitteilung der Kommission an das Europäische Parlament und den Rat, Ein neuer EU-Rahmen zur Stärkung des Rechtsstaatsprinzips vom 11.03.2014, $\operatorname{COM(2014)~} 158$ final, S. 8. Der Hinweis auf die "grundsätzliche“ Dreistufigkeit findet sich auch in der englischen und französischen Fassung („as a rule“/,en principe“).

1368 S. dazu insbesondere Frank Schorkopf, Art. 7 EUV, in: Eberhard Grabitz, Meinhard Hilf \& Martin Nettesheim (Begr./Hrsg.): Das Recht der Europäischen Union, C.H. Beck, München, 68. EL 2019, Rn. 48: demnach ist Art. 7 Abs. 1 EUV zwar eine entschleunigende Wirkung zuzuschreiben, was dafür ficht, regelmäßig zunächst diese Verfahrensstufe zu bemühen, es seien aber durchaus Szenarien vorstellbar, in denen unmittelbar die Verfahrensstufe des Absatzes 2 heranzuziehen sei.

1369 Europäische Kommission, Mitteilung der Kommission an das Europäische Parlament und den Rat, Ein neuer EU-Rahmen zur Stärkung des Rechtsstaatsprinzips vom 11.03.2014, $\operatorname{COM(2014)~} 158$ final, S.3, Wertung bei Matthias Schmidt \& Piotr Bogdanowicz, "The Infringement Procedure in the Rule of Law Crisis“, S. 1073. 
chen Aufsichtsmaßnahmen des Unionsrechts findet, ${ }^{1370}$ wirft die Frage auf, ob die Kommission möglicherweise ersatzweise zu einer späteren Nutzung des Art. 7 EUV die Erkenntnisse aus dem EU-Rahmenverfahren auch in ein Vertragsverletzungsverfahren gegenüber dem Mitgliedstaat einfließen lassen könnte. Gegenüber Polen hat die Kommission dies dahingehend beantwortet, dass sie kumulativ das Verfahren nach Art. 7 EUV und das Vertragsverletzungsverfahren im Anschluss an den EU-Rahmen zu nutzen gedenkt. ${ }^{1371}$

Die erste Verfahrensstufe des EU-Rahmens bezeichnet die Kommission als sog. Sachstandsanalyse (assessment/évaluation). ${ }^{1372}$ Sie besteht selbst indes aus zwei weiteren Teilstufen, einer Informationseinholungs- und Verarbeitungsphase, in der, wie die Kommission formuliert „ein Schriftwechsel und Treffen mit den zuständigen Behörden vorausgehen" kann, und schließlich, für den Fall, dass die Kommission hieraus schöpfend das materielle Tatbestandskriterium der „systemischen Gefährdung der Rechtsstaatlichkeit" bejaht, einer sog. Stellungnahme zur Rechtsstaatlichkeit. ${ }^{1373}$ Die Stellungnahme ist eine in Art. 288 UAbs. 4 AEUV explizit vorgesehene rechtsunverbindliche Handlungsform des Unionsrechts.

Da sich in der Nutzungspraxis gerade gegenüber Polen gezeigt hat, dass das Ergehen der Stellungnahme eine deutliche Zäsur darstellt, wäre es rückblickend sinnvoller gewesen, die Sachstandsanalyse im engeren Sinne von der späteren Stellungnahme deutlicher zu trennen.

Die zweite Stufe des Verfahrens ist zugleich die zentrale Verfahrensstufe, sie firmiert als sog. Empfehlung zur Rechtsstaatlichkeit. ${ }^{1374}$ Die Empfehlung als Handlungsform ist, wie die Stellungnahme, ebenso in Art. 288 UAbs. 4 AEUV explizit genannt. Der rahmenspezifische Unterschied zur

1370 Nämlich im Hinblick auf die Handlungsformen der Europäischen Finanzaufsichtsagenturen, dazu Johanna Elisabeth Dickschen, Empfehlungen und Leitlinien als Handlungsform der Europäischen Finanzaufsichtsbehörden, S. 130.

1371 Europäische Kommission, „Rechtsstaatlichkeit: Europäische Kommission verteidigt Unabhängigkeit der Justiz in Polen“, Pressemitteilung vom 20.12.2017, $\mathrm{IP} / 17 / 5367$.

1372 Europäische Kommission, Mitteilung der Kommission an das Europäische Parlament und den Rat, Ein neuer EU-Rahmen zur Stärkung des Rechtsstaatsprinzips vom 11.03.2014, COM(2014) 158 final, S. 8.

1373 Europäische Kommission, Mitteilung der Kommission an das Europäische Parlament und den Rat, Ein neuer EU-Rahmen zur Stärkung des Rechtsstaatsprinzips vom 11.03.2014, COM(2014) 158 final, S. 8.

1374 Europäische Kommission, Mitteilung der Kommission an das Europäische Parlament und den Rat, Ein neuer EU-Rahmen zur Stärkung des Rechtsstaatsprinzips vom 11.03.2014, COM(2014) 158 final, S. 9. 
vorangehenden Stellungnahme lässt sich auf drei Punkte zusammenfassen: erstens ergeht die Stellungnahme gegenüber dem Mitgliedstaat, im Unterschied zur späteren Empfehlung vertraulich, die Empfehlung hingegen wird im Amtsblatt veröffentlicht ${ }^{1375}$ und ist allgemein zugänglich. Damit erhöhen sich bei Nichtbefolgung, trotz Rechtsunverbindlichkeit, die politischen Kosten für den Mitgliedstaat und folglich die Wirksamkeit des Mechanismus.

Der zweite Unterschied betrifft den Duktus und die Grundeinstellung der Kommission in der Interaktion mit dem Mitgliedstaat. Für die erste Verfahrensstufe und damit die Stellungnahme betont die Kommission die Dialogform, in welcher sie ihre „Bedenken“ zum Ausdruck bringt, sowie die Gelegenheit, über alle möglichen Kanäle die offenen Fragen zu klären. ${ }^{1376}$ Tritt das Verfahren aber in die zweite Stufe ein, verschärft die Kommission den Duktus und die Anforderungen an den Mitgliedstaat. Die Kommission erwartet jetzt Handlungen. Sie schreibt entsprechend:

„In ihrer Empfehlung legt die Kommission in klaren Worten die Gründe für ihre Bedenken dar und setzt dem Mitgliedstaat eine Frist, innerhalb deren er die beanstandeten Probleme zu beheben hat.“1377

Ein dritter Unterschied ist die mit der Empfehlung eintretende Einschränkung des Entschließungs- und Handlungsermessens des Mitgliedstaats, da diesem nun nicht nur Defizite aufgezeigt, sondern auch die Notwendigkeit des Handelns und konkrete Vorschläge hierzu deutlich gemacht werden.

1375 Die Kommission spricht in ihrer Mitteilung, S.9, zwar nur davon, sie werde "die Versendung“ und „den wesentlichen Inhalt" der Empfehlung bekanntgeben, die Empfehlungen gegenüber Polen sind allerdings sämtlich im Amtsblatt veröffentlicht worden.

1376 Europäische Kommission, Mitteilung der Kommission an das Europäische Parlament und den Rat, Ein neuer EU-Rahmen zur Stärkung des Rechtsstaatsprinzips, S. 8.

1377 Europäische Kommission, Mitteilung der Kommission an das Europäische Parlament und den Rat, Ein neuer EU-Rahmen zur Stärkung des Rechtsstaatsprinzips, S. 9. 


\section{c. Allgemeine Rezeption in der Literatur}

In der rechtswissenschaftlichen Literatur ist der EU-Rahmen recht intensiv besprochen worden. ${ }^{1378}$

Als erste Beobachtung teilen die Analysten eine echte Notwendigkeit für ein neues Verfahren und bestätigten damit auch die Denkanstöße, die zuvor überwiegend aus der Praxis an die Kommission herangetragen worden waren. Regelmäßig wird dabei darauf abgestellt, dass in den Verträgen eine Lücke zwischen dem Verfahren des Art. 7 EUV und dem Vertragsverletzungsverfahren bestehe, die durch die hohen Hürden für die Nutzung des ersten Verfahrens und die Kleinschrittigkeit für das zweite entstünde und die geschlossen werden müsse. ${ }^{1379}$

Zum zweiten betont man den Beitrag des EU-Rahmens für ein besseres Verständnis der Krise, nämlich u.a. für den Begriff der Rechtsstaatlichkeit, die Frage der Erfassung ihrer Herausforderungen und die Positionierung der Kommission betreffend ihre eigene Rolle, ohne darüber aber zwingend danach zu fragen, ob und wie der neue Mechanismus mit anderen

1378 Für die Einschätzung durch Kommissionsbeamte selbst insb. Emmanuel Crabit \& Nicolaas Bel, „The EU Rule of Law Framework“; Sodann Armin von Bogdandy \& Michael Ioannidis, „Das systemische Defizit“, Stefanie Schmahl, „Filling a Legal gap?: Das neue EU-Monitoring-Verfahren bei Rechtsstaatsdefiziten", in: Christian Calliess (Hrsg.), Herausforderungen an Staat und Verfassung: Völkerrecht, Europarecht, Menschenrechte ; Liber Amicorum für Torsten Stein zum 70. Geburtstag, Nomos, Baden-Baden, 2015, S. 834-855; Matthias Oesch, „Das Rechtsstaatlichkeitsverfahren der EU gegen Polen Bestandsaufnahme und Zwischenfazit“, in: Zeitschrift für Europarecht 18 (2016), S. 130-140, S. 134 ff. v.a. mit Darstellung des Verfahrens und ersten Entwicklungen zu Polen; Hannes Hofmeister, „Polen als erster Anwendungsfall des neuen ,EU Rahmens zur Stärkung des Rechtsstaatsprinzips““; Bernd Martenczuk, „Art. 7 EUV und der Rechtsstaatsrahmen als Instrumente der Wahrung der Grundwerte der Union“, insb. S. $47 \mathrm{ff}$., aus der NGO-Praxis s. weiter das Gutachten der sog. Meijers-Kommission, Note on the Commission Communication "A new EU Framework to strengthen the Rule of Law", CM1406, vom 15.06.2014.

1379 Vgl. Armin von Bogdandy \& Michael Ioannidis, „Das systemische Defizit“, S. 287, ebenso Dimitry Kochenov, Laurent Pech \& Sébastien Platon, „Ni panacée, ni gadget: le ,nouveau cadre de l'Union européenne pour renforcer l'État de droit“", in: Revue Trimestrielle de Droit Européen (2014), S. 689-714, S. $694 \mathrm{ff}$. ; Thomas Giegerich, „Verfassungshomogenität, Verfassungsautonomie und Verfassungsaufsicht in der EU“, S.517ff. ; Hannes Hofmeister, „Polen als erster Anwendungsfall des neuen ,EU Rahmens zur Stärkung des Rechtsstaatsprinzips“", bei Fn. 28 und ff.; Stefanie Schmahl, „Filling a Legal gap?“, S. $843 \mathrm{f}$. 
Verfahren koordiniert werden sollte, schließlich stand seine Novellierungsoder Lückenfüllereigenschaft im Vordergrund. ${ }^{1380}$

Drittens aber ist der EU-Rahmen der Beginn eines Schismas in der Rechtswissenschaft, was die Beurteilung der Maßnahmen der Kommission - und später anderer Unionsorgane - hinsichtlich des effektiven Umgangs mit der Rechtsstaatlichkeitskrise angeht. Diejenigen Forscher, die die Maßnahmen begrüßten, standen und stehen denjenigen gegenüber, die, obwohl von einer vergleichbaren Sorge um das Rechtsstaatsprinzip getragen, die Kritik in den Vordergrund stellen. ${ }^{1381}$

\section{d. Die Kompetenzfrage}

Die Frage, ob die Europäische Kommission den EU-Rahmen erlassen durfte, ist in der Literatur wiederholt gestellt worden. Ihre Beantwortung darf nicht unter Verweis auf die spätere Nutzung des Rahmens und damit seine Eigenschaft als fait accompli entfallen. Denn zum einen stünde die Verneinung der Kommissionskompetenz der zukünftigen Nutzung des Rahmenverfahrens entgegen, zum zweiten ist anzumerken, dass ausgerechnet ein Verfahren zur Stärkung des Rechtsstaatsprinzips sich nicht vorwerfen lassen darf, eine Grundregel der Ausübung von Hoheitsgewalt, nämlich die Befugnis hierzu, zu missachten.

$\mathrm{Ob}$ die Kommission überhaupt einer Kompetenz für den Erlass des EU-Rahmens bedarf, ist, neben dem zuvor bereits erwähnten Gutachten des Juristischen Dienstes des Rates, in der Literatur umstritten gewesen.

Auch in einigen Mitgliedstaaten ist die Kritik geteilt worden. Der tschechische Senat nannte den EU-Rahmen in einer nicht legislativen Entschließung „nützliches Informationsmaterial“, hielt die starke Rolle der Kommission aber für unverhältnismäßig und verwies die Kommission

1380 Exemplarisch etwa bei Hannes Hofmeister, „Polen als erster Anwendungsfall des neuen ,EU Rahmens zur Stärkung des Rechtsstaatsprinzips““, Fn. 47 ff, vor Fn. 58; weiter Stefanie Schmahl, „Filling a Legal gap?“, S. 843 f.; Thomas Giegerich, „Verfassungshomogenität, Verfassungsautonomie und Verfassungsaufsicht in der EU“, S. 529 f.

1381 Zum EU-Rahmenverfahren explizit begrüßend etwa Armin von Bogdandy \& Michael Ioannidis, „Das systemische Defizit“, S. 324; begrüßend hinsichtlich des Handlungsentschlusses der Kommission, aber kritisch in Bezug auf die Umsetzung Dimitry Kochenov, Laurent Pech \& Sébastien Platon, „Ni panacée, ni gadget, S. 709-710 insb. 
ersatzweise auf den Beitritt zur EMRK, ${ }^{1382}$ was wohl dahingehend gemeint war, man möge in Brüssel zunächst vor der eigenen Haustür kehren. Das „European Scrutiny Committee“ (Ausschuss für europäische Fragen) des britischen Unterhauses lehnte den EU-Rahmen, unter Zitat von Positionspapieren der britischen Regierung, u.a. wegen möglicher Doppelung von Verfahren, der Gefahr einer Ausdehnung des Mandats der FRA und einer zu weiten Definition der Rechtsstaatlichkeit ab. Es bestehe die Gefahr, dass sich die Kommission auch in rein mitgliedstaatsinterne Vorgänge, inklusive demokratischer Prozesse, einschalte. ${ }^{1383}$ Das Feld „legal base“ für die Archivierung der Kommentare notiert bezeichnenderweise nur „-“.

Bei genauerem Hinsehen lässt sich die Kompetenzfrage aber zufriedenstellend klären.

Jedenfalls ist es nicht zwingend erforderlich und auch der Lage nicht mehr angemessen gewesen, wie Roland Bieber und Francesco Maiani dies als Ersatz angeregt haben, allein die Ausübung der Befugnisse aus Art. 7 Abs. 1 EUV zu erläutern, ${ }^{1384}$ und damit im Wesentlichen die Programmmitteilung von 2003 zum Artikel-7-Verfahren zu novellieren, auch wenn dieser Vorschlag kumulativ im EU-Rahmen durchaus einen Mehrwert hätte.

Die Kompetenz der Kommission für den EU-Rahmen ist von der Reichweite des Art. 5 Abs. 1 S. 1 i.V.m. Abs. 2 EUV, dem sog. Prinzip der begrenzten Einzelermächtigung, abhängig. Von Bogdandy und Ioannidis hatten im März 2014 zunächst die Erforderlichkeit einer Kompetenznorm unter Hinweis auf - in der Tat bestehende - offene Fragen zu Art. 5 EUV bündig verneint.

„Solange die Institutionen [...] nicht unilateral bindende Akte gegen Mitgliedstaaten und Individuen erlassen, steht Art. 5 EUV einem uni-

1382 Senat der Tschechischen Republik, 520th Resolution of the Senate, Delivered on the 22nd session held on 18th June 2014 on the Communication from the Commission to the European Parliament and the Council - A new EU Framework to strengthen the Rule of Law (Senate Press no. K 125/09), amtl. Übersetzung.

1383 Britisches Unterhaus, European Scrutiny Committee, Documents considered by the Committee on 7 May 2014, 1 Rule of Law in EU Member States, (35878) 7632/14 + ADD $1 \operatorname{COM(14)~158,~Commission~Communication:~A~}$ new EU Framework to strengthen the Rule of Law, s. insb. Punkte $1.22 \mathrm{ff}$. (Conclusion).

1384 Roland Bieber \& Francesco Maiani, „Enhancing centralized enforcement of EU law: Pandora's toolbox?", in: Common Market Law Review 51 (2014), S. 1058-1092, S. 1086, Fn. 118. 
onsrechtlichen Begriff und Handeln nicht entgegen. In diesem Sinne sind das sog. EU-Justizbarometer, der vorgeschlagene Rechtsstaatlichkeitsdialog oder das neue Rechtsstaatlichkeitsaufsichtsverfahren der Kommission zulässig. “"1385

Giegerich, der die Frage umfassend problematisiert hat, lehnte diese Position ab. ${ }^{1386}$ Er sieht mehrere Probleme. Zu beginnen ist mit seiner Feststellung, dass die Kommission sicherstellen müsse, dass der EU-Rahmen „wirklich keine Rechtswirkungen“ erzeuge. Denn ansonsten riskiere die Kommission, dass der EuGH einer Nichtigkeitsklage eines Mitgliedstaats als sog. privilegiertem Kläger nach Art. 263 Abs. 1 AEUV gegen den EURahmen stattgebe, weil er in ständiger Rechtsprechung Klagen gegen nur vermeintlich rechtsunverbindliche Rechtsakte der Organe zulasse. ${ }^{1387}$

Hinter dieser zunächst prozessrechtlichen Frage des Individual- bzw. hier mitgliedstaatlichen Rechtsschutzes vor dem EuGH verbirgt sich der Einstieg in die Kompetenzfrage betreffend den EU-Rahmen.

Die Verträge beantworten, obwohl sie ausdrücklich die Existenz „nicht verbindlicher" Handlungsformen in Art. 288 UAbs. 4 AEUV kennen, die Frage, welche Kompetenzregeln für sie gelten, nicht. ${ }^{1388}$ Sie ist aber in einer vielbeachteten Trias von Grundsatzentscheidungen des Gerichtshofs geklärt worden, an welchen sich 2016 eine vierte Entscheidung angeschlossen hat, deren Schlussanträge vorrangige Berücksichtigung verdienen. Diese Rechtsprechung ist, obwohl zu Empfehlungen ergangen, auch auf Mitteilungen, wie den EU-Rahmen, anwendbar. ${ }^{1389}$ Zudem wäre es einem Mitgliedstaat nicht zu verbieten, statt der Kassation des Rahmens als solchem auch, für den Fall einer Adressierung, die Kassation z.B. der Stellungnahme oder der Empfehlung zur Rechtsstaatlichkeit anzustreben.

1385 Armin von Bogdandy \& Michael Ioannidis, „Das systemische Defizit“, S. 294.

1386 Thomas Giegerich, „Verfassungshomogenität, Verfassungsautonomie und Verfassungsaufsicht in der EU“, S. $532 \mathrm{ff}$., 534, er sieht überdies einen Widerspruch zu früheren Beiträgen von Bogdandys, bei Fn. 144 insb.

1387 Zur Reichweite der Kompetenzerfordernisse nach Art. 5 EUV umfassend Jürgen Bast, Art. 5 EUV, in: Eberhard Grabitz, Meinhard Hilf \& Martin Nettesheim (Begr./Hrsg.): Das Recht der Europäischen Union, C.H. Beck, München, 68. EL, Oktober 2019, Rn. 23 ff., speziell zu Anforderungen für Mitteilungen Rn. 27.

1388 Für eine Diskussion möglicher Reformansätze vgl. daher auch Heike Adam, Die Mitteilungen der Kommission, S. 149 ff.

1389 Berücksichtigung weiterführender Entscheidungen auch bei Heike Adam, Die Mitteilungen der Kommission, S. 143 ff. 
In der AETR-Entscheidung hatte der Gerichtshof die Nichtigkeitsklage, ungeachtet der Autoqualifizierung eines Rechtsakts ${ }^{1390}$,gegen alle Handlungen der Organe, die dazu bestimmt sind, Rechtswirkungen zu erzeugen, ohne Unterschied ihrer Rechtsnatur oder Form [für] zulässig“ erklärt. ${ }^{1391}$ Damit war prinzipiell die Überprüfung aller, eben auch rechtsunverbindlicher, Rechtsakte vor dem Gerichtshof möglich. Aber welche Anforderungen an ihren Erlass, nämlich insbesondere an ihre Kompetenz zu richten waren, blieb damit offen.

In seiner weiteren Rechtsprechung hat der EuGH diese Frage niemals abschließend geklärt. Für den Bereich des soft law hat der Gerichtshof vielmehr eine uno-actu-Prüfung des Rechtsakts entwickelt, in welchem Zulässigkeit, Erkenntnis über die Kompetenzwidrigkeit und Begründetheit des Rechtsakts in einen Gedankenschritt zusammenfallen. ${ }^{1392}$ Wie der EuGH eine solche „Requalifikation" speziell für Mitteilungen durchführt, lässt sich sehr gut der Rechtssache Frankreich ./. Kommission entnehmen. ${ }^{3393}$

Dabei hat der EuGH in seiner bisherigen Rechtsprechung in keinem Fall einem rechtsunverbindlichen Rechtsakt volle Justiziabilität zugestanden, sofern die Norm nicht zusätzliche Befugnisse für die Kommission schafft und Verbindlichkeiten gegenüber dem Mitgliedstaat begründet. ${ }^{1394}$ Es gibt also mit anderen Worten im Unionsrecht de lege lata kein Urteil des EuGH, das in der Sache die Frage der Kompetenzen für unionales soft law beantwortet. Es gibt lediglich eine umfangreiche Rechtsprechung zur Rechtswidrigkeit „requalifizierten“ Sekundärrechts, das als rechtsunverbindliches soft law vor den Gerichtshof gebracht wurde, aber als rechtsverbindliches, kompetenzlos ergangenes und daher insgesamt rechtswidriges Sekundärrecht endete. Auch vermeintliche Neuerungen bei mutmaßlich atypischen, verbindlichen Mitteilungsformen lösen sich anhand

1390 Jürgen Bast, Grundbegriffe der Handlungsformen der EU, S. 17 und 18.

1391 EuGH, Rs. 22/70, Kommission ./. Rat, “AETR”, Urteil v. 31.03.1971, Slg. 1971, 264, ECLI:EU:C:1971:32, Rn. 38/42.

1392 Vgl. Jürgen Bast, Grundbegriffe der Handlungsformen der EU, S. 80.

1393 EuGH, Rs. C-57/95, Frankreich ... Kommission, Urteil vom 20.03.1997, Slg. 1997 I-1640, ECLI:EU:C:1997:164, Besprechung auch bei Heike Adam, Die Mitteilungen der Kommission, S. 145.

1394 Heike Adam, Die Mitteilungen der Kommission, S. 144-145 unter Verweis bei Fn. 640 u.a. auf EuGH, Rs. C-366/88, Frankreich ./. Kommission, Urteil vom 09.10.1991, Slg. 1990, I-3595, ECLI:EU:C:1990:348, Rn. 21-25 der Urteilsbegründung; EuGH, Rs.C-303/90, Frankreich ./. Kommission, Urteil vom 13.11.1991, Slg. 1991, I-5340, ECLI:EU:C:1991:424, Rn. 7 ff. der Urteilsbegründung; EuGH, Rs. C-325/91, Frankreich ./. Kommission, Urteil vom 16.06.1993, Slg. 1993, I-3303, ECLI:EU:C:1993:245, Rn. 22-23 der Urteilsbegründung. 
dieser Grundsätze auf. ${ }^{1395}$ In seinem Grimaldi-Urteil hat der Gerichtshof die Debatte über „Rechtswirkungen“, die dieses soft law über „Berücksichtigungspflichten“ gleichwohl erzeugen könnte, zusätzlich angeheizt. ${ }^{1396}$

Der EuGH hat allerdings auch zur Kompetenzfrage für rechtsunverbindliche Handlungen 2018 Hilfestellung in der Rechtssache Belgien ./. Kommission angeboten, wobei insbesondere Generalanwalt Michal Bobek seine Schlussanträge zu umfassenden didaktischen und dogmatischen Ausführungen genutzt hat. ${ }^{1397}$ In dieser Rechtssache hatte der Gerichtshof über die Nichtigkeitsklage Belgiens gegen eine Empfehlung der Kommission

1395 Dies gilt insbesondere auch pars pro toto für die bei Heike Adam, Die Mitteilungen der Kommission, S. 110 ff. zur Erläuterung ihrer Kategorie der ,verbindlichen Mitteilung" genannte Entscheidung des EuGH in der Rs. C-311/94 Ijssel Vliet Combinatie BV ... Minister van Economische Zaken, Slg. 1996 I-5046, dort Rn. 49 der Urteilsbegründung. Es ist zutreffend, dass der EuGH hier einer Leitlinie der Kommission Rechtsbindungswirkung gegenüber dem Mitgliedstaat zugestand. Es handelt sich jedoch um den Sonderfall der bewussten Selbstbindung des Mitgliedstaats, welcher an der hier aufgestellten Beobachtung also nichts ändert. Ausführlich zu diesem Sonderfall auch Markus U. Brohm, Die „Mitteilungen“ der Kommission im Europäischen Verwaltungsund Wirtschaftsraum, S. 152-158, dort auch, S. 155, Fn. 690 ff. ausf. Nachweise der w. Rspr. Nichts anderes gilt für die Rs. EuGH, Rs.310/85, Deufil ./. Kommission; Slg. 1987, 321; ECLI:EU:C:1987:96. Rn.22. Wie Oana Ştefan, Soft Law in Court: Competition Law, State Aid and the Court of Justice of the European Union, Kluwer Law International, Alpen aan den Rijn, 2013, S. 183-184 hervorhebt, war eigentlicher Kern der Entscheidung die Frage des Vertrauensschutzes und der Umgang mit allgemeinen Rechtsgrundsätzen und damit eine Auseinandersetzung mit den Umständen des Falls. Einen weiteren Sonderfall bilden Stellungnahmen des EuGH in der Sache bei Selbstbindung von Mitgliedstaaten oder eines EU-Organs, vgl. dazu Markus U. Brohm, Die „Mitteilungen“ der Kommission im Europäischen Verwaltungs- und Wirtschaftsraum, S. 56 f., 95 f.; Ştefan, Soft Law in Court: Competition Law, State Aid and the Court of Justice of the European Union, S. 185 f.; Heike Adam, Die Mitteilungen der Kommission, S. 146-147 („Regelung einer Verwaltungspraxis“); weiter die Rs. EuGH, Rs. C-313/90, Comité international de la rayonne et des fibres synthétiques ./. Kommission, Urteil vom 24.03.1993, Slg. 1993 I-1177, ECLI:EU:C:1993:111, Rn. 36 der Urteilsbegründung und EuGH, Verb. Rs. C-189/02 u.a., Dansk Rørindustri u.a. ./. Kommission, Slg. 2002 I-5488, ECLI:EU:C:2005:408, Rn. 211.

1396 EuGH, Rs. C-322/88, Salvatore Grimaldi ./. Fonds des maladies professionnelles, Urteil vom 13.12.1989, Slg. 1989, 4416, ECLI:EU:C:1989:646, Rn. 14, vgl. auch Linda Senden, Soft Law in European Community Law, S. $387 \mathrm{ff}$.

1397 EuGH, Rs. C-16/16 P, Belgien ./. Kommission, „Online-Glücksspiel“, Urteil (GK) vom 20.02.2018, ECLI:EU:C:2018:79; Schlussanträge des Generalanwalts Bobek vom 12.12.2017, ECLI:EU:C:2017:959. 
betreffend das Online-Glücksspiel zu entscheiden. Das Gericht (erster Instanz) hatte sie mangels Rechtsverbindlichkeit und damit Kassationskompetenz i.R.v. Art. 263 Abs. 1 AEUV abgewiesen. Hiergegen legte Belgien Rechtsmittel ein, griff dabei indes nicht die Einstufung des Gerichts selbst, sondern den Umstand an, dass das Unionsrecht keine Kassation von soft law zuließ. Es müsse möglich sein, so Belgien, auch Verfahrensfehler und Verstöße gegen andere Grundsätze ungeachtet der Frage der Rechtsverbindlichkeit anzugreifen. ${ }^{1398}$ Der Generalanwalt schloss sich den Ausführungen an ${ }^{1399}$ und begründete dies insbesondere mit der umfassend gestiegenen Bedeutung des soft law und den in der Rechtsprechung verbleibenden Unklarheiten. ${ }^{1400}$ Bobek wies dabei zurecht daraufhin, dass auf nationaler Ebene die Bedeutung des soft law inzwischen Gerichte und Verwaltungen umfassend beschäftigt habe - so hatte der französische Conseil d'État 2013 zu diesem Thema eine umfassende Studie mit Vorschlägen zur besseren gerichtlichen Handhabung vorgelegt - und man auf europäischer Ebene gleichziehen sollte. ${ }^{1401}$ Der Gerichtshof ist dem nicht gefolgt, sondern hat die Klage abgewiesen.

Wenn dies auch, entgegen einiger Kommentierung in der Literatur, ${ }^{1402}$ angesichts der Gebotenheit weiterer Klärung zu bedauern ist, erleichtert die Entscheidung doch insofern hier die Arbeit, als dass es weiterhin, und auf absehbare Zeit, bei den Grundsätzen der vorherigen Rechtsprechung insbesondere aus dem Urteil Grimaldi bleibt. Das Grimaldi-Urteil etabliert nämlich nicht nur den Grundsatz von Berücksichtigungspflichten von

1398 EuGH, Rs. C-16/16 P, Belgien ./. Kommission, Rn. 28 des Urteils, vgl. auch vorgehend ab Rn. 9 ff. und $18 \mathrm{ff}$. zum Verfahrensgang und den aufgeworfenen Fragen.

1399 EuGH, Rs. C-16/16 P, Belgien ./. Kommission, Schlussanträge des Generalanwalts Bobek vom 12.12.2017, ECLI:EU:C:2017:959, Rn. 85.

1400 EuGH, Rs. C-16/16 P, Belgien ./. Kommission, Schlussanträge des Generalanwalts Bobek vom 12.12.2017, ECLI:EU:C:2017:959, Rn. 54 ff., $72 \mathrm{ff}, 81 \mathrm{ff}$.

1401 EuGH, Rs. C-16/16 P, Belgien ./. Kommission, Schlussanträge des Generalanwalts Bobek vom 12.12.2017, ECLI:EU:C:2017:959, Rn. 85; vorgehend Conseil d'État, Le droit souple, Étude annuelle 2013, Serie „Les rapports du Conseil d'État (ancienne collection Étude et documents du Conseil d'État)“, sodann id. Urteil vom 21. März 2016, Numericable, no. 390023 (Rec.), und vom 21. März 2016, Société Fairvesta International GmbH, no 368082 (Rec.). Zu diesem Punkt weiter auch Jörg Gundel, „Rechtsschutz gegen Empfehlungen der EU-Kommission? - Anmerkung zum Urteil des EuGH (GK) v. 20.2.2018, Rs. C-16/16 P (Belgien/Kommission)“, in: Europarecht 53 (2018), S. 593-605, S. 605 .

1402 Jörg Gundel, „Rechtsschutz gegen Empfehlungen der EU-Kommission?“, S. 605 . 
unionalem soft law. Es erlaubt auch, wie Bobek herausarbeitet, ${ }^{1403}$ die Beantwortung der Frage nach Kompetenzen für den Erlass von soft law mit einer weiteren Formel des Gerichtshofs, die auf zwei Alternativen zurückgreift. Demnach kann derartiges Recht

„im allgemeinen dann von den Organen der Gemeinschaft ausgesprochen werden, wenn diese nach dem EWG-Vertrag nicht ermächtigt sind, rechtsverbindliche Maßnahmen zu erlassen, oder wenn nach ihrer Ansicht kein Anlaß zu einer zwingenderen Regelung besteht". 1404

Von Bogdandys und Ioannidis 2014 gemachte Kompetenzaussage stützt sich implizit auf die erste Alternative dieser Formel des Gerichtshofs: immer dann, wenn die Unionsorgane nicht zum Erlass von verbindlichem Recht ermächtigt sind, dürfen sie jedenfalls soft law erlassen. Bobek hat ebendiese Variante kritisiert, weil damit insbesondere Empfehlungen eine Ersatzgesetzgebungsqualität erwachsen könnte. ${ }^{1405}$ Sie ist aber hier nicht einschlägig. Vielmehr ist die Kompetenz des Erlasses des EU-Rahmens durch Rückgriff auf die zweite Variante der durch Bobek nochmals betonten Grimaldi-Formel sachnäher ${ }^{1406}$ und daher vorzugswürdig, also, dass das handelnde Unionsorgan noch keine Notwendigkeit für eine „zwingendere“, d.h. verbindliche, Regelung sieht. Das ist doch gerade dann der Fall, wenn die Kommission, bei Nutzung des EU-Rahmens, noch keine Notwendigkeit für eine Nutzung von Art. 7 EUV sieht. Die Kommission stellt klar, dass sie sich ihrer Kompetenz „im Vorfeld“ des Art. 7 EUV

1403 EuGH, Rs. C-16/16 P, Belgien ./. Kommission, Schlussanträge des Generalanwalts Bobek vom 12. Dezember 2017, ECLI:EU:C:2017:959, Rn. 92.

1404 EuGH, Rs. C-322/88, Salvatore Grimaldi ./. Fonds des maladies professionnelles, Urteil vom 13.12.1989, ECLI:EU:C:1989:646, Slg. 1989, 4416, Rn. 13.

1405 EuGH, Rs. C-16/16 P, Belgien ./. Kommission, Schlussanträge des Generalanwalts Bobek vom 12. Dezember 2017, ECLI:EU:C:2017:959, Rn. 94-95. Beachtlich dort insb. die Feststellung, wonach dann „das „soft law" von heute zum „hard law" von morgen“ würde.

1406 Zur Sachnähe als Kriterium bei der Entscheidung von Kompetenzkonkurrenzen vgl. EuGH, Gutachten 2/00 vom 6. Dezember 2001, „Protokoll von Cartagegna“, Slg. 2001, I-9717, ECLI:EU:C:2001:664, Rn. 22, unter Verweis auf „Ziel und der Inhalt des Rechtsakts“; EuGH, Rs. C-281/01, Energy Star, Slg. 2002, I-12075 Rn. 39 zur Erheblichkeit des verfolgten Ziels und der Gebotenheit einer einheitlichen Rechtsgrundlage. Kommentierung beider Entscheidungen bei Christoph Vedder \& Stefan Lorenzmeier, Art. 133 EGV, in: Eberhard Grabitz, Meinhard Hilf \& Martin Nettesheim (Begr./Hrsg.): Das Recht der Europäischen Union, C.H. Beck, München, 40. EL 2009, Rn. 56. 
und zur Ausfüllung verbleibender Lücken bedient. ${ }^{1407}$ Kernstück des EURahmens ist die Empfehlung zur Rechtsstaatlichkeit, die unselbständige, vorherige Auskunftsersuchen und eine erste Stellungnahme zur Lage in sich aufnimmt.

Diese Beobachtungen vorausgeschickt, kommen nun Giegerichs weitere Überlegungen zum Tragen. Er hatte, wie im Übrigen der Juristische Dienst des Rates, ${ }^{1408}$ eine Herleitung der Kompetenz aus der Pflicht der loyalen Zusammenarbeit (Art. 4 Abs. 3 EUV) oder dem allgemeinen Auskunftsanspruch der Kommission nach Art. 337 AEUV erwogen. ${ }^{1409}$ Konsequent ist er davon ausgegangen, dass die Maßnahme als Minus zur Kompetenz der Kommission aus Art. 7 Abs. 1 EUV sowie ihrer allgemeinen Empfehlungskompetenz des Art. 292 S. 4 AEUV herzuleiten ist. ${ }^{1410}$ Darüber müssen separate Kompetenzgrundlagen etwa für Auskunftsrechte der Kommission nicht zusätzlich bemüht werden, diese sind vielmehr in Art. 7 Abs. 1 EUV bereits angelegt.

Unter Verweis auf diese Überlegungen in Rechtsprechung und Literatur entfällt folglich auch die etwa durch den Juristischen Dienst des Rates aufgeworfene Überlegung, wonach insbesondere Art. 7 EUV Sperrwirkung gegenüber weniger intensiven Maßnahmen entfalte. ${ }^{1411}$

Den vorgenannten Überlegungen haben sich von Bogdandy u.a., mich inbegriffen, später als überzeugendster Lösung angeschlossen. Die Kompetenz für den Erlass des EU-Rahmens ist also mittels a maiore ad minusSchluss aus Art. 7 Abs. 1 EUV i.V.m. Art. 292 S. 4 AEUV nach den Verträgen zulässig. ${ }^{1412}$ Weitere Stütze erfährt diese Ansicht abschließend auch

1407 Europäische Kommission, Mitteilung der Kommission an das Europäische Parlament und den Rat, Ein neuer EU-Rahmen zur Stärkung des Rechtsstaatsprinzips vom 11.03.2014, $\operatorname{COM}(2014) 158$ final, S. 3.

1408 Dieser hatte u.a. einen Rückgriff auf Art.70, 241, 337, 352 AEUV geprüft, vgl. Juristischer Dienst des Rates, „Mitteilung der Kommission „Ein neuer EU-Rahmen zur Stärkung des Rechtsstaatsprinzips": Vereinbarkeit mit den Verträgen“, vom 27.05.2014, 10296/14, Rn. 20-23.

1409 Vgl. Thomas Giegerich, „Verfassungshomogenität, Verfassungsautonomie und Verfassungsaufsicht in der EU“, S. 535-536.

1410 Thomas Giegerich, „Verfassungshomogenität, Verfassungsautonomie und Verfassungsaufsicht in der EU“, S. $534 \mathrm{ff}$.

1411 Juristischer Dienst des Rates, „Mitteilung der Kommission „Ein neuer EURahmen zur Stärkung des Rechtsstaatsprinzips": Vereinbarkeit mit den Verträgen“, vom 27.05.2014, 10296/14, Rn. 16-19, 18 insb.

1412 S. Armin von Bogdandy, Piotr Bogdanowicz, Iris Canor, Maciej Taborowski \& Matthias Schmidt, „Guest Editorial: A potential constitutional moment for the European rule of law - The importance of red lines“, S. 987. 
in der älteren Literatur. So hat bereits Schorkopf, lange vor Erlass des EURahmens, darüber nachgedacht, Art. 7 Abs. 1 EUV weitere, eigenständige Vorfeldmaßnahmen vorzulagern. Diese könnten sich aus „Sinn und Zweck" der Norm ergeben, gründeten im effet utile-Grundsatz des Unionsrechts und fänden ihre Grenze im Prinzip der Verhältnismäßigkeit. ${ }^{1413}$ Er dachte auch bereits darüber nach, welche Form derartige eigenständige Maßnahmen im Vorfeld haben könnten:

„In Betracht kommen deshalb Warnungen, öffentliche Diskussionen, Stellungnahmen oder Empfehlungen. Denkbar wäre auch, dass die Kommission in einem Mitgliedstaat im Rahmen der Öffentlichkeitsarbeit eine aus dem Gemeinschaftshaushalt finanzierte, auf die besonderen mitgliedstaatlichen Verhältnisse zugeschnittene Aktion wie beispielsweise Plakatkampagnen, Zeitungsanzeigen oder öffentliche Diskussionen durchführt." ${ }^{\text {1414 }}$

Die heutige Rechtspraxis hat dies weitgehend bestätigt.

\section{e. Regelfallverbindlichkeit des EU-Rahmens}

Keine Notwendigkeit, auf die Frage der Kompetenzen zurückzukommen, besteht aufgrund einer vermeintlichen Verbindlichkeit des EU-Rahmens, welche dann nach den obigen Grundsätzen der Grimaldi-Rechtsprechung doch eine Umqualifizierung zur Folge hätte. $\mathrm{Zu}$ dieser Annahme könnte man gelangen, da die Kommission betont, dass der Ablauf und das Verhalten des adressierten Mitgliedstaats den EU-Rahmen in besonderem Maße prägt. Bedeutung erlangt dabei insbesondere die dritte Verfahrensstufe, das sog. "follow-up“. Dass dabei an den Mitgliedstaat eine konkrete Erwartungshaltung gerichtet ist, macht die Kommission unmissverständlich deutlich:

1413 Frank Schorkopf, Die Maßnahmen der XIV EU-Mitgliedstaaten gegen Österreich, S. $65 \mathrm{ff}, 66$.

1414 Frank Schorkopf, Die Maßnahmen der XIV EU-Mitgliedstaaten gegen Österreich, S. 67. 
„Kommt der Mitgliedstaat der Empfehlung innerhalb der gesetzten Frist nicht zufriedenstellend nach, prüft die Kommission die Möglichkeit, eines der Verfahren nach Artikel 7 EUV einzuleiten." 1415

Der scheinbare Widerspruch zwischen rechtsunverbindlicher Mitteilung und Erwartungshaltung bei Androhung mit rechtsverbindlichen Konsequenzen wird allerdings durch die Figur der Regelfallverbindlichkeit systemkonform aufgelöst.

Für diese Einschätzung folge ich der bei Bast für die deutsche Europarechtswissenschaft insbesondere etablierten Terminologie, wonach das Unionssekundärrecht zunächst rechtsverbindliches, wie rechtsunverbindliches, gleichwohl aber rechtswirksames, da nämlich z.B. Steuerungseffekte oder politische Kosten für den Adressaten bei Ignorierung schaffendes Recht, unterscheidet. ${ }^{1416}$ Daneben aber besteht bei Bast eine dritte, als Zwischenstufe ausgeprägte Verbindlichkeitsform, die dort sog. Regelfallverbindlichkeit, ${ }^{1417}$ und zu der er, höchst treffend, gerade bestimmte Mitteilungen der Kommission zählt. Bast definiert:

„Solche Handlungen legen das erlassende Organ und seine nachgeordneten Dienststellen zwar nicht strikt auf ein bestimmtes Vorgehen fest, eine Abweichung setzt jedoch das Vorliegen besonderer Umstände voraus und erfordert die Angabe von Gründen“. ${ }^{1418}$

Es liegt also ein an anderer Stelle sog. „comply or explain“-Mechanismus vor, der insbesondere über den „Druck der öffentlichen Meinung“ funktioniert. ${ }^{1419}$

1415 Europäische Kommission, Mitteilung der Kommission an das Europäische Parlament und den Rat, Ein neuer EU-Rahmen zur Stärkung des Rechtsstaatsprinzips vom 11.03.2014, $\operatorname{COM(2014)~} 158$ final, S. 9.

1416 Jürgen Bast, Grundbegriffe der Handlungsformen der EU, S. 181 ff. Der Klärung der Unterscheidung von rechtsverbindlichen und rechtsunverbindlichen Handlungsformen in der Union haben sich zahlreiche andere Arbeiten verschrieben, s. dazu in ganzer Breite insb. Linda Senden, Soft Law in European Community Law; zudem nochmals die Ausführungen bei Generalanwalt Michal Bobek zur Rs. C-16/16 P, Belgien ./. Kommission, Schlussanträge vom 12.12.2017, ECLI:EU:C:2017:959.

1417 Jürgen Bast, Grundbegriffe der Handlungsformen der EU, S. 183-184.

1418 Jürgen Bast, Grundbegriffe der Handlungsformen der EU, S. 183-184, unter Rückgriff auf Armin von Bogdandy, Gubernative Rechtsetzung, S. $466 \mathrm{ff}$.

1419 Ausführlich zu dieser Figur anhand der Empfehlungen und Leitlinien der ESMA als in in seiner Funktion besonderen unionalen soft laws Alexander Frank, Die Rechtswirkungen der Leitlinien und Empfehlungen der Europäischen Wertpapier- und Marktaufsichtsbehörde, Nomos, Baden-Baden, 2012, 
Die Regelfallverbindlichkeit führt zwar nicht zu einer rechtlichen Rechtsverbindlichkeit - weswegen ich es für zulässig halte, verkürzend an anderer Stelle gleichwohl weiter von einem rechtsunverbindlichen Verfahren zu sprechen - wohl aber zu enormen faktischen und politischen Kosten der Nichteinhaltung.

Für den EU-Rahmen ergibt sich eine sehr große Übereinstimmung mit dieser Funktionslogik.

Hinzuweisen ist insbesondere auf die Ausführungen der Kommission, wonach sie eine loyale Zusammenarbeit mit dem adressierten Mitgliedstaat gem. Art. 4 Abs. 3 EUV erwartet und ankündigt: „Der Umstand, dass ein Mitgliedstaat nicht kooperiert oder das Verfahren sogar behindert, wird bei der Beurteilung der Schwere der Gefährdung berücksichtigt. "1420 Auch der Hinweis, dass der Mitgliedstaat die Kommission über ergriffene Schritte zu informieren hat, ${ }^{1421}$ entspricht der „comply-or-explain“-Logik.

Keine Abweichung hiervon ergibt sich dadurch, dass die Kommission bei mangelnder Kooperation der Mitgliedstaaten die Einleitung des Verfahrens nach Art. 7 EUV androht, denn dessen Verbindlichkeit trägt zwar durchaus zum politischen und öffentlichen Druck des EU-Rahmens bei, resultiert aber allein aus diesem Verfahren selbst und unterliegt den dortigen Anforderungen. Ein Blick auf den dort ebenso angesprochenen „comply-or-explain“-Mechanismus der Europäischen Finanzaufsichtsbehörden bekräftigt diese Auffassung. Johanna Dickschen hat gezeigt, dass die dortigen Stellungnahmen und Leitlinien ebenso durch einen separaten Sanktionsmechanismus begleitet werden. ${ }^{1422}$

S. 124. Für die Einordnung als regelfallverbindliche Handlungsformen vgl. Johanna Elisabeth Dickschen, Empfehlungen und Leitlinien als Handlungsform der Europäischen Finanzaufsichtsbehörden, S. 152 ff., ebenso dort zur comply or explain-Logik S. 124 ff., S. 158.

1420 Europäische Kommission, Mitteilung der Kommission an das Europäische Parlament und den Rat, Ein neuer EU-Rahmen zur Stärkung des Rechtsstaatsprinzips vom 11.03.2014, $\operatorname{COM(2014)~} 158$ final, S. 8. Zur Herleitung von Befolgungserwartungen für regelfallverbindliche Handlungsnormen ebenso Jürgen Bast, Grundbegriffe der Handlungsformen der EU, S. 184.

1421 Europäische Kommission, Mitteilung der Kommission an das Europäische Parlament und den Rat, Ein neuer EU-Rahmen zur Stärkung des Rechtsstaatsprinzips vom 11.03.2014, COM(2014) 158 final, S. 9.

1422 Johanna Elisabeth Dickschen, Empfehlungen und Leitlinien als Handlungsform der Europäischen Finanzaufsichtsbehörden, S. 124 ff., $130 \mathrm{ff}$. 
f. Der EU-Rahmen als Beispiel des Typus der „primärrechtsergänzenden“ Mitteilung

Eine weitere durch den EU-Rahmen aufgeworfene Frage ist nicht nur diejenige seiner Rechtsverbindlichkeit, sondern auch seine funktionale Einordnung im Rahmen des Korpus des unionalen soft law. Der EU-Rahmen ist in mehrfacher Hinsicht ungewöhnlich, denn er kündigt in einem soft law-Akt die strukturierte Nutzung weiterer soft law-Handlungsformen an und fasst diese zusätzlich in einem, immerhin anderen Verfahren des Primärrechts ähnelnden, aber substantiell neuen, Verfahren zusammen.

Für Mitteilungen im Allgemeinen haben z.B. Linda Senden, Markus Brohm und Heike Adam Taxonomien angeboten. Ein Vergleich mit den Beispielen aus dem Korpus der Mitteilungen zeigt, dass der EU-Rahmen keinem der bislang identifizierten Typen entspricht. Adam ${ }^{1423}$ unterschied in ihrer Typologie Mitteilungen im direkten und indirekten Verwaltungsvollzug und zur Verwirklichung der Grundfreiheiten. Augenscheinlich ist der EU-Rahmen keinem dieser Typen zuzurechnen. Gleiches gilt für die von Brohm gemachte dreifache Unterscheidung von Mitteilungen im Kontext europäischer Rechtsetzung und vollzugsbezogenen Mitteilungen, die entweder unionseigenen Vollzug oder denjenigen durch die Mitgliedstaaten vorbereiten sollen. ${ }^{1424}$ Der EU-Rahmen vollzieht nicht, insbesondere nicht den nachfolgenden Art. 7 EUV, er regelt keine Verwirklichung von Grundfreiheiten oder eben allenfalls sehr mittelbar, da die Rechtsstaatlichkeit eine Voraussetzung hierfür ist, und er bereitet einen solchen auch nicht vor. Auch Sendens Vorschlag, ${ }^{1425}$ Mitteilungen als ,informative Instrumente" zu bezeichnen, greift hier zu kurz, darüber geht der EU-Rahmen hinaus. Selbst ihre Beobachtung zu Empfehlungen an anderer Stelle, wonach diese durchaus in der Absicht herausgegeben werden könnten, ,to lay down new rules, which are not necessarily linked to existing legislation or Treaty provisions and cannot be said to be inherent to the existing legal framework", ${ }^{1426}$ scheint mir hier aufgrund der Art der Ausgestaltung übertroffen.

Gewisse Schnittmengen zeigt die Mitteilung über den EU-Rahmen mit der Serie an Mitteilungen, die die Kommission seit Mitte der 1990er

1423 Heike Adam, Die Mitteilungen der Kommission, S. $13 \mathrm{ff}$.

1424 Markus U. Brohm, Die „Mitteilungen“ der Kommission im Europäischen Verwaltungs- und Wirtschaftsraum, S. $27 \mathrm{ff}$.

1425 Linda Senden, Soft Law in European Community Law, S. 132 ff.

1426 Linda Senden, Soft Law in European Community Law, S. 221. 
Jahre zur Ausgestaltung des heutigen Art. 260 AEUV, des dem Vertragsverletzungsverfahren nachgelagerten Sanktionsverfahrens, vorgelegt hat. Die Kommission hatte hierzu 1996 eine erste Mitteilung erlassen, ${ }^{1427}$ diese 2005 umfassend novelliert ${ }^{1428}$ und schließlich 2019, nach diversen Aktualisierungen der Berechnungsdetails, infolge des sog. „ENAE“-Urteils ${ }^{1429}$ nochmals wesentlich überholt. ${ }^{1430}$ Wie diese Mitteilungsserie zu Art. 260 AEUV kommt dem Rahmenverfahren eine Selbstbindungswirkung und eine Klärungswirkung der Kommission zu. Die Kommission hat in diesen Mitteilungen bekanntlich ein gesondertes, im Wortlaut des Art. 260 AEUV nicht angelegtes, präzises Berechnungsverfahren für die Sanktionen nach dieser Norm eingeführt, die hiermit gegenüber gerade auch den Mitgliedstaaten Klarheit schaffen und sich selbst binden wollen. Dem EU-Rahmen kommt in ähnlicher Weise die Schaffung zusätzlicher prozessualer Vorgaben und, vor dem Hintergrund des Grundsatzes der Rechtssicherheit, ebenso eine Klärungsfunktion gegenüber den Mitgliedstaaten zu. Emmanuel Crabit und Nicolaas Bel haben dies auch explizit deutlich gemacht, wenn sie schreiben: „By establishing the EU Framework to strengthen the Rule of Law (the Framework) the Commission seeks to provide clarity and enhance predictability as to the actions it may take in the future in

1427 Europäische Kommission, „Mitteilung [in anderen Sprachfassungen auch: „Memorandum“] über die Anwendung von Artikel 171 EG-Vertrag, ABl. (EG), C 242/6 vom 21.8.1996.

1428 Europäische Kommission, Mitteilung der Kommission, „Anwendung von Artikel 228 EG-Vertrag“, SEK(2005) 1658.

1429 EuGH, Rs. C-93/17, Kommission ./. Griechenland, Ellinika Nafpigeia AE ENAE, Urteil vom 14.11.2018, ECLI:EU:C:2018:903. Der Gerichtshof hatte mit diesem Urteil substantielle Teile der früheren Berechnungsmethode für mit dem Unionsrecht unvereinbar erklärt.

1430 Europäische Kommission, Mitteilung der Kommission, „Änderung der Berechnungsmethode für Pauschalbeträge und Tagessätze für das Zwangsgeld, die von der Kommission im Rahmen von Vertragsverletzungsverfahren vor dem Gerichtshof der Europäischen Union vorgeschlagen werden“, ABl. (EU) C 70/1 vom 25.02.2019; jüngste Aktualisierung als „Mitteilung der Kommission - Aktualisierung der Daten für die Berechnung der Pauschalbeträge und Zwangsgelder, die die Kommission dem Gerichtshof der Europäischen Union bei Vertragsverletzungsverfahren vorschlägt“, ABl. (EU) C 309/1 vom 13.09.2019; zur Problematik aus der jüngeren Literatur Alexander Kornezov, „Imposing the Right Amount of Sanctions Under Article 260(2) TFEU: Fairness v. Predictability, or How to "Bridge the Gaps"“, in: Columbia Journal of European Law 20 (2014), S. 283-307; das „ENAE“-Urteil scheint bislang in der Literatur unberücksichtigt. Ich habe hierzu Stellung bezogen in „Le manquement perpétué en droit de l'Union européenne“, S. 38 ff. 
this area." ${ }^{1431}$ Allerdings geht der EU-Rahmen bei genauerem Hinsehen deutlich über die Funktion der Mitteilungsserie zu Art. 260 AEUV hinaus, er ergänzt nicht nur den Wortlaut des Art. 7 EUV durch zusätzliche Ausführungen als norminterpretierende Mitteilung, ${ }^{1432}$ sondern er führt unbestreitbar ein gänzlich neues, niedrigschwelliges Verfahren im Unionsrecht ein und ist damit nicht lediglich primärrechtserläuternd.

Ich schlage vor dem Hintergrund dieser Beobachtungen vor, den EURahmen dem neuen Typus der primärrechtsergänzenden Mitteilung zuzuordnen, denn er dient aus Sicht ihres Urhebers ausdrücklich der Lückenschließung zwischen mehreren Verfahren des EUV und AEUV, ${ }^{1433}$ ohne aber selbst Teil des Vertrags zu werden. Der Begriff der primärrechtsergänzenden Mitteilung mag auf den ersten Blick irritieren, er weckt möglicherweise den Verdacht, hier werde einer Vertragsänderungskompetenz seitens der Kommission das Wort geredet, was ich keinesfalls behaupte. Deswegen gilt es hier sogleich Einschränkungen zu machen. Der Umstand der Primärrechtsergänzung durch eine Mitteilung ist strikt bedingt und abhängig vom höchst speziellen Kontext des Art. 7 EUV, es erscheint zweifelhaft, ob er sich überhaupt an anderer Stelle der Verträge reproduzieren lässt. Festzustellen ist, dass Art. 7 EUV erstens, ein auf Verfassungskernnormen der Union abzielendes Aufsichtsverfahrens höchst politischer Natur einführt. Zweitens hängt es an sehr hohen formellen wie materiellen Tatbestandskriterien und dies trotz vorheriger Anpassung. Drittens hatte es aufgrund konkreter Anlässe, viertens, einen weit überwiegenden, nämlich durch viele, wenn nicht alle Unionsorgane und Mitgliedstaaten geteilten Konsens zur Folge, nämlich, dass das Verfahren der unmittelbaren Ergänzung bedürfe. Für diese Ergänzung, fünftens, erschien eine Änderung der Verträge selbst nicht praktikabel. Der gewählte Ausweg ist dann der hiesige im Wege des a-maiore-ad-minus-Schlusses zur Füllung einer Regelungslücke.

Diese Erwägungen spiegeln sich in der Praxis wider.

Reding sprach in diesem Zusammenhang zudem von "the need for a better developed set of instruments that would fill the space that exists at present between the Commission's infringement role as guardian of the Treaties, and the Article 7 procedure“. ${ }^{1434}$ Ebenso legte sie offen, wie die

1431 Emmanuel Crabit \& Nicolaas Bel, „The EU Rule of Law Framework“, S. 197.

1432 Zum Typus der „norminterpretierenden Verwaltungsvorschriften oder Auslegungsrichtlinien", Armin von Bogdandy, Gubernative Rechtsetzung, S. 472.

1433 Vgl. Europäische Kommission, Mitteilung der Kommission an das Europäische Parlament und den Rat, Ein neuer EU-Rahmen zur Stärkung des Rechtsstaatsprinzips vom 11.03.2014, $\operatorname{COM}(2014) 158$ final, S. 3.

1434 Viviane Reding, „The EU and the Rule of Law - What next?", S. 7. 
Mehrstufigkeit sowohl des Art. 7 EUV-Verfahrens als auch des Vertragsverletzungsverfahrens ${ }^{1435}$ als Blaupause für die künftige Entwicklung des EU-Rahmens dienen sollte:

„The wording of Article 7(1) TEU suggests that such a process is possible, as it gives the Commission the right to issue a ,reasoned proposal' at the start of an Article 7 procedure. ,Reasoned proposal ${ }^{6}$ this can remind us of the "reasoned opinion" that the Commission issues in Treaty infringement proceedings under Article 258 TFEU. In infringement proceedings, we chose many years ago the practice of preceding a reasoned opinion with a letter of formal notice, a kind of formalised first warning by which we present our concerns to a Member State and then give this Member State an opportunity to submit its observations. I believe we could take a similar approach for Article 7 procedures, by giving ,formal notice' to a Member State where we have reason to believe that a systemic rule of law crisis is on the way to developing. We could lay down this new manner of proceeding in a new policy Communication of the Commission, which could be politically endorsed by the European Council and the European Parliament.“1436

Der Begriff und die Beobachtung von primärrechtsergänzendem soft law ist, auch nach Erledigung der Kompetenzfrage, wie oben ausgeführt, indes niemals unproblematisch und bleibt einem konstanten Rechtfertigungserfordernis unterworfen. Wird er überdehnt, erwüchse den Unionsorganen eine Rechtschaffungskompetenz über die Grenzen von Art. 5 EUV hinaus.

Es ist nicht Aufgabe dieser Arbeit, allgemeine Maßstäbe dafür zu entwickeln, wann die Kommission derart primärrechtsergänzende Mitteilungen erlassen kann. Sie finden ihre Grenzen jedenfalls, nach jetziger Rechtsprechung, in der Grimaldi-Rechtsprechungslinie des Europäischen Gerichtshofs und den speziellen Bedingungen des Art. 7 EUV.

1435 Auf einzelne Punkte, bei denen diese Anleihen besonders gut deutlich sind, gehe ich unten bei der Erläuterung der Verfahrensschritte nochmals ein.

1436 Viviane Reding, „The EU and the Rule of Law - What next?“, S. 10. 
g. Die Sachstandsanalyse: zugleich eine allgemeine Darstellung der Informationsgewinnung und -verarbeitung der Kommission in der Rechtsstaatlichkeitskrise

Bevor die Kommission darüber entscheidet, ob sie gegenüber einem Mitgliedstaat in der ersten Verfahrensstufe des EU-Rahmens eine „Stellungnahme zur Rechtsstaatlichkeit" erlässt und damit überhaupt mit Außenwirkung den neuen EU-Rahmen aktiviert, muss dienststellenintern und nachfolgend auf Kabinetts- und Kollegiumsebene darüber befunden werden, ob der Mitgliedstaat Anlass für die Verwirklichung des materiellen Tatbestands der systemischen Gefährdung der Rechtsstaatlichkeit bietet. Diese Entscheidungsfindung bedingt eine Informationsgewinnung und -verarbeitung, die die Kommission für so beachtlich gehalten hat, dass sie ihr mit der Sachstandsanalyse eine eigene Verfahrensstufe gewidmet hat.

Ich möchte diesen Prozess, die ergebnisorientierte Informationsverarbeitung im „Binnenbereich“ 1437 der Kommission, breiter darstellen, als dies bislang in der Literatur erfolgt zu sein scheint, ${ }^{1438}$ und sehe eine auszufüllende Forschungslücke. Denn die nachfolgenden Ausführungen können meiner Einschätzung nach nicht nur Geltung für den EU-Rahmen beanspruchen, sondern auch für die gut kommentierten Verfahren nach Art. 7 EUV oder das Vertragsverletzungsverfahren, für welche ich indes beobachte, dass dieses Verfahrensstadium nur in Grundzügen beschrieben worden ist.

Ich hatte zuvor auf den meines Erachtens festzustellenden Arbeitsgrundsatz der „Einheitlichkeit der Sorgfalt" der Kommission bei aller Arbeit im Umfeld der Rechtsstaatlichkeitskrise, ungeachtet des gewünschten Outputs, hingewiesen. Dieser Grundsatz findet nicht nur bei der Formulie-

1437 S. dazu Friedrich Schoch, „Öffentlich-rechtliche Rahmenbedingungen einer Informationsordnung“, in: Werner Hoppe (Red.), Der Grundrechtseingriff: Öffentlich-rechtliche Rahmenbedingungen einer Informationsordnung, Veröffentlichungen der Vereinigung der Deutschen Staatsrechtslehrer, Bd. 57, De Gruyter, Berlin, 1998, S. 158-215, S. 161, der dies (für den Staat) von der Informationsbeziehung Staat-Bürger und Wirtschaft-Gesellschaft trennt.

1438 In der mutmaßlich aktuellsten Studie zur Kommission ist die Informationsgewinnung sogar nur als Machtfaktor in dort beobachteten „turf wars“ zwischen Generaldirektionen beschrieben worden, s. nämlich bei Hussein Kassim, „Cabinets and Services: Coordination inside the Commission“, in: Hussein Kassim u.a., The European Commission of the Twenty-First Century, Oxford University Press, Oxford, 2013, S. 181-209, S. 183 und 187 insb. Das ist aber lediglich einer unter vielen möglichen Aspekten der Frage von Informationsflüssen in der Kommission. 
rung des späteren „Textprodukts“ Anwendung, sondern auch bei der dazu erforderlichen Informationsgewinnung und -verarbeitung. Die Masse der Information, die dabei zu bewältigen ist, ist eher eine „sozio-kulturelle Problemlage“ 1439 denn ein rechtliches Problem der Rechts- und Verwaltungspraxis. Bereits aus sich selbst heraus ist diese Informationsmenge eine Herausforderung. Es gilt insbesondere, sie effektiv zu bewältigen und dabei zu wissen, welche Quellen besonderer Berücksichtigung bedürfen. Dies ist ein Prozess, der z.B. über die wissenschaftliche Informationsverarbeitung deutlich hinausreicht.

Die Einheitlichkeit der Informationsgewinnung und -verarbeitung bedeutet nicht, dass darüber Entscheidungsprozesse und Beteiligungsabläufe der verschiedenen Verfahren, denen diese Informationen ggf. zugeführt werden, unterschiedslos wären, wohl aber, dass der Informationsgewinnungsprozess innerhalb der Dienststellen einheitlich erfolgt und darüber durchaus eine Beeinflussung verschiedener Verfahren in Betracht kommt. Der Leser ist daher gehalten, sich die hier gemachten Ausführungen für die anderen in dieser Arbeit begutachteten Verfahren in Erinnerung zu rufen, selbst wenn auf sie nicht nochmals eingegangen wird.

Die Informationsgewinnung und -verarbeitung seitens der Unionsorgane hat in der Unionsrechtswissenschaft erhebliche Beachtung gefunden, insbesondere mit Blick auf ihre Einbettung in Aufsichtsmechanismen. ${ }^{1440}$ Sie ist durch die Kommission selbst einmal als „Lebensnerv und Kernstück“ ihrer Tätigkeit beschrieben worden. ${ }^{1441}$ Armin Hatje befand die Information selbst, d.h. das Wissen um etwas, für so bedeutend, dass er den Umgang mit dieser sogar als eigene Handlungsform erwog. ${ }^{1442}$

1439 Begriff bei Friedrich Schoch, „Öffentlich-rechtliche Rahmenbedingungen einer Informationsordnung“, S. 177.

1440 Vgl. Meike Eekhoff, Die Verbundaufsicht, S. 113 f. Elisabeth Göttlinger, Auskunftsrechte der Kommission im Recht der Europäischen Union, Nomos, Baden-Baden, 2013, S. 55. Ausführlich zu den Strukturen, insbesondere in Bezug auf die Frage der Qualität von Informationen auch Kristina Heußner, Informationssysteme im Europäischen Verwaltungsverbund, Mohr Siebeck, Tübingen, 2007, S. $164 \mathrm{ff}$.

1441 Elisabeth Göttlinger, Auskunftsrechte der Kommission im Recht der Europäischen Union, S. 55 unter Verweis auf die Einlassung des Bevollmächtigten der Kommission in der mündlichen Verhandlung zur Rs. C-426/93, Deutschland ./. Rat, Schlussanträge des Generalanwalts Francis Jacobs vom 15.06.1995, Slg. 1995, I-3726, ECLI:EU:C:1995:184, Rn. 35.

1442 Armin Hatje, „Informationsaustausch und Datenschutz in der Europäischen Union - primärrechtliche Grundlagen, Grundzüge und Probleme des aktuellen Sekundärrechts“, in: Siegfried Magiera \& Karl-Peter Sommermann (Hrsg.), 
Von Bogdandy hat später die Forschungsmaxime vorgegeben, die im Hinblick auf die Auswertung der unionalen Informationsgewinnung stehen müsse:

„Da dieser Prozess verfahrensrechtlich kaum eingebunden ist, sind an dieser Stelle die einschlägigen Informationsbeziehungen ausgehend von den tatsächlichen Prozessen und nicht von den rechtlichen Regeln zu beschreiben." 1443

Dem schließe ich mich hier an, es soll also versucht werden, diese tatsächlichen Prozesse etwas aufzuhellen, gerade, weil dessen ungeachtet sich die Rechtswissenschaft vorrangig für stark verrechtlichte Informationsbeziehungen interessiert und damit für solche, bei denen eine anlassspezifische Auskunftsanfrage der Kommission gegenüber einem Mitgliedstaat im Vordergrund steht und diese ex post rechtlich einzuordnen ist. Ausführlich hat sich dieser Konstellation, vor dem Hintergrund des Art. 337 AEUV, etwa Elisabeth Göttlinger gewidmet. ${ }^{1444}$ Bei Hatje, der sich auch der „interadministrativen Kooperation“ gewidmet hat, stand der Informationsaustausch gleichwohl im Vordergrund. ${ }^{1445}$

Indes ist ein solcher Austausch oder das förmliche Ersuchen der Kommission um Informationen auf Seiten des Mitgliedstaats oder gar die eigene Informationsgewinnung vor Ort - man denke an Ermittlungen etwa durch das OLAF - nur eine Seite der Medaille. Gerade in der Rechtsstaatlichkeitskrise, in welcher ernsthafte Kooperation, in grundsätzlich krassem Widerspruch zu Art. 4 Abs. 3 EUV, ${ }^{1446}$ bei den betroffenen Mitgliedstaaten nicht mehr uneingeschränkt garantiert ist, steht die Frage einer allgemei-

Verwaltung in der Europäischen Union: Vorträge und Diskussionsbeiträge auf dem 1. Speyerer Europa-Forum vom 10. bis 12. April 2000 an der Deutschen Hochschule für Verwaltungswissenschaften Speyer, Duncker \& Humblot, Berlin, 2001, S. 193-217, S. 198.

1443 Armin von Bogdandy, „Die Informationsbeziehungen im europäischen Verwaltungsverbund“, in: Wolfgang Hoffmann-Riem, Eberhard Schmidt-Aßmann \& Andreas Voßkuhle, Grundlagen des Verwaltungsrechts, Bd. 2., C.H. Beck, München, 2. Aufl. 2012, S. 365-434, S. 390.

1444 Elisabeth Göttlinger, Auskunftsrechte der Kommission im Recht der Europäischen Union; vgl. aber auch Armin von Bogdandy, „Die Informationsbeziehungen im europäischen Verwaltungsverbund“, S. $371 \mathrm{f}$.

1445 Armin Hatje, „Informationsaustausch und Datenschutz in der Europäischen Union", S. 199 und ff.

1446 Dieser ist aber in der Literatur als Rechtsgrundlage des allgemeinen Informationsaustausches herangezogen worden, s. dazu Armin Hatje, „Informationsaustausch und Datenschutz in der Europäischen Union“, S. 201. 
nen Informationsbeschaffung ohne Hilfe oder sogar potentiell gegen das aktive Zutun des Mitgliedstaats im Vordergrund. Die Kommission lässt in der Mitteilung über den EU-Rahmen bereits erkennen, dass sie mit einem solchen Fall rechnet. Wie bereits angesprochen, benennt sie explizit Art. 4 Abs. 3 EUV als Grundlage für eine Kooperationspflicht des Mitgliedstaats und mahnt: „Der Umstand, dass ein Mitgliedstaat nicht kooperiert oder das Verfahren sogar behindert, wird bei der Beurteilung der Schwere der Gefährdung berücksichtigt." 1447

In der Literatur ist speziell diese Phase des EU-Rahmens wenig beachtet worden. ${ }^{1448}$ Dies mag auch daran liegen, dass für ihre Beurteilung ein näherer Einblick in die Arbeitspraxis der Kommissionsdienststellen, hier namentlich in der Generaldirektion Justiz der Europäischen Kommission, erforderlich ist. Die Phase der Sachstandsanalyse ist indes rechtssoziologisch höchst spannend.

aa. Grundsätze und Problemfelder der Informationsbeschaffung und -verwertung

Die Informationsgewinnung der Kommission im Rahmen der Rechtsstaatlichkeitskrise ist grundsätzlich verschieden von den vorgenannten Informationsauskunftsansprüchen der Kommission gegenüber Dritten. Im Unterschied zu diesen ist sie vorrangig faktisch, wobei unter Fakten auch die Ermittlung des Stands der mitgliedstaatlichen Rechtslage im Vorfeld späterer Analyse stehen kann, sie ist noch nicht verwendungsspezifisch, d.h. insbesondere regelmäßig nicht einzelfallbezogen und universell.

Ungeachtet dieser Breite lassen sich dabei einige organisatorische Besonderheiten herausarbeiten.

Der erste Grundsatz bei der Quellensammlung ist die Universalität der gesichteten Quellen. Das bedeutet, dass kommissionsintern im Grunde zunächst jegliche Information von besonderem Interesse gesammelt wird, es findet also kein per-se-Ausschluss statt, oder anders ausgedrückt: es besteht

1447 Europäische Kommission, Mitteilung der Kommission an das Europäische Parlament und den Rat, Ein neuer EU-Rahmen zur Stärkung des Rechtsstaatsprinzips vom 11.03.2014, $\operatorname{COM(2014)~} 158$ final, S. 8, s. bereits bei Fn. 1416.

1448 Sehr bündig etwa Stefanie Schmahl, „Filling a Legal gap?“, S. 847-848; Dimitry Kochenov \& Laurent Pech, „Better Late than Never? On the European Commission's Rule of Law Framework and its First Activation“, in: Journal of Common Market Studies 54 (2016), S. 1062-1074, S. 1066. 
kein Quellenkanon, der von vornherein bestimmte Quellen für unzulässig erklären würde. Eine Sortierung erfolgt erst im zweiten Schritt.

Das hat in der Literatur wenig Beachtung gefunden. Prete vermerkt im Rahmen seiner großen Studie zum Vertragsverletzungsverfahren lediglich, die Kommission erhalte Informationen "from a variety of sources“. ${ }^{1449}$ Ähnlich bündig heißt es bei Ibañez:

„[...] the Commission, before initiating an infringement procedure against a Member State [...] usually has to conclude that a breach of EU law may exist. For this, the Commission obviously needs information, which can be obtained from complainants, oral and written questions from Members of the European Parliament, reports of the European Court of Auditors, or through the Commission's own powers of inspection and of obtaining information." 1450

Für Göttlinger ist diese Form der Informationserlangung „rechtlich unproblematisch, da sie weder Rechtspositionen der Mitgliedstaaten noch Rechte Privater berührt“..1451

\section{bb. Allgemeine Quellen}

Die im Rahmen der Krise zuständigen Dienststellen der Kommission betreiben zur Informationsgewinnung eine permanente Sichtung verfügbarer Quellen.

Aus beobachtender Perspektive zu strukturieren ist dieser Prozess nach Art der Informationsbeschaffung und Art der Quelle. Was den ersten Punkt angeht, sind die Formen der allgemeinen Beschaffung „en passant", die aktive Anforderung und das Antragen von Informationen zu unterscheiden. Die Beschaffung „en passant“ kann im Praxisalltag durch Auswertung der Tagespresse und online verfügbarer Quellen, wissenschaftlicher oder journalistischer Publikationen im festen Umlauf erfolgen, sie

1449 Luca Prete, Infringement Proceedings in EU Law, S. 135-136. Ganz anders für dieses Verfahrensstadium der Problemzuschnitt bei Emanuel C. Ionescu, Innerstaatliche Wirkungen des Vertragsverletzungsverfahrens, Mohr Siebeck, Tübingen, 2016, S. 76 ff., der allein auf das Entschließungsermessen der Kommission abstellt.

1450 Alberto J. Gil Ibáñez, „The Administrative Supervision and Enforcement of EC Law“, S. 63-64.

1451 Elisabeth Göttlinger, Auskunftsrechte der Kommission im Recht der Europäischen Union, S. 56. 
werden zuständigen Referenten regelmäßig vorgelegt oder sind Ergebnis von eigenständigen Nachforschungen.

Die aktive Anforderung bezeichnet hier diejenige, die in der Literatur bislang am stärksten berücksichtigt worden ist, also den Austauschprozess mit Mitgliedstaaten und anderen Stellen, der ggf. auch in Form einer „mission“, also eines Arbeitsbesuchs vor Ort, erfolgen kann, wie sie auch die Venedig-Kommission im Vorfeld ihrer Gutachtenerstattung ausrichtet.

Die dritte Form, nämlich das Antragen von Informationen, ist eine solche, in der die Kommission, im Unterschied zur wissenschaftlichen Forschung und den Gubernativen der meisten Mitgliedstaaten, wohl in einzigartiger Weise privilegiert ist. Aufgrund ihrer zentralen Rolle etwa als Empfängerin von Beschwerden, aber auch aufgrund eines gut ausgebauten Informationsnetzwerks, ist sie regelmäßig besonders schnell und auch besonders umfassend durch Dritte in Kenntnis gesetzt, selbst wenn sie von der Existenz der Information zuvor noch nichts wusste. Hinzu kommt ihr privilegierter Zugang zu unionseigenem Material, etwa durch Vorabkommentare zu Vorlagefragen, die beim EuGH anhängig sind und die den für die Verfassungsaufsicht zuständigen Dienststellen nach Vorsortierung durch das Generalsekretariat zugeleitet werden. Sie hat dadurch regelmäßig einen enormen Wissensvorsprung, selbst z.B. vor Wissenschaftlern, die sich mit der Materie gut auskennen.

Um der Masse der entstehenden Informationen Herr zu werden, bedarf es in der Kommission im Anschluss an die zunächst universelle Quellenwürdigung gleichwohl einer Priorisierung und Privilegierung bestimmter Quellen. Es kann nicht überraschen, dass zu solchen jedenfalls Publikationen der Unionsorgane und -stellen, in überragendem Maße selbstredend alle Veröffentlichungen des Gerichtshofs, fallen, weiter Informationen aus den Mitgliedstaaten und derjenigen zwischenstaatlichen Akteure, mit denen die Kommission in besonderem Maße in Austausch steht, wie ganz vorrangig die Venedig-Kommission oder auch die „Europäische Kommission für die Effizienz der Justiz“ (CEPEJ).

Einzelne Mitgliedstaaten wissen um dieses Vorgehen der Kommission und schneiden Informationsangebote speziell auf die Verarbeitung durch sie zu. Ich hatte bereits mit Beispielen darauf hingewiesen, ${ }^{1452}$ dass insbesondere die ungarische Regierung mit den Seiten „kormany.hu“ und „abouthungary.hu“ Webauftritte unterhält, die nicht nur als Kommunikationsplattform der jeweiligen Regierung dienen, sondern darüber hinaus klassische Definitionen der Propaganda erfüllen, nämlich die „systemati-

1452 S. etwa in der Einleitung. 
sche Verbreitung politischer, weltanschaulicher o. ä. Ideen und Meinungen mit dem Ziel [zum Gegenstand haben], das allgemeine Bewusstsein in bestimmter Weise zu beeinflussen“. ${ }^{1453}$ Auch die polnische Regierung hat entschieden, der Kommission spezifisch eine aus ihrer Sicht aufbereitete Darstellung der dortigen Rechtslage zuzuleiten, das bereits zuvor genannte „White Paper“. ${ }^{1454}$

Unter die privilegierte Sichtung allgemeiner Quellen fällt auch die Auswertung von rechtlichen Primärquellen der Mitgliedstaaten, nämlich von Gesetzestexten, Exekutivakten und Urteilen insbesondere. Es ergibt sich dabei im Vergleich zum Recht der Union und des Europarates nach meiner subjektiven Einsicht häufig eine Umkehrung der Priorisierungsreihenfolge dieser Quellen, d.h., während für die Union und für den Europarat ganz besonders Urteile interessieren, ist es auf mitgliedstaatlicher Ebene zunächst das positive Recht und erst dann das Urteil hierzu, abgesehen von solchen Urteilen, die unmittelbare Relevanz für das Unionsrecht haben, wie Leitentscheidungen der Verfassungsgerichte.

Was das mitgliedstaatliche positive Recht angeht, steht die korrekte, erschöpfende, aber nicht unterschiedslose und zudem problemorientierte Wiedergabe und Aufbereitung im Vordergrund. In der Stellungnahme und Empfehlung zur Rechtsstaatlichkeit hat dies für den EU-Rahmen eine exemplarisch große Bedeutung. Aber auch andere Vorgänge, z.B. die in der Krise eingeleiteten Vertragsverletzungsverfahren oder die im Auftrag des Rates dort vorgestellten Übersichten beruhen zu großen Teilen auf der Rechtsdarstellung im Mitgliedstaat.

Die Probleme für die Kommission und der Vorteil, der dadurch für den Mitgliedstaat entsteht, sind erheblich, denn der Arbeitsaufwand hierfür ist immens. Hinter einer scheinbar einfachen Rechtswiedergabe in einer einzelnen Randnummer können dutzende Arbeitsstunden ganzer Referentengruppen stehen.

War in einer Union der 6 oder 15 noch damit zu rechnen, dass überwiegend alle Referenten der Kommission die Amtssprachen der Union hinreichend beherrschen, um zumindest passiv Informationen zu verwerten, ist dies heute häufig ein Ding der Unmöglichkeit, wozu die geringe Zahl an Sprechern osteuropäischer Sprachen und die erheblichen grammatikalischen wie lexikalischen Unterschiede der slawischen und finnougrischen zu den romanischen und germanischen Sprachfamilien der Gründungs-

1453 Vgl. Duden, Eintrag „Propaganda“.

1454 Kanzlei des polnischen Premierministers, White Paper on the Reform of the Polish Judiciary vom 07.03.2018. 
mitgliedstaaten beitragen. ${ }^{1455}$ In einer Union der 28 bzw. 27 erfordert die Sichtung von Urteilen, Exekutivakten oder Gesetzestexten, auch wenn diese heute ganz überwiegend online verfügbar sind, regelmäßig muttersprachliche Sprach- und insbesondere einheimische Rechtskenntnisse, die für Osteuropa mit wenigen Ausnahmen nur von dort sozialisierten Referenten zu erbringen sind. Ein Extrembeispiel ist Ungarn. Die Kommission löst das dabei entstehende Übersetzungsproblem nach Kräften, kann jedoch jenseits des muttersprachlichen Zugriffs auf diese Quellen nur mit einer gewissen Verzögerung reagieren. Da die in der Zivilgesellschaft beliebte Lösung über allgemein verfügbare maschinelle Übersetzungen (etwa "Google Translate“) dienstintern aus diversen Gründen undenkbar ist, hat die Kommission eigene, sehr leistungsfähige, Übersetzungstools 1456 und bietet mit dem als „Poetry“ bekannten Übersetzungsdienst der GD Übersetzung professionelle Unterstützung an. ${ }^{1457}$ Angesichts häufig voluminöser Texte und ihrer Technizität bleiben ungeachtet erheblichen Ressourceneinsatzes Verzögerungen aber häufig spürbar. Erschwerend kommt hinzu, dass die Kommission nach meiner Beobachtung grundsätzlich dazu übergegangen ist, bereits beigefügte unverbindliche Übersetzungen ins Englische durch den Mitgliedstaat (sog. „courtesy translations“, bis auf die frankophonen Staaten allgemein gängig) nochmals zu übersetzen, um Fehler oder bewusste Irreführungen auszuschließen. Der Mitgliedstaat hat dabei selbst in der Hand, wie zugänglich Informationen sind. Verschleierungstaktiken, wie sog. „Omnibus"-Gesetze, in denen der relevante Rechtstext in einem Konvolut irrelevanten Materials ertrinkt oder schlicht „handwerklich schlechte“ Gesetzgebung, also z.B. unklare Rechtsbegriffe, fehlende Definitionen oder komplizierte, teils fragmentarische Normverweisketten, erschweren sowohl die Entdeckung als auch Auswertung relevanten Materials.

1455 Lediglich 1\% der Europäer etwa spricht Polnisch als zweite Sprache. Eine Übersicht, leider bereits von 2005, findet sich in der Studie „Die Europäer und ihre Sprachen“ = Eurobarometer Spezial der Europäischen Kommission, abrufbar unter https://ec.europa.eu/commfrontoffice/publicopinion/archives/e bs/ebs_243_sum_de.pdf, zu den Polnischkenntnissen dort S. 4.

1456 Als „etranslation“ auch für öffentliche Verwaltungen außerhalb der Kommission zugänglich, vgl. unter: https://ec.europa.eu/info/resources-partners/machine -translation-public-administrations-etranslation_en.

1457 Vertiefend Łucja Biel, "Quality in institutional EU translation: Parameters, policies and practices“, in: Tomáš Svoboda, Łucja Biel \& Krzysztof Łoboda (Hrsg.), Quality aspects in institutional translation, Language Science Press, Berlin, 2017, S. 31-57, Überblick über verschiedene dienstinterne „tools“, S. 49 und $f$. 
Neben die vorgenannten privilegierten Quellen, ganz besonders der Rechtsprechung des EuGH, treten hier sog. nicht privilegierte Quellen, die mehr oder minder regelmäßig gesichtet werden.

Die Sichtung dieser nachrangigen Quellen erfolgt im Rahmen der Verwaltungsgewohnheit und kann in erhöhtem Maße von den Präferenzen, Kenntnissen (insbesondere bei Sprachen) und der wissenschaftlichen Sozialisierung einzelner Referenten abhängen. Während z.B. gerade deutschsprachige Referenten den Umgang mit Großkommentaren kennen, die auf Englisch oder Französisch häufig nicht vorliegen, sind es umgekehrt gerade französischsprachige Referenten, die das répertoire des EuGH mit großer Effektivität nutzen können.

$\mathrm{Zu}$ den nicht privilegierten Quellen zählen wissenschaftliche Beiträge jeglicher Form, wie Kommentare, Periodika und Fachwerke, die bei Bedarf in regelmäßigen Abständen auch kurz bei Besprechungen referiert werden. Weiter berücksichtigt werden frei verfügbare Veröffentlichungen von NGOs, Regierungen und sodann schließlich in großem Umfang journalistische Erzeugnisse wie Tagespresse, Tele- und Onlinemedien. Noch zu den priorisierten Quellen zu zählen ist hingegen der unionseigene Fernsehdienst EbS, ${ }^{1458}$ der insbesondere Plenar- und Ausschusssitzungen des Parlaments (wenn auch natürlich nicht des Rates) bereitstellt. Tagespresse wird neben der spezifischen Sichtung durch zuständige Referenten auch durch den kommissionseigenen Pressedienst aufbereitet. Dabei verdient das Kuriosum der auf den Ausländer zugeschnittenen Presse Erwähnung. Ein Beispiel ist der in der Slowakei auf Englisch erscheinende „Slovak Spectator", der sich einiger Beliebtheit bei nicht slowakischsprachigen Beobachtern erfreute.

Über tagesrelevante Informationen, inklusive relevanter Besprechungen in- und außer Haus werden für die beteiligten Dienste zur Information und Nachverfolgung, insbesondere auch was die Entwicklung neuer Sprachregelungen angeht, Kurzbriefings (sog. Flashs) erstellt. Das gilt ggf. auch für die aktuelle Rechtsprechung.

cc. Durchgestochene und platzierte Quellen

Zunehmend Relevanz erlangen in der Rechtsstaatlichkeitskrise durchgestochene („geleakte“) Informationen, d.h. Fälle, in denen interne Vorgänge, insbesondere der Unionsorgane oder in den Mitgliedstaaten, der Öf-

1458 Europe by Satellite, https://ec.europa.eu/avservices/index.cfm?sitelang=en. 
fentlichkeit zugänglich gemacht werden. Die Schädigung, aber auch die Beeinflussung bestimmter Debatten oder die Vorteilsgewinnung sind dabei ein potentielles Motiv. Die Problematik des „Leaks“, bislang - in der Politikwissenschaft - vorrangig als Frage des Informationsabflusses aus der Kommission selbst von Interesse gewesen, ${ }^{1459}$ soll hier nicht beurteilt werden. Es fragt sich vielmehr, wie die Kommission in ihrer Informationsverarbeitung mit durchgestochenen Informationen anderer öffentlicher Stellen umgehen kann.

Exemplarisch ist etwa für das Jahr 2019 die Offenlegung von Chatprotokollen einer geschlossenen Gruppe des Dienstes WhatsApp durch eine polnische Enthüllungsplattform zu nennen. Die Chatteilnehmer, sämtlich Beschäftigte oder enge Vertraute des polnischen Justizministeriums, hatten sich der Gruppe zwecks Vorbereitung von Verleumdungen polnischer Richter bedient, nannten sich selbst „Hejter“ (von engl. Hater = Hassredner) oder auch nur die „Kaste“ und bedienten sich derart drastischer und direkter Umgangsformen, dass sich der polnische Ministerpräsident zu einer öffentlichen Verurteilung und das Ministerium zu „Kururlauben“ für die Beteiligten veranlasst sah. ${ }^{1460}$ Umgekehrt scheint bis heute ungeklärt, wer 2018 die technischen Mittel und das Wissen besaß, das geheime - und mutmaßlich gut gesicherte - Gutachten des Juristischen Dienstes des Parlaments zur Beurteilung seiner Einleitung des Art. 7 EUV-Verfahrens gegenüber Ungarn auf einer File-Sharing-Webseite durchzustechen, von welcher es die Presse verbreitete. ${ }^{1461}$

Ungeachtet der Verwerflichkeit der etwa in der o.g. Chatgruppe gemachten Äußerungen war die Veröffentlichung von im privaten Umfeld gemachten Äußerungen der Teilnehmer mit hoher Wahrscheinlichkeit

1459 Vgl. entsprechend Ronny Patz, „Just the TTIP of the Iceberg? Dynamics and Effects of Information Leaks in EU Politics“, in: European Journal of Risk Regulation 7 (2017), S. 242-246; Ronny Patz, „Leaking, leak prevention, and decoupling in public administrations: the case of the European Commission", in: West European Politics 41 (2017), S. 1049-1071; Matthew Castle, Matthew \& Krzysztof J. Pelc, ,The Causes and Effects of Leaks in International Negotiations“, in: International Studies Quarterly 63 (2019), S. 1147-1162.

1460 Vgl. Gerhard Gnauck, „Nach Kritik wird suspendiert“, Frankfurter Allgemeine Zeitung vom 07.01.2020, mit ausführlichem Bericht über den Vorgang. In Ungarn haben ähnliche Vorgänge eine gleichwertige innenpolitische Bedeutung, dazu Paul Lendvai, Orbán, S. 86, S. 178.

1461 Europäisches Parlament, Opinion of the Legal Service, Clarification of the voting procedure concerning Article 7 TEU, SJ-0612/18, vom 07.09.2018, abrufbar unter: https://www.politico.eu/wp-content/uploads/2018/09/Legal-Service-Note _voting-procedure.pdf. 
nach nationalem Recht rechtswidrig und die Veröffentlichung ein Eingriff in die Privatsphäre der Teilnehmer. Bei durch Dritten veröffentlichten, durchgestochenen Informationen erhält die Kommission keine Stütze aus der jüngst in Kraft getretenen sog. „Whistleblower"-Richtlinie, ${ }^{1462}$ denn ihr Schutzzweck ist nicht die Informationsverwertung, sondern der Umgang mit denjenigen Personen, die die Informationen bereitstellen. Auch die in der Judikatur dichter werdenden Maßstäbe betreffend sog. Verwertungsverbote von Informationen durch die Kommission werden im Allgemeinen noch nicht weiterhelfen, denn sie beziehen sich bislang auf durch die Kommission durch Maßnahmen mit Außenwirkung, etwa nach Auskunftsanfrage oder andere Maßnahmen wie Durchsuchungen von Liegenschaften, erhaltene Informationen. ${ }^{1463}$ Dabei handelt es sich aber um im Rahmen kundiger Umschau selbst legal, in der Quelle indes potentiell rechtswidrig erlangter Interna. Der Europäische Gerichtshof hat, soweit ersichtlich, hierzu bislang keine Gelegenheit einer Beurteilung gehabt und keine übergreifende Linie wie etwa vergleichbar der aus dem US-Recht so geläufigen Doktrin der "fruit of the poisonous tree“ aufgestellt. Um dennoch zu einem Ergebnis zu gelangen, ist sachnah zu differenzieren.

Verarbeitet die Kommission eine bereits vorherige Auswertung durchgestochener Quellen etwa in der Tagespresse oder auf entsprechenden Online-Plattformen oder wird in diesen die Primärquelle angeführt oder bereitgestellt, etwa über einen Link, so handelt es sich um klassische Fälle von Enthüllungsjournalismus, in denen Interna durch journalistische Arbeit der Allgemeinheit zugänglich gemacht worden sind und die Information damit Allgemeingut darstellt. Der potentielle Vorwurf der Verwerflichkeit oder Rechtswidrigkeit ist dann nur in der Relation des Journalisten gegenüber der Quelle zu erheben und seine Beurteilung eine Frage der (nationalen) Justiz. Die Kommission wird dann grundsätzlich diejenigen Informationen, die abstrahiert von den einzelnen Betroffenen für ihre Arbeit nützlich sind, verarbeiten können, hat dabei aber die unnötige Offenlegung weiterer privater Informationen zu unterlassen. So kann sie im o.g. Fall berücksichtigen, dass es im polnischen Justizministerium

1462 Richtlinie (EU) 2019/1937 des Europäischen Parlaments und des Rates vom 23. Oktober 2019 zum Schutz von Personen, die Verstöße gegen das Unionsrecht melden, ABl. (EU) L 305/17 vom 26.11.2019.

1463 Überblick über die Rspr. bei Liv Jaeckel, Art. 337 AEUV, in: Eberhard Grabitz, Meinhard Hilf \& Martin Nettesheim (Begr./Hrsg.): Das Recht der Europäischen Union, C.H. Beck, München, 68. EL 2018, Rn. 55 ff.; ergänzend Bernhard W. Wegener, Art. 337 AEUV, in: Christian Calliess \& Matthias Ruffert, EUV/AEUV, 5. Aufl., C.H. Beck, München, 2016, Rn. 11-12. 
eine Verleumdungskampagne gegen Richter gab, die Personalien der Beteiligten sind für sie aber grundsätzlich irrelevant und daher auch nicht über das gebotene Maß hinaus zu reproduzieren.

Umgekehrt aber, wenn der Kommission direkt und ungefragt Informationen zugespielt werden, wird sie genauer differenzieren müssen.

In einer ersten Konstellation handelt es sich um Dritte, die der Kommission ohne Absicht etwa der Einleitung einer weiteren Beschwerde oder sonstiger eigener Vorteilsgewinnung, Informationen, wie der Kommission potentiell noch nicht bekannte amtliche Veröffentlichungen, sonstige allgemein zugängliche Quellen, inklusive durchgestochener Dokumente, oder eigene Ausarbeitungen, wie Rechtsgutachten, zuleiten. Insbesondere kommt in Betracht, dass nationale Beamte so handeln könnten.

Erfolgt der Hinweis auf eine durchgestochene Quelle, wird die Kommission zunächst die Art der Bereitstellung berücksichtigen müssen. Ist die Quelle allgemein zugänglich, gilt das bereits Gesagte, ist sie aber nur für die Kommission selbst einsehbar, etwa als E-Mail-Anhang, muss die Kommission weitere rechtliche Überlegungen, wie den Schutz des Informanten über Art. 4 Abs. 1 lit. a i.V.m. 19 Schutzwirkung der zuvor genannten Whistleblower-Richtlinie, anstellen. Gleichzeitig folgen, insbesondere aus Art. 4 Abs. 3 EUV, Rücksichtsnahmepflichten gegenüber dem Mitgliedstaat und dessen Rechtsordnung. ${ }^{1464}$

Jenseits mitgliedstaatlicher Interna kann die Kommission die durch Informationskanäle zur Verfügung gestellten Informationen als Ergebnis der eigenen Analyse- oder Rechercheleistung des Urhebers nach vernünftiger und kritischer Sichtung als Quelle in ihren Entscheidungsprozess einfließen lassen. Das gilt etwa für "klassische“ Hinweise auf tagesaktuelle Gesetzgebung oder Rechtsprechung, die ohnehin frei verfügbar gewesen wäre, wie auch Rechtsgutachten. In ihnen kann ggf. auch die Erfüllung einer Pflicht eines Dritten liegen, etwa wenn ein nationaler Beamter, der im Rahmen seiner Dienstausübung mit der Kommission zusammenarbeitet und vereidigt ist, seine Arbeit zum allgemeinen Wohl auszuüben, die Kommission entsprechend informiert. Teils hebt die Kommission derartige Kontakte auch offen hervor. So werden wesentliche Teile der Primärquellen des EU-Justizbarometers vertraglich für die Kommission von der

1464 Dazu Stephan Schill \& Christoph Krenn, Art. 4 EUV, in: Eberhard Grabitz, Meinhard Hilf \& Martin Nettesheim (Begr./Hrsg.), Das Recht der Europäischen Union, C.H. Beck, München, 68. EL 2019, Rn. 126. 
CEPEJ erarbeitet, ${ }^{1465}$ und sie steht ebenso im engen Austausch mit mitgliedstaatlichen Justizbehörden.

Auch hat die Kommission mehrfach festgehalten, dass und welche Quellen sie bei ihrer Analyse, gerade für das EU-Rahmenverfahren, privilegieren wird: so sollen „anerkannte[...] Institutionen, unter anderem von Einrichtungen des Europarats und der Agentur der Europäischen Union für Grundrechte“ Berücksichtigung fänden. ${ }^{1466}$ Im späteren Verordnungsvorschlag betreffend generalisierte Mängel hat die Kommission diesen Grundsatz der Quellenuniversalität bei gleichzeitiger Privilegierung bestimmter Urheber wiederholt:

„Die Feststellung eines generellen Mangels bedarf einer qualitativen Prüfung seitens der Kommission. Diese Bewertung könnte auf Informationen aus allen verfügbaren Quellen und von anerkannten Institutionen fußen, darunter Urteile des Gerichtshofs der Europäischen Union, Berichte des Rechnungshofes und Schlussfolgerungen und Empfehlungen einschlägiger internationaler Organisationen und Netze wie des Europarats oder der Europäischen Netze oberster Gerichtshöfe und Justizräte. “1467

Anders gelagert ist der zweite Fall, in dem der Kommission Informationen durch Dritte zugeleitet werden, die sich hiervon Vorteile wie Parteinahme in einem Rechtsstreit oder Abhilfe bei Beschwer durch mitgliedstaatliche Stellen erhoffen. So ist denkbar, dass ein Mitgliedstaat gegen Akteure der Zivilgesellschaft vorgeht und die Adressaten dieser Handlung sich nicht nur informatorisch, sondern hilfesuchend in re sua an die Kommission wenden. In einem solchen Fall kann die Kommission zugeleitete Quellen zwar nach besonders gründlicher Prüfung auf mögliche Tendenz verwenden, muss aber dabei besonders kritisch prüfen.

1465 Vgl. schon Europäische Kommission, Mitteilung der Kommission an das Europäische Parlament, den Rat, die Europäische Zentralbank, den Europäischen Wirtschafts- und Sozialausschuss und den Ausschuss der Regionen, Ein Instrument für eine leistungsfähige, wachstumsfördernde Justiz: EU-Justizbarometer 2013, $\operatorname{COM(2013)~} 160$ final, vom 27.03.2013, S. 3.

1466 Europäische Kommission, Europäische Kommission, Mitteilung der Kommission an das Europäische Parlament und den Rat, Ein neuer EU-Rahmen zur Stärkung des Rechtsstaatsprinzips vom 11.03.2014, COM(2014) 158 final, S. 8.

1467 Europäische Kommission, Vorschlag für eine Verordnung des Europäischen Parlaments und des Rates über den Schutz des Haushalts der Union im Falle von generellen Mängeln in Bezug auf das Rechtsstaatsprinzip in den Mitgliedstaaten, $\operatorname{COM}(2018) 324$ final vom 02.05.2018, S. 8, Erwägungsgrund 12. 
Der dritte Fall, dessen Darstellung ich hier nicht im Einzelnen bespreche, ist das förmliche Auskunftsersuchen der Kommission gegenüber dem Mitgliedstaat. Die Kommission hat, gerade für den EU-Rahmen, regelmäßig und formularmäßig Polen ersucht, gewünschte Informationen bereitzustellen. So heißt es z.B. in der letzten, 4. Empfehlung zur Rechtsstaatlichkeit, die mittels des EU-Rahmens an Polen ergangen ist:

„Die Kommission fordert die polnischen Behörden auf, die in dieser Empfehlung dargelegten Probleme innerhalb von drei Monaten nach Erhalt der Empfehlung zu beheben und der Kommission die hierzu unternommenen Schritte mitzuteilen." ${ }^{4168}$

Polen hat es indes vorgezogen, vorrangig durch Nichtbeantwortung denn durch Beschreiten z.B. des Rechtswegs gegen derartige Ersuchen vorzugehen.

Das führt zu der umstrittenen und etwa bei Göttlinger umfassend geprüften Frage eines selbstständigen Informationsanspruchs der Kommission, insbesondere nach Art. 337 AEUV. ${ }^{1469}$ Die Frage ist zunächst von der Frage zu trennen, ob Art. 337 AEUV auch Ermächtigungsgrundlage ist, wie zuvor diskutiert. ${ }^{1470}$ Es ist allerdings nicht erforderlich, hierzu nochmals Stellung zu nehmen, denn die Kommission hat darauf verzichtet, in der Krise einen selbstständigen Auskunftsanspruch, insbesondere explizit gestützt auf diese Norm, gegenüber Mitgliedstaaten zu bemühen.

\section{dd. Die Beschwerde}

Die Beschwerde, die nicht an ein bestimmtes Verfahren geknüpft ist, sondern durch Dritte weitgehend formlos bei der Kommission erhoben werden kann, ist im Rahmen der Informationsgewinnung traditionell eines der bedeutendsten Mittel für die Kommission, ${ }^{1471}$ und sie hat an dieser

1468 Europäische Kommission, Empfehlung (EU) 2018/103 der Kommission vom 20. Dezember 2017 zur Rechtsstaatlichkeit in Polen in Ergänzung der Empfehlungen (EU) 2016/1374, (EU) 2017/146 und (EU) 2017/1520, ABl. (EU) L 17/50 vom 23.01.2018, Rn. 49.

1469 Streitstandsdarstellung, m. w. N., bei Elisabeth Göttlinger, Auskunftsrechte der Kommission im Recht der Europäischen Union, S. 97 ff., S. 99-100.

$1470 \mathrm{Zu}$ den Unterschieden Elisabeth Göttlinger, Auskunftsrechte der Kommission im Recht der Europäischen Union, S. 102.

1471 Ausführlich auch Elisabeth Göttlinger, Auskunftsrechte der Kommission im Recht der Europäischen Union, S. 56 ff. 


\section{E. Das Rechtsregime der Verfassungsaufsicht der Europäischen Union}

Stellung auch im Rahmen der Rechtsstaatlichkeitskrise, unabhängig vom Verfahren, nicht an Rang und Bedeutung eingebüßt. Wie Prete spezifisch für das Vertragsverletzungsverfahren ausführlich dargestellt hat, ${ }^{1472}$ registriert die Kommission seit 1961 systematisch alle Beschwerden, die auf diversen Wegen (Brief, Fax, ggf. Anruf, heute ganz vorrangig per E-Mail oder Ausfüllen eines Kontaktformulars) durch die unterschiedlichsten Urheber (Private, Anwälte, Organisationen diverser Form, ggf. staatliche Stellen) bei ihr eingehen. Seit 1989 bietet die Kommission zur weiteren Kanalisierung der Beschwerden ein Formular an, das zuletzt 2012 per Mitteilung aktualisiert wurde und sukzessive mit immer stärkeren Dienstaufsichtszuständigkeiten des Europäischen Bürgerbeauftragten ergänzt wurde. ${ }^{1473}$ Heute findet sich das Kontaktformular für Beschwerden zur Europäischen Kommission online. ${ }^{1474}$

Die Kommission betreut eingehende, gerade rechtsstaatlichkeitsspezifische, Beschwerden mittels zweier digitaler Plattformen, genannt ARES ${ }^{1475}$ und CHAP, ${ }^{1476}$ ggf. schriftlich eingehende Beschwerden werden durchgängig digitalisiert. Die Plattform CHAP ist dabei in der Praxis nur für Beschwerden heranzuziehen, denen wenigstens der ernsthafte Anschein einer Rechtsverletzung des Unionsrechts durch staatliche Stellen im Zuständigkeitsbe-

1472 Luca Prete, Infringement Proceedings in EU Law, S. $320 \mathrm{ff}$.

$1473 \mathrm{Zu}$ den jüngeren Entwicklungen Luca Prete, Infringement Proceedings in EU Law, S. 327 f.; Europäische Kommission, Mitteilung der Europäischen Kommission an den Rat und das Europäische Parlament, Aktualisierung der Mitteilung über die Beziehungen zu Beschwerdeführern in Fällen der Anwendung von Unionsrecht, $\operatorname{COM}(2012) 154$ final vom 02.04.2012. Die Mitteilung verweist mutmaßlich erstmals auf das 2009 eingeführte CHAP-Datenbanksystem und führt es damit auch gegenüber der Öffentlichkeit ein, (s. sogleich infra). Weiter zu den Wahrnehmungen des Bürgerbeauftragten in der breiten Öffentlichkeit im Rahmen von Beschwerden, ebenso zu den Beschwerden zum Bürgerbeamten bei Rüge etwa von Rechtsfehlern der Kommission, Naomi Creutzfeld, Ombudsmen and ADR: A Comparative Study of Informal Justice in Europe, Palgrave Macmillan/Springer International Publishing, Cham, 2018. S. $104 \mathrm{ff}$.

1474 https://ec.europa.eu/info/about-european-commission/contact/problems-a nd-complaints/complaints-about-breaches-eu-law/how-make-complaint-eu-level_en.

1475 Akronym für „Advanced Records System“. In der ARES-Datenbank verwaltet die Kommission grundsätzlich alle für den internen Dienstgebrauch vorgesehenen und in ihm zirkulierenden Dokumente unterschiedlichen Typs, aber auch den Briefwechsel mit Dritten.

1476 Akronym für „Complaints Handling/Accueil Plaignants“. In dieser Datenbank verwaltet die Kommission vorrangig Beschwerden. 
reich der Kommission zukommt. Dieser Grundsatz lässt sich auch aus den 2012 per Mitteilung gefassten Bedingungen für die Nachverfolgung von Beschwerden ableiten. ${ }^{1477}$

Die Aufgabe, Beschwerden zu sichten, fällt den mit dem Rechtsstaatlichkeitsdossier vertrauten Referenten der GD JUST im Rahmen ihres Deputats zu. Aufgrund der großen Anzahl und des hohen Prozentsatzes an evident unbegründeten oder sogar an Querulanteneingaben kann diese Arbeit durchaus mühselig sein, wird allerdings, nicht zuletzt auch aufgrund des Willens, sich mit dem Anliegen von Unionsbürgern zu befassen und der potentiellen Aufsicht durch den Bürgerbeauftragten, sehr ernsthaft und gewissenhaft durchgeführt.

Der betreuende Referent hat nach Eingang der Beschwerde, deren Gegenstand und Urheber sehr weit sein können, ${ }^{1478}$ nach den o.g. Kriterien eine Prüfung über die weitere Bearbeitung durchzuführen. Prete hat unter Berufung auf Ignace Maselis und Hans Gilliams gefolgert, mit der Beschwerde erfolge keine „Klageeinreichung“ o.ä. bei der Kommission, sondern eine nach deren Ermessen zu überprüfendes Ersuchen um weiteres Vorgehen. ${ }^{1479}$ Dem ist zuzustimmen.

Die von der Kommission unter „Registrierung“ der Beschwerde gehaltene Prüfung ähnelt vielmehr einer durch die zuständigen Referenten vorgenommenen Annahme zur Entscheidung.

Ist sie erfolgreich, erfolgt ein Eintrag im Beschwerderegister der Kommission, ist sie es nicht, was für eine Vielzahl an Schreiben gilt, wird sie als reguläre Posteingabe und Verschiebung aus dem CHAP- in das ARESRegister, außerhalb des Beschwerdefahrens weiterbearbeitet (im Kommissionsjargon auch sog. „déchaper“). Die Antwortfristen sind strikt und werden durch regelmäßige computergestützte Hilfen genau protokolliert

1477 Vgl. Mitteilung der Kommission an den Rat und das Europäische Parlament, Aktualisierung der Mitteilung über die Beziehungen zu Beschwerdeführern in Fällen der Anwendung von Unionsrecht, vom 2.4.2012, COM(2012) 154 final, S. 4-5.

1478 Mitteilung der Kommission an den Rat und das Europäische Parlament, Aktualisierung der Mitteilung über die Beziehungen zu Beschwerdeführern in Fällen der Anwendung von Unionsrecht, vom 2.4.2012, COM(2012) 154 final, S. 2,4 .

1479 Luca Prete, Infringement Proceedings in EU Law, 2017, S. 320 mit Verweis auf Ignace Maselis \& Hans A. Gilliams, „Rights of complainants in Community law“, in: European Law Review 22 (1997), S. 103-124, S. 104-105. 
und in Erinnerung gerufen. Für die Entscheidung vom Eingang bis zum Entschluss über das weitere Vorgehen darf maximal ein Jahr vergehen. ${ }^{1480}$

Auf den Inhalt einzelner Beschwerden, die im Rahmen der Rechtsstaatlichkeitskrise in der Kommission berücksichtigt worden sind, ist hier nicht einzugehen. Es ist allerdings festzuhalten, dass die teilnehmende Beobachtung an der Arbeit zuständiger Dienststellen offenbart, dass sie in Qualität und Brisanz eine große Bandbreite abdecken und sehr unterschiedliche Urheber haben, einerseits sogar bei staatlichen Funktionsträgern, andererseits bei einer großen Vielzahl an Privaten, die teils erschütternde persönliche Schicksale mitteilen, ohne dass aber die Kommission hiergegen unmittelbar, also namentlich anstelle der mitgliedstaatlichen Justiz, hätte tätig werden können oder auch sollen. Hierin ähnelt die Arbeit am Beschwerdedeputat derjenigen für eingehende Beschwerden beim Europäischen Gerichtshofs für Menschenrechte. ${ }^{1481}$

Die Kommissionstatistiken zur Anwendung des Unionsrechts weisen bis 2018 - dem letzten verfügbaren Datensatz - einen steilen Anstieg justiz- und verbraucherbezogener Beschwerden nach. Allerdings gelten die Datensätze nur für registrierte (d.h. in das System CHAP aufgenommene) Beschwerden und sind überdies mitgliedstaatsspezifisch nicht durchweg aussagekräftig. Für Polen steigen sie, nach einem Abfall, von $152 \mathrm{im} \mathrm{Jahr}$ 2016 auf 237 im Jahr 2018, für Ungarn hingegen sind sie, nach 96 im Jahr 2015 auf nur noch 38 im Jahr 2018 gefallen. ${ }^{1482}$ Die jeweiligen Ursachen für die Entwicklungen lassen sich nur vermuten. Gerade für Polen scheint

1480 Mitteilung der Kommission an den Rat und das Europäische Parlament, Aktualisierung der Mitteilung über die Beziehungen zu Beschwerdeführern in Fällen der Anwendung von Unionsrecht, vom 2.4.2012, COM(2012) 154 final, S. 7. Dort heißt es, die Beschwerde soll „in der Regel“ binnen eines Jahres entschieden werden. Im Internetauftritt gegenüber dem Bürger (https://ec.eur opa.eu/info/about-european-commission/contact/problems-and-complaints/ complaints-about-breaches-eu-law/how-make-complaint-eu-level_en) hat die Kommission dies indes im Sinne einer Pflicht ausgestaltet, binnen 12 Monaten zu entscheiden oder erneut zu informieren. Eine Eingangsbestätigung erfolgt binnen 15 Arbeitstagen.

1481 Dieser Vergleich beruht auf Beobachtungen eines Kommissionsreferenten, der zuvor für den EGMR tätig war, und ihn durch persönliches Anschauungsmaterial bekräftigt hat.

1482 Europäische Kommission, Monitoring the Application of Union Law 2018 Annual Report, Part II: policy areas, S. 59, verfügbar unter: https://ec.europa.eu /info/publications/2018-commission-report-monitoring-application-eu-law_en, weiter Part III: Member States, S. 111 und 138, verfügbar unter: https://ec.euro pa.eu/info/sites/info/files/report-2018-commission-staff-working-document-mo nitoring-application-eu-law-member-states-part3_0.pdf. 
aber der Anstieg auch durch den Reflex zumal älterer Bürger begründet, bei wirklichen Mängeln im System ihren Vertrauensverlust neben einem möglichen Beschreiten des Rechtswegs durch Eingaben an die höchstmögliche Stelle zu begleiten, welche in sozialistischen Rechtssystemen den Verwaltungsrechtsweg weitestgehend ersetzte.

Ist die Kommission der Auffassung, dass die Beschwerde Anlass zur weiteren Nachforschung bietet oder sogar begründet ist, so zeigt sich in der Praxis der Grundsatz des Entschließungsermessens der Nachverfolgung. Dies bedeutet, dass die Dienststellen und ggf. Kabinette nach sachgemäßem Ermessen entscheiden, in welcher Form die Berücksichtigung erfolgt, ob sie einen Vorgang etwa im Rahmen eines Vertragsverletzungsverfahrens verfolgen oder ihn als weitere Bestätigung für die Analyse etwa im EURahmen nutzen. Dem folgt das Prinzip der hier sog. Informationsquerverwertung nach. Damit ist bezeichnet, dass die eingebundenen Referate der Kommission grundsätzlich alle im Rahmen eines Informationsprozesses oder Verfahrens gewonnenen Erkenntnisse auch in anderen Verfahren berücksichtigen, sofern dem rechtliche Beschränkungen, wie insbesondere der Schutz persönlicher Daten, nicht entgegenstehen. Insbesondere können also Informationen einer Individualbeschwerde Einfluss auf ein Verfahren der nicht primär individualschützenden Verfassungsaufsicht haben. Es erfolgt grundsätzlich keine Trennung der Information nach Verfahren oder Vorgang. Wie bereits aus dem Grundsatz der Einheitlichkeit der Sorgfalt zu folgern ist, macht es dabei auch hier keinen Unterschied, was das Ziel der Informationsverwertung ist.

\section{ee. Die dienstinterne Privilegierung von Informationen}

Schließen möchte ich den Abschnitt zur Informationsverarbeitung mit einigen Beobachtungen zur internen Verwertung von Informationen. Keineswegs jeder Referent einer Hierarchie wird hierbei eingebunden. Dies ist häufig schon bedingt durch den bloßen Zuschnitt des einzelnen Deputats oder die Spezialisierung des jeweiligen Referenten. Die Weitergabe von Informationen, insbesondere dann auch zwischen Direktoraten oder Generaldirektoraten und Kabinetten und die Frage "who is holding the pen“, kann allerdings auch zu Rivalitäten führen. ${ }^{1483}$

1483 Vgl. dazu schon Hussein Kassim, Cabinets and Services: Coordination inside the Commission, in : Hussein Kassim, John Peterson, Michael W. Bauer, Sara Connolly, Renaud Dehousse, Liesbet Hooghe, \& Andrew Thompson (Hrsg.), 
Der Informationsgewinnung und (Quer-)Verwertung folgt der interne Verwertungs- und Verarbeitungsprozess nach. Hier erlangen Vertraulichkeitsgesichtspunkte besondere Relevanz. Nach eigener Beobachtung unterscheide ich drei Formen der Weiterverarbeitung im Rahmen eines Verfassungsaufsichtsverfahrens eines mit der Rechtsstaatlichkeitskrise vertrauten Referats: die nicht privilegierte Informationsverwertung, die Informationsverwertung im Rahmen relativer Privilegierung und schließlich die Informationsverwertung im Rabmen absoluter Privilegierung.

Nicht privilegierte Informationsverwertung bezeichnet die Verwertung der aus der Allgemeinheit nicht nur zugänglichen, sondern auch sichtbaren und bekannten Quellen. Sie ist der Regelfall. Derartige Vorgänge werden regelmäßig an nach Sprachkenntnis und Deputat interessierte Referenten und ggf. Vorgesetzte weitergeleitet und nach Kapazität zwischen Referenten allgemein ausgetauscht, dies ist sogar erwünscht. Der Charakter des Kontinuums der Informationsgewinnung tritt am deutlichsten zutage.

Die zweite Form der Informationsverwertung ist die hier sog. relative Privilegierung. Sie betrifft zunächst Quellen, die nur bestimmten Referenten aufgrund persönlicher Fähigkeiten oder Zuleitungen zugänglich sind. Relativ ist die Privilegierung zu nennen, weil sie dabei nicht von den höchstpersönlichen Merkmalen des einzelnen Referenten abhängt. In diese Kategorie fällt z.B. die Auswertung von Quellen in wenig gesprochen Sprachen. Rückversicherung und Austausch ist hier zwar immer noch möglich und erwünscht, indes hat z.B. ein Muttersprachler notwendigerweise einen anderen Zugriff auf die Materie und ist darüber zentraler Ansprechpartner. Die beobachtete Barriere ist häufig das klassische Problem mangelnder Vertrautheit mit fremden Rechtssystemen. Aufgrund der $\mathrm{Zu}-$ sammensetzung der Referate sind Referenten mit entsprechender Kenntnis meist allein verantwortlich für die Informationsgewinnung ihres Kultur-, Rechts- und Sprachraums und tragen entsprechende Verantwortung, insbesondere für die akkurate Wiedergabe der geltenden Rechtslage im Austausch mit ihren Kollegen. Schon aus diesem Grund legen die Dienststellen Wert auf große Heterogenität ihrer Referenten. Zu Quellen, die „relativ privilegiert" sind, gehören auch solche, die einzelnen Referenten aufgrund der ihnen zugeteilten Dokumente unter der Verwaltung des Generalsekretariats zugehen.

Die letzte Gruppe, die der absolut privilegierten Informationen, ist von der höchstpersönlichen Befähigung und Position des einzelnen Sachbearbeiters

The European Commission of the Twenty-First Century, Oxford University Press, Oxford, 2013, S. 181-209, S. 181 ff, S. $201 \mathrm{ff}$. 
bzw. Referenten abhängig. Befähigung meint hier nicht die fachliche Fähigkeit zur Erfassung der Materie - sie wird bei allen Referenten gleichermaßen vorausgesetzt und ist in aller Regel garantiert - sondern zunächst die besondere Vertrautheit mit ihr. Gerade Vorgänge wie in Polen und Ungarn haben in der Praxis eine Komplexität entwickelt, ob derer die zuständigen Referenten über die Jahre eine derartige Expertise gewonnen haben, dass Dritte nur schwer zügig einzuarbeiten sind. Zum anderen gelangt hier das ganz besondere Vertrauen der Diensthierarchie in den Bearbeiter zum Tragen. Zunächst fallen hierunter Informationen geschützter Urheber (z.B. Beschwerden von Amtsträgern), aber auch dienstinterne vertrauliche Vorgänge sowie Zugang zu Verschlusssachen oder Zugang zu Datenbanken mit restriktiver Freigabe, etwa die NIF-Datenbank, in der die Kommission Vertragsverletzungsverfahren verwaltet. Erster Bezugspunkt für diese Quellen ist naturgemäß aufgrund der Diensthierarchie der Referatsleiter. Fachgebietsabhängig leitet dieser die Information an häufig nur einen mit der Materie besonders vertrauten Referenten weiter. Entscheiden beide Beamte positiv hinsichtlich der besonderen Relevanz der Thematik, wird nach Bedarf eine enggesteckte Gruppe an Sachbearbeitern als teils auch sog. Task Force auf den Sachverhalt angesetzt, die die Sache, selbst im engsten Kollegenkreis, hinter verschlossenen Türen behandelt und nur auf konkrete Veranlassung andere Referenten einbezieht.

\section{h. Die Stellungnahme zur Rechtsstaatlichkeit}

Führt im Rahmen der zuvor erfolgten Sachstandsanalyse, deren Strukturen die Arbeit soeben zu schildern versucht hat, eine Prüfung zu dem Ergebnis, dass die materiellen Tatbestandsvoraussetzungen des EU-Rahmens, also die sog. „Gefährdung des Rechtsstaatsprinzips“, vorliegen, ${ }^{1484}$ so ergeht an den Mitgliedstaat eine Stellungnahme zur Rechtsstaatlichkeit.

Im EU-Rahmen selbst macht die Kommission zum konkreten Inhalt dieser Handlungsform und Verfahrensstufe keinerlei Ausführungen, sondern äußert sich lediglich zu drei Begleitumständen des Verfahrens, nämlich der parallel geführten Erörterungen mit dem Mitgliedstaat, der Vertraulichkeit dieser Verhandlungen und des Dokuments selbst sowie der

1484 Hierzu sogleich, infra. 
Erwartung der Kommission betreffend eine den Pflichten des Art. 4 Abs. 3 EUV entsprechende Mitwirkung des adressierten Mitgliedstaats. ${ }^{1485}$

Eine erste „Frühphase“ der Existenz des EU-Rahmens umfasst den Zeitraum ab seiner Vorstellung im März 2014 bis zu seiner erstmaligen Nutzung im Januar 2016, als die Kommission bekanntgab, es habe eine „Orientierungsaussprache des Kollegiums über die jüngsten Entwicklungen in Polen und den Rahmen zur Stärkung des Rechtsstaatsprinzips" ${ }^{1486}$ gegeben - womit gemeint war, die Kommission sei in die erste Phase der Sachstandsermittlung des EU-Rahmens eingetreten.

Vor der erstmaligen Nutzung des EU-Rahmens, die infolge einer äußerst schnelllebigen Entwicklung erfolgte - zwischen der polnischen Parlamentswahl zum Sejm am 25. Oktober 2015 und der Einleitung des Rahmenverfahrens am 13.01.2016 lagen keine vier Monate -, stand in der Literatur vorrangig die Frage nach der Kompetenz der Kommission zur Schaffung des EU-Rahmenverfahrens im Raum. Die genaue Ausgestaltung der Maßnahmen hat darüber bislang wenig interessiert.

aa. Aufbau der Stellungnahme gegenüber Polen

Genaue Rückschlüsse auf die Ausgestaltung und Argumentationsweise der Kommission in der Stellungnahme sind gleichwohl möglich, denn ungeachtet ihrer ursprünglichen Vertraulichkeit hat die Kommission infolge einer Anfrage von Pech, ${ }^{1487}$ der erfolgreich argumentierte, angesichts der späteren - und öffentlichen - Empfehlungen bestünde für die Kommission kein Geheimhaltungsinteresse mehr, die bis dato einzige ergangene Stellungnahme, diejenige gegenüber Polen, veröffentlicht. ${ }^{1488}$ Ein Mitte

1485 Europäische Kommission, Mitteilung der Kommission an das Europäische Parlament und den Rat, Ein neuer EU-Rahmen zur Stärkung des Rechtsstaatsprinzips vom 11.03.2014, COM(2014) 158 final, S. 8-9.

1486 Europäische Kommission, „Orientierungsaussprache des Kollegiums über die jüngsten Entwicklungen in Polen und den Rahmen zur Stärkung des Rechtsstaatsprinzips“, MEMO/16/62, Factsheet vom 13.01.2016.

1487 Laurent Pech, Commission Opinion of 1 June 2016 regarding the Rule of Law in Poland: Full text now available, http://eulawanalysis.blogspot.de/2016/0 8/commissionopinion-of-1-june-2016.html, dort mit der Stellungnahme im Anhang; PDF-Fassung auch verfügbar unter http://phavi.umcs.pl/at/attachmen ts/2016/1001/122909-ruleof-law-opinion-poland-1-6-2016.pdf.

1488 Europäische Kommission, Commission Opinion of 1.6.2016 regarding the Rule of Law in Poland, C(2016) 3500 final = Ares(2016)4443856 (bislang nur in englischer Sprache verfügbar). 
2015 „mit Nachdruck“ gemachter ${ }^{1489}$ und Ende des gleichen Jahres erneuerter $^{1490}$ Vorschlag des Parlaments, den EU-Rahmen auch gegenüber Ungarn zu nutzen, ist nicht umgesetzt worden.

An dieser Stelle, wie auch für die späteren Empfehlungen, ist die Würdigung des Verfahrens daher in ganz besonderem Maße vom bisher einzigen Präzedenzfall seiner Nutzung abhängig.

Der überwiegende Teil der Stellungnahme besteht aus dem von der Kommission selbst so bezeichneten „factual context“" ${ }^{1491}$ dem eine Art Eingangsformel mit Betonung der Bedeutung der Unionswerte und eine kurze rekapitulierende Darstellung des EU-Rahmens ${ }^{1492}$ nachfolgt. Die so ausgearbeitete Faktenanalyse besteht zunächst aus der Wiedergabe der in der Entwicklung der Rechtsstaatlichkeitskrise in Polen anhand von entsprechenden Entwicklungsschritten, ${ }^{1493}$ insbesondere anhand von Daten. Hinzu kommt eine auswertende und topische, also nach jeweils aufgeworfenen Problemkomplexen strukturierte, Darstellung der im Raum stehenden polnischen Gesetze, hier insbesondere betreffend das polnische Verfassungsgericht. ${ }^{1494}$ Identifizierte Topoi sind z.B. das „attendance quorum“ oder die „voting majority“. Ziel hier ist also die selektiv-auswertende und akkurate Wiedergabe der zu beurteilenden Gesetzestexte.

Ein „Assessment“ (Analyse), das im Grundsatz jeden der zuvor identifizierten Topoi wieder aufgreift, folgt nach. ${ }^{1495}$ Dabei erfolgt seitens der

1489 Europäisches Parlament, P8_TA(2015)0227, Lage in Ungarn: Entschließung des Europäischen Parlaments vom 10. Juni 2015 zur Lage in Ungarn (2015/2700(RSP)), (2016/C 407/06), ABl.(EU) C 407/46 vom 04.11.2016, Rn. 11; P8_TA(2015)0461, Lage in Ungarn: Folgemaßnahmen zur Entschließung des Europäischen Parlaments vom 10. Juni 2015, Entschließung des Europäischen Parlaments vom 16. Dezember 2015 zur Lage in Ungarn (2015/2935(RSP)), (2017/C 399/13), ABl.(EU) C 399/127 vom 24.11.2017, Rn. 8.

1490 Europäisches Parlament, P8_TA(2017)0216, Lage in Ungarn, Entschließung des Europäischen Parlaments vom 17. Mai 2017 zur Lage in Ungarn (2017/2656(RSP)), Erwägungsgrund 8.

1491 Europäische Kommission, Commission Opinion of 1.6.2016 regarding the Rule of Law in Poland, C(2016) 3500 final, S. 4-8, S. 8-9.

1492 Europäische Kommission, Commission Opinion of 1.6.2016 regarding the Rule of Law in Poland, C(2016) 3500 final, S. 2-3.

1493 Europäische Kommission, Commission Opinion of 1.6.2016 regarding the Rule of Law in Poland, C(2016) 3500 final, insb. S. 4-8.

1494 Europäische Kommission, Commission Opinion of 1.6.2016 regarding the Rule of Law in Poland, C(2016) 3500 final, S. 8-9.

1495 Europäische Kommission, Commission Opinion of 1.6.2016 regarding the Rule of Law in Poland, C(2016) 3500 final, S. 12 ff. 
Kommission keine Subsumtion, etwa unter den Begriff der Rechtsstaatlichkeit, noch gar eine Beurteilung nach nationalem Recht. Die Kommission stellt vielmehr auf eine Unterwanderung der Effektivität, hier des Verfassungsgerichts, ab. So heißt es an einer resümierenden Stelle repräsentativ:

"the Commission takes the view that the effect of the amendments concerning the attendance quorum, the voting majority, the handling of cases in chronological order and the minimum delay for hearings, in particular their combined effect, undermine the effectiveness of the Constitutional Tribunal as a guarantor of the Constitution."1496

Das Rekurrieren auf den Grundsatz der Effektivität, den die Kommission hier nicht gesondert herleitet, findet seine teleologisch-systematische Verankerung an späterer Stelle in der Feststellung:

"Where a constitutional justice system has been established, its effectiveness is a key component of the rule of law."1497

bb. Argumentationsweise der Kommission und fünf Charakteristika der Stellungnahme

Rein aufgrund der Feststellung der Existenz der Topoi der Stellungnahme gelangt die Kommission folglich, ohne zusätzliche rechtliche Würdigung, zu dem Ergebnis, dass im adressierten Mitgliedstaat Polen ein „systemic threat to the rule of law" vorliegt. ${ }^{1498}$

Die Kommission macht in ihrer Stellungnahme gegenüber Polen insbesondere keine weiteren Ausführungen betreffend diesen Rechtsbegriff, auch die im EU-Rahmen selbst zu findenden Ausführungen werden nicht aufgegriffen.

Fünf grundlegende Charakteristika der Stellungnahme zur Rechtsstaatlichkeit sind hier festzuhalten:

Erstens und sehr wesentlich ist, dass in der Stellungnahme, ungeachtet ihrer Niedrigschwelligkeit und frühen Position im Rahmenverfahren, zu einem Zeitpunkt, als die Einleitung des Art. 7 EUV-Verfahrens gegenüber

1496 Europäische Kommission, Commission Opinion of 1.6.2016 regarding the Rule of Law in Poland, C(2016) 3500 final, S. 12.

1497 Europäische Kommission, Commission Opinion of 1.6.2016 regarding the Rule of Law in Poland, C(2016) 3500 final, S. 18, Rn. 85.

1498 Europäische Kommission, Commission Opinion of 1.6.2016 regarding the Rule of Law in Poland, C(2016) 3500 final, S. 18. 
Polen noch in weiter Ferne war, wesentliche Aufbau- und Argumentationsmuster desselben bereits angelegt waren. Dies betrifft insbesondere, was die Argumentationsweise der Kommission angeht, das Zusammenfallen von juristischem und politischen Urteil. ${ }^{1499}$ Dabei nutzt die Kommission eine deutlich an den gerichtlichen Argumentationsstil des französischen Verwaltungsrechts erinnernde Schlussfolgerungsweise. ${ }^{1500}$

Zum zweiten verdeutlicht das Abstellen auf die „Effektivität“ des Verfassungsgerichtssystems in Polen als tangiertem Schutzgut dem aufmerksamen Beobachter die Interaktion des EU-Rahmens mit dem Justizbarometer und den impliziten Rückgriff auf die dort angelegte Untersuchungsweise. Denn darin ist bereits seit 2013 festzuhalten, dass die Kommission Justizsysteme anhand ihrer „Effektivität“ bzw. „Leistungsfähigkeit“ vergleicht, ${ }^{1501}$ und es findet sich ebenso regelmäßig der Satz, dass die Union ihren Mitgliedstaaten keine direkten Vorgaben betreffend insbesondere das Bestehen eines Verfassungsgerichts mache, sich dieses indes, wo es bestehe, ebenso am Effektivitätsgrundsatz zu messen lassen habe. Die Kommission hat dem Grundsatz 2018 eine so zentrale Rolle zugewiesen, dass sie ihn sogar zum Titel einer entsprechenden Konferenz erhob. ${ }^{1502}$

1499 Dazu bereits, inklusive der Beobachtung einer Parallele zwischen beiden Verfahren, Armin von Bogdandy u.a, „Guest Editorial: A potential constitutional moment for the European rule of law - The importance of red lines“, S. 986.

1500 Dazu nochmals auch im Detail unter E.VI. im Hinblick auf die Fortsetzung dieses Stils im begründeten Vorschlag; zu den Charakteristika vgl. René Chapus, Droit administratif général, 1. Bd., 8. Aufl. 1994, zit. in Thomas von Danwitz, Verwaltungsrechtliches System und europäische Integration, Mohr Siebeck, Tübingen, 1996, S. 44, mit weiteren Ausführungen zum französischen Urteils- und Argumentationsstil.

1501 Vgl. Europäische Kommission, Mitteilung der Kommission an das Europäische Parlament, den Rat, die Europäische Zentralbank, den Europäischen Wirtschafts- und Sozialausschuss und den Ausschuss der Regionen: Das EUJustizbarometer: Ein Instrument für eine leistungsfähige, wachstumsfördernde Justiz, $\operatorname{COM(2013)~} 160$ final vom 27.03.2013. S. 1 der engl. Originalfassung spricht von der „effectiveness of national justice systems“. Dass in der deutschen Terminologie man sich der präzisen Unterscheidung zwischen Effektivität und Effizienz zu Anfang noch nicht gänzlich bewusst war, zeigt die synonyme Verwendung, S. 2 der dt. Fassung. S. später insb. Europäische Kommission, Mitteilung der Kommission an das Europäische Parlament, den Rat, die Europäische Zentralbank, den Europäischen Wirtschafts- und Sozialausschuss und den Ausschuss der Regionen: EU-Justizbarometer 2019, COM(2019) 198 final, vom 26.04.2019, S. 4, dort als „Leistungsfähigkeit“ übersetzt.

1502 Vgl. Europäische Kommission, Mitteilung der Kommission an das Europäische Parlament, den Rat, die Europäische Zentralbank, den Europäischen Wirtschafts- und Sozialausschuss und den Ausschuss der Regionen: EU-Justiz- 
Der EU-Rahmen hat diese Überlegung im Fall Polen konkret zur Anwendung gebracht.

Zum dritten ist der Stellungnahme zur Rechtsstaatlichkeit zu entnehmen, dass die Kommission, wenn auch vorsichtig, über das bloße „Begründen von Bedenken“, wie sie hierzu noch im EU-Rahmen geschrieben hat, hinausgegangen ist. Während sich an zwei Stellen der Vorschlag findet, dass die polnischen Behörden einem Umsetzungsvorschlag folgen „sollten“ („should“), verknüpft die Kommission dies insbesondere mit der Notwendigkeit der Veröffentlichung ausstehender Urteile („it is necessary“) und der dringenden Notwendigkeit der Behebung der „systemischen Gefährdung der Rechtsstaatlichkeit" als solcher.

Viertens zeigt die Auswertung der Schlussformel der Stellungnahme, dass die Kommission, mit Blick auf das frühe Verfahrensstadium, sich eindeutig am Vertragsverletzungsverfahren orientiert und damit den seitens Viviane Reding gemachten Vorschlag, dies zu tun, ${ }^{1503}$ aufgegriffen hat. Der Wortlaut ist sehr ähnlich.

Die Schlussformel der Stellungnahme zur Rechtsstaatlichkeit lautet:

„The Commission invites the Polish Government to submit its observations on the foregoing within two weeks of receipt of this opinion. On the basis of these observations, the Commission stands ready to pursue the constructive dialogue with the Polish government with a view to finding solutions to the concerns set out in this opinion. If the concerns have not been satisfactorily resolved within a reasonable time, the Commission may issue a recommendation."1504

Die Standardschlussformel der ersten Stufe des Vertragsverletzungsverfahrens, eines Mahnschreibens (letter of formal notice/lettre de mise en démeure, „LFN“), lautet in der englischen Fassung:

„The Commission invites your Government, in accordance with [Art. 258 TFEU] to submit its observations on the foregoing within [two/three etc.] months of receipt of this letter.

barometer 2019, $\operatorname{COM(2019)~} 198$ final, vom 26.04.2019, S. 2 zur „Conference on the Effectiveness of Justice Systems“ („Konferenz über die Leistungsfähigkeit von Justizsystemen“).

1503 Bereits supra unter E.IV. 3; Viviane Reding, „The EU and the Rule of Law What next?", S. 10.

1504 Europäische Kommission, Commission Opinion of 1.6.2016 regarding the Rule of Law in Poland, C(2016) 3500 final, S. 18, Rn. 90. 
After examining these observations, or if no observations have been submitted within the prescribed time-limit, the Commission may, if appropriate, issue a Reasoned Opinion as provided for in the same Article. “1505

Der Eindruck der Anleihen beim Vertragsverletzungsverfahren und dort bei dem LFN insbesondere wird weiter dadurch verstärkt, dass die Kommission, wie dort, und wiederum ohne dass dies bereits in der Mitteilung über den EU-Rahmen angelegt gewesen wäre, eine Fristsetzung gegenüber dem adressierten Mitgliedstaat vornimmt. Diese ist indes, offensichtlich sowohl unter Rücksicht auf die frühe Phase des EU-Rahmens selbst und im Hinblick auf die Rechtsunverbindlichkeit des gesamten Verfahrens, höchst vorsichtig formuliert und abgeschwächt: "If the concerns have not been satisfactorily resolved within a reasonable time, the Commission may issue a recommendation." 1506

Als fünftem Charakteristikum ist darauf hinzuweisen, dass die Stellungnahme zur Rechtsstaatlichkeit in Aufbau und Telos nicht den unterschiedlichen Funktionen entspricht, die bislang in der Literatur der Stellungnahme als Handlungsform zugeschrieben worden ist. ${ }^{1507}$

Senden sieht, gerade im Unterschied zur Empfehlung, die Funktion der Stellungnahme häufig entweder in der Vorbereitung späterer Gesetzgebung (sog. „pre-law“-Funktion) oder als Ergänzung von Entscheidungen („post-law“-Funktion) oder sogar in der Aufgabe, temporär Gesetzgebung zu ersetzen („,para-law“-Funktion). ${ }^{1508}$ Armin von Bogdandy, Jürgen Bast und Felix Arndt haben die Stellungnahme als „Gutachten der Kommission“,

1505 Repräsentativ (hier aber ohne sachlichen Zusammenhang) vgl. Europäische Kommission, Letter of Formal Notice: Infringement 2014/0216 > 2014/0225, SG Greffe(2014) D/976 vom 27.01.2014, abrufbar unter: https:/www.asktheeu. org/en/request/1840/response/11492/attach/4/UK\%20258MDH.PDF.pdf?cooki e_passthrough $=1$.

1506 Europäische Kommission, Commission Opinion of 1.6.2016 regarding the Rule of Law in Poland, C(2016) 3500 final, S. 18.

1507 Für Martin Nettesheim, Art. 288 AEUV, in: Eberhard Grabitz, Meinhard Hilf \& Martin Nettesheim (Begr./Hrsg.), Das Recht der Europäischen Union, C.H. Beck, München, 68. EL Oktober 2019, Rn. 205 ff., bestehen zwischen Stellungnahme und Empfehlung sogar überhaupt keine wesentlichen Unterschiede, er behandelt sie durchweg zusammen.

1508 Linda Senden, Soft Law in European Community Law, insb. S. 188 insb., s. dort auch den Verweis auf die Kategorie einer "decision-making opinion", S. 170 . 
die „Empfehlung“, den Beobachtungen von Senden vergleichbar, als „unverbindliche Richtlinie“ bezeichnet. ${ }^{1509}$

Keine dieser Funktionen ist hier erfüllt. Die Stellungnahme zur Rechtsstaatlichkeit ist, gleich der Empfehlung, eine unselbstständige Teilstufe eines eigenen Mechanismus, der allenfalls, wie Matthias Ruffert, indes noch ohne Kenntnis dieser speziellen Stellungnahme, gemeint hat, eine „weiche[...], influenzierende[...] Steuerung"1510 zukommt. Rufferts Beobachtung stützt nochmals meine zuvor vorgeschlagene Deutung des EURahmens insgesamt als eines „primärrechtsergänzenden“ soft-law-Mechanismus.

\section{i. Die Empfehlung zur Rechtsstaatlichkeit}

Bleibt die Stellungnahme zur Rechtsstaatlichkeit aus Sicht der Kommission unzureichend umgesetzt, endet damit die erste Stufe des EU-Rahmens. Es ergeht, im Rahmen der zweiten Stufe, die Empfehlung zur Rechtsstaatlichkeit. Sie ist unausgesprochen das Herzstück des Mechanismus, denn hier kann die Kommission Tatbestandswürdigung und rechtliche Analyse einer „systemischen Gefährdung“ der Rechtsstaatlichkeit mit politischem Druck und insbesondere eben mit Handlungsempfehlungen an den Mitgliedstaat kombinieren. Der EU-Rahmen selbst sieht eine einzige, öffentlich ergehende, Empfehlung vor.

Im bislang einzigen Anwendungsfall gegenüber Polen hat die Kommission, ohne dass dies in ihrer Mitteilung von 2014 explizit angelegt gewesen wäre, den Verfahrensschritt indes dreimal wiederholt, also insgesamt in einem Zeitraum von gut 18 Monaten - vier Empfehlungen herausgegeben. ${ }^{1511}$ Als Motiv hierfür hat die Kommission ausdrücklich die jeweilige

1509 Armin von Bogdandy, Jürgen Bast \& Felix Arndt: „Handlungsformen im Unionsrecht", S. $115 \mathrm{ff}$., S. $118 \mathrm{ff}$.

1510 Matthias Ruffert, Art. 288 AEUV, in: Christian Calliess \& Matthias Ruffert (Hrsg.), EUV/AEUV, C.H. Beck, München, 5. Aufl. 2016, Rn. 95.

1511 1.: Europäische Kommission, Empfehlung der Kommission vom 27.07.2016 zur Rechtsstaatlichkeit in Polen, C(2016) 5703 final, (EU) 2016/1374, ABl. (EU) L 217/53 vom 12.08.2016, nachfolgend auch erste Empfehlung der Kommission zur Rechtsstaatlichkeit in Polen; 2.: Europäische Kommission, Empfehlung der Kommission vom 21.12.2016 zur Rechtsstaatlichkeit in Polen in Ergänzung zur Empfehlung (EU) 2016/1374, C(2016) 8950 final, (EU) 2017/146, ABl. (EU) L 22/65 vom 27.01.2017, nachfolgend auch zweite Empfehlung der Kommission zur Rechtsstaatlichkeit in Polen; 3.: Europäische Kommission, Empfehlung (EU) 2017/1520 der Kommission vom 26. Ju- 
Ergänzung der vorangegangen aufgrund weiterer Entwicklungen der Lage in Polen genannt. ${ }^{1512}$ Nicht die Figur der Klageerweiterung, wohl aber die im Vertragsverletzungsverfahren bekannte Praxis der Erweiterung des Rügegegenstands durch ein neues Mahnschreiben ist hier der einschlägige Parallelfall, ${ }^{1513}$ wodurch sich nochmals verdeutlicht, dass die Kommission durchaus Anleihen bei diesem Verfahren gemacht hat. Darüber hinaus ist in der wiederholten Empfehlung an Polen, anstatt bereits das Verfahren nach Art. 7 EUV einzuleiten, ein politisches Zugeständnis und das Ersuchen um weiteren Dialog zu sehen.

Schwierig einzustufen ist dabei der Umstand, dass die letzte (vierte) Empfehlung zeitgleich mit der Einleitung des EU-Rahmens am 20.12.2017 ergangen ist und damit in der Praxis keinen eigenständigen Wert mehr hatte. Neben zusätzlichem politischen Druck mag man hierin auch erkennen, dass die Kommission einen möglichst nahtlosen und nicht überraschenden Übergang vom EU-Rahmen zum verbindlichen Verfahren des Art. 7 EUV betonen wollte. ${ }^{1514}$

li 2017 zur Rechtsstaatlichkeit in Polen in Ergänzung der Empfehlungen (EU) 2016/1374 und (EU) 2017/146, C(2017) 5320 final, ABl. (EU) L 228/19 vom 02.09.2017, nachfolgend auch dritte Empfehlung der Kommission zur Rechtsstaatlichkeit in Polen; 4. Europäische Kommission, Empfehlung (EU) 2018/103 der Kommission vom 20. Dezember 2017 zur Rechtsstaatlichkeit in Polen in Ergänzung der Empfehlungen (EU) 2016/1374, (EU) 2017/146 und (EU) 2017/1520, ABl. (EU) L 17/50 vom 23.01.2018, nachfolgend auch vierte Empfehlung der Kommission zur Rechtsstaatlichkeit in Polen.

1512 Exemplarisch Europäische Kommission, Empfehlung (EU) 2018/103 der Kommission vom 20. Dezember 2017 zur Rechtsstaatlichkeit in Polen in Ergänzung der Empfehlungen (EU) 2016/1374, (EU) 2017/146 und (EU) 2017/1520, ABl. (EU) L 17/50 vom 23.01.2018 (vierte Empfehlung zur Rechtsstaatlichkeit), insb. Rn. 2.

1513 Dazu etwa Matthias Pechstein, Art. 258 AEUV, in: Matthias Pechstein, Carsten Nowak \& Ulrich Häde (Hrsg.), Frankfurter Kommentar zu EUV, GRC und AEUV, Mohr Siebeck, Tübingen, 2017, Rn. 22.

1514 Zur Motivlage hat die Kommission selbst nicht Stellung bezogen, sondern lediglich die Gleichzeitigkeit festgehalten, s. Europäische Kommission, Empfehlung (EU) 2018/103 der Kommission vom 20. Dezember 2017 zur Rechtsstaatlichkeit in Polen in Ergänzung der Empfehlungen (EU) 2016/1374, (EU) 2017/146 und (EU) 2017/1520, ABl. (EU) L 17/50 vom 23.01.2018 (vierte Empfehlung zur Rechtsstaatlichkeit), Rn. 50. 
aa. Aufbau der Empfehlung und wesentlicher Inhalt im Fall Polen

Die vier gegenüber Polen ergangenen Empfehlungen bauen inhaltlich aufeinander auf. Während die ersten beiden Empfehlungen ausschließlich die Lage des polnischen Verfassungsgerichts zum Gegenstand hatten, wobei die zweite Empfehlung die Rüge der ersten um die Ernennung und die Auswahl des Präsidenten und Vizepräsidenten des Gerichts ergänzte, ${ }^{1515}$ erweitert die dritte Empfehlung die Rüge auf die nunmehr auf die ordentlichen Gerichtsbarkeit zugeschnittenen Gesetze. Die vierte Empfehlung ergänzte diesen Punkt nochmals. ${ }^{1516}$

Die zuvor im einleitenden Teil der Stellungnahme erfolgte Sachstandsanalyse als Tatbestandssicherung findet sich in der Empfehlung ebenso, und zwar in den Erwägungsgründen. In späteren als der ersten Empfehlung hat die Kommission darüber aber detailliert aufgeführt, welche dieser Punkte sie bereits in vorangegangen Empfehlungen gerügt hat. Es schließt sich in jeder Empfehlung ein funktional zentraler und mit dem Titel „Geltungsbereich der Empfehlung“, bzw. für die vierte Empfehlung vom Dezember 2017, mit dem Titel „Geltungsbereich und Ziel der Empfehlung“ bezeichneter Teil an. Dieser Teil erinnert entfernt an einen Klageantrag. Er fasst nämlich die konkreten Rügen gegenüber dem Mitgliedstaat thesenartig zusammen. Soweit mir bekannt, hat sich keine andere Empfehlung der Kommission in anderen Bereichen bislang eines derartigen Zuschnitts bedient.

An diesen Geltungszuschnitt schließt sich, wie schon für die Stellungnahme, eine nach Problemkomplexen anhand der gegenständlichen Gesetzesmaterie gegliederte Analyse an. Diese nimmt, wie dort, keine Subsumtion unter Rechtssätze vor, sondern stellt vorrangig auf die Bezeichnung

1515 Europäische Kommission, Empfehlung der Kommission vom 21.12.2016 zur Rechtsstaatlichkeit in Polen in Ergänzung zur Empfehlung (EU) 2016/1374, C(2016) 8950 final, (EU) 2017/146, ABl. (EU) L 22/65 vom 27.01.2017 (zweite Empfehlung zur Rechtsstaatlichkeit), Rn. 2, Punkt (4).

1516 Europäische Kommission, Empfehlung (EU) 2017/1520 der Kommission vom 26. Juli 2017 zur Rechtsstaatlichkeit in Polen in Ergänzung der Empfehlungen (EU) 2016/1374 und (EU) 2017/146, C(2017) 5320 final, ABl. (EU) L 228/19 vom 02.09.2017, (dritte Empfehlung zur Rechtsstaatlichkeit), Rn. 2, Punkt (2); Europäische Kommission, Empfehlung (EU) 2018/103 der Kommission vom 20. Dezember 2017 zur Rechtsstaatlichkeit in Polen in Ergänzung der Empfehlungen (EU) 2016/1374, (EU) 2017/146 und (EU) 2017/1520, ABl. (EU) L 17/50 vom 23.01.2018, (vierte Empfehlung zur Rechtsstaatlichkeit), Rn. 2 und 3. 
konkreter rechtlich erheblicher Auswirkungen ab. ${ }^{1517}$ So wird exemplarisch, ohne indes dies an einer bestimmten Rechtsnorm oder -ordnung festzumachen, auf das Gebot der loyalen Zusammenarbeit zwischen Staatsorganen abgestellt. Ebenso abgestellt wird auf die „Unsicherheit und Uneinigkeit", die durch die Weigerung der Befolgung und Veröffentlichung der verfassungsgerichtlichen Urteile entsteht, was auf den Grundsatz der Rechtssicherheit hindeutet. ${ }^{1518}$

Alternativ heißt es:

„Nach Auffassung der Kommission kann die Tatsache, dass ein politisches Gremium über eine vom Verfassungsgericht vorgeschlagene Disziplinarmaßnahme entscheidet (und sich somit auch weigern kann, eine solche zu ergreifen), mit Blick auf die Unabhängigkeit der Justiz ein Problem darstellen, da das Parlament (als politisches Gremium) seine Entscheidungen auf der Grundlage politischer Erwägungen treffen dürfte. [...] Dies gibt Anlass zu Bedenken hinsichtlich der Gewaltenteilung und der Unabhängigkeit des Verfassungsgerichts, da der Vorschlag des Gerichts, einen Richter zu entlassen, vom Sejm abgelehnt werden könnte." ${ }^{1519}$

Auch wird auf gesamteuropäische Standards zur Unterstützung abgestellt, etwa im Hinblick auf das Quorum bei der Beschlussfassung des Verfassungsgerichts. Hierzu heißt es exemplarisch: „Die Kommission stellt fest und dies wird von der Venedig-Kommission bestätigt -, dass der weitaus größte Teil der europäischen Rechtsordnungen nur eine einfache Mehrheit verlangt. “1520

1517 Ausdrücklich dazu etwa Europäische Kommission, Empfehlung (EU) 2018/103 der Kommission vom 20. Dezember 2017 zur Rechtsstaatlichkeit in Polen in Ergänzung der Empfehlungen (EU) 2016/1374, (EU) 2017/146 und (EU) 2017/1520, ABl. (EU) L 17/50 vom 23.01.2018, (vierte Empfehlung zur Rechtsstaatlichkeit), Rn. 25.

1518 Europäische Kommission, Empfehlung (EU) 2018/103 der Kommission vom 20. Dezember 2017 zur Rechtsstaatlichkeit in Polen in Ergänzung der Empfehlungen (EU) 2016/1374, (EU) 2017/146 und (EU) 2017/1520, ABl. (EU) L 17/50 vom 23.01.2018, (vierte Empfehlung zur Rechtsstaatlichkeit), Rn. 17 und 21.

1519 Europäische Kommission, Europäische Kommission, Empfehlung der Kommission vom 27.07.2016 zur Rechtsstaatlichkeit in Polen, C(2016) 5703 final, (EU) 2016/1374, ABl. (EU) L 217/53 vom 12.08.2016 (erste Empfehlung zur Rechtsstaatlichkeit), Rn. 39.

1520 Europäische Kommission, Empfehlung (EU) 2018/103 der Kommission vom 20. Dezember 2017 zur Rechtsstaatlichkeit in Polen in Ergänzung der Empfeh- 
An dieses „issue spotting“ und eine bereits teilweise Verknüpfung etwa mit europäischen Standards schließt sich ein argumentativer Teil betreffend das Vorliegen einer „systemischen Gefährdung der Rechtsstaatlichkeit“ im konkreten Mitgliedstaat an. Der juristische Argumentationsstil entspricht dabei nur lose der deutschen Subsumtionstechnik. Zum einen steht die Interpretation verschiedener zuvor beobachteter Topoi im Hinblick auf die dahinterstehende Intention des polnischen Gesetzgebers im Vordergrund, wie die Neubesetzung des polnischen Verfassungsgerichts. Zum anderen erfolgt eine Verknüpfung der zuvor benannten Topoi mit „europäischen Standards“, für welche die Kommission u.a. auf die Venedig-Kommission rekurriert. Dabei, so hält die Kommission ausdrücklich fest, geht es ihr nicht darum, dem Mitgliedstaat konkrete Vorgaben hinsichtlich der Ausgestaltung seines Justizsystems zu machen. Indes bescheinigt die Kommission dem Mitgliedstaat, ungeachtet seines Ausgestaltungsermessens hierin nicht völlig frei, sondern eben gleich einem Rahmen durch die europäischen Standards gebunden zu sein. Die Kommission stützt also ihre auf dieser Verknüpfung von Topos zu Standard beruhende Argumentation schließlich unter abschließendem Verweis auf die abstrakte Bedeutung der Rechtsstaatlichkeit und die große Zahl der sie in ihren Schlussfolgerungen unterstützenden Akteure..$^{1521}$

Im direkten Vergleich zur Stellungnahme gehen die Empfehlungen, ungeachtet ihrer Anknüpfung an die zuvor gewählte Vorgehensweise der Problemidentifizierung, basierend auf der Auswertung von Gesetzestexten, deutlich über die Komplexität und Dichte der dort noch vergleichsweise kursorischen Ausführungen hinaus. Darüber hinaus ergibt sich schließlich auch ein erheblicher Gleichlauf mit den Gutachten der Venedig-Kommission, auf welche die Kommission umfassend verweist, ebenso wie auf die Rechtsprechung des EGMR und selbstredend diejenige des EuGH. ${ }^{1522}$ Die

lungen (EU) 2016/1374, (EU) 2017/146 und (EU) 2017/1520, ABl. (EU) L 17/50 vom 23.01.2018, (vierte Empfehlung zur Rechtsstaatlichkeit), Rn. 32.

1521 Vgl. am umfassendsten insbesondere Europäische Kommission, Empfehlung (EU) 2018/103 der Kommission vom 20. Dezember 2017 zur Rechtsstaatlichkeit in Polen in Ergänzung der Empfehlungen (EU) 2016/1374, (EU) 2017/146 und (EU) 2017/1520, ABl. (EU) L 17/50 vom 23.01.2018, (vierte Empfehlung zur Rechtsstaatlichkeit), Rn. $36 \mathrm{ff}$.

1522 Europäische Kommission, Empfehlung (EU) 2018/103 der Kommission vom 20. Dezember 2017 zur Rechtsstaatlichkeit in Polen in Ergänzung der Empfehlungen (EU) 2016/1374, (EU) 2017/146 und (EU) 2017/1520, ABl. (EU) L 17/50 vom 23.01.2018, (vierte Empfehlung zur Rechtsstaatlichkeit), Rn. 10 und 11 zur Venedig-Kommission, weiter insb. L 17/55 zur Rechtsprechung. 
Kommission schreibt hier die Operationalisierung des Rechtsstaatsprinzips mittels Konsolidierung eines Rechtsprechungskorpus, gerade zu allgemeinen Rechtsgrundsätzen und europäischen Standards, fort.

\section{bb. Frist beim Übergang zum Verfahren nach Art. 7 Abs. 1 EUV}

Der ursprüngliche EU-Rahmen von 2014 implizierte, dass sich an die Empfehlung zur Rechtsstaatlichkeit eine gewisse Karenzzeit („follow-up“) als dritter Phase anschloss, in der die Kommission die Umsetzung der Empfehlung überprüfen und ggf. per Monitoring weitere Maßnahmen überwachen würde, wobei die Kommission hierfür eine Fristsetzung ankündigte. ${ }^{1523}$ Diese Fristsetzung ist in der Rechtspraxis gegenüber Polen auch erfolgt, die Kommission setzte zuletzt im Dezember 2017 eine Frist von 3 Monaten, was im Grundsatz mit demjenigen Rahmen vergleichbar ist, den die Kommission auch im Vertragsverletzungsverfahren zugrunde legt. ${ }^{1524}$

Allerdings ist in der Praxis gegenüber Polen die Einhaltung der Karenzzeit durch die Kommission selbst, und damit im Grunde das follow-up als Ganzes, entfallen. Die letzte Empfehlung zur Rechtsstaatlichkeit ist zeitgleich mit der Einleitung des Art. 7-EUV-Verfahrens ergangen. Es fragt sich, ob die Kommission zumindest die sich selbst gesetzte Dreimonatsfrist hätte einhalten müssen. Für das Vertragsverletzungsverfahren, dem einzigen Verfahren, welches hier vergleichbar ist und Stütze bietet, ist zumindest in der Literatur vertreten worden, dass in besonders eklatanten Verletzungsfällen die Kommission eine Frist von wenigen Tagen und sogar Stunden setzen könne. ${ }^{1525}$ Allerdings ist der Fall hier anders gelagert,

1523 Europäische Kommission, Mitteilung der Kommission an das Europäische Parlament und den Rat, Ein neuer EU-Rahmen zur Stärkung des Rechtsstaatsprinzips vom 11.03.2014, $\operatorname{COM}(2014) 158$ final, S. 9.

1524 Dort hat sich, wobei Abweichungen nach oben und unten möglich sind, im Grundsatz eine Zweimonatsfrist eingebürgert, s. Martin Burgi, $\$ 6$ Vertragsverletzungsverfahren, in: Hans-Werner Rengeling, Andreas Middeke, Martin Gellermann, Handbuch des Rechtsschutzes in der Europäischen Union, C.H. Beck, München, 3. Aufl. 2014, Rn. 22 ff.

1525 Ulrich Karpenstein, Art. 258 AEUV, in: Eberhard Grabitz, Meinhard Hilf \& Martin Nettesheim (Begr./Hrsg.), Das Recht der Europäischen Union, C.H. Beck, München, Rn. 34, mit Verweis auf Diane de Bellescize, „L'article 169 du Traité de Rome, et l'efficacité du contrôle communautaire sur les manquements des états membres", in: Revue trimestrielle de droit européen 13 (1977), S. 173-213, S. 195. In der dort zit. Rs. 117/75, Kommission ./. Frank- 
die Kommission hat nicht eine sehr kurze Frist gesetzt, sondern die selbstgesetzte Frist unterschritten, was ihr im Vertragsverletzungsverfahren in jedem Fall verwehrt sein dürfte. ${ }^{1526}$

Soweit ersichtlich ist dieser Punkt nicht gesondert zwischen der Kommission und Polen problematisiert worden. Allerdings ficht für die Möglichkeit der Fristunterschreitung auch seitens der Kommission im hiesigen Rahmen, dass die Kommission zum wiederholten Male eine Empfehlung an Polen erlassen hat, der Mitgliedstaat überhaupt nicht auf diese reagierte und überdies zusätzliche, die Lage verschlimmernde, Handlungen unternahm. Damit entfällt ein schützenswertes Interesse seitens Polens spätesten im Falle der vierten Empfehlung zur Rechtsstaatlichkeit. Überdies war aus Sicht der Kommission der Tatbestand des Art. 7 Abs. 1 EUV verwirklicht. Schließlich war die Empfehlung nicht rechtsverbindlich, der Mitgliedstaat konnte sich hiergegen also nicht unmittelbar wenden, sodass ihm aus der kurzen Reaktionszeit auch keine Nachteile erwuchsen.

\section{j. Materieller Tatbestand der „systemischen Gefährdung der Rechtsstaatlichkeit“}

Die Nutzung des EU-Rahmens beruht auf der Feststellung durch die Kommission, dass eine „systemische Gefährdung an Rechtsstaatlichkeit“" in einem Mitgliedstaat besteht. In der deutschen Fassung lautet die Formulierung, es müsse eine Gefährdung vorliegen, „die ihrem Wesen nach systemimmanent ist“ („of a systemic nature“/“de nature systémique“). ${ }^{1527}$

Obwohl hinsichtlich der Ausgestaltung möglich, hat die Kommission den Begriffsbestandteil der "Gefährdung“ im EU-Rahmen selbst zunächst nicht getrennt definiert, ${ }^{1528}$ allenfalls von "aller Wahrscheinlichkeit“ ge-

reich, ECLI:EU:C:1976:64 (aus dem Register gestr.), stand eine Vertragsverletzung durch eine Steuer im Raum, die Frankreich unmittelbar nach dem Mahnschreiben aussetzte.

1526 Hierzu, und zum durch die Frist auch geschützten Interesse der Mitgliedstaaten, Ulrich Karpenstein, Art. 258 AEUV, in: Eberhard Grabitz, Meinhard Hilf \& Martin Nettesheim (Begr./Hrsg.), Das Recht der Europäischen Union, C.H. Beck, München, 68. EL 2019, Rn. 34.

1527 Europäische Kommission, Mitteilung der Kommission an das Europäische Parlament und den Rat, Ein neuer EU-Rahmen zur Stärkung des Rechtsstaatsprinzips vom 11.03.2014, COM(2014) 158 final, S. 7.

1528 A.A. Frank Schorkopf, in: Eberhard Grabitz, Meinhard Hilf \& Martin Nettesheim (Begr./Hrsg.), Das Recht der Europäischen Union, C.H. Beck, München, 68. EL Oktober 2019, Rn. 62. Das dortige Zitat bezieht sich aber m.E. überwie- 
sprochen. ${ }^{1529}$ Sie hatte das Tatbestandsmerkmal indes 2019 dahingehend umrissen, dass sie von „Warnzeichen“ („warning signs“/“signes annonciateurs") sprach, die sie - wenngleich dort ohne explizite Nennung des EU-Rahmens - auf den Zustand in einem Mitgliedstaat bezog.

Eine Abgrenzung und die Wabrung des Abstandsgebots zum Begriff der „Gefahr“, die Art. 7 Abs. 1 EUV fordert, bleibt damit gleichwohl offen, allerdings ist dabei anzumerken, dass der begriffliche Gleichlauf von "Gefährdung“ und „Gefahr" im Deutschen besonders gut sichtbar ist. Im Englischen und Französischen besteht zwischen dem Wortlaut des EU-Rahmens und Art. 7 Abs. 1 EUV mit „threat“/,menace“ und „risk“/,risque" eine deutlichere Unterscheidung. Um die Tatbestände gleichwohl abzugrenzen, mache ich folgenden Vorschlag: es bleibt für den EU-Rahmen und den dortigen Begriff der Gefährdung bei den Grundsätzen, insbesondere des polizeirechtlichen Begriffs der konkreten Gefahr, den die deutsche Rechtswissenschaft wiederholt für Art. 7 Abs. 1 EUV angeregt hat. ${ }^{1530}$ Erforderlich ist also ein Zustand, der ohne weiteres Zutun des Mitgliedstaats aller Voraussicht nach in eine Rechtsgutsgefährdung umschlagen wird. ${ }^{1531}$ Allerdings ist, im Unterschied zu Art. 7 Abs. 1 EUV, die Gefahrenintensität substantiell vermindert, der Zeitpunkt erscheint also

gend auf die konkret erforderlichen Handlungen des Mitgliedstaats als Teil des Attributs des „systemischen“, nicht der Gefährdung selbst.

1529 Europäische Kommission, Mitteilung der Kommission an das Europäische Parlament und den Rat, Ein neuer EU-Rahmen zur Stärkung des Rechtsstaatsprinzips vom 11.03.2014, $\operatorname{COM}(2014) 158$ final, S. 7.

1530 Insbesondere bei Ulrike Kassner, Die Unionsaufsicht, S. 128: Ulrike Kassner nimmt eine Gesamtschau der Gefahrbegriffe des deutschen Polizeirechts, des Straf- und Umweltrechts sowie der EMRK und der UN-Antifolterkonvention vor. Auf ihr aufbauend und ergebnisgleich Katharina Serini, Sanktionen der Europäischen Union bei Verstoß eines Mitgliedstaats gegen das Demokratieoder Rechtsstaatsprinzip, S. 195-196; Stelio Mangiameli und Gabriella Saputelli knüpfen den Gefahrbegriff an die „Dringlichkeit der Umstände“ (periculum in mora) und die Wahrscheinlichkeit der späteren Bejahung der ex-ante-Prognose, ähnlich der Beurteilung im vorläufigen Rechtsschutz (fumus boni iuris), Art. 7 TEU in: Hermann-Josef Blanke \& Stelio Mangiameli (Hrsg.), The Treaty on European Union: A Commentary, Springer, Heidelberg, 2013, Rn. 26.

1531 Bei Ulrike Kassner, Die Unionsaufsicht, S. 130, lautet der aus der o.g. Gesamtschau abgeleitete Gefahrdefinition: „Gefahr“ im Sinne des Art. 7 Abs. 1 EUV bedeutet demnach eine Situation, in welcher aufgrund einer Wahrscheinlichkeitsprognose - also der kritischen Beurteilung des Gegenwärtigen - eine Entwicklung erwartet wird, die zu einer schwerwiegenden Verletzung eines der in Art. 6 Abs. 1 EUV genannten Grundsätze führt. Hinzu kommt, daß es sich um eine eindeutige Gefahr handeln muß.“ 
noch weiter in der Zukunft, die Anhaltspunkte sind weniger eindeutig. ${ }^{1532}$ Gleichwohl, und dies greift nun die Formulierung „threat“/,menace“ auf, ist $\mathrm{zu}$ beobachten, dass die einzelnen Schritte, die dieser Kausalverlauf nehmen wird, bereits früh deutlich hervortreten. Das trägt der Staatskrise in Polen Rechnung. Zwar erschien Ende des Jahres 2015 die Befürchtung, die polnische Justiz werde durch Gesetzgeber und Regierung in ihrer Funktion beeinträchtigt, noch in weiter Ferne, doch die Schritte hierzu waren früh umso deutlicher. Das gilt umso mehr, je vorsätzlicher die Handlungen sind. Damit ist die Gefährdung selbst nicht „eindeutig“ i.S.d. Art. 7 Abs. 1 EUV, doch die potentielle Entwicklung des Kausalverlaufs ist bereits deutlich erkennbar.

Hat man etwas Mühe bei der Abgrenzung der Tatbestandsmerkmale „Gefährdung" und „Gefahr“, so hat die Kommission das qualifizierende Adjektivattribut „systemisch“ umso genauer umschrieben. Die Bejahung der „systemischen“ Natur hängt demnach an drei gesonderten Tatbestandskriterien.

Erforderlich ist zunächst die Gefährdung eines Schutzgutes, nämlich der Rechtsstaatlichkeit, ${ }^{1533}$ die hier dergestalt operationalisiert ist, dass im Wesentlichen die Funktionsfähigkeit der Verfassungs- und Rechtsordnung eines Mitgliedstaats betroffen sein muss. Die Kommission schreibt:

„Die Gefährdung muss sich gegen die politische, institutionelle und/ oder rechtliche Ordnung eines Mitgliedstaats als solche, die verfassungsmäßige Struktur, die Gewaltenteilung, die Unabhängigkeit oder Unparteilichkeit der Justiz oder das System der richterlichen Kontrolle einschließlich der Verfassungsjustiz (sofern vorhanden) richten und

1532 Diese Logik diskutiert, für die Abgrenzung der „eindeutigen“ Gefahr i.S.d. Art. 7 Abs. 1 EUV von anderen Gefahren bereits Ulrike Kassner, Die Unionsaufsicht, S. 131, die für Art. 7 Abs. 1 EUV die „Eindeutigkeit“" an besonders klare Anhaltspunkte knüpft und eine Berücksichtigung der Gefahrintensität ausschließt. Ähnlich Frank Schorkopf, Art. 7 EUV, in: Eberhard Grabitz, Meinhard Hilf \& Martin Nettesheim (Begr./Hrsg.), Das Recht der Europäischen Union, C.H. Beck, München, 68. EL 2019, C.H. Beck, München, Rn. 21.

1533 Ähnlich Frank Schorkopf, Art. 7 EUV, in: Eberhard Grabitz, Meinhard Hilf \& Martin Nettesheim (Begr./Hrsg.), Das Recht der Europäischen Union, C.H. Beck, München, 68. EL 2019, Rn. 62 („Das primäre Schutzgut ist der Wert der

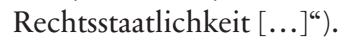


beispielsweise von neuen Maßnahmen oder weit verbreiteten Praktiken der Behörden und fehlendem Rechtsschutz ausgehen. "1534

Diese Aufzählung ist als Bestätigung von Verfassungsfunktionskriterien eines Mitgliedstaats zu sehen, bei deren Betroffenheit der systemische Charakter der Gefährdung in jedem Fall bejaht wird, ohne aber, dass die Enumeration abschließend wäre.

Zum zweiten müssen das so umrissene Schutzgut der Rechtsstaatlichkeit bzw. ein einzelnes Subprinzip derselben, durch eine konkrete Handlung der mitgliedstaatlichen Staatsgewalt gefährdet sein. Ausgeschlossen sind also Eingriffe von außen, höhere Gewalt usw. Die Schutzguttangierung wird zugleich nochmals bekräftigt:

„Der neue EU-Rahmen gelangt zur Anwendung, wenn die Behörden eines Mitgliedstaats Maßnahmen ergreifen oder Umstände tolerieren, die aller Wahrscheinlichkeit nach die Integrität, Stabilität oder das ordnungsgemäße Funktionieren der Organe und der auf nationaler Ebene zum Schutz des Rechtsstaats vorgesehenen Sicherheitsvorkehrungen systematisch beeinträchtigen. "1535

Drittens hängt die Bejahung der systemischen Natur an der Prüfung einer aufdrängenden und einer abdrängenden Handlungsbedarfsverweisung an die Kommission. Zu prüfen ist zum einen (aufdrängende Handlungsbedarfsverweisung) als quantitatives Merkmal das Vorliegen einer kritischen Fallzabl: „Bei vereinzelten Grundrechtsverstößen oder Justizirrtümern [...] soll das neue EU-Verfahren nicht greifen". ${ }^{1536}$ Hiernach und abschließend ist zu prüfen (abdrängende Handlungsbedarfsverweisung), ob die nationalen Stellen zunächst selbst handeln können: „Das neue EU-Verfahren kommt zum Einsatz, wenn die nationalen Vorkehrungen zum Schutz der Rechtsstaatlichkeit nicht ausreichend erscheinen, um die Gefährdung

1534 Europäische Kommission, Mitteilung der Kommission an das Europäische Parlament und den Rat, Ein neuer EU-Rahmen zur Stärkung des Rechtsstaatsprinzips vom 11.03.2014, COM(2014) 158 final, S. 7.

1535 Europäische Kommission, Mitteilung der Kommission an das Europäische Parlament und den Rat, Ein neuer EU-Rahmen zur Stärkung des Rechtsstaatsprinzips vom 11.03.2014, COM(2014) 158 final, S. 7.

1536 Europäische Kommission, Mitteilung der Kommission an das Europäische Parlament und den Rat, Ein neuer EU-Rahmen zur Stärkung des Rechtsstaatsprinzips vom 11.03.2014, COM(2014) 158 final, S. 7. 
effektiv abzustellen." ${ }^{1537}$ Das entspricht der Beobachtung bei Bieber und Maiani von einer "Zentralisierungstendenz" ${ }^{1538}$ allerdings hat die Kommission dafür einen triftigen Grund: das Versagen nationaler Stellen, selbst Abhilfe zu schaffen.

Die Kommission stützt die Herleitung und die Begriffsquellen des Attributs des „systemischen“ spezifisch für den EU-Rahmen ganz besonders auf die zuvor genannte „N.S.“-Rechtsprechung des EuGH. ${ }^{1539} \mathrm{Ob}$ ihr damals schon weitere Entwicklungsstränge, wie die sog. „Irish-Waste“-Rechtsprechung des EuGH, konkret vor Augen standen, lässt sie aber offen.

Auch aus diesem Grund ist hier nochmals zu wiederholen, dass der Begriff der systemischen Gefährdung zwar Material für die Herausbildung des dogmatischen Rechtsbegriffs des systemischen Defizits bietet, sich mit diesem aber nicht deckt.

Die Prüfung dieser Kriterien obliegt der Europäischen Kommission nach ihrem Ermessen, wobei sie allerdings, wie zuvor gezeigt, umfassend auch auf Vorerkenntnisse gerade der Venedig-Kommission zurückgreifen kann. Die Bemühung weiterer Dritter, etwa sog. „unabhängiger Persönlichkeiten", die im Rahmen von Art. 7 Abs. 1 EUV möglich bleiben soll, ist in der Praxis bislang nicht aktiv verfolgt worden.

Die Operationalisierung der systemischen Gefährdung gerade im Rahmen der Entwicklung in Polen hat weiter bedingt, dass die Kommission das Verfahren ganz vorrangig auf die Unabhängigkeit der Justiz zugeschnitten hat, auch wenn dies ursprünglich nicht angelegt war. Neben den Funktionskriterien, die die Kommission unmittelbar dem Mechanismus selbst zugrunde legt, dient der Anhang I der Mitteilung auch der weiteren Vergewisserung hinsichtlich der Operationalisierung der Rechtsstaatlichkeit in der Rechtsprechung des EuGH, im Recht des Europarates und im nationalen Recht. Unter den dort genannten Kriterien findet sich u.a. auch die wirksame Grundrechtsgewähr als Teil des Rechtsstaatsprinzips. ${ }^{1540}$

1537 Europäische Kommission, Mitteilung der Kommission an das Europäische Parlament und den Rat, Ein neuer EU-Rahmen zur Stärkung des Rechtsstaatsprinzips vom 11.03.2014, $\operatorname{COM}(2014) 158$ final, S. 8.

$1538 \mathrm{Zu}$ dieser Beobachtung im Allgemeinen Roland Bieber \& Francesco Maiani, „Enhancing centralized enforcement of EU law: Pandora's toolbox?" in: Common Market Law Review 51 (2014), S. 1058-1092, S. 1059.

1539 Europäische Kommission, Mitteilung der Kommission an das Europäische Parlament und den Rat, Ein neuer EU-Rahmen zur Stärkung des Rechtsstaatsprinzips vom 11.03.2014, COM(2014) 158 final, S. 7, bei Fn. 18.

1540 Europäische Kommission, Mitteilung der Kommission an das Europäische Parlament und den Rat, Ein neuer EU-Rahmen zur Stärkung des Rechtsstaats- 
Die Kommission ging, im Unterschied zu frühen Vorschlägen in der Literatur, ${ }^{1541}$ also von einem breiten, materiellen und nicht nur formellen Verständnis der Rechtsstaatlichkeit aus, das macht sie im EU-Rahmen unter Berufung auf den EuGH auch ausdrücklich deutlich. ${ }^{1542}$ Erst die polnische Krise hat die Debatte ganz auf die Justizgewähr zulaufen lassen. In ihrer Mitteilung vom Juli 2019 hat die Kommission darüber sogar festgehalten: „Die Justiz ist das Kernstück der Rechtsstaatlichkeit“. ${ }^{1543}$ Gleichwohl scheint mir damit das Verfahren nicht irreversibel ausschließlich auf einen solchen Fall allein festgelegt, mit anderen Worten: der EU-Rahmen ist kein Verfahren zur Gewährleistung der Unabhängigkeit der Justiz allein, er bleibt auf die Gesamtheit der Subprinzipien der Rechtsstaatlichkeit bezogen, auch wenn er derzeit ganz unter dem Eindruck der Krise in Polen steht.

Bleibt die Nutzung des EU-Rahmens zur Stärkung der Rechtsstaatlichkeit ohne zufriedenstellendes Ergebnis, so leitet die Kommission das Verfahren nach Art.7 EUV ein, wie am 20.12.2017 gegenüber Polen erfolgt. Ich erörtere die Entwicklung dieses Verfahrens in der Rechtsstaatlichkeitskrise im nachfolgenden Abschnitt. Zuvor ist aber auf das Justizbarometer einzugehen.

prinzips vom 11.03.2014, $\operatorname{COM(2014)~} 158$ final, Anhang I: Das Rechtsstaatsprinzip als tragendes Prinzip der Union, S. 2, lit d).

1541 Etwa bei Armin von Bogdandy \& Michael Ioannidis, „Das systemische Defizit“, S. 288.

1542 Europäische Kommission, Mitteilung der Kommission an das Europäische Parlament und den Rat, Ein neuer EU-Rahmen zur Stärkung des Rechtsstaatsprinzips vom 11.03.2014, COM(2014) 158 final, S. 4, bei Fn. 11 insb.

1543 Europäische Kommission, Mitteilung der Kommission an das Europäische Parlament, den Rat, die Europäische Zentralbank, den Europäischen Wirtschafts- und Sozialausschuss und den Ausschuss der Regionen, EU-Justizbarometer 2018, Part 1/2, $\operatorname{COM(2018)~} 364$ final, vom 28.05.2018, S. 5, vgl. insb. auch die engl. Ausgabe, z.B. S. 5 der Broschürenfassung; vgl. weiter Mitteilung der Kommission an das Europäische Parlament, den Rat, die Europäische Zentralbank, den Europäischen Wirtschafts- und Sozialausschuss und den Ausschuss der Regionen, EU-Justizbarometer 2019, COM(2019) 198 final, vom 26.04.2019, S. 8 ff. 


\section{Das EU-Justizbarometer}

a. Grundlagen

\section{aa. Begriff des Barometers}

Ein weiteres Verfahren der „partiellen“ Verfassungsaufsichtsinstrumente, dem also eine Berichtigungsphase fehlt, ist das EU-Justizbarometer. Dafür nutzt die Europäische Kommission es für eine umso genauere Beobachtung und wirkt auf diese Weise umso subtiler, vorrangig im politischen Austausch mit den Mitgliedstaaten, auf eine Berichtigung hin, ohne dass das Verfahren selbst berichtigt. Es wird in der Praxis durch dieselben zuständigen Dienststellen verwaltet, denen auch die anderen hier beschriebenen Instrumente unterstehen, nämlich insbesondere durch das Referat C. 1 der Direktion C der GD JUST. ${ }^{1544}$

Der Begriff des „Barometers“ bzw. insbesondere des griffigeren „Scoreboard“ im Englischen hat in der Literatur etwas irritiert; ${ }^{1545}$ es ist allerdings darauf hinzuweisen, dass die Kommission diverse „Scoreboards“ unterhält, die dabei so heterogen sind, dass sie sich nicht bündig auf einen Nenner bringen lassen. ${ }^{1546}$ Besondere Prominenz hat auch das

1544 Noch zum Referatszuschnitt in der Barroso-Kommission vgl. Nina Peršak \& Jože Štrus, „Legitimacy and Trust-Related Issues of Judiciary: New Challenges for Europe“, in: Nina Peršak (Hrsg.), Legitmacy and Trust in Law, Policy and Justice: Norms, Procedures, Outcomes, Routledge, London/New York, 2016, S. 89-110, S. 103. Die jetzige Zuständigkeit ist ableitbar etwa aus dem Sitzungsprotokoll der Kommission mit ihren Kontaktpersonen, vgl. unter: https://ec.eu ropa.eu/transparency/regexpert/index.cfm?do=groupDetail.groupDetailDoc\&i $\mathrm{d}=35052 \&$ no $=1$.

1545 Christoph Kern in: Christian Baldus, Christoph Kern, Aurélien Raccah, Ioannis Mantzouranis, Remo Caponi, Fernando Gascón Inchausti, \& Radovan Dávid: „Das ,EU Justice Scoreboard“ der Europäischen Kommission“, in: Zeitschrift für das Privatrecht der Europäischen Union, Zeitschrift für das Gesamte Privatrecht (GPR) (2016), S. 108-115, S. 109.

1546 So veröffentlicht die Kommission bereits seit 2001 das „Staatshilfebarometer“ (State Aid Scoreboard), http://ec.europa.eu/competition/state_aid/scoreb oard/index_en.html. Der Vorgänger desselben war, bereits seit 1988, der "Survey of State Aids in the European Community“, vgl. Pressemitteilung der Kommission IP(89)362, ohne Titel/Datum. Seit 2009 veröffentlicht sie zusätzlich das „Regionale Innovationsbarometer“ (Regional Innovation Scoreboard), https://ec.europa.eu/growth/industry/innovation/facts-figures/regional_e n. Weiter unterhalten werden ein „Verbraucherbarometer" (Consumer Scoreboard), https://ec.europa.eu/info/strategy/consumers/consumer-protection/e 
„Scoreboard“ zur makroökonomischen Überwachung, das im Rahmen des sog. „Six Pack“ eingeführt wurde, erlangt. ${ }^{1547}$ Die Kommission erfasst mit ihnen, weit auch in mitgliedstaatliche Zuständigkeitsbereiche hinreichend, Politikgestaltung und Rechtsetzung in diversen und weitgefassten Bereichen. Das bedingt eine selbstständige Würdigung des „Scoreboard“Begriffs für das Justizbarometer, der dahingehend zu verstehen ist, vorrangig auf den analytischen Vergleich einzelner Aspekte mitgliedstaatlicher Justizsysteme abzuzielen.

vidence-based-consumer-policy/consumer-scoreboards_en, ein „Europäisches Innovationsbarometer", (European Innovation Scoreboard), http://ec.europa. eu/growth/industry/innovation/facts-figures/scoreboards_de, ein „Digitalbarometer" (Digital Scoreboard), https://ec.europa.eu/digital-single-market/en/po licies/scoreboard, ein „Binnenmarktbarometer“ (Single Market Scoreboard), https://ec.europa.eu/internal_market/scoreboard/, und sogar jüngst ein „Sozialbarometer" (Social Scoreboard), http://ec.europa.eu/internal_market/s coreboard/. Sehr breit geschnitten ist auch der sog. „REFIT-Anzeiger“ (REFIT Scoreboard), https://op.europa.eu/webpub/com/refit-scoreboard/en/index.htm 1. Weitere Ausführungen zu diesen Mechanismen müssen hier aus Platzgründen unterbleiben. Ein Sonderfall, da nicht regelmäßig herausgegeben, und daher eher einem Strategiepapier entsprechend, ist das sog. „Roma-Scoreboard“, dazu Communication from the Commission to the European Parliament, the Council, the European Economic and Social Committee and the Committee of the Regions: An EU Framework for National Roma Integration Strategies up to 2020, $\operatorname{COM}(2011)$ 173/4, ohne Datum, nur in engl. Spr.; weiter Communication to the European Parliament and the Council, Midterm review of the EU framework for national Roma integration strategies, EU Framework for National Roma Integration Strategies, COM (2017) 458 final vom 30.08.2017, nur in engl. Spr., zu den Parallelen dieser Papiere mit dem Justizbarometer s. Elisabeth van Rijckevorsel, „The EU and the indirect promotion of its values: an analysis of the EU Justice Scoreboard and of the Roma Framework", in: Journal européen des droits de l'homme/European Journal of Human Rights 3 (2016), S. 444-468, S. 458 ff.

1547 Auch in der deutschen Fassung ist der Titel „Scoreboard“ beibehalten worden, die Rechtsgrundlage ist Art. 4 der VO 1176/2011 des Europäischen Parlaments und des Rates vom 16. November 2011 über die Vermeidung und Korrektur makroökonomischer Ungleichgewichte, ABl. (EU) L 306/25 vom 23.11.2011. Kommentierung bei Jens Hamer, Art. 126 AEUV, in: Hans von der Groeben, Jürgen Schwarze \& Armin Hatje (Begr./Hrsg.), Europäisches Unionsrecht, Nomos, Baden-Baden, 7. Aufl. 2015, Rn. 35, weiter Antonio Estella, Legal Foundations of EU Economic Governance, Cambridge University Press, Cambridge, 2018, S. $177 \mathrm{f}$. 
bb. Genese, Telos und Leitbegriffe des Justizbarometers

Das EU-Justizbarometer ist zunächst ein erstmals 2013 vorgestellter und genutzter, jährlich und zyklisch - durchaus vergleichbar dem Europäischen Semester - gegenüber allen Mitgliedstaaten unterschiedslos und anlasslos zur Anwendung gelangender Sachstandserhebungs- und Evaluierungsmechanismus, ${ }^{1548}$ der die Effektivität mitgliedstaatlicher Justizsysteme misst und vergleicht, die Rechtsstaatlichkeit selbst hat erst sukzessive im Justizbarometer an Bedeutung gewonnen. In der Literatur ist insbesondere darauf hingewiesen worden, dass etwa die Länge rechtshängiger Verfahren Rückschlüsse auf die Verwirklichung des fair-trial-Grundsatzes in einem Mitgliedstaat ermögliche; auch ermögliche die Ressourcenbereitstellung ähnliche Rückschlüsse für die adäquate Funktionsweise eines Justizsystems. ${ }^{1549}$

Die Kommission betont regelmäßig, das Barometer sei ein „Informationsinstrument" (information tool), das keine globale Rangliste der Justizsysteme erstelle, sondern einen Überblick über diejenigen Aspekte der Funktionsweise nationaler Justizsysteme bereitstelle, die von gemeinsamem Interesse seien. Damit ist es, gänzlich unterschieden zum EU-Rahmen, kein anlassbezogenes und lediglich gegenüber einem einzelnen Mitgliedstaat zur Anwendung gelangendes Verfahren. Was die Qualität als „Informationsinstrument" betrifft, ist aber anzumerken, dass das Justizbarometer sehr wohl über die reine Information hinausgeht. ${ }^{1550}$ Das Barometer selbst ist also die Präsentation von Analyseergebnissen, nicht bloße Beschreibung, und zumindest in Teilbereichen des Barometers wird jedenfalls ein Vergleich („ranking“) der nationalen Justizsysteme erstellt.

Die Entstehung des Justizbarometers beruht auf einem doppelten Impetus: zum einen der sich seit Beginn der sog. Jahreswachstumsberichte als Teil des Europäischen Semesters abzeichnende Bedarf der Beurteilung mit-

1548 Die Sammlung aller bislang ergangenen Justizbarometer und einführende Erläuterungen finden sich unter: https://ec.europa.eu/info/policies/justice-and-fu ndamental-rights/upholding-rule-law/eu-justice-scoreboard_en.

1549 Elaine Mak \& Sanne Taekema, „The European Union's Rule of Law Agenda: Identifying Its Core and Contextualizing Its Application“, in: Hague Journal on the Rule of Law 8 (2016), S. 25-50, S. 32.

1550 Vgl. Europäische Kommission, Mitteilung der Kommission an das Europäische Parlament, den Rat, die Europäische Zentralbank, den Europäischen Wirtschafts- und Sozialausschuss und den Ausschuss der Regionen, EU-Justizbarometer 2019, COM(2019) 198 final, vom 26.04.2019, S. 4. 
gliedstaatlicher Justizsysteme ${ }^{1551}$ und die Positionierung von Justizkommissarin Reding 2013, wonach die Krisenbeobachtungen in Ungarn und Rumänien unmittelbar in die Entwicklung des Justizbarometers gemündet seien. Reding sah in ihm ursprünglich sogar die mögliche Basis für die Entwicklung weiterer Instrumente:

"This could become the basis for a more comprehensive tool in the future." ${ }^{1552}$ Umso überraschender ist es, dass dieser Aspekt erst im Zuge der Krise zum Tragen kam.

Der die Analyse strukturierende Leitbegriff der Effektivität (effectiveness/effectivité), im Deutschen teils auch als „Leistungsfähigkeit“" übersetzt, ist ein analytisches Kompositum, das drei einzelne Analysebereiche umfasst: Effizienz, Qualität und Unabhängigkeit. ${ }^{1553}$ Obwohl die Ausgabe von 2019 die Unabhängigkeit in der Einleitung stets als erstes nennt, wodurch ihre Bedeutung betont wird, beginnt die Analyse im Justizbarometer traditionell mit der Effizienz. ${ }^{1554}$ Sie wird im Justizbarometer nicht definiert, meint indes die Fähigkeit des Justizsystems, möglichst hohe Fallumsatzund Fallerledigungsraten auch bei hohen Falleingangszahlen („heavy caseload“) zu erzielen und dabei den Prozess unter Wahrung sonstiger Grundsätze guter Rechtsprechung maximal zu rationalisieren, d.h. z.B. durch möglichst klare Gerichtsorganisation und Zuständigkeitsverteilung, eingeschliffenes Prozessrecht usw.

Die Qualität der Justizsysteme wird von der Kommission operationalisiert, sie hängt an vier Kriterien: erstens der „Zugänglichkeit der Justizsysteme für Bürger und Unternehmen“, zweitens den „angemessenen

$1551 \mathrm{Zu}$ diesem Aspekt Elisabeth van Rijckevorsel, „The EU and the indirect promotion of its values", S. 449.

1552 Viviane Reding, „The EU and the Rule of Law - What next?“, S.9, weiter Adriani Dori, „The EU Justice Scoreboard - Judicial Evaluation as a New Governance Tool“, MPILux Working Paper Series, No. 2/2015, Max Planck Institute Luxembourg for International, European and Regulatory Procedural Law, S. 12 ff., mit ausführlicher Dokumentation auch zahlreicher Reden.

1553 Zur Unterscheidung und dem Begriff der Effektivität s. Europäische Kommission, Mitteilung der Kommission an das Europäische Parlament, den Rat, die Europäische Zentralbank, den Europäischen Wirtschafts- und Sozialausschuss und den Ausschuss der Regionen, EU-Justizbarometer 2019, COM(2019) 198 final vom 26.04.2019, S. 3 der dt. und engl., S. 4 der franz. Fassung, weiter das Vorwort (nur in der engl. Fassung), dazu auch bereits unter C.III.4.

1554 Zur Unterscheidung s. Europäische Kommission, Mitteilung der Kommission an das Europäische Parlament, den Rat, die Europäische Zentralbank, den Europäischen Wirtschafts- und Sozialausschuss und den Ausschuss der Regionen, EU-Justizbarometer 2019, $\operatorname{COM(2019)~} 198$ final vom 26.04.2019, S. 14 ff. 
materiellen und personellen Ressourcen“, drittens der „Einführung von Bewertungsinstrumenten“ und schließlich der „Anwendung von Qualitätsstandards“. ${ }^{1555}$ Die Zugänglichkeit umfasst dabei z.B. Erhebungen zu den öffentlich einsehbaren Informationen über die Justiz oder betreffend Prozesskostenhilfe, aber auch die Verfügbarkeit elektronischer Hilfsmittel. Während der zweite Punkt selbsterklärend ist, meint der dritte Punkt justizeigene Kontrollen, wie Umfragen und Statistiken. Dies leitet einigermaßen fließend in den letzten Punkt, die Nutzung von Standards z.B. für die Zeitplanung, über.

Den letzten ihrer Analyse zugrunde gelegten Begriff, die Unabhängigkeit - wahlweise ist von richterlicher Unabhängigkeit oder Unabhängigkeit der Justiz die Rede -, misst und erhebt die Kommission indirekt. Sie bedient sich dazu Umfragen in der Bevölkerung sowie externer, insbesondere durch das Weltwirtschaftsforum erhobener Daten, die auf das Vertrauen der Rechtssubjekte in die mitgliedstaatliche Justiz abstellen. ${ }^{1556}$ Es ergibt sich hier eine Parallele insbesondere zu Korruptionsstatistiken, bei denen es ebenso als wenig sinnvoll erscheint, die staatlichen Stellen selbst zu befragen.

\section{cc. Diagrammtypen und Quellen}

Zur Darstellung und Strukturierung ihrer Ergebnisse bedient sich die Kommission, neben Erläuterungen im Fließtext, vier Typen graphischer Darstellungen. Den überwiegenden Teil nehmen dabei klassische Balkendiagramme, ${ }^{1557}$ insbesondere im Leistungsvergleich einzelner Kriterien,

1555 Europäische Kommission, Mitteilung der Kommission an das Europäische Parlament, den Rat, die Europäische Zentralbank, den Europäischen Wirtschafts- und Sozialausschuss und den Ausschuss der Regionen, EU-Justizbarometer 2019, COM(2019) 198 final vom 26.04.2019, S. 28-29.

1556 Europäische Kommission, Mitteilung der Kommission an das Europäische Parlament, den Rat, die Europäische Zentralbank, den Europäischen Wirtschafts- und Sozialausschuss und den Ausschuss der Regionen, EU-Justizbarometer 2019, $\operatorname{COM(2019)~} 198$ final vom 26.04.2019, S. 55 ff.

1557 Eine Variante ist dabei die insb. in Schaubild 47 und 49 des Justizbarometer 2019 erfolgende Wiedergabe zweier korrespondierender Werte in einem Balkendiagramm, vgl. Europäische Kommission, Mitteilung der Kommission an das Europäische Parlament, den Rat, die Europäische Zentralbank, den Europäischen Wirtschafts- und Sozialausschuss und den Ausschuss der Regionen, EU-Justizbarometer 2019, $\operatorname{COM(2019)~} 198$ final, vom 26.04.2019, S. 55 und 56, zur Wahrnehmung richterlicher Unabhängigkeit. 
und gestapelte Balkendiagramme (stacked bar charts) ein, die die Kumulation von Kriterien verdeutlichen. Zwei speziell in späteren Ausgaben des Justizbarometers prominent genutzte Sonderformen ${ }^{1558}$ sind die hier sog. qualitativen Einkriteriendiagramme bzw. Mehrkriteriendiagramme, mit denen die Kommission das Vorhandensein sowie die rechtssystemspezifische Ausprägung bestimmter Kriterien, wie z.B. die Art und den Aufbau der Richterernennung, in einem Mitgliedstaat verdeutlicht.

Sie sehen exemplarisch wie folgt aus (jeweils aus dem Justizbarometer 2019):

Diagrammtyp Balkendiagramm:

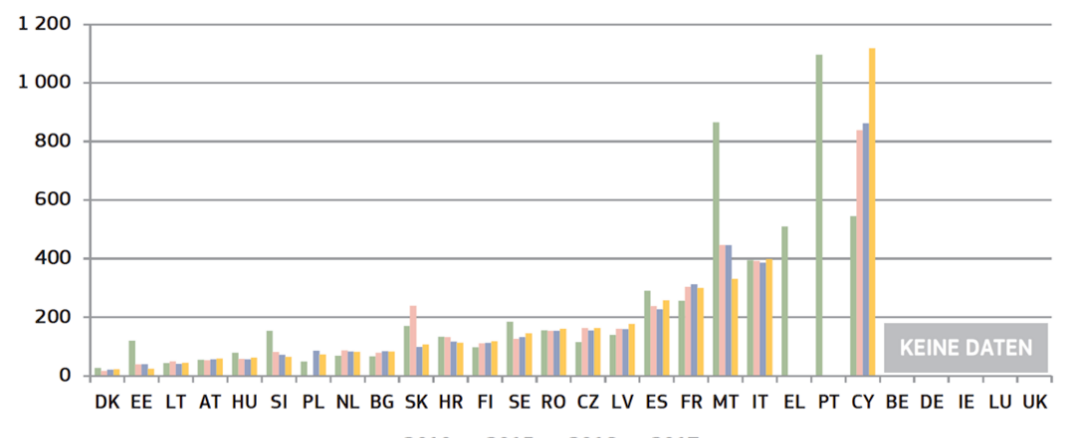

(*) Nach der CEPEJ-Methodik gehören zu dieser Kategorie alle streitigen und nichtstreitigen Zivil- und Handelssachen, nichtstreitige Grundbuch- und Unternehmensregistersachen, andere Registersachen, sonstige nichtstreitige Rechtssachen, Verwaltungssachen und sonstige Rechtssachen außer Strafsachen. Änderung der Methodik in SK. In CZ und (bis 2016) in SK umfassen die anhängigen Rechtssachen alle Instanzen.

Abbildung 1: Schaubild 5 - Für den Abschluss von Zivil-, Handels-, Verwaltungs- und sonstigen Rechtssachen erforderliche Zeit

1558 Vgl. Europäische Kommission, Mitteilung der Kommission an das Europäische Parlament, den Rat, die Europäische Zentralbank, den Europäischen Wirtschafts- und Sozialausschuss und den Ausschuss der Regionen, EU-Justizbarometer 2019, COM(2019) 198 final, vom 26.04.2019, S. $63 \mathrm{ff}$. 
Diagrammtyp gestapeltes Balkendiagramm (hier ohne erläuternden Begleittext):

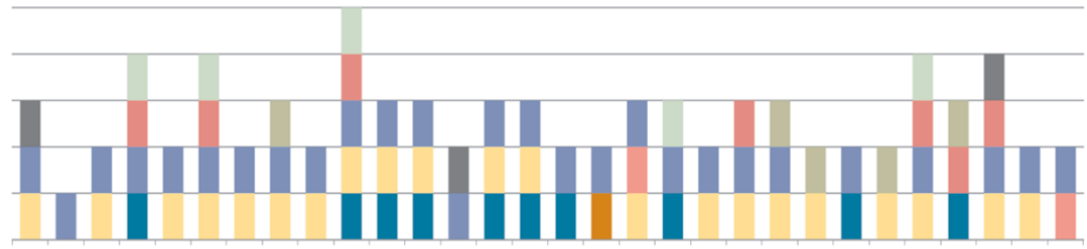

BE BG CZ DK DE EE IE EL ES FR HR IT CY LV LT LU HU MT NL AT PL PT RO SI

- Judikative definiert Kriterien

= Parlament definiert Kriterien

- Betrag basiert auf historische/tatsächliche Kosten

Anzahl der abgeschl. Verfahren wird berücksichtigt

(EN (NI) (SC)

- Anzahl der abgeschl. Verfahr

Abbildung 2: Schaubild 30 - Kriterien zur Festlegung der finanziellen Ressourcen für das Justizwesen

Diagrammtyp hier sog. qualitatives Einkriteriendiagramm (hier ohne erläuternden Begleittext):

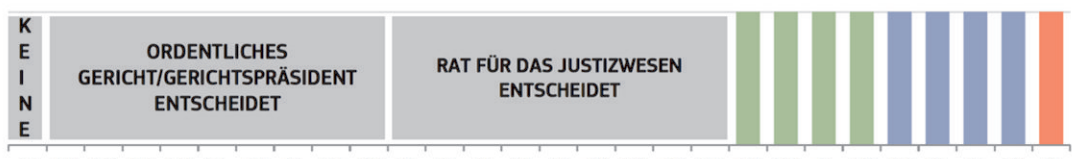

IE BE DK DE LU NL AT FI SE UK BG ES FR HR IT CY MT PT RO LT HU SI SK CZ EE EL LV PL

a Sondergericht, das sich aus vom Justizminister ausgewählten Richtern zusammensetzt

- Sondergericht, das sich aus von Richtern ausgewählten Richtern zusammensetzt

- Sondergericht, dessen Mitglieder vom Rat für das Justizwesen ausgewählt werden

Abbildung 3: Schaubild 52 - Behörde, die über Disziplinarmaßnahmen für Richter entscheidet 
Diagrammtyp hier sog. qualitatives Mehrkriteriendiagramm bzw. Prozessverlaufsdiagramm (hier ohne erläuternden Begleittext):

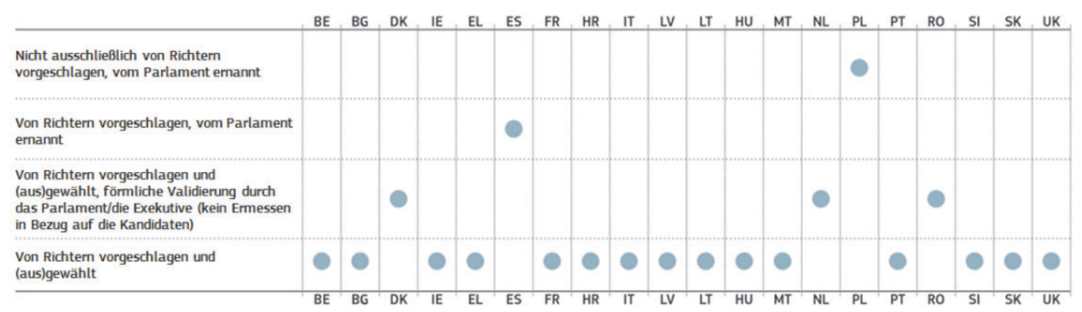

Abbildung 4: Schaubild 54 - Ernennung von den Räten für das Justizwesen angehörenden Richtern: Rolle der Justiz

Bestand das Justizbarometer 2013 noch aus 24 Diagrammen (Schaubildern), war das Justizbarometer 2018 bis auf 68 Schaubilder angewachsen. Um die Übersichtlichkeit nicht zu gefährden, wurden im Justizbarometer 201911 Schaubilder gestrichen, sodass nur noch 57 Schaubilder gezeigt werden. Außerdem hat die Kommission von Ausgabe zu Ausgabe in Ausnahmefällen einzelne Schaubilder aus der Darstellung herausgenommen und dadurch den Zuschnitt variiert.

Der Typus der Sachstandserhebung und Evaluierung im Justizbarometer wird von der Kommission als Monitoring bezeichnet. Ich hatte festgehalten, dass er grundsätzlich auf alle partiellen Verfassungsaufsichtsmaßnahmen passt. Der Begriff des Monitoring ist bereits im EU-Rahmen zur Kennzeichnung des follow-up zwar auch erwähnt, aber nicht weiter entwickelt worden. ${ }^{1559}$ Verschiedentlich ist der Begriff, wenn auch eher „en passant“, im Unionsrecht Gegenstand näherer Konzeptualisierung gewesen. Martin Scheinin hat den Begriff, wenn auch dort vorrangig für das Feld der internationalen, also in Drittstaaten erfolgenden, Menschenrechtseinhaltung untersucht und festgehalten, der Begriff bezeichne Beobachtungsund Evaluierungsvorgänge, die über die reine Feststellung hinausgingen, da sie normative Implikationen hätten. ${ }^{1560}$ Bei Anne Peters stand eher die

1559 Europäische Kommission, Mitteilung der Kommission an das Europäische Parlament und den Rat, Ein neuer EU-Rahmen zur Stärkung des Rechtsstaatsprinzips vom 11.03.2014, COM(2014) 158 final, S. 9.

1560 Vgl. Martin Scheinin, „The Relationship between the Agency and the Network of Independent Experts“, in: Philip Alston \& Olivier de Schutter (Hrsg.), Fundamental Rights in the EU: The Contribution of the Fundamental Rights 
wiederkehrende Natur der Verfahren und die besondere Genauigkeit und Abdeckung des Untersuchungsgebiets im Vordergrund. ${ }^{1561}$ In keinem Fall ist der Begriff des Monitoring darüber dogmatisch derart verdichtet worden, dass man ihn als möglichen Ersatz zum hier verwendeten Aufsichtsbegriff in Betracht ziehen sollte.

Das EU-Justizbarometer bestätigt, dass die in der Literatur beobachteten Aspekte des Monitoring über die reine Beobachtung oder die Evaluierung hinausgehen. Bereits in der Ausgabe von 2013 grenzt die Kommission den Begriff des Monitoring von der Evaluierung ab. Das Monitoring erscheint dort zunächst als besonders genaue Datenerhebung, worauf die Evaluierung auswertend aufbaut. ${ }^{1562}$ In den Ausgaben von 2018 und 2019 hat die Kommission dann implizit durchblicken lassen, dass sie unter das Monitoring auch die Begleitung von "Justizreformen“ in den Mitgliedstaaten fasst ${ }^{1563}$ und erläutert dies bereits im ersten Hauptteil der Mitteilung („2. Kontext") ausführlich.

Agency, Hart, Oxford/Portland, Oregon, 2005, S.73-90, insb. S.74-75; s. auch Michael O'Flaherty, „Human Rights Field Operations“, in: Alfredsson Gundmundur, Jonas Grimheden, Bertrand G. Ramcharan \& Alfred de Zayas (Hrsg.): International Human Rights Monitoring Mechanisms, Martinus Nijhoff, Leiden/Boston, 2009, S. 205-217, S. 214, der dem Monitoring auch eine "präventive" Rolle zusätzlich zur Beobachtung zuspricht.

1561 Anne Peters, „European Democracy after the 2003 Convention“, in: Common Market Law Review 41 (2004), S. 37-85, insb. S. 62. Implizit auf diesen Aspekt, betreffend die Reaktionen der Mitgliedstaaten abstellend, s. auch bei Alberto J. Gil Ibáñez, „The Administrative Supervision and Enforcement of EC Law“, S. $258 \mathrm{ff}$.

1562 Europäische Kommission, Mitteilung der Kommission an das Europäische Parlament, den Rat, die Europäische Zentralbank, den Europäischen Wirtschafts- und Sozialausschuss und den Ausschuss der Regionen, Das EU-Justizbarometer, Ein Instrument für eine leistungsfähige, wachstumsfördernde Justiz, $\operatorname{COM(2013)~} 160$ final vom 27.03.2013, S. 4 und 5, viel deutlicher in der engl. Fassung, ebda.

1563 Europäische Kommission, Mitteilung der Kommission an das Europäische Parlament, den Rat, die Europäische Zentralbank, den Europäischen Wirtschafts- und Sozialausschuss und den Ausschuss der Regionen, EU-Justizbarometer 2018, Part 1/2, $\operatorname{COM(2018)~} 364$ final, vom 28.05.2018, S. 5, vgl. insb. auch die engl. Ausgabe, z.B. S. 5 der Broschürenfassung: weiter Europäische Kommission, Mitteilung der Kommission an das Europäische Parlament, den Rat, die Europäische Zentralbank, den Europäischen Wirtschafts- und Sozialausschuss und den Ausschuss der Regionen, EU-Justizbarometer 2019, $\operatorname{COM}(2019) 198$ final vom 26.04.2019, S. 8 ff. Weiter: Lucy Moxham \& Justine Stefanelli, „Safeguarding the Rule of Law, Democracy and Fundamental Rights: A Monitoring Model for the European Union“, Bericht für das British 
Die Daten für das Justizbarometer bezieht die Kommission aus drei Quellen, wobei zwischen vorrangig quantitativ-statistischen Daten und qualitativen Daten zu trennen ist.

Einen kleinen Teil der statistischen Primärdaten erstellt die Kommission selbst, indes dann aufgrund von frei verfügbaren Rohdaten. ${ }^{1564}$

Einen sehr großen Teil der Datensätze bezieht die Kommission von externen Dritten, entweder, weil diese die Daten sowieso bereitstellen wie das Europäische Statistikamt Eurostat ${ }^{1565}$ - oder weil die Kommission die Erstellung kommerziell in Auftrag gegeben hat. Vorrangiger Vertragspartner ist die CEPEJ, die Kommission greift aber auf eine ganze Reihe an NGOs und Netzwerken zurück, die sie auch detailliert auflistet. ${ }^{1566}$

Gerade die Statistiken der CEPEJ sind, insbesondere für die Effizienz der mitgliedstaatlichen Justiz im ersten Teil des Barometers, grundlegend. ${ }^{1567}$ Zur Erhebung der Daten bedient sich die CEPEJ ${ }^{1568}$ eines standardisierten

Institute of International and Comparative Law/Bingham Centre for the Rule of Law, London, April 2013, S. $31 \mathrm{ff}$.

1564 Für das Justizbarometer 2019 etwa für das Schaubild 34: „Anteil weiblicher Berufsrichter an obersten Gerichtshöfen 2017 und 2018“.

1565 Für das Justizbarometer 2019 etwa das Schaubild 31: „Gesamtausgaben des Staates für die Gerichte“.

1566 Europäische Kommission, Mitteilung der Kommission an das Europäische Parlament, den Rat, die Europäische Zentralbank, den Europäischen Wirtschafts- und Sozialausschuss und den Ausschuss der Regionen, EU-Justizbarometer 2019, $\operatorname{COM}(2019) 198$ final vom 26.04.2019, S. 4-5, demnach sind beteiligt: „die Gruppe der Ansprechpartner für die nationalen Justizsysteme, das Europäische Netz der Räte für das Justizwesen (ENCJ), das Netz der Präsidenten der obersten Gerichtshöfe der EU (NPSJC), die Vereinigung der Staatsräte und der obersten Verwaltungsgerichte der EU (ACA-Europe), das Europäische Wettbewerbsnetz (ECN), der Kommunikationsausschuss (COCOM), die Europäische Beobachtungsstelle für Verletzungen von Rechten des geistigen Eigentums, die Expertengruppe für Geldwäsche und Terrorismusfinanzierung (EGMLTF), Eurostat, das Europäische Netz für die Aus- und Fortbildung von Richtern und Staatsanwälten (EJTN) und das Weltwirtschaftsforum (WEF) $(20)^{\text {“. }}$

1567 Für das Justizbarometer 2019 die Schaubilder $2 \mathrm{ff}$.

1568 Übersicht unter: https://www.coe.int/en/web/cepej/cepej-study-for-the-eu-j ustice-scoreboard. Zur Arbeit der CEPEJ im Detail Marco Fabri: „Pitfalls in data gathering to assess judiciaries“, in: International Journal for Court Administration 9 (2018), S. 67-75, insb. S. 68-69. Kritisch zur Vergleichbarkeit der jährlichen Ausgaben des Justizbarometers mit der Rüge, Daten seien inkonsistent, Elena Alina Ontanu, Marco Velicogna \& Francesco Contini, Francesco, „How Many Cases? Assessing the Comparability of EU Judicial Datasets“, in: Comparative Law Review 8 (2017), S. 1-39, S. 21 und f. insb. 
Fragebogens ${ }^{1569}$ und eines begleitenden Memorandums. ${ }^{1570}$ Alle Daten sind vollständig öffentlich zugänglich. Es zeigt sich aus den Unterschieden zwischen ihnen und dem auf ihm beruhenden Justizbarometer auch, dass die Kommission die Daten umfassend aufarbeitet und auf größtmögliche Eingängigkeit abzielt. Wie die Kommission weiter klarstellt, ${ }^{1571}$ sind die hierfür wiederum erforderlichen Kontaktpersonen der Mitgliedstaaten entweder über das Europäische Netzwerk der Justizräte in den jeweiligen Nationalen Justizräten bereitgestellt worden oder - falls der Mitgliedstaat mangels Justizrat, wie Deutschland, nicht Mitglied im ENCJ ist - durch das Netzwerk der Präsidenten der Obersten Gerichtshöfe der Europäischen Union vermittelt worden. Die Auswahl liegt also in den Händen der nationalen Gerichtsbarkeiten, regelmäßig handelt es sich um hochrangige Richter oder, so etwa im Fall Deutschlands zumindest für einen Evaluierungszyklus, nach meiner Beobachtung um einen entsprechend hochqualifizierten wissenschaftlichen Mitarbeiter beim Bundesgerichtshof.

Neben den Vorstudien der CEPEJ ist ganz besonders auf die Arbeiten der ACA-Europe ${ }^{1572}$ (Netzwerk der obersten europäischen Verwaltungsgerichte) hinzuweisen. Deutschland ist hier vertreten durch das Bundesverwaltungsgericht. Die ACA-Europe hat die Originalantworten zu ihren Fra-

1569 Vgl. z.B. für 2019, CEPEJ, 2019 data - CEPEJ study for EU Scoreboard, ohne Az. abrufbar unter: https://rm.coe.int/2019-cepej-study-for-eu-scoreboard-questi onnaire-13032020/16809cff48.

1570 Vgl. CEPEJ, Explanatory Note to the Scheme for Evaluating Judicial Systems 2018 - 2020 Cycle, vom 25.03.2019, CEPEJ(2018)17, abrufbar https://rm.coe.in t/cepej-explanatory-note-25-mars/168093ad3e.

1571 Europäische Kommission, Mitteilung der Kommission an das Europäische Parlament, den Rat, die Europäische Zentralbank, den Europäischen Wirtschafts- und Sozialausschuss und den Ausschuss der Regionen, EU-Justizbarometer 2017, vom 10.4.2017, $\operatorname{COM}(2017) 167$ final, S. 52, Fn. 89.

1572 Association of the Councils of State and Supreme Administrative Jurisdicitions of the European Union. Vgl. die Übersichtsseite auch beim BVerwG unter: https://www.bverwg.de/Das-Gericht/Internationale-Beziehungen/ACA-Europ e, dort auch der nachfolgende Hinweis: „Mitglieder von ACA-Europe sind die obersten Verwaltungsgerichte aller Mitgliedstaaten der Europäischen Union, Norwegens und der Schweiz sowie der Europäische Gerichtshof. Montenegro, Serbien und die Türkei nehmen als Beobachter teil." Von 2018-2020 hatte Deutschland, unter dem BVerwG, die Präsidentschaft der ACA inne, der Präsident des BVerwG war in dieser Zeit zugleich Präsident der ACA, vgl. dazu https://www.bverwg.de/Das-Gericht/Internationale-Beziehungen/ACA-Praesid ent. 
gebögen, mit denen die Kommission gearbeitet hat, ins Netz gestellt. ${ }^{1573}$ Wer sich also gerade für den Datenverarbeitungsprozess in der Kommission interessiert, findet hier authentische Quellen (lediglich die Kontaktdetails der Antwortenden sind anonymisiert). Die Erhebungen zur „Qualität von Urteilen“ kann dabei als substantielle Neuerung im Fragezuschnitt gelten.

Die dritte Quelle ist ein Netzwerk eigener sog. „nationaler Kontaktpersonen“. Dass die Kommission ihre hauseigenen Daten über sog. „nationale Kontaktpersonen" ermittelt, hat sie erstmals - rückwirkend bis 2013 - im Justizbarometer 2015 offengelegt. ${ }^{1574}$ Demnach sind die Mitgliedstaaten gehalten, neben der Kooperation mit der CEPEJ jeweils eine Kontaktperson aus der Justiz und eine aus dem Justizministerium zu benennen. Die Mitgliedstaaten sind dem in sehr unterschiedlicher Weise nachgekommen. Um wen es sich genau handelt, verrät die Europäische Kommission nicht, allerdings lässt das Transparenzregister der Kommission Rückschlüsse zu. ${ }^{1575}$ Demzufolge fand das letzte Treffen im Dezember 2018, ausnahmsweise in einem Konferenzsaal des Ausschusses der Regionen, statt (anstatt im Borschette-Gebäude der Kommission), und es sprachen vorrangig Angehörige mitgliedstaatlicher Justizministerien, eine Vertreterin der Weltbank, aber auch Referenten der Kommission selbst. ${ }^{1576}$ Auch an anderer Stelle hat die Kommission über die Strukturen der regelmäßig abgehaltenen Konferenzen mit den Mitgliedstaaten informiert. ${ }^{1577}$

1573 Abrufbar unter: http://www.aca-europe.eu/index.php/en/transversal-analysis. S. insb. den Fragebogen von 2018, „Quality of judgments“, ohne Az. und Datum sowie den zugehörigen, Quality of judgments: Survey response, ohne Az. und Datum. Der Datensatz enthält die Antworten auch von EU-Drittstaaten und Antworten des EuGH.

1574 Europäische Kommission, Mitteilung der Kommission an das Europäische Parlament, den Rat, die Europäische Zentralbank, den Europäischen Wirtschafts- und Sozialausschuss und den Ausschuss der Regionen, Das EU-Justizbarometer 2015, $\operatorname{COM(2015)~} 116$ final, S. 3, Rn. 4 und S. 4, Fn. 7.

1575 Die nationalen Kontaktpersonen sind als Expertengruppe unter der Nr. E302022 im Transparenzregister der Kommission (http://ec.europa.eu/trans parency/regexpert/index.cfm?do=groupDetail.groupDetail\&groupID=3022) zu finden.

1576 Europäische Kommission, Meeting of the Contact Persons on National Justice Systems, 18 December 2018, ohne Az., abzurufen über die o.g. Homepage. Die Teilnehmer sind namentlich angeführt.

1577 Ausführlich z.B. Europäische Kommission, Mitteilung der Kommission an das Europäische Parlament, den Rat, die Europäische Zentralbank, den Europäischen Wirtschafts- und Sozialausschuss und den Ausschuss der Regionen, Das EU-Justizbarometer 2015, COM(2015) 116 final, PART 1/2, S. 4, bei Fn. 7. 
Für die nationalen Kontaktpersonen hat die Kommission einen eigenen Fragebogen erstellt. Dieser wird regelmäßig im Herbst des Vorjahres an die Kontaktpersonen versandt mit Bitte um Rücksendung vor Jahresende, regelmäßig im November, so dass ein ungefährer zeitlicher Gleichlauf mit den internen Vorbereitungen für das Europäische Semester besteht. Eine Möglichkeit zur Erzwingung der Rücksendung hat die Kommission nicht. Wie aus den teils freibleibenden Feldern verschiedener Schaubilder („no data") ersichtlich, kommt es durchaus vor, dass aus einzelnen Mitgliedstaaten Informationen nicht zur Verfügung stehen. Alternativ ist es auch der Fall gewesen, dass Mitgliedstaaten Daten mit umfassenden Begleitmemoranden versehen haben. Der Fragebogen ist als Blankotabelle eines WordDokuments so ausgestaltet, dass die nationalen Kontaktpersonen grundsätzlich klare Ja/Nein-Fragen durch Setzen eines Hakens entsprechend der nationalen Rechtslage beantworten können. Der Fragebogen selbst ist nicht öffentlich, teilweise hat die Kommission das Originalformat, inklusive der Einzelfragen, im Wesentlichen aber - ausgenommen die hier erfolgte Aggregation - beibehalten und sich dabei auch zur Antwortpraxis einzelner Mitgliedstaaten geäußert, wie das folgende Beispiel zeigt: ${ }^{1578}$

1578 Auszug aus Europäische Kommission, Mitteilung der Kommission an das Europäische Parlament, den Rat, die Europäische Zentralbank, den Europäischen Wirtschafts- und Sozialausschuss und den Ausschuss der Regionen, EU-Justizbarometer 2016, $\operatorname{COM(2016)} 199$ final, PART 2/2, S. 40. Begleittext im Original. 


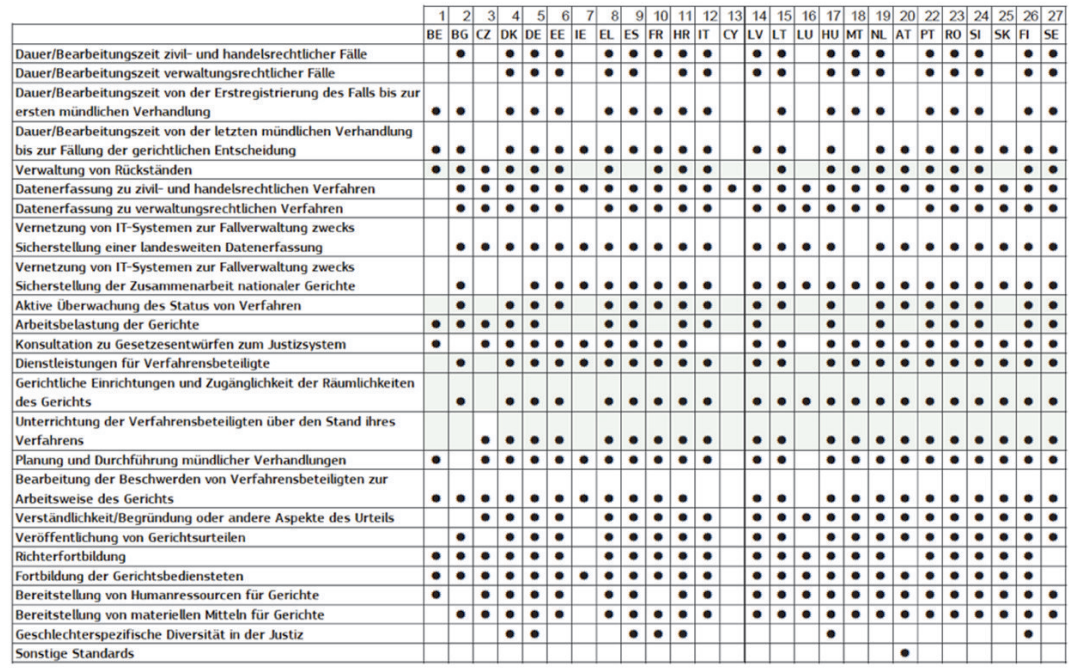

* Es sei darauf hingewiesen, dass freie Felder bei Standards zu verwaltungsrechtlichen Fallen darauf zurilckzufithren sein können, dass keine spezielle Kategorie „verwaltungsrechtliche Verfahren “ vorhanden ist ( $z$. B. IE). PL und UK haben keine Angaben zu Standards iibermittelt. In den hervorgehobenen Bereichen werden die Standards vorwiegend durch Gerichte, einschließlich durch bewährte Gerichtspraktiken, festgelegt. In allen anderen Bereichen sind die Standards vorwiegend gesetzlich festgelegt.

1 Im Jahreswachstumsbericht 2016 (siehe COM(2015) 690 final) wird auf die notwendige Verbesserung der Qualität der Justiz hingewiesen, „u. a. durch die Verwendung von Qualitätsstandards“.

2 Standards können gesetzlich festgelegt sein oder von Gerichten (unter anderem über bewährte Gerichtspraktiken), von den Räten für das Justizwesen (oder sonstigen unabhängigen Gremien) oder von anderen Stellen festgelegt werden (so werden beispielsweise in CZ Standards meistens vom Justizministerium formuliert).

3 Die Daten beziehen sich auf das Jahr 2015 und wurden in Zusammenarbeit mit der Gruppe der Ansprechpartner für die nationalen Justizsysteme erhoben.

Abbildung 5: Schaubild 42 - Festgelegte Standards zu Aspekten des Justizsystems

Es besteht für die nationalen Kontaktpersonen die Möglichkeit, Besonderheiten des eigenen Rechtssystems zu erläutern. Hiervon machen die Mitgliedstaaten sehr unterschiedlich Gebrauch. Die im Fragebogen abgefragten Punkte entsprechen nicht der Struktur des Justizbarometers, die Schaubilder sind folglich regelmäßig eine Vereinfachung der Antworten. Die verbleibenden Informationen stehen der Kommission - ggf. auch rückwirkend - als Informationsreserve, etwa für künftige Erweiterungen des Justizbarometers, selbstredend aber auch zur bereits erwähnten sog. Informationsquerverwertung zur Verfügung. Im Frühjahr jeden Jahres, insbesondere im Januar-März, werden die Antworten in das neue Justizba- 
rometer eingearbeitet und ggf. bilateral durch E-Mail oder telefonische Rücksprache mit den Kontaktpersonen geklärt.

\section{b. Interpretationen in der Literatur}

Will man das Justizbarometer funktional interpretieren, gibt es dafür mehrere Vorschläge in der Literatur.

Der erste ist der von Christoph Kern gewählte, ${ }^{1579}$ der das Justizbarometer in einen größeren Kreis von Indikatoren einordnet, deren Entstehung durch die vergleichende Volkswirtschaftslehre befördert und vorangetrieben wird. ${ }^{1580}$ András Jakab und Viktor Lörincz haben hierzu eine umfassende vergleichende Studie vorgelegt, die typische Probleme bei der Konzeptualisierung justizanalysierender Indizes präsentiert und das Justizbarometer mit einer ganzen Reihe an Vorgängern vergleicht - es schneidet dort recht gut ab. ${ }^{1581}$ Kern hingegen sieht das Justizbarometer skeptisch. Seine Kritik lässt sich in vier Punkten zusammenfassen: erstens bemängelt er das nur indirekte, im Ergebnis aber eben doch erfolgende Ranking der Mitgliedstaaten anhand verschiedener Schaubilder, ${ }^{1582}$ zweitens hält er die Analyse der „großen und abstrakten“ „Oberthemen“ angesichts ihrer Bedeutung für unterkomplex, drittens hält er sie zudem für methodologisch unsauber ${ }^{1583}$ und viertens bemängelt er die unzureichende Transparenz der Ausarbeitungs-, Deliberierungs- und Datenbeschaffungsprozesse.

1579 Teilbeitrag von Christoph Kern, in: Christian Baldus u.a.: „Das ,EU Justice Scoreboard“ der Europäischen Kommission“, GPR 2016, S. 108-115, S. 109-111.

1580 Sehr eingängig zur allgemeinen Entwicklung die Einleitung bei Christoph Kern, Justice Between Simplification and Formalism: A Discussion and Critique of the World Bank Sponsored Lex Mundi Project on Efficiency of Civil Procedure, Mohr Siebeck, Tübingen, 2007, S. $1 \mathrm{ff}$.

1581 András Jakab \& Viktor Lőrincz: „International Indices as Models for the Rule of Law Scoreboard of the European Union: Methodological Issues“, in: MPIL Research Paper Series No. 2017/21, Heidelberg, 2017, insbesondere zur Konzeptualisierung S. 3 ff., weiter die Übersichtstabelle S. 7 ff. Demnach ist das Justizbarometer ein „klassisch statistisches Instrument“ mit „hoher Transparenz" aber recht simpler („mainly basic“) Aufbereitung der Daten. Im Unterschied zu zuvor diskutierten sozialwissenschaftlichen Vorschlägen zur Defizitmessung der Rechtsstaatlichkeit steht hier die Erfassung konkreter Formen der Justizsysteme im Vordergrund, insofern ergeben sich klare Abgrenzungen.

1582 Christoph Kern, in: Christian Baldus u.a.: „Das ,EU Justice Scoreboard“ der Europäischen Kommission“, GPR 2016, S. 109.

1583 So bemängelt er z.B. „problematische Zusammenfassungen und fragwürdige Gewichtungen“ (S.109) oder hält fest, S.111: „Man wird daher einige der 
Kerns resümierende Kritik ob dieser Beobachtungen ist deutlich:

„Wissenschaftlich ernstzunehmen ist das Scoreboard nach alldem sicher nicht, weder für Sozialwissenschaftler noch für Juristen. Vielmehr handelt es sich, wie seine Machart und vor allem seine Texte zeigen, um ein politisches Dokument, mag dessen genaue Stoßrichtung auch etwas unklar sein. Ganz ohne Interesse für Gesetzgebung und Wissenschaft braucht das Scoreboard indes ebenfalls nicht zu sein. Im Interesse einer seriösen Nutzung muss man allerdings die naiven, fast gar populistischen Texte mit ihren Wertungen ganz außen vor lassen und sich auf diejenigen Schaubilder konzentrieren, deren Entstehung halbwegs nachvollziehbar ist und die aufgrund eigener Anschauung plausibel erscheinen. Welche Folgerungen aus diesen Schaubildern dann zu ziehen sind, darf nicht den Autoren des Scoreboards überlassen bleiben, sondern muss jeder Nutzer selbst gut überlegen und vor allem: selbst verantworten. “1584

Der zweite Interpretationsvorschlag in der Literatur betont, ohne auf die Kritik Kerns einzugehen (im Gegenteil), die rein politische Natur des Justizbarometers als „naming and shaming“ defizitärer, da nicht effizienter Justizsysteme in Mitgliedstaaten. Die erhobenen Daten werden dabei nicht angezweifelt, noch wird auf sie im Detail eingegangen, sie werden vielmehr in ihrer Gesamtschau als treffende Bemängelung des Zustands in einem Mitgliedstaat gewertet, die politischen Anstoß zu einer Verbesserung geben müsse. Dieser Impetus hat dabei Vorrang vor einer akkuraten wissenschaftlichen Unterfütterung. So haben sich z.B. Fernando Gascón Inchausti oder Radovan David positioniert. ${ }^{1585}$

Dieser Einstufung steht eine dritte Lesart gegenüber, die exemplarisch Adriani Dori vorgetragen hat. Sie sieht im Justizbarometer zunächst, wie

Schaubilder und ihre Auswertung mit Vorsicht genießen müssen, wie man auch bei der Interpretation der farbigen Darstellungen vorsichtig sein muss, da sie sich teilweise nicht intuitiv erschließen." Ähnlich kritisch zur Methode des Justizbarometers auch Michael Blauberger, „Europäischer Schutz gegen nationale Demokratiedefizite“, S. 291-292.

1584 Christoph Kern in: Christian Baldus u.a.: „Das ,EU Justice Scoreboard` der Europäischen Kommission“, GPR 2016, S. 111.

1585 S. die Teilbeiträge von Fernando Gascón Inchausti und Radovan Dávid in Christian Baldus u.a.: „Das ,EU Justice Scoreboard' der Europäischen Kommission“, S. 114-115. Ähnlich wohl, nämlich von einem „soft governance tool“ intergouvernementaler Natur ausgehend, Alexander Strelkov, „EU Justice Scoreboard: a new policy tool for ,deepening' European integration?", in: Journal of Contemporary European Studies (2018), S. 1-13, s. insb. S. 1, 3, 9. 
Kern, eine Fortschreibung einer stark ökonomisch aufgeladenen „statistischen Rechtsvergleichung“. ${ }^{1586}$ Dori sieht die Europäische Kommission in einem Dialog mit dem Europarat und den Mitgliedstaaten, ${ }^{1587}$ einer „experimental governance technique“. ${ }^{1588}$ Das Telos des Justizbarometers sieht sie in seiner Bedeutung für die Entwicklung des Binnenmarktes durch Förderung insbesondere eines investitionsfreundlichen Klimas in den Mitgliedstaaten sowie in der Entscheidungsvorbereitung der Kommission in anderen Verfahren. Sie betont, die Ergebnisse des Justizbarometers dienten insbesondere dazu, im Europäischen Semester makroökonomische Evaluierungen zu erleichtern. ${ }^{1589}$ Sehr interessant sind schließlich ihre Aussagen zur Methodik des Justizbarometers. Wie Kern kritisiert sie diese als unzureichend, sieht den Fehler indes nicht primär im Vorgehen der Kommission, sondern vielmehr auf der Ebene der Mitgliedstaaten begründet. So seien die erhobenen Daten dort vielfach zu heterogen, unvollständig, oder es sei nur eine Stelle beauftragt, was die Validierung erschwere. ${ }^{1590}$ Den Aufbau der Informationsgewinnungsphase und ihre Prozesse, wie etwa die dadurch seitens der Kommission bemühte Expertenkommission, hält sie nicht für nachteilig, sondern bescheinigt der Expertengruppe etwa infolge der fehlenden Prozesse, die sie leiteten, besondere Flexibilität. ${ }^{1591}$

Schließlich ist auf die Analyse von Elisabeth van Rijckevorsel hinzuweisen. Für sie ist das Justizbarometer ein Instrument der indirekten Effektivitätsförderung der Justiz in Mitgliedstaaten. ${ }^{1592}$ Sie sieht dabei nämlich ungeachtet der wirtschaftspolitischen Komponenten, dass das Justizbaro-

1586 Adriani Dori, „The EU Justice Scoreboard - Judicial Evaluation as a New Governance Tool“, S. 5. Sie stützt sich dabei u.a. auf die Vorarbeiten von Mathias M. Siems: „Numerical Comparative Law: Do We Need Statistical Evidence in Law in Order to Reduce Complexity“, in: Cardozo Journal of International and Comparative Law 13 (2005), S. 521-540, Mathias M. Siems, „Statistische Rechtsvergleichung“, in: Rabels Zeitschrift für ausländisches und internationales Privatrecht 72 (2008), S. 354-390.

1587 Adriani Dori, „The EU Justice Scoreboard - Judicial Evaluation as a New Governance Tool", S. $12 \mathrm{ff}$.

1588 Adriani Dori, „The EU Justice Scoreboard - Judicial Evaluation as a New Governance Tool", S. 23.

1589 Adriani Dori, „The EU Justice Scoreboard - Judicial Evaluation as a New Governance Tool“, S. $17 \mathrm{ff}$.

1590 Adriani Dori, „The EU Justice Scoreboard - Judicial Evaluation as a New Governance Tool", S. 26 ff.

1591 Adriani Dori, „The EU Justice Scoreboard - Judicial Evaluation as a New Governance Tool", S. 29.

1592 Elisabeth van Rijckevorsel, „The EU and the indirect promotion of its values“, vgl. insb. S. $454 \mathrm{ff}$. 
meter zukünftig, gerade im Hinblick auf Polen und Ungarn eine zentrale Rolle spielen könne. Die Trennung beider Verfahren „does not prevent the Scoreboard from complementing this new framework. "1593 Mit dieser Vermutung lag sie in der Retrospektive sehr richtig, und ich schließe mich ihr daher im Grundsatz an.

\section{c. Eigener Vorschlag zur Handhabung und Interpretation des Justizbarometers im Rahmen der Rechtsstaatlichkeitskrise}

So wie die Wissenschaft ganz unterschiedliche Perspektiven auf das Justizbarometer entwickelt hat - effektives Rechtsstaatlichkeitsmonitoring hier, politisches Druckmittel da, schließlich „politisches Dokument“ besonderer „Machart" dort - so spricht das Justizbarometer meiner Auffassung nach auch nach Intention der Praxis zu verschiedenen Beobachtern.

Primär, das hat die Kommission immer wieder betont, dient das Justizbarometer der zielgerichteten Datenerhebung zur weiteren Berücksichtigung im Europäischen Semester. „The EU Justice Scoreboard feeds the European Semester process providing a comparative overview of how justice systems function in all EU countries". ${ }^{1594}$ Das bedeutet, dass die Ergebnisse (performance data) beim Zuschnitt auch der makroökonomischen Semesterdokumente der Länderberichte und länderspezifischen Empfehlungen besondere Berücksichtigung finden. Die Betonung der „Verbesserung der Leistungsfähigkeit der nationalen Justizsysteme" im Hinblick auf ihren „Einfluss auf Investitionsentscheidungen und auf die Anziehung von Unternehmen“ und damit auch als „Priorität des Europäischen Semesters" tritt bis in die Ausgabe 2019 immer als ein tragender argumentativer Strang für die Begründung der Existenz und des Zuschnitts des Justizbarometers hervor. ${ }^{1595}$ Das Europäische Semester ist dabei selbst im Sinne einer stärkeren Fokussierung fortentwickelt worden. Bevor - im nächsten Abschnitt - auf das Europäische Semester einzugehen ist, formt

1593 Elisabeth van Rijckevorsel, „The EU and the indirect promotion of its values“, vgl. S. 458.

1594 Vgl. die zugehörige Beschreibung unter: https://ec.europa.eu/info/policies/justi ce-and-fundamental-rights/upholding-rule-law/improving-effectiveness-nationa 1-justice-systems_en.

$1595 \mathrm{Zu}$ den Zitaten vgl. Europäische Kommission, Mitteilung der Kommission an das Europäische Parlament, den Rat, die Europäische Zentralbank, den Europäischen Wirtschafts- und Sozialausschuss und den Ausschuss der Regionen, EU-Justizbarometer 2019, COM(2019) 198 final vom 26.04.2019, S. 3. 
sich indes, mit der Entwicklung des Justizbarometers über die Jahre zunehmend ein zweiter Strang an Argumenten, verknüpft mit Beobachtungen und Überprüfungen rechtsstaatsinhärenter Aspekte der Justizsysteme in Mitgliedstaaten, sodass dem Justizbarometer daraus eine Verfassungsaufsichtsqualität erwächst.

Das Justizbarometer ist indes niemals nur Rohdatensammlung noch Effektivitätsmonitoring der Mitgliedstaaten, noch allein Input für das Semester gewesen. Es hat immer auch den genuin eigenen Zweck verfolgt, besser Bescheid zu wissen über die Lage der Justizsysteme in den Mitgliedstaaten und darüber qualifizierte Rückschlüsse zu ermöglichen. Die Kommission hat dabei methodologisch einen doppelten Ansatz verfolgt, der die Absicht hatte, sich soweit wie möglich der eigenen Analyse und Wertung zu enthalten, man wollte nicht in den Verdacht geraten, qualitative Gesamturteile über 28 Rechtsordnungen abzugeben. Sie hat daher zum einen, soweit möglich, die Beurteilung an externe Spezialisten ausgelagert - namentlich an die CEPEJ - und zum anderen die Mitgliedstaaten ihrem Ermessen nach für sich selbst sprechen lassen. Das setzt voraus, den Mitgliedstaaten einen gewissen Spielraum bei ihrer Selbstdarstellung zu lassen. ${ }^{1596}$

Darüber hat das Justizbarometer früh eine politische Komponente erhalten, wobei diese indes, neben statistischen Beweislagen, anfänglich ganz in den Händen der Mitgliedstaaten lag. Die Mitgliedstaaten, nicht die Kommission, hatten es zunächst in der Hand, die Entwicklung politisch zu gestalten. Bestes Beispiel dafür ist, dass die Kontaktstellen bestimmter Mitgliedstaaten die Herausgabe von Datensätzen ganz oder teilweise verweigert haben, was sich im Justizbarometer durch den Platzhalter „keine Daten“ zeigt. Systemische Defizite standen dabei nicht im Vordergrund, sondern das „alltägliche Funktionieren nationaler Justizsysteme“. 1597 In der Literatur ist aus diesem Grund, etwa bei Scheppele, das Potential des Justizbarometers als rechtsstaatsspezifisches Instrument lange vor seiner Ausrichtung hierauf auch erkannt und der Zuschnitt kritisiert worden. ${ }^{1598}$

Erst im Zuge der Rechtsstaatlichkeitskrise ist zu diesem ursprünglichen Zuschnitt eine kommissionseigene politische Komponente bezogen auf das Rechtsstaatsprinzip durch die hier sog. Neuausrichtung des Verfahrens hin-

1596 Kritisch zu diesem Punkt Elaine Mak \& Sanne Taekema, „The European Union's Rule of Law Agenda", S. 35.

1597 Vgl. Nina Peršak \& Jože Štrus, „Legitimacy and Trust-Related Issues of Judiciary: New Challenges for Europe“, S. 104.

1598 Kim Lane Scheppele, „Constitutional Coups in EU Law“, S. 462, insb. bei Fn. 53, m.w.N., die das Justizbarometer als Abwandlung von „checklist approaches to the rule of law" sieht und diese für nicht überzeugend hält. 
zugetreten. Der Prozess der Neuausrichtung bezeichnet die teleologisch orientierte Aufnahme rechtsstaatlichkeits- und justizsystemspezifischer Inhalte und Maßstäbe, mit Beobachtungs-, Überprüfungs- und ggf. Berichtigungsetappen in Verfahren, in denen gerade diese Funktion ursprünglich nicht angelegt war. Er findet sich, neben dem Justizbarometer, vor allem im Europäischen Semester und dem Vertragsverletzungsverfahren, die ich hier nachfolgend daher ebenso berücksichtige. Ebenso ist er fragmentarisch in einzelnen anderen Mechanismen der Kommission anzutreffen, wie z.B. jedenfalls 2018 im sog. „Konvergenzbericht“, 1599 der allerdings für die Rechtsstaatlichkeitskrise selbst mutmaßlich keine Berücksichtigung erfahren hat, sodass ich ihn hier ausblende.

Ich möchte nachfolgend diesen Prozess und seine Techniken darstellen und sodann erörtern, warum das Justizbarometer auch die Merkmale eines Aufsichtsinstruments erfüllt.

Die Entwicklung dieser Neuausrichtung des Justizbarometers, die an seiner Qualität als Mitteilung nichts ändert, ist, im Unterschied zu einem ähnlichen Prozess für das Vertragsverletzungsverfahren, ${ }^{1600}$ rechtswissenschaftlich kaum zu fassen. Sie bezeichnet taktische und subtile Änderungen im Umgang mit einem bestehenden Instrumentarium im tatsächlichen und nicht im rechtlichen Zuschnitt. Das Konzept der späteren Neuausrichtung findet allerdings etwas Stütze in der Auseinandersetzung mit der Absicht des Urhebers eines soft-law-Aktes nicht nur aus „subjektiv-historischer" Perspektive, sondern auch unter Berücksichtigung eines späteren Wandels dieser Absicht. ${ }^{1601}$ Wie zuvor angesprochen, ${ }^{1602}$ war

1599 Der Konvergenzbericht wird von der Europäische Kommission, parallel zu demjenigen der EZB (hierzu: https:/www.ecb.europa.eu/pub/convergence/h tml/ecb.cr201805.en.html), nach Art. 140 AEUV mindestens alle zwei Jahre für Mitgliedstaaten erstellt, die dem Euro beitreten möchten bzw. sollen, s. Europäische Kommission, Commission Staff Working Document, Convergence Report 2018, Accompanying the document Report from the Commission to the European Parliament and the Council, Convergence Report 2018, (prepared in accordance with Article 140(1) of the Treaty on the Functioning of the European Union), SWD(2018) 350 final vom 23.05.2018, S. 70. Die Kommission nutzte an dieser Stelle den Bericht, um eine zusätzliche Absicherung für den Präsidenten der polnischen Nationalbank zu verlangen, unter Hinweis auf die Lage der Rechtsstaatlichkeit in Polen und ansonsten möglicherweise mangelnden Rechtsschutz.

1600 Näher unter E. VIII.

1601 Hierzu nochmals illustrativ EuGH, Rs. C-16/16 P, Belgien ./. Kommission, Schlussanträge des Generalanwalts Michal Bobek vom 12.12.2017, ECLI:EU:C:2017:959, Rn. 76-79.

1602 Supra unter a.bb. 
die Nutzung des Justizbarometers im Umfeld rechtsstaatlicher Krisen in Mitgliedstaaten gerade durch Reding ursprünglich vage erwogen worden, wurde aber zunächst nur in Grundzügen angelegt, nicht entwickelt. Die Richtung eines möglichen späteren Zuschnitts ihres Monitoring findet sich in der Feststellung: „Unabhängig vom Modell des nationalen Justizsystems oder der Rechtstradition, in der dieses System verankert ist, gehören fristgerechte Abwicklung, Unabhängigkeit, Erschwinglichkeit und leichter Zugang zu den wesentlichen Parametern eines funktionierenden Justizsystems. " 1603 Diese Aussage ist seitdem im Wesentlichen unverändert in jeder Ausgabe des Justizbarometers enthalten gewesen, und seit 2014 beruft sich die Kommission zur Stützung dieser Ausrichtung und ihrer schrittweisen Ausweitung auf ein Mandat des Parlaments. ${ }^{1604}$ Die Aussage ermöglicht also, ungeachtet und unter Respekt für nationale Eigenheiten, einen Zugriff auf qualitative Parameter bei der Analyse mitgliedstaatlicher Justizsysteme. Im Justizbarometer von 2013 legte die Kommission aber im Übrigen noch Schaubilder vor, die im Wesentlichen auf der Darstellung rein quantitativer Daten beruhten. Das änderte sich sukzessive.

In der Ausgabe von 2014, dort in einem „Anhang: Strukturelle Richterliche Unabhängigkeit“ fand sich in zwei Schaubildern zur Unabsetzbarkeit und der Möglichkeit der Entlassung von Richtern ${ }^{1605}$ eine qualitative Aufbereitung von strukturellen Merkmalen mitgliedstaatlicher Justizsysteme, deren Potential im Hinblick auf die Rechtsstaatlichkeitskrise schnell deutlich werden sollte: aus ihnen lässt sich, angesichts der Vielzahl unterschiedlicher Kriterien und der untersuchten Mitgliedstaaten, erstens ein

1603 Europäische Kommission, Mitteilung der Kommission an das Europäische Parlament, den Rat, die Europäische Zentralbank, den Europäischen Wirtschafts- und Sozialausschuss und den Ausschuss der Regionen, Ein Instrument für eine leistungsfähige, wachstumsfördernde Justiz: EU-Justizbarometer 2013, $\operatorname{COM}(2013) 160$ final, vom 27.03.2013, S. 2-3.

1604 Europäische Kommission, Mitteilung der Kommission an das Europäische Parlament, den Rat, die Europäische Zentralbank, den Europäischen Wirtschafts- und Sozialausschuss und [scil.: den] Ausschuss der Regionen, Das EU-Justizbarometer 2014, $\operatorname{COM(2014)~} 155$ final vom 17.03.2014, S.3; zuvor Europäisches Parlament, P7_TA(2014)0064, Das EU-Justizbarometer, Entschließung des Europäischen Parlaments vom 4. Februar 2014 zu dem EU- Justizbarometer - Zivil- und Verwaltungsjustiz in den Mitgliedstaaten (2013/2117(INI)).

1605 Europäische Kommission, Mitteilung der Kommission an das Europäische Parlament, den Rat, die Europäische Zentralbank, den Europäischen Wirtschafts- und Sozialausschuss und [scil.: den] Ausschuss der Regionen, Das EUJustizbarometer 2014, COM(2014) 155 final vom 17.03.2014, Anhang, S. 34 ff. 
Überblick über die gesamte Bandbreite mitgliedstaatlicher Rechtstraditionen bei der Handhabung dieser rechtspolitisch brisanten, gleichzeitig eine Rechtsordnung strukturierenden Fragen, einschließlich von Absicherungen, gewinnen und zweitens darüber Ansätze für europäische Standards ableiten. Drittens sind dann sowohl traditionelle Ausnahmen als auch echte Abweichungen von Standards in mitgliedstaatlichen Justizsystemen feststellbar.

Das EU-Justizbarometer führt also nicht zu einer zusätzlichen unmittelbaren Überprüfung der Mitgliedstaaten anhand des Prinzips der Rechtsstaatlichkeit, es greift auf einen spezifischen Teil der Operationalisierung dieses Prinzips zurück, wobei es zunehmend zu einer Wechselwirkung mit der Rechtsprechung des Europäischen Gerichtshofs kommt. Diese Taktik der Sichtung mitgliedstaatlicher Traditionen zur möglichen Ableitung von Standards und zugleich zur Herausarbeitung von Abweichungen von ebenjenen Standards baute die Kommission 2015 weiter aus. Im Abschnitt "Strukturelle Unabhängigkeit“" des Justizbarometers finden sich nun neun Schaubilder, einschließlich von Darstellungen zu rechtspolitisch höchst brisanten Punkten wie der Kompetenz zur Festlegung der finanziellen Ausstattung der Justizsysteme oder zu „Verfahren bei Bedrohung der richterlichen Unabhängigkeit". ${ }^{1606} \mathrm{~W}$ ie die Kommission eine derartige, hier sog. „Abweichung“ identifiziert, zeigt erstmals das Schaubild 50 dieser Ausgabe, nachfolgend abgedruckt ist die Fassung (Schaubild 30) der Ausgabe 2019.

1606 Europäische Kommission, Mitteilung der Kommission an das Europäische Parlament, den Rat, die Europäische Zentralbank, den Europäischen Wirtschafts- und Sozialausschuss und den Ausschuss der Regionen, EU-Justizbarometer 2019, $\operatorname{COM}(2019) 198$ final vom 26.04.2019, S. 39, s. weiter auch Europäische Kommission, Mitteilung der Kommission an das Europäische Parlament, den Rat, die Europäische Zentralbank, den Europäischen Wirtschaftsund Sozialausschuss und den Ausschuss der Regionen, Das EU-Justizbarometer 2015, $\operatorname{COM(2015)~} 116$ final, PART 2/2, vom 09.03.2015, S. 42 ff, insb. auch S. 49, Schaubild $55 \mathrm{zu}$ „Verfahren bei Bedrohung der richterlichen Unabhängigkeit“, aus dem der hier interessierende Punkt weniger eindeutig hervorgeht und das daher hier nicht abgebildet ist. 


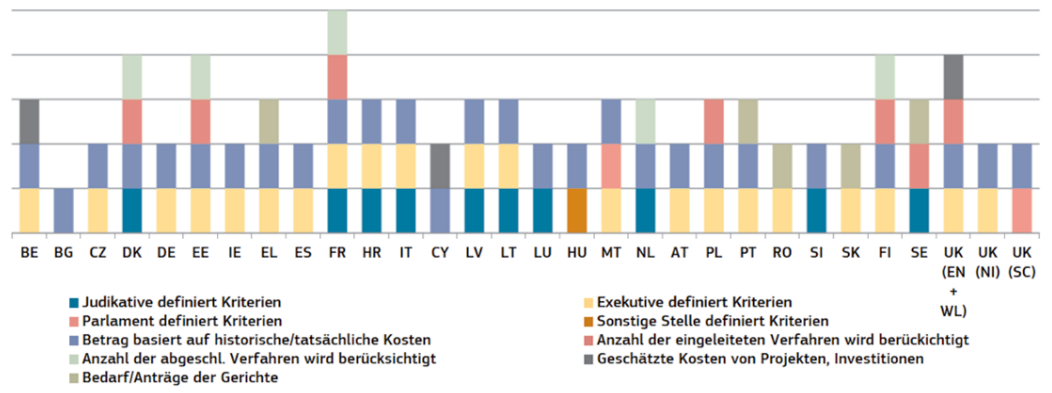

(*) DK: Die Zahl der bei den Gerichten erster Instanz eingeleiteten und abgeschlossenen Verfahren wird berücksichtigt. DE: Berücksichtigt nur den Haushalt des Bundesgerichtshofs - in Bezug auf die Gerichte erster und zweiter Instanz. Das Justizsystem ist von Bundesland zu Bundesland unterschiedlich. EE: Zahl der bei den Gerichten erster und zweiter Instanz eingeleiteten und abgeschlossenen Verfahren. FR: Zahl der bei den Gerichten aller Instanzen eingeleiteten und abgeschlossenen Verfahren. Die Zahl der abgeschlossenen Verfahren wird auf der Grundlage einer Evaluierung der Kosten für die Gerichte berïcksichtigt. IT: Das Justizministerium legt Kriterien für die Zivil- und Strafgerichte fest, während der Rat für das Justizwesen (CPGA) die Kriterien für die Verwaltungsgerichte bestimmt. HU: Laut Gesetz miissen die Gehälter der Richter so im Zentralen Haushaltsgesetz festgelegt werden, dass der Betrag nicht geringer ist als der des Vorjahres. NL: Die Zahl der abgeschlossenen Verfahren wird auf der Grundlage einer Evaluierung der Kosten fiur die Gerichte berücksichtigt. FI: Die Zahl der abgeschlossenen Verfahren wird auf der Grundlage einer Evaluierung der Kosten fir die Gerichte beriicksichtigt.

\section{Abbildung 6: Schaubild 30 - Kriterien zur Festlegung der finanziellen Ressour- cen für das Justizwesen}

Das primäre Ziel dieses Schaubildes ist es, darzustellen, wie Mitgliedstaaten finanzielle Mittel für die Justiz bereitstellen, d.h. welche Akteure dort beteiligt sind, und ob es Absicherungen im Rahmen der Gewaltenteilung (Vetospieler) gibt. Es braucht nicht erläutert zu werden, dass der Topos höchst bedeutend ist: wer der Justiz den Geldhahn zudrehen kann, hat größten Einfluss auf sie.

Unschwer zu erkennen ist hier die Besonderheit in Ungarn („HU“), dass dort eine „sonstige Stelle“ (gemeint ist das nationale Justizamt), dargestellt mittels des braunen Balkens, über die Mittelzuwendung entscheidet, und dass allein Ungarn, trotz aller Heterogenität unter den Mitgliedstaaten, eine derartige Möglichkeit des Zugriffs gestattet. Darüber hinaus ergibt sich, dass im Unterschied zu anderen Mitgliedstaaten keine zusätzliche Verfahrenssicherung durch Beteiligung von Vetospielern besteht. Ungarn weicht also von den üblichen Standards anderer Mitgliedstaaten ab. Der zweite Typus eines im Grundsatz potentiell schwachen Verfahrens, wie nämlich z.B. in Deutschland und Österreich die exekutive Mittelzuwendung ohne weitere Sicherung, gegen die man durchaus Bedenken haben könnte, wird im Vergleich zu Ungarn dadurch im Grundsatz unangreifbar, weil sich dieser Typus als ein europäischer Standard herauskristalli- 
siert. Er findet sich u.a. auch in Spanien. Frankreich und Belgien, die 2015 noch dasselbe Modell aufweisen, haben es seitdem modifiziert. Darüber verstärkt sich der für Ungarn bereits isoliert bestehende pejorative Charakter der Abweichung, der allerdings allein in der Sphäre des Betrachters entsteht. Er muss, gleich einer Bildinterpretation, die Intention der Kommission aus dem Schaubild herausarbeiten.

Auch das Diagramm, das ich anfangs zur Verdeutlichung des sog. Mehrkriteriendiagramms herangezogen hatte, ermöglicht einen derartigen Rückschluss, dort auf Polen bezogen: es zeigt sich, dass allein in Polen die Richter, die dem Justizrat angehören, nicht ausschließlich von Richtern vorgeschlagen und vom Parlament ernannt werden.

Die Darstellung derart abweichender Strukturen und Verfahren von europäischen Standards bietet der Kommission die Möglichkeit, dies als Schwäche subtil und zugleich eindeutig zu bemängeln und gegenüber dem Mitgliedstaat eine rechtspolitische Druckposition aufzubauen, ganz wie Gascón Inchausti und David dies vermutet und befürwortet haben.

Allerdings zeigt diese Methode des Hervorhebens auch Schwächen bzw. birgt die Gefahr in sich, unverdächtige Mitgliedstaaten unter Beschuss zu nehmen, wenn der rechtshistorische Kontext fehlt. Das zeigt sich z.B. gut am folgenden Schaubild derselben Ausgabe des Justizbarometers aus dem Jahr 2015: ${ }^{1607}$

Dieses Schaubild zeigt, welche Behörden in den verschiedenen Mitgliedstaaten die Entlassung von Richtern an Gerichten erster und zweiter Instanz vorschlagen und darüber entscheiden können. ${ }^{64}$ Der obere Teil der Säule zeigt an, wer die abschließende Entscheidung trifft ${ }^{65}$, der untere Teil hingegen, wer - gegebenenfalls - die Entlassung vorschlägt bzw. wer vor Erlass der Entscheidung konsultiert werden muss. Erstmals wird auch dargestellt, wie viele Richter 2013 entlassen wurden und ob eine Überprüfung der Entlassung vor einem Gericht, einem Verfassungsgericht oder einer anderen unabhängigen Stelle möglich ist.

1607 Europäische Kommission, Mitteilung der Kommission an das Europäische Parlament, den Rat, die Europäische Zentralbank, den Europäischen Wirtschafts- und Sozialausschuss und den Ausschuss der Regionen, Das EU-Justizbarometer 2015, $\operatorname{COM(2015)~} 116$ final, PART 2/2, vom 09.03.2015 S. 46 und 47 , Zwischenraum entfallen. 


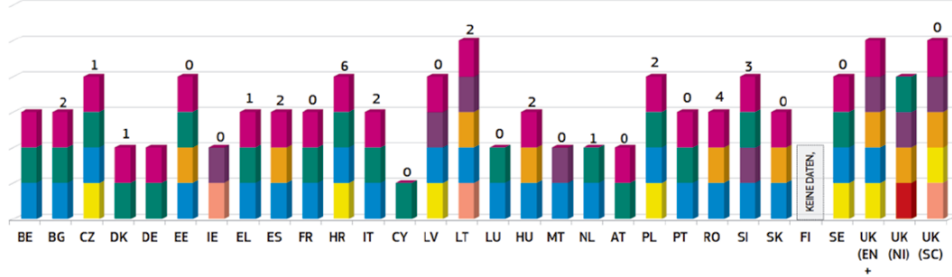

\# Überprüfung der Entlassung vor einem Gericht / durch das Verfassungsgericht / durch eine sonstige unabhängï̌b) Stelle n Entscheidung durch Rat für das Justizwesen / Gericht

- Entscheidung durch Parlament

= Entscheidung durch Justizminsterium / Premierminister / Staatsoberhaupt

= Vorschlag seitens der Gerichtsbarkeit (Rat für das Justizwesen / Gericht) oder einer anderen unabhängigen Stelle

= Vorschlag des Justizministeriums / Premie rministers / Staatsoberhaupts / Justizkanzlers

= Vorschlag des Parlaments

- Vorschlag des Parlaments / einer unabhängigen Stelle / des Justizminste riums / des Gerichts möglich

* Die Zahl über der Säule gibt an, wie viele Richter 2013 entlassen wurden (keine Zahl bedeutet, dass keine Daten verfïgbar waren). EL: Ein Richter wurde aus der Zivil-/Strafgerichtsbarkeit entlassen; VK (EN+WL): keine Vollzeitrichter wurden entlassen. Es wurden nur (gebïhrenbezahlte) Teilzeitrichter entlassen, nämlich ein Tribunal Judge, vier Recorders (mit gewöhnlich 15 Verhandlungstagen jährlich) und acht (ehrenamtliche) Magistrates; in einigen Ländern hat die Exekutive die (gesetzliche oder praktische) Verpflichtung, einem

Vorschlag durch den Rat fiir das. Justizwesen zu folgen und einen Richter zu ernennen oder zu entlassen (z.B. ES).

\section{Abbildung 7: Schaubild 52 - Entlassung von Richtern an Gerichten erster und zweiter Instanz}

Hier gerät potentiell Irland („IE“) ins Visier - ein bislang in der Rechtsstaatlichkeitskrise im Allgemeinen unverdächtiger ${ }^{1608}$ Mitgliedstaat: allein sein Rechtssystem sieht vor, dass über die Entlassung von Richtern das Parlament völlig autonom, nämlich insbesondere ohne richterliches $\mathrm{Zu}$ tun und Rechtsmittel, und allein aufgrund eines Vorschlags ebenso des Parlaments entscheidet. Es ist offensichtlich, dass dieses System potentiell missbrauchsanfällig ist, man stelle sich eine Parlamentsmehrheit einer Partei vor, die gerne Einfluss auf die Justiz gewinnen möchte. Würde es sich bei Irland um einen EU-Beitrittskandidaten handeln, die Union würde vermutlich insistieren, dass diese Besonderheit abgeschafft wird. Allein, in Irland hat diese Regel Verfassungsrang, sie ist niemals angewandt worden,

1608 S. aber Venedig-Kommission, CDL-JU(2019)013, Recent Legislative Proposals and Case Law of Ireland - Sarahrose Murphy and Patrick Conboy, Senior Executive Legal Officer and Executive Legal Officer, Supreme Court, Ireland (18th meeting of the Joint Council on Constitutional Justice Mini-Conference on „Independence of the Judiciary, The role of Constitutional Courts“), vom 22.10.2019. 
gilt bei der irischen Richterschaft als unverdächtig ${ }^{1609}$ und war in einer Entscheidung des irischen Obersten Gerichtshofs Gegenstand umfassender Qualifizierung. ${ }^{1610}$ Eine derartige Kontextualisierung ist daher in vielen Fällen unerlässlich. Ein Jahr später ergänzte die Kommission das Schaubild, Irland betreffend, um den Zusatz eines dort bestehenden Rechtsmittels, ${ }^{1611}$ ob nach Hinweis auf eben jenes Urteil, ist nicht öffentlich geworden. Der Effekt ist indes, Druck von einem Mitgliedstaat zu nehmen, den man nicht unter Druck setzen wollte.

In der Ausgabe 2016 - die Entwicklung in Polen ist im vollen Gange - dreht die Kommission die Schraube der Neuausrichtung des Verfahrens weiter. Sprach die Einleitung im Jahr 2015 noch recht vorsichtig von „neuen Impulsen für einen Wandel“ (scil.: im Anschluss an die sog. Euro-Krise) und: „In dieser Ausgabe des Justizbarometers sollen Trends aufgezeigt werden“, ${ }^{1612}$ so hatte sich der Duktus ein Jahr später deutlich gewandelt. Das Justizbarometer beginnt mit einem neuen Einleitungssatz, der sehr entfernt die Funktion eines Obersatzes deutscher Prägung einnimmt, einem sog. chapeau: ${ }^{1613}$ „Leistungsfähige Justizsysteme spielen eine maßgebliche Rolle bei der Wahrung der Rechtsstaatlichkeit und der Grundwerte der Union." ${ }^{1614}$ Damit ist die Neuausrichtung des Instruments vollzogen, die

1609 Vgl. dazu die Stellungnahme des irischen Richterbundes zu Art. 35 Abs. 4 der irischen Verfassung, unter https://aji.ie/the-judiciary/removal-from-judicial-offi ce/.

1610 Sog. Curtin-Urteil, Irischer Supreme Court, Brian Curtin, Applicant v. Dáil Éireann, Seanad Éireann, Denis O’Donovan, Jerry Cowley, James O'Keefe, Jan O'Sullivan, John Dardis, Geraldine Feeney, Michael Finucane, Ireland and the Attorney General, Respondents [2006] IESC 14, [S.C. Nos. 198 and 203 of 2005], Irish Reports [2006] 556.

1611 Europäische Kommission, Mitteilung der Kommission an das Europäische Parlament, den Rat, die Europäische Zentralbank, den Europäischen Wirtschafts- und Sozialausschuss und den Ausschuss der Regionen, EU-Justizbarometer 2016, $\operatorname{COM(2016)~} 199$ final, vom 11.04.2016, Part 2/2, S. 56, Schaubild 55: Abberufung und Ablehnung von Richtern.

1612 Europäische Kommission, Mitteilung der Kommission an das Europäische Parlament, den Rat, die Europäische Zentralbank, den Europäischen Wirtschafts- und Sozialausschuss und den Ausschuss der Regionen, EU-Justizbarometer 2015, COM(2015) 116 final, PART 1/2, vom 09.03.2015, S 2.

1613 Auf die Funktion des „chapeau“ werde ich für das Europäische Semester zurückkommen. Der Begriff des chapeau entstammt dem klassischen französischen Aufbau eines Argumentativaufsatzes, der „dissertation“. Er findet in der dienstinternen Praxis der Kommission Verwendung.

1614 Europäische Kommission, Mitteilung der Kommission an das Europäische Parlament, den Rat, die Europäische Zentralbank, den Europäischen Wirt- 
nun durch Ausbau dieser Sprachregelung durch die Kommission schrittweise gefestigt wird.

2016 nutzt die Kommission den einleitenden Teil des Justizbarometers, um die Vorgänge in Polen offen anzusprechen und die Bedeutung des Justizbarometers für das Semester zu betonen. Sie verschafft sich u.a. durch Betonung der länderspezifischen Empfehlungen im Semester Raum für zusätzliche Beurteilungen und verknüpft erstmals die Nutzung der ESI-Fonds der Union mit konkreten Zahlen bezogen ausdrücklich auf die Justizsystemreform ${ }^{1615}$ - ein konzeptioneller Nukleus ihres 2017 gemachten Vorschlags zur weiteren Konditionalisierung des Unionshaushalts im Rahmen des „Fonds für Justiz, Rechte und Werte“.

Die Ausgabe 2017 des Justizbarometers flankiert die außerhalb des Instruments getroffenen Maßnahmen zum Schutz der Rechtsstaatlichkeit weiter. Im Unterpunkt „Strukturelle Unabhängigkeit“ wird ein neuer Abschnitt „Garantien für Richter" eingefügt, der die Bedeutung teils bereits bekannter Schaubilder hervorhebt, teils andere Schaubilder neu einfügt.

Neu aufgenommen wurde das Schaubild 56. Es ist ein hier sog. Mehrkriterien- bzw. Prozessverlaufsdiagramm, benennt nämlich, geordnet nach den Stufen „Prüfung, Vorschlag, Ernennung“ die verschiedenen zuständigen staatlichen Stellen im Verfahren der Richterernennung, und bereitet diese graphisch auf. Erneut tritt hier, wie in dem zuvor genannten Beispiel, für Ungarn eine in den sonstigen Mitgliedstaaten unbekannte Beteiligung des nationalen Justizamtes hervor, das ob seiner speziellen Beschaffenheit nicht den übrigen Justizräten zugeschlagen wird. Aber auch die Schwierigkeit, über die Schaubilder Defizite präzise abzugrenzen, zeigt sich erneut. Im Schaubild 57 sind es Irland und Schweden, deren Exekutive nach freiem Ermessen, und ohne Rechtsmittel gegen die Entscheidung, Richter ernennen kann.

schafts- und Sozialausschuss und den Ausschuss der Regionen, EU-Justizbarometer 2016, $\operatorname{COM(2016)~} 199$ final, vom 11.04.2016, S. 2.

1615 Vgl. Europäische Kommission, Mitteilung der Kommission an das Europäische Parlament, den Rat, die Europäische Zentralbank, den Europäischen Wirtschafts- und Sozialausschuss und den Ausschuss der Regionen, EU-Justizbarometer 2016, $\operatorname{COM}(2016) 199$ final, vom 11.04.2016, S. 5, dort insb.: „Von 2014 bis 2020 wird die EU über die europäischen Struktur- und Investitionsfonds (ESI-Fonds) bis zu 4,2 Mrd. EUR zur Förderung von Justizreformen bereitstellen." Der direkte Vergleich mit der Vorjahresausgabe, dort S. 5, zeigt, dass die dortigen Zahlen noch pauschaler auf die Kapazitätsförderung der öffentlichen Verwaltung bezogen sind. 
Für beide Schaubilder kontextualisiert die Kommission daher in ausführlichen Fußnoten. So erfährt der Leser für das Schaubild 56, dass in Deutschland die Verfahren zur Richterernennung zwischen den Ländern zu stark variierten, um sie übernehmen zu können - womit die Kommission zugleich durchblicken lässt, dass sie dennoch genau informiert ist. Für das Schaubild 57 hingegen hält die Kommission fest, sie wisse um mitgliedstaatsinterne Überprüfungen hinsichtlich der Kandidatenauswahl. ${ }^{1616}$ Abgedruckt ist nachfolgend das Schaubild 56.

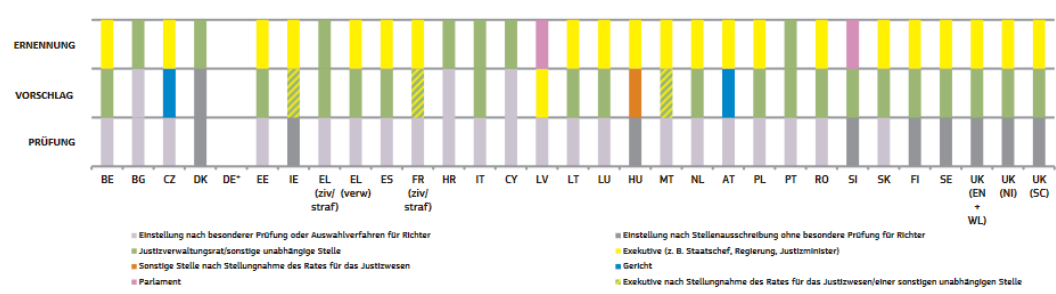

* In mehreren Ländern können oder sollen andere Behörden oder Organe (z. B. Ratspräsidenten, Richter) zu den Richteramtsanwärtern konsultiert werden oder beratend mitwirken (z. B. in $B E, C Z, D E, E E, L T, H U, N L, A T, U K(E N+W L)$ und $U K(S C))$. In einigen Ländern (z. B. LT und PL) sind bestimmte Kandidaten aufgrund früherer Qualifizierungen oder Erfahrung von der Teilnahme an der besonderen Prüfung befreit. CZ: Formal ernennt der Präsident die Richter; der Justizminister entscheidet über die Zuweisung eines Richters zu einem bestimmten Gericht. In der Praxis werden die Richteramtsanwärter durch die Präsidenten der Bezirksgerichte nominiert. Danach wird die Kandidatenliste an das Justizministerium weitergeleitet, das die Kandidatenliste (nach Prüfung aller Umstände) an das Staatsoberhaupt weiterleitet. DE: Das Verfahren ist von Bundesland zu Bundesland sehr unterschiedlich. In der Hälfte der 16 Bundesländer nehmen Richterwahlausschüsse an der Einstellung teil. In einigen Bundesländern ist hierfür allein das Justizministerium zuständig, während in anderen Bundesländern die Befugnis zur Entscheidung über die Einstellung und (erste) Ernennung den Präsidenten der Oberlandesgerichte übertragen worden ist. In einigen Bundesländern ist die Teilnahme eines Richterrates vorgeschrieben. In anderen ist die gemeinsame Ernennung durch den zuständigen Minister und einen Vermittlungsausschuss erforderlich, falls der Richterrat widerspricht. In einigen Bundesländern werden die Richter vom Landesparlament gewählt und müssen von der Landesexekutive ernannt werden. IE: Der „Judicial Appointments Advisory Board" [Beirat für die Ernennung von Richtern] empfiehlt der Regierung mindestens sieben Richter zur Ernennung. Im Anschluss an die Entscheidung der Regierung ernennt der Präsident den Richter formal; er kann die Ernennung des vorgeschlagenen Kandidaten nicht ablehnen. FR: Die Richteramtsanwärter werden im Wege einer besonderen Prüfung ausgewählt und nach ihrem Prüfungsergebnis auf eine Rangliste gesetzt. Nach einem Gespräch zwischen den Anwärtern und dem Justizministerium über die Zuweisung zu einem bestimmten Gericht muss der Conseil Supérieur de la Magistrature eine Stellungnahme zur ersten Ernennung der Anwärter abgeben; anschließend leitet der Justizminister die Liste an den Präsidenten der Republik weiter, der die Richteramtsanwärter durch Dekret formal ernennen muss, wobei er nicht über Ermessen verfügt. LV: Der aus Richtern bestehende und von Richtern gewählte Ausschuss für die Qualifikation im Justizwesen gibt nach drei Jahren eine Stellungnahme zur Beurteilung der beruflichen Tätigkeit eines Richters ab. NL: Die Entscheidung, einen Richter zur Ernennung vorzuschlagen, wird formal von einem Gerichtspräsidenten getroffen, wobei dieser sich auf die Empfehlung eines unabhängigen Wahlausschusses stützt. RO: Die Zahl bezieht sich auf die Ernennung von obersten Richtern. UK (EN+WL): Es gelten unterschiedliche Verfahren für die erste Ernennung der Richter an höheren Gerichten (High Court Judges und darüber), die oben dargestellt sind, und für die Ernennung der Richter an unteren Gerichten (Circuit Judges und darunter).

\section{Abbildung 8: Schaubild 56 - Ernennung von Richtern: vorschlagende und er- nennende Behörden}

1616 S. für beide Schaubilder: Europäische Kommission, Europäische Kommission, Mitteilung der Kommission an das Europäische Parlament, den Rat, die Europäische Zentralbank, den Europäischen Wirtschafts- und Sozialausschuss und den Ausschuss der Regionen, EU-Justizbarometer 2017, vom 10.04.2017, $\operatorname{COM}(2017) 167$ final, S. 53-54. 
Mit dem Justizbarometer 2019 hat die Kommission ihre Taktik des qualitativen Zuschneidens von Schaubildern zur Verdeutlichung der Abweichung von europäischen Standards durch einzelne Mitgliedstaaten nochmals auf eine neue Stufe gehoben. Gleich drei Schaubilder (52-54) verdeutlichen hier in zwei Fällen, hervorgehoben durch ein Signalrot, das Abweichen Polens vom europäischen Konsens, und zeichnen graphisch wesentliche Punkte der Topoi der polnischen Verfassungskrise nach, die die Kommission zwischenzeitlich in ihrem EU-Rahmen als systemische Gefährdung der Rechtsstaatlichkeit und in Art. 7 Abs. 1 EUV als eindeutige Gefahr einer ernsthaften Verletzung eines Unionswerts eingestuft hatte. Abgedruckt sind nachfolgend die Schaubilder 52 und 53, je ohne Begleittext:

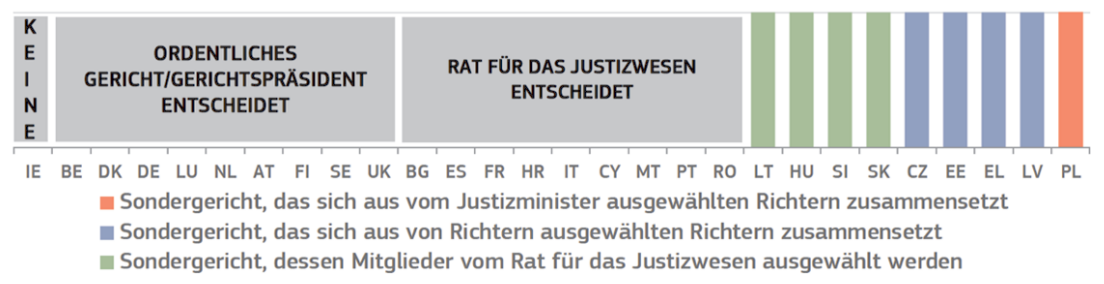

\section{Abbildung 9: Schaubild 52 - Behörde, die über Disziplinarmaßnabmen für} Richter entscheidet

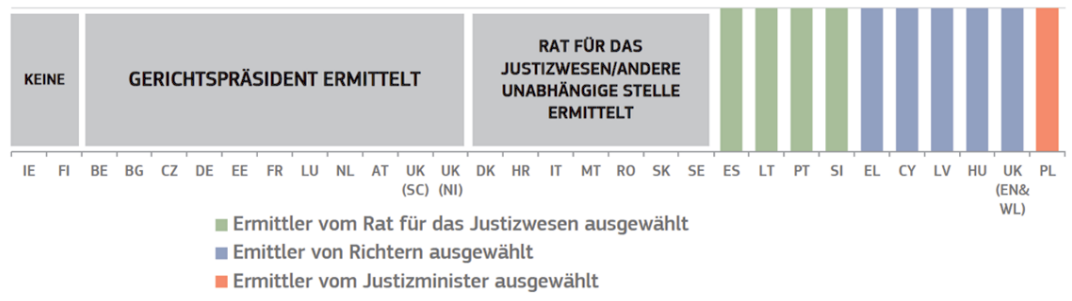

Abbildung 10: Schaubild 53 - Mit förmlichen Disziplinarmaßnabmen gegen Richter beauftragte Ermittler

Deutlicher kann die Kommission kaum werden: Polen ist ein am weit rechten Rand positionierter, rot aufleuchtender Abweichler von europä- 
ischen Standards, der sich völlig isoliert und die europäische Wertegemeinschaft zu verlassen droht.

Auch die „Beobachtungen zu den Justizreformen“, die die Kommission in ihre Einleitung aufnimmt, sind von besonderer Bedeutung: unter dem Stichwort der „Beobachtung der Reformbemühungen der Mitgliedstaaten“, insbesondere der "Gewährleistung der richterlichen Unabhängigkeit“" ${ }^{1617}$ greift die Kommission ihren beiden Mitteilungen vom April und Juli 2019 und der dortigen Verklammerung der dargestellten Mechanismen zu einer gemeinsamen „Toolbox“ vor.

\section{d. Aufsichtsqualität der Maßnahmen}

Hinsichtlich der in den vorherigen Abschnitten herausgearbeiteten Maßnahmen seitens der Europäischen Kommission fragt sich in besonderem Maße, ob sie den in der Rechtswissenschaft getroffenen Festlegungen im Hinblick auf föderale Aufsichtsmaßnahmen im öffentlichen Recht entsprechen und ob darüber mittelbar auch von einer Verfassungsaufsichtsmaßnahme gesprochen werden kann, selbst, wenn hier nur der Anspruch erhoben wird, dass es sich bei den Maßnahmen um partielle Aufsichtsverfahren handelt.

Unstreitig ist dem Justizbarometer eine genaue, strukturierte Beobachtungsphase zuzusprechen, sowie zusätzlich ein die Informationsbeschaffung, die ich zuvor spezifisch für das EU-Rahmenverfahren dargestellt hatte, strukturiert ergänzender Informationsbeschaffungsprozess gerade im Austausch mit den nationalen Kontaktpersonen oder der CEPEJ.

Die Überprüfungsphase herauszuarbeiten, fällt indes schon deutlich schwerer: die Kommission zeigt zwar bei genauem Hinsehen auf, dass sie bestimmte Vorgänge in Mitgliedstaaten als Abweichung von der europäischen Norm auffasst, indes erteilt sie keinem Mitgliedstaat hierüber konkrete Verbesserungsvorschläge oder rügt diese Missstände. Soweit sie auf derartige Rügen verweist, tut sie dies regelmäßig durch Rückgriff auf parallellaufende Verfahren. ${ }^{1618}$

1617 Europäische Kommission, Mitteilung der Kommission an das Europäische Parlament, den Rat, die Europäische Zentralbank, den Europäischen Wirtschafts- und Sozialausschuss und den Ausschuss der Regionen, EU-Justizbarometer 2019, $\operatorname{COM}(2019) 198$ final vom 26.04.2019, S. 11.

1618 Vgl. dazu nochmals die Verfahrenszusammenstellung in: Europäische Kommission, Mitteilung der Kommission an das Europäische Parlament, den Rat, die Europäische Zentralbank, den Europäischen Wirtschafts- und So- 
Darüber fragt sich, ob das Verfahren nicht vielmehr die Qualität eines lenkenden ${ }^{1619}$ statt eines beaufsichtigenden Verfahrens aufweist, also ein solches ist, mit dem die Kommission ihre an anderer Stelle in konkreten Einzelverfahren genutzten Maßstäbe überprüft und abstrakt-generell weiterentwickelt. Die breit angelegte Sichtung aller Mitgliedstaaten und die unter dem Stichwort der Effektivität betriebene Beurteilung mitgliedstaatlicher Standards ficht sehr dafür, dem Justizbarometer jedenfalls auch eine lenkende Qualität zuzuschreiben, ohne darüber aber die partielle Aufsichtsqualität des Justizbarometers, gelesen vor dem Hintergrund gerade der zusätzlichen und komplementären Beobachtung und Überprüfung defizitärer Entwicklungen in Mitgliedstaaten, abzulehnen. Darin bestätigt sich die bei Kahl gemachte Beobachtung, dass letztlich die Grenze zwischen Aufsicht und Lenkung permeabel ist. ${ }^{1620}$ Die im Justizbarometer auch angelegte Lenkung bleibt dabei indes sehr allgemein gehalten, eine spezifische „Programmierung“, wie genau mitgliedstaatliche Justizsysteme beschaffen zu sein haben, lässt sich dem Justizbarometer nicht entnehmen, und die Kommission hat sich regelmäßig dagegen verwahrt, gerade ein bestimmtes Modell - etwa unter Schaffung eines Verfassungsgerichts oder eines Justizrates - zugrunde zu legen.

\section{e. Effektivität und Stichhaltigkeit der rechtsstaatsspezifischen Rügen im Rahmen des Justizbarometers - auch zum Problem des sog. relativierenden Rechtsvergleichs}

Drängender als die rekapitulierende Bejahung der partiellen Aufsichtsqualität des Justizbarometers ist die Frage, wie effektiv die Ausgestaltung des Justizbarometers durch die Kommission im Hinblick auf diese Funktion in der Rechtsstaatlichkeitskrise der Union ist. Denn die Kommission steht, bei aller Rüge einzelner Standardabweichungen z.B. in Polen und Ungarn, vor zwei erheblichen Problemen, die noch anders gelagert sind, als die bereits geschilderte Kritik in der Wissenschaft an der konkreten Ausgestaltung des Instruments.

zialausschuss und den Ausschuss der Regionen, EU-Justizbarometer 2019, $\operatorname{COM}(2019) 198$ final vom 26.04.2019, S. 11 ff.

1619 Zum Begriff der Lenkung, noch für das Gemeinschaftsrecht, aber unverändert gültig, Meike Eekhoff, Die Verbundaufsicht, S. $6 \mathrm{ff}$.

1620 Wolfgang Kahl, Die Staatsaufsicht, S. 359. 
Zum einen zeigen sich in vielen Schaubildern der Kommission, wie oben teils bereits verdeutlicht, auch potentielle Fälle erheblicher konzeptueller Schwächen in mitgliedstaatlichen Justizsystemen, gerade etablierter und tradierter west- und nordeuropäischer Mitgliedstaaten. Ihre Hervorhebung kann in den entsprechenden Mitgliedstaaten in Praxis und Wissenschaft durchaus einen Abwehrreflex gegen das Justizbarometer auslösen. Nachweise hierfür sind zahlreich zu finden. Insbesondere rügt z.B. der Bundesrat jährlich das Justizbarometer, ${ }^{1621}$ und mangelnde Daten zu bestimmten Mitgliedstaaten sind auch dadurch zu erklären, dass die entsprechenden Kontaktpersonen eine oberflächliche Darstellung der eigenen Rechtssysteme fürchten und sich der Kooperation verweigern. ${ }^{1622}$ Damit einher geht auch der durch andere Mitgliedstaaten geäußerte Verdacht, das Justizbarometer diene der Durchsetzung einheitlicher Justizsysteme, insbesondere wurden in Großbritannien wiederholt kritische Stimmen laut. ${ }^{1623}$

Vermeintliche Schwächen in Mitgliedstaaten sind sehr häufig traditionell gewachsen und in der nationalen Rechtsgeschichte tief verwurzelt. Sie werden indes überlagert von einem dichten, und bei Ausblendung von Faktoren außerhalb des vorrangig positiven Rechts nicht direkt sichtbaren, Sicherungssystem aus Rechtstradition, Gewaltenverschränkung, Fallrecht und vorrangig loyaler Zusammenarbeit der Staatsorgane. Bei Blick allein auf den Gesetzeswortlaut können diese vermeintlichen Schwächen irritieren. In der Praxis erscheint ihre Realisierung indes völlig oder jedenfalls durchaus abwegig.

1621 Exemplarisch: Beschluss des Bundesrates, Mitteilung der Kommission an das Europäische Parlament, den Rat, die Europäische Zentralbank, den Europäischen Wirtschafts- und Sozialausschuss und den Ausschuss der Regionen: EUJustizbarometer $2019 \operatorname{COM(2019)} 198$ final, BR-Drucks. 294/19 (Beschluss), vom 20.09.19, s. insb. dort Rn. 3 insb. zum „mangelnden belastbaren Datenmaterial“. Vgl sodann die Replik als „Stellungnahme der Europäischen Kommission zu dem Beschluss des Bundesrates zur Mitteilung der Kommission an das Europäische Parlament, den Rat, die Europäische Zentralbank, den Europäischen Wirtschafts- und Sozialausschuss und den Ausschuss der Regionen: EU-Justizbarometer 2019“, zu BR-Drucks. 294/19 vom 28.01.2020, C(2019) 8563 final.

1622 Vgl. Nikolaj Nielsen, „EU justice scoreboard upsets some member states“, EU Observer, vom 17.03.2014.

1623 Nikolaj Nielsen, id. unter Zitat des damaligen britischen Justizministers Chris Grayling, der sich gegen die Beförderung eines „one size fits all“-Justizsystems wehrte. Vgl. weiter, mit detaillierter Diskussion der Position der britischen Regierung die Stellungnahme des EU Scrutiny Committee des britischen Unterhauses, Commission Communication: The 2014 EU Justice Scoreboard, (35888) 7910/14 COM(14) 155, vom 17.03.2014. 
Ein prominentes Beispiel ist die traditionell starke Rolle des Justizministers in vielen Mitgliedstaaten, die dazu führt, dass diesem bei der Richterernennung und -kandidatenauswahl einerseits und andererseits, zumindest hypothetisch in einigen Mitgliedstaaten ein Weisungsrecht gegenüber der Staatsanwaltschaft zugestanden wird. Dies ist u.a. auch in den Niederlanden und in Deutschland der Fall. Auf die jüngere Rechtsprechung des EuGH in diesem Zusammenhang ist bereits hingewiesen worden. ${ }^{1624}$ In der Rechtspraxis haben derartige Weisungen indes dort nicht stattgefunden, oder aber ihre Ausübung wird durch Gewohnheitsrecht und öffentlichen Druck genau geregelt und ggf. verhindert, ${ }^{1625}$ auch wenn Kontroversen fortbestehen. ${ }^{1626}$ Dadurch sind sie in der Sache grundsätzlich nicht missbrauchsanfällig.

In der Rechtsstaatlichkeitskrise adressierte Mitgliedstaaten wie Ungarn und Polen haben es vielfach verstanden, im Wege eines hier sog. relativierenden Rechtsvergleichs, einer Variante des klassischen „tu quoque“-Einwands, also eines auf die Nivellierung ihrer Unterschiede zu anderen Mitgliedstaaten abzielenden Pauschalverweises, derartige im positiven Recht bestehende Merkmale anderer Rechtssysteme als Rechtfertigung für eigenes Vorgehen heranzuziehen. So hat die polnische Regierung in ihrem White Paper wiederholt auf die Rechtslage in Deutschland, aber auch in Frankreich oder in anderen westeuropäischen Staaten hingewiesen und dabei gerade das Justizbarometer der Kommission in einem recht offensichtlichen Versuch, diese „mit eigenen Waffen zu schlagen“, herangezogen. Das Justizbarometer diente hier etwa zum Vergleich der absoluten und

1624 Dazu bereits etwa unter B.IV.5.c.; Anm. Kai Ambos: „EuGH, Urteil v. 27. 5. 2019 - verb. Rs. C-508/18 und C-82/19 PPU, OG, PI“, in: Juristenzeitung 74 (2019), S. 728-735, s. auch Johannes Graf von Luckner, „German Prosecutors are insufficiently independent to issue European Arrest Warrants“, in European Law Blog, vom 11.06.2019; Einordnung der deutschen Besonderheiten in den historischen Kontext, mit Ausblick auf mögliche Reformen bei Ernst S. Carsten, Ernst \& Erardo C. Rautenberg, Die Geschichte der Staatsanwaltschaft in Deutschland bis zur Gegenwart: Ein Beitrag zur Beseitigung ihrer Weisungsabhängigkeit von der Regierung im Strafverfahren, Nomos, BadenBaden, 2015, S. 535 ff. Zur Rechtslage in den Niederlanden: Henk van de Bunt \& Jean-Louis van Gelder, „The Dutch Prosecution Service“, in: Crime and Justice 41 (2012), S. 117-140.

1625 Für die Niederlande vgl. Henk van de Bunt \& Jean-Louis van Gelder, „The Dutch Prosecution Service“, S. 122-123.

1626 Für den Stand der Debatte in Deutschland ausführlich: Jörg Eisele \& Christian Trentmann, „Die Staatsanwaltschaft - „objektivste Behörde der Welt"?“, in: Neue Juristische Wochenschrift 72 (2019), S. 2365-2368. 
pro-Einwohner-Zahlen von Richtern, für Budgetfragen, ${ }^{1627}$ aber auch als Aufhänger für „rechtskundige“ Vergleiche, so etwa betreffend die Einzelheiten der Richterwahl zu den Instanzgerichten. ${ }^{1628}$

Es bedarf aber sorgfältiger Unterscheidung zwischen den festzustellenden Strukturmerkmalen in einigen Mitgliedstaaten und der darüber festgestellten Unionsrechtswidrigkeit von systemischen Defiziten bezogen auf den gleichen Funktionsträger in anderen Mitgliedstaaten. Ob die im Justizbarometer identifizierten besonderen Merkmale einzelner mitgliedstaatlicher Rechtssysteme wirkliche Schwächen, gar Anhaltspunkte für systemische Defizite, darstellen, kann sich folglich im Zweifelsfall nicht in derart pauschalen Verweisen erschöpfen, sondern bedingt einen tiefgründigen und kundigen Rechtsvergleich, der derzeit im Justizbarometer nicht zum Ausdruck kommt. Die Kommission ist daher gehalten, der Annahme entgegenzutreten, als erschöpfe sich ihre Sichtung allein im Material des Justizbarometers, als sei ihr Ansatz „highly reductionist“. ${ }^{1629}$ Lösungsansätze für weitergehende Studien in Anknüpfung an das Justizbarometer zu nationalen Rechtssystemen, die derartigen relativierenden Rechtsvergleichen entgegentreten könnten, sind in der Literatur vereinzelt bereits unternommen worden, ${ }^{1630}$ die Praxis muss indes noch weiter gehen und steht dahinter bislang zurück.

Jedenfalls geht die Kommission in parallelen Verfahren, wie dem Verfahren nach Art. 7 EUV oder dem Vertragsverletzungsverfahren, deutlich

1627 Für beide vorgehenden Punkte s. Kanzlei des polnischen Premierministers, White Paper on the Reform of the Polish Judiciary vom 07.03.2018, ohne Az., S. 9, Rn. 4 ff. zur Nutzung des Justizbarometers hinsichtlich des Abschneidens Polens im mitgliedstaatsübergreifenden Vergleich, Rn. 181 ff., insb. zum Vergleich mit der Lage in Deutschland.

1628 Kanzlei des polnischen Premierministers, White Paper on the Reform of the Polish Judiciary vom 07.03.2018, ohne Az., Rn. $130 \mathrm{ff}$.

1629 Vgl. auch die Überlegungen bei Mark Dawson, The Governance of EU Fundamental Rights, S. 146.

1630 Beachtlich jüngst Maciej Małolepszy (Hrsg.), Die Kriterien und das Verfahren der Richterwahl für die ordentliche Gerichtsbarkeit in Europa im Rechtsvergleich, Duncker \& Humblot, Berlin, 2019, s. darin, auch als Rückversicherung für die Lage in Deutschland, den Beitrag von Heinrich Amadeus Wolff, „Die Kriterien und das Verfahren der Richterwahl im Lichte des Grundgesetzes in Deutschland“, S. 15-25 sowie Klaus-Christoph Clavée, „Die Kriterien und das Verfahren der Richterwahl in Deutschland am Beispiel des Landes Brandenburg“, S. 77-84, sodann, bereits mit Berücksichtigung der diversen Änderungen, aber auch zur vorherigen Rechtslage, Lech Jamróz, „Das Verfahren der Richterernennung im Rahmen der ordentlichen Gerichtsbarkeit im Lichte der polnischen Verfassung“, S. 27-41. 
detaillierter auf rechtliche Fragen in Mitgliedstaaten ein. Im Übrigen hat sie im April 2019 mit der ausdrücklichen Ankündigung reagiert, im Rahmen ihres neuen „Überprüfungszyklus" ihr Monitoring inhaltlich gerade in Bezug auf mitgliedstaatsinterne rechtliche Vorgänge zu vertiefen. ${ }^{1631}$ Welche Form die Vertiefung haben wird, ist noch offen. ${ }^{1632}$ Eine Option ist es, die intendierte Selektivität und Eingängigkeit des Justizbarometers als bewusst gewählte Merkmale stärker zu betonen. Andererseits könnte es langfristig aber geboten sein, umfassende rechtsvergleichende Berichte unter Einbeziehung der Rechtswissenschaft in ähnlichen Formaten zu erstellen, wie sie in der Wissenschaft, den Gutachten der Venedig-Kommission oder in Berichten parlamentarischer wissenschaftlicher Dienste zum Ausdruck kommen. Es wäre denkbar, diese als justizsystem- oder gar rechtsstaatsspezifische Länderberichte in Form eines „Staff Working Document" dem Justizbarometer als umfassendem Anhang beizufügen oder in anderer Form die Mitgliedstaaten stärker einzubringen. Das Europäische Semester liefert hierzu bereits eine Vorlage, erheblicher Widerstand von allen Mitgliedstaaten ob einer so detaillierten Begutachtung ist aber zu erwarten. Erforderlich wäre dann möglicherweise auch ein erweiterter administrativer Unterbau, ggf. nämlich permanente und dezidierte ,justice system desks“ in den zuständigen Dienststellen der Kommission. Anleihen könnten dabei die Strukturen des Semesters selbst bieten, die derartige country desks de facto schon kennen. Für das permanente Kontakthalten zu nationalen Stellen wiederum böte sich an, das System dezidierter Kontaktpersonen, wie etwa im Hinblick auf die Zusammenarbeit mit der Antici-Gruppe im Rat, weiter auszubauen.

Das zweite Problem der Kommission im Rahmen der Nutzung des Justizbarometers als Verfassungsaufsichtsverfahren ist der Widerspruch, der dadurch entsteht, dass in der Rechtsstaatlichkeitskrise adressierte Mitgliedstaaten gerade im Hinblick auf die Effizienz ihrer Justizsysteme vorbildlich abschneiden. Das schwächt das Aufbauen rechtspolitischen Drucks und der dadurch entstehenden Mängelrügen gegenüber Mitgliedstaaten, denen an anderer Stelle systemische Defizite bescheinigt werden und die durch

1631 Europäische Kommission, Mitteilung der Kommission an das Europäische Parlament, den Europäischen Rat und den Rat, Die weitere Stärkung der Rechtsstaatlichkeit in der Union: Aktuelle Lage und mögliche nächste Schritte $\operatorname{COM}(2019) 163$ final, vom 03.04.2019, S. 10.

1632 S. dazu aber nochmals die Ankündigung der Europäischen Kommission, sog. Rechtsstaatlichkeitsberichte herausgeben zu wollen, verfügbar unter: https://ec .europa.eu/info/policies/justice-and-fundamental-rights/upholding-rule-law/rul e-law/rule-law-report_en. 
andere Instrumente des Verfassungsaufsichtsregimes sanktionsbewehrt zu einer Änderung ihrer Rechtslage angehalten werden. Diese Diskrepanz wirft auch Fragen im Hinblick auf die Konsistenz der Datenerhebung auf. Ungarn z.B. ist regelmäßig „top performer“, was die Bearbeitungsgeschwindigkeit neu rechtshängiger Verfahren in seinem Justizsystem angeht. ${ }^{1633}$ Derartigen vermeintlich entkräftenden Argumenten ist nach meinem Dafürhalten bestmöglich mit der hier gewählten Typisierung systemischer Defizite, dabei dem Fokus auf vorsätzliche Unterwanderungen und schließlich der topischen Sichtung mitgliedstaatlicher Entwicklungen zu begegnen. Die Kommission wird indes ihre eigene Vorgehensweise finden müssen, die Unterschiede zwischen effizienten Justizsystemen in Mitgliedstaaten einerseits und solchen, die darüber an anderer Stelle qualitativ rechtsstaatlich defizitär sind, noch mehr zu betonen.

Darüber hinaus ist es für die Kommission bislang sehr mühsam, überhaupt stichhaltig zu evaluieren, welchen politischen Druck und welche rechtlichen Konsequenzen ihre „Mängelrüge“ durch das Justizbarometer im Einzelfall hat. Das Justizbarometer wird jährlich im Rahmen einer Pressekonferenz vorgestellt, aus den Reihen der anwesenden Journalisten werden regelmäßig kurze Berichte insbesondere über das Abschneiden des eigenen Systems erstellt; in Deutschland berichten traditionell insbesondere der Spiegel und die FAZ. ${ }^{1634}$ Derartige Sichtungen in der Presse, wie auch Reaktionen in den Mitgliedstaaten, sind nach meiner Beobachtung Gegenstand interner impact assessments durch die zuständigen Dienststellen, was nicht überraschen sollte.

Seitens mitgliedstaatlicher Stellen sind offensichtliche Reaktionen, wie das genannte Weißbuch der polnischen Regierung, die Ausnahme. Ebenso wohl die Ausnahme geblieben ist das Heranziehen des Justizbarometers zur Verteidigung der eigenen Lage, wie etwa durch Spanien. ${ }^{1635}$ Es überwiegt, in verschiedenen Nuancen, nicht die selbstkritische Berücksichtigung der aufgezeigten Mängel, ${ }^{1636}$ sondern die offene Zurückweisung,

1633 S. dazu bereits unter C. V. 3.

1634 Für die Ausgabe 2019 vgl.: „Deutsche Justiz braucht 204 Tage für ein Urteil“, Der Spiegel vom 26.04.2019; Marcus Jung, „Deutsche Justiz braucht 190 Tage für ein Urteil“, Frankfurter Allgemeine Zeitung vom 11.04.2017.

1635 Vgl. dazu die Stellungnahme der damaligen spanischen Justizministerin Dolores Delgado, „Spanien erfüllt alle Rechtsstaatsnormen“, Frankfurter Allgemeine Zeitung vom 08.02.2019.

1636 Eine Ausnahme für Deutschland machte der FDP-Bundestagsabgeordnete Wieland Schinnenburg, „Teuer, altmodisch, ineffizient“, Beilage „Einspruch“ der Frankfurter Allgemeinen Zeitung vom 09.07.2019. 
zum einen aus Mitgliedstaaten, die sich nicht in der Kritik sehen, das Barometer aber aus Gründen der Kompetenz und Handlungsfreiheit ablehnen, und gerade auch durch solche, die kritisiert werden. ${ }^{1637}$ Sehr interessant, aber seitens mitgliedstaatlicher Regierungen und Parlamente wohl unberücksichtigt geblieben, ist der 2017 durch mehrere oberste Gerichtshöfe in Mitgliedstaaten veröffentlichte „best practice guide“ für die Gerichtsverwaltung in Höchstinstanzen, den die Kommission wiederum auszugsweise aufgegriffen hat. ${ }^{1638}$ Hier kommt es also, zusätzlich zum Austausch mit den nationalen Kontaktpersonen und Richtervereinigungen, zu einem Dialog zwischen Kommission und mitgliedstaatlichen Höchstgerichten, in welchen sich die anderen mitgliedstaatlichen Gewalten bislang vermutlich wenig eingeklinkt haben.

Eine unmittelbare Nachverfolgung dieser Reaktionen findet seitens der Kommission nicht statt, sie kann die Mitgliedstaaten nicht direkt aufgrund einer Feststellung im Rahmen des Justizbarometers zu konkreten Änderungen anhalten. Mittelbar kann sie durch sog. Informationsquerverwertung indes sehr wohl tätig werden. Diese Informationsquerverwertung lässt sich zwischenzeitlich bis vor den Europäischen Gerichtshof nachverfolgen, so griff Generalanwalt Tanchev in der Rechtssache A.K. auch auf Ergebnisse des Justizbarometers zurück. ${ }^{1639}$ Die Kommission selbst indes hat es vermieden, das Justizbarometer offen in anderen, hier als Aufsichtsinstrumente gewerteten, Verfahren zu berücksichtigen. In keiner justizsystembezogenen Vertragsverletzungsklage, noch im begründeten Vorschlag nach Art. 7 EUV in Bezug auf Polen, hat sie das Justizbarometer zitiert.

Nur in einem weiteren Verfahren, nämlich im Prozess des Europäischen Semesters, ist es ihr also bislang möglich, die Ergebnisse des Justizbarome-

1637 Pressemmitteilung der ungarischen Regierung, „Minister of State Zoltán Kovács criticised European Commission's justice scoreboard of last week" vom 29.04.2019, abrufbar unter: https:/www.kormany.hu/en/government-spokespe rson/news/minister-of-state-zoltan-kovacs-criticised-european-commission-s-just ice-scoreboard-of-last-week.

1638 „Best practice guide for managing Supreme Courts“, veröffentlicht durch die Obersten Gerichtshöfe Lettlands, Ungarns, Spaniens und Litauens, die Universitäten von Antwerpen und Laibach, ohne Az., 2017; vgl. weiter Europäische Kommission, Mitteilung der Kommission an das Europäische Parlament, den Rat, die Europäische Zentralbank, den Europäischen Wirtschafts- und Sozialausschuss und den Ausschuss der Regionen, EU-Justizbarometer 2019, $\operatorname{COM}(2019) 198$ final vom 26.04.2019, S. 34, Fn. 81.

1639 EuGH, Rs. Verb. Rs. C-585/18 u.a., A. K. ./. Krajowa Rada Sądownictwa, u.a., Schlussanträge des Generalanwalts Evgeni Tanchev vom 27.07.2019, ECLI:EU:C:2019:551, Rn. 144 bei Fn. 96. 
ters unmittelbar im Prozess der Verfassungsaufsicht heranzuziehen. Dieser Prozess des "feeding“ ist in der Literatur aufgegriffen, aber wenig untersucht worden. ${ }^{1640}$ Dies soll nun vertieft und damit auf diejenigen Verfahren übergeleitet werden, die im dreistufigen Aufsichtsschema nicht mehr nur eine Beobachtungs- und eine Überprüfungsphase kennen, sondern die auch eigenständige Berichtigungsmaßnahmen beinhalten.

\section{Verfassungsaufsichtsverfahren mit Berichtigungsphase}

\section{Das Europäische Semester}

Die Verknüpfung des Justizbarometers mit den übrigen Instrumentarien der unionalen Verfassungsaufsicht verdeutlicht sich in besonderem Maße durch die Berücksichtigung des Prozessflusses, den seine Ergebnisse im jährlichen Turnus der Kommissionsarbeit nehmen, nämlich durch sein Fortwirken im Europäischen Semester. Wie für das Zusammenspiel zwischen EU-Rahmenverfahren und dem ihm nachfolgenden Art. 7 EUV-Verfahren ergibt sich dabei ein gestuftes Verhältnis. Das Justizbarometer geht dem Europäischen Semester vorweg, wie das EU-Rahmenverfahren im Falle Polens dem Verfahren nach Art. 7 Abs. 1 EUV vorangegangen ist. Die Relation Justizbarometer-Semester unterliegt aber einer anderen Funktionslogik als jene beiden Verfahren.

Das Europäische Semester - eigentlich „Europäisches Semester für die wirtschaftspolitische Koordinierung" 1641 - ist zunächst Teil des im Zuge

1640 Nur kurz z.B. bei Andreas J. Kumin, „Global Activities and Current Initiatives in the Union to Strengthen the Rule of Law: A State of Play“, in: Werner Schroeder (Hrsg.), Strengthening the Rule of Law in Europe, Hart, Oxford/Portland, 2016, S. 207-220, S. 218; Weiter Monica Claes \& Matteo Bonelli: "The Rule of Law and the Constitutionalisation of the European Union“, in: Werner Schroeder (Hrsg.), Strengthening the Rule of Law in Europe, Hart, Oxford, 2016, S. 265-289, S. 278; Dimitry Kochenov \& Laurent Pech, „Monitoring and Enforcement of the Rule of Law in the EU: Rhetoric and Reality“, in: European Constitutional Law Review 11 (2015), S. 512-540, S. 538 .

1641 Vgl. Art. 2-a der Verordnung (EG) Nr. 1466/97 in der geänderten Fassung des Art. 1 Nr. 3 der Verordnung Nr. 1175/2011 des Europäischen Parlaments und des Rates vom 16. November 2011 zur Änderung der Verordnung (EG) Nr. 1466/97 des Rates über den Ausbau der haushaltspolitischen Überwachung und der Überwachung und Koordinierung der Wirtschaftspolitiken, ABl. (EU) L 306/12 vom 23.11.2011, S. 15. 
der europäischen Wirtschafts- und Finanzkrise umfassend überarbeiteten Rechtsregimes der makroökonomischen Governancestruktur ${ }^{1642}$ der Union in der sog. „präventiven Komponente“ („preventive arm“) des Stabilitäts- und Wachstumspaktes. Abweichend sind die Regelungen auch als „regelbasierte[...] Überwachung im Zuschnitt der Rechnungshofkontrolle“ bezeichnet worden. ${ }^{1643}$ Ziel dieses Rechtsregimes ist es, durch genauere Aufsicht über die Haushaltsplanung und Wirtschaftsentwicklung der Mitgliedstaaten durch die Kommission und im Rat neue fiskalische Schieflagen zu vermeiden und auf Wachstum und Entwicklung gerichtete Volkswirtschaften in nunmehr allen Mitgliedstaaten zu fördern. Griechenland unterfiel bis 2018 durch Beschluss des Rates der sog. „korrektiven Komponente" des SWP und nahm daher am Semester nicht teil. Es unterlag vielmehr einem sog. wirtschaftlichen Anpassungsprogramm. ${ }^{1644}$ Durch Beschluss vom 19.09.2017 hat der Rat dieses beendet und Griechenland dem Semester unterstellt, ${ }^{1645}$ das damit für alle Mitgliedstaaten gilt.

\section{a. Genese, Rechtsgrundlage und Rechtsverbindlichkeit}

Das Semester als Teil des SWP entstand in drei Schritten. ${ }^{1646}$ Bereits 2010 entschied sich der Europäische Rat in sog. Schlussfolgerungen, dass es zur Koordinierung der Haushaltspolitiken durch die sog. Stabilitätsund Konvergenzprogramme eines Prozesses der Koordinierung zwischen

1642 Zur Einordnung als „soft governance tool“ bei Aleksandra Maatsch, „Effectiveness of the European Semester: Explaining Domestic Consent and Contestation", in: Parliamentary Affairs 70 (2017), S. 1-19, S. 2; zum Begriff der Governance und der Ableitung des Begriffs der Wirtschaftsregierung für die deutsche Rechtssprache vgl. Carlino Antpöhler, „Emergenz der europäischen Wirtschaftsregierung“, S. $359 \mathrm{ff}$.

1643 Ulrich Hufeld, „\$22 Das Recht der Europäischen Wirtschaftsunion“, Rn. 60.

1644 Eine Übersicht zum Programm für Griechenland findet sich unter: https://ww w.consilium.europa.eu/en/policies/financial-assistance-eurozone-members/gr eece-programme/. Die hiernach eingereichten „national plans“ sind einsehbar unter: https://ec.europa.eu/info/archive-european-semester-documents-greece_ en.

1645 Rat der Europäischen Union, Beschluss des Rates zur Aufhebung der Entscheidung 2009/415/EG über das Bestehen eines übermäßigen Defizits in Griechenland, 11240/17, vom 19.09.2017, s. dort insb. Erwägungsgrund 17.

1646 Überblick auch bei Walter Obwexer, „Das System der „Europäischen Wirtschaftsregierung" und die Rechtsnatur ihrer Teile: Sixpack - Euro-Plus-Pakt - Europäisches Semester - Rettungsschirm“, in: Zeitschrift für öffentliches Recht 67 (2012), S. 209-251, S. 229-230. 
Mitgliedstaaten und Kommission bedürfe, der zunächst die Bezeichnung „europäisches [sic] Semester“ erhielt. ${ }^{1647}$ Daraufhin griff der Rat das nun „Europäische Semester“ als Koordinationszyklus nicht nur für die Haushaltspolitik, sondern bereits für die „Koordinierung der Wirtschaftspolitik“ in den Mitgliedstaaten auf und nutzte als Rechtsgrundlage eine Änderung im Verhaltenskodex zum Stabilitäts- und Wachstumspakt. ${ }^{1648}$ Die Kommission kündigte daraufhin an, das Semester auf eine ordentliche sekundärrechtliche Grundlage stellen zu wollen. ${ }^{1649}$ Die Umsetzung findet sich insbesondere in Art. 1 UAbs. 3 der Verordnung 1175/2011, die die ursprüngliche Verordnung des Rates über den sog. Stabilitäts- und Wachstumspakt abändert. ${ }^{1650}$ Die Verordnung 1175/2011 ist Teil des sog. „Six Pack“, eines Maßnahmenbündels bestehend aus fünf Verordnungen und einer Richtlinie, das sekundärrechtlich den „Stabilitäts- und Wachstumspakt" von 1997 vor dem Hintergrund der Finanzkrise nach einer ersten Reform von 2005 weiter fortentwickeln soll. ${ }^{1651}$ Damit hat das Semester, im Unterschied zu den bisher dargestellten Mechanismen und ungeachtet seines Rückgriffs auf unionales soft law zu seiner Durchführung, eine aus Legitimationsgesichtspunkten unstrittige Rechtsgrundlage und ist rechtsverbindlich.

Das Semester ist auch sanktionsbewehrt. Policy-Output des Semesters sind nach Art. 3 UAbs. 3 der Verordnung 1175/2011, welcher wiederum

1647 Europäischer Rat, Schlussfolgerungen zur Tagung am 17.06.2010, EUCO 13/10, vom 17.06.2010, S. 5, Nr. 11, lit. c. Zu diesen Ursprüngen Jens Hamer, Art. 126 AEUV, in: Hans von der Groeben, Jürgen Schwarze \& Armin Hatje (Begr./Hrsg.), Europäisches Unionsrecht, Nomos, Baden-Baden, 7. Aufl. 2015, Rn. 51.

1648 Der Verhaltenskodex bezeichnet zusammengefasst vom Rat 1998 aufgestellte und seitdem mehrfach modifizierte „Leitlinien für die Aufstellung der Stabilitäts- und Konvergenzprogramme durch die Mitgliedstaaten“, vgl. Rüdiger Bandilla, Art. 121 AEUV, in: Eberhard Grabitz, Meinhard Hilf \& Martin Nettesheim (Begr./Hrsg.), Das Recht der Europäischen Union, C.H. Beck, München, 68. EL 2019, Rn. 24, weiter Pressemitteilung des Rates zur 2212. Sitzung vom 12.10.1998, C/98/334 11825/98 (Presse 334), Anlage III.

$1649 \mathrm{Zu}$ beiden Punkten vgl. Rat der Europäischen Union, Pressemitteilung, 13161/10, vom 07.10.2010, S. 6, Hinweis bei Carlino Antpöhler, „Emergenz der europäischen Wirtschaftsregierung“, S. 364, der diesbezüglich von „Durchführungsbestimmungen der Kommission" spricht.

1650 Vgl. Carlino Antpöhler, „Emergenz der europäischen Wirtschaftsregierung“, S. 364 .

1651 Zum sog. „Six Pack“ konzise Jens Hamer, Art. 126 AEUV, in: Hans von der Groeben, Jürgen Schwarze \& Armin Hatje (Begr./Hrsg.), Europäisches Unionsrecht, Nomos Baden-Baden, 7. Aufl. 2015, Rn. 25 ff. 
Art. 2-a der Verordnung 1466/97 abändert, zunächst „Leitlinien“ des Rates, die, ungeachtet ihrer teils irreführenden Bezeichnung, die eine reine soft law-Natur suggeriert, von den Mitgliedstaaten „gebührend“ zu berücksichtigen sind. Die im Umkehrschluss nicht gebührende Berücksichtigung ermöglicht infolge des Art. 1 UAbs. 3 der VO 1175/2011, der wiederum einen Art. 2-a Abs. 3, UAbs. 3, lit. a) bis c) in die VO 1466/97 einfügt, ein gestuftes Sanktionsregime. Dieses ist seiner Logik nach aus dem EU-Rahmen, dem Vertragsverletzungsverfahren und Art. 7 EUV geläufig und reicht von nochmaligen Empfehlungen, einer Verwarnung nach Art. 121 Abs. 4 AEUV, bis hin zu Durchgriffsmaßnahmen. ${ }^{1652}$ Es umfasst damit klassisch alle drei Stufen der föderalen Aufsicht, nämlich Beobachtung, Überprüfung und Berichtigung.

\section{b. Einordnung in der Literatur}

In der Literatur hat das Europäische Semester selten im ausschließlichen Fokus gestanden ${ }^{1653}$ und wenn ja, dann aus politikwissenschaftlicher Sicht vor allem im Hinblick auf die Auswirkungen im Bereich der europäischen Wirtschaftspolitik sowie des normativen Unterbaus seiner Ausgestaltung, den z.B. Jonathan Zeitlin und Bart Vanhercke als "reflexiven Lernprozess“ zwischen Mitgliedstaaten und Kommission bezeichnet haben. ${ }^{1654}$ In der

1652 Unter Verweis auf die Verordnungen 1467/97 und 1176/2011.

1653 Eine bedeutende Ausnahme sind die Beiträge des Heftes 2 des Journal of European Public Policy 2018, später auch veröffentlicht als Sammelband: Jonathan Zeitlin \& Amy Verdun (Hrsg.), EU Socio-Economic Governance since the Crisis: The European Semester in Theory and Practice, Routledge, Abingdon, 2018. Ich zitiere nachfolgend, wo geboten, die jeweils einzelnen Aufsätze. Zur Wirkung des Semesters in einem Mitgliedstaat (hier: Italien) vgl. Edoardo D’Alfonso Masarié, „Parlamentarische Budgetsouveränität auf der Probe der europäischen Haushaltsdisziplin: Der Streit um den italienischen Staatshaushalt 2019 und die Entscheidung der Corte Costituzionale“, in: Zeitschrift für ausländisches öffentliches Recht und Völkerrecht 79 (2019), S. 995-1026, S. $1001 \mathrm{f}$. Sehr übersichtlich auch die Literaturauswertung bei Howard Stevenson, „The European Semester: A literature review: Published as part of the project: Public service trade unions - effective intervention in the European Semester: Financed by the European Commission“, April 2019, der ganz die wirtschaftspolitische Perspektive betont.

1654 Jonathan Zeitlin \& Bart Vanhercke, „Economic governance in Europe 2020: socialising the European Semester against the odds", in: David Natali \& Bart Vanhercke (Hrsg.), Social policy in the European Union: state of play 2015, ETUI aisbl, Brüssel, 2015, S. 65-95, S. 91. 
Rechtswissenschaft hat seine „Einbettung“ von Anfang an in das geänderte unionale Wirtschaftsrecht regelmäßig dazu geführt, dass es in Relation zu den anderen Änderungen betrachtet wurde, die gerade im Zuge dieser Krise neu geschaffen wurden und die sowohl zur Ergänzung des Primärrechts durch den sog. Fiskalpakt, ${ }^{1655}$ als auch zur Schaffung neuen Sekundärrechts geführt haben. Darüber hat das Semester regelmäßig nicht den Eindruck erweckt, von herausgehobener Bedeutung zu sein.

Für Carlino Antpöhler war es Teil einer auf zwei Mechanismen beruhenden, mit dem Six Pack neu eingeführten Erweiterung des unionalen Kontrollinstrumentariums, bestehend einerseits aus der Verordnung 1176/2011 zur Behebung makroökonomischer Ungleichgewichte - die später weiteren Ausbau erfahren hat ${ }^{1656}$ - und andererseits dem Semester selbst. Bei Antpöhler erscheint das Semester indes recht nachrangig, es schaffe zusätzliche Berichts- und Berücksichtigungspflichten und wird unter den Begriff der „Kontrolle“ gefasst, dabei aber von anderen Sanktionen abgegrenzt. ${ }^{1657}$ Auch bei Ioannidis erscheint das Europäische Semester als im Hinblick auf seine Intensität wenig einschneidendes und zurückhaltendes Instrument unter der Vielzahl der im Rahmen der Eurokrise neu geschaffenen Verfahren. Er sieht in ihm ein Verfahren der „normal fiscal surveillance", das in rechtspolitischen Überlegungen der Mitgliedstaaten als niedrigschwellig angesehen wurde. ${ }^{1658}$ In der Kommentarliteratur wirkt diese Einstufung fort.

Bei Jens Hamer z.B. ist das Semester Teil des „Frühwarnsystems“ des Stabilitäts- und Wachstumspakts, eine Rolle, die seine Eigenständigkeit

1655 Überblick bei Roland Bieber, Astrid Epiney, Marcel Haag \& Markus Kotzur: Die Europäische Union, 13. Aufl., Nomos, Baden-Baden, 2019, $\$ 24$ Wirtschafts- und Währungsunion, Rn. 8-11; weiter Jens Hamer, Art. 126 AEUV, in: Hans von der Groeben, Jürgen Schwarze \& Armin Hatje (Begr./Hrsg.), Europäisches Unionsrecht, Nomos, Baden-Baden, 7. Aufl. 2015, Rn. 54 ff. Ähnlich im Zuschnitt Alica Hinarejos, „Fiscal Federalism in the European Union: Evolution and Future Choices for EMU“, in: Common Market Law Review 50 (2013), S. 1621-1642.

1656 Vgl. Verordnung Nr. 472/2013 des Europäischen Parlaments und des Rates vom 21. Mai 2013 über den Ausbau der wirtschafts- und haushaltspolitischen Überwachung von Mitgliedstaaten im Euro-Währungsgebiet, die von gravierenden Schwierigkeiten in Bezug auf ihre finanzielle Stabilität betroffen oder bedroht sind, ABl. (EU) L 140/1 vom 27.05.2013.

1657 Carlino Antpöhler, „Emergenz der europäischen Wirtschaftsregierung“, S. 364.

1658 Michael Ioannidis, „EU Financial Assistance Conditionality after ,Two Pack““, in: Zeitschrift für ausländisches öffentliches Recht und Völkerrecht 74 (2014), S. 61-104, S. 75. 
und Tragweite deutlich reduziert, ${ }^{1659}$ ähnlich bündig äußern sich weitere Kommentierungen. ${ }^{1660}$

Dabei fiele es völlig aus dem Zuschnitt dieser Arbeit heraus, aufgrund des Interesses hier am Semester nun eine umfassende Sichtung des „Eurokrisenrechts" der Union vorzunehmen. ${ }^{1661}$

Ich möchte stattdessen vielmehr drei andere Punkte betonen: zum einen, dass es möglich und hier sogar notwendig ist, das Semester aus dem Gefüge der makroökonomischen Governance der Union herauszulösen und dabei über die bloße Aussage, es greife das Justizbarometer auf, hinauszugehen und dadurch in dieser Diskussion erheblich aufzuwerten. ${ }^{1662}$ Zum zweiten, dass sodann ein bestimmter Teil des Zyklus zu interessieren hat, und drittens, dass das Semester eine eigenständige Funktion im unionalen Verfassungsaufsichtsregime hat, die zwar die Rolle des Justizbarometers fortführt, sich darin aber nicht erschöpft. Ob es in Zukunft rechtspolitisch noch zu erweitern ist, ist hier als Frage de lege ferenda nicht zu beantworten. ${ }^{1663}$

1659 Jens Hamer, Art. 126 AEUV, in: Hans von der Groeben, Jürgen Schwarze \& Armin Hatje (Begr./Hrsg.), Europäisches Unionsrecht, Nomos, Baden-Baden, 7. Aufl. 2015, Rn. 51-53.

1660 S. bei Rüdiger Bandilla, Art. 121 AEUV, in: Eberhard Grabitz, Meinhard Hilf \& Martin Nettesheim (Begr./Hrsg.), Das Recht der Europäischen Union, C.H. Beck, München, 68. EL 2019, Rn. 33; in der Kommentierung von Bernhard Kempen, Art. 126 AEUV, in: Rudolf Streinz (Hrsg.), EUV/AEUV, 3. Aufl. 2018, C.H. Beck, München, z.B. wohl ohne weiteren Verweis.

1661 Vgl. dazu insb. Kaarlo Tuori \& Klaus Tuori: The Eurozone Crisis: A Constitutional Analysis, Cambridge University Press, Cambridge, 2014, S. 61 ff., die auf die volkswirtschaftliche Dimension der Krise abstellen; Michael Ioannidis, „Europe's New Transformations “, S. 1238-1239, der die Literatur hierzu konzise auswertet.

1662 In diesem Sinne der Verweis auf den Länderbericht zu Polen in: Armin von Bogdandy, Piotr Bogdanowicz, Iris Canor, Maciej Taborowski \& Matthias Schmidt, "Guest Editorial: A potential constitutional moment for the European rule of law - The importance of red lines", S. 986.

1663 Durchaus interessante Vorschläge hierzu (Aufnahme eines verstärkten Grundrechts-Monitoring im Semester) bei Gabriel N. Toggenburg \& Jonas Grimheden, „Managing the Rule of Law in a Heterogeneous Context", S. 230-231. Fernliegend hingegen die Forderung bei Andi Hoxhaj, The EU Anti-Corruption Report: A Reflexive Governance Approach, Routledge, London, 2019, S. 203, Punkt 7.5.1, ff., wonach das Semester verstärkt Einzelfälle wie den Fall Daphne Galizia aufgreifen solle. 
c. Telos und Ablauf, hier mit besonderer Berücksichtigung als Verfassungsaufsichtsinstrument der Kommission

Inhaltlich stellt sich das Europäische Semester als Interaktionszyklus zwischen Mitgliedstaaten, Rat und Kommission dar, in welchem die Kommission Vorschläge und Kritik zur besseren Handhabung der nationalen Haushalte und ihrer wirtschaftlichen Entwicklung im Allgemeinen macht, der Rat diese Vorschläge nach gründlicher Prüfung und regelmäßig nach Abmilderung genehmigt und die Mitgliedstaaten diese umsetzen. Aus dieser Logik ist der Ausdruck der "präventiven Komponente“ des SWP entstanden.

Die hier interessierende Verfassungsaufsichtsqualität erwächst dem Semester bzw. präziser einem Teil des Semesters von der Erstellung des sog. Länderberichts bis zur Veröffentlichung der länderspezifischen Empfehlung, weil es die Kommission verstanden hat, in diesem Instrument der grundsätzlich wirtschaftspolitischen Begutachtung Elemente des Justizsystem- und Rechtsstaatlichkeitsschutzes zu verankern. Wie für das Justizbarometer ist dieser Prozess der einer Neuausrichtung, und wie dort handelt es sich um einen höchst subtilen, im Tatsächlichen statt im Rechtlichen ablaufenden Dialog zwischen Kommission und Mitgliedstaat. Darüber muss, wie dort, erneut die Frage der Effektivität dieses Vorgehens interessieren.

aa. Das „autumn package“ (Herbstpaket)

War es für das erste Semester zutreffend, den Zyklus im Januar mit dem sog. "Jahreswachstumsbericht“ der Kommission beginnen zu lassen, ${ }^{1664} \mathrm{er}-$ scheint es heute richtiger, gedanklich im Herbst eines Jahres N, beim sog. „autumn package“ („Herbstpaket“) der Kommission anzusetzen. ${ }^{1665}$ Bis zum November des Jahres $\mathrm{N}$ betreibt die Kommission in diesem zunächst

1664 So Walter Obwexer, „Das System der „Europäischen Wirtschaftsregierung“ und die Rechtsnatur ihrer Teile: Sixpack - Euro-Plus-Pakt - Europäisches Semester - Rettungsschirm“, S. 230.

1665 Für diese Darstellung auch die „Infographic - Who does what in the European Semester" des Rates, abrufbar unter: https://www.consilium.europa.eu/en/inf ographics/european-semester/. Nicht berücksichtigt hier ist die durch die von der Leyen-Kommission geplante Angleichung des Semesters an die Sustainable Development Goals, vgl. dazu: https://ec.europa.eu/info/sites/info/files/semeste r_sdgs_timeline.pdf. 
ein „stock taking“ bezogen auf die Ergebnisse des vorangegangenen Jahres. Der hieraufhin veröffentliche Jahreswachstumsbericht der Kommission ist nur eines von vier Dokumenten bzw. Berichten, dabei indes der bedeutendste Teil des Herbstpaketes. Für das Jahr 2019 ist das Herbstpaket am 17. Dezember veröffentlicht worden. ${ }^{1666}$ Ist das Herbstpaket veröffentlicht, beginnt zunächst eine Periode äußerst intensiver Arbeit für die Kommission. Sie dauert vom Erlass der sog. Länderberichte (country reports) unter ausschließlicher Verantwortung der Kommission bis zur Erstellung sog. länderspezifischer Empfehlungen (country-specific recommendations, im Kommissionsjargon schlicht: CSR) unter Beteiligung und zuletzt Alleinverantwortlichkeit des Rates. Besondere Entwicklungen - wie nämlich Fragen betreffend den Warnbericht u.a. - werden hier ausgeblendet. Die Arbeit konzentriert sich auf diesen für die unionale Verfassungsaufsicht der Kommission entscheidenden Teil des Semesterzyklus.

Die Kommission schreibt zu dieser Phase recht bündig: „Nach der Veröffentlichung des Jahreswachstumsberichts setzt die Kommission den Dialog mit den Mitgliedstaaten, Interessenträgern und Sozialpartnern fort, um ein gemeinsames Verständnis der in den EU-Ländern bestehenden Herausforderungen zu entwickeln." ${ }^{1667}$ In der Praxis ist dies bedeutend vielschichtiger.

bb. Singuläre Bedeutung des Länderberichts und sein Erarbeitungsprozess

Das zentrale Dokument, in dem die Kommission alle Beobachtungen, Überprüfungen und Berichtigungsvorschläge versammelt, die den Mitgliedstaat in Bezug auf Rechtsstaatlichkeit und Justizpolitik beaufsichtigen, ist der Länderbericht, denn er unterliegt, im Unterschied zur länderspezifischen Empfehlung, der ausschließlichen Verantwortung der Kommission. Der Länderbericht ergeht, regelmäßig im Februar des Jahres N+1, als sog. Arbeitsdokument der Kommission (SWD/"Staff Working Document") in

1666 Dies sind der Gemeinsame Beschäftigungsbericht, die Empfehlung für das Euro-Währungsgebiet und der Warnmechanismusbericht, vgl. unter: https:/ec .europa.eu/info/business-economy-euro/economic-and-fiscal-policy-coordinatio n/eu-economic-governance-monitoring-prevention-correction/european-semest er/european-semester-timeline/autumn-package-explained_de.

1667 Vgl. unter: https://ec.europa.eu/info/business-economy-euro/economic-and-fisc al-policy-coordination/eu-economic-governance-monitoring-prevention-correct ion/european-semester/european-semester-timeline/autumn-package-explained -de. 
Anlage zur summarischen „Semester-Mitteilung“, die zeitgleich ergeht. ${ }^{1668}$ Als SWD sind die Anforderungen an die Konsenserzielung im Unterschied zur späteren Mitteilung geringer, gleichwohl erfolgt eine Abstimmung nach meiner Beobachtung zumindest auf Ebene der Direktorate, und es ist anzunehmen, dass bis in die Kabinette der Generaldirektoren und Kommissare um Rückversicherung bei der Ausarbeitung nachgesucht wird.

Mangels Beteiligung anderer Unionsorgane ist der politische Gestaltungsfreiraum der Kommission für den Länderbericht am größten, eingeschränkt indes durch beträchtliche Kräfte in ihrem Inneren. Der Bericht dient ausschließlich dem Dialog mit dem jeweiligen Mitgliedstaat, was sich u.a. darin äußert, dass er lediglich auf Englisch (de-facto Arbeitssprache der Kommission) und der Amtssprache des jeweils adressierten Mitgliedstaats vorliegt. Ich konzentriere mich hier vorrangig und exemplarisch auf die Berichte des Jahres 2019. ${ }^{1669}$

Wie ein Gesetzgebungsakt in der interservice consultation (ISC), so ist auch das Semester das Produkt des Zusammenwirkens einer Mehrzahl von Generaldirektionen und nachgeordneten Abteilungen. Allerdings gilt nach meiner Beobachtung für das Semester nicht, wie für das embryonale, kommissionsinterne Stadium des Gesetzgebungsprozesses ${ }^{1670}$ das primus inter pares-Prinzip, sondern es besteht ein genuines Zuständigkeits- und dadurch Einflussgefälle. Den größten Einfluss auf das Semester und das für die Kommission primäre Produkt des Länderberichts haben die sog. „core DGs“ (auch „core group“) unter der Koordination des Generalsekretariats. ${ }^{1671} \mathrm{Zu}$ den core DGs zählt, neben dem Generalsekretariat, in überragendem Maße die Generaldirektion Wirtschaft und Finanzen (ECFIN), sodann die Generaldirektion Beschäftigung (EMPL) sowie die GD Steu-

1668 Vgl. für 2019, Europäische Kommission, Communication from the Commission to the European Parliament, the European Council, the Council, the European Central Bank and the Eurogroup, „2019 European Semester: Assessment of progress on structural reforms, prevention and correction of macroeconomic imbalances, and results of in-depth reviews under Regulation (EU) No 1176/2011”, $\operatorname{COM}(2019) 150$ final vom 27.02.2019.

1669 Für das Jahr 2020 war das Semester bei Abschluss des Manuskripts noch nicht vollständig durchlaufen.

1670 Illustrativ zur ISC auch Diane Sombrowski, Inputevaluation in der europäischen Forschungspolitik: Gestaltung und Implementation der Projektauswahl durch die EU-Kommission, Deutscher Universitäts-Verlag, Wiesbaden 2005, S. $120 \mathrm{ff} .$, insb. S. 121.

1671 Jonathan Zeitlin \& Bart Vanhercke, „Socializing the European Semester: EU social and economic policy co-ordination in crisis and beyond", in: Journal of European Public Policy 25 (2017), S. 149-174, S. 165. 
ern und Zollunion (TAXUD). ${ }^{1672}$ Wenn auch themenabhängig weitere Dienststellen sehr bedeutend sein können, folgt daraus, dass die mit der Justizpolitik und der Rechtsstaatlichkeit betrauten Dienststellen der Kommission keine prioritär zuständigen Referate im Schaffungsprozess des Länderberichts stellen. Sie sind darauf angewiesen, dass ihre Vorschläge im äußerst knapp bemessenen Raum, den die „core DGs“ hierfür zur Verfügung stellen, einerseits ein Maximum an Information verarbeiten, gleichzeitig aber auch ein Maximum an Gestaltungsfreiheit lassen, also anderen Verfahren nicht vorgreifen oder Angriffsfläche bieten. Das ist ein zentraler Unterschied zur Erstellung des Justizbarometers, überhaupt aller anderen in dieser Arbeit gesichteten Verfahren, bei welchen die GD JUST (bzw. der Juristische Dienst) einer derartigen horizontalen Rechtfertigungspflicht gar nicht oder nur wenig unterliegen, sondern sich allein vertikal, also im Austausch mit den Kabinetten, behaupten müssen.

Der Rechtfertigungsdruck für die Einbeziehung justizpolitischer und rechtsstaatsbezogener Aussagen im Semester ist, trotz der Verknüpfung dieser mitgliedstaatlichen Strukturmerkmale mit der volkswirtschaftlichen Entwicklung, sehr hoch. Das Semester kann und soll kein Instrument sein, in dem die Kommission frontal einen Mitgliedstaat angreift. Jegliche Kritik muss zwar deutlich erfolgen, aber sich strikt im Rahmen eines impliziten Rücksichtnahmeprotokolls, einem genau auschoreographierten rechtspolitischen Dialog mit dem Mitgliedstaat, bewegen. Die daraus resultierende Argumentation und Kritik an Mitgliedstaaten ist damit ähnlich subtil und politisch, wie diejenige, die die Kommission im Justizbarometer zum Ausdruck bringt. Da das Semester indes vorrangig textbasiert operiert, hat die Kommission die Möglichkeit, in diesem präferierten Format ihre Kritik vorzubringen.

Der aufmerksame Leser des Semesters muss dabei mehrere Teile des Länderberichts unterscheiden. In der Primärstruktur sind zunächst - die Anhänge außen vorgelassen - das Executive Summary, die Befolgungsbewertung der CSRs und die Umsetzung der von der Kommission definierten wirtschaftspolitischen Prioritäten auseinanderzuhalten. Die Struktur ist für alle Mitgliedstaaten gleich, und alle Mitgliedstaaten erhalten länder-

$1672 \mathrm{Zu}$ dieser Arbeitsverteilung Jonathan Zeitlin \& Bart Vanhercke, „Economic governance in Europe 2020: socialising the European Semester against the odds", in: David Natali \& Bart Vanhercke (Hrsg.), Social policy in the European Union: state of play 2015, ETUI aisbl, Brüssel, 2015, S. 65-95, S- 71; dort auch zu weiteren GDs, die fallabhängig hinzutreten können. 
spezifische Empfehlungen. In der Sekundärstruktur interessiert der Aufbau der einzelnen Teile des Semesters hierzu sogleich.

Das Executive Summary hat in der Primärstruktur des Berichts rechtspolitisch die größte Bedeutung. Findet sich hier eine bestimmte Aussage, so legt die Kommission auf sie größten Wert und priorisiert diese im Dialog mit dem Mitgliedstaat. Eine Rüge erhält durch die Aufnahme auch in das Executive Summary also besonderes Gewicht. Bestimmte Sprachregelungen finden hier eine lineare Fortsetzung und eine Rückkoppelung mit anderen Verfahren. Das zeigt sich z.B. sehr gut an den Länderberichten 2019 zu Polen und Ungarn: die Kommission verfolgt die Entwicklungen in Polen spezifisch unter dem Aspekt der Rechtsstaatlichkeit, in Ungarn überwiegen speziellere Aspekte der einzelnen innerstaatlichen Maßnahmen, die ich hier als Topoi der dortigen Rechtsstaatlichkeitskrise erarbeitet habe. Konsequenterweise ist im Executive Summary zu Polen der Begriff der Rechtsstaatlichkeit enthalten, darunter insbesondere unter Hinweis auf die Aussage „Investment remains affected by uncertainty“, eine in der Logik des Semesters sehr scharfe Kritik. ${ }^{1673}$ Im ungarischen Bericht ist die Feststellung einer Beeinträchtigung der Rechtsstaatlichkeit hingegen sorgsam vermieden. Dass die Kommission ihn gleichwohl im Blick hat, wird nur durch eine affirmative Nennung sichtbar, im Übrigen findet sich stattdessen ein Verweis auf die „Effektivität des Justizsystems“, ein vertrauter Begriff des Justizbarometers. ${ }^{1674}$ An das Executive Summary schließt sich eine etwas eingehendere Analyse unter dem Titel „Economic Situation" mit einem „Outlook" sowie ein Follow-Up-Teil betreffend die im vorangegangenen Jahr spezifisch gegenüber jedem Mitgliedstaat ergangenen CSRs an. Die Beurteilung erfolgt anhand von vier "Notenstufen": „substantial progress“, „some progress“, „limited progress“, „, no progress“.

1673 Europäische Kommission, Country Report Poland 2019, SWD(2019) 1020 final, vom 27.02.2019, S. 6, s. zuvor auch S.3.

1674 Europäische Kommission Country Report Poland 2019, SWD(2019) 1020 final, vom 27.02.2019, S. 3 und 6 (zur Rechtsstaatlichkeit), S. 42 („effective justice system)"; Country Report Hungary 2019, SWD(2019) 1016 final vom 27.02.2019, S. 6 („effectiveness of the justice system“) 41 (zur Rechtsstaatlichkeit). Im ein Jahr später ergangenen Bericht sind weite Teile der Rügen zu Ungarn betreffend die 2019 noch im Raum stehende Verwaltungsgerichtsreform entfallen, vgl. Country Report Hungary 2020, SWD(2020) 516 final, vom 26.02.2020, s. allerdings S. 45 zu ,persistent concerns over judicial independence“. S. zugleich Country Report Poland 2020, SWD(2020) 520 final vom 26.02.2020, S. 36 mit sehr deutlicher phrase d'attaque/chapeau: „The risk of a serious breach of the rule of law in Poland continues to exist with potentially negative consequences for investors' trust." 
Der Beurteilung wird eine "Gesamtnote" anhand dieser Stufen vorangestellt. Aufgrund des sehr starken Zugriffs der core DGs auf diese Teile und des ganz vorrangig makroökonomischen Zuschnitts ist es den an der Verfassungsaufsicht beteiligten Dienststellen nur selten möglich, an diesen Stellen Druckpositionen zu platzieren. Hinzuweisen ist indes darauf, dass für die Gesamtsituation in Polen 2019 immerhin „retroaktiv“ auf die Bedeutung der Rechtsstaatlichkeit für die zurückliegende wirtschaftliche Entwicklung in Polen verwiesen wurde. ${ }^{1675}$

Weit mehr Spielraum als das Executive Summary - und daher in seiner rechtspolitischen Bedeutung nur unwesentlich geringer - hat der inhaltliche Hauptteil des Länderberichts, die Beurteilung der Umsetzung der Reformprioritäten (Teil 3). Er besteht, wie schon zuvor die anderen Teile, in der Sekundärstruktur aus inhaltlich gegliederten, sorgsam getrennten Textblöcken, den sog. building blocks. Pro Block bzw. Abschnitt sind, je nach behandeltem Topos, sehr unterschiedliche Generaldirektionen und dort sachlich zuständige Referate mit der Abfassung befasst. Chef de file bleiben die "core DGs"; insbesondere die ECFIN. Jeder building block besteht aus einem hervorgehobenen Einleitungssatz, der im Kommissionsjargon auch sog. phrase d'attaque. Sie beinhaltet stets eine thematisch eindeutige Aussage zu Fortschritten im Hinblick auf den jeweiligen Topos und darüber ggf. mangels Fortschritts eine Mängelrüge. Alternativ kann sie auch, einem Obersatz ähnelnd, ein Prüfprogramm vorgeben. RegelmäBig zusammen mit dem nachfolgenden Satz übernimmt die phrase d'attque erneut die Funktion eines sog. chapeau, eines analysierend-kritischen und ein weiteres Prüfprogramm aufzeigenden Einleitungsabschnitts. Für Polen verdienen im Bericht von 2019 mehrere building blocks aus Warte der Verfassungsaufsicht der besonderen Aufmerksamkeit. Sie finden sich im Abschnitt „3.4.4. Institutional Quality and Governance“, in welchem sich die Kommission mit der Lage der Rechtsstaatlichkeit befasst. ${ }^{1676}$ Für Ungarn übernehmen building blocks zum Justizsystem die Funktion der rechtsstaatsbezogenen Mängelrüge. ${ }^{1677}$

Im ungarischen Bericht insbesondere zeigt sich deutlich die subtile Ausgestaltung des rechtspolitischen Dialogs mit dem Mitgliedstaat. Es gelingt der Kommission, eine Mängelrüge durch Benennung eines Aufsichtsmaßstabs aufzustellen, ohne aber die Abweichung von diesem Maßstab selbst

1675 Country Report Poland 2019, SWD(2019) 1020 final, vom 27.02.2019, S. 7.

1676 Country Report Poland 2019, SWD(2019) 1020 final, vom 27.02.2019, S. 41-43, insb. S. 42.

1677 Country Report Hungary 2019, SWD(2019) 1016 final vom 27.02.2019, S. 42. 
festzustellen. Sie schreibt zur nunmehr obsoleten Verwaltungsgerichtsreform:

„The Commission is analysing the new administrative courts system as regards the existence of effective safeguards to protect judicial independence, including the appointment of judges and court presidents, the powers of and the procedure for the appointment of the President of the Higher Administrative Court, the central administration of the new courts, the transfer and the evaluation of judges, the supervisory role of judicial bodies, and the uniformisation of case law. The forthcoming opinion of the Venice Commission will feed into this analysis." 1678

Damit ist festgehalten, anhand welcher Punkte die Kommission eine Rüge entwickelt hätte, ohne dass diese bejaht werden. Hinsichtlich der konkreten Operationalisierung besteht, ungeachtet der Ankündigung der Kommission, dass das spätere Gutachten der Venedig-Kommission Berücksichtigung finden werde, bereits eine gewisse Übereinstimmung mit ihrer späteren Analyse, ${ }^{1679}$ was den Maßstab absichert. Da eine Rüge fehlt, kann der Mitgliedstaat aber nicht erwidern, dass die Kommission ungerechtfertigterweise eine materiell-rechtliche Festlegung getroffen hätte. Er kann dies dann auch nicht etwa in späteren Gerichtsverfahren in Luxemburg zugrundelegen. Damit ist der building block rekursfest. Die Verknüpfung mit makroökomischen Fragen, die im chapeau regelmäßig vorliegt, ist an dieser Stelle des building block nicht mehr gegeben. Die zuständigen Dienststellen der GD JUST haben Raum für die Aufnahme ihrer eigenen policy message in höchst konzentrierter Form. Es ist auffällig, dass die Kommission ein Jahr später ihre Kritik in Bezug auf die Lage der ungarischen Justiz in Umfang und Deutlichkeit weit zurückgefahren hat, wenn auch der chapeau eindeutig geblieben ist. ${ }^{1680}$ Das lässt darauf schließen,

1678 Country Report Hungary 2019, SWD(2019) 1016 final vom 27.02.2019, S. 42.

1679 Vgl. CDL-AD(2012)001, Opinion 663/2012, Opinion on Act CLXII of 2011 on the Legal Status and Remuneration of Judges and Act CLXI of 2011 on the Organisation and Administration of Courts of Hungary vom 19.03.2012, Rn. 119.

1680 Country Report Hungary, SWD(2020) 516 final, vom 26.02.2020, S. 45, "Persistent concerns over judicial independence may impact the business environment. The independence, efficiency and quality of the justice system are essential elements for the business environment and crucial to enhancing productivity and ensuring sustainable economic growth.” 
dass man 2020 der Entwicklung des ungarischen Justizsystems GD-übergreifend deutlich weniger Priorität eingeräumt hat.

Die Erarbeitung der building blocks in der Praxis übernehmen, nach Mitgliedstaat geordnet, informell sog. „country desks“. Nicht alle am Semester beteiligten Referate unterhalten für alle Mitgliedstaaten derartige Desks. Sie bestehen nach meiner Beobachtung anlassbezogen nur zu bestimmten Mitgliedstaaten und füllen das Deputat der zuständigen Referenten auch nicht aus. Der sachliche Austausch zwischen thematisch verwandten Desks zu verschiedenen Mitgliedstaaten ist die Regel. Pro Referat bzw. Direktion übernimmt ein sog. „Semesterkoordinator“ die zunächst dienststelleninterne Koordinierung der building blocks. Der Austausch mit anderen Generaldirektionen, dabei ganz besonders den „core DGs“, erfolgt in nach Mitgliedstaat getrennten sog. „country teams“ bzw. „country team meetings“ („CTM“), die grundsätzlich im 1-2 monatlichen Turnus im Berlaymont stattfinden. Alleinige Arbeitssprache ist Englisch, eine Übersetzung erfolgt nicht, ausgenommen die Übersetzung des Berichts in die Amtssprache(n) des Mitgliedstaats. Dem country team sitzt ein Beamter vor, der nach ständiger Verwaltungspraxis nicht die Nationalität des begutachteten Mitgliedstaats haben soll. Abhängig vom Mitgliedstaat sind indes mehr oder minder große Prozentzahlen "einheimischer" Kommissionsbeamter an der Ausarbeitung beteiligt, dies bedingt schon die erforderliche Kenntnis des jeweiligen Wirtschafts- und Rechtssystems und die Beherrschung der jeweiligen Fachsprache. Erhöht wird die Anzahl Beamter mit gleicher Nationalität des beaufsichtigten Staates überdies regelmäßig durch die Einbeziehung der Kommissionsvertretungen in den nationalen Hauptstädten, die zu den CTM per Video zugeschaltet sind. Damit beantwortet sich hier schließlich auch die Frage, inwieweit das Justizbarometer tatsächlich das Semester beeinflusst („feeds“). Man wird angesichts der eigenständigen Ausarbeitung zum Semester, auch im Hinblick auf die justizpolitisch relevanten Teile, von einer bedeutenden, allerdings keinesfalls ausschließlichen Vorprägung sprechen müssen. Das Semester beinhaltet also, im Hinblick auf Rechtsstaatlichkeit und Zustand der Justizsysteme, regelmäßig auch eigenständig entwickelte Ergebnisse. Erfolgt ihre Erarbeitung in den ersten CTM in der Regel noch auf Referentenebene, sind bei späteren Treffen Vorgaben der Direktionen für die zu verhandelnden building blocks genau zu berücksichtigen.

Der Arbeitsaufwand ist nicht trotz, sondern gerade wegen der sehr komprimierten Form der Länderberichte immens. Dies gilt sowohl in der Materialerarbeitung als auch -berücksichtigung. Hinter wenigen Sätzen können umfassende Rechtsgutachten stehen. Auf die Ausführungen zum 
oben sog. Prinzip der Einheitlichkeit der Sorgfalt bei der Abfassung von Texten der Kommission sei nochmals verwiesen. Die Kommission erhebt die Semesterdaten grundsätzlich selbst, insbesondere durch intensiven Austausch mit den nationalen Verwaltungen, auch durch Dienstreisen vor Ort, ${ }^{1681}$ bzw. greift auf statistische Vorarbeiten zurück. In wenigen Fällen, gerade aber im Bereich der justizbezogenen building blocks, sind Verweise auf den Europarat, darunter die GRECO und die Venedig-Kommission, gängig. ${ }^{1682}$ Verweise auf wissenschaftliche Literatur sind möglich, aber selten.

d. Der weitere Verlauf des Europäischen Semesters bis zur Veröffentlichung der länderspezifischen Empfehlungen (CSR)

Ist in der Kommission Konsens über die Gestalt des Länderberichts erzielt worden, werden diese in einer Entwurfsfassung, noch vor Veröffentlichung, den Mitgliedstaaten zur Kommentierung eingereicht. Kommentare können diverse Formen annehmen, sie reichen von Ergänzungen bis hin zum diplomatischen Druck, bestimmte Passagen zu streichen. Unmittelbare Reaktionen seitens der Kommission auf derartigen Druck haben sich nicht feststellen lassen.

Die Länderberichte ergehen für alle Mitgliedstaaten zeitgleich, für den Zyklus 2019 sind sie am 27.02.2019 und für 2020 am 26.02.2020 veröffentlicht worden. ${ }^{1683}$ Es schließt sich eine Phase der intensiven Deliberation mit den Vertretern der einzelnen Mitgliedstaaten und im Rat zur Ausarbeitung der länderspezifischen Empfehlungen an. Sie sind für die Beurteilung der Mitgliedstaaten und folglich für die Aufsichtsfunktion des Semesters zentral. ${ }^{1684}$ Denn in ihnen manifestieren sich nicht nur konkrete Mängelrügen für die Mitgliedstaaten (Beobachtungsfunktion und Vorphase der Berichtigungsfunktion), sie sind auch Grundlage für den „korrektiven

1681 Jonathan Zeitlin \& Bart Vanhercke, „Economic governance in Europe 2020“, S. 72, sprechen sogar von „intelligence-gathering“, das die Kommission hier betreibe.

1682 Exemplarisch sehr einprägsam: Country Report Hungary 2019, SWD(2019) 1016 final vom 27.02.2019, S. 42.

1683 Abrufbar unter: https://ec.europa.eu/info/publications/2019-european-semester -country-reports_en für 2019 und https:/ec.europa.eu/info/publications/2020-e uropean-semester-country-reports_en für 2020.

1684 Vgl. auch Jonathan Zeitlin \& Bart Vanhercke, „Economic governance in Europe $2020^{\prime \prime}$, S. 78, „culmination of the European Semester“. 
Arm“ späterer Sanktionen, da auf ihnen die weiteren Leitlinien des Rates beruhen, die Anfang Juli des Jahres $\mathrm{N}+1$ ergehen. ${ }^{1685}$ Für die Kommission lautet das Ziel, so viel wie möglich an Inhalt aus den Länderberichten in die CSR „hinüberzuretten“. Wie dies gelingt, soll hier exemplarisch für das Jahr 2019 betreffend Polen sowie Ungarn berücksichtigt werden. Dabei ist zu beachten, dass der Inhalt des Länderberichts gleich zwei Politikgestaltungsfilter passieren muss. Der Ratsempfehlung ist nämlich eine „Empfehlung für eine Empfehlung“ der Kommission vorgelagert, die im Juni des Jahres N+1 ergehen. ${ }^{1686}$ Für das Jahr 2019 war dies der 05.06.2019. Bereits die Kommissionsempfehlung muss selektieren, nur die aussagekräftigsten chapeaux und ihre Begleittexte haben eine Chance auf Aufnahme in den Text. Auf sie baut wiederum eine Empfehlung des Rates vom Juli des Jahres $\mathrm{N}+1$, für 2019 vom 09.07.2019, auf, ${ }^{1687}$ wobei der Rat in der Rezeption des Kommissionsvorschlags, entfernt ähnlich der Rezeption z.B. des Vorschlags nach Art. 7 Abs. 1 EUV, freies Ermessen genießt. Allein die Ratsempfehlung, nicht aber diejenige der Kommission, werden im Amtsblatt veröffentlicht. Sie allein sind definitive Vorlage für die späteren Leitlinien, die gegenüber dem Mitgliedstaat eine Berücksichtigungspflicht entfalten.

Für die Aspekte der Verfassungsaufsichtsfunktion dieser Empfehlungen zeigt sich, dass der Rat regelmäßig Aussagen abändert und abschwächt.

Für Polen zeigt sich in der Fassung der Kommission, dass der Verweis auf die schwelende Rechtsstaatlichkeitskrise in einem Erwägungsgrund im weiteren Text (wenn auch nicht im chapeau), nicht aber im „Tenor“ der Empfehlung enthalten ist. ${ }^{1688}$ In der Fassung des Rates ist der Hinweis beibehalten, aber deutlich abgeschwächt, die Festlegung auf „schwerwiegende Verstöße gegen die Rechtsstaatlichkeit in Polen" und die Formulierung, dass „sich die Lage weiter verschlechter“ habe, ist entfallen. ${ }^{1689}$

1685 Christoph Gröpl, „Schritte zur Europäisierung des Haushaltsrechts“, in: Der Staat 52 (2013), S. 1-25, S. 18.

1686 Zum weiteren Verlauf nach Veröffentlichung der Länderberichte insb. Christoph Gröpl, „Schritte zur Europäisierung des Haushaltsrechts“, S. 18.

1687 Abrufbar unter: https://ec.europa.eu/info/publications/2019-european-semester -country-specific-recommendations-council_en.

1688 Europäische Kommission, Empfehlung für eine Empfehlung des Rates zum nationalen Reformprogramm Polens 2019 mit einer Stellungnahme des Rates zum Konvergenzprogramm Polens 2019, COM(2019) 521 final vom 05.06.2019, S. 7, Erwägungsgrund 18.

1689 Empfehlung des Rates vom 9. Juli 2019 zum nationalen Reformprogramm Polens 2019 mit einer Stellungnahme des Rates zum Konvergenzprogramm Polens 2019 (2019/C 301/21), ABl. (EU) C301/123, S. C301/127, Rn. 18. 


\begin{tabular}{|l|l|}
\hline Fassung der Kommission & Fassung des Rates \\
„18. [...] Die Kommission ist & „18. [...] Die Gewährleistung der \\
der Auffassung, dass die Gefahr & Rechtsstaatlichkeit und der Unab- \\
schwerwiegender Verstöße gegen & hängigkeit der Justiz sind in die- \\
die Rechtsstaatlichkeit in Polen & sem Zusammenhang ebenfalls von \\
fortbesteht und sich die Lage wei- & grundlegender Bedeutung. Es sei \\
ter verschlechtert, da viele der bean- & daran erinnert, dass die Kommissi- \\
standeten Maßnahmen umgesetzt & on dem Rat im Dezember 2017 \\
und verfestigt werden. Diese Beden- & einen begründeten Vorschlag vor- \\
ken sind Gegenstand laufender Ver- & gelegt hat, wonach festgestellt wer- \\
fahren vor dem Europäischen Ge- & den sollte, dass die eindeutige Ge- \\
richtshof und im Zusammenhang & fahr einer schwerwiegenden Verlet- \\
mit Artikel 7 EUV. Rechtssicherheit & zung der Rechtsstaatlichkeit durch \\
und das Vertrauen in die Qualität & Polen besteht. Es ist bereits ein ent- \\
und Berechenbarkeit von Politik & sprechendes Urteil ergangen, und \\
und Institutionen in den Bereichen & diese Bedenken sind Gegenstand \\
Gesetzgebung und Steuern und & weiterer laufender Verfahren vor \\
in anderen Bereichen sind wichti- & dem Gerichtshof der Europäischen \\
ge Faktoren für das Investitionsum- & Union. Rechtssicherheit und das \\
feld.“ & Vertrauen in die Qualität und Be- \\
& rechenbarkeit von Politik und Insti- \\
& tutionen in den Bereichen Gesetz- \\
gebung und Steuern und in ande- \\
ren Bereichen sind wichtige Fakto- \\
ren für das Investitionsumfeld.“
\end{tabular}

Für Ungarn zeigt sich für die beiden CSR im Jahr 2019 das gleiche Phänomen. Im Kommissionskonsens hat es die Kritik an der bevorstehenden Verwaltungsgerichtsreform und die Lage des Justizrates in einen Erwägungsgrund geschafft. ${ }^{1690}$ Der Rat verknüpft diese Entwicklungen mit der Bedeutung für das Wirtschaftssystem unter Nutzung des Effektivitätskonzepts des Justizbarometers und schwächt zentrale Aussagen ab. Statt „Anlass zur Sorge“ heißt es hier etwa, es seien „Fragen aufgeworfen“

1690 Europäische Kommission, Empfehlung für eine Empfehlung des Rates zum nationalen Reformprogramm Ungarns 2019 mit einer Stellungnahme des Rates zum Konvergenzprogramm Ungarns 2019, COM(2019) 517 final, vom 05.06.2019, Rn. 17. 
worden. ${ }^{1691}$ Die Ergänzung um die mögliche Erledigung der Reform war hingegen geboten.

\begin{tabular}{|l|l|}
\hline Fassung der Kommission & Fassung des Rates \\
„17. Das System von Kontrolle und & „1. Die Unabhängigkeit, Effizi- \\
Gegenkontrolle [im Engl.: checks & enz und Qualität des Justizwesens \\
and balances], das für die Gewähr- & sind von entscheidender Bedeu- \\
leistung einer unabhängigen Justiz & tung, wenn es darum geht, Unter- \\
so entscheidende Bedeutung hat, & nehmen anzuziehen und das Wirt- \\
wurde in der ordentlichen Gerichts- & schaftswachstum zu fördern. Das \\
barkeit weiter geschwächt. Der Lan- & System von Kontrolle und Gegen- \\
desrichterrat hat immer größere & kontrolle, das für die Gewährleis- \\
Schwierigkeiten, ein Gegengewicht & tung einer unabhängigen Justiz so \\
zu den Befugnissen des Präsiden- & entscheidende Bedeutung hat, wird \\
ten des Landesgerichtsamts zu bil- & als in der ordentlichen Gerichtsbar- \\
den. Dies gibt Anlass zur Sorge um & keit weiter unter Druck stehend ge- \\
die Unabhängigkeit der Justiz. Was & sehen. Der Landesrichterrat steht \\
das Gesetz über die Verwaltungs- & vor immer größeren Herausforde- \\
gerichte betrifft, so sei darauf hin- & rungen, wenn es darum geht, ein \\
gewiesen, dass die Regierung am & Gegengewicht zu den Befugnissen \\
30. Mai 2019 einen Gesetzesentwurf & des Präsidenten des Landesgerichts- \\
zur Rücknahme des Gesetzes über & amts zu bilden. Fragen zu den Aus- \\
das Inkrafttreten sowie Übergangs- & wirkungen auf die Unabhängigkeit \\
regelungen für die Verwaltungsge- & der Justiz sind aufgeworfen wor- \\
richte vorgelegt hat.“ & den. Was das Gesetz über die Ver- \\
waltungsgerichte betrifft, so sei da- & rauf hingewiesen, dass die Regie- \\
rung am 30. Mai 2019 einen Geset- & zesentwurf zur Rücknahme des Ge- \\
setzes über das Inkrafttreten sowie & Übergangsregelungen für die Ver- \\
waltungsgerichte vorgelegt hat.“ & \\
&
\end{tabular}

1691 Empfehlung des Rates vom 9. Juli 2019 zum nationalen Reformprogramm Ungarns 2019 mit einer Stellungnahme des Rates zum Konvergenzprogramm Ungarns 2019 (2019/C 301/17), ABl. (EU) C 301/101 vom 05.09.2019, Rn. 17. 
e. Effektivität des Europäischen Semesters als

Verfassungsaufsichtsinstrument

Wie für das Justizbarometer, so ist auch für das Europäische Semester zu fragen, wie effektiv es die Absicht der Kommission umsetzt, gegenüber Mitgliedstaaten Aufsicht im Falle systemischer Defizite an Rechtsstaatlichkeit auszuüben, d.h. welche Ergebnisse es konkret liefern kann.

Das ist zunächst von den Sanktionen abhängig, die es nach sich ziehen kann. Dabei sollte man sich nicht dadurch irritieren lassen, dass das Semester dem sog. „preventive arm“ des SWP zugerechnet wird. Die Leitlinien, und damit mittelbar die CSR und die Länderberichte des Semesters, begründen nicht nur eine klare Berichtigungserwartung, sondern können nach Art. 2-a Abs. 3 UAbs. 3 der Verordnung 1175/2011 zu weiteren Sanktionen gegenüber Mitgliedstaaten führen, auch wenn diese bislang noch nicht genutzt worden sind und sich hier folglich eine ähnliches hypothetische Lage ergibt, wie vor der erstmaligen Nutzung des Verfahrens nach Art. 7 EUV. Die Rechtsverbindlichkeit dieser Sanktionen ist indes fraglich, womit sich sehr deutlich zeigt, dass es im Unionsrecht durchaus zu einem Auseinanderfallen von Rechtsverbindlichkeit und Aufsichtsverfahren mit Berichtigungsfunktion kommen kann.

Zwei der Sanktionen des Art. 2-a Abs. 3 UAbs. 3 der soeben genannten Verordnung, ${ }^{1692}$ nämlich die dortigen lit. a) und lit b), beinhalten nochmalige Empfehlungen oder eine sog. „Verwarnung“ i.S.d. Art. 121 Abs. 4

1692 Die unionsrechtlichen Gesetzesmaterialien sind leider unübersichtlich. Es empfiehlt sich, mit der konsolidierten Fassung der Verordnung zu arbeiten, abrufbar unter: https://eur-lex.europa.eu/legal-content/DE/TXT/PDF/?uri=CEL EX:01997R1466-20111213\&from=EN. Zur Beachtung: Der Text im Amtsblatt divergiert dabei: Art. 2-a in der dt. und engl. Fassung ist Art. 2-bis in der franz. Fassung. Die Formulierung in der dt. Fassung „Art. 212 Absatz 4 AEUV“ ist offensichtlich falsch, es muss heißen: Art. 121 Abs. 4 AEUV.

Der hier interessierende Verordnungstext lautet auszugsweise:

„Art. 2-a [...]

(3) Im Sinne einer rechzeitigen und integrierten politischen Beratung im Hinblick auf makrofinanzpolitische und makrostrukturpolitische Vorhaben erstellt der Rat im Verlauf des Europäischen Semesters nach Bewertung dieser Programme auf der Grundlage der Empfehlungen der Kommission unter Nutzung der Rechtsinstrumente gemäß Artikel 121 und 148 AEUV und dieser Verordnung sowie der Verordnung (EU) Nr. 1176/2011 in der Regel Leitlinien für die Mitgliedstaaten.

Die Mitgliedstaaten berücksichtigen die an sie gerichteten Leitlinien bei der Entwicklung ihrer Wirtschafts-, Beschäftigungs- und Haushaltspolitik gebührend, ehe sie die wesentlichen Beschlüsse über die nationalen Haushalte für 
AEUV, die an den Mitgliedstaat im Falle mangelnder Kooperation im Rahmen des Semesters zu richten sind. Sie führen also den politischen, rechtsunverbindlichen Druck der Empfehlungen fort, ${ }^{1693}$ sodass der Mehrwert dieser Maßnahmen sehr situationsabhängig sein wird. Unklar ist die dritte Möglichkeit, lit. c), der Pauschalverweis auf die Verordnung 1467/97. Versteht man diesen Verweis äußerst weit, d.h. als Möglichkeit der Heranziehung jedweder Sanktionsvorschrift dieser Verordnung, so erscheinen als schärfstes Schwert dort die Maßnahmen nach deren Art. 6, der allerdings systematisch dem Verfahren der Stabilitätsprogramme, nicht unmittelbar dem Semester selbst, angehört. Selbst bei Bejahung der Nutzbarkeit des Art. 6 der Verordnung ist die maximale „Eskalation“ dieser Norm ein Beschluss des Rates über die Nichteinhaltung zuvor abgegebener Empfehlungen, der dann wiederum bei Nichtbefolgung Gegenstand einer Vertragsverletzungsklage sein könnte. ${ }^{1694}$ Rechtsverbindliche Maßnahmen ergeben sich daher im Anschluss an das Semester nur sehr indirekt. Wie im EURahmen (lässt man den dort durchscheinenden Art. 7 Abs. 1 EUV außen vor) und dem Justizbarometer wirkt das Semester folglich ganz vorrangig durch politischen Druck.

Zeigt sich damit, dass die Sanktionen, die an das Semester anschließen, obwohl vorhanden, eher rechtsunverbindliche follow-up Maßnahmen zu

die kommenden Jahre fassen. Die entsprechenden Fortschritte werden von der Kommission kontrolliert.

Handelt ein Mitgliedstaat nicht entsprechend den an ihn gerichteten Leitlinien, so kann dies folgende Maßnahmen nach sich ziehen:

a) weiteren Empfehlungen für spezifische Maßnahmen;

b) einer Verwarnung durch die Kommission gemäß Artikel 212 Absatz 4 [scil.: Art. 121 Abs. 4] AEUV;

c) Maßnahmen gemäß dieser Verordnung, der Verordnung (EG) Nr. 1467/97 oder der Verordnung (EU) Nr. 1176/2011.

Die Umsetzung dieser Maßnahmen wird von der Kommission verstärkt überwacht und kann Überwachungsmissionen gemäß Artikel -11 dieser Verordnung einschließen."

1693 Vgl. Rüdiger Bandilla, Art 121 AEUV, in: Eberhard Grabitz, Meinhard Hilf \& Martin Nettesheim (Hrsg.), Das Recht der Europäischen Union, Rn. 27 ff., wonach die Rechtsnatur der Verwarnung noch nicht eindeutig geklärt ist, sich aber diese Maßnahme und die zusätzliche Empfehlung vorrangig in politischem Gruppendruck, insbesondere bei Veröffentlichung letzterer, erschöpfen werden.

1694 Zur Sanktionierung der Sekundärrechtsverletzung im Rahmen von Art. 258 AEUV näher Ulrich Karpenstein, Art. 258 AEUV, in: Eberhard Grabitz, Meinhard Hilf \& Martin Nettesheim (Begr./Hrsg.), Das Recht der Europäischen Union, C.H. Beck, München, Rn. $29 \mathrm{ff}$. 
sein scheinen, ist der zweite Faktor, der auf die Effektivität des Semesters Einfluss hat, ganz ähnlich wie für das Justizbarometer, seine konkrete Ausgestaltung. Das Semester wendet sich, noch weniger als das Justizbarometer, an den allgemeinen Beobachter. Seine „target audience“ sind Entscheider in den mitgliedstaatlichen Verwaltungen, die ein anderes Auge auf vermeintlich wenig relevante Festlegungen haben als die Öffentlichkeit oder sogar die Wissenschaft. Der Aussage etwa bei Andi Hoxhaj, wonach das Semester an zu wenig deutlichen Rügen mitgliedstaatlicher Defizite kranke, vermag ich nicht zuzustimmen. ${ }^{1695}$ Vielmehr, und dies scheint mir gleichwohl kritisch zu begutachten zu sein, steht die Kommission, wie im Justizbarometer, vor dem Problem der stichhaltigen Abgrenzung der Mitgliedstaaten. Denn die Kommission hat nicht ausschließlich die hier im Rahmen der Rechtsstaatlichkeitskrise der Union im Fokus stehenden Mitgliedstaaten in Bezug auf ihre Justizsysteme gerügt, sondern vielfach auch Mitgliedstaaten episodisch zu Verbesserungen derselben aufgefordert, ohne dass damit ein systemisches Defizit an Rechtsstaatlichkeit festgestellt gewesen wäre, weder in der Praxis, noch in der Wissenschaft. Das Europäische Semester ist also, selbst reduziert auf diejenigen Abschnitte und Teile, in denen die hierfür zuständigen Dienststellen besonders wirken, nicht allein Verfassungsaufsichtsinstrument, sondern bleibt auch allgemeines Justizmonitoring. Der Leser hat dabei eine recht eingängige Möglichkeit, sich zu vergewissern, für welche Mitgliedstaaten pro Jahr justizsystemspezifische CSRs ergangen sind, die Kommission listet diese im Justizbarometer auf, um den Berücksichtigungsprozess der dortigen Ergebnisse zu verdeutlichen. Die Kommission unterscheidet dabei die Gruppe an Mitgliedstaaten mit derartigen justizsystembezogenen Empfehlungen von anderen Mitgliedstaaten, die „vor besonderen Herausforderungen bezüglich ihrer Justizsysteme, einschließlich Rechtsstaatlichkeit und Unabhängigkeit der Justiz“ stehen. ${ }^{1696}$ Gerade diese Gruppe ist aber im Hinblick auf den qualitativen Zuschnitt rechtspolitischer Rügen weit gefasst, angesprochen sind „BE, BG, IE, EL, ES, LV, HU, MT, PL, RO und SI." Diese Ausrichtung läuft dadurch Gefahr, die Druckposition und die Klarheit von Beobachtung und Berichtigungsaufforderung im Semester unnötig zu schwächen. Soll die Effektivität des Semesters erhöht werden,

1695 Andi Hoxhaj, The EU Anti-Corruption Report, insb. S. 203 f., Punkt 7.5.2.

1696 Vgl. Europäische Kommission, Mitteilung der Kommission an das Europäische Parlament, den Rat, die Europäische Zentralbank, den Europäischen Wirtschafts- und Sozialausschuss und den Ausschuss der Regionen, EU-Justizbarometer 2019, $\operatorname{COM}(2019) 198$ final vom 26.04.2019, S. 9. 
könnte gerade an diesem Punkt angesetzt, also nicht die Art des Aufsichtszuschnitts geändert, sondern die qualitative Abstufung verschiedener justiz- und rechtsstaatsbezogener Rügen im Semester deutlicher werden und diesbezüglich z.B. eine dritte Gruppe (etwa nur Polen, Ungarn und ggf. Rumänien) gesondert beaufsichtigt werden. Mit einer solchen Forderung liefe man allerdings gegen die offene Opposition etwa der ungarischen Regierung an, die sich einer Spezifizierung der Aufsicht im Semester regelmäßig entgegenstellt hat. ${ }^{1697}$ Auch innerhalb der Kommission scheint fraglich, ob die sog. „core DGs“ eine derartige weitere Neuausrichtung des Semesters mittragen würden.

\section{Das Verfahren nach Art. 7 EUV}

Es mag überraschen, dass die Arbeit das Verfahren nach Art. 7 EUV, das bei aller Analyse der gegenwärtigen Rechtsstaatlichkeitskrise am Anfang der Diskussion gestanden hat, erst an dieser Stelle, vor allem getrennt zum EU-Rahmenverfahren, anspricht. Diese Trennung entspricht, ungeachtet der systematischen Verknüpfung mit dem EU-Rahmen, indes seinem Eintritt als aktives Instrument im Verlauf der Krise. Es ist erst relativ spät, zum Ende des Jahres 2017, von der Kommission gegenüber Polen eingeleitet und damit zugleich die Aussage des früheren Kommissionspräsidenten Barrosos von der „Atombombe“, die im Verfahren angelegt sei, widerlegt worden. $\mathrm{Zu}$ diesem Zeitpunkt war nicht nur der EU-Rahmen bereits seit gut zwei Jahren aktiv, auch Justizbarometer und Semester konnten bereits auf mehrere Ausgaben zurückblicken.

Ungeachtet dieser Vorentwicklung hat das Verfahren nach Art. 7 EUV die Rechtsstaatlichkeitskrise politisch wie rechtlich auf eine neue Stufe gehoben. Ich hatte zuvor festgehalten, dass das Verfahren vielfach Gegenstand exzellenter Arbeiten gewesen ist, die seine Funktion, Genese, seinen Verlauf und seine Tatbestände erarbeitet haben. Vor diesem Hintergrund ist es nicht nur nicht erforderlich, sondern auch nicht geboten, die Ausführungen zu wiederholen. Einen Mehrwert zum Stand der Forschung möchte ich vielmehr durch Nachzeichnung der Entwicklung des Verfah-

1697 S. etwa Pressemitteilung der ungarischen Regierung, „Equal treatment afforded to all Member States is an issue of credibility for EU", vom 27.02.2018, abrufbar unter: https://www.kormany.hu/en/prime-minister-s-office/news/equa 1-treatment-afforded-to-all-member-states-is-an-issue-of-credibility-for-eu. 
rens nach Art. 7 EUV seit seiner erstmaligen Nutzung des Verfahrens gegenüber Polen leisten.

a. Stand des Verfahrens gegenüber Polen

aa. Begründeter Vorschlag und Kreis der Antragssteller in der Rechtspraxis

(1) Entwicklung seit Dezember 2017

Spricht man, Stand der Entwicklung zu Anfang des Jahres 2020, davon, dass die Europäische Union gegenüber Polen das Verfahren nach Art. 7 EUV genutzt habe, so sind sogleich zwei Einschränkungen zu machen. „Das" Verfahren nach Art. 7 EUV hat es in der Praxis nicht gegeben. Es ist am 20.12.2017 ein „begründeter Vorschlag“ nach Art. 7 Abs. 1 EUV durch die Kommission vorgelegt worden, ${ }^{1698}$ der seitdem, seit über zwei Jahren, im Rat debattiert worden ist. Es ist nach derzeitiger Lage fraglich, ob das Verfahren allein nach Art. 7 Abs. 1 EUV in einer „Feststellung“ „mit der Mehrheit von vier Fünfteln" der Mitglieder des Rates zum Abschluss gebracht werden wird, wie die Norm vorsieht. Noch schwieriger abzusehen ist eine mögliche Fortführung nach Abs. 2 der Norm. Im Vergleich zum Vertragsverletzungsverfahren nach Art. 258 AEUV ist dies in etwa so, als ob die Kommission eine begründete Stellungnahme an den Gerichtshof geschickt hätte, das weitere Verfahren indes dort fortlaufend in der Schwebe bliebe, ohne beschieden oder beendet zu werden.

Zum zweiten zeigt sich, dass in der Praxis die Kommission zwar große Unterstützung durch eine Gruppe an Mitgliedstaaten erhält, diese aber im Rat bislang keine wirksamen Maßnahmen getroffen haben, um das Verfahren voranzutreiben.

(2) Wesentliche Merkmale und Argumentationsstil des begründeten Vorschlags

Dies steht im Kontrast zur Ausgestaltung und Deutlichkeit des begründeten Vorschlags der Kommission. Als erstem Exemplar seiner Art kommt

1698 Der Vorschlag wurde am 22.12.2017 an die Delegationen der Mitgliedstaaten weitergeleitet, vgl. den Übermittlungsvermerk 16007/17 gleichen Datums. 
ihm, als eigene Handlungsform, ${ }^{1699}$ eine erhebliche Prägewirkung zu. Das Europäische Parlament hat sich in der Ausgestaltung seines Vorschlags ersichtlich an ihm orientiert.

Der Vorschlag besteht aus zwei Teilen, dem eigentlichen Vorschlag und der ihm vorgelagerten Begründung, diese wiederum nach Problemen gegliedert. ${ }^{1700}$ Hauptfunktionen der Darstellung sind die Problemidentifizie-

1699 In der deutschen Fassung des LM-Urteils (EuGH, Rs. C-216/18 PPU, LM (Mängel des Justizsystems), Urteil (GK) vom 25.07.2018, ECLI:EU:C:2018:586), Rn. 17-20, ist konsequenter Weise, gleich einem Eigennamen, auch von einem „Begründeten Vorschlag“ (sic) die Rede. In der Rs. C-619/18, Kommission ./. Polen, „Unabhängigkeit des Obersten Gerichts“, Schlussanträge des Generalanwalts Evgeni Tanchev vom 11.04.2019, ECLI:EU:C:2019:325, Rn. 49, findet sich im englischen Original ebenfalls die Wiedergabe i.S.e. proper noun als „Reasoned Propsal“, ebenso in der deutschen, nicht aber in der französischen Fassung.

1700 Da die Kommission keine Inhaltsübersicht abgedruckt hat, hier zur besseren Orientierung der Aufbau:

1. Einleitung

2. Sachverhalt und Verfahren

2.1. Aktivierung des Rahmens zur Stärkung des Rechtsstaatsprinzips

2.2. Stellungnahme zur Rechtsstaatlichkeit

2.3 Empfehlung zur Rechtsstaatlichkeit (EU) [sic, scil.: Empfehlung (EU)...] 2016/1374 (1. Empfehlung)

2.4. Empfehlung (EU) 2016/146 zur Rechtsstaatlichkeit (2. Empfehlung)

2.5. Empfehlung (EU) 2017/1520 zur Rechtsstaatlichkeit (3. Empfehlung)

3. Fehlen einer unabhängigen und legitimen verfassungsgerichtlichen Kontrolle

3.1. Zusammensetzung des Verfassungsgerichtshofs

3.2. Die Veröffentlichung der Urteile des Verfassungsgerichtshofs

3.3. Die Ernennung des Präsidenten des Gerichtshofs und die weiteren Entwicklungen

3.4. Kombinierte Auswirkungen auf die Unabhängigkeit und die Legitimität des Gerichtshofs

4. Gefährdung der Unabhängigkeit der Ordentlichen Gerichtsbarkeit

4.1. Gesetz über das Oberste Gericht

4.1.2. Befugnis zur Verlängerung der Amtszeit von Richtern am Obersten Gericht

4.1.3. Außerordentlicher Rechtsbehelf

4.1.4. Weitere Bestimmungen

4.2. Gesetz über den Landesrat für Gerichtswesen

4.3. Gesetz über die Ordentlichen Gerichte

4.3.1. Pensionsalter und Befugnis zur Verlängerung der Amtszeit von Richtern 4.3.2. Gerichtspräsidenten

[Nummerierung fehlt] Absetzungsbefugnis

[Nummerierung fehlt] Ernennungsbefugnis 
rung und die Tatbestandssicherung. Um dies zu erreichen, ist die Nennung einzelner Entwicklungsschritte und Daten umfassend, darüber aber in der Lektüre langwierig. War bereits die Empfehlung zur Rechtsstaatlichkeit des EU-Rahmens in ihrer Dichte und Detailfülle eine Steigerung gegenüber der Stellungnahme, so setzt sich diese Steigerung, ohne dass dies hier überraschen sollte, nochmals fort. Die Detailfülle und Akribie ähnelt in dieser Darstellungsform entfernt eher einer strafrechtlichen Anklageschrift, die zur Wahrung des Unmittelbarkeitsgrundsatzes alle Anklagepunkte ohne Rücksicht auf die Eingängigkeit abhandeln muss. ${ }^{1701}$ Eine alternative Interpretation kann, sofern man mit den Parallelen zum Strafrecht fremdelt, auf die beachtlichen Überschneidungen zwischen dem Aufbau des begründeten Vorschlags und demjenigen eines französisches verwaltungsgerichtlichen Urteils hinweisen. Für Anleihen an diesem, noch vor Parallelen zum Urteilsaufbau etwa seitens des EuGH, sprechen, dass bei französischen Urteilen der Rekapitulation des Verfahrensgangs regelmäßig eine bedeutende Rolle vor der Wiedergabe der Rechtsauffassung der Parteien zukommt, sodass die Urteilserwägungen häufig aus deutscher Sicht Leitsätzen ähneln und dass sich an diese unmittelbar der Tenor ohne zusätzliche Subsumtion anschließt. Es finden sich Passagen, die dem deutschen Urteilsstil ähneln, sie verkörpern diesen aber nicht völlig. ${ }^{1702}$

René Chapus und ihm folgend Thomas von Danwitz hätten vermutlich von einer elliptischen Argumentationsweise im Sinne der französischen

[Nummerierung fehlt] Auswirkungen der Absetzungs- und Ernennungsbefugnis

4.3.3. Weitere Bedenken

4.4. Weitere Rechtsvorschriften

4.4.1. Gesetz über die Staatliche Richterhochschule

4.4.2. Weitere Gesetze

5. Feststellung der eindeutigen Gefahr einer schwerwiegenden Verletzung der in Artikel 2 des Vertrags über die Europäische Union genannten Werte

1701 Parallelen zwischen dem Verfahren nach Art. 7 EUV und strafprozessualen Grundsätzen sind in der Literatur immer wieder gezogen worden, vgl. Frank Schorkopf, Homogenität in der Europäischen Union, S. 123; Ulrike Kassner, Die Unionsaufsicht, S. 191, zum Strafcharakter des Art. 7 Abs. 3 EUV und Art. 309 EGV nach Rechtslage vor dem Vertrag von Lissabon.

1702 Vgl. insb. Europäische Kommission, Begründeter Vorschlag nach Artikel 7 Absatz 1 des Vertrags über die Europäische Union zur Rechtsstaatlichkeit in Polen für einen Beschluss des Rates zur Feststellung der eindeutigen Gefahr einer schwerwiegenden Verletzung der Rechtsstaatlichkeit durch die Republik Polen, COM(2017) 835 final, 2017/0360 (NLE), vom 20.12.2017, S. 1, Rn. 116-118 betreffend den Obersten Gerichtshof. 
Verwaltungsrechtsprechung ${ }^{1703}$ gesprochen. Selbst wenn man dem entspricht, hindert dies nicht daran, zu einem insgesamt positiven Ergebnis zu gelangen. So ist zuvor ähnliches festgehalten worden:

„The Commission's proposal merits close attention. It is detailed and extensive. It integrates the findings of other institutions [...]. This fends off accusations that the findings are partisan. By demonstrating that many institutions share its findings, the Commission makes itself the voice of a broad alliance. The Commission's proposal thus evidently aims to be two things at the same time: a convincing political value judgement, as well as a legally sound analysis. This is not paradoxical but rather how political institutions should decide. The legal reasoning of the Commission as to why there is a clear risk of serious breach might appear somewhat thin, as it does not really develop what the threshold requires. However, one needs to consider that institutional developments towards an authoritarian regime tend to be hard to grasp from a legal standpoint, because legal analysis focuses on individual acts. Taken individually, such measures lend themselves more easily to justification (although most of the Polish measures against the Constitutional Tribunal seem rather clear cases)."1704

Mit der Entscheidung der Kommission gehen indes zwei aus Sicht der Rechtswissenschaft sicherlich nicht gänzlich zufriedenstellende Punkte einher. Zum einen hat die Kommission keine Ausführungen zu den materiellen Tatbeständen des Art. 7 EUV unternommen, insbesondere nicht zum Tatbestand der „eindeutigen Gefahr einer schwerwiegenden Verletzung" i.S.d. Absatzes 1. Sie bleibt damit auch hinter den Ausführungen ihrer Mitteilung zu Art. 7 EUV aus dem Jahr 2003 zurück. ${ }^{1705}$ Zum zwei-

1703 René Chapus, Droit administratif général, 1. Bd., 8. Aufl. 1994, Rn. 12 („motivation [...] elliptique“), zit. in Thomas von Danwitz, Verwaltungsrechtliches System und europäische Integration, S. 44, bei Fn. 156, mit weiteren Ausführungen zum französischen Urteils- und Argumentationsstil. S. zuvor auch unter E.V. im Hinblick auf die Stellungnahme zur Rechtsstaatlichkeit.

1704 Armin von Bogdandy, Piotr Bogdanowicz, Iris Canor, Maciej Taborowski \& Matthias Schmidt, „Guest Editorial: A potential constitutional moment for the European rule of law - The importance of red lines“, S. 988.

1705 Dort hatte die Kommission zu den Tatbestandsvoraussetzungen Stellung bezogen, sodass ein Aufgreifen der Ausführungen konsequent gewesen wäre. Vgl. Mitteilung der Kommission an den Rat und an das Europäische Parlament zu Artikel 7 des Vertrags über die Europäische Union: Wahrung und Förderung der Grundwerte der Europäischen Union, $\operatorname{KOM(2003)~} 606$ endgültig vom 15.10.2003, S. 7 und f. 
ten hat die Kommission das Verhältnis der Tatbestände des EU-Rahmens (systemische Gefährdung des Rechtsstaatsprinzips) und des Art. 7 Abs. 1 nicht endgültig aufgelöst.

Sie hat aber immerhin festgehalten, dass sich „die systemische Gefährdung der Rechtsstaatlichkeit in Polen erheblich verschärft" habe. ${ }^{1706}$ Auch an anderer Stelle hat die Kommission dieses Motiv der Verschlimmerung der Lage herangezogen. Sie rügt, insbesondere z.B. in Bezug auf den Verfassungsgerichtshof, dass nicht nur ihren vorangegangenen Empfehlungen im EU-Rahmen nicht nachgekommen wurde, sondern dass sich in Polen die Rechtslage weiter verschlechtert habe. ${ }^{1707}$

(3) Operationalisierung der Rechtsstaatlichkeit über die Funktionsfähigkeit der Justiz

Ungeachtet der vorhergehenden Ausführungen betreffend den auch von der französischen Verwaltungsrechtsprechung geprägten Stil des begründeten Vorschlags wäre es unzutreffend, von einem Dokument ohne juristische Begründung zu sprechen. Wie schon aus den Zwischenüberschriften der Punkte 3 und 4 des Vorschlags hervorgeht, unterscheidet die Kommission zunächst dort die unmittelbare Funktionsfähigkeit zweier Gerichtszweige, nämlich der Verfassungsgerichtsbarkeit sowie der ordentlichen Gerichtsbarkeit, die wiederum in Instanzgerichte und Obersten Gerichtshof untergliedert ist, von Strukturveränderungen, die mittelbar auf diese Gerichtszweige Einfluss haben können. Für beide legt sie im Anschluss an die Darstellung der Entwicklung eine Prüfung im Rahmen einer Gesamtschau vor. ${ }^{1708}$ Aus ihnen geht hervor, dass das Leitmotiv der Beanstandung

1706 Europäische Kommission, Begründeter Vorschlag nach Artikel 7 Absatz 1 des Vertrags über die Europäische Union zur Rechtsstaatlichkeit in Polen für einen Beschluss des Rates zur Feststellung der eindeutigen Gefahr einer schwerwiegenden Verletzung der Rechtsstaatlichkeit durch die Republik Polen, COM(2017) 835 final, 2017/0360 (NLE) vom 20.12.2017, Rn. 5, Punkt 2).

1707 Europäische Kommission, Begründeter Vorschlag nach Artikel 7 Absatz 1 des Vertrags über die Europäische Union zur Rechtsstaatlichkeit in Polen für einen Beschluss des Rates zur Feststellung der eindeutigen Gefahr einer schwerwiegenden Verletzung der Rechtsstaatlichkeit durch die Republik Polen, COM(2017) 835 final, 2017/0360 (NLE) vom 20.12.2017, Rn. 111 und 113.

1708 Europäische Kommission, Begründeter Vorschlag nach Artikel 7 Absatz 1 des Vertrags über die Europäische Union zur Rechtsstaatlichkeit in Polen 
die Sorge um die Funktionsfähigkeit der Gerichtsbarkeit ist, womit die Operationalisierung der Rechtsstaatlichkeit über dieses Funktionsmerkmal nochmals zum Tragen kommt. Die Kommission hält z.B. fest:

„Nach Auffassung der Kommission haben die Gesetze aus dem Jahr 2016 und die Entwicklungen im Anschluss an die Ernennung der kommissarischen Präsidentin die Unabhängigkeit und Legitimität des Verfassungsgerichtshofs stark beeinträchtigt, sodass die Verfassungsmäßigkeit der polnischen Gesetze nicht mehr wirksam gewährleistet werden kann.“1709

Die Kommission schlägt weiter argumentativ die Brücke von diesen Schlussfolgerungen zur Rechtsstaatlichkeit als Wert der Union. Demnach ergibt sich die Notwendigkeit einer Rüge der Rechtsstaatlichkeit als Wert aufgrund der Garantenfunktion des Verfassungsgerichts für die gesamte Rechtsordnung: „Die Tatsache, dass die Verfassungsmäßigkeit der polnischen Gesetze nicht mehr wirksam garantiert werden kann, ist mit Blick auf die Wahrung der Rechtsstaatlichkeit besonders besorgniserregend, da wie in den Empfehlungen vom 27. Juli und 21. Dezember 2016 erläutert - das polnische Parlament eine Reihe besonders heikler neuer Rechtsakte verabschiedet hat $[\ldots]$. " 1710

Im folgenden Abschnitt 4 betreffend die Unabhängigkeit des polnischen Obersten Gerichtshofs nutzt die Kommission statt der Herausarbeitung der Funktionsfähigkeit desselben im Allgemeinen den Rückgriff auf die Judikatur des Gerichtshofs zu einzelnen Ausprägungen dieses Prinzips und schlägt damit die notwendige Brücke zur Rechtsstaatlichkeit als Gan-

für einen Beschluss des Rates zur Feststellung der eindeutigen Gefahr einer schwerwiegenden Verletzung der Rechtsstaatlichkeit durch die Republik Polen, $\operatorname{COM}(2017) 835$ final, 2017/0360 (NLE) vom 20.12.2017, vgl. Teil 3.4. (Rn. 109 ff.) und die Schlussteile der folgenden Abschnitte.

1709 Europäische Kommission, Begründeter Vorschlag nach Artikel 7 Absatz 1 des Vertrags über die Europäische Union zur Rechtsstaatlichkeit in Polen für einen Beschluss des Rates zur Feststellung der eindeutigen Gefahr einer schwerwiegenden Verletzung der Rechtsstaatlichkeit durch die Republik Polen, COM(2017) 835 final, 2017/0360 (NLE) vom 20.12.2017, Rn. 109.

1710 Europäische Kommission, Begründeter Vorschlag nach Artikel 7 Absatz 1 des Vertrags über die Europäische Union zur Rechtsstaatlichkeit in Polen für einen Beschluss des Rates zur Feststellung der eindeutigen Gefahr einer schwerwiegenden Verletzung der Rechtsstaatlichkeit durch die Republik Polen, COM(2017) 835 final, 2017/0360 (NLE) vom 20.12.2017, Rn. 112. 
zes. ${ }^{1711}$ Diese Bemühung des EuGH-Fallrechts im Argumentationsverlauf führt aber dazu, dass die Kommission, anders als im EU-Rahmen, dieses Fallrecht nicht nochmals gesondert voranstellt.

bb. Gleichlauf der Ausführungen der Europäischen Kommission mit denjenigen des Europäischen Gerichtshofs in späterer Rechtsprechung

Der begründete Vorschlag ging wichtiger Grundsatzrechtsprechung zur richterlichen Unabhängigkeit des Gerichtshofs, darunter insbesondere den Rechtssachen ASJP und den nachfolgenden Urteilen des Europäischen Gerichtshofs zur Rechtslage in Polen, zeitlich voraus und kann diese naturgemäß nicht berücksichtigen. Umgekehrt ist es aber interessant, sich zu fragen, welchen Einfluss der begründete Vorschlag auf die Rechtsprechung des Gerichtshofs gehabt hat.

Der EuGH hatte sich mit der Frage der Erheblichkeit des begründeten Vorschlags in seinem LM-Urteil zu beschäftigen. Er hat es dort vermieden offenzulegen, ob die Feststellungen der Kommission für ihn selbst Grundlage der juristischen Argumentation waren, ganz abgesehen von der Frage, ob er gewillt wäre, sich von einer dort getroffenen Feststellung leiten oder sogar binden zu lassen. Auch gegenüber Gerichten der Mitgliedstaaten ist eine solche Festlegung nicht erfolgt. Vielmehr heißt es: „Die Informationen in einem begründeten Vorschlag, der jüngst von der Kommission auf der Grundlage des Art. 7 Abs. 1 EUV an den Rat gerichtet wurde, stellen dabei besonders relevante Angaben dar." ${ }^{1712}$ Überdies hat er es den mitgliedstaatlichen Gerichten, zusätzlich zur ohnehin verlangten Prüfung der konkreten Auswirkungen i.S.d. Aranyosi-Urteils, verwehrt, von der Existenz eines derartigen begründeten Vorschlags automatisch auf eine Auswirkung im konkreten Einzelfall zu schließen. ${ }^{1713}$ Während

1711 Europäische Kommission, Begründeter Vorschlag nach Artikel 7 Absatz 1 des Vertrags über die Europäische Union zur Rechtsstaatlichkeit in Polen für einen Beschluss des Rates zur Feststellung der eindeutigen Gefahr einer schwerwiegenden Verletzung der Rechtsstaatlichkeit durch die Republik Polen, COM(2017) 835 final, 2017/0360 (NLE) vom 20.12.2017, Rn. 116-118.

1712 EuGH, Rs. C-216/18 PPU, LM (Mängel des Justizsystems), Urteil (GK) vom 25.07.2018, ECLI:EU:C:2018:586, Rn. 61.

1713 EuGH, Rs. C-216/18 PPU, LM (Mängel des Justizsystems), Urteil (GK) vom 25.07.2018, ECLI:EU:C:2018:586, Rn. 69. 
letzteres, abhängig vom Mitgliedstaat, kritikwürdig sein kann, ${ }^{1714}$ ist die Beschreibung als „besonders relevante Angabe“ vollumfänglich zu begrüßen. Sie würdigt den seitens der Kommission betriebenen Recherche- und Argumentationsaufwand, wie die politischen Umstände des Verfahrens, lässt den Gerichten aber die mit Blick auf die Gewaltenteilung gebotene Freiheit.

In späteren Entscheidungen des Europäischen Gerichtshofs hat sich die Berücksichtigung des begründeten Vorschlags in Schlussanträgen zur Entwicklung in Polen fest etabliert, ${ }^{1715}$ allerdings hat das Verfahren darüber keine herausragende Funktion eingenommen, sondern als „a fortiori“-Material gedient. Der begründete Vorschlag steht also, was die Ausführungen in der Sache angeht, von der Rechtsprechung des Gerichtshofs eher getrennt und geht im Rat seinen eigenen Gang.

\section{cc. Ausgestaltung der Handhabung des Verfahrens im Rat}

Seit Zuleitung des begründeten Vorschlags an die Mitgliedstaaten ist im Rat, auch bei wohlwollender Betrachtung, allenfalls ein partieller Fortschritt festzustellen, egal, ob man dabei eine Bejahung des materiellen Tatbestands des Art. 7 Abs. 1 EUV befürwortet oder die Einstellung des Verfahrens fordert. Dabei verlief das Verfahren zunächst recht zügig. Am 19.01.2018 informierte die Kommission im Coreper II die Mitgliedstaaten

1714 S. dazu Armin von Bogdandy u.a., „Drawing Red Lines and Giving (Some) Bite - the CJEU's Deficiencies Judgment on the European Rule of Law“, o. S.: "The Court should have adhered to the test developed in N.S., so that the systemic or generalized deficiencies and hence the abstract risk for the individual concerned should suffice to refuse a surrender. There are also practical concerns: it is difficult to imagine how the "dialogue" on judicial independence between the executing authority on the one side and the issuing juridical authority and its government on the other side can meaningfully take place. At the same time, it is clear that once a systemic deficiency has been established, the burden of proof shifts to the country issuing the arrest warrant, (para. 78). In dubio pro libertate."

1715 S. etwa EuGH, Rs. C-619/18, Kommission ./. Polen, „Unabhängigkeit des Obersten Gerichts“, Schlussanträge des Generalanwalts Evgeni Tanchev vom 11.04.2019, ECLI:EU:C:2019:325, Rn. 49; Verb. Rs. C-585/18 u.a., A.K. (Unabhängigkeit der Disziplinarkammer des Obersten Gerichtshofs), Schlussanträge des Generalanwalts Evgeni Tanchev, Rn. 1, Fn. 3 insb.; Verb. Rs. 558/18 und C-563/18, Miasto Łowicz, Rn. 1. 
in einem sog. „AOB“-Punkt erstmals über ihren Vorschlag. ${ }^{1716}$ Seitdem ist das Verfahren regelmäßig bei den monatlichen Zusammenkünften insbesondere des Rates für Allgemeine Angelegenheiten (General Affairs Council, GAC) auf die Tagesordnung gesetzt worden. ${ }^{1717}$ Protokolle dieser Aussprachen („Outcomes of the Council Meeting“), die neben den Minutes des Coreper den Großteil der Verfahrensdokumentation im Rat einnehmen, sind, soweit verfügbar, wenig aufschlussreich. Es handelt sich, ungeachtet der bis dato vier Präsidentschaften, die die Sache zu verwalten hatten (Bulgarien, Österreich, Rumänien und Finnland), um Statusberichte im Stil eines „Holding Letter“, die inhaltlich weder das Verfahren voranbringen noch Rückschlüsse auf den Meinungsstand der Mitgliedstaaten erlauben. So heißt es exemplarisch, z.B. im September 2018:

„Ministers continued their in-depth exchange with Poland on the concerns identified in the Commission's reasoned proposal under Article 7(1) TEU. The Council will return to this issue.”1718

Allerdings sind hiervon zwei Ausnahmen zu machen.

Zunächst ist festzuhalten, dass der Rat, in beachtlicher Parallele zur Kooperation der Kommission mit der Venedig-Kommission, selbst eine Zusammenarbeit mit Einrichtungen des Europarates gesucht hat, die recht gut dokumentiert ist. Der Austausch ist demnach vorrangig mit dem Generalsekretariat des Europarates im Rahmen des sog. CATS-Ausschusses im Rat erfolgt, wobei auch in Planungsabsichten der Ratspräsidentschaft Einsicht gewährt wurde. ${ }^{1719}$

Zum zweiten hat der Rat, innerhalb seiner Aussprachen zu Art. 7 Abs. 1 EUV im Vorfeld seiner Feststellung weitgehende Verfahrensausgestaltungen getroffen, die dort nicht angelegt sind. Art. 7 Abs. 1 EUV macht dem

1716 Rat der Europäischen Union, „2653rd meeting of the Permanent Representatives Committee held in Brussels on 20 December 2017", 15883/17 vom 19.01.2018, S. 13.

1717 Exemplarisch, um hier nicht alle Dokumente aufzuzählen, Rat der Europäischen Union (Allgemeine Angelegenheiten), Draft Minutes vom 27.04.2018, 8086/18 PV CONS 24 zum Treffen vom 17.04.2018. Im Dokumentenregister des Rates sind derartige Minutes in monatlicher Folge abrufbar. Aus den Minutes ist regelmäßig die Existenz weiterer interner Dokumente ableitbar.

1718 Rat der Europäischen Union, Outcome of the Council Meeting, President, 3636th Council meeting, General Affairs, vom 18.09.2018, 12279/18, S. 6.

1719 Rat der Europäischen Union, EU (CATS) - Council of Europe meeting, Brussels, 14 June 2018, 10628/18, vom 28.06.2018, insb. S. 5-6. Der CATS-Ausschuss ist ein Koordinierungsausschuss für den Bereich der polizeilichen und justiziellen Zusammenarbeit in Strafsachen. 
Rat nämlich drei Vorgaben, die Anhörung des Mitgliedstaats vor Feststellung, die Möglichkeit zusätzlicher Empfehlungen und die regelmäßige Überprüfung der Beschlussgrundlage nach Feststellung. Die Ausgestaltung dieser Vorgaben durch den Rat geht darüber hinaus. Sie haben zwar nicht die Verdichtung erfahren, mit der die Kommission per EU-Rahmen ihr Vorschlagsrecht ausgestaltet hat, aber sie zeigen gewisse Parallelen. Anders als der EU-Rahmen sind die Vorgänge im Rat allerdings reines Organinnenrecht.

Am 18.06.2018 ließ sich der Rat erstmals erkennbar länger zur Sache ein und hielt u.a. fest, es bedürfe einer organinternen Strukturierung der Anhörung des Mitgliedstaats. Der Rat umriss sie als Grundlage für alle weiteren Anhörungen Polens wie folgt:

„Die in Artikel 7 Absatz 1 EUV vorgesehene Anhörung stellt im Wesentlichen ein Peer- Review-Verfahren dar, das es den Mitgliedern des Rates ermöglicht, einen tiefergehenden Austausch mit Polen über die wichtigsten Bedenken zu führen.

[1] Zu Beginn der Anhörung erhält die Kommission Gelegenheit, über die wichtigsten Bereiche, die Anlass zu Besorgnis geben und Gegenstand dieser Anhörung sind, Bericht zu erstatten und eine aktuelle Einschätzung abzugeben.

[2] Polen wird Gelegenheit zu einleitenden Ausführungen über die besagten Bereiche erhalten.

[3] Anschließend können die Delegationen, die dies wünschen, Polen Fragen zu diesen wichtigsten Bedenken stellen. Nach jeder Frage wird Polen Gelegenheit zur Antwort erhalten.

[4] Am Schluss kann die Kommission Bemerkungen zu Polens Antworten machen und Polen seine eigenen Ansichten und Bemerkungen vorbringen.

[5] Abschließend wird der Vorsitz verfahrenstechnische Schlussfolgerungen ziehen.

[6] Diese werden im Protokoll über die Anhörung vermerkt. Außerdem wird das Generalsekretariat des Rates einen förmlichen Bericht über die Anhörung anfertigen." 1720

1720 Rat der Europäischen Union, „Rechtsstaatlichkeit in Polen / Artikel 7 Absatz 1 EUV Begründeter Vorschlag - Anhörung Polens am 26. Juni 2018“, 9997/18 vom 18.06.2018, vgl. Rn. 8-14 insb. (meine Nummerierung im Zitat). 
Eine derartige Festlegung im Innenbereich des Rates zur besseren Handhabung ist im Grundsatz nicht zu beanstanden. Er entfaltete allerdings in der Folge ein beträchtliches Eigenleben.

Beginnend mit dem 21.06.2018 reichte die Kommission in unterschiedlichen Abständen einen „Sachstandsbericht" (state of play) zur Lage in Polen, später auch in Ungarn ein. Auch dies ist in Art. 7 Abs. 1 EUV nicht vorgesehen. Die Kommission sah hierin aber ganz offensichtlich die Möglichkeit, in den regelmäßigen Sitzungen des Rates zur Sache das Verfahren aktiv zu gestalten. Der Sachstandsbericht resümiert, gegliedert nach Problempunkten des begründeten Vorschlags, zunächst die ursprüngliche Rüge, trägt dann neue Entwicklungen vor und bietet hierfür eine zusätzliche Analyse an. ${ }^{1721}$

In späteren Fortschreibungen dieses Dokuments, so vom 11.09.2018, hat die Kommission auch „jüngste Entwicklungen“, die im ursprünglichen Vorschlag noch nicht enthalten waren, aufgenommen. ${ }^{1722}$ Man kann in ihnen daher eine implizite Erweiterung des begründeten Vorschlags sehen. Der dafür seitens der Kommission betriebene Aufwand ist hoch. Gesetze werden umfassend ausgewertet und, wie im begründeten Vorschlag, die Darstellung anhand bestimmter Problemkomplexe strukturiert.

Ebenso am 11.09.2018, und damit genau einen Tag vor der EntschlieBung des Parlaments betreffend Ungarn, präzisierte der Rat dieses Verfahren mit weiteren Ausführungen, ${ }^{1723}$ auf die ich bereits im Abschnitt zu den in der Krise beteiligten Organen ${ }^{1724}$ hingewiesen habe. In ihnen kann man nicht weniger erblicken als eine rudimentäre „Artikel-7-Verfahrensordnung“. Es hieß nun:

„[1] Die in Artikel 7 Absatz 1 EUV vorgesehene Anhörung stellt im Wesentlichen ein Peer- Review-Verfahren dar, das es den Mitgliedern des Rates ermöglicht, einen tiefergehenden Austausch mit Polen über die wichtigsten Bedenken zu führen. Polen hat die Möglichkeit, das

1721 Europäische Kommission, Rechtsstaatlichkeit in Polen / Begründeter Vorschlag nach Artikel 7 Absatz 1 EUV - Beitrag der Europäischen Kommission für die Anhörung Polens am 26. Juni 2018, 10351/18 vom 21.06.2018.

1722 Europäische Kommission, Rechtsstaatlichkeit in Polen / Begründeter Vorschlag nach Artikel 7 Absatz 1 EUV - Beitrag der Europäischen Kommission für die Anhörung Polens am 18. September 2018, 12034/18 vom 11.09.2018.

1723 Rat der Europäischen Union, Rechtsstaatlichkeit in Polen / Begründeter Vorschlag nach Artikel 7 Absatz 1 EUV - Anhörung Polens am 26. Juni 2018, 10354/18, vom 21.06.2018.

1724 Supra unter E. II. 
Format seiner Delegation an die Besonderheiten der Zusammenkunft anzupassen.

[2] Zu Beginn der Anhörung erhält die Kommission Gelegenheit, den neuesten Stand der Dinge in den wichtigsten Bereiche[n, sic], die Anlass zu Besorgnis geben und Gegenstand dieser ersten Anhörung sind, darzulegen.

[3] Polen wird Gelegenheit zu Ausführungen über die besagten Bereiche erhalten.

[4] Anschließend können die Delegationen an Polen jeweils bis zu zwei Fragen richten, die sich nur auf den inhaltlichen Gegenstand der Anhörung beziehen dürfen. Der Vortrag einer Frage sollte nicht länger als zwei Minuten in Anspruch nehmen. Nach jeder Frage erhält Polen Gelegenheit zur Antwort ohne zeitliche Begrenzung. Bedarf es weiterer Klarstellungen, so können die Delegationen Anschlussfragen stellen - wiederum unter Einhaltung der zeitlichen Begrenzung von zwei Minuten. Erforderlichenfalls erhält Polen die Möglichkeit, seine Antworten schriftlich weiter auszuführen.

[5] Am Schluss erhält die Kommission Gelegenheit, die von Polen vorgetragenen Fakten zu kommentieren, und Polen kann seine eigenen Ansichten und Bemerkungen vorbringen.

[6] Abschließend wird der Vorsitz verfahrenstechnische Schlussfolgerungen ziehen. In diesem Stadium findet keine inhaltliche Bewertung der Thematik statt.

[7] Der Rat könnte beschließen, die Anhörung auf einer der nächsten Tagungen des Rates (Allgemeine Angelegenheiten) fortzusetzen.

[8] Die verfahrenstechnischen Schlussfolgerungen werden im Protokoll über die Anhörung vermerkt. Ferner wird das Generalsekretariat des Rates einen förmlichen Bericht über die Anhörung anfertigen. “1725

Die Kommission hat dem Ratsvorschlag betreffend das Verfahren zugestimmt. ${ }^{1726}$

1725 Rat der Europäischen Union, „Rechtsstaatlichkeit in Polen / Begründeter Vorschlag nach Artikel 7 Absatz 1 EUV - Anhörung Polens am 26. Juni 2018“, 10354/18, vom 21.06.2018, meine Nummerierung, im Original S. 3, Rn. 8 ff.

1726 Rat der Europäischen Union, Outcome of the Council meeting, 3710th Council meeting, 11337/19, S. 6. 
Es fällt auf, dass das Parlament in diesem Prozess nicht beteiligt wird. Dabei kann von Einfluss gewesen sein, dass das Parlament erst Anfang März 2018 den Vorschlag ausdrücklich begrüßte. ${ }^{1727}$

Wie geschildert, verfügte die finnische Ratspräsidentschaft Ende 2019 den Ausschluss des Parlaments von allen Sitzungen betreffend Art. 7 EUV in Bezug auf Ungarn, ${ }^{1728}$ in Bezug auf Polen scheint dies nie im Raum gestanden zu haben. Ebenso auffällig sind die gestärkte Rolle des Mitgliedstaats - seine Ausführungen sind zeitlich nicht begrenzt, die der anderen Delegationen schon - und die Entscheidung einer Fortsetzung des Verfahrens von Fall zu Fall, ohne dass konkrete Vorgaben für eine Beendigung gemacht werden.

Mit der Entschließung des Parlaments vom September 2018 zu Ungarn hatte der Rat zwei Verfahren zu berücksichtigen. In der Folge sind diese, beginnend mit der GAC-Sitzung vom 16.10.2018, regelmäßig zur gemeinsamen Aussprache verbunden worden. ${ }^{1729}$ Auf diesem Stand befindet sich das Verfahren derzeit. Die letzte Aussprache hat bei Abschluss des Manuskripts am 11.03.2020 stattgefunden. ${ }^{1730}$ Solange das Verfahren nicht weiter fortschreitet, wird sich mutmaßlich wenig Gelegenheit ergeben, zu den dogmatischen Fragen gerade der späteren Verfahrensstufen neue Erkenntnisse zu gewinnen.

b. Stand des Verfahrens gegenüber Ungarn

aa. Einleitung und Streit um das erforderliche Quorum

Das Verfahren nach Art. 7 Abs. 1 EUV gegenüber Ungarn beruht, anders als dasjenige für Polen, nicht auf einer Kollegiumsmehrheit der Europäischen Kommission, sondern auf einer Entschließung des Europäischen

1727 Europäisches Parlament, P8_TA-PROV(2018)0055, Beschluss der Kommission, im Hinblick auf die Lage in Polen das Verfahren gemäß Artikel 7 Absatz 1 EUV einzuleiten: Entschließung des Europäischen Parlaments vom 1. März 2018 zu dem Beschluss der Kommission, im Hinblick auf die Lage in Polen das Verfahren gemäß Artikel 7 Absatz 1 EUV einzuleiten (2018/2541(RSP)).

1728 Vlagyiszlav Makszimov, „MEPs shut out of Hungary Council hearing as rule of law situation worsens", Euractiv vom 22.11.2019.

1729 Rat der Europäischen Union, 3644th Council meeting, Outcome of the Concil Meeting, General Affairs, vom 16.10.2018, 13125/18.

1730 Rat der Europäischen Union, Summary Record, Permanent Representatives Committee, 7074/20, vom 11.03.2020. 


\section{E. Das Rechtsregime der Verfassungsaufsicht der Europäischen Union}

Parlaments vom 12.09.2018. ${ }^{1731}$ Es ist ohne vorangegangenes EU-Rahmenverfahren eingeleitet worden. ${ }^{1732}$ Das Parlament hatte bereits 2012 in seiner Entschließung zum Tavares-Bericht ${ }^{1733}$ seine Konferenz der Präsidenten (Gremium des Parlamentspräsidenten und der Fraktionsvorsitzenden) beauftragt, die Einleitung eines Verfahrens nach Art. 7 EUV eigenständig zu prüfen, eine Umsetzung erfolgte indes noch nicht. Auch die Literatur $^{1734}$ hatte zuvor in regelmäßigen Abständen von der Kommission gefordert, in Bezug auf Ungarn mit der Behandlung gegenüber Polen gleichzuziehen. Wie Tuori festgehalten hat, wurde dies aber weder gegenüber Ungarn noch gegenüber Rumänien ernsthaft erwogen, ${ }^{1735}$ obwohl etwa Barrosos Digitalkommissarin Neelie Kroes eine Nutzung des Verfahrens nach Art. 7 EUV gegenüber Ungarn öffentlich ins Spiel gebracht hatte. ${ }^{1736}$

Am 12.09.2018 nahm das Parlament der Kommission die Entscheidung mit einer Entschließung aus der Hand, die in ihrem Anhang einen „Vorschlag für einen Beschluss des Rates zur Feststellung der eindeutigen Gefahr einer schwerwiegenden Verletzung der Werte, auf die sich die Union gründet, durch Ungarn, im Einklang mit Artikel 7 Absatz 1 des Vertrags über die Europäische Union“ enthält. Der Zusatz „begründet (reasoned/motivé)“ fehlt, im Unterschied zum Vorschlag der Kommissi-

1731 Europäisches Parlament, P8_TA(2018)0340, Die Lage in Ungarn, EntschlieBung des Europäischen Parlaments vom 12. September 2018 zu einem Vorschlag, mit dem der Rat aufgefordert wird, im Einklang mit Artikel 7 Absatz 1 des Vertrags über die Europäische Union festzustellen, dass die eindeutige Gefahr einer schwerwiegenden Verletzung der Werte, auf die sich die Union gründet, durch Ungarn besteht (2017/2131(INL)), (2019/C 433/10), ABl. (EU) C 433/66 vom 23.12.2019, Begleitbrief von Antonio Tajani an Sebastian Kurz, zu diesem Zeitpunkt Präsident des Rates, vom 18.09.2018 (ohne zusätzlichen Inhalt) beim Rat unter der Nr. 12266/18.

1732 Hierzu näher unter $b$.

1733 Europäisches Parlament, P7_TA(2012)0053, Politische Entwicklungen in Ungarn in letzter Zeit Entschließung des Europäischen Parlaments vom 16. Februar $2012 \mathrm{zu}$ den aktuellen politischen Entwicklungen in Ungarn (2012/2511(RSP)), Erwägungsgrund 7.

1734 In diesem Sinne schon Anonym, „Editorial Comments: The Rule of Law in the Union, the Rule of Union Law and the Rule of Law by the Union: Three interrelated problems", in: Common Market Law Review (2016), S. 597-606, S. 601; sehr deutlich Bojan Bugarič \& Tom Ginsburg: „The Assault on Postcommunist Courts“, in: Journal of Democracy 27 (2016), S. 69-82, S. 76.

1735 Kaarlo Tuori, „From Copenhagen to Venice“, S. 226.

1736 Hinweis bei Agnes Batory, „Defying the Commission“, S. 692; weiter der dort. zit. Beitrag von Nikolaj Nielsen, "Kroes threatens nuclear option against Hungary”, EU Observer vom 09.02.2012. 
on, er ist aber ein derart „begründeter“ Vorschlag, auch, da Art. 7 Abs. 1 EUV für die Form zwischen dem Vorschlag der Antragsberechtigten nicht unterscheidet. Überdies rügte das Parlament, im Unterschied zur Kommission, gerade keine Gefahr der Verletzung nur der Rechtsstaatlichkeit, sondern unspezifischer aller Werte der Union, was das Generalsekretariat des Rates, das die Entschließung den Mitgliedstaaten zuzuleiten hatte, zunächst selbst durcheinanderbrachte. ${ }^{1737}$ Art. 7 Abs. 1 EUV ermöglicht seinem Wortlaut nach eine derartige pauschalisierte Feststellung.

Die Entschließung wurde mit 448 Ja-Stimmen gegen 197 Nein-Stimmen bei 48 Enthaltungen angenommen. ${ }^{1738}$ Aus Art. 7 Abs. 1 EUV geht ein Quorum für den Vorschlag des Parlaments nicht hervor, allerdings wird die Abstimmungsmodalität primärrechtlich in Art. 354 Abs. 4 AEUV präzisiert, was Art. 83 Abs. 3 der GeschOEP in der Fassung von 2017 wortgleich übernimmt. Demnach gilt eine „Mehrheit von zwei Dritteln der abgegebenen Stimmen und mit der Mehrheit seiner Mitglieder“. Die Vorgaben gelten sowohl für die eigenständigen Entschließung des Parlaments zur Einleitung des Verfahrens, wie hier, als auch für die spätere Zustimmung des Parlaments für den Fall des Vorschlags durch ein anderes antragsberechtigtes Organ (wie ggf. im Falle Polens), ${ }^{1739}$ die Art. 7 Abs. 1 EUV konstitutiv erforderlich macht.

Am 17.10.2018, also gut einen Monat nach Ergehen der Entschließung, erhob Ungarn Klage vor dem Gerichtshof. ${ }^{1740}$ Eine derartige Klageerhebung ist, ungeachtet der Justiziabilitätsbeschränkungen des Art. 19 i.V.m.

1737 Rat der Europäischen Union, „Vorschlag für einen Beschluss des Rates zur Feststellung der eindeutigen Gefahr einer schwerwiegenden Verletzung der Werte, auf die sich die Union gründet, durch Ungarn“, Korrigendum zum Übermittlungsvermerk, 12266/1/18 REV 1 COR 1, vom 25.09.2018.

1738 Vgl. Europäisches Parlament, Results of vote in Parliament, Statistics 2017/2131(INL), A8-0250/2018, Final vote, 12/09/2018, abrufbar unter: https:/ /oeil.secure.europarl.europa.eu/oeil/popups/sda.do?id=31378\&l=de. Das Abstimmungsergebnis trägt den Zusatz "Rules relating to the European Maritime and Fisheries Fund by reason of the withdrawal of the United Kingdom from the Union", hiervon sollte man sich nicht verwirren lassen. Zum Abstimmungsergebnis auch Jennifer Ranking, "MEPs vote to pursue action against Hungary over Orbán crackdown”, The Guardian vom 12.09.2018.

1739 Ausführliche Kommentierung mit Quotenberechnung bei Frank Schorkopf, Art. 7 EUV, in: Eberhard Grabitz, Meinhard Hilf \& Martin Nettesheim (Begr./ Hrsg.), Das Recht der Europäischen Union, C.H. Beck, München, 68. EL 2019, Rn. 24.

1740 EuGH, Rs. C-650/18, Ungarn ./. Europäisches Parlament, Klage, eingereicht am 17. Oktober 2018 - Ungarn/Europäisches Parlament, ABl. (EU) vom 03.12.2018, C 436/33. 
Art. 269 AEUV, der Art. 7 EUV der Überprüfung in der Sache dem EuGH entzieht, ${ }^{1741}$ möglich, denn Ungarn hat sich allein auf den Angriff auf Verfahrensvorgaben betreffend die Einleitung des Verfahrens selbst, mittels vier Rügen, gestützt.

Die vierte Rüge, nämlich dass bereits durch die Annahme der Entschließung das Parlament gegen den Grundsatz der loyalen Zusammenarbeit verstoßen habe, ist als offensichtlich unbegründet zurückzuweisen. In der Ausübung der in den Verträgen ermöglichten Antragskompetenz nach Art. 7 Abs. 1 EUV kommt die Kontrollfunktion des Parlaments, als Teil auch dieser Zusammenarbeit, ja gerade erst zum Ausdruck. Auch die dritte Rüge, wonach bei der Abstimmung Grundprinzipien der parlamentarischen Arbeit nicht eingehalten worden seien, ist eine Schutzbehauptung. Gerade die Stimmenthaltung, die Ungarn als nicht möglich gerügt hat, ist ja anzutreffen. Schließlich ist auch die zweite Rüge, die mangelnde Beteiligung des Parlamentsausschusses für konstitutionelle Fragen (AFCO) eher überraschend denn substantiiert. Die Entschließung folgt dem Sargentini-Bericht nach, der wiederum Ergebnis umfassender Ausschussarbeit im LIBE-Ausschuss war. ${ }^{1742}$ Will ein anderer Ausschuss, unter Geltendmachung seiner Zuständigkeit, in diesem Verfahrensstadium beteiligt sein, so regelt Art. 52 GeschoEP diesen Fall. Demnach, Abs. 1, kann der Ausschuss die Überweisung bei der Konferenz der Präsidenten beantragen. Im vorliegenden Fall war der AFCO-Ausschuss aber beteiligt und hat die Mehrheitsentscheidung mit $15 \mathrm{zu} 4$ Stimmen bei 5 Enthaltungen unterstützt. ${ }^{1743}$

Allerdings rügt Ungarn schließlich auch noch, in der Plenarabstimmung sei das Mehrheitsquorum verfehlt worden. Die Frage, ob das ZweiDrittel-Quorum im konkreten Fall der Verfahrenseinleitung gegenüber Ungarn erfüllt worden ist, wie von Art.354 Abs. 4 AEUV verlangt, ist genauer zu prüfen.

Sind 751 Abgeordnete anwesend und kommt es zu keiner Enthaltung, so bilden jedenfalls 501 abgegebene Ja-Stimmen die Zwei-Drittel-Mehr-

1741 Im Einzelnen: Frank Schorkopf, Art. 7 EUV, in: Eberhard Grabitz, Meinhard Hilf \& Martin Nettesheim (Begr./Hrsg.), Das Recht der Europäischen Union, C.H. Beck, München, 68. EL 2019, Rn. 50-53.

1742 Der gesamte Verfahrensverlauf ist dokumentiert unter: https://www.europarl.e uropa.eu/doceo/document/A-8-2018-0250_DE.html.

1743 Stellungnahme des Ausschusses für konstitutionelle Fragen für den Ausschuss für bürgerliche Freiheiten, Justiz und Inneres zur Lage in Ungarn (gemäß der Entschließung des Europäischen Parlaments vom 17. Mai 2017) (2017/2131(INL)), vom 26.03.2018. 
heit. ${ }^{174}$ Verringert sich die Zahl der anwesenden Abgeordneten, die Stimmen abgeben, so verringert sich auch die Zahl des Zwei-Drittel-Quorums (vgl. den Wortlaut des Art. 354 Abs. 4 AEUV „abgegebene Stimmen“).

Die Norm sagt hingegen nichts darüber aus, was mit Enthaltungen zu geschehen hat. Im Falle Ungarns waren 693 Abgeordnete anwesend $(448+$ $197+48) .{ }^{1745}$ Zwei Drittel hiervon sind gerundet 462 Abgeordnete. Damit wäre das Quorum im Parlament verfehlt. Zählt man die Abgeordneten, die sich enthalten haben, nicht mit, so sind 645 Abgeordnete zu berücksichtigen, das Quorum wäre damit erreicht (gerundet 430).

In einem Gutachten vom 07.09.2018, also eine gute Woche vor der entscheidenden Abstimmung, erstattete der Juristische Dienst des Parlaments ein vertrauliches Gutachten an Parlamentspräsident Tajani, das prompt öffentlich wurde (vgl. hierzu oben im Abschnitt zum EU-Rahmenverfahren und der Frage durchgestochener Quellen). ${ }^{1746}$ Anscheinend sah man die Gefahr einer Quorumsverfehlung voraus. Der Juristische Dienst des Parlaments verwies zutreffend darauf, dass die Formulierung „abgegebene Stimmen“ („votes cast“) die Frage der Enthaltungen offenlasse. Er folgerte, die Abstimmungsmehrheiten bestimmten sich nach Art. 178 Abs. 3 der Geschäftsordnung, ${ }^{1747}$ der sich in deren Kapitel 5 „Beschlussfähigkeit, Änderungsanträge und Abstimmung“ findet. Er sei Grundlage für die Beurteilung, wie weit diese Formulierung gehe. Laut dieser Norm sind „nur die abgegebenen Ja- und Neinstimmen bei der Berechnung des Abstimmungsergebnisses [zu berücksichtigen], ausgenommen in den Fällen, für die in den Verträgen eine spezifische Mehrheit vorgesehen ist" (meine Hervorhebung). Damit hängt allerdings die Anwendbarkeit dieser Norm, ungeachtet aller Präzedenzfälle, die der Juristische Dienst hierfür heranzieht, an der Aus-

1744 Berechnung bei Frank Schorkopf, Art. 7 EUV, in: Eberhard Grabitz, Meinhard Hilf \& Martin Nettesheim (Begr./Hrsg.), Das Recht der Europäischen Union, C.H. Beck, München, 68. EL 2019, Rn. 24.

1745 Abrufbar als „Results of vote in Parliament: Statistics - 2017/2131(INL), A8-0250/2018", unter: https://oeil.secure.europarl.europa.eu/oeil/popups/s da.do? id=31378\&l=en.

1746 Europäisches Parlament, Juristischer Dienst, Note to the attention of Mr. Antonio Trajani, President oft he European Parliament, Clarification of the voting procedure concerning Article 7 TEU, SJ-0612/18, NL/NG/ab, $\mathrm{D}(2018) 34453$.

1747 Europäisches Parlament, Juristischer Dienst, Note to the attention of Mr. Antonio Trajani, President oft he European Parliament, Clarification of the voting procedure concerning Article 7 TEU, SJ-0612/18, NL/NG/ab, D(2018)34453, Rn. 10. 
nahme des 2. HS. In Art. 354 Abs. 4 AEUV sieht der Juristische Dienst aber keine „spezifische Mehrheit“i.S.d. Art. 178 Abs. 3 GeschoEP.

"Contrary to Article 354(1) which regulates the vote in the Council, Article 354(4) TFEU does not stipulate how abstentions are to be treated. Therefore, [Article] 354(4) does not constitute an ,exception' in the sense of Rule 178(3) RoP. Parliament is free to use its right of auto-organisation enshrined in Article 232(1) TFEU and determine that abstentions do not count when considering whether or not a text has been adopted." 1748

Diese Rechtsauffassung vermag mich aus vier Gründen nicht zu überzeugen, die alle dafür fechten, in Art. 354 Abs. 4 AEUV, zum Nachteil des Parlaments im hiesigen Fall, eine „spezifische Mehrheit“ i.S.d. Art.178 Abs. 3 seiner Geschäftsordnung zu sehen.

Das erste Argument folgt aus dem Wortlaut. Art.354 Abs. 1 und 4 beginnen wortgleich: „Für die Zwecke des Artikels 7“. Benennt Art.354 Abs. 1 AEUV eine spezifische Mehrheit, so auch der Juristische Dienst des Parlaments, so ist zu vermuten, dass eine wortlautgleiche Norm drei Absätze weiter dies genauso tut. Das zweite Argument folgt aus dem Inhalt der Norm. Beide Normen regeln, ungeachtet gewisser lexikalischer Unterschiede (Abs. 1 benennt den Zweck des Verfahrens des Art. 7 EUV), die Berücksichtigung von Stimmen zur Feststellung von Schritten ebendieses Verfahrens. Abs. 1 regelt die Abstimmung im Rat, Abs. 4 im Parlament. Beides allein ficht schon, überdies aufgrund der systematischen Verklammerung beider Bestimmungen in einer Norm (drittes Argument), sehr für den teleologischen Gleichlauf der Absätze als Abstimmungsbesonderheiten.

Das entscheidende Argument gegen die Auffassung des juristischen Dienstes des Parlaments ist hingegen ein Umkehrschluss, der aus Art. 354 Abs. 1 AEUV entnommen werden muss. Satz 2 dieses Absatzes lautet für den Rat: „Die Stimmenthaltung von anwesenden oder vertretenen Mitgliedern steht dem Erlass von Beschlüssen nach Absatz 2 des genannten Artikels nicht entgegen." Soll heißen, im Rat sind Enthaltungen nicht zu berücksichtigen. Eine Entsprechung dieser Ausnahme fehlt für Absatz 4 im Hinblick auf das Parlament. Den Vertraggebern wäre es aber unbenom-

1748 Europäisches Parlament, Juristischer Dienst, Note to the attention of Mr. Antonio Trajani, President of the European Parliament, Clarification of the voting procedure concerning Article 7 TEU, SJ-0612/18, NL/NG/ab, $\mathrm{D}(2018) 34453, \mathrm{Rn} .15$. 
men gewesen, sie dort zu wiederholen, was gerade nicht erfolgt ist. Das ist nur so zu verstehen, dass hier keine Verwirrung im Hinblick auf die Geschäftsordnung des Parlaments erzeugt werden sollte. Dort nämlich, so die logische Folge, soll die Stimmenthaltung, entgegen Art. 178 Abs. 31. HS GeschoEP, aber in Einklang mit dessen 2. HS, gerade berücksichtigt werden. Das ist auch teleologisch sinnvoll. Stimmenthaltungen im Parlament können diverse Gründe haben, gerade bei politisch so heiklen Verfahren wie dem nach Art. 7 EUV. Größtmögliche Legitimität ist dort aber erforderlich, die Vertraggeber wünschen ein klares Ja oder Nein der direkt gewählten Vertreter, während sie dem Rat, den „peers“ des begutachteten Mitgliedstaats, offensichtlich politischen Handlungsspielraum wahren wollten. Im Ergebnis bedeutet das: für die Feststellung des Parlaments zur Einleitung eines Verfahrens nach Art. 7 Abs. 1 EUV ist zwingend eine Zwei-Drittel-Mehrheit der Ja-Stimmen der Mehrheit der Mitglieder des Parlaments bei Berücksichtigung aller Nein-Stimmen und Enthaltungen erforderlich. ${ }^{1749}$ Diese wurde im Falle Ungarns verfehlt, sodass eine Nichtigkeit der Entschließung in Betracht kommt. ${ }^{1750}$ Ungarns derzeit vor dem Gerichtshof rechtshängige Rüge ist also im Grundsatz begründet.

Die Frage ist nun, wie die Quorumsverfehlung im konkreten Fall zu behandeln ist, nämlich insbesondere, ob im konkreten Fall eine Heilung der verfehlten Zwei-Drittel-Mehrheit eingetreten ist. Die Heilung nichtiger Parlamentsakte ist in der Rechtsprechung für grundsätzlich möglich, wenn auch außerhalb der Beurteilungskompetenz der Gerichte befindlich erachtet worden. ${ }^{1751}$ Die Verträge regeln dies im speziellen Fall nicht, sie erscheint mir aber aufgrund der Besonderheiten des Verfahrens nach Art. 7 Abs. 1 EUV vertretbar. Es ist nämlich beachtlich, dass der Rat nach Eingang der Entschließung des Parlaments entschieden hat, sich ungeachtet der Rüge der Quorumsverfehlung durch Ungarn mit dem Verfahren auch in der Sache auseinanderzusetzen und es regelmäßig und über einen langen Zeitraum mit dem Verfahren zu Polen zur gemeinsamen Aussprache verbunden hat, ohne eine Nichtigkeit der Parlamentserschließung in

1749 So im Ergebnis auch schon Frank Schorkopf, Homogenität in der Europäischen Union S. 152, Rn. 244.

1750 In diesem Sinne zur Fehlerfolge mangelnder parlamentarischer Ermächtigung (Nichtigkeit einer Handlung des Generalsekretärs bei mangelnder Ermächtigung durch das Präsidium), vgl. EuG, Rs. T-146/04, Koldo Gorostiaga Atxalandabaso ./. Parlament, Urteil vom 22.12.2005, Slg. 2005, II-5995, ECLI:EU:T:2005:584, Rn. 97.

1751 Nochmals EuG, Rs. T-146/04, Koldo Gorostiaga Atxalandabaso ./. Parlament, Urteil vom 22.12.2005, Slg. 2005, II-5995, ECLI:EU:T:2005:584, Rn. 98. 
Erwägung zu ziehen. Es sind keine substantiellen Bedenken hiergegen durch eine Gruppe an Mitgliedstaaten bekanntgeworden. Damit erfolgte die Entscheidung der Fortsetzung des Verfahrens jedenfalls mit den Stimmen eines Drittels der Mitgliedstaaten, womit ersatzweise zum Quorum des Parlaments der begründete Vorschlag auch auf dieses Drittel der Mitgliedstaaten gestützt werden könnte. Es käme dann zu einer Substitution des einen Antragsbefugten (Parlament) durch einen anderen (Drittel der Mitgliedstaaten). Der Minderheitenschutz im Parlament, der besondere Bedeutung genießt, wird dadurch nicht unterlaufen, denn auch sonst wäre es den Mitgliedstaaten unbenommen, einen im Parlament gescheiterten Vorstoß selbsttätig aufzugreifen. Ebenso wenig ist deshalb der betroffene Mitgliedstaat schutzwürdig. Die Heilung ist damit als erfolgreich zu werten. Damit kann die Rüge Ungarns ungeachtet ihrer Begründetheit im Ursprung im weiteren Verfahrensverlauf keinen Erfolg haben, das Verfahren gegen Ungarn kann im Rat weiterverfolgt werden.

bb. Unterschiede und Gemeinsamkeiten des begründeten Vorschlags gegenüber Ungarn im Vergleich zum Verfahren gegenüber Polen

Auf den Verfahrensstand im Rat und die Verbindung des Verfahrens mit demjenigen in Polen hatte ich bereits hingewiesen, dies ist hier nicht zu wiederholen. Im Hinblick auf den vom Parlament konkret vorgelegten Vorschlag ergeben sich indes Unterschiede. Während die Kommission ihre Begründung dem Antrag voranstellt, übernehmen für das Parlament nicht die Erwägungsgründe der Entschließung diese Funktion, sondern der Schwerpunkt der Begründungslast ist in den eigentlichen Antrag ausgelagert. Aus den Ausführungen geht hervor, dass das Parlament in zahlreichen gesellschaftlichen und politischen Bereichen Ungarns, nicht allein im Hinblick auf das Justizsystem, Missstände sieht, ${ }^{1752}$ was sich mit der

1752 Europäisches Parlament, P8_TA-PROV(2018)0340, Die Lage in Ungarn: Entschließung des Europäischen Parlaments vom 12. September 2018 zu einem Vorschlag, mit dem der Rat aufgefordert wird, im Einklang mit Artikel 7 Absatz 1 des Vertrags über die Europäische Union festzustellen, dass die eindeutige Gefahr einer schwerwiegenden Verletzung der Werte, auf die sich die Union gründet, durch Ungarn besteht (2017/2131(INL)), Erwägungsgrund 1: „[...] weist darauf hin, dass die Bedenken des Parlaments folgende Punkte betreffen:

- die Funktionsweise des Verfassungs- und des Wahlsystems; 
Breite des Antrags, eine Gefahr für alle Werte des Art. 2 EUV festzustellen, deckt.

Das Parlament folgt der Grundentscheidung der nach Problembereichen gegliederten und iterativen Darstellung, die die Kommission in ihrem begründeten Vorschlag genutzt hat. Die Darstellung erscheint indes weit tatsachenorientierter als im begründeten Vorschlag der Kommission, eine Rückführung der gemachten Ausführungen auf z.B. Prinzipien des Unionsrechts unterbleibt weitgehend. Eine Subsumtion oder argumentative Verbindung der jeweiligen Abschnittsüberschriften des Vorschlags mit dem präsentierten Material fehlt. Das Parlament rügt auch Einzelfälle von Betroffenen aus der Bevölkerung, ${ }^{1753}$ ein Vorgehen, dass die Kommission mit Ausnahme zentraler Funktionsträger stets vermieden hatte. Dieses Hervorheben von Einzelfällen ist kritisch zu sehen, weil es die systemische Natur der konkreten Vorgänge nicht belegt, solange nicht hierzu weitere Beobachtungen gemacht werden. ${ }^{1754}$

Die Dichte an unterstützendem Material, also Sichtung an Rechtsprechung und Einlassungen anderer Akteure, scheint in etwa gleich derjenigen, die die Kommission in ihrem Bericht zugrunde gelegt hat. Das Parlament schöpft die Möglichkeit, ungeachtet der Kompetenzzuweisung des Art. 5 EUV, im Rahmen des Art. 7 EUV Vorgänge in Mitgliedstaaten

- die Unabhängigkeit der Justiz und anderer Institutionen sowie die Rechte der Richter,

- Korruption und Interessenkonflikte,

- Privatsphäre und Datenschutz,

- das Recht auf freie Meinungsäußerung,

- die akademische Freiheit,

- die Religionsfreiheit,

- die Vereinigungsfreiheit,

- das Recht auf Gleichbehandlung,

- die Rechte von Personen, die einer Minderheit angehören, einschließlich Roma und Juden, und den Schutz vor hetzerischen Äußerungen, die gegen diese Minderheiten gerichtet sind,

- die Grundrechte von Migranten, Asylsuchenden und Flüchtlingen,

- wirtschaftliche und soziale Rechte."

1753 Europäisches Parlament, P8_TA-PROV(2018)0340, Die Lage in Ungarn: Entschließung des Europäischen Parlaments vom 12. September 2018 zu einem Vorschlag, mit dem der Rat aufgefordert wird, im Einklang mit Artikel 7 Absatz 1 des Vertrags über die Europäische Union festzustellen, dass die eindeutige Gefahr einer schwerwiegenden Verletzung der Werte, auf die sich die Union gründet, durch Ungarn besteht (2017/2131(INL)), Rn. 69 des Beschlusses, betreffend eine Haftstrafe für einen Asylsuchenden.

1754 Vgl. dazu auch meine Beobachtungen unter C. VI. 


\section{E. Das Rechtsregime der Verfassungsaufsicht der Europäischen Union}

beobachten und überprüfen zu können, vollständig aus. Es erfolgt eine Gesamtschau diverser thematisch völlig unterschiedlich gelagerter Sachstände. Teils gelingt es dem Parlament dabei, noch unbekanntes Material vorzustellen, so z.B. im Hinblick auf Vorgänge betreffend das Hochschulsystem, die die Kommission in ihrem Verfahren betreffend die CEU noch nicht berücksichtigt hatte. ${ }^{1755}$

Aus den Beobachtungen leitet das Parlament eine Tangierung aller Kriterien des Art. 2 S. 1 und 2 EUV ab. ${ }^{1756}$ Die Klärung von Folgefragen, wie z.B., ob bestimmte Werte in besonderem Maße betroffen sind, ob das Parlament eine Hierarchisierung dieser Werte in Betracht zieht, wie auch die in der Literatur erörterte Frage der systematischen Beziehung zwischen Art. 2 S. 1 und S. 2,1757 sind nicht erkennbar erörtert worden, sodass sich die Gelegenheit nicht ergibt, zusätzliches zum in der Rechtswissenschaft bereits Erwogenen beizutragen.

Für Ungarn ist ein EU-Rahmenverfahren, wie für Polen, nicht durchlaufen worden. Dessen ungeachtet gelangt das Parlament zunächst zu der Schlussfolgerung, die aufgezählten Punkte stellten eine „systemrelevante Bedrohung“ (systemic threat/menace systémique) der Werte der Europäischen Union dar. ${ }^{1758}$ Ausgeführt oder sonst hergeleitet wird dieser

1755 Europäisches Parlament, P8_TA-PROV(2018)0340, Die Lage in Ungarn: Entschließung des Europäischen Parlaments vom 12. September 2018 zu einem Vorschlag, mit dem der Rat aufgefordert wird, im Einklang mit Artikel 7 Absatz 1 des Vertrags über die Europäische Union festzustellen, dass die eindeutige Gefahr einer schwerwiegenden Verletzung der Werte, auf die sich die Union gründet, durch Ungarn besteht (2017/2131(INL)), Erwägungsgrund, Rn. 36.

1756 Europäisches Parlament, P8_TA(2018)0340, Die Lage in Ungarn: EntschlieBung des Europäischen Parlaments vom 12. September 2018 zu einem Vorschlag, mit dem der Rat aufgefordert wird, im Einklang mit Artikel 7 Absatz 1 des Vertrags über die Europäische Union festzustellen, dass die eindeutige Gefahr einer schwerwiegenden Verletzung der Werte, auf die sich die Union gründet, durch Ungarn besteht (2017/2131(INL)), (2019/C 433/10), ABl. (EU) C 433/66 vom 23.12.2019, Erwägungsgrund A.

1757 Zur Frage der „Wertehierarchie“ im Hinblick auf den Zuschnitt des Verfahrens durch die Kommission Frank Schorkopf, „Wertesicherung in der Europäischen Union“, S. 158; zur dogmatischen Unterscheidung von S. 1 und S. 2 des Art. 2 EUV überzeugend ders./Meinhard Hilf, in: Eberhard Grabitz, Meinhard Hilf \& Martin Nettesheim (Begr./Hrsg.), Das Recht der Europäischen Union, C.H. Beck, München, 68. EL 2019, Rn. 43 ff.

1758 Europäisches Parlament, P8_TA-PROV(2018)0340, Die Lage in Ungarn: Entschließung des Europäischen Parlaments vom 12. September 2018 zu einem Vorschlag, mit dem der Rat aufgefordert wird, im Einklang mit Artikel 7 Absatz 1 des Vertrags über die Europäische Union festzustellen, dass die ein- 
Begriff allerdings nicht, auch ein Verweis auf den EU-Rahmen der Kommission fehlt. Dafür hatte das Parlament 2017 in einer vorangehenden Entschließung zu Ungarn zu verschiedenen Punkten „möglicherweise eine systemische Bedrohung der Rechtstaatlichkeit in diesem Mitgliedstaat" („emerging systemic threat to the rule of law"/,émergence d'une menace systémique pour l'état de droit“") ${ }^{1759}$ festgestellt. Das Nichtaufgreifen des EU-Rahmens kann auch als Folge der mehrfachen Ablehnung seitens der Kommission gewertet werden, dieses Verfahren gegenüber Ungarn zu nutzen, was seitens des Parlaments bedauert wurde. ${ }^{1760}$

Im Sargentini-Bericht, der der Entschließung vorausging, findet sich indes die Formulierung:

„ist der Ansicht, dass die in der Anlage zu dieser Entschließung genannten Sachverhalte und Tendenzen in ihrer Gesamtheit eine systemrelevante Bedrohung der in Artikel 2 EUV genannten Werte und die eindeutige Gefahr ihrer schwerwiegenden Verletzung darstellen“. ${ }^{1761}$

Im Englischen ist hier der Begriff „systemic threat“, im Französischen „menace systémique“ genutzt, womit zumindest dort angedeutet wird, dass die Berichterstatterin die Logik und Abstufung im Sinne der Kommission

deutige Gefahr einer schwerwiegenden Verletzung der Werte, auf die sich die Union gründet, durch Ungarn besteht (2017/2131(INL)), Erwägungsgrund 2. Wohl aber verweist das Parlament nochmals auf seinen Vorschlag betreffend einen „DRF-Pakt“, dazu id., 10. Spgstr.

1759 Europäisches Parlament, P8_TA(2017)0216, Lage in Ungarn, Entschließung des Europäischen Parlaments vom 17. Mai 2017 zur Lage in Ungarn (2017/2656(RSP)), insb. Erwägungsgrund 2 zur Verklammerung diverser Vorgänge unter diesen Begriff, nochmals Erwägungsgrund 8.

1760 S. dazu bereits supra unter V. 2. h., P8_TA(2017)0216, Lage in Ungarn, Entschließung des Europäischen Parlaments vom 17. Mai 2017 zur Lage in Ungarn (2017/2656(RSP)), Erwägungsgrund 8. Wohl aufgrund der Ignorierung dieser Aufforderung und aufgrund des schwelenden Streits betreffend den eigenen DRF-Pakt hat sich das Parlament, Rn. 15 des Beschlussvorschlags, den Seitenhieb nicht verkneifen können, dass die Kommission auf Unionsrechtskonformität früheren Verhaltens Ungarns in Bezug auf die Richterpensionierung erkannt habe, ein Vorgang, den man nun (scil.: deswegen) wieder aufgreifen müsse.

1761 Europäisches Parlament, A8-0250/2018, Bericht über einen Vorschlag, mit dem der Rat aufgefordert wird, im Einklang mit Artikel 7 Absatz 1 des Vertrags über die Europäische Union festzustellen, dass die eindeutige Gefahr einer schwerwiegenden Verletzung der Grundwerte der Europäischen Union durch Ungarn besteht, (2017/2131(INL)), Ausschuss für bürgerliche Freiheiten, Justiz und Inneres, Berichterstatterin: Judith Sargentini, Erwägungsgrund 2. 
aufzugreifen gedachte. Allerdings fallen beide Tatbestände, derjenige des EU-Rahmens und der nachfolgende des Art. 7 Abs. 1 EUV („und“), in eins ohne Unterscheidung zusammen.

Auch wenn die Kommission ebenso ihrem begründeten Vorschlag nicht nur den Charakter eines rechtlichen, sondern eines politischen Instruments gegeben hat, so ist doch gerade die politische Natur der EntschlieBung des Parlaments gegenüber Ungarn, um hier eine Gesamtbetrachtung anzubieten, besonders auffällig. Zahlreiche konkrete rechtliche Fragen bleiben offen. Andererseits verdeutlicht sich gerade hierin in der Praxis die Unterscheidung des Verfahrens nach Art. 7 EUV von solchen unter Einbeziehung des Europäischen Gerichtshofs. Parlament und Kommission sind nicht rechtsprechende Gewalt. Konsequenterweise kann es auch nicht überraschen, wenn ihre Vorschläge ein Urteil nicht ersetzen noch ihm ähneln.

Wie seitens der Kommission für Polen, so endet der Beschlussvorschlag des Parlaments für Ungarn mit einem verfügenden Teil, nachfolgend sind beide zum Vergleich gegenübergestellt: 


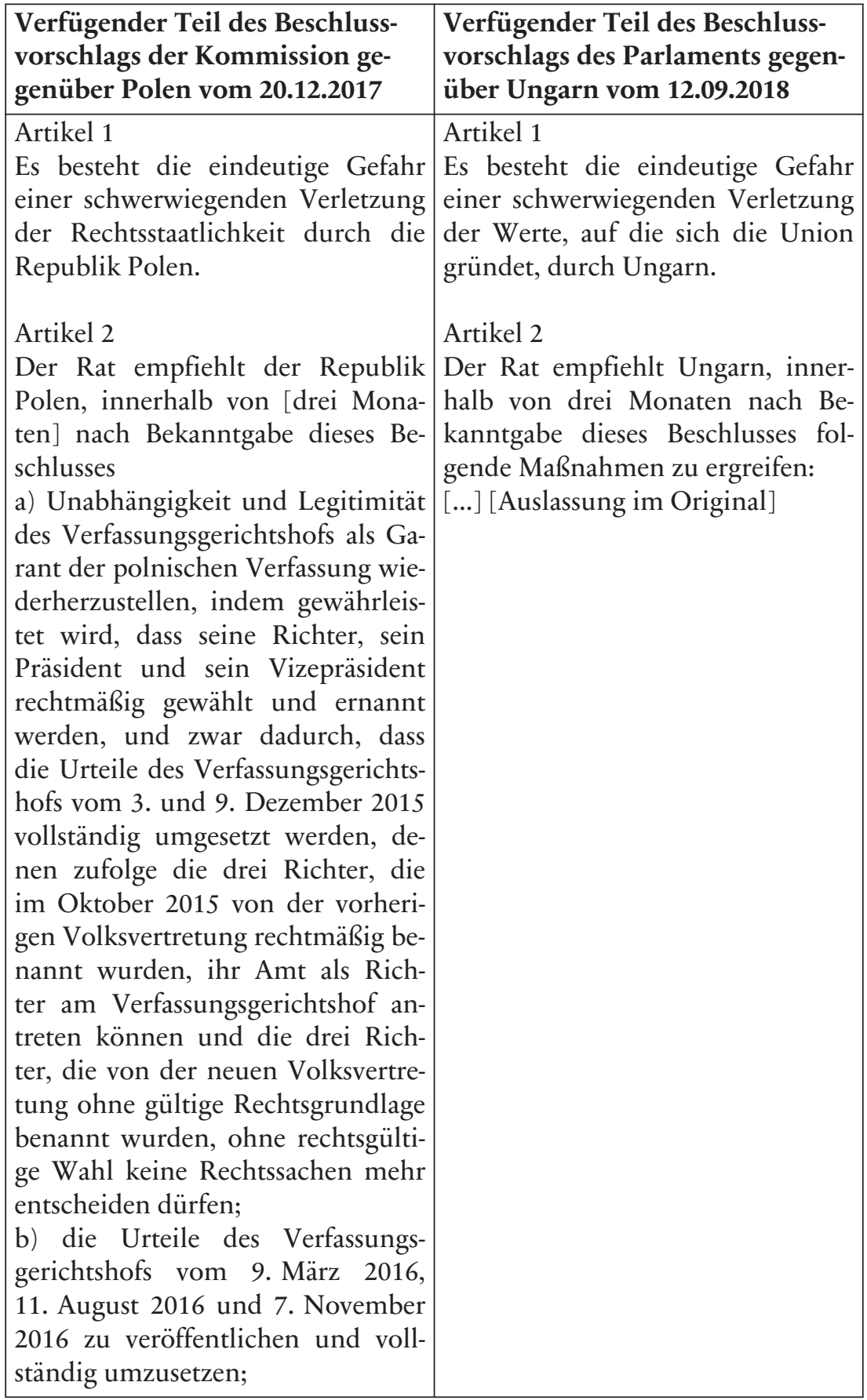


c) dafür zu sorgen, dass das Gesetz über das Oberste Gericht, das Gesetz über die ordentlichen Gerichte, das Gesetz über den Landesrat für Gerichtswesen und das Gesetz über die Staatliche Richterhochschule geändert werden, um zu gewährleisten, dass sie den Anforderungen an die Unabhängigkeit der Justiz, die Gewaltenteilung und die Rechtssicherheit entsprechen;

d) dafür zu sorgen, dass Justizreformen in enger Zusammenarbeit mit der Justiz und allen interessierten Kreisen, einschließlich der VenedigKommission, ausgearbeitet werden;

e) Maßnahmen und öffentliche Äußerungen zu unterlassen, die die Legitimität des Verfassungsgerichtshofs, des Obersten Gerichts, der ordentlichen Gerichte, der Richter als Einzelpersonen oder als Gruppe - oder der Justiz als Ganzes weiter schwächen könnten. Dieser Beschluss ist an die Republik Polen gerichtet.

Geschehen zu Brüssel am [...] Im Namen des Rates

Der Präsident

Artikel 3

Dieser Beschluss tritt am [...] Tag nach seiner Veröffentlichung im Amtsblatt der Europäischen Union in Kraft.

Artikel 4

Dieser Beschluss ist an Ungarn gerichtet.

Geschehen zu Brüssel am Im Namen des Rates

Der Präsident 
Auffälligster Unterschied ist, dass das Parlament die konkreten „Empfehlungen“ gegenüber Ungarn auslässt, es stellt sie also in das freie Ermessen des Rates. Warum dieser Schritt erfolgt ist, bleibt offen.

Die Kommission hat gegenüber Polen konkrete Ausführungen zur Behebung der Lage gemacht. Weder dies noch aber die Ausgestaltung gerade als „Empfehlung“ im Rahmen eines Beschlusses, der selbst unstrittig rechtsverbindlich ist, wohingegen die Empfehlung Rechtsunverbindlichkeit andeutet, ist in Art. 7 Abs. 1 EUV vorgesehen. Die Möglichkeit („kann“) seitens des Rates, „an diesen Mitgliedstaat geeignete Empfehlungen zu richten", findet sich allerdings in Art. 7 Abs. 1 S. 1 EUV a.E. in der Fassung des Vertrags von Nizza. Seitens der Kommission muss die Ausgestaltung als Empfehlung daher so verstanden werden, dass man diese Möglichkeit nach der alten Vertragsfassung wie auch im Vertrag von Lissabon für implizit möglich erachtet hat. Meines Erachtens hätte der Vertragswortlaut der Lissabonner Fassung es auch ermöglicht, das Verb „empfiehlt" durch ein stärkeres, etwa „fordert auf“/"empfiehlt mit Nachdruck" o.ä. zu ersetzen. Die Ausgestaltung als Empfehlung ist indes insofern konsequent, als die Kommission offensichtlich ein letztes Mal, wissend um die politische Wirkung des Beschlussvorschlags, Druck auf Polen zur Behebung der gerügten Mängel vor der Besprechung im Rat ausüben wollte. Das Parlament hat sich der Vorentscheidung der Kommission angeschlossen, dem adressierten Mitgliedstaat konkrete Maßnahmen zur Behebung der Lage zu „empfehlen“.

Nach derzeitigem Stand hat sich dies weder gegenüber Polen noch gegenüber Ungarn erfüllt.

\section{Das Vertragsverletzungsverfahren}

a. Die Kontroverse um die Nutzung des Verfahrens in der Rechtsstaatlichkeitskrise

Seit der durch die Europäische Kommission ausgerichteten Konferenz „Assises de la Justice“ im Spätherbst 2013, auf der Scheppele ihren Vorschlag $\mathrm{zu}$ „systemic infringement actions“1762 vorgestellt hat, ist im Verlauf der Rechtsstaatlichkeitskrise die Nutzung des Vertragsverletzungsverfahrens

1762 Kim Lane Scheppele, „What Can the European Commission Do when Member States Violate Basic Principles of the European Union? The Case for Systemic Infringement Actions“. 
diskutiert worden. Die Kontroverse entzündet sich mit Blick auf die Frage, ob das Vertragsverletzungsverfahren nicht „viel zu fallspezifisch“ ist, um systemische Probleme im Unionsrecht zu beheben. ${ }^{1763}$

\section{aa. Streitstand}

Scheppeles Überlegungen waren indes keinesfalls die ersten, die dieses Verfahren im Kontext des Werteschutzes auf Ebene der Union zum Gegenstand hatten. Froweins Vorschlag aus den frühen 1980er Jahren, lange vor der Schaffung des Art. 7 EUV, sich zwar nicht des „ordentlichen“ Vertragsverletzungsverfahrens nach Art. 258 AEUV, sondern vielmehr des heute in Art. 348 AEUV geregelten besonderen Vertragsverletzungsverfahrens zu bedienen, ${ }^{1764}$ ist gerade in Deutschland viel diskutiert worden. ${ }^{1765}$ Art. 348 Abs. 2 AEUV ermöglicht ohne Vorverfahren die unmittelbare Beschreitung des gerichtlichen Vertragsverletzungsverfahrens für den Fall, dass nach Auffassung der Kommission ein Mitgliedstaat sich zu Unrecht auf die in den Art. 346 und Art. 347 AEUV vorgesehenen Ausnahmetatbestände zur zeitweiligen Missachtung der vertraglichen Pflichten, insbesondere im Bereich des Binnenmarktes, bei inneren Notlagen ${ }^{1766}$ beruft.

Dabei wurde in der deutschen Literatur gerade zu Art. 7 EUV Anfang der 2000er Jahre die Nutzung des Vertragsverletzungsverfahrens für Verstöße gegen Art. 6 EUV (Nizza), den Vorgänger des heutigen Wertekatalogs des Art. 2 EUV, in Parallele zu Art. 7 EUV abgelehnt. Ein Argument war dabei die systematische Trennung von Gemeinschafts- und Unionsrecht nach alter Rechtslage. ${ }^{1767}$ Aber es bestanden auch grundlegendere Zweifel. Exemplarisch für diese damalige wohl herrschende Meinung hielt Schorkopf fest:

1763 So Armin von Bogdandy \& Michael Ioannidis, „Das systemische Defizit“, S. 287; ähnlich auch Stefan Kadelbach, „Krise, Umbruch und neue Ordnung“, S. 13.

1764 Jochen Abr. Frowein, „Die rechtliche Bedeutung des Verfassungsprinzips der parlamentarischen Demokratie für den europäischen Integrationsprozeß“, S. $312 \mathrm{ff}$.

1765 Frank Schorkopf, Homogenität in der Europäischen Union, S. 109 ff.; Thomas Pforr, Die allgemeine Unionsaufsicht, S. 46 ff; Ulrike Kassner, Die Unionsaufsicht, S. $205 \mathrm{ff}$.

1766 Die Konstellation entspricht dem zuvor gerade in Bezug auf die Arbeit von Wirbel diskutierten „Unionsnotstand“.

1767 Frank Schorkopf, Homogenität in der Europäischen Union, S. 107-108. 
„Das interne Streitschlichtungssystem der Gemeinschaftsverträge ist für Einzelfälle konzipiert. Es hat die Aufgabe, bei prinzipieller Bejahung der Integration durch die Mitgliedstaaten, den Streit über die spezifischen Rechte und Verpflichtungen durch eine unabhängige Instanz entscheiden zu lassen. Verletzt aber ein Mitgliedstaat die Grundsätze der Freiheit, Demokratie, Rechtsstaatlichkeit und des Menschenrechtsschutzes, so stellt er die Integration als solche in Frage.“1768

Dem haben sich später insbesondere Pforr und Kassner angeschlossen. ${ }^{1769}$ Träbert hat diese Logik für die Sanktionsstadien von Art. 7 EUV und dem Vertragsverletzungsverfahren, dem damaligen Art. 228 EGV (heute Art. 260 AEUV), fortgeführt. Ein Verstoß gegen den EG-Vertrag sei etwas grundlegend anderes als ein Verstoß gegen die Grundsätze des Art. 2 EUV, und auch die Rechtsfolgenseite lasse auf nichts anderes schließen. Der Entziehung von Stimmrechten im Rat, Art. 7 Abs. 3 EUV, stehe die Finanzsanktion des Art. 260 Abs. 2 AEUV gegenüber. ${ }^{1770}$

Nach Inkrafttreten des Vertrags von Lissabon schien Dietrich Murswiek die Debatte um die Nutzung des Vertragsverletzungsverfahrens endgültig beendet zu haben. Er verwandte sich vehement für eine Nutzung des Vertragsverletzungsverfahrens in Bezug auf die Einhaltung von Art. 2 EUV ${ }^{1771}$ - aber nicht, um der Union zur Hilfe zu kommen, sondern um das Vorgehen zu diskreditieren und nachzuweisen, dass der Vertrag von Lissabon letztendlich nichts anderes bezwecke als die „Herabstufung der nationalen Verfassungen zu ,Landesverfassungen““. 1772

1768 Frank Schorkopf, Homogenität in der Europäischen Union, S. 108.

1769 Dazu, wie soeben bereits zitiert, Thomas Pforr, Die allgemeine Unionsaufsicht, S. 46 ff; Ulrike Kassner, Die Unionsaufsicht, S. 205 ff.

1770 Katrin Träbert, Sanktionen der Europäischen Union gegen ihre Mitgliedstaaten, S. 370, zur Rechtslage vor dem Vertrag von Lissabon.

1771 Dietrich Murswiek, „Die heimliche Entwicklung des Unionsvertrages zur europäischen Oberverfassung: Zu den Konsequenzen der Auflösung der Säulenstruktur der Europäischen Union und der Erstreckung der Gerichtsbarkeit des EU-Gerichtshofs auf den EU-Vertrag“, in: Neue Zeitschrift für Verwaltungsrecht 28 (2009), S. 481-486, S. 482.

1772 Dietrich Murswiek, „Die heimliche Entwicklung des Unionsvertrages zur europäischen Oberverfassung“", S. 482. 
Nur vereinzelt setzten sich Verfasser gleichwohl für eine parallele Anwendbarkeit beider Verfahren ein, so insbesondere Christophe Hillion ${ }^{1773}$ und Frank Hoffmeister. ${ }^{1774}$

bb. Der Vorschlag Kim Lane Scheppeles zu „systemic infringement actions" und die Diskussion in der Literatur

Scheppele schlug vor, sich der Krise ganz unter Nutzung des ordentlichen Vertragsverletzungsverfahrens nach Art. 258 AEUV zu widmen. Dafür sollte ein neuer Typus des Zuschnitts des Verfahrens durch die Kommission eingeführt werden, den sie „systemic infringement actions“, also in etwa „Vertragsverletzungsverfahren bei systemischen Vertragsverletzungen“ nannte. ${ }^{1775}$ Scheppeles Überlegungen waren wohl als ein Vorstoß de lege ferenda gedacht, ${ }^{1776}$ wobei sie die Möglichkeit von Vertragsänderungen andachte, sie aber nicht für strikt notwendig hielt. ${ }^{1777}$

(1) Prozessualer Zuschnitt

Scheppele forderte:

„The Commission could signal systemic breach of fundamental Treaty obligations by a Member State by bundling a group of specific alleged violations together to argue before the Court of Justice of the Euro-

1773 Christophe Hillion, „Overseeing the Rule of Law in the EU: Legal Mandate and Means", S. $66 \mathrm{ff}$.

1774 Frank Hoffmeister, „Enforcing the EU Charter of Fundamental Rights in Member States“, S. 205-206 insb.; s. bereits zuvor, C. IV. 1. a.

1775 Ausführliche Würdigung ihres Vorschlags, mwN, bei Matthias Schmidt \& Piotr Bogdanowicz, "The Infringement Procedure in the Rule of Law Crisis“, S. 1066 ff. S. später auch Pettra Bárd \& Anna Śledzińska-Simon, „Rule of law infringement procedures".

1776 Vgl. in diesem Sinne Kim Lane Scheppele, „What Can the European Commission Do when Member States Violate Basic Principles of the European Union? The Case for Systemic Infringement Actions“, später Kim Lane Scheppele, "Enforcing the Basic Principles of EU Law through Systemic Infringement Actions“, S. 108, „using the common infringement procedure in new ways”.

1777 Kim Lane Scheppele, „Enforcing the Basic Principles of EU Law through Systemic Infringement Actions“, S. 130. 
pean Union (ECJ) that the infringement of EU law in a Member State is not minor or transient, but systemic and persistent." 1778

Zentral für die Feststellung der Kommission und den Zuschnitt ihres Klageantrags in Form insbesondere einer Bündelung, für welchen Scheppele ebenso das Attribut „systemic“ verwendet, sollte ein „Muster“ („pattern“) der Vertragsverletzung sein. ${ }^{1779}$ Damit stärkt Scheppele zunächst den in dieser Arbeit genutzten Begriff des systemischen Defizits. Darüber hinaus zielte Scheppeles Vorschlag vor allem darauf ab, der Kommission die Verfolgung einer durch Telos und Systematik der Vertragsverletzung verbundenen Mehrheit an Vorgängen seitens des Mitgliedstaats in nur einer Vertragsverletzungsklage zu ermöglichen, sich also der an anderer Stelle beklagten Fallspezifizität des Verfahrens zu entledigen, bei welchem die Kommission von einer einzelnen Vertragsverletzung in Bezug auf einen einzelnen Sekundärrechtsakt abstellte. Hierauf, und auf entsprechende Beispiele gerade im Falle Ungarns, ist in dieser Arbeit bereits eingegangen worden. Scheppele berief sich dabei, zutreffend, auf die bereits angeführten Schlussanträge von Generalanwalt Geelhoed in der Rs. Irish Waste und zog insbesondere dessen Ausführungen zur „Skalendimension“ 1780 seiner Figur der generellen und anhaltenden Verletzung heran. ${ }^{1781}$

\section{(2) Maßstab}

Mit der Forderung der prozeduralen Verknüpfung von in Verbindung stehenden Vorgängen im Mitgliedstaat geht bei Scheppele der Vorschlag einher, auch den materiellen Prüfungsmaßstab neu auszurichten. Sie fokussiert dabei, im Hinblick auf den ihrer Auffassung nach nicht nur prozedural zu schmalen, ${ }^{1782}$ sondern auch materiell nicht ausreichenden Zuschnitt

1778 Kim Lane Scheppele, „Enforcing the Basic Principles of EU Law through Systemic Infringement Actions“, S. 107.

1779 Kim Lane Scheppele, „Enforcing the Basic Principles of EU Law through Systemic Infringement Actions", S. 108.

1780 EuGH, Rs. C-494/01, Kommission .. Irland, „Irish Waste“, Schlussanträge des Generalanwalts L. A. Geelhoed vom 23.9.2004, Slg. 2005, I-3338, ECLI:EU:C:2004:546, Rn. 44, ausf. zuvor B. II. 3.

1781 Kim Lane Scheppele, „Enforcing the Basic Principles of EU Law through Systemic Infringement Actions“, S. 113. S. dort auch weitere Nennungen zu Folgeentscheidungen.

1782 Kim Lane Scheppele, „Enforcing the Basic Principles of EU Law through Systemic Infringement Actions“, vgl. dazu S. 109. 
vergangener Verfahren der Kommission, auf das Primärrecht, wobei eine Mehrzahl an Normen für sie in Betracht kommen. Neben dem Rechtsstaatsprinzip des Artikel 2 EUV stellt sie ausdrücklich auf Artikel 4 Abs. 3 EUV und den hier enthaltenen Grundsatz der loyalen Zusammenarbeit (mutual trust) ab. Das Argument seitens der Kommission habe zu lauten, so Scheppele hier, dass eine systemische Hintertreibung („interference“) der Wirksamkeit des Unionsrechts im Rechtsverantwortungsbereich der Mitgliedstaaten einer Verletzung der Loyalitätspflichten aus eben dieser Norm gleichkomme und damit eine ahndungsfähige Vertragsverletzung darstelle. ${ }^{1783}$

cc. Wesentliche Argumente für die Fortführung von Scheppeles Ansatz

Vier Argumente fechten für die Fortführung von Scheppeles Ansatz zu „systemic infringement actions“: ${ }^{1784}$

(1) Kongruenz mit der rechtspolitischen Ausrichtung des Verfahrens durch die Kommission

Das erste, kautelarjuristische, Argument ist die Betonung der Suche nach einer effektiven Lösung zu weiteren Verfahren, die die Kommission ihrer heute sog. „tool box“ an Mechanismen zur Seite stellen sollte. Im Raum steht die wirkliche Machbarkeit des Vorschlags im institutionellen Gefüge der Kommission und damit letztlich die größtmögliche Kongruenz mit etablierten Sprachregelungen. Darüber hinaus ist festzuhalten, dass die Nutzung des Vertragsverletzungsverfahrens zur Behebung systemischer Defizite an Rechtsstaatlichkeit unter Effektivitätsgesichtspunkten besonders eingängig und mit Blick auf die politisch Linie der Kommission konsequent ist, da sich die Kommission selbst nicht nur im EU-Rahmen den Rückgriff auf das Verfahren nach Art. 7 EUV vorbehalten hatte, ${ }^{1785}$ sondern in min-

1783 Kim Lane Scheppele, „Enforcing the Basic Principles of EU Law through Systemic Infringement Actions“, S. 118.

1784 Sie beruhen alle auf den Feststellungen in Matthias Schmidt \& Piotr Bogdanowicz, "The Infringement Procedure in the Rule of Law Crisis“, s. dort insb. S. $1066 \mathrm{ff}$.

1785 Matthias Schmidt \& Piotr Bogdanowicz, „The Infringement Procedure in the Rule of Law Crisis“, S. 1073, vgl. Europäische Kommission, Mitteilung der Kommission an das Europäische Parlament und den Rat, Ein neuer EU-Rah- 
destens zwei weiteren Mitteilungen - und damit mit Mehrheit des Kollegiums - angedeutet hatte, dass sie Scheppeles Auffassung folgen könnte. So hatte die Kommission bereits 2002 in einer Mitteilung 1786 eigenständig die Idee eines „systembedingten Verstoßes“ festgehalten. Zum zweiten hatte die Kommission, lange nach Beginn der Krise, zum Jahresbeginn 2017 ihre sog. „Better Results“-Mitteilung vorgestellt, die ein rechtspolitisches Programm zur Neuausrichtung des Vertragsverletzungsverfahrens enthält, das die Neuausrichtung anderer Verfahren, wie ich sie vorab erläutert habe, noch weit übertrifft. ${ }^{1787}$ Die Nutzung des Vertragsverletzungsverfahrens auch für systemische Defizite ist damit nur konsequent.

men zur Stärkung des Rechtsstaatsprinzips vom 11.03.2014, COM(2014) 158 final, S. 3.

1786 Europäische Kommission, Mitteilung der Kommission zur besseren Kontrolle der Anwendung des Gemeinschaftsrechts, $\operatorname{KOM}(2002) 725$ endgültig vom 11.12.2002, S. 12, im Englischen „systemic infringements“, im Französischen „infractions systémiques“, Hinweis bereits bei Damien Chalmers, Gareth Davies \& Giorgio Monti, European Union Law, S. 320-324.

1787 Europäische Kommission, Mitteilung der Kommission, EU-Recht: Bessere Ergebnisse durch bessere Anwendung, ABl. (EU) C 18/10 vom 19.01.2017, S. C 18/14. Dort heißt es:

„Die Verpflichtung, die erforderlichen Maßnahmen zu treffen, um einem Urteil des Gerichtshofs nachzukommen, entfaltet die größte Wirkung, wenn durch die geforderten Maßnahmen systemische Schwächen in der Rechtsordnung des Mitgliedstaats angegangen werden. Deshalb wird die Kommission denjenigen Verstößen oberste Priorität einräumen, durch die systemische Schwächen zutage treten, die das Funktionieren des institutionellen Rahmens der EU beeinträchtigen. Dies gilt insbesondere für Verstöße, die Auswirkungen auf die Fähigkeit der nationalen Rechtssysteme haben, zur wirksamen Durchsetzung des EU-Rechts beizutragen. Die Kommission wird daher allen Fällen strikt nachgehen, in denen nationale Rechtsvorschriften oder übliche Praktiken Vorabentscheidungsverfahren des Gerichtshofs behindern oder nationales Recht die nationalen Gerichte daran hindert, den Vorrang des EURechts anzuerkennen. Sie wird auch eingreifen, wenn das nationale Recht bei Verstößen gegen EU-Recht keine wirksamen Rechtsbehelfe vorsieht oder auf andere Weise verhindern, dass nationale Rechtssysteme die wirksame Anwendung des EU-Rechts nach rechtsstaatlichen Grundsätzen und des Artikels 47 der EU-Grundrechtecharta gewährleisten.

Ferner wird die Kommission gewährleisten, dass die nationalen Rechtsvorschriften mit dem EU-Recht vereinbar sind, denn fehlerhafte nationale Rechtsvorschriften berauben Bürger systematisch der Möglichkeiten, ihre Rechte einschließlich der Grundrechte durchzusetzen und die Vorteile des EU-Rechts in vollem Umfang auszuschöpfen. Darüber hinaus wird die Kommission ein besonderes Augenmerk auf Fälle richten, in denen Mitgliedstaaten das EU-Recht fortdauernd nicht korrekt anwenden." 
(2) Parallelität mit dem Verfahren nach Art. 7 EUV

Ein zweites, auf die systematische Anwendbarkeit des Verfahrens selbst bezogenes Argument zielt auf eine Unterstützung der Annahme Scheppeles ab, wonach das Vertragsverletzungsverfahren parallel zum Verfahren nach Art. 7 EUV anwendbar ist. Hier ist hervorzuheben, dass Art. 46 EUV (Nizza), der in lit.d) die gerichtliche Überprüfung von Art. 6 EUV (Nizza), des Vorläufers von Art. 2 EUV, beschränkte, ersatzlos gestrichen worden ist und Art. 32 UAbs. 1 S. 3 EUV an seine Stelle nun die Feststellung gesetzt hat, „[d]ie Mitgliedstaaten gewährleisten durch konvergentes Handeln, dass die Union ihre Interessen und ihre Werte auf internationaler Ebene geltend machen kann, “ was a fortiori für ebendiese Gewährleistung verpflichtend auch nach innen spricht, dies gleichzeitig aber zu einer überprüfbaren Pflicht macht. Diese folgt auch aus Art. 42 Abs. 5 EUV, einer Norm, die dem Rat die Beauftragung von Mitgliedstaaten mit Missionen „zur Wahrung der Werte der Union“ ermöglicht und diese Werte damit ebenso zu einem mittels Vertragsverletzungsverfahren überprüfbaren Tatbestandsmerkmal macht. Abgesehen von den Beschränkungen der Kompetenz des EuGH aus 275 Abs. 1 AEUV für die GASP insbesondere i.S.d. Art. 24 AEUV besteht derzeit keine „political question doctrine“ im Unionsrecht, die der Berücksichtigung der Werte, und gerade der Rechtsstaatlichkeit, auch im Vertragsverletzungsverfahren entgegensteht. ${ }^{1788}$

Auf die in Art. 7 Abs. 1 bis 3 EUV gemachte Unterscheidung nach der Schwere der Verletzung kommt es dabei zunächst im Vertragsverletzungsverfahren nicht an. Auch eine „Gefahr“ i.S.d. Art. 7 Abs. 1 EUV ist bereits eine Verletzung.

\section{(3) Möglichkeit des prozessualen Zuschnitts}

Ein drittes Argument ist die Betonung des prozessualen Zuschnitts der Vertragsverletzungsverfahrens, d.h. die Möglichkeit auch komplexe und sachlich unterschiedlich gelagerte Vorgänge aufzugreifen, die sowohl vereinzelt wie auch in einer Gesamtschau eine Vertragsverletzung darstellen. Dieses Argument beruht, wie bei Scheppele, auf der sog. Irish-Waste-Rechtsprechung des Europäischen Gerichtshofs und der dort eingeführten Figur der generellen und anhaltenden Vertragsverletzung, beschränkt sich aber nicht

1788 Matthias Schmidt \& Piotr Bogdanowicz, „The Infringement Procedure in the Rule of Law Crisis“, S. 1070-1071, mit umfassenden weiteren Nennungen. 
allein auf die Anzahl der Fälle, (Skalendimension), ${ }^{1789}$ sondern betont, wie Generalanwalt Geelhoed, insgesamt drei „Dimensionen“ des Konzepts entwickelt hat, nämlich auch Schwere und Zeitdimension. ${ }^{1790}$ Dies ist bereits im Hinblick auf die Entwicklung des Konzepts des systemischen Defizits ausgeführt worden ${ }^{1791}$ und macht dabei auch deutlich, dass sich damit auch der Zuschnitt des Verfahrens auf so unterschiedliche Entwicklungen wie in Polen und Ungarn nutzen lässt, ohne für beide Mitgliedstaaten getrennte Vorgehen entwickeln zu müssen.

Es zeigt sich hier, dass der Begriff des systemischen Defizits also nicht nur mitgliedstaatsübergreifend, sondern auch verfahrensübergreifend ist, und sich mit ihm nicht nur im Verfahren nach Art. 7 EUV oder partiellen Verfassungsaufsichtsmechanismen, sondern auch in einem Vertragsverletzungsverfahren nutzen lässt.

\section{(4) Materiell-rechtlicher Maßstab}

Als letzter Erwägung gilt es, Scheppeles materiellen Prüfstandard, nämlich das aus Art. 2 EUV entnommene Rechtsstaatsprinzip und zusätzlich Art. 4 Abs. 3 EUV zu stützen. Der Bemühung Scheppeles, diesen Prüfstandard im Rahmen des Vertragsverletzungsverfahrens primärrechtlich nicht allein auf eine, sondern mehrere Primärrechtsnormen zu stützen, ist grundsätzlich beizupflichten.

Der Gerichtshof hat, wenn auch die Begriffe der loyalen Zusammenarbeit oder des gegenseitigen Vertrauens dort fehlen, ebenso bereits im Verfahren Irish Waste die Linie vorgegeben, dass diese Norm (noch in der Gestalt des Art. 10 EGV) auch, allerdings sekundär, heranzuziehen ist. ${ }^{1792}$ Spieker hat dies weiter untermauert und nachgewiesen, dass der

1789 EuGH, Rs. C-494/01, Kommission ./. Irland, „Irish Waste“, Schlussanträge des Generalanwalts L. A. Geelhoed vom 23.9.2004, Slg. 2005, I-3338, ECLI:EU:C:2004:546, Rn. 44.

1790 EuGH, Rs. C-494/01, Kommission ... Irland, „Irish Waste“, Schlussanträge des Generalanwalts L. A. Geelhoed vom 23.9.2004, Slg. 2005, I-3338, ECLI:EU:C:2004:546, Rn. 45 und 46.

1791 Supra unter B. IV., weiter auch Matthias Schmidt \& Piotr Bogdanowicz, „The Infringement Procedure in the Rule of Law Crisis“, S. 1082-1085.

$1792 \mathrm{EuGH}$, Rs. C-494/01, Kommission ./. Irland, „Irish Waste“, Urteil vom 26.04.2005, Slg. 2005 I-3382, ECLI:EU:C:2005:250, Rn. 195-199. Hierzu auch Matthias Schmidt \& Piotr Bogdanowicz, „The Infringement Procedure in the Rule of Law Crisis“, S. 1088. 
in Art. 4 Abs. 3 EUV niedergelegte Grundsatz nicht nur zwischen den Mitgliedstaaten, also horizontal, sondern auch vertikal zwischen Union und Mitgliedstaaten wirkt. ${ }^{1793}$ Demnach ließe sich durchaus argumentieren, dass ein systemisches Versagen bei der Einhaltung von Rechtspflichten eines Mitgliedstaats aus dem Rechtsstaatsprinzip, das zu einer Selbsteintrittspflicht der Union oder anderer Mitgliedstaaten in diese Rechtspflichten führt, ein Verstoß gegen den Grundsatz der loyalen Zusammenarbeit nach Art. 4 Abs. 3 EUV und den Grundsatz des gegenseitigen Vertrauens ist. Allerdings wird diesem Argument bis auf Weiteres jene Plastizität und Unmittelbarkeit fehlen, wie sie der Argumentation innewohnt, dass z.B. Zwangspensionierungen von Richtern den Grundsatz der richterlichen Unabhängigkeit verletzen. Der Gerichtshof hat es daher bislang vermieden, gerade im Kontext der Rechtsstaatlichkeitskrise das Prinzip des gegenseitigen Vertrauens stärker in den Blick zu nehmen, ganz im Unterschied zu Verfahren betreffend die Aufnahme von Flüchtlingen, die der Gerichtshof an anderer Stelle zu verhandeln hatte. ${ }^{1794}$

Es ist daher nach wie vor geboten, sich auf den Maßstab der Rechtsstaatlichkeit des Art. 2 EUV zu konzentrieren. Wie der EuGH damit aber umgegangen ist, habe ich ebenso, bezogen auf dessen Operationalisierung, bereits erörtert.

b. Durchbruch der Akzeptanz des Verfahrens infolge der Rechtssache „Unabhängigkeit des polnischen Obersten Gerichtshofs“

aa. Ausführungen von Generalanwalt Evgeni Tanchev

In der Rechtssache betreffend die Unabhängigkeit des polnischen Obersten Gerichtshofs deutete sich im April 2019 an, dass der Europäische

1793 Luke Dimitrios Spieker, „Breathing Life into the Union's Common Values“, S. 1212 bei Fn. 218, unter Verweis auf EuGH, Rs. C-5/94, The Queen v Ministry of Agriculture, Fisheries and Food, ex parte: Hedley Lomas (Ireland) Ltd, Urteil vom 23.05.1996, ECLI:EU:C:1996:205, Rn. 19; Rs. C-297/07, Strafverfahren gegen Klaus Bourquain, Schlussanträge des Generalanwalts Dámaso Ruiz-Jarabo Colomer vom 08.04.2008, ECLI:EU:C:2008:206 Rn. 45.

1794 EuGH, Verb. Rs. C-715/17, C-718/17 und C-719/17, Kommission ./. Polen, u.a., Urteil vom 02.04.2020, ECLI:EU:C:2020:257, Rn. 164 und das dort zit. Urt. vom 06.09.2017 in den verb. Rs. C-643/15 und C-647/15, Slowakei und Ungarn ./. Rat, ECLI:EU:C:2017:631, Rn. 309. 
Gerichtshof auf die Linie der Nutzung des Vertragsverletzungsverfahrens im Rahmen der Rechtsstaatlichkeitskrise einschwenken würde.

Generalanwalt Tanchev hielt insbesondere fest:

„Es gibt gute Gründe für die Annahme, dass es sich bei Art. 7 EUV und Art. 258 AEUV um zwei verschiedene Verfahren handelt, die gleichzeitig eingeleitet werden können. Insbesondere enthält der Wortlaut der Bestimmungen nichts darüber, dass sich die Verfahren gegenseitig ausschließen, und die Bezugnahme auf „eine Verpflichtung aus den Verträgen" in Art. 258 AEUV umfasst, wie bereits bemerkt [...], grundsätzlich alle Rechtsvorschriften des Unionsrechts mit Ausnahme der GASP. Dafür sprechen auch das verschiedenartige System und der unterschiedliche Zweck der Verfahren [...]. Art. 7 EUV ist dem Wesen nach „ein politisches Verfahren“ zur Bekämpfung einer „schwerwiegenden und anhaltenden Verletzung“ der in Art. 2 EUV genannten Werte durch einen Mitgliedstaat, für das eine hohe Schwelle gilt und das dazu führen kann, dass die Mitgliedschaftsrechte dieses Mitgliedstaats, einschließlich seiner Mitwirkungsrechte, ausgesetzt werden. Art. 258 AEUV ermöglicht den unmittelbaren „Rechtsweg“, um vor dem Gerichtshof die Durchsetzung des Unionsrechts durch die Mitgliedstaaten sicherzustellen, ist auf die Feststellung einer Vertragsverletzung gerichtet und kann im Verfahren nach Art. 260 AEUV auch zu finanziellen Sanktionen führen, um den Mitgliedstaat zur Beendigung der Verletzungshandlung zu veranlassen. Diese Unterschiede lassen erkennen, dass diese Verfahren eigenständiger, in der Tat einander ergänzender Natur sind und parallel angewandt werden können. Auch sollte der Umstand, dass Art. 269 AEUV, wonach die Rechtmäßigkeit eines nach Art. 7 EUV erlassenen Rechtsakts des Europäischen Rates oder des Rates in Zweifel gezogen werden kann, die Zuständigkeit des Gerichtshofs auf die „Verfahrensbestimmungen“ in Art. 7 EUV beschränkt, den Gerichtshof nicht daran hindern, aufgrund seiner $\mathrm{Zu}$ ständigkeit nach Art. 258 AEUV zu entscheiden. ${ }^{1795}$

Die Große Kammer hat sich dem im Urteil der gleichen Rechtssache angeschlossen, ohne auf diese Ausführungen zurückzukommen.

1795 EuGH, Rs. C-619/18 R, Kommission ./. Polen, „Unabhängigkeit des Obersten Gerichts“, Schlussanträge des Generalanwalts Evgeni Tanchev vom 11.04.2019, ECLI:EU:C:2019:325, Rn. 50. 
bb. Klageerledigung, einstweilige Anordnungen und Beschleunigung des Verfahrens

Mehrere Vorzüge dieses Vorgehens sind, selbstredend neben der Überprüfung der Lage in der Sache, dabei unmittelbar deutlich geworden.

Zum einen hat der Europäische Gerichtshof hervorgehoben, „dass das Vorliegen einer Vertragsverletzung nach ständiger Rechtsprechung anhand der Situation zu beurteilen ist, in der sich der Mitgliedstaat bei Ablauf der Frist befand, die in der mit Gründen versehenen Stellungnahme festgesetzt worden war, und später eingetretene Veränderungen vom Gerichtshof nicht berücksichtigt werden können. " 1796 Damit waren Vorstöße Polens hinfällig, das Verfahren durch Behauptung einer Klageerledigung aufgrund späterer Gesetzesänderungen zu Fall zu bringen. Das ist sehr bedeutend, weil damit den Mitgliedstaaten die Möglichkeit genommen wird, durch noch nicht abschließend zu beurteilende Übergangsregelungen, Wiedereinsetzungen in den vorherigen Stand oder etwa eine verfrühte Verfahrensbeendigung zu erreichen. ${ }^{1797}$

Der zweite Vorzug des Vertragsverletzungsverfahrens, der das Verfassungsaufsichtsinstrumentarium entscheidend komplementiert, ${ }^{1798}$ ist die seitens der Kommission immer stärker ${ }^{1799}$ genutzte Möglichkeit der Beantragung einstweiliger Anordnungen nach Art. 279 AEUV i.V.m. Art. 160 Abs. 3 der Verfahrensordnung des Gerichtshofs, eine wesentliche Möglichkeit vorläufigen Rechtsschutzes im Unionsrecht, ${ }^{1800}$ sowie die verstärkte

1796 EuGH, Rs. C-619/18 R, Kommission ./. Polen, „Unabhängigkeit des Obersten Gerichts“, Urteil (GK) vom 24.06.2019, ECLI:EU:C:2019:531, Rn. 30.

1797 Dazu schon EuGH, Rs. C-334/94, Kommission ./. Frankreich (Französisches Flaggenregister), Schlussanträge des Generalanwalts Nial Fennelly vom 16.11.1995, ECLI:EU:C:1995:393, insb. Rn. 21 ff., s. auch Matthias Schmidt \& Piotr Bogdanowicz, „The Infringement Procedure in the Rule of Law Crisis“, S. 1077.

1798 Hierzu bereits Matthias Schmidt \& Piotr Bogdanowicz, „The Infringement Procedure in the Rule of Law Crisis“, S. $1078 \mathrm{ff}$. Die nachfolgenden Ausführungen beruhen auf den Vorarbeiten zu Matthias Schmidt \& Piotr Bogdanowicz, „Recent developments regarding the infringement procedure in the EU's rule of law crisis", i.V.

1799 Kurz vor Manuskriptschluss noch etwa EuGH, Rs. C-791/19 R, Kommission ./. Polen (Indépendance de l'Izba Dyscyplinarna (chambre disciplinaire) du Sąd Najwyższy (Cour suprême, Pologne)), Beschluss (GK) vom 08.04.2020, ECLI:EU:C:2020:277.

1800 Überblick, auch zu den Möglichkeiten der Vollzugsaussetzung, bei Bernhard W. Wegener, $\mathbb{} 20$ Einstweilige Anordnungen, in: Hans-Werner Rengeling, 
Nutzung des Antrags auf Verfahrensbeschleunigung gem. 133 bis 136 der Verfahrensordnung. Auch wenn sich die Beschleunigung des Verfahrens aus dem vorläufigen Rechtsschutz entwickelt hat, handelt es sich heute grundsätzlich um zwei getrennte Möglichkeiten der Verfahrensgestaltung, ${ }^{1801}$ die die Kommission im Rahmen der Krise, und gerade gegenüber Polen, kombiniert angewendet hat.

Die Beantragung einstweiliger Anordnungen ist, ähnlich wie im deutschen Recht auch, ein der Hauptsache vorgelagertes und zu ihr akzessorisches Verfahren. ${ }^{1802}$ Prete hat nachgewiesen, dass nach altem Entwicklungsstand die Kommission bislang nur sehr selten gewillt war, sich dieser Möglichkeit zu bedienen. ${ }^{1803}$ Dafür mag gesprochen haben, dass der Gerichtshof ursprünglich sehr hohe Hürden an den Antrag gestellt hat. ${ }^{1804}$

Der Kommission konnte im Verfahren Puszcza Biatowieska die Möglichkeit vorläufigen Rechtsschutzes spezifisch gegenüber Polen erfolgreich testen ${ }^{1805}$ - wobei Wennerås festhielt, von Danwitz habe angedeutet, dem Gerichtshof habe die Möglichkeit der Hinwegsetzung über Unionsrecht aufgrund der rechtsstaatsbezogenen Vorgänge sehr wohl vor Augen gestanden. ${ }^{1806}$ Die Rechtssache Puszcza Biatowieska, in welcher die Kommission über Rodungsmaßnahmen im ostpolnischen Naturschutzgebiet der Bialowiezer Heide zu entscheiden hatte, ist aber nicht nur als „Testballon“ für spätere, unmittelbar rechtsstaatsbezogene einstweilige Anordnungen inter-

Andreas Middeke, Martin Gellermann, Handbuch des Rechtsschutzes in der Europäischen Union, C.H. Beck, München, 3. Aufl. 2014, Rn. 8 ff.

1801 Zur Genese und dem Zusammenhang beider Verfahrensgestaltungen Jorg Sladič, Einstweiliger Rechtsschutz im Gemeinschaftsprozessrecht: Eine Untersuchung des EG/EU-Prozessrechts, Nomos, Baden-Baden 2008. S. 161 und ff.

1802 So auch Jorg Sladič, Einstweiliger Rechtsschutz im Gemeinschaftsprozessrecht, S. 120, der sich mit den Begriffen Akzessorietät und Konnexität auseinandersetzt.

1803 Luca Prete, Infringement Proceedings in EU Law, S. 237.

1804 EuGH, Verb. Rs. 43/59 bis 45/59., Eva von Lachmüller u.a. ./. Kommission, Verfügung des Präsidenten des Gerichtshofes vom 20.10.1959, nicht nummerierte Rn. 11 der Begründung, Slg. 1959, 1019, ECLI:EU:C:1959:24, wonach erforderlich war, dass „eine starke Vermutung dafür spricht, daß ihr Antrag zur Hauptsache begründet ist"; vgl. weiter, auch zu diesem Urteil, Jorg Sladič, Einstweiliger Rechtsschutz im Gemeinschaftsprozessrecht, S. 174 ff., 178.

1805 EuGH, Rs. C-441/17 R, Kommission ./. Polen (Puszcza Białowieska), Beschluss (GK) vom 20.11.2017, ECLI:EU:C:2017:877.

1806 Pål Wennerås, „Saving a forest and the rule of law: Commission v. Poland Case C-441/17 R, Commission v. Poland, Order of the Court (Grand Chamber) of 20 November 2017, EU:C:2017:877“, in: Common Market Law Review 56 (2019), S. 541-558, S. 541, bei Fn. 3. 
essant, sondern auch, weil der Gerichtshof überraschend der Kommission die Möglichkeit zugestand, Finanzsanktionen unmittelbar im Verfahren des vorläufigen Rechtsschutzes zu beantragen, und damit dem Vertragsverletzungsverfahren bereits an dieser Stelle zu einer von Art. 260 AEUV unabhängigen Berichtigungsphase verhalf, ihm zusätzlichen Nachdruck verlieh.

Die - rein teleologische - Begründung, die der Gerichtshof für diese implizite Schaffung des in Art. 279 AEUV so nicht vorgesehenen finanziellen Sanktionsverfahrens anbot, war äußerst bemerkenswert:

„Dass ein Mitgliedstaat dazu veranlasst wird, den von dem für die Gewährung vorläufigen Rechtsschutzes zuständigen Richter erlassenen einstweiligen Anordnungen nachzukommen, weil die Verhängung eines Zwangsgeldes für den Fall vorgesehen wird, dass diesen Anordnungen nicht nachgekommen wird, soll nämlich die wirksame Anwendung des Unionsrechts sicherstellen, die dem Wert des in Art. 2 EUV verankerten Rechtsstaatsprinzips, auf dem die Union gründet, inhärent ist. “ 1807

Die Rechtsstaatlichkeit, an anderer Stelle bereits als Schutzgut operationalisiert, wurde hier zur causa für die Schaffung weiterer Schutzmechanismen.

Kein Wunder also, dass sich die Kommission in den rechtsstaatsspezifischen Folgeverfahren, nun betreffend die polnische Justiz, nicht lange bitten ließ, auch dort den Weg des einstweiligen Rechtsschutzes zu gehen, nach derzeitigem Stand insbesondere im Verfahren hinsichtlich des polnischen Obersten Gerichtshofs und der Disziplinarkammer, nicht indes in Bezug auf die Altersregelungen in der ordentlichen Gerichtsbarkeit und am OGH.

Im Verfahren bezüglich des polnischen Obersten Gerichtshofs ergingen dabei gleich zwei vorläufige Anordnungen, auch dies meiner Kenntnis nach eine grundlegende Neuerung im Verfahren, zunächst diejenige der Vizepräsidentin des Gerichtshofs Silva de Lapuerta ${ }^{1808}$ und im Anschluss

1807 EuGH, Rs. C-441/17 R, Kommission ./. Polen (Puszcza Białowieska), Beschluss (GK) vom 20.11.2017, ECLI:EU:C:2017:877, Rn. 102, ausführliche Besprechung dieses Vorgangs bei Pål Wennerås, „Saving a forest and the rule of law", S. $544 \mathrm{ff}$.

1808 EuGH, Rs. C-619/18, Kommission ./. Polen, „Unabhängigkeit des Obersten Gerichts“, Beschluss der Vizepräsidentin des Gerichtshofs vom 19.10.2018, ECLI:EU:C:2018:852, nicht in dt. Spr. 
daran ein Beschluss der Großen Kammer. ${ }^{1809}$ Mit der ersten Verfügung hielt de Lapuerta, quasi als „vorläufige Anordnung zur Sicherung der vorläufigen Anordnung“, unter Berufung auf Art. 160 Abs. 7 der Verfahrensordnung fest, es gelte, bereits vor Erlass der vorläufigen Anordnung weiteres Vorgehen zu verhindern. ${ }^{1810}$ Der Gerichtshof ging damit zur unmittelbaren Regelung von Sachverhalten allerhöchster Dringlichkeit über.

Im nachfolgenden Beschluss der Großen Kammer wandte der Gerichtshof zugunsten der Kommission eine in vorangegangenen Verfahren etablierte dreistufige und niedrigschwellige Prüfung an, deren Schritte „kumulativ" erfüllt sein müssen: „die Notwendigkeit der Anordnung in tatsächlicher und rechtlicher Hinsicht glaubhaft gemacht wurde (fumus boni iuris)“, „wenn sie in dem Sinne dringend ist, dass sie zur Verhinderung eines schweren und nicht wiedergutzumachenden Schadens für die Interessen des Antragstellers“ sowie "gegebenenfalls“ nach einer „Abwägung der widerstreitenden Interessen“. ${ }^{1811}$ Der fumus boni iuris darf dabei „auf den ersten Blick nicht ohne ernsthafte Grundlage erschein[en]. Dies ist insbesondere der Fall, wenn einer dieser Gründe komplexe rechtliche Fragen aufwirft, die nicht für irrelevant erklärt werden können, sondern einer eingehenden Prüfung bedürfen“. ${ }^{1812}$ Der Europäische Gerichtshof erlegt die Beweislast dem Mitgliedstaat auf. ${ }^{1813}$ Obwohl es für den einstweiligen Rechtsschutz des Unionsrechts bei der „summarischen Prüfung“ bleibt, ${ }^{1814}$ ist der Gerichtshof, gerade im Verfahren betreffend den polnischen OGH, weit ins Detail gegangen.

Der Begriff des „schweren und nicht wiedergutzumachenden Schadens“, bezogen eigentlich auf die Gefahr der Vorwegnahme der Hauptsache, scheint vom Gerichtshof zusätzlich in Richtung einer weiteren Prüfung gefährdeter Schutzgüter ausgebaut zu werden. Im vorläufigen Rechtsschutzverfahren betreffend die Vertragsverletzungsklage der Kommission in Be-

1809 EuGH, Rs. C-619/18, Kommission ./. Polen, „Unabhängigkeit des Obersten Gerichts“, Beschluss (GK) vom 17.12.2018, ECLI:EU:C:2018:1021.

1810 EuGH, Rs.C-619/18, Beschluss der Vizepräsidentin des Gerichtshofs vom 19.10.2018, „Unabhängigkeit des Obersten Gerichts“, ECLI:EU:C:2018:852, Rn. $12 \mathrm{ff}$.

1811 EuGH, Rs. C-619/18, Kommission ./. Polen, „Unabhängigkeit des Obersten Gerichts“, Beschluss (GK) vom 17.12.2018, ECLI:EU:C:2018:1021, Rn. 29.

1812 EuGH, Rs. C-619/18, Kommission ./. Polen, „Unabhängigkeit des Obersten Gerichts“, Beschluss (GK) vom 17.12.2018, ECLI:EU:C:2018:1021, Rn. 30.

1813 EuGH, Rs. C-619/18, Kommission ... Polen, „Unabhängigkeit des Obersten Gerichts“, Beschluss (GK) vom 17.12.2018, ECLI:EU:C:2018:1021, Rn. $44 \mathrm{ff}$, insb. Rn. 47.

1814 Jorg Sladič, Einstweiliger Rechtsschutz im Gemeinschaftsprozessrecht, S. 123. 
zug auf die polnische Disziplinarkammer ging die Große Kammer über die Ermittlung des Schadens rein für die Interessen des Antragsstellers ${ }^{1815}$ hinaus und bezog den drohenden Schaden nunmehr auf die Interessen der Union selbst:

„La Cour a, ainsi, déjà jugé que le fait que l'indépendance du Sąd Najwyższy (Cour suprême) puisse ne pas être garantie est susceptible d'entraîner un grave préjudice, par nature irréparable, à l'ordre juridique de l'Union et, partant, aux droits que les justiciables tirent du droit de l'Union ainsi qu'aux valeurs, énoncées à l'article 2 TUE, sur lesquelles cette Union est fondée, notamment, celle de l'État de droit.“1816

So zugeschnitten wird das Verfahren im einstweiligen Rechtsschutz zu einem höchst effektiven Mittel der Kommission. Die weitere Entwicklung in der Krise dürfte dies bestätigen. Ob sich die Kommission dabei auch der Sanktionsmöglichkeiten bedienen wird, ist noch offen.

$\mathrm{Zu}$ den Maßnahmen im vorläufigen Rechtsschutz tritt die Möglichkeit der Beschleunigung des Verfahrens. Gerichtspräsident Lenaerts erklärte sie ausdrücklich für parallel anwendbar. ${ }^{1817}$

Diese Entwicklung ist weiter offen, obwohl der Gerichtshof bemüht scheint, auch ohne explizite Verfahrensbeschleunigung rechtsstaatsbezogene Verfahren nun prioritär zu behandeln. In den Parallelverfahren der ungarischen Richterpensionierung und des dortigen Datenschutzbeauftragten betrug die Zeitspanne zwischen den Urteilen - wobei nur das Verfahren der Richterpensionierung beschleunigt wurde - noch fast zwei Jahre. ${ }^{1818}$ In den Verfahren zum polnischen OGH, das beschleunigt wurde, und desjenigen zur polnischen Pensionierungspraxis, das nicht beschleu-

1815 Dazu aber EuGH, Rs. C-791/19 R, („Indépendance de l'Izba Dyscyplinarna (chambre disciplinaire) du Sąd Najwyższy (Cour suprême, Pologne)"), Beschluss (GK) vom 08.04.2020, Rn. 51.

1816 EuGH, Rs. C-791/19 R, Kommission ./. Polen, „Indépendance de l'Izba Dyscyplinarna (chambre disciplinaire) du Sąd Najwyższy (Cour suprême, Pologne)“, Beschluss (GK) vom 08.04.2020, Rn. 92.

1817 EuGH, Rs. C-619/18, Kommission ./. Polen, „Unabhängigkeit des polnischen Obersten Gerichtshofs“, Beschluss des Präsidenten des Gerichtshofs, vom 15.11.2018, ECLI:EU:C:2018:91, Rn. 26-27.

1818 Das Urteil in der Rs.C-286/12, ungarische Richterpensionierung, ECLI:EU:C:2012:687, ist am 06.11.2012 ergangen, dasjenige in der Rs. C-288/12, ungarischer Datenschutzbeauftragter, gute zwei Jahre später am 08.04.20214. 
nigt wurde, betrugt der Unterschied noch gute sechs Monate, wobei hier indes die Klage früher eingereicht worden war. ${ }^{1819}$

c. Entwicklungsperspektiven des Vertragsverletzungsverfahrens: Verfahren nach Art. 259 AEUV und die Streithilfe im Rahmen des Art. 258 AEUV

Neben diesen Entwicklungen im Hinblick auf das Vertragsverletzungsverfahren nach Art. 258 AEUV besteht in der Literatur der Vorschlag, insbesondere Kochenovs, statt des Verfahrens des Art. 258 dasjenige des Art. 259 AEUV zu nutzen, in welchem den Mitgliedstaaten die Klageerhebung zufällt. ${ }^{1820}$ Dieser Vorstoß ähnelt damit in gewisser Hinsicht frühen Überlegungen zum Rückgriff auf besondere Vertragsverletzungsarten, wie schon bei Frowein.

Kochenovs zentrales Argument für die Nutzung der Verfahrensvariante des Art. 259 AEUV ist die politische Legitimität. Den Herren der Verträge falle es bedeutend leichter, so Kochenov, in der Rechtsstaatlichkeitskrise ihr politisches Gewicht einzubringen, um einen der ihren vor dem Gerichtshof auf grundlegende Bedenken hinsichtlich europäischer Werte hinzuweisen. Der Gerichtshof hat in jüngster Zeit, trotz der historischen Marginalität dieses Klageverfahrens aufgrund politischer Zurückhaltung der Mitgliedstaaten, ${ }^{1821}$ gleich zwei Verfahren dieser Variante des Vertragsverletzungsverfahrens zu entscheiden gehabt. ${ }^{1822}$ Diese Beispiele zeigen indes, dass die Mitgliedstaaten nur dann zu einer solchen Klage bereit sind, wenn es sich um „klassische“ Nachbarschaftsstreitigkeiten handelt, der innenpolitische Druck und die allgemeine Aufmerksamkeit der Öffentlichkeit hierzu besonders hoch ist, gleichzeitig aber ein politischer

1819 Das Urteil in der Rs. C-619/18 stammt vom 24.06.2019 mit Klage vom 02.10.2018, dasjenige zur Richterpensionierung, Rs. C-192/18 vom 05.11.2019 mit Klage vom 15.03.2018.

1820 Dimitry Kochenov, „Biting Intergovernmentalism: The Case for the Reinvention of Article 259 TFEU to Make It a Viable Rule of Law Enforcement Tool“, in: Hague Journal on the Rule of Law 7 (2015), S. 153-174, insb. S. $170 \mathrm{f}$.

1821 Dazu Matthias Pechstein, Art. 259 AEUV, in: Matthias Pechstein, Carsten Nowak \& Ulrich Häde, Frankfurter Kommentar, Band IV: AEUV, Mohr Siebeck, Tübingen, 2017, Rn. 3.

1822 EuGH, Rs. C-591/17, Österreich ./. Deutschland (Deutsche PKW-Autobahnmaut), Urteil (GK) vom 18.06.2019, ECLI:EU:C:2019:504; Rs. C-457/18, Slowenien ./. Kroatien (Slowenisch-kroatische Land- und Seegrenze), Urteil (GK) vom 31.02.2020, ECLI:EU:C:2020:65. 
Schaden nicht zu erwarten ist, da sonst verlorene Rechtspositionen zu verteidigen sind oder der Schaden eng begrenzt werden kann. Keiner dieser Faktoren ist derzeit in der gegenwärtigen Rechtsstaatlichkeitskrise trotz aller Entwicklung so prominent gewesen, dass darüber ein Mitgliedstaat bereit gewesen wäre, diesen Weg zu gehen, zumal ersichtlich ist, dass die Kommission mutmaßlich die Sache ohnehin aufgreifen dürfte. Daher ist dieser Ansatz hier, bis auf Weiteres, zwar interessant, aber nicht der von den Mitgliedstaaten gewählte.

Stattdessen zeigt sich vermehrt ein anderer Weg, in welchem die Mitgliedstaaten ihre Unterstützung gegenüber der Kommission zum Ausdruck bringen und der taktisch vielleicht sogar noch sinnvoller ist: derjenige der in Art. 40 der Satzung i.V.m. Art. 129-132 der VerfO-EuGH geregelten Streithilfe im Rahmen des ordentlichen Vertragsverletzungsverfahrens. Dabei lassen die öffentlich werdenden Dokumente wenig Rückschlüsse darüber zu, ob und in welchem Umfang und mit welchen Ressourcen die Vorbereitung und Durchführung dieser Streithilfe zwischen Mitgliedstaaten bzw. Mitgliedstaaten und Kommission zu einem Austausch geführt hat. In jedem Fall aber zählt schon die Geste. So war Ungarn Streithelfer Polens im Verfahren betreffend den polnischen OGH. Im gegen Polen anhängigen Verfahren zur Disziplinarkammer am OGH sind Belgien, Dänemark, die Niederlande, Finnland und Schweden als Streithelfer der Kommission dem Verfahren beigetreten. Das ist, ohne das juristische Können der beteiligten Abteilungen in Abrede zu stellen, vorrangig als politisches Signal an die Klagegegnerin zu werten. Es wäre ein umso stärkeres Signal, wenn mit Ausnahme Polens und Ungarns, ggf. Rumäniens, alle Mitgliedstaaten „en bloc" bei nächster Gelegenheit eine solche Streithilfe erwägen würden.

Es handelt sich bei den bisher beteiligten Mitgliedstaaten auch um solche, die im Rat jüngst offen die Entwicklung der von Belgien und Deutschland angestoßenen „Periodic Peer Review“ unterstützt haben.

Hiermit ist zum letzten Teil dieser Arbeit überzuleiten. 


\section{F. Entwicklungsperspektiven der Verfassungsaufsicht}

Diese Arbeit schließen möchte ich mit einigen, auf neue Verfahrensvorschläge fokussierende, Entwicklungsperspektiven der unionalen Verfassungsaufsicht, die sich konkret andeuten.

Sonstige Rückschlüsse oder Vorschläge sind derzeit nicht seriös zu bewerkstelligen, dafür ist die Situation nach wie vor zu sehr im Umbruch und höchst dramatisch. Es ist auch nicht abzusehen, ob und wie Vertraggeber und Unionsorgane das hier beschriebene Rechtsregime fortentwickeln.

Bestand haben wird indes die Rollenverteilung der Organe, die sich in der Krise gefestigt hat, sowie der exemplarisch beschriebene Arbeitsprozess gerade kommissionsintern, den ich anhand des EU-Rahmens zur Stärkung des Rechtsstaatsprinzips dargelegt habe.

\section{Aufsicht über die Wertetreue europäischer Parteien}

Die Rechtswissenschaft ist in der gegenwärtigen Rechtsstaatlichkeitskrise der Europäischen Union nicht müde geworden, weitere Vorschläge zu machen, von denen einige als „offene Enden“ der deutlicheren Berücksichtigung in der Praxis harren. Das Verfahren nach Art. 70 EUV, aber auch der Vorschlag des Parlaments zum „DRF-Pakt“ sind solche Beispiele, die hier nicht vertieft zu werden brauchen, solange die Praxis nicht mehr Konturierung liefert. Ein weiteres ist etwas eingehender zu besprechen. Es handelt sich um die nochmals durch Schorkopf, ${ }^{1823}$ dort als „europäisches Parteiverbotsverfahren" bezeichnete, erstmals vorgestellte Überlegung, man möge sich der Novelle der europäischen Parteienverordnung ${ }^{1824}$ bedienen, um insbesondere Parteien wie Fidesz und PiS stärker zu beaufsichtigen. Sie zu nutzen würde bedeuten, die unionale Verfassungsaufsicht um einen sekundärrechtlichen Aufsichtsmechanismus zu erweitern und darüber hi-

1823 Frank Schorkopf, „Wertesicherung in der Europäischen Union“, S. 154.

1824 Verordnung (EU, Euratom) Nr. 1142/2014 des Europäischen Parlaments und des Rates vom 22. Oktober 2014 über das Statut und die Finanzierung europäischer politischer Parteien und europäischer politischer Stiftungen, ABl. (EU) L 317/1 vom 04.11.2014. 
naus eine Agentur der Union in den Kreis der Beaufsichtigenden aufzunehmen.

Wie Schorkopf selbst dort anmerkt, fehlt es bislang an einer vertieften Auseinandersetzung mit diesem Rechtsakt in der Rechtswissenschaft. Dies mag daran liegen, dass die Verordnung ungeachtet ihres Erlasses im Jahr 2014 eine Legisvakanz von knapp 3 Jahren vorsah, erst zu Beginn des Jahres 2017 in Kraft trat und überdies die Posten der durch sie geschaffenen Behörde, namentlich ihres Direktors, sowie des Ausschusses der unabhängigen Persönlichkeiten im Rahmen des Aufsichtsverfahrens zu besetzen waren. In letzteren wurde im Juni 2017 u.a. der in dieser Arbeit bereits zitierte deutsche Staatsrechtler Christoph Möllers berufen. ${ }^{1825}$

Die Europäische Parteienverordnung schafft eine neue europäische Behörde mit eigener Rechtspersönlichkeit und Sitz in Brüssel, die europäische Behörde für europäische politische Parteien und Stiftungen (APPF). ${ }^{1826} \mathrm{Ihr}$ Zweck ist die „Eintragung, Kontrolle und Sanktionierung von europäischen politischen Parteien“. Die Behörde überprüft „regelmäBig ${ }^{\text {"1827, }}$ ob eine eingetragene europäische Partei die Eintragungsvoraussetzungen erfüllt. Zu diesen zählt ausdrücklich die Frage, ob die europäische politische Partei die in Art 2 EUV genannten und in der Verordnung nochmals wiederholten Werte der Union achtet. Dies gilt sowohl, was das Programm, d.h. das ex ante festgesetzte Ziel und Handeln der Partei, als auch die tatsächliche Tätigkeit der Partei angeht. ${ }^{1828}$ Dieser doppelte Gegenstand der Überprüfung ermöglicht der Behörde einen umfassenden Nachvollzug des Parteihandelns auch für den Fall, dass die Partei ihre wahre politische Zielsetzung durch ein anders lautendes Programm zu verbergen sucht. Anders als der Aufsatz von Schorkopf vermuten lässt, war auch nach alter Rechtslage eine solche Überprüfung bereits möglich,

1825 Art. 1 des Beschlusses (EU, Euratom) 2017/1108 des Rates vom 20. Juni 2017 zur Ernennung von zwei Mitgliedern des Ausschusses unabhängiger Persönlichkeiten gemäß Artikel 11 Absatz 1 der Verordnung (EU, Euratom) Nr. 1141/2014 des Europäischen Parlaments und des Rates über das Statut und die Finanzierung europäischer politischer Parteien und europäischer politischer Stiftungen, ABl. (EU) L 160/35 vom 22.6.2017.

1826 Agency for Political Parties and Foundations, APPF, Rechtsgrundlage ist Art. 6 der VO 1141/2014. s. auch http://www.appf.europa.eu/appf/de/authority/legal -background.html.

1827 Art. 10 Abs. 1 der VO 1141/2014.

1828 Art. 3 Abs. 1 lit. c der VO 1141/2014. 
sie fiel allerdings im Wege echter Legislativaufsicht dem Europäischen Parlament zu. ${ }^{1829}$ Ausgeübt worden ist sie meiner Kenntnis nach nie.

Abgesehen von ihrer Eigeninitiative kann die nach jetziger Rechtslage bestehende neue Behörde auch durch Parlament, Rat oder Kommission zu der Überprüfung einer europäischen Partei aufgefordert werden. ${ }^{1830}$ Für diesen Fall muss die Behörde sich an einen, auch nach neuer Rechtslage bestehenden, Ausschuss unabhängiger Persönlichkeiten wenden und dessen Stellungnahme abwarten. Auch umgekehrt kann die Behörde von sich aus auf die Unionsorgane zugehen, wenn ihr Tatsachen bekannt werden, die Zweifel darüber aufkommen lassen, ob eine europäische politische Partei die in Art. 2 EUV genannten Werte achtet. Unter Berücksichtigung der Stellungnahme des Ausschusses kann die Behörde zu dem Schluss gelangen, dass dies nicht mehr der Fall ist. Die Rechtsfolge dieser Feststellung ist die Löschung der europäischen politischen Partei aus dem europäischen Parteienregister ${ }^{1831}$ und in der Folge der Verlust der Voraussetzungen für die Finanzierung der Partei aus den hierfür bereitgestellten Mitteln aus dem Unionshaushalt. ${ }^{1832}$ Für die Löschung ist, auch wenn die Behörde bei dem „ob“ ihrer Entscheidung bei wortlautnaher Auslegung freies Ermessen genießt, der qualifizierte Tatbestand des „offensichtlichen und schwerwiegenden" Verstoßes für den positiven Befund der Löschungseignung der Partei zu erfüllen. Zu einem „Verbot“ der Partei kommt es hingegen insofern nicht, als dass diese sehr wohl durch Vereinigungen auf Ebene der Mitgliedstaaten fortbestehen kann, die Behörde hat hier keine Durchgriffsbefugnisse. Das Aufsichtsverfahren der APPF zeigt einige Parallelen mit dem Verfahren des Art.7 EUV. Der Wortlaut des „offensichtlichen

1829 Art. 5 Abs. 2 der Verordnung (EG) Nr. 2004/2003 des Europäischen Parlaments und des Rates vom 4. November 2003 über die Regelungen für die politischen Parteien auf europäischer Ebene und ihre Finanzierung, ABl. L 297/1 vom 15.11.2003.

1830 Das Verfahren der Überprüfung europäischer politischer Parteien ist in Art. 10 der VO 1141/2014 geregelt, s. dort insb. Art. 10 Abs. 3 S. 1 zum Antrag.

1831 Art. 10 Abs. 3 UAbs. 5 der VO 1141/2014. Das Register ist unter: http://www.ap pf.europa.eu/appf/en/parties-and-foundations.html einsehbar.

1832 Art. 17 der VO 1141/2014 sowie Art. 221 ff. der Verordnung (EU, Euratom) 2018/1046 des Europäischen Parlaments und des Rates vom 18. Juli 2018 über die Haushaltsordnung für den Gesamthaushaltsplan der Union, zur Änderung der Verordnungen (EU) Nr. 1296/2013, (EU) Nr. 1301/2013, (EU) Nr. 1303/2013, (EU) Nr. 1304/2013, (EU) Nr. 1309/2013, (EU) Nr. 1316/2013, (EU) Nr. 223/2014, (EU) Nr. 283/2014 und des Beschlusses Nr. 541/2014/EU sowie zur Aufhebung der Verordnung (EU, Euratom) Nr. 966/2012, ABl. (EU) L 193/1 vom 30.07.2018. 
und schwerwiegenden" Verstoßes erinnert an Art. 7 Abs. 2 EUV. Ebenso kannte Art. 7 Abs. 1 EUV a.F. ein Gremium „unabhängiger Persönlichkeiten", welches erhebliche Parallelen mit dem in der Parteienverordnung eingeführten Ausschuss zeigt. ${ }^{1833}$

\section{Die „Dialoge“ im Rat-Rechtsstaatlichkeitsdialog und „Periodic Peer Review"}

Ist die Parteienaufsicht zwar konkret möglich, aber wenig praxisrelevant, so ist bei zwei weiteren Verfahren das Gegenteil richtig: sie sind sehr praxisrelevant, aber wenig konkret.

Das erste dieser Verfahren, der sog. „Rechtsstaatlichkeitsdialog“ des Rates, ${ }^{1834}$ hat, schon aufgrund des vorab ergangenen Gutachtens des juristischen Dienstes des Rates, seinen Zweck nie verhehlt, sich in Konkurrenz zum EU-Rahmen der Kommission zu setzen. Ähnlich dichotom hat Bernd Martenczuk den Dialog vom EU-Rahmenverfahren getrennt. ${ }^{1835}$

Der Rechtsstaatlichkeitsdialog, wie auch die spätere Idee des „peer review" in der Union, das zweite dieser Verfahren, findet seine Vorbilder in der Außenpolitik der Union, etwa mit einem „strukturieren Rechtsstaatlichkeitsdialog " gegenüber dem Kosovo, ${ }^{1836}$ und im Völkerrecht. Nach verschiedenen Evaluationsverfahren Internationaler Organisationen, etwa der DAC-Peer Review der OECD, ${ }^{1837}$ ist das wohl prominenteste dieser Verfahren die „Universal Periodic Review“ (UPR) des Menschenrechtsrates der Vereinten Nationen, welcher diesen rechtsunverbindlichen Mechanismus 2006 eingeführt hatte. ${ }^{1838}$ Gegenstand der UPR ist insbesondere die „Erfüllung der Menschenrechtsverpflichtungen“. ${ }^{1839}$ Im Rahmen der UPR steht es UN-Mitgliedstaaten zu, neben sog. „advance questions“ auch

1833 Zu dieser Einschätzung gelangt auch Frank Schorkopf, „Wertesicherung in der Europäischen Union", S. 154.

1834 S. bereits kurz unter E.II.1.b. betreffend die Relation Kommission-Rat.

1835 Bernd Martenczuk „Art. 7 EUV und der Rechtsstaatsrahmen als Instrumente der Wahrung der Grundwerte der Union“, S. 49.

1836 Rat der Europäischen Union, „Special report No 18/2012: European Union Assistance to Kosovo related to the rule of law", 16619/12 vom 22.11.2012.

1837 Das Kürzel DAC steht für „Development Assistance Committee“. Es besteht seit 1960 und umfasst derzeit 30 Mitglieder, darunter auch die 2018 „überprüfte" Europäische Union selbst. Vgl. www.oecd.org/dac/peer-reviews.

1838 Rechtsgrundlage ist die Resolution 60/251 der Generalversammlung der Vereinten Nationen vom 15.03.2006, A/RES/60/251.

1839 Vgl. Punkt 5 (a) der vorbenannten Resolution. 
im Plenum Empfehlungen und Feststellungen an den betroffenen Staat zu richten. Die Untersuchung mündet in einen Bericht dreier durch das Los bestimmter Mitgliedstaaten, der sog. „Troika“. ${ }^{1840}$ Die anlasslose Überprüfung erfolgt in sog. Zyklen, der derzeit dritte Zyklus dauert von 2017-2022. Während des ersten Zyklus wurden alle Mitgliedstaaten der Vereinten Nationen überprüft, hiernach 42 jedes Jahr.

Die UPR hat, gerade gegenüber Polen, eine beachtliche politische Wirkung entfaltet. Mit gewissen Einschränkungen könnte man auch davon sprechen, dass der Rat der EU-Mitgliedstaaten, vor laufender Kamera, hier einen Außentermin hatte.

Während der Aussprache vom 09.05.2017, ${ }^{1841}$ zu welcher nach meiner Zählung insgesamt 73 Delegationen anwesend waren, sprachen volle 22 Mitgliedstaaten der EU. ${ }^{1842}$ Bereits in den sog. "advance questions“ fragten namentlich die Niederlande und Deutschland direkt zur Lage der Justiz in Polen an. ${ }^{1843}$ Während der Aussprache liegt der Schwerpunkt, einhergehend mit den Vorgaben des Menschenrechtsrates, auf den Grundrechten. Folglich kamen mehrere Mitgliedstaaten der EU, etwa Lettland, auf die Frauenrechte in Polen zu sprechen. Gleichwohl mahnten verschiedene Mitgliedstaaten, darunter Spanien und Schweden Verbesserungen spezifisch hinsichtlich der Rechtsstaatlichkeit an, die Niederlande etwa hinsichtlich der Umsetzung von EGMR-Urteilen. Spanien rügte ausdrücklich die Lage der Justiz und empfahl die Rücknahme der Personalunion von Generalstaatsanwalt und Justizminister. Auch Österreich rügte eine „Gefährdung der Gewaltenteilung, der Unabhängigkeit der Justiz und

1840 Übersicht zu diesen Verfahrenseinzelheiten auf der Seite „Basic facts about the UPR“, abrufbar unter: https:/www.ohchr.org/en/hrbodies/upr/pages/basicfacts .aspx.

1841 Die vollständige Videoaufzeichnung der Aussprache im Menschenrechtsrat ist verfügbar unter: http://webtv.un.org/search/poland-review-27th-session-of-uni versal-periodic-review/5425972482001/?term=\&lan=english\&cat=Universal\%2 0Periodic\%20Review\&sort=date\&page=9. Es liegt meiner Kenntnis nach kein stenographischer Bericht vor.

1842 In der Reihenfolge ihrer Stellungnahmen waren dies: Litauen, Spanien, Schweden, Großbritannien, Österreich, Belgien, Bulgarien, Kroatien, Zypern, Tschechien, Dänemark, Estland, Finnland, Frankreich, Deutschland, Griechenland, Ungarn, Irland, Italien, Slowenien, die Niederlande und Rumänien.

1843 Die vollständige Verfahrensdokumentation ist verfügbar unter: http://www.oh chr.org/EN/HRBodies/UPR/Pages/PLIndex.aspx und https:/www.upr-info.o rg/en/review/Poland/Session-27---May-2017/Civil-society-and-other-submissio ns. Die folgenden EU-Mitgliedstaaten richteten an Polen „advance questions“: Belgien, die Niederlande, Schweden, Tschechien, Slowenien, Großbritannien, Deutschland und Spanien.. 
der Rechtsstaatlichkeit“ in Polen. Dänemark nahm ausdrücklich auf das laufende EU-Rahmenverfahren mit der Kommission Bezug. In gleichem Maße umfassende Empfehlungen kamen von deutscher und französischer Seite. Die polnische Seite nahm durch eine große Delegation zu den Empfehlungen Stellung, ließ dabei aber grundsätzlich, wie schon zuvor, keine Bereitschaft erkennen, diesen nachzukommen.

Ein gutes Dreivierteljahr nach Vorstellung des EU-Rahmens setzte der Rat, im Dezember 2014, mit dem sog. „Rechtsstaatlichkeitsdialog“ ein Verfahren um, ${ }^{1844}$ das der UPR sehr ähnelt, indes nicht öffentlich abläuft. Die streng konsensuale Natur des Rechtsstaatlichkeitsdialoges unter den Mitgliedstaaten macht sich auch in der Eingangsformel des entsprechenden Grundlagendokuments bemerkbar. In der Eingangsformel heißt es „Schlussfolgerungen des Rates und der im Rat vereinigten Mitgliedstaaten" statt schlicht „Schlussfolgerungen des Rates“. ${ }^{1845}$ Ein erstes Positionspapier von 2014, in direkter Reaktion auf die Vorstellung des EU-Rahmens, wiederholte neben einem klaren Bekenntnis zur Rechtsstaatlichkeit auch die bereits zuvor aufgestellte Aufforderung an die Kommission „,[to] take forward the debate in line with the Treaties“. Der "politische Dialog“ zur Rechtsstaatlichkeit des Rates selbst erscheint in diesem Papier noch genuin von dem Wunsch geleitet, die Vorstöße der Kommission nicht abzuschwächen, sondern mit gleicher Stoßrichtung zu ergänzen. ${ }^{1846}$

Auch die parallelen Reaktionen des Rates im Austausch mit dem Europarat sind vielversprechend, da der Rat nicht nur auf die Bedeutung des Rechts- sondern auch des Demokratieprinzips einging und Teilproblemfelder skizzierte, in welchen er eine Zusammenarbeit für besonders nützlich und erforderlich hielt. ${ }^{1847}$

In der weiteren Entwicklung hat der Rechtsstaatlichkeitsdialog die in ihn auch gesetzten Erwartungen indes nicht erfüllt. Zu einer praktisch oder rechtswissenschaftlich verwertbaren Entwicklung wichtiger paralleler

1844 Rat der Europäischen Union, Schlussfolgerungen des Rates der EU und der im Rat vereinigten Mitgliedstaaten über die Gewährleistung der Achtung der Rechtsstaatlichkeit, 16134/14 vom 12.12.2014.

1845 Auf diese Besonderheit weist auch hin Roberto Baratta, „Rule of Law ,Dialogues' Within the EU: A Legal Assessment“, in: Hague Journal on the Rule of Law 8 (2016), S. 357-372, S. 370.

1846 Rat der Europäischen Union, Gewährleistung der Achtung der Rechtsstaatlichkeit in der Europäischen Union, 15206/14 vom 14.11.2014.

1847 Generalsekretariat des Rates der Europäischen Union, „Prioritäten der EU für die Zusammenarbeit mit dem Europarat (2016-2017)“, 5339/16, vom 18.01.2016. 
Konzepte, wie der systemischen Gefährdung der Rechtsstaatlichkeit, ist es seitens des Rates ebenso wenig gekommen wie zu einer Begutachtung systemischer Defizite in Mitgliedstaaten. Folgemaßnahmen haben auf den Dialog nicht aufgebaut. Das Urteil muss daher hier hart ausfallen: der Rechtsstaatlichkeitsdialog des Rates hätte durchaus eine Komplementierung des Verfassungsaufsichtsinstrumentariums der Union sein können, aber er ist es nicht. Peter Oliver und Justine Stefanelli haben zurecht die peer-review-Qualität des Rates in Zweifel gezogen. ${ }^{1848}$

Der „Rechtsstaatlichkeitsdialog“ hat zwischen den Jahren 2015 bis 2019 in insgesamt vier Auflagen stattgefunden. ${ }^{1849}$ Der letzte Dialog im November 2019 erfolgte im Rahmen einer GAC-Sitzung in Brüssel, er selbst hatte hingegen nur die Evaluierung des Dialogs als Instrument selbst zum Gegenstand. ${ }^{1850}$ Andere Dialoge haben thematische Schwerpunkte gesetzt. Der erste Dialog fand im Oktober 2015 statt und setzte sich, auch wenn z.B. Herausforderungen der Digitalisierung und nicht systemische Herausforderungen auf der Tagesordnung standen, durchaus ernsthaft mit der Materie auseinander. ${ }^{1851}$

Spätere Auflagen haben bereits durch ihre Aufmachung klargemacht, dass der Rat nicht gewillt schien, dies durchzuhalten. Die Auflage von 2016 - unter immerhin niederländischer Ratspräsidentschaft - beschränkte sich im Wesentlichen auf einen kurzen Tagungsbericht, ${ }^{1852}$ inhaltlich hatte die Frage der Migration im Vordergrund gestanden.

1848 Peter Oliver \& Justine Stefanelli, „Strengthening the Rule of Law in the EU“, S. 1079.

1849 Übersicht bis 2017 in Rat der Europäischen Union/Estnische Ratspräsidentschaft, „Non-Paper des Vorsitzes für die Tagung des Rates (Allgemeine Angelegenheiten) am 17. Oktober 2017 - Jährlicher Dialog über Rechtsstaatlichkeit”/ Rat (Allgemeine Angelegenheiten), 17. Oktober 2017 Dialog über Rechtsstaatlichkeit: Non-Paper des estnischen Vorsitzes ,Medienpluralismus und Rechtsstaatlichkeit im digitalen Zeitalter“", 12671/17 vom 29.09.2017.

1850 So der Bericht der FRA, „Annual Rule of law dialogue in the Council“, vom 19.11.2019, abrufbar unter: https://fra.europa.eu/en/event/2019/annual-rule-la w-dialogue-council.

1851 Rat der Europäischen Union, Outcome of the Council Meeting, General Affairs, 3427th Council meeting, 14185/15, vom 17. und 18.10.2015, S. 3 sowie die dazu vorgelegten Diskussionspapiere "Gewährleistung der Achtung der Rechtsstaatlichkeit“ und „Rechtsstaatlichkeit im Zeitalter der Digitalisierung“, in: Gewährleistung der Achtung der Rechtsstaatlichkeit - Dialog und Gedankenaustausch, 13744/15 vom 09.11.2015.

1852 Rat der Europäischen Union, Non-Paper des Vorsitzes für die Tagung des Rates (Allgemeine Angelegenheiten) am 24. Mai 2016 - Dialog über Rechtsstaatlichkeit, 8774/16 vom 13.05.2016. 
Ein Höhepunkt an Bedeutungsrelativierung des Rechtsstaatlichkeitsdialoges findet sich in einem Dokument des estnischen Ratsvorsitzes von 2017. Es ist - in höchst erstaunlichem Kontrast zu seiner Thematik - mit Hintergrundbildern eines Waldes unterlegt, die mutmaßlich touristisch für Estland werben sollen. Der kurze Passus zum Rechtsstaatlichkeitsdialog endet in dem Satz: „[...] the Presidency would like to invite the Ministers to explore the specific challenges to media pluralism and the rule of law brought about by the digital age." Ungeachtet der Entwicklung hatte der Rat den Dialog nämlich ausschließlich auf „Fragen der Digitalisierung" beschränkt. ${ }^{1853}$ Auch 2018 beschränkte man sich augenscheinlich auf ein „Expertenseminar“. 1854

Mit dieser Entwicklung war man offensichtlich, angesichts der Entwicklung der Lage, auch im Rat selbst nicht einverstanden. Zweimal ist der Rechtsstaatlichkeitsdialog deswegen „evaluiert“ worden, zunächst 2016, ${ }^{1855}$ sodann ein zweites Mal im Jahr 2018, die Ergebnisse wurden dabei erst 2019 besprochen. ${ }^{1856}$ Im Hinblick auf die letzte Evaluierung ist die Zukunft des Formats und des Inhalts des Dialogs offen. Der Rat hat zwar eine grundsätzliche Fortführung angeregt, dabei allerdings eine „Überschneidung" mit weiteren Maßnahmen zu vermeiden gesucht. Der belgisch-deutsche Vorschlag, betreffend eine sog. „periodic peer review“, 1857 ist in die-

1853 Rat der Europäischen Union, Presidency non-paper for the Council (General Affairs) on 17 October 2017 - Annual rule of law dialogue, 12671/17 vom 29.09.2017, Annex: General Affairs Council, 17 October 2017 Rule of Law Dialogue Non-paper of the Estonian Presidency „Media Pluralism and the Rule of Law in the Digital Age“.

1854 Rat der Europäischen Union, "„Council Conclusions on the application of the Charter of Fundamental Rights in 2017”, 12884/18, vom 10.10.2018, Rn. 11 (zum Dialog 2018), „EU (CATS) - Council of Europe meeting, Brussels, 10628/18“, vom 28.06.2018, S. 5.

1855 Rat der Europäischen Union, „Rule of Law - Evaluation of mechanism“, 13980/16, vom 09.11.2016.

1856 Rat der Europäischen Union, „Presidency conclusions - Evaluation of the annual rule of law dialogue“, 14173/19, vom 19.11.2019.

1857 Dazu „Discours du Ministre D. Reynders lors de la 5ème Conférence belgo-allemand [sic] (Debeko), axée cette année sur les thèmes de la digitalisation, l'énergie et le transport", of 18 March 2019, S. 5, abrufbar unter: https:/diplomatie.belgium.be/sites/default/files/downloads/discours_debeko_ 20190318.pdf; Die deutsche Unterstützung findet sich in Form der „Opening speech by Minister of State for Europe Michael Roth at the Peer-Review-Workshop on Rule of Law“, vom 07.11.2018, disponible sous: https://www.auswa ertigesamt.de/en/newsroom/news/-/2158210. Der Begriff entstammt mutmaß- 
sem Dokument bereits angesprochen. ${ }^{1858}$ Dass es der jetzige Justizkommissar Didier Reynders war, der sich hinter diesen Vorschlag stellte, verleiht dem Vorschlag beachtliches Gewicht.

Die belgische Delegation im Rat, unterstützt durch Deutschland und die Niederlande, hat hierzu einen sehr detaillierten Vorschlag gemacht. Öffentlich geworden ist, dass der Mechanismus substantiell auf die Rechtsstaatlichkeit fokussieren wird und unter Aufgreifen der Formulierung des Art. 7 Abs. 1 (Nizza) nicht nur regelmäßige Konsultierungen eigener „Rechtsstaatlichkeitsexperten“ beabsichtigt, sondern dies möglicherweise perpetuieren könnte. ${ }^{1859}$ Mutmaßlich geplant ist auch eine offene Verzahnung mit Maßnahmen der Kommission. Belgien hat hierzu den Begriff der "tool box" der Kommission ausdrücklich aufgegriffen.

\section{Die Vorschläge der Kommission - neue Rechtsstaatsinitiative und Konditionalisierung des ESI-Fonds-Rechts}

Die Kommission hat im April 2019 und Juli 2019, wie bereits angesprochen, zwei eigene Programmmitteilungen zur Fortentwicklung des Verfassungsaufsichtsinstrumentariums vorgelegt. Erst mit Antritt der von der Leyen-Kommission ist hieraus allerdings, nicht unähnlich den Ankündigungen des Jahres 2013, eine konkrete Policy-Ankündigung in Form des "Comprehensive European Rule of Law Mechanism“ erwachsen. ${ }^{1860}$ Wie dieser aussehen wird, ist offen. Es scheint indes, als solle er ebenso einen jährlichen Evaluierungszyklus gegenüber Mitgliedstaaten bilden. Ob alle oder nur bestimmte Mitgliedstaaten diesem unterzogen werden sollen,

lich dem US-amerikanischen Vokabular zur regelmäßigen Begutachtung der Leistungskontrolle im Hochschulbereich.

1858 Rat der Europäischen Union, „Schlussfolgerungen des Vorsitzes - Bewertung des jährlichen Rechtsstaatlichkeitsdialogs“, 14173/19, vom 19.11.2019, Rn. 15.

1859 Vgl. dazu den offenen Brief von Didier Reynders, hier noch als belgischer AuBenminister, Michael Roth als deutscher Europastaatssekretär und Stefan Blok, niederländischer Außenminister, „Fundamental values check-up: let's intensify our dialogue!“, vom 20.03.2019, abrufbar unter: https://www.auswaertiges-amt .de/en/newsroom/news/article-roth-reynders-blok/2201508, erschienen als „Die Rechtsstaatlichkeit aller EU-Mitglieder prüfen" vom 20.03.2019.

1860 Vgl. den Mission Letter von der Leyens an Didier Reynders vom 01.12.2019, abrufbar unter: https://ec.europa.eu/commission/commissioners/sites/comm-c wt2019/files/commissioner_mission_letters/mission-letter-didier-reynders-2019 _en.pdf. 
war lange ebenso unklar. ${ }^{1861}$ Die Kommission hat sich indes später darauf festgelegt, sog. „Rechtsstaatlichkeitsberichte“ (rule of law reports), betreut durch das Referat C.1 der GD JUST, zu allen Mitgliedstaaten erlassen, für die sie im Mai 2020 eine - erneute und spezifische - Stakeholder-Befragung beendet hat. ${ }^{1862}$ Die Berichte sollen im September erscheinen. ${ }^{1863}$ Weiteres ist bislang noch nicht bekannt. Es scheint indes nicht ausgeschlossen, dass der neue Zyklus dieser Berichte sich zu einem tragenden Aufsichtsinstrument des hier dargestellten Rechtsregimes entwickelt, der möglicherweise auch bereits existierende Instrumente in sich aufnehmen kann und die Systematik ihres Zusammenwirkens weiterentwickelt.

Für die Wissenschaft, wie aber auch für die Praxis, ergibt sich aus dieser Schwebelage eine erhebliche Ungewissheit, die eine solide Analyse dieses Vorstoßes erschwert.

Das gilt auch für den immer noch offenen Verordnungsvorschlag der Kommission vom 02.05.2018. Ich hatte diesen bereits mit Blick auf seinen Beitrag zu einer möglichen Positivdefinition der Rechtsstaatlichkeit im Unionsrecht berücksichtigt.

Die Kommission hatte mit dem Verordnungsvorschlag überlegt, generelle Mängel an Rechtsstaatlichkeit gerade bei „Beeinträchtigung“ oder „Drohung einer Beeinträchtigung“ der „wirtschaftliche Haushaltsführung oder den Schutz der finanziellen Interessen der Union“ zum materiellen Tatbestandskriterium für Sanktionsmaßnahmen zu erklären, die der Rat mit umgekehrter Mehrheit auf Vorschlag der Kommission beschließen sollte. ${ }^{1864}$ Gestützt ist der Vorschlag auf Art. 322 Abs. 1 lit. a AEUV und Art. 106 lit. a des Euratom-Vertrags. ${ }^{1865}$ Das Potential dieses Vorschlags ist enorm, die Forderung nach effektiven finanziellen Sanktionen wird

1861 Vgl. entsprechend unter https:/ec.europa.eu/info/strategy/priorities-2019-2024/ promoting-our-european-way-life_en.

1862 https://ec.europa.eu/info/policies/justice-and-fundamental-rights/upholding-rul e-law/rule-law/rule-law-report_en\#documents.

1863 Bulletin quotidien vom 14.05.2020, „Commission promises to closely monitor lifting of emergency measures implemented during the pandemic“, o.S.

1864 Vgl. Art. 3 und 5 des Vorschlags für eine Verordnung des Europäischen Parlaments und des Rates über den Schutz des Haushalts der Union im Falle von generellen Mängeln in Bezug auf das Rechtsstaatsprinzip in den Mitgliedstaaten, $\operatorname{COM}(2018) 324$ final, vom 02.05.2018.

1865 Vorschlag für eine Verordnung des Europäischen Parlaments und des Rates über den Schutz des Haushalts der Union im Falle von generellen Mängeln in Bezug auf das Rechtsstaatsprinzip in den Mitgliedstaaten, COM(2018) 324 final, vom 02.05.2018, S.3. 
regelmäßig gestellt. ${ }^{1866}$ Art. 4 des Verordnungsvorschlags sah - allerdings begrenzt auf den Fall der gemeinsamen Mittelausführung der Kommission im Haushalt - eine Reihe von Sanktionsmaßnahmen vor, die nach Art. 4 Abs. 1 lit.b (6) im schärfsten Fall die Aussetzung von Zahlungen an den betroffenen Mitgliedstaat zur Folge gehabt hätte, wobei diese Aussetzung aufgrund des Art. 1 Budgetpositionen des gesamten Haushalts erfasst hätte.

Der Verordnungsvorschlag trägt damit implizit der Auffassung Rechnung, dass die derzeit in Kraft befindliche sog. „Common Provisions Regulation“ („CPR“), die Verordnung über die gemeinsamen Bestimmungen der ESI-Fonds oder der ,allgemeine Teil des Strukturfondsrechts“, ${ }_{1867}$ keine Möglichkeit bietet, bei systemischen Defiziten in einem Mitgliedstaat eine Zahlung zu begutachten, von Auflagen abhängig zu machen, auszusetzen oder sogar zurückzufordern. ${ }^{1868}$ Art. 142 i.V.m. Art. 83 dieser Verordnung lässt zwar die Aussetzung von Zahlungen und Art. 144 i.V.m. Art. 85 und 145 lässt sog. „finanzielle Berichtigungen“ zu, allerdings ist dafür, vgl. Art. 144 Abs. 1 lit. a, ein sog. „gravierender Mangel bei der wirksamen Funktionsweise des Verwaltungs- und Kontrollsystems für das operationelle Programm“, also eine konkrete Missverwaltung erforderlich, die trotz potentieller Überschneidungen wie Korruption regelmäßig in Mitgliedstaaten, die unter systemischen Defiziten leiden, nicht anzutreffen ist. Diese Mechanismen sind keinesfalls ineffektiv - sie kosteten z.B. Ungarn Ende 2019 wegen chronischer Misswirtschaft eine Rekordsumme von ca. 1,39 Milliarden Euro, ${ }^{1869}$ - aber sie beschränken sich auf bestimmte

1866 Zum Stand der Lage bei Schluss des Manuskripts vgl. Klaus Geiger, „Bundesregierung übt scharfe Kritik an Ungarn“, Die Welt, vom 03.04.2020.

1867 Verordnung (EU) Nr. 1303/2013 des Europäischen Parlaments und des Rates vom 17. Dezember 2013 mit gemeinsamen Bestimmungen über den Europäischen Fonds für regionale Entwicklung, den Europäischen Sozialfonds, den Kohäsionsfonds, den Europäischen Landwirtschaftsfonds für die Entwicklung des ländlichen Raums und den Europäischen Meeres- und Fischereifonds sowie mit allgemeinen Bestimmungen über den Europäischen Fonds für regionale Entwicklung, den Europäischen Sozialfonds, den Kohäsionsfonds und den Europäischen Meeres- und Fischereifonds und zur Aufhebung der Verordnung (EG) Nr. 1083/2006 des Rates, ABl. L 347/320 v. 20.12.2013.

1868 Erwägungen für Formulierungen, die derartige Rückforderungen bereits de lege lata erlauben sollen, stellt aber an Gábor Halmai, „The possibility and desirability of economic sanction: Rule of law conditionality requirements against illiberal EU Member States“, EUI Working Paper LAW 2018/06, insb. S. 19.

1869 Martin Dunai \& Timothy Heritage, „Hungary accepts big penalty for mismanaging EU funds“, Reuters, vom 12.11.2019. Die Summe in Landeswährung betrug 500 Milliarden Forint. 


\section{F. Entwicklungsperspektiven der Verfassungsaufsicht}

Fälle. Der Verordnungsvorschlag würde zusätzlich eine sog. „postakzessorische“, soll heißen: nach Beitritt zur Union geltende „Konditionalität“, ${ }^{1870}$ eine sowohl ex ante wie ex post im Hinblick auf die Mittelverwendung zu wahrende Obliegenheit schaffen, bei deren Verletzung der Mitgliedstaat sich proaktiv eines Zuwendungsverlustes oder reaktiv einer Mittelrückforderung aussetzen würde. Sollte der Vorschlag in Kraft treten, wäre er insbesondere als Ergänzung der Sanktionsmaßnahmen nach Art. 7 Abs. 3 EUV zu sehen. ${ }^{1871}$ Zwischenzeitlich haben verschiedene andere Unionsorgane zu dem Vorschlag Stellung bezogen. ${ }^{1872}$ Der Juristische Dienst des Rates hat in einem Gutachten, vergleichbar demjenigen, das zuvor zum EU-Rahmen ergangen ist, umfassende Zweifel gerade an der Vereinbarkeit des Verordnungsvorschlags mit den Verträgen angemeldet. Dies notiert jedenfalls Iris Goldner Lang, die Einsicht in dieses Dokument hatte. ${ }^{1873}$

Parlament und Rat sind jedoch nach wie vor nicht dazu übergegangen, den Vorschlag und den Begleitvorschlag über die Schaffung eines zusätzlichen Fonds für "Justiz, Rechte und Werte" in eine Form zu gießen, die

1870 Zum Begriff der „conditionality“ konzise Michael Ioannidis, „EU Financial Assistance Conditionality after, Two Pack““, S. 62, bei Fn. 1.

$1871 \mathrm{Zu}$ Überlegungen betreffend den nach Art. 7 Abs. 3 EUV möglichen Maßnahmen bereits Frank Schorkopf, Homogenität in der Europäischen Union, Duncker \& Humblot, Berlin, 2000, S. $168 \mathrm{ff}$.

1872 Vgl. 1. Europäischer Wirtschafts- und Sozialausschuss, Stellungnahme des Europäischen Wirtschafts- und Sozialausschusses zu dem „Vorschlag für eine Verordnung des Europäischen Parlaments und des Rates über den Schutz des Haushalts der Union im Falle von generellen Mängeln in Bezug auf das Rechtsstaatsprinzip in den Mitgliedstaaten" (COM(2018) 324 final 2018/0136 (COD)), ABl. (EU) C 62/173 (1) vom 15.02.2019, 2. Europäischer Ausschuss der Regionen, Stellungnahme des Europäischen Ausschusses der Regionen - Das Paket für den Mehrjährigen Finanzrahmen für die Jahre 2021-2027, ABl. (EU) C 461/70 vom 21.12.2018, 3. Europäischer Rechnungshof, Stellungnahme Nr.1/2018 (gemäß Artikel 322 Absatz 1 Buchstabe a AEUV) zu dem Vorschlag vom 2. Mai 2018 für eine Verordnung des Europäischen Parlaments und des Rates über den Schutz des Haushalts der Union im Falle von generellen Mängeln in Bezug auf das Rechtsstaatsprinzip in den Mitgliedstaaten, ABl. (EU) C 291/1 vom 17.08.2018 - 4. Bericht für den Haushaltsausschuss (BUDG) des Europäischen Parlaments über den Vorschlag für eine Verordnung des Europäischen Parlaments und des Rates über den Schutz des Haushalts der Union im Falle von generellen Mängeln in Bezug auf das Rechtsstaatsprinzip in den Mitgliedstaaten, (COM(2018)0324 - C8-0178/2018 - 2018/0136(COD)), vom 17.12.2018.

1873 Iris Goldner Lang, "The Rule of Law, the Force of Law and the Power of Money in the EU“", in: Croatian Yearbook of European Law and Policy 15 (2019), S. 1-26, S. 8 ff. Das Gutachten ist bislang nicht öffentlich zugänglich. 
eine konkrete und nicht mehr oder minder spekulative Kommentierung erlauben würde, auch wenn hierzu 2019 ein Trilog-Kompromiss ergangen ist. ${ }^{1874}$

\section{Schlussbemerkungen und Abriss in Thesen}

Die vorliegende Arbeit hat zum Ziel, nach topischer Sichtung der sog. Rechtsstaatlichkeitskrise der Europäischen Union, das Rechtsregime der unionalen Verfassungsaufsicht herauszuarbeiten, das derzeit die Debatte um Bestand und Zukunft der Union wesentlich prägt.

Die Rechtsstaatlichkeitskrise bezeichnet eine in Ablauf und Problematik sehr heterogene, nicht abgeschlossene Entwicklung in der sog. Polykrise der Europäischen Union. Der Begriff selbst ist kein dogmatisch vollständig geformter Rechtsbegriff, sondern ermöglicht eine Analyse durch Hinführung auf den Begriff des systemischen Defizits an Rechtsstaatlichkeit.

Die Entwicklung des Begriffs des systemischen Defizits kann dabei auf verschiedene Stränge im Recht der Europäischen Union und des Europarats, insbesondere der Rechtsprechung von EGMR und EuGH zurückgreifen, die allerdings sorgfältig auf ihren Gewinn für das Begriffsverständnis zu sichten sind. Das gilt auch für die Defektforschung der Politikwissenschaft. Systemische Defizite i.S. der vorliegenden Arbeit sind insbesondere dann gegeben, wenn sie zwischen Mitgliedstaaten zu einem intersystemischem Konflikt bzw. zu einem Selbsteintritt eines anderen Akteurs im europäischen Rechtsraum führen. Systemische Defizite können dabei derzeit in zwei wesentlichen Typen auftreten, staatlicher Schwäche und vorsätzlicher Unterwanderung des Rechtsstaatsprinzips, von denen allein der zweite hier interessiert.

Derartige systemische Defizite bestehen nach derzeitigem Entwicklungsstand jedenfalls in Polen, Ungarn und Rumänien, wobei Rechtswissen-

1874 Rat der Europäischen Union, „Proposal for a Regulation of the European Parliament and of the Council establishing the Rights and Values programme for the period 2021-2027 - Progress report on the negotiations with the European Parliament - Confirmation of the common understanding", 7249/1/19 vom 12.03.2019. Polen und Ungarn haben angekündigt, sich gegenseitig in Schutz zu nehmen, vgl. James Shotter \& Valerie Hopkins, „Poland pledges to veto sanctions against Hungary", Financial Times vom 12.09.2018; Valerie Hopkins, „Hungary optimistic over swift end to ,absurd' EU rule-of-law row Member states are tiring of proceedings against Budapest, minister believes“, Financial Times vom 29.09.2019. 
schaft und -praxis diese nur dann konzise erfassen können, wenn topisch gearbeitet wird. Ähnliche Entwicklungen in anderen Mitgliedstaaten müssen davon abgegrenzt werden.

Die Arbeit ist insbesondere auf die Entwicklung in Polen und Ungarn eingegangen und hat dargestellt, dass diese sich in ihren Topoi und der in Polen eher monothematischen, in Ungarn eher polythematischen Entwicklung unterscheiden.

Nach der Erarbeitung systemischer Defizite des vorsätzlichen Typs in Mitgliedstaaten hat die Arbeit gezeigt, dass in der deutschen und hiernach in der deutschsprachigen Europarechtswissenschaft mit dem Begriff der Verfassungsaufsicht ein Begriff besteht, der die Maßnahmen zur Behebung systemischer Defizite an Rechtsstaatlichkeit erfassen kann. Der Begriff der Verfassungsaufsicht bezeichnet nämlich solche Bundesaufsichtsmaßnahmen der föderalen Unionsverfassung, die dem Schutz ihres Verfassungskerns dienen, zu dem das Rechtsstaatsprinzip zählt, und welches tangiert ist, wenn es in Mitgliedstaaten vorsätzlich systemisch missachtet wird.

Die Arbeit hat sodann, gründend auch auf eigene Anschauung infolge von Abordnung zum Referat Justizpolitik und Rechtsstaatlichkeit (C.1) der Generaldirektion Justiz und Verbraucher der Europäischen Kommission, den Blick auf verschiedene Maßnahmen geworfen, die zusammen das Rechtsregime der Verfassungsaufsicht in der Europäischen Union bilden. Bei der Analyse wird innerhalb eines dreistufigen Aufsichtsverständnisses, bestehend aus Beobachtungs-, Überprüfungs- und Berichtigungsfunktion, unterschieden. Es ergibt sich, dass das Unionsrecht neben Maßnahmen, die alle drei dieser Stufen aufzeigen, auch sog. partielle Verfahren kennt, denen die letzte Stufe fehlt.

Sie und ihre Funktions-, Nutzungs- und Entwicklungsgrundsätze wurden, unter Rückgriff auf Ergebnisse der teilnehmenden Beobachtung, umfassend aufgearbeitet. Die Arbeit ficht dabei auch dafür, die hierbei erbrachte Leistung, gerade der Europäischen Kommission als wesentlicher Akteur im Sinne einer europäischen Gubernative, positiv zu werten.

Zur ersten Jahreshälfte 2020, gute sechs Jahre nach ersten Verfahrensschritten der Europäischen Kommission, die im weiteren Verlauf der Rechtsstaatlichkeitskrise der Europäischen Union zu dem hier dargestellten Verfassungsaufsichtsinstrumentarium der Union geführt haben, bleiben sowohl die Krise als auch die Reaktionen auf sie weiter im Fluss. Gleichwohl lassen sich bereits jetzt wichtige Rückschlüsse aus der Entwicklung ziehen, vor allem dahingehend, dass es der Europäischen Union, und vor allem der Europäischen Kommission, gelungen ist, ein facettenreiches und effektives Verfassungsaufsichtsregime in Antwort auf diese 
Krise vorzulegen. Dieses herauszuarbeiten und den gegenwärtigen Kenntnisstand in der Rechtswissenschaft darzustellen, ist das Anliegen dieser Arbeit. 


\section{Literaturverzeichnis}

Ohne Urteile, Gesetzesmaterialien, Beiträge aus der Tagespresse und Online-Nachrichtenportalen. Letzte Kontrolle aller Links: April 2020.

Abélès, Marc; Bellier, Irène \& McDonald, Maryon: „Approche anthropologique de la Commission européenne“, Studie des Centre National de la Recherche Scientifique, Paris und der University of West London im Auftrag der Europäischen Kommission, 1993.

Adam, Heike: Die Mitteilungen der Kommission: Verwaltungsvorschriften des Europäischen Gemeinschaftsrechts? Eine Untersuchung zur rechtsdogmatischen Einordnung eines Instruments der Kommission zur Steuerung der Durchführung des Gemeinschaftsrechts, Nomos, Baden-Baden, 1999.

Adams, Maurice; Meuwese, Anne \& Hirsch Ballin, Ernst (Hrsg.): Constitutionalism and the Rule of Law: Bridging Idealism and Realism, Cambridge University Press, Cambridge, 2017.

Ahtisaari, Martti; Frowein Jochen \& Oreja, Marcelino: „Report on the Austrian Government's Commitment to the Common European Values, in particular concerning the Rights of Minorities, Refugees and Immigrants, and the Evolution of the Political Nature of the FPÖ (the Wise Men Report)", in: International Legal Materials 40 (2000), S. 102-123.

Alemann, Florian von: Die Handlungsform der interinstitutionellen Vereinbarung: Eine Untersuchung des Interorganverhältnisses der europäischen Verfassung, Springer, Heidelberg, 2006.

Alemann, Ulrich von \& Tönnesmann, Wolfgang: „Grundriß: Methoden in der Politikwissenschaft“, in: Ulrich von Alemann (Hrsg.), Politikwissenschaftliche Methoden: Grundriß für Studium und Forschung, VS Verlag für Sozialwissenschaften, Wiesbaden, 1995, S. 17-140.

Alen, André \& Muylle, Koen: Handboek van het Belgisch staatsrecht, Wolters Kluwer, Mechelen, 2011.

Alston, Philip \& Weiler, Joseph H. H.: „An ,Ever Closer Union“ in Need of a Human Rights Policy“, in: European Journal of International Law (1998), S. 658-723.

Ambos, Kai: „EuGH, Urteil v. 27. 5. 2019 - verb. Rs. C-508/18 und C-82/19 PPU, OG, PI“, in: Juristenzeitung 74 (2019), S. 728-735.

Andersen, Stine: The Enforcement of EU Law: The Role of the European Commission, Oxford University Press, Oxford, 2012.

Anonym: „Editorial Comments: The Rule of Law in the Union, the Rule of Union Law and the Rule of Law by the Union: Three interrelated problems", in: Common Market Law Review (2016), S. 597-606. 


\section{Literaturverzeichnis}

Antpöhler, Carlino: „Emergenz der europäischen Wirtschaftsregierung - Das Six Pack als Zeichen supranationaler Leistungsfähigkeit“, in: Zeitschrift für ausländisches öffentliches Recht und Völkerrecht 72 (2012), S. 353-394.

Arnauld, Andreas von: „Erster Beratungsgegenstand: Öffnung der öffentlich-rechtlichen Methode durch Internationalität und Interdisziplinarität: Erscheinungsformen, Chancen, Grenzen: 2. Referat", in: Volkmann, Uwe (Hrsg.): Veröffentlichungen der Vereinigung der Deutschen Staatsrechtslehrer, Bd. 74, De Gruyter, Berlin, 2015, S. 39-87.

Audretsch, Huub A. H.: Supervision in European Community Law: Observance by the Member States of their Treaty Obligations: A Treatise on International and Supranational Supervision, North Holland, Amsterdam, New York, Oxford, 1978 sowie 2. Aufl. 1986.

Augsberg, Steffen: „\$2 Akteure im Verfahren“, in: Stefan Leible \& Jörg-Philipp Terhechte (Hrsg.): Europäisches Rechtsschutz- und Verfahrensrecht, Band 3 der Enzyklopädie Europarecht, Nomos, Baden-Baden, 2014, S. 63-74.

Avbelj, Matej: „Failed Democracy: The Slovenian Patria Case - (Non)Law in Context", SSRN-Working Paper, 2014, abrufbar unter: https://papers.ssrn.com/sol3/ papers.cfm?abstract_id=2462613.

Avbelj Matej: „Will Slovenia join Hungary and Romania as examples of constitutional back-sliding?” Verfassungsblog vom 14.06.2014, abrufbar unter: https://ve rfassungsblog.de/slovenia-bound-jail-opposition-leader-electoral-period-2/.

Avbelj, Matej: „Crises and Perspectives in building a European Nation - The Case of Slovenia“, in: Jambrek, Peter (Hrsg.): Nation's Transitions - Social and Legal issues of Slovenia's Transitions 1945-2015, Tiskarna Januš/Graduate School of Government and European Studies, Brdo pri Kranju and European Faculty of Law, Kraj/Nova Gorica, 2015, S. 395-410.

Avbelj, Matej: „Pluralism and Defiance in the EU“, in: Kochenov, Dimitry \& Jakab, András (Hrsg.): The Enforcement of EU Law and Values: Ensuring Member States' Compliance, Oxford University Press, Oxford, 2017, S. 44-61.

Avbelj, Matej: „Constitutional and Administrative Pluralism in the EU System of Banking Supervision“, in: Goldmann, Matthias \& Steininger, Silvia (Hrsg.): Democracy and Financial Order: Legal Perspectives, Springer, Heidelberg, 2018, S. 77-94.

Avbelj, Matej; Letnar, Jernej \& Gorazd, Justinek: The Impact of European Institutions on the Rule of Law and Democracy: Slovenia and Beyond, Hart, Oxford, 2020.

Bachmann, Klaus: Der Bruch: Ursachen und Konsequenzen des Umsturzes der Verfassungsordnung Polens 2015-2016, Peter Lang, Frankfurt a.M., 2016.

Bader, Katarina \& Zapart, Tomasz: „Polarisiert, politisiert, vielfältig: Polens Medien 27 Jahre nach dem Systemwechsel“, in: Osteuropa 66 (2016), S. 131-148.

Bailleux, Juli: „The role of the legal service of the European executives in the invention of EC Law and the birth of the Common Market Law Review“, in: Common Market Law Review 50 (2013), S. 359-367. 
Baldus, Christian; Kern, Christoph; Raccah, Aurélien; Mantzouranis, Ioannis; Caponi, Remo; Gascón Inchausti, Fernando \& Dávid, Radovan: „Das ,EU Justice Scoreboard" der Europäischen Kommission“, in: Zeitschrift für das Privatrecht der Europäischen Union, Zeitschrift für das Gesamte Privatrecht (GPR) (2016), S. 108-115, jeweils als einzelne Kurzbeiträge.

Ballin, Ernst Hirsch: „Mutual Trust: The Virtue of Reciprocity - Strengthening the Acceptance of the Rule of Law through Peer Review“, in: Closa, Carlos \& Kochenov, Dimitry (Hrsg.): Reinforcing Rule of Law Oversight in the European Union, Cambridge University Press, Cambridge, 2016, S. 133-146.

Bandell, Dieter: Die Aufsicht der Europäischen Gemeinschaften über die Mitgliedstaaten, verglichen mit der Bundesaufsicht und unter Berücksichtigung der internationalen Kontrolle, Walter Kleikamp, Köln, 1965.

Bánkuti, Miklós; Halmai, Gábor \& Scheppele, Kim Lane: „Disabling the Constitution“, in: Journal of Democracy 23 (2012), S. 138-146.

Baraník, Kamil: „Symposium on ,The Slovak Constitutional Court Appointments Case -Perplexities of the Appointment Process Resolved by Means of ,Fire and Fury““, I.CONnect Blog vom 26.01.2018, abrufbar unter: http://www.iconnectbl og.com/2018/01/symposium-slovak-appointments-case-baranik/, o.S.

Baratta, Roberto: „Rule of Law „Dialogues“ Within the EU: A Legal Assessment“, in: Hague Journal on the Rule of Law 8 (2016), S. 357-372.

Bárd, Petra \& Śledzińska-Simon, Anna: „Rule of law infringement procedures: A proposal to extend the EU's rule of law toolbox“, CEPS Papers in Liberty and Security, 2019-09 vom Mai 2019, abrufbar unter: https://www.ceps.eu/wp-conte nt/uploads/2019/05/LSE-2019-09_ENGAGE-II-Rule-of-Law-infringement-proced ures.pdf.

Bárd, Pétra: „The von der Leyen Commission and the Future of the Rule of Law“, Verfassungsblog vom 11.11.2019, abrufbar unter: https://verfassungsblog.de/the -von-der-leyen-commission-and-the-future-of-the-rule-of-law/.

Bariatti, Stefania: Cases and Materials on EU Private International Law, Hart, Oxford \& Portland, 2011.

Bast, Jürgen: Grundbegriffe der Handlungsformen der EU: entwickelt am Beschluss als praxisgenerierter Handlungsform des Unions- und Gemeinschaftsrechts, Springer, Heidelberg, 2006.

Batory, Agnes: „Defying the Commission: Creative Compliance and Respect for the Rule of Law in the EU“, in: Public Administration 94 (2016), S. 685-699.

Baumann, Jessica: Das Piloturteilsverfahren als Reaktion auf massenhafte Parallelverfahren: eine Bestandsaufnahme der Rechtswirkungen der Urteile des Europäischen Gerichtshofs für Menschenrechte, Duncker \& Humblot, Berlin, 2016.

Beaud, Olivier : „La question de l'homogénéité dans une fédération“, in: Lignes 13 (2004), S. 110-128.

Behrendt, Christian \& Vrancken, Martin: Principes de droit constitutionnel belge, La Charte, Brüssel, 2019. 


\section{Literaturverzeichnis}

Belavusau, Uladzislau: „On age discrimination and beating dead dogs: Commission v. Hungary Case C-286/12, Commission v. Hungary, Judgment of the Court of Justice (First Chamber) of 6 November 2012, nyr.“, in: Common Market Law Review 50 (2013), S. 1145-1160.

Bell, Daniel A. \& Jayasuriya, Kanishka: „Understanding Illiberal Democracy: A Framework" in: Bell, Daniel A.; Brown, David; Jayasuriya, Kanishka \& Jones, David Martin (Hrsg.): Towards Illiberal Democracy in Pacific Asia, St. Martin's Press/Palgrave Macmillan, Houndmills/Basingstoke/London, 1995, S. 1-16.

Beltrán de Felipe, Miguel: Myths and Realities of Secessionisms: A Constitutional Approach to the Catalonian Crisis, Palgrave Macmillan/Springer Nature Switzerland, Cham, 2019.

Bermeo, Nancy: „On Democratic Backsliding“, in: Journal of Democracy 27 (2016), S. 5-19.

Bernstorff, Jochen von: „Kerngehaltsschutz durch den UN-Menschenrechtsausschuss und den EGMR: Vom Wert kategorialer Argumentationsformen“, in: Der Staat 50 (2011), S. 165-190.

Besselink, Leonard: „The Bite, the bark and the howl: Article 7 TEU and the Rule of Law Initiatives“, in: Jakab, András \& Kochenov, Dimitry (Hrsg.): The Enforcement of EU Law and Values: Ensuring Member States' Compliance, Oxford University Press, Oxford, 2017, S. 128-144.

Beyme, Klaus von \& Nohlen, Dieter: „Systemwechsel“, in: Nohlen, Dieter (Hrsg.): Wörterbuch Staat und Politik, Pieper, München, 3. Aufl. 1995, S. 765-776.

Beyme, Klaus von: Transition to Democracy in Eastern Europe, Macmillan, Basingstoke und London, 1996.

Bieber, Roland; Epiney, Astrid; Haag, Marcel \& Kotzur, Markus: Die Europäische Union, 13. Aufl., Nomos, Baden-Baden, 2019.

Bieber, Roland \& Maiani, Francesco: „Enhancing centralized enforcement of EU law: Pandora's toolbox?“, in: Common Market Law Review 51 (2014), S. 1058-1092.

Biel, Łucja: „Quality in institutional EU translation: Parameters, policies and practices“, in: Svoboda, Tomáš; Biel, Łucja; Łoboda, Krzysztof (Hrsg.): Quality aspects in institutional translation, Language Science Press, Berlin, 2017, S. 31-57.

Blanke, Hermann-Josef: „Erweiterung ohne Vertiefung? Zur „Verfassungskrise” der Europäischen Union“, in: Europarecht 41 (2005), S. 787-801.

Blanke, Hermann-Josef \& Mangiameli, Stelio (Hrsg.): The Treaty on European Union: A Commentary, Springer, Heidelberg, 2013, zit. nach Bearbeiter, Art., Rn.

Blauberger, Michael: „Europäischer Schutz gegen nationale Demokratiedefizite?“, in: Leviathan 44 (2016), S. 280-302.

Böttner, Robert: „Project Teams in the European Commission - A fair balance between efficiency and politics?“, in: Ege, Jörn; Bauer, Michael W. \& Becker, Stefan: The European Commission in Turbulent Times: Assessing Organizational Change and Policy Impact, Nomos, Baden-Baden, 2018, S. 113-132. 
Bogdandy, Armin von: „Die Europäische Union als supranationale Föderation“, in: Integration 22 (1999), S. 95-112.

Bogdandy, Armin von: Gubernative Rechtsetzung: eine Neubestimmung der Rechtsetzung und des Regierungssystems unter dem Grundgesetz in der Perspektive gemeineuropäischer Dogmatik, Mohr Siebeck, Tübingen, 2000.

Bogdandy, Armin von: „Grundprinzipien“, in: Bogdandy, Armin von \& Bast, Jürgen (Hrsg.): Europäisches Verfassungsrecht, Springer, Heidelberg, 2009, S. 13-71.

Bogdandy, Armin von: „Grundrechtsschutz durch die Europäische Grundrechteagentur“, in: Merten, Detlef \& Papier, Hans-Jürgen (Hrsg.): Handbuch der Grundrechte in Deutschland und Europa: Band VI/: Europäische Grundrechte I, C. F. Müller, Heidelberg, 2010, S. 1241-1266.

Bogdandy, Armin von: „Die Informationsbeziehungen im europäischen Verwaltungsverbund“, in: Hoffmann-Riem, Wolfgang; Schmidt-Aßmann, Eberhard \& Voßkuhle, Andreas (Hrsg.): Grundlagen des Verwaltungsrechts, Bd. 2., C.H. Beck, München, 2. Aufl., 2012, S. 365-434.

Bogdandy, Armin von: „Principles and Challenges of a European Doctrine of Systemic Deficiencies“, MPIL Research Paper Series, No. 2019-14, Heidelberg, 2019.

Bogdandy, Armin von: „Tyrannei der Werte? Herausforderungen und Grundlagen einer europäischen Dogmatik systemischer Defizite“, in: Zeitschrift für ausländisches öffentliches Recht und Völkerrecht 79 (2019), S. 503-551.

Bogdandy, Armin von; Antpöhler, Carlino \& Ioannidis, Michael: „Protecting EU values: Reverse Solange and the Rule of Law Framework“, in: Jakab, András \& Kochenov, Dimitry (Hrsg.): The Enforcement of EU Law and Values, Oxford University Press, Oxford, 2017, S. 218-233.

Bogdandy, Armin von; Bast, Jürgen \& Arndt, Felix: „Handlungsformen im Unionsrecht: Empirische Analysen und dogmatische Strukturen in einem vermeintlichen Dschungel“, in: Zeitschrift für ausländisches öffentliches Recht und Völkerrecht 62 (2002), S. 77-161.

Bogdandy, Armin von \& Hinghofer-Szalkay, Stephan: „Das etwas unheimliche Ius Publicum Europaeum: Begriffsgeschichtliche Analysen im Spannungsfeld von europäischem Rechtsraum, droit public de l'Europe und Carl Schmitt“, in: Zeitschrift für ausländisches öffentliches Recht und Völkerrecht 73 (2013), S. 209-248.

Bogdandy, Armin von \& Bast, Jürgen: „Der verfassungsrechtliche Ansatz und das Unionsrecht: Von einem Konstitutionalismus der Verrechtlichung zwischenstaatlicher Beziehungen zu einer liberaldemokratischen Politisierung der EU“, in: Bogdandy, Armin von \& Bast, Jürgen (Hrsg.): Europäisches Verfassungsrecht: Theoretische und dogmatische Grundzüge, Springer, Heidelberg, 2. Aufl., 2009.

Bogdandy, Armin von \& Bernstorff, Jochen von: „Die Europäische Agentur für Grundrechte in der europäischen Menschenrechtsarchitektur und ihre Fortentwicklung durch den Vertrag von Lissabon“, in: Europarecht 46 (2010), S. 141-165. 


\section{Literaturverzeichnis}

Bogdandy, Armin von; Kottmann, Matthias; Antpöhler, Carlino; Dickschen, Johanna; Hentrei, Simon \& Smrkolj, Maja: „Ein Rettungsschirm für europäische Grundrechte - Grundlagen einer unionsrechtlichen Solange-Doktrin gegenüber Mitgliedstaaten“, in: Zeitschrift für ausländisches öffentliches Recht und Völkerrecht 72 (2012), S. 45-78.

Bogdandy, Armin von; Bogdanowicz, Piotr; Canor, Iris; Schmidt, Matthias; Taborowski, Maciej: „Drawing Red Lines and Giving (Some) Bite - the CJEU's Deficiencies Judgment on the European Rule of Law“, Verfassungsblog vom 03.08.2018, abrufbar unter: https://verfassungsblog.de/drawing-red-lines-and-givi ng-some-bite-the-cjeus-deficiencies-judgment-on-the-european-rule-of-law/.

Bogdandy, Armin von; Bogdanowicz, Piotr; Canor, Iris; Taborowski, Maciej \& Schmidt, Matthias: „Guest Editorial: A potential constitutional moment for the European rule of law - The importance of red lines“, in: Common Market Law Review 55 (2018), S. 983-996.

Bogdandy, Armin von \& Ioannidis, Michael: „Das systemische Defizit: Merkmale, Instrumente und Probleme am Beispiel der Rechtsstaatlichkeit und des neuen Rechtsstaatlichkeitsaufsichtsverfahrens“, in: Zeitschrift für ausländisches öffentliches Recht und Völkerrecht 74 (2014), S. 283-328.

Bogdandy, Armin von; Ioannidis, Michael \& Antpöhler, Carlino: „Enforcing EU Values - Reverse Solange and a Systemic Deficiency Committee“, MPIL Research Paper Series, No. 2016-04, Heidelberg, 2016.

Bogdandy, Armin von \& Nettesheim, Martin: „Die Verschmelzung der Europäischen Gemeinschaften in der Europäischen Union“, in: Neue Juristische Wochenschrift (1995), S. 2324-2328.

Bogdandy, Armin von \& Schill, Stephan: „Die Achtung der nationalen Identität unter dem reformierten Unionsvertrag: Zur unionsrechtlichen Rolle nationalen Verfassungsrechts und zur Überwindung des absoluten Vorrangs“, in: Zeitschrift für ausländisches öffentliches Recht und Völkerrecht 70 (2010), S. 701-734.

Bogdandy, Armin von \& Schill, Stephan: „Overcoming absolute primacy: Respect for national identity under the Lisbon Treaty“, in: Common Market Law Review 48 (2011), S. 1417-1454.

Bollen, Kenneth A.: „Issues in the Comparative Measurement of Political Democracy“, in: American Sociological Review 45 (1980), S. 370-390.

Borzsák, Levente: The Impact of Environmental Concerns on the Public Enforcement Mechanism under EU Law: Environmental Protection in the 25th Hour, Kluwer, Alphen aan den Rijn, 2011.

Brohm, Markus U.: Die „Mitteilungen“ der Kommission im Europäischen Verwaltungs- und Wirtschaftsraum: Typologie, Rechtsnatur und Bindungswirkung für die Behörden der Mitgliedstaaten, 1 Aufl., Bd. 1, Nomos, Baden-Baden, 2012.

Bühlmann, Marc; Merkel, Wolfgang; Müller, Lisa; Giebler, Heiko \& Weßels, Bernhard: „Demokratiebarometer: ein neues Instrument zur Messung von Demokratiequalität“, in: Zeitschrift für Vergleichende Politikwissenschaft 6 (2012), S. 115-159. 
Bugarič, Bojan: „A crisis of constitutional democracy in post-Communist Europe: ,Lands in-between ' democracy and authoritarianism", in: International Journal of Constitutional Law 13 (2015), S. 219-245.

Bugarič, Bojan \& Ginsburg, Tom: „The Assault on Postcommunist Courts“, in: Journal of Democracy 27 (2016), S. 69-82.

Bugarič, Bojan \& Kuhelj, Alenka: „Slovenia in crisis: A tale of unfinished democratization in East-Central Europe", in: Communist and Post-Communist Studies 48 (2015), S. 273-279.

Bullinger, Martin: „Der Anwendungsbereich der Bundesaufsicht“, in: Archiv des öffentlichen Rechts N.F. 44 (1958), S. 279-308.

Buquicchio, Gianni \& Granata-Menghini, Simona: „The Venice Commission Twenty Years on“, in: van Roosmalen, Marjolein; Vermeulen, Ben; van Hoof, Fried; Oosting, Marten (Hrsg.): Fundamental Rights and Principles: Liber Amicorum Pieter van Dijk, Intersentia, Cambridge u.a., 2013, S. 241-254.

Burchhardt, Dana: „Die Ausübung der Identitätskontrolle durch das Bundesverfassungsgericht - Zugleich Besprechung des Beschlusses 2 BvR 2735/14 des BVerfG vom 15.12.2015 ("Solange III"/“Europäischer Haftbefehl II”)“, in: Zeitschrift für ausländisches öffentliches Recht und Völkerrecht 76 (2016), S. 527-551.

Calliess, Christian: „Bausteine einer erneuerten Europäischen Union: Auf der Suche nach dem europäischen Weg: Überlegungen im Lichte des Weißbuchs der Europäischen Kommission zur Zukunft Europas“, in: Neue Zeitschrift für Verwaltungsrecht 37 (2018), S. 1-9.

Calliess, Christian; Ruffert, Matthias (Hrsg.): EUV/AEUV: Das Verfassungsrecht der Europäischen Union mit Europäischer Grundrechtecharta, 5. Aufl. C.H. Beck, München, 2016, zit. nach Bearbeiter, Art. Rn.

Carrera Núñez, Sergio: „How much does EU citizenship cost? The Maltese citizenship-for-sale affair: A breakthrough for sincere cooperation in citizenship of the union?“،, in: Carrera Núñez, Sergio \& de Groot, Gerard-René (Hrsg.): European Citizenship at the Crossroads: The Role of the European Union on Loss and Acquisition of Nationality, Oisterwijk, WLP, 2014, S. 293-326.

Carsten, Ernst S. \& Rautenberg, Erardo C.: Die Geschichte der Staatsanwaltschaft in Deutschland bis zur Gegenwart: Ein Beitrag zur Beseitigung ihrer Weisungsabhängigkeit von der Regierung im Strafverfahren, Nomos, Baden-Baden, 2015.

Cartou, Louis: Europäische Organisationen, Eurobuch-Verlag Lutzeyer, Freudenstadt, 1967.

Castle, Matthew \& Pelc, Krzysztof J.: „The Causes and Effects of Leaks in International Negotiations“, in: International Studies Quarterly 63 (2019), S. 1147-1162.

Chalmers, Damian; Davies, Gareth \& Monti, Giorgio: European Union Law, Cambridge University Press, Cambridge, 2010.

Claes, Monica \& Bonelli, Matteo: „The Rule of Law and the Constitutionalisation of the European Union“, in: Schroeder, Werner (Hrsg.): Strengthening the Rule of Law in Europe, Hart, Oxford, 2016, S. 265-289. 


\section{Literaturverzeichnis}

Closa, Carlos; Kochenov, Dimitry \& Weiler, Joseph H. H.: „Reinforcing Rule of Law Oversight in the European Union“, RSCAS 2014/25, EUI Working Papers, San Domenico di Fiesole, 2014.

Closa, Carlos: „Reinforcing EU Monitoring of the Rule of Law: Normative Arguments, Institutional Proposals and the Procedural Limitations“, in: Closa, Carlos \& Kochenov, Dimitry (Hrsg.): Reinforcing Rule of Law Oversight in the European Union, 2016, S. 15-35.

Crabit, Emmanuel \& Bel, Nicolaas: „The EU Rule of Law Framework“, in: Werner Schroeder (Hrsg.): Strengthening the Rule of Law in Europe: From a Common Concept to Mechanisms of Implementation, Hart, Oxford/Portland, 2016, S. 197-206.

Crabit, Emmanuel \& Perego, Anna: „L'État de droit: une politique de l'Union européenne“, in: Revue du Droit de l'Union européenne 20 (2019), S. 7-14.

Craig, Paul: „Transnational Constitution-Making: The Contribution of the Venice Commission on Law and Democracy“, in: UC Irvine Journal of International, Transnational, and Comparative Law 2 (2017), S. 57-86.

Craig, Paul \& de Búrca, Gráinne: EU Law: Text, Cases and Materials, 6. Aufl., Oxford University Press, Oxford, 2015.

Creutzfeld, Naomi: Ombudsmen and ADR: A Comparative Study of Informal Justice in Europe, Palgrave Macmillan/Springer International Publishing, Cham, 2018.

Curtin, Deirdre: Executive Power of the European Union: Law, Practices, and the Living Constitution, Oxford University Press, Oxford, 2009.

Dahl, Robert Alan: Polyarchy: Participation and Opposition, Yale University Press, New Haven u.a., 1971.

D’Alfonso Masarié, Edoardo: „Parlamentarische Budgetsouveränität auf der Probe der europäischen Haushaltsdisziplin: Der Streit um den italienischen Staatshaushalt 2019 und die Entscheidung der Corte Costituzionale“, in: Zeitschrift für ausländisches öffentliches Recht und Völkerrecht 79 (2019), S. 995-1026.

Dann, Philipp: Parlamente im Exekutivföderalismus: Eine Studie zum Verhältnis von föderaler Ordnung und parlamentarischer Demokratie in der Europäischen Union, Springer, Heidelberg, 2004.

Danwitz, Thomas von: Verwaltungsrechtliches System und europäische Integration, Mohr Siebeck, Tübingen, 1996.

Danwitz, Thomas von: „The Rule of Law in the Recent Jurisprudence of the ECJ“, in: Fordham International Law Journal 37 (2014), S. 1311-1348.

Dawson, Mark: The Governance of EU Fundamental Rights, Cambridge University Press, Cambridge, 2017.

Dawson, Mark \& Muir, Elise: „Hungary and the Indirect Protection of EU Fundamental Rights and the Rule of Law“, in: German Law Journal 14 (2013), S. 1959-1979.

De Bellescize, Diane: „L'article 169 du Traité de Rome, et l'efficacité du contrôle communautaire sur les manquements des états membres“, in: Revue trimestrielle de droit européen 13 (1977), S. 173-213. 
de Búrca, Gráinne: „Beyond the Charter: How Enlargement Has Enlarged the Human Rights Policy of the European Union“, in: Fordham International Law Journal 27 (2003), S. 679-714.

de Visser, Maartje: „A Critical Assessment of the Role of the Venice Commission in Processes of Domestic Constitutional Reform“, in: American Journal of Comparative Law 63 (2015), S. 963-1008.

Di Fabio, Udo: „Bewahrung und Veränderung demokratischer und rechtsstaatlicher Verfassungsstruktur in den internationalen Gemeinschaften“, in: Archiv des öffentlichen Rechts 141 (2018), S. 106-116.

Dickschen, Johanna Elisabeth: Empfehlungen und Leitlinien als Handlungsform der Europäischen Finanzaufsichtsbehörden: eine dogmatische Vermessung, Springer, Heidelberg/Berlin, 2017.

Dori, Adriani: „The EU Justice Scoreboard - Judicial Evaluation as a New Governance Tool“, MPILux Working Paper Series, No. 2/2015, Max Planck Institute Luxembourg for International, European and Regulatory Procedural Law, 2015.

Drugda, Simon: „Symposium on "The Slovak Constitutional Court Appointments Case"-Intermezzo to the Constitutional Conflict in Slovakia: A Case Critique",I.CONnect Blog vom 24.012018.

Dux, Günter: Bundesrat und Bundesaufsicht, Duncker \& Humblot, Berlin, 1963.

Dzankic, Jelena: „The Pros And Cons Of Ius Pecuniae: Investor Citizenship In Comparative Perspective“, in: EUI Working Papers RSCAS 2012/14, European University Institute, Florenz, 2012.

Eekhoff, Meike: Die Verbundaufsicht: Gemeinschaftsrechtliche Aufsichtsverfahren und -mechanismen außerhalb des Vertragsverletzungsverfahrens, Mohr Siebeck, Tübingen, 2006.

Ehrenzeller, Bernhard; Schindler, Benjamin; Schweizer, Rainer J.;Vallender, Klaus A. (Hrsg.): St. Galler Kommentar, Dike, Zürich, 3. Aufl. 2014, zit. nach: Bearbeiter, Art., Rn.

Eisele, Jörg \& Trentmann, Christian: „Die Staatsanwaltschaft - „objektivste Behörde der Welt"“?, in: Neue Juristische Wochenschrift 72 (2019), S. 2365-2368.

Emling, Gisela: Johannes Heckel: Leben und Wirken (1889 - 1963), Peter Lang, Frankfurt a.M. u.a., 2011.

Estella, Antonio: Legal Foundations of EU Economic Governance, Cambridge University Press, Cambridge, 2018.

Fabri, Marco: „Pitfalls in data gathering to assess judiciaries“, in: International Journal for Court Administration 9 (2018), S. 67-75.

Fenno, Jr., Richard F.: „Observation, Context, and Sequence in the Study of Politics“, in: American Political Science Review 80 (1986), S. 3-15.

Fernandez Esteban, Maria Luisa: The Rule of Law in the European Constitution, Kluwer, Den Haag u.a., 1999.

Flanagan, Finola: „The Venice Commission and the Protection of Human Rights“, in: van Roosmalen, Marjolein; Vermeulen, Ben; van Hoof, Fried \& Oosting, Marten (Hrsg.): Fundamental Rights and Principles: Liber Amicorum Pieter van Dijk, Intersentia, Cambridge u.a., 2013, S. 255-265. 


\section{Literaturverzeichnis}

Fomina, Joanna \& Kucharczyk, Jacek: „Populism and Protest in Poland“, in: Journal of Democracy 27 (2016), S. 58-68.

Forsthoff, Ernst: „Die unmittelbare Reichsaufsicht“, in: Archiv des öffentlichen Rechts 58 (N.F. 19) (1930), S. 61-82.

Frank, Alexander: Die Rechtswirkungen der Leitlinien und Empfehlungen der Europäischen Wertpapier- und Marktaufsichtsbehörde, Nomos, Baden-Baden, 2012.

Frowein, Jochen: Die selbständige Bundesaufsicht nach dem Grundgesetz, Röhrscheid, Bonn, 1961.

Frowein, Jochen Abr.: „Die rechtliche Bedeutung des Verfassungsprinzips der parlamentarischen Demokratie für den europäischen Integrationsprozeß“, in: Europarecht 18 (1983), S. 301-317.

Funk, Bernd-Christian: „Die Bedeutung gliedstaatlichen Verfassungsrechts für die Gegenwart", in: Martin Kriele (Hrsg.): Veröffentlichungen der Vereinigung der Deutschen Staatsrechtslehrer, Band 46, De Gruyter, Berlin \& New York, 1988, S. 57-91.

Fyrnys, Markus: „Expanding Competences by Judicial Lawmaking: The Pilot Judgment Procedure of the European Court of Human Rights“, in: German Law Journal 12 (2011), S. 1231-1260.

Gallie, Walter Bryce: „Essentially Contested Concepts“, in: Proceedings of the Aristotelian Society 56 (1956), S. 167-198.

Georgakakis, Didier \& de Lassalle, Marine: „Where Have all the Lawyers Gone? Structure and Transformations of Top European Officials' Legal Training “, in: Vauchez/de Witte (Hrsg.), Lawyering Europe: European Law as a Transnational Social Field, Hart, Oxford \& Portland, 2013, S. 137-151.

Gerhardt, Michael J.: „Why Gridlock Matters“, in: Notre Dame Law Review 88 (2013), S. 2107-2120.

Gherghina, Sergiu \& Hein, Michael: „Romania“, in: Fruhstorfer, Anna \& Hein, Michael (Hrsg.): Constitutional Politics in Central and Eastern Europe: From Post-Socialist Transition to the Reform of Political Systems, Springer VS, Wiesbaden, 2016, S. 173-198.

Giegerich, Thomas: „Verfassungshomogenität, Verfassungsautonomie und Verfassungsaufsicht in der EU: Zum „neuen Rechtsstaatsmechanismus" der Europäischen Kommission“, in: Christian Calliess (Hrsg.): Herausforderungen an Staat und Verfassung: Völkerrecht - Europarecht - Menschenrechte: Liber Amicorum für Torsten Stein zum 70. Geburtstag, Nomos, Baden-Baden, 2015, S. 499-542.

Gil Ibáñez, Alberto J.: The Administrative Supervision and Enforcement of EC Law: Powers, Procedures and Limits, Hart, Oxford/Portland, Oregon, 1999.

Göttlinger, Elisabeth: Auskunftsrechte der Kommission im Recht der Europäischen Union, Nomos, Baden-Baden, 2013.

Goldmann, Matthias: Internationale öffentliche Gewalt: Handlungsformen internationaler Institutionen im Zeitalter der Globalisierung, Springer, Heidelberg, 2015. 
Goldner Lang, Iris: „The Rule of Law, the Force of Law and the Power of Money in the EU“, in: Croatian Yearbook of European Law and Policy 15 (2019), S. 1-26.

Gonzalez, Carmen: „The Catalan National Identity and Catalonia's Bid for Independence“, in: Connecticut Journal of International Law 32 (2016), S. 115-145.

Gould, Robert: „Roma rights and Roma expulsions in France: Official discourse and EU responses“, in: Critical Social Policy 35 (2014), S. 24-44.

Grabitz, Eberhard; Hilf, Meinhard \& Nettesheim, Martin (Begr./Hrsg.): Das Recht der Europäischen Union, C.H. Beck, München, Loseblatt; zit. nach Bearbeiter, Art., Rn., Ergänzungslieferung (EL).

Graf von Luckner, Johannes: „German Prosecutors are insufficiently independent to issue European Arrest Warrants“, in European Law Blog vom 11.06.2019, abrufbar unter: https://europeanlawblog.eu/2019/06/11/german-prosecutors-are-i nsufficiently-independent-to-issue-european-arrest-warrants/.

Grimm, Dieter: „Verfassungserfüllung - Verfassungsbewahrung - Verfassungsauflösung: Positionen der Staatsrechtslehre in der Staatskrise der Weimarer Republik", in: Winkler, Heinrich August (Hrsg.): Die deutsche Staatskrise 1930-1933: Handlungsspielräume und Alternativen, Oldenbourg, München, 1992, S. 183-199.

Gröpl, Christoph: „Schritte zur Europäisierung des Haushaltsrechts“, in: Der Staat 52 (2013), S. 1-25.

Gundel, Jörg: „Der Schutz der unternehmerischen Freiheit durch die EU Grundrechtecharta", in: Zeitschrift für das gesamte Handels- und Wirtschaftsrecht 180 (2016), S. 323-357.

Gundel, Jörg: „Rechtsschutz gegen Empfehlungen der EU-Kommission? - Anmerkung zum Urteil des EuGH (GK) v. 20.2.2018, Rs. C-16/16 P (Belgien/Kommission)“, in: Europarecht 53 (2018), S. 593-605.

Haider, Dominik: The Pilot-Judgment Procedure of the European Court of Human Rights, Brill u. Martinus Nijhoff, Leiden/Boston, 2013.

Halmai, Gábor: „The Application of European Constitutional Values in EU Member States“, in: European Journal of Law Reform 20 (2018), S. 10-34.

Halmai, Gábor: „The Rise and Fall of Constitutionalism in Hungary“, in: Blokker, Paul (Hrsg.): Constitutional Acceleration within the European Union and Beyond, Routledge, London/New York, 2018, S. 217-233.

Halmai, Gábor: „The possibility and desirability of economic sanction: Rule of law conditionality requirements against illiberal EU Member States“, EUI Working Paper LAW 2018/06, abrufbar unter: https://cadmus.eui.eu/bitstream/handle/18 14/51644/LAW_2018_06.pdf?sequence=1\&isAllowed=y.

Hanschel, Dirk: Konfliktlösung im Bundesstaat: Die Lösung föderaler Kompetenz-, Finanz und Territorialkonflikte in Deutschland, den USA und der Schweiz, Mohr Siebeck, Tübingen, 2012. 


\section{Literaturverzeichnis}

Hatje, Armin: „Informationsaustausch und Datenschutz in der Europäischen Union - primärrechtliche Grundlagen, Grundzüge und Probleme des aktuellen Sekundärrechts“, in: Siegfried Magiera \& Sommermann (Hrsg.), Karl-Peter: Verwaltung in der Europäischen Union: Vorträge und Diskussionsbeiträge auf dem 1. Speyerer Europa-Forum vom 10. bis 12. April 2000 an der Deutschen Hochschule für Verwaltungswissenschaften Speyer, Duncker \& Humblot, Berlin, 2001, S. 193-217.

Hatje, Armin \& Förster, Stine von: „\$10 Organordnung der Europäischen Union“, in: Müller-Graff, Peter-Christian \& Hatje, Armin (Hrsg.): Enzyklopädie Europarecht, Band 1: Europäisches Organisations- und Verfassungsrecht, Nomos, Baden-Baden, 2014, S. 543-621.

Hau, André: Sanktionen und Vorfeldmaßnahmen zur Absicherung der europäischen Grundwerte: Rechtsfragen zu Art. 7 EU, Nomos, Baden-Baden, 2002.

Heckel, Johannes: „Das Urteil des Staatsgerichtshofs vom 25.10.1932 in dem Verfassungsstreit Reich-Preußen“, in: Archiv des öffentlichen Rechts 62, N.F. 23 (1933), S. 183-246.

Hegedüs, Daniel: „Fighting Fire with Fire: Věra Jourova might be the EU's next rule of law Commissioner", in Verfassungsblog vom 06.09.2019, abrufbar unter: https://verfassungsblog.de/fighting-fire-with-fire/.

Hein, Michael: „Bulgaria“, in: Fruhstorfer, Anna \& Hein, Michael (Hrsg.): Constitutional Politics in Central and Eastern Europe: From Post-Socialist Transitions to the Reform of Political Systems, Springer Fachmedien, Wiesbaden, 2016, S. 145-171.

Hellwig, Fritz: „Die supranationalen Vollmachten der Hohen Behörde, dargestellt an ihrer Willensbildung in Krisensituationen", in: Zellentin (Hrsg.), Formen der Willensbildung in den Europäischen Organisationen, Athenäum, Frankfurt a.M./Bonn, 1965, S. 31-48.

Hennis, Wilhelm: „Aufgaben einer modernen Regierungslehre“, in: Politische Vierteljahresschrift 6 (1965), S. 422-441.

Hering, Laura: „Das Vertragsverletzungsverfahren als Instrument zum Schutz der Unionswerte - Zugleich Bemerkungen zu EuGH, Urt. v. 24.6.2019, C-619/18, Kommission/Polen“, in: Die öffentliche Verwaltung 73 (2020), S. 293-302.

Heuschling, Luc: État de droit, Rechtsstaat, rule of law, Dalloz, Paris, 2002.

Heußner, Kristina: Informationssysteme im Europäischen Verwaltungsverbund, Mohr Siebeck, Tübingen, 2007.

Hillion, Christophe: „Overseeing the Rule of Law in the EU: Legal Mandate and Means“, in: Closa, Carlos \& Kochenov, Dimitry (Hrsg.): Reinforcing Rule of Law Oversight in the European Union, Cambridge University Press, Cambridge, 2016, S. 59-81.

Hinarejos, Alica: „Fiscal Federalism in the European Union: Evolution and Future Choices for EMU“, in: Common Market Law Review 50 (2013), S. 1621-1642.

Hoffmann-Riem, Wolfgang: „The Venice Commission of the Council of Europe - Standards and Impact“, in: European Journal of International Law 25 (2014), S. 579-597. 
Hoffmeister, Frank: „Enforcing the EU Charter of Fundamental Rights in Member States: How Far are Rome, Budapest and Bucharest from Brussels?" in: Bogdandy, Armin von \& Sonnevend, Pál (Hrsg.): Constitutional Crisis in the European Constitutional Area, C.H.Beck/Hart/Nomos, München/Oxford/ Baden-Baden, 2015, S. 195-233.

Hofmann, Tobias: „How long to compliance? Escalating infringement proceedings and the diminishing power of special interests“, in: Journal of European Integration 40 (2018), S. 785-801.

Hofmeister, Hannes: „Polen als erster Anwendungsfall des neuen ,EU Rahmens zur Stärkung des Rechtsstaatsprinzips““, in: Deutsches Verwaltungsblatt (2016), S. 869-875.

Hohnerlein, Jakob: „Rechtliche Pfadabhängigkeiten als Legitimations- und Verfassungsproblem“, in: Wagner, Eva Ellen, u.a. (Hrsg.): Pfadabhängigkeit hoheitlicher Ordnungsmodelle: 56. Assistententagung Öffentliches Recht, Nomos/Helbing-Lichtenhahn, Baden-Baden/Basel, 2016, S. 133-154.

Hoxhaj, Andi: The EU Anti-Corruption Report: A Reflexive Governance Approach, Routledge, London, 2019.

Hufeld, Ulrich: „\$22 Das Recht der Europäischen Wirtschaftsunion“, in: MüllerGraff, Peter Christian (Hrsg.): Enzyklopädie Europarecht, Band 4: Europäisches Wirtschaftsordnungsrecht, Nomos, Baden-Baden, 2014, S. 1299-1386.

Iancu, Bogdan: „Separation of Powers and the Rule of Law in Romania: The Crisis in Concepts and Contexts“, in: Bogdandy, Armin von \& Sonnevend, Pál (Hrsg.): Constitutional Crisis in the European Constitutional Area, C.H. Beck/ Hart/Nomos, München/Oxford/Baden-Baden, 2015, S. 153-169.

Imbert, Pierre-Henri: „Follow-up to the Committee of Ministers' Recommendations on the implementation of the Convention at the domestic level and the Declaration on ,Ensuring the effectiveness of the implementation of the European Convention on Human Rights at national and European levels"“, in: Directorate General of Human Rights of the Council of Europe (Hrsg.): Reform of the European Human Rights System: Proceedings of the high-level seminar, Oslo, 18 October 2004“, Straßburg, 2004, S. 33-43.

Ioannidis, Michael: „EU Financial Assistance Conditionality after ,Two Pack““, in: Zeitschrift für ausländisches öffentliches Recht und Völkerrecht 74 (2014), S. 61-104.

Ioannidis, Michael: „Europe's New Transformations: How the EU Economic Constitution changed during the Eurozone Crisis“, in: Common Market Law Review 53 (2016), S. 1237-1282.

Ioannidis, Michael: „Weak Members and the Enforcement of EU Law“, in: András Jakab \& Dimitry Kochenov (Hrsg.), The Enforcement of EU Law and Values: Ensuring Member States' Compliance, Oxford University Press, Oxford, 2017, S. 476-492.

Ionescu, Emanuel C.: Innerstaatliche Wirkungen des Vertragsverletzungsverfahrens: Die Aufsichtsklage im föderalen Gefüge der Europäischen Union, Mohr Siebeck, Tübingen, 2016.

Ipsen, Hans Peter: Europäisches Gemeinschaftsrecht, Mohr, Tübingen, 1972. 


\section{Literaturverzeichnis}

Ipsen, Hans Peter: „Über Verfassungs-Homogenität in der Europäischen Gemeinschaft“, in: Maurer, Hartmut (Hrsg.), Das akzeptierte Grundgesetz: Festschrift für Günter Dürig zum 70. Geburtstag, C.H. Beck, München, 1990, S. 159-182.

Jäckle, Sebastian; Wagschal, Uwe \& Bauschke, Rafael: „Das Demokratiebarometer: „basically theory driven“?", in: Zeitschrift für Vergleichende Politikwissenschaft 6 (2012), S. 99-125.

Jäckle, Sebastian; Wagschal, Uwe \& Bauschke, Rafael: „Allein die Masse macht's nicht - Antwort auf die Replik von Merkel et al. zu unserer Kritik am Demokratiebarometer“, in: Zeitschrift für Vergleichende Politikwissenschaft 7 (2013), S. 143-153.

Jakab, András: „Das Grunddilemma und die Natur des Staatsnotstandes - Eine deutsche Problematik mit ausländischen Augen“, in: Kritische Justiz 38 (2005), S. 323-336.

Jakab, András \& Lőrincz, Viktor: „International Indices as Models for the Rule of Law Scoreboard of the European Union: Methodological Issues“, in: MPIL Research Paper Series No. 2017/21, Heidelberg, 2017.

Jakab, András \& Sonnevend, Pál: „Kontinuität mit Mängeln: Das neue ungarische Grundgesetz", in: Zeitschrift für ausländisches öffentliches Recht und Völkerrecht 72 (2012), S. 79-102.

Jakab, András Jakab \& Kochenov, Dimitry: „Introductory Remarks“, in: Jakab, András \& Kochenov, Dimitry (Hrsg.): The Enforcement of EU Law and Values: Ensuring Member States' Compliance, Oxford University Press, Oxford, 2017, S. 1-5.

Jeschke, Mareike: „Justizielle Autonomie in Europa“, in: Albrecht, Peter-Alexis (Hrsg.), Autonomie für eine Dritte Gewalt in Europa: Transferaufgabe für aufgeklärte Gesellschaften der Vernunft, Berliner Wissenschaftsverlag, Berlin, 2016, S. 495-818.

Kadelbach, Stefan: „Krise, Umbruch und neue Ordnung“, in: ders./Günther, Klaus (Hrsg.), Europa: Krise, Umbruch und neue Ordnung, Nomos, Baden-Baden, 2014, S. 9-16.

Kadelbach, Stefan: „Verfassungskrisen“, in: ders. (Hrsg.), Verfassungskrisen in der Europäischen Union, Nomos, Baden-Baden, 2018, S. 9-22.

Kahl, Wolfgang: Die Staatsaufsicht: Entstehung, Wandel und Neubestimmung unter besonderer Berücksichtigung der Aufsicht über die Gemeinden, Mohr Siebeck, Tübingen, 2000.

Kahl, Wolfgang: „Dogmatik im EU-Recht“, in: Archiv des öffentlichen Rechts 144 (2019), S. 159-201.

Kassim, Hussein; Peterson, John; Bauer, Michael W.; Connolly, Sara; Dehousse, Renaud; Hooghe, Liesbet; Thompson, Andrew (Hrsg.): The European Commission of the Twenty-First Century, Oxford University Press, Oxford, 2013.

Kassner, Ulrike: Die Unionsaufsicht: Ausmaß und Bedeutung des Überwachungsmechanismus nach Artikel 7 des Vertrags über die Europäische Union, Peter Lang, Frankfurt a. M. u. a., 2003. 
Kaufhold, Ann-Katrin: „Systemaufsicht: Der Europäische Ausschuss für Systemrisiken im Finanzsystem als Ausprägung einer neuen Aufsichtsform“, in: Die Verwaltung 46 (2013), S. 21-57.

Kaufhold, Ann-Katrin: Systemaufsicht: Anforderungen an die Ausgestaltung einer Aufsicht zur Abwehr systemischer Risiken entwickelt am Beispiel der Finanzaufsicht, Mohr Siebeck, Tübingen, 2014.

Kelemen, Katalin: „The New Hungarian Constitution: Legal Critiques from Europe“, in: Review of Central and East European Law 42 (2017), S. 1-49.

Kern, Christoph: Justice Between Simplification and Formalism: A Discussion and Critique of the World Bank Sponsored Lex Mundi Project on Efficiency of Civil Procedure, Mohr Siebeck, Tübingen, 2007.

Klamert, Marcus: „Die Durchsetzung finanzieller Sanktionen gegenüber den Mitgliedstaaten“, in: Europarecht (2018), S. 159-174.

Klamt, Martin: Die Europäische Union als streitbare Demokratie: rechtsvergleichende und europarechtliche Dimensionen einer Idee, Utz, München, 2012.

Kochenov, Dimitry: EU Enlargement and the Failure of Conditionality: Pre-accession Conditionality in the Fields of Democracy and the Rule of Law, Wolters Kluwer, Alphen aan den Rijn, 2008.

Kochenov, Dimitry: „Case C-135/08, Janko Rottmann v. Freistaat Bayern, Judgment of the Court (Grand Chamber) of 2 March 2010“, in: Common Market Law Review 47 (2010), S. 1831-1846.

Kochenov, Dimitry: „Europe's Crisis of Values“, in: Revista catalana del dregt public (2014), S. 106-118.

Kochenov, Dimitry: „Biting Intergovernmentalism: The Case for the Reinvention of Article 259 TFEU to Make It a Viable Rule of Law Enforcement Tool“, in: Hague Journal on the Rule of Law 7 (2015), S. 153-174.

Kochenov, Dimitry: „The EU and the Rule of Law - Naïveté or a Grand Design?“, in: Adams, Maurice; Meuwese, Anne \& Hirsch Ballin, Ernst: Constitutionalism and the Rule of Law, 2017, S. 419-445.

Kochenov, Dimitry \& Pech, Laurent: „Monitoring and Enforcement of the Rule of Law in the EU: Rhetoric and Reality“, in: European Constitutional Law Review 11 (2015), S. 512-540.

Kochenov, Dimitry \& Pech, Laurent: „Better Late than Never? On the European Commission's Rule of Law Framework and its First Activation“, in: Journal of Common Market Studies 54 (2016), S. 1062-1074.

Kochenov, Dimitry; Pech, Laurent \& Platon, Sébastien: „Ni panacée, ni gadget : le ,nouveau cadre de l'Union européenne pour renforcer l'État de droit““, in: Revue Trimestrielle de Droit Européen (2014), S. 689-714.

Kohler-Koch, Beate: „Zur Empirie und Theorie internationaler Regime“, in: dies. (Hrsg.), Regime in den internationalen Beziehungen, Nomos, Baden-Baden, 1989, S. 17-85.

Kokott, Juliane \& Sobotta, Christoph: „The Kadi Case - Constitutional Core Values and International Law - Finding the Balance?", in: European Journal of International Law 23 (2012), S. 1015-1024. 


\section{Literaturverzeichnis}

Kollmorgen, Raj; Merkel, Wolfgang \& Wagener, Hans-Jürgen: Transformation und Transformationsforschung: Zur Einführung, in: dies. (Hrsg.), Handbuch Transformationsforschung, Springer VS, Wiesbaden, 2015, S. 11-27.

Koncewicz, Tomasz Tadeusz: „Of institutions, democracy, constitutional self-defence and the rule of law: The judgments of the Polish Constitutional Tribunal in Cases K 34/15, K 35/15 and beyond“, in: Common Market Law Review 53 (2016), S. 1753-1792.

Konstadinides, Theodore: The Rule of Law in the European Union: The Internal Dimension, Hart, Oxford, 2017.

Kornai, János: „Hungary's U-Turn: Retreating from Democracy“, in: Journal of Democracy 26 (2015), S. 34-48.

Kornezov, Alexander: „Imposing the Right Amount of Sanctions Under Article 260(2) TFEU: Fairness v. Predictability, or How to ,Bridge the Gaps““, in: Columbia Journal of European Law 20 (2014), S. 283-307.

Kosař, David \& Vyhnánek, Ladislav: „Constitutional Identity in the Czech Republic: A new twist on the old fashioned idea?", MUNI Law Working Paper Series No. 2017.05, Masaryk University Law Faculty, Brünn, 2017.

Krisch, Nico: „The Backlash against International Courts“, Verfassungsblog vom 16.12.2014, abrufbar unter: https://verfassungsblog.de/backlash-international-co urts-2/.

Kritikos, Mihalis: EU Policy-Making on GMOs, Palgrave Macmillan, London, 2018.

Kublik, Agnieszka: „Auf Linie gebracht: Polens öffentlich-rechtlicher Rundfunk unter PiS-Kuratel“, in: Osteuropa 66 (2016), S. 153-159.

Kugelmann, Dieter: „Gleichheitsrechte und Gleichheitsgrundsätze“, in: Merten, Detlef \& Papier, Hans-Jürgen (Hrsg.): Handbuch der Grundrechte, Bd. VI/1: Europäische Grundrechte I, Springer, Heidelberg, 2010, S. 979-1029.

Kulick, Andreas: „Rechtsstaatlichkeitskrise und gegenseitiges Vertrauen im institutionellen Gefüge der EU“, in: Juristenzeitung 75 (2020), S. 223-231.

Kumin, Andreas J: „Global Activities and Current Initiatives in the Union to Strengthen the Rule of Law: A State of Play“, in: Schroeder, Werner (Hrsg.): Strengthening the Rule of Law in Europe, Hart, Oxford/Portland, 2016, S. 207-220.

Kunig, Philip: Das Rechtsstaatsprinzip: Überlegungen zu seiner Bedeutung für das Verfassungsrecht der Bundesrepublik Deutschland, Mohr Siebeck, Tübingen, 1986.

Läufer, Dirk: Krisen in den europäischen und atlantischen Organisationen, Duncker \& Humblot, Berlin, 1974.

Lalík, Tomáš: „Constitutional Court Crisis in Slovakia: Still Far Away from Resolution“, in: I.CONnect-Blog vom 05.08.2016, o.S., abrufbar unter: http://www.ico nnectblog.com/2016/08/constitutional-court-crisis-in-slovakia-still-far-away-from -resolution/. 
Lalík, Tomáš: „Symposium on “The Slovak Constitutional Court Appointments Case"-Born is the King: The Day When Effective Judicial Review Arrived“ “, in: I.CONnect-Blog vom 27.01.2018, abrufbar unter: http://www.iconnectblog.c om/2018/01/symposium-slovak-appointments-case-lalik/.

Landy, Ernest Alfred: The effectiveness of international supervision: 30 years of I.L.O. experience, Stevens \& Sons, London, 1966.

Landy, Ernest Alfred: „Implementation Procedures of the International Labor Organization“, in: Santa Clara Law Review 20 (1980), S. 633-663.

Lang, Kai-Olaf: „Zwischen Rückbesinnung und Erneuerung: Polens PiS und Ungarns Fidesz im Vergleich“, in: Osteuropa 66 (2016), S. 61-78.

Larenz, Karl: Methodenlehre der Rechtswissenschaft, 2. Aufl., Springer, Heidelberg, 1969.

Lastra, Rosa M.: „Multilevel Governance in Banking Regulation“, in: Edoardo Chiti \& Vittorio Santoro (Hrsg.): The Palgrave Handbook of European Banking Union Law, Palgrave Macmillan/Springer Nature, Cham, 2019, S. 3-17.

Launhardt, Agnes: Topik und Rhetorische Rechtstheorie: Eine Untersuchung zu Rezeption und Relevanz der Rechtstheorie Theodor Viehwegs, Peter Lang, Frankfurt a.M. u.a., 2010.

Lauth, Hans-Joachim; Pickel, Gert \& Welzel, Christian: „Grundfragen, Probleme und Perspektiven der Demokratiemessung“, in: Lauth, Hans-Joachim; Pickel, Gert \& Welzel, Christian (Hrsg.), Demokratiemessung: Konzepte und Befunde im internationalen Vergleich, VS Verlag für Sozialwissenschaften, Wiesbaden, 2000, S. 7-26.

Lauth, Hans-Joachim \& Sehring, Jenniver: „Putting Deficient Rechtsstaat on the Research Agenda: Reflections on Diminished Subtypes“, in: Comparative Sociology 8 (2009), S. 165-201.

Łazowski, Adam: „European Union do not Worry, Croatia is Behind you: A Commentary on the Seventh Accession Treaty,“, in: Croatian Yearbook of European Law and Policy 8 (2012), S. 1-39.

Legrand, Pierre: „The Impossibility of Legal Transplants“, in: Maastricht Journal of European and Comparative Law 4 (1997), S. 111-124.

Lenaerts, Koen: „Kooperation und Spannung im Verhältnis von EuGH und nationalen Verfassungsgerichten“, in: Europarecht 50 (2015), S. 3-27.

Lenaerts, Koen: „Die Werte der Europäischen Union in der Rechtsprechung des Gerichtshofs der Europäischen Union: eine Annäherung“, in: Europäische Grundrechtezeitschrift (2017), S. 639-642.

Lenaerts, Koen: „La Vie après l'avis: Exploring the Principle of Mutual (yet not blind) Trust“, in: Common Market Law Review 54 (2017), S. 804-850.

Lenaerts, Koen: „On Judicial Independence and the Quest for National, Supranational and Transnational Justice: Speech at the National Congress of the Polish Bar, Katowice“, Redemanuskript vom 20.052017. 


\section{Literaturverzeichnis}

Lenaerts, Koen \& Gutiérrez-Fons, José A.: „The European Court of Justice as the Guardian of the Rule of EU Social Law", in: Vandenbroucke, Frank; Barnard, Catherine \& De Baere, Geert (Hrsg.), A European Social Union after the Crisis, Cambridge University Press, Cambridge, 2017, S. 433-456.

Lendvai, Paul: Orbán: Europe's New Strongman, Oxford University Press, Oxford, 2017, (abweichender Titel auf dem Einband: Orbán: Hungary's Strongman; um ein neues Kapitel ergänzte Übersetzung der dt. Ausgabe: Orbáns Ungarn, Kremayr \& Scheriau, Wien, 2016).

Levinson, Sanford \& Balkin, Jack M.: „Constitutional Crises“, in: University of Pennsylvania Law Review 157 (2009), S. 707-753.

Levitz, Philip \& Pop-Eleches, Grigore: „Why No Backsliding? The European Union's Impact on Democracy and Governance Before and After Accession“, in: Comparative Political Studies 43 (2009), S. 457-485.

Lipset, Seymor Martin: „Some Social Requisits of Democracy: Economic Development and Political Legitimacy“, in: American Political Science Review 53 (1959), S. 69-105.

Lühmann, Hans: „Von der Staatsaufsicht zur Unionsaufsicht?“, in: Deutsches Verwaltungsblatt (1999), S. 752-764.

Luther, Jörg: „Die Verfassung in Zeiten des ,Übergangs': Italienische Betrachtungen“, in: Jahrbuch des öffentlichen Rechts der Gegenwart N.F. 1950 (2002), S. 331-360.

Maatsch, Aleksandra: „Effectiveness of the European Semester: Explaining Domestic Consent and Contestation“, in: Parliamentary Affairs 70 (2017), S. 1-19.

Magyar, Bálint: Post-Communist Mafia State: The Case of Hungary, Central European University Press, Budapest, 2016.

Mak, Elaine \& Taekema, Sanne: „The European Union's Rule of Law Agenda: Identifying Its Core and Contextualizing Its Application“, in: Hague Journal on the Rule of Law 8 (2016), S. 25-50.

Małolepszy, Maciej (Hrsg.): Die Kriterien und das Verfahren der Richterwahl für die ordentliche Gerichtsbarkeit in Europa im Rechtsvergleich, Duncker \& Humblot, Berlin, 2019.

Marcinkiewicz, Kamil: „Der politische Rechtsruck in Polen: Analyse von Ursachen und außenpolitischen Konsequenzen“, in: Zeitschrift für Außen- und Sicherheitspolitik 9 (2016), S. 463-476.

Martenczuk, Bernd: „Art. 7 EUV und der Rechtsstaatsrahmen als Instrumente der Wahrung der Grundwerte der Union“, in: Kadelbach, Stefan: (Hrsg.), Verfassungskrisen in der Europäischen Union, Nomos, Baden-Baden, 2018, S. 41-59.

Maselis, Ignace \& Gilliams, Hans A.: „Rights of complainants in Community law“, in: European Law Review 22 (1997), S. 103-124.

Maunz, Theodor \& Dürig, Günter: Grundgesetz-Kommentar, Loseblatt, C.H. Beck, München, zit. nach: Bearbeiter, Rn., EL (Ergänzungslieferung).

Mendelski, Martin: „Rule of Law Reforms in the Shadow of Clientelism: The Limits of the EU's Transformative Power in Romania“, in: Polish Sociological Review 174 (2011), S. 235-253. 
Mendelski, Martin: „Das europäische Evaluierungsdefizit der Rechtsstaatlichkeit“, in: Leviathan 44 (2016), S. 366-398.

Merkel, Wolfgang: Systemwechsel: Theorien, Ansätze und Konzeptionen, Leske + Budrich, Opladen, 1996.

Merkel Wolfgang: Systemtransformation: Eine Einführung in die Theorie und Empirie der Transformationsforschung, Leske + Budrich, Opladen, 1999.

Merkel, Wolfgang; Puhle, Hans-Jürgen; Croissant, Aurel; Eicher, Claudia \& Thiery Peter: Defekte Demokratie, Band 1: Theorie, Springer Fachmedien, Wiesbaden, 2003.

Merkel, Wolfgang; Tanneberg, Dag \& Bühlmann, Marc: „„Den Daumen senken“: Hochmut und Kritik“, in: Zeitschrift für Vergleichende Politikwissenschaft 7 (2013), S. 75-84.

Merlingen, Michael; Mudde, Cas \& Sedelmeier, Ulrich: „The Right and the Righteous? European Norms, Domestic Politics and the Sanctions Against Austria“, in: Journal of Common Market Studies 39 (2001), S. 59-77.

Mertens de Wilmars, Josse \& Verougstraete, Ivan M.: „Proceedings against Member States for Failure to Fulfil Their Obligations“, in: Common Market Law Review 7 (1970), S. 385-406.

Meyer, Frank: Chapter 4: An Area of Freedom, Security and Justice, in: Böse, Martin; Meyer, Frank \& Schneider, Anne (Hrsg.): Conflicts of Jurisdiction in Criminal Matters in the European Union, Volume II: Rights, Principles and Model Rules, Nomos, Baden-Baden, 2014, S. 169-213.

Minkenberg, Michael: The Radical Right in Eastern Europe: Democracy under Siege?, Palgrave Macmillan, New York, 2017.

Moxham, Lucy \& Stefanelli, Justine: „Safeguarding the Rule of Law, Democracy and Fundamental Rights: A Monitoring Model for the European Union“, Bericht für das British Institute of International and Comparative Law/Bingham Centre for the Rule of Law, London, April 2013.

Murswiek, Dietrich: „Die heimliche Entwicklung des Unionsvertrages zur europäischen Oberverfassung: $\mathrm{Zu}$ den Konsequenzen der Auflösung der Säulenstruktur der Europäischen Union und der Erstreckung der Gerichtsbarkeit des EUGerichtshofs auf den EU-Vertrag", in: Neue Zeitschrift für Verwaltungsrecht 28 (2009), S. 481-486.

Möllers, Christoph \& Schneider, Linda: Demokratiesicherung in der Europäischen Union: Studie zu einem Dilemma, Mohr Siebeck, Tübingen, 2018.

Møller, Jørgen \& Skaaning, Svend-Erik: „On the limited interchangeability of rule of law measures“, in: European Political Science Review 3 (2011), S. 371-394.

Møller, Jørgen \& Skaaning, Svend-Erik: „Sub-components of the Rule of Law: Reassessing the Relevance of Diminished Subtypes", in: Comparative Sociology 12 (2013), S. 391-421.

Møller, Jørgen \& Skaaning, Svend-Erik: The Rule of Law: Definitions, Measures, Patterns and Causes, Palgrave Macmillan, Basingstoke, 2014.

Müller, Jan-Werner: „Defending Democracy within the EU“, in: Journal of Democracy 24 (2013), S. 138-149. 
Müller, Jan-Werner: „The Commission gets the point - but not necessarily the instruments“,Verfassungsblog, 15.03.2014, abrufbar unter: https://verfassungsbl og.de/the-commission-gets-the-point-but-not-necessarily-the-instruments/.

Müller, Jan-Werner: „Protecting the Rule of Law (and Democracy!) in the EU: The Idea of a Copenhagen Commission“, in: Closa, Carlos \& Kochenov, Dimitry (Hrsg.): Reinforcing Rule of Law Oversight in the European Union, 2016, S. 206-224.

Nergelius, Joakim, „The Role of the Venice Commission in Maintaining the Rule of Law in Hungary and in Romania“, in: Bogdandy, Armin von \& Sonnevend, Pál (Hrsg.): Constitutional Crisis in the European Constitutional Area, C.H. Beck/Hart/Nomos, München/Oxford/Baden-Baden, 2015, S. 291-308.

Nickel, Dietmar: „Integrationspolitische Herausforderungen an den Europäischen Rechtsstaat: „Zur Zukunft der europäischen Rechts- und Wertegemeinschaft““, in: Europarecht 52 (2017), S. 663-680.

Niedobitek, Matthias: „Right and duty to pursue the “wrongdoer” and a possible abuse of Art. 7 TEU”, in: Armin Hatje \& Tichý Luboš (Hrsg.): Liability of Member States for the Violation of Fundamental Values of the European Union, Europarecht, Beiheft 1, Nomos, Baden-Baden, 2018, S. 233-242.

Nugent, Neill (Hrsg.): At the Heart of the Union: Studies of the European Commission, Macmillan, Houndmills, Basingstoke/London, 1997.

Obwexer, Walter: „Das System der „Europäischen Wirtschaftsregierung“ und die Rechtsnatur ihrer Teile: Sixpack - Euro-Plus-Pakt - Europäisches Semester Rettungsschirm“, in: Zeitschrift für öffentliches Recht 67 (2012), S. 209-252.

Oesch, Matthias: „Das Rechtsstaatlichkeitsverfahren der EU gegen Polen - Bestandsaufnahme und Zwischenfazit“, in: Zeitschrift für Europarecht 18 (2016), S. 130-140.

O’Flaherty, Michael: „Human Rights Field Operations“, in: Gundmundur, Alfredsson; Grimheden, Jonas; Ramcharan, Bertrand G. \& de Zayas, Alfred (Hrsg.): International Human Rights Monitoring Mechanisms, Martinus Nijhoff, Leiden/ Boston, 2009, S. 205-217.

Oliver, Peter \& Stefanelli, Justine: „Strengthening the Rule of Law in the EU: The Council's Inaction“, in: Journal of Common Market Studies 54 (2016), S. 1075-1084.

Ontanu, Elena Alina; Velicogna, Marco \& Contini, Francesco: „How Many Cases? Assessing the Comparability of EU Judicial Datasets“, in: Comparative Law Review 8 (2017), S. 1-39.

Oppermann, Thomas: Europarecht: ein Studienbuch, C.H. Beck, München, 1. Aufl. 1991.

Orator, Andreas: „The competence entanglements of the EU Fundamental Rights Agency“, in: Kammerlander (Hrsg.), Expertenforum SpringerRecht.at, Springer, Wien, 2010, S. 123-155.

Ovádek, Michal: Slovakia Tackles Its Constitutional Skeleton in the Closet, in: I.CONnect-Blog vom 05.08.2016, o.S. 
Paris, Davide: „Carrot and Stick: The Italian Constitutional Court's Preliminary Reference in the Case Taricco“, in: Questions of International Law - Questioni di diritto internazionale 37 (2017), S. 5-20.

Pasztory, Blaise G.A.: „Audretsch, Supervision in European Community Law: Observance by the Member States of Their Treaty Obligations (2d Rev. Ed.)“, in: Fordham International Law Journal 11 (1987), S. 453-460.

Patz, Ronny: "Just the TTIP of the Iceberg? Dynamics and Effects of Information Leaks in EU Politics“, in: European Journal of Risk Regulation 7 (2017), S. 242-246.

Patz, Ronny: „Leaking, leak prevention, and decoupling in public administrations: the case of the European Commission“, in: West European Politics 41 (2017), S. 1049-1071.

Pech, Laurent: Commission Opinion of 1 June 2016 regarding the Rule of Law in Poland: Full text now available, vom 19.08.2016, abrufbar unter: http://eulawan alysis.blogspot.de/2016/08/commissionopinion-of-1-june-2016.html.

Pech, Laurent: „The Rule of Law as a Constitutional Principle of the European Union“, Jean Monnet Working Paper 04/09, NYU School of Law, New York, 2009.

Pech, Laurent: „Lex CEU: On the Commission's Refusal to Disclose its Letter of Formal Notice in the Name of Mutual Trust“, Verfassungsblog vom 07.07.2017, o.S., abrufbar unter: verfassungsblog.de/lex-ceu-on-the-commissions-refusal-todisclose-its-letter-of-formal-notice-in-the-name-of-mutual- trust/.

Pech, Laurent \& Wójcik, Anna: „A Bad Workman always Blames his Tools‘: an Interview with Laurent Pech“, Verfassungsblog vom 28.05.2018, o.S., abrufbar unter: verfassungsblog.de/a-bad-workman-always-blames-his-tools-an-interview-with-laurent-pech/.

Pech, Laurent; Kochenov, Dimitry \& Platon, Sébastien: „The European Parliament Sidelined“, Verfassungsblog vom 08.12.2019, o.S., abrufbar unter: verfassungsblog.de/the-european-parliament-sidelined/.

Pech, Laurent; Perju, Vlad; Platon, Sébastien: „How to Address Rule of Law Backsliding in Romania“, Verfassungsblog vom 29.05.2019, o.S., abrufbar unter: verfassungsblog.de/how-to-adress-rule-of-law-backsliding-in-romania/.

Pech, Laurent \& Platon, Sébastien: „Menace systémique envers l'Etat de droit en Pologne : entre action et procrastination“, Question d'Europe/Fondation Robert Schuman Policy Papers, Fondation Robert Schuman, 2017.

Pech, Laurent \& Platon, Sébastien: „Judicial Independence under Threat:The Court of Justice to the rescue in the ASJP case: Case C-64/16, Associação Sindical dos Juízes Portugueses, Judgment of the Court of Justice (Grand Chamber) of 27 February 2018, EU:C:2018:117“, in: Common Market Law Review 55 (2018), S. 1827-1854.

Pech, Laurent \& Scheppele, Kim Lane: „Illiberalism Within: Rule of Law Backsliding in the EU“, in: Cambridge Yearbook of European Legal Studies (2017), S. $1-45$. 


\section{Literaturverzeichnis}

Pernthaler, Peter \& Weber, Karl: Theorie und Praxis der Bundesaufsicht in Österreich, Braumüller, Wien, 1979.

Peršak, Nina \& Štrus, Jože: „Legitimacy and Trust-Related Issues of Judiciary: New Challenges for Europe“, in: Peršak, Nina (Hrsg.): Legitimacy and Trust in Law, Policy and Justice: Norms, Procedures, Outcomes, Routledge, London \& New York, 2016, S. 89-110.

Peters, Anne: „European Democracy after the 2003 Convention“, in: Common Market Law Review 41 (2004), S. 37-85.

Peters Anne: „Populist International Law? The Suspended Independence and the Normative Value of the Referendum on Catalonia“, EJIL Talk vom 12.10.2017, o.S., abrufbar unter: ejiltalk.org/populist-international-law-the-suspended-independence-and-the-normative-value-of-the-referendum-on- catalonia/.

Pforr, Thomas: Die allgemeine Unionsaufsicht, Peter Lang, Frankfurt a.M. u. a., 2004.

Pickel, Gert \& Pickel: Susanne: Politische Kultur- und Demokratieforschung, VS Verlag für Sozialwissenschaften, Wiesbaden, 2006.

Polakiewicz, Jörg: „Addressing systemic Rule of Law Deficiencies“, in NYU Global and Comparative Law Colloquium, Europarat, Straßburg, 2019.

Polakiewicz, Jörg \& Sandvig, Jenny: „Council of Europe and the Rule of Law“, in: Journal of Civil \& Legal Sciences, (4) 2015, o. S.

Polakiewicz, Jörg \& Sandvig, Jenny: „The Council of Europe and the Rule of Law“, in: Schroeder, Werner (Hrsg.): Strengthening the Rule of Law in Europe: From a Common Concept to Mechanisms of Implementation, Hart, Oxford, 2016, S. 115-133.

Pollack, Mark A.: The Engines of European Integration, Oxford University Press, Oxford, 2003.

Poltorak, Nina: „Enlargement and administrative law: The Polish Experience“, in: Harlow, Carol; Leino, Päivi \& della Cananea, Giacinto (Hrsg.), Research Handbook on EU Administrative Law Edward Elgar, Cheltenham/Northampton, MA, 2017, S. 521-544.

Polzin, Monika: Verfassungsidentität: Ein normatives Konzept des Grundgesetzes?, Mohr Siebeck, Tübingen, 2018.

Porter-Szűcs, Brian: Faith and Fatherland: Catholicism, Modernity, and Poland, Oxford University Press, Oxford, 2011.

Poulet-Gibot Leclerc, Nadine: Droit administratif: sources, moyens, contrôles Bréal, Rosny-sous-Bois, 2007.

Prete, Luca: Infringement Proceedings in EU Law, Kluwer, Alphen aan den Rijn, 2017.

Prete Luca \& Smulders, Ben: „The Coming of Age of Infringement Procedures“, in: Common Market Law Review 47 (2010), S. 9-61.

Preuß, Ulrich K.: „Die Krise der Europäischen Union als Ausnahmezustand?“, in: Kritische Justiz 50 (2017), S. 51-67. 
Quint, Peter E.: „\$109 Der Einfluss des Supreme Court der Vereinigten Staaten von Amerika auf die Verfassungsgerichtsbarkeit in Europa“, in: Bogdandy, Armin von; Grabenwarter, Christoph \& Huber, Peter M. (Hrsg.): Handbuch Ius Publicum Europaeum: Band VI: Verfassungsgerichtsbarkeit in Europa: Institutionen, C. F. Müller, Heidelberg, 2017, S. 1031-1099.

Ragone, Sabrina: „Das Unabhängigkeitsreferendum in Katalonien - Wie ist der Stand aus vergleichender und kontextualer Perspektive?", in: Die öffentliche Verwaltung 71 (2018), S. 341-350.

Russo, Anna Maria: „La cittadanza ,sostanziale“ dell'UE alla luce della proposta del Gruppo di Heidelberg: Verso una ,Reverse Solange‘?"،, in: Federalismi 12 (2014), S. 1-19.

Sadurski, Wojciech: Poland's Constitutional Breakdown, Oxford University Press, Oxford, 2019.

Schaub, Bernhard: Die Aufsicht des Bundes über die Kantone, Dissertation, H. R. Sauerländer \& Co. Aarau, Zürich, 1957.

Scheffs, Łukas: „,Recht und Gerechtigkeit‘ (PiS) als Protestpartei? Eine kurze politologische Reflexion“, in: Bingen, Dieter; Jarosz, Maria \& Loew, Oliver (Hrsg.): Legitimation und Protest: Gesellschaftliche Unruhe in Polen, Ostdeutschland und anderen Transformationsländern nach 1989, Harrassarowitz, Wiesbaden, 2012, S. 70-84.

Scheinin, Martin: „The Relationship between the Agency and the Network of Independent Experts“, in: Alston, Philip \& de Schutter, Olivier (Hrsg.): Fundamental Rights in the EU: The Contribution of the Fundamental Rights Agency, Hart, Oxford/Portland, Oregon, 2005, S. 73-90.

Scheppele, Kim Lane: „What Can the European Commission Do when Member States Violate Basic Principles of the European Union? The Case for Systemic Infringement Actions“, undatiertes Working Paper, 2013, verfügbar unter: https:// verfassungsblog.de/wp-content/uploads/2013/11/scheppele-systemic-infringeme nt-action-brussels-version.pdf.

Scheppele, Kim Lane: „Constitutional Coups and Judicial Review: How Transnational Institutions Can Strengthen Peak Courts at Times of Crisis (With Special Reference to Hungary)“, in: Transnational Law \& Contemporary Problems 23 (2014), S. 51-118.

Scheppele, Kim Lane: „Understanding Hungary's Constitutional Revolution“, in: Bogdandy, Armin von \& Sonnevend, Pál (Hrsg.): Constitutional Crisis in the European Constitutional Area, C.H. Beck/Hart/Nomos, München/Oxford/ Baden-Baden, 2015, S. 111-124.

Scheppele, Kim Lane: „Enforcing the Basic Principles of EU Law through Systemic Infringement Actions“, in: Closa, Carlos \& Kochenov, Dimitry (Hrsg.): Reinforcing Rule of Law Oversight in the European Union, Cambridge University Press, Cambridge, 2016, S. 105-132.

Scheppele, Kim Lane: „Constitutional Coups in EU Law“, in: Adams, Maurice; Meuwese, Anne \& Hirsch Ballin, Ernst (Hrsg.): Constitutionalism and the Rule of Law, Cambridge University Press, Cambridge, 2017, S. 446-478. 


\section{Literaturverzeichnis}

Scheppele, Kim Lane \& Kelemen, R. Daniel: „Defending Democracy in EU Member States: Beyond Article 7 TEU“, in: Bignami, Francesca (Hrsg.): EU Law in Populist Times: Crises and Prospects, Cambridge University Press, Cambridge, 2020, S. 413-456.

Schmahl, Stefanie: „Filling a Legal gap?: Das neue EU-Monitoring-Verfahren bei Rechtsstaatsdefiziten“, in: Calliess, Christian (Hrsg.), Herausforderungen an Staat und Verfassung: Völkerrecht, Europarecht, Menschenrechte ; Liber Amicorum für Torsten Stein zum 70. Geburtstag, Nomos, Baden-Baden, 2015, S. 834-855.

Schmidt, Matthias: „Le manquement perpétué en droit de l'Union européenne Remarques sur le contexte et le cadre juridique du refus persistant d'un État membre de satisfaire ses obligations suite à un arrêt en vertu de l'art. 260 (2) TFUE“, unveröffentlichte Abschlussarbeit der École nationale d'administration/Université Paris 1 Panthéon-Sorbonne, Betreuer: Prof. Dr. Antoine Vauchez, Manuskript vom 20.11.2019.

Hinweis zur Quelle: das Manuskript ist erhältlich durch formlose Zuschrift an den Verfasser unter matthias.schmidt@alumni.ena.fr.

Schmidt, Matthias \& Bogdanowicz, Piotr: „The Infringement Procedure in the Rule of Law Crisis: How to make effective use of Article 258 TFEU“, in: Common Market Law Review 55 (2018), S. 1061-1100.

Schmidt, Matthias \& Bogdanowicz, Piotr: „Ascertaining the ,Guarantee of Guarantees': Recent Developments Regarding the Infringement Procedure in the EU's Rule of Law Crisis“, in: Bogdandy, Armin; Bogdanowicz, Piotr; Canor, Iris; Grabenwarter, Christoph; Taborowski, Maciej; Schmidt, Matthias (Hrsg.): Defending Checks and Balances in EU Member States: Taking Stock of Europe's Actions, Springer, Heidelberg, 2021, S. 207-236.

Schmidt, Manfred G.: Sozialpolitik der DDR, VS Verlag für Sozialwissenschaften, Wiesbaden, 2013.

Schmitt, Carl: Politische Theorie - Vier Kapitel zur Lehre von der Souveränität, 2. Aufl., Duncker \& Humblot, München und Leipzig, 1934.

Schneider, Peter \& Ehmke, Horst: „Erster Beratungsgegenstand: Prinzipien der Verfassungsinterpretation“, in (ohne Red./Hrsg.): Prinzipien der Verfassungsinterpretation: Gefährdungshaftung im öffentlichen Recht, Veröffentlichungen der Vereinigung der Deutschen Staatsrechtslehrer, Bd. 20, De Gruyter, Berlin, 1963, S. 1-134.

Schoch, Friedrich: „Öffentlich-rechtliche Rahmenbedingungen einer Informationsordnung“, in: Hoppe, Werner (Red.): Der Grundrechtseingriff: Öffentlich-rechtliche Rahmenbedingungen einer Informationsordnung, Veröffentlichungen der Vereinigung der Deutschen Staatsrechtslehrer, Band 57, De Gruyter, Berlin, 1998, S. 158-215.

Schönberger, Christoph: „Die Europäische Union als Bund: zugleich ein Beitrag zur Verabschiedung des Staatenbund-Bundesstaat-Schemas“, in: Archiv des öffentlichen Rechts 129 (2004), S. 81-120. 
Schöne, Helmar: „Die teilnehmende Beobachtung als Datenerhebungsmethode in der Politikwissenschaft: methodologische Reflexion und Werkstattbericht", in: Historical Social Research 30 (2005), S. 168-199.

Schorkopf, Frank: Homogenität in der Europäischen Union - Ausgestaltung und Gewährleistung durch Art. 6 Abs. 1 und Art. 7 EUV, Duncker \& Humblot, Berlin, 2000.

Schorkopf, Frank: Die Maßnahmen der XIV EU-Mitgliedstaaten gegen Österreich: Möglichkeiten und Grenzen einer „streitbaren Demokratie“ auf europäischer Ebene, Springer, Heidelberg, 2002.

Schorkopf, Frank: „Gestaltung mit Recht: Prägekraft und Selbststand des Rechts in einer Rechtsgemeinschaft“, in: Archiv des öffentlichen Rechts 136 (2011), S. 323-344.

Schorkopf, Frank: „Finanzkrisen als Herausforderung der internationalen, europäischen und nationalen Rechtsetzung“, in: Wolfram Höfling (Red.): Fragmentierungen. Veröffentlichungen der Vereinigung der Deutschen Staatsrechtslehrer, Bd. 71, De Gruyter, Berlin, 2012, S. 183-225.

Schorkopf, Frank: „Wertesicherung in der Europäischen Union. Prävention, Quarantäne und Aufsicht als Bausteine eines Rechts der Verfassungskrise?“, in: Europarecht (2016), S. 147-164.

Schroeder, Werner: „The European Union and the Rule of Law - State of Affairs and Ways of Strengthening“, in: Schroeder (Hrsg.), Strengthening the Rule of Law in Europe: From a Common Concept to Mechanisms of Implementation, Oxford University Press, Oxford, 2016, S. 3-34.

Schwarze, Jürgen (Hrsg.): EU-Kommentar, Nomos, Baden-Baden, 2. Aufl. 2009, zit. nach: Bearbeiter, Rn.

Schwarze, Jürgen: „Zwischen Tradition und Zukunft: Die Rolle allgemeiner Rechtsgrundsätze im Recht der Europäischen Union“, in: ders. (Hrsg.), Europarecht: Strukturen, Dimensionen und Wandlungen des Rechts der Europäischen Union: Ausgewählte Beiträge, Nomos, Baden-Baden, 2012, S. 114-127.

Sedelmeier, Ulrich: „Political safeguards against democratic backsliding in the EU: the limits of material sanctions and the scope of social pressure", in: Journal of European Public Policy 24 (2016), S. 337-351.

Senden, Linda: Soft Law in European Community Law, Hart, Oxford/Portland, 2004.

Serini, Katharina: Sanktionen der Europäischen Union bei Verstoß eines Mitgliedstaats gegen das Demokratie- oder Rechtsstaatsprinzip, Duncker \& Humblot, Berlin, 2009.

Siems, Mathias M.: „Numerical Comparative Law: Do We Need Statistical Evidence in Law in Order to Reduce Complexity“, in: Cardozo Journal of International and Comparative Law 13 (2005), S. 521-540.

Siems, Mathias M., „Statistische Rechtsvergleichung“, in: Rabels Zeitschrift für ausländisches und internationales Privatrecht 72 (2008), S. 354-390. 


\section{Literaturverzeichnis}

Sijniensky, Romina I.: „From the Non-Discrimination Clause to the Concept of Vulnerability in International Human Rights Law: Advancing on the Need for Special Protection of Certain Groups and Individuals“, in: Haeck, Yves; McGonigle Ley, Brianne; Burbano Herrera, Clara; Contreras Garduno, Diana (Hrsg.): The Realisation of Human Rights: When Theory Meets Practice: Studies in Honour of Leo Zwaack, Intersentia, Cambridge, 2014, S. 259-272.

Skaaning, Svend-Erik: „Measuring the Rule of Law“, in: Political Research Quarterly 63 (2010), S. 449-460.

Skouris, Vassilios: „Die Rechtsstaatlichkeit in der Europäischen Union“, in: Hatje, Armin (Hrsg.): Verfassungszustand und Verfassungsentwicklung der Europäischen Union, Europarecht Beiheft 2 (2015), S. 8-19.

Skouris, Vassilios: Demokratie und Rechtsstaat: Europäische Union in der Krise, C.H. Beck, München 2018.

Sladič, Jorg: Einstweiliger Rechtsschutz im Gemeinschaftsprozessrecht: Eine Untersuchung des EG/EU-Prozessrechts, Nomos, Baden-Baden, 2008.

Sobota, Katharina: Das Prinzip Rechtsstaat: Verfassungs- und Verwaltungsrechtliche Aspekte, Mohr Siebeck, Tübingen, 1997.

Sokhi-Bulley, Bal: „The Fundamental Rights Agency of the European Union: A New Panopticism“, in: Human Rights Law Review 11 (2011), S. 683-706.

Soley, Ximena: „The Transformative Dimension of Inter-American Jurisprudence“, in: Bogdandy, Armin von; Ferrer Mac-Gregor, Eduardo; Morales Antoniazzi, Mariela; Piovesan, Flávia (Hrsg.): Transformative Constitutionalism in Latin America, Oxford University Press, Oxford, 2017, S. 337-355.

Soley, Ximena \& Steininger, Silvia: „Parting ways or lashing back? Withdrawals, backlash and the Inter-American Court of Human Rights“, in: International Journal of Law in Context 14 (2018), S. 237-257.

Sombrowski, Diane: Inputevaluation in der europäischen Forschungspolitik: Gestaltung und Implementation der Projektauswahl durch die EU-Kommission, Deutscher Universitäts-Verlag, Wiesbaden, 2005.

Sonnevend, Pál; Jakab, András \& Csink, Lóránt: „ The Constitution as an Instrument of Everyday Party Politics: The Basic Law of Hungary “, in: Bogdandy, Armin von \& Sonnevend, Pál (Hrsg.): Constitutional Crisis in the European Constitutional Area, Hart, Oxford, 2015, S. 33-109.

Spendzharova, Aneta B. \& Vachudova, Milada Anna: „Catching Up? Consolidating Liberal Democracy in Bulgaria and Romania after EU Accession“, in: West European Politics 35 (2012), S. 39-58.

Spieker, Luke Dimitrios: „From Moral Values to Legal Obligations: On how to activate the Union's common values in the EU rule of law crisis”, MPIL Research Paper Series, No. 2018-24, Heidelberg, 2018.

Spieker, Luke Dimitrios: „Breathing Life into the Union's Common Values: On the Judicial Application of Article 2 TEU in the EU Value Crisis“, in: German Law Journal 20 (2019), S. 1182-1213. 
Starski, Paulina: „The Power of the Rule of Law: The Polish Constitutional Tribunal's Forceful Reaction“, Verfassungsblog vom 17.03.2016, o.S., abrufbar unter: https://verfassungsblog.de/the-power-of-the-rule-of-law-the-polish-con stitutional-tribunals-forceful-reaction/.

Ştefan, Oana: Soft Law in Court: Competition Law, State Aid and the Court of Justice of the European Union, Kluwer Law International, Alpen aan den Rijn, 2013.

Stern, Joachim: „Ius Pecuniae - Staatsbürgerschaft zwischen ausreichendem Lebensunterhalt, Mindestsicherung und Menschenwürde“, in: Dahlvik, Julia; Fassmann, Heinz \& Sievers, Wiebke (Hrsg.): Migration und Integration - wissenschaftliche Perspektiven aus Österreich. Jahrbuch 1/2011, Vienna University Press, Wien, 2011, S. 55-74.

Stevenson, Howard: „The European Semester: A literature review: Published as part of the project: Public service trade unions - effective intervention in the European Semester: Financed by the European Commission", April 2019, abrufbar unter: https://www.epsu.org/sites/default/files/article/files/Literature\%20revi ew_0.pdf.

Stolleis, Michael: Geschichte des öffentlichen Rechts in Deutschland, Dritter Band: 1914-1945, C.H. Beck, München, 1999.

Stolleis, Michael: Geschichte des öffentlichen Rechts in Deutschland: Vierter Band: Staats- und Verwaltungsrechtswissenschaft in West und Ost, C.H. Beck, München, 2012.

Strelkov, Alexander: „EU Justice Scoreboard: a new policy tool for ,deepening' European integration?", in: Journal of Contemporary European Studies (2018), S. 1-13.

Taekema, Sanne \& van Klink, Bart: „On the Border. Limits and Possibilities of Interdisciplinary Research“, in: van Klink/Taekema (Hrsg.), Law and Method: Interdisciplinary Research into Law, Mohr Siebeck, Tübingen, 2011, S. 7-32.

Thiele, Alexander: Finanzaufsicht: Der Staat und die Finanzmärkte, Mohr Siebeck, Tübingen, 2014.

Thiery, Peter \& Croissant, Aurel: „Defekte Demokratie: Konzept, Operationalisierung und Messung“, in: Lauth, Hans-Joachim; Pickel, Gert \& Welzel, Christian (Hrsg.): Demokratiemessung: Konzepte und Befunde im internationalen Vergleich, Springer Fachmedien, Wiesbaden, 2000, S. 89-111.

Thio, Li-Ann: „Constitutionalism in Illiberal Polities“, in: Rosenfeld, Michel \& Sajó, András (Hrsg.): The Oxford Handbook of Comparative Constitutional Law, Oxford University Press, Oxford, 2012, S. 133-152.

Toggenburg, Gabriel N. \& Grimheden, Jonas: „Managing the Rule of Law in a Heterogeneous Context: A Fundamental Rights Perspective on Ways Forward“, in: Schroeder, Werner (Hrsg.): Strengthening the Rule of Law in Europe: From a Common Concept to Mechanisms of Implementation, Hart, Oxford, 2016, S. 221-240. 


\section{Literaturverzeichnis}

Toggenburg, Gabriel N. \& Grimheden, Jonas: „Upholding Shared Values in the EU: What Role for the EU Agency for Fundamental Rights?", in: Journal of Common Market Studies 54 (2016), S. 1093-1104.

Toggenburg, Gabriel N.: „Menschenrechtspolitik“, in: Weidenfeld, Werner \& Wessels, Wolfgang (Hrsg.): Jahrbuch der Europäischen Integration 2018, Nomos, Baden-Baden, 2018, S. 229-234.

Tomuschat, Christian: Die gerichtliche Vorabentscheidung nach den Verträgen über die Europäischen Gemeinschaften, Carl Heymanns, Köln, 1964.

Träbert, Katrin: Sanktionen der Europäischen Union gegen ihre Mitgliedstaaten: Die Sanktionsverfahren nach Art. 228 Abs. 2 EGV und Art. 7 EUV, Peter Lang, Frankfurt am Main, 2010.

Triantafyllou, Dimitris: „Zur Verantwortung des Staates für die Geldwirtschaft. Auf dem Weg zu einer europäischen Bankenaufsicht", in: Europarecht 45 (2010), S. 585-597.

Triepel, Heinrich: Die Reichsaufsicht, Springer, Berlin, 1917.

Tuleja, Piotr: „\$103 Der polnische Verfassungsgerichtshof“, in: Bogdandy, Armin von; Grabenwarter, Christoph \& Huber, Peter M. (Hrsg.): Ius Publicum Europaeum Band VI: Verfassungsgerichtsbarkeit in Europa, C. F. Müller, Heidelberg, 2015, S. 471-518.

Tuleja, Piotr: „The Polish Constitutional Tribunal“, in: Bogdandy, Armin von; Huber, Peter M. \& Grabenwarter, Christoph (Hrsg.): The Max Planck Handbooks of Public Law in Europe: Volume III: Constitutional Adjudication: Institutions, Oxford University Press, Oxford, 2020, S. 619-672.

Tuori, Kaarlo: „From Copenhagen to Venice“, in: Closa, Carlos \& Kochenov, Dimitry (Hrsg.): Reinforcing Rule of Law Oversight in the European Union, Cambridge University Press, Cambridge, 2015, S. 225-246.

Tuori, Kaarlo \& Tuori, Klaus: The Eurozone Crisis: A Constitutional Analysis, Cambridge University Press, Cambridge, 2014.

Tushnet, Mark: „Authoritarian Constitutionalism“, in: Cornell Law Review 100 (2015), S. 391-461.

Uitz, Renáta: „EU Rule of Law Dialogues: Risks - in Context“, Verfassungsblog vom 23.01.2020, o.S., abrufbar unter: verfassungsblog.de/eu-rule-of-law-dialogues-risks-in-context/.

Uriás, Joaquín: „Spain has a Problem with its Judiciary“, Verfassungsblog vom 15.01.2020, abrufbar unter: https://verfassungsblog.de/spain-has-a-problem-with -its-judiciary/.

Vachudova, Milada Anna: „Why Improve EU Oversight of Rule of Law?: The Two-Headed Problem of Defending Liberal Democracy and Fighting Corruption“, in: Closa, Carlos \& Kochenov, Dimitry (Hrsg.): Reinforcing Rule of Law Oversight in the European Union, 2016, S. 270-289.

van Cleynenbreugel, Pieter: Market Supervision in the European Union: Integrated Administration in Constitutional Context, 7, Martinus Nijhoff, Leiden, 2014.

van de Bunt, Henk \& van Gelder, Jean-Louis: „The Dutch Prosecution Service“, in: Crime and Justice 41 (2012), S. 117-140. 
van Rijckevorsel, Elisabeth: „The EU and the indirect promotion of its values: an analysis of the EU Justice Scoreboard and of the Roma Framework“, in: Journal européen des droits de l'homme/European Journal of Human Rights 3 (2016), S. 444-468.

Vanhanen, Tatu: „A New Dataset for Measuring Democracy, 1810-1998“, in: Journal of Peace Research 37 (2000), S. 252-265.

Viehweg, Theodor: Topik und Jurisprudenz: Ein Beitrag zur rechtswissenschaftlichen Grundlagenforschung, 4., durchgesehene Aufl., C.H. Beck, München, 1969 [1953].

Vogel, Klaus: „Selbständige Bundesaufsicht‘ nach dem Grundgesetz, besonders bei der Anwendung europäischen Rechts“, in: Burmeister, Joachim (Hrsg.): Verfassungsstaatlichkeit: Festschrift für Klaus Stern zum 65. Geburtstag, C.H. Beck, München, 1997, S. 819-829.

Volpe, Valentina: „Drafting Counter-Majoritarian Democracy: The Venice Commission's Constitutional Assistance“, in: Zeitschrift für ausländisches öffentliches Recht und Völkerrecht (2016), S. 811-843.

von der Groeben, Hans; Schwarze, Jürgen \& Hatje, Armin (Begr./Hrsg.): Europäisches Unionsrecht, Nomos, Baden-Baden, 7. Aufl. 2015, zit. nach: Bearbeiter, Art., Rn.

Walter, Maja: „Integrationsgrenze Verfassungsidentität - Konzept und Kontrolle aus europäischer, deutscher und französischer Perspektive“, in: Zeitschrift für ausländisches öffentliches Recht und Völkerrecht 72 (2012), S. 177-200.

Waschkuhn, Arno: „Robert A. Dahl, Polyarchy: Participation and Opposition, New Haven 1971“, in: Kailitz, Steffen (Hrsg.), Schlüsselwerke der Politikwissenschaft, VS Verlag für Sozialwissenschaften, Wiesbaden, 2007, S. 86-88.

Watson, Alan: „Legal Transplants and European Private Law”, in: Ius Commune Lectures on European Private Law, 2, Maastricht, 2000, o.S.

Weidenfeld, Werner: „Die Berichte der Europäischen Gemeinschaft zur Reform des Gemeinschaftssystems seit 1972“, in: Hartwich, Hans Hermann (Hrsg.): Gesellschaftliche Probleme als Anstoß und Folge von Politik: Wissenschaftlicher Kongreß der DVPW: 4.-7. Oktober 1982 in der Freien Universităt Berlin: Tagungsbericht, Springer Fachmedien, Wiesbaden, 1982, S. 296-302.

Weinzierl, Sebastian: „Die EU Task-Force für Griechenland: Internationale Beratung am Beispiel der griechischen Steuerverwaltung“, in: Klemm, Ulf-Dieter \& Schultheiß, Wolfgang (Hrsg.): Die Krise in Griechenland: Ursprünge, Verlauf, Folgen, Campus, Frankfurt/New York, 2015, S. 448-459.

Weller, Matthias: „Mutual trust: in search of the future of European Union private international law", in: Journal of Private International Law 11 (2015), S. 64-102.

Wendel, Mattias: „Kompetenzrechtliche Grenzgänge: Karlsruhes Ultra-vires-Vorlage an den EuGH“, in: Zeitschrift für ausländisches öffentliches Recht und Völkerrecht 74 (2014), S. 615-670.

Wendel, Mattias: „Rechtsstaatlichkeitsaufsicht und gegenseitiges Vertrauen - Anmerkung zum Urteil des EuGH v. 25.7.2018, Rs. C-216/18 PPU (Minister for Justice and Equality gegen LM)“, in: Europarecht 54 (2019), S. 111-131. 
Wennerström, Erik O.: The Rule of Law and the European Union, Iustus Förlag, Uppsala, 2007.

Wennerås, Pål: „A new dawn for Commission Enforcement under Articles 226 and 228 EC: General and Persistent (Gap) Infringements, Lump Sums and Penalty Payments“, in: Common Market Law Review 43 (2006), S. 31-62.

Wennerås, Pål: „Saving a forest and the rule of law: Commission v. Poland Case C-441/17 R, Commission v. Poland, Order of the Court (Grand Chamber) of 20 November 2017, EU:C:2017:877“, in: Common Market Law Review 56 (2019), S. 541-558.

Wennerås, Pål: „Making Effective Use of Article 260 TFEU“, in: Jakab, András \& Kochenov, Dimitry (Hrsg.): The Enforcement of EU law and Values, Oxford University Press, Oxford, 2017, S. 79-98.

White, Jonathan: „Emergency Europe“, in: Political Studies 63 (2015), S. 300-318.

White, Jonathan: Politics of last resort: governing by emergency in the European Union, Oxford University Press, Oxford, 2020.

Wildhaber, Luzius: „Pilot Judgments in Cases of Structural or Systemic Problems on the National Level“, in: Wolfrum, Rüdiger \& Deutsch, Ulrike (Hrsg.): The European Court of Human Rights Overwhelmed by Applications: Problems and Possible Solutions: International Workshop Heidelberg, December 17 - 18, 2007, Springer, Heidelberg, 2009, S. 69-75.

Wirbel, Klaus: Der Ausnahmezustand im Gemeinschaftsrecht - Zu Inhalt und Grenzen des Art. 224 EG-Vertrag, zugleich Bonn, Rheinische Friedrich-Wilhelms-Universität, Diss.; verlegt ohne Verlag (Universitätsdruck), Bonn, 1994.

Wittmayer, Leo: „Heinrich Triepel, Die Reichsaufsicht. Untersuchungen zum Staatsrecht des Deutschen Reiches“, in: Archiv des öffentlichen Rechts 41 (1921), S. 107-112.

Wolfrum, Rüdiger \& Deutsch, Ulrike (Hrsg.): The European Court of Human Rights Overwhelmed by Applications: Problems and Possible Solutions: International Workshop Heidelberg, December 17 - 18, 2007, Springer, Heidelberg, 2009.

Wollenschläger, Peter: Die Gemeinschaftsaufsicht über die Rechtsprechung der Mitgliedstaaten, Duncker \& Humblot, Berlin, 2006.

Wolter, Jürgen (Hrsg.): Systematischer Kommentar zur Strafprozessordnung, Band IX, Carl Heymanns, Köln, 5. Aufl. 2016; zit. nach Bearbeiter, Art., Rn.

Woodbury, Westel: Constitutional Law of the United States, Baker, Voorhis \& Co., New York, 1910, S. 175-193.

Würtenberger, Thomas \& Tkaczyński, Jan W.: „Nowe ramy Unii Europejskiej na rzecz umocnienia prawor-ządności (analiza krytyczna)", in: Pańtswo i Prawo 71 (2017), S. 16-29.

Wymeersch, Eddy; Hopt, Klaus J. \& Ferrarini, Guido: Financial Regulation and Supervision: A post-crisis analysis, Oxford University Press, Oxford, 2012.

Yang, Nele: Die Leitentscheidung: Zur Grundlegung eines Begriffs und seiner Erforschung im Unionsrecht anhand des EuGH-Urteils Kadi, Springer, Heidelberg, 2017. 
Zakaria, Fareed: „The Rise of Illiberal Democracy“, in: Foreign Affairs 76 (1997), S. 22-43.

Zeitlin, Jonathan \& Vanhercke, Bart: „Economic governance in Europe 2020: socialising the European Semester against the odds", in: Natali, David \& Vanhercke, Bart (Hrsg.): Social policy in the European Union: state of play 2015, ETUI aisbl, Brüssel, 2015, S. 65-95.

Zeitlin, Jonathan \& Vanhercke, Bart: „Socializing the European Semester: EU social and economic policy co-ordination in crisis and beyond“, in: Journal of European Public Policy 25 (2017), S. 149-174.

Zellentin, Gerda: „Krisen der europäischen Integration. Ursachen und Wirkungen“, in: Integration: Vierteljahreshefte zur Europaforschung 2 (1970), S. 20-37.

Zuleeg, Manfred: „Die Kompetenzen der Europäischen Gemeinschaften gegenüber den Mitgliedstaaten“, in: Jahrbuch des öffentlichen Rechts der Gegenwart N.F. 20 (1971), S. 1-64.

Zuleeg, Manfred: „Die föderativen Grundsätze der Europäischen Union“, in: Neue Juristische Wochenschrift (2000), S. 2846-2851.

Zuleeg, Manfred: „Die Vorzüge der Europäischen Verfassung“, in: Bogdandy, Armin von \& Bast, Jürgen (Hrsg.), Europäisches Verfassungsrecht, Springer, Heidelberg/Berlin, 2009, S. 1045-1076.

Zürn, Michael: „Introduction: Law and compliance at different levels“, in: Zürn, Michael \& Joerges, Christian (Hrsg.), Law and Governance in Postnational Europe: Compliance beyond the Nation-State, Cambridge University Press, Cambridge 2005, S. 1-39. 
